Sprache intermedial 


\section{Institut für Deutsche Sprache Jahrbuch 2009}




\section{Sprache intermedial}

Stimme und Schrift, Bild und Ton

Herausgegeben von

Arnulf Deppermann und Angelika Linke

De Gruyter 


\section{Redaktion: Franz Josef Berens}

ISBN 978-3-11-022205-0

e-ISBN 978-3-11-022361-3

Bibliografische Information der Deutschen Nationalbibliothek

Die Deutsche Nationalbibliothek verzeichnet diese Publikation in der Deutschen Nationalbibliografie; detaillierte bibliografische Daten sind im Internet über http://dnb.d-nb.de abrufbar.

(C) 2010 Walter de Gruyter GmbH \& Co. KG, Berlin/New York

Druck: Hubert \& Co. GmbH \& Co. KG, Göttingen

$\infty$ Gedruckt auf säurefreiem Papier

Printed in Germany

www.degruyter.com 


\section{Inhalt}

Arnulf Deppermann / Angelika Linke: Einleitung: Warum „Sprache intermedial"?

Ludwig M. Eichinger: Begrüßung: Vom Wandel der modalen

Zeiten. Oder: Wie hoch das Wort zu schätzen sei...................................1

\section{Die Materialität von Stimme und Schrift}

Sybille Krämer: Sprache, Stimme, Schrift: Zur impliziten Bildlichkeit sprachlicher Medien

Ines Bose: Stimmlich-artikulatorischer Ausdruck und Sprache

Elisabeth Reber / Elizabeth Couper-Kuhlen: Interjektionen zwischen Lexikon und Vokalität: Lexem oder Lautobjekt?....

Jürgen Spitzmüller: Typografische Variation und (Inter-)Medialität.

Zur kommunikativen Relevanz skripturaler Sichtbarkeit.

\section{Leiblichkeit und Räumlichkeit sprachlicher Praktiken}

Angelika Linke: Historische Semiotik des Leibes in der Kommunikation: Zur Dynamisierung von Körper und Sprache im ausgehenden 17. und im 18. Jahrhundert

Heiko Hausendorf: Interaktion im Raum. Interaktionstheoretische Bemerkungen zu einem vernachlässigten Aspekt von Anwesenheit

Reinhold Schmitt / Arnulf Deppermann: Die multimodale

Konstitution eines imaginären Raums als interaktive

Problemlösung.

Stephan Habscheid / Jan Gerwinski / Tobias Dyrks / Sebastian

Denef / Leonardo Ramirez: Artikulationsarbeit und mediengestützte Ortserkundung. Multimodale und multilokale Kommunikation in Notfalleinsätzen.

Peter Auer: Sprachliche Landschaften. Die Strukturierung des

öffentlichen Raums durch die geschriebene Sprache. 


\section{Intermediale Relationen}

Ludwig Jäger: Intermedialität - Intramedialität - Transkriptivität. Überlegungen zu einigen Prinzipien der kulturellen Semiosis

Martin Steinseifer: Prägnanzen. Bilder und ihre Effekte in der pragmatischen Linguistik

Werner Holly: Besprochene Bilder - bebildertes Sprechen.

Audiovisuelle Transkriptivität in Nachrichtenfilmen und

Polit-Talkshows

Ulrich Schmitz: Schrift an Bild im World Wide Web. Articulirte

Pixel und die schweifende Unbestimmtheit des Vorstellens

Jannis Androutsopoulos: Multimodal - intertextuell - hetero-

glossisch: Sprach-Gestalten in „Web 2.0“-Umgebungen.

Angela Keppler: Die wechselseitige Modifikation von Bildern und Texten in Fernsehen und Film

Christofer Jost / Klaus Neumann-Braun / Axel Schmidt:

Bild-Text-Ton-Analysen intermedial - am Beispiel von Musik(video)clips

Alle Abbildungen dieses Bandes findet man auch auf der Internetseite des Instituts für Deutsche Sprache unter http://www.ids-mannheim.de/pub/laufend/ jahrbuch/jb2009_bilder/. 
Arnulf Deppermann / Angelika Linke

\section{Einleitung: Warum „Sprache intermedial“?}

,Intermedialität' ist seit einigen Jahren zu einem Leitbegriff der Medienund Kulturwissenschaften geworden ist (z.B. Rajewsky 2002; Leschke 2003). In der Sprachwissenschaft wurde dieses Stichwort dagegen bislang noch kaum aufgegriffen. Dieser Band möchte zeigen, wieso die Sprache einer intermedialen Betrachtungsweise und die Linguistik einer eigenständigen Theoretisierung dieses Zugangs bedürfen. Er geht zurück auf die Referate der 45. Jahrestagung des Instituts für Deutsche Sprache, die vom 10.-12. März 2009 unter dem Titel „Sprache intermedial: Stimme und Schrift, Bild und Ton" stattfand. Die Beiträge des Bandes erkunden die neuen Perspektiven, die sich einer Linguistik eröffnen, die ihren Gegenstand konsequent als medial verfassten und in intermedialen Bezügen konstituierten begreift und empirisch erforscht.

Ausgangspunkt für diesen Ansatz sind zunächst einmal zwei ganz triviale, überall und von jedem zu machende Beobachtungen:

- Sprache kommt nie als solche, sondern immer in einer bestimmten medialen (und materiell gebundenen) Erscheinungsform, als gesprochene Rede, geschriebener Text oder in Gebärdenform vor.

- Sprache kommt nicht allein, sondern im Verhältnis mit anderen Modalitäten der Kommunikation, mit Mimik, Gestik, Blick, Bild, Geräusch, Musik etc. vor.

Diese beiden Beobachtungen sind Ausgangspunkt für eine neue Sicht des Gegenstands ,Sprache diesseits seiner disziplinären Idealisierung und Zurichtung als System und als Produktion von nach schriftsprachlichen Standards wohlgeformten Sätzen. Sprache wird in der Linguistik weitenteils immer noch als ein abstraktes, prämediales System begriffen, das mündlich oder schriftlich realisiert werden kann. Wie unter anderem Krämer (2002) zeigt, war diese medialitätsindifferente Konzeption von Sprache, die meist an der traditionellen Rezeption von de Saussure festgemacht wird, konstitutiv für die Ausdifferenzierung der Lingustik als Wissenschaft mit einem eigenständig konstituierten Gegenstandsbereich und damit für einen Prozess, den Ludwig Jäger als „Geschichte der Sprachwissenschaft als Erosionsgeschichte ihres Gegenstandes" (Jäger 1993) beschrieben hat. Die amediale Auffassung von ,Sprache“ blieb auch ungeachtet späterer paradigmatischer Umwälzungen in der Linguistik bestehen, so insbesondere im lange Zeit hegemonialen, generativen Paradigma mit Chomskys Konzeption der mentalen i-language, die im Unterscheid zur als Rede und Text rea- 
lisierten e-language den eigentlichen und einzig systematischen Gegenstand der Linguistik ausmache (Chomsky 1986). Die sogenannte „Pragmatische Wende" der Sprachwissenschaft in den 70er Jahren des letzten Jahrhunderts hatte zwar zu einer neuen Aufmerksamkeit auf die konkreten Erscheinungsformen von Sprache geführt und mit Textlinguistik und Gesprächsanalyse neue Forschungsfelder erschlossen, eine entsprechend grundlegende sprachtheoretische Diskussion bzw. Selbstreflexion der Sprachwissenschaft war jedoch ausgeblieben.

In den letzten Jahren mehren sich aber die Stimmen, die in der konkreten medialen Verfasstheit von Sprache-im-Gebrauch und in ihrer intermedialen Einbettung in nicht-sprachliche Aktivitäten und mediale Konfigurationen nicht eine sekundäre Akzidenz, der sich marginale Bindestrichlinguistiken widmen dürfen, sondern den Schlüssel zu einem besseren, gegenstandsadäquaten Verständnis von Sprache überhaupt sehen. Sie setzen an drei eng miteinander verknüpften Ausgangspunkten an: a) der Materialität, b) der Leiblichkeit und c) der intermedialen Relationierung sprachlicher Phänomene.

\section{Die Materialität von Stimme und Schrift}

Mit der seit gut 20 Jahren intensivierten linguistischen Erforschung der Unterschiede von Mündlichkeit und Schriftlichkeit (Koch/Oesterreicher 1986; Raible 1994), die auch wichtige Anstöße aus Nachbardisziplinen erhalten hat (Gumbrecht/Pfeiffer (Hg.) 1988; Wiethölter/Pott/Messerli (Hg.) 2008), ist die Frage nach der Relevanz der Materialität sprachlicher Phänomene zu einem zentralen Anliegen der Sprachtheorie geworden (vgl. z.B. Krämer/König (Hg.) 2002; Linke/Feilke (Hg.) 2009). Die neuere Forschungsgeschichte macht deutlich, dass es sich hier nicht nur um eine randständige Differenz medialer Realisierungen handelt. Mit „Stimme“ und "Schrift" sind prototypisch vollkommen verschiedene Konstitutionsbedingungen sprachlicher Praxis angesprochen (wie gegebene vs. nicht gegebene Kopräsenz von Sprecher und Hörer, geteiltes vs. divergentes Hintergrundwissen, gemeinsamer vs. unterschiedlicher Wahrnehmungsraum, Bekanntheit vs. Anonymität, Multi- vs. Monomodalität der Kommunikation etc.). Diese Faktoren liefern Explananda für die Funktionen, Formen, Regeln und Realisierungs- und Verwendungspotenziale der verschiedenen Erscheinungsformen von Sprache (vgl. z.B. Fiehler et al. 2004; Stetter 1997). Darüber hinaus haben nicht zuletzt die neueren Erkenntnisse aus der Erforschung von Gebärdensprachen gezeigt, dass auch die Figuration eine mögliche - evolutionär allenfalls primäre - sprachliche Medialität darstellt (Jäger 2001). Ebenso deutlich geworden ist in der neueren, mediensensiblen sprachtheoretischen Diskussion, dass das gesellschaftlich wie wissenschaftshistorisch eingespielte Verständnis der Natur der Sprache und ihres Ver- 
hältnisses zu Denken und Wirklichkeit, dass Debatten über die sozialen Aufgaben von Sprache, über ihre sprachplanerische Gestaltung und ihren richtigen Gebrauch sowie über den Zusammenhang von Sprache und gesellschaftlicher Entwicklung ganz wesentlich davon abhängen, ob Schrift oder Stimme jeweils als Zentrum oder als Epiphänomen angenommen werden (vgl. z.B. Linell 2005 vs. Derrida 1974).

In diesem Band wird der Gedanke der Irreduzibilität der materialen Erscheinung von Sprache als Stimme und Schrift zunächst grundlegend von Sybille Krämer entfaltet, die sich dann spezifisch der Ikonizität der Schrift als Schriftbildlichkeit zuwendet. Diese Auseinandersetzung mit dem semiotischen Potential von Schrift, die sowohl zu einem neuen Verständnis von Schrift und Schriftlichkeit als auch von Bildlichkeit führt, ist ohne ein neues Verständnis für die materiale Seite von Sprache nicht denkbar. Diese materiale Perspektive hat in den letzten Jahren Phänomene ins Zentrum der linguistischen Aufmerksamkeit gerückt, die bislang allenfalls in Grenzgebieten der Linguistik angesiedelt wurden. Die analogen Eigenschaften der Schrift und der Stimme rühren an die Grenzen der Vorstellung von der Sprache als einem reinen System von Oppositionen konventioneller Types (s.a. Krämer 2003). Die Rede ist hier vor allem von der Prosodie und weiteren Aspekten des Sprechausdrucks sowie vokalischen Produktionen jenseits kanonischer Lexikalisierungen (Couper-Kuhlen/Ford (Hg.) 2004). Ines Bose sowie Elisabeth Reber und Elizabeth Couper-Kublen erkunden in ihren Beiträgen solche Erscheinungen der vokalen Kommunikation, in denen kommunikative Erscheinungen jenseits der disziplinär eingespielten Grenzen des linguistischen Systems und im Übergang zum psychophysischen Körperausdruck wirksam werden, die als in der Kommunikation systematisch eingesetzte soziale Praktiken zu rekonstruieren sind. Traditionelle Grenzen von Verbalem und (bloß) Vokalem, Lexem und Lautgestalt, Stimme, Prosodie und Phonetik werden von den Phänomenen her fraglich und sind von ihnen aus neu zu denken. Beide Beiträge zeigen für das Sprechen ebenso wie Jürgen Spitzmüller für die Schrift in seinem Beitrag zur Typographie, dass Sprache nicht nur und oft gar keine referenziell-propositionale, sondern ästhetische, beziehungsbezogen-soziale, normative und affektive Qualitäten und Funktionen hat, die sie nicht als abstraktes System besitzen kann, sondern nur kraft ihrer Materialität, als visuelle, akustische und leibliche Erscheinung in ihrer jeweiligen konkreten Situiertheit zu gewinnen vermag.

\section{Leiblichkeit und Räumlichkeit sprachlicher Praktiken}

Die Leiblichkeit des Sprechens manifestiert sich nicht nur im vokalen Ausdruck. Seit einigen Jahren wächst in der Gesprächsforschung die Einsicht, dass Gespräche nicht einfach im Austausch verbaler Turns zwischen Spre- 
chern und Hörern bestehen, sondern dass es sich um Interaktionen von multimodal Beteiligten handelt (Goodwin 2000; Norris 2004; Schmitt (Hg.) 2007). Der klassische konversationsanalytische Ansatz erweist sich unter dieser neuen Perspektive als reduktionistisch. Damit stellt sich die Frage danach, wie Sprechen nicht nur sequentiell, in der Reihung aufeinander folgender Handlungen, sondern auch simultan, in der Koordination mit Gestik, Mimik, Blick, dem Umgang mit Objekten und der Bewegung im Raum organisiert ist. Leib und Raum treten damit als konstitutive Elemente sprachlicher Praxis in den Vordergrund; neben der Zeit erscheint auch der Raum als eine nicht nur für die Schriftlichkeit, sondern in spezifischer Weise auch für die Mündlichkeit grundlegende Dimension, deren sprach- und interaktionstheoretische Aufarbeitung allerdings erst noch zu leisten ist. Die Beiträge von Hausendorf, Schmitt/Deppermann und Habscheid/Gerwinski/Dyrks/ Denef/Ramirez befassen sich mit der unhintergehbaren leiblich-räumlichen Situiertheit sprachlicher Praktiken, mit denen zugleich Räume durch und für die Interaktionsteilnehmer sprachlich selektiv relevant gemacht, strukturiert und mit Bedeutung gefüllt werden. Der Raum erweist sich so nicht nur als Voraussetzung und Ressource kommunikativer Praxis, sondern gleichzeitig als deren Produkt, der Körper nicht nur als Trägermedium von Sprache, sondern als semiotisch relevante Komponente jeglicher face-to-faceKommunikation. Leiblichkeit und Räumlichkeit sprachlicher Praktiken sind dabei - wie auch Sprache selbst - historischen Veränderungen und Zurichtungen unterworfen. In ihrem Beitrag diskutiert Angelika Linke in historisch-mentalitätsgeschichtlicher Perspektive die grundlegende Bedeutung und den epochalen Wandel der Auffassungen von Leiblichkeit und Räumlichkeit und ihres Verhältnisses zur Sprache im Übergang vom adlig geprägten Barock- zum bürgerlich geprägten Aufklärungszeitalter. Peter Auer zeigt zudem, dass die Gleichzeitigkeit von Raumgebundenheit und Raumkonstitutivität nicht nur für die Mündlichkeit, sondern auch in theoretisch bisher kaum beachteter Weise für viele schriftliche Erscheinungsformen von Sprache konstitutiv ist.

\section{Intermediale Relationen}

Die leibliche Kommunikation ist selbst bereits intrinsisch intermedial, wenn unter „Medium“ eine jeweils materialspezifische semiotische Ressource (wie Stimme, Blick, Mimik) mit eigenen Produktionsbedingungen und einem eigenen Formenrepertoire mit jeweiligen semiotischen Potenzialen verstanden wird. Ludwig Jäger konzeptualisiert inter- und intramediale Bezüge zeichentheoretisch als ,Transkription', durch die die Bedeutungskonstitution mit nicht still zu stellenden semiotischen Transformationsmöglichkeiten ausgestattet ist, welche sie für Störungen ebenso anfällig wie stets zur Neu- 
kontextualisierung und -interpretation offen sein lassen. Das Transkriptionskonzept wird im Beitrag von Werner Holly in der vergleichenden Untersuchung verschiedener Fernsehgattungen empirisch konkretisiert. Er zeigt, wie TV-Nachrichten und Diskussionssendungen unterschiedliche transkriptive Verhältnisse zwischen Bild und Sprechen realisieren. Intermedialität im Verständnis des Zusammenspiels unterschiedlicher materialer Ressourcen der Sinnkonstitution ist damit ein Schlüsselkonzept für die Analyse von Medienprodukten - „Medien“ hier verstanden im Sinne technisch vermittelter Aufzeichnung und Übertragung von Kommunikaten. Angela Keppler argumentiert für die Unabdingbarkeit der intermedialen Betrachtungsweise, die Bild und Filmtext bzw. die Sprache im Film als „gleichursprünglich“ behandelt, für eine gegenstandsangemessene Filmanalyse. Während die traditionell-disziplinäre Konzeptualisierung von Sprache in der Linguistik suggeriert, dass monomediale bzw. monomodale Kommunikation der Normalfall und eine entsprechend fokussierte Analyseperspektive hinreichend sei, erzwingt das Ausgehen von Sprache-im-Gebrauch, d.h. von den Phänomenen der gesellschaftlichen Kommunikationspraxis, diese grundsätzlich als multimodal bzw. multimedial zu verstehen (vgl. a. Kress/van Leeuwen 2001; Baldry/Thibaut 2005). Nicht erst in Film und Fernsehen, sondern schon in statischen Druckerzeugnissen und Websites sind dabei Text-Bild-Verhältnisse zentral (Stöckl 2004). Martin Steinseifer sieht in seinem Beitrag den besonderen, über die Leistungsmöglichkeiten der Schrift hinausgehenden und sie ergänzenden Prägnanzeffekt von Bildern für den Rezipienten in ihrem spezifischen Verhältnis von (erstmaligem) Zeigen und Wiedererkennen begründet. Wenn im vorliegenden Tagungsband von „Intermedialität“ die Rede ist, sind damit also nicht erst die neuen „hybriden“ Medien gemeint, die Text, Bild, Animation und Ton in einem Kommunikat verbinden. Doch natürlich stellen sie aufgrund ihrer Komplexität und Veränderungsdynamik ein Forschungsfeld par excellence für intermediale Relationen dar. Ulrich Schmitz diskutiert die radikalen Veränderungen, die eine neu situierte, nämlich in Bilder und Sehflächen-Designs eingepasste „tertiäre Schriftlichkeit“, wie sie sich gegenwärtig im World Wide Web entwickelt, im Vergleich zu traditionellen, von der Buchkultur bestimmten Vorstellungen von Grammatikalität, Referenzkonstitution und Textdisposition, erfährt. Jannis Androutsopoulos untersucht Web 2.0-Angebote in Bezug auf die Präferenzen und Gestaltungsprinzipien, die die sprachliche Produktion im Kontext interaktiver und multimedialer Gestaltungsmöglichkeiten einerseits, spezifischer sozialer Konstellationen von Adressaten und Zugehörigkeitskonstellationen andererseits prägen. Hier meldet sich eine weitere Dimension von Intermedialität an, nämlich eine der Produktion von Kommunikaten inhärente Intertextualität bzw. Interdiskursivität (vgl. schon Bachtin 1981), die besonders durch den anknüpfenden Verweis 
auf frühere Kommunikate und durch die Situierung in und die aktive Herstellung von Medienverbünden (z.B. durch Verlinkung) selbsttranszendierend und bedeutungskonstituierend genutzt wird. Im Beitrag von Jost, Neumann-Braun und Schmidt werden schließlich die komplexen intermedialen Bezüge im Musikvideo zum Thema, welche nicht nur die in der Forschungsliteratur bereits vielfach beachtete Relation zwischen Bild und Musik, sondern auch die weiteren Ebenen der Instrumentierung, des Texts und der Stimme betreffen. Neben der Interdiskursivität wird hier einmal mehr besonders am Gesang deutlich, wie sehr die konnotativen, sozial und emotional relevanten Dimensionen des Kommunikationsereignisses in seiner Materialität verkörpert und von ihr unablösbar sind - doch der wissenschaftlichen Durchdringung ungleich mehr Widerstand entgegen setzen als die propositionalen und diegetischen Strukturen der Kommunikation.

Obgleich ,Intermedialität ${ }^{\star}$ ein abgeleiteter Begriff ,zweiter Ordnung' ist, steht er also nicht für eine sekundäre, eine reine Sprache nachträglich in ihren Kontext setzende und ihre Realisierungsformen hervorhebende Perspektive. ,Intermedialität ${ }^{`}$ verweist vielmehr auf genau das Gegenteil: Der Begriff lenkt den Blick auf die konkrete Verfasstheit, in der uns Sprache in ihren Kontexten begegnet. Die Beiträge des Bandes fragen zum einen, was die Sprachwissenschaft aus den neuen Erkenntnissen und den Debatten der Medien- und Literaturwissenschaft, der Sozialwissenschaft und Geographie, der Sprechwissenschaft und Philosophie für ihr Gegenstandsverständnis und ihre Methodologie lernen kann. Umgekehrt aber will dieser Band auch der Stimme der Sprachwissenschaft in der Diskussion über Intermedialität mehr Gehör verschaffen. Wurde nämlich vor gar nicht so langer Zeit die Welt als Text konzeptualisiert (im Poststrukturalismus: z.B. Derrida in Engelmann 1990; in der objektiven Hermeneutik: z.B. Garz/ Kraimer 1994; in der Kulturwissenschaft: z.B. Bachmann-Medick (Hg.) 1996) und damit einseitig der Sprache assimiliert, so scheint nun in der Umkehrbewegung des visual bzw. pictorial turn (Boehm (Hg.) 1994; Mitchell 2008) oft vergessen zu werden, wie entscheidend unsere Wahrnehmung und unsere Interpretationen von Bildern (und anderen nicht-sprachlichen Phänomenen) sprachlich vorgeprägt und gerahmt werden und nur in Interaktion mit Sprache entstehen. Die Sprachwissenschaft hat also hier die Aufgabe und die Chance, die Sprache als material konstituiert und in intermedialen Bezügen fungierend zu begreifen, um zeigen zu können, wie eine so konzeptualisierte Sprache selbst eine integrale und prägende Konstituente intermedialer Konstellationen ist. 


\section{Literatur}

Bachmann-Medick, Doris (Hg.) (1996): Kultur als Text. Die anthropologische Wende in der Literaturwissenschaft. Frankfurt a.M.

Bachtin, Michael M. (1981): Die Ästhetik des Wortes. Frankfurt a.M.

Baldry, Anthony/Thibault, Paul (2005): Multimodal transcription and text analysis: A multimedia toolkit and coursebook. London.

Boehm, Gottfried (Hg.) (1994): Was ist ein Bild? München.

Chomsky, Noam (1986): Knowledge of language. New York.

Couper-Kuhlen, Elizabeth/Ford, Cecilia (Hg.) (2004): Sound patterns in interaction. Amsterdam.

Derrida, Jacques (1974): Grammatologie. Frankfurt a.M.

Engelmann, Peter (1990): Einführung: Postmoderne und Dekonstruktion. In: Engelmann, Peter (Hg.): Postmoderne und Dekonstruktion. Stuttgart, S. 5-32.

Fiehler, Reinhard/Barden, Birgit/Elstermann, Mechthild/Kraft, Barbara (2004): Eigenschaften gesprochener Sprache. Theoretische und empirische Untersuchungen zur Spezifik mündlicher Kommunikation. (= Studien zur Deutschen Sprache 30). Tübingen.

Garz, Detlev/Kraimer, Klaus (1994): Welt als Text. Frankfurt a.M.

Goodwin, C. (2000): Action and embodiment within situated human interaction. In: Journal of Pragmatics 32, S. 1489-1522.

Gumbrecht, Hans Ulrich/Pfeiffer, K. Ludwig (Hg.) (1988): Materialität der Kommunikation. Frankfurt a.M.

Jäger, Ludwig (1993): „Language, what ever that may be“. Die Geschichte der Sprachwissenschaft als Erosionsgeschichte ihres Gegenstandes. In: Zeitschrift für Sprachwissenschaft 12,1, S. 77-106.

Jäger, Ludwig (2001): Sprache als Medium. Über die Sprache als audio-visuelles Dispositiv des Medialen. In: Wenzel, Horst/Seipel, Wilfried/Wunberg, Gotthart (Hg.): Audiovisualität vor und nach Gutenberg - Zur Kulturgeschichte der medialen Umbrüche. (= Schriften des Kunsthistorischen Museums 6). Wien, S. 19-42.

Koch, Peter/Oesterreicher, Wulf (1985): Sprache der Nähe - Sprache der Distanz. Mündlichkeit und Schriftlichkeit im Spannungsfeld von Sprachtheorie und Sprachgeschichte. In: Romanistisches Jahrbuch 36, S. 15-43.

Krämer, Sybille (2002): Sprache - Stimme - Schrift. Sieben Gedanken über Performativität als Medialität. In: Wirth, Uwe (Hg.): Performanz: zwischen Sprachphilosophie und Kulturwissenschaften. Frankfurt a.M., S. 323-346.

Krämer, Sybille (2003): Negative Semiologie der Stimme. In: Epping-Jäger, Cornelia/ Linz, Erika (Hg.): Medien/Stimmen. Köln, S. 65-84.

Krämer, Sybille (2006): Die ,Rehabilitierung der Stimme‘. Über die Oralität hinaus. In: Krämer, Sybille/Doris Kolesch (Hg.): Stimme. Annäherung an ein Phänomen. Frankfurt a.M., S. 269-295. 
Krämer, Sybille/König, Ekkehard (Hg.) (2002): Gibt es eine Sprache hinter dem Sprechen? Frankfurt a.M.

Kress, Gunter/van Leeuwen, Theo (2001): Multimodal discourse: The modes and media of contemporary communication. London.

Leschke, Rainer (2003): Einführung in die Medientheorie. München.

Linke, Angelika/Feilke, Helmuth (Hg.) (2009): Oberfläche und Performanz. Untersuchungen zur Sprache als dynamischer Gestalt. (= Reihe Germanistische Linguistik 283). Tübingen.

Linell, Per (2005): The written language bias in linguistics: Its nature, origins, and transformations. London.

Mitchell, William J. Thomas (2008): Bildtheorie. Frankfurt a.M.

Norris, Sigrid (2004): Analyzing multimodal interaction. London.

Raible, Wolfgang (1994): Orality and literacy. In: Günther, Hartmut/Ludwig, Otto (Hg.) (1994): Schrift und Schriftlichkeit. Writing and its use. Ein interdisziplinäres Handbuch internationaler Forschung. Berlin/New York, S. 1-17.

Rajewsky, Irina O. (2002): Intermedialität. Tübingen.

Schmitt, Reinhold (Hg.) (2007): Koordination: Analysen zur multimodalen Interaktion. (= Studien zur Deutschen Sprache 38). Tübingen.

Stetter, Christian (1997): Schrift und Sprache. Frankfurt a.M.

Stöckl, Hartmut (2004): Die Sprache im Bild - das Bild in der Sprache: zur Verknüpfung von Sprache und Bild im massenmedialen Text. (= Linguistik - Impulse \& Tendenzen 3). Berlin.

Wiethölter, Waltraud/Pott, Hans-Georg/Messerli, Alfred (Hg.) (2008): Stimme und Schrift. Zur Geschichte und Systematik sekundärer Oralität. München. 
Ludwig M. Eichinger

\section{Begrüßung: Vom Wandel der modalen Zeiten Oder: Wie hoch das Wort zu schätzen sei}

\section{Sprache verstehen - verstehen, was das meint}

Dass sich Linguisten mit der Sprache, ihrem systemhaften Aufbau und ihrer Strukturierung auf verschiedenen Ebenen beschäftigen, muss man eigentlich gar nicht erwähnen. Wer sollte das sonst tun?

Auch wenn man das feststellt, steckt dahinter schon etwas, was im Rahmen der 45. Jahrestagung des IDS im Jahr 2009 bei ihrem Thema „Sprache intermedial: Stimme und Schrift, Bild und Ton" allerdings noch eine größere Rolle spielt. Hier gilt nämlich besonders, dass die Erkennbarkeit bestimmter Bestandteile oder Aspekte sprachlicher Interaktion, die Möglichkeit, sie zur Beobachtung festzuhalten, zu wiederholen oder dem Experiment zugänglich zu machen, die Voraussetzung dafür ist, sie eigentlich erst mit einem wissenschaftlichen Blick zu erfassen. Was heißt das praktisch? Manches davon hat bei den Themen unserer Tagungen in den vergangenen Jahren ebenfalls eine Rolle gespielt. Gelegentlich ganz explizit, so wenn es beim „Text-Verstehen“ um „Grammatik - und darüber hinaus “1 geht, häufiger implizit, etwa, wenn klar wird, dass sich mit der Existenz großer Sprachkorpora bestimmte Fragen überhaupt erst stellen lassen, wenn man die Chance auf eine empirisch begründete Antwort haben will, ${ }^{2}$ oder wenn man sieht, dass erst die Nutzung bildgebender Verfahren der Neurophysiologie Antworten z.B. auf die Frage der Interaktion zwischen Prosodie und Grammatik erlaubt. ${ }^{3}$ Man sieht auch hier schon, dass es nicht zuletzt neue technische Möglichkeiten der Dokumentation und Analyse sind, die den wissenschaftlichen Prozess in ungeahnter Weise voranbringen. Dass die Materialität der Kommunikation ein wesentlicher Faktor sprachlicher Entwicklung ist, ist ein einigermaßen gängiger Gedanke; ein doch deutlicher Schub in den technischen Dokumentationsmöglichkeiten hat uns zumindest praktisch auch alle gelehrt, dass die Möglichkeiten der Erfassung Antworten auf Fragen zu geben erlauben, die man ohne sie kaum in das ernsthafte Spektrum der eigenen wissenschaftlichen Tätigkeit aufgenommen hätte.

Was die Erhebungs-, Dokumentations- und Analysemöglichkeiten angeht, so gilt das in ganz besonderem Maße für die wissenschaftliche Bearbeitung gesprochener Sprache. Harald Thun (1993) hat in erhellender Weise dargelegt und nachvollzogen, wie die Miniaturisierung der Tonaufnahmegeräte

Siehe Blühdorn/Breindl/Waßner (Hg.) (2006).

Siehe Kallmeyer/Zifonun (Hg.) (2007).

Siehe Kämper/Eichinger (Hg.) (2008). 
die Forschungspraxis in der Dialektologie verändert hat. Aber daran sieht man auch schon, dass es nicht die Techniken allein sind, sondern die Techniken in Interaktion mit den methodologischen und linguistischen Diskussionsständen. ${ }^{4}$ Und so haben wir seit einiger Zeit jedenfalls eine genauere Vorstellung zur Distribution und Schichtung regionaler Sprachformen. ${ }^{5}$

Es ist das eine sachlich gut passende Stelle um anzumerken und meiner Freude darüber Ausdruck zu geben, dass auf der Jahrestagung 2009 des IDS der Hugo-Moser-Preis an Alexandra Lenz verliehen werden konnte, eine junge Sprachwissenschaftlerin, deren Arbeiten in diesem Bereich deutliche Zeichen gesetzt haben. Den Preis bekam sie für ein Vorhaben zugesprochen, in dem ein zentraler und für verschiedene grundlegende Funktionen zur Verfügung stehender Bereich des verbalen Wortschatzes des Deutschen untersucht werden soll, nämlich der der Besitzwechsel-Verben.

Die Darstellungsweise meiner bisherigen Ausführungen, die den Einbezug weiterer Faktoren in die sprachwissenschaftliche Analyse als eine Art Ausgreifen von einem linguistischen Kern aus beschrieben hat, ist aber nicht hinreichend, wenn man erläutern will, welche Idee die diesjährige Tagung leitet. Zwar stimmt auch für diesen Kontext, dass der ganz andere Blick ohne die problemlose Verfügbarkeit, Analysierbarkeit und Reproduzierbarkeit von Video-Daten kaum denkbar ist, aber sich nur darauf zu berufen, wäre eine zu technizistische Sicht einer konzeptuellen Wendung. Beim Verstehen der Interaktionen in unserer Welt ist die Sprache ein - wenn auch phänotypisch und strukturell - herausgehobener Modus im Inventar der verständnissichernden Techniken. Wir verstehen, wenn man so will, was geschieht und dabei werden wir auch, aber nicht nur, sprachlich instruiert. ${ }^{6}$

\section{Verstehen-Wollen und Verstanden-werden-Wollen}

\subsection{Die Schrift und die Reduktion der Modi}

Fokussiert wird auf der diesjährigen Tagung aber eben jene von der Untersuchung der Sprache und ihres variierenden Gebrauchs aus gesehen andere Seite, nämlich die, dass man sich beim Verstehen- und Verstanden-WerdenWollen all der verschiedenen Möglichkeiten bedient, die einem zur Verfügung stehen - und eigentlich tut man das im Normalfall, ohne sich dabei all die Optionen bewusst zu machen, die man nutzt.

Im Hinblick auf die Verfügbarkeit von Korpora vgl. dazu Eichinger (2007).

5 Das IDS leistet dazu einen Beitrag mit dem Projekt „Deutsch heute“, das die Basis für eine präzisere Beschreibung standardsprachlicher und -naher Sprechformen bietet. Vgl. Eichinger/Kallmeyer (Hg.) (2005).

6 Wie sich das im Ablauf der Tagung entfaltet, wird in der Einführung der Herausgeber erläutert. 
Bei der Interaktion mittels der Schrift, also beim Lesen von Büchern zum Beispiel und beim Schreiben fällt das nicht so sehr auf. Man kann allerdings beim Lesenden und wohl auch beim Schreibenden manchmal ein Stirnrunzeln oder auch ein Lächeln entdecken, das erkennbar einen Teil der über die Schrift vermittelten Verständigung darstellt. Und es mag durchaus schriftliche Texte geben, die mit solchen Reaktionen rechnen und auf ihre Möglichkeit Bezug nehmen. Beim Alleinlesen, das seit dem beginnenden neunzehnten Jahrhundert unseren Umgang mit Geschriebenem und Gedrucktem prägt, wird man nicht viel mehr von dem finden, was man multimodal nennen könnte. Das gilt zumindest, wenn man darunter die mimischen und gestischen Aktionen und Reaktionen der Beteiligten versteht. Gedruckte Texte jedenfalls sind ja im Prinzip von ihrem Autor und seinen auf der angedeuteten Linie liegenden Möglichkeiten abgeschnitten.

Schriftlichkeit selbst ist prototypisch vom Modus der Distanz geprägt und hat daher in entfalteten Schriftkulturen wie der Deutschen auch Techniken entwickelt, die das deutlich signalisieren. Die Tiefe der Orthographien, in denen die Sprachen der europäischen Schriftkulturen kodiert werden, ist ein Mittel zu dieser Auszeichnung.

\subsection{Die anderen Seiten schriftlicher Interaktion}

\subsubsection{Typo- und Orthographisches}

Allerdings hat der Autor, auch über Fragen der gewählten Sprachform und des praktizierten Stils hinaus, durchaus Möglichkeiten, über Eigenheiten der Materialität gedruckter Texte zumindest die Leseerwartung zu steuern. Eine nicht unwichtige Rolle spielt dabei die typografische Gestaltung. Man kann damit mancherlei signalisieren.

Um ein historisches Beispiel heranzuziehen, könnte man darauf verweisen, dass zu Zeiten, als gebrochene Schriften den Normalfall für die Schreibung des Deutschen darstellten, Wörter aus anderen Sprachen, nicht zuletzt aus dem Lateinischen, in lateinischer Schrift wiedergegeben wurden. Aber auch bis in unseren heutigen Alltag des Schreibens reicht diese Erscheinung hinein. Wir, die wir nun die meisten unserer Texte als Computerausdrucke, also irgendwie gedruckt sehen - die Schreibmaschine machte ihrem Namen noch Ehre, mit ihr schrieben wir noch -, haben in den letzten Jahrzehnten eine typographische Entwicklung mitgemacht, die uns auch signalisiert, dass es nun um „Gedrucktes“ geht. So waren die Anfänge des schreibenden Computer-Alltags geprägt von zwei Arten von typographischen Einstiegen. Als Schreibmaschinenschreiber wurden wir abgeholt mit einer einfachen Serifenschrift vom Typ Courier, die uns unser Tun als eine Art avanciertes Schreibmaschineschreiben erscheinen ließ. Die - kärgliche Modernität des Neuen repräsentierte gleichzeitig eine dünne und eckige serifenlose Schrift, wobei beide Fonts ihre Beliebtheit wohl ihrer Affinität 
zu den Möglichkeiten des Nadeldruckers verdankten. Zwischenzeitlich sind wir nun in die Druckwelt hineingewachsen, indem wir eine Buch-Serifenschrift wie Times New Roman als unsere normale Schreibschrift nutzen und eine gestaltete, wenn auch etwas gröbere - serifenlose Schrift vom Typ Arial als die moderne Variante, die zudem - wenn man die üblichen Titelund Überschriften-Vorlagen in gängigen Schreibprogrammen betrachtet - gleichzeitig die Funktion solcher Schriften als gedruckte Hervorhebungschriften teilen.

Aber die Nutzung der materialen Eigenheiten graphischer Kommunikation geht deutlich darüber hinaus. Ein ebenso einschlägiges wie neues Beispiel dafür stellt die Handhabung der Orthographie dar: so haben die größeren gedruckten Massenmedien immer schon eine Hausorthographie mit bestimmten Eigenheiten gehabt, und jetzt im Gefolge der Diskussion um die Orthographiereform, hat die Wahl einer nicht den aktuellen Regelungen folgenden orthographischen Praxis deutlich an Informationsgehalt gewonnen.

Bei Büchern zum Beispiel spielt dabei auch die weitere materiale Kontextualisierung eine Rolle - vom gesetzten gebundenen Buch bis zur im einfachen Schreibprogramm formatierten und gehefteten Broschüre reicht hier die Bandbreite, die unsere Rezipientenhaltung nicht zuletzt im Hinblick auf die Ernsthaftigkeit der übermittelten Information steuert.

\subsubsection{Interaktion der Zeichentypen}

Mehr noch wird diese Art der Rahmung konstitutiver Teil des modalen Ensembles, wenn wir in den Raum der öffentlichen Schriftlichkeit kommen, der sich mit öffentlichen Anschriften, Hinweisschildern und dergleichen beschäftigt. In den Forschungen zum lingustic landscaping hat sich dazu ja direkt eine eigene Forschungsrichtung entwickelt. Wir wollen dem hier nicht weiter nachgehen, man kann aber darauf hinweisen, dass mit der Integration ikonischer Elemente und anderer analoger Mittel im Prinzip eine Ebene genutzt wird, die im Hinblick auf traditionellere Schriftlichkeit als eine Möglichkeit der Differenzierung von Texttypen beschrieben wird. In diesem Kontext werden dabei aber eher Fragen gestellt, die darauf zielen, welche Texttypen etwa durch die Nutzung von Tabellen, Graphiken, Illustrationen oder dergleichen gekennzeichnet seien.

Da wir den Weg gewählt haben, uns von traditionelleren Aspekten der Sprachwissenschaft her dem diesjährigen Thema anzunähern, sind die Bemerkungen, die wir gemacht haben, nicht aus dem die Tagungskonzeption eigentlich leitenden Konzept der Multimodalität her geschrieben, sondern entlang traditioneller Argumentationsstränge, die zwar über lange Zeit hin bedeutsam waren, nun aber seit etwa zwei Jahrhunderten deutlich an gesellschaftlicher Geltung verloren haben. 
Die aufgeklärte Rhetorik - und daran angelehnte Interaktionstheorien wie etwa die des Dramas - betrachten die sprachliche Vermittlung auch als einen von Regeln gesteuerten und getriebenen Umsetzungsmechanismus für Gefühle. Wenn eine klassische Formulierung in diesem Kontext lautet, si vis me flere, dolendum est primum ipsi tibi, ist klar, dass hier eine harte sprechakttheoretische Kausalverbindung angenommen wird, die ihre Antwort in unmittelbarer Körperlichkeit findet. In der Situation des Lesenden, aber auch des Zusehenden ist das normalerweise aber auch das Ende der Interaktion. Dass auch die Schrift selbst in einen neben der zentralen Kodierungsfunktion für Inhalte stehenden Modus eintreten kann, konnten wir schon an den Beispielen zur Nutzung ikonischer Elemente des Schreibens und des Druckens sehen. So kann man, um das noch in eine etwas andere Richtung weiter zu führen, handschriftlich niedergelegte Nachrichten nicht nur in einem graphologischen Sinne im Hinblick auf den Schreiber deuten, ein fest aufgedrückter Bleistift, hervorgehobene Majuskeln oder Unterstreichungen und die Wahl von Satzzeichenhäufungen können durchaus im Hinblick auf die Ausdrucksfunktion gelesen werden, die etwa mit einem appellativen Text verbunden ist. Nicht umsonst nutzt die gedruckte Werbung die Variation solcher Mittel in entsprechender Weise. Von diesem eher indexikalischen Modus der Interaktion ist kein besonders weiter Weg zu dem analogischen Konzept der Verständigung über ikonische Zeichen, von den Herzen in Liebesbriefen über die Emoticons und Piktogramme der Moderne, aber auch zu den Bildgedichten durch die Zeiten.

Und wenn uns auch in der Moderne das Wissen um und der Glaube an die Lesbarkeit der Welt, von der die emblematischen Zeiten unserer Kultur lebten, abhandengekommen sind, wir haben nicht nur ein Inventar an Symbolen lesen gelernt und nutzen sie je nach unseren intertextuellen Erfahrungen, vielmehr lösen wir auch Bilder und Bildfolgen nach unseren Vorstellungen von Szenen und Ablaufsrahmungen auf bzw. interpretieren sie je nach Kontext auf diesem Hintergrund. So haben wir etwa auch mit Gesetzen filmischer Ikonographie leben gelernt und können ihre Muster nutzen. Aber das ist eigentlich wieder ein Umschwung in der Ordnung der sinnlichen Wahrnehmung, der gelernt werde musste: und so ist es nicht überraschend, dass aus den Anfangstagen öffentlicher Filmvorführung davon berichtet wird, die Zuschauer seien in Angst vor einem auf sie zufahrenden Zug geflohen. Welchen Weg wir seither gegangen sind, mag man daran sehen, dass wir unlängst staunend vor der Meldung standen, dass sich die Avatare zweier auch in unserer ersten Welt verheirateter Personen scheiden lassen wollten, wobei offenbar den beiden Beteiligten nicht ganz klar war, was das für ihre „unavatare“ Wirklichkeit zu bedeuten hätte.

Das wäre die Stelle, wo man über die Mittel von ideographischen und Alphabetschriften räsonieren könnte - aber das würde zu weit führen. 


\section{Die Reihenfolge der Wahrnehmung}

\subsection{Die Welt im Buch}

Wir können das auf sich beruhen lassen. Wir waren ja bei jener historischen Stufe angekommen, zu der die Lesbarkeit des - emblematischen - Bildes die alltägliche Welt verließ und sich als symbolische Rekonstruktion in esoterischere Räume eingeweihter Deuter zurückzog. Was allerdings bleibt, ist die Vorrangstellung des Auges als des Sinnesorgans, mittels dessen wir uns Wissen einverleiben, und nicht das Ohr, dessen Wahrnehmung insgesamt als vorübergehend und nicht rückholbar angesehen wird. Das Auge allerdings, es nimmt mit der Vorherrschaft der gelesenen (und geschriebenen) Sprache die Welt geradezu besser durch die sinnvollen Buchstabenfolgen als durch einen direkten Blick auf die Welt wahr. Und so signalisiert es ganz deutlich eine nicht nur logozentrische, sondern auch "skriptozentrische“ Sichtweise, wenn Carl Philipp Moritz im Jahr 1783 in sein „Neues A.B.C. Buch" folgendermaßen beginnen lässt:

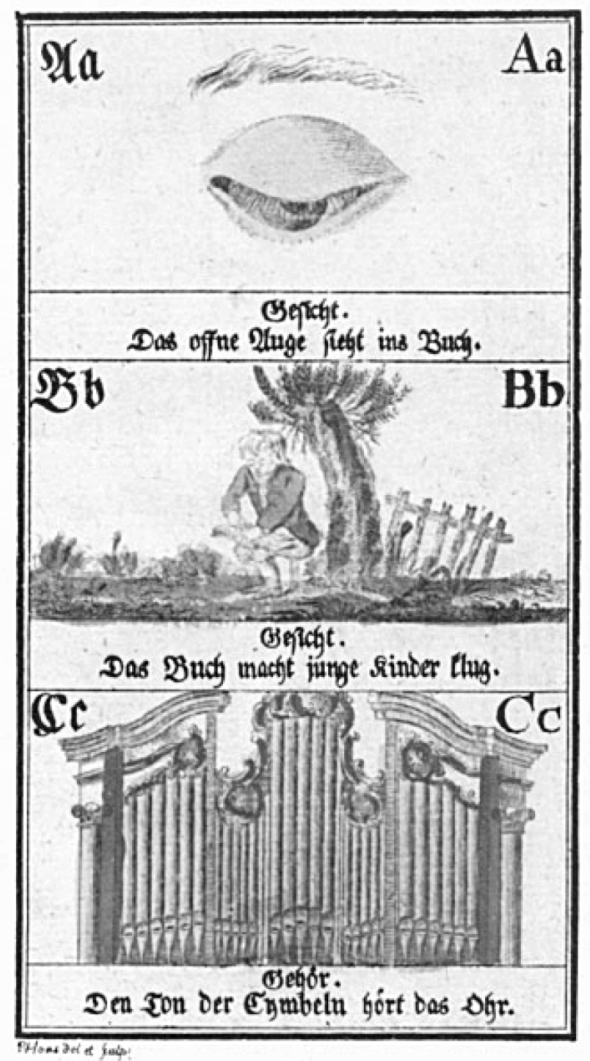


Erstes Bild.

In diesem Buche stehen Bilder und Buchstaben. Das erste Bild stellt das Auge vor, womit ich die Bilder sehe.

\section{Zweites Bild.}

Das zweite Bild stellt einen Knaben vor, der unter einem Baum sitzt, und in einem Buche lieset. Der Knabe hält den rechten Zeigefinger auf das Buch, damit er in der rechten Zeile bleibe. Der Knabe ist sehr aufmerksam und gaft nicht umher. Bei den Bildern stehen Buchstaben. Unter den Bildern stehen Worte. Wer nicht lesen kann, der besiehet nur die Bilder. Wer aber lesen kann, der lieset auch die Worte, die darunter stehen. Das offene Auge sieht ins Buch. Mein Auge ist offen, und ich sehe damit ins Buch. Das Buch macht junge Kinder klug. Ich will in diesem kleinen Buche fleißig lesen lernen, damit ich noch mehr Bücher lesen kann, wodurch ich klüger werde.

(www.hs-augsburg.de/ harsch/germanica/Chronologie/18Jh/Moritz/mor_ab0a.html\#01)

Das Buch ist es, dessen Wahrnehmung über das Auge die ,jungen Kinder“ klug macht. Das ist, wie marginal das Beispiel als solches sein mag, durchaus als Symptom lesbar, dass wir in ein Zeitalter der Schriftlichkeit eintreten, die auch durch eine weitgehende Alphabetisierung der Bevölkerung getragen wird. So ist es nicht zuletzt zunächst die Orthographie, die geregelt wird, es geht um das Lesen und das Schreiben.

\subsection{Die Dichte der Information}

Man kann dann im Verlauf des neunzehnten Jahrhunderts sehen, wie sich die Untersuchung ,wirklich“ gesprochener Sprache, wie sie zu dieser Zeit die Dialektologie unternimmt, müht, der Andersartigkeit des Phänomens mit schriftlichen Mitteln beizukommen, was bei der Aufnahme zweifellos ein noch größeres Problem ist als bei der wissenschaftlichen „Weiterverarbeitung“. Erst allmählich haben sich die Aufnahmebedingungen für gesprochene Sprache soweit perfektioniert, dass sich allmählich das Problem auf die andere Seite verschoben hat. Die Menge und die Informationshaltigkeit des Aufgenommenen erschwert uns nun die klassifizierende Beschreibung - und fordert auf jeden Fall einen außerordentlich erhöhten Analyseaufwand, der sich zumindest derzeit noch nicht über automatische Prozeduren in hinreichendem Maße reduzieren lässt. Dieses Problem verschärft sich noch einmal dramatisch, wenn die Möglichkeit der Video-Aufnahme eine multiaspektuelle Kontextualisierung verlangt. So wird die Verbindung einer möglichst weitgehenden Interaktionsanalyse mit der Typisierung der Ergebnisse sicher nicht leichter. Gerade ihr sollten wir aber nachgehen wollen, wenn wir verstehen wollen, wie wir in solchen medial überlagerten Kontexten funktionieren können, wenn wir sehen wollen, wie wir unter diesen Umständen verstehen können, worum es geht. Natürlich erkennen 
wir auch in dieser Interaktion Muster, so haben wir etwa gut gelernt, bestimmte filmische Abläufe auch in ihrer spezifischen Räumlichkeit und körperlichen Interaktion zu erkennen. Andererseits ist Schriftlichkeit in ihrer öffentlichen Funktion zum Teil sehr stark an ikonische oder indexikalische Kontexte rückgebunden, so dass wir mit geringerer Explizitheit zurechtkommen können.

\subsection{Wandel der Alltäglichkeit}

Da die Beherrschung von Schriftlichkeit seit dem Ende des achtzehnten Jahrhunderts die Teilhabe an der bürgerlich-demokratischen Entwicklung der folgenden Zeit ermöglichte, markiert ihre Dominanz einen wichtigen diskurshistorischen Schritt: Teilhabe am kommunikativen Gedächtnis und der Niederlegung des kulturellen Gedächtnisses in diesem digitalen Aufschreibsystem. Mit der Zunahme des Hörens und Bildersehens und nicht zuletzt auch des medial vermittelten Sprechens in den medialen Schritten des zwanzigsten Jahrhunderts, werden die Verhältnisse von individueller sowie näheorientierter und fest gewordener distanzorientierter Formen der Interaktion neu gemischt. Unter diesem Aspekt ist die technische Meisterung der Beobachtung der verschiedensten Modalitäten bei (auch) sprachlicher Interaktion zwar ein wichtiger Punkt für den Aufschwung dieses Tuns, aber andererseits ihrerseits auch nur ein Aspekt der Entwicklung, der dieser Art von Beobachtung eine Bedeutung verleiht, die darüber hinausgeht, sie als paralinguistisch zu sehen. Neben manch anderem mögen die in diesem Band versammelten Beiträge unserer Jahrestagung auch als Anregungen zu einer diskurs- und techniksensiblen theoretischen Modellierung dieser Sachverhalte zu lesen sein. ${ }^{8}$

\section{Schluss}

Zum Zeitpunkt der Dokumentation dieser Tagung kann man sagen, dass die Vielfalt, die sie gekennzeichnet hat, für Sprachwissenschaftler der verschiedensten Provenienz nicht nur Anregung, sondern auch Wissenswertes zu bieten hatte. Zu danken ist allen, die auf dieser Tagung referiert haben, nicht zuletzt, den Nichtlinguisten darunter, die uns halfen, einen fachspezifischen Tunnelblick zu vermeiden. Wie immer haben die für die Organisation der Tagung verantwortlichen Mitarbeiterinnen und Mitarbeiten des Hauses für einen glatten und problemlosen Ablauf gesorgt, wofür Ihnen Dank gebührt. Die inhaltliche Planung und Vorbereitung lag in den Händen von Arnulf Deppermann und Angelika Linke. Für die konzeptionelle

\footnotetext{
$8 \quad$ Ihr Zusammenhang und der Aufbau der Tagung wird in dem Beitrag von Arnulf Depper-
} mann und Angelika Linke dargestellt. 
und organisatorische Planung und Leitung des Ablaufs sei ihnen ebenfalls herzlich gedankt. Zu guter letzt möchte ich dankbar daran erinnern, dass die Stadt Mannheim und ihr Oberbürgermeister nicht nur nach guter Gewohnheit die Teilnehmer zu einem Empfang geladen hat, sondern dem Institut geholfen hat, die noch immer etwas ungewohnte Bürde der mit dem Tagungsort Rosengarten verbundenen finanziellen Lasten zu tragen. All die Genannten haben dazu beigetragen, dass die Tagung erfolgreich und in guter Atmosphäre stattfinden konnte.

\section{Literatur}

Auer, Peter (1993): Über $\bigcap$. In: Schlieben-Lange (Hg.), S. 104-138.

Blühdorn, Hardarik/Breindl, Eva/Waßner, Ulrich (Hg.) (2006): Text - Verstehen. Grammatik und darüber hinaus. (= Jahrbuch des Instituts für Deutsche Sprache 2005). Berlin/New York.

Bühler, Karl (1934): Sprachtheorie. Die Darstellungsfunktion der Sprache. Jena.

Deppermann, Arnulf/Linke, Angelika (i.d.Bd.): Einleitung: Warum „Sprache intermedial"?

Eco, Umberto (1994): Die Suche nach der vollkommenen Sprache. München.

Eco, Umberto (2000): Kant und das Schnabeltier. München.

Friederici, Angela D. (2008): Sprache und Gehirn. In: Kämper/Eichinger (Hg.), S. 51-72.

Eichinger, Ludwig M. (1993): Vor Augen geführt bekommen. Text-Bild-Kombinationen als Merkhilfen. In: Dirscherl, Klaus (Hg.): Bild und Text im Dialog. (= PINK 3). Passau, S. 429-449.

Eichinger, Ludwig M. (2007): Linguisten brauchen Korpora und Korpora Linguisten Wege zu wohl dokumentierten und verlässlichen Aussagen über Sprache. In: Kallmeyer/Zifonun (Hg.), S. 1-8.

Eichinger, Ludwig M./Kallmeyer, Werner (Hg) (2005): Standardvariation. Wie viel Variation verträgt die deutsche Sprache? (= Jahrbuch des Instituts für Deutsche Sprache 2004). Berlin/New York.

Gessinger, Joachim (1994): Auge \& Ohr: Studien zur Erforschung der Sprache am Menschen 1700-1850. Berlin/New York.

Harras, Gisela (2004): Handlungssprache und Sprechhandlung. Eine Einführung in die theoretischen Grundlagen. 2. erw. u. durchges. Aufl. Berlin/New York.

Kallmeyer, Werner/Zifonun, Gisela (Hg.) (2007): Sprachkorpora - Datenmengen und Erkenntnisfortschritt. (= Jahrbuch des Instituts für Deutsche Sprache 2006). Berlin/New York.

Kämper, Heidrun/Eichinger, Ludwig M. (Hg.) (2008): Sprache - Kognition - Kultur. Sprache zwischen mentaler Struktur und kultureller Prägung. (= Jahrbuch des Instituts für Deutsche Sprache 2007). Berlin/New York. 
Konopka, Marek/Strecker, Bruno (Hg.) (2009): Deutsche Grammatik - Regeln, Normen, Sprachgebrauch. (= Jahrbuch des Instituts für Deutsche Sprache 2008). Berlin/New York.

Lessing, Gotthold Ephraim/Mendelssohn, Moses/Nicolai, Friedrich ([1756/57] 1972): Briefwechsel über das Trauerspiel. Hrsg. u. komm. v. Jochen Schulte-Sasse. München.

Moritz, Karl Philipp (1794): Neues A.B.C. Buch, welches zugleich eine Anleitung zum Denken für Kinder enthält. 2. Aufl. Berlin. (Hier nach: www.hs-augsburg.de/ harsch/ germanica/Chronologie/18Jh/Moritz/mor_ab0a.html\#01, Stand: November 2009).

Schlieben-Lange, Brigitte (Hg.) (1993): Materiale Bedingungen der Sprachwissenschaft. (= Zeitschrift für Literaturwissenschaft und Linguistik 23, 90/91). Göttingen.

Schön, Erich (1993): Der Verlust der Sinnlichkeit oder: Die Verwandlungen des Lesers. Stuttgart.

Stetter, Christian (1997): Schrift und Sprache. Frankfurt a.M.

Thun, Harald (1993): Was hat sich in der Dialektologie durch die Benutzung von Tongeräten geändert? In: Schlieben-Lange (Hg.), S. 139-156.

Weinrich, Harald (1997): Lethe. Kunst und Kritik des Vergessens. München.

Widmaier, Rita (Hg) (1990): Leibniz korrespondiert mit China: der Briefwechsel mit den Jesuitenmissionaren (1689-1714). Frankfurt a.M. 
Die Materialität von Stimme und Schrift 



\title{
Sprache, Stimme, Schrift: Zur impliziten Bildlichkeit sprachlicher Medien
}

\begin{abstract}
Die zeichentheoretische Entgegensetzung von Sprache und Bild ist überaus geläufig. Die hier zu entwickelnde These ist jedoch, dass medial verkörperte Sprache eine implizite Ikonizität zukommt: Sprachlichkeit kommt nicht ohne Bildlichkeit, das Sagen nicht ohne das Zeigen aus. Was dies bedeutet, wird in einer Betrachtung der Performanz des Lautlichen sowie des Phänomens der Schriftbildlichkeit erläutert. Sowohl bezüglich der Stimme wie auch der Schrift, zeigt sich eine intrinsische ,Intermedialität' der Sprache. Die Wirksamkeit der Stimme beruht auf ihrer Vereinigung von Somatik und Semantik, eines physiognomischen und propositionalen Aspektes. Die Leistungskraft von Schriften besteht in der Verschränkung von diskursiven und visuellen, von linguistischen und graphischen Aspekten. Friedrich Nietzsche hat auf überraschende Weise eine der Sprache inhärente Intermedialität reflektiert, insofern er die Lautsprache hervorgehen lässt aus der Vereinigung von Musik und Bild.
\end{abstract}

\section{Eine methodische Bemerkung vorab}

Die Reflexion über Begriffe, die für das wissenschaftliche Arbeiten fundamental sind, kann zwei Wege einschlagen: Sie kann analytisch verfahren und Begriffe in ihrer Verschiedenheit voneinander schärfen; sie kann aber auch synthetisch vorgehen und somit die herkömmlichen Grenzen zwischen Termini ein Stück weit durchlässig machen. Im Horizont eines solchen ,synthetischen Gestus' kann dann gezeigt werden, dass das, was unsere Begriffe definitiv trennen (müssen), jedenfalls als ein raum-zeitlich situiertes Phänomen betrachtet, zumeist als ,Mischungsverhältnis' gegeben ist. Was kategorial getrennt ist, wird dann phänomenal in seinem Zusammenhang begreifbar. In dieser synthetischen Perspektive mildert sich das Entwederoder unserer binären Begriffschemata zum Sowohl-als-auch, welches für nahezu alles raum-zeitlich Gegebene charakteristisch ist. Solches ,Denken in Konjunktionen' substituiert allerdings nicht die analytische Begriffsarbeit, sondern setzt sie notwendig voraus: Denn etwas als vermischt zu betrachten, gelingt nur, wenn konzeptuell zugleich ein Unterschied gemacht werden kann.

Der Unterschied nun, um den es uns im Folgenden zu tun ist, ist derjenige von Sprache und Bild. Und auf die uns dabei interessierende Vermischung stoßen wir im Zusammenhang einer Bildkraft, welche aller medial verkörperten Sprache implizit ist. 


\section{Eine ,Bildlichkeit‘ im Sprachgebrauch?}

Die zeichentheoretische Entgegensetzung von Sprache und Bild ist überaus geläufig; diese kanonische Bifurkation in Bezug auf unsere symbolischen Vermögen bildet eine Präsupposition, deren Echo sich seit Lessings Trennung von Wortkunst und Bildkunst ${ }^{1}$ in einer Fülle von terminologischen Unterscheidungen wieder findet, etwa in derjenigen von , diskursiv ${ }^{c}$ und ,ikonisch', ,arbiträr' und ,ähnlich', ,repräsentativ und ,präsentativ', ,digital' und ,analog', ,Sagen' und ,Zeigen'. Zweifelsohne kommen diese Begriffsschemata untereinander nicht zur Deckung; doch die begriffliche Opposition, die dabei jeweils zum Ausdruck kommt, betrifft im Kern die Unterscheidbarkeit von Wort und Bild. Unsere Annahme ist nun, dass ,Diskursivität' verstanden als Sprache im Gebrauch immer auch des Einschlusses einer ,Ikonizität' bedarf. Spracblichkeit kommt obne Bildlichkeit, das Sagen kommt obne das Zeigen nicht aus. Eben das ist unsere Hypothese. ${ }^{2}$

Vorab drängt sich ein Einwand auf: Die Frage nach der ,Bildlichkeit im Sprachgebrauch 'scheint längstens gestellt und vielfach bearbeitet, etwa durch Karl Bühler, ${ }^{3}$ der uns nachhaltig darauf aufmerksam gemacht hat, dass die Indexikalität und damit das ,Zeigen' jeder natürlichen Sprache inhärent ist und das Lebenselixier ihrer Weltverankerung ausmacht. Überdies wissen wir um die Rolle von Metaphern für das Wachstum natürlicher Sprachen und wir sind ästhetisch-poetologisch vertraut mit der Bildkraft literarischer Produktionen. Warum also jetzt noch einmal die Frage aufwerfen nach einer impliziten Bildlichkeit im Sprachgebrauch?

An dieser Stelle nun kommen die Medialität und die Intermedialität ins Spiel, die diesem Band sein Thema vorgeben. Unsere Vermutung ist, dass die Intermedialität der Sprache sich (auch) darin zeigt, dass unsere Sprachverwendung in Kommunikation und Kognition Phänomene des Bildlichen einschließt. Die Sprachmedialität ist hier angesprochen, insofern sich unsere Erörterung einer impliziten Bildlichkeit der Sprache nicht einfach auf die ,Sprache an sich' bzw. auf die ,Sprache als System', sondern auf die zwei elementaren Medien der Sprache bezieht: auf die Stimme und die Schrift. Und noch mehr ist wichtig: Es geht dabei nicht um das Verhältnis zwischen Sprache und Bild, sondern um ikonische Dimensionen, die innerbalb unserer Sprachvollzüge selbst wirksam werden. Und es geht auch weniger um ein Wechselverhältnis zwischen Stimme und Schrift, sondern um ein Zusammenspiel von Diskursivem und Ikonischem, das sich innerhalb der stimmlichen und der geschriebenen Kommunikation jeweils zeigt. Indem wir den Anteil des

Vgl. Lessing (1990, S. XVL).

2 Die mit dieser Hypothese verbundenen Gedanken sind auch entfaltet in: Krämer (2003a, 2003b, 2005b, 2006c, 2008).

3 Bühler (1934, S. 79 ff.) hat die Deixis als Grundoperation innerhalb der Sprache der Prädikation sogar gleichgestellt. 
Ikonischen - wie es durchaus nahe liegt - nicht nur in der Schrift und ihrer Visualität aufsuchen, sondern auch in der 'Tonspur' der Stimme, ist eines vorab klar und auch eigens zu betonen: ,Bildlichkeit' darf nicht mit der Visualität und dem Optischen identifiziert werden. Worauf es ankommt sind also (auch) Formen nichtoptischer Ikonizität. Was das bedeutet, wird deutlicher, sobald wir uns nun der Rolle der Stimme zuwenden.

\section{Zur Doppelnatur der Sprechstimme}

Durch die Stimme realisiert sich eine ,pathische', eine ,physiognomische Dimension in der Rede, die eben jene nichtvisuelle Form des Ikonischen bildet, welche der mündlichen Sprache inhärent ist. Was ist damit gemeint?

Wenn wir die Stimme als das ursprüngliche, Vollzugsorgan' des Sprechens betrachten, kann dies in (mindestens) drei Perspektiven geschehen: Wir können die 1) Materialität und Körperlichkeit der Stimme, ihre 2) Affektivität und ihren Appellcharakter, sowie 3) ihre Semantizität und Reflexivität thematisch werden lassen. Da dies an anderer Stelle ausführlicher geschehen ist (Krämer 2003a, 2006a), sei diese Trias von Aspekten der Wirksamkeit der Stimme hier nur kurz rekapituliert:

1) Materialität und Körperlichkeit: Der, Ort' der unaufgezeichneten Stimme, deren Laute sich - kaum ausgesprochen - auch schon verflüchtigen, ist die Aktivität unseres Körpers. In der Verlautbarung wird unser Leib und seine elementare Motorik zum Stimmapparat. Die ,Immaterialität des Atemhauchs tritt in ein Wechselverhältnis mit der materialen Widerständigkeit und Vibrationsfähigkeit der Stimmbänder und der Resonanzfähigkeit höhlenartiger Organe. Im Horizont dieser leiblichen Aktivität - tote Dinge haben keine Stimme - bildet die Stimme in ihrer immer auch unkontrollierten Ereignishaftigkeit die unbewusste Spur des Körpers im Sprechen. Unser Körper zeigt sich in der Stimme; ${ }^{4}$ die Stimme zeugt von unserer Gestimmtheit. Eine sublime Verwandtschaft zu den unwillkürlichen Anteilen in Gebärde und Mimik wird hier wirksam.

2) Affektivität und Appellcharakter: In der Lautlichkeit der Kommunikation wird eine präverbale, vorsymbolische und nicht-propositionale Dimension wirksam, in der es weniger auf das, Was', vielmehr auf das, Wie des Sagens ankommt. Und obwohl dieses ,Wie‘ in Stil und Rhetorik der Rede mit einer Fülle grammatischer, lexikalischer Attribute arbeitet, ist der Ton der Rede die immer noch nachhaltigste Weise eines intersubjek-

4 Ob mit Männer- oder Frauenstimme, ob im ,Brustton' oder mit ,Kopfstimme', ob eher schrill oder sonor: Die Stimme ist geprägt von den geschlechtlichen und organischen Dispositionen wie auch von dem aktuellen Muskeltonus und dem Druck und der Geschwindigkeit des geformten Luftstroms. 
tiv bedeutungs- und machtvollen Sprechens. Bedenken wir nur: Anders als das Auge, ist das Ohr nicht verschließbar; Töne können uns aus dem Tiefschlaf wecken (Senf 1989, S. 22). Wie alles Akustische haben Stimmen also eine Eindringlichkeit, die mit der Aufdringlichkeit im Bunde sein kann. Das Mischungsverhältnis von Brust- und Kopftton - das zeigen biophonetische Untersuchungen (Trojan 1982) - kündet von Imponiergehabe und Aggressivität oder von Unsicherheit und Selbstzurücknahme. In der stimmengebundenen Kommunikation vollzieht sich also eine elementare, sowohl appellative wie auch affektive Bezugnahme auf den anderen. Die Stimmlichkeit konstituiert eine Form von Zwischenmenschlichkeit, eine elementare Vergemeinschaftungsleistung, deren Wirksamkeit weder vom Gehalt einer Äußerung zehrt, noch gar - wie in der universalpragmatischen Kommunikationstheorie angenommen (Habermas 1984, S. 353 ff.) - in wechselseitig zu erhebenden Geltungsansprüchen gründet. Der Lautgebung ist ein Bindungspotenzial ebenso eigen, wie eine Entzweiungsenergie. Denn eine Stimme kann kaum neutral sein: Sie zieht an oder sie stößt ab (Barthes 1990, S. 280 f.).

Die Stimme - und darauf kommt es uns hier an - drückt also nicht einfach eine körperliche Verfassung aus, vielmehr ist sie Teil dieser körperlichen Verfassung und Bewegung. Daher wollen wir die Lautlichkeit als die ,pathische', die ,physiognomische' Dimension im Sprachgebrauch charakterisieren. ${ }^{5}$ Diese Dimension ist es, die ein ikonisches Potenzial birgt. Und eben dieses Potenzial der Stimme geht aus dem Zeigen hervor. ${ }^{6}$

3) Semantizität und Reflexivität: Dass die Stimme nicht nur pathische Funktionen einer elementaren Sozialität erfüllt, vielmehr auch fein schattierte propositional-semantische Aspekte der Rede zur Geltung bringt, versteht sich fast von selbst. Daher wollen wir hier - über diese semantische Dimension hinaus - die kognitiven und epistemischen Aspekte betonen, die im Phänomen unserer Lautlichkeit verankert sind. Allzu lange wurde innerhalb jener Positionen, die mit der Entdeckung der Unterscheidung von Oralität und Literalität diese zugleich zu epochalen Mentalitätsformen verallgemeinerten, ${ }^{7}$ die kognitiven und reflexiven Leistungen im Sprachgebrauch vorrangig mit der Schrift assoziiert, an der gemessen dann die Mündlichkeit zur ,Sachwalterin' des Vordiskursiven, Vorrationalen und Nichtpropositionalen degenerierte. Doch

Auf diese ,physiognomische Dimension“ verweist Sample (1996, S. 113-126).

Der Kunsthistoriker und Bildtheoretiker Gottfried Boehm (2007, S. 19 ff.) hat explizit das ,Zeigen' als die Wurzel des Bildes bestimmt und damit eine Form von Tätigkeit, die gerade nicht auf das Visuelle begrenzt ist sondern allem eigen ist, was als Spur fungiert. Zum Zusammenhang von Spur und Zeigen: Krämer (2007).

Exemplarisch: Goody (1986); Havelock (1963); Ong (1982). 
dieses Bild des kognitiv eingeschränkten Potenzials, bloßer' mündlicher Rede erfuhr nachhaltige Korrekturen, systematisch wie auch historisch: ${ }^{8}$ Einmal, indem nachgewiesen wurde, dass ursprünglich allein Schriftkulturen zugesprochene Diskriminierungsfähigkeiten wie etwa die Unterscheidung von Objekt- und Metasprache, die Existenz von Textgenres, Paraphrasierung und Explikation, sowie die Existenz von Grammatiken sich - fallweise - auch in oralen Gesellschaften finden lassen (Falk 1990; Vansina 1973; Schott 1995; Fleisher Feldman 1991). Darüber hinaus wird das kognitive, reflexive Potenzial in der Lautlichkeit des Sprechens frei gelegt und untersucht. Metaleptische (Linz 2003, S. 54 f.) und transkriptive (Jäger 2002, S. 19 ff.) Verfahren in der mündlichen Kommunikation, die zutage fördern, wie erst das Hören auf den eigenen Redefluss die ,anfänglichen' Sprecherintentionen nachträglich entstehen lässt, zeigen, dass das Sich-sprechen-hören eine ,Differenzwahrnehmung' (Linz 2003, S. 57 ff.) konstituiert, die mit einer Fülle epistemischer Aspekte verknüpft ist. Derridas ,Phonozentrismusvorwurf hatte die abendländische Stimmen-Reflexion allzu lange als Quelle der Identifikation der Stimme mit der abstandlosen und differenzlosen Selbsterfahrung und Selbstgewissheit abgewertet (Derrida 1974). Doch eine Relektüre von Hegel und Humboldt im Horizont der Stimmlichkeit als Elementarerfahrung einer Abstandnahme von sich selbst zeigt, wie stark für beide Denker die sich vom Körper ablösende Exteriorität des Sprachlautes zur Springquelle wird für eine Selbstdistanzierung, die dann wiederum zum Nährboden wird für die Ausbildung von Bewusstsein, Intelligenz, Denkfähigkeit und Geist. ${ }^{9}$

Worauf es uns bei dieser Auseinanderlegung in drei Perspektiven, in denen die Stimme sprachlich jeweils wirksam werden kann, ankommt, ist, dass alle drei Funktionen - in allerdings graduell je unterschiedlichen ,Mischungsverhältnissen' - in jedem Sprechereignis wirksam werden. Wir wollen das jetzt zuspitzen auf einen ,Doppeleffekt': Somatik und Semantik, Affekt und Intellekt, die physiognomische und die propositionale Dimension der Sprache verschränken sich. Wir können das in der Terminologie von Colin Sample so ausdrücken: ,Semiotische ${ }^{6}$ und ,mimetische“ Bedeutungsfunktionen innerhalb der Stimme sind voneinander unterscheidbar und arbeiten doch einander zu (Sample 1996, S. 114 ff.). Während das Semiotische - in Samples Sicht - mit der Diskursivität, Arbitrarität und Konventionalität verbunden ist, kommt mit dem Mimetischen die Expressivität, Wahrnehmbarkeit, Kin-

Ausführlicher dazu: Krämer (2005a, S. 192 ff.).

Für Hegel (1970, S. 280) gestaltet sich erst mit der Äußerlichkeit des Lautes „die Intelligenz“ selbst ,zu einem Sächlichen“, und gibt es Gedanken überhaupt erst im Zusammenhang des Sprechens. Humboldt (1903-1936, Bd. VI, S. 26) wiederum dialogisiert diese kognitiven Errungenschaften der Lautsprache, insofern die Objektivität von Gedanken auf den Resonanzboden des Anderen angewiesen ist; dazu auch: Krämer (2006a, S. 278 ff.). 
ästhesie und Körperlichkeit im Sprachgebrauch zur Geltung. Und genau in dieser keineswegs auf die buchstäbliche Mimik zu reduzierenden mimetischen Dimension, die in der Vokalisierung beheimatet ist, vollzieht sich, was am Sprechen ,ein Bild gibt": „presenting an image“ (Sample 1996, S. 114).

\section{Schriftbildlichkeit}

Wir sind - inspiriert, aber auch gebannt von der abendländischen Tradition der phonographischen Schrift - gewohnt ,Schrift' mit aufgeschriebener mündlicher Sprache zu assoziieren. ${ }^{10}$ In Kauf genommen ist damit allerdings der Ausschluss sowohl der nichtphonetischen (und damit meist auch der nichtalphabetischen) Schriften, wie auch der musikalischen, choreographischen, mathematischen, logischen, informatischen, naturwissenschaftlichen Notationssysteme aus dem Begriff der Schrift. Doch selbst wenn die Schrift, lediglich' als aufgeschriebene Sprache in den Blick kommt, zehrt das Darstellungspotenzial von Texten nicht nur von der Stabilität und Kontrollierbarkeit einer räumlich-linearen Struktur, welche das Nacheinander des fluiden Wortes in das Nebeneinander von Buchstabenketten zu bannen vermag. Vielmehr wird überall da, wo Schrift in Gestalt von Texten vorkommt, von der Zweidimensionalität der Fläche Gebrauch gemacht, indem unaussprechliche Anordnungsrelationen Unterschiede in simultaner Präsentation auszudrücken ermöglichen, welche in der flüchtigen Sukzession der gesprochenen Sprache kein Vorbild finden (Groß 1990; Harris 1986; Cancik-Kirschbaum/Mahr 2005; Krämer 2005b). Für diese Zweidimensionalität gibt das nicht verlautierbare Kreuzworträtsel zweifelsohne ein - wenn auch radikales - Exempel ab. Doch die ,Schriftbildlichkeit' ist kein Refugium von Sprachspielen, welche den Allokationscharakter der Schrift im buchstäblichem Sinne der Anagramme und Palindrome nutzen und spielerisch aus ,Leben' ${ }^{6}, \mathrm{Nebel}^{6}$ werden lassen oder das ,Lagerregal' von vorne oder hinten lesbar machen (Glück 1987, S. 203 ff.; Greber 2002). Denn bereits der verschriftete mündliche Sprachfluss arbeitet mit Markierungen und damit Unterscheidungen - denken wir nur an die Wortabstände, Satzzeichen, Groß- und Kleinschreibung -, für die es kaum ein Analogon gibt im Fluss des Sprechens.

$10 \quad$ Vgl. in dem Handbuch Schrift und Schriftlichkeit. Writing and its Use von Günther/Ludwig (Hg.) (1994, S. VIII), dass dort (als erstes Merkmal) die Schrift als „die Menge der graphischen Zeichen, mit denen gesprochene Sprache festgehalten wird [...]“ eingeführt ist. Auch im Lexikon der Sprachwissenschaften, Bußmann (1990, S. 667): „Schrift. Auf konventionalisiertem System von graphischen Zeichen basierendes Mittel zur Aufzeichnung von mündlicher Sprache." Auch Koch (1997, S. 58) auf den die Unterscheidung (zusammen mit Oesterreicher 1985) von ,medialer und konzeptioneller' Mündlichkeit bzw. Schriftlichkeit zurückgeht), reserviert den Schriftbegriff für die Vereinigung von Graphé und Phoné. 
All dies ist in einer Fülle von Studien durchaus sondiert. ${ }^{11}$ Worauf es uns hier ankommt ist, dass die - zumal im linguistischen Diskurs verbreitete - Betrachtung der Schrift als eine Modalität und Form von Sprache verdeckt, dass die gerade auch sprachlich relevanten Leistungen der Schrift sich einem Zusammenwirken von diskursiven und ikonischen Elementen verdanken.

Im Horizont der Bifurkation von Wort und Bild müssen wir sagen: Die Schrift ist immer schon ein intermediales Phänomen in dem Sinne, dass sie ein ,vermischtes , ein hybrides System bildet, welches in seiner graphischen Diskursivität - oder sollten wir sagen: in seinem diskursiven Graphismus? eigenständig ist, sowohl gegenüber der gesprochenen Sprache wie gegenüber dem gewöhnlichen Bild; und indem die Schrift die Attribute und Potenziale beider Seiten verbindet und nutzt, vermag sie in ihrer Darstellungsleistung zugleich die Grenzen von akustischer Sprache und visuellem Bild zu überschreiten. In der Perspektive dieser ,Schriftbildlichkeit ${ }^{12}$ bzw. ,notationalen Ikonizität ${ }^{\star}$ zeichnet sich ein lautsprachenneutrales Schriftkonzept ab, welches durch ein Quartett von Attributen: Diskretheit, Wabrnebmbarkeit, Operativität und Referentialität charakterisiert werden kann und geeignet ist, den sprachwissenschaftlichen Schriftbegriff mit außersprachlichen Notationssystemen zu verbinden. Vergegenwärtigen wir uns kurz diese für die notationale Ikonizität grundlegenden Prädikate:

1) Die Diskretheit betont, dass nicht einfach ,Räumlichkeit', vielmehr ,Zwischenräumlichkeit' konstitutiv ist für Schriften. Gemeint ist damit - um hier eine Terminologie von Nelson Goodman anzuführen, - dass Schriften durch ,endliche Differenziertheit ${ }^{\star}$ und ,Disjunktivität ${ }^{6}$ charakterisiert werden können (Goodman 1995, S. 130 ff.). Die ,endliche Differenziertheit' gewährleistet die diskrete, nicht kontinuierliche Anordnung von Schriftzeichen: Zwischen zwei benachbarten Schriftzeichen kann sich nicht noch ein drittes Zeichen befinden, ${ }^{13}$ es bleibt eine ,Leerstelle dazwischen. Die ,Disjunktivität' stellt dann sicher, dass die Schriftzeichen Abstraktionsklassen sind, die sich in ihren Elementen nicht überschneiden: ein , $\mathrm{a}^{6}$ darf nicht zugleich ein , $\mathrm{d}^{6}$ oder, $\mathrm{p}^{6}$ sein, während alle Versionen von , $\mathrm{a}^{a}$ sich wechselseitig vertreten können. ${ }^{14}$

$11 \quad$ U.a.: Coulmas (1993); Harris (1986); Raible (1991, 1993, 1997); Stetter (1997); Strätling/Witte (Hg.) (2006); Wenzel (1995).

12 Zu diesem Begriff: Krämer (2003b (engl. Version: ,notational iconicity': 2003c); 2006c). Auf diesem Konzept beruht ein jüngst von der DFG an der FU Berlin bewilligtes Graduiertenkolleg: „Schriftbildlichkeit. Über Materialität, Wahrnehmbarkeit und Operativität von Notationen".

13 Insofern gilt dieses Kriterium selbstverständlich auch für die ,Schreibschriften', die Worte als ein Kontinuum von Buchstaben notieren.

14 Dazu: Krämer (2003b, S. 162 f.). 
2) Bei der Wahrnebmbarkeit ist zu beachten - denken wir nur an die Blindenschrift - dass die Aisthesis, also die sinnliche Perzeptivität von Schriften, welche für den Schriftbegriff unabdingbar ist, nicht mit ihrer Visualität in eins fällt. Die Räumlichkeit und Zwischenräumlichkeit, nicht das Optisch-Visuelle ist für den Präsenzaspekt der Schrift zentral. Denn es ist diese Räumlichkeit der Schrift, die ihren Anordnungscharakter ausmacht (Cancik-Kirschbaum/Mahr 2005; Kogge 2005, S. 137 ff.). Ein Schriftzeichen hat, wo es Teil von Texten wird, stets eine bestimmte Position inne. Und im Unterschied zu transitorischen Zeichen wie Sprachlauten, Musikklängen oder Bewegungsbildern ist die positionsbezogene Stabilität und Dauerhaftigkeit der Präsenz des Schriftbildes die Bedingung dafür, dass Schriften dann auch ein operatives Medium verkörpern, in welchem Inskriptionen als textuelle Anordnungen hergestellt, verändert oder gelöscht werden können (Greber/Assmann/ Ehlich/Müller 2002).

3) Operativität bedeutet, dass Schriftstrukturen beobachtbar, kontrollierbar und vor allem veränderbar sind. ${ }^{15}$ Insofern sind Schriftsysteme nicht nur Darstellungssysteme, sondern sie sind zugleich auch ein Instrument zum operativen Umgehen mit dem Dargestellten. Diese Operativität birgt viele Facetten: denken wir nur an das ,epistemische Schreiben (Raible 2004), welches daran erinnert, wie sehr sich die Gedanken erst im Schreibakt bilden; an die Komposition, bei der musikalische Notationen nicht nur Aufführungsanweisungen sind, sondern ein exploratives Medium musikalischen Schaffens darstellen (Gottschewski 2005); an die Kalkülisierung, der wir das schriftliche Rechnen, aber auch logische Inferenzen und mathematische Beweise verdanken (Krämer 1988, 1991); oder denken wir an die Programmierung, bei der die unaussprechlichen Programmier,sprachen' sich stets als Schriften erweisen müssen, die nur als Inskriptionen dann auch in die Stromimpulse des Computers übersetzbar sind.

4) Die Referenzialität, im Sinne einer ,Semantizität', macht es möglich, Schriften von Ornamenten zu unterscheiden. Schriften müssen da, wo sie die Form von Texten annehmen, eine Bedeutung haben, also durch die Bezugnahme auf etwas, das sie nicht selber sind, charakterisiert werden können. Zum angemessenen Verständnis dieser Bezugnahme ist allerdings wesentlich: Referenzialität bedeutet nicht die Vorgängigkeit dessen, was durch Schrift dargestellt wird. Die Symbolisierungsleistung von Schriften liegt gerade auch darin, etwas Unsichtbares wie theoretische Entitäten und abstrakte Gegenstände, kurz: ,Wissensdinge' durch Inskription dem Register des Sinnlichen zugänglich zu machen (Rheinberger 1992, 1999). Das Zeichen ,0‘, ursprünglich eingeführt als Lücken-

15 Zur Genese des operativen Schriftgebrauchs: Krämer (1988). 
zeichen für das Fehlen einer Ziffer im dezimalen Positionssystem, wird schließlich zu einem Zeichen für eine wohl bestimmte Zahl: die Null. Erst das operative Umgehen mit der Ziffer , $0^{\circ}$, hat die Zahl Null als ein mathematisches Objekt hervorgebracht und konstituiert (Krämer 2006c). Unschwer lassen sich Parallelen dazu etwa in den Strukturen der Grammatiken von natürlichen Sprachen finden, die erst durch die ,hochsprachliche' Normierung im Medium der Schrift den Status grammatischer Regeln, also von Vor-Schriften angenommen haben.

Halten wir fest: Sobald wir Schrift nicht einfach als aufgeschriebene Form mündlicher Sprache verstehen, sondern als eine graphische Struktur, die durch die vier dargelegten Attribute, ikonischer Notationalität ${ }^{\star}$ gekennzeichnet werden kann, gewinnen wir einen lautsprachenneutralen Begriff von Schrift. Die heißt nicht, die Bedeutung zu schmälern, die der Bezugnahme von Schriften auf die Lautsprache zukommt, zumal diese ja keineswegs nur für alphabetische sondern auch für nicht-alphabetische Schriften gilt, wie wir dies selbst von den altägyptischen Hieroglyphen her wissen. Gleichwohl hilft dieses lautsprachenneutrale Schriftkonzept den Alphabet-Zentrismus von Anbeginn zu vermeiden und das Band zu erkennen, welches aufgeschriebene natürliche Sprachen und die Entfaltung künstlicher Ausdruckssysteme in Wissenschaft und Kunst miteinander mit einander verwoben sein lässt. Die Schrift wird damit Teil jener Kulturtechniken, die vom Graphismus der Inskription Gebrauch machen und uns unter anderem in Form von Formeln, Tabellen, Diagrammen und Karten begegnen (Krämer 2009). Der Horizont einer Kulturtechnik der Verräumlichung gerade auch nichträumlicher Sachverhalte und der Visualisierung insbesondere auch von Unsichtbarem ist damit eröffnet, vor dem das, was Schriften leisten, sich deutlich konturiert. So zeigen sich Schriften als wirkmächtige Instrumente sowohl der Kommunikation wie der Kognition und sie vermögen dies, indem sie - entgegen der kategorischen Abgrenzung zwischen Sprache und Bild - stets diskursive und ikonische Momente vereinigen und nutzen.

\section{Friedrich Nietzsche: Die Dualität der Sprache}

Hier nun müssen wir auf einen Denker zu sprechen kommen, der wie kaum einer vor ihm versucht hat die Sprache von ihrer innersten Anlage her , intermedial ${ }^{k}$ zu denken. Es ist Friedrich Nietzsche, bei dem sich eine duale Sprachauffassung angelegt findet, die unser Sprechen hervorgehen lässt aus einem Zusammenwirken von Gebärdensprache und Tonsprache. ${ }^{16}$ Damit - und das ist wesentlich für das Verständnis von Nietzsches Denkansatz - ist nicht die Unterscheidung zwischen Gestik und Lautlichkeit ge-

16 Dazu: Caduff (1997); Fietz (1992); Krämer (2003a, 2005b). 
meint, wie es zuerst einmal von seinem Wortgebrauch her nahe liegt. Vielmehr zielt Nietzsche auf eine Doppelung, die im gesprochenen Wort selbst wirksam wird und innerhalb der mündlichen Sprache selbst „uranfänglich vorgebildet" (Nietzsche 1980, Bd. 7, S. 362) ist.

Insoweit die Sprachgebärde von einer Vorstellung begleitet wird, ist sie der Domäne des Bildlichen zugehörig und Nietzsche nennt sie ,Mundgeberde' (Nietzsche 1980, Bd. 1, S. 575 f.). Zu dieser Gebärdensymbolik zählen dann die Konsonanten und Vokale und zwar nur als Stellung der Sprechorgane aufgefasst, also ganz ohne Klang: In dieser ,tonlosen' Dimension hat die Diskursivität der Sprache ihren Ort, welche Nietzsche - und das ist für ihn signifikant - gerade mit dem Bildlichen assoziiert. Das Bildliche wird hier aufgefasst in jenem spezifisch ,apollinischen Sinne' (wir kommen darauf zurück), welcher für Nietzsche mit intellektuellen Eigenschaften wie Proportionalität, Rationalität und Erkenntnis verbunden ist. Der ,Ton' dagegen ist nicht mit Vorstellungen, sondern mit „Strebungen des Willens“ (ebd., S. 572) verknüpft; er bekundet Gefühle von Lust und Unlust und wird mit dem Musikalischen identifiziert, dessen Elemente Rhythmus, Dynamik und Harmonie sind. Diese „Tonuntergrund“ der Sprache verkörpert eine Schicht im Sprechen, die - anders als die konventionengestützte ,Geberdensprache ${ }^{6}$ - für alle Menschen zugänglich und auch verständlich ist. Sie bildet den Nährboden jener universellen Sprache, aus dem die „Mannichfaltigkeit der Sprachen“ (ebd., Bd. 7, Fragment 12 [1], S. 361) überhaupt erst erwachsen kann.

Worauf es uns nun ankommt und was Nietzsche für ein Denken der Intermedialität der Sprache so aufschlussreich macht, ist: Die gesprochene Sprache geht erst aus der Verschmelzung von Bild und Musik hervor.

Die innigste und häufigste Verschmelzung von einer Art Geberdensymbolik und dem Ton nennt man Sprache. Im Wort wird durch den Ton und seinen Fall, die Stärke und den Rhythmus seines Erklingens das Wesen des Dinges symbolisiert, durch die Mundgeberde die begleitende Vorstellung, das Bild, die Erscheinung des Wesens. (Nietzsche 1980, Bd. 1, S. 575 f.)

Indem Nietzsche hier von, Wesen' und ,Erscheinung' redet, zeigt sich, dass er Gebärde und Ton nicht gleichrangig setzt, vielmehr macht er den Tonuntergrund der Sprache - wir zitieren hier Corinna Caduffs aufschlussreichen Aufsatz (Caduff 1997, S. 48) - „zum alleinigen und universellen Ursprungsort" der menschlichen Sprachlichkeit. In der Lautlichkeit des Sprechens artikuliert sich der Mensch somit als „Gattungsmensch“ (Nietzsche 1980, Bd. 1, S. 575).

Nur beiläufig sei erwähnt, dass Nietzsche die kunsthistorisch einflussreich gewordene Unterscheidung von ,apollinisch ' und ,dionysisch ${ }^{6}$ als Ordnungsformen künstlerischer Artikulation ursprünglich als eine sprachtheoretische Unterscheidung in Gestalt der Differenz von ,Gebärde“ und ,Ton` 
und ihrer Verschmelzung im Sprechen eingeführt hat. Nietzsche hat herausgestellt, dass Differenz und Zusammenspiel der dionysisch-apollinischen Künste für ihn ihr Vorbild finden in den zwei Seiten der Sprache: in Ton und Gebärde. ${ }^{17}$ Während die apollinische Gestaltungskraft mit Grenzziehung, Maß, Proportionalität, Distanz und Intellektualität verknüpft ist, ist die dionysische Energie grenzeinreissend, maßlos, distanzüberspringend und gemeinschaftsorientiert.

Hier stoßen wir also auf die Frühform der Unterscheidung zwischen den semiotischen und den mimetischen, den digitalen und den analogen, den propositionalen und den pathischen Dimensionen menschlicher Kommunikation, verbunden allerdings mit der Einsicht in deren unauflösliches Zusammenwirken.

\section{Das Zusammenwirken von Bild und Musik im Sprachgebrauch: Einige Anschlussüberlegungen an Nietzsche}

Nietzsche ist als Denker der Sprache und ihrer Medialität wenig bekannt. ${ }^{18}$ Und doch lassen seine Überlegungen in der Perspektive einer Frage nach der Intermedialität der Sprache interessante Schlussfolgerungen zu. Wir wollen diese in drei Hinsichten akzentuieren:

1) Sprache: Die Polarität von Sprache und Bild als Unterschied zwischen diskursiven und ikonischen Ordnungsformen ist - denken wir nur an die Ansprüche von ,linguistic $c^{6}$ und ,iconic turn' - zumeist als elementar und unhintergehbar gedacht. Nietzsche allerdings geht hinter diese Polarität zurück, indem er nicht Sprache und Bild, vielmehr Bild (,Geberde') und Musik (,Ton') als die beiden ,Urformen' symbolischer Artikulationsmedien auszeichnet. Das hat für das Verständnis von Sprache dann die Konsequenz, die gesprochene Sprache selbst als ein ,Mischwesen', modisch gesprochen: als ein Hybrid zu konzipieren, geboren' aus der Vereinigung von Bild und Musik. Damit ist die Intermedialität im Herzen unseres Sprachvermögens angesiedelt.

2) Stimme: Dort, wo die mediale Unterscheidung zwischen ,mündlich' und ,schriftlich ' und insbesondere der Übergang zur, Literalität' zu einer Art von Epochenschwelle verallgemeinert wurde, erschien die Alphabetschrift als Königsweg wissenschaftlicher und letztlich sogar politischer Aufklärung. Indem Nietzsche seine Unterscheidung zwischen Musik und Bild, zwischen dem Dionysischen und dem Apollinischen in die

17 In einem Fragment von 1870 führt er aus: „... so gewiß nämlich der einzelne Ton, dem Bild gegenüber, bereits dionysisch und das einzelne Bild, sammt Begriff und das Wort, der Musik gegenüber apollinisch ist" (Nietzsche, Bd. 7, Fragment 7 [127], S. 186).

18 Anders jedoch: Caduff (1997); Fietz (1992). 
Lautsprache selbst hinein verlegt, wird ein subtilerer Blick auf die Leistungen der Oralität möglich, insofern Propositionales und Nicht-Propositionales gerade auch in der mündlichen Rede unabdingbar zusammen wirken (müssen). Um es mit sperrigem Wort zu sagen: die Stimme ist ,multifunktional' und in dieser Eigenschaft ist sie stets vieldeutig.

3) Schrift: Wir betonten, dass entscheidende Leistungen der Schrift als Darstellungsmittel, als Explorations- und Denkraum wie auch als Operationsinstrument, sich ihren ikonischen, auf Raumrelationen bezogenen Elementen verdankt. Dadurch werden Spielräume des Kognitiven eröffnet, für die sich weder in der ,reinen' Sprache, noch bei ,gewöhnlichen' Bildern ein Vorbild findet. Indem Nietzsche - und zwar gegen unser intuitives Verständnis, mit dem wir das Bild allzu gerne mit dem assoziieren, was nicht propositional ist, - im Begriff des ,Apollinischen ${ }^{6}$ Bild und Intellektualität zusammen führt, erfährt auch unsere Idee, die intellektuelle Schubkraft der Schrift gerade mit ihrer Schriftbildlichkeit zu verbinden, eine Stütze.

\section{Literatur}

Barthes, Roland (1990): Der entgegenkommende und der stumpfe Sinn. Kritische Essays III. Frankfurt a.M.

Boehm, Gottfried (2007): Wie Bilder Sinn erzeugen. Die Macht des Zeigens. Berlin.

Bühler, Karl (1934): Sprachtheorie. Die Darstellungsfunktion der Sprache. Jena.

Bußmann, Hadumod (1990): Lexikon der Sprachwissenschaften. 2. Aufl., Stuttgart.

Caduff, Corina (1997): Vom Urgrund zum Supplement. Musik in den Sprachtheorien von Rousseau, Nietzsche und Kristeva. In: Musik und Ästhetik 1, 3, S. 37-54.

Cancik-Kirschbaum, Eva/Mahr, Bernd (2005): Anordnung und ästhetisches Profil. In: Bildwelten des Wissens. Kunsthistorisches Jahrbuch für Bildkritik. Bd. 3.1: Diagramme und bildtextile Ordnungen. Hrsg. v. Horst Bredekamp, Gabriele Werner u. Matthias Bruhn. Berlin, S. 97-114.

Corballis, Michael C. (1999): The gestural origins of language. In: American Scientist 87,2 , S. 138-145.

Coulmas, Florian (1993): Das ABC der Wissenschaft. In: Merkur 3, S. 390-398.

Derrida, Jacques (1974): Grammatologie. Frankfurt a.M.

Ehlich, Konrad (2001): Graphematics/[Transindividual] Graphology. In: de Cillia, Rudolf/Krumm, Hans Jürgen/Wodak, Ruth (Hg.): Loss of communication on the information age/Kommunikationsverlust im Medienzeitalter. Wien, S. 61-76.

Ehlich, Konrad (2002): Schrift, Schriftträger, Schriftform: Materialität und semiotische Struktur. In: Greber/Assmann/Ehlich/Müller (Hg.), S. 91-111. 
Epping-Jäger, Cornelia/Linz, Erika (Hg.) (2003): Medien/Stimmen. Köln.

Falk, Harry (1990): Goodies for India. Literacy, orality, and Vedic culture. In: Raible, Wolfgang (Hg.): Erscheinungsformen kultureller Prozesse. Jahrbuch 1988 des Sonderforschungsbereiches, Übergänge und Spannungsfelder zwischen Mündlichkeit und Schriftlichkeit‘. (= ScriptOralia 13). Tübingen, S. 103-120.

Fietz, Rudolf (1992): Medienphilosophie. Musik, Sprache und Schrift bei Friedrich Nietzsche. Würzburg.

Fleisher Feldman, Carol (1991): Oral metalanguage. In: Olson, David R./Torrance, Nancy (Hg.): Literacy and orality. Cambridge, MA, S. 47-65.

Glück, Helmut (1987): Schrift und Schriftlichkeit. Eine sprach- und kulturwissenschaftliche Studie. Stuttgart.

Goodman, Nelson (1995): Sprachen der Kunst. Entwurf einer Symboltheorie. Frankfurt a.M.

Goody, Jack (1986): The logic of writing and the organization of society. Cambridge, MA.

Gottschewski, Hermann (2005): Musikalische Schriftsysteme und die Bedeutung ihrer ,Perspektive' für die Musikkultur. Ein Vergleich europäischer und japanischer Quellen. In: Grube/Kogge/Krämer (Hg.), S. 253-278.

Greber, Erika (2002): Wendebuchstaben, Wendebilder: Palindromanie der Jahrtausendwende. In: Greber/Assmann/Ehlich/Müller (Hg.), S. 131-150.

Greber, Erika/Assmann, Jan/Ehlich, Konrad/Müller, Jan-Dirk (Hg.) (2002): Materialität und Medialität von Schrift. (= Schrift und Bild in Bewegung 1). Bielefeld.

Groß, Sabine (1990): Schrift-Bild. Die Zeit des Augenblicks. In: Zeitzeichen. Hrsg. v. Georg Christoph Tholen u. Michael O. Scholl. Weinheim, S. 231-246.

Grube, Gernot/Kogge, Werner/Krämer, Sibylle (Hg.) (2005): Schrift. Kulturtechnik zwischen Auge, Hand und Maschine. München.

Günther, Hartmut (1995): Die Schrift als Modell der Lautsprache. In: Osnabrücker Beiträge zur Sprachtheorie 51, S. 15-32.

Günther, Hartmut/Ludwig, Otto (Hg.) (1994): Schrift und Schriftlichkeit. Writing and its use. Ein interdisziplinäres Handbuch internationaler Forschung. 2 Bde. Berlin/ New York.

Habermas, Jürgen (1984): Was heißt Universalpragmatik. In: Habermas, Jürgen: Vorstudien und Ergänzungen zur Theorie des kommunikativen Handelns. Frankfurt a.M., S. 353-440.

Harris, Roy (1986): The Origin of writing. London.

Harris, Roy (1989): How does writing restructure thought? In: Language \& Communication 9, S. 99-106.

Harris, Roy (1994): Semiotic aspects of writing. In: Günther/Ludwig (Hg.), Bd. I, S. $41-$ 47.

Havelock, Eric A. (1963): Preface to Plato. Cambridge, MA. 
Hegel, Georg Wilhelm Friedrich (1970): Werke in zwanzig Bänden. Frankfurt a.M.

Humboldt, Wilhelm von (1903-1936 [1967/68]): Gesammelte Schriften. I.A. der Königlich Preußischen Akademie der Wissenschaften hg. v. Albert Leitzmann. Berlin. [Unveränd. photomech. Nachdr. d. Ausg. 1903-1936. Berlin 1967/68].

Jäger, Ludwig (2002): Transkriptivität. Zur medialen Logik der kulturellen Semantik. In: Transkribieren: Medien/Lektüre. Hrsg. v. Ludwig Jäger u. Georg Stanitzek. München, S. 19-41.

Koch, Peter (1997): Graphé. Ihre Entwicklung zur Schrift, zum Kalkül und zur Liste. In: Koch/Krämer (Hg.), S. 43-82.

Koch, Peter/Oestereicher, Wulf (1985): Sprache der Nähe - Sprache der Distanz. Mündlichkeit und Schriftlichkeit im Spannungsfeld von Sprachtheorie und Sprachgeschichte. In: Romanistisches Jahrbuch 36, S. 15-43.

Koch, Peter/Krämer, Sybille (Hg.) (1997): Schrift, Medien, Kognition. Über die Exteriorität des Geistes. (= Probleme der Semiotik 19). Tübingen.

Kogge, Werner (2005): Erschriebene Denkräume. Grammatologie in der Perspektive einer Philosophie der Praxis. In: Grube/Kogge/Krämer (Hg.), S. 137-170.

Krämer, Sybille (1988): Symbolische Maschinen. Die Idee der Formalisierung in geschichtlichem Abriss. Darmstadt.

Krämer, Sybille (1991): Berechenbare Vernunft. Kalkül und Rationalismus im 17. Jahrhundert. Berlin/New York.

Krämer, Sybille (2001): Sprache, Sprechakt, Kommunikation. Sprachtheoretische Positionen im 20. Jahrhundert. Frankfurt a.M.

Krämer, Sybille (2003a): Negative Semiologie der Stimme. In: Epping-Jäger /Linz (Hg.), S. $65-84$.

Krämer, Sybille (2003b): ,Schriftbildlichkeit` oder: Über eine (fast) vergessene Dimension der Schrift. In: Bild, Schrift, Zahl. Hrsg. v. Sybille Krämer u. Horst Bredekamp. München, S. 207-210.

Krämer, Sybille (2003c): Writing, notational iconicity, calculus. On writing as a cultural technique. In: Modern Languages Notes - German Issue 118, 3, S. 518-537.

Krämer, Sybille (2005a): Mündlichkeit/Schriftlichkeit. In: Roesler, Alexander/Stiegler, Bernd (Hg.): Grundbegriffe der Medientheorie. München, S. 192-199.

Krämer, Sybille (2005b): Medienphilosophie der Stimme. In: Systematische Medienphilosophie. Hrsg. v. Mike Sandbothe u. Ludwig Nagel. (= Deutsche Zeitschrift für Philosophie, Sonderbd. 7). Berlin, S. 221-238.

Krämer, Sybille (2005c): ,Operationsraum Schrift‘. Über einen Perspektivenwechsel in der Betrachtung der Schrift. In: Schrift. Kulturtechnik zwischen Auge, Hand und Maschine. Hrsg. v. Gernot Grube, Werner Kogge u. Sybille Krämer. München, S. 23-60.

Krämer, Sybille (2006a): Die ,Rehabilitierung der Stimme‘. Über die Oralität hinaus. In: Stimme. Annäherung an ein Phänomen. Hrsg. v. Doris Kolesch u. Sybille Krämer. Frankfurt a.M., S. 269-295. 
Krämer, Sybille (2006b): ,Leerstellen-Produktivität'. Über die mathematische Null und den zentralperspektivischen Fluchtpunkt. Ein Beitrag zur Konvergenz zwischen Wissenschaft und Kunst in der frühen Neuzeit. In: Instrumente in Wissenschaft und Kunst. Zur Architektonik kultureller Grenzen im 17. Jahrhundert. Hrsg. v. Helmar Schramm, Ludger Schwarte u. Jan Lazardig. Berlin/New York, S. 502 527.

Krämer, Sybille (2006c): Die Schrift als Hybrid aus Sprache und Bild. Thesen über die Schriftbildlichkeit unter Berücksichtigung von Diagrammatik und Kartografie. In: Bilder. Ein (neues) Leitmedium? Hrsg. v. Thorsten Hoffmann u. Gabiele Rippl. Göttingen, S. 79-92.

Krämer, Sybille (2007): Was also ist eine Spur? Und worin besteht ihre epistemologische Rolle? Eine Bestandsaufnahme. In: Spur. Spurenlesen als Orientierungstechnik und Wissenskunst. Hrsg. v. Sybille Krämer, Gernot Grube u. Werner Kogge. Frankfurt a.M., S. 11-36.

Krämer, Sybille (2008): Die Heterogenität der Stimme. Oder: Was folgt aus Friedrich Nietzsches Idee, dass die Lautsprache hervorgeht aus der Verschmelzung von Bild und Musik? In: Wiethölter, Waltraud/Pott, Hans Georg/Messerli, Alfred (Hg.): Stimme und Schrift. Zur Geschichte und Systematik sekundärer Oralität. München, S. 57-74.

Krämer, Sybille (2009): Operative Bildlichkeit. Von der ,Grammatologie‘ zu einer ,Diagrammatologie? Reflexionen über erkennendes Sehen. In: Hessler, Martina/Mersch, Dieter (Hg.): Logik des Bildlichen. Zur Kritik der ikonischen Vernunft. Bielefeld, S. $94-123$.

Lessing, Gotthold Ephraim (1990): Laokoon oder über die Grenzen der Malerei und Poesie. Bibliographisch erg. Aus. 1987. Stuttgart.

Linz, Erika (2003): Die Reflexivität der Stimme. In: Epping-Jäger/Linz (Hg.), S. 50-64.

Mersch, Dieter (2000): Jenseits von Schrift. Die Performativität der Stimme. In: Dialektik. Zeitschrift für Kulturwissenschaft 2, S. 79-92.

Mersch, Dieter (2002): Was sich zeigt. Materialität, Präsenz, Ereignis. München.

Nagl, Ludwig/Sanbothe, Mike (Hg.) (2005): Systematische Medienphilosophie. Berlin.

Nietzsche, Friedrich (1956): Die Unschuld des Werdens. Nachlass, ausgewählt und geordnet von Alfred Baeumler. Bd. I. Stuttgart.

Nietzsche, Friedrich (1980): Sämtliche Werke. Kritische Studienausgabe in 15 Bänden. Hrsg. v. Giorgio Colli u. Mazzino Montinari. Berlin/München.

Ong, Walter (1982): Orality and literacy. The technologizing of the word. London/New York.

Raible, Wolfgang (1991): Die Semiotik der Textgestalt. Erscheinungsformen und Folgen eines kulturellen Evolutionsprozesses. Heidelberg.

Raible, Wolfgang (1993): Die Entwicklung ideographischer Elemente bei der Verschriftlichung des Wissens. In: Vermittlung und Tradierung von Wissen in der griechischen Kultur. Hrsg. v. Wolfgang Kullmann u. Jochen Althoff. (= ScriptOralia 61). Tübingen, S. 15-37. 
Raible, Wolfgang (1994): Orality and literacy. In: Günther/Ludwig (Hg.), S. 1-17.

Raible, Wolfgang (1997): Von der Textgestalt zur Texttheorie. Beobachtungen zur Entwicklung des Text-Layouts und ihren Folgen. In: Koch/Krämer (Hg.), S. 29-42.

Raible, Wolfgang (2004): Über das Entstehen der Gedanken beim Schreiben. In: Performativität und Medialität. Hrsg. v. Sybille Krämer. München, S. 191-214.

Rheinberger, Hans-Jörg (1992): Experiment, Differenz, Schrift. Zur Geschichte epistemischer Dinge. Marburg.

Rheinberger, Hans-Jörg (1999): Alles, was überhaupt zu einer Inskription führen kann. In: Wissensbilder. Strategien der Überlieferung. Hrsg. v. Ulrich Raulff u. Gary Smith. Berlin, S. 265-277.

Sample, Colin (1996): Living words: Physiognomic and aesthetic language. In: The incorporated self. Interdisciplinary perspectives on embodiment. Hrsg. v. Michael O'Donovan-Anderson. Lanham u.a., S. 113-126.

Schott, Rüdiger (1995): Formen und Funktionen mündlicher Traditionen bei den Bulsa in Nordghana. In: Formen und Funktion mündlicher Tradition. Vorträge eines Akademiesymposions in Bonn, Juli 1993. Hrsg. v. Walter Heissig. Opladen, S. 79-92.

Senf, Wolfgang (1989): Anthropologische Gesichtspunkte der Stimme. In: Sprache Stimme - Gehör 13, S. 19-25.

Stetter, Christian (1997): Schrift und Sprache. Frankfurt a.M.

Strätling, Susanne/Witte, Georg (Hg.) (2006): Die Sichtbarkeit der Schrift. München.

Trojan, Felix (1982): Die Generatoren des stimmlichen Ausdrucks. In: Scherer, Klaus R. (Hg.): Vokale Kommunikation: nonverbale Aspekte des Sprachverhaltens. Weinheim/Basel, S. 59-77.

Vansina, Jan (1973): Oral tradition. A study in historical methodology. Aus dem Franz. übers. v. H.M. Wright. Chicago.

Wenzel, Horst (1995): Hören und Sehen. Schrift und Bild. Kultur und Gedächtnis im Mittelalter. München. 
Ines Bose

\title{
Stimmlich-artikulatorischer Ausdruck und Sprache
}

\begin{abstract}
Seit einigen Jahren befassen sich zahlreiche geisteswissenschaftliche Arbeiten verstärkt mit der Stimme in ihrer Bedeutung für die menschliche Kommunikation. Aufgrund der Vielschichtigkeit und Ambivalenz des Phänomens wird oft von einem sehr weiten, eher metaphorischen Begriff von Stimme ausgegangen. In der Sprechwissenschaft, die traditionell einen vor allem empirischen und didaktischen Zugriff auf die Sprechstimme hat, wird dagegen mit einem vergleichsweise engen, physiologischen Begriff von Stimme operiert, im Sinne einer Körperfunktion, als Muskelaktivitätsmuster unterschiedlicher Ausprägung, Gestalt und Funktion. In engem Bezug zur klinischen Sprechstimmdiagnostik und Phoniatrie wird Stimme betrachtet als Organ, dessen Anatomie und Physiologie zu beschreiben ist. In engem Bezug zur Phonetik werden Stimmgebung und -wirkung, stimmlich-artikulatorische Ausdrucksformen merkmalsanalytisch auditiv und akustisch beschrieben. In engem Bezug zur Linguistik, Rhetorik und Soziophonetik wird Stimme betrachtet als Resultat der Stimmgebung; Gegenstand sind Sprechwirkung und interaktive Ausarbeitung der Stimme in ihrer Verwobenheit mit sprachlichen und körperlichen Ausdrucksformen. Hierbei wird die Stimme als Bestandteil des stimmlich-artikulatorischen Ausdrucks aufgefasst, insofern als Teil von persönlicher und sozialer Identität, als Trägerin von ästhetisch-künstlerischem und emotionalem Ausdruck.

Methoden zur empirischen Beschreibung des sprechstimmlichen Ausdrucks werden exemplarisch vorgestellt, sowohl anhand von Arbeiten, in denen stimmlichartikulatorische Merkmale beschrieben und klassifiziert werden (Stimmphysiologie-, Emotionsforschung), als auch anhand von Arbeiten, in denen der stimmlichartikulatorische Ausdruck in seiner Wirkung auf Hörer (Sprechwirkungsforschung) und in seiner interaktiven Ausarbeitung (Gesprächsforschung) betrachtet wird. Aus den Ergebnissen der empirischen Studien wird deutlich, inwieweit stimmlichartikulatorische Ausdrucksformen als Bedeutungsträger fungieren und zur Vereindeutigung der Verständigung beitragen können.
\end{abstract}

\section{Einleitung}

Eine Stimme ruft bei Hörern zunächst einen Gesamteindruck hervor, aufgrund dessen sie Zuordnungen treffen, z.B. zur geografischen Herkunft, zur Nationalität oder zur Stimmung des Sprechers. Sie tun das auch dann, wenn sie den verbalen Gehalt nicht verstehen, und sogar dann, wenn die Hinweise aus dem Gehörtem widersprüchlich sind. Diese Alltagserfahrung hat bereits Edgar Allan Poe vor mehr als 150 Jahren in seiner Kurzgeschichte „Die Morde in der Rue Morgue“ sehr treffend und eindrucksvoll verarbeitet: Nach einem vollkommen unerklärlichen Doppelmord an zwei Pariser Frauen sagen zahlreiche Ohrenzeugen aus, dass sie im Haus der Opfer einen Streit gehört hätten. Neben den ihnen bekannten Stimmen der bei- 
den Frauen hätten sie noch eine weitere, unbekannte Stimme wahrgenommen. Diese schrille Stimme deuten die Zeugen allerdings sehr verschieden, und der geniale Detektiv Auguste Dupin stutzt:

Doch was die schrille Stimme angeht, ist das Eigenartige nicht, dass sie uneins waren - sondern dass, obwohl ein Italiener, ein Engländer, ein Spanier, ein Holländer und ein Franzose sie zu beschreiben versuchten, jeder von der Stimme eines Ausländers sprach. Jeder ist sich sicher, dass es nicht die Stimme eines seiner Landsleute war. Mehr noch, ein jeder vergleicht sie, nicht mit der Stimme eines Sprechers einer Nation, mit deren Sprache er vertraut ist, sondern im Gegenteil. Der Franzose hält sie für die Stimme eines Spaniers, und ,hätte einzelne Wörter ausmachen können, wäre er des Spanischen mächtig'. Ein Holländer beharrt darauf, dass es die Stimme eines Franzosen gewesen sei, doch entnehmen wir der Aussage, dass der Zeuge, der kein Französisch spreche, von einem Übersetzer befragt wurde`. Der Engländer hält die Stimme für die eines Deutschen, und ,versteht kein Deutsch'. Der Spanier, ist sich sicher', dass es ein Engländer war, doch er urteilt , nur nach der Betonung', da ,er über keine Englischkenntnisse verfüge‘. Der Italiener glaubt, es war ein Russe, ,doch er habe nie mit einem gebürtigen Russen gesprochen'. Ein zweiter Franzose ist anderer Meinung als der erste, und ist sich sicher, dass es die Stimme eines Italieners war; er habe sich, da er jener Sprache nicht mächtig sei', wie der Spanier, von der Betonung überzeugen lassen'. Wie überaus eigenartig muss die Stimme in Wirklichkeit gewesen sein, um solche Zeugenaussagen hervorzurufen! - in deren Klängen selbst die Bewohner von fünf großen Teilen Europas nichts Vertrautes erkennen konnten! (Poe 1841 [2009], S. 35 f.)

Dupin kommt es also höchst eigentümlich vor, dass die Aussagen so stark voneinander abweichen. Als guter Feldforscher unterstellt der Detektiv den Zeugen nicht generelle Unfähigkeit zu präziser Beschreibung bzw. Zuordnung, sondern vermutet wichtige Gründe im stimmlichen Signal. So aufmerksam geworden, findet er im Hause der Ermordeten weitere höchst ungewöhnliche Spuren und kann schließlich den eigentlichen Täter identifizieren: einen Orang Utan.

Rezipienten deuten eine konkrete Stimme immer vor dem Hintergrund ihrer Erfahrungen bzw. Erwartungen als Ausdruck von Persönlichkeitseigenschaften, Emotionen, Einstellungen und Interaktionsrollen. Für diese Deutungen greifen sie auf verschiedene Signale gleichzeitig zu, im oben angeführten Beispiel neben dem Stimmklang z.B. auch auf Akzentuierung und Rhythmus, und sie können das Gehörte gezielt analysieren, sich auf bestimmte Eigenschaften der Stimme konzentrieren und andere unterdrücken.

\section{Begriffsbestimmungen}

\subsection{Stimme}

Die Sprechstimme ist traditioneller Forschungsgegenstand vor allem in Phonetik, Sprechwissenschaft und Sprecherziehung, Rhetorik, Phoniatrie. 
Seit einigen Jahren widmet ihr die Geisteswissenschaft verstärkte Aufmerksamkeit, so z.B. aus philosophischer Perspektive (vgl. z.B. Connor 2004; Krämer 2005, 2006 und in diesem Band; Mersch 2006; Waldenfels 2006), aus kultur- und theaterwissenschaftlicher Perspektive (vgl. etwa Chion 2003; Kolesch 2005, 2006a, b; Meyer-Kalkus 2001, 2004), aus medien- und kommunikationswissenschaftlicher Perspektive (vgl. beispielsweise Hartel/Kaspar 2004; Peters 2004; Westphal 2002), aus linguistischer Perspektive (vgl. z.B. Bogner 2000 und 2005; Dolar 2004; Drumbl 2005; König/Brandt 2006) und aus anthropologisch-evolutionärer Perspektive (vgl. z.B. Fitch 2004).

Viele dieser Autoren weisen zu Recht darauf hin, dass die Stimme vielschichtig und ambivalent ist, ein sog. ,Schwellenphänomen“: „Denn die Stimme ist immer zweierlei: sie ist sinnlich und sinnhaft, somatisch und semantisch, diskursiv und ikonisch, indexikalisch und symbolisch, natürlich und künstlich, affektiv und kognitiv, physisch und psychisch [...] Körper und Geist, Natur und Kultur, Gefühl und Intellekt" (Krämer 2005, S. 88); sie ist ,individuell und sozial, [...] Aktion der Sprecherin und Passion des Ohres“ (Krämer 2006, S. 12). Nach Dolar (2004, S. 215) ist „die Stimme als Stütze des Sprechens [...] allgegenwärtig und trivial“, gelegentlich wird sie als ,Nukleus der Geistes-, Human- und Kunstwissenschaften' bezeichnet (Kolesch/Krämer 2006, S. 7) oder sogar als Nukleus aller Wissenschaft (Peters 2004, S. 85) und tendenziell als Metapher für Sprechstile (im Sinne Bachtins, vgl. z.B. 1972) oder sogar für Sprechen an sich verwendet. Damit sind Schwierigkeiten bei der begrifflichen Bestimmung und Abgrenzung, vor allem aber für die empirische Beschreibung verbunden.

Die Sprechwissenschaft operiert dagegen mit einem vergleichsweise engen, anatomisch-physiologischen Begriff von Stimme, im Sinne einer Körperfunktion, als Muskelaktivitätsmuster unterschiedlicher Ausprägung, Gestalt und Funktion:

- In engem Bezug zur klinischen Sprechstimmdiagnostik und Phoniatrie wird Stimme betrachtet als Organ; Gegenstand sind z.B. die Physiologie und Anatomie des Kehlkopfes, des Ansatzrohres, der Resonanzräume. Untersucht wird die gesunde und kranke Stimme.

- In engem Bezug zur Phonetik werden Stimmgebung und -wirkung, stimmlich-artikulatorische Ausdrucksformen merkmalsanalytisch auditiv und akustisch beschrieben.

- In engem Bezug zur Linguistik, Rhetorik und Soziophonetik wird Stimme betrachtet als Resultat der Stimmgebung; Gegenstand sind z.B. die Sprechwirkung und die interaktive Ausarbeitung der Stimme in ihrer Verwobenheit mit sprachlichen und körperlichen Ausdrucksformen. Hierbei wird die Stimme als Bestandteil des, stimmlich-artikulatorischen Ausdrucks' aufgefasst und untersucht, insofern als Teil von persönlicher und sozialer Identität, als Trägerin von ästhetisch-künstlerischem und emotionalem Ausdruck. 
- Einen praktischen bzw. praxisbezogenen Zugang zur Stimme hat die Sprecherziehung als angewandte Sprechwissenschaft: In engem Bezug zur Sprechbildung und Gesangspädagogik wird Stimme betrachtet als Tätigkeit der Stimmgebung; Gegenstand sind z.B. die Trainierbarkeit und Optimierung der Laut- und Stimmbildung und der Bezug von Stimme und Körper als unterschiedliche menschliche Ausdrucksdimensionen. Zugrunde liegt zumeist ein physiologisches und ästhetisches Stimmideal westlicher Prägung, das am italienischen Operngesang entwickelt wurde: die anstrengungslose, klangvolle, klare, leistungsfähige Stimme.

\subsection{Stimmlich-artikulatorischer Ausdruck}

Im oben zitierten Kriminalfall konnte zwar keiner der Ohrenzeugen in den befremdlichen Vokalisationen des Orang Utans ein bekanntes Stimmausdrucksmuster identifizieren, dennoch interpretierten die Zeugen ihren Eindruck von Fremdheit in der gehörten Stimme in Bezug auf den konkreten Situationskontext, als Äußerungen in einer ihnen unbekannten Sprache. Rezipienten versuchen, eine konkrete Stimme bzw. Sprechweise in einer konkreten Situation

vor dem Hintergrund der ,normalen' individuum-spezifischen Stimmlautheit, Stimmhöhe, Klangfarbe, Geschwindigkeit oder Artikulationsweise als eine Variante [zu erfassen], die erst durch die Bedingungen oder Erfordernisse der Situation ausgelöst wurde und die dadurch als situationsbezogener Ausdruck verstanden werden kann. (Stock 1987, S. 57 f.)

Für situations- und stimmungsadäquat konventionalisierte Gestaltungsweisen im Sprechschall, mit denen Sprecher u.a. Rollen-, Gruppen-, Handlungsmuster realisieren, existiert in der Sprechwissenschaft der Begriff ,Stimmlich-artikulatorischer Ausdruck' oder auch ,Sprechausdruck' (z.B. Stock 1987, Gutenberg 1998, Bose 2003). Er ist weniger biologisch, sondern stärker sozial und kulturell determiniert und eng verwoben mit der sprachlichen Ebene des Sprechens.

Grundlage bildet der sog. physiognomische Stimmausdruck,

der physiologisch bedingte (durch individuelle Besonderheiten im Bau des Kehlkopfes und des Ansatzrohres) bzw. habitualisierte (durch gewohnheitsmäßige Einstellung der Muskelspannung in den Artikulationsorganen und des subglottalen Luftdrucks) quasikonstante Stimmklang mit seiner individuell spezifischen Lautheit und Tonhöhe [...sowie] jene Modifikationen [...], die bei starken Emotionen wie Wut, Ekel, Lust hervorgebracht werden, oft für die Dauer des Kommunikationsereignisses konstant bleiben und mit instinktmäßiger oder reflektorischer Aktivität zu erklären sind. (Stock 1987, S. 75) 
Durch Entfaltung und Ergänzung dieser angeborenen Grundmuster werden im Verlaufe der Kommunikationsbiografie stärker intendierte stimmlich-artikulatorische Ausdrucksmuster erworben: differenziertere, strukturiertere Formen, die „bei der Äußerungsgenerierung in Einheit mit dem Wortlaut und als notwendiger ,Kommentar ${ }^{6}$ zu diesem geplant und realisiert" werden (Stock/Suttner 1991, S. 64).

Die Verwendung des Begriffs ,Ausdruck' verweist auf die Tradition der ausdruckspsychologischen Sprechstimmforschung (stellvertretend z.B. Werner 1932; Bühler 1933 und 1934; Trubetzkoy 1939; Trojan 1948; Kirchhoff 1965), welche stimmliche Äußerungsformen als Ausdruck, als äußere Erscheinungsformen innerer Veranlagungen, Empfindungen und Leidenschaften deutet. Nach Görlitz (1972, S. 62) deckt der Begriff allgemein „vieles von dem, was alltäglich als, wie jemand spricht" begegnet". Allerdings ist der Ausdrucksbegriff wegen seiner Polyvalenz bis hin zur Überdehnung und wegen seiner Äquivokationen oft kritisiert worden (vgl. stellvertretend die Diskussion in Görlitz 1972; Rothe 2006). Stimmlich-artikulatorischer Ausdruck wird einerseits verstanden als die Realisierung von Expressivem (z.B. Trojan 1948), andererseits als Oberbegriff, als die Realisierung von Rollen-, Gruppen-, Handlungsmustern im Sprechschall (z.B. Geißner 1981). Ausdruck ist

im phänographischen Zugang ein unmittelbar Antreffbares, ist unvermitteltes Erscheinen, während Ausdruck im funktional-sematologischen Zugang ein als Zeichen fungierendes Medium ist, das für etwas anderes (Befindlichkeit, Positionalität, personales Sosein) steht. Die konditionale Fassung schließlich bezieht sich auf die Ausdruck konstituierenden Faktoren. (Görlitz 1972, S. 55; ähnlich auch Kirchhoff 1991)

Interessant ist der Ausdrucksbegriff, weil er nicht nur auf das Individuum verweist, das seinen Empfindungen willkürlich oder unwillkürlich Ausdruck gibt, sondern auch auf den Adressaten, bei dem Empfindungen erregt werden, und damit auf den Interaktionsprozess; Ausdruck ist immer Ausdruck von jemandem für jemanden in einer konkreten Situation.

Wahrnehmung und Deutung des stimmlich-artikulatorischen Ausdrucks enthalten Urteile sowohl über den physiognomischen als auch über den pathognomischen Stimmausdruck, weil Sprechen beides enthält, nämlich ,immer auch Ausdruck habitueller kognitiver, emotionaler und voluntativer Geprägtheiten des Sprechenden [...], immer auch Ausdruck und Vollzug okkasioneller kognitiver, emotionaler und voluntativer Prozesse" (Gutenberg 2001, S. 73). Die Bewertung des pathognomischen Ausdrucks hängt von der des physiognomischen ab. Über den Vergleich mit Ausdruckserscheinungen anderer Sprecher in ähnlichen Situationen „bilden sich innerhalb eines Kulturkreises, einer Sprachgemeinschaft oder einer sozialen Gruppe bestimmte Erwartungsvorstellungen über das mögliche bzw. zulässige Ausdrucksverhalten heraus“ (Stock 1987, S. 57 f.). Den Ausdrucksmus- 
tern entsprechen also gesellschaftlich bedingte Hörmuster, interiorisierte Normen bzw. Erwartungsmuster zur Angemessenheit stimmlich-artikulatorischer Gestaltung als situationsadäquate Realisation bestimmter Sprechhandlungs-, Rollen-, Sozialmuster (vgl. Gutenberg 2001; ähnlich Geißner 1984; Selting 1997). Mit eindeutigen Zuordnungen ist allerdings nicht zu rechnen, denn Musterbildungen der Sprechtätigkeit sind heterogen, können sich also wechselseitig überschneiden und einander interdependent durchdringen. Kinder erwerben Hör- und Ausdrucksmuster gemeinsam mit der Sprache anhand von Wahrnehmung, Abstraktion und kreativer Umsetzung der jeweils individuell ausgeführten Ausdrucksweisen der kommunikativen Umgebung.

Bei der auditiven Wahrnehmung ist nach Bühler (1927) der ganze psychophysische Organismus beteiligt, und Hörer vergegenwärtigen sich beim Wahrnehmen von Stimmen die ganze Person. Was als Ausdruck hervorgebracht wird, löst einen Verhaltensimpuls im Adressaten aus, kann in seiner Bedeutung nicht ohne dessen Reaktionen verstanden werden, vgl. z.B. Trubetzkoy (1939 [1989], S. 18):

\footnotetext{
Wenn wir jemanden reden hören, so hören wir, wer spricht, in welchem Tone er spricht und was er sagt. Es liegt ja eigentlich nur ein einziger akustischer Eindruck vor. Wir zerlegen ihn aber in seine Bestandteile, und zwar immer vom Standpunkte der drei Bühlerschen Sprachfunktionen: gewisse Eigenschaften des wahrgenommenen Schalles fassen wir auf als Kundgabe, als Symptom des Sprechers (z.B. seine Stimmlage), gewisse andere als Mittel zur Auslösung bestimmter Gefühle beim Hörer, und endlich noch andere als Merkmale, an denen die Wörter mit bestimmten Bedeutungen und die aus ihnen bestehenden Sätze erkannt werden.
}

In ihrem Eindruck reproduzieren Rezipienten nicht einfach das vom Sprecher Ausgedrückte, sondern ziehen Rückschlüsse auf zugrundeliegende Befindlichkeiten, und zwar vor einem situativen, historischen und kulturellen Horizont von Traditionen, Praktiken, Medien, Kultur- und Kunstformen. Eindruck umfasst demnach sowohl die Wahrnehmung von Ausdruck als auch die Verknüpfung des Wahrgenommenen mit eigenen Assoziationen und die Musterzuschreibung durch den Vergleich mit Erinnerungen - also die Ergänzung um Informationen, die nicht unmittelbar im Geäußerten enthalten sind (Bühler 1933). Rezipienten identifizieren Ganzheiten, die im Verlauf der Kommunikation als Sukzessivgestalten erscheinen. Dadurch weist die Wahrnehmung bzw. Deutung stimmlich-artikulatorischen Ausdrucks individuelle Spielräume, Varianten, Unschärfen bis hin zu Irrtümern auf, dennoch ist sie ein unverzichtbares Mittel der sozialen Orientierung.

\subsection{Parameter des stimmlich-artikulatorischen Ausdrucks}

Stimmlich-artikulatorischer Ausdruck stellt einen Merkmalskomplex aus stimmlich-melodischen, aber auch aus temporalen, dynamischen und arti- 
kulatorischen Parametern dar, die an auditiv wahrnehmbaren physiologischakustischen Grundlagen der Stimmproduktion und Artikulation orientiert sind. Allerdings ist der Zusammenhang zwischen akustischen Grundlagen und Hörempfindungen nicht linear. Bezugsgrößen sind deshalb keine (absoluten, objektiven) Messwerte, sondern konsequent auditive Eindrücke. Entsprechende Termini und Beschreibungssysteme stammen aus der ausdruckspsychologischen Sprechstimmforschung (z.B. Trojan 1948 und 1975; Fährmann 1960; Höffe 1965), der Sprechwissenschaft (z.B. Winkler 1969; Krech/Richter/Stock/Suttner 1991; Stock 1996; Gutenberg 1998; Heilmann 2001), der klinischen Sprechstimmforschung (z.B. Pfau/Streubel 1982; Seidner/Wendler 1982; Vieregge 1989 und 1996; Wendler/Seidner/Kittel/ Eysoldt 1996) und aus der Phonetik (z.B. Laver 1980 und 2000; Terhardt 1998; Neppert 1999; Kent/Ball 2000; Ketzmerick 2007).

Stimmlich-artikulatorischer Ausdruck ist beschreibbar anhand folgender Parameter (ausführlich hierzu Bose 2001 und 2003 und die dort genannte Literatur):

- Sprechtonböhe (hoch vs. tief, bewegt vs. monoton), abhängig von Periodizität und der Periodendauer der Schallsignale, aber auch von Spektralmerkmalen der Stimme. Physiologisch entstehen Tonhöhenveränderungen durch Veränderungen in der Stimmlippenspannung, verschiedene Einstellungen des Spannapparates der Kehlkopfmuskulatur und Veränderungen des subglottischen Drucks.

- Stimmklang, abhängig von der Tätigkeit der Glottis, der Klangbildung und Resonanzwirkung im Ansatzrohr und der Atmung. Zum Stimmklang gehören Merkmale wie

- Klangfülle (klangvoll vs. klangarm), physiologisch bedingt durch die Regelmäßigkeit im Schwingungsablauf der Stimmlippen und durch Resonanzeigenschaften des Ansatzrohres, die die Teiltonstruktur des Spektrums bestimmen.

- Klangfarbe (hell vs. dunkel), physiologisch bedingt durch die Formung des Ansatzrohres, aber auch durch die Tonhöhe.

- Faukale Distanz (weit vs. eng), physiologisch bedingt durch die Gestaltung des Rachenraumes, genauer durch die Weite bzw. Enge im Bereich der hinteren Gaumenbögen, durch die Lage der Zungenwurzel und die Lage des Kehlkopfes während der Stimmgebung,

- Stimmein- und-ausschwingphasen (weich vs. hart), physiologisch bedingt durch die Stimmlippenspannung und die Stärke des subglottischen Drucks.

- Geräuschanteil (klar vs. geräuschhaft, also z.B. behaucht, rau, gepresst, geknarrt), physiologisch bedingt durch die Regelmäßigkeit bzw. Unregelmäßigkeit der Stimmlippenschwingungen. 
- Lautheit (laut vs. leise), abhängig von der physikalisch messbaren SchallAmplitude. Physiologisch entstehen Lautheitsveränderungen durch Veränderungen des subglottischen Drucks, aber auch durch Veränderungen im Schwingungsablauf der Stimmlippen.

- Sprechgeschwindigkeit (schnell vs. langsam), verstanden als Realisierung bestimmter sprachlicher Einheiten (Laute/Silben/Wörter) in einer bestimmten Zeiteinheit (s/min). Ihre auditive Wahrnehmung bzw. Beurteilung hängt aber auch von Sprechpausen, Akzentuierungsstärke, Artikulationspräzision, Lautdehnungen usw. ab.

- Akzentuierung (stark vs. schwach, eher melodisch vs. dynamisch vs. temporal), beschrieben anhand der Position, Stärke und Form auditiv wahrnehmbarer Akzentstellen.

- Sprechrbythmus (staccato vs. legato, skandierend vs. nicht skandierend), verstanden als zeitgliedernde Erscheinung, die die Regelung des Wechsels zwischen akzentuierten, nicht akzentuierten und schwach akzentuierten Silben betrifft und sich mit den Kategorien ,Spannung' und ,Entspannung' beschreiben lässt.

- Sprechspannung (gespannt vs. ungespannt), abhängig von Stimmlippenspannung, Expirationsdruck und relativer Spannung der Artikulationsmuskulatur.

- Artikulation, verstanden als Realisierung der Sprechlaute. Bezugsgrößen sind Aussprachenormen ebenso wie emotionale Gestimmtheit. Zur Artikulation gehören Merkmale wie:

- Artikulationspräzision (präzise vs. unpräzise), der Sorgfältigkeitsgrad bei der Ausspracherealisierung, abhängig von Artikulationsspannung, Lippentätigkeit, Kieferöffnungsweite, Zungenlage, Gaumensegelfunktion, Kehlkopfstand.

- Lippenstellung (gestülpt vs. gespreizt), die auditiv auffällige Überformung der Artikulation durch Lippenbewegungen, die nicht ursprünglich zur Schall- bzw. Lauterzeugung gehören.

- Lautdauer (gedehnt vs. verkürzt) in Bezug auf die Position innerhalb der Sprachäußerung, abhängig von der Sprechgeschwindigkeit.

Wie bereits aus dieser knappen Darstellung hervorgeht, kommen Beschreibung und Interpretation der einzelnen Parameter aufgrund komplexer, nicht immer genau aufzuschlüsselnder Höreindrücke zustande, sind also nicht eindimensional (die Einschätzung von Stimmklangfarbe ist z.B. nicht unabhängig von der Sprechstimmhöhe; die Einschätzung der Sprechstimmlagen geschieht auch über das Nachempfinden von Spannungsverhältnissen usw.). Ebenso ist nicht klar zu trennen zwischen i.e.S. ausschließlich stimmlichen $v s$. prosodischen $v$ s. artikulatorischen Gestaltungsweisen. 


\section{Empirische Erforschung des stimmlich-artikulatorischen Ausdrucks}

Nicht nur theoretisch, sondern auch methodisch stehen viele neuere empirische Arbeiten zur Beschreibung, Klassifikation und Wirkung stimmlichartikulatorischen Ausdrucks in der Tradition der ausdruckspsychologischen Sprechstimmforschung. Deshalb werden zunächst stellvertretend zwei einflussreiche ausdruckspsychologische Arbeiten vorgestellt, danach exemplarisch Vorgehensweisen und Erkenntnisse der Sprechwissenschaft bei der empirischen Erforschung des sprechstimmlichen Ausdrucks. Ausgewählt wurden sowohl Arbeiten, in denen Merkmale beschrieben und klassifiziert werden (Stimmphysiologie-, Emotionsforschung), als auch Arbeiten, in denen der stimmlich-artikulatorische Ausdruck in seiner Wirkung auf Hörer (Sprechwirkungsforschung) und in seiner interaktiven Ausarbeitung (Gesprächsforschung) betrachtet wird.

\subsection{Ausdruckspsychologische Sprechstimmforschung}

Ziel ausdruckspsychologischer Sprechstimmforschungen ist die Beschreibung des stimmlich-artikulatorischen Ausdrucks anhand von phonischen Merkmalen, die Klärung seiner Funktion in der mündlichen Kommunikation und die Bestimmung der Bedingungen für bestimmte Gestaltungsmuster. Gemeinsam ist ihnen die Verwendung experimentell erstellten bzw. konstruierten Materials in kontrollierten Situationen. Aus der ausdruckspsychologischen Sprechstimmforschung sind Konzeptualisierungen zum stimmlich-artikulatorischen Ausdruck und typologisch ausgerichtete Ordnungsversuche hervorgegangen, darüber hinaus Beiträge zur Kultivierung und ästhetischen Normierung des sprechstimmlichen Erscheinungsgehaltes (vgl. hierzu die Diskussion in Görlitz 1972; Meyer-Kalkus 2001; Rothe 2006). Vorgestellt werden eine Perzeptionsstudie (Bühler 1933) und eine merkmalsanalytische Arbeit (Trojan 1948).

Zusammen mit Kollegen und Schülern hat Bühler eine bemerkenswerte Massenbefragung zum „Zusammenhang von Stimme und Persönlichkeit“ durchgeführt (Bühler 1933; Herzog 1933), in der statt des klassischen Laborversuchs das neue Medium Rundfunk genutzt wurde. Im sog. physiognomischen Radio-Experiment sollte geklärt werden, welche Informationen Hörer aus einer Radiostimme entnehmen können und inwiefern sie in ihren Urteilen übereinstimmen. Neun Sprecher/innen unterschiedlichen Alters aus allen Schichten der Wiener Bevölkerung wurden gebeten, eine Ballade und einen Sachtext zu sprechen. Diese Sprechfassungen wurden zusammen mit einem Fragenkatalog im Radio gesendet. 2700 Radiohörer gaben ihren Eindruck darüber kund, ob ihnen die jeweilige Stimme sympathisch war, welche Vermutungen sie über Geschlecht, Alter, Aussehen, 
Beruf der Sprecher/innen hatten u.a.m. Die Auswertung ergab eine weithin eindeutige Identifizierung des Geschlechts der Sprechenden, eine große Übereinstimmung in der Einschätzung von Größe und Gestalt, dagegen Unsicherheiten in der Bestimmung von Alter und Beruf.

Bühler (1933 [1968], S. 192 ff.) schlussfolgert, dass Rezipienten mit einem Mechanismus der Unterstellung arbeiten, d.h. dass sie ihre Interpretationen über einen unbekannten Sprecher aus dem Vergleich mit Eigenschaften einer bekannten Person gewinnen, deren Stimme Ähnlichkeiten mit der gehörten aufweist. Nach Bühler funktioniert dieser Mechanismus der Unterstellung als Resonanzverfahren (Einfühlung bzw. unwillkürliche Ansprechbarkeit durch den Ausdruck anderer Menschen) und als Indizienverfahren (Spurenlesen, um das auf indirekte Weise Ausgedrückte zu verstehen). Damit misst Bühler der Subjektleistung bei der Konstitution von Wahrnehmungseindrücken eine entscheidende Rolle zu. Die Bedeutungszuschreibung in der Kommunikation fasst er als Top-Down-Verarbeitung unter Mitwirkung zentraler Antizipationen auf und betont die Relevanz von Konventionen und von Situationsindizien (vgl. hierzu auch die Diskussion in Ehlich 2004; Nothdurft 2004; Hirschfeld/Stock ersch. 2009). Kommunikationsbeteiligte ziehen demnach ihre Schlüsse darüber, wie etwas, was der andere sagt bzw. meint, zu verstehen und zu interpretieren ist, aufgrund von Hinweisreizen, Kontexthilfen und Situationsindizien, zu denen auch der stimmlich-artikulatorische Ausdruck gehört. Allerdings sind diese Hinweisreize nicht zweifelsfrei zu identifizieren oder vorherzusagen, weil sich die Kommunizierenden aus dem Gesamtkomplex der Kommunikation bedienen und das nicht immer auf die gleiche Weise (Bühler 1933; vgl. hierzu auch Stock 1991; Hirschfeld/Stock ersch. 2009).

Trojan (1948), Bühler-Schüler und Sprecherzieher, hat mit Rückgriff auf die Phonologie Trubetzkoys (1939) eine Typologie des sprechstimmlichen Ausdrucks vorgelegt, die sog. ,phonetische Lautstilistik ${ }^{\star}$, verstanden als eine Art zweites semantisches Zeichensystem. Gegenstand der Untersuchung sind Gestaltungs- und Formungsregeln des sozial adressierten Ausdrucks und das Verhältnis von Ausdrucksmitteln und -inhalten. Trojan nimmt sog. Schallbilder der gesprochenen Sprache an, Zeichen mit Ausdrucks- und Appellfunktion: Schallbilder

stellen meist unselbständig auftretende, phonisch-artikulatorische Zeichen dar, die in der Regel instinktiv gesendet werden, koexistierend angeordnet sind und in der Hauptsache existentielle Vorgänge im Zeichensender ausdrücken oder vorgeben; sie haben sich aus vorsprachlichen Rudimentärformen entwickelt, sind mit der Sprache eine sehr innige Fusion eingegangen und haben sich eben dadurch außerordentlich verfeinert und differenziert. (Trojan 1948, S. 45)

Die Schallbilder sind nicht ausschließlich reflektorisch oder affektiv bedingt, sondern können auch intendiert und situationsbezogen verwendet (und unterdrückt) werden, und sie unterliegen in gewissem Umfang den glei- 
chen Bildungsprinzipien wie die sprachlichen Zeichen (Trojan 1948., S. 2). Den Schallbildern liegen interne Normen zugrunde, die sog. Akueme, wobei die konkreten Realisationen ,innerhalb eines Spielraumes, den ihnen eben diese Normen gewähren, eine gewisse Freiheit und Selbständigkeit [bewahren]“ (ebd., S. 11). Um die Akueme zu beschreiben, sucht Trojan aus pathognomischer Perspektive nach Konstanz des Affektausdrucks bei verschiedenen Individuen, aus physiognomischer Perspektive sucht er beim Ausdruck unterschiedlicher Affekte nach personeller Konstanz, die durch „Bau und Zustand des Körpers, Bevorzugung einer bestimmten seelischen Grundhaltung" bedingt ist (ebd., S. 15).

Material für die Untersuchung bildete ein Satz (Und das ist von nun an mein Tun und Treiben), der von drei Schauspielern in zehn vorher festgelegten Schallbildern (z.B. ,Angst, Ekel, freudige Rührung, Langeweile, zielbewusster Wille') gesprochen wurde. Die sprechstimmlichen Realisationen wurden vom Autor auf ihre Treffsicherheit beurteilt und von geschulten Hörern auditiv-akustisch beschrieben: mittels eines Beurteilungskatalogs mit phonetisch-physiologisch basierten Merkmalen, wie z.B. Atmungsform, Stimmregister, Akzentform, Artikulationsspannung, Stimmeinsatz u.a.m. (Trojan 1948, S. 104 ff.). Ergebnisse dieser Untersuchungen sind eine Merkmalssammlung zur phonetisch-physiologisch basierten Beschreibung der Schallbilder und Lehrsätze einer Stildiagnostik auf sprachinhaltlicher und sprechexpressiver Grundlage.

Durch ein solches Vorgehen können zwar wichtige Erkenntnisse über phonische Auslösefaktoren und dadurch erzeugte Wirkungen gewonnen werden, aber zur interaktiven Relevanz des stimmlich-artikulatorischen Ausdrucks im Kommunikationsprozess sind nur eingeschränkte Aussagen möglich. Jüngere Untersuchungen über Form-Funktions-Beziehungen im stimmlich-artikulatorischen Ausdruck, z.B. zur Sprechwirkung, sind zwar ebenfalls als Kommunikationsexperimente mit konstruiertem Material angelegt, aber mit theoretisch veränderten Konzepten und verfeinerten Methoden.

\subsection{Stimmphysiologie und -pathologie}

Phoniatrie, Logopädie und klinische Sprechwissenschaft befassen sich mit der Diagnostik und Therapie der Sprech- und Singstimme. Voraussetzung ist eine möglichst klare und transparente Beschreibung stimmlicher Eigenschaften, sowohl apparativ als auch auditiv. $\mathrm{Da}$ für die meisten akustischen Erhebungen gehaltene Vokale mit ausreichender Dauer produziert werden müssen, sind diese Verfahren für die Beschreibung stimmlicher Qualitäten bei fortlaufendem Sprechen (noch) nicht geeignet (vgl. stellvertretend Nawka/Anders 1996; Anders 1997). Deswegen spielt in der klinischen Praxis die auditive Beurteilung nach wie vor eine sehr große Rolle. Sie bietet die ein- 
fachste und schnellste Möglichkeit, eine Stimmstörung verlässlich zu bewerten bzw. zu dokumentieren (vgl. stellvertretend Schneider/Bigenzahn 2007).

Allerdings steht für die Beschreibung von Hörwahrnehmungen der Stimme nur ein sehr begrenzter Wortschatz zur Verfügung:

\begin{abstract}
Wenn man sich exklusiv auf auditive Kategorien beschränkt, bleibt letztlich ein Adjektivpaar übrig, nämlich laut und leise. Alle anderen Kennzeichnungen, wie hoch oder tief, hell oder dunkel, strahlend oder stumpf, sind metaphorische Umschreibungen mit Anleihen aus anderen Sinnesbereichen. Der Mangel an spezifischen sprachlichen Ausdrucksmöglichkeiten für gehörte Eindrücke führt zu einer großen Vielfalt bei der Wahl geeignet erscheinender Wörter. Im Falle des menschlichen Stimmklangs kommt erschwerend hinzu, daß dieser selbst in außergewöhnlicher Vielfalt auftritt, mit individuellen Ausprägungen, wie sie von Gesichtern und Fingerabdrücken bekannt sind. (Wendler 1996, S. 3)
\end{abstract}

Aus der therapeutischen Erfahrung heraus sind zahlreiche Kataloge zur Beurteilung von stimmlichen Eigenschaften und Leistungen entstanden, die oft eine Vielzahl von solchen metaphorischen Umschreibungen enthalten (vgl. z.B. angenehm, schrill, metallisch, spitz, hoch/tief; klein/groß, warm/kalt, schneidend, rund, glatt). In einem Überblick über solche Systeme nennt Sonninen (1970) z.B. allein zur Beschreibung heiserer Stimmen 59 Adjektive. Aufgrund ihrer Idiosynkrasie und Unübersichtlichkeit haben solche Kataloge nur eingeschränkte Verbreitung gefunden.

\title{
3.2.1 Parameterbasierte Beschreibungssysteme
}

Für die klinische Praxis wurden deshalb transparente Beurteilungssysteme für stimmliche Eigenschaften entwickelt, die sich auf Erkenntnisse über die Anatomie, Physiologie und Pathologie der Stimme stützen. Stellvertretend wird auf drei international anerkannte und verbreitete Systeme zur Beurteilung einer Stimmstörung verwiesen. Gemeinsam ist ihnen die Orientierung an klar definierten Bewertungssystemen und die Konzentration auf wenige wesentliche Klangphänomene der Stimme, die skaliert beschrieben werden. Anhand dieser Systeme sind zunächst grobe Beschreibungen und Kategorisierungen von Stimmen möglich, an die sich exakte Diagnosen anschließen können.

Die sog. GRBAS-Skala (Hirano 1981) stützt sich auf fünf Parameter: $\mathrm{G}$ - overall grade for degree (Gesamtgrad der Störung, Instabilität), R - rough (Rauigkeit), B - breathy (Behauchtheit), A - asthenic (Asthenie, Schwachheit), S - strained quality (Spannung, Gepresstheit). Der Ausprägungsgrad dieser Parameter wird auditiv mit Hilfe einer vierstufigen Skala bestimmt: 0 - nicht vorhanden, 1 - geringgradig, 2 - mittelgradig, 3 - hochgradig vorhanden.

Da sich in der Anwendung des Systems zwei Parameter als uneindeutig erwiesen (Parameter A wegen seiner Korrelation vor allem mit B und Parameter $\mathrm{S}$ wegen zu stark streuender Beurteilungen), wurde diese Skala über- 
arbeitet und auf drei Faktoren eingeschränkt, z.B. in der sog. RBH-Klassifikation (Wendler/Rauhut/Krüger 1986; Nawka/Anders 1996; Nawka/Evans 2005). Sie berücksichtigt ebenfalls vier Ausprägungsgrade und beruht auf den Parametern H - Heiserkeit, R - Rauigkeit, B - Behauchtheit. Maßstab ist die sog. euphone Stimme ( $\mathrm{R} 0-\mathrm{B} 0-\mathrm{H} 0)$. Heiserkeit wird als „unspezifisches Leitsymptom einer Stimmstörung" definiert. Sie entsteht durch die beiden Hauptkomponenten ,phonatorisch unkontrollierter Luftverbrauch“ (Behauchtheit) und „irreguläre Schwingungen“ (Rauigkeit). Die Heiserkeit wird immer von einer der beiden untergeordneten Dimensionen dominiert, stellt also kein völlig unabhängiges Urteil dar (Nawka/Anders 1996, S. 114).

Ähnlich aufgebaut ist auch das System Consensus Auditory-Perceptual Evaluation of Voice (CAPE-V) der American Speech-Language-Hearing Association (ASHA) (2002). Es verwendet sechs Parameter: allgemeine Einschätzung der Störung (overall severity), Rauigkeit (roughness), Behauchtheit (breathiness), Gepresstheit (strain), Grundfrequenz (pitch), Stimmstärke (loudness). Der Stärkegrad ist anders als in den anderen beiden Systemen mittels Analogskalen stufenlos anzugeben, darüber hinaus wird vermerkt, ob das betreffende Merkmal konsistent (consistent) oder nur gelegentlich (intermittent) auftritt.

Heiserkeit ist aufgrund physikalisch messbarer und physiologisch definierbarer Grundlagen des Stimmschalls nicht eindeutig zu beschreiben, da ihr unterschiedliche pathophysiologische Mechanismen zugrunde liegen. Trotz ihrer unterschiedlichen Qualitäten ist sie aber auditiv durchaus erkennbar und klassifizierbar (Evans/Nawka 2007, S. 313). Die auditive Beurteilung von Heiserkeit ist vor allem dann zuverlässig, wenn sie auf Gruppenurteilen nach Hörtraining basiert. Deswegen sehen die drei genannten Systeme auch Hörtrainings vor. Dem RBH-System liegt z.B. eine Übungs$\mathrm{CD}$ mit Klangbeispielen bei, die von Expertengruppen übereinstimmend eingeschätzt worden sind. In der therapeutischen Praxis werden mit der ordinalen Merkmalsskalierung sehr einhellige Hörerurteile erzielt, die auch nach langen Zeiträumen reproduzierbar sind.

Auch gesunde Stimmen entsprechen nicht immer den Kriterien einer euphonen Stimme, sondern weisen oft gering- und mittelgradige Heiserkeiten auf, die sowohl habituellen Ursprungs als auch Ausdruck situationsbezogener Stimmverwendung sein können. Deshalb sind solche parameterbasierten Systeme zur Beschreibung und Beurteilung von Stimmklängen durchaus auch außerhalb der therapeutischen Praxis nutzbar, z.B. für die Analyse gesprochener Äußerungen in der Gesprächskommunikation (vgl. ausführlich Bose/Schwarze/Wendt ersch. 2009).

Notwendige Voraussetzung für die Beschreibung und Beurteilung stimmlich-artikulatorischer Ausdrucksformen ist das sog. funktionell-analytische Hören, „die Fertigkeit, Sprechereignisse mit Hilfe des Gehörs segmental und suprasegmental mit Hilfe von Beurteilung, Skalierung und Transkription in Merkmale und Merkmalskomplexe zu zerlegen“" (Vieregge 
1996, S. 1). Aufgrund eines intensiven Hörtrainings sind Hörer in der Lage, auf einzelne stimmlich-artikulatorische Merkmale des auditiv wahrnehmbaren Komplexsignals zu achten und sie zu kennzeichnen (Bottom-Up-Hören im Gegensatz zum normalerweise ganzheitlichen, vorrangig semantisch orientierten Top-Down-Wahrnehmungsprozess in der Kommunikation). Mit Hilfe des analytischen Hörens wird das Gehörte auf eine internalisierte Erwartung hin geprüft. Zwar können sich auch trainierte Hörer nie ganz von ihrer Kulturzugehörigkeit, von ihrem Vorwissen über die gehörte Sprache und von ihren Angemessenheitsvorstellungen über stimmlich-artikulatorische Äußerungen lösen, sie haben aber durch Hörtraining gelernt, sich möglichst wenig um diesen ,semantischen Rest' (Vieregge 1996, S. 21) zu kümmern. Analytisches Hören kann immer nur einen relativen, nie einen absoluten Status beanspruchen, deshalb ist eine Arbeit in Hörergruppen sinnvoll. Bei Verwendung eines transparenten Bezugssystems steigt die $\mathrm{Zu}$ verlässigkeit auditiver Beschreibungen mit der Übereinstimmung unter den Gruppenmitgliedern. Das Maximum an Objektivität einer auditiven Deskription stellt die sog. Konsensusdeskription dar, mit der alle Gruppenmitglieder einverstanden und von deren Objektivität sie überzeugt sind (vgl. ausführlich Bose/Schwarze/Wendt ersch. 2009). Auch bei einem solchen Verfahren ist natürlich nicht auszuschließen, dass verschiedene Gruppen zu verschiedenen Ergebnissen kommen können.

\subsubsection{Kulturgebundenheit von Stimmbeurteilungen}

Auf die Kulturgebundenheit von stimmlich-artikulatorischem Ausdruck und seiner Beurteilung weisen Ergebnisse aus Studien zum Stimmgebrauch in anderen Kulturen hin. So hat Grawunder (2009) in einer Feldstudie die Anatomie, Physiologie und Akustik des südsibirischen Kehlgesangs untersucht, einer kulturgebundenen kunstvollen Stimmproduktion. Vergleichbar dem westlichem Obertongesang werden einzelne Obertöne verstärkt und bilden die Melodie. Wesentlich für den Kehlgesang ist aber das besondere Timbre, das sich aus dem Zusammenspiel von verstärkten Obertönen und zwei grundlegenden Phonationsmodi mit starker laryngaler Verengung ergibt: einer gespannten, fast gepressten Stimmqualität und einer tief rau pulsierenden Stimmqualität. Aufgrund des eigenen physiologischen Optimums des Kehlgesangs ist seine Untersuchung grundsätzlich interessant für das Verständnis von Stimmproduktion an sich.

25 Kehlsänger wurden vor Ort mit einer nichtinvasiven Methode untersucht, der Endoskopie (mittels Drei-Kanal-Aufnahmen: Mikrofon-, Elektroglottografie-, Brustresonanzsignal). Nach Grawunder (ebd., S. 35) sind die phonetischen Termini, die im westlichen Kulturkreis zur Beschreibung für solche Stimmqualitäten zur Verfügung stehen (gepresst, rau), eng verknüpft mit Beschreibungen von Stimmstörungen. Insofern weicht der 
Kehlgesang sehr stark vom westlichen Stimmideal ab und könnte potentiell stimmgefährdend sein. Die Untersuchung zeigt allerdings, dass gute Sänger den Kehlgesang jahrzehntelang professionell produzieren können, ohne Stimmschäden davonzutragen (was selbstverständlich ebenfalls für gute Sänger im westlichen Kulturraum gilt, die extreme Stimmklänge nutzen, wie z.B. im Heavy Metal). Darüber hinaus weist Grawunder (2009., S. 79) darauf hin, dass die im Kehlgesang verwendeten Phonationsarten in einigen Sprachen auch linguistisch mit distinktiver Funktion genutzt werden, z.B. im rauen, gepressten Tieftonregister des Bai (Sinutibetisch) (Esling 2002) oder im Phonationstyp ,strident ${ }^{\star}$ des !Xoon (Khoisan) (Traill 1986).

Gauß (2008 und 2009) hat den Bereich der praktischen Sprechbildung in verschiedenen Kulturen betrachtet. Unter Sprechbildung wird die Ausbildung von Körper, Stimme, Haltung und Artikulation in Bezug auf konkretes situationsadäquates und partnerbezogenes Sprechhandeln verstanden, unter Stimmbildung speziell die Ausbildung einer tragfähigen Stimme und deutlichen Artikulation für sprechintensive Berufe und sprechkünstlerische Tätigkeit. Ziel dieser, westlichen' Stimmbildung (McAllister-Viel 2006) ist es, die Stimme leicht und entspannt (,frei und natürlich') zu produzieren, ohne jede übermäßige Anstrengung, die Stimmbelastungen und -schäden oder zumindest Klangverzerrungen zur Folge hat. Basis dieses Stimmideals wie auch seiner didaktischen Vermittlung ist die Orientierung an Anatomie und Physiologie des Sprechens. Methodisch bilden Körperund Stimmtraining eine Einheit, z.B. durch Balance-, Resonanz-, Impuls-, Spannungs-/Entspannungsübungen. Partner- und Situationsbezug des Sprechens, die sog. Ansprechhaltung, werden vermittelt nach dem Prinzip des ,gestischen Sprechens', z.B. durch die Entwicklung möglichst konkreter, klarer Vorstellungen und Aktivierung entsprechender Erlebnisinhalte. Ausdruck und innere Haltung werden also als Einheit begriffen (vgl. Klawitter/Minnich/Honigmann/Mont'agh 1981; Aderhold 1993; Klawitter/ Köhler 2004).

Eine solche Vorstellung von einer guten Stimme gilt durchaus nicht für alle Kulturen, wie Gauß das für die traditionelle koreanische Ausbildung des sog. P'ansori zeigt. P'ansori ist eine Erzähl- und Gesangskunst, deren stimmliche Interpretation bis in detaillierte Klangfarben und melodische Ornamentierungen hinein festgelegt ist und die allein über auditive Nachahmung gelernt wird. Aus einer vergleichenden Analyse beider sprechbildnerischer Konzepte (McAllister-Viel 2006) geht hervor, dass damit jeweils unterschiedliche psychophysische Konzepte verbunden sind, d.h. Vorstellungen davon, was der Mensch ist, wie sein Körper und seine Stimme funktionieren bzw. wie sie zu gebrauchen sind und mit welchen Methoden sie zu formen sind. Während die Grundlage der westlichen Sprechbildung in der schulmedizinischen Auffassung von Stimmhygiene zu suchen ist, liegt sie für das P'ansori in der Körperauffassung der chinesischen Medizin. 
Trainingstradition und Ästhetik des P'ansori rütteln nach Gauß (2009, S. 44) am

\footnotetext{
Dogma der westlichen Sprechbildung und ihren medizinischen Kategorien. Zwar hat das intensive Training auf den Stimmbändern der P'ansorisängerin physiologische Spuren hinterlassen und die Alltagsstimme einen heiseren Klang, dennoch kann nicht von ,Stimmschädigung' gesprochen werden, wenn es sich im Sinne der Kultur um eine ,ausgebildete' Stimme handelt, der Klang der Stimme geschätzt wird und die Alltagskommunikation nicht eingeschränkt ist.
}

Die Autorin (ebd.) macht außerdem darauf aufmerksam, dass sich auch innerhalb der westlichen Tradition verstärkt Stimmkultivierungsmethoden etablieren, die übermäßige Spannung und extreme Stimmklängen nutzen (vgl. hierzu z.B. auch Meyer-Kalkus 2004; Kolesch 2005).

Wie ein erweiterter ethnografischer Blick zeigt, sind Anatomie und Physiologie als grundlegende Bezugsgrößen der Sprechbildung nicht universell. Trotz gemeinsamer biologischer Basis der Stimmfunktion entwickeln sich in verschiedenen Kulturen Stimmgebrauch und -beurteilung nicht unabhängig von kulturell-historisch geprägten Auffassungen zu Körperlichkeit und Körpergebrauch (vgl. dazu u.a. auch Bogner 2000 und 2005; Waldenfels 2006; Mersch 2006). Für Bogner (2005, S. 109) ist die Kulturgebundenheit der Stimme deshalb auch Gegenstand einer interkulturellen Linguistik. Wie die Arbeiten von Grawunder (2009) und Gauß (2009) zeigen, sind kulturvergleichende oder interkulturelle Forschungen zu diesem Bereich als komplexer hermeneutischer Verstehensprozess mit verschiedenen Methoden zu konzipieren (ethnografisch basierte Feldforschung, Teilnahme an sprechbildnerischer und sprechkünstlerischer Ausbildung, Expertengespräch, terminologische und phonetische Analyse). Nur so sind auch die eigenen kulturellen Prägungen der wissenschaftlichen Beschreibung von stimmlich-artikulatorischem Ausdruck aufzudecken. SolchermaBen gewonnene Erkenntnisse haben auch sehr konkrete Auswirkungen, z.B. auf die Analyse und Notation stimmlich-artikulatorischen Ausdrucks in Gesprächsforschungen, welche Parameter überhaupt als relevant wahrgenommen werden und wie sie zu notieren sind.

\subsection{Stimmlich-artikulatorischer Emotionsausdruck}

Empirische Studien zum sprechstimmlichen Emotionsausdruck und -eindruck sind neben der Musterkennzeichnung auf merkmalsanalytische Beschreibungen angewiesen. Sie basieren meist auf Kommunikationsexperimenten mit speziell hergestellten Stimuli, z.B. Einzelwörtern, Sätzen, (seltener) Texten, die von professionellen Sprechern mit kontrolliert intendiertem Emotionsausdruck gesprochen werden (vgl. z.B. Zilliken 1991; Neuber 2002; Wendt 2007; Redecker 2008). Vergleichbare Untersuchungs- 
designs wurden bereits von der frühen Ausdruckspsychologie entworfen, vgl. z.B. die oben angeführten physiognomischen Radioexperimente oder die Forschungen zur phonetischen Lautstilistik; methodisch verfeinert sind sie noch immer etabliert, neben der Sprechwissenschaft z.B. auch in Emotionspsychologie und Psycholinguistik (vgl. z.B. Tischer 1993; Scherer 1995 und 2003; Klasmeier 1999; Scherer/Banse/Wallbott 2001; Paeschke 2003). Der komplexe, multifaktoriell bestimmte Prozess des Emotionsausdrucks und seiner Verarbeitung wird auf möglichst wenige kontrollierbare Variablen reduziert. Ausgangspunkt hierfür ist die Alltagserfahrung, dass trotz der genannten Komplexität Kommunikationsbeteiligte ständig intuitiv Voraussagen über Wirkungen machen, Wirkungen und darauf bezogene Reaktionen im voraus abschätzen, sich also im Komplexgeschehen anhand einzelner Merkmale orientieren.

\subsubsection{Emotionsforschung anhand von Einzelwörtern}

Exemplarisch wird das „Gesprochene Wortkorpus für Untersuchungen zur auditiven Verarbeitung von Sprache und emotionaler Prosodie“ ( $\mathrm{WaSeP}^{\odot}$ ) vorgestellt (Wendt 2007). Im Leibniz-Institut für Neurobiologie in Magdeburg wird dieses Korpus für Grundlagenforschungen zur Sprach- und Emotionsverarbeitung im Gehirn verwendet, z.B. mit Hilfe von Verhaltenstests und Methoden der nicht-invasiven Bildgebung (z.B. fMRI, EEG). Bei diesen Messmethoden muss auf den kommunikativen Kontext verzichtet werden, und die Probanden, sowohl Gesunde als auch Patienten mit neurologischen Störungen, sind in der Regel nicht im analytischen Hören trainiert.

Ausgehend von der These, dass der stimmlich-artikulatorische Ausdruck von Emotionen sehr robust ist und es ,auch dem untrainierten Hörer möglich [ist], stimmliche Emotionsausdrücke ohne kommunikativen Kontext noch relativ sicher zu erkennen und zuzuordnen bzw. zu decodieren" (Wendt 2007, S. 86), hat die Autorin ein Korpus aus zweisilbigen deutschen Substantiven und Pseudowörtern ohne kommunikativen Kontext erstellt. Diese Wörter wurden von je einer Schauspielerin und einem Schauspieler mit simuliertem Emotionsausdruck zu vorgegebenen Basisemotionen gesprochen (Freude, Trauer, Wut, Angst, Ekel, zum Kontrast: Sachlichkeit). Auf diese Weise sind Prototypen stimmlich-artikulatorischen Emotionsausdrucks entstanden. Zwar bilden reine Basisemotionen in der kommunikativen Realität eher die Ausnahme, für neurologische Untersuchungen ist diese begrenzte Vorgabe aber nach Wendt zugunsten der Überschaubarkeit für die Probanden und der Interpretierbarkeit der Ergebnisse hinnehmbar.

Das Wortkorpus ist mittels Hörerbefragungen (Identifizierung des intendierten Emotionsausdrucks), auditiven Expertenbeurteilungen und exemplarischen akustischen Beschreibungen (phonische Merkmale) validiert worden. Es liegen Konsensusbeurteilungen der stimmlich-artikulatorischen 
Merkmale für die genannten Emotionsausdrücke vor, außerdem für ein Pseudowort in allen Emotionen auch akustische Messungen. In der Tendenz waren bestimmte akustische Merkmale für bestimmte emotionale Ausdrucksmuster zu finden, ebenso Übereinstimmungen zwischen akustischer und auditiver Beschreibung. Es liegt aber keine eindeutige Korrelation zwischen auditiven und akustischen Beurteilungen vor, die Ausdrucksmuster sind nicht ausschließlich durch Merkmalscluster charakterisiert. Es handelt sich um Gestalten, für deren Wahrnehmung weniger ihre einzelnen Komponenten als die Relationen zwischen ihnen ausschlaggebend sind. Nach akustischer Messung und auditiver Beurteilung kommen die Unterschiede zwischen den Sprechfassungen der einzelnen Basisemotionen nicht nur durch stimmliche Variation zustande, sondern beide Sprecher variieren systematisch auch zahlreiche andere sprecherische Merkmale (z.B. Lautheit, Sprechspannung, Artikulationspräzision, Lautdauer). Es handelt sich also um einen Komplex an Ausdrucksmerkmalen. Darüber hinaus weisen die Sprechfassungen trotz der kurzen Wort-Stimuli und der klaren Emotionsvorgaben individuelle Ausdrucksvarianten auf.

Ein Vorteil dieses standardisierten Korpus liegt neben der guten technischen Qualität der Audioaufnahmen in der Vergleichbarkeit der Sprechfassungen aufgrund der identischen Wortvorgaben. Solche strikt experimentell vorgehenden Untersuchungen können gerade durch die bewusste Abstraktion von der Komplexität der Kommunikationswirklichkeit Erkenntnisse über die (mögliche) Relevanz einzelner Variablen, über die Interdependenz von Merkmalsausprägung und Hörerbeurteilung und über die Entwicklung und Validierung analytischer Beschreibungskategorien liefern. Die Übertragbarkeit der Ergebnisse auf Bedingungen authentischer Kommunikation ist aber fraglich, denn hier kommt stimmlich-artikulatorischer Ausdruck reiner Basisemotionen ausgesprochen selten vor, typisch sind dagegen abgeschwächte Mischrealisationen in verschiedenen Schattierungen, die sich zudem abhängig vom Prozess der Kommunikation verändern. Im vorliegenden Wortkorpus sind dagegen die stimmlich-artikulatorischen Realisationen der vorgegebenen Emotionen aufgrund der sehr kurzen Wörter statisch. Dieses Material kann jedoch ebenso wie die parameterorientierten Beschreibungssysteme aus der klinischen Sprechstimmforschung für das Training im funktionell-analytischen Hören genutzt werden (ausführlich vgl. Bose/Schwarze/Wendt ersch. 2009).

\subsubsection{Emotionsforschung anhand von quasi-authentischen Sprachäußerungen}

Andere Studien verwenden als Stimuli umfangreicheres quasiauthentisches sprachliches Material und verbinden Analysen des Emotionsausdrucks mit experimentellen Untersuchungen zu seiner Wirkung. So haben Braun/ 
Heilmann (stellvertretend 2005) emotionale Ausdrucksmuster im synchronisierten Film untersucht. Anhand von Kurzszenen der der Serie „Ally McBeal" (amerikanische Originalfassung, deutsche und japanische Übersetzung) wurde die stimmliche Ausgestaltung einiger Basisemotionen (Angst, Trauer, Wut, Freude) phonetisch analysiert und ihre interkulturelle Erkennbarkeit und Akzeptanz (durch deutsche, amerikanische und japanische Hörer und Zuschauer) wurde anhand von Fragebögen mit vorgegebenen Emotionen geprüft. Für einige Basisemotionen (Trauer und kalte Wut) weisen die Autorinnen sowohl im Ausdruck als auch im Eindruck interkulturelle Asymmetrien nach (Braun/Heilmann 2005, S. 187).

Nebert (2007 und 2009) hat die sprachspezifische Verwendung der mittleren Sprechstimmlage für zwei Sprachen (russisch und deutsch) untersucht. Unter der mittleren Sprechstimmlage wird die wahrgenommene durchschnittliche Sprechtonhöhe verstanden, um die sich die Tonhöhenvariationen beim Sprechen bewegen. Sie wird u.a. durch emotionale Erregung beeinflusst, ist aber auch sprachspezifisch determiniert (vgl. Braun 1994 und 2001).

Deutsche Hörer bewerten Deutsch sprechende Russinnen oft als emotional, auch in sachlich intendierten Äußerungen, und geben als Grund deren hohe Sprechstimmlage an. Mittels akustischer Messungen weist Nebert (2007) jedoch nach, dass die mittlere Sprechstimmlage in beiden Sprachen sehr ähnlich ist - die russischen Sprecherinnen sprechen im Mittel lediglich einen Halbton höher. Dabei nutzen sie aber einen größeren Sprechtonumfang und die Tonhöhen sind ungleich verteilt: Im Vergleich zu den deutschen Sprecherinnen verwenden die russischen Sprecherinnen höhere Frequenzen häufiger. Sie sprechen bei gleicher Sprechstimmlage außerdem häufiger im Kopfregister, wodurch ein hellerer Klang entsteht, und ihre Sprechmelodie steigt in akzentuierten Silben kurzzeitig an. Bei den deutschen Sprecherinnen ist dagegen eine Tendenz zum Brustregister festzustellen, verbunden mit eher dunklem Stimmklang. Deutsche Hörer interpretieren diese Stimmverwendungsmuster vermutlich deshalb als emotional, weil im Deutschen bereits geringe Abweichungen der Tonhöhe von einem Halbton an oberen Positionen der Sprechmelodie als emotionale Markierung gelten.

Nach Nebert (2009) übertragen die Sprecherinnen den Stimmverwendungsmodus der Muttersprache in die Fremdsprache: Russische Muttersprachlerinnen klagen oft über Stimmbeschwerden, weil sie die vermeintlich tiefere Lage des Deutschen auf unphysiologische Weise zu erreichen versuchen (Pressen, Drücken, Verlagern der Stimme). Im Gegensatz dazu versuchen deutsche Sprecherinnen, die vermeintlich höhere Lage des Russischen mit enger, gespannter Stimmgebung zu erreichen. 


\subsection{Perzeption von stimmlich-artikulatorischem Ausdruck}

\subsubsection{Sprechwirkungsforschung}

Gegenstand der Sprechwirkungsforschung ist der beobachtbare bzw. messbare Effekt, den gesprochene Äußerungen bei Rezipienten auslösen (z.B. Krech/Richter/Stock/Suttner 1991; Hirschfeld/Neuber/Stock 2009). Untersucht werden vor allem Wirkungen stimmlich-artikulatorischer Ausdruckserscheinungen in ihrer Interdependenz mit sprachlichen und nonverbalen Mitteln. Wirkungen entstehen im Rezeptionsprozess; sie können zwar vom Sprecher intendiert sein, aber er hat keine Garantie für die Umsetzung seiner Intentionen. Denn Wirkungen hängen wesentlich davon ab, welche Motive ein Rezipient dem Sprecher unterstellt, wie er Inhalte und antizipierte Folgen der Äußerungen bewertet, welche Relevanz er der Situation zuschreibt (Hirschfeld/Neuber/Stock 2009, S. 773). Diese bewussten und unbewussten Bewertungen basieren auf subjektiven Antizipationen und Wahrnehmungsfiltern, die die Erwartungen an das Handeln des Partners und die Wahl der eigenen, auf den Partner zielenden Handlungen steuern (ebd., S. 779). Zugrunde gelegt wird ein prozessdynamisches Rezeptionsmodell der Integration von Kognition und Emotion, der Interdependenz sprechsprachlicher Komplexsignale mit nichtsprachlichen Umgebungsinformationen, gespeichertem deklarativem Wissen und Bewertungen der bereits vorliegenden Informationen (z.B. Herrmann 1995).

Sprechwirkungsforschungen zielen vor allem auf interindividuelle und vorhersagbare, systematische Gemeinsamkeiten im kommunikativen Effekt. Damit verbunden sind überwiegend experimentelle Versuchanordnungen aus einer externen Perspektive (Variablenisolierung, Kommunikationsexperimente, Hörerbefragungen). Das hat zwar den Vorteil, dass ein Zugriff auf das komplexe Ursachen-Wirkungsgefüge relativ gut möglich ist, weil Auslösefaktoren und dadurch erzeugte Wirkungen kontrolliert werden können. Das hat jedoch auch den Nachteil, dass so kaum Erkenntnisse über die Funktionsweise der beobachteten Zusammenhänge im Kommunikationsprozess, also über die Interpretation der beobachteten Phänomene durch die Beteiligten im Kommunikationsprozess und ihre Relevanz für die gemeinsame Gesprächskonstitution zu gewinnen sind. Stellvertretend werden zwei Arbeiten knapp vorgestellt, die mit speziell hergestellten, systematisch variierten Sprachstimuli arbeiten, um den Einfluss bestimmter Variablen auf Rezipienten zu testen.

Neuber (2002) hat zwei Vorlesefassungen einer Erzählung - eindringlich versus monoton - phonetisch analysiert und bezüglich ihrer Wirkung (Fragebogen zur Bewertung von Text und Sprecher, Behaltenstest) an etwa 200 Hörern getestet. Er konnte nachweisen, dass stimmlich-artikulatorischer Ausdruck wesentlich für die Bildung globaler Textkohärenz verant- 
wortlich ist: Die eindringliche Sprechfassung wurde nicht nur besser bewertet (als verständlicher, strukturierter, interessanter, emotionaler) als die monotone Fassung, sondern auch besser behalten (vor allem aufgrund von Melodie- und Tempogestaltung, Sprechgliederung und Pausen-AkzentStruktur).

Redecker (2008) hat den Einfluss verschiedener stimmlich-artikulatorischer Parameter auf die Perzeption eines Werbevideos für Parfüm geprüft. Es wurden drei Varianten hergestellt: während Bilderfolge und Kurztext jeweils gleich blieben, variierte ein professioneller Sprecher die sprecherische Realisation (mit den Assoziationen eines ,frischen und leichten', athletischen und dynamischen', ,würzigen und schweren' Duftes; vgl. Redecker 2008, S. 88 ff.). Die Sprechfassungen wurden auditiv und akustisch analysiert. Drei Probandengruppen (insgesamt etwa 150 Befragte) wurden mit jeweils einer Variante des Werbevideos konfrontiert und mit einem Fragebogen nach ihrem Eindruck befragt. Es zeigte sich, dass bereits geringe stimmlich-artikulatorische Veränderungen hochsignifikante Veränderungen in den Angaben zur Kaufabsicht und zur Bewertung von Werbespot, Duft und dargestellter Person zur Folge hatten.

\subsubsection{Perzeption von pathologischem Fremdakzent}

Im Folgenden wird eine Perzeptionsstudie vorgestellt, die in gewisser Weise an das literarische Beispiel von Edgar Allan Poe anknüpft, da auch hier Hörer durch ungewöhnlichen stimmlich-artikulatorischen Ausdruck irritiert sind und ihn fälschlich als fremdsprachlich interpretieren. Es geht um einen Fall von pathologischem Fremdakzent (Wendt/Bose/Sailer/ Scheich/Ackermann 2007; Bose/Wendt ersch. 2010). Das sog. Fremdakzentsyndrom ist eine sehr seltene Sprach- und Sprechstörung, die z.B. nach einem Schlaganfall auftreten kann (vgl. stellvertretend Monrad-Krohn 1947; Blumstein/Kurowski 2006). Beobachtet werden immer verschiedene leichtere sprachliche und sprecherische Auffälligkeiten im Sprechen der Betroffenen, wodurch diese auf ihre Umgebung wie Sprecher einer Fremdsprache wirken.

Im vorliegenden Fall handelt es sich um eine 35-jährige Frau (AL) aus Sachsen-Anhalt, monolingual deutsch, mit Media-Infarkt links, hemiparetischen Störungen und motorischer Aphasie. Die Patientin berichtet, dass fremde Gesprächspartner sie z.B. beim Einkaufen als „,russische Muttersprachlerin“" oder „Russlanddeutsche“ wahrnehmen würden. Sie selbst bemerke an sich diesen Fremdakzent nicht. Zusätzlich zu den vorhandenen körperlichen und kommunikativen Schwierigkeiten nach der Krankheit erlebe sie diese Erfahrung aber als Identitätsverlust: 
abe:r wEnn ich mAl AUf dem mA:rkt bin und EIer KAUfe:- |

DANN:, (.) frAgen sie MICH- (.) ge!NAU!so. ।

WO:- (.) WO stAmmen SIE denn HE:R' |

$[\ldots]$

und äh ich !mEr!ke das nicht dass ich so kOmisch SPREche; | |

Freies Sprechen und Vorlesen von AL weisen unspezifische Auffälligkeiten auf, sowohl in Lexik und Grammatik als auch in Artikulation und Prosodie. Die phonetischen Auffälligkeiten ergeben allerdings nicht das typische Gesamtbild eines russischen Akzents im Deutschen (vgl. hierzu u.a. Müller 2002; Stock/Velichkova 2002; Gorozhanina 2007), sondern erweisen sich als kaum systematisch. Sie liefern nur sehr eingeschränkte Hinweise darauf, warum fremde Kommunikationspartner die Patientin als russische Muttersprachlerin wahrnehmen. Es ist zu vermuten, dass sowohl segmentale als auch suprasegmentale Abweichungen dafür verantwortlich sind, insbesondere fehlende Reduktion unbetonter Endsilben, Sprechunflüssigkeit und atypische Sprechgliederung (vgl. ausführlich Wendt/Bose/Sailer/Scheich/ Ackermann 2007 mit Klangbeispielen).

Für die Perzeptionsstudie wurden aus der Audioaufnahme eines Gesprächs zwischen der Patientin und einer Logopädin über Alltagsthemen sieben kurze Äußerungen von AL ausgewählt (Umfang 14 bis 37 Wörter). Diese Gesprächsausschnitte wurden bisher in Interviews 46 deutschsprachigen Nicht-Expert/inn/en unterschiedlicher regionaler Herkunft vorgespielt (vgl. Bose/Wendt ersch. 2010). Nach dem Hören jedes Ausschnitts wurden die Hörer/innen ohne inhaltliche Vorgabe um Assoziationen zum Gehörten gebeten. Hier einige Ergebnisse, zunächst zu den Angaben über die Sprecherin:

- Oft schon nach dem Hören des ersten oder zweiten Ausschnitts äuBerten sich die Befragten zur Herkunft der Sprecherin. In 42 Interviews wurde die Sprecherin als „nichtdeutsch“ klassifiziert. Als Muttersprache wurde in 35 Interviews eine osteuropäische Sprache vermutet, in 25 Interviews speziell Russisch.

- In 35 Interviews wurde eine pathologische Ursache für die auffällige Sprechweise vermutet (Sprach-, Sprech-, Hörstörungen oder eine kognitive Störung), meist erst nach dem Hören der vierten oder fünften Äußerung.

- Die Befragten stellten Vermutungen an über die Stimmung der Sprecherin (z.B. kraftlos/leidend/hoffnungslos), über ihren Charakter und sozialen Status (z.B. träge/langsam denkend/ isoliert/bildungsfern).

Viele Befragte machten darüber hinaus konkrete Angaben zu den gehörten Äußerungen: 
- Die sprachliche Gestaltung wurde ebenso als auffällig beurteilt (z.B. sehr einfacher Stil/ unvollständige, abgebrochene Sätze/viele Wiederholungen) wie der stimmlich-artikulatorische Ausdruck (z.B. eigenartig/angestrengt) rögernd).

- Beschrieben wurden aber auch zahlreiche konkrete stimmlich-artikulatorische Merkmale: z.B. Sprechtonhöhe/Melodie (tief/monoton), Stimmklang (dumpf/dunkel/klagend), Lautheit und Sprechspannung (leise/monoton/lasch), Sprechgeschwindigkeit (schleppend/sehr langsam), Rhythmus (stockend/ abgehackt), Akzentuierung (falsche Betonungen/gleichförmig), Artikulation (bemüht sebr deutlich/Laute und Silben entweder verschluckt oder langgezogen/ nicht typisch deutsch).

Angesichts dessen, dass hier kein authentischer Fremdakzent vorliegt und dass die phonetische Beschreibung kein einheitliches Bild ergibt, erstaunt die Schnelligkeit der Urteile ebenso wie die große Übereinstimmung in der Zuschreibung der fremdsprachlichen Herkunft. Als Anhaltspunkte für das Urteil „russische Sprecherin“ nannten die Befragten vor allem Abweichungen in der Artikulation (z.B. abweichende Lautbildungen, Dehnung äußerungsfinaler Silben), in der Prosodie (z.B. merkwürdiger Melodieverlauf, abweichende Äußerungsakzentuierung, fremder Sprechrhythmus), seltener sprachliche Auffälligkeiten (z.B. sehr kurze und simple Sätze).

Die Patientin bedient die erfahrungsbasierten Erwartungen fremder Kommunikationspartner an situationsangemessene Sprachverwendung und stimmlich-artikulatorischen Ausdruck nicht ausreichend. Ihre Abweichungen sind aber offensichtlich nicht groß genug, dass sie sofort als pathologisch diagnostiziert würden, deswegen verursachen sie den Eindruck von Fremdheit. Die sehr schnell entstehenden Eindrücke über die Sprechweise und die daraus resultierende Bewertung der Sprecherin haben die Wahrnehmung und Deutung der Informationen auf der verbalen Ebene gesteuert: Die meisten Hörer/innen haben die Sprecherin zunächst als "Ausländerin“ identifiziert und deshalb die wahrgenommenen sprachlichen Fehler und sehr einfachen sprachlichen Strukturen als Zeichen ,guter Fremdsprachenbeherrschung" interpretiert. Etwa die Hälfte der Befragten blieb bei der einmal getroffenen Diagnose, die anderen zeigten sich zunehmend irritiert, je mehr Ausschnitte sie hörten, und änderten ihre Diagnosen mehrfach. Offensichtlich war die Dauer der Hörwahrnehmung ausschlaggebend: Je mehr Äußerungen diese Hörer/innen analysieren konnten, umso unsicherer wurden sie speziell in der Einschätzung der Sprecherin als Ausländerin. Offensichtlich entdeckten sie nach und nach zu viele widersprüchliche verbale und phonische Hinweisreize, die nicht mit dem zunächst identifizierten Fremdsprachenakzent übereinstimmten, so dass sie die erste Interpretation durch eine andere ersetzten (z.B. Sprach-, Hör- oder Kognitionsstörung). 
Die Befragung zeigt, dass Rezipienten, selbst wenn sie nur kurze ÄuBerungen einer unbekannten Sprecherin gehört haben, nicht nur komplexe Zuschreibungen äußern (über die Herkunft, die Situation und die Stimmung der Sprecherin), sondern auch differenziert Auskunft zu einzelnen Merkmalen geben können. Sie nehmen dabei sowohl auf die sprachliche als auch auf die stimmlich-artikulatorische Ebene Bezug und nutzen beide für Diagnose und Identifikation von Sprecherzustand und -intention. D.h., Rezipienten bewerten Äußerungen und Sprecherin sowohl hinsichtlich einer individuellen Spezifik (Physiognomik), z.B. in der Zuschreibung als „Ausländerin“, als auch hinsichtlich einer situationsbezogenen Spezifik (Pathognomik), z.B. in der Zuschreibung von Einstellungen als „unmotiviert/unschlüssig“. Vermutlich handelt es sich um Mustererkennungsprozesse im Sinne der Gestaltpsychologie: Wenn Hörer auf ,signifikante Hinweisreize ${ }^{6}$ der verbalen oder phonischen Ebene stoßen, dann ergänzen sie die dazugehörige Gestalt, indem sie das aktuell Gehörte mit internen Mustern und situationsbezogenen Erfahrungen und Erwartungen vergleichen.

\subsection{Stimmlich-artikulatorischer Ausdruck in der Interaktion}

Im Folgenden werden Arbeiten vorgestellt, in denen mit einem gesprächsanalytischen Zugang stimmlich-artikulatorischer Ausdruck als kommunikative Ressource im Gespräch analysiert wird. Anhand von Aufzeichnungen authentischer Kommunikationsereignisse wird in gesprächsanalytischen Forschungen die Prozesshaftigkeit von Gesprächen berücksichtigt, Gesprächsordnung und wahrnehmbare systematische und meist routinisierte Gesprächspraktiken werden rekonstruiert (für die Methode vgl. z.B. Deppermann 1999). Dazu gehören nicht nur sprachliche Verfahren - in gesprächsanalytischen Arbeiten wurde die Relevanz prosodischer wie auch die nonverbaler Mittel für die verbale Interaktion nachgewiesen (vgl. z.B. stellvertretend Selting 1995; Couper-Kuhlen/Selting 1996; Auer/Couper-Kuhlen/Müller 1999; Couper-Kuhlen/Reber in diesem Band; Schmidt/Deppermann in diesem Band). Daran schließen sprechwissenschaftliche Studien zu Repertoires stimmlich-artikulatorischer Ausdrucksmuster in spielerischen und ernsthaften Interaktionsmodalitäten (Kallmeyer 1979) zwischen vertrauten Partnern an. Ihnen gemeinsam ist, dass der stimmlich-artikulatorische Ausdruck in engem Bezug zur verbalen Interaktionsebene in authentischen Gesprächen analysiert wird.

In der mündlichen Kommunikation ist grundsätzlich von polyrelationalen Form-Funktions-Beziehungen auszugehen, deswegen werden zu ihrer Beschreibung verschiedene Methoden miteinander verknüpft - sowohl naturwissenschaftlich messend-beurteilende Arbeitsformen aus Sprechwissenschaft und Phonetik als auch sozialwissenschaftlich rekonstruktiv-inter- 
pretierende Arbeitsformen aus der Gesprächsforschung. Die Praktiken im Umgang mit stimmlich-artikulatorischem Ausdruck und ihre interaktive Relevanz für den Gesprächsverlauf werden rekonstruiert anhand wiederkehrender Phasen und Verfahren zur Gesprächssteuerung, anhand von Kommentaren über die Angemessenheit vs. Unangemessenheit der Gestaltung stimmlich-artikulatorischer Ausdrucksmuster und anhand von Interpretationsbedingungen und -regeln, denen die Beteiligten im Gespräch folgen. Höreindrücke über die verwendeten stimmlich-artikulatorischen Ausdrucksweisen werden mittels auditiver Beurteilungen durch Hörergruppen und exemplarischer instrumentalphonetischer Analysen intersubjektiviert. Stimmlich-artikulatorische Ausdrucksweisen werden sowohl holistisch interpretiert (Mustererkennung und -interpretation) als auch hinsichtlich ihrer Einzelmerkmale beschrieben.

\section{Soziale Rollenspiele von Vorschulkindern}

Aus einer empirischen Langzeitstudie zum stimmlich-artikulatorischen Ausdruck im sozialen Rollenspiel von Vorschulkindern (Bose 2003) geht hervor, dass Kinder stimmlich-artikulatorischen Ausdruck systematisch als kommunikative Ressource nutzen. Sie bauen in ihren Rollenspielen interaktiv Ausdrucksrepertoires auf, erwerben so miteinander stimmlich-artikulatorische Ausdruckskompetenz und differenzieren sie im Verlaufe ihrer Spielbiografie aus. Dabei orientieren sie sich an Vorbildern aus ihrer Kommunikationsumwelt, an frühen Eltern-Säuglings-Kommunikationen ebenso wie an Sprechrollenmustern und Praktiken vertrauter Erwachsener. Offensichtlich nehmen sie die jeweils individuellen stimmlich-artikulatorischen Ausführungen (z.B. von Bezugspersonen, aber auch in Institutionen und Medien) als konventionalisiert-musterhaft wahr, d.h. also als Praktiken der Performanz von Interaktionsrollen, Emotionen und Einstellungen, kategorisieren sie und wenden sie selbst spielerisch an. Die Untersuchung zeigt, dass Kinder im Vorschulalter bereits über die nötige Kompetenz verfügen, kulturell bedingte stimmlich-artikulatorische Ausdrucksmuster im Spiel so treffend zu gestalten, dass externe erwachsene Hörer sie wiedererkennen und sich an eigenes Kommunikationsverhalten erinnert fühlen. Dennoch gestalten die Kinder ihre spielerischen Kommunikationen nach eigenständigen Regeln bzw. Konventionen; es handelt sich um kindliche Typisierungen und Stilisierungen vorgefundener Muster in sehr expressiver Form. Insofern sind die gespielten Ausdrucksmuster eigene Schöpfungen der Kinder, was unter anderem in veränderten Situationsbezügen, in Hinzufügungen und Auslassungen von Ausdrucksformen deutlich wird.

Die beobachteten Kinderpaare gestalten mit musterhaften stimmlichartikulatorischen Ausdrucksweisen Spielrollen und inszenieren fiktive Dialoge zwischen den Spielfiguren. Oft markieren sie allein durch eine pla- 
kativ-kontrastierende, funktional eingesetzte stimmlich-artikulatorische Ausdrucksgestaltung, wer in welcher Haltung spricht, ohne das auch verbal zu erläutern (vgl. die Analysen in Bose 2001 und 2003 mit Klangbeispielen). Damit erweist sich die stimmlich-artikulatorische Ausdrucksform als unabdingbar für das Verständnis der entworfenen Spielsituation.

Mit Hilfe stimmlich-artikulatorischer Ausdrucksmuster stützen und strukturieren die Kinder zudem ihre Interaktion, indem sie den Spielrahmen aufrecht erhalten bzw. wieder herstellen, den Wechsel zwischen verschiedenen Spielebenen anzeigen oder bestimmte Aktionen als spielerisch bzw. ernsthaft markieren. Und sie gestalten ihre Beziehung zum Spielpartner, indem sie mittels Ausdruckskongruenz (Konsonanz, Iteration, Ergänzung) die besondere Nähe zum Partner und die Zustimmung zu seinen Spielhandlungen unterstreichen, inhaltliche Korrekturen zu den Partneräußerungen vorbringen, potenzielle Auseinandersetzungen verhindern oder abschwächen, aber auch Imageverletzungen deutlich machen.

Die Studie zeigt, dass kindliche Kommunikationskompetenz neben der Sprachhandlungskompetenz auch die Kompetenz im stimmlich-artikulatorischen Ausdruck einschließt. Hierunter werden überwiegend implizite Kenntnisse über und Fähigkeiten zur situations- und stimmungsabhängigen Variation von stimmlich-artikulatorischen Ausdrucksweisen verstanden, die als Regulationsbasis für kommunikatives Handeln dienen. Sie sind mit interiorisierten Erwartungsvorstellungen über die Adäquatheit konkreter Ausdrucksgestaltungen verbunden, haben also Bezug zur Kommunikationsund Kulturgemeinschaft, in der die Kinder aufwachsen. Die Analysen belegen die Verbindlichkeit, die Kinder bestimmten stimmlich-artikulatorischen Ausdrucksmustern für bestimmte Spielrollen zumessen. Aus der interaktiven Verwendung der untersuchten Ausdrucksmuster der Spielrollenidentität in entsprechenden fiktiven Situationskontexten ist auf eine implizite Musterkenntnis der beobachteten Vorschulkinder zu schließen. Diese zeigt sich unter anderem in praktizierten Formen (z.B. systematische Gestaltung stimmlich-artikulatorischen Ausdrucks in Abhängigkeit von realen sozialen Rollen und Situationen) und in gespielten Formen (z.B. Gestaltungen von Spielrollen oder Spielebenen in inszenierten fiktiven Spielrahmen). Aus Wiederholungen und Variationen verschiedener Ausdrucksgestaltungen durch den Spielpartner, oft begleitet von metakommunikativ kommentierendem Lachen, vor allem aber aus gelegentlichen metasprachlichen Benennungen und Bewertungen bestimmter Ausdrucksweisen wird deutlich, dass die Kinder auch ein explizites Musterwissen haben.

\section{Freizeitinteraktionen vertrauter Jugendlicher}

Auch vertraute Jugendliche nutzen in ihren Freizeitinteraktionen solche Repertoires ausgiebig und kreativ, um z.B. mittels Performance und Expres- 
sivität Geselligkeit herzustellen (Schäfer 2003; vgl. die Zusammenfassung in Bose/Ehmer 2007). Vor allem geht es ihnen um Identifizierung und Gestaltung von sozialen und medialen Klischees oder Dialekten. Die Jugendlichen spielen sowohl mit dem stimmlich-artikulatorischen Ausdruck konkreter Personen als auch mit demjenigen sozialer Rollen und Muster und integrieren ihn ebenso wie die Kinder in neue, spielerische Kontexte. Sie greifen überdies auf ein Repertoire an kommunikativen Erfahrungen der Gruppe zurück (z.B. Handlungsstereotype) und erfinden stimmlich-artikulatorische Spiele (z.B. Beschimpfungsrituale). Interaktiv wird in mehreren Runden sowohl kooperativ als auch kompetitiv die beste sprecherische Gestaltung herausgearbeitet; die verschiedenen Gestaltungsversuche werden kommentiert, bewertet und korrigiert, besonderes gelungene Gestaltungen werden honoriert (z.B. durch Lachen). Der stimmlich-artikulatorische Ausdruck ist komplex mit dem Gesamtgeschehen verwoben und erfüllt vielfältige Funktionen (z.B. Themeninitiierung und -progression, Markierung von Kontext und Interaktionsmodalität, Ausdruck von Haltungen und Bewertungen).

\section{Gesellige Tischgespräche vertrauter Erwachsener}

Gesellige Tischgespräche vertrauter junger Erwachsener weisen spontane Inszenierungen bzw. gemeinsame Fiktionalisierungen (Kotthoff 1999) auf (Ehmer 2004; vgl. die Zusammenfassung in Bose/Ehmer 2007). Diese Gesprächspraktik ist mit den kindlichen Rollenspielen vergleichbar, denn die Sprecher übernehmen ebenfalls andere als ihre alltagsweltlichen Rollen und animieren fiktive Figuren. Damit geht ein Wechsel der Interaktionsmodalität in eine humorvolle, spielerische Modalität einher. Hergestellt wird diese Modalität sowohl durch Lachen als auch über einen Rahmenbruch, der durch die Etablierung von Innen- und Außenperspektive entsteht. Dabei überbieten sich die Gesprächsteilnehmer gegenseitig, indem sie immer neue Pointen setzen, die von den anderen durch Lachen honoriert werden. Die Beteiligten sprechen nicht nur über die Szene bzw. Spielwelt, sondern agieren in Spielidentitäten bzw. animieren Figuren. Wesentlich stärker als die spielenden Kinder nehmen die erwachsenen Sprecher eine ,kritische Distanz ${ }^{`} \mathrm{zu}$ den animierten Figuren ein, was besonders in der Ausdifferenzierung von Innen- und Außenperspektive deutlich wird.

Der stimmlich-artikulatorische Ausdruck leistet einen wesentlichen Beitrag zur Strukturierung der konversationellen Praktik. So wird die Inszenierung mitunter über einen interaktiv hergestellten Rhythmus im Wechsel der Sprechbeiträge als gestalthafte Ganzheit vom umgebenden Gespräch abgesetzt. Ähnlich wie in den kindlichen Rollenspielen trägt der stimmlichartikulatorische Ausdruck auch dazu bei, zwischen dem Sprechen in der alltagsweltlichen Identiät und dem Sprechen als Figur zu unterscheiden. 
Wie schon die untersuchten Kinder und Jugendlichen übernehmen die erwachsenen Sprecher Ausdrucksgestaltungen ihrer Interaktionspartner, variieren und pointieren sie in spielerischem Wettstreit.

\section{Fernsehkommunikation in Familien}

Ähnliche Phänomene zeigt Baldauf (1998 und 2002) für fernsehbegleitende Kommunikation in Familien auf. Es handelt sich um offene Sprechsituationen (Goffman 1981), in denen die Zuschauer sowohl auf das im Fernsehen Gezeigte reagieren als auch untereinander darüber kommunizieren können. Auch hier stellen die Beteiligten oft eine spielerische, unernste Interaktionsmodalität her, überwiegend mit sprachlich knappen, pointierten Äußerungen als Kommentar zur laufenden Sendung. Gerade die verbale Kürze und Knappheit provoziert nach Baldauf (2002), phonische Ausführlichkeit', üppig ausgearbeitete spielerische stimmlich-artikulatorische Ausdrucksformen. Eine große Rolle spielen sog. , minimale körpernahe Äußerungsformen' wie z.B. Lachen, Stöhnen, Seufzen oder Aufschreien, die Baldauf (1998, S. 40) als ,lautlich, aber nicht notwendig sprachlich“ definiert. In ihnen wird die Körperlichkeit des Sprechens offenbar und die Beteiligten stellen Informalität und Vertrautheit der Kommunikation heraus. Die Autorin weist nach, dass es sich bei diesen körpernahen Äußerungsformen nicht ausschließlich um individuelle, unwillkürliche Affektausdrücke handelt, sondern dass sie gleichzeitig auch eine kommunikative Funktion haben: Sie werden in den sprachlichen Kontext sequenziell eingebunden, richten sich auch an die anderen Familienmitglieder - und sie werden von diesen aufgegriffen und gemeinsam verarbeitet.

\section{Konfliktäre Gespräche vertrauter Partnerinnen}

Auch in ernsthaften Interaktionsmodalitäten werden komplexe Handlungen mittels stimmlich-artikulatorischer Ausdrucksgestaltungen lokal charakterisiert. Schwarze (2009) zeigt das in einer Studie zu Formen und Funktionen der Topoiverwendung in konfliktären Gesprächen zwischen Müttern und ihren jugendlichen Töchtern. Hier trägt der stimmlich-artikulatorische Ausdruck nicht vordergründig zur Charakterisierung von performativen Praktiken oder Interaktionsrollen bei, sondern dient zur Kennzeichnung bestimmter Toposverwendungsweisen. Diese Verwendungsweisen unterscheiden sich im Hinblick auf die Interaktivität bei der Herstellung des Topos, also ob ein Topos von einer Partnerin allein oder von beiden Partnerinnen gemeinsam hergestellt wird. Topoi treten nach Schwarze (ebd.) vorzugsweise in der einen oder anderen Herstellungsweise auf. Weitere Unterscheidungskriterien liefern die Ebenen der Gesprächsorganisation, der toposbezogenen interaktiven Konsequenzen sowie der Äußerungsge- 
staltung und Formulierungsdynamik (zu den Kategorien dieser Analyseebenen vgl. Deppermann 1999, S. 56 ff.).

Die Verschränkung von stimmlich-artikulatorischer Ebene, Äußerungsgestaltung und Formulierungsdynamik wird in den Analysen beispielsweise an prosodischen Parametern wie Sprechgeschwindigkeit, Sprechgliederung, Akzentposition und -häufigkeit deutlich, die Aufschluss über die Sprechplanung und über die Formelhaftigkeit bzw. Vorgeformtheit der Äußerungen geben (vgl. u.a. Bose 1994 und 2003). Insbesondere Akzentuierung und sprecherische Gliederung ermöglichen Inferenzen und können in der Argumentationsanalyse für die Rekonstruktion von Prämissen und Argumentstrukturen genutzt werden (vgl. Bose/Gutenberg 2003; Schwarze 2009). Es handelt sich bei den prosodischen Realisationen also nicht um Oberflächenerscheinungen, sondern sie sind Ergebnis eines Entscheidungsprozesses darüber, was nach Annahme der Sprecherin für ihre Partnerin in der konkreten Gesprächssituation besonders wichtig bzw. unwichtig ist.

In den auditiven Analysen der Konfliktgespräche fielen stimmlichartikulatorische Gestalten auf, die auf der Handlungsebene mit einem individuell hergestellten Topos kookkurieren, außerdem mit flüssiger, ungestörter Formulierungsdynamik und mit Formelhaftigkeit auf der lexiko-semantischen Ebene. Diese Formelhaftigkeit (Phraseologismen, Stereotype usw.) weist auf allgemeine Topoi bzw. Gemeinplätze (loci communes) hin; nach Schwarze Anzeichen für eine, Orientierung am Modell' (DausendschönGay/Gülich/Krafft 2007, S. 184), also für „eine diskursive Routine, bei der ein in spezieller, teils konventionalisierter sprachlicher Form etabliertes Modell in der laufenden Interaktion Bestand hat und von den Interagierenden aufgegriffen wird.“ (Schwarze 2009, S. 130). Die damit einhergehende stimmlich-artikulatorische Gestalthaftigkeit ist allerdings keine obligatorische, sondern eine fakultative Eigenschaft der Toposverwendung. Schwarze wertet sie als Bestandteil rhetorischer Verfahren, als phonische Kennzeichnung besonderer elocutioneller Gestaltung im Sinne einer Amplificatio.

Diese enge Verwobenheit der rhetorischen, argumentativ-topischen und ausdrucksbezogenen Gesprächsarbeit in Konfliktgesprächen hat, anders als in der Modalität der spielerischen Geselligkeit, keine unterhaltende und illustrierende Funktion. Sie dient vielmehr der Herstellung von Kohärenz und somit der Erkennbarkeit der Argumentationssequenz, damit spezifisch argumentationsbezogenen individuellen Zielen und Zwecken der Gesprächsteilnehmerinnen im Gespräch.

Die vorgestellten gesprächsanalytischen Studien zeigen, dass vertraute Kommunikationspartner den stimmlich-artikulatorischen Ausdruck als kommunikative Ressource nutzen, um verschiedene Gesprächspraktiken (kindliches Rollenspiel, Beschimpfungsrituale, spontane Inszenierungen, konversationelle Karikaturen, aber auch konfliktäre Argumentationen) zu 
organisieren. Zum einen gestalten Sprecher ihre Äußerungen entsprechend konventioneller und damit wiedererkennbarer Muster, wodurch relevantes Wissen auf verschiedenen Ebenen verfügbar gemacht werden kann (soziale Konnotationen, Sprechrollen, Gestalthaftigkeit, Toposverwendung usw.). Zum anderen wird der stimmlich-artikulatorische Ausdruck von den Sprechern variiert. Die Variabilität bietet den Gesprächsteilnehmern die Möglichkeit, sowohl Gemeinsamkeit zu schaffen als auch mit den anderen zu kompetitieren.

\section{Zusammenfassung}

Die in neueren geisteswissenschaftlichen Arbeiten diskutierte Vielschichtigkeit bzw. Komplexität des Phänomens Stimme spiegelt sich in den hier dargestellten theoretischen Modellvorstellungen und Methoden zur empirischen Beschreibung von stimmlich-artikulatorischem Ausdruck wider. In ihnen werden unterschiedliche Aspekte der Sprechstimme fokussiert - ihre Physiologie (Stimme als Organ) und ihre kommunikative Funktion und soziale Determiniertheit (Stimme als Bestandteil des stimmlich-artikulatorischen Ausdrucks, beschreibbar in engem Bezug zur Sprache als individuelle Ausdrucksweise oder als konventionalisiertes Muster). Entsprechend wurden in den ausgewählten empirischen Studien sowohl stimmlich-artikulatorische Merkmale beschrieben und klassifiziert (Stimmphysiologie-, Emotionsforschung) als auch stimmlich-artikulatorischer Ausdruck in seiner Wirkung auf Hörer (Sprechwirkungs-, Perzeptionsforschung) und in seiner interaktiven Ausarbeitung (Gesprächsforschung) betrachtet.

Stimmlich-artikulatorischer Ausdruck dient zur Charakterisierung von Sprecher und Situation, von Zugehörigkeit zu bestimmten sozialen oder regionalen Gruppen u.a.m.; er verweist nicht nur auf das Individuum, das seinen Empfindungen willkürlich oder unwillkürlich Ausdruck gibt, sondern auch auf den Adressaten, bei dem Empfindungen und Assoziationen angeregt werden, und damit auf den Interaktionsprozess. Rezipienten deuten einen konkreten stimmlich-artikulatorischen Ausdruck vor dem Hintergrund ihrer Erfahrungen bzw. Erwartungen über angemessenes Ausdrucksverhalten als Ausdruck von Persönlichkeitseigenschaften, von Emotionen und Einstellungen, von Interaktionsrollen. Ein Problem der Beschreibung des stimmlich-artikulatorischen Ausdrucks besteht darin, dass nicht alle Merkmale für eine konkrete Situation relevant sein müssen. Kommunikationsbeteiligte ziehen ihre Schlüsse darüber, wie etwas, was der andere sagt bzw. meint, zu verstehen und zu interpretieren ist, aufgrund von Hinweisreizen, Kontexthilfen und Situationsindizien, zu denen auch der stimmlichartikulatorische Ausdruck gehört. Allerdings sind diese Hinweisreize nicht zweifelsfrei zu identifizieren oder vorherzusagen. 
Aus dem Überblick über empirische Arbeiten zum stimmlich-artikulatorischen Ausdruck geht hervor, dass validierte parameterbasierte Beschreibungssysteme zur Verfügung stehen, die auf physiologischen und phonetischen Kriterien basieren (vgl. 2.3 und 3.2). Gemeinsam ist ihnen die Orientierung an klar definierten, transparenten Bewertungsmaßstäben und die Konzentration auf wenige wesentliche Klangphänomene der Stimme, die meist skaliert beschrieben werden. Dennoch kommen Beschreibung und Interpretation der einzelnen Parameter oft aufgrund komplexer, nicht immer genau aufzuschlüsselnder Höreindrücke zustande, und sie sind kulturabhängig (3.2.3). Der Zusammenhang zwischen akustischen Grundlagen und Hörempfindungen ist nicht linear, und es ist nicht klar zu trennen zwischen ausschließlich stimmlichen, prosodischen oder artikulatorischen Gestaltungsweisen. Vor allem aber ist der Komplex des stimmlich-artikulatorischen Ausdrucks anhand seiner physiologisch bestimmbaren Merkmale allein nicht adäquat zu erfassen.

In vielen empirischen Arbeiten wird der multifaktoriell bestimmte Prozess des stimmlich-artikulatorischen Ausdrucks und seiner Verarbeitung auf möglichst wenige kontrollierbare Variablen reduziert, indem experimentell erstelltes Sprachmaterial in kontrollierten Situationen analysiert und/oder in seiner Hörerwirkung getestet wird (vgl. 3.3 und 3.4.1). Dahinter steht die These, dass die untersuchten Merkmale in der Bündelung das Ausdrucksmuster zwar vielleicht nicht vollkommen erfassen, aber doch hinreichend beschreiben. Allerdings bestehen komplizierte Relationen zwischen Merkmalen und Mustern, die auf anthropologisch-evolutionärer Grundlage stark kulturell und sprachlich überformt und kontextuell abgestimmt sind. Strikt experimentell vorgehende Untersuchungen können deswegen zwar nachweisen, dass stimmlich-artikulatorische Ausdrucksformen als Bedeutungsträger fungieren und zur Vereindeutigung der Verständigung beitragen können; sie erbringen Erkenntnisse über die (mögliche) Relevanz einzelner Variablen, über die Interdependenz von Merkmalsausprägung und Hörerbeurteilung und tragen zur Entwicklung und Validierung analytischer Beschreibungskategorien bei. Die Übertragbarkeit der Ergebnisse auf die interaktive Relevanz des stimmlich-artikulatorischen Ausdrucks im Kommunikationsprozess ist aber nur sehr eingeschränkt möglich.

In der mündlichen Kommunikation ist nicht mit konstanten Merkmalskombinationen für bestimmte Funktionen zu rechnen: Kommunizierende können bestimmte Funktionen mit vielen verschiedenen sprecherischen Mitteln gestalten, die sie verschieden miteinander kombinieren. Dadurch ergeben sich eine hohe Varianz und eine prinzipielle Mehrdimensionalität der Ausdrucksformen in wechselnder Hierarchie und Kombination und eine Multifunktionalität von Mustern und Merkmalen. Diesen komplexen 
Zusammenhang versuchen Perzeptionsstudien anhand von Interviews über Assoziationen zu authentischen Äußerungen zu erfassen (vgl. 3.4.2). Daraus geht hervor, dass der stimmlich-artikulatorische Ausdruck das Verständnis des Gesagten entscheidend beeinflusst, weil Rezipienten ihm außerordentlich schnell Indizien für die Diagnose und Identifikation von Sprecherpersönlichkeit und -intention entnehmen. Außerdem zeigt sich, dass Hörer nicht nur einen Gesamteindruck haben, sondern das Gehörte auch gezielt analysieren können, wobei sie gleichermaßen sowohl auf die sprachliche als auch auf die stimmlich-artikulatorische Ebene Bezug nehmen.

In gesprächsanalytischen Arbeiten werden die kommunikativen Praktiken im Umgang mit stimmlich-artikulatorischem Ausdruck und seine interaktive Relevanz in engem Bezug zur verbalen Interaktionsebene in authentischen Gesprächen untersucht (vgl. 3.5). Es zeigt sich, dass Gesprächsteilnehmer die Relevanz von stimmlich-artikulatorischen Ausdrucksformen interaktiv aushandeln und dass der stimmlich-artikulatorische Ausdruck komplex mit dem Gesamtgeschehen verwoben ist und vielfältige Funktionen erfüllt (z.B. Themeninitiierung und -progression, Markierung von Kontext und Interaktionsmodalität, Ausdruck von Haltungen und Bewertungen, Inszenierung von Sprechrollenmustern, Wiedergabe fremder stimmlich-artikulatorischer Ausdrucksmuster).

Hier bietet sich eine Verknüpfung der Arbeiten zum stimmlich-artikulatorischen Ausdruck mit den Konzepten der Kontextualisierung und der Performanz an. Methodisch arbeiten die vorgestellten Studien mit einer Kombination erstens aus rekonstruktiven Analysen von Gesprächsverlauf und -steuerung, zweitens aus externen (kulturbezogenen) Musterkennzeichnungen und drittens aus phonetischen Merkmalsbeschreibungen. Durch diese systematischen Methoden- und Perspektivenwechsel können die jeweiligen Interpretationen wechselseitig validiert werden.

Um den Komplex von stimmlich-artikulatorischen Ausdrucksformen in Interdependenz zu sprachlichen und körperlichen Ausdrucksformen umfassend theoretisch und empirisch zu erforschen, sind weitere, vor allem interdisziplinäre Forschungen nötig. Insbesondere sind die zahlreichen geisteswissenschaftlichen Perspektiven, aus denen Stimme und stimmlichartikulatorischer Ausdruck aktuell thematisiert wird, zu berücksichtigen und miteinander in Beziehung zu bringen - durchaus im Sinne einer Forderung von Bühler (1933 [1982], S. 111): die Vertreter der beteiligten Disziplinen mögen „den Mut aufbringen, jeder dem anderen ins Konzept zu sprechen“. 


\section{Literatur}

Aderhold, Egon (1993): Sprecherziehung des Schauspielers. Grundlagen und Methoden. 4. Aufl. Berlin.

The American Speech-Language-Hearing Association (ASHA) (2002): Consensus Auditory-Perceptual Evaluation of Voice (CAPE-V). Internet: www.asha.org/NR/ rdonlyres/3FA67246-279B-4DA2-84D8-BEFCA5D99345/0/22559_1.pdf (Stand: Juli 2009).

Anders, Lutz Christian (1997): Spektrale Analysen gestörter Stimmen. Habilitationsschrift Universität Jena. Unveröff. Typoskript.

Auer, Peter/Couper-Kuhlen, Elizabeth/Müller, Frank (1999): Language in time: The rhythm and tempo of spoken interaction. New York/Oxford.

Bachtin, Michail (1972 [1981]): Slovo v romane. In: Voprosy Literatury 6/1972, S. 54 86. [Engl. Übers.: Discourse in the novel. In: Holquist, Michael (Hg.): The dialogic imagination. Four essays. Austin 1981, S. 259-422].

Baldauf, Heike (1998): Aufschreien und Stöhnen - Äußerungsformen emotionaler Beteiligung beim Fernsehen. In: Brock, Alexander/Hartung, Martin (Hg.): Neuere Entwicklungen in der Gesprächsforschung: Vorträge der 3. Arbeitstagung des Pragmatischen Kolloquiums Freiburg. (= ScriptOralia 108). Tübingen, S. 37-54.

Baldauf, Heike (2002): Knappes Sprechen. (= Reihe germanistische Linguistik 227). Tübingen.

Blumstein, Sheila/Kurowski, Kathleen (2006): The FAS: a perspective. In: Neurolinguistics 19, S. 346-355.

Bogner, Andrea (2000): Stimmen hören. Das Phänomen der Stimme in der interkulturellen Kommunikation. In: Wierlacher, Alois (Hg.): Kulturthema Kommunikation. Konzepte - Inhalte - Funktionen. Möhnesee, S. 209-217.

Bogner, Andrea (2005): Grenzgänge. Zur konstitutiven Fremdheit der Stimme. In: Jahrbuch Deutsch als Fremdsprache 31, S. 108-130.

Bose, Ines (1994): Zur temporalen Struktur frei gesprochener Texte. (= Forum Phoneticum 5). Frankfurt a.M.

Bose, Ines (2001): Methoden der Sprechausdrucksbeschreibung am Beispiel kindlicher Spielkommunikation. In: Gesprächsforschung - Onlinezeitschrift zur verbalen Interaktion 2, S. 262-303. Internet: www.gespraechsforschung-ozs.de (Stand: Juli 2009).

Bose, Ines (2003): dóch da sín ja ' nur mûster // - Kindlicher Sprechausdruck im sozialen Rollenspiel. (= Hallesche Schriften zur Sprechwissenschaft und Phonetik 9). Frankfurt a.M. u.a.

Bose, Ines/Ehmer, Oliver (2007): Formen und Funktionen des Sprechausdrucks in geselliger Kommunikation. In: Velichkova, Ludmila (Hg.): Klangsprache im Fremdsprachenunterricht (IV) - Forschung und Praxis. Woronesh, S. 33-49.

Bose, Ines/Gutenberg, Norbert (2003): Enthymeme and prosody. A contribution to empirical research in the analysis of intonation as well as argumentation. In: van Eemeren, Frans H./Blair, J. Anthony/Willard, Charles Arthur (Hg.): Proceedings of the 5th International Conference on Argumentation (ISSA), Amsterdam June 25-28, 2002. Amsterdam, S. 139-140. 
Bose, Ines/Schwarze, Cordula/Wendt, Beate (ersch. 2009): Transkription von Sprechausdruck. In: Gesprächsforschung - Onlinezeitschrift zur verbalen Interaktion. Internet: www.gespraechsforschung-ozs.de (Stand: August 2009).

Bose, Ines/Wendt, Beate (ersch. 2010): Sprechwissenschaftliche Studien zu einem Fall von Fremdakzentsyndrom (russischer Fremdakzent im Deutschen). In: Velichkova, Ludmila (Hg.): Klangsprache im Fremdsprachenunterricht (VI) - Forschung und Praxis. Woronesh.

Braun, Angelika (1994): Sprechstimmlage und Muttersprache. In: Zeitschrift für Dialektologie und Linguistik 1/61, S. 170-178.

Braun, Angelika (2001): Is voice quality language-dependent? In: Braun, Angelika/Masthoff, Herbert R. (Hg.): Phonetics and its applications. Stuttgart, S. 453-463.

Braun, Angelika/Heilmann, Christa (2005): Fremde Stimmen und fremde Körper. Zum Ausdruck von Emotionen im synchronisierten Film. In: Jahrbuch Deutsch als Fremdsprache 31, S. 164-189.

Bühler, Karl (1927 [1978]): Die Krise der Psychologie. Jena. [Ungek. Ausg. 1978. Stuttgart/Frankfurt a.M./Berlin/Wien].

Bühler, Karl (1933 [1968]): Ausdruckstheorie. Das System an der Geschichte aufgezeigt. Jena. [2., unveränd. Aufl. 1968. Stuttgart/New York].

Bühler, Karl (1934 [1982]): Sprachtheorie: die Darstellungsfunktion der Sprache. Jena. [Ungek. Neudr. d. Ausg. Jena 1934. Mit einem Geleitwort von Friedrich Kainz. 1982. Stuttgart/New York].

Chion, Michel (2003): Mabuse - Magie und Kräfte des „Acousmêtre“. Auszüge aus „Die Stimme im Kino“. In: Epping-Jäger, Cornelia/Linz, Erika (Hg.): Medien/ Stimmen. Köln, S. 124-159.

Connor, Steven (2004): „The Strains of the Voice“. In: Felderer (Hg.), S. 158-172.

Couper-Kuhlen, Elizabeth/Selting, Margret (Hg.) (1996): Prosody in conversation: interactional studies. Cambridge.

Couper-Kuhlen, Elizabeth/Reber, Elisabeth (i.d.Bd.): Interjektionen zwischen Lexikon und Vokalität: Lexem oder Lautobjekt?

Dausendschön-Gay, Ulrich/Gülich, Elisabeth/Krafft, Ulrich (2007): Vorgeformtheit als Ressource im konversationellen Formulierungs- und Verständigungsprozess. In: Hausendorf, Heiko (Hg.): Gespräch als Prozess. Linguistische Aspekte der Zeitlichkeit verbaler Interaktion. (= Studien zur deutschen Sprache 37). Tübingen, S. 181-219.

Deppermann, Arnulf (1999): Gespräche analysieren. Eine Einführung in konversationsanalytische Methoden. (= Qualitative Sozialforschung 3). Opladen.

Dolar, Mladen (2004): Sechs Lektionen über Stimme und Bedeutung. In: Felderer (Hg.), S. 199-222.

Drumbl, Johann (2005): Sprechen in vielen Stimmen als Aufgabe des Sprachunterrichts. In: Jahrbuch Deutsch als Fremdsprache 31, S. 92-107.

Ehlich, Konrad (2004): Karl Bühler - zwischen Zeichen und Handlung oder: von den Mühen des Entdeckens und seinen Folgen. In: Ehlich/Meng (Hg.), S. 273-292. 
Ehlich, Konrad/Meng, Katharina (Hg.) (2004): Die Aktualität des Verdrängten. Studien zur Geschichte der Sprachwissenschaft im 20. Jahrhundert. (= Studien zur Wissenschafts- und Universitätsgeschichte 4). Heidelberg.

Ehmer, Oliver (2004): Spontane Inszenierungen in Alltagsgesprächen. Unveröff. Dipl. arbeit. Univ. Halle a.d.S.

Esling, John H. (2002): Laryngoscopic analysis of tibetan chanting modes and their relationship to register in sino-tibetan. In: Proceedings of the 7th International Conference on Spoken Language Processing (ICSLP), Bd. 2. Denver, S. 1081-1084.

Evans, Ruth/Nawka, Tadeus (2007): Skalen für die auditive Stimmbewertung. In: Bose, Ines (Hg.): Sprechwissenschaft. 100 Jahre Fachgeschichte an der Universität Halle. (= Hallesche Schriften zur Sprechwissenschaft und Phonetik 22). Frankfurt a.M. u.a., S. 313-318.

Fährmann, Rudolf (1960): Die Deutung des Sprechausdrucks. Studien zur Einführung in die Praxis der charakterologischen Stimm- und Sprechanalyse. Bonn.

Felderer, Brigitte (Hg.) (2004): Phonorama. Eine Kulturgeschichte der Stimme als Medium. Berlin.

Fitch, Tecumseh (2004): Die Stimme - aus biologischer Sicht. In: Felderer (Hg.), S. 86-102.

Gauß, Eva Maria (2008): Sprechbildung für Schauspieler/innen. Das Praxiskonzept von Tara McAllister-Viel im Kontext der Diskurse zu kulturübergreifendem Theater und zu Stimmlichkeit. Unveröff. Dipl.-Arb. Univ. Halle-Wittenberg.

Gauß, Eva Maria (2009): Welche Fragen wirft eine interkulturelle Mikroanalyse von Sprechbildungskonzepten für die Sprechwissenschaft auf? In: Hirschfeld, Ursula/ Neuber, Baldur (Hg.): Aktuelle Forschungsthemen der Sprechwissenschaft: Phonetik, Rhetorik und Sprechkunst. (= Hallesche Schriften zur Sprechwissenschaft und Phonetik). Frankfurt a.M. u.a., S. 31-50.

Geißner, Hellmut (1981): Sprechwissenschaft. Theorie der mündlichen Kommunikation. Königstein.

Geißner, Hellmut (1984): Über Hörmuster. Gerold Ungeheuer zum Gedenken. In: Gutenberg, Norbert (Hg.): Hören und Beurteilen: Gegenstand und Methode in Sprechwissenschaft, Sprecherziehung, Phonetik, Linguistik und Literaturwissenschaft. (= Sprache und Sprechen 2). Frankfurt a.M., S. 13-56.

Görlitz, Dietmar (1972): Ergebnis und Probleme der ausdruckspsychologischen Sprechstimmforschung. Meisenheim.

Goffman, Erving (1981): Forms of talk. Philadelphia.

Gorozhanina, Natalja (2007): Deutsch-russische rhythmische Interferenzen. In: Zeitschrift für Interkulturellen Fremdsprachenunterricht 12, 2. Internet: http://zif.spz. tu-darmstadt.de/jg-12-2/navigation/startbei.htm (Stand: August 2009).

Grawunder, Sven (2009): On the physiology of voice production in South-Siberian throat singing - analysis of acoustic and electrophysiological evidence. Berlin.

Gutenberg, Norbert (1998): Einzelstudien zu Sprechwissenschaft und Sprecherziehung. Arbeiten in Teilfeldern. Göppingen. 
Gutenberg, Norbert (2001): Einführung in Sprechwissenschaft und Sprecherziehung. Frankfurt a.M. u.a.

Hartel, Gaby/Kaspar, Frank (2004): Die Welt und das geschlossene Kästchen: Stimmen aus dem Radio - und über das Radio. In: Felderer (Hg.), S. 132-144.

Heilmann, Christa (2001): Neue Ansätze sprechwissenschaftlicher Gesprächsforschung. Habilitationsschrift Universität Jena.

Herrmann, Theo (1995): Allgemeine Sprachpsychologie: Grundlagen und Probleme. 2. Aufl. Weinheim.

Herzog, Herta (1933): Stimme und Persönlichkeit. In: Zeitschrift für Psychologie 130, S. 300-369.

Hirano, Minoru (1981): Clinical examination of voice. (= Disorders of human communication 5). Wien/New York.

Hirschfeld, Ursula/Neuber, Baldur/Stock, Eberhard (2009): Sprach- und Sprechwirkungsforschung. In: Fix, Ulla/Gardt, Andres/Knape, Joachim (Hg.): Rhetorik und Stilistik. Ein internationales Handbuch historischer und systematischer Forschung. 1. Halbbd. Berlin/New York, S. 772-786.

Hirschfeld, Ursula/Stock, Eberhard (ersch. 2009): Gedanken Karl Bühlers zur Phonetik und Phonologie. In: Bachmann, Armin R./El Mogharbel, Christliebe/Himstedt, Katja (Hg.): Form und Struktur in der Sprache. Festschrift für Elmar Ternes. (= Tübinger Beiträge zur Linguistik 499). Tübingen.

Höffe, Wilhelm (1965): Gesprochene Sprache. Ratingen.

Kallmeyer, Werner (1979): (Expressif) eh ben dis donc, hein ,pas bien`-Zur Beschreibung von Exaltation als Interaktionsmodalität. In: Kloepfer, Rolf/Rothe, Arnold/ Krauß, Henning/Kotschi, Thomas (Hg.): Bildung und Ausbildung in der Romania. München, S. 549-568.

Kent, Raymond D./Ball, Martin J. (Hg.) (2000): Voice quality measurement. San Diego.

Ketzmerick, Bettina (2007): Zur auditiven und apparativen Charakterisierung von Stimmen. (= Studientexte zur Sprachkommunikation 47). Dresden.

Kirchhoff, Robert (1965): Grundfragen der Ausdruckspsychologie. In: Kirchhoff, Robert (Hg.): Handbuch der Psychologie, Bd. 5: Ausdruckspsychologie. Göttingen, S. 117-219.

Kirchhoff, Robert (1991): Ausdruck. In: Arnold, Wilhelm/Eysenck, Hans Jürgen/Meili, Richard (Hg.): Lexikon der Psychologie. 3. Aufl. Freiburg/Basel/Wien, S. 185-194.

Klasmeyer, Gudrun (1999): Akustische Korrelate des stimmlich emotionalen Ausdrucks in der Lautsprache. (= Forum Phoneticum 67). Berlin/Offenbach.

Klawitter, Klaus/Köhler, Kerstin (2004): Gestisches Sprechen. In: Köhler, Kerstin/ Skorupinski, Cäcilie (Hg.): Wissenschaft macht Schule. Sprechwissenschaft im Spiegel von 10 Jahren Sommerschule der DGSS. (= Sprechen \& Verstehen 21). St. Ingbert, S. 151-162.

Klawitter, Klaus/Minnich, Herbert/Honigmann, Ingeborg/Mont'agh, Imre (1981): Zur Sprecherziehung für Schauspieler. Berlin. 
König, Ekkehard/Brandt, Johannes G. (2006): Die Stimme - Charakterisierung aus linguistischer Perspektive. In: Kolesch/Krämer (Hg.), S. 111-129.

Kolesch, Doris (2005): Wilde Laute und mediale Resonanzen. Fremde Stimmen im Theater der Gegenwart. In: Jahrbuch Deutsch als Fremdsprache 31, S. 208-215.

Kolesch, Doris (2006a): Zehn Thesen über die Stimme. In: Bischoff, Doerte/WagnerEngelhaaf, Martina (Hg.): Mitsprache, Rederecht, Stimmgewalt. Genderkritische Strategien und Transformationen der Rhetorik. Heidelberg, S. 341-356.

Kolesch, Doris (2006b): Wer sehen will, muss hören. Stimmlichkeit und Visualität in der Gegenwartskunst. In: Kolesch/Krämer (Hg.), S. 40-64.

Kolesch, Doris/Krämer, Sibylle (2006): Stimmen im Konzert der Disziplinen. In: Kolesch/Krämer (Hg.), S. 7-15.

Kolesch, Doris/Krämer, Sybille (Hg.) (2006): Stimme. Annäherung an ein Phänomen. Frankfurt a.M.

Kotthoff, Helga (1999): Coherent keying in conversational humor: Contextualising joint fictionalisation. In: Bublitz, Wolfram/Lenk, Uta/Ventola, Eija (Hg.): Coherence in spoken and written discourse. How to create it and how to describe it. Amsterdam u.a., S. 125-150.

Krämer, Sibylle (2005): Nachdenken über die Stimme. In: Jahrbuch Deutsch als Fremdsprache 31, S. 82-91.

Krämer, Sibylle (2006): Die ,Rehabilitierung der Stimme'. Über die Oralität hinaus. In: Kolesch/Krämer (Hg.), S. 269-295.

Krämer, Sybille (i.d.Bd.): Sprache, Stimme, Schrift: Zur impliziten Bildlichkeit sprachlicher Medien.

Krech, Eva-Maria/Richter, Günther/Stock, Eberhard/Suttner, Jutta (1991): Sprechwirkung. Grundfragen, Methoden und Ergebnisse ihrer Erforschung. Berlin (Ost).

Laver, John (1980): Phonetic evaluation of voice quality. San Diego, S. 37-47.

Laver, John (2000): The phonetic description of voice quality. Cambridge.

McAllister-Viel, Tara (2006): Toward an intercultural/interdisciplinary approach to training actor's voices. Thesis for the degree of PhD-Performance Practice. Unveröff. Typoskript. Univ. Exeter.

Mersch, Dieter (2006): Präsenz und Ethizität der Stimme. In: Kolesch/Krämer (Hg.), S. 211-236.

Meyer-Kalkus, Reinhart (2001): Stimme und Sprechkünste im 20. Jahrhundert. Berlin.

Meyer-Kalkus, Reinhart (2004): Literatur für Stimme und Ohr. In: Felderer (Hg.), S. 173-186.

Monrad-Krohn, Georg Herman (1947). Dysprosody or altered ,melody of language. In: Brain 70, S. 405-415.

Müller, Ursula (2002): Russisch. In: Hirschfeld, Ursula/Müller, Ursula/Kelz, Heinrich P. (Hg.): Phonetik international. Von Afrikaans bis Zulu. Kontrastive Studien für Deutsch als Fremdsprache. Internet: www.phonetik-international.de/p-phonetik (Stand: August 2009). 
Nawka, Tadeus/Anders, Lutz Christian (1996): Die auditive Bewertung heiserer Stimmen nach dem RBH-System. Doppel-Audio-CD mit Stimmbeispielen. Stuttgart/ New York.

Nawka, Tadeus/Evans, Ruth (2005): RBH-Training und Diagnostik. Forchheim (CD$\mathrm{ROM})$

Nebert, Augustin Ulrich (2007): Tonhöhe und Sprechstimme - Unterschiede in Mutter- und Fremdsprache. In: Zeitschrift für Interkulturellen Fremdsprachenunterricht 12, 2, Internet: http://zif.spz.tu-darmstadt.de/jg-12-2/navigation/startbei.htm (Stand: August 2009).

Nebert, Augustin Ulrich (2009): Stimmübungen im Fremdsprachenunterricht? In: Deutsch als Fremdsprache. Heft II, S. 105-113.

Neppert, Joachim (1999): Elemente einer Akustischen Phonetik. Hamburg.

Neuber, Baldur (2002): Prosodische Formen in Funktion. (= Hallesche Schriften zur Sprechwissenschaft und Phonetik 7). Frankfurt a.M. u.a.

Nothdurft, Werner (2004): ,Wahrnehmung ${ }^{6}$ als Denkmuster für Verstehen in der Sprachtheorie Karl Bühlers. In: Ehlich/Meng (Hg.), S. 125-136.

Paeschke, Astrid (2003): Prosodische Analyse emotionaler Sprechweise. Berlin.

Peters, John Durham (2004): The Voice and modern media. In: Kolesch, Doris/ Schödl, Jenny (Hg.): Kunst-Stimmen. (= Theater der Zeit: Recherchen 21). Berlin, S. $85-100$.

Pfau, Eva-Maria/Streubel, Hans-Gerhard (Hg.) (1982): Die Behandlung der gestörten Sprechstimme - Stimmfunktionstherapie. Leipzig.

Poe, Edgar Allan (1841 [2009]): Die Morde in der Rue Morgue (Originaltitel: The murders in the Rue Morgue). [n: Detektivgeschichten. Aus dem Englischen von Sophie Zeitz. 2009. München, S. 7-59].

Redecker, Beate (2008): Persuasion und Prosodie. (= Hallesche Schriften zur Sprechwissenschaft und Phonetik 25). Frankfurt a.M.

Rothe, Friederike (2006): Zwischenmenschliche Kommunikation: Eine interdisziplinäre Grundlegung. Wiesbaden.

Schäfer, Anke (2003): Interaktive Funktionen des Sprechausdrucks am Beispiel eines Peergroup-Gesprächs. Unveröff. Diplomarb. Univ. Halle a.d.S.

Scherer, Klaus R. (1995): Expression of emotion in voice und music. In: Journal of Voice 9, S. 235-248.

Scherer, Klaus R. (2003): Vocal communication of emotion: a review of research paradigms. In: Speech Communication 40, S. 227-256.

Scherer, Klaus R./Banse, Rainer/Wallbott, Harald G. (2001): Emotion inferences from vocal expression correlate across languages and cultures. In: Journal of Cross-Cultural Psychology 32 (1), S. 76-92.

Schmitt, Reinhold/Deppermann, Arnulf (i.d.Bd.): Die multimodale Konstitution eines imaginären Raums als interaktive Problemlösung. 
Schneider, Berit/Bigenzahn, Wolfgang (2007): Stimmdiagnostik. Ein Leitfaden für die Praxis. Wien/New York.

Schwarze, Cordula (2009): Formen und Funktionen von Topoi im Gespräch. Phil. Diss. (unveröff. Typoskript). Univ. Halle a.d.S.

Seidner, Wolfram/Wendler, Jürgen (1982): Die Sängerstimme. Phoniatrische Grundlagen für die Gesangsausbildung. Berlin (Ost).

Selting, Margret (1995): Prosodie im Gespräch: Aspekte einer interaktionalen Phonologie der Konversation. (= Linguistische Arbeiten 329). Tübingen.

Selting, Margret (1997): Interaktionale Stilistik: Methodologische Aspekte der Analyse von Sprechstilen. In: Selting, Margret/Sandig, Barbara (Hg.): Sprech- und Gesprächsstile. Berlin/New York, S. 9-44.

Sonninen, Aatto (1970): Phoniatric viewpoint on hoarseness. In: Acta Otolaryngologica 263, S. 68-81.

Stock, Eberhard (1987): Ergebnisse der Wirkungsforschung im Bereich von Stimme und Artikulation. In: Krech, Eva-Maria/Suttner, Jutta/Stock, Eberhard (Hg.): Ergebnisse der Sprechwirkungsforschung. (= Kongress- und Tagungsberichte der Martin-Luther-Universität Halle-Wittenberg 19/F 67). Halle a.d.S., S. 50-124.

Stock, Eberhard (1991): Emotionserkennung und Stimme. In: Kutter, Uta/Wagner, Roland (Hg.): Stimme. (= Sprache und Sprechen 25). Frankfurt a.M., S. 173-181.

Stock, Eberhard (in Zusammenarbeit mit J. Suttner) (1991): Wirkungen des Stimm- und Sprechausdrucks. In: Krech/Richter/Stock/Suttner, S. 59-142.

Stock, Eberhard (1993): Zur Rolle der ,lautlichen Qualität' in der sprechsprachlichen Kommunikation. In: Richter, Günther (Hg.): Methodische Grundfragen der Erforschung gesprochener Sprache. Frankfurt a.M., S. 77-85.

Stock, Eberhard (1996): Deutsche Intonation. Berlin u.a.

Stock, Eberhard/Veličkova, Ludmila (2002): Sprechrhythmus im Russischen und Deutschen. Frankfurt a.M. u.a.

Terhardt, Ernst (1998): Akustische Kommunikation: Grundlagen mit Hörbeispielen. Berlin u.a.

Tischer, Bernd (1993): Die vokale Kommunikation von Gefühlen. Weinheim.

Traill, Anthony (1986): The laryngeal sphincter as a phonatory mechanism in !xóo bushman. In: Singer, Ronald/Lundy, John K. (Hg.): Variation, culture and evolution in African populations. Papers in honour of Dr Hertha de Villiers. Johannesburg, S. 123-131.

Trojan, Felix (1948): Der Ausdruck von Stimme und Sprache. Eine phonetische Lautstilistik. Wien.

Trojan, Felix (1975): Biophonetik. Mit einem Beitrag von Günter Tembrock; hrsg. u. vervollständigt von Herbert Schendl. Mannheim/Wien/Zürich.

Trubetzkoy, Nikolaj S. (1939 [1989]): Grundzüge der Phonologie. (= Traveaux du Cercle Linguistique de Prague 7). Prag. [7. Aufl. 1989. Göttingen]. 
Vieregge, Wilhelm H. (1989): Phonetische Transkription. Theorie und Praxis der Symbolphonetik. (= Zeitschrift für Dialektologie und Linguistik - Beihefte 60). Stuttgart.

Vieregge, Wilhelm H. (1996): Patho-Symbolphonetik: auditive Deskription pathologischer Sprache. Unter Mitarbeit von Johannes Pahn und Harm K. Schutte. (= Zeitschrift für Dialektologie und Linguistik - Beihefte 100). Stuttgart.

Waldenfels, Bernhard (2006): Das Lautwerden der Stimme. In: Kolesch/Krämer (Hg.), S. 191-210.

Wendler, Jürgen (1996): Geleitwort. In: Nawka, Tadeus/Anders, Lutz Christian: Die auditive Bewertung heiserer Stimmen nach dem RBH-System. Doppel-Audio-CD mit Stimmbeispielen. Stuttgart/New York, S. 3-4.

Wendler, Jürgen/Rauhut, Andreas/Krüger, Horst (1986): Classification of voice qualities. In: Journal of Phonetics 14, S. 483-488.

Wendler, Jürgen/Seidner, Wolfram/Kittel, Gerhard/Eysoldt, Ulrich (1996): Lehrbuch der Phoniatrie und Pädaudiologie. 3., völlig neu bearb. u. erw. Aufl. Stuttgart/New York.

Wendt, Beate (2007): Analysen emotionaler Prosodie. (= Hallesche Schriften zur Sprechwissenschaft und Phonetik 20). Frankfurt a.M. u.a.

Wendt, Beate/Bose, Ines/Sailer, Michael/Scheich, Henning/Ackermann, Herrmann (2007): Speech rhythm of a woman with Foreign Accent Syndrome (FAS). In: Barry, William J./Trouvain, Jürgen (Hg.): Proceedings of the 16th International Congress of Phonetic Sciences (ICPhS) Saarbrücken, Aug. 6-10, 2007. Saarbrücken. Internet: www.icphs2007.de (Stand: August 2009).

Werner, Heinz (1932): Grundfragen der Sprachphysiognomik. Leipzig.

Westphal, Kristin (2002): Wirklichkeiten von Stimmen: Grundlegung einer Theorie der medialen Erfahrung. Frankfurt a.M. u.a.

Winkler, Christian (1969): Deutsche Sprechkunde und Sprecherziehung. 2., überarb. u. erw. Aufl. Düsseldorf.

Zilliken, Franziska (1991): Beziehungskonstituierende Wirkungen des Sprechausdrucks. Frankfurt a.M. u.a. 


\title{
Elisabeth Reber / Elizabeth Couper-Kuhlen
}

\section{Interjektionen zwischen Lexikon und Vokalität: Lexem oder Lautobjekt?}

\begin{abstract}
Anstelle der herkömmlichen Wortklasse Interjektion plädiert dieser Beitrag für eine erweiterte Auffassung von Lautobjekten (hier auch ,Vokalisierungen' genannt), wie sie von tatsächlichen Sprechern in konkreten Interaktionszusammenhängen produziert werden. Fokussiert wird der Gebrauch von Lautobjekten als affektgeladene Reaktion auf eine Mitteilung im Gespräch. Anhand eines Korpus von natürlich vorkommenden englischen Alltagsgesprächen werden drei Thesen erläutert: (1) Manche Lautobjekte bilden Lexeme, deren Form eine konventionalisierte prosodische Lautgestalt einschließt, (2) Lautobjekte werden als Teil einer körperlichen Gestalt produziert und (3) manche nicht-lexikalisierten Lautobjekte können ähnliche Funktionen wie lexikalisierte Lautobjekte übernehmen. Zum Schluss wird auf die sprachtheoretische Relevanz von Lautobjekten eingegangen.
\end{abstract}

\section{Einführung}

Spätestens seit der Verbreitung von „sound words“ in der Chat- und Instant-messaging-Welt ist die Interjektionsforschung wieder modern geworden. Denn obwohl Comicbücher - und damit ihre Soundwörter - durch den Animationsfilm zunächst verdrängt wurden, genießen Interjektionen und sonstige „dazwischen geworfenen“ Einheiten jetzt im so genannten Netspeak eine regelrechte Renaissance. Tabelle 1 zeigt ein paar Beispiele, entnommen einer jüngst erschienenen Arbeit zum Instant Messaging (Kessler 2008).

Diese Beispiele werfen unseres Erachtens einige Fragen auf: Sind Interjektionen und ,sound“-Wörter überhaupt Wörter? Und sind sie wirklich so chaotisch „dazwischen geworfen“, wie die Etymologie des Wortes Interjektion nahelegt? Welche Vokalisierungen gehören zu der Kategorie von Interjektion bzw. Lautobjekt und welche nicht? Und welchen Status haben diese im sogenannten Sprachsystem? Auf diese und ähnliche Fragen soll im Folgenden eingegangen werden.

\section{Was sind Interjektionen?}

Es gibt inzwischen eine beachtliche deutschsprachige Literatur zu dieser Frage, u.a. Ehlich (1986), Fries (2002), Kehrein/Rabanus (2001), Kowal/ O'Connell (Hg.) (2004), Nübling (2001, 2004), Schmidt (2001), DUDEN (2005). Wir wollen uns hauptsächlich an Nüblings Verständnis von Inter- 


\begin{tabular}{|c|c|}
\hline Soundwort & Beispiel aus dem Korpus \\
\hline hmmm & $\begin{array}{l}\text { Datum und Uhrzeit: 09/14/2006 03:31 PM } \\
\text { Sie haben eine Nachricht gesendet an C } \\
\text { hmmm aber }\end{array}$ \\
\hline hehe & $\begin{array}{l}\text { Datum und Uhrzeit: 12/10/2006 08:09 PM } \\
\text { Sie haben eine Nachricht gesendet an E } \\
\text { hehe ich auch ;-) }\end{array}$ \\
\hline haha & $\begin{array}{l}\text { Datum und Uhrzeit: 04/02/2007 02:40 PM } \\
\text { Sie haben eine Nachricht empfangen von E } \\
\text { haha }\end{array}$ \\
\hline hihi & $\begin{array}{l}\text { Datum und Uhrzeit: } 02 / 09 / 200708: 26 \mathrm{PM} \\
\text { Sie haben eine Nachricht empfangen von B } \\
\text { hihi }\end{array}$ \\
\hline höhö & $\begin{array}{l}\text { Datum und Uhrzeit: } 02 / 03 / 200706: 57 \mathrm{PM} \\
\text { Sie haben eine Nachricht empfangen von B } \\
\text { min Mii rockt rächt, höhö }\end{array}$ \\
\hline tsss & $\begin{array}{l}\text { Datum und Uhrzeit: } 09 / 28 / 200611: 55 \mathrm{AM} \\
\text { Sie haben eine Nachricht gesendet an C } \\
\text { du bist in ro, und gehts online? } \\
\text { tsss }\end{array}$ \\
\hline öhm & $\begin{array}{l}\text { Datum und Uhrzeit: } 12 / 16 / 200608: 39 \text { PM } \\
\text { Sie haben eine Nachricht gesendet an C } \\
\text { öhm zeit? }\end{array}$ \\
\hline ehm & $\begin{array}{l}\text { Datum und Uhrzeit: 10/09/2006 11:32 AM } \\
\text { Sie haben eine Nachricht empfangen } \\
\text { von G } \\
\text { ehm 8oder } 9 \wedge \text { A }\end{array}$ \\
\hline autsch & $\begin{array}{l}\text { Datum und Uhrzeit: } 12 / 29 / 2006 \text { 04:20 PM } \\
\text { Sie haben eine Nachricht gesendet an C } \\
\text { autsch }\end{array}$ \\
\hline hmpf & $\begin{array}{l}\text { Datum und Uhrzeit: 10/29/2006 09:46 PM } \\
\text { Sie haben eine Nachricht empfangen von B } \\
\text { hmpf }\end{array}$ \\
\hline grmbl & $\begin{array}{l}\text { Datum und Uhrzeit: } 12 / 18 / 2006 \text { 06:10 PM } \\
\text { Sie haben eine Nachricht gesendet an C } \\
\text { da waren scheins zwei kleinere faruen die } \\
\text { ziemlich üss gewesen seien (laut D) und D } \\
\text { sagte zu F hey schau die wären doch was } \\
\text { und F jäääh grmbl nein hmpf blabla }\end{array}$ \\
\hline
\end{tabular}

Tab. 1: Soundwörter (Kessler 2008, S. 27)

jektionen anschließen. Nach diesem Verständnis ist die Kategorie Interjektion eine prototypisch organisierte Kategorie, bei der sich die Mitglieder unterschiedlich nah zum oder entfernt vom prototypischen Zentrum der Kategorie positionieren. Die Zugehörigkeit einer Einheit zur Kategorie Interjektion kann somit graduell sein: Einheiten können mehr oder weniger ,Interjektionalität' vorweisen. Zur MINIMALDEFINITION einer Interjektion werden laut Nübling folgende konstitutive Merkmale gerechnet (Nübling 2004, S. 13):

- expressiver Ausdruck einer spontanen Emotion,

- Abwesenheit referentieller Bedeutung,

- Unflektierbarkeit,

- syntaktische Autonomie,

- eventuelles Vorhandensein onomatopoetischer Strukturen. 
Nach dieser Minimalbestimmung gehören zu den prototypischen Interjektionen vor allem EMPFINDUNGSWÖRTER wie ach, au, ih, igitt, pfui usw., jedoch nicht ikonische schallnachahmende Wörter wie tatütata, klingeling, miau oder Denotativa (,vollkonventionalisierte Lexeme mit stilistisch neutralem Wert') wie Knall oder Kuckuck.

Nübling (2004, S. 15) führt folgende (unvollständige) Liste prototypischer Interjektionen im Deutschen auf:

\begin{tabular}{|c|c|}
\hline$a b !$ & (Erstaunen, Überraschung, Schmerz) \\
\hline ach! & $\begin{array}{l}\text { (Bewunderung, Erstaunen, aber auch Enttäuschung, Ab- } \\
\text { lehnung) }\end{array}$ \\
\hline aha! & (Überraschung, Genugtuung) \\
\hline au(a)/autsch! & (Schmerz) \\
\hline bäh! & (Ekel) \\
\hline brrr! & (Kälte, Abscheu) \\
\hline$h m !$ & (viele Funktionen je nach Länge und Tonem) \\
\hline bihi! & (Schadenfreude) \\
\hline hoppla! & (Überraschung) \\
\hline$b u(c h) !$ & (Erschrecken) \\
\hline bui! & (Bewunderung, Überraschung) \\
\hline burra! & (Sieg, Freude) \\
\hline$i b !$ & (Ekel, Abscheu, Entsetzen) \\
\hline igitt! & (Ekel) \\
\hline jubu! & (Freude) \\
\hline$n a !$ & (Ungeduld, Ungehaltenheit) \\
\hline naja! & (Ratlosigkeit) \\
\hline nanu! & (Verwunderung, Befremden) \\
\hline$o i !$ & (Überraschung, Bewunderung) \\
\hline$o b !$ & (Betroffenheit, Enttäuschung, Bewunderung) \\
\hline obo! & (Ver-/Bewunderung, Erstaunen) \\
\hline oje! & (Enttäuschung, Mitleid, Verachtung)) \\
\hline pab! & (Verachtung, Geringschätzung) \\
\hline pfui! & (Ekel, Abscheu) \\
\hline phb! & (Gleichgültigkeit, Verachtung) \\
\hline pub! & (Erleichterung, auch Ekel bei Gestank) \\
\hline tja! & (Ratlosigkeit) \\
\hline uff! & (Erleichterung) \\
\hline uh! & (Angst) \\
\hline ui! & (Überraschung, Bewunderung) \\
\hline
\end{tabular}

Damit wird klar, dass es die sogenannten PRIMÄREN Interjektionen sind, die als prototypisch betrachtet werden. 


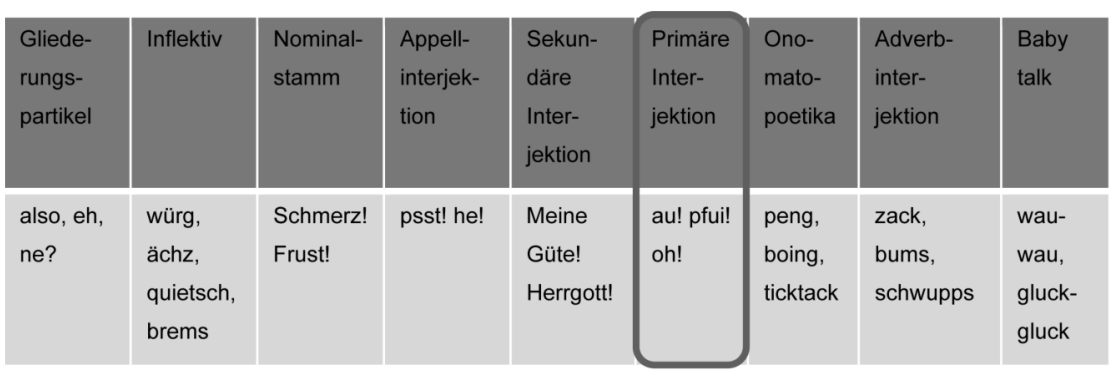

Tab. 2: Das interjektionale Spektrum (Nübling 2004, S. 34-35)

Ausgeschlossen aus der Kategorie der prototypischen Interjektionen sind sekundäre Interjektionen, ${ }^{1}$ die sich aus lexiko-syntaktischem Material entwickelt haben (meine Güte!, Herrgott!), sowie Appellinterjektionen bzw. Zurufe (psst! he!), Nominalstämme (Schmeræ! Frust!) und Inflektive (würg, quietsch). Weiterhin zählen Onomatopoetika (peng, boing), ,Baby talk' (wau-wau) und Adverbinterjektionen (zack, bums) nicht zu den prototypischen Interjektionen, genau so wenig wie Gliederungspartikel (also, ne, eh), weil sie nach Nübling keine - oder nur wenige - Emotionalität ausdrücken (siehe Tabelle 2). ${ }^{2}$

Doch welche EIGENSCHAFTEN haben Mitglieder der Kategorie der prototypischen primären Interjektionen? Im Folgenden sind einige in der Literatur rekurrente Merkmale aufgelistet:

1) Interjektionen sind NICHT REFERENTIELL. Mit Bühler (1982) haben Interjektionen statt einer Darstellungsfunktion eine Kundgabefunktion: sie stellen eine Befindlichkeitsmitteilung dar (Kehrein/Rabanus 2001, S. 47). Weinrich konstatiert: „der Sprecher [gibt mit ihrer Hilfe] mehr oder weniger intensiv eine Gefühlslage zu erkennen“ (2005, S. 859). „In Grenzfällen (Überraschung, Schmerz ...) dient [die Interjektion] der Triebabfuhr" (ebd., S. 857).

2) Interjektionen bilden SPRECHAKTE. Diese gehören wohl zu den Expressiva: „Hiermit teile ich Dir mit, dass ich traurig bin“. In Verbindung mit Sätzen sind Interjektionen als ,illokutive Indikatoren“ (Nübling 2004, S. 20) zu betrachten, d.h. sie tragen zur Illokution der Proposition bei (siehe auch die Diskussionen in Ameka 1992; Wharton 2003; Wilkins 1992).

$1 \quad$ Die Unterscheidung zwischen primären und sekundären Interjektionen geht auf Wundt (1907) zurück. Siehe weiterhin Reisigl (1999) zu sekundären Interjektionen.

2 Mit dem Kriterium der Emotionalität legt Nübling (2004) somit eine enge Definition des Interjektionsbegriffs vor, die auf die Antike zurückgeht (Ehlich 1986, S. 20). Ein weiter gefasstes Verständnis des Interjektionsbegriffs zeigt z.B. Fries (2002), indem er zwischen verschiedenen Teilklassen nach Emotionsausdruck (ach, ob), körperlichem Empfinden (aua, brr, uff) und Appellfunktion (hallo, prost, pst) unterscheidet (ebd., S. 656). 
3) Interjektionen können MONOLOGISCH verwendet werden. Ein Hinweis hierfür soll sein, dass sie auch in gesprächspartnerlosen Situationen geäußert werden können (Weinrich 2005, S. 257; Sornig 2002, S. 463). Kehrein/Rabanus (2001, S. 47) stellen eine vergleichbare These für Interjektionen auf, die als Diskurspartikel (z.B. ja, hm) verwendet werden: „Äußerungen von Diskurspartikeln, die primär [Symptomcharakter] tragen, beziehen sich unabhängig von der sequenziellen Gesprächsstruktur auf den Sprecher selbst." [Hervorhebung im Original].

4) Interjektionen sind phonologisch und prosodisch EXZENTRISCH. Zum einen können sie phonologische und phonotaktische Abweichungen vom deutschen Sprachsystem aufweisen, z.B. ohne Vokal vorkommen (psst) bzw. fremde Laute (brrr, tsk) oder Lautverbindungen ( $p f u i)$ enthalten. Zum anderen haben sie abweichend von sonstigen Wörtern im Deutschen und Englischen eine distinktive tonale Struktur. Ehlich (1986) stellt fünf unterschiedliche Tonverläufe bei den deutschen Interjektionen hm, ah, oh, ih, au, ei, oi, hoi und na fest, die jeweils mit kurzen, langen oder reduplizierten Silben vorkommen können. Tabelle 3 zeigt einen Überblick der für hm ausgemachten Töne und Silbenlängen (Ehlich 1986, S. 75):

\begin{tabular}{|c|c|c|c|}
\hline Fon & einfach & kurz & redupliziert \\
\hline$\gamma$ & $\begin{array}{l}\text { hm } \\
\text { IV }\end{array}$ & $\begin{array}{l}\text { hm' } \\
\quad \mathrm{IV}^{\mathrm{K}}\end{array}$ & hmhǹ̀ \\
\hline & hm & $\begin{array}{l}\mathrm{hm}^{\prime} \\
\quad \|^{\mathrm{K}}\end{array}$ & hmhm' \\
\hline - & hm̄̄ & $\mathrm{hm}^{-\mathrm{\prime}}$ & $*$ \\
\hline$V$ & hm̌ & $\mathrm{hm}^{\prime}$ & hmhm̌r \\
\hline$\wedge$ & $\mathrm{hm}_{2}$ & & \\
\hline
\end{tabular}

Tab. 3: Matrix der Eigenschaften von HM (Ehlich 1986, S. 75)

Jedoch: so überzeugend die bisherige linguistische Beschreibung der Wortklasse Interjektion sein mag, so kann sie doch nicht darüber hinwegtäuschen, dass bis heute recht wenig über den tatsächlichen Gebrauch dieser 
Objekte im Gespräch bekannt ist. Angesichts der heutigen Kenntnislage über die Verwendung von Sprache in Interaktionszusammenhängen plädieren wir hier für eine alternative Auffassung hinsichtlich der erwähnten Interjektionsmerkmale:

ad 1: REINE KUNDGABE? Goffmans Arbeiten zu „response cries“ (1978) veranschaulichen, dass mit Schmerzausrufen, Stöhnen bei Anstrengung, Überraschungslauten, Ekelausrufen, Jubellauten und dergleichen zwar momentane Gedanken und Gefühle lautlich kundgetan werden, jedoch werden diese in einer ritualisierten Art und Weise und als Teil eines „,social arrangement" produziert. Das Individuum hat seinen Auftritt in der Öffentlichkeit genug unter Kontrolle, um z.B. beim Anstoßen seines Zehs ein „Verdammt nochmal" in einem Kindergarten zu unterdrücken. Andererseits muss ein erfreutes „Oh“ beim Auspacken einer hässlichen Vase nichts über die wahren Gefühlsregungen des Geburtstagskinds über das Geschenk der Schwiegermutter aussagen. Diese und weitere empirische Beobachtungen lassen erhebliche Zweifel daran aufkommen, dass Interjektionen nur „eine Gefühlslage zu erkennen“ geben (Weinrich 2005, S. 859) oder zur reinen „Triebabfuhr" dienen (ebd., S. 857). Vielmehr ist es denkbar, dass sie auch für sozialkommunikative Zwecke produziert werden.

ad 2: SPRECHAKT? ILLOKUTIVER INDIKATOR? Solche Bezeichnungen legen nahe, dass Interjektionen, auch wenn sie multifunktional sind, eindeutige Emotionen ausdrücken. Wie unklar die Bedeutungen einzelner Interjektionen jedoch sind, zeigt gerade der Vergleich von Arbeiten, in denen Interjektionen mit spezifischen Emotionszuschreibungen aufgelistet werden: Während z.B. Weinrich (2005, S. 859) ab und ob als Ausdruck von neutraler oder positiver Überraschung klassifiziert, steht bei Nübling (2004, S. 15) $a h$ ! für Erstaunen, Überraschung, Schmerz und $o$ ! für Betroffenheit, Enttäuschung, Bewunderung. Die Kontextualisierungstheorie (Gumperz 1982; Auer/di Luzio (Hg.) 1992) konstatiert in diesem Zusammenhang, dass gerade nicht-referentielle sprachliche Zeichen als Hinweis auf mögliche Deutungsschemata fungieren. Sie lösen kontextabhängige Inferenzen aus, die im späteren Verlauf der Interaktion ausgehandelt, d.h. bestätigt oder verworfen werden. Nach dieser Theorie bestünde der Beitrag einer Interjektion darin, nicht kontextlos den inneren Zustand eines Sprechers, z.B. Ärger, kundzutun, sondern im sequenziellen Rahmen darauf hinzuweisen, dass Ärger ein mögliches Interpretationsschema für sein Verhalten bieten könnte.

ad 3: MONOLOGISCH? Im Verwendungszusammenhang, d.h. im fokussierten Gespräch (Goffman 1963) - auch im öffentlichen Selbstgespräch sind sprachliche Äußerungen genauso wie ihre Abwesenheit immer kommunikativ. Dies ist damit erklärbar, dass ein fokussiertes Gespräch aus einem strukturierten Geflecht von Beitragspositionen besteht. Je nach Aktivitätsbzw. Sequenztyp sind bestimmte Handlungen an bestimmten Stellen erwart- 
bar. Abweichungen von diesen Erwartbarkeiten sind rechenschaftspflichtig (accountable) und interpretierbar (Heritage 1984b). Wenn also eine bestimmte Interjektion an einer bestimmten Stelle im Gespräch produziert wird, wird sie im sequenziellen Rahmen bedeutsam, d.h. sie legt Inferenzen nahe, die es den Rezipienten ermöglichen, zu entscheiden, was als Nächstes getan werden soll. Zum Beispiel: Nach einer Mitteilung in englischen Alltagsgesprächen zeigt die Rezeption mit oh an, dass sich der Informationsstand des Rezipienten verändert hat (Heritage 1984a, S. 304). Die Mitteilung wird damit als möglicherweise vollständig behandelt. Im Gegensatz dazu wird mit der Produktion von yeah eine Fortsetzung der Mitteilung nahegelegt. $O b$ und yeah besitzen also verschiedene Folgeimplikationen: Während ob in Mitteilungssequenzen als ein „change-of-state token“ fungiert und potentiell sequenzterminierend ist, kann yeab sequenzexpandierend wirken (Heritage 1984a, S. 301-302).

ad 4: DISTINKTIVITÄT NUR DURCH TONVERLAUF UND DAUER? Die intuitive Annahme, dass die Produktion von Interjektionen durch eine bestimmte Intonationskontur und oft durch Längung gekennzeichnet ist, ist sicherlich richtig. Jedoch deuten Studien zur Prosodie im Gespräch darauf hin, dass nicht nur Tonhöhe und Dauer, sondern auch Lautstärke, Rhythmus, Tonhöhenumfang, Tonhöhenregister und Pause an der prosodischen Gestalt von sprachlichen Äußerungen maßgeblich beteiligt sein können (Couper-Kuhlen/Selting (Hg.) 1996; Auer/Couper-Kuhlen/Müller 1999; CouperKuhlen/Ford (Hg.) 2004). Hinzu kommen die in letzter Zeit als phonetisch propagierten Merkmale, z.B. die artikulatorische Einstellung, die artikulatorische Stärke und die Stimmqualität bzw. Phonationsart, die zu unterschiedlichen stimmlichen Effekten und Qualitäten führen können. Alle diese Merkmale tragen mit dazu bei, dass die Gestalt einer Interjektion (wieder)erkennbar und im Kontext interpretierbar wird.

ad 5: GRAPHISCHE BESCHRÄNKUNG? Auffällig bei den gängigen Listen von Interjektionen ist die Beschränkung auf Vokalisierungen, für die eine graphische Form (wenn auch unnormiert) existiert. Zudem wird durch die gängige Hinzufügung eines Ausrufezeichens suggeriert, dass Interjektionen als exklamative Äußerungen realisiert werden. Bei rein lautlichen Phänomenen nur von der graphischen Form auszugehen, deutet aber auf einen gewissen „written language bias“ (Linell 2005) hin. Unklar bei einem solchen graphembasierten Verfahren bleibt, wie viele (möglicherweise halbkonventionalisierte) Vokalisierungen OHNE graphische Form dadurch unentdeckt bleiben. Wie ertragreich ein Entdeckungsverfahren „von unten“, d.h. ausgehend von der lautlichen Seite der Rede, sein kann, zeigen die Befunde von Ward (2006) für das Englische, hier als Übersichtstabelle: ${ }^{3}$

3 Bei dieser Darstellung sind die phonetischen Formen der belegten Vokalisierungen durch folgende Erweiterungen der englischen Orthographieregeln dargestellt: „u/uu“ = Schwa, 
All conversational non-lexical sounds in the corpus, with numbers of occurrences

$\begin{array}{llll}\text { <clear-throat> 2 } & \text { hmmmmm 1 } & \text { okay 8 } & \text { unkay 1 } \\ \text { <tongue-click> 22 } & \text { hn 1 } & \text { okay 1 } & \text { unununu 1 } \\ \text { <click>neeu> 1 } & \text { hn-hn 1 } & \text { ooa 1 } & \text { uu 6 } \\ \text { <click>nuu 1 } & \text { huh 2 } & \text { ookay 1 } & \text { uuh 1 } \\ \text { <click>ohh 1 } & \text { I1 } & \text { oooh 1 } & \text { uum 6 } \\ \text { <click>yeahh 1 } & \text { iiyeah 1 } & \text { ooooh 1 } & \text { uumm 1 } \\ \text { <noisy-inhale> 1 } & \text { m-hm 2 } & \text { oop-ep-oop 1 } & \text { uun 1 } \\ \text { achh 1 } & \text { mm 2 } & \text { u-kay 1 } & \text { uuuh 1 } \\ \text { ah 6 } & \text { mm-hm 1 } & \text { u-uh 4 } & \text { uuuuuuu 1 } \\ \text { ahh 1 } & \text { mm-mm 1 } & \text { u-uun 1 } & \text { wow 1 } \\ \text { ai 1 } & \text { mmm 3 } & \text { uam 1 } & \text { yah-yeah 1 } \\ \text { am 1 } & \text { myeah 2 } & \text { uh 36 } & \text { ye 1 } \\ \text { aoa 1 } & \text { nn-hn 4 } & \text { uh-hn 2 } & \text { yeah 70 } \\ \text { aoo 1 } & \text { nn-nnn 1 } & \text { un-hn-uh-hn 1 } & \text { yeah-okay 1 } \\ \text { aum 5 } & \text { nu 1 } & \text { uh-huh 3 } & \text { yeah-yeah 1 } \\ \text { eah 1 } & \text { nuuuuu 1 } & \text { uh-mm 1 } & \text { yeahh 2 } \\ \text { ehh 1 } & \text { nyaa-haao 1 } & \text { uh-uh 2 } & \text { yeahuuh 1 } \\ \text { h-hmm 1 } & \text { nyeah 1 } & \text { uh-uhmmm 1 } & \text { yegh 1 } \\ \text { haah 1 } & \text { o-w 1 } & \text { uhh 4 } & \text { yeh-yeah 1 } \\ \text { hh 3 } & \text { oa 1 } & \text { uhhh 1 } & \text { yei 1 } \\ \text { hh-aaaah 1 } & \text { oh 20 } & \text { ukay 2 } & \text { yo 1 } \\ \text { hhh 1 } & \text { oh-eh 1 } & \text { um 20 } & \text { yyeah } \\ \text { hhh-uuuh 1 } & \text { oh-kay 1 } & \text { um-hm-uh-hm 1 } & \\ \text { hhn 1 } & \text { oh-okay 2 } & \text { umm 5 } & \\ \text { hmm 2 } & \text { oh-yeah 1 } & \text { ummum 1 } & \end{array}$

Tab. 4: Vorkommen und Häufigkeit nicht-lexikalischer Laute in einem mittelgroßen Korpus amerikanischer Alltagsgespräche (Ward 2006, S. 130)

Im Folgenden soll diese alternative Perspektive auf Interjektionen mit Beispielen aus unserer Forschung auf den Punkt gebracht werden.

\section{Statt Interjektionen: „Lautobjekte“ in ihren sequenziellen und interaktionalen Umgebungen}

Unsere Arbeit zielte darauf ab, Antworten auf die Fragen zu finden: Wann und wie werden Vokalisierungen ${ }^{5}$ von ,echten ${ }^{6}$ Sprechern unter natürlichen Bedingungen systematisch verwendet? Wie werden sie rezipiert? Damit sollte der mangelnde Kenntnisstand über die Formen und den Gebrauch

",“ = starke Grenze zwischen Silben, Wiederholung eines Buchstaben = Längung bzw. schwache Grenze zwischen Silben, „gh“ = velarer Frikativ, „chh“ = palataler Frikativ, „оO“ = /u/ (Ward 2006, S. 138).

4 Wohl ist auch diese Tabelle im Bezug auf Prosodie, erweiterte Phonetik und stimmliche Realisierung defizitär.

5 In der Gesprächsanalyse werden Interjektionen als Vokalisierungen (Goffman 1978) bezeichnet, was für die folgende Darstellung übernommen werden soll. ,Vokalisierung' gilt allerdings hier als Oberbegriff für sämtliche mit den menschlichen Sprechorganen hergestellten Laute und Geräusche. Damit werden sowohl lexikalisierte Interjektionen (wie oben eingeführt) als auch Produktionen jenseits des phonologischen Systems einer Sprache erfasst. In dieser Verwendungsweise schließt Vokalisierung sowohl vokalische als auch nichtvokalische Laute ein. 
von Interjektionen und sonstigen systematisch verwendeten Vokalisierungen gefüllt werden. Um die Kategorie der rekurrent vorkommenden und kommunikativ wirksamen Vokalisierungen zu erfassen, wird der Begriff „Lautobjekt“ eingeführt (Reber 2008).

In unseren Daten treten Vokalisierungen systematisch am häufigsten als Reaktion auf eine Mitteilung auf:

A: Mitteilung

B: Vokalisierung

Mit solchen Mitteilungen können Sprecher verschiedene Handlungen auf der funktionalen Ebene durchführen, z.B. über eine Neuigkeit informieren, ein Verständnisproblem beheben (Reparatur) oder einen Vorschlag ablehnen. Entsprechend können Rezipienten mit Vokalisierungen derartige Handlungen ratifizierend aufnehmen und gleichzeitig ihre affektive Haltung dazu darstellen.

Die Arbeiten von Heritage (1984a) über Mitteilungen, die mit ob aufgenommen werden, sind für unsere Untersuchung richtungsweisend. Im Gegensatz zu Heritage beschränkt sich unsere Arbeit jedoch auf Vokalisierungen, die eine eigene Turnkonstruktionseinheit bilden, und schließt jegliche Art von solchen Vokalisierungen in dieser sequenziellen Position ein. Ähnlich wie bei Heritage und bei Ward (2006) wird ein gebrauchsbasierter Ansatz, von unten'verfolgt: Unsere DATENGRUNDLAGE stützt sich auf ein Korpus von natürlich vorkommenden Gesprächen, d.h. Gesprächen, die auch unabhängig von der Aufnahme für Forschungszwecke stattgefunden hätten. Das Korpus umfasst englische Alltagsgespräche zwischen Freunden und Familienangehörigen und Radiosendungen mit Hörerbeteiligung.

Unser METHODISCHES VORGEHEN orientiert sich am methodologischen Ansatz der Interaktionalen Linguistik (Couper-Kuhlen/Selting (Hg.) 1996; Selting/Couper-Kuhlen 2000, (Hg.) 2001). Für unseren Forschungsgegenstand heisst das, dass Vokalisierungen sowohl formal als auch funktional im Bezug auf ihren Beitrag zur Interaktion betrachtet werden. Daraus folgt unsere spezifische Fragestellung: Welche lautlichen FORMEN und welche sequenziell-organisatorischen und interaktionalen FUNKTIONEN haben VOKALISIERUNGEN, mit denen REZIPIENTEN auf eine MITTEILUNG reagieren? Im folgenden werden drei Thesen vorgestellt, die sich unmittelbar aus unseren Forschungsergebnissen ableiten lassen.

\section{These 1: Manche Lautobjekte bilden Lexeme, ${ }^{6}$ deren Form eine kon- ventionalisierte prosodische Lautgestalt einschließt.}

Diese These soll anhand der verschiedenen Formen und Verwendungen der Vokalisierungen, die im Englischen allgemein mit dem Graphem ob oder 0 verschriftlicht sind, erläutert werden. Unser erstes Fallbeispiel be-

\footnotetext{
Für den Begriff des Lexems siehe u.a. Bauer (1983).
} 
schäftigt sich mit einem so genannten ,extra hohen und spitzen' oh, mit dem Sprecher auf eine Reparatur mit unerwartetem Inhalt, also die Klärung eines Verständnisproblems auf unerwartete Weise, affektiv reagieren können.

In diesem Telefongespräch erkundigt sich Leslie, eine Lehrerin, bei ihrer Kollegin Robin, wie es Mary, einer dritten, unter Allergien leidenden Kollegin, geht. Robin berichtet, dass Mary neue Kleider trägt, die ihr gut stehen.

\section{(1) „Allergies“ [Holt:M88:1:5]}

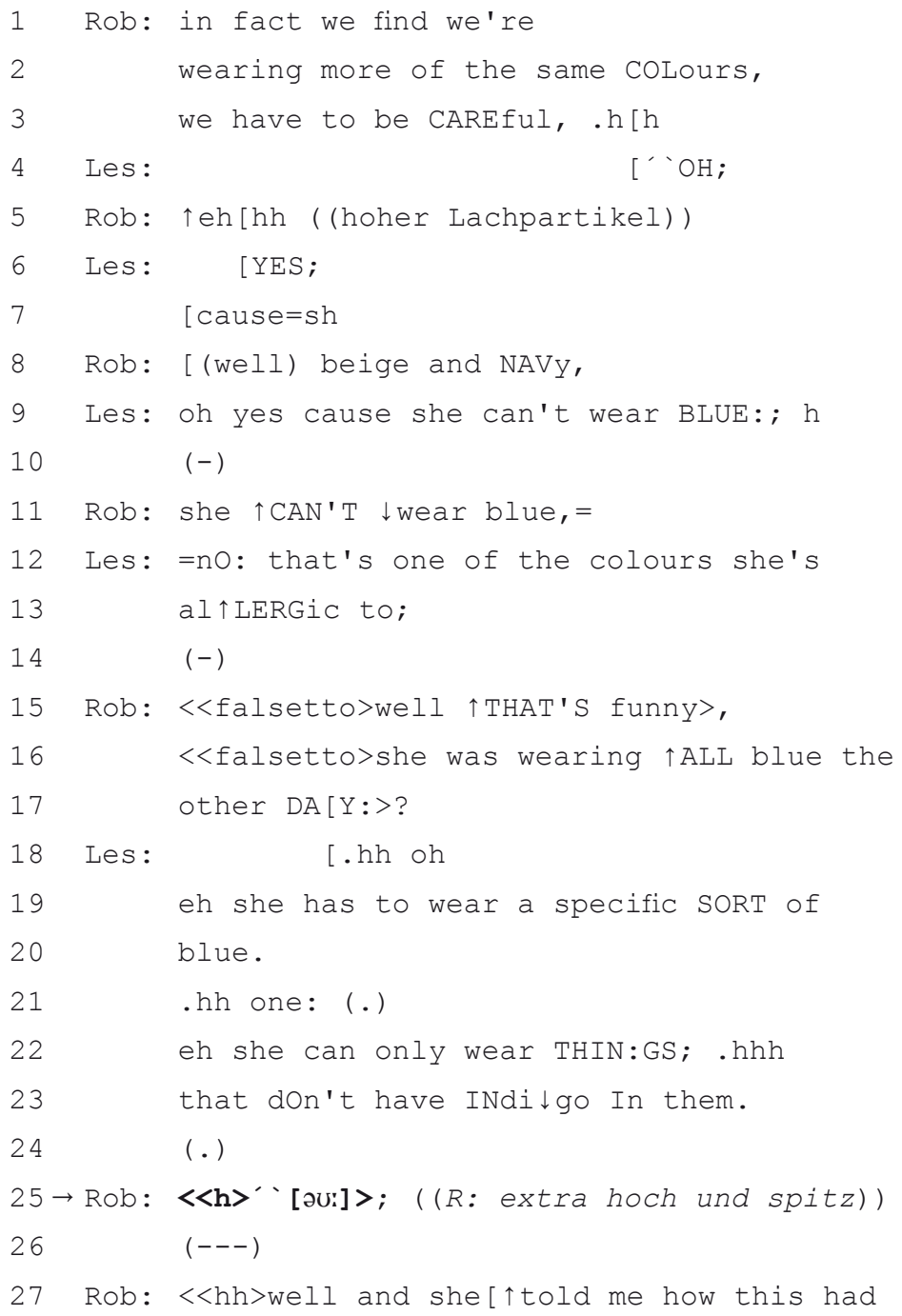




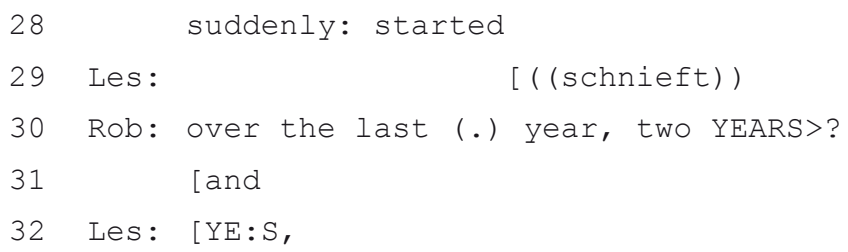

Das ob in Z. 25 bildet aufgrund seiner prosodisch-phonetischen Form ein Beispiel für ein ,extra hohes und spitzes $o b^{6}$ (Reber 2008): Die SEGMENTALE SUBSTANZ besteht aus dem Diphtong [əU]. Weiterhin werden derartige obs mit einer PROSODISCH-PHONETISCHEN FORM realisiert, die sich durch eine Reihe obligatorischer Eigenschaften auszeichnet: Das ob ist gelängt, wird auf einer global sehr hohen, steigend-fallenden Tonhöhenbewegung produziert und folgt speziell in Reparatursequenzen auf den nächsten Schlag. Außerdem weist dieses ob eine große artikulatorische Stärke auf (siehe Tabelle 5).

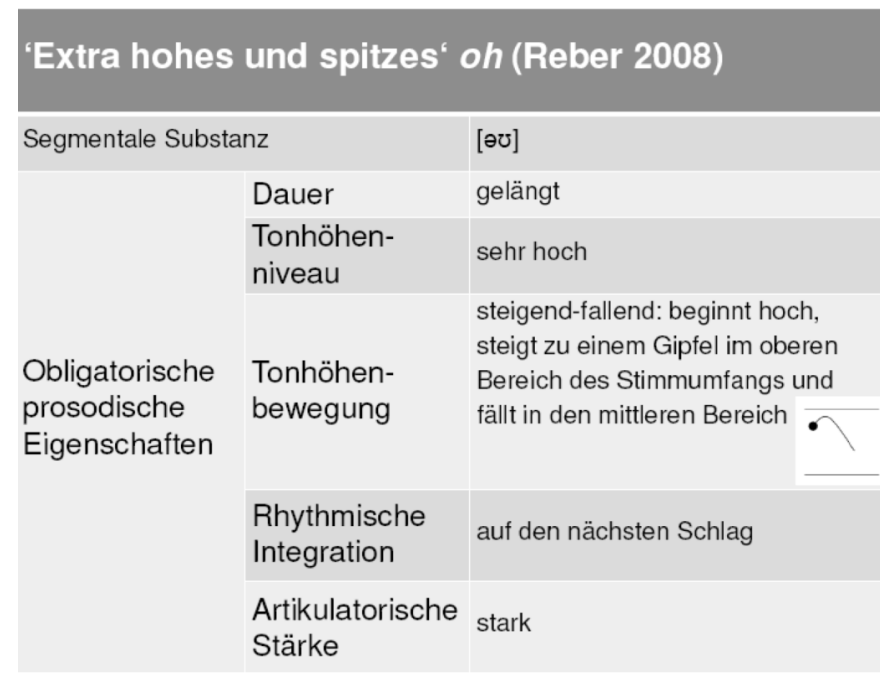

Tab. 5: ,Extra hohes und spitzes` ob (Reber 2008)

Die fakultativen Merkmale umfassen eine höhere Lautstärke als im vorherigen Beitrag derselben Sprecherin, einen initialen Glottalverschluss und behauchte Stimmqualität.

Die SEQUENZANALYSE kommt zu folgendem Ergebnis: Robin agiert in diesem Ausschnitt als Nachrichtenproduzentin über die gemeinsame Kollegin Mary. Robin teilt Leslie mit, dass sie und Mary vorsichtig sein müssen: Sie trügen in letzter Zeit beide Kleidung in denselben Farben, nämlich in 
beige und marineblau (Z. 1-3, 8). In Z. 9 produziert Leslie dagegen den Einwand, dass Mary gar kein Blau tragen kann. Im Gegenzug zeigt Robin Ungläubigkeit über Leslies Mitteilung an und initiiert eine Reparatursequenz (Z. 11). Leslie vollzieht die Reparatur in Z. 18-23, indem sie erklärt, dass Mary nur ein Blau tragen kann, das kein Indigo, einen Farbstoff, enthält. Robin produziert darauf ein extrahohes und spitzes oh (Z. 25). Das Lautobjekt erfüllt an dieser Stelle zwei Funktionen: 1) Eine SEQUENZ-ORGANISATORISCHE FUNKTION, indem mit ihm die Reparatur aufgenommen und ratifiziert wird. 2) Eine INTERAKTIONALE FUNKTION, indem die ob-Produzentin mit dem Lautobjekt ,Überraschung' darstellt. Die Evidenz für diese Feststellung erfolgt sequenzanalytisch. Da die Reparatur aufgrund von abweichenden Erwartungen bzgl. des Reparandums (siehe Z. 11 bzw. 15-17) initiiert wurde, kann geschlossen werden, dass die Reparatur auf der inhaltlichen Ebene unerwartet ist. Eine affektive Reaktion auf eine unerwartete Mitteilung wurde in der gesprächsanalytischen Literatur vielfach als Darstellung von ,Überraschung ${ }^{6}$ beschrieben (,the public display of finding something counter to expectation", Wilkinson/Kitzinger 2006, S. 152; siehe auch Selting 1996; Schegloff 1998). Das, extra hohe und spitze $o b^{6}$ dient also zur überraschten Reparaturaufnahme.

Im nächsten Beispiel wird $o b$ in Form eines zweiten Lautobjekts produziert, nämlich des so genannten ,gedämpften ${ }^{\prime} o h$. Das ,gedämpfte $o b$ wird unter anderen von Sprechern verwendet, um Mitteilungen auf affektive Weise aufzunehmen, mit denen der Gesprächspartner einen Vorschlag oder eine Bitte ablehnt. In unseren Daten kann diese Art von ob als Darstellung von ,Enttäuschung' interpretiert werden.

Bei Beispiel 2 handelt es sich um einen Ausschnitt aus einem Telefongespräch zwischen Leslie und ihren Mann Skip. Leslie macht ihrem Mann den Vorschlag, ihn auf einer Geschäftsreise zu begleiten. Er lehnt jedoch ab, was Leslie mit einem, gedämpften' ob aufnimmt.

(2) „Other chap“ (Holt Sept-Oct 1988 II)

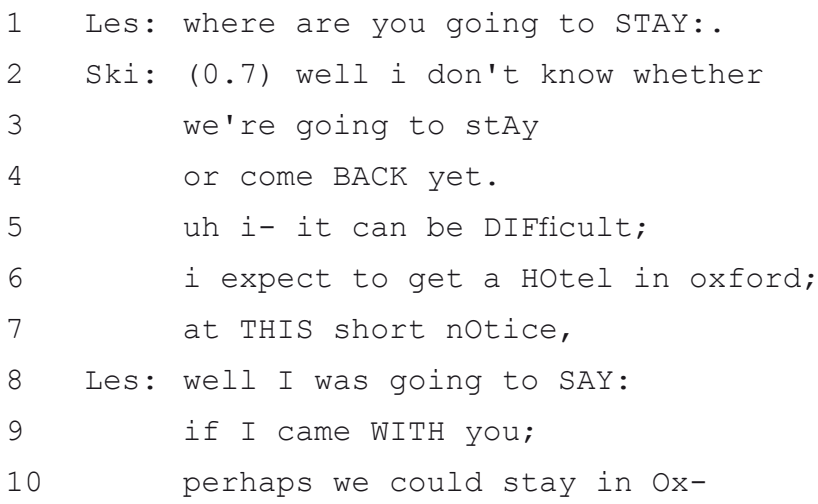




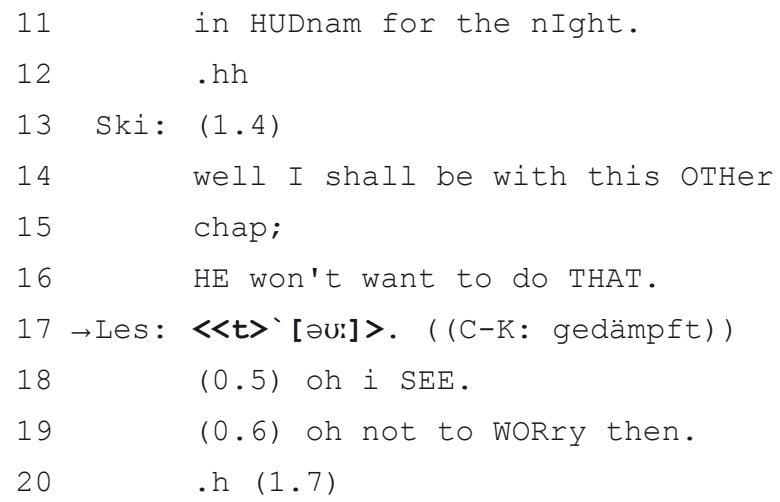

Die lautliche Form des so genannten, gedämpften $o b^{\varsigma}$ (Couper-Kuhlen im Erscheinen a) in Z. 17 kann wie folgt beschrieben werden: Während es in der SEGMENTALEN SUBSTANZ dem extrahohen und spitzen $o b$ ähnelt, unterscheidet es sich in seiner PROSODISCH-PHONETISCHEN FORM: Das ,gedämpfte $o b$ ist gelängt, hat ein tiefes Tonhöhenniveau und wird mit einer geringen und leicht fallenden Tonhöhenbewegung produziert. Es wird leiser als üblich, weder zu früh noch zu spät, mit schwacher artikulatorischer Stärke produziert. Die Phonation ist behaucht und weich im Auslaut (,trailoff', Local/Kelly 1986) (siehe Tabelle 6).

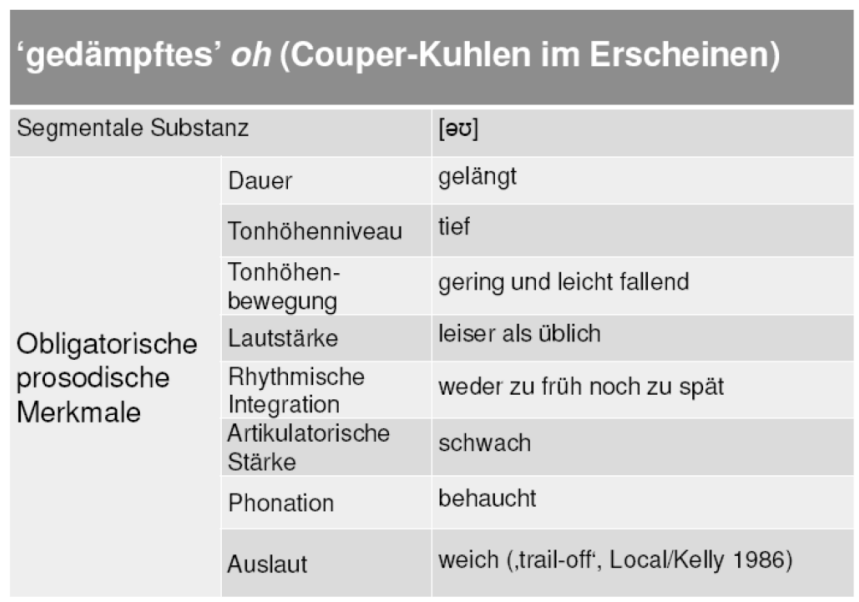

Tab. 6: ,Gedämpftes` oh (Couper-Kuhlen im Erscheinen a)

Die SEQUENZANALYSE lautet wie folgt: Leslie macht in Z. 8-11 den Vorschlag, zusammen mit ihrem Mann in einem Ort namens Hudnam zu übernachten. Nach einer langen Pause lehnt Skip dies ab, indem er darauf verweist, dass sein Kollege dort nicht übernachten wolle (Z. 14-16). Leslie nimmt die Ablehnung mit einem, gedämpften' ob auf (Z. 17). Das Laut- 
objekt erfüllt sowohl eine SEQUENZ-ORGANISATORISCHE FUNKTION als auch eine INTERAKTIONALE FUNKTION: Der Gesprächskontext (konkret: die Sequenz Angebot - Ablehnung - ob) und die prosodischphonetische Realisierung des, gedämpften ${ }^{6}$ ob lassen eine Interpretation dieses ob als Ratifizierungssignal der Ablehnung, das gleichzeitig ,Enttäuschung' anzeigt, zu.

Es wurde verdeutlicht, dass das Graphem ob in Form von verschiedenen Lautobjekten produziert werden kann. Sprecher verwenden die unterschiedlichen Lautobjekte in verschiedenen sequenziellem Kontexten, um unterschiedliche Handlungen mit unterschiedlicher affektiver Qualität zu vollziehen.

Die eben gezeigten Ausschnitte stammen aus Telefongesprächen, in denen die Teilnehmer/innen gefordert waren, allein über ihre Stimme zu kommunizieren, um Emotionen darzubieten. Untersucht man nun Videoaufnahmen von Interaktionen von Angesicht zu Angesicht, entdeckt man, dass solche Vokalisierungen kein ausschließlich lautliches Phänomen sind, sondern als Teil einer körperlichen Gestalt enaktiert werden. Deshalb lautet unsere zweite These:

\section{These 2: Lautobjekte werden als Teil einer körperlichen Gestalt pro- duziert.}

Diese These soll anhand eines Fallbeispiels erläutert werden, in dem ein schmerzerfüllter Laut in Reaktion auf die Ablehnung einer Bitte körperlich enaktiert wird.

Bei diesem Ausschnitt handelt es sich um eine Aufnahme eines Tischgesprächs in einer Kleinfamilie. Anwesend sind Mom, ihr erwachsener Sohn Wesley, seine Verlobte Prudence sowie Virginia, die jüngste Tochter im Teenageralter. Für unsere Analyse zentral ist die Sequenz, in der Virginia ihre Mutter bittet, ein gewisses Sommerkleid aus deren Boutique zu bekommen (Z. 1, 3-4). Die Mutter lehnt die Bitte ab, was von der Tochter unter anderen mit einem Schmerzenslaut (Z. 13) und einem Schnalzlaut (Z.16) aufgenommen wird.

(3) „Summer dress“ [Virginia 00:01:27-00:01:48min]

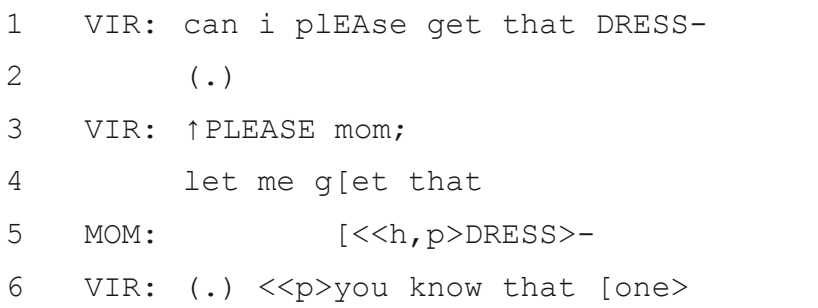




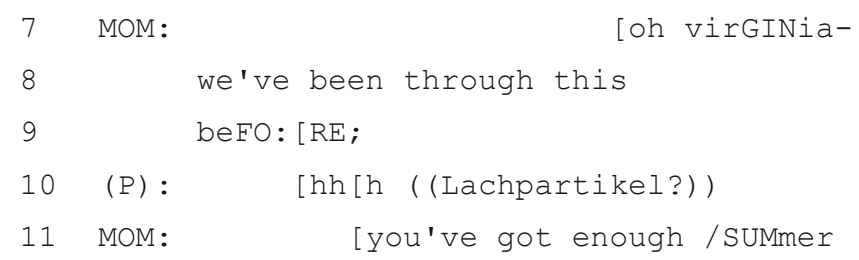

Zunächst zur formalen Analyse des Schmerzenslauts (Z. 13): Die SEGMENTALE SUBSTANZ lässt sich als aspirierter Schwa ([əh]) beschreiben. Die PROSODISCH-PHONETISCHE FORM umfasst folgende Eigenschaften: eine Längung, ein tiefes Tonhöhenniveau, eine flache und leicht fallende Kontur und eine geringe Lautstärke. Der Laut kommt verfrüht, ist von

$\overline{7} \quad$ Das phonetische Symbol stellt einen (post)alveolaren Schnalzlaut dar. 
schwacher Artikulationsstärke, ist behaucht und weich im Auslaut (,trailoff', Local/Kelly 1986). Gleichzeitig gibt die Sprecherin konkordante VISUELL-RÄUMLICHE SIGNALE: Sie wendet ihren Kopf ab und richtet den Blick nach unten.

Der alveolare Schnalzlaut (Z. 16) wird dagegen weder zu früh noch zu spät produziert und folgt auf eine visuell-räumliche Gestalt, in der die Teilnehmerin erneut ihren Kopf abwendet und die Augen niederschlägt (siehe Tabelle 7).

\begin{tabular}{|c|c|c|c|}
\hline \multicolumn{4}{|c|}{ Schmerzerfüllter Laut / Schnalzlaut } \\
\hline \multicolumn{2}{|c|}{ Segmentale Substanz } & [əh] & {$[!]$} \\
\hline \multirow{8}{*}{$\begin{array}{l}\text { Prosodische } \\
\text { Merkmale }\end{array}$} & Dauer & gelängt & - \\
\hline & Tonhöhenniveau & tief & - \\
\hline & $\begin{array}{l}\text { Tonhöhen- } \\
\text { bewegung }\end{array}$ & $\begin{array}{l}\text { gering und leicht } \\
\text { fallend }\end{array}$ & - \\
\hline & Lautstärke & leiser als üblich & - \\
\hline & $\begin{array}{l}\text { Rhythmische } \\
\text { Integration }\end{array}$ & zu früh & $\begin{array}{l}\text { weder zu früh } \\
\text { noch zu spät }\end{array}$ \\
\hline & $\begin{array}{l}\text { Artikulatorische } \\
\text { Stärke }\end{array}$ & schwach & - \\
\hline & Phonation & behaucht & - \\
\hline & Auslaut & $\begin{array}{l}\text { weich (,trail-off', } \\
\text { Local/Kelly 1986) }\end{array}$ & - \\
\hline \multicolumn{2}{|c|}{ Visuelle-räumliche Merkmale } & $\begin{array}{l}\text { Abwenden des } \\
\text { Kopfes, Blick } \\
\text { nach unten }\end{array}$ & $\begin{array}{l}\text { (Abwenden des } \\
\text { Kopfes, Blick } \\
\text { nach unten) }\end{array}$ \\
\hline
\end{tabular}

Tab. 7: Schmerzerfüllter Laut und Schnalzlaut

Unsere SEQUENZANALYSE kommt zu folgendem Ergebnis:

Die Tochter nutzt den Moment, in dem die Mutter ihr den Brotkorb reicht, geschickt aus, um sie um ein Sommerkleid aus deren Laden (Z. 1, 3-4) zu bitten. Da sich beide Teilnehmerinnen zueinander zuwenden, hat sich zu diesem Zeitpunkt der physische Abstand zwischen den beiden Interagierenden verringert. Die Mutter lehnt die Bitte auf emotionale Weise ab (Z. 7-9, 11-12). Virginia reagiert auf die Ablehnung, indem sie sich zunächst auf ihre Ausgangsposition zurückzieht und dann die physische Distanz durch das Abwenden des Kopfes noch weiter vergrößert. Das Abwenden des Kopfes wird durch ein gequältes Ausatmen begleitet. Diese lautlich-visuelle Aufnahme kann als Ratifikation der Ablehnung und gleichzeitig als Darstellung von ,Frustration“ interpretiert werden (vgl. Couper-Kuhlen im Erscheinen b). Sie verläuft simultan mit der Rede der Mutter, die ihren Turn mit einem Angebot fortsetzt (Z. 14-15).

Auch das Angebot wird erneut mit einer lautlich/visuell-räumlichen Aufnahme aufgenommen: Nach kurzen Blickkontakt zur Mutter wendet Virginia wieder den Kopf ab und vergrößert damit die physische Distanz 
zur Mutter. Darauf folgt der Schnalzlaut. Wie im ersten Fall kann das verkörperte Lautobjekt als Ratifizierung der verbalen Mitteilung der Mutter interpretiert werden. Gleichzeit signalisiert die Rezipientin eine affektive Haltung zur Mitteilung, auch diesmal ,Frustration“.

Es wurde deutlich, dass Sprecher Ablehnungen von Bitten in Gesprächen von Angesicht zu Angesicht mit stimmlich/visuell-räumlichen Darstellungen auf affektive Weise ratifizieren können. In diesen Fällen wird das Lautobjekt zum Teil einer visuell-räumlichen Gestalt, die als ganzheitliches Signal wahrgenommmen wird.

Unsere nächste These vertieft die Beobachtung noch weitergehend:

\section{These 3: Manche nicht-lexikalisierten Lautobjekte können ähnliche Funktionen wie lexikalisierte Lautobjekte (d.h. die affektgeladene Aufnahme einer Mitteilung) übernehmen. ${ }^{8}$}

Die dritte These soll anhand eines Fallbeispiels über einen Pfeiflaut (Reber 2008) erläutert werden, der als Reaktion auf eine Nachricht, in der eine Zahl genannt wird, produziert wird. Das Beispiel stammt aus einem Telefongespräch zwischen Mark und seiner Kusine Hilary. In diesem Gespräch teilt Hilary Mark mit, dass ihre Tochter und ihr zukünftiger Schwiegersohn Mike gerade dabei sind, ein gemeinsames Haus zu kaufen. Mike will dabei die Übertragung des Eigentums eigenständig erledigen, weil er damit 1800 Pfund spart. Mark nimmt diese gute Nachricht mit einem Pfeiflaut auf (Z.11).

(4) „conveyancing“ [Holt:M88:2:4]

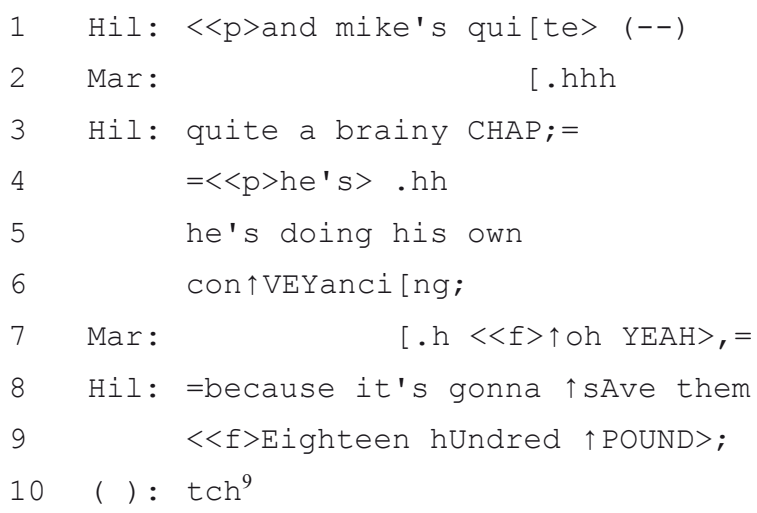

$8 \quad$ Für den Begriff der Lexikalisierung siehe Bauer (1983).

9 Dieser Laut wurde von Gail Jefferson im Originaltranskript dem Rezipienten Mark zugeordnet und als „tch“ notiert. Auf der Grundlage der vorliegenden Audioaufnahme ist der Laut als Schnalzlaut hörbar, jedoch lässt die Qualität der Aufnahme keine nähere Bestimmung des Artikulationsorts noch eine Sprecherzuordnung zu. Da der Schnalzlaut und der Pfeiflaut sehr eng aufeinanderfolgend produziert werden, erscheint es zweifelhaft, ob beide Laute von 


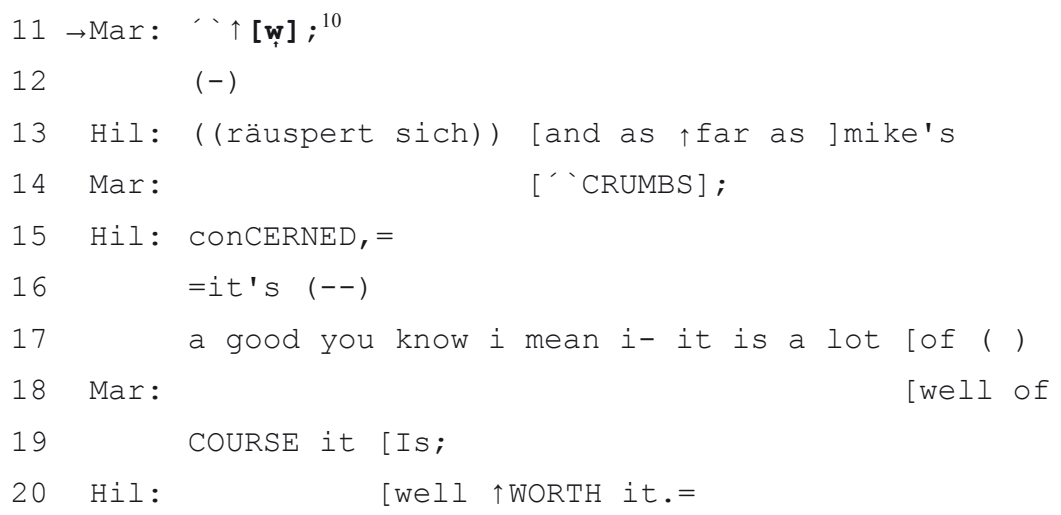

Die SEGMENTALE SUBSTANZ des Pfeiflauts ist in der Literatur als ,recreational labial whistling" (Shosted 2006, S. 2; vgl. auch Shadle 1997, S. 53) beschrieben worden. „Recreational whistling“ unterscheidet sich z.B. von gepfiffenen Frikativen mit Phonemfunktion, wie sie u.a. in einigen Südbantu-Sprachen auftreten. Es zeichnet sich durch ein sehr geringes Reibungsgeräusch aus und kann in einem Frequenzumfang von $500-4000 \mathrm{~Hz}$ auftreten (Shadle 1997, S. 53). Bzgl. der Funktionen konstatiert Shosted ebenso vage wie eindeutig: „Recreational labial whistling is the familiar whistle used to produce a melody or serve any number of paralinguistic functions" (2006, S. 2).

PROSODISCHE MERKMALE des Lautes bilden eine Längung, eine sehr hohe und hoch fallende Tonhöhenbewegung, eine sehr hohe Lautstärke, eine rythmische Integration auf den nächsten Schlag und ein weicher Auslaut (,trail-off“, Local/Kelly 1986). Auch wenn eine Videoaufnahme des Telefonats nicht vorliegt, kann bezüglich VISUELL-RÄUMLICHER MERKMALE davon ausgegangen werden, dass der Produzent beim Pfeifen die Lippen spitzt (siehe Tabelle 8).

Zur SEQUENZANALYSE: Die Nachricht, die mit dem Pfeiflaut (Z. 11) aufgenommen wird, wird als Pointe einer kleinen Erzählung über den Hauskauf dargeboten: Indem die Sprecherin die genaue Summe nennt (Z. 8-9), begründet sie, warum die Hauptfigur, Mike, die Übertragung der Eigentumsrechte selbst übernimmt (Z. 5-6). Außerdem liefert die Sprecherin Evidenz für ihre anfängliche Behauptung in Z. 1 und 3, dass ihr zukünftiger Schwiegersohn ein intelligenter Kerl ist. ${ }^{11}$

ein und demselben Produzenten stammen. Aufgrund dieser Unsicherheiten wird der Schnalzlaut nicht in die Analyse mit einbezogen.

10 Dieses phonetisches Zeichen stellt einen Pfeiflaut (,,recreational labial whistling“) dar.

11 Durch dieses Beispiel wird zudem klar, dass Lautobjekte nicht nur in der dritten Position (wie in den Beispielen 1-3), sondern auch in der zweiten Position einer Sequenz vorkommen können. 


\begin{tabular}{|c|c|c|}
\hline \multicolumn{3}{|c|}{ Pfeiflaut (Reber 2008) } \\
\hline \multicolumn{2}{|c|}{ Segmentale Substanz } & [w] \\
\hline \multirow{6}{*}{$\begin{array}{l}\text { Prosodische } \\
\text { Merkmale }\end{array}$} & Dauer & gelängt \\
\hline & Tonhöhenniveau & sehr hoch \\
\hline & $\begin{array}{l}\text { Tonhöhen- } \\
\text { bewegung }\end{array}$ & hoch fallend \\
\hline & Lautstärke & laut \\
\hline & $\begin{array}{l}\text { Rhythmische } \\
\text { Integration }\end{array}$ & $\begin{array}{l}\text { auf den nächsten } \\
\text { Schlag }\end{array}$ \\
\hline & Auslaut & $\begin{array}{l}\text { weich (,trail-off', } \\
\text { Local/Kelly 1986) }\end{array}$ \\
\hline \multicolumn{2}{|c|}{ Visuelle-räumliche Merkmale } & (gespitzte Lippen) \\
\hline
\end{tabular}

Tab. 8: Pfeiflaut (Reber 2008)

Wie lexikalisierte Vokalisierungen ist der Pfeiflaut multifunktional: Zum einen kann eine SEQUENZ-ORGANISATORISCHE FUNKTION festgestellt werden: Mit dem Pfeiflaut ratifiziert der Rezipient auf der sequenzorganisatorischen Ebene die Neuigkeit als berichtenswert.

Gleichzeitig wird eine INTERAKTIONALE FUNKTION erfüllt: Mit dem Pfeiflaut signalisiert der Sprecher auf affektive Weise seine, Anerkennung ' ,Wertschätzung', ohne die Neuigkeit eindeutig als positiv oder negativ zu bewerten. Auch die sekundäre Interjektion CRUMBS (Z. 14), mit der der Turn nach einer Pause expandiert wird, ist affektgeladen, signalisiert aber keine wertende Sprechereinstellung. ${ }^{12}$ Die Reaktion der Erzählerin liefert Evidenz für diese Interpretation: Sie produziert die fehlende positive Bewertung selbst (Z. 16-17, 20).

Zusammenfassend zeigt dieses Beispiel, dass Sprecher mit einem Pfeiflaut ebenso wie mit ob emotional auf eine Mitteilung reagieren können. Der Pfeiflaut kann eine ähnliche soziale Handlung in sprachlichen Interaktionen erfüllen wie eine lexikalisierte Vokalisierung.

Die vorgestellten Ergebnisse liefern Evidenz, dass Lautobjekte zur Steuerung sozialer Beziehungen verwendet werden, sie sowohl responsiv wirken als auch den nachfolgenden Interaktionsverlauf beeinflussen und somit interaktiv wirksam sind, ihre Form durch ein Bündel von prosodisch-phonetischen (und visuell-räumlichen) Merkmalen bestimmt wird und dass mit lexikalisierten und nichtlexikalisierten Formen vergleichbare Handlungen ausgeführt werden können.

12 Crumbs ist in dieser (britischen) Verwendung ein schwacher Ausdruck des Erstaunens, der dem amerikanischen gosh ungefähr entspricht. 
Darüber hinaus decken sich unsere Ergebnisse mit allgemeinen Ergebnissen, die in der konversationsanalytischen Literatur zu einer Reihe von Sprachen gemacht worden sind. Neben weiteren Arbeiten zum Englischen (Gardner 2001; Goodwin 1986; Local/Walker 2008; Wiggins 2002) wären Untersuchungen z.B. zum Deutschen (z.B. Golato/Betz 2008; Golato/Fagyal 2008), Finnischen (Sorjonen 2001), Französischen (Drescher 1997, 2003), Italienischen (Müller 1996) und Japanischen (Endo 2007) zu nennen.

\section{3. Über die sprachtheoretische Relevanz von Lautobjekten}

Die Befunde, über die wir hier berichtet haben, lassen sich durch Untersuchungen zu weiteren systematisch verwendeten Vokalisierungen im Gespräch ergänzen. Als Analysekriterien schlagen wir dazu ein Schema wie in Tabelle 9 vor:

\begin{tabular}{|c|c|}
\hline Lautobjekt & \\
\hline Segmentale $\varsigma$ & bstanz \\
\hline & Dauer \\
\hline & Tonhöhenniveau \\
\hline & Tonhöhenbewegung \\
\hline Prosodische & Lautstärke \\
\hline Merkmale & Rhythmische Integration \\
\hline & Artikulatorische Stärke \\
\hline & Phonation \\
\hline & Auslaut \\
\hline Visuelle-räum & he Merkmale \\
\hline Sequenzielle & atzierung \\
\hline Sequenz-orga & isationelle Funktion \\
\hline Interaktionale & unktion \\
\hline Turnexpansio & bzw. Sprecherwechsel \\
\hline
\end{tabular}

Tab. 9: Schema für die Analyse von Lautgestalten

Lautobjekte mögen klein und für einige epiphänomenal sein, aber wie anhand eines solchen Schemas sichtbar wird, hat ihre Verwendung im Gespräch eine Systematik. Und diese Systematik ist nicht unwichtig für die Sprachtheorie. In der Tat haben die Befunde zu Lautobjekten Konsequenzen für die Art und Weise, in der wir uns Sprache vorstellen, d.h. für Modelle des so genannten Sprachsystems und für seine Grundlage. Nicht zuletzt wird somit das über Jahrhunderte mühsam errichetete Gebäude der Sprachwissenschaft durch die Befunde zu Lautobjekten tangiert. Im Folgenden sollen vier Fragen bzw. Fragestellungen angesprochen werden, deren Behandlung dazu anregen kann, unsere Konzeptualisierung von Sprache und vom ,Sprachsystem`zu überdenken. 


\subsection{Welche Einheiten gehören zur Sprache?}

Bislang ist es so, dass nur voll LEXIKALISIERTE Einheiten als minimale, bedeutungstragende Teile der Sprache erachtet werden. Als Voraussetzung für die Lexikalisierung werden eine stabile Bedeutungskomponente sowie eine phonologische und eine graphische Form erachtet. Diese Bedingungen treffen (laut dem Duden Universalwörterbuch von 2007) auf die meistens der von Nübling (2004) aufgeführten prototypischen Interjektionen zu: acb!, ab!, aba!, autsch!, bäh!, brr!, bm!, bibi!, boppla!, bu!, buil, burra!, igitt!, jubu!, na!, nanu!, ob!, obo!, oje!, pab!, pfui!, pub!, tja!, uff!, ub!, ui!. Letztere wären infolgedessen regelrechte Lexeme und würden als solche zur Sprache gehören. Jedoch treffen die Lexikalisierungsbedingungen auf ib!, naja!, oi! und phb! nicht zu: diese vier prototypischen Interjektionen sind im Duden-Universalwörterbuch (2007) nicht aufgeführt. Hier wurde offenbar entschieden, dass die Bedeutung bzw. Graphie dieser Exemplare zu instabil sei. Sie wären infolgedessen keine Lexeme. Was sind sie aber dann?

Es lassen sich in der Tat weitaus mehr Vokalisierungen identifizieren als die im Wörterbuch angegebene Interjektionen - Vokalisierungen, die im Gespräch eine systematische Verwendung genießen, darunter für das Englische z.B. den Schnalzlaut (siehe auch Reber 2008; Wright 2005) und den Pfeiflaut. Letztere sind zwar nicht lexikalisiert, sie sind aber im hohen Maße konventionalisiert bzw. institutionalisiert (Bauer 1983). D.h., sie werden wiedererkannt, ihre Produktionsweise ist z.T. voraussagbar und ihr Kontextualisierungspotenzial ist situativ und kontextbezogen eingrenzbar. Darüber hinaus werden sie für ähnliche Funktionen wie die lexikalisierten Vokalisierungen verwendet. Sollten sie nicht deswegen auch zur Sprache gehören? Aus unserer Sicht sollten diese Laute nicht in die paralinguistische Ecke verbannt werden, sondern als zur Sprache gehörig betrachtet werden. Deshalb ziehen wir bewusst den Terminus „Lautobjekt" vor (Reber 2008). Solche Vokalisierungen stellen GESTALTEN dar, weil sie eine holistische Einheit von prosodisch-phonetischen Eigenschaften auf der einen Seite sowie von visuell-räumlichen Eigenschaften auf der anderen bilden. Und als solche holistische Einheiten erfahren sie eine systematische Verwendung im Gespräch.

\subsection{Was für ein System ist Sprache?}

Mit der Erweiterung der Kategorie Lexem, um Lautobjekte zu erfassen, stellt sich fast zwangsläufig die Frage nach dem Sprachsystem. In der Tat stellen die Befunde zu Lautobjekten im Gespräch die herkömmliche Auffassung der Sprache als geschlossenes System in Frage. Denn Realiät ist, dass manche Lautobjekte lexikalisiert, aber andere nur konventionalisiert sind. Und wiederum andere sind erst auf dem Weg zur Konventionalisierung 
(z.B. im Englischen das Lautobjekt /u:/; Reber 2008). Nicht ohne Grund spricht daher Pompino-Marschall bei interjektionsartigen Äußerungen von einem Kontinuum zwischen „Tierlaut“ und „sprachlicher Artikulation“ (2004). Wir sind daher der Meinung, dass man bei der Sprache allenfalls von einem offenen System sprechen kann, offen im Sinne von Hopper (1987, 1988, 1998), dass es ständig in der Emergenz begriffen ist, und zwar in einer Emergenz, die sich aus rekurrenten Verwendungen im Diskurs ergibt:

The linguist's task is $[\ldots]$ to study the whole range of repetition (,formal recurrences') in discourse, and in doing so to seek out those regularities which promise interest as incipient sub-systems. Structure [...] in this view is not an overarching set of abstract principles, but more a question of a spreading of systematicity from individual words, phrases, and small sets (Hopper 1987, S. 142).

Sowohl lexikalisierte als auch konventionalisierte und sich konventionalisierende Vokalisierungen bilden indes eins dieser ,incipient subsystems“ und verdienen es, als emergente Struktur im Sprachsystem betrachtet zu werden.

\subsection{Welche Rolle spielen prosodische sowie visuell-räumliche Modalitäten bei sprachlichen Einheiten?}

Offen ist das Sprachsystem auch in einer anderen Hinsicht. Die Betrachtung der Lautobjekte als holistische Einheiten, bestehend aus Vokalem und Visuell-räumlichem, zeigt auf, dass sprachliche Zeichen mehr als nur Segmente mit entsprechenden Graphemen sind. Im Falle von Interjektionen und Lautobjekten sind sie zunächst auch PROSODISCHE Gestalten (im Unterschied zu anderen Lexemen im Deutschen und Englischen) - in dem Sinne, dass ihre Produktionsweise (ob laut oder leise, hoch oder tief, steigend oder fallend, gespannt oder ungespannt, verspätet oder unverspätet usw.) starken Beschränkungen unterliegt: ihr prosodisches Format ist innerhalb eines gewissen Rahmens vorhersagbar. Mit anderen Worten: Die Art und Weise, wie die Vokalisierung produziert wird, ist mit einer bestimmten sequenzgebundenen Funktion verknüpft.

Diese lautliche Seite ist aber auch mit einer VISUELLEN verflochten: Z.B. ist die Mundstellung für ob anders als die für $a$ h, und erst recht anders als die für einen Pfeiflaut. Beide, Laut und Verkörperung des Lauts, sind intrinsische Bestandteile der Einheit. ${ }^{13}$ Somit dienen die visuellen (und vielleicht auch räumlichen) Aspekte von sprachlichen Einheiten nicht nur zur Unterstützung und zur Erweiterung von lautlichen Aspekten (Stivers/Sidnell 2005, S. 6); sie sind mit der verbalen Substanz verschmolzen und bilden eine einheitliche Gestalt. Eine Trennung wird auf der Wahrnehmungsebene nicht gemacht; sie kann allenfalls analytisch vorgenommen werden.

13 Die auf physiologische Konstitutionsbedingungen zurückzuführenden visuellen Aspekte eines Lautobjekts sind allerdings nicht mit eher kontingenten Begleiterscheinungen wie, gehobene Augenbrauen' oder, weit geöffnete Augen' gleichzusetzen. 


\subsection{Wie sollen wir Sprache untersuchen/modellieren?}

Es folgt daraus, dass sprachliche Untersuchungen zunächst ganzheitlich zu erfolgen haben: Wie Goodwin sagen würde, auf dem Hintergrund eines „reichen multimodalen Kontextes“ (Goodwin 2002). Fokussierungen auf Verbales, Prosodisches, Gestisches bzw. Räumliches sind selbstverständlich aus analytischen Gründen zulässig, müssen aber immer wieder ins Verhältnis zum Gesamten gesetzt werden. Für Lautobjekte speziell, aber auch für andere sprachlichen Konstrukte - allesamt im hohen Grade indexikalisch ist es unabdingbar, sie im situierten Kontext ihrer Verwendung zu untersuchen. Für das Gespräch heisst das, dass Lautobjekte und andere sprachliche Konstrukte im sequenziellen und interaktiven Zusammenhang zu verorten und zu analysieren sind. Denn nur so ist es möglich, ihre Indexikalität zu fassen. Verallgemeinerungen, z.B. für das Lexikon oder für das Inventar an Konstruktionen, haben dieser Kontextbezogenheit Rechnung zu tragen.

Interjektionen und erst recht Lautobjekte sind bisher von der Sprachwissenschaft aufgrund ihrer vermeintlich fehlenden Integration ins Sprachsystem eher stiefmütterlich behandelt worden. Mit der vorgelegten Auswahl an Fallstudien sollte verdeutlicht werden, dass dies zu Unrecht geschehen ist: Wenn man Lautobjekte auf der Gesprächsebene betrachtet, sind sie in ihrer ganzen Lautlichkeit und Körperlichkeit sehr wohl integriert und zwar in eine Grammatik des Redens im Gespräch. ${ }^{14}$ An bestimmten Stellen im Gespräch dürfen solche Lautobjekte nicht fehlen. Somit kann für ein- und allemal mit ihrem Status als „Dazwischengeworfenes“ abgerechnet werden. Sie sind nicht dazwischengeworfen, sondern in ihrer sequenziellen Gesprächsumgebung im hohem Masse systematisch und funktional.

\section{Literatur}

Ameka, Felix (1992): The meaning of phatic and conative interjections. In: Journal of Pragmatics 18, 2/3, S. 245-271.

Auer, Peter/Couper-Kuhlen, Elizabeth/Müller, Frank (1999): Language in time: The rhythm and tempo of spoken interaction. New York.

Auer, Peter/di Luzio, Aldo (Hg.) (1992): The contextualization of language. Amsterdam.

Bauer, Laurie (1983): English word-formation. Cambridge.

Betz, Emma/Golato, Andrea (2008): Remembering relevant information and withholding relevant next actions: The German token achja. In: Research on Language and Social Interaction 41, 1, S. 55-98.

Bühler, Karl (1982): Sprachtheorie. Ungekürzter Neudruck der Ausgabe Jena 1934. Stuttgart/New York.

14 D.h., sie sind in Bezug auf Handlungssequenzen funktional zu beschreiben. 
Couper-Kuhlen, Elizabeth (im Erscheinen a): A sequential approach to affect: The case of ,disappointment‘. In: Haakana, Markku/Laakso, Minna/Lindström, Jan (Hg.): Talk in interaction - comparative dimensions. (= Studia Fennica Linguistica 14). Helsinki.

Couper-Kuhlen, Elizabeth (im Erscheinen b): On preference in responses to rejection. In: Kärkkäinen, Elise/Du Bois, John W. (Hg.): Stance and affect in interaction: Sequential and dialogic perspectives. (Text and Talk Sonderheft).

Couper-Kuhlen, Elizabeth/Ford, Cecilia E. (Hg.) (2004): Sound patterns in interaction. Cross-linguistic studies from conversation. Amsterdam.

Couper-Kuhlen, Elizabeth/Selting, Margret (Hg.) (1996): Prosody in conversation: Interactional studies. Cambridge.

Cruse, David A./Hundsnurscher, Franz/Job, Michael/Lutzeier, Peter Rolf (Hg.) (2002): Lexikologie: Ein Internationales Handbuch zur Natur und Struktur von Wörtern und Wortschätzen. (= Handbücher zur Sprach- und Kommunikationswissenschaft 21.1). Berlin/New York.

Drescher, Martina (1997): Emotions in discourse. French interjections and their use in discourse. In: Niemeier, Susanna/Dirven, René (Hg.): The language of emotions. Conceptualization, expression, and theoretical foundation. Amsterdam, S. 233-246.

Drescher, Martina (2003): Sprachliche Affektivität. Darstellung emotionaler Beteiligung am Beispiel von Gesprächen aus dem Französischen. (= Linguistische Arbeiten 468). Tübingen.

Duden (2005): Duden. Bd. 4: Die Grammatik. 7., völlig neu erarb. und erw. Aufl. Hrsg. v.d. Dudenredaktion. Mannheim/Leipzig/Wien/Zürich.

Duden (2007): Universalwörterbuch. 6., überarb. u. erw. Aufl. Mannheim/Leipzig/ Wien/Zürich. [Online-Version Langenscheidt Berlin].

Ehlich, Konrad (1986): Interjektionen. (= Linguistische Arbeiten 111). Tübingen.

Endo, T. (2007): Sharedness in comprehension and alignment: A::: in Japanese conversation. Unveröff. Qualifizierungsarbeit. Asian Languages and Cultures, UCLA.

Fries, Norbert (2002): Die Wortart ,Interjektionen‘. In: Cruse/Hundsnurscher/Job/ Lutzeier (Hg.), S. 654-657.

Gardner, Rod (2002): When listeners talk: Response tokens and listener stance. Amsterdam.

Goffman, Erving (1963): Behavior in public places. New York.

Goffman, Erving (1978): Response cries. In: Language 54, S. 787-815.

Golato, Andrea/Betz, Emma (2008): German ach and achso in repair uptake: resources to sustain or remove epistemic asymmetry. In: Zeitschrift für Sprachwissenschaft 27, 1, S. 7-37.

Golato, Andrea/Fagyal, Zsuzsanna (2008): Comparing single and double sayings of the German response token $j a$ and the role of prosody - a conversation analytic perspective. In: Research on Language and Social Interaction 41, 3, S. 1-30. 
Goodwin, Charles (1986): Between and within: alternative treatments of continuers and assessments. In: Human Studies 9, S. 205-217.

Goodwin, Charles (2002): Time in action. In: Current Anthropology 43, S. 19-35.

Gumperz, John Joseph (1982): Discourse strategies. Cambridge.

Heritage, John (1984a): A change-of-state-token and aspects of its sequential placement. In: Atkinson, John Maxwell/Heritage, John (Hg.): Structures of social action. Studies in conversation Analysis. Cambridge u.a., S. 299-345.

Heritage, John (1984b): Garfinkel and ethnomethodology. Cambridge.

Hopper, Paul (1987): Emergent grammar. General session and parasession on grammar and cognition. In: Berkeley Linguistic Society 13, S. 139-157.

Hopper, Paul (1988): Emergent grammar and the a priori grammar postulate. In: Tannen, D. (Hg.): Linguistics in context: Connecting observation and understanding. Norwood, S. 117-134.

Hopper, Paul (1998): Emergent grammar. In: Tomasello, Michael (Hg.): The new psychology of language: Cognitive and functional approaches to language structure. Mahwah, S. 155-175.

Kehrein, Roland/Rabanus, Stefan (2001): Ein Modell zur funktionalen Beschreibung von Diskurspartikeln. In: Germanistische Linguistik 157-158, S. 33-50.

Kessler, Florence (2008): Instant Messaging. Eine neue interpersonale Kommunikationsform. In: Net.worx 52, S. 1-72. [www.mediensprache.net/networx/networx-52.pdf (Stand: Oktober 2009)]

Kowal, Sabine/O'Connell, Daniel C. (Hg.) (2004): Zeitschrift für Semiotik 26, 1 /2 [Sonderband zu Interjektionen].

Linell, Per (2005): The written language bias in linguistics: Its nature, origins and transformations. London/New York.

Local, John (1996): Conversational phonetics: Some aspects of news receipts in everyday talk. In: Couper-Kuhlen/Selting (Hg.), S. 175-230.

Local, John/Kelly, John (1986): Projection and ,silences': Notes on phonetic and conversational structure. In: Human Studies 9, S. 185-204.

Local, John/Walker, Gareth (2008): Stance and affect in conversation: On the interplay of sequential and phonetic resources. In: Text \& Talk 28, 7, S. 723-747.

Müller, Frank E. (1996): Affiliating and disaffiliating with continuers: prosodic aspects of recipiency. In: Couper-Kuhlen/Selting (Hg.), S. 131-176.

Nübling, Damaris (2001): Von ob mein Jesus! zu oje! Der Interjektionalisierungspfad von der sekundären zur primären Interjektion. In: Deutsche Sprache 1, 1, S. $20-45$.

Nübling, Damaris (2004): Die prototypische Interjektion: Ein Definitionsvorschlag. In: Zeitschrift für Semiotik 26, $1 / 2$ [Sonderband zu Interjektionen], S. 11-45.

Pompino-Marschall, Bernd (2004): Zwischen Tierlaut und sprachlicher Artikulation: Zur Phonetik der Interjektionen. In: Zeitschrift für Semiotik 26, 1/2 [Sonderband zu Interjektionen], S. 71-84. 
Reber, Elisabeth (2008): Affectivity in talk-in-interaction: Sound objects in English. Unveröff. Diss. Univ. Potsdam.

Reber, Elisaebth (2009): Zur Affektivität in englischen Alltagsgesprächen. In: Buss, Mareike/Habscheid, Stephan/Jautz, Sabine/Liedtke, Frank/Schneider, Jan (Hg.): Theatralität des sprachlichen Handelns. Eine Metaphorik zwischen Linguistik und Kulturwissenschaften. München, S. 193-215.

Reisigl, Martin (1999): Sekundäre Interjektionen: eine diskursanalytische Annäherung. (= Arbeiten zur Sprachanalyse 33). Frankfurt a.M.

Schegloff, Emanuel A. (1998): Reflections on studying prosody in talk-in-interaction. In: Language and Speech, 41, 3/4, S. 235-263.

Schmidt, Jürgen Erich (2001): Bausteine der Intonation? In: Germanistische Linguistik 157-158, S. 9-32.

Schwitalla, Johannes (2006): Gesprochenes Deutsch. Eine Einführung. 3., neu bearb. Aufl. (= Grundlagen der Germanistik 33). Berlin.

Selting, Margret (1996): Prosody as an activity-type distinctive signalling cue in conversation. The case of so-called , astonished questions' in repair-initiation. In: CouperKuhlen/Selting (Hg.), S. 231-270.

Selting, Margret/Couper-Kuhlen, Elizabeth (2000): Argumente für die Entwicklung einer, interaktionalen Linguistik'. In: Gesprächsforschung - Online-Zeitschrift zur verbalen Interaktion (OZS) 1, S. 76-95. [www.gespraechsforschung-ozs.de/heft2000/ ga-selting.pdf (Stand: Oktober 2009)].

Selting, Margret/Couper-Kuhlen, Elizabeth (Hg.) (2001): Studies in interactional linguistics. Amsterdam.

Shadle, Christine (1997): The aerodynamics of speech. In: Hardcastle, William J./Laver, John (Hg.): The handbook of phonetic sciences. Oxford, UK/Cambridge, MA, S. 33-64.

Shosted, Ryan K. (2006): Just put your lips together and blow? The whistled fricatives of Southern Bantu. [http://linguistics.berkeley.edu/phonlab/annual_report/documents/ 2006/whistleISSP.pdf (Stand: Oktober 2009)].

Sorjonen, Marja-Leena (2001): Responding in conversation. A study of response particles in Finnish. Amsterdam/Philadelphia.

Sornig, Karl (2002): Lexikalische Einheiten mit wortähnlichem Status. In: Cruse/Hundsnurscher/Job/Lutzeier (Hg.), S. 461-465.

Stivers, Tanya/Sidnell, Jack (2005): Introduction: Multimodal Interaction. In: Semiotica 156, S. 1-20.

Ward, Nigel (2006): Non-lexical conversational sounds in American English. In: Pragmatics \& Cognition 14, 1, S. 129-182.

Weinrich, Harald (2005): Textgrammatik der deutschen Sprache. 3., rev. Aufl. Hildesheim.

Wharton; Tim (2003): Interjections, language and the ,showing-saying' continuum. In: Pragmatics \& Cognition 11, S. 39-91. 
Wiggins, Sally (2002): Talking with your mouth full. Gustatory Mmms and the embodiment of pleasure. In: Journal of Language and Social Interaction 35, 3, S. 311-36.

Wilkins, David P. (1992): Interjections as deictics. In: Journal of Pragmatics 18, S. 119 158.

Wilkinson, Sue/Kitzinger, Celia (2006): Surprise as an interactional achievement: Reaction tokens in conversation. In: Social Psychology Quarterly 69, 2, S. 150-182.

Wright, Melissa (2005): Studies of the Phonetics-Interaction Interface: Clicks and interactional structures in English conversation. Unveröff. Diss. Univ. York.

Wundt, Wilhelm (1907): Schallnachahmungen und Lautmetaphern in der Sprache. In: Allgemeine Zeitung (Beilage 40), S. 313-316.

\section{Transkriptionskonventionen in Anlehnung an GAT (Selting et al. 1998)}

\section{Sequenzielle Struktur/Verlaufsstruktur}

[ ]

[ ]

$=$

\section{Pausen}

(.)

Mikropause

$(-),(--),(---)$

(2.85) heiten
Überlappungen und Simultansprechen

schneller, unmittelbarer Anschluß neuer Turns oder Ein-

\section{Sonstige segmentale Konventionen}

and $=$ uh

Verschleifungen innerhalb von Einheiten

$:,::,:::$ :

Dehnung, Längung, je nach Dauer

eh, uh, etc.

Verzögerungssignale, sog. ,gefüllte Pausen“

Abbruch einer Einheit

Lachen

so $(h) \circ$

Lachpartikeln beim Reden

Akzentuierung

akZENT

Primär- bzw. Hauptakzent

akzEnt

Sekundär- bzw. Nebenakzent

ak! ZENT!

\section{Tonhöhenbewegung am Einheitenende}

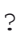

?
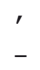

; hoch steigend

mittel steigend

gleichbleibend

mittel fallend

tief fallend 


\section{Auffällige Tonhöhensprünge \\ $\uparrow \quad$ nach oben \\ $\downarrow \quad$ nach unten}

\section{Verändertes Tonhöhenregister}

$\begin{array}{ll}<<\mathrm{t}>> & \text { tiefes Tonhöhenregister } \\ <<\mathrm{h}>> & \text { hohes Tonhöhenregister } \\ <<\mathrm{hh}>> & \text { sehr hohes Tonhöhenregister } \\ <<\text { falsetto }>> & \text { Kopfstimme }\end{array}$

\section{Akzenttonhöhenbewegungen}

$\begin{array}{ll}\text { `so } & \text { fallend } \\ \text { 'so } & \text { steigend } \\ \text { ‘so } & \text { steigend-fallend }\end{array}$

Lautstärke- und Sprechgeschwindigkeitsveränderungen

$$
\begin{array}{ll}
<<\mathrm{f}>> & =\text { forte, laut } \\
<<\mathrm{ff}>> & =\text { fortissimo, sehr laut } \\
<<\mathrm{p}>> & =\text { piano, leise } \\
<<\mathrm{pp}>> & =\text { pianissimo, sehr leise } \\
<<\text { len }>> & =\text { lento, langsam }
\end{array}
$$

\section{Ein- und Ausatmen}

$\begin{array}{ll}. h, . h h, . h h h & \text { Einatmen, je nach Dauer } \\ h, h h, \text { hhh } & \text { Ausatmen, je nach Dauer }\end{array}$

\section{Sonstige Konventionen}

$\begin{array}{ll}\text { ( (hustet) } & \begin{array}{l}\text { para- und außersprachliche Handlungen und Ereignisse, in- } \\ \text { terpretierender Transkribentenkommentar } \\ \text { sprachbegleitende para- und außersprachliche Handlungen } \\ \text { und Ereignisse mit Reichweite }\end{array} \\ \text { ( ) } & \text { unverständliche Passage je nach Länge } \\ \text { ( solche) } & \text { vermuteter Wortlaut } \\ \text { (H) ose } & \text { vermuteter Laut } \\ \rightarrow & \text { Verweis auf im Text behandelte Transkriptzeile } \\ / & \text { Beginn gleichzeitig ablaufender visueller Handlungen }\end{array}$


Jürgen Spitzmüller

\title{
Typografische Variation und (Inter-)Medialität Zur kommunikativen Relevanz skripturaler Sichtbarkeit
}

\begin{abstract}
Nachdem sich verschiedene linguistische Teildisziplinen in den vergangenen Jahren der Medialität, Materialität und ,Multimodalität ${ }^{\dagger}$ von Kommunikation zugewandt haben, hat zuletzt auch die typografische Gestaltung von Texten als spezifischer Aspekt dieses Komplexes verstärkte Aufmerksamkeit im Fach gefunden. Das Thema wurde, mit entsprechend unterschiedlichen Erkenntnisinteressen, in mehreren Fachbereichen (z.B. in der Text- und Graphostilistik, der Sozialsemiotik, der Werbesprachforschung, der Schriftlinguistik, der Verständlichkeitsforschung, der Metalexikographie und der Historischen Linguistik) aufgegriffen, darüber hinaus wird es mittlerweile auch in Nachbardisziplinen wie der Literatur- und Editionswissenschaft verstärkt diskutiert. Dabei wurde gezeigt, dass paraskripturale Phänomene in mehrfacher Hinsicht (etwa als Aufmerksamkeits- und Lesesteuerungssignal, als Emblem oder als Kontextualisierungshinweis) kommunikativ relevant werden können.

Der Beitrag gibt erstens einen Einblick in dieses heterogene Feld linguistischer Forschung und versucht, die kommunikative Relevanz skripturaler Sichtbarkeit und damit auch die Relevanz des Gegenstandsbereichs für das Fach zu begründen. Zweitens diskutiert er mit Blick auf das Rahmenthema des vorliegenden Bandes die Frage, inwiefern sich (Inter-)Medialität und Visualität gegenseitig bedingen. Dabei soll weniger die kaum zu bestreitende These im Mittelpunkt stehen, dass sich die Medialität des Kommunikats in deren visueller Gestaltung niederschlägt (bzw. den Gestaltungsrahmen vorgibt), sondern es soll umgekehrt vor allem danach gefragt werden, ob und inwiefern Medialität durch (typo-)grafische Variation mitkonstruiert wird, inwiefern die Medialität also selbst das Produkt sozial verankerter kommunikativer Praktiken wie der Textgestaltung ist.
\end{abstract}

\section{The Crystal Goblet}

Imagine that you have before you a flagon of wine. You may choose your own favourite vintage for this imaginary demonstration, so that it be a deep shimmering crimson in colour. You have two goblets before you. One is of solid gold, wrought in the most exquisite patterns. The other is of crystal-clear glass, thin as a bubble, and as transparent. Pour and drink; and according to your choice of goblet, I shall know whether or not you are a connoisseur of wine.

Mit diesem reizvollen Gedankenspiel beginnt Beatrice Warde am 7. Oktober 1930 einen Vortrag vor der British Typographers' Guild in London, einen Vortrag mit dem Titel The Crystal Goblet (,Der Kristallbecher), der in der zwei Jahre später publizierten Form zu einem Klassiker der metatypografischen Literatur wurde (Warde [1932] 1991, Zitat: S. 109). 
Ein Grund dafür ist wohl auch die Allegorie, mit der Warde ihren Vortrag beginnt. Diese Allegorie ist deshalb geschickt gewählt, weil Wein im kulturellen Umfeld, in dem sich der Vortrag positioniert, nicht irgendein Nahrungsmittel ist, sondern, wie Michael Silverstein es ausgedrückt hat, „a perduringly constant prestige comestible“ (Silverstein 2003, S. 222): „its consumption is the culminating moment of cooperative performance art, to be sure, in which ,educated connoisseurship' can be manifested while doing away with the artifact of perceptual encounter" (Silverstein 2003, S. 222). Die soziale (und nicht zuletzt natürlich auch religiös präformierte) Praktik des Weintrinkens, die den Rahmen für Wardes weitere Ausführungen bildet, ist ein für die „elite identity“ (Silverstein 2003, S. 227) innerhalb der westlichen Kultur konstitutiver Vorgang. Die dabei vollzogenen rituellen Handlungen - die Wahl des Weins und des Bechers, das Einschenken, das Anstoßen, das Reden über Weine usw. - sind, wie Silverstein betont, „the paraphernalia of the correctly-indexical ,life style' (identity-byvisible-consumption)“" (Silverstein 2003, S. 227). Kurzum: Das Nippen am Weinglas ist zwar auch Flüssigkeitsaufnahme, in allererster Linie aber ist es „the mastery of which distinguishes professional and serious avocational tasters from all others" (Silverstein 2003, S. 223).

Vor diesem Hintergrund ist die Entscheidung, vor die Warde ihr Auditorium stellt, sozial hochgradig brisant. Und entsprechend einschneidend ist das Urteil, das die New Yorker Journalistin und Typografin über die Becherwahl fällt:

For if you have no feelings about wine one way or the other, you will want the sensation of drinking the stuff out of a vessel that may have cost thousands of pounds; but if you are a member of that vanishing tribe, the amateurs of fine vintages, you will choose the crystal, because everything about it is calculated to reveal rather than hide the beautiful thing which it was meant to contain. (Warde [1932] 1991, S. 109)

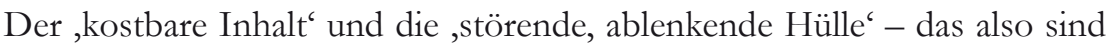
Wardes zentrale Bewertungskriterien. Aber natürlich geht es ihr nicht primär um Wein. Das Thema ihres Vortrags sind Texte und ihre Gestalt, darüber hinaus aber auch schriftliche und mündliche Kommunikation in einem umfassenden Sinn. Für diese jedoch, für die Textgestalt und für Kommunikation allgemein, haben Warde zufolge die genannten Kriterien ebenfalls zu gelten. Auch deren ,Inhalt', die ,Gedanken', ,Ideen' und ,Bilder', könne nur dann ,rein erstrahlen', wenn die ,Hülle ${ }^{6}$ weitestgehend verschwinde. Der Kristallbecher, die ,durchsichtige Form', wird somit zum ,heiligen Gral' der Kommunikation erhoben, deren einziges Ziel für Warde die ,Übermittlung' eben der ,Gedanken', ,Ideen' und ,Bilder' von einem Sender zu einem Empfänger ist: 
Talking, broadcasting, writing, and printing are all quite literally forms of thought transference, and it is the ability and eagerness to transfer and receive the contents of the mind that is almost alone responsible for human civilization. If you agree with this, you will agree with my one main idea, i.e. that the most important thing about printing is that it conveys thought, ideas, images, from one mind to other minds. This statement is what you might call the front door of the science of typography. (Warde [1932] 1991, S. 110)

Es ist sicher kein Zufall, dass dieser Text in den 1930er-Jahren entstanden ist, in einer Zeit, in der Kommunikation auch anderweitig mit der ,Übertragung' von Nachrichten gleichgesetzt wird. Man denke beispielsweise an Claude Shannons Kommunikationsmodell, welches im selben Jahrzehnt entwickelt wurde (vgl. Shannon 1948). Auf diese wissenschaftsgeschichtlichen Zusammenhänge kann an dieser Stelle nicht weiter eingegangen werden. Was allerdings für das Thema dieses Beitrags wichtig ist, ist die Vorstellung, die sich mit solchen Konzepten verbindet, die Vorstellung, dass das Medium und die Form reine ,Vehikel' sind und zu ,Störquellen' werden, sobald die Vehikelfunktion überschritten wird: ${ }^{1}$

A public speaker is more ,audible' in that sense when he bellows. But a good speaking voice is one which is inaudible as a voice. It is the transparent goblet again! I need not warn you that if you begin listening to the inflections and speaking rhythms of a voice from a platform, you are falling asleep. (Warde [1932] 1991, S. 111)

Und so wie die Stimme ,unhörbar ${ }^{6}$ zu sein hat, hat die Schrift ,unsichtbar ${ }^{6}$ zu werden:

Type well used is invisible as type, just as the perfect talking voice is the unnoticed vehicle for the transmission of words, ideas. [...] The book typographer has the job of erecting a window between the reader inside the room and that landscape which is the author's words. (Warde [1932] 1991, S. 111/113)

Nicht zufällig ergänzt Warde hier die Metapher des Kristallbechers um die der Fensterscheibe, die einen möglichst ungetrübten Blick des Lesers auf den ,Inhalt' des Textes gewähren soll. Sie schließt damit an eine alte und im metastilistischen Diskurs weit verbreitete Metaphorik an, die Joseph Gusfield (1976, S. 16) treffend als ,window pane theory“ bezeichnet hat. Wie Heinz L. Kretzenbacher in einem einschlägigen Aufsatz zur ,Durchsichtigkeit' der Wissenschaftssprache verdeutlicht, ist es das Ziel dieser letztlich auf das Perspicuitas-Ideal der antiken Rhetorik zurückgehenden Metaphorik, „den medialen Eigencharakter der Sprache so weit wie möglich zurückzudrängen“ (Kretzenbacher 1995, S. 18).

Die Metatypographie ist dem Warde'schen Imperativ - Printing should be invisible! - zunächst mehrheitlich gefolgt. Insbesondere in der ersten Hälfte des 20. Jahrhunderts weisen viele einflussreiche Typografen immer wieder und mit großem Nachdruck auf diesen Imperativ hin - was wiederum kein

Eine Vorstellung, die seit Reddy (1995) bekanntlich als ,Rohrpostmetapher' (conduit metaphor) kritisiert wird. 
Zufall ist, sondern auch als Gegenbewegung zum typografischen Manierismus des 19. Jahrhunderts und zur aufkommenden Werbetypografie (vgl. Twyman 1993; Friedl/Ott/Stein 1998 (Hg.), S. 60-61) zu verstehen ist.

Stanley Morison etwa, der berühmte englische Typograf und Schöpfer der Times New Roman, schreibt in einem Text, der ursprünglich ein Artikel zum Lemma Typography in der Encyclopadia Britannica war (vgl. Morison 1929; im Folgenden zitiert aus einer späteren, ausgearbeiteten Fassung):

Typography is the efficient means to an essentially utilitarian and only accidentally aesthetic end, for enjoyment of patterns is rarely the reader's chief aim. Therefore, any disposition of printing material which, whatever the intention, has the effect of coming between author and reader is wrong. It follows that in the printing of books meant to be read there is little room for ,bright' typography. Even dullness and monotony in the typesetting are far less vicious to a reader than typographical eccentricity or pleasantry. (Morison 1930, S. 61; Herv. J.S.)

Und Jan Tschichold, der wohl einflussreichste Typograf im deutschsprachigen Raum, stellt fest:

Gute Typographie ist, wie ein idealer Diener gewesen sein mag: da und doch nicht bemerkbar; unauffällig, aber eine Voraussetzung des Wohlbefindens; lautlos, geschmeidig. (Tschichold 2001, S. 16)

Vor allem ab der zweiten Hälfte des 20. Jahrhunderts mehren sich jedoch die Gegenstimmen. Die folgende Auswahl illustriert dies. So schreiben etwa Albert Kapr und Walter Schiller:

Schon wiederholt wurde darauf hingewiesen, daß die erste und eigentliche Aufgabe darin besteht, einen vorgegebenen Text lesbar und faßlich wiederzugeben. Aber selbst wenn sich die Typographie auf diese Aufgabe beschränkt, wird das visuelle Bild einen bestimmten emotionellen Eindruck machen. Das Druckerzeugnis kann nüchtern, sachlich, harmonisch oder unsicher, unentschieden, disharmonisch wirken, auch wenn der Gestalter überhaupt nicht an eine solche Wirkung dachte. Jede Sinnesempfindung, jede sinnliche Wahrnehmung ruft Gefühle hervor, auch wenn diese nicht immer vordergründig wirksam werden. Es ist also gar nicht möglich, die Typographie lediglich auf ein Lesbarmachen des Textes zu reduzieren. Das Lesen hat immer einen zweifachen Aspekt, einen kognitiven und einen affektemotionalen. (Kapr/Schiller 1977, S. 20)

Ganz ähnlich betont der Schriftdesigner Erik Spiekermann:

Selbst wenn man eine „neutrale“ Schrift wählt, hat man damit eine Wahl getroffen, die dem Leser sagt, dass diese Mitteilung „,neutral“ ist. Oder sein will.

Jede Gestaltung fügt eine Interpretation hinzu. [...] Allein die Wahl der Schrift kann den Inhalt eines Wortes manipulieren. (Spiekermann 2004, S. 103)

Auch Hans-Peter Willberg und Friedrich Forssman schreiben in ihrem einschlägigen Handbuch Lesetypographie:

Schrift nimmt Bequg zum Inhalt, jede Schriftwahl ist Interpretation, ,neutrale‘ Schriften kann es nicht geben. (Willberg/Forssman [1997] 2005, S. 72; Herv. i. Orig. fett) 
Und in expliziter Opposition zu Beatrice Warde postuliert der niederländische Typograf Gerard Unger:

Invisible typefaces do not exist. (Unger [1992] 2003, S. 110)

Ähnliche Aussagen finden sich in der neueren metatypografischen Literatur in großer Zahl. Das ist eine bemerkenswerte Entwicklung, denn was hier zum Teil ganz grundsätzlich in Frage gestellt wird, ist nichts weniger als das „Leitprinzip typographischer Gestaltungsarbeit“ seit Beginn des 19. Jahrhunderts (vgl. König 2004, Zitat: S. 43). Die Entstehung dieses Leitprinzips ist auch diskurstheoretisch hochinteressant, denn das Prinzip ist in vielfacher Weise mit dem allgemeinen geistesgeschichtlichen Diskurs verflochten.

Sehr schön herausgearbeitet hat diese Zusammenhänge Friedrich Kittler, der darauf hingewiesen hat, dass „,[i]m Aufschreibesystem um 1800“, im Zusammenhang mit der Entstehung einer ,neuen Innerlichkeit‘, „Sprache überhaupt bloßer Kanal“" wird (Kittler [1985] 2003, S. 140), ein Kanal nämlich zur möglichst störungsfreien, Übermittlung` der seelischen Empfindungen des romantischen Dichters an die empfindsamen Seelen seiner Leser, die Kittler zufolge vor allem bürgerliche Leserinnen waren. „Mit dem reinen stimmlichen Signifikat, vor dem alle Signifikanten zu Übersetzungen herabsinken“, also un-vermittelt, und das heißt auch, „ohne sie mit Schrifttypen zu behelligen“, „spricht der Dichter ihre Seelen an“ (Kittler [1985] 2003, S. 125). Nicht zufällig, so Kittler weiter, haben die Schriftschneider in Italien Giambattista Bodoni (1818), in Deutschland Johann Friedrich Unger (1793 [1971]) - just in dieser Zeit damit angefangen, „Buchstaben [...] auf mühelosen Konsum [zu] berechne[n]“ (Kittler [1985] 2003, S. 150), also die Tauglichkeit ihrer Schriftentwürfe mithilfe von Lesbarkeitsexperimenten zu prüfen (vgl. dazu auch König 2004, S. 43-45). Denn es sei, wie Kittler an anderer Stelle festhält,

für zaghafte Bürgermädchen [...] alles darauf an[gekommen], vor der Materialität von Druckbuchstaben buchstäblich zu ,erblinden'. Sonst hätten sie ihnen im Imaginären (oder gar am Pianoforte) keine Melodie aus dem eigenen Herzen unterlegen können. (Kittler 1986, S. 110)

Skripturale ,Unsichtbarkeit` wäre demzufolge also keine kommunikative Notwendigkeit, sondern vielmehr ein wirkmächtiges diskursives Konstrukt - ein Konstrukt, dessen Auflösung wir gerade erleben, wie die soeben zitierten Aussagen belegen. ${ }^{2}$ Gleichwohl ist zu konstatieren, dass der Unsichtbarkeitstopos seine Wirkmächtigkeit noch nicht verloren hat - sonst müssten die Typografen nicht so vehement dagegen anschreiben.

2 Belege dafür finden sich auch in Texten außerhalb der Gestaltungstheorie (vgl. etwa den inspirierenden Essay von Barthes [1973] 2006 sowie grundsätzlich wiederum Kittler [1985] 2003). Darauf kann an dieser Stelle nicht näher eingegangen werden. 
Wenn wir allerdings die vielbeklagte „Medienindifferenz“ (Bittner 2003, S. 53) bzw. „Medialitätsvergessenheit“ (Jäger 2000, S. 26) als diskursives Produkt ansehen, so müssen wir auch dessen Gegenkonzept, die „Materialität der Kommunikation“ (Gumbrecht/Pfeiffer (Hg.) [1988] 1995) und die skripturale ,Sichtbarkeit', als (freilich ebenfalls faktisch wirksames) diskursives Konstrukt betrachten, was übrigens Kittler ([1985] 2003) auch tut. Auf diesen Punkt wird zurückzukommen sein.

Zunächst jedoch soll der Frage nachgegangen werden, welche Relevanz die soeben beschriebenen Konzeptionen von Schriftlichkeit und Visualität für die Linguistik haben. Ich meine, mehrfache. Zum einen wäre, wenn ,Sichtbarkeit‘ und ,Materialität' von Schrift tatsächlich in der gegenwärtigen Wahrnehmung derart an Bedeutung gewonnen hätten, wie es die Zitate nahelegen, Typografie ein Gegenstand der Linguistik, da ihr kommunikative Relevanz zukäme, womit sie bei der Analyse schriftsprachlicher Kommunikation berücksichtigt werden müsste. Dass dies so ist, dafür wird der Beitrag im weiteren Verlauf sprachwissenschaftliche Argumente beisteuern, wobei auch der Gegentopos, dass Typografie ,immer Interpretation hinzufügt, kritisch geprüft werden soll. Zweitens jedoch horcht man als Linguistin und Linguist angesichts dieser Diskussion und der darin vertretenen Konzepte unmittelbar auf. Denn den Wandel, der sich hier in der Wahrnehmung des Gegenstandes vollzogen hat, kennen Sprachwissenschaftler nur allzu gut. Die Disziplin hat, was etwa die Beurteilung der Relevanz parasprachlicher, performativer und medialer Phänomene sowie die Multifunktionalität von Sprache und die Multireferenzialität von Zeichen angeht, eine ähnliche Entwicklung durchgemacht. Der vorliegende Band und die ihm vorausgegangene Jahrestagung zeigen sehr deutlich, wie sehr sich das Fach mittlerweile von Fensterscheibentheorien und Rohrpostmetaphern distanziert hat.

Allein, was die Visualität von Schrift betrifft, hinkt die Linguistik nicht nur dem metatypografischen Diskurs, sondern in gewisser Weise auch ihrem eigenen Standard immer noch hinterher. Diese wurde auch lange Zeit, nachdem non- und parasprachliche Phänomene etwa in der Gesprächslinguistik längst als konstitutiv erkannt und beschrieben worden waren, immer noch als kommunikativ irrelevant eingestuft (oder aber schlicht ignoriert), ${ }^{3}$ und man hat den Eindruck, dass die Gestaltung von Texten vielfach immer noch als reine ,Hülle' verstanden wird, die beim Lesen restlos durchsichtig wird und durchsichtig zu werden hat (vgl. dazu unten Abschnitt 3). Mittlerweile jedoch hat sich vieles geändert. Immer mehr Linguistinnen und Linguisten erkennen die Textgestalt als relevanten Fachgegenstand an. Die Visualität der Texte ist mithin auf dem Weg, ein ernsthafter Forschungsgegenstand zu werden. Der folgende Abschnitt verdeutlicht dies. ${ }^{4}$

Vgl. hierzu Waller (1996); Stöckl (2004); Spitzmüller (2006, 2009).

Vgl. für einen ausführlicheren Forschungsüberblick Spitzmüller (2006). 


\section{Die Textgestalt als Forschungsgegenstand}

Das linguistische Interesse an der Textgestalt verteilt sich mehr oder weniger auf zwei grundsätzlich zu unterscheidende Kategorien von Funktionen, die der Textgestaltung zugeschrieben werden: auf textorganisierende Funktionen und auf stilistische Funktionen.

Arbeiten, die sich vor allem für den ersten Bereich interessieren, prüfen, inwieweit die mikrotypografische Gestaltung von Einzelelementen (etwa die Auszeichnung von Wörtern und Phrasen oder die Verwendung bestimmter Schrifttypen) sowie auch die makrotypografische Gesamtgestaltung (das Seitenlayout, die Kombination von Text mit pikturalen Elementen, die Verwendung von Elementen wie Fußnotenapparaten, Überschriften, Absatzausrichtungen usw.) die Textorganisation bestimmt und damit die ,Lesbarkeit' des Textes beeinflusst. Entsprechende Arbeiten finden sich in der Textverständlichkeitsforschung, der Metalexikografie, der Text- und der Medienlinguistik. ${ }^{5}$

Arbeiten, die sich mehr für den stilistischen Bereich interessieren, untersuchen, inwieweit spezifische Textgestaltungen kontextkonstitutiv sind, inwieweit sie also den Interpretationsrahmen mitprägen. Auch hier kommt sowohl die Mikro- als auch die Makroebene der Gestaltung in den Blick. Wichtige Fragestellungen sind in diesem Zusammenhang etwa, inwieweit die Gestaltung von Texten Textsortenvorerwartungen generiert, inwieweit einzelne Elemente oder die Gesamtkomposition spezifische Schemata aufrufen, welche eine bestimmte Lesart des Textes nahelegen, inwieweit Gruppenzugehörigkeiten durch spezifische grafische Elemente signalisiert werden, inwieweit die Gestaltungselemente expressiv und appellativ wirken und inwieweit die grafischen Mittel mit anderen Textmodalitäten interagieren. Dieser Bereich wird derzeit vor allem durch Arbeiten aus der Text- und Graphostilistik, der Sozialstilistik (insbesondere der Social Semiotics) und der Werbesprachforschung ausgeleuchtet. ${ }^{6}$ Der textstilistische Bereich ist es auch, der in einigen sprachgeschichtlichen Arbeiten (etwa Polenz 1996 und Ehlers 2004) ins Zentrum gerückt wird.

Über diese beiden Hauptforschungsgebiete hinaus finden sich auch linguistische Arbeiten, die weitere Fragestellungen untersuchen. Erwähnt seien hier nur medien- und druckgeschichtliche Fragestellungen (denen etwa Herbert Brekle in vielen Arbeiten nachgeht; vgl. Brekle 1993, 1994,

$5 \quad$ Vgl. für Beispiele aus der Textverständlichkeitsforschung Sauer (1997, 1999), Ballstaedt et al. (1981), Doerfert (1980) und Schröder (1993), für die Metalexikografie Bergenholtz (1995), Almind/Bergenholtz (2000) und Wiegand (1999, 2000), für die Textlinguistik Hagemann (2007), Wienen (2007) sowie Hausendorf/Kesselheim (2008, passim) und für die Medienlinguistik Bucher (2007). Vgl. für eine historische Perspektive außerdem Raible (1991).

6 Vgl. etwa Spillner (1982); Antos (2001); Fix (2001, 2008); Androutsopoulos (2004); Scollon/ Scollon (2003); Stöckl (2004, 2008); Sandig (2006); van Leeuwen (2005, 2006); Meier (2007). 
1997) sowie schriftlinguistische Versuche, Typografie schriftsystematisch zu klassifizieren (etwa in den Arbeiten von Peter Gallmann 1985 und Hartmut Günther 1988, 1993).

Nach diesem kurzen Einblick in die Forschungslandschaft, der zeigt, dass Textgestaltung bzw. Typografie in der Linguistik vielfach und mit ganz unterschiedlichen Interessen zum Gegenstand gemacht worden ist, soll der Fokus im Folgenden auf Fragestellungen gelenkt werden, die für das Rahmenthema des vorliegenden Bandes besonders relevant sind. Im Wesentlichen konzentrieren sich die Ausführungen dabei auf den Bereich der (Sozial-)Stilistik.

\section{Variation und Wissen}

Eine für die Frage nach der kommunikativen Relevanz skripturaler Visualität wichtige Frage ist, inwiefern grafische Mittel soziale Wirklichkeit mitkonstituieren. Diese Frage steht im Mittelpunkt der folgenden Überlegungen. Grafische Gestaltung wird dabei als eine sozial konstitutive, performative Praxis - als Prozess, nicht als Produkt - betrachtet. Als Zugang zu dieser Praxis wird ein primär soziolinguistisch-interaktionstheoretisches Vorgehen mit diskurstheoretischer bzw. epistemologischer Verankerung gewählt. Die Kernkonzepte, auf denen Analysen solcher Praktiken aufbauen, sind daher die beiden Kernkonzepte aus der Soziolinguistik und der Diskurstheorie: Variation und Wissen.

Die erste These, die sich hieraus ergibt, ist: Grafische Gestaltung ist als eine Form kommunikativer Variation zu verstehen, wobei angenommen wird, dass Variation potenziell sozial distinktiv ist. Dies ist bekanntlich eine Grundannahme der Soziolinguistik, und zwar sowohl der variationslinguistisch ausgerichteten als auch der interpretativen. Die folgenden beiden exemplarischen Zitate von Vertretern jeweils einer dieser beiden soziolinguistischen Ausrichtungen verdeutlichen dies:

The foundations of variationist sociolinguistics come from the rudimentary observation that the variants that occur in everyday speech are linguistically insignificant but socially significant. (Chambers 2003, S. 3)

[...] function is affected by the social , values ${ }^{6}-$ in a politico-ecomomic sense attributed to particular linguistic resources [...]. In general, we can say that every difference in language can be turned into difference in social value - difference and inequality are two sides of a coin, a point often overlooked or minimised in analysis. (Blommaert 2005, S. 68-69)

Die Zitate zeigen zugleich aber auch, wie unterschiedlich die Grundannahme der sozialen Wirksamkeit kommunikativer Variabilität von den Vertretern der beiden soziolinguistischen ,Schulen` verstanden wird. Während 
die Variationslinguistik (hier exemplarisch Jack Chambers) Variation primär als Index sozialer Zugehörigkeit ansieht und deshalb vor allem an der Klassifikation soziokommunikativer Struktureinheiten (Variablen und Varietäten) und deren gesellschaftlicher Stratifikation interessiert ist, betrachten sie die Vertreter der interpretativen Soziolinguistik (hier Jan Blommaert) als kommunikativen Prozess, als Praxis der Ko-Konstruktion einer prinzipiell dynamischen sozialen Wirklichkeit, in der sich die Kommunikationsteilnehmer positionieren. Wie das zweite Zitat zeigt, gehört hierzu nicht zuletzt auch die Ko-Konstruktion gesellschaftlicher Unterschiede und Ungleichheiten. ${ }^{7}$ Die vorliegenden Ausführungen schließen an die Überlegungen der interpretativen Soziolinguistik an.

Auf grafische Kommunikation übertragen heißt dies, dass es nicht gleichgültig ist, welche Mittel ein Textproduzent wählt, sondern dass einzelne Mittel mit spezifischen sozialen Werten assoziiert werden bzw. auf ,indexikalische Ordnungen " ${ }^{\text {( }}$ hinweisen, dass sie also sozialsymbolisch kodiert sind. Das hat ja übrigens schon Beatrice Warde so gesehen. Zumindest impliziert ihre Weinbecher-Allegorie, dass die Wahl der Mittel für sie sozial distinktiv ist: Wer die ,transparente“ Form wählt, gibt sich ihr als Experte zu erkennen (genauer, er wird von ihr als Experte eingestuft), wer die, ornamentale ${ }^{\natural}$ Form wählt, als Banause ${ }^{9}$ - und welche sozialen Konsequenzen dies vor dem Hintergrund des "priestly charisma of connoisseurship" (Silverstein 2003, S. 224) haben kann, welches es ja bekanntlich auch im Bereich kommunikativen Handelns gibt, haben die obigen Ausführungen gezeigt.

Weiterhin wird angenommen, dass die sozialsymbolischen Zuschreibungen unterschiedlich stark stratifiziert, die indexikalischen Ordnungen also unterschiedlich weitreichend sind. Ob und wie stark bestimmte grafische Mittel mit sozialsymbolischen Werten in Verbindung gebracht werden, hängt einerseits vom sozialen Hintergrund der Kommunikationsteilnehmer ab (vgl. dazu unten), andererseits aber auch von der konkreten Kommunika-

$7 \quad$ Vgl. zu den theoretischen und methodischen Unterschieden zwischen variationslinguistischer und interpretativer Soziolinguistik grundsätzlich Coupland (2007, S. 1-53). Coupland selbst bindet Variation dabei an das Konzept des Stils an, welches er ebenfalls im Sinne eines dynamischen Prozesses versteht: ,[...] what matters for linguistic style is more to do with process than with product, more to do with use than with structure" (Coupland 2007, S. 3).

8 Vgl. Silverstein (2003), der das Konzept in die Soziolinguistik eingeführt und am Beispiel des erwähnten „wine talks“ exemplifiziert hat. Unter „,indexical orders“ versteht Silverstein sozialsymbolische Systeme oder Ordnungen, in denen bestimmte metapragmatische Wertzuschreibungen gelten, die die Beurteilung der kommunikativer Praktiken von Interaktionsteilnehmern sowie auch deren sozialen Status und ihre „Diskursfähigkeit“ (Voice) innerhalb bestimmter sozialer Gruppierungen bestimmen. Vgl. hierzu auch Blommaert (2005, S. 68-97).

9 Vgl. dazu auch die Warde-Interpretation von Salen (2001). 
a A RAR R

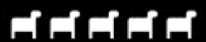

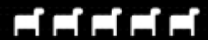

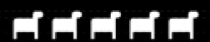

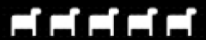

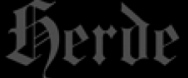
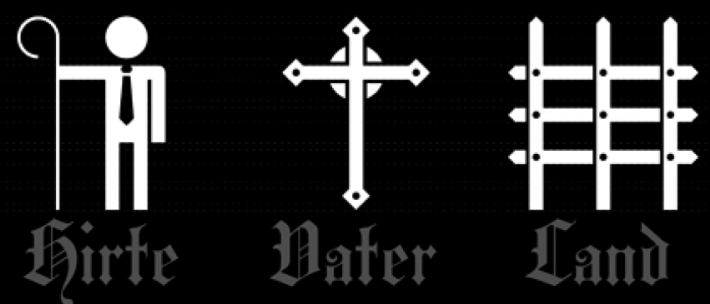

Das Schweizer Gesellschaftsmodell im 21. Jahrhundert?

fsip.ch

(a)

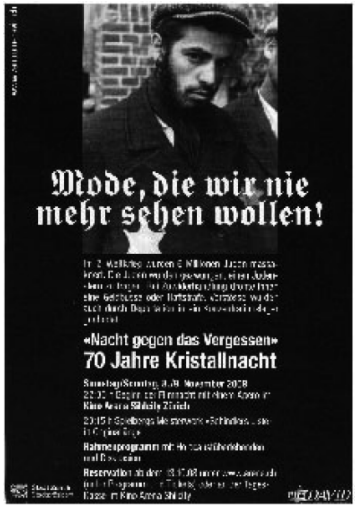

(b)

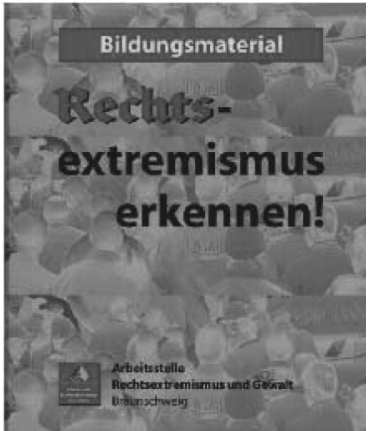

(c)

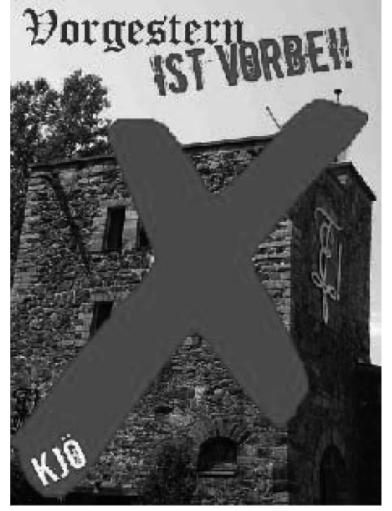

(d)

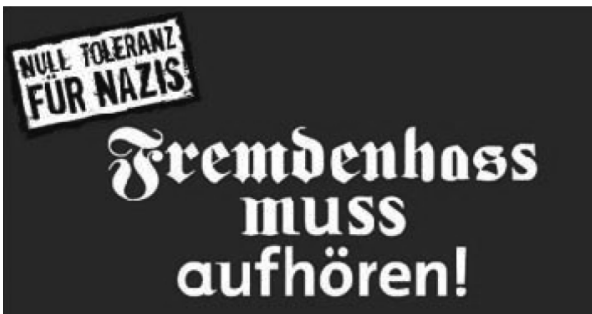

(e)

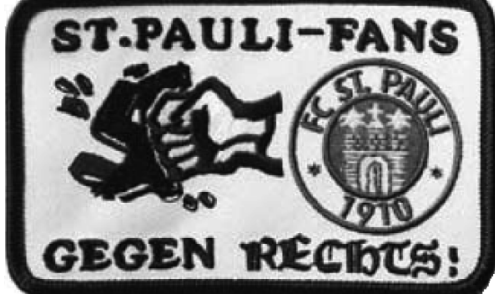

(f)

Abb. 1: Sozialsymbolische Zuschreibungen: gebrochene Schriften 

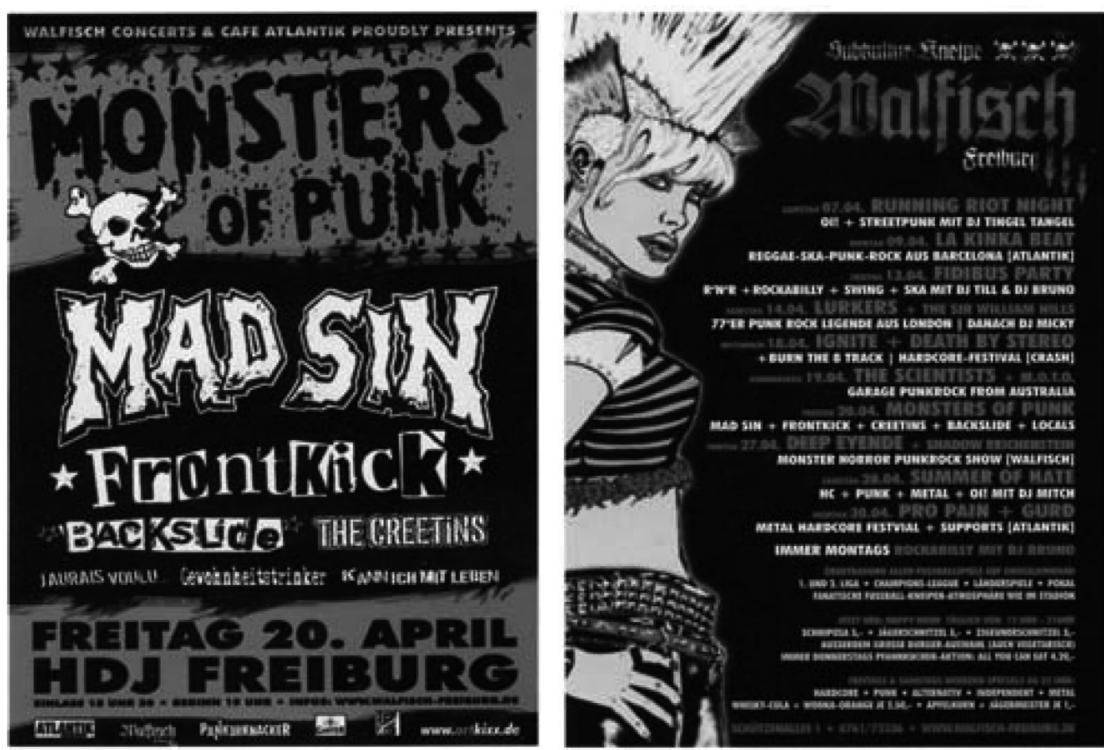

(a)

(b)

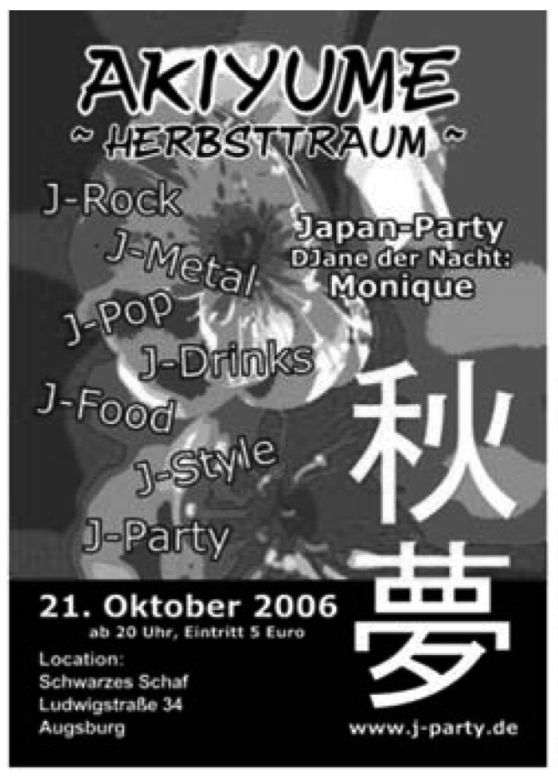

(c)

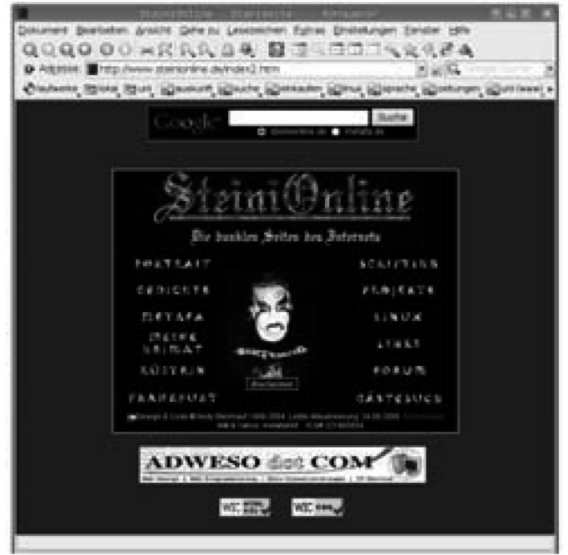

(d)

Abb. 2: Sozialsymbolische Zuschreibungen: popkulturelle Szenekommunikation 
tionssituation und dem dabei interaktiv ${ }^{10}$ (vom Textproduzenten und vom Rezipienten durch kommunikative und andere Praktiken) generierten Kontext. Allerdings ist auch davon auszugehen, dass die sozialsymbolische Reichweite mancher grafischer Mittel größer ist als die anderer. So gibt es Mittel, denen in ganz verschiedenen Situationen und von Interaktionsteilnehmern mit ganz unterschiedlicher soziokultureller Verortung bestimmte Werte zugeschrieben werden, die also weniger an konkrete kommunikative Konstellationen gebunden sind als andere. Ein Beispiel hierfür sind gebrochene Schriften, die in vielen Kontexten immer noch mit Nationalismus oder gar Nationalsozialismus in Verbindung gebracht werden (vgl. Abbildung 1). ${ }^{11}$ Im Fall anderer Mittel sind die Zuschreibungen sehr viel latenter bzw. gruppenspezifischer. Dies gilt etwa für die spezifischen grafischen Ausdrucksmittel der Popkultur (vgl. Abbildung 2), die als "genre cues“ (Androutsopoulos 2001, S. 20) fungieren, von den Anhängern aber auch als Gruppenindikatoren verwendet werden (vgl. Androutsopoulos 2004; Spitzmüller 2007). Darüber hinaus gibt es Zuschreibungen, die nur innerhalb sehr exklusiver Gruppen vorgenommen werden. So berichtet etwa Brenda Danet (2001, S. 289-344) von einer Gruppierung im Internet, die sich weigert, Morisons Times New Roman zu verwenden und die diejenigen, die das tun, für genau das halten, was Morison als geringeres Übel der Textgestaltung bezeichnet hat: für langweilig und monoton. Ein sicherlich noch extremeres Beispiel ist die folgende Aussage eines Textgestalters, bei der die Gestaltung vollends zum sozialen Ausschlusskriterium wird:

Ich erhielt einen Brief von einem Verantwortlichen des Designer-Verbandes mit der Aufforderung zur Mitarbeit in einem Ausschuß.

Der Brief war in der 10 Punkt Avant Garde gesetzt, Blocksatz, sehr lange Zeilen, sehr große Löcher zwischen den Wörtern, ohne Durchschuß. Da habe ich lieber gleich abgesagt. (Willberg/Forssman [1999] 2001, S. 78)

Dass diese sozialsymbolischen Zuschreibungen funktionieren, lässt sich mit dem zweiten Kernkonzept erklären, dem des Wissens. Wissen meint hier im epistemologischen Sinn eine nicht notwendigerweise explizierbare Form kollektiver Annahmen. ${ }^{12}$ Die zweite These lautet also, dass die sozialsym-

10 Der Interaktionsbegriff, auf den sich dieser Beitrag bezieht, ist weiter als der in der Konversationsanalyse übliche. Aufgrund der zeitlichen und räumlichen Trennung von Textproduzent und Textrezipient ist die Reziprozität/Dialogizität naturgemäß (seitens des Produzenten auf Rezeptionskontext- und -steuerungssignale) eingeschränkt, weshalb die Konversationsanalyse hier nicht von Interaktion sprechen würde. Wenn dies dennoch getan wird, dann deshalb, weil der Beitrag davon ausgeht, dass Sinn vom Textproduzenten und vom Textrezipienten gemeinschaftlich, in einem interaktiven (also gemeinschaftlich-handelnden), dynamischen Prozess, hergestellt wird, weshalb er auch für einen interaktionstheoretischen Zugang (unter Berücksichtigung dieser Unterschiede) plädiert.

11 Vgl. Bain/Shaw/Bertheau (Hg.) (1998); Schopp (2002); Spitzmüller (im Druck); MeierSchuegraf (2005).

12 Dieser Wissensbegriff ist angelehnt an die wissenssoziologischen bzw. epistemologischen Konzepte von Foucault (v.a. 1981) und Berger/Luckmann (2003) sowie an die linguistischen 
bolischen Zuschreibungen Teil eines grafischen oder semiotischen Wissens sind, das die Mitglieder einer sozialen Gemeinschaft teilen bzw. zu teilen glauben. Die Verwendung grafischer Mittel erfolgt auf der Basis dieser Grundannahmen. Solche Annahmen können sein, dass bestimmte Mittel bestimmte ,Werte' oder ,Unwerte' zum Ausdruck bringen, aber auch, dass sie besonders ,geeignet' oder ,typisch' für die gegebene Kommunikationsform oder Textsorte sind, also den Erwartungen entsprechen. Dies impliziert freilich, dass die Produzenten davon ausgehen, dass die Rezipienten die Zuschreibungen teilen. ${ }^{13}$

Damit wäre auch, wie es in den in Abschnitt 1 zitierten Äußerungen zum Ausdruck gebracht wurde, die Wahl so genannter ,neutraler' oder, unauffälliger ${ }^{\top}$ Mittel eine soziale Entscheidung im Sinne einer Einordnung in das, was der Produzent des Textes für die ,Norm` oder das ,Erwartete' hält. Diese Wahlen müssen nicht bewusst erfolgen. In sehr vielen Fällen tun sie dies, wie auch die sprachstilistischen Wahlen, vermutlich nicht. Dennoch ist anzunehmen, dass die Erfahrungen und Werthaltungen der Textproduzenten die Basis dafür bilden, welche konkreten Mittel sie verwenden.

Wenn das grafische Wissen die Produktion von Texten prägt, so gilt dies umgekehrt auch für deren Rezeption. Grafische Mittel lassen sich in diesem Zusammenhang als Kontextualisierungshinweise (im Sinne von Auer 1986; Auer/ di Luzio (Hg.) 1992) verstehen, die dieses Wissen evozieren und damit den Interpretationsrahmen der Textrezeption konstituieren. Das impliziert freilich, dass sie nur Möglichkeiten der Interpretation anbieten und dass sie mit weiteren Kontextualisierungshinweisen, etwa den verbalen und den medialen, interagieren. All diese Kontextualisierungshinweise legen den Rezipienten, aufgrund ihres kommunikativen Wissens, bestimmte Schlüsse nahe, die grafischen etwa hinsichtlich der Textsorte, der Entstehungszeit des Textes oder den sozialen Hintergründen des Produzenten. Sie prägen somit die Lektüre vor.

Vor dem Hintergrund der Annahme, dass das grafische Wissens sozial verankert ist, lässt es sich auch erklären, warum spezifische grafische Elemente für unterschiedliche Interaktionsteilnehmer offenbar unterschiedlich ,bedeutsam` sind. Mit Rudi Keller (1995) kann man hier argumentieren, dass diese Mittel nur dann „Bedeutung“ haben und „Zeichen“ sind, wenn sie von den Interaktanden als distinktive Merkmale - soziolinguistisch gesprochen: als Varianten - wahrgenommen und zeichenhaft interpretiert werden. ${ }^{14}$

$\mathrm{Ob}$ dies geschieht, hängt vermutlich nicht nur von der Rezipientengruppe ab, sondern auch vom Gesamtkontext. Wenn wir davon ausgehen, dass Texte multimodal sind und dass, wie in der Textstilistik betont wird,

Wissenstheorien von Dietrich Busse (1987), Helmuth Feilke (1994) u.a.

13 Vgl. hierzu detailliert Antos/Spitzmüller (2007) und Spitzmüller (2009).

14 Vgl. zur Einbindung von Kellers handlungstheoretischer Zeichentheorie in das Konzept des „grafischen Wissens“ Antos/Spitzmüller (2007); Spitzmüller (2009). 
sprachliche und nichtsprachliche Zeichen gemeinsam das Sinnangebot eines Textes konstituieren (vgl. etwa Fix 2001, S. 114/118), dann ist zu erwarten, dass die Wirkung grafischer Elemente nicht unerheblich vom multimodalen Umfeld abhängt. Das unterschiedliche Wirkungspotenzial von gebrochenen Schriften in den verschiedenen Textsorten, in denen sie verwendet werden, ist auch hierfür ein illustratives Beispiel - man denke etwa an zeitgenössische politische Texte, an Hip-Hop-Cover, an Bieretiketten, an Zeitungslogos und an historische deutschsprachige Bücher wie beispielsweise den Erstdruck von Kants Critik der reinen Vernunft.

Wichtig ist es in diesem Zusammenhang aber auch, die einzelnen Textmodalitäten funktional zu differenzieren. Im Interaktionsprozess erfüllen die jeweiligen Modalitäten unterschiedliche kommunikative Funktionen, die in diesem Prozess sehr wahrscheinlich auch in unterschiedlicher Art und Weise bzw. in unterschiedlichen Phasen auftreten. Vermutlich hat Beatrice Warde nicht grundsätzlich Unrecht mit ihrer Überlegung, dass die Textgestalt für die Übermittlung von Informationen in den Hintergrund zu treten hat, zumindest dann nicht, wenn sie die Buchtypografie und damit eine Kommunikationsform vor Augen hat, bei der die Darstellung in aller Regel stark im Vordergrund steht und in aller Regel auch dominant durch verbale Mittel geleistet wird. ${ }^{15}$ Der Fehler in ihrer Argumentation ist aber, dass Warde Kommunikation weitgehend auf diese eine Funktion sowie auf die Phase der ,Informationsentnahme reduziert und den anderen Funktionen und Rezeptionsphasen gar keine Relevanz beimisst. Dass die Materialität zurücktreten muss, damit der Blick auf den Inhalt ,frei' wird, ist nun aber eine Annahme, die sich auch in kommunikations- und zeichentheoretischen Arbeiten zum Leseprozess häufig findet. So schreibt etwa Aleida Assmann, bezeichnenderweise ebenfalls unter Rückgriff auf die Durchsichtigkeitsmetaphorik ${ }^{16}$ :

Wer sich in die Materialität der Zeichen verstrickt, kann sie nicht verstehen, so wenig der stumpfe Blick des übermüdeten oder unkundigen Lesers es vermag, den Vorhang der Buchstaben aufzuziehen. [...] Der flüssige und behende Duktus wird gehemmt, ja u.U. ganz zum Stillstand gebracht, wenn die Buchstaben eine resistente Materialität annehmen.

[...] Der Text wird selbst zum Bild, das den Betrachter in den Bann schlägt und ihm nicht gestattet, kurzerhand zur Sache zu kommen. [...]

Lesen ist ein transitorisches Verfahren. Es erfordert die schnelle Bewegung des Intellekts vom Buchstaben zum Geist, vom Besonderen zum Allgemeinen, von der Oberfläche zur Tiefe. (Assmann [1988] 1995, S. 238/241)

15 Allerdings macht Warde selbst diesen Unterschied gerade nicht, wenn sie betont: „And if what I said is true for book printing, it is fifty times more obvious in advertising, where the one and only justification for the purchase of space is that you are conveying a message that you are implanting a desire, straight into the mind of the reader" (Warde [1932] 1991, S. 113-114).

16 Vgl. hierzu auch Groß (1994). 
Was in diesem Zusammenhang zentral ist, ist das, was Karl Bühler ([1934] 1999, S. 42-46) das Prinzip der abstraktiven Relevanz genannt hat. Demzufolge abstrahieren wir vom multimodalen Gesamtkomplex das für die jeweilige kommunikative Funktion jeweils Irrelevante. Das heißt, grafische Elemente treten dann in den Hintergrund der Rezeption, wenn wir ihnen keine Darstellungsfunktion zumessen und wenn es um die Information über Gegenstände und Sachverhalte geht. Allerdings ist wichtig, und Bühler selbst hat das sehr genau gesehen, dass das Abstrahierte nicht grundsätzlich irrelevant ist, sondern nur irrelevant für die betreffende Funktion.

Und mehr als das: Eine sehr bedenkenswerte These Bühlers ist es ja, dass die für eine bestimmte Funktion irrelevanten Elemente gerade deshalb wichtig werden können, weil sie semiotisch damit für andere Funktionen zur Verfügung stehen. Bühler verdeutlicht das am Beispiel der Prosodie (dem „Ton“, wie er es nennt), der seines Erachtens für die Darstellungsfunktion im Deutschen nahezu irrelevant ist, aber gerade deswegen „dem Ausdruck und Appell frei[stehe]“ (Bühler [1934] 1999, S. 46). Insofern könnte man argumentieren, dass grafische Elemente besonders dann, wenn ihnen keine Referenzfunktion im klassischen Sinn zukommt, für den Ausdruck etwa sozialer Beziehungen oder von Werthaltungen geeignet sind.

Das gilt nicht nur für typografische Elemente. Ein illustratives Beispiel ist die Verwendung von Umlauten im Englischen im Sinne eines Foreign Branding (vgl. Abbildung 3). Gerade weil die Umlaute im Englischen graphematisch und damit denotativ irrelevant sind, können sie als Indikatoren etwa für Fremdheit oder - wie im Heavy Metal - als Genre-Indikatoren und damit als soziales Signal verwendet werden (vgl. dazu Spitzmüller 2007). Etwas Ähnliches ist auch mit dem $<\beta>$ im Kontext der Rechtschreibreform passiert: Gerade weil dieser Buchstabe in bestimmten Schreibungen seine graphematische Funktion verloren hat (und dadurch auch, sichtbar' wurde), konnte er sozialsymbolisch aufgeladen und zu einer, Fahnenletter bzw. zu einem sozialen Ikon der Reformgegner werden. Reformkritische Titel wie "Geheimsache ,B““ (Röhrig 2004) und „, $\beta^{\star}$ - ein Buchstabe wird vermisst“ (Müller 2008) verdeutlichen dies sehr gut.

Die vorgestellten Überlegungen gelten also nicht nur für Typografie. Typografische Gestaltung ist nur eine spezifische Form der grafischen Variation neben anderen, die teilweise ganz ähnlich, teilweise anders funktionieren. Eine „Soziolinguistik von Schriftlichkeit“, wie sie neuerdings von verschiedener Seite gefordert wird (vgl. Androutsopoulos 2007, S. 86; Sebba 2007, S. 5), wird daher nicht nur die Textgestalt ins Auge fassen müssen, sondern das gesamte interdependente Arsenal skripturaler Varianten, auf das die Interaktionsteilnehmer zurückgreifen, um sich kommunikativ im sozialen Gefüge zu positionieren (neben typographischen Varianten also etwa Varianten in der Schreibung, im Schreibstil bzw. der Gattungsanbindung, der Verwendung von Zeichen- und Schriftsystemen usw.; vgl. dazu ausführlicher Spitzmüller 2007). 


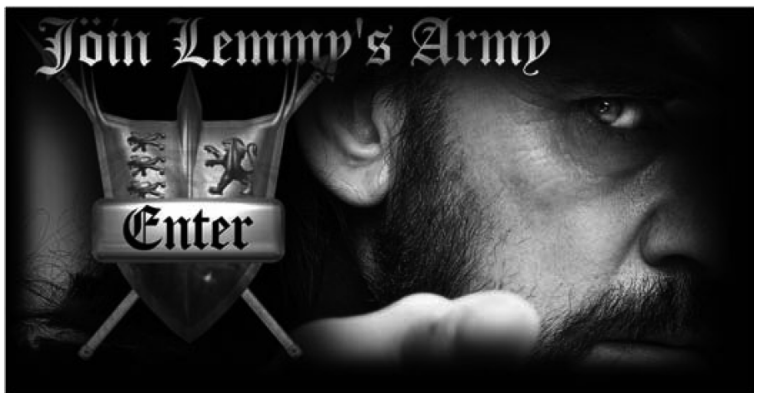

(a)

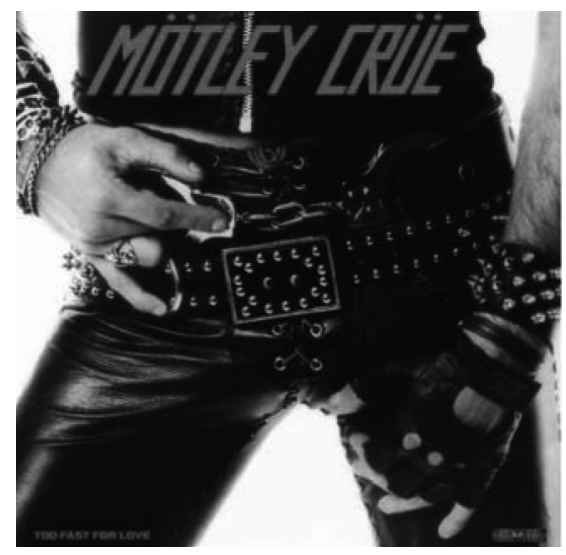

(c)

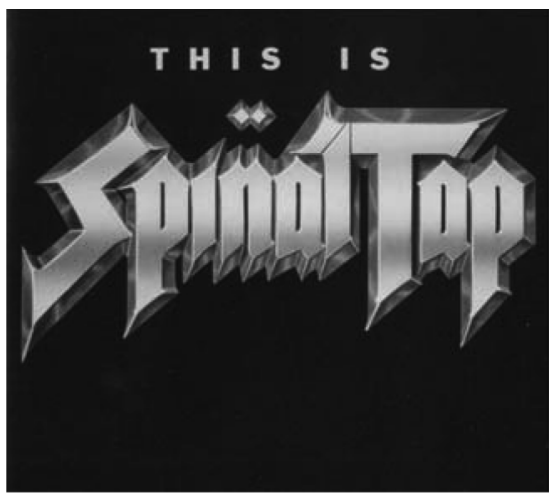

(e)

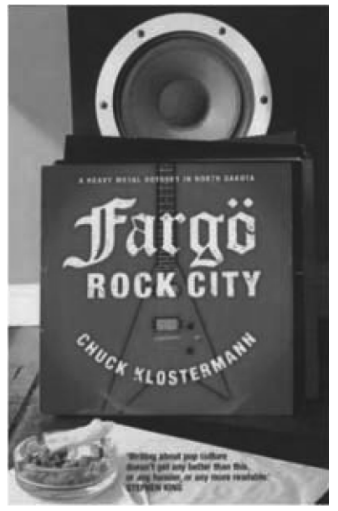

(b)

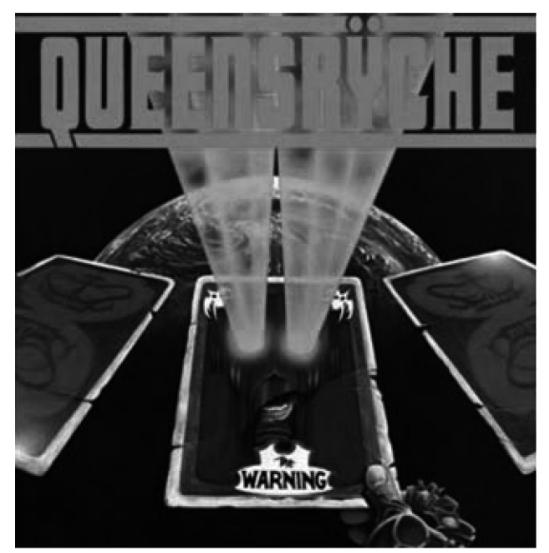

(d)

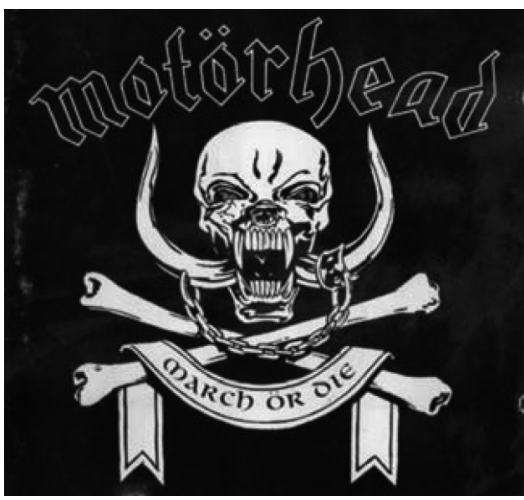

(f)

Abb. 3: Sozial kodierte Umlaute 


\section{Intermedialität}

Der letzte Teil dieses Beitrags fokussiert nun den Kerngegenstand des vorliegenden Bandes: Intermedialität. Dabei können nur einige Schnittstellen zwischen Visualität und Intermedialität genannt werden, die alle weitergehender Diskussionen bedürfen. Das Ziel des vorliegenden Abschnitts ist es, einige wichtige Theorien und Befunde der Forschung zur Textgestaltung mit Intermedialität in Verbindung zu bringen. Unter Intermedialität wird dabei mit Rajewsky (2002, S. 13) die Inbezugsetzung verschiedener „,konventionell als distinkt wahrgenommene[r] Medien" verstanden, entweder in Form der Medienkombination, des Medienwechsels oder der Herstellung intermedialer Bezüge. Wie in der Intermedialitätsforschung üblich (vgl. Rajewsky 2002, S. 7), wird dabei ein relativ weiter Medienbegriff herangezogen. Medien werden also nicht im engen übertragungstechnischen Sinn (als Kanal) verstanden, wie dies etwa in der Medienlinguistik üblich ist (vgl. Holly 1997). Der Begriff umfasst auch verschiedenartige rezipientenseitige Konzeptionen sprachlicher, Vermitteltheit', welche vielfach über technische Medienkonzeptionen hinausgehen bzw. mit diesen konfligieren. Was aus einer technischen Perspektive bzw. aus der Perspektive der Forschenden als $\mathrm{Me}$ dium definiert wird, interessiert die Intermedialitätsforschung im Grunde nicht. Sie ist vielmehr daran interessiert, welche Phänomene die Kommunikationsteilnehmer selbst als distinkte Vermittlungsformen ansehen bzw. was „konventionell im Sinne eines kognitiven frame of reference als distinkt angesehenes Kommunikationsdispositiv" (Wolf 2002, S. 165) gilt, unabhängig davon, ob es sich dabei im technischen Sinn um ,Medien', um ,Kommunikationsformen', um ,Textsorten', um ,Zeichenmodalitäten' oder um sonstige Phänomene handelt. In einer sehr weiten Lesart werden somit auch Stimme und Schrift, also die kommunikativen Kodes, sowie „die Literatur“ und „der Film [...] als ,(Einzel-)Medien““ (Rajewsky 2002, S. 7) bezeichnet. Dieser weite Medienbegriff birgt natürlich eine ganze Reihe von Gefahren und ist Anlass für allerlei Verwirrungen, wie Vertreter der Medienlinguistik bereits kritisch angemerkt haben (vgl. etwa Wagner 2006). Der Vorteil des Begriffs ist jedoch, dass er das Phänomen der ,Medialität nicht an vorgefertigte Kategorien bindet, sondern versucht, es aus Sicht der Kommunikationsteilnehmer zu betrachten. Damit können insbesondere auch Medialitätswahrnehmungen, Medialitätserwartungen und Medialitätsbewertungen berücksichtigt werden, was für die Frage der sozialen Verortung von Medialität, der der vorliegende Beitrag nachgeht, von grundlegender Bedeutung ist.

Soweit ich sehe, ist Intermedialität in der Forschung zur typographischen Kommunikation bislang noch nicht ausführlich diskutiert worden - zumindest nicht unter diesem Label. Vieles jedoch, was in den Kulturwis- 
senschaften unter dem „termine ombrellone“ (Rajewsky 2002, S. 6) Intermedialität verhandelt wird, wird in der Forschung mithilfe anderer Konzepte, beispielsweise Multimodalität, Konvergenz oder Transkriptivität, gefasst. Damit werden jeweils spezifische Phänomene beschrieben, die die Intermedialitätsforschung der Intermedialität subsumiert, nämlich das Zusammenwirken verschiedener Zeichenressourcen in einem Kommunikat (Multimodalität), die die Intermedialitätsforschung bisweilen bereits als Form der Medienkombination auffasst (vgl. Rajewsky 2002, S. 201), die formale und funktionale Annäherung verschiedener Medien aneinander (Konvergens) sowie durch Medienwechsel bedingte semiotische Transformationsprozesse (Transkriptivität). Es gibt also zahlreiche Schnittstellen.
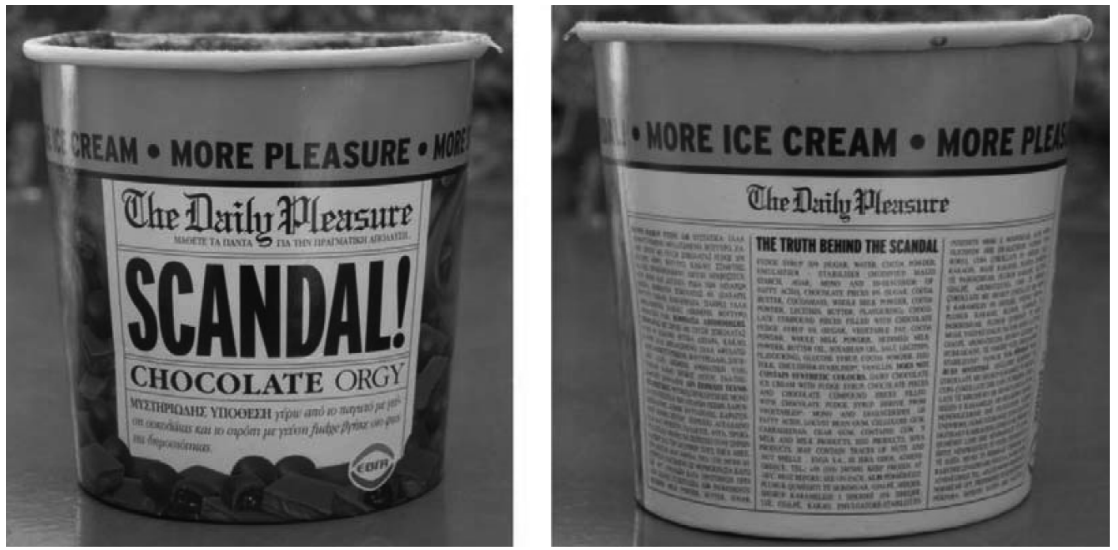

Abb. 4: Eisbecher aus Griechenland (Sommer 2008)

Ein wichtiger Anschlusspunkt ist die bereits angesprochene Möglichkeit, mittels Textdesign Textsortenvorerwartungen zu generieren. In neueren $\mathrm{Ar}-$ beiten aus der Textlinguistik und der Textstilistik wird betont, dass zu unseren Textsortenschemata auch typische visuelle Gestaltungsformen gehören, etwa die Verwendung von Fußnotenapparaten in wissenschaftlichen Texten, deren Verwendung im Umkehrschluss unsere Erwartungen an einen Text prägen können (vgl. Sandig 2006; Fix 2008; Hausendorf/Kesselheim 2008). In der Forschung hat sich hierfür mittlerweile der von Susanne Wehde (2000, S. 119-133) geprägte Terminus typographisches Dispositiv eingebürgert. Interessant ist dieses Konzept für Intermedialität, weil Textsortenschemata ja auch ein für die Textsorte typisches Medium mit einschließen. Typographische Dispositive generieren also mit Textsortenerwartungen zugleich auch Medialitätserwartungen. Daher ermöglichen diese Dispositive neben Referenzen von einer Textsorte auf eine andere auch intermediale Referenzen. Ein Beispiel dafür zeigt Abbildung 4. Ganz offensichtlich emuliert die Gestaltung auf diesem Eisbecher die Textsorte ,Zeitungsbericht ${ }^{\varsigma}$ 
bzw. die Kommunikationsform ,Zeitung'. Entsprechende Kontextualisierungshinweise sind die Schriftwahl (gebrochene Schriften hier als Indikatoren von Zeitungslogos, fette Serifenlose als Indikatoren von Headlines), die makrotypographische Gestaltung (etwa die Spalten auf der Becherrückseite) sowie auch verbale Elemente wie Scandall, The Daily $\langle X\rangle$, The truth bebind the scandal. Da wir in der Regel keine Zeitungen auf Eisbechern lesen, sondern auf Papier oder dem Bildschirm, liegt hier über die Referenz auf eine andere, unerwartete Textsorte und Kommunikationsform auch ein latenter intermedialer Verweis vor. In einem ähnlichen Zusammenhang kann man auch die Verwendung traditioneller Formen des Zeitungsdesigns in Online-Ausgaben sehen (vgl. Abbildung 5 für ein Beispiel), die zumindest in den Anfangstagen wohl auch die Rezeptionserwartungen und das Prestige der herkömmlichen Zeitungen auf das neue Medium zu übertragen versuchten (vgl. dazu Bucher 2006).

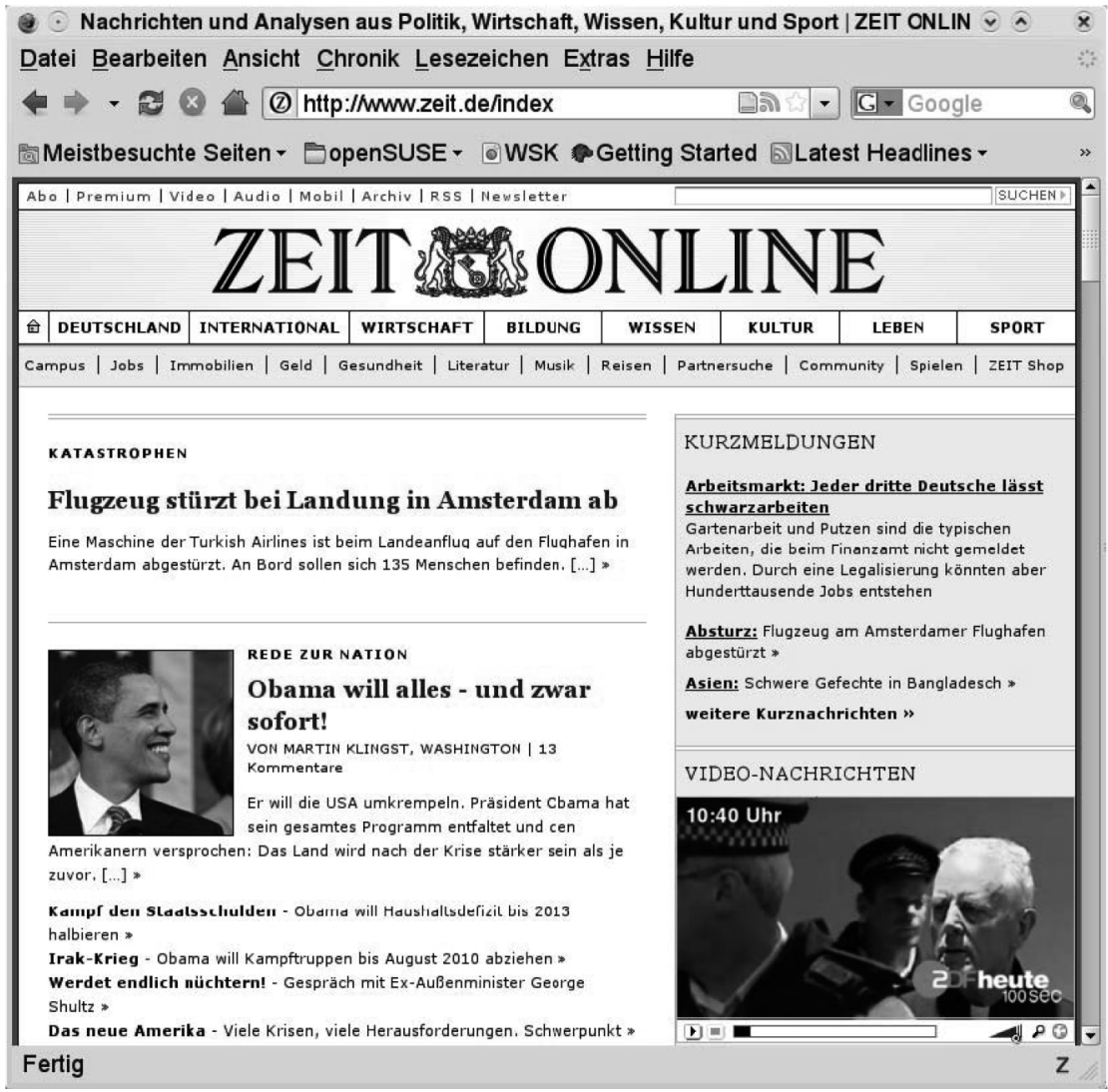

Abb. 5: Online-Zeitung 
Intermediale Bezüge in einem engeren Sinn liegen dann vor, wenn Kommunikationsformen aus anderen Medien in typographischer Form emuliert werden. Das ist etwa dann der Fall, wenn Handschrift digitalisiert wird. Hierfür hat Sonja Neef (2008) viele eindrückliche Beispiele gesammelt und ausgewertet - von eingescannten Unterschriften über Bildschirmschoner bis hin zum PDA und Tablet PC. Nicht zuletzt die zahlreichen Anbieter im Internet, die jede beliebige Handschrift zu digitalisieren und in eine für den Auftraggeber exklusive Schriftdatei - ,your very own font ${ }^{\text {“17 }}$ - zu transformieren versprechen, zeugen davon, dass für solche intermedialen Bezüge offenbar Bedarf besteht. Die entsprechenden Verkaufsversprechen („Add a personal touch to your computer"18) verdeutlichen dabei sehr gut, worum es, auch Neef zufolge, hierbei häufig geht: um die direkte Anbindung an einen identifizierbaren Schreiber bzw. um ,Authentizität'. Dass dies offenbar so wahrgenommen wird, obwohl digitalisierte Handschriften ja gerade nicht echte Originale, sondern beliebig replizierbare Kopien sind, hat wiederum mit den sozialsymbolischen Werten zu tun, die der Handschriftlichkeit zugeschrieben werden - Werte, die einen Medienwechsel offenbar zumindest teilweise überstehen. Auch solche vordergründig bloß ästhetisch-spielerischen Anwendungen digitalisierter Handschriftlichkeit wie die in Abbildung 6 gezeigte Präsentationsvorlage, die mit allen Mitteln versucht, einen Tafelanschrieb zu emulieren, beziehen ihre Wirkung letztlich aus diesen Werten. Ihr ,Unterhaltungswert' ${ }^{6}$ resultiert aus der intermedial-sozialsymbolischen Spannung zwischen ,traditionell-analoger' und ,modern-digitaler ${ }^{`}$ Präsentationstechnik, zwischen sozialsymbolischen Zuschreibungen von ,Authentizität' und ,Modernität', mit denen solche Beispiele bzw. diejenigen, die auf diese Gestaltungsformen zurückgreifen, auch bewusst spielen. Die Verwendung einer solchen Präsentationsvorlage zielt mithin auf mehr als nur auf luzide Trompe-l'CEil-Effekte. Sie verortet den Akt der Präsentation in einem mediensozialgeschichtlichen Kontext und ist damit auch ein metapragmatischer Kommentar zur Medialität der Präsentation sowie zu den Leistungen, Grenzen und sozialen Werten der beiden hier intermedial aufeinander bezogenen Präsentationsmedien. Im Spannungsfeld zwischen ,Effekthascherei ind ,Professionalität', in dem Beamer-Präsentationen (nicht zuletzt in den Geisteswissenschaften) gerne kontrovers verhandelt werden, kann die Verwendung einer solchen Präsentationsvorlage aufgrund ihres Rückbezugs auf die, gute alte Zeit' der Schiefertafel also ebenso wie der bewusste Verzicht auf diese Präsentationstechnik bzw. umgekehrt der Einsatz technisch anspruchsvoller Animationstechniken auch eine (wenn auch augenzwinkernde) Stellungnahme bzw. eine soziale Verortung sein.

\footnotetext{
17 www.yourfonts.com (Stand: Februar 2009).

18 www.yourfonts.com (Stand: Februar 2009). Beispiele für weitere Seiten, die wörtlich ,,a personal touch" versprechen, sind www.handwritingfonts.com (Stand: April 2009), www.fontifier.com (Stand: April 2009) und www.fontsource.com/index.htm (Stand: April 2009).
} 


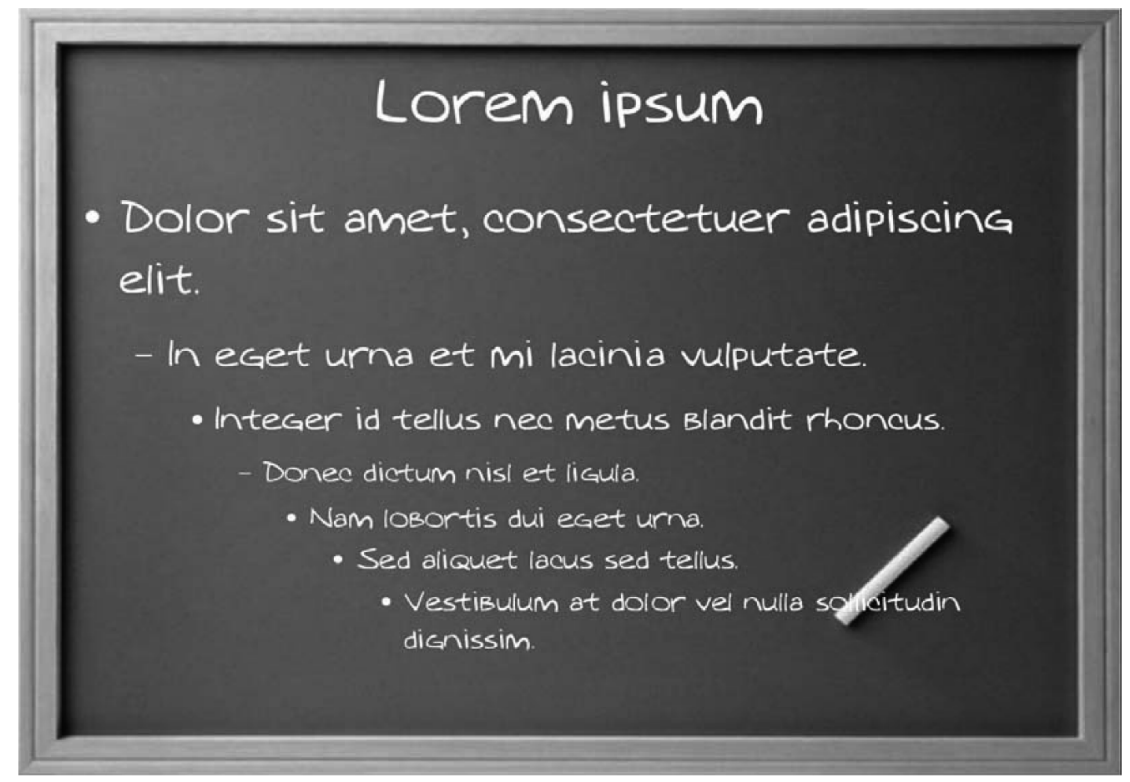

Abb. 6: Präsentationsvorlage „Chalkboard“

In dem erwähnten Buch hat Neef sehr schön herausgearbeitet, dass es gerade die Intermedialität ist, vor deren Hintergrund sich solche Werte häufig entfalten. Im Fall der Handschrift argumentiert Neef überzeugend, dass diese ihre Aufwertung gerade dadurch erfahren hat, dass die Druckschriftlichkeit entstanden ist und die Handschrift von gewissen Aufgaben entlastet hat: „Die Erfindung der Kopie war die Geburtsstunde des Originals“, schreibt sie (Neef 2008, S. 162). Nicht zufällig, so Neef weiter, entstehen in der Nachfolge drucktechnischer Entwicklungen auch solche prestigeträchtigen Handschreibewerkzeuge wie der Füllfederhalter. Intermediale Bezüge sind daher immer auch als Hinweis darauf zu verstehen, was das jeweilige Medium kann und was es nicht kann. In gegenseitigem Bezug aufeinander werden so die Grenzen der jeweiligen Medien (bzw. unserer Konzepte davon) abgesteckt.

Damit kommen wir zu einem letzten, wichtigen Punkt, mit dem zugleich ein Bogen zum Ausgangspunkt der Überlegungen geschlagen werden soll. Wenn es tatsächlich so ist, wie Kittler vermutet, dass das ,Unsichtbarmachen' der Materialität in Verbindung steht zu dem Bestreben, Medialität zurückzudrängen, dann würde dies im Umkehrschluss bedeuten, dass Sichtbarkeit auch Medialität generiert: dass wir ein Medium als Medium vor allem dann wahrnehmen, wenn es mit medienspezifischen, oder aber gerade, durch intermediale Bezüge, mit medienuntypischen, Mitteln 
sichtbar gemacht wird. ${ }^{19}$ In diesem Sinne ist die im Abstract dieses Beitrags formulierte These zu verstehen, dass sich nicht nur die medialen Bedingungen in der Gestaltung niederschlagen, sondern dass graphische Variation die Medialität mitkonstruiert. Somit wäre auch Medialität sozial bzw. diskursiv gerahmt.

Wenn dies so ist, muss man weiterhin auch annehmen, dass Medialität als Gegenstand wissenschaftlicher Reflexion ebenfalls in Korrelation zu ihrer Sichtbarmachung steht. Dies würde bedeuten, dass die Tatsache, dass derzeit in den Kulturwissenschaften allenthalben von Medialität, Intermedialität, Visualität, Pikturalität usw. die Rede ist, nur bedingt mit wissenschaftlichen Modeerscheinungen zu tun hat und schon gar nicht damit, dass den Kulturwissenschaftlern plötzlich die Schuppen von den Augen fallen, sondern wesentlich mit der kommunikativen Praxis. Denn erst durch die Erscheinung der Form in der kommunikativen Performanz wäre der der Gegenstand dann zu einem Gegenstand geworden, den die Wissenschaft als solchen erkennen und anerkennen kann - wenn auch mit etwas Verzögerung. Insofern wäre der aktuelle wissenschaftliche Trend, der sich in Sammelbänden wie dem vorliegenden niederschlägt, auch und zu nicht geringen Teilen ein Resultat der diskursiven Praxis, den die Wissenschaftler aus der Distanz zu beobachten glauben.

\section{Fazit: Um Variation wissen}

Das entwertet nun aber die Beschäftigung mit dem Gegenstand keineswegs - im Gegenteil: Die kommunikative Relevanz, und mit ihr die sprachwissenschaftliche Relevanz, emergieren aus der kommunikativen Praxis. Daher gilt es genau diese im Auge zu behalten.

Ein wesentlicher Faktor kommunikativer Praxis wiederum ist kommunikative Variation. Daher ist es zunächst einmal erforderlich, dass wir als Sprachwissenschaftler - um die hier präsentierten Thesen auf vier Worte zu verdichten - um die Variation wissen, um die ja schon Beatrice Warde gewusst hat, auch wenn sie gegen die offenbar zunehmende und ihrer Meinung nach ,eskalierende“ Praxis anzukämpfen versuchte. Dass Variation Widerstand und Einengungsbestrebungen evoziert, wissen wir als Sprachwissenschaftler nur allzu gut. ${ }^{20}$ Wir selbst sollten uns diesen (aus soziolinguistischer Sicht durchaus nachvollziehbaren) Einengungsbestrebungen aber nicht ohne Not unterwerfen, wenn wir ernsthaft versuchen, die Vielfältigkeit von Kommunikation zu verstehen. Denn so ungern es die Hüter indexi-

19 Ludwig Jäger (2004; vgl. auch Jägers Beitrag in diesem Band) hat diesen Prozess, interessanterweise unter Rückgriff die oben beschriebene Metaphorik, als Wechselspiel von Transparen₹ (,Unsichtbarmachen') und Störung (,Sichtbarmachen') bezeichnet.

20 Vgl. dazu Moschonas/Spitzmüller (im Druck). 
kalischer Ordnungen, die selbst ernannten Connaisseure dieser Welt, sehen mögen: Man kann Wein durchaus auf verschiedene Weise trinken, und nicht immer ist der Kristallbecher die beste Wahl (siehe Abbildung 7).
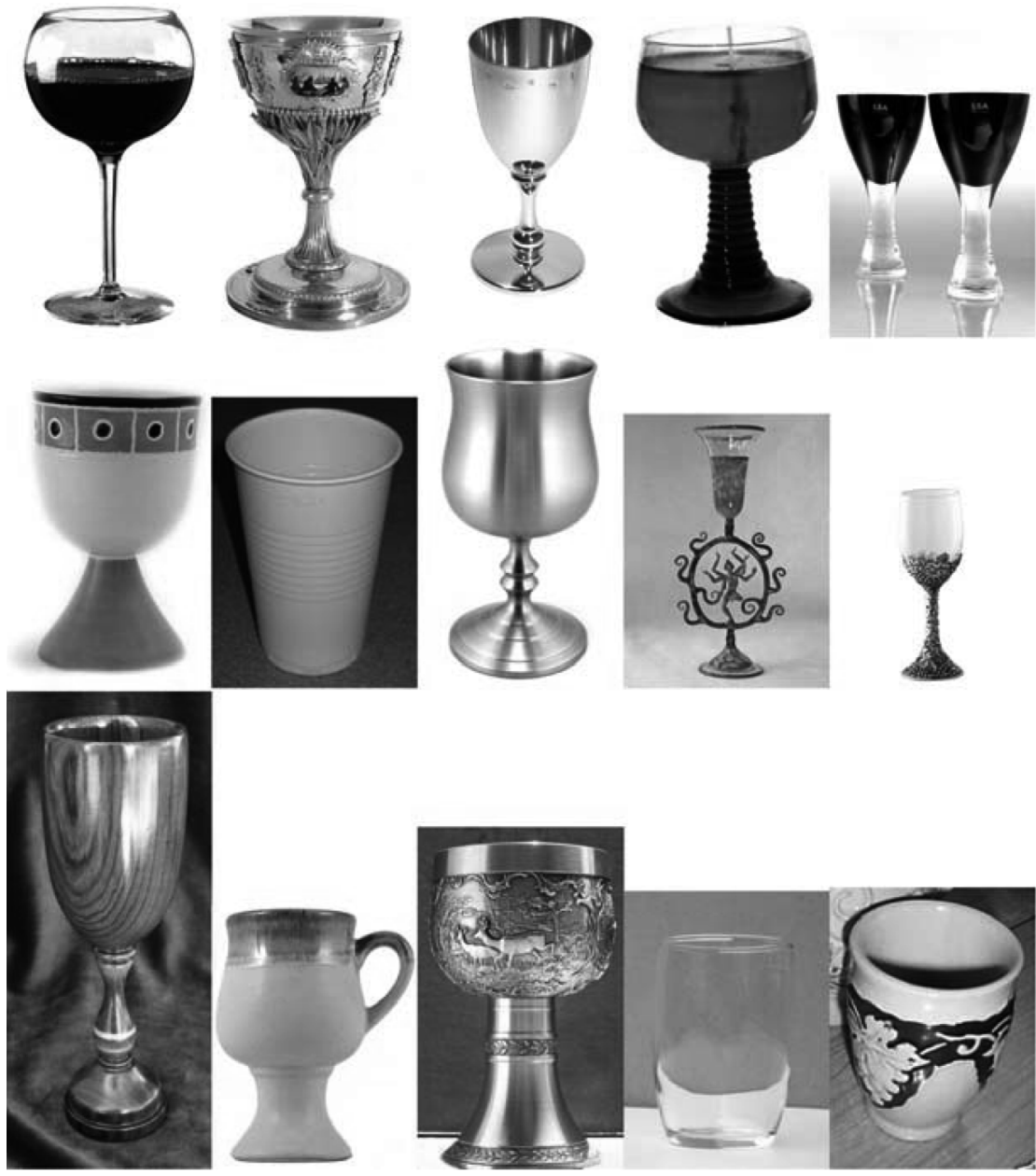

Abb. 7: Weingefäße (im pikturalen Universum von Google Images)

\section{Abbildungsnachweise}

Abb. 1: Sozialsymbolische Zuschreibungen: gebrochene Schriften.

(a) Plakat „Das Schweigen der Lämmer“, Hauptbahnhof Zürich, Dezember 2007.

(b) Flyer zur „Nacht gegen das Vergessen“ anlässlich des 70. Jahrestages der nationalsozialistischen Pogromnacht im November 1938, Zentrum David Zürich, Oktober 2008. 
(c) Bildungsmaterial „Rechtsextremismus erkennen!“ (Borchert et al. (Hg.) 2002), Titelseite.

(d) Plakat der Kommunistischen Jugend Österreichs (KJÖ) gegen ein BurschenschafterTreffen in Linz, September 2007. www.kjoe.at/article.php?story=20070911093944695 (Stand: Dezember 2008).

(e) Banner der SPD Schorndorf, Oktober 2008. www.spd-schorndorf.de/index.php?nr= 12286 (Stand: Dezember 2008).

(f) Aufnäher,„St. Pauli-Fans gegen Rechts!“www.fcstpauli-shop.de/images/product_images/ popup_images/FC2806.jpg (Stand: April 2009).

Abb. 2: Sozialsymbolische Zuschreibungen: popkulturelle Szenekommunikation

(a) Flyer „Monsters of Punk“, Freiburg i.Br., April 2007.

(b) Flyer „Walfisch“, Freiburg i.Br., April 2007.

(c) Flyer „Akiyume“, Augsburg, Oktober 2006.

(d) Website www.steinionline.de/index2.html (Stand: Februar 2007).

Abb. 3: Sozial kodierte Umlaute

(a) Website www.joinlemmysarmy.com (Stand: April 2009).

(b) Plattencover Motörhead: March ör Die. Epic Records 1992.

(c) Plattencover Mötley Crüe: Too Fast for Love. Elektra Records 1981.

(d) Plattencover Queensrÿche: The Warning. EMI Records 1984.

(e) DVD-Cover This is Spinal Tap (Ausschnitt). MGM Home Entertainment 2004.

(f) Titelseite Chuck Klosterman: Fargo Rock. City. A Heary Metal Odysey in Rural Nörth Daköta. New Edition. New York: Scribner 2002.

Abb. 4: Eisbecher aus Griechenland (Sommer 2008)

Fotografie von Jürgen Spitzmüller.

Abb. 5: Online-Zeitung

www.zeit.de/index. Ausgabe vom 26.02.2009.

Abb. 6: Präsentationsvorlage „Chalkboard“

www.kde-files.org/content/show.php/Chalkboard+Presentation?content=31393 (Stand: April 2009).

Abb. 7: Weingefäße (im pikturalen Universum von Google Images).

Ausgewählte Ergebnisse einer Suchanfrage bei http://images.google.de vom 25.02.2009 unter Verwendung der Lemmata Weingefäß, Weinkelch und wine goblet.

\section{Literatur}

Almind, Richard/Bergenholtz, Henning (2000): Die ästhetische Dimension der Lexikographie. In: Fix, Ulla/Wellmann, Hans (Hg.): Bild im Text - Text im Bild. (= Sprache - Literatur und Geschichte 20). Heidelberg, S. 259-288.

Androutsopoulos, Jannis (2001): What names reveal about the music style: A study of naming patterns in popular music. In: Németh, Enikő T. (Hg.): Pragmatics in 2000. Selected papers from the $7^{\text {th }}$ International Pragmatics Conference. Bd. 2. Antwerpen, S. 16-29. 
Androutsopoulos, Jannis (2004): Typography as a resource of media style: Cases from music youth culture. In: Mastoridis, Klimis (Hg.): Proceedings of the $1^{\text {st }}$ International Conference on Typography and Visual Communication. Thessaloniki, S. 381-392.

Androutsopoulos, Jannis (2007): Neue Medien - neue Schriftlichkeit? In: Mitteilungen des deutschen Germanistenverbandes 54/1, S. 72-97.

Antos, Gerd (2001): Sprachdesign als Stil? Lifting oder: Sie werden die Welt mit anderen Augen sehen. In: Jakobs/Rothkegel (Hg.), S. 55-76.

Antos, Gerd/Spitzmüller, Jürgen (2007): Was ,bedeutet‘ Textdesign? Überlegungen zu einer Theorie typographischen Wissens. In: Roth/Spitzmüller (Hg.), S. 35-48.

Assmann, Aleida (1995): Die Sprache der Dinge. Der lange Blick und die wilde Semiose. In: Gumbrecht/Pfeiffer (Hg.) ([1988] 1995), S. 237-251.

Auer, Peter (1986): Kontextualisierung. In: Studium Linguistik 19, S. 22-47.

Auer, Peter/di Luzio, Aldo (Hg.) (1992): The contextualization of language. (= Pragmatics \& Beyond, N. S. 22). Amsterdam/Philadelphia.

Bain, Peter/Shaw, Paul/Bertheau, Philipp Th. (Hg.) (1998): Blackletter. Type and national identity. New York.

Ballstaedt, Steffen-Peter/Mandl, Heinz/Schnotz, Wolfgang/Tergan, Sigmar-Olaf (1981): Texte verstehen, Texte gestalten. München/Wien/Baltimore.

Barthes, Roland ([1973] 2006): Variations sur l'écriture/Variationen über die Schrift. Französisch - Deutsch. (= excerpta classica II). Mainz. [Zuerst: unveröff. Ms. 1973].

Bergenholtz, Henning (1995): Layout. In: Bergenholtz, Henning/Tarp, Sven (Hg.): Manual of specialized lexicography. Preparation of specialised dictionaries. Amsterdam, S. 224-230.

Berger, Peter L./Luckmann, Thomas (2003): Die gesellschaftliche Konstruktion der Wirklichkeit. Eine Theorie der Wissenssoziologie. 19. Aufl. Frankfurt a.M.

Bittner, Johannes (2003): Digitalität, Sprache, Kommunikation. Eine Untersuchung zur Medialität von digitalen Kommunikationsformen und Textsorten und deren varietätenlinguistischer Modellierung. (= Philologische Studien und Quellen 178). Berlin.

Blommaert, Jan (2005): Discourse. A critical introduction. Cambridge.

Bodoni, Giambattista (1818): Manuale tipografico del Cavaliere Giambattista Bodoni. Parma.

Borchert, Diana et al. (Hg.) (2002): Bildungsmaterial Rechtsextremismus erkennen! Braunschweig.

Brekle, Herbert E. (1993): Anmerkungen zur Klassifikations- und Prioritätsdiskussion um die frühesten Druck-Antiquaschriften in Deutschland und Italien. In: Gutenberg-Jahrbuch 68, S. 30-43.

Brekle, Herbert E. (1994): Typographie. In: Günther, Hartmut/Ludwig, Otto (Hg.): Schrift und Schriftlichkeit. Ein interdisziplinäres Handbuch internationaler Forschung. Bd. 1. (= Handbücher zur Sprach- und Kommunikationswissenschaft 10.1). Berlin/New York, S. 204-227. 
Brekle, Herbert E. (1997): Das typographische Prinzip. Versuch einer Begriffsklärung. In: Gutenberg-Jahrbuch 72, S. 58-63.

Bucher, Hans-Jürgen (2006): Gedrucktes im Internet. Online-Zeitungen und OnlineMagazine auf dem Weg zu einer eigenständigen Mediengattung. In: Schlobinski, Peter (Hg.): Von *hdl* bis *cul8r*. Sprache und Kommunikation in den neuen Medien. (= Thema Deutsch 7). Mannheim/Leipzig/Wien/Zürich, S. 210-232.

Bucher, Hans-Jürgen (2007): Textdesign und Multimodalität. Zur Semantik und Pragmatik medialer Gestaltungsformen. In: Roth/Spitzmüller (Hg.), S. 49-76.

Bühler, Karl ([1934] 1999): Sprachtheorie. Die Darstellungsfunktion der Sprache. Stuttgart. [Originalausg:: Jena 1934].

Busse, Dietrich (1987): Historische Semantik. Analyse eines Programms. (= Sprache und Geschichte 13). Stuttgart.

Chambers, Jack K. (2003): Studying language variation: An informal epistemology. In: Chambers, Jack K./Trudgill, Peter/Schilling-Estes, Natalie (Hg.): The handbook of language variation and change. Oxford/Cambridge, S. 3-14.

Coupland, Nikolas (2007): Style. Language variation and identity. Cambridge.

Danet, Brenda (2001): Cyberpl@y: Communicating online. Oxford.

Doerfert, Frank (1980): Zur Wirksamkeit typografischer und grafischer Elemente in gedruckten Fernstudienmaterialien. (= Bericht zum Ziff-Forschungsprojekt 1.2). Hagen.

Ehlers, Klaas-Hinrich (2004): Raumverhalten auf dem Papier. Der Untergang eines komplexen Zeichensystems dargestellt an Briefstellern des 19. und 20. Jahrhunderts. In: Zeitschrift für Germanistische Linguistik 32, S. 1-31.

Feilke, Helmuth (1994): Common sense-Kompetenz. Überlegungen zu einer Theorie ,sympathischen' und ,natürlichen' Meinens und Verstehens. Frankfurt a.M.

Fix, Ulla (2001): Zugänge zu Stil als semiotisch komplexer Einheit. Thesen, Erläuterungen und Beispiele. In: Jakobs/Rothkegel (Hg.), S. 113-126.

Fix, Ulla (2008): Nichtsprachliches als Textfaktor: Medialität, Materialität, Lokalität. In: Zeitschrift für Germanistische Linguistik 36/3, S. 343-354.

Foucault, Michel (1981): Archäologie des Wissens. Übersetzt von Ulrich Köppen. Frankfurt a.M.

Friedl, Friedrich/Ott, Nicolaus/Stein, Bernhard (Hg.) (1998): Typography - when who how/Typographie - wann wer wie/Typographie - quand qui comment. Köln.

Gallmann, Peter (1985): Graphische Elemente der geschriebenen Sprache. Grundlagen für eine Reform der Orthographie. (= Reihe Germanistische Linguistik 60). Tübingen.

Groß, Sabine (1994): Lese-Zeichen. Kognition, Medium und Materialität im Leseprozeß. Darmstadt.

Gumbrecht, Hans Ulrich/Pfeiffer, K. Ludwig (Hg.) ([1988] 1995): Materialität der Kommunikation. 2. Aufl. Frankfurt a.M. [1. Aufl.: Frankfurt a.M. 1988]. 
Günther, Hartmut (1988): Schriftliche Sprache. Strukturen geschriebener Wörter und ihre Verarbeitung beim Lesen. (= Konzepte der Sprach- und Literaturwissenschaft 40). Tübingen.

Günther, Hartmut (1993): Graphetik - Ein Entwurf. In: Baurmann, Jürgen/Günther, Hartmut/Knoop, Ulrich (Hg.): Homo scribens. Perspektiven der Schriftlichkeitsforschung. (= Reihe Germanistische Linguistik 134). Tübingen, S. 29-42.

Gusfield, Joseph (1976): The literary rhetoric of science: Comedy and pathos in drinking driver research. In: American Sociological Review 41, S. 16-34.

Hagemann, Jörg (2007): Typographie und logisches Design. In: Roth/Spitzmüller (Hg.), S. 77-91.

Hausendorf, Heiko/Kesselheim, Wolfgang (2008): Textlinguistik fürs Examen. (= Linguistik fürs Examen 5). Göttingen.

Holly, Werner (1997): Zur Rolle von Sprache in den Medien. Semiotische und kommunikationsstrukturelle Grundlagen. In: Muttersprache 107/1, S. 64-75.

Jäger, Ludwig (2000): Die Sprachvergessenheit der Medientheorie. Ein Plädoyer für das Medium Sprache. In: Kallmeyer, Werner (Hg.): Sprache und neue Medien. (= Jahrbuch 1999 des Instituts für Deutsche Sprache). Berlin/New York, S. 9-30.

Jäger, Ludwig (2004): Störung und Transparenz. Skizze zur performativen Logik des Medialen. In: Krämer, Sybille (Hg.): Performativität und Medialität. München. S. 35-73.

Jakobs, Eva-Maria/Rothkegel, Annely (Hg.) (2001): Perspektiven auf Stil. (= Reihe Germanistische Linguistik 226). Tübingen.

Kapr, Albert/Schiller, Walter (1977): Gestalt und Funktion der Typografie. Leipzig.

Keller, Rudi (1995): Zeichentheorie. Tübingen/Basel.

Kittler, Friedrich A. (1986): Grammophon Film Typewriter. Berlin.

Kittler, Friedrich A. ([1985] 2003): Aufschreibesysteme 1800 • 1900. 4., vollst. überarb. Neuaufl. München. [Originalausg.: München 1985].

König, Anne Rose (2004): Lesbarkeit als Leitprinzip der Buchtypographie. Eine historische Untersuchung zum Forschungsstand und zur Entwicklung des Konzeptes ,Lesbarkeit‘. (= Alles Buch. Studien der Erlanger Buchwissenschaft VII). Internet: www.buchwiss.uni-erlangen.de/AllesBuch/Koenig/Koenig.pdf (Stand: Juli 2006). Erlangen.

Kretzenbacher, Heinz L. (1995): Wie durchsichtig ist die Sprache der Wissenschaften? In: Kretzenbacher, Heinz L./Weinrich, Harald (Hg.): Linguistik der Wissenschaftssprache. Berlin/New York, S. 15-39.

Van Leeuwen, Theo (2005): Typographic meaning. In: Visual Communication 4/2, S. 137-143.

Van Leeuwen, Theo (2006): Towards a semiotics of typography. In: Information Design Journal 14/2, S. 139-155.

Meier-Schuegraf, Stefan (2005): Merkmale rechtsextremistischer visueller Kommunikation im Internet. In: Hofmann, Wilhelm/Leeske, Franz (Hg.): Politische Identität - visuell. (= Studien zur visuellen Politik 1). Münster, S. 153-173. 
Meier, Stefan (2007): Vom Stil zum Style - Typografie als intermediales Phänomen. In: Kodikas/Code. Ars Semeiotica - An International Journal of Semiotics 29/1-3, S. $59-77$.

Morison, Stanley (1929): Typography. In: The Encyclopædia Britannica. Bd. 22: Textiles to vascular system. 14. Aufl. London/New York, S. 650-652.

Morison, Stanley (1930): First principles of typography. In: The Fleuron. A Journal of Typography 7, S. 61-72.

Moschonas, Spiros A./Spitzmüller, Jürgen (im Druck): Prescriptivism in and about the media: A comparative analysis of corrective practices in Greece and Germany. In: Johnson, Sally/Milani, Tommaso M. (Hg.): Language ideologies and media discourse: Texts, practices, politics. London.

Müller, Frank (2008): B - Ein Buchstabe wird vermisst. Frankfurt a.M.

Neef, Sonja (2008): Abdruck und Spur. Handschrift im Zeitalter ihrer technischen Reproduzierbarkeit. Berlin.

Polenz, Peter von (1996): Die Ideologisierung der Schriftarten in Deutschland im 19. und 20. Jahrhundert. In: Böke, Karin/Jung, Matthias/Wengeler, Martin (Hg.): Öffentlicher Sprachgebrauch. Praktische, theoretische und historische Perspektiven. Opladen, S. 271-282.

Raible, Wolfgang (1991): Die Semiotik der Textgestalt. Erscheinungsformen und Folgen eines kulturellen Evolutionsprozesses. (= Abhandlungen der Heidelberger Akademie der Wissenschaften. Philosophisch-historische Klasse Jg. 1991, Abh. 1). Heidelberg.

Rajewsky, Irina O. (2002): Intermedialität. Tübingen/Basel.

Reddy, Michael J. (1995): The conduit metaphor. A case of frame conflict in our language about language. In: Ortony, Andrew (Hg.): Metaphor and thought. Reprint der 2. Aufl. 1993. Cambridge, S. 164-201.

Röhrig, Johannes (2004): Geheimsache B. Wie die Allianz von Springer („Bild“) und „Spiegel“ gegen die neue RECHTSCHREIBUNG über Monate vorbereitet wurde und warum es am Ende dann doch hopplahopp gehen musste. In: Der Stern, 19.08.2004. Internet: www.stern.de/politik/deutschland/528596.html (Stand: September 2009).

Roth, Kersten Sven/Spitzmüller, Jürgen (Hg.) (2007): Textdesign und Textwirkung in der massenmedialen Kommunikation. Konstanz.

Salen, Katie (2001): Surrogate multiplicities: Typography in the age of invisibility. In: Visible Language 35/2, S. 132-153.

Sandig, Barbara (2006): Textstilistik des Deutschen. 2., völlig neu bearb. u. erw. Aufl. Berlin/New York.

Sauer, Christoph (1997): Visualisierung inbegriffen: Textüberarbeitung und Umgestaltung. In: Jakobs, Eva-Maria/Knorr, Dagmar (Hg.): Schreiben in den Wissenschaften. (= Textproduktion und Medium 1). Frankfurt a.M. u.a., S. 91-106.

Sauer, Christoph (1999): Die Verständlichkeit von Texten, Visualisierungen und Bildschirmen. Untersuchungen zur Leseaufgabenunterstützung. In: Jakobs, Eva-Ma- 
ria/Knorr, Dagmar/Pogner, Karl-Heinz (Hg.): Textproduktion. HyperText, Text, KonText. (= Textproduktion und Medium 5). Frankfurt a.M. u.a., S. 93-109.

Schopp, Jürgen F. (2002): Typographische Schrift als Mittel nationaler Identifikation. Beobachtungen zur Semiose von Druckschriften. In: Höfner, Eckhard/Schröder, Hartmut/Wittmann, Roland (Hg.): Valami más. Beiträge des Finnisch-Ungarischen Kultursemiotischen Symposiums „Zeichenhafte Aspekte der Veränderung“ (25.28.11.1998, Berlin, Frankfurt (Oder) - Slubice). (= Nordeuropäische Beiträge aus den Human- und Gesellschaftswissenschaften 22). Frankfurt a.M. u.a., S. 95-126.

Schröder, Hartmut (1993): Semiotische Aspekte multimedialer Texte. In: Schröder, Hartmut (Hg.): Fachtextpragmatik. (= Forum für Fachsprachenforschung 19). Tübingen, S. 189-213.

Scollon, Ron/Scollon, Suzie Wong (2003): Discourses in place. Language in the material world. London/New York.

Sebba, Mark (2007): Spelling and society. The culture and politics of orthography around the world. Cambridge.

Shannon, Claude E. (1948): A mathematical theory of communication. In: Bell System Technical Journal 27, S. 379-423/623-656.

Silverstein, Michael (2003): Indexical order and the dialectics of sociolinguistic life. In: Language and Communication 23/3-4, S. 193-229.

Spiekermann, Erik (2004): ÜberSchrift. Mainz. [Engl. Orig.: Stop stealing sheep \& find out how type works. Mountain View, CA 1993].

Spillner, Bernd (1982): Stilananalyse semiotisch komplexer Texte. In: Kodikas/Code. Ars Semeiotica 4-5/1, S. 91-106.

Spitzmüller, Jürgen (2006): Typographie. In: Dürscheid, Christa: Einführung in die Schriftlinguistik. 3., überarb. u. erg. Aufl. (= Studienbücher zur Linguistik 8). Göttingen, S. 207-238.

Spitzmüller, Jürgen (2007): Graphisches Crossing. Eine soziolinguistische Analyse graphostilistischer Variation. In: Zeitschrift für Germanistische Linguistik 35/3, S. 397-418.

Spitzmüller, Jürgen (2009): Typographisches Wissen: die Oberfläche als semiotische Ressource. In: Feilke, Helmuth/Linke, Angelika (Hg.): Oberfläche und Performanz. Untersuchungen zur Sprache als dynamische Gestalt. (= Reihe Germanistische Linguistik 283). Tübingen, S. 459-486.

Spitzmüller, Jürgen (im Druck): Floating ideologies: Metamorphoses of graphic ,Germanness'. In: Jaffe, Alexandra/Androutsopoulos, Jannis/Sebba, Mark (Hg.): Orthography as social action: Scripts, spelling, identity and power. Berlin/New York.

Stöckl, Hartmut (2004): Typographie: Gewand und Körper des Textes - Linguistische Überlegungen zu typographischer Gestaltung. In: Zeitschrift für Angewandte Linguistik 41, S. 5-48.

Stöckl, Hartmut (2008): Werbetypographie - Formen und Funktionen. In: Held, Gudrun/Bendel, Sylvia (Hg.): Werbung - grenzenlos. Multimodale Werbetexte im interkulturellen Vergleich. (= Sprache im Kontext 31). Frankfurt a.M., S. 13-36. 
Tschichold, Jan (2001): Erfreuliche Drucksachen durch gute Typographie. Eine Fibel für jedermann. Augsburg. [Faksimile-Nachdruck d. Originalausg. Ravensburg 1960].

Twyman, Michael (1993): The bold idea: The use of bold-looking types in the Nineteenth Century. In: Journal of the Printing Historical Society 22, S. 107-143.

Unger, Gerard ([1992] 2003): Legible? In: Emigre 65, S. 100-111. [Zuerst in: Emigre 23 (1992)].

Unger, Johann Friedrich (1793 [1971]): Probe einer neuen Art Deutscher Lettern. Berlin. [Nachdruck in: Sichowsky, Richard von/Tiemann, Hermann (Hg.) (1971): Typographie und Bibliophilie. Aufsätze und Vorträge über die Kunst des Buchdrucks aus zwei Jahrhunderten (Jahresgabe der Maximilian-Gesellschaft 1969). Hamburg, S. 24-29].

Wagner, Franc (2006): Zur Intermedialität in den neuen Medien. In: Kodikas/Code Ars Semeiotica 29/1-3, S. 45-56.

Waller, Robert (1996): Typography and discourse. In: Barr, Rebecca/Kamil, Michael L./ Mosenthal, Peter (Hg.): Handbook of reading research. Bd. 2. Mahwah, S. 341-380.

Warde, Beatrice ([1932] 1991): Printing should be invisible. In: Bennett, Paul A. (Hg.): Books and printing. A treasury for typophiles. Savannah, S. 109-114. [Originalausg.: New York 1932].

Wehde, Susanne (2000): Typographische Kultur. Eine zeichentheoretische und kulturgeschichtliche Studie zur Typographie und ihrer Entwicklung. (= Studien und Texte zur Sozialgeschichte der Literatur 69). Tübingen.

Wiegand, Herbert Ernst (1999): Artikel einsprachiger Lernerwörterbücher, Textgestaltungswahrnehmung und Suchbereichsstrukturen. Plädoyer für übersichtliche Printwörterbücher im Zeitalter der neuen Medien. In: Skibitzki, Bernd/Wotjak, Barbara (Hg.): Linguistik und Deutsch als Fremdsprache. Festschrift für Gerhard Helbig zum 60. Geburtstag. Tübingen, S. 259-281.

Wiegand, Herbert Ernst (2000): Über Suchbereich, Suchzonen und ihre textuellen Strukturen in Printwörterbüchern. Ein Beitrag zur Theorie der Wörterbuchform. In: Wiegand, Herbert Ernst (Hg.): Wörterbücher in der Diskussion IV. Vorträge auf dem Heidelberger Lexikographischen Kolloquium. (= Lexicographica: Series Maior 100). Tübingen, S. 233-301.

Wienen, Markus (2007): Multisensorische Textrezeption. Zum texttheoretischen Potential einer Semiolinguistik des Textes. In: Zeitschrift für Angewandte Linguistik, S. 69-95.

Willberg, Hans Peter/Forssman, Friedrich ([1999] 2001): Erste Hilfe in Typographie. Ratgeber für Gestaltung mit Schrift. 3. Aufl. Mainz. [Originalausg.: Mainz 1999].

Willberg, Hans Peter/Forssman, Friedrich ([1997] 2005): Lesetypographie. 4., komplett überarb. u. erw. Aufl. Mainz. [Originalausg.: Mainz 1997].

Wolf, Werner (2002): Intermedialität. Ein weites Feld und eine Herausforderung für die Literaturwissenschaft. In: Foltinek, Herbert/Leitgeb, Christoph (Hg.): Literaturwissenschaft: intermedial - interdisziplinär. Wien, S. 163-192. 
Leiblichkeit und Räumlichkeit sprachlicher Praktiken 

Angelika Linke

\title{
Historische Semiotik des Leibes in der Kommunikation: Zur Dynamisierung von Körper und Sprache im ausgehenden 17. und im 18. Jahrhundert
}

\begin{abstract}
Die Wahrnehmung menschlicher Kommunikation ist historisch geprägt; entsprechend veränderlich sind die Normen und Werte, an denen kommunikatives Verhalten zu unterschiedlichen Zeiten gemessen wird. So führt die „Entdeckung“ der Multimodalität menschlicher Kommunikation in der gegenwärtigen Gesprächsforschung und die damit verbundene neue Aufmerksamkeit auf die Zeichenhaftigkeit des Körpers wie auf die Dimension des Raumes zu einem neuen Verständnis von Kommunikation und zu einer veränderten Beurteilung sprachlicher Phänomene.

Doch schon in frühmoderner Zeit war der gesellschaftliche Blick auf den kommunizierenden Menschen in einer für heutige Massstäbe bemerkenswerten Weise auf die „Beredsamkeit des Leibes“ (Kemp 1975, S. 111) gerichtet. Sprachlichkeit wird als an Leiblichkeit gebunden wahrgenommen, als Teil eines komplexen, raumbezogenen kommunikativen Auftritts, der ständisch geregelt und normiert ist. Dies gilt für das 17. und auf weite Strecken auch noch für das 18. Jahrhundert erst das bürgerliche Sprachprojekt löst in der Wahrnehmung die Sprache zunehmend vom Leib.

Vom 17. ins 18. Jahrhundert hinein lassen sich allerdings Veränderungen im Beschreibungsvokabular für den körperlich-sprachlichen Auftritt beobachten, und in Text- wie Bildzeugnissen zeigt sich ein Wandel in diesem Auftritt bzw. im Blick der Zeitgenossen darauf. Diese Veränderungen werden im Folgenden als (kollektiv)stilistischer Wandel beschrieben und der Zeichenwert dieses Wandels wird als ,Verschlankung' und ,Dynamisierung' bestimmt. Und insofern diese (kollektiv)stilistischen Veränderungen als Medium der Selbstformierung der tragenden Sozialformation der Zeit, d.h. der Adelsgesellschaft um 1800, verstanden werden, wird der beobachtete Stilwandel als Prozess der Selbst-Dynamisierung der gesellschaftlichen Leitformation ${ }^{1}$ der Epoche gedeutet.
\end{abstract}

\section{Einleitung}

Neuorientierungen in den Wissenschaften sind nicht selten mit technischen Neuerungen verbunden. Dies gilt auch für die ,Entdeckung' interaktiver Multimodalität in der Gesprächsforschung. Die neue Aufmerksamkeit auf die kommunikative Zeichenhaftigkeit des Körpers, auf den Raum als Ressource und Produkt von Interaktion sowie auf die kommunikative

Ich spreche hier und an anderer Stelle von Formation, wenn ich in ,neutraler ${ }^{6}$ Weise auf eine gesellschaftliche Gruppierung referiere und dabei die ideologischen Konnotationen oder auch wissenschaftsgeschichtlichen Diskursbindungen vermeiden möchte, welche die Ausdrücke Stand, Klasse, Schicht immer schon mitführen. 
Nutzung materieller Objekte ist nicht zuletzt ein Effekt neuer Technologien, die es Forschenden erlauben, in handlicher Weise die visuellen Aspekte von Interaktionen zu verdauern und der minutiösen Analyse zugänglich zu machen.

Doch auch wenn technische Neuerungen dazu führen können, dass bestimmte Phänomene der wissenschaftlichen Untersuchung überhaupt erst oder aber zumindest einfacher zugänglich werden, werden dadurch nicht zwangsläufig neue Forschungsfragen ausgelöst oder unsere Wahrnehmung der untersuchten Phänomene verändert. Denn diese Wahrnehmung ist immer auch kulturell und historisch geprägt, in alltäglichen wie in wissenschaftlichen Kontexten. Dies gilt auch für die Wahrnehmung menschlicher Kommunikation. Die Ausblendung von Körper und Raum aus der wissenschaftlichen Beschäftigung mit menschlicher Kommunikation und die Fokussierung auf eine weitgehend körperfrei gedachte Sprache ist deshalb sicher nicht nur der Schwierigkeit geschuldet, die multimodale Komplexität von Face-to-Face-Kommunikation technisch zugänglich zu machen, sondern ebenso der Tatsache, dass - um eine Begriffsdichotomie von Hans Ulrich Gumbrecht aufzugreifen - Sprache und Kommunikation seit dem 18. Jahrhundert zunehmend als sinnkulturelle und weniger als präsenzkulturelle Phänomene bzw. Konzepte modelliert wurden (Gumbrecht 2004, passim).

Dass und in welcher Weise unsere Wahrnehmung des kommunizierenden Menschen kulturell definiert und geschult ist, wird nicht zuletzt dann deutlich, wenn wir uns mit historischen Texten - auch Bildern - beschäftigen, die uns erlauben, diese Wahrnehmung in früheren Epochen zu rekonstruieren und mit heutigen Wahrnehmungsmustern zu vergleichen.

Etwas plakativ lässt sich sagen: Was in der Gesprächs- und Kommunikationsforschung gegenwärtig als Neuerung betrachtet werden muss, ist für die Gesellschaftsethik und den gelehrten wie den populären Umgangsdiskurs der Frühmoderne selbstverständlich: Der gesellschaftliche Blick auf den kommunizierenden Menschen ist auch und oft als erstes auf den Körper gerichtet. Die Beredsamkeit des Mundes ist im Bewusstsein der Zeitgenossen stets mit einer „Beredsamkeit des Leibes“2 verknüpft; Sprachlichkeit wird als an Leiblichkeit gebunden wahrgenommen, als Teil eines komplexen, raumbezogenen kommunikativen Auftritts, der ständisch geregelt und normiert ist. Dies gilt für das 17. und auf weite Strecken auch noch für das 18. Jahrhundert - erst das bürgerliche Sprachprojekt löst in der Wahrnehmung menschlicher Kommunikation die Sprache zunehmend vom Leib.

\footnotetext{
Ich entlehne diese Formulierung aus dem Titel eines Beitrages von Wolfgang Kemp zur „Körpersprache als künstlerisches und gesellschaftliches Problem der bürgerlichen Emanzipation“ (Kemp 1975). Kemp trifft mit dieser Formulierung sehr genau das Verständnis, welches im adlig geprägten Umgangsdiskurs des 17. und frühen 18. Jahrhunderts mit Blick auf die Funktion des Körpers in der Kommunikation zum Tragen kommt.
} 
Trotz der grundlegenden und gleichbleibenden Körperorientiertheit der Umgangs- und Kommunikationsethik des 17. und 18. Jahrhunderts - zu der auch die Rhetorik zu zählen ist - lassen sich in diesem Zeitraum Veränderungen im Beschreibungsvokabular für den körperlich-sprachlichen Auftritt beobachten, und in Text- wie Bildzeugnissen zeigt sich ein Wandel im Blick der Zeitgenossen auf das, was in den Ausdrücken der Zeit als Conduite und Conversation bezeichnet wird.

Im Folgenden möchte ich sowohl der bemerkenswerten Körperorientierung des frühmodernen Umgangsdiskurses nachgehen als auch die Veränderungen dieses Diskurses vom 17. ins 18. Jahrhundert skizzieren und in ihrer Sozialsemiotik beleuchten. Die Quellen, auf die ich mich dabei stütze, sind in erster Linie normative bzw. reflexive Quellen: Umgangs- und Klugheitslehren, Complimentier- und Gesprächsbücher, zeitgenössische Berichte und Memoiren. Diese Quellen lassen die Rekonstruktion faktischen kommunikativen Verhaltens nur indirekt und mit grossem Vorbehalt zu. Was sie aber zeigen, ist der kulturelle Blick, ist der Wahrnehmungsfilter, den zeitgenössische Beobachter anlegen. Wir können davon ausgehen, dass kommunikative Verhaltensweisen, die in normativ-reflexiven Quellen thematisiert werden, im Umgangsdiskurs der Zeit als sozial relevant und eben deshalb auch als kommentarwürdig gelten. ${ }^{3}$ Der Einblick, den uns diese Quellen ermöglichen, betrifft also nur selten das kommunikative Verhalten in unmarkierten Alltagssituationen, sondern in erster Linie Verhalten in förmlicheren bzw. öffentlichen sozialen Situationen, denen besondere soziokulturelle Aufmerksamkeit zukommt.

\section{Die „Beredsamkeit des Leibes“}

Im Umgangsdiskurs des 17. wie auch noch des 18. Jahrhunderts kommt körperkommunikativen Praktiken eine aus heutiger Sicht oft befremdliche Aufmerksamkeit zu. „Galante Conduite“ und „recommendable Politesse“ - zeitgenössische Leitbegriffe idealen gesellschaftlichen Verhaltens - werden in den Klugheitslehren der Zeit nie nur an den ,zierlichen Reden“ allein, sondern immer auch an den ,wolanständigen Gebehrden" ${ }^{\text {“4 festge- }}$ macht. Es reicht nicht - wie es im 1703 in Leipzig erschienenen „Commode[n] Manual, Oder Hand=Buch“ des gesellschaftlichen Umgangs heisst - ,höffliche und glatte Worte zu geben“, sondern es gilt auch, „eine gute Mine / auch darneben eine freundliche stellage und liebreiches Ansehen zu machen", ja, die Leser werden sogar aufgefordert, ,,ingleichen sich einen wohl=proportionierlichen Leib anzugewehnen“, eine Aufgabe, ,worzu denn die öfftere Übung im Tantzen das meiste contribuiren kan“" (Manual 1703, S. 6 f., Her-

\footnotetext{
$3 \quad$ Vgl. ausführlicher Linke (1996, S. 34 ff.).

4 Formulierungen aus dem Titel des Manual (1703).
} 
vorhebung A. Linke). ${ }^{5}$ Der Hinweis auf die Nützlichkeit der Tanzkunst für den Auftritt in der gesellschaftlichen Kommunikation begegnet in den Umgangslehren der Zeit immer wieder, eine Tanzkunst im Übrigen, in welcher der Mann im Mittelpunkt steht und die vom männlichen Part eine hohe Körperbeherrschung erfordert. ${ }^{6}$ Die Darstellung eines tanzenden Paares aus der zweiten Hälfte des 17. Jahrhunderts in Abb. 1 kann dies illustrieren. ${ }^{7}$

Der kommunikative Auftritt wird im Umgangsdiskurs des 17. und 18. Jahrhunderts also als ein körperlicher Auftritt konstruiert - entsprechend häufig begegnet in der normativen Beschreibung kommunikativen Verhaltens die Zwillingsformel „Worte und Geberden“ oder auch „Geberden und Worte“ ${ }^{8}$ Die Aneignung geselliger Tugenden, manierlicher Tischsitten sowie der Kunst des Gesprächs erscheint eingebettet in die Ausbildung des leiblichen Anstands und ist im weitesten Sinne als Teil dieser Ausbildung zu verstehen. ${ }^{9} \mathrm{Ja}$, die ,annehmliche Gesprächsamkeit“ selbst hat - so eine Umgangslehre von 1694 - ,ihr Absehen auf drey Stücke / auf die Reden / auf die Leibesstellung und auf die Kleider" (Stands-Person 1695, S. 177, Hervorhebung A. Linke). ${ }^{10}$ Hier werden also Sprachlichkeit, Körperlichkeit und Kleidung im Begriff der „Gesprächsamkeit“ zusammengefasst. Entsprechend

$5 \quad$ Auch Rudolf zur Lippe konstatiert in seiner dichten und gewichtigen Untersuchung zur „Naturbeherrschung am Menschen" für das italienische 16. Jahrhundert, dass mit Blick auf die leiblichen Formen des gesellschaftlichen Auftritts „,der choreographierte Tanz [...] offensichtlich als eine besonders pointierte, aber nicht grundsätzlich unterschiedene Form des Auftretens verstanden [wird]" (zur Lippe 1974, S. 236).

6 Das hauptsächliche Zielpublikum war sowohl im Tanzunterricht als auch in den Umgangslehren ein männliches - in einer Anstandslehre von 1630 wird explizit und bedauernd vermerkt: „Es ist fürwar [...] ein grosse Schand / daß das Adelicht Frawenzimmer nicht eben sowol / als die jungen Adelspersonen tanzen lernen / damit ein Vnderschid seye vnder jhnen vnd dem gemainen Gesindel“ (Hobelbank 1630, S. 49). Und noch in der ersten Hälfte des 18. Jahrhunderts vermerkt Franz Theodor von Fürstenberg, ,[nicht] um ein paar kleine Töchter [...] sondern wegen meiner Söhne habe ich ad tempus ein Sprachmeister [...] als wie ein Tanzmeister [...] in mein Haus aufgenommen" (Archiv v. Fürstenberg-Opladen 23/10m, hier zitiert nach Reif 1979, Anm. 67 zu S. 146).

7 Bei dieser Abbildung handelt es sich um einen Ausschnitt aus einem Gemälde des flämischen Malers Gonzales Coques, 1618-1684. Coques erhielt seine Ausbildung bei Pieter Brueghel dem Jüngeren und David II Rijckaert und war bereits zeitgenössisch vor allem als Maler von sog. „Conversationsstücken“ bekannt und geschätzt. Die Abbildung habe ich Boehn (1923a) entnommen (Abb. 26, ohne Pag.).

8 Vgl. etwa für beide Reihenfolgen innerhalb kürzerer Textabschnitte: Galant Homme (1694, $\mathrm{A} 4 \mathrm{v}$ und $\mathrm{A} 6 \mathrm{v})$.

9 Es geht, wie es der Titel einer Verhaltenslehre von 1694 formuliert, darum, „wie man sich in der Galanten Welt in Worten und Geberden / in Aufwarten / gehen / sitzen / essen / trinkken / Habit etc. Manierlich aufführen und beliebt machen kan“ (Galant Homme 1694).

10 Auch bei der näheren Erläuterung der „annehmlichen“ Rede werden die körperlichen Aspekte von Prosodie und Aussprache vor den inhaltlichen Aspekten gewürdigt bzw. reglementiert: „Die Rede soll rein und wollautend seyn / nicht geradebrecht / nicht allzu laut / auch allzu leisse / nit stammelnd / sondern deutlich; der Inhalt soll Erbar und verständig seyn / nicht gering noch gezwungen / sondern auff die Materie / davon man redet / klappend.“ (Stands-Person 1695, S. 177 f.). 


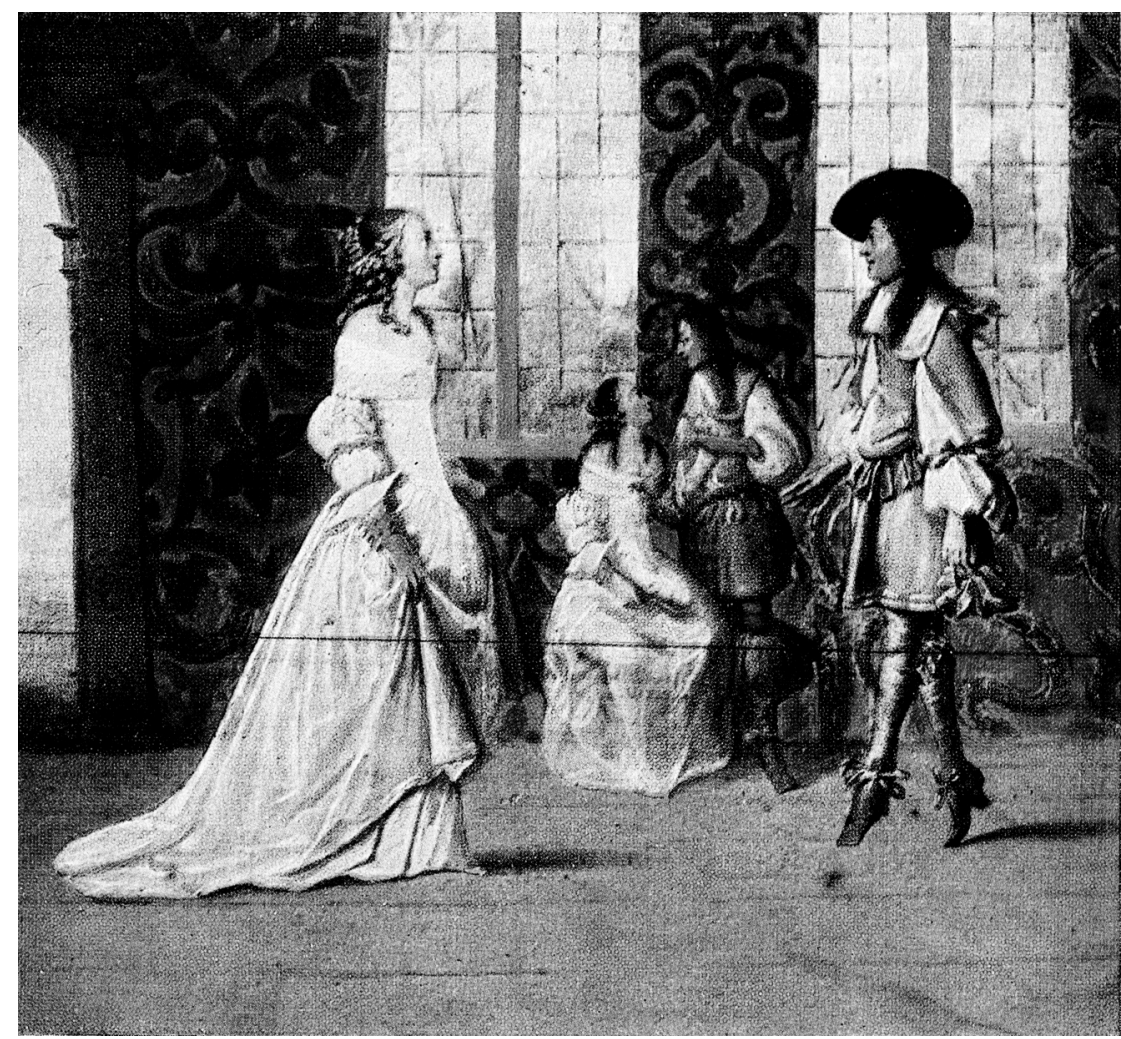

Abb. 1

ist auch die Semantik des Begriffs Conversation im 17. Jahrhundert noch eine andere. Sie ist noch nicht auf die verbale Interaktion verengt - dies ist ein Prozess, der im Verlauf des 18. Jahrhunderts stattfindet - sondern umfasst extensional auch Interaktionsformen, die nicht zwingend vom Gespräch begleitet sein müssen, wie etwa die Promenade, das gemeinsame Musizieren, das Kartenspiel oder eben den Tanz. ${ }^{11}$ Ähnliches gilt für den Begriff des Compliments, der als Programmbegriff im Umgangsdiskurs der Frühmoderne noch sehr unterschiedliche interaktive Praktiken subsummieren kann: Gruss, Höflichkeitsgeste, Aufmerksamkeitssignal oder Mitgefühlsbezeigung. Wo der Complimentbegriff auf die Mündlichkeit bezogen ist im 17. und zum Teil auch noch im 18. Jahrhundert bezieht sich der Begriff

$11 \quad$ Vgl. zu dieser semantischen Entwicklung ausführlicher Linke (1996, S. 132 ff.). Vgl. zudem Burke (1993, S. 95), der mit Verweis auf den Titel von Stefano Guazzos La civil conversazione von 1574 (einer der ersten und gattungsbegründenden Umgangslehren in der europäischen Literatur) die weite Semantik des italienischen Ausdrucks conversazione auch noch im 18. Jahrhundert hervorhebt und als mögliche Übersetzung soviel wie „Gesellschaft“ bzw. „gesellschaftlicher Umgang" vorschlägt. 
auf Mündlichkeit und Schriftlichkeit gleichermassen -, verbindet sich in den damit bezeichneten Praktiken der sprachliche mit dem leiblichen Ausdruck, ${ }^{12}$ wobei die nonverbale Komponente die selbständigere ist: ${ }^{13}$ Complimente, „so in schicklichen Geberden und Stellung des Leibes bestehen“ (Complimentir-Büchlein, o.J. [1. Hälfte 18. Jh.], S. 13) sind ohne weiteres möglich, während das „Wort-Compliment“" ohne entsprechende Gebärde undenkbar ist. ${ }^{14}$

Wort und Gebärde, Leibesstellung und Kleidung bilden im 17. und frühen 18. Jahrhundert in der Wahrnehmung menschlicher Kommunikation ein semiotisches Ensemble.

Dieses Ensemble allerdings ist ein ständisch markiertes. Umgangsdiskurs und Gesellschaftsethik sind im 17. Jahrhundert dezidiert adlig geprägt und noch weit ins 18. Jahrhundert hinein zumindest adlig grundiert ${ }^{15}-$ alle bisher zitierten Passagen beziehen sich auf einen höfischen Kontext, sind als Anleitungen zu einem Habitus im Sinne Bourdieus zu lesen, der adlig konnotiert ist, auch wenn zweifellos hofnahe bürgerliche Kreise daran partizipieren. Die Aufmerksamkeit, die in den Anstandslehren des 17. und 18. Jahrhunderts der „ehrbaren Stellung des Leibs“, der „geziemend eingerichteten“ Bewegung oder dem ,abgemessenen“16 Gang zukommt - all dies gängiges zeitgenössisches Beschreibungsvokabular -, dokumentiert also eine aus heutiger Perspektive bemerkenswert scharfe Wahrnehmung (und Reglementierung) des Körpers als kommunikatives Medium und als Zeichen, ${ }^{17}$ gleichzeitig aber - und dies darf nicht übersehen werden - auch die Standesgebundenheit und damit die deutliche Sozialsemiotik dieser Beredtsamkeit des Leibes. ${ }^{18}$

12 So gibt auch das Zedler'sche Universallexikon die Definition: „Compliment, nennt man Höfflichkeiten, die man einem mit Worten und Geberden bezeiget" (Zedler 1732-1754, Bd. 6, Sp. 874).

13 Manfred Beetz (1990, S. 19) weist darauf hin, dass bis ins 18. Jahrhundert hinein in den Umgangslehren kein Unterschied zwischen mündlichen und schriftlichen Complimenten gemacht wurde. Die Vorlagen für verbale Complimente zu den unterschiedlichsten Gelegenheiten (Besuche, Geburtstage, Aufwartungen zu Feiertagen, Verabschiedungen vor längeren Abwesenheiten, Taufen, Hochzeiten etc.), wie sie in vielen Anstandslehren über manchmal hunderte von Seiten abgedruckt wurden, waren - allenfalls mit kleinen individuellen Abänderungen - sowohl für den schriftlichen wie für den mündlichen Gebrauch gedacht.

14 Auch Adelung (1793-1801) definiert Compliment noch als „eine Verbeugung aus Ehrfurcht oder Hochachtung“. Vgl. zur Begriffsgeschichte von „Compliment“ ausführlicher Linke (1996, S. 104 ff.).

15 Zum Teil macht schon der (oft sehr ausführliche) Titel von Umgangslehren klar, dass sie sich an „Adelspersonen“ (Hobelbank 1630) bzw. an Personen ,vornehmen Stands“ (Stands=Person 1695) richten oder zumindest in erster Linie davon handeln, ,wie man bey Hofe sich aufzuführen hat" (Scharffenberg 1718) etc.

16 Alle Belegzitate aus Complimentist (1729, S. 287, 290, 291).

17 Dies zeigt sich auch daran, dass häufig die ersten Kapitel von Klugheitslehren dem Körperverhalten gewidmet sind, vgl. Linke (1996, S. 65 f.).

18 Dabei darf man sich die adlige ,Beredtsamkeit des Leibes' nicht als ein völlig einheitliches, sondern muss sie sich vielmehr als in sich variables, nach sozialen Parametern ausdifferen- 


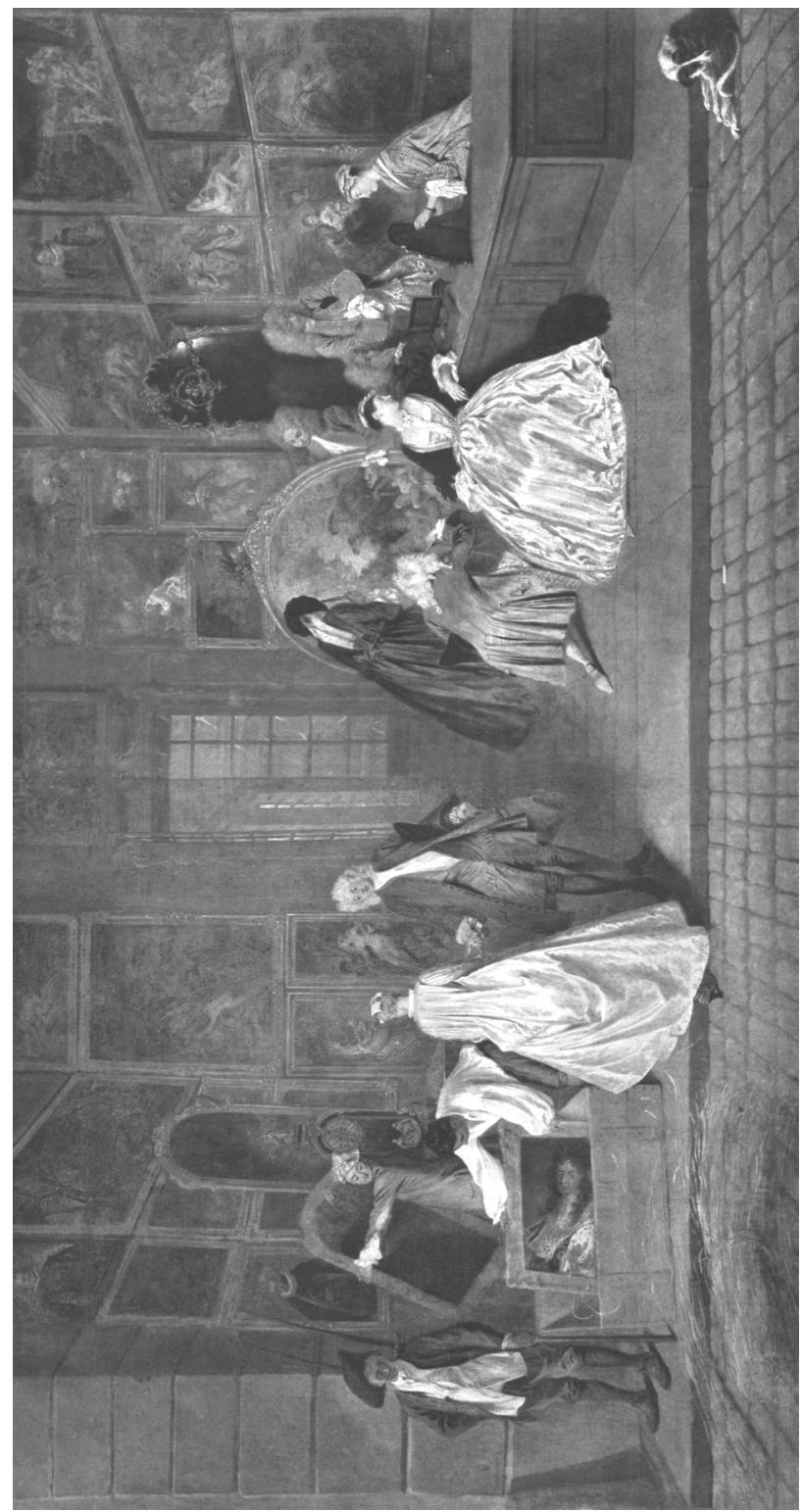

Abb. 2

ziertes System vorstellen. Wie dies auch für sprachliche Ausdrucksformen gilt, haben wir sowohl mit regionalen ,Varietäten' als auch mit einem gewissen Unterschied zwischen ländlichen und residenziellen Verhältnissen zu rechnen sowie auch mit spezifischen Traditionen einzelner Höfe. Auch ,der' Adel ist - ebensowenig wie ,das` Bürgertum - keine homogene Sozialformation, was gerade die neuere Adelsforschung vermehrt betont und berücksichtigt hat, vgl. exemplarisch Reif (1999, S. 6 ff.; Bauer 1993). 
Dies wird exemplarisch greifbar auf einem Gemälde Antoine Watteaus (Abb. 2), das 1720 als Ladenschild für den Pariser Kunsthändler Edmé Gersaint ausgeführt und später von Friedrich II. erworben wurde und das heute in Schloss Charlottenburg in Berlin ausgestellt ist. Seinen Wert als historische Quelle erhält das Bild nicht zuletzt aus denjenigen Gründen, die der Auftraggeber auch als ausschlaggebend für den grossen Erfolg des Gemäldes beim zeitgenössischen Publikum anführt, dass es nämlich, so Edmé Gersaint - „nach dem Leben gemacht [war]“ und „die Posen [...] so wahrheitsgetreu und so natürlich [waren]" (Gersaint 1744, S. 183 f., zitiert nach Rosenberg 1985, S. 447). Mit Blick auf diese von Gersaint attestierte „Natürlichkeit" der Posen ist in unserem Kontext vor allem das Paar in der Bildmitte interessant (vgl. den Ausschnitt in Abb. 3), das im Figurenreigen des Gemäldes nicht nur durch den Hell-Dunkel-Kontrast der Kleidung hervorgehoben ist, sondern ebenso durch die ganz auf repräsentative, Conversation' ausgerichtete Präsentation der Körper. Dies wird bei der männlichen Figur in ihrer Frontalstellung zum Betrachter hin besonders deutlich. Sowohl Kopfhaltung, Körperbiegung, die angedeutete Armbewegung als auch die Standbein-Spielbein-Stellung des jungen Kavaliers verraten eine Körperspannung, die jedoch ohne einen augenfälligen äusserlichen Bezugspunkt, ohne praktisch-instrumentelle Funktion ist, der aber gerade in dieser vordergründigen Absichtslosigkeit (und damit auch Schmuckhaftigkeit) hohe soziokulturelle Zeichenhaftigkeit als Mittel der Selbstauszeichnung zukommt. ${ }^{19}$ Kontrastiert wird dieser Körperauftritt durch die stärker in sachfunktionaler Bewegung und Drapierung gehaltene Gruppe rechts davon sowie durch die männliche Figur links aussen, in der vielleicht der Lastträger dargestellt ist, der später die Holzkisten auf sein Tragegestell laden wird. Die Darstellung dieses Mannes, seine ungespannte Körperhaltung mit durchgedrückten Knien, das Körpergewicht gleichmässig auf beide Beine verteilt und zusätzlich auf einen Stock gestützt, sowie die einfache, nachlässig getragene und so die Körpersilhouette mehr verwischende als betonende Kleidung ${ }^{20}$ machen im Kontrast zum mittleren Paar die performative Potenz von Körperlichkeit in der ständischen Zuordnung deutlich und zeichnen den so Dargestellten als Angehörigen der unteren Mittelschicht aus, der im Gegensatz zum Paar in der Bildmitte - im Bewusstsein der Zeitgenossen über keinen kulturell zeichenhaften Körper verfügt.

19 Auf diesen Effekt verweist auch Rudolf zur Lippe für den italienischen Kontext, wenn er die grundsätzliche Bedeutung des quattrocentonischen Ideals des „,ben portar la vita“, des ,Tragens der Taille für den „Benimm in der grossen Welt“ (zur Lippe 1974, S. 236, mit Bezug auf Caroso 1581) auch noch weit über das Quattrocento hinaus herausstellt. Die damit angesprochene Körperspannung und Körperbewusstheit kann als höfische Überformung des kriegerischen Körpers gedeutet werden, als Spielform im Sinne Simmels (Simmel 1920, S. 54 ff.) und damit als ,Erinnerung' der Sozialformation an für die zeitgenössische Gegenwart kaum mehr relevante Körperfunktionen, deren ursprüngliche identitätsstiftende Funktion jedoch in symbolischer Form erhalten wird.

20 Diese Darstellung ist ebenso wie die des Kavaliers in erster Linie eine Interpretation Watteaus. 


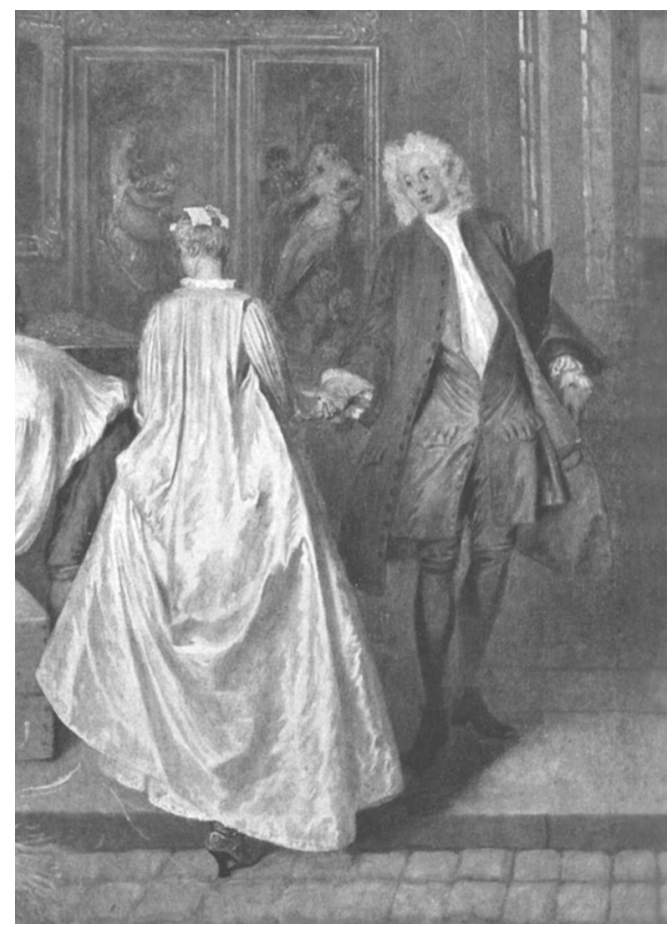

Abb. 3

Watteaus Gemälde ist als Programmbild zu lesen, das die kultur- und sozialgeschichtlichen Widersprüche der Zeit einfängt und das vielleicht noch mehr um dieser Spannung als um seiner naturalistischen Effekte willen den dokumentierten Erfolg beim zeitgenössischen Publikum hatte. Denn hier wird einerseits in beinahe schon karikaturhafter Weise der epochale Umbruch des 18. Jahrhunderts, die gesellschaftshistorische Verabschiedung der absolutistischen Adelsgesellschaft thematisiert - der Ladendiener versorgt soeben das Portrait Ludwigs des Vierzehnten in einer Holzkiste ${ }^{21}$ - und andererseits wird im selben Gemälde der ästhetischen Körperlichkeit adlig konnotierter Kommunikationskultur ein glänzender Auftritt gewährt. ${ }^{22}$

$21 \quad$ Kunstgeschichtliche Studien konstatieren hier meist einen direkten Bezug zum berühmten Bild Ludwigs XIV. von Hyacinthe Rigaud, vgl. Rosenberg (1985, S. 450).

22 Die Ansichten über die ständische Zuordnung des Paares in der Mitte gehen in der wissenschaftlichen Literatur zu Watteaus Bild auseinander. Marita Bombek identifiziert die Dame aufgrund des Mantelkleides (auch: Contouche) als „wohlhabende[n] Frau des städtischen Bürgertums“" (Bombek 2005, S. 280), eine ständische Verortung des Kavaliers erfolgt dagegen nicht, auch wenn Bombek festhält, dass seine Bekleidung vornehm ist. Thiel (1987, S. 250) konstatiert die allgemeine Beliebtheit des Mantelkleides in der Zeit der Régence, in der auch Watteaus Gemälde entsteht, zitiert aber auch Liselotte von der Pfalz, welche die Contouche als „kammermegtisch“ ablehnt. Worauf genau sich diese Charakterisierung bezieht, wird allerdings nicht klar. Die im Mantelkleid der Dame besonders prominenten, von 
Angesichts solchen Körperzeremoniells erscheint es aus heutiger Perspektive zunächst doppelt unverständlich, wenn etwa Wilhelmine von Bayreuth, preussische Prinzessin und Lieblingsschwester Friedrichs des Grossen, in ihren Memoiren nicht nur davon berichtet, wie sie als junge Prinzessin am preussischen Hof von ihrem Vater bei Auseinandersetzungen immer wieder geschlagen und an den Haaren gezerrt wird, sondern dass ihr Vater auch ihrem Bruder sowie seiner Gemahlin gegenüber im Zorn handgreiflich wird. ${ }^{23}$ Die kulturelle Konstruktion eines lesbaren Körpers ist ganz offensichtlich nicht mit dessen fleischlicher Unantastbarkeit verbunden, im Gegenteil: Im 17., aber auch noch im 18. Jahrhundert sind modern-westliche Körperschwellen noch nicht existent. Hinweise darauf, dass man im Gespräch dem Gegenüber nicht am Rock herumzupfen, nicht an dessen Knöpfen drehen ${ }^{24}$ und sich dem Gesprächspartner insgesamt nicht allzusehr nähern solle, weil nicht jedermann der Geruch fremden Atems angenehm sei, ${ }^{25}$ gehören ebenso zum Kanon der Umgangsregeln wie Anweisungen für die Durchführung einer galanten Reverenz, mit der sowohl der eigene wie der Status des Gegenübers bestätigt bzw. erhöht wird. Der von Norbert Elias geschilderte „Prozess der Zivilisation“ (Elias 1976), d.h. die zunehmende, stark auf den Körper bezogenen Sozialdisziplinierung, die mit einer kontinuierlichen Erhöhung der Peinlichkeitsschwellen einhergeht, ist mit der semiotischen Aufladung und Nutzung des Körpers zwar wohl verschränkt, wird von dieser aber nicht etwa vorausgesetzt - der zeichenhafte und der biologische Körper sind in ihrer Funktionalität wenig interdependent.

Watteau oft gemalten und deshalb auch so genannten „Watteaufalten“ in der Rückenlinie des mantelartigen Obergewandes markieren besonders deutlich die durchgehende Form des Kleides, welche durch das Weglassen oder die optische Vertuschung der Taillennaht erreicht wird. Da diese durchgehende Stofflinie im 17. und auch noch im 18. Jahrhundert für das adlige Damenkleid typisch war, könnte die Bekleidung der Dame aber auch eine entsprechende ständische Zuordnung der Trägerin signalisieren. (Diesen und weitere hilfreiche Hinweise auf relevante Entwicklungen in der Damenmode verdanke ich Julia Burde.) Unabhängig von dieser allenfalls auch zeitgenössisch gegebenen Unschärfe der exakten sozialen Verortung des Paares ist jedoch die adlige Konnotierung des dargestellten Körperausdrucks des jungen Kavaliers.

23 Wilhelmine führt in ihren Memoiren immer wieder entsprechende Szenen an (Memoiren 2007, S. 86, 100, 104, 109, 137). Vgl. für ähnliche Berichte handgreiflicher familiärer Auseinandersetzungen gerade in höchsten Adelskreisen Boehn (1923a, S. 155). Und auch in Umgangslehren finden sich immer wieder Hinweise darauf, dass ungebührliches Verhalten gegenüber Ranghöheren im schlimmeren Fall dazu führen kann, dass man von deren Entourage bei sich bietender Gelegenheit „ein wenig ausgeklopfft“ (Manier 1738, S. 119) wird. Die „Formalität-Informalitäts-Spanne“ (Elias 1989, passim) ist gegenüber dem 19. und 20. Jahrhundert, wo sich diese, so die Diagnose von Norbert Elias, zunehmend verringert und deutlich „,in die Richtung auf gleiches Verhalten in allen Lebenslagen“ (Elias 1989, S. 42) tendiert, also noch sehr gross.

24 Vgl. beispielhaft für viele ähnliche Passagen in anderen Umgangslehren etwa Mouton (1744, S. 93): „Allein es ist sehr lächerlich, wenn man mit jemandem redet, dessen Knöpfe anzufassen, und daran, wie auch an den Zipfelns des Schnuptuchs, an dem Wehr=Gehänge, an seinem Mantel zu ziehen, oder ihm einen Stoß mit dem Ellbogen zu geben [...].“ 
Eine wesentliche Voraussetzung des Körperbezugs adliger Kommunikationskultur hingegen ist der dezidierte Raumbezug adliger Identität: Ersterer ist ohne letzteren nicht zu denken.

\section{Die Sozialsemiotik des Raumes}

Es ist die Dimensionalität des Raumes, die wie keine andere Dimension die adlige Lebenswelt in den unterschiedlichsten Erscheinungsformen praktisch wie semiotisch prägt. Dies gilt bereits für die grundlegende Bedeutung der Herrschaft über den Raum in Form des adligen Grundbesitzes, und es gilt für die ornamental überhöhte Inszenierung von Raum in Schlössern, Parkanlagen und in residenzstädtischer Architektur. ${ }^{26}$

Raum und Raumbezüge werden zudem für die performative Herstellung und Darstellung gesellschaftlicher Hierarchie und sozialer Machtpositionen jenseits der Ausübung körperlicher Gewalt genutzt. Die adlige Raumsemiotik des 17. und 18. Jahrhunderts projiziert die traditionell durch Vertikalität symbolisierte Macht, das Oben und Unten, allerdings vermehrt auf die Horizontalität von Nähe und Distanz, d.h. auf den Raumbezug zum Herrscher als dem Zentrum eines Machtkreises - nicht zuletzt in der Architektur ist die mittelalterliche Machtsemiotik der „Burg auf dem Berg“ (Paravicini 1997, S. 25) und des hohen Turmes weitgehend ersetzt durch die Semiotik der ausladenden Pracht von Schlossanlagen in der Ebene. ${ }^{27}$ Die Zeichenhaftigkeit des Raumes gilt aber auch im kleineren Massstab: Den Sitzordnungen bei zeremoniellen Mahlzeiten, der Frage, wer bei Empfängen das Anrecht auf einen Armsessel hat oder mit einem Taburett vorlieb nehmen muss und wer bei Zusammenkünften von weitgehend Ranggleichen den Vortritt hat, wird in Hofordnungen wie in Klugheitslehren, in Chroniken und Festbeschreibungen, in Tagebuchaufzeichnungen und Korrespondenzen entsprechend viel Aufmerksamkeit geschenkt - nicht nur im Kontext absolutistischer Machtformation des 17. Jahrhunderts, sondern zeitlich noch weit über die aufgeklärten Brechungen höfisch-monarchischer Selbstund Fremddefinition hinaus. Was als Urszene höfischer Raumsemiotik des Mittelalters in die deutsche Literaturgeschichte eingegangen ist - der Streit zwischen Kriemhild und Brünhild um den Vortritt beim Besuch der Messe im Dom zu Worms - findet noch in den Memoiren der bereits erwähnten Wilhelmine, Markgräfin von Bayreuth, seinen vielfachen Widerhall.

Die gegenüber heutigem Mass höhere Sensibilisierung auf die Zeichenhaftigkeit von Körper und Raum in der Kommunikation dürfte zudem nicht zuletzt mit der Tatsache zusammenhängen, dass die „Territorien des

26 Vgl. ausführlicher Linke (2004, S. 264 ff.).

27 Diese Überlegung übernehme ich aus dem äusserst instruktiven, informationsdichten Beitrag von Paravicini (1997), der vom „Pathos der Höhe und Ferne“ gegenüber dem „Pathos des symmetrischen Raums in der Ebene“ (ebd., S. 25) spricht. 
Selbst" ${ }^{\text {“ }}{ }^{28}$ um einen Ausdruck Erving Goffmans zu verwenden, in einer ständisch strukturierten Gesellschaft anders konstituiert sind und entsprechend anderer performativer Stützen bedürfen, aber auch andere semiotische Nutzungen erlauben. So erstreckt sich etwa der von Goffman so benannte „persönliche Raum“ (Goffman 1974, S. 56), im Gegensatz zu heutigen westlichen Standards, bei Angehörigen des frühmodernen Adels durchaus auch auf die im Rücken einer Person liegende Zone, und die einzelne adlige „Stands=Person“ erzeugt darüber hinaus immer auch eine Semiotisierung bzw. eine soziale Hierarchisierung des sie umgebenden Raumes, insofern linke und rechte Körperseite in ihrer ehrenden (und entsprechend auch attrahierenden) Potenz unterschiedlich besetzt sind. Diese hierarchische Strukturierung des Raumes durch die sich in ihm aufhaltenden „Stands=Personen“ sowie die Raum-Effekte, die sich in der Begegnung bzw. im Nebeneinander von dergestalt semiotisch aufgeladenen Körperterritorien ergeben, erfordern in der Interaktion vor allem beim bewegten Körper permanente Anpassungsleistungen und ein komplexes Raumperformativ. Dies kann z.B. die folgende Anleitung zum schicklichen Verhalten in Promenaden aus einer Umgangslehre von 1729 verdeutlichen, wo es heisst:

Wann mehr Personen gleiches Standes nebeneinander spatziern / so erfordert die Höfflichkeit / daß die / welche währender Zeit / da man den Spatzier=Gang oder das Zimmer einmal auf= oder abgangen / in der Mitte gewesen / wenn sie am Ende sind / auf die Seite tretten / und die Mittelstelle denen / so am weitesten davon gewesen / überlassen; welches dann diese hinwiederum / wann sie auch zu Ende sind / gleichfalls zu beobachten haben / und so immer einer nach dem andern. (Complimentist 1729, S. 292)

Ein solcher „Spatzier=Gang“ ist also zwar einerseits eine rekreativ-gesellige Unternehmung, dient gleichzeitig aber auch praxeologisch-performativ der Herstellung bzw. Bestärkung sozialer Ordnung. Das Beispiel macht zudem deutlich, dass die semiotische Konstruiertheit des Raumes immer auch historisch wie sozial bestimmt zu denken ist.

\section{Paradigmenwechsel}

Ich habe in meiner bisherigen Darstellung das 17. und 18. Jahrhundert quasi in einem Atemzug behandelt und herausgestellt, dass in der Wahrnehmung kommunikativen Umgangs dem menschlichen Körper ebenso wie der Dimension des Raumes in beiden Jahrhunderten ein Gewicht zukommt, das aus heutiger Perspektive nur noch bedingt nachvollziehbar ist. Im Rahmen dieser insgesamt stark ausgeprägten Körper- und Raumorientierung des

28 So der Titel des für den gegebenen Zusammenhang relevanten Kapitels in Goffman (1974, S. 54-96). 
frühmodernen Umgangsdiskurses zeichnen sich nun bei genauerem Hinsehen im Verlauf der hier untersuchten Periode doch semiotisch signifikante Veränderungen $\mathrm{ab}^{29}$

\subsection{Körper und Kleidung: Vom Positionalen zum Fliessenden}

Diese Veränderungen demonstriert uns in ebenso komprimierter wie plakativer Weise das Frontispiz einer der wohl einflussreichsten Klugheitslehren des frühen 18. Jahrhunderts, der 1728 erschienenen Einleitung zur Ceremoniel $=$ Wissenschafft der Privat $=$ Personen von Julius Bernhard von Rohr ${ }^{30}$ (Abb. 4). In diesem Titelkupfer werden in Wort und Bild ,alte Teutsche“ und ,jetzige Teutsche“ einander gegenübergestellt, wobei sich die beiden Figurenpaare nicht nur in ihrem Äusseren, sondern auch in der architektonischen Ausgestaltung des Hintergrunds, vor den sie gestellt sind, unterscheiden. Das linke Paar, das die „alten Teutschen“ repräsentiert, trägt eine auf das frühe 17. Jahrhundert verweisende Tracht im sogenannt spanischen Stil ${ }^{31}$ und dieser Rückverweis in der Zeit wird durch Haartracht, Hutformen sowie durch die gotisierende Stadtarchitektur des Hintergrundes noch zusätzlich akzentuiert. ${ }^{32}$ Die ,jetzigen Teutschen“ dagegen, verkörpert im rechten Paar, entsprechen in ihren mit reicher Stickerei versehenen Justeaucorps sowie mit Allonge-Perücke und völliger Bartlosigkeit in vollkommener Weise dem Herrenmode-Ideal des frühen 18. Jahrhunderts, ${ }^{33}$ als dessen Kulisse dann auch eine französisierende Schlossanlage mit Laubengalerie und ornamentaler Gartenbepflanzung gewählt ist.

$29 \quad$ Peter Burke, der in seinen kulturgeschichtlichen Studien wiederholt Umgangslehren als Quellen nutzt, betont, dass ,,a closer study of the manuals [gemeint sind Umgangs- und Klugheitslehren, A. Linke] reveals small yet significant changes over time, especially over the long term, changes in emphasis or, inflections" which are well worth the attention of historians of language and social behaviour" (Burke 1993, S. 95).

30 Julius Bernhard von Rohr (1688-1742) ist u.a. Schüler von Christian Wolff und Verfasser einschlägiger rechtswissenschaftlicher wie ökonomischer Werke, er gilt als einer der wichtigsten Vertreter der sogenannten „Hausväterliteratur“. Das Zedler'sche Universallexikon widmet von Rohr eine mehrere Seiten umfassende biographische Darstellung sowie ein ausführliches Verzeichnis seiner Schriften.

31 Boehn beschreibt die spanische Tracht als ,charakterisiert [...] durch enge und durch steife Formen, sie hindert die Beweglichkeit der Glieder und zwingt dem Körper eine unnatürliche Haltung auf“ (Boehn 1923a, S. 83). Boehns Urteil über die „Unnatürlichkeit“ der durch die spanische Tracht erzwungenen Körperhaltung ist eine ex post-Zuschreibung: Was aus heutiger Perspektive als „unnatürlich“ erscheint, war im zeitgenössischen Blick wohl in erster Linie eine kulturelle bzw. sozialdistinktive Errungenschaft und Medium eines ,gravitätischen“ Auftritts. Der Massstab der Natürlichkeit ist zeitgenössisch kaum in Betracht zu ziehen, und wohl ebenso wenig wurde die Haltung zeitgenössisch als erzwungen empfunden.

32 Wir haben es mit einer Stadtarchitektur zu tun, bei der noch ,etwas Gotisches oder Altväterisches zu spüren“ ist, eine Charakterisierung, die Maximilien Misson in seinen Reisebeschreibungen 1687 auf Nürnberg anwendet (zit. nach Boehn 1923a, S. 52, dort leider ohne genauere Quellenangabe), eine Architektur also, die bereits im späten 17. Jahrhundert als nicht mehr zeitgemäss gilt.

33 Vgl. für diese Zuordnung Boehn (1923b, S. 201 ff., 212 ff.). 


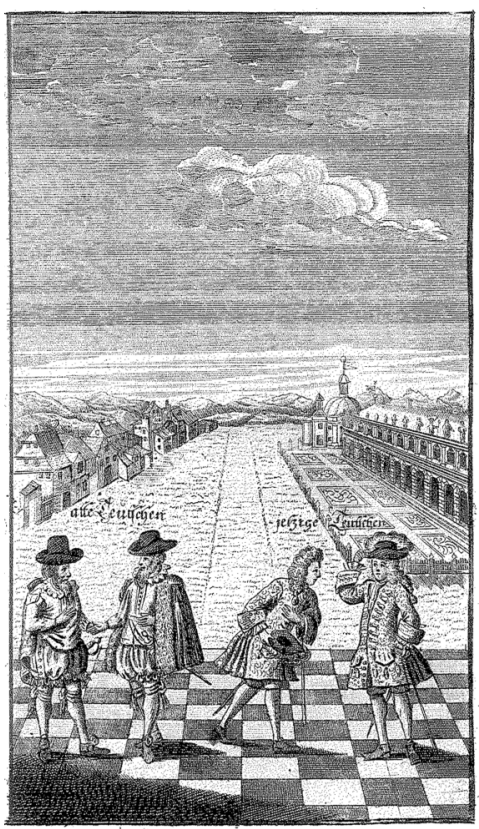

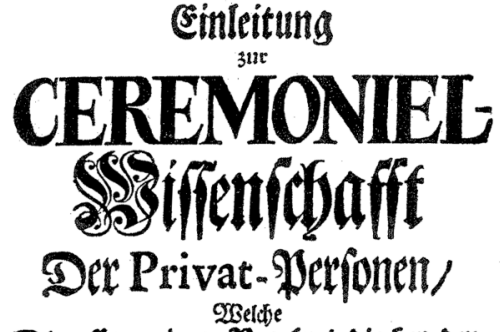

Die allgemeinen Regern / Die bey Det Mode, Den Titulaturen/Dem $\Re$ iange/Den Complimens, Den Ëeberoen, uno bey Syofen abertbaupt, als auch bey Den geiftl. Szandlungen, in oer Converfation, bei) Der Correfpondenz, bei) Vifiten, Affembleen, Spieien, Umgang mit Dames, Gaftereyen, Diverrifemens, 24ümeublitung Der Bimmer,

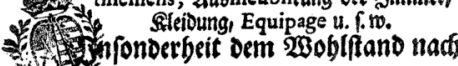
ettemjungen teutifónen Cavalier in Dbact zu nebmen/ vortrige,

Finige Feblet entoecfet und verbefiert, und fie bin uns sieder mit einigen moralifthen und bifforifisen Sintmercfungen begleitet, abgefaft von

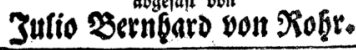

Berlin, bey Jobann 24noreas Siùiger, 1728 .

Abb. 4

Besonders frappant und im gegebenen Zusammenhang relevant ist jedoch, dass mit der unterschiedlichen historischen Verortung der Figurenpaare auch ein anderes körperkommunikatives Verhalten einhergeht: Zwar erscheinen beide Paare gesprächsweise einander zugewandt, doch während dies bei den Herren der linken Bildhälfte mit einer verhaltenen Gestik verbunden ist, bei der Arme und Hände von beiden Figuren beinahe spiegelbildlich auf Taillenhöhe gehalten werden, wird das rechte Paar in schwungvoller Körperbewegung gezeigt, mit ausladender (Gruss-)Gestik der Arme, die den Körperraum von der Hüfte aufwärts bis zur Scheitelhöhe ausnutzt. ${ }^{34}$ Damit deutet sich in den Leibesgesten der Figuren ein Paradigmenwechsel an, der in einer ersten groben Fassung als ein Wechsel von Ruhe zu Bewegung charakterisiert werden kann und der durch die Darstellung der Kleidung noch gestützt wird: Die spanische Tracht der ,alten“ Deutschen fällt in schweren, unbewegten Linien an den Körpern herab, wogegen die auf Taille geschnittenen und mit schwingenden Rockfalten versehenen Justeaucorps der ,jetzigen“ Deutschen die körperliche Bewegtheit der Gruppe unterstreichen.

\footnotetext{
Dieser Armgestik entspricht auch die Anweisung im Kapitel „Über die Arme, Ellenbogen und Hände“ in Franz Langs „Abhandlung über die Schauspielkunst“ von 1727, wo es u.a. heisst: ,[...] dass beide Arme sich nicht in gleicher Ausdehnung und in gleicher Weise bewegen sollen, sondern der eine sei höher, der andere gesenkter, der eine mehr gestreckt und gerade, der andere gebeugter, auch wenn er erhoben ist [...] “ (Lang 1727, S. 179, hier zitiert aus der dem lateinischen Original angefügten Übersetzung des Werkes).
} 
Die in diesem Frontispiz bildlich dargestellte Veränderung im Körperverhalten ${ }^{35}$ lässt sich nun auch im Spiegel des Umgangsdiskurses erfassen, unter anderem im Wechsel entsprechender Schlüsselwörter. Zentral ist dabei das der Gravität. Der Ausdruck lässt sich seit dem 16. Jahrhundert im Deutschen belegen ${ }^{36}$ und wird, wie das davon abgeleitete Adjektiv, in erster Linie zur Beschreibung eines körperkommunikativen Auftretens verwendet, seltener auch zur Charakterisierung verbalen Verhaltens. ${ }^{37}$ So wird etwa in einer ,alamodischen“ Sittenlehre von 1630 von jungen Frauen gefordert, dass sie „fein züchtig / erbar vnd grauitätisch“ (Hobelbank 1630, S. 49 f.) tanzen sollen, und von einem jungen Kavalier wird erwartet, er solle ,gerad mit dem Leib vnd Kopff daher gehen / und die Leuth frölich vnd redlich ansehen / mit einer schönen Grauitet" (ebd., S. 72). Geradezu phraseologische Qualität hat im 17. Jahrhundert die Wendung ,gravitätisch wie ein Spanier", die meist mit Bezug auf die Art und Weise des Gehens verwendet wird (DWb, Eintrag ,gravitätisch“). ${ }^{38}$ Doch während vor allem in der ersten Hälfte des 17. Jahrhunderts die Begriffe Gravität bzw. gravitätisch durchwegs positiv verwendet werden - als Synonyme finden sich ansehnlich und ernsthaft (Manual 1703, S. 149), ${ }^{39}$ würdevoll, gemessen, gewichtig ${ }^{40}$-, gilt dies schon gegen Ende des Jahrhunderts nicht mehr unbedingt. So will zwar eine Anstandslehre von 1695, die an ein Zielpublikum königlich-fürstlicher und gräflicher Hofmeister gerichtet ist (Stands=Person 1695), ${ }^{41}$,in der Gesprächlichkeit ${ }^{\text {“ }}$ eine „Stand=mässige Hoheit und ziemende Gravität [nicht] ausgeschlossen haben“, mahnt aber bereits zu einem „Mittel=Weeg“" zwischen „Würdigkeit

35 Dass bei von Rohr die Veränderung der „Teutschen“ anhand männlicher Figurenpaare dargestellt wird und nicht anhand von männlich-weiblichen Paaren, liegt einerseits in der allgemein patriarchalen Struktur sowohl der deutschen als auch überhaupt europäischer Gesellschaften der Zeit begründet, verweist aber zudem auf das Faktum, dass in der sozialsemiotischen Selbstbewusstheit der Oberschichten dem Körperauftritt des Mannes ein besonderes Gewicht zugemessen wird.

36 Vgl. DWb, Eintrag „Gravität“.

37 Burke (1998, S. 98) belegt für das spätere 16. Jahrhundert die lateinische Formulierung „gestum gravem“ in der Beschreibung italienischer Körperkultur durch Hieronymus Turler.

38 Auch der Wörterbuch-Teil des Manual (1703) gibt als Beleg für , gravitätisch“‘ ,,er hat einen gravitätischen Gang an sich / wie ein Spanier“ (Manual 1703, S. 149).

39 Vgl. auch Zedler (1732-1754, Bd. 8, Sp. 1738): „Ernsthafftigkeit und Grauität ist denen Worten nach einerley“.

40 Vgl. DWb, Eintrag „Gravität“, wo unter anderem folgende Belege und Erläuterungen gegeben werden: „die ehrentänze, sonder hüpfen, mit stiller gravität verknüpfen, und par bey par in ordnung stehn: [...] hierauf mit wolanständgen grüssen, und ernsthaft fortgesetzten füssen, bedachtsam auf und nieder gehen poesie d. Niedersacbsen (1721) 6, 140 Weichmann “; „ähnlich in der kennzeichnung würdevoller, gemessener, gewichtiger art zu reden: dasz du nicht durch eine spanische und pedantische gravität deine zuhörer verdruszlich machst THOMAsius ausïbung $d$. vernunff-lebre (1699) 136“.

41 Im Titel von Stands=Person (1695) heisst es mit Blick auf das Zielpublikum explizit: „Allen Hoffmeistern / und denen Königl. Fürstl. und Gräffliche Kinder anvertrauet / hochnützlich zu gebrauchen". 
und Anmuth“ (Stands=Person 1695, S. 182 f.). ${ }^{42}$ Und Julius Bernhard von Rohr selbst hält zwar einerseits fest, dass ,,manch ansehnlich geistlich und weltlich Amt [...] eine gravitaetische und ernsthaffte Mine“ (von Rohr 1728, S. 189) erfordere, andererseits rückt die Bezeichnung ,gravitätisch“ auch bei ihm bereits in die Nähe von negativen Charakterisierungen des kommunikativen Auftritts wie „finster“ oder auch ,albern“ (ebd., S. 194). ${ }^{43}$

Dieser Wandel in den Normen für körperkommunikative Praktiken zeigt sich zudem in der sich verändernden Wahrnehmung des Körpers in anderen Kontexten, wie dies etwa Rudolf Braun und David Gugerli (Braun/ Gugerli 1993) für die Geschichte des Tanzes und Henning Eichberg (1978) für die adligen Exerzitien gezeigt haben. Das Geometrische, Ausladende und Positionelle, das im 17. und in Teilen auch noch bis weit bis ins 18. Jahrhundert hinein adliges Körperverhalten auszeichnet, wird allmählich durch die Ideale des Leichten, Schlanken und Bewegten ersetzt. ${ }^{44}$ Während es etwa zu Beginn des 18. Jahrhunderts zumindest für die Begrüssung einer vornehmen Person noch angemessen erscheint, dass man die Hand bei der Verneigung „bald bis zur Erden führet" (Menantes [d.i. Christian Friedrich Hunold] 1724, S. 167), so erscheint solches ausladende Körperverhalten den Zeitgenossen schon bald als übertrieben, und am Ende des Jahrhunderts gilt eine Verbeugung, bei welcher der Kopf unter die Taillenlinie fällt, auch gegenüber noch so hochstehenden Personen als unschicklich, ja als lächerlich. ${ }^{45}$ Es ist nun die „sanfte“ (Claudius 1800, S. 38) Verbeugung, die gefordert ist, vertikal wie horizontal ausladende, ,gewaltthätige Bewegungen“ (ebd., S. 62) hingegen werden abgelehnt. Neben diesen eher quantitativen, auf das (Aus-)Mass der Körperbewegung bezogenen Veränderungen lassen sich aber auch solche qualitativer Art beobachten, die stärker auf die Form von Körperhaltung und Körperbewegung ausgerichtet sind. Dem einem veränderten ästhetisch-semiotischen Ideal verpflichteten Blick ist nun etwa der eckige Win-

$42 \quad$ Es ist eine beständige Gefahr, solche Belegstellen einer Überinterpretation zu unterwerfen. Dennoch soll hier angemerkt werden, dass in der Kontrastierung von „Würdigkeit“ und „Anmuth“ allenfalls auch der Gegensatz einer auf Distanznahme („Würdigkeit“) bzw. einer auf Nähe und personelle Attraktivität („Anmuth“) ausgerichteten sozialen Ordnung angesprochen ist.

43 Noch in Kotzebues dramatischer Satire „Die Kleinstädter“, 1802 uraufgeführt, ist „Gravität“ das Hauptwort der die alte Generation verkörpernden Frau Staar, einer Exponentin eben jenes kleinstädtischen Bürgertums, das sich an überkommenen adligen Verhaltensidealen orientiert und sich auf diese Weise eine nach „oben“ orientierte Identität zuweist (so etwa in der Äusserung: „Zu meiner Zeit liess sich keiner malen, der nicht in Amt und Würden stand, oder wenigstens zehn Jahre verheiratet war. Dann geschah es aber auch mit der gehörigen Gravität, in Lebensgrösse, einer Spitzenhalskrause, und einem Blumenstrausse in der Hand." (Kotzebue 1972, S. 403).

Dass Kotzebue noch am Beginn des 19. Jahrhunderts produktiv auf diesen Schlüsselbegriff zurückgreifen kann, ist ein Beleg für die epochenübergreifende Reichweite des alten Gravitas-Ideals und damit auch ein Beleg des , langen‘ kollektiven Gedächtnisses.

44 Vgl. auch Linke (2006, S. 52 f.).

45 Vgl. Claudius (1800, S. 116 f.). 
kel des Armes ein „widerlicher Anblick“ (ebd.), wogegen „die Wellenlinie als für die Schönheitslinie anerkannt" (ebd.) gilt. ${ }^{46}$

Wenn wir nach dieser Wahrnehmungs-Anleitung nun nochmals die Darstellung der ,alten“ und der ,jetzigen Teutschen“ bei Julius Bernhard von Rohr betrachten, so zeigt sich,

- dass beim linken Paar die Armhaltung eben eine solche „widerliche“ eckige ist, die zudem speziell herausgestellt wird (der Zeichner lässt den Mantel über die Schulter der Figur zurückfallen und gibt damit den Blick auf den Arm frei),

- dass hingegen bei den beiden ,jetzigen“ Deutschen die Armwinkel sogar dort, wo sie anatomisch unvermeidlich sind, in der Darstellung abgerundet erscheinen und auch ansonsten in der Darstellung der Figuren dem Ideal der Wellenlinie Genüge getan wird.

Wie langlebig dieses neue Schreckbild des eckigen Winkels ist, zeigt sich auch noch in der im Göttinger Taschenkalender auf das Jahr 1789 veröffentlichten berühmten Kupferstich-Serie zu den „Handlungen des Lebens“ von Daniel Chodowiecki. Diese „Handlungen“ werden, von bissigen Kommentaren Georg Christoph Lichtenbergs begleitet, in Doppelbildern illustriert, wobei jeweils „Natur und Affektation“ (Lichtenberg 1971, S. 33) gegeneinander gestellt werden. ${ }^{47}$

In dem in Abb. 5 wiedergegebenen Doppelbild, das die Handlung des Grusses zeigt, sind die eckigen Winkel als prägendes Charakteristikum des ,affektierten', d.h. explizit abgelehnten Körperauftritts nicht zu übersehen. Das ,natürliche“ Paar hingegen entspricht vollendet dem Ideal der Wellenlinie - sowohl im Bewegungsverhalten als auch im Bekleidungsstil. Allerdings: Wir haben es hier - ein halbes Jahrhundert nach Erscheinen der von Rohr'schen Ceremoniel=Wissenschaft mit ihrem Frontispiz - nicht mehr mit adliger, sondern mit bürgerlicher Selbstthematisierung zu tun, ${ }^{48}$ genauer: mit bürgerlicher Kritik an adligem bzw. als adlig konnotiertem Körperverhalten, die hier im Dienst der Karikatur allerdings auf ein bereits bei von Rohr als nicht mehr gültig formuliertes Ideal zurückgreift. Ich komme am Schluss meiner Überlegungen nochmals auf diesen Punkt zurück.

46 Dieser Form-Gegensatz lässt sich auch auf den Wandel in der Gartenkunst vom Ideal des französischen Gartens mit seinen formal-ornamentalen Anlagen (mit dem Prototyp der Anlagen von Versailles) zum Ideal des englischen Landschaftsgartens, wie er etwa durch die Gartenanlagen von Wörlitz-Dessau repräsentiert wird, beziehen - ein Hinweis, den ich Arnulf Deppermann verdanke.

47 Dieses Ideal der „Natürlichkeit“ ist programmatisch bürgerlich konnotiert, auch in den Darstellungen Chodowieckis - in vielen Doppelbildern sind die „,natürlichen“ Paare entsprechend deutlich einfacher gekleidet als ihre Gegenstücke. Vgl. auch Linke (1996, S. 77 ff.).

48 Dass wir in diesen primär an ein bürgerliches Publikum gerichteten Darstellungen nun auch nicht mehr männliche, sondern männlich-weibliche Paare vorgestellt bekommen, kann als Verweis auf die zunehmende sozialsemiotische Aufladung des weiblichen Körperauftritts gelesen werden. 

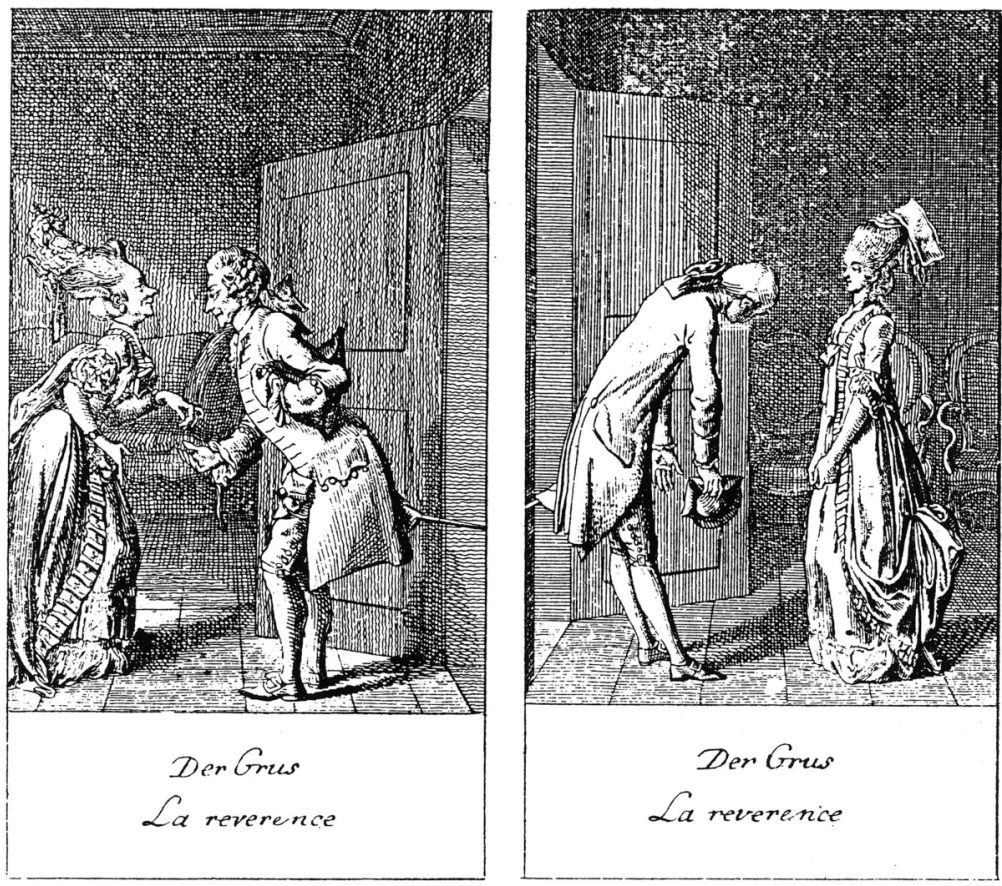

Abb. 5

Insgesamt ist jedoch zu konstatieren, dass sich in der Kleidermode bzw. in der Kostümgeschichte von der zweiten Hälfte des 17. ins 18. Jahrhundert hinein trotz des insgesamt wenig einheitlichen Bildes vor allem in der Herrenmode eine zunehmende Schmälerung und ,Verkurvung' der Silhouette beobachten lässt. Dazu kommt der Wegfall von ausladenden Schmuckelementen an Kragen, Ärmeln, Kniebund, Wade und Schuh, in der Haartracht die Abflachung und Verkürzung der Perücken und in der Kopfbedeckung in der zweiten Hälfte des 17. Jahrhunderts zunächst der Ersatz des steifen und steilen Hutes, wie er auch auf dem Frontispiz bei von Rohr als Auszeichnung der „alten Teutschen“ zu sehen ist, durch den ausladendschwungvollen Plumagenhut der ,jetzigen Teutschen“ und dann, an der Wende zum 18. Jahrhundert, durch den deutlich kleineren Dreispitz. ${ }^{49}$ Die Analogien zu dieser Verschlankung in der Damenmode sind weniger augenfällig, aber dennoch beobachtbar. ${ }^{50}$ Charakteristisch ist die Verkleinerung

$49 \quad$ Vgl. Thiel (1987, S. 231 f. sowie 236).

50 Dies gilt allerdings nicht für die (auch am österreichischen Hof gepflegte) spanische Hoftracht, die bis weit ins 18. Jahrhundert hinein am grossen Reifrock festhielt (Thiel 1987, S. 224; Boehn 1923b, S. 136 ff.). Der Reifrock, wie er dann im Rokoko in ganz Mitteleuropa - in recht unterschiedlichen Ausführungen - wieder typisch wurde, war insgesamt leichter und beweglicher und in erster Linie seitlich ausladend. Von der Seite betrachtet erscheinen die Kleider flach und besitzen kein Volumen. 
des Kopfes von der hohen Fontangefrisur zum Lockenkopf des Rokoko sowie vor allem für die Zeit nach 1715 eine Verfeinerung der Stoffe, der Ersatz grossblumiger barocker Muster durch Ranken- und kleinere Blütenmuster sowie eine allgemeine Reduktion üppiger Schmuckelemente. ${ }^{51}$

\subsection{Sprachliche Muster und Formen: \\ Vom Ausladenden zum Schlanken}

Es fragt sich nun, ob sich zu den im Körperzeremoniell und in der Mode konstatierten Verschiebungen homologe Veränderungen im Sprachgebrauch finden lassen. Dies scheint - gerade mit Blick auf bestimmte ,Üppigkeiten des Sprachgebrauchs - der Fall zu sein. So zeigt sich das 17. Jahrhundert in der Sprachgeschichte des Deutschen als die „Blütezeit des überlangen und mehrgliedrigen Satzgefüges“ (Admoni 1985, S. 1540), in dem zudem die Verwendung von Satz- und Satzgliedkonnektoren einen Höhepunkt erreicht. ${ }^{52}$ Gerade letzteres ist insofern interessant, als die einzelnen Konnektoren zum Teil noch wenig spezialisiert sind (ebd., S. 352) - ihre gehäufte Verwendung in sehr unterschiedlichen Textsorten lässt sich deshalb nur bedingt sachfunktional begründen, könnte aber der Effekt eines gewissen sprachlichen Schmuckbedürfnisses sein. Neben dem Satzgefüge nimmt zudem auch der durchschnittliche Elementarsatz im 17. Jahrhundert an Umfang deutlich zu. ${ }^{53}$ Und nicht zuletzt zeichnet sich die Literatursprache durch jene „Amplifikation“ und „Steigerung ${ }^{\text {“54 }}$ aus, die zum stilistischen Signum der Epoche erhoben wird. ${ }^{55} \mathrm{Im}$ Verhältnis dazu ist die Entwicklung der Literatur- wie der Kanzlei- und Wissenschaftssprache im 18. Jahrhundert gegenläufiger Natur, d.h. sie ist durch eine auffällige Umfangsverkürzung

51 Vgl. Thiel (1987, S. 251). Insgesamt erscheint die (höfische) Herrenmode in ihrer Entwicklung, konsistenter ${ }^{6}$ und in ihrem sozialsemiotischen Ausdruckswert eindeutiger als die Damenmode; und auch wenn sich einige Parallelen erkennen lassen, ist die sozialsemiotische „Besetzung“ von Herren- und Damenmode nicht denselben Mustern bzw. Relationen unterworfen.

52 Vgl. Admoni (1980, S. 352 und 1985, S. 1540).

53 Vgl. Admoni (1985, S. 1540).

54 Diese Termini benutzt unter anderen Manfred Kaempfert zur Beschreibung der Charakteristika der Literatursprache des 17 . Jahrhunderts und subsumiert darunter etwa die „Verbreiterung des Ausdrucks“ durch „Erweiterung bzw. Umschreibung des Ausdrucks“ (Kaempfert 1985, S. 1815) oder die „Häufung, in meist asyndetischer Reihung gleicher Satzteile“ (ebd., S. 1816).

55 Ein interessantes Phänomen bilden die von Admoni mehrfach beschriebenen „,unpräzisen Konstruktionen“ des Satzgefüges (vgl. etwa Admoni 1980, S. 352, 1990b, S. 196 f.). Es handelt sich dabei um umfangreiche Satzgefüge aus mehreren Nebensätzen, die aber keinen Hauptsatz enthalten und die ohne einen solchen ,architektonischen' Bezugspunkt entsprechend schwer verständlich sind. Eine mögliche Interpretation wäre auch hier, dass die Satzkonstruktion sich weniger dem Bemühen um logische Präzisierung des Inhalts verdankt, sondern vielmehr als ein spezifischer Sprachgestus mit einem bestimmten soziokulturellen Ausdruckswert zu lesen ist. 
der Ganzsätze sowie eine Häufigkeitsverschiebung von Hypotaxe zu Parataxe charakterisiert, eine Veränderung, die Vilmos Ágel als ,tendenziell epochentypisch“ (Ágel 2000, S. 1879) bezeichnet. Auch die Syntax wird also, wenn man das so formulieren will, schlanker. Und wenn Wladimir Admoni zur zusammenfassenden Beschreibung der von ihm erarbeiteten Charakteristika des Satzbaus in absolutistischer Zeit den Terminus „gespanntes Gestaltungssystem " ${ }^{\text {56 }}$ (Admoni 1990a, passim) wählt, so ist es sicherlich zu einem Teil, aber vielleicht doch nicht ausschliesslich terminologische Verführung, wenn man hierin eine gewisse Parallele zum Körpermerkmal der Spannung in adliger Leibesgestik sieht.

Die zunehmende Abkehr von dieser „gespannten“ und ausladenden Gestaltung des Sprachgebrauchs zeigt sich auch im Metadiskurs der Umgangslehren. Hier sind nun, so die Forderung in einer Conversationslehre vom Ende des 18. Jahrhunderts - „leichte aber feine Komplimente“ (Trusler/Rode 1799, S. 58 f.) gefragt, wer dagegen „keine Maaß hält / und zu sehr damit ausschweiffet“ (Manier 1738, S. 8) oder sich der ,altfränkischen Perioden [bedient], denen man die ängstliche Drechseley ansieht" (Claudius 1800, S. 136), der passt nicht mehr in die Zeit. ${ }^{57}$

Die Forderung nach „Leichtigkeit“"58 und „Feinheit“ im Compliment wird in der Ablehnung der „altfränkischen Perioden“ also auch im Umgangsdiskurs auf konkrete syntaktische Muster bezogen. Vor allem aber bezieht sie sich auf den schieren Umfang von Complimenten und Redebeiträgen.$^{59}$ So belegt Manfred Beetz (1990) in seiner gewichtigen Studie zur frühmodernen Höflichkeit ${ }^{60}$ eine deutliche Verkürzung von Tanzkomplimen-

56 Vgl. hierzu auch Polenz (1994, S. 279). Umgekehrt spricht Admoni mit Blick auf die Entwicklung der Syntax des Deutschen seit dem ausgehenden 17. Jahrhundert davon, dass die Sprache „biegsamer und beweglicher“ werde (Admoni 1990a, S. 10).

57 Die Vokabel „altfränkisch“ begegnet im Umgangsdiskurs des 18. Jahrhunderts immer wieder als Negativcharakterisierung für alles Überholte.

58 Die durchgängige Bedeutsamkeit dieser normativen Schlüsselwörter für das Sprachbewusstsein im 18. Jahrhundert belegen auch die von Gotthard Lerchner aus Christoph Martin Wielands „Teutschem Merkur“ ausgezogenen sprachkommentierenden Ausdrücke, wo „Zierlichkeit“, „Glätte“ und „Leichtigkeit“ (Lerchner 1991, S. 57) unter den häufig gebrauchten rangieren. Lerchner führt auch Wielands explizite Forderung an den zeitgenössischen Sprachgebrauch an, „leicht und nett“ zu sein. (Teutscher Merkur 1797, I, S. 77; hier zitiert nach Lerchner 1991, S. 55).

59 Interessant sind auch die jeweiligen Begründungen der Normen. Wie Manfred Beetz belegt, werden im 17. Jahrhundert durchaus auch vorkommende Hinweise darauf, dass man sich hohen Herren gegenüber eher kurz zu halten habe, im Kontext der Decorums-Vorstellungen begründet: Wer Untergebenen Zeit und Aufmerksamkeit widmet, schadet seinem eigenen Decorum. Im 18. Jahrhundert hingegen wird zunehmend mit sachbegründetem Zeitdruck argumentiert: Höhergestellte haben Wichtigeres zu tun als Untergebenen zuzuhören. (Beetz 1990, S. 282 f.) In gewisser Weise wird also im 17. Jahrhundert Zeit noch als symbolischer ,Raum'verrechnet.

60 Ich verdanke dieser detailreichen, immens dichten Arbeit, mit der Manfred Beetz den Grundstein für eine Kulturgeschichte der Höflichkeit vorgelegt hat, sehr viele Anregungen, auch über diejenigen hinaus, die sich in konkreten Textverweisen festmachen lassen. 
ten, d.h. von Aufforderungen zum Tanz, vom 17. ins 18. Jahrhundert ${ }^{61}$. Und da in Umgangslehren und Complimentierbüchern oft lange Listen mit ausformulierten Vorlagen für Complimente verschiedenster Funktion gegeben werden, serielle Untersuchungen hier also ohne weiteres möglich sind - im übrigen ein noch ungenutztes Feld historischer Soziopragmatik - lässt sich die Beobachtung von Beetz leicht an weiteren Beispielen überprüfen und bestätigen. Als plakatives Beispiel auf knappem Raum können die drei nachfolgenden Texte dienen, die aus unterschiedlichen Umgangslehren von 1729, 1736 und 1753 stammen, aber alle drei als Vorlage für ein sogenanntes Gratulationscompliment gegenüber einem vornehmen Herrn gedacht sind. Es wird bereits auf den ersten Blick deutlich, dass die in chronologischer Abfolge angeordneten Versionen (die sich inhaltlich und auch in einzelnen Formulierungen durchaus ähneln ${ }^{62}$ ) immer kürzer werden und der Vorlagentext von 1753 gegenüber der Version von 1729 nur noch knapp halb soviel Wörter umfasst.

\section{Beispieltexte für Gratulationscomplimente gegenüber einem vornehmen Herrn}

I

Hochgeehrtester Herr. Indem ich ihnen bißhero alle Jahre zu dessen Geburts=Tage gratuliret habe / so würde ich unrecht thun / wann ich solches heur unterlassen wollte. Es dürffte zwar derselbe aus diesen Worten den Schluß machen / als ob ich es nur aus Gewohnheit thäte / oder den angefangenen Gebrauch darum fortsetzen begehrete / damit derselbe nicht Ursach hätte / mich einer Hinläßigkeit zu beschuldigen; ich versichere aber dabey / daß es von Grund des Hertzens auch [!] Hochachtung und Liebe zu dero werthesten Person geschiehet/ die ich wegen ihrer mit gewidmeten Wohlgewogenheit sehr hoch schätze / und mich dahero bey allen Gelegenheiten bestrebe / denselben die Ergebenheit meines verbundenen Gemüts kund zu machen. Hiervon nun abermal eine Probe abzuleben / bediene ich mich hierzu ihres morgenden Geburts=Tages / den der Allerhöchste ihn noch viele Jahr bey guter Gesundheit und aller selbst erwünschter Prosperität erleben lassen; auch ihn dabey allzeit mit neuer Zufriedenheit erfreuen wolle. Was meinem Wunsch an Worten und Nachdruck abgehet/ das will ich in meinem Gebett von GOtt zu erbitten niemal aufhören. (Complimentist 1729, S. 133 f.)

\section{II}

Ew. Wolgeb. (Hochedelgeb.) erlauben gnädig, daß mich der Kühnheit unterfange Ihnen an Dero hoch-erfreulichen Geburtstags-Fest meinen unterthänigen Glükwunsch abzustatten. Die hohe Ehre, welche von Ew. Wolgeb. schon geraume Zeit

61 Vgl. ausführlicher Beetz (1990, S. 281 ff.). Beetz spricht in diesem Zusammenhang ebenfalls von „ästhetischer Verschlankung“ (ebd., S. 281).

62 Grundsätzlich ist davon auszugehen, dass die Verfasser von Umgangslehren (auch) im 18. Jahrhundert Vorgängertexte rezipieren und nutzen. Zum Teil lassen sich direkte Textübernahmen nachweisen. Gerade deshalb jedoch sind deutliche Abweichungen bei funktional/inhaltlich ähnlich orientierten Texten/Passagen aussagekräftig: Sie sind am ehesten veränderten Normen und Idealen verpflichtet. 
hero ganz unverdient geniesse, treibet mich zur inbrünstigen Bitte gegen dem Höchsten, Selbige, wie bißhero, als auch hinfüro noch lange und undenkliche Jahre, in dessen Protection und gnädige Erhaltung zu befehlen. Damit sie dem gantzen Vatterland zu Nuz, ihren hohen Angehörigen zum reichen Trost und Vergnügen, deren sämtlichen Clienten, und mir insonderheit, zum gnädigen Schuz, bis an ihr spates Alter, in allem hohen Flor und gesegneter Prosperität, grünen und blühen mögen. Der ich mich Ew. Wolgeb. Gnade und hohen Gewogenheit fernerhin unterthänig empfehle. (Kürtzliche Anweisung 1736, S. 150 f.)

\section{III}

Ew. HochEhrw. (HochEdelgeb.) HochEdl. etc. habe zu diesem Dero hocherfreulichem Geburts-Feste gehorsamst gratuliren und wünschen sollen, daß der grosse GOtt dieselben wie bißher, also auch ferner in seinen väterlichen Schutz nehmen, sie für allem Unglück gnädiglich behüten, und Ihnen noch lange Zeit diesen frohen Tag sehen lassen wolle, damit ich noch oft Gelegenheit habe, mich über das Glück meines Patrons zu erfreuen, und Dero Schutzes und unschätzbaren Gewogenheit ferner zu geniessen. (Ethophilus 1753, S. 168)

Christian Friedrich Hunold, der in seiner 1738 erschienenen „Manier, Höflich und wohl zu Reden und Leben“ ebenfalls Verkürzungen als Verbesserungen vorschlägt, vermerkt denn auch explizit, dass die „Weitläufftigkeit“ in Complimenten zu vermeiden sei und begründet: „Je weniger ein Compliment ausstudiret scheinet / desto bessere Grace hat es bey einem Patron" (Manier 1738, S. 82). Es geht nun nicht mehr um Gravität, sondern um „Grace“, eine Verschiebung, die offensichtlich auch mit einem Ersatz von Quantität durch Qualität zu tun hat, sowohl in verbaler wie in körperkommunikativer Hinsicht, denn, wie es bei Hunold an anderer Stelle heisst:

Eine gute Art / womit es [das Compliment: A. Linke] vorgebracht wird, und eine ehrerbietige Stellung / indem man so lange von seinem Stuhl sich mit gebogenem Leibe erhebet / gibt so wenigen Worten mehr Nachdruck / als weitläuffige Complimenten / die vornehme und gescheute Leute niemahls gern [...] hören. (Manier 1738, S. 24)

Die „gute Art“ und der „gebogene Leib“ ersetzen nun sowohl verbale Ausführlichkeit als auch die tiefe Verbeugung, körperliche wie verbale Geste sind damit verschlankt.

Zur ,guten Art“ scheint zudem auch eine gewisse ,Entschmückung' der Rede zu gehören. So fällt beim Vergleich von Text III mit Text II der wenn auch nicht ganz konsequent durchgehaltene - Verzicht auf Wortbzw. Formulierungsverdoppelungen sowie die Streichung von amplifizierenden Adjektiven auf, so dass etwa aus lange und undenkliche Jahre (Text II, Z. 5) nun einfach lange Zeit (Text III, Z. 4), aus Protection und gnädige Erbaltung (Text II, Z. 6) der väterliche Schutz. (Text III, Z. 3) und aus in hohem Flor und gesegneter Prosperität (Text II, Z. 9) das einfache Glück (Text III, Z. 6) wird wir haben hier sozusagen ein zeitgenössisches Schulbuchexempel des Rückbaus barocker Amplifikation. 
Unter das Verdikt des „ausstudierten“ und „gedrechselten“ Sprachgebrauchs fällt im übrigen auch aus der Perspektive der Zeitgenossen der zu üppige Gebrauch von Konnektoren sowie deren Auswahl - so vermerkt gerade Hunold unter anderem, dass es ihm ,ganz nicht [gefalle] / mit denen Bindungs=Wörtern: Zuvorderst / sintemabl / nachdem aber / biernächst / im übrigen wie nun etc. also in Complimenten aufgezogen zu kommen" - und zwar deshalb, „weil diese Connexions-Formuln auch in Briefen sparsam müssen gebrauchet werden / und es besser / wenn alles auseinander selber fliesset; wievielmehr in Complimenten. “63 (Manier 1738, S. 85)

Der Begriff des „Fliessens“, zu dem Hunold hier greift, passt zu den bereits genannten neuen Schlüsselbegriffen des „Leichten“ und „Feinen“ sowie zur Ästhetik der Wellenlinie in der Körpergestik und stellt einen weiteren Gegenbegriff zum Gravitas-Ideal des frühen 17. Jahrhunderts dar. Gleichzeitig verweist Hunolds Bemerkung darauf, dass nunmehr, in Kontrast zum Anstandsdiskurs des 17. Jahrhunderts, wo bei Beispieltexten für zeremoniellen Sprachgebrauch nicht zwischen Mündlichkeit und Schriftlichkeit getrennt wird, ein deutlicherer Unterschied zwischen geschriebener Sprache - „in Briefen“ - und gesprochener Sprache - „in Complimenten“ - gemacht wird und dass die neuen Anforderungen des Leichten, Feinen und Fliessenden die Mündlichkeit stärker betreffen als die Schriftlichkeit.

Des weiteren sei an dieser Stelle auch noch kurz hingewiesen auf eine Veränderung in der Schriftlichkeit oder, um einen Begriff von Sybille Krämer (Krämer in diesem Band) für den hier gegebenen Kontext anzuwenden, in der Schriftbildlichkeit der beobachteten Epoche: Im 17. und frühen 18. Jahrhundert finden wir im Schriftbild bzw. in der Typographie geschriebener Texte noch eine (zweidimensionale) Raumsemiotik der Höflichkeit (bzw. des Machtgefälles), die sich auf die semiotische Nutzung von Raum und Körperabständen in der Face-to-Face-Kommunikation - v.a. unter Standesungleichen - beziehen lässt. Hierher gehört, um ein Beispiel zu geben, die Nutzung von Ehrenabständen zwischen der Anrede der in Widmungstexten von Büchern angesprochenen Ehrenpersonen und dem folgenden Widmungstext selbst oder auch der Ehrenabstand zwischen der Anredeformel und dem eigentlichen Haupttext in Briefen - ein Abstand, der bei höhergestellten Adressaten ganze Leerseiten umfassen konnte -, aber auch die Nutzung von Grossbuchstaben wie von sehr grossem Schriftsatz für die Schreibung von Titeln und Ehrenbezeichnungen sowie von ganzen Texten, die sich an Respektspersonen wenden. Diese Raumsemiotik der ehrenden Distanz bzw. der „Vergrösserung“ des Adressaten verschwindet im Verlauf des 18. Jahrhunderts bis auf kleinere Relikte, wie wir sie etwa auch heute noch in der Grossschreibung pronominaler Höflichkeitsanreden finden. Eine allgemeine Verschlankung und Reduktion also auch hier.

63 Die Ablehnung des übermässigen Gebrauchs von Konnektoren sowie die Forderung nach einfachem Satzbau finden sich dann auch bei Gottsched (vgl. Polenz 1994, S. 277). 
Der Wechsel vom Ideal der Gravitas zu dem der Leichtigkeit, vom Positionalen und Ausladenden zum Fliessenden und Schlanken lässt sich also sowohl mit Blick auf die Normen und Muster des Sprachgebrauchs, auf den Ausführungsmodus körperkommunikativer Praktiken wie auf die Linienführung und die Voluminosität des Kostüms beobachten. Die eingangs zitierten „drey Stücke“ der „Gesprächsamkeit" - Reden, Leibesstellung und Kleider bilden also auch mit Blick auf die skizzierten Veränderungen ein Ensemble.

Dieser Ensemble-Effekt, genauer: die Transmedialität der beobachteten Veränderung lässt sich nun - dies meine erste abschliessende These - als

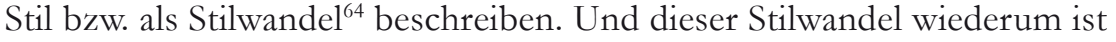
- dies meine zweite These - Ausdruck und Medium einer (Selbst-)Dynamisierung der soziokulturell tragenden Schichten, die zu den gesellschaftlichen Entwicklungen der Zeit, v.a. aber auch zu den Entwicklungen der Kulturund Wissensgeschichte in einem engen Begründungszusammenhang steht. Diese beiden Thesen seien abschliessend noch etwas ausführlicher erläutert.

\section{Stilwandel und Dynamisierung}

Zunächst zum Stichwort ,Stil': Die skizzierte Entwicklung als eine stilistische zu beschreiben, ist einerseits sehr naheliegend, bedarf aber andererseits doch einer Begründung, zumal ,Stil' in der neueren Sprachwissenschaft ein prekäres Konzept ist - erst in neuerer Zeit wird es in der Textlinguistik sowie in der Variationslinguistik wieder diskutiert und als Beschreibungskategorie genutzt. ${ }^{65}$ Wenn ich nun im gegebenen Zusammenhang ebenfalls darauf zurückgreife, so verstehe ich ,Stil' hier immer schon als ,Kollektivstil' und bezeichne damit Ausdrucksmuster in den Hervorbringungen einer Kommunikationsgemeinschaft, die als kulturelle Muster mit sozialer Bindung und entsprechendem identitätsbildendem bzw. distinktiven Potenzial verstanden werden können und deren Wandel einen Akt der kulturellen Selbstveränderung einer Sozialformation darstellt. Wenn Peter von Polenz in seiner Beschreibung der Entwicklung der deutschen Schriftsprache festhält, dass der „langatmige deutsche Satzbau in der Zeit des Absolutismus“ nur sehr ,wenig mit einem allgemeinen Strukturwandel der deutschen Sprache zu tun“ habe, sondern als „Variantenpräferenz" und „ständisches Pres-

64 Unter soziologischer Perspektive liegt hier auch der Begriff des Habitus im Sinne Bourdieus nahe. Mit dem Begriff des Stils hebe ich jedoch bewusst auf die beobachtbaren Ausdrucksgestalten ab, ohne dabei gleichzeitig eine soziale/soziologische Bindung in den Vordergrund zu rücken. Ich vermute vielmehr eine umfassendere kulturelle Dispositionsverschiebung, die im beschriebenen Stilwandel zum Ausdruck kommt, auch wenn sich solcher Stilwandel im Einzelfall an bestimmten (nicht notwendig an den hegemonialen) gesellschaftlichen Gruppierungen festmachen lässt.

65 Vgl. hierzu exemplarisch (und mit zum Teil recht unterschiedlichen Interpretationen und Nutzungen des Stilbegriffs): Hinnenkamp/Selting (Hg.) (1989); Selting/Sandig (Hg.) (1997); Eckert (2004); Auer (Hg.) (2007); Keim (2007). 
tigesymbol" einer sozialen Elite zu sehen sei (Polenz 1994, S. 279), so stimme ich dieser Diagnose grundsätzlich zu, möchte aber den Terminus der Variantenpräferen₹ durch den des Kollektivstils ersetzen, da dieser stärker auf das sozialkonstruktivistische Potential solcher Stilisierungsprozesse verweist. Was allerdings nicht heisst, dass solche Prozesse intentional begründet oder überhaupt intentional begründbar sind. Im Gegenteil, die konzeptuelle Pointe am Begriff des Kollektivstils ist vielmehr, dass die beobachteten Ausdrucksmuster als ungesteuerter Effekt eines gleichartig-gemeinschaftlichen Weltund Selbstverstandes der zugehörigen Kommunikationsgemeinschaft interpretiert werden und ihnen damit ein indexikalischer Charakter zugesprochen wird. Eben deshalb sind Kollektivstile - unabhängig von ihrer jeweiligen medialen oder praxeologischen Verankerung - immer auch als soziale bzw. kulturelle Stile zu lesen. ${ }^{66}$

So verstanden fungiert Stil-Praxis als Scharnier, als Transportriemen zwischen dem individuellen Subjekt als Träger-Akteur von Kultur und kulturellen Veränderungen einerseits und der kulturellen Gemeinschaft andererseits.

Wenn ich schliesslich den an Körpergestik, Sprachgebrauch und Mode beobachteten Stilwandel als Ausdruck und Medium einer ,Dynamisierung ${ }^{6}$ der Gesellschaft im späteren 17. und beginnenden 18. Jahrhundert interpretiere, so geschieht dies natürlich nicht zuletzt mit Rückgriff auf unser historisches Wissen um den allmählichen Umbau der Adelsgesellschaft seit dem Ende des 17. Jahrhunderts, der im Verlauf des 18. Jahrhunderts zum epochalen Wechsel von der adlig dominierten Standesgesellschaft zur Bürgergesellschaft führt, sowie mit Blick auf die Veränderungen in der Wissens- und Wissenschaftsgeschichte, die mit dem metaphorischen Label „Aufklärung“ vielleicht nicht ganz zureichend charakterisiert sind.

Ich deute also die von mir exemplarisch vorgeführten stilistischen Veränderungen im Körperauftritt, im zeremoniellen Sprachverhalten wie in der äusseren Herrichtung des Körpers - allesamt Praktiken des Selbst, ${ }^{67}$ gleichzeitig aber auch Praktiken der Sozialität - als Ausdruck und Katalysator einer Dynamisierung des gesellschaftlichen Selbst- und Weltverhältnisses der tragenden sozialen Schichten, welche die gesellschaftlichen, kulturellen und wissensgeschichtlichen Umwälzungsprozesse des 18. Jahrhunderts nicht nur begleitet, sondern über ihre stilistische Fassung als ausdrucksseitiges Formativ auch gleichsam die Bedingung der Möglichkeit dieser Prozesse mit konstituiert. ${ }^{68}$

\footnotetext{
${ }_{66}$ Vgl. ausführlicher Linke (im Druck).

67 Die Assoziation zum entsprechenden Begriff bei Foucault ist beabsichtigt, ohne dass ich mich hier weitergehend auf Foucault beziehe.

68 Interessant, wenn auch ohne detailliertere Untersuchungen in ihrem stilistischen Ausdruckswert nicht im Einzelnen zu klären, ist, dass die Tendenz zu Satzverkürzung und Parataxe, die das ganze 18. Jahrhundert auszeichnet, sich zwischen 1800 und 1850, d.h. in einer Zeit der
} 


\section{Fazit}

In der historischen Rückschau auf länger zurückliegende Epochen ergibt sich zwangsläufig ein ,optischer ${ }^{\varsigma}$ Verkleinerungseffekt, durch den, im Gegensatz zur Wahrnehmung eigener Lebensgegenwart, halbe und ganze Jahrhunderte in einer Weise überblickbar werden, dass wir - wie im hier vorgeführten Fall - auch weiter auseinander liegende Veränderungen einem Kohärenzbogen unterstellen können. Solche, Unterstellungen' müssen allerdings dem Generalverdacht der unzulässigen Entdifferenzierung ausgesetzt werden und bedürfen deshalb einer möglichst detaillierten Plausibilisierung, die hier nur in Ansätzen geleistet werden konnte. Dennoch seien abschliessend die folgenden Punkte als vorläufige Ergebnisse der Untersuchung herausgehoben:

- Die Adelsgesellschaft des 17. und auch noch des 18. Jahrhunderts zeichnet sich durch eine hochentwickelte Repräsentationskultur des Leibes aus, mit der auch eine hohe reflexive Aufmerksamkeit auf die sozialsemiotische Signifikanz körperkommunikativen Verhaltens sowie der äusseren Herrichtung des Körpers durch Kleidung und Körperschmuck einhergeht. Sprache erscheint in diesem Kontext als ein mit anderen körperkommunikativen Praktiken verschränktes Körpermedium, ${ }^{69}$ das zudem mit der Sozialsymbolik von Bekleidungsformen korrespondiert. ${ }^{70}$

- Die von mir nachgezeichneten stilistischen Veränderungen in den Ausdrucksdomänen von Rede, Leibesgestik und Kleidung, deren Zeichenwert ich als Dynamisierung bestimmt habe, ist in erster Linie auf das Kollektiv der tragenden Sozialformation der Zeit bezogen, d.h. auf die Adelsgesellschaft - allerdings unter Einschluss der auf diese Leitfor-

politischen Restauration und Verstetigung, kurzfristig nochmals in ihr Gegenteil verkehrt, d.h., dass es in dieser Zeitspanne zu einer erneuten Zunahme von Hypotaxe und durchschnittlicher Satzlänge kommt, auch wenn , die barocken Werte nicht mehr wiederhergestellt“ (Ágel 2000, S. 1879) werden. Es erscheint jedoch problematisch, hierin einfach einen stilistisch markierten „Rückfall“ in der historischen Entwicklung zu sehen, zumal gerade im Herrenkostüm dieser Epoche (das sich u.a. durch sehr enge Taillenführung von Frack und Weste wie durch kurvigen Schnitt der Männerhüte auszeichnet) kein Rückbezug auf ausladende und steife Formen zu erkennen ist, und auf der anderen Seite die soziale Zeichenhaftigkeit des Körperauftritts in der zunehmend bürgerlich dominierten Gesellschaft gleichzeitig deutlich zurückgenommen wird. In der ersten Hälfte des 19. Jahrhunderts ist damit eher eine Neukonfiguration der Bezüge zwischen den Ausdrucksdomänen des Körperauftritts, des Sprachgebrauchs und der Mode anzusetzen, deren Verständnis wiederum zum Verständnis der gesellschaftshistorischen Entwicklung der Zeit beitragen könnte.

69 Entsprechend kommt der Stimme als dem körperlichsten Moment von Sprache eine hohe soziokulturelle Aufmerksamkeit zu, vgl. Linke (2008b).

70 Falls es heute nicht sowieso zum Grundverständnis der weitgehend konstruktivistisch orientierten Kulturwissenschaften gehörte, so liesse sich an der hier deutlich werdenden Historizität des Blicks auf Körper und Sprache der grundsätzliche Konstruktcharakter des Konzepts Körper wie des Konzepts Sprache aufzeigen. 
mation hin orientierten nicht-adligen Gruppierungen. Und insofern ich diese (kollektiv)stilistischen Veränderungen als Ausdruck wie als Medium der Selbstformierung des Träger-Kollektivs verstehe, postuliere ich damit eine Selbst-Dynamisierung der gesellschaftlichen Leitformation der Epoche. In welchem Verhältnis diese Selbst-Dynamisierung dann letztlich zum Umbau der adligen Standesgesellschaft zur bürgerlichen Klassengesellschaft steht (der sie vorausgeht), wäre noch näher zu bestimmen.

- Was mit einiger Evidenz festgehalten werden kann, ist, dass der Übergang zu einer kulturell bürgerlich dominierten Gesellschaft, der spätestens um die Mitte des 19. Jahrhunderts vollzogen ist, mit einer weiteren Reduktion des Raumbezugs in den Körperpraktiken sowie mit einer weiteren Verschlankung und Entschmückung des Körpers einhergeht, die nun allerdings - dies macht nicht zuletzt der bürgerliche Anstandsdiskurs deutlich - mit einem auffallenden Verlust der Aufmerksamkeit auf den Körper als kommunikativem Medium verbunden ist. Die weitere Verschlankung im gesamten Körperausdruck, wie sie auch die Chodowiecki'schen „Handlungen des Lebens“ programmatisch zeigen bzw. fordern, erscheint deshalb weniger als Fortführung der stilistischen Geste der Dynamisierung $^{71}$ sondern vielmehr als Effekt einer Verlagerung der soziokulturellen Selbstformation und Selbstdarstellung weg vom Medium des Körpers auf das der Sprache, den ich an anderer Stelle ausführlicher dokumentiert und diskutiert habe. ${ }^{72}$ Es handelt sich damit um einen erneuten Paradigmenwechsel: Die Dominanz der Sozialsymbolik des Leibes wird im bürgerlichen Sprachprojekt durch eine Dominanz der Sozialsymbolik der Sprache bzw. des Sprachgebrauchs ersetzt.

- Unabhängig von diesen Differenzierungen ist jedoch das aus den dargelegten Beobachtungen abgeleitete Postulat der Wirksamkeit (kollektiv)stilistischer Muster als Medium der Selbstversicherung und Selbstverständigung sozialer Gruppierungen. Die kollektive Ausbildung von semiotisch signifikanten Formen ${ }^{73}$ erscheint als wirkmächtiger Prozess

71 Andere Stiche derselben Serie zeigen sehr deutlich, dass ein betont schwungvoller Körperausdruck nur den adligen Figuren zugeschrieben wird, während die „natürlichen“ Paare sich durch sehr gefasste und ruhige Körperhaltungen auszeichnen.

72 Vgl. hierzu v.a. Linke (1996) sowie zusammenfassend Linke (2008a). Plakativ zeigt sich dieser Wandel unter anderem in der signifikanten Reduktion nonverbaler Elemente von Grussund Komplimentverhalten vom 18. ins 19. Jahrhundert bei gleichzeitigem Ausbau der verbalen Elemente, in einer allgemeinen Aufmerksamkeitsverschiebung des Anstandsdiskurses vom Körperauftritt auf den sprachlichen Auftritt als dem genuinen Darstellungsmedium bürgerlicher ,Bildungsreligion', sowie in der zunehmenden Hochwertung einer korrekten (standardsprachlichen) Aussprache bei gleichzeitigem Verlust der Aufmerksamkeit auf die ästhetischen Qualitäten der Stimme als der Körperspur der Sprache.

73 Vgl. zum Terminus ,signifikante Form“ Linke (im Druck). 
in der kulturellen Selbstformierung einer Kommunikationsgemeinschaft. ${ }^{74}$ Dabei sind es nicht zuletzt die von sachfunktionalen Zusammenhängen eher entlasteten Lebensbereiche und Ausdrucksdomänen, in denen sich entsprechende stilistische Veränderungen beobachten lassen - der Bereich der Mode erscheint hier prototypisch - und die als Zeichenorte der kommunikativen Herstellung kollektiver Dispositionen erscheinen.

Stilistische Entwicklungen wären damit nicht nur als ,irgendwie' in gesellschaftliche Umorientierungen eingebunden zu denken, sondern als deren ausdrucksseitiges Dispositiv und ihnen damit zum Teil auch vorgängig.

- Richtet man den auf Ausdrucksmuster sensibilisierten Blick schliesslich über die Mitte des 19. Jahrhunderts hinaus weiter auf Körper und Mode, so zeigt sich, dass in der nun bürgerlich dominierten Gesellschaft vor allem die Bekleidung und äussere Herrichtung des Mannes von den 60er Jahren des 19. Jahrhunderts bis zur Mitte des 20. Jahrhunderts durch dunkle Farben, gerade, schlichte Schnitte, kantige Formen und das weitgehende Fehlen von Schmuck gekennzeichnet ist. ${ }^{75}$ Deutlichere Veränderungen in dieser optischen Zurücknahme des männlichen Körpers zeigen sich erst wieder seit den 50er und 60er Jahren des 20. Jahrhunderts, wo - zunächst über jugendkulturelle Szenen - farbige Hemden, bunte Muster, körperbetonende Schnitte und Schmuck wie Halsketten und Armbänder wieder ins Spektrum des männlichen Kostüms aufgenommen werden. ${ }^{76}$ Inwiefern sich diese Veränderungen auf das Faktum beziehen lassen, dass in den Kulturwissenschaften ebenfalls seit den 60er Jahren ein neuartiges Interesse am Körper als Gegenstand wissenschaftlicher Aufmerksamkeit zu beobachten ist und mit Adam Kendons Stu$\operatorname{dien}^{77}$ die ersten grundlegenden Arbeiten zur Zeichenhaftigkeit körperkommunikativer Praktiken entstehen, kann hier nicht mehr beantwortet werden. Die Frage danach sei zumindest gestellt.

74 Auch Manfred Beetz spricht in seiner Studie über die frühmoderne Höflichkeit von der „Eingebundenheit ästhetischer Entwicklungen in gesellschaftliche Umorientierungen" (Beetz 1990, S. 281, Hervorhebung A. Linke). Dass die reflektierte und sprachlich explizite Selbstausdeutung der entsprechenden Gemeinschaften den beobachteten Stilphänomenen und ihrer möglichen Ausdeutung aus nicht-zeitgenössischer Sicht allerdings nicht unbedingt entsprechen muss, hebt Brigitte Schlieben-Lange in ihren Überlegungen zur stilistischen Selbstinterpretation der Revolutionsepoche in Frankreich hervor (Schlieben-Lange 1986, S. 164).

75 Vgl. ausführlich Brändli (1998).

76 Vgl. auch Thiel $(1987$, S. 425).

77 Vgl. die in Kendon (1990) zusammengestellten, meist in den späteren 60er und frühen 70er Jahren durchgeführten und publizierten Studien, so etwa die auch aus heutiger Perspektive noch innovative „Description of some human greetings“ (Kap. 6 in eben diesem Band). 


\section{Quellen (alphabetisch nach Kürzel)}

Adelung (1793-1801) = Adelung, Johann Christoph (1793-1801): Grammatisch-kritisches Wörterbuch der Hochdeutschen Mundart mit beständiger Vergleichung der übrigen Mundarten, besonders aber der Oberdeutschen. 4 Bde. Leipzig. [Neudr. Hildesheim/New York 1970].

Claudius (1800) = Claudius, Georg Karl (1800): Kurze Anweisung zur wahren feinen Lebensart nebst den nöthigsten Regeln der Etikette und des Wohlverhaltens in Gesellschaften für Jünglinge, die mit Glück in die Welt treten wollen. Leipzig.

Complimentist $(1729)=$ Der Allzeit fertige Complimentist, Darinnen deutlich und zierlich vorgestellt wird; Wie ein jeder bey Hohen und Niedern Stands=Personen / beederley Geschlechts / In allen vorfallenden Begebenheiten / sich zu verhalten habe. Alles der Galanten Welt zu besonderem Nutzen ans Licht gestellt von Ge. Heinr. Feyerabend. Rothenburg / Bey Georg Adam Marschall. 1729.

DWb = Deutsches Wörterbuch von Jacob Grimm und Wilhelm Grimm. 16 Bde. in 32 Teilbdn. Leipzig. 1854-1960.

Ethophilus $(1753)=$ Neues und wohl eingerichtetes Complimentir= und Sitten=Buch. Darinnen gezeiget wird, Wie sich sonderlich Personen Bürgerlichen Standes, bey denen im gemeinen Leben vorfallenden Begebenheiten, als: Anwerbungen, Verlöbnissen, Hochzeiten, Geburten, Gevatterschafften, Kind=Tauffen, Kranckheiten, Absterben, Begräbnissen, Gastereyen, Geburts=, Nahmens=, Neu=Jahrs=Tagen, u.d. gl. In Worten und Wercken so klug als höflich verhalten, und durch gute Aufführung beliebt machen sollen. Alles durch geschickte Complimente, Anleitung zur guten Aufführung, und Höflichkeit überhaupt, als auch was jedes Orts ins besondere in Acht zu nehmen ausgeführet, und nebst Einem Trenchier=Büchlein mitgetheilet von Ethophilo. Fünfte vermehrte Auflage. Mit Kön. Poln. und Churfürstl. Sächsis. allergn. Privilegio. Nordhausen, bey Joh. Heinr. Groß, privil. Buchhändler. 1753.

Galant Homme (1694) = Galant Homme, oder Wie man sich in der Galanten Welt In Worten und Geberden / in Aufwarten / gehen / sitzen / essen / trincken / Habit etc. Manierlich aufführen und beliebt machen kann. Der zu Torgau Studierenden Jugend zum besten / und Model lebendiger Anführung / kürtzlich entworffen Von M.G.S. Leipzig / zu finden bey Friedr. Lanckischns sel. Erben / Anno 1694.

Gersaint (1744) = Gersaint, Edmé F. (1744): Abrégé de la vie d'Antoine Watteau. Catalogue raisonné des diverses curiosités du cabinet de feu M. Quentin de Lorangère. Paris.

Hobelbank (1630) = Alamodischer Hobelbank. Daß ist: Ein sehr lustiger vnnd artlicher Discurs, zweyer Adelspersonen / welche sie von den Alamodischen / ja vilmehr von den jetzigen im schwung gehenden vnhöfflichen Sitten / närrischen Gebräuch vnd Mißbräuchen / als da ist in Klaidern / Gebärden / gehen / vnd Basolaßmanos machen / so sie bey etlichen Völckern im Durchraisen / sonderlichen aber bey den vngewanderten Teutschen wargenommen / halten. Gedruckt zu Augspurg / durch Andream Aperger / auff vnser lieben Frawen Thor. M, DC. XXX.

Kotzebue (1972) = Kotzebue, August von (1972): Die deutschen Kleinstädter. In: Mathes, Jürg (Hg.): August von Kotzebue. Schauspiele. Frankfurt a.M., S. 399-466. 
Kürtzliche Anweisung (1736) = Kürtzliche Anweisung zu Complimenten und höflicher Condvite für Personen bürgerlichen Standes, Bey Geburten, Gevatterschafften, Kindtauffen, Anwerbungen, Verlöbnissen, Hochzeiten, Gastereyen, Geburts=Nahmens= und Neu=Jahrs=Tagen, Kranckheiten, Absterben, und Begräbnissen. Nebst einem wohl=eingerichteten Trenchier-Büchlein, in möglichster Deutlichkeit verfasset. Franckfurt und Leipzig. 1736.

Lang (1727) = Lang, Franz (1727): Abhandlung über die Schauspielkunst. [Dissertatio de actione scenica]. München. [Nachdruck übers. und hrsg. v. Alexander Rudin. Bern/München. 1975].

Manier (1738) = Die Manier Höflich und wohl zu Reden und Leben, so wohl mit hohen / vornehmen Personen, seines gleichen und Frauenzimmer / Als auch Wie das Frauenzimmer eine geschickte Aufführung gegen uns gebrauchen könne, ans Licht gestellet Von Menantes. Hamburg. Bey Christian Wilhelm Brandt, Buchhändler im Dohm. 1738.

Manual $(1703)=$ Commodes MANUAL, Oder Hand=Buch / Darinnen zu finden: I. Eine compendieuse Methode zu einer galanten Conduite / wie auch recommendablen Politesse in zierlichen Reden u. wolanständigen Gebehrden zu gelangen; II. Ein vollkömmliches Dictionaire / in welchem die meisten in civili vitâ vorkommenden Termini und gewöhnlichen Redens=Arten ordine Alphabetico eingerichtet / erkläret / und mit Exemplis illustriret seynd / nebst einem vollständigen Teutschen Indice. III. Die vornehmsten Heydnischen Nomina Propria, so in Romänen/Operen/Poesie, Mahlereyen / und sonst gebrauchet werden / gleichfals nach dem Alphabet eingerichtet und erkläret. IV. Le Secretaire d'Amour, oder : Ein Fascicul etlicher bey einer familieren Correspondence gewechselten und aus einem vertraulichen Liebes-Cabinet genommenen Brieffe / nebst andern nach heutiger façon stylisirten wiewohl ingesamt promiscuè gesetzten Missiven und unterschiedenen eingemischten Sorten derer so genannten Billets Doux; V. Allerhand mündliche Complimenten in Teutsch= und Frantzosischer Sprache / auff die gewöhnlichsten Fälle kürtzlich nach dem Alphabet ihrer Materie auffgesetzt / nebenst denen Beantwortungen darauff / auff inständiges Begehren also verfertiget / und ediret von Johann Christian Wächtlern/Jur.Cult. Leipzig / zu finden bey Lanckischens Erben. Anno 1703.

Memoiren (2007) = Memoiren einer preußischen Königstochter. Markgräfin Wilhelmine von Bayreuth. Übersetzung, Anmerkungen und Nachwort von Günter Berger. Bayreuth. 2007.

Menantes (1724) = La Civilité moderne, oder die Höflichkeit der heutigen Welt. Nach der neuesten Französischen Edizion übersetzt von Menantes. Hamburg. 1724.

Mouton (1744) = Mouton, Carl (1744): La Civilité Moderne. Oder die Höflichkeit der heutigen Welt. Woraus man sehen kann, wie man sich zu verhalten habe, damit man in dem Umgange mit artigen Leuten beliebt seyn möge. Neue Auflage. Nachgesehen, verbessert und um ein vieles vermehret. Hamburg.

Scharffenberg (1718) = Die Kunst Complaisant und Galant zu Conversiren, Oder In Kurtzen sich zu einen Menschen von guter Conduite zu machen. Vorinnen auf das deutlichste gewiesen wird, (I.) Wie eine rechtschaffene Conduite müsse beschaffen seyn. (II.) Wie man bey Hofe sich aufzuführen hat. (III.) Wie man mit Ministern umgehen muß. (IV.) Was auf Reisen erfordert wird. (V.) Auf Universitäten. 
(VI.) Cum Eruditis. (VII.) Mit Leuten geringen Standes, und endlich wie man gegen Frauenzimmer sich complaisant und galant erzeigen soll. Auf Verlangen der Complaisanten Welt zum Besten herausgegeben Von Friedrich Wilhelm Scharffenberg. Chemnitz, bey Conrad Stößeln / 1718.

Stands=Person $(1695)$ = Die Wohlerzogene Stands=Person Oder: Kurzer Unterricht / was einem jungen Herrn / vornehmenn Stands / zur Beförderung guter Erziehung und künfftigen klugen Verhaltens / beyzubringen. Allen Hoffmeistern / und denen Königl. Fürstl. und Gräffliche Kinder anvertrauet / hochnützlich zu gebrauchen. Nürnberg / In Verlegung Paul Fürstens Seel. Wittib und Erben. Anno M. DC. XCV.

Trusler/Rode (1799) = Anfangsgründe der feinen Lebensart und Weltkenntniß, zum Unterricht für die Jugend beiderlei Geschlechts, auch zur Beherzigung für Erwachsene, von Dr. John Trusler. Aus dem Englischen übersetzt von Karl Philipp Moritz. Zweite Auflage, umgearbeitet, auch mit Zusätzen und einer Nachlese aus Chesterfield und anderen, imgleichen hin und wieder mit einigen Abänderungen versehen durch August Rode. Berlin. 1799.

von Rohr (1728) = von Rohr, Julius Bernhard (1728): Einleitung zur Ceremoniel=Wissenschafft der Privat=Personen. Berlin, bey Johann Andreas Rüdiger.

Zedler (1732-1754) = Grosses vollständiges Universal-Lexicon aller Wissenschafften und Künste. 64 Bde., 4 Suppl. Bde. Halle/Leipzig. Verlegts Johann Heinrich Zedler. [Photomech. Nachdr. Graz. 1961].

\section{Literatur}

Admoni, Wladimir (1980): Zur Ausbildung der Norm der deutschen Literatursprache im Bereich des neuhochdeutschen Satzgefüges, 1470-1730: ein Beitrag zur Geschichte des Gestaltungssystems der deutschen Sprache. (= Bausteine zur Geschichte des Neuhochdeutschen 56/4). Berlin.

Admoni, Wladimir (1985): Syntax des Neuhochdeutschen seit dem 17. Jahrhundert. In: Besch/Betten/Reichmann/Sonderegger (Hg.), S. 1538-1556.

Admoni, Wladimir (1990a): Die Entwicklung des Gestaltungssystems als Grundlage der historischen Syntax. In: Betten, Anne (Hg.): Neuere Forschungen zur historischen Syntax des Deutschen. Referate der internationalen Fachkonferenz Eichstätt 1989. (= Reihe Germanistische Linguistik 103). Tübingen, S. 1-13.

Admoni, Wladimir (1990b): Historische Syntax des Deutschen. Tübingen.

Ágel, Vilmos (2000): Syntax des Neuhochdeutschen bis zur Mitte des 20. Jahrhunderts. In: Besch, Werner/Reichmann, Oskar/Sonderegger, Stefan (Hg.): Sprachgeschichte. Ein Handbuch zur Geschichte der deutschen Sprache und ihrer Erforschung. 2. Halbbd. 2. vollst. neu bearb. u. erw. Aufl. Berlin/New York, S. 1855-1903.

Auer, Peter (Hg.) (2007): Style and Social Identities: Alternative Approaches to Linguistic Heterogeneity. (= Language, Power and Social Process 18). Berlin/New York.

Bauer, Volker (1993): Die höfische Gesellschaft in Deutschland von der Mitte des 17. bis zum Ausgang des 18. Jahrhunderts. Versuch einer Typologie. (= Frühe Neuzeit 12). Tübingen. 
Beetz, Manfred (1990): Frühmoderne Höflichkeit. Komplimentierkunst und Gesellschaftsrituale im altdeutschen Sprachraum. Stuttgart.

Besch, Werner/Betten, Anne/Reichmann, Oskar/Sonderegger, Stefan (Hg.) (1985): Sprachgeschichte. Ein Handbuch zur Geschichte der deutschen Sprache und ihrer Erforschung. 2. Halbbd. Berlin/New York.

Boehn, Max von (1923a): Die Mode. Menschen und Moden im siebzehnten Jahrhundert. Nach Bildern und Stichen der Zeit, ausgewählt und geschildert von Max von Boehn. 3. Aufl. München.

Boehn, Max von (1923b): Die Mode. Menschen und Moden im achtzehnten Jahrhundert. Nach Bildern und Stichen der Zeit, ausgewählt von Dr. Oskar Fischel. Text von Max von Boehn. 3., verb. Auflage. München.

Brändli, Sabina (1998): Der herrlich biedere Mann. Vom Siegeszug des bürgerlichen Herrenanzuges im 19. Jahrhundert. Zürich.

Braun, Rudolf/Gugerli, David (1993): Macht des Tanzes, Tanz der Mächtigen. Hoffeste und Herrschaftszeremoniell 1550-1914. München.

Bombek, Marita (2005): Kleider der Vernunft. Die Vorgeschichte bürgerlicher Präsentation und Repräsentation in der Kleidung. Münster.

Burke, Peter (1993): The art of conversation. Cambridge.

Burke, Peter (1998): Die Sprache der Gestik im Italien der Frühen Neuzeit. In: Burke, Peter: Eleganz und Haltung. Berlin, S. 85-106.

Caroso, Fabritio (1581): Il ballerino. Venedig.

Eckert, Penelope (2004): The meaning of style. In: Chiang, Wai-Fong/Chun, Elaine/ Mahalingappa, Laura/Mehus, Siri (Hg.): Salsa 11. Proceedings of the 13th Annual Symposium about Language and Society. (= Texas Linguistics Forum 47). Austin, S. $41-53$.

Eichberg, Hennig (1978): Leistung, Spannung, Geschwindigkeit, Sport und Tanz im gesellschaftlichen Wandel des 18./19. Jahrhunderts. Stuttgart.

Elias, Norbert (1976): Über den Prozess der Zivilisation. Bd. 1. Frankfurt a.M.

Elias, Norbert (1989): Studien über die Deutschen. Machtkämpfe und Habitusentwicklung im 19. und 20. Jahrhundert. Frankfurt a.M.

Goffman, Erving (1974): Das Individuum im öffentlichen Austausch. Mikrostudien zur öffentlichen Ordnung. Übersetzt von R. und R. Wiggershaus. Frankfurt a.M. [Originaltitel: Relations in public. Microstudies of the public order].

Gumbrecht, Hans Ulrich (2004): Diesseits der Hermeneutik. Die Produktion von Präsenz. Übersetzt von Joachim Schulte. Frankfurt a.M.

Hinnenkamp, Volker/Selting, Margret (Hg.) (1989): Stil und Stilisierung. Arbeiten zur interpretativen Soziolinguistik. (= Linguistische Arbeiten 235). Tübingen.

Kaempfert, Manfred (1985): Die Entwicklung der Sprache der deutschen Literatur in neuhochdeutscherZeit. In: Besch/Betten/Reichmann/Sonderegger(Hg.), S. 1810 1837. 
Keim, Inken (2007): Die türkischen Powergirls. Lebenswelt und kommunikativer Stil einer Migrantinnengruppe in Mannheim. (= Studien zur deutschen Sprache 39). Tübingen.

Kemp, Wolfgang (1975): Die Beredtsamkeit des Leibes - Körpersprache als künstlerisches und gesellschaftliches Problem der bürgerlichen Emanzipation. In: StädelJahrbuch Neue Folge 5, S. 111-134.

Kendon, Adam (1990): Conducting interaction. Patterns of behavior in focused encounters. Cambridge u.a.

Lerchner, Gotthard (1991): Deutsche Kommunikationskultur des 18. Jahrhunderts aus der Sicht Wielands im ,Teutschen Merkur'. In: Zeitschrift für Phonetik, Sprachwissenschaft und Kommunikationsforschung, 44, 1, S. 52-60.

Lichtenberg, Georg Christoph (1971): Handlungen des Lebens. Erklärungen zu 72 Monatskupfern von Daniel Chodowiecki. Vorwort von Carl Brinitzer. Neudruck. Stuttgart.

Linke, Angelika (1996): Sprachkultur und Bürgertum: Zur Mentalitätsgeschichte des 19. Jahrhunderts. Stuttgart.

Linke, Angelika (2004): Das Unbeschreibliche. Zur Sozialsemiotik adeligen Körperverhaltens im 18. und 19. Jahrhundert. In: Conze, Eckart/Wienfort, Monika (Hg.): Adel und Moderne. Deutschland im europäischen Vergleich im 19. und 20. Jahrhundert. Köln, S. 247-268.

Linke, Angelika (2006): „Ich“: Zur kommunikativen Konstruktion von Individualität. In: Friedrich, Hans-Edwin/Jannidis, Fotis/Willems, Marianne (Hg.): Bürgerlichkeit im 18. Jahrhundert. (= Studien und Texte zur Sozialgeschichte der Literatur 105). Tübingen, S. 45-67.

Linke, Angelika (2008a): Integration und Abwehr. Standardsprachlichkeit als zentrales Moment bürgerlicher Selbstdefinition im 19. Jahrhundert. In: Eichinger, Ludwig M./ Plewnia, Albrecht (Hg.): Das Deutsche und seine Nachbarn. Über Identitäten und Mehrsprachigkeit. (= Studien zur Deutschen Sprache 46). Tübingen, S. 43-61.

Linke, Angelika (2008b): Mit schöner Stimme - von schöner Hand. Zur Sozialsemiotik von Sprechstimme und Handschrift im 18. und 19. Jahrhundert. In: Wiethölter, Waltraud/Pott, Hans-Georg/Messerli, Alfred (Hg.): Stimme und Schrift. Zur Geschichte und Systematik sekundärer Oralität. München, S. 75-90.

Linke, Angelika (im Druck): Stil und Kultur. Artikel 76. In: Fix, Ulla/Gardt, Andreas/ Knape, Joachim (Hg.): Rhetorik und Stilistik. Ein internationales Handbuch historischer und systematischer Forschung. Zweiter Teilb. Berlin/New York.

Paravicini, Werner (1997): Zeremoniell und Raum. In: Paravicini, Werner (Hg.): Zeremoniell und Raum. Sigmaringen, S. 11-27.

Polenz, Peter von (1994): Deutsche Sprachgeschichte vom Spätmittelalter bis zur Gegenwart. Bd. II: 17. und 18. Jahrhundert. Berlin/New York.

Reif, Heinz (1979): Westfälischer Adel: 1770-1860. Vom Herrschaftsstand zur regionalen Elite. Göttingen.

Reif, Heinz (1999): Adel im 19. und 20. Jahrhundert. München. 
Rosenberg, Pierre (1985): Die Gemälde. In: Grasselli, Margaret Morgan/Rosenberg, Pierre: Watteau 1684-1721. Berlin, S. 241-458.

Selting, Margret/Sandig, Barbara (Hg.) (1997): Sprech- und Gesprächsstile. Berlin/New York.

Schlieben-Lange, Brigitte (1986): „Athènes éloquente“/,Sparte silencieuse“. Die Dichotomie der Stile in der Französischen Revolution. In: Gumbrecht, Hans Ulrich/ Pfeiffer, K. Ludwig (Hg.): Stil. Geschichten und Funktionen eines kulturwissenschaftlichen Diskurselements. Frankfurt a.M., S. 155-168.

Simmel, Georg (1920): Grundfragen der Soziologie. (Individuum und Gesellschaft). 2. Aufl. Berlin/Leipzig.

Thiel, Erika (1987): Geschichte des Kostüms. Die europäische Mode von den Anfängen bis zur Gegenwart. 4. Aufl. Berlin.

zur Lippe, Rudolf (1974): Naturbeherrschung am Menschen. II.: Geometrisierung des Menschen und Repräsentation des Privaten im französischen Absolutismus. Frankfurt a.M. 
Heiko Hausendorf

\title{
Interaktion im Raum \\ Interaktionstheoretische Bemerkungen zu einem vernachlässigten Aspekt von Anwesenheit
}

\begin{abstract}
Es ist nicht zu übersehen, dass die neuere Gesprächsforschung der Zeitlichkeit der Interaktion, also der Organisation von Nacheinander und Reihenfolge, viel mehr Aufmerksamkeit geschenkt hat als der Räumlichkeit der Interaktion, also der Organisation der Verortung und Platzierung Anwesender im Raum. Für Zeitlichkeit haben wir mit dem Konzept der Sequentialität eine methodologische Leitorientierung, die sich in unzähligen Analysen empirisch bewährt hat und theoretisch explizierbar ist. Für Räumlichkeit gilt das (trotz der Pionierarbeiten von Goffman, Hall, Birdwhistell, Kendon und anderen) offenkundig nicht, obwohl man mit Fug und Recht behaupten kann, dass Raum und Räumlichkeit - genauso wie Zeit und Zeitlichkeit - interaktiv in Anspruch genommen und interaktiv hergestellt werden. Kann man daraus schließen, dass der Raum für die Interaktion weniger wichtig ist als die Zeit? Oder hat es damit zu tun, dass Raum und Räumlichkeit für eine an sprachlichen Erscheinungsformen orientierte linguistische Gesprächsforschung empirisch und methodisch schwerer zu fassen sind? Und welcher Art sind die Phänomene, die man zu sehen bekommt, und die Konzepte, die man braucht, wenn man Räumlichkeit als Aspekt von Anwesenheit zu thematisieren versucht? Was schließlich leistet Sprache für die interaktive Inanspruchnahme von Raum und Räumlichkeit?

Diesen und ähnlichen Fragen geht der folgende Beitrag am Beispiel einer Interaktionsepisode in einer Kunstausstellung nach.
\end{abstract}

\section{Einleitung}

Wenn wir sprechen und zuhören, setzen wir einen umgebenden Raum fast immer voraus. In vielen Fällen ist das ein architektonisch irgendwie gestalteter, „umbauter" oder ,freier“, öffentlicher oder privater Raum; jedenfalls ein Raum, in dem sich die Interaktion abspielt. Es ist das „hier“, von dem keine Interaktion und kein Gespräch abstrahieren können. Sprechen und Zuhören geschieht nie raum- und ortlos, wie sehr dieses „hier“ in einer konkreten Interaktionsepisode oder im Verlauf der Interaktion auch immer in den Hintergrund treten mag. Es sind die weniger sprachlastigen Interaktionsereignisse, die uns diese Raum- und Ortsbindung der Interaktion sofort deutlich vor Augen führen: Man denke an einen Boxkampf oder ein Fußballspiel, wenn man Beispiele sucht für Interaktionen, in denen zwar auch gesprochen und zugehört wird, in denen aber primär raumbezogen inter- 
agiert wird. Nicht zufällig hat man vom Fußballer (nicht vom Fernsehkommentator) Günther Netzer gesagt, dass er aus der Tiefe des Raumes kam, wenn man seine Interaktionsfähigkeiten auf dem Spielfeld beschreiben wollte.

Wer so argumentiert, argumentiert von der Interaktion her - und es ist kein Zufall, dass Erving Goffman, einer der Pioniere dieser Denkrichtung, von Anfang an neben das Gespräch den Boxkampf (und das Kartenspiel, das Tanzpaar oder das Chirurgieteam im Operationssaal) als gleichrangige Beispiel für fokussierte Interaktion gestellt hat (Goffman 1964, S. 135). Argumentiert man dagegen stärker von sprech- und zuhörlastigen Interaktionen wie dem „Gespräch“ her, ist man naturgemäß sprachfixiert. Und es wird mit dieser Sprachfixierung - des Gesprächs selbst im Sinne eines durch Gesprochen-Gehörtes dominierten Interaktionstyps, aber natürlich auch der Sprachfixierung der linguistischen Gesprächsforschung - zu tun haben, dass wir uns in der Gesprächslinguistik für den Raum bislang viel weniger interessiert haben als beispielsweise für die Zeit. Anders als die Zeitlichkeit des Gesprächs ist die Räumlichkeit des Gesprächs deshalb ein vernachlässigter Aspekt von Anwesenheit. Ob zu Recht, soll hier die Frage sein.

Mein Interesse an Räumlichkeit als Aspekt von Anwesenheit ist Teil eines größeren linguistischen Forschungsverbunds zum Zusammenhang von Sprache und Raum, der gleich im Anschluss kurz skizziert wird (siehe unten 2.). Ich werde mich dann ganz auf die interaktionstheoretischen Aspekte der Thematik konzentrieren und vorschlagen, mit der „Situierung“ eine auf Räumlichkeit bezogene Interaktionsaufgabe zu profilieren (siehe unten 3.). Mittel und Formen der Situierung sollen dann an einem Fallbeispiel aus dem Bereich der Kunstkommunikation illustriert werden: Es ist die Situation vor dem Kunstwerk, an der ich zeigen möchte, wie Räumlichkeit für Interaktion relevant wird und was man daran gesprächslinguistisch untersuchen kann (siehe unten 4.).

Das Ziel des vorliegenden Beitrags besteht gleichwohl nicht darin, eine gesprächslinguistische Untersuchung der behandelten Interaktionsepisoden vorzuführen. Auch geht es nicht darum, Ergebnisse einer empirischen Studie zur Interaktion in Kunstausstellungen vorzustellen. Sowohl zur gesprächslinguistischen Untersuchung raumbezogener Kooperation und Koordination als auch zur Analyse von Ausstellungskommunikation liegen solche empirischen Studien vor (auf die ich im Folgenden noch eingehen werde). Im vorliegenden Beitrag geht es vielmehr darum, einen theoretischmethodologischen Rahmen für die Thematisierung raumbezogener Interaktionsbeobachtungen zu skizzieren. An dieser Stelle, so meine ich, besteht angesichts einer schnell anwachsenden Zahl empirischer Detailanalysen ein konzeptioneller Nachholbedarf der Gesprächsforschung. 


\section{Sprache und Raum}

Die hier vorzustellenden Überlegungen verstehen sich als Beitrag zu einem größeren linguistischen Forschungsverbund, in dem es um das Verhältnis von Sprache und Raum geht. ${ }^{1}$

Wenn man keine Angst vor groben Vereinfachungen hat, kann man zwei Richtungen unterscheiden, aus denen man sich der Beziehung zwischen Sprache und Raum nähern kann:

So kann man z.B. sagen, dass Sprache grundsätzlich im Raum stattfindet. Mit „Sprache“ muss man dann den Gebrauch und die Verwendung von Sprache meinen, also so etwas wie Sprechen/Zuhören und Schreiben/Lesen. Sprachräume sind dann notgedrungen „Sprech-“ und „Zuhörräume“.2 Ein Sprech- und Zuhörraum kann etwas sehr Konkretes und sehr Kleines sein, z.B. eine Ecke in einem Zimmer. Er kann aber auch etwas sehr Abstraktes und flächenmäßig Großes sein, z.B. ein geographisches Areal. Es gibt viele und unterschiedliche linguistische Forschungstraditionen zu solchen Sprech- und Zuhörräumen: natürlich die Sprachgeographie und Dialektologie, natürlich die mikroanalytische Interaktionsforschung, aber auch die Soziolinguistik mit der Korrelation von Raumvariablen mit Sprachvariablen. Auch an die frühe Stadtsoziologie und Sozialgeographie könnte man in diesem Zusammenhang denken (Park 1926). Gerade angesichts dieser disparaten linguistischen und interdisziplinären Forschungstraditionen, die in der Regel mehr oder weniger isoliert voneinander gepflegt und aktualisiert werden (siehe aber unten!), ist es wichtig, sich klar zu machen, dass wir es in allen diesen Fällen mit „Sprech-“ und „Zuhörräumen“ zu tun haben, die nicht unabhängig vom Sprechen und Zuhören bestehen, sondern sich durch und mit dem Sprechen und Zuhören allererst konstituieren und zu einer sozialen Wirklichkeit werden, auf die man sich beziehen kann und die man - z.B. sprachwissenschaftlich - als diatopische Distribution objektivieren und kartographieren kann. Kein Sprechen und Zuhören ist davon ausgenommen, einen wie auch immer impliziten, häufig aber auch unüberhörbaren Bezug auf eine raumgebundene Zugehörigkeit zu artikulieren. „Mundarten“ sind dafür das vielleicht eindringlichste Beispiel.

\footnotetext{
1 Die Initiative zu diesem Forschungsverbund geht auf Gespräche mit meinen Zürcher Kolleginnen Elvira Glaser und Angelika Linke, auf Diskussionen mit Peter Auer und auf einen kontinuierlichen Austausch mit Wolfgang Kesselheim und Reinhold Schmitt zurück - vieles davon ist in diesen Beitrag eingeflossen, ohne dass ich das immer kenntlich machen kann.

2 Es gibt auch Schreib- und Leseräume: Auch das Schreiben und Lesen findet stets in Räumen statt, obwohl man sich die Schrift lange Zeit situations- und damit auch raumentbunden vorgestellt hat (vgl. kritisch dazu Peter Auer in diesem Band); textlinguistisch muss man entsprechend die Situation der Lektüre und die auf den Wahrnehmungsmöglichkeiten in einer Lektüresituation beruhenden Textualitätshinweise mit einbeziehen (Vorschläge dazu bei Hausendorf/Kesselheim 2008). Unter dem Stichwort „linguistic landscapes“ ist diese Räumlichkeit der Schrift neuerdings wieder vielfach ein Thema (vgl. Backhaus 2007; Scollon/Scollon 2003; Auer in diesem Band).
} 
Aus einer anderen Richtung kommend kann man sich auch für den Raum innerbalb der Sprache interessieren: für die Grammatik und das Lexikon, in denen Raum und Räumlichkeit eine Rolle spielen. Es geht dann, etwas zugespitzt, um den Raum in der Sprache und um die Erstarrungen, in denen sich Sprechräume in einer Sprache als Sprachräume niedergeschlagen haben. Mit dieser Erstarrung geht die oben bereits angedeutete Objektivierung und Repräsentierung (z.B. in Form der Kartographierung) von Räumen einher. Sprachräume können sich auf diese Weise vom Sprechen und Zuhören unabhängig machen - und ihrerseits dann sehr nachhaltig auf die Konstitution von Sprech- und Zuhörräumen einwirken. Unterschiedliche Sprachen haben, so ist gesagt worden, ihre jeweils eigene Weise, ihre Sprechräume zu kodieren, sie haben ihre jeweils eigenen ,grammars of space“ (Levinson/Wilkins (Hg.) 2006). Auch zu dieser Tradition gibt es eine Reihe von Arbeiten, z.B. aus der Typologie mit Arbeiten zur Deixis (Hickmann/Robert (Hg.) 2006), zur Grammatik und Semantik der Orts- und Raumreferenz (Vater 1991; Bernhard/Siller-Runggaldier 2008) und traditionell natürlich zur Toponymie bzw. Toponomastik.

Beide Zugangsweisen sind für sich genommen konzeptionell nicht recht überzeugend: Im einen Fall (Sprache im Raum) überlässt man den Raum mehr oder weniger den Geographen, den Architekten und Städteplanern und korreliert Räumliches mit Sprachlichem unterschiedlichster Art, wie es dem „correlational drive“ der frühen Soziolinguistik entspricht (Goffman 1964). Raum wird dabei als Kontext der Interaktion modelliert - für die Analyse ist er dann im Grunde verschenkt.

Im anderen Fall (Raum in der Sprache) reduziert man den Raum auf seine sprachlichen Reflexionen (in Grammatik und Lexikon), verbleibt ganz in der Sprache und erfasst das Sprachlose des Raumes gerade nicht. Räumlichkeit, könnte man übertreibend sagen, erscheint nurmehr als Fluchtpunkt sprachlicher Referenz und Lokalisierung, kaum aber als sprachlich und sensorisch-motorisch hervorgebrachte soziale Wirklichkeit (siehe aber unten!). So sehr unsere Raumwahrnehmung und unser Erleben und Behandeln von Raum durch Sprache gesteuert und geprägt sein mögen, so wenig lässt sich der Raum auf die Spuren seiner Reflexion in der Sprache reduzieren; die Räumlichkeit der sozialen Welt ist jedenfalls nicht auf Sprachlichkeit angewiesen, weder onto-, noch phylogenetisch. ${ }^{3}$

Es gibt in der Linguistik nach wie vor kaum Arbeiten, die beide Perspektiven miteinander verbinden. Aber es mehren sich Versuche, aus jeweils einer dieser Richtungen über die Brücke zu gehen, wenn man so sagen darf. Beispiele dafür gibt es etwa

3 Hinzuweisen wäre hier auf die „zoologische Evolution unseres Raumbezuges“, die wesentlich durch die „sensorische Ausstattung“ des Menschen und sein „sensorisches Dispositiv“ geprägt ist (Leroi-Gourhan 1980, S. 350 f.). 
- in der Arealtypologie, wenn man fragt, ob „Areal“ letztlich ein linguistischer oder geographischer Begriff ist (Bickel/Nichols 2006);

- in Beiträgen zu einer Ethnodialektologie und Ethnogeographie, die danach fragen, wie über Sprachräume auch außerhalb der wissenschaftlichen Dialektologie und Geographie gesprochen wird (Auer 2004; Jones et al. (2008); Schlottmann 2005);

- in der neueren Deixisforschung, die die „Sprechsituation“ mehr und mehr als eine sprachlich und gestisch hergestellte kognitive Wirklichkeit versteht und die sprachlichen Anteile an dieser Konstruktion zu bestimmen sucht (z.B. Hanks 1990; als Überblick jetzt Fricke 2007);

- oder auch in einer - oftmals typologisch orientierten - kognitiven Linguistik, die sich über Sprachräume einen Zugang zu so etwas wie „Raumkognition“ („spatial cognition“) verspricht (Levinson 1996; Herrmann/ Schweizer 1998; Hickmann/Robert 2006).

Dabei ist nicht zu übersehen, dass fast alle ambitionierten neueren Arbeiten zum Thema „Sprache und Raum“ sich letztlich für Kognition und Raum interessieren. Man braucht nur einen der vielen Sammelbände der letzten rund 15 Jahre aufzuschlagen, deren Titel mit den Bestimmungsstücken „Sprache“ und „Raum“ operieren, um sich wie selbstverständlich in der kognitiven Linguistik wieder zu finden. ${ }^{4}$

Weitaus seltener findet man in der Linguistik Studien, die programmatisch nach dem Verhältnis von Kommunikation und Raum oder - wenn wir zunächst in der Welt des Sprechens und Hörens bleiben - nach dem Verhältnis von Interaktion und Raum fragen. Mit dieser Umfokussierung rückt naturgemäß die andere Nachbardisziplin der Linguistik in den Blick, also nicht die Psychologie (und ihre Spielarten), sondern die Soziologie. Hier gibt es einerseits eine ältere soziologische Tradition (insbesondere, aber nicht nur, verbunden mit den Arbeiten von Erving Goffman), die zumindest in Teilen der Linguistik gut bekannt ist. ${ }^{5}$ Andererseits gibt es auch eine neuere, seit einiger Zeit sehr lebhaft voran getriebene Soziologie des Raumes, die stärker kommunikationstheoretisch interessiert ist (vgl. z.B. Löw 2001; Dünne/Günzel (Hg.) 2006, Kap. IV; Schroer 2007; oder aus „,kultursoziologischer" Perspektive Richardson/Jensen 2003). Sie ist in der Linguistik noch so gut wie gar nicht rezipiert worden, und die Linguistik kommt ihrerseits in dieser neueren Raumsoziologie als Bezugsdisziplin so gut wie nicht vor. Das wäre ein eigenes Thema, auf das ich hier nicht weiter eingehen möchte. Im Folgenden soll stattdessen gezeigt werden, wie man ausgehend von einer interaktionstheoretischen Programmatik die skizzierte Dichotomie von Sprech- und Sprachräumen überwinden kann.

$4 \quad$ Vgl. dazu z.B. Bloom (Hg.) (1996); Pütz/Dirven (Hg.) (1996); Hickmann/Robert (Hg.) (2006); Levinson (2003); Tendenzen dazu auch schon in der etwas älteren Forschung zu Sprache und Raum (vgl. als Überblick z.B. Schweizer (Hg.) 1985).

5 Darauf komme ich noch zurück (siehe unten 4.). 


\section{Räumlichkeit als Aspekt von Anwesenheit}

Wenn man interaktionstheoretisch ansetzt, muss man Räumlichkeit als einen Aspekt von Anwesenheit konzipieren: In dem Moment, in dem Anwesenheit interaktiv hergestellt wird, also vereinfacht gesagt mit dem Blickkontakt des Von-Angesicht-zu-Angesicht (face-to-face), sind unweigerlich Personen, Zeit und Raum mitinbegriffen: Personen als ich und $d u$, als wir ${ }^{6}$ Zeit als ein jetzt, von dem aus prospektiv und retrospektiv Erwartungen manifestiert werden können, und Raum als ein hier, das all das umfasst an orts-, platz- und raumgebundener Umgebung, was gerade relevant sein soll für die laufende Interaktion. ${ }^{7}$ Räumlichkeit muss m.E. auf dieses „hier“ der Origo bezogen und als Teil der Sprechsituation (Bühler) konzipiert werden. Man muss sich dazu die Vielfalt und die Breite all dessen vor Augen halten, was in einem Gespräch ein ,hier" sein kann, also an all das denken, worauf sich Sprecher und Sprecherinnen in ihrem kommunikativen Alltag beziehen können, wenn sie den Ausdruck ,hier" verwenden - dann hat man sofort die ganze Welt möglicher Sprachräume im Sprech- und Zuhörraum! ${ }^{8}$

Als Aspekt von Anwesenheit muss Räumlichkeit - wie alles andere in der Sprechsituation auch - interaktiv hergestellt werden. Unabhängig davon, ob es einen Raum und ob es Räumlichkeit als physikalische Wirklichkeit gibt oder nicht geben mag (eine Frage für Physiker und Physikerinnen): Wenn ein Raum und wenn Räumlichkeit für die Interaktion relevant werden sollen, müssen wir beschreiben können, in welchen konkreten Erscheinungsformen der Interaktion sich diese interaktive Herstellung des Raumes vollzieht. Räumlichkeit ist, konversationsanalytisch gesagt, ein „interactive achievement", und nur als ein ,interactive achievement" ist Räumlichkeit für die Gesprächslinguistik von Bedeutung. Die Herausforderung besteht dann darin, diesen Gedanken auch konzeptionell und empirisch umzusetzen - also immer dann, wenn wir geneigt sind, doch wieder auf irgendeine Art von physikalischem Raum zurückgreifen zu wollen, Erscheinungsformen von Interaktion zu postulieren und nachzuweisen, in denen der Raum eben auch in seiner Physis für die Interaktion in Anspruch genommen

6 A. Schütz hat das bekanntlich zum Ausgangspunkt genommen, die „Gesichtsfeldbeziehung“ auch als „Wir-Beziehung“" zu kennzeichnen (Schütz 1972).

$7 \quad \mathrm{Ob}$ und in welcher Weise ein solches bier an die sinnliche Wahrnehmung der Anwesenden oder an ihre Erinnerung oder an ihre Vorstellungskraft appelliert, ist dabei noch nicht entschieden. Ein bier kann eben auch ein räumliches Setting sein, das sich die Anwesenden z.B. narrativ vergegenwärtigen (unabhängig davon, ob sie dabei auch den Ausdruck „hier“ verwenden). Vgl. dazu den Beitrag von Schmitt und Deppermann (in diesem Band).

8 In einer Spielerklärung beispielsweise kann ein „hier“ ein Punkt auf einem Spielbrett (das "Ziel") sein: Und wo muss ich hin? hier, das ist das Ziel / / reigt auf Zielpunkt des Malefiz-Bretts/ / (Hausendorf 2003, S. 253). In einem Gespräch an einem Bücherstand in Ostberlin kann ein „hier" ein politisch-geographisch definiertes Territorium (das der DDR) sein: der / zeigt auf ausliegendes Buch von Chomsky// war bier ja lange verpönt ne? (Hausendorf 2000, S. 188). 
wird. ${ }^{9}$ Der Vorschlag, der in diesem Beitrag vorgestellt werden soll, besteht darin, eine für Interaktion konstitutive Aufgabe zu postulieren, die sich genau aus dieser Anforderung der Herstellung von Räumlichkeit ergibt. Diese Aufgabe soll hier „Situierung“" genannt werden.

\section{Situierung als Interaktionsaufgabe}

Wer von „Situierung“ als Interaktionsaufgabe spricht, darf von anderen konstitutiven Interaktionsaufgaben nicht schweigen. In und mit Interaktion werden unterschiedliche Interaktionsaufgaben gleichzeitig gelöst - eine Herausforderung für interaktionsanalytische Studien jedweder Couleur. Interaktion als Problem- und Aufgabenlösung zu sehen, ist konzeptionell nicht neu. In theoretischer Perspektive umrissen wird sie etwa in Goffmans Einleitung zur „frame analysis“ (Goffman 1977). In analytischer Perspektive entspricht sie vor allem der Grundvorstellung der frühen Konversationsanalyse (Gesprächsbeendigung als konversationelles „Problem“: Schegloff/ Sacks 1973). Konversationsanalytische Studien operieren deshalb durchgängig mit der Idee konversationeller Probleme und/oder Aufgaben (vgl. dazu z.B. die in Hausendorf 2007 (Hg.) veröffentlichten Beiträge). Eine übergreifende Modellierung der für Interaktion allgemein konstitutiven Aufgaben wird gleichwohl nur selten versucht. Konzeptionell wegweisend ist hier nach wie vor die frühe Einführung in die ethnomethodologische Konversationsanalyse von Kallmeyer und Schütze (Kallmeyer/Schütze 1976). Sie hat in mancherlei Hinsicht vorweggenommen, was inzwischen auf empirische Weise in zahllosen Beiträgen zur Gesprächsforschung erarbeitet, differenziert und weiter entwickelt worden ist. Genügend Gründe also, um eine solche Modellierung der für Interaktion konstitutiven Aufgaben wieder in Angriff zu nehmen.

Die folgende Darstellung, die einen bereits an anderer Stelle publizierten Gedanken wieder aufnimmt (Hausendorf 2007), geht davon aus, dass Interaktion als soziales System (im Sinne Goffmans, aber auch im Sinne der Luhmannschen Systemtheorie: Hausendorf 1992) verstanden werden kann. Dass dieses Interaktionssystem ein multi-tasking system ist, gehört zu den Grundeinsichten der letzten rund 35 Jahre linguistischer Gesprächsforschung; wenn wir nach den einzelnen Aufgaben fragen, die in und mit Interaktion gleichzeitig bearbeitet werden, stoßen wir sofort auf lauter alte Bekannte, auf die üblichen Verdächtigen der Konversations- und Interaktionsanalyse. Das folgende Schaubild bringt diese gut bekannten Interaktionsaufgaben in Form von Fragen zum Ausdruck:

$9 \quad$ Wir werden sehen, dass dieser Gedanke vor allem dazu zwingt, Wahrnehmung (in der ganzen Bandbreite menschlicher Sensorik) und Bewegung (in der ganzen Bandbreite menschlicher Motorik) als Erscheinungsformen von Interaktion auffassen zu können (siehe unten 5.). 


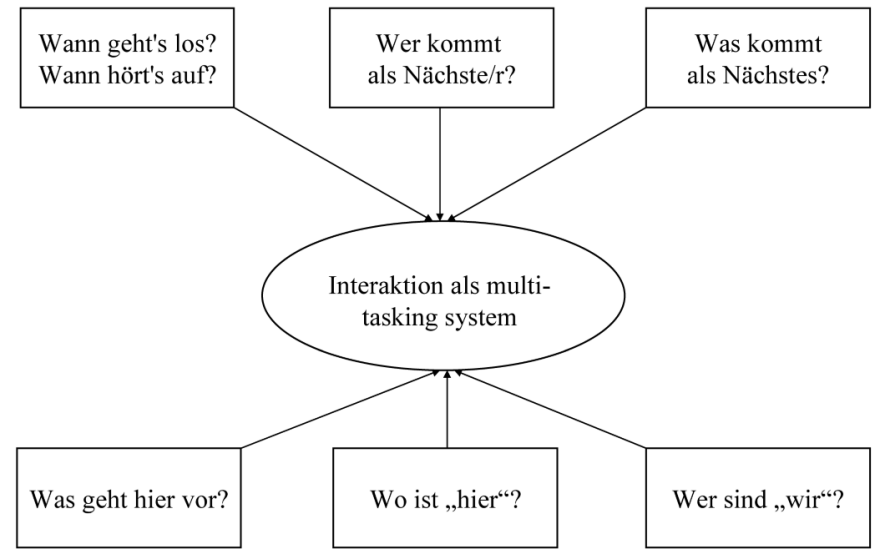

Abb. 1: Interaktion als multi-tasking

Hinter diesen Fragen stehen jeweils viel beschriebene interaktive Aufgaben:

- die Herstellung, Aufrechterhaltung und Auflösung von Anwesenheit (Wann geht's los? Wann hört's auf?),

- der Sprecherwechsel (Wer kommt als Nächster?),

- die Organisation von Beiträgen und Themen (Was kommt als Nächstes?),

- die Kontextualisierung und Rahmung des Geschehens (Was geht hier vor?),

- die Selbst- und Fremddarstellung (Wer sind „wir“?) und eben auch

- die Situierung des Geschehens (Wo ist „hier"?).

Es ist hier nicht der Ort, die Anzahl und Benennung dieser Aufgaben zu diskutieren. ${ }^{10}$ Behauptet werden soll aber, dass es sich bei diesen Aufgaben tatsächlich um interaktionskonstitutive Aufgaben handelt, die also immer irgendwie bearbeitet (,gelöst“) werden müssen. Behauptet werden soll weiterhin, dass die Bearbeitung dieser Aufgaben jeweils im interaktiven Hinter- oder Vordergrund geschehen kann, woraus sich wie von selbst eine Typologie unterschiedlicher Interaktionsereignisse ergibt. Wichtig(er) für den vorstehenden Zusammenhang ist die Frage, wo und wie Raum und Räumlichkeit in diesem Aufgabenszenario auftauchen.

Zunächst kann man leicht sehen, dass Raum und Räumlichkeit offenkundig auch für andere Interaktionsaufgaben relevant sind: Der Raum kann beispielsweise auch zum Thema von Beiträgen werden, zu dem also, worü-

$\overline{10} \quad$ Ein Indiz für die Angemessenheit dieses Modells sehe ich darin, dass man es gut zum Ausgangspunkt nehmen könnte, eine Einführung in die Gesprächslinguistik zu verfassen: Maßgebliche Ergebnisse gesprächslinguistischer Forschung ließen sich ohne große Mühe entlang dieser Aufgaben präsentieren (vgl. dazu die gerade erschienene Einführung in die Konversationsanalyse von E. Gülich und L. Mondada (2008), die diesen Eindruck m.E. sehr anschaulich belegt). 
ber man spricht und zu dem, was man sprachlich und gestisch-spielend in Szene setzen kann, z.B. beim Erzählen (Aufgabe: Themen- und Beitragsorganisation; vgl. dazu den Beitrag von Schmitt und Deppermann im vorliegenden Band); Raum kann auch zur Zugehörigkeitsressource werden, also zur „Verortung“ der TeilnehmerInnen genutzt werden (Aufgabe: Selbstund Fremddarstellung; vgl. dazu z.B. die Relevanz von Herkunftsprädikaten für die Klärung von Zugehörigkeit: Hausendorf 2000, S. 197 ff.), er trägt in vielen Fällen maßgeblich zum Sprecherwechsel, aber auch zur Rahmung bei. ${ }^{11}$ Diese Relevanz von Raum und Räumlichkeit auch für die anderen Interaktionsaufgaben ist konzeptionell dadurch erfasst, dass die Bearbeitung der unterschiedlichen Interaktionsaufgaben grundsätzlich gleichzeitig erfolgt, sich also empirisch sehr funktionale Überlappungen zwischen den Aufgaben und ihrer Bewältigung ergeben.

Die Übersicht (siehe oben Abb. 1) lässt des Weiteren erkennen, dass die Situierung als eigenständige Interaktionsaufgabe in der Konversationsanalyse und Gesprächsforschung bislang weit weniger Aufmerksamkeit gefunden hat als die anderen Aufgaben. Wenn man z.B. sieht, wie die naturgemäß sehr prominenten „Wer/Was kommt als Nächster/s“-Fragen ${ }^{12}$ dazu geführt haben, Zeitlichkeit im Sinne von Sequentialität zu einem herausragenden Konzept zu entwickeln, kann man auch sagen: Räumlichkeit ist als Aspekt von Anwesenheit bislang fast noch ein blinder Fleck.

Diese Diagnose gilt auch dann, wenn man weiss, dass es eine sehr ehrwürdige sozialwissenschaftliche Tradition gibt, die unter dem etwas unglücklichen Titel „Context Analysis“ bekannt geworden ist und die von Bateson über Birdwhistell bis Kendon reicht (um nur drei Namen zu nennen) und in der Situierung immer ein Thema war. ${ }^{13}$ Wenn diese und verwandte Traditionen der sozialwissenschaftlichen Interaktionsanalyse heute an vielen Stellen aufgenommen und wieder belebt werden (vgl. Schmitt 2007), dann zeigt sich darin eben auch, wie lange wir in der Gesprächsforschung die Situierung als Interaktionsaufgabe - und mit ihr den Raum - mehr oder weniger vergessen hatten. ${ }^{14}$

$11 \quad$ Im Falle der Rahmung ist die Überschneidung mit der Situierung besonders deutlich. Wir werden deshalb darauf noch zurückkommen (siehe unten 6.).

12 „The practical question par excellence, "What to do next?”' (Garfinkel 1967, S. 12); „What's next?" (Schegloff/Sacks 1973).

13 Hinweise auf diese Tradition finden sich z.B. bei Kendon (1990, S. 15 ff. („Some context for context analysis: a view of the origins of structural studies of face-to-face interaction")); vgl. zusammenfassend auch Knoblauch (2005, S. 267 f.).

14 Neben den Arbeiten zur „Multimodalität der Interaktion“ (Schmitt 2006; Norris 2004) wären hier auch die work-place-studies zu nennen, aus denen in den letzten Jahren viele neue Impulse gekommen sind (z.B. Heath/Hindmarsh 2000; Hindmarsh/Heath 2000). „Situatedness“, „Embodiment“, „Multimodality“ und „Discourses in Place“ sind im Grunde neue Stichworte, mit denen die Relevanz der Aufgabe der Situierung aus jeweils unterschiedlichen Perspektiven und mit unterschiedlichen Gewichtungen in den letzten Jahren hervorgehoben worden ist (vgl. z.B. Goodwin 2000; Frank et al. (Hg.) 2008; Scollon/Scollon 2003; Überblick z.B. bei Mondada 2007). 
Wenn man sich der Situierung zuwendet, ist zunächst nicht zu übersehen, dass - wie Goffman formuliert - „das natürliche Zuhause von Sprache" eines ist, in dem die Sprache nicht immer gegenwärtig ist. ${ }^{15}$ Die an den Anfang dieses Beitrags gestellten Beispiele aus dem Sport (das Fußballspiel), aber auch aus dem Krankenhaus (Operation) liefern dafür sehr anschauliche Belege. Situierung lebt entsprechend, das werde ich im empirischen Teil zu zeigen versuchen (siehe unten 5.), zunächst von der Ausnutzung von Anwesenheit im Vollsinne der Gegenwart von Menschen: also von der Sensorik, der Motorik und der Kognition Anwesender. Der Sprechund Zuhörraum ist insofern immer auch ein Wahrnehmungs-, ein Bewegungs- und ein Handlungsraum, der als solcher nicht auf Sprechen und Zuhören, wohl aber auf Anwesenheit angewiesen ist.

Wenn und sobald gesprochen und zugehört wird (und das ist oft genug der Fall), kann die Situierung dann natürlich auch auf Sprache zurückgreifen: auf Deixis in einem engeren Sinne (siehe unten 5.), auf die Grammatikalisierung räumlicher Verhältnisse im weitesten Sinne und auf die Lexik und Semantik möglicher Räume, Plätze und Orte. Es sind dies ja letztlich nichts anderes als Erstarrungen und Verfestigungen, sprachlich routinisierte Lösungen kommunikativ-interaktiver Situierungsaktivitäten. Das gilt diachron wie synchron, typologisch wie einzelsprachlich und phylogenetisch wie ontogenetisch. Empirisch fällt die Konstitution von Sprech- und Zuhörräumen deshalb mit der Konstitution von Sprachräumen zusammen (so sehr sich auch die Untersuchung der Phänomene disziplinär und interdisziplinär unterscheiden mag, siehe oben 2).

Schließlich wird sich zeigen, dass man sich den Raum selbst nicht als tabula rasa vorstellen sollte. Es gibt, etwas zugespitzt, eine genuine Lesbarkeit des Raumes (Kesselheim/Hausendorf 2007), und die interaktive Lösung der Situierungsaufgabe wäre ohne solche Anschlussmöglichkeiten im Raum oft gar nicht denkbar. Wenn wir uns für Situierung interessieren, dürfen wir also solche nicht interaktiven, also nicht an Kopräsenz gebundenen, sondern kommunikativ-dauerhaften Konstitutionen von Räumlichkeit nicht übersehen. In ihnen vor allem vollzieht sich hintergründig die gesellschaftliche Rahmung von Interaktion (siehe unten 6.).

Anwesenheit, Sprachlichkeit und die Lesbarkeit des Raumes sind die wesentlichen Ressourcen, auf die die Situierung zurückgreifen kann, wie das folgende Schaubild vorausgreifend zum Ausdruck bringt:

15 „Note then that the natural home of speech is one in which speech is not always present.“ (Goffman 1964, S. 135). Goffman meint mit dem „natürlichen Zuhause“ der Sprache die soziale Situation der face-to-face Interaktion, wie sie über eine lange Zeit als eigenständiger Gegenstand mehr oder weniger ignoriert worden ist. 


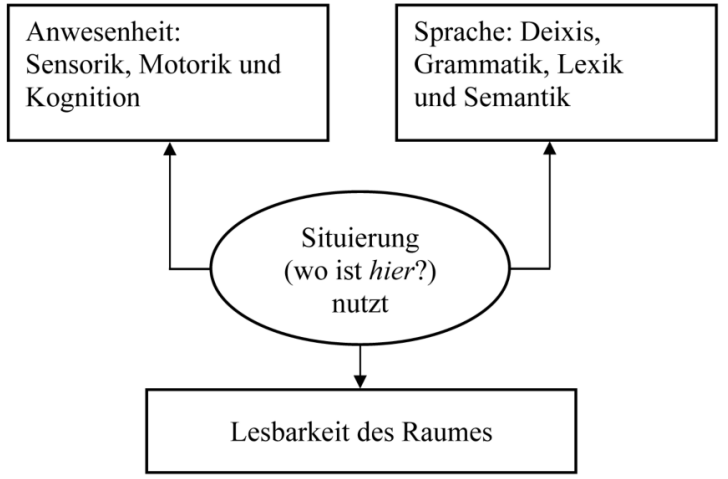

Abb. 2: Ressourcen der Situierung

Empirisch tut sich an dieser Stelle ein großes und weites Feld auf, das die Linguistik bislang nur sehr ausschnittweise betreten hat (siehe oben) - und das sie in theoretisch-konzeptioneller Hinsicht, wenn man z.B. an den „spatial“ oder „topographical turn" in den Kulturwissenschaften denkt (Döring/Thielmann (Hg.) 2008; Schroer 2008; Schlögel 2003, S. 60-71; Weigel 2002), weitgehend anderen Disziplinen überlassen hat. Auch das wäre ein eigenes Thema.

Mit dem folgenden Fallbeispiel werde ich vor allem das Nutzen von Anwesenheit in seinen senso-motorischen Aspekten zu illustrieren versuchen. ${ }^{16}$ Den Bereich des Sprachlichen, aber auch die Lesbarkeit des Raumes werde ich dabei nur andeuten, nicht aber systematisch erörtern können. Das Fallbeispiel soll, wie eingangs betont, der Illustration eines Forschungsrahmens dienen, nicht der empirischen Analyse der Details der Raumkonstitution.

\section{Situierung vor dem Kunstwerk}

Im Mittelpunkt der folgenden Beobachtungen steht eine alltägliche Szene: Ein paar Leute gehen zusammen in eine Ausstellung. Was so einfach und so trivial klingt, ist gleichwohl Moment einer ausgewachsenen sozialen Praxis:

$16 \quad$ Wie die Räumlichkeit sind auch die senso-motorischen Grundlagen der Interaktion bislang stark vernachlässigt worden - obwohl es insbesondere in der phänomenologischen Tradition viele Anknüpfungspunkte gibt, an die die linguistische Gesprächsforschung anschließen könnte. Vgl. dazu die theoretische Diskussion der Thematik bei Loenhoff (2002), die mit den hier vorzustellenden empirischen Beobachtungen ausgesprochen kompatibel scheint. Loenhoff geht bei seinen Überlegungen nicht von Räumlichkeit aus, sondern von der Art und Weise, wie Kommunikationstheorien Körperlichkeit zu thematisieren gestatten, kommt dabei dann aber auch auf Räumlichkeit zu sprechen (speziell ebd., S. 53 ff.: „Der Körper und die situative Räumlichkeit"). 
der sozialen Praxis des gemeinsamen Ausstellungsbesuchs. Ich werde zu zeigen versuchen, dass diese Praxis eine Vielzahl von Situierungsaktivitäten verlangt. Die Welt der Ausstellungen ist deshalb für unser Thema besonders geeignet - was andere auch schon vor mir bemerkt haben (z.B. Kesselheim 2009; z.B. Vom Lehn/Heath 2007).

Der Videoausschnitt, den ich im Folgenden besprechen werde, ${ }^{17}$ beginnt damit, dass Claudia und Melanie einen Ausstellungsraum betreten haben und gemeinsam auf ein am Boden befindliches Objekt zusteuern, sich dann hinunterbeugen und - mit dem ins Bild kommenden Nils - um das Objekt herum hockend verweilen:

Ausschnitt 1: öbis zwüsche bimbeermarmelade und bluet ${ }^{18}$

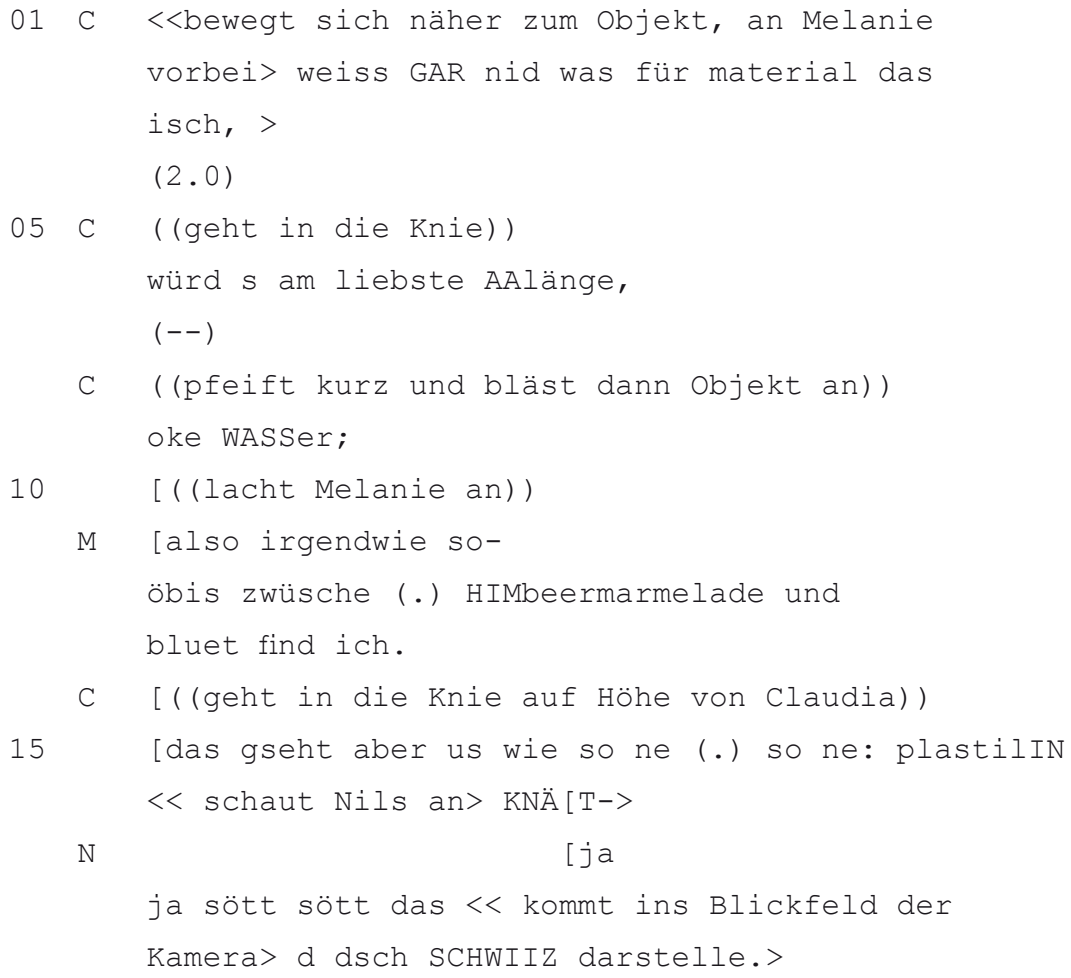

$17 \quad$ Ich verdanke das Beispielmaterial Sabina Gröner, die es im Rahmen einer Lehrveranstaltung („Kunstgespräche“, Zürich, FS 2007) erhoben, transkribiert und analysiert hat. Den an der Szene beteiligten Personen sei für die Verwendung und den Abdruck der Standbilder gedankt!

18 Transkription: Sabina Gröner. Transkriptionszeichen in Anlehnung an GAT, grobe Wiedergabe mundartlicher Besonderheiten des Schweizerdeutschen mit literaler Umschrift. 
Keine spektakuläre, vielmehr alltägliche Szene aus einem gemeinsamen Ausstellungsbesuch. Im Folgenden interessiert, wie in diesem Ausschnitt „Raum“ und „Räumlichkeit" ins Spiel kommen. Ich werde den Raum dazu nach und nach als Wahrnehmungs- (5.1), Bewegungs- (5.2), Handlungs- (5.3) und Spielraum (5.4) vorstellen.

\subsection{Wahrnehmung}

Für die soziale Praxis des gemeinsamen Ausstellungsbesuchs, der wir gerade beiwohnen, ist zunächst und offenkundig die sinnliche Wahrnehmung, insbesondere die visuelle Wahrnehmung, ist das Sehen der Anwesenden von besonderer Bedeutung. Der Raum ist, das lässt sogar noch die sprachfixierte Transkription erkennen, für die Interaktion neben allem anderen, was er noch sein mag, ein Wahrnehmungsraum. Es geht dann darum, aus der Fülle an Möglichkeiten des Wahrnehmbaren die für die Interaktion gerade relevanten Wahrnehmungen auszuwählen und interaktiv zu etablieren. Dafür gibt es unter Anwesenden nur einen Weg: die fraglichen Wahrnehmungen müssen selbst wahrnehmbar (gemacht) werden. Derartige „Wahrnehmungswahrnehmungen " (Luhmann) sind für Interaktionsforscher und Interaktionsforscherinnen nichts Ungewöhnliches. Schon der Blickkontakt ist ja genau das: Indem mit dem Blickkontakt in der Regel wahrgenommen werden kann, dass wahrgenommen wird, erzeugt er in einer Art Kurzschluss „Anwesenheit" als Interaktionsbedingung. ${ }^{19}$ Das erfasst zunächst und primär die Anwesenden in ihrer Kopräsenz, also das „wir“. Für das „hier“ müssen dann andere Phänomene aufkommen, die garantieren, dass das Sehen von etwas Drittem (das nicht der Andere ist) selbst sichtbar wird. Ich greife dazu zwei bekannte Phänomene heraus.

Das erste für die Etablierung gemeinsam geteilter Aufmerksamkeit relevante Phänomen zeigt sich schon in der Annäherung an das Objekt:

19 Ich greife an dieser Stelle auf Vorarbeiten interaktionssoziologischer (Goffman 1964) und systemtheoretischer (Luhmann 1984, S. 560 ff.) Provenienz zurück. In beiden Traditionen wird übereinstimmend die Relevanz von Wahrnehmungswahrnehmungen für die Emergenz von Interaktion betont (vgl. Hausendorf 1992). 
Ausschnitt 2: was für material das isch

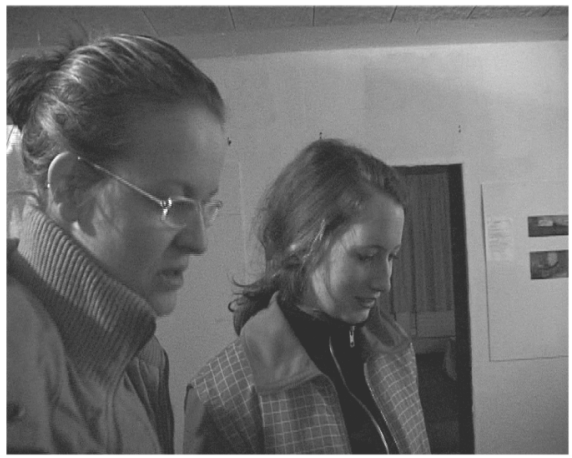

$01 \mathrm{C}<<$ bewegt sich näher zum Objekt, an Melanie vorbei> weiss GAR nid was für material das isch, > $(2.0)$

Das Bild in Ausschnitt 2 illustriert die Synchronisierung der Ausrichtung der Wahrnehmungsorgane (Blickrichtung und Köperzuwendung) von Claudia und Melanie: Dadurch, dass Claudia und Melanie in die gleiche Richtung schauen und ihre Sinnes- bzw. Kommunikationsorgane auf ein gleiches Ziel ausrichten, wird die Wahrnehmung von etwas „,orne unten“ selbst wahrnehmbar. Das Sehen wird sozusagen sichtbar gemacht. Man könnte das Ko-Orientierung nennen (siehe unten).

Noch deutlicher zeigt diesen Mechanismus der folgende Ausschnitt, der einsetzt, nachdem die Beteiligten um das Objekt herum in die Knie gegangen sind:

Ausschnitt 3: schwiizerkrüz

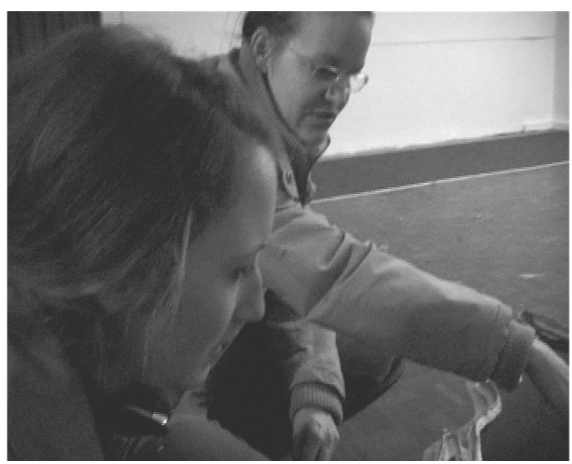

N ja sött sött das $<<$ kommt ins Blickfeld der

Kamera> d dsch SCHWIIZ darstelle.> 
Ausschnitt 3 zeigt ein Beispiel für verbale und nonverbale Deixis (Demonstrativum und Zeigegeste): Deixis ist - eng gefasst (Hausendorf 2003) - nichts Anderes als das Sichtbarmachen des Sehens, ${ }^{20}$ die visuelle Wahrnehmung eines bestimmten Details wird selbst unmissverständlich wahrnehmbar gemacht. Der ausgestreckte Arm mit dem ausgestreckten Finger fungiert gewissermaßen als verlängerter Blick. Unterstützt wird das hier - wie so oft - durch Sprache, durch das Demonstrativum „das“, das wie ein „shifter" (Jakobson) dazu dient, auf Wahrnehmung als relevante Interaktionsmodalität gleichsam umzuschalten. Der Hinweis, dass Wahrnehmung wahrgenommen werden soll, ist der Sinn der demonstratio ad oculos et ad aures (Bühler 1982). Mit „Zeigen“ oder „Lokalisieren“ hat das nicht viel zu tun (vgl. dazu auch de Mulder 1996).

Wenn in diesem Beitrag von Deixis die Rede ist, ist immer dieser Spezialfall gemeint, der nach Weinrich (1993, S. 444 f.) am Rande der Sprache steht und ein Signal an der Grenze zwischen Code und Situation ist. Das gilt nicht für alle Sprachzeichen, die landläufig unter dem Sammelbegriff „Deixis" subsumiert werden. Nur dann, wenn ein mit Anwesenheit grundsätzlich unterstellbares Minimum an geteilter Aufmerksamkeit zugunsten von Spezialwahrnehmungen in irgendeiner Hinsicht expandiert werden soll, sind deiktische Hinweise im oben erläuterten engeren Sinne notwendig. Wahrnehmung kann auch ohne Deixis - z.B. durch die Verwendung der verba sentiendi - wahrnehmbar gemacht werden, aber mit und durch Deixis geschieht das unvergleichlich ökonomisch, unvergleichlich effektiv und unvergleichlich unscheinbar.

Synchronisation und Deixis sind zwei herausragende Phänomene, die illustrieren, wie im Medium von Wahrnehmungswahrnehmung z.B. Objekte im Raum interaktiv relevant gemacht und in diesem Sinne tatsächlich „hergestellt" werden können.

$20 \quad$ Dieses Verständnis von Deixis ist natürlich begründungspflichtig. Es schließt eng an Bühlers Konzeption an (Hausendorf 2003). Für die Argumentation im vorliegenden Beitrag muss es aber nicht vorausgesetzt werden. 
Wenn der Raum stets ein Wahrnehmungspotential für die Sinnesorgane der Anwesenden darstellt, ergibt sich daraus eine Daueranforderung für die Interaktion: Die für die Interaktion gerade relevanten Wahrnehmungen im Raum müssen ausgewählt und etabliert werden. Ich nenne das „Ko-Orientierung". Ko-Orientierung vollzieht sich in Relation zu den Sinnesorganen der Anwesenden: oben und unten, vorne und hinten, rechts und links Ausdrücke wie diese liefern Beispiele für Orientierungen, wie sie für die Navigation im Nahbereich der Interaktion unerlässlich sind. Die Ko-Orientierung greift als Aspekt der Situierung vor allem auf die Sensorik der Anwesenden zurück. Man kann an diesem Feld anschaulich machen, was es heißt, dass die Anwesenden zu den "Sensoren des Interaktionssystems“ werden (Luhmann 1984, S. 558). Ohne Ko-Orientierung wäre die soziale Praxis eines gemeinsamen Ausstellungsbesuchs undenkbar.

Nicht immer, aber sehr häufig sind Ko-Orientierungen der Ausgangspunkt für Konfigurationen, die Bewegung implizieren.

\subsection{Bewegung}

Für die soziale Praxis des Ausstellungsbesuches ist neben der Wahrnehmung unübersehbar auch die Bewegung der Anwesenden relevant, wenn man so will: die Motorik und die Kinesik der Navigation im Ausstellungsraum. Das „hier“ erscheint in dieser Hinsicht nicht nur als Wahrnehmungs-, sondern auch als Bewegungsraum. ${ }^{21}$ Stärker noch als das Wahrnehmungspotential von Räumlichkeit bedroht ihr Bewegungspotential die Interaktion akut: Anwesende können durch Bewegung im Raum jederzeit Abwesenheit wählen! Bei Bewegung der Anwesenden ist Interaktion also ständig durch Selbstauflösung bedroht. Das Problem ist dann - wenn man nicht gerade zusammen sitzt -, die Interaktion trotz und bei Bewegung aufrechtzuerhalten, vereinfacht gesagt: zusammen zu bleiben. In einer Ausstellung ist das ein vertrautes Problem: Es soll nicht jeder für sich die Ausstellung besuchen, sondern die TeilnehmerInnen sollen gemeinsam die Ausstellung besuchen. Man muss also Konfigurationen finden, die den Ausstellungsbesuch immer wieder als gemeinsames Ereignis aufrechterhalten, erfahrbar und erlebbar machen. ${ }^{22}$

$21 \quad$ In einer konkreten Situation wie der hier besprochenen fallen der Wahrnehmungs- und der Bewegungsraum empirisch mehr oder weniger zusammen. Gleichwohl scheint mir die Unterscheidung von Wahrnehmung und Bewegung analytisch ausgesprochen fruchtbar, weil die auf Sensorik beruhende Herstellung von Raum und Räumlichkeit von der auf Motorik beruhenden Herstellung von Raum und Räumlichkeit unterschieden werden kann und muss. $\mathrm{Ob}$ und in welcher Weise Bewegung Wahrnehmung impliziert und Wahrnehmung umgekehrt Bewegung impliziert, ist dafür nicht ausschlaggebend.

22 Von „Konfigurationen“ ist in unmittelbar vergleichbarem Zusammenhang auch bei Vom Lehn/Heath (2007) die Rede. Bei Kendon (1990) heißt es mit ähnlicher Bedeutung auch „spatial positioning“. 
Eine typische, für die soziale Praxis des gemeinsamen Ausstellungsbesuchs zentrale Konfiguration ist das gemeinsame Verweilen vor dem Kunstwerk. Ausschnitt 1 zeigt den Beginn dieser Konfiguration, der folgende Ausschnitt zeigt ihre Aufrechterhaltung und Auflösung:

Ausschnitt 4: ich glaub es isch jugoslawie lueg (Fortsetzung von Ausschnitt 1)

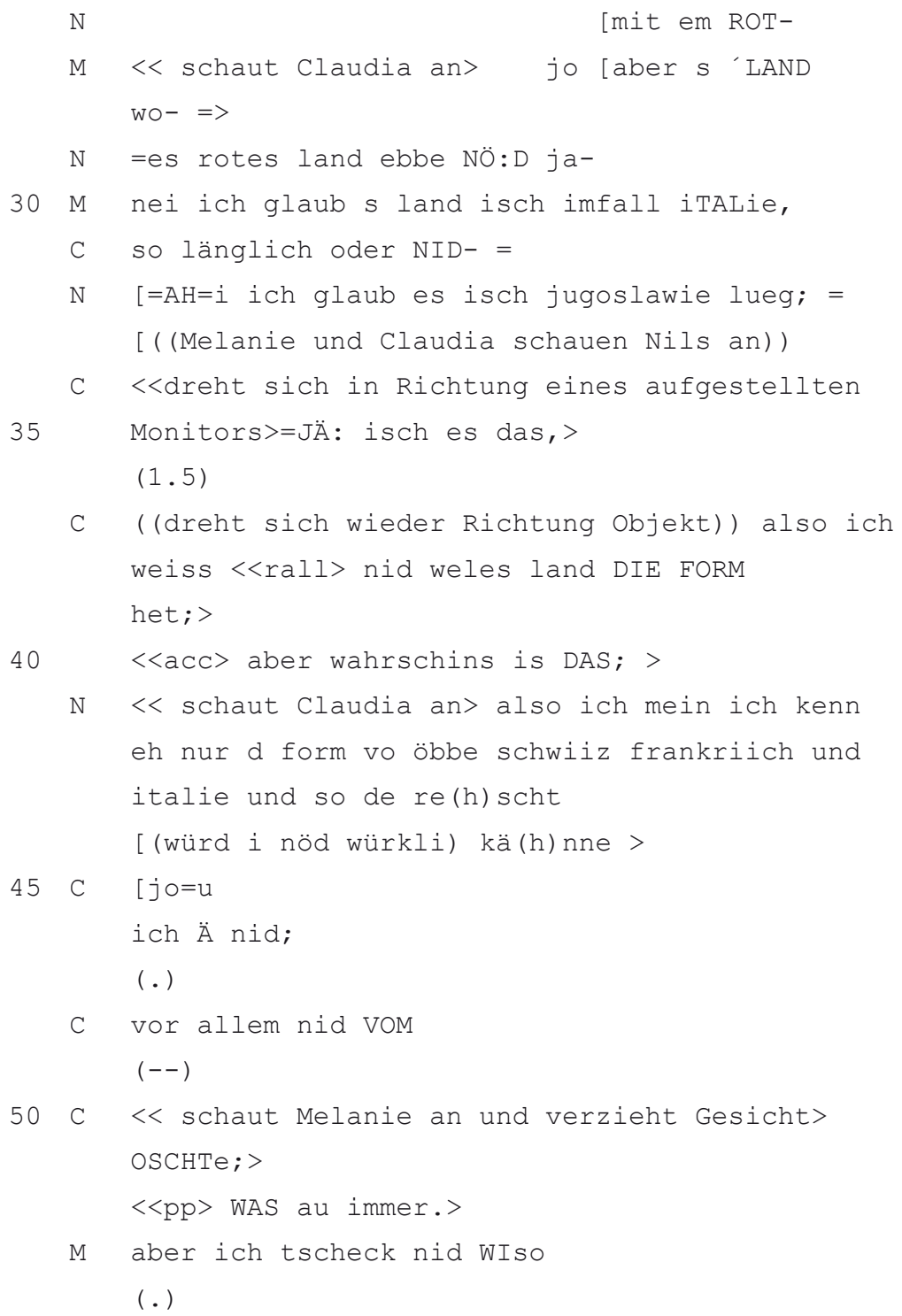

(.) 
55 M ah weisch WIso;

$(-)$

M jo ich glaub es isch scho $<<$ h $>$ irgendwie $>$ BLUET $<<t>$ aso->=

C $=j \circ \mathrm{s} s$ het öbis BLUE

60 [tigs; (verzieht kurz Gesicht)

M [d SCHWIIZ wo irgendwie öbis bluetigs <<steht auf> in däm LAND irgendwie het> oder so.=

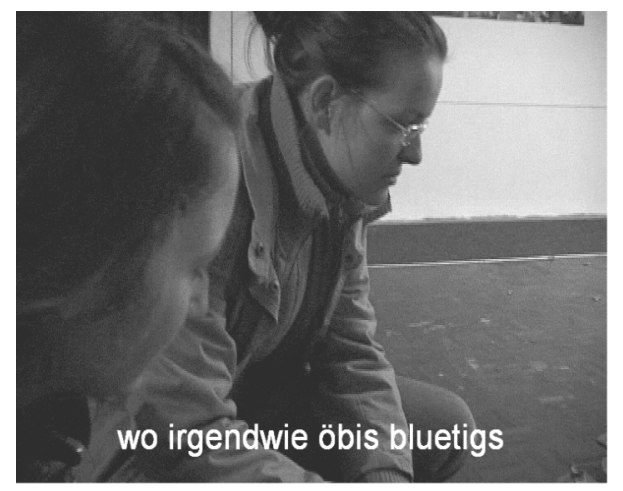

Z. 61

$\mathrm{C}=j \circ \mathrm{s} \mathrm{s}$ het öbis BLUE

60 [tigs; (verzieht kurz Gesicht)

M [d SCHWIIZ wo irgendwie öbis bluetigs $<<$ steht auf> in däm LAND irgendwie het> oder so.=

$\mathrm{N}=$ ja döte

$65 \mathrm{C} \quad<$ steht auf und verzieht Gesicht $><<$ p $>$ KEI ahn $[$ ig. $>>$

$\mathrm{N}$ <<steht auf> [ebbe halt> ähm HAja oke:; (2.5)

C $\quad<$ schaut Melanie an> aber d finger hän si jo 70 nid im SPIIL ka; $(--)$

C WäHRend em krieg oder $<<$ hebt Schultern an $>$ WEISCH->>= =ich glaub $\mathrm{s}$ si=ch ich WEISS es nid aber 

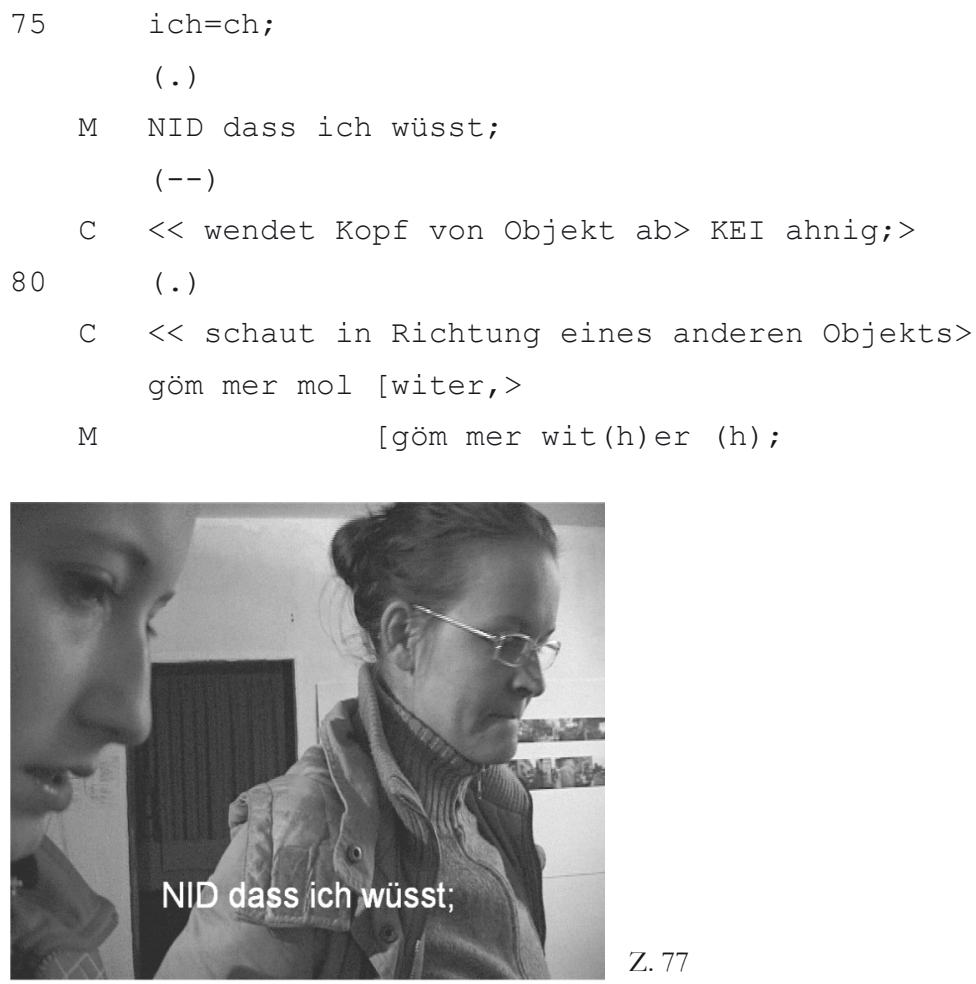

Ungeachtet ihrer großen Selbstverständlichkeit fallen Konfigurationen wie das hier illustrierte gemeinsame Verweilen vor dem Kunstwerk nicht vom Himmel, sondern müssen hergestellt, aufrechterhalten und auch wieder aufgelöst werden. Das erfordert spezielle Koordinierungsaktivitäten. Man kann sie am vorstehenden Ausschnitt leicht anschaulich machen, weil die fragliche Konfiguration in diesem Fall (das Wahrnehmungsobjekt befindet sich auf dem Boden) motorisch und kinetisch anspruchsvoll ist. Wir wollen uns im Folgenden ganz auf die Auflösung der Konfiguration beschränken (siehe oben Ausschnitt 4, etwa ab Z. 56). Je mehr diese Auflösung als eine synchronisierte Bewegung ausgeführt wird, desto weniger bedroht sie offenkundig die Interaktion. Synchron ausgeführte Bewegungen, in diesem Fall: das gleichzeitige Aufstehen und Weggehen, erfordern eine anspruchsvolle Choreographie, die nicht umstandslos vorausgesetzt werden kann. Typischerweise kommt es in solchen Fällen im Alltag zu Verzögerungen und Verlangsamungen, häufig auch zu unmittelbaren Folgebewegungen. So folgen Claudia und Nils im vorliegenden Fall mehr oder weniger synchron Claudia in ihrer Aufstehbewegung und Wegorientierung: 
Ausschnitt (5): Gemeinsames Aufstehen in zwei Etappen

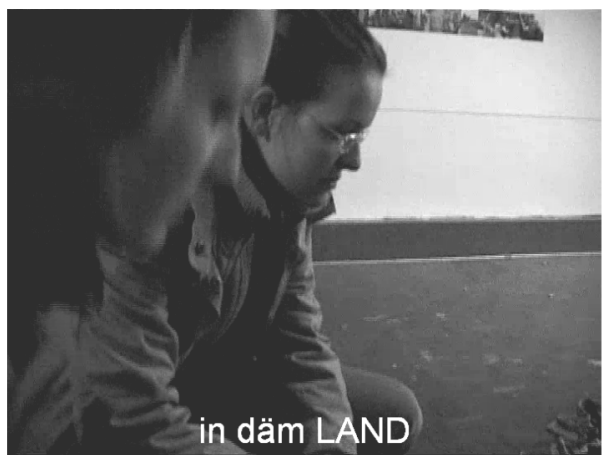

Z. 62: Melanie (links im Bild) während des Aufstehens

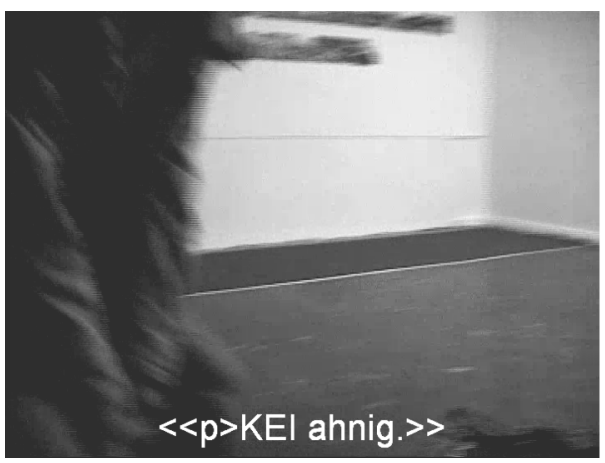

Z. 65-66: Claudia und Nils (nicht im Bild) folgen Melanies Aufstehbewegung

Folgebewegungen wie diese hat Goffman als Beispiele für typisches Gruppen- bzw. „Rudel“"verhalten beschrieben:

Tierische soziale Gruppen - Herden, Rudel, Scharen, Banden, Meuten, Schwärme - zeigen die besondere Eigenschaft, daß die Mitglieder jeder dieser Gruppen gewöhnlich in gegenseitiger Wahrnehmungsreichweite bleiben. (Goffman 1974, S. 19)

Typischerweise werden Auflösungen von Konfigurationen im Alltag (also nicht in professionell herbei- und ausgeführten Konstellationen wie etwa beim gemeinsamen Tanzen) ${ }^{23}$ durch gut sicht- und hörbare Rückversicherungs- und Steuerungsphänomene unterstützt. Das geschieht im vorliegenden Beispiel vor allem durch Blickkontakt: Blickkontakt vor dem Auf-

23 Gemeinsames Tanzen ist ein Prototyp für die professionelle Steigerung von Konfigurationsherstellungen und -auflösungen, die zu hoch unwahrscheinlichen Ko-Ordinierungsleistungen führt (vgl. dazu Loenhoff 2003 und Müller/Bohle 2007 mit vielen weiteren Literaturhinweisen zur Phänomenologie des Tanzens). 
stehen, Blick in die Runde, rhythmische Aufwärtsbewegung des Kopfes als Einladung zum Weitergehen und Rückversicherung der Bereitschaft zur Auflösung der Konfiguration:

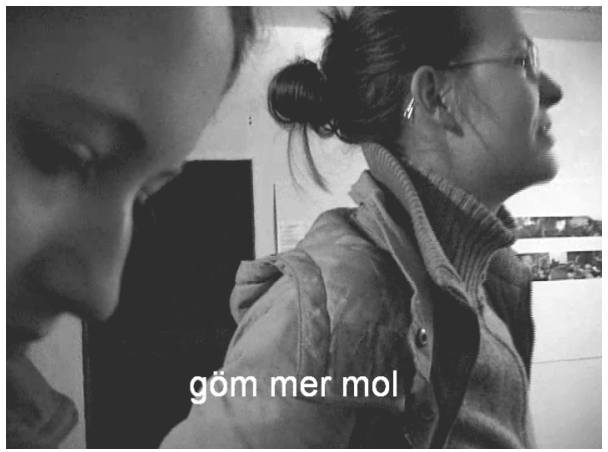

Z. 82: Demonstrative Blickorientierung Claudias zu einem anderen („nächsten“) Wahrnehmungsobjekt

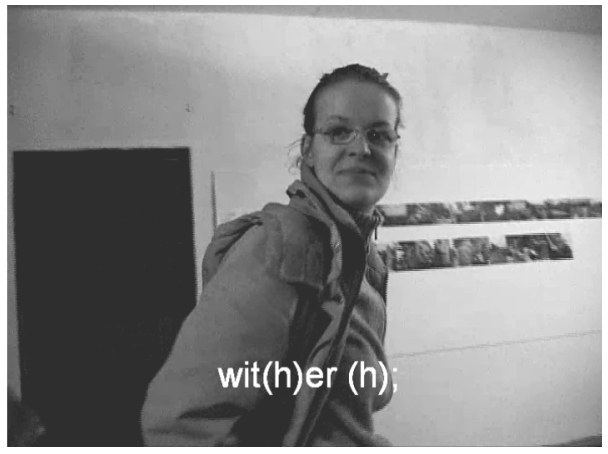

Z. 83: Rückversicherung vor dem Weggehen: Claudia blickt zu Melanie (nicht im Bild)

Nicht zufällig erfolgt in dieser für die Auflösung der Konfiguration kritischen Sequenz auch ein sprachlicher Steuerungshinweis (,göm mer mol witer"), der punktgenau das anstehende kommunikative Koordinationsproblem thematisiert: die Bewegung, auf die es ankommt (weiter gehen), die Gemeinsamkeit dieser Bewegung (wir) und die Modalisierung der Herbeiführung des Aufbruchs im Sinne eines handlungsauslösenden Vorschlags (mal).

Es versteht sich von selbst, dass diese Beschreibung analytisch noch zu verfeinern und auszubauen wäre. Man sieht aber vielleicht auch so, wie sich aus dem „hier“ als Bewegungsraum zwangsläufig eine Daueraufgabe der Ko-Ordinierung ergibt, um der Gefahr der Selbstauflösung der Interaktion durch Bewegung zu entgehen. ${ }^{24}$

24 „Koordinierung“ bzw. „Koordination“ ist ein in Interaktionsstudien immer wieder anzutreffender Terminus. Er wird z.B. auch schon bei Kendon in vergleichbaren Zusammenhängen gebraucht. Explizit eingeführt wird er bei Deppermann/Schmitt (2007). 
Ko-Orientierung und Ko-Ordinierung sind grundlegende Anforderungen, die illustrieren, was Situierung konkret bedeutet und wie sie die Sensorik und Motorik der InteraktionsteilnehmerInnen als Ressource von Anwesenheit nutzt. Situierung erschöpft sich aber nicht darin. Die durch Ko-Orientierung und Ko-Ordinierung interaktiv relevant gemachten Wahrnehmungen und Bewegungen sind immer schon Teil einer sozialen Handlungspraxis.

\subsection{Handlung}

Wenn man die soziale Praxis des gemeinsamen Ausstellungsbesuchs erfassen möchte, kann man sich nicht (ethologisch) auf Wahrnehmung und Bewegung beschränken. Ko-Orientierungs- und Ko-Ordinierungsaktivitäten müssen auf das bezogen werden, was im Raum an sozialen Handlungen möglich und wahrscheinlich ist. In dieser Hinsicht ist das „hier“ auch ein Handlungsraum. Ko-Orientierungen und Ko-Ordinierungen sind ja kein Selbstzweck, sondern eingebettet in eine voraussetzungsreiche soziale Praxis, die Wahrnehmungen und Bewegungen sozial sinnvoll macht und gleichzeitig eine soziale Raumkognition auf Seiten der Teilnehmenden voraussetzt.

Wenn wir uns für diese soziale Praxis interessieren, können wir nicht länger von dem abstrahieren, was gesprochen und gehört wird. Die soziale Praxis des gemeinsamen Ausstellungsbesuchs ist nicht nur eine Praxis wechselseitig abgestimmter Wahrnehmung und Bewegung, sondern eben auch eine Praxis des Redens über Kunst, eine gesellschaftliche Praxis der Kunstkommunikation.

Kunstkommunikation impliziert, das zeigt dieses Beispiel sehr anschaulich, eine Reihe typischer Zugzwänge, zu denen das Beschreiben (Was gibt es zu sehen?), das Deuten (Was steckt dahinter?), das Erläutern (Was weiß man darüber?) und das Bewerten (Was ist davon zu halten?) gehören. Es handelt sich jeweils um kleinformatige interaktive Aufgaben mit typischen sprachlichen Mitteln und Formen. Typisch für das Beschreiben ist z.B. die Verwendung der verba sentiendi, um z.B. Gesehenes im Sinne eines Anscheins zu thematisieren: das gseht aber us wie so ne so ne plastilinknät. Z. 1516; typisch für das Deuten ist z.B. die Thematisierung einer Mitteilungsabsicht im Modus des unsicheren Für-Wahr-Haltens (Polenz 1988, S. 214): ja sött sött das d dsch schwiiz darstelle: Z. 18-19; typisch für das Erläutern ist z.B. die Thematisierung von (Nicht)Wissen: also ich weiss nid weles land die form het: Z. 37-39; typisch für das Bewerten ist der Ausdruck von Ge- oder Missfallen: hö das find i no cool toll (im transkribierten Ausschnitt nicht enthalten). ${ }^{25}$

Auch ohne an dieser Stelle in eine vertiefende Analyse einzusteigen, sieht man leicht, dass mit diesen Aufgaben der Kunstkommunikation spe-

$25 \quad$ Vgl. dazu Hausendorf (2006). 
ziell die Themenorganisation als Aufgabenbereich in den Vordergrund rückt, also die Organisation von Beiträgen zu Themen (siehe oben 2.). Es hat den Anschein, dass das Finden einer Konfiguration (hier: das Verweilen vor dem Kunstwerk) das Zurücktreten der Situierung hinter stärker sprechund zuhörorientierte Interaktionsaufgaben nach sich zieht. Interessant ist schließlich auch, dass und wie die Kunstkommunikation im Angesicht des Kunstwerks gleichwohl auf Ko-Orientierung und Ko-Ordination angewiesen ist, genauer gesagt: auf die Konstitution dessen, was in den oben angedeuteten Fragen des Deutens, Beschreibens, Erläuterns und Bewertens immer schon impliziert ist: das Kunstwerk als gesichertes Wahrnehmungsobjekt ${ }^{26}$ Vielleicht kann man behaupten, dass gerade in der Konfiguration des gemeinsamen Verweilens und der in dieser Konfiguration sinnfällig werdenden Wahrnehmungsmuße (Oevermann 1996) die Zugzwänge des Beschreibens, Deutens, Erläuterns und Bewertens aufkommen, die für die Kunstkommunikation so charakteristisch sind. Ausstellungsmacher und Ausstellungsmacherinnen könnten dann auf die Idee kommen, dass man Interaktionsteilnehmer nur dazu bringen muss, gemeinsam in Wahrnehmungsmuße vor einem „Objekt“" zu verweilen, damit Kunstkommunikation als soziale Praxis wahrscheinlich wird. ${ }^{27}$

Wenn der Raum, zusammenfassend gesagt, ein Handlungsraum ist, dann ist neben der Ko-Orientierung und Ko-Ordinierung auch die KoOperation der Beteiligten eine interaktive Anforderung: Ko-Operation im Hinblick auf die für die fragliche soziale Praxis relevanten kommunikativen Zugzwänge und Aufgaben. Selbstverständlich ist eine solche Ko-Operation nicht. Wenn man an Ausstellungsbesuche mit Kindern denkt, weiß man, wie anspruchsvoll diese Anforderung der Ko-Operation sein kann - und was sie, nebenbei bemerkt, an Sozial- und Körperdisziplinierung immer schon voraussetzt.

Im Falle der Ko-Orientierung und der Ko-Ordinierung liegt der Raumbezug der Interaktion auf der Hand. Man könnte sich aber fragen, ob dagegen die Ko-Operation nicht mehr oder weniger unabhängig vom Raum vonstatten geht. Dass dies nicht der Fall ist, wird sofort deutlich, wenn wir uns den Raum, in dem die fragliche Episode spielt, genauer anschauen.

\subsection{Spielen}

Der Raum, der die Anwesenden umgibt, ist keine tabula rasa. Die Situierung, wie sie bislang mit Bezug auf Wahrnehmung, Bewegung und Handlung beschrieben worden ist, schließt vielmehr in all ihren Facetten an raumbasierte

\footnotetext{
$26 \quad$ Speziell dazu Vom Lehn/Heath (2007)

27 Das funktioniert vor allem dann, wenn es Anknüpfungspunkte im Raum gibt, die einen Kunstverdacht unterstützen. Im vorliegenden Beispiel ist das zweifellos der Fall - darauf kommen wir gleich noch zu sprechen (siehe unten 5.4).
} 
Kommunikation an..$^{28}$ Man kann das so verstehen, dass das „hier“ immer auch ein Spielraum ist, eine Bühne, die betreten und auf der aufgetreten werden will. Mit dieser Begriffswahl sollen keine spieltheoretischen oder anspruchsvollen theatermetaphorischen Ambitionen verknüpft werden. Es geht darum, dass der Raum, der die Anwesenden umgibt, mit dem Naheliegenden lockt, und zwar nicht erst mit Bezug auf die in ihm möglichen kooperativen Handlungen, sondern schon mit Bezug auf die in ihm möglichen Ko-Orientierungen und Ko-Ordinierungen. Die Situierung kommt so gesehen zwangsläufig einer Aktivierung räumlicher Anschlussmöglichkeiten gleich.

Wenn man anfängt, den Raum so zu sehen, ist er voll von wahrnehmungs-, bewegungs- und handlungsrelevanten Markierungen, die wir in der Regel ohne langes Nachdenken durch koorientierte Wahrnehmung, koordinierte Bewegung und kooperatives Handeln ,aktivieren“. Bedeutung entsteht dabei unmittelbar durch Bewegung, auf Schritt und Tritt, wenn man so will.

Man übersieht schnell, dass es ja alles andere als selbstverständlich ist, was in einem Raum unsere Wahrnehmung anzieht und Bewegungen provoziert. Im Raum selbst gibt es dafür eine Art unsichtbarer Markierungen, denen wir in vielen Fällen folgen: Attraktionen für Wahrnehmung, Zonen von Betretbarkeit und Zugänglichkeit, Fokuszonen zum Verweilen, Tabuzonen zum Auslassen. Es gibt Räume, in denen die Markierung von relevanten Wahrnehmungs-, Bewegungs- und Handlungsräumen sofort sehr anschaulich wird. Dazu gehören Mehrzwecksporthallen: ${ }^{29}$
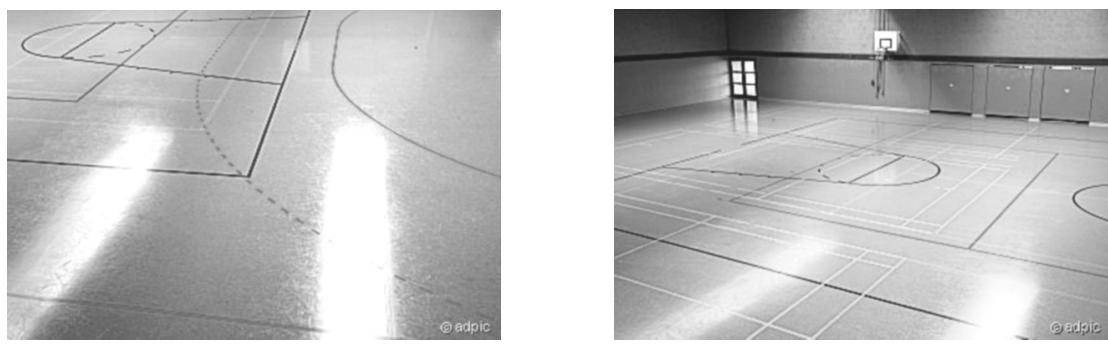

Abb. 3 u. 4: Markierungen im Raum ${ }^{30}$

28 Begriff und Konzept von raumbasierter Kommunikation werden in Kesselheim/Hausendorf (2007) eingeführt. Im Folgenden wird dieses Konzept mit Bezug auf die Konstitution des Spielraums entwickelt.

29 Wir kommen auf das bislang behandelte Beispiel des Ausstellungsraumes noch zurück, wollen den Gedankengang im Folgenden aber zunächst an einem besonders klaren Fall veranschaulichen.

30 Quelle: www.adpic.de/data/picture/detail/turnhalle_68745.jpg; www.adpic.de/data/picture/detail/turnhalle_68744.jpg (Stand Oktober 2009). 
Die farblich unterschiedlich markierten Linien und Striche auf dem Hallenboden illustrieren in großer Anschaulichkeit zwei Beobachtungen:

- Die Markierungen sind Vorgaben, die der Raum für mögliche Spiele macht, Anschlussmöglichkeiten für Anwesende, an die Interaktion anschließen kann, aber nicht anschließen muss: Man kann in einer Turnhalle alles Mögliche machen, auch ein sit in mit Kaffee und Kuchen. Ihren speziellen Mehrwert für die Interaktion kann die Turnhalle aber erst entfalten, wenn ihre Linien und Striche als Markierungen von Spielräumen genutzt werden.

- Die Markierungen müssen also verstanden werden in dem Sinne, dass Anwesende auf die Idee kommen, einen Unterschied zu machen zwischen der Information, dass da etwas farblich markiert ist auf dem Hallenboden (Linien), und der Mitteilung, dass hinter diesen Markierungen (Linien) Spieloptionen stecken.

Es ist die Auffälligkeit (graphisch und farblich), die ein solches Verstehen in diesen Fällen wohl fast unvermeidbar macht (auch wenn man nicht weiß, welche Spiele „hier“ wie zu spielen sind), die Unwahrscheinlichkeit solcher Linien, die Kommunikation in solchen Fällen anlaufen lässt - anders als im Falle der Kratzer auf dem Fußboden, die wir ebenfalls sehen mögen, aber hinter denen wir in der Regel keine Mitteilungsabsicht verstehen. ${ }^{31}$

Was es heißt, den Raum auf diese Weise zu „verstehen“, zeigt die Nutzung der Mehrzwecksporthalle in großer Anschaulichkeit:
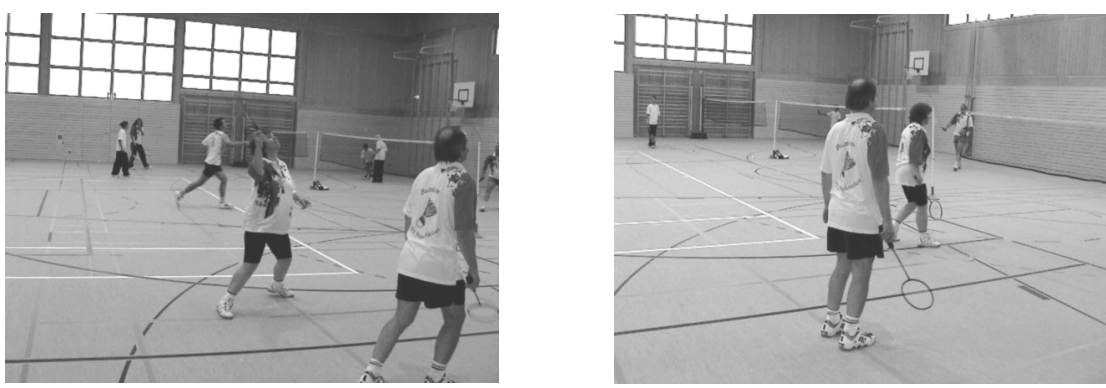

Abb. 5 u. 6: den Raum verstehen ${ }^{32}$

Es handelt sich um ein in Ko-Orientierung, Ko-Ordinierung und KoOperation ausgedrücktes Verstehen des Raumes, das sich sogar auf diesen Zufallsbildchen ausdrückt, wenn man z.B. darauf schaut, wie der „Spie-

$31 \quad$ Man kann das kommunikationstheoretisch (z.B. mit Luhmann 1984), aber auch zeichentheoretisch (z.B. mit Keller 1995) begründen.

32 Quelle: www.naunet.de/Landshuter/turnhalle/DSC00072.jpg; www.naunet.de/Landshuter/turnhalle/DS C00071. jpg (Stand: Oktober 2009). 
ler" im Vordergrund die blaue Linie durch seine Position in ihrer interaktiven Relevanz bestätigt - und andere gleichzeitig interaktiv außer Kraft setzt. Ist es nicht sehr illustrativ zu sehen, wie der Raum durch solche Markierungen zu einer Bühne für sehr voraussetzungsreiche Interaktionsspiele gemacht werden kann? Wer solche Interaktionsspiele beobachten will, wird gut daran tun, sich die Markierungen im Raum sehr genau anzugucken.

Auch wenn es in den meisten Räumen, in denen wir unsere Alltagsspiel(ch)e(n) machen, keine farblichen Markierungen und erst recht keinen „Linienrichter“" gibt, so gibt es doch fast immer eine Lesbarkeit des Raumes im Hinblick auf seine wahrnehmungs-, bewegungs- und handlungsrelevanten Markierungen. Das „hier“ ist also auch ein Spielraum und die Ko-Aktivierung dieses Raumes eine weitere interaktive Anforderung. Wir könn(t)en jedenfalls viel über unsere Alltagsräume lernen, wenn wir sie in dieser Weise als Spielfelder zu beobachten anfangen und nach ihren Markierungen fragen. Eine solche interaktionstheoretisch fundierte und linguistisch informierte Analyse des Raumes und seiner Markierungen steht noch am Anfang. Auch die Interaktionsforschung in der Tradition der "Context Analysis“ (siehe oben 3.) hat davor bis in unsere Tage hinein zurückgescheut. ${ }^{33} \mathrm{An}$ knüpfen ließe sich aber beispielsweise an semiotische Analysen zur zeichenbasierten Orientierung im Raum. ${ }^{34}$

Um auf die hier untersuchte soziale Praxis der Kunstkommunikation in der Ausstellung zurückzukommen: Worauf unsere Teilnehmer ihre Wahrnehmung ko-orientieren und wie sie ihre Bewegungen ko-ordinieren, ist ja durch die Gestaltung des Ausstellungsraumes bereits hochgradig nahegelegt: Es handelt sich um einen unmöblierten Raum, an dessen Wänden z.T. Objekte angebracht sind und in dessen Mitte auf dem Fußboden das oben im Mittelpunkt von Wahrnehmung, Bewegung und Handlung stehende Objekt platziert ist.

33 Vgl. aber etwa am Beispiel des Klassenraums Willems/Eichholz (2008); Breidenstein (2004); am Beispiel der Orientierung in Bibliotheken Crabtree (2000) oder am Beispiel des Museums Kesselheim/Hausendorf (2007). In evolutionärer Hinsicht sehr instruktiv sind die Ausführungen zum „humanisierten Raum“ bei Leroi-Gourhan (1980, S. 395 ff.).

34 Einschlägig dafür z.B. die Analysen zur Raumorientierung im Straßenverkehr in Posner/ Krampen (Hg.) (1995). Vgl. auch Schmauks (2002) am Beispiel der Raumorientierung beim Wandern. Hinweise zur semiotischen Analyse der Museumskommunikation finden sich in Kesselheim/Hausendorf (2007). Siehe dazu auch den Beitrag von Habscheid et al. (in diesem Band) zu Markierungen und ihrer Interpretation in Notfalleinsätzen. 


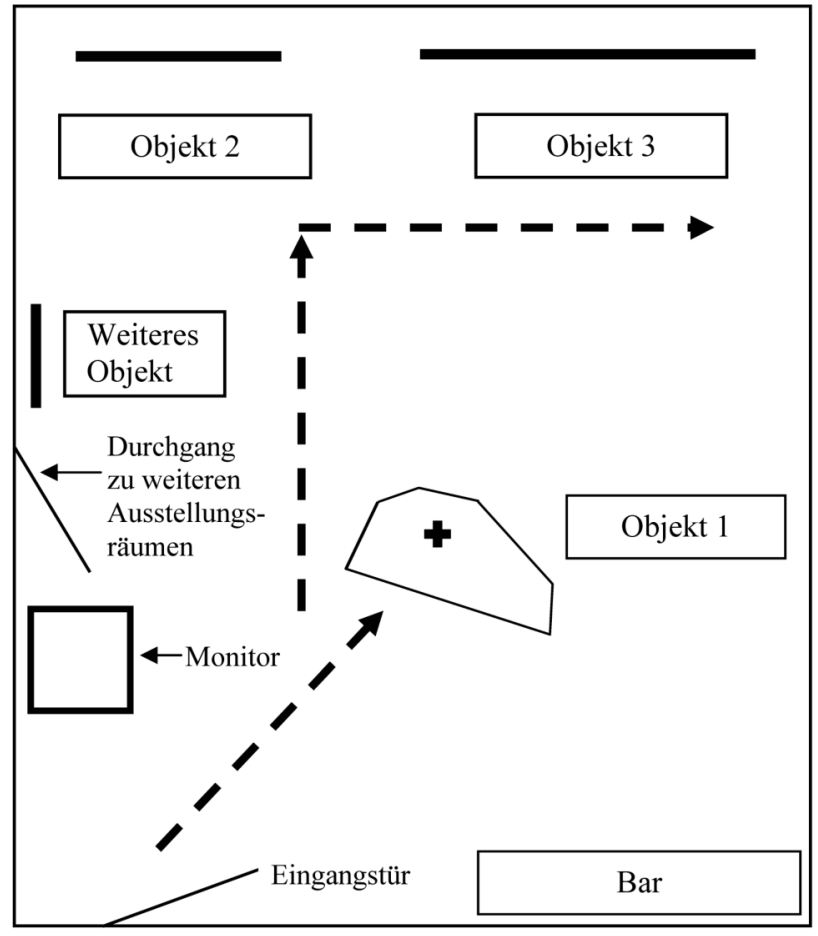

Legende:

$\longrightarrow-\rightarrow=$ grober Laufweg von $\mathrm{C}, \mathrm{M}$ und $\mathrm{N}$

$=$ an der Wand hängende Objekte

Abb. 7: Skizze des Ausstellungsraumes ${ }^{35}$

Scheinbar wie von selbst wirken die auf diese Weise als „Exponate“ auffällig gemachten Objekte als Attraktoren für Wahrnehmung, Bewegung und Handlung. An dieser Stelle kommt über den Raum und seine Gestaltung eine ganze Kultur der Ausstellungskommunikation als raumgebundene kommunikative Ressource ins Spiel. Indem das, was wir oben im Einzelnen an Ko-Orientierung, -Ordination und -Operation beschrieben haben, den Exponat-Charakter der Objekte zur Geltung bringt, haben wir es also längst mit Ko-Aktivierung zu tun - auch wenn das in diesem Fall nicht so anschaulich sein mag wie beim Spiel in der Mehrzwecksporthalle, das scheinbar wie von selbst der Markierung von Spielräumen folgt. Auch die fokale Zone vor einem Objekt und um ein Objekt herum ist insofern im wahrsten Sinne des Wortes ein Spielraum.

35 Diese Skizze stammt im Original von Sabina Gröner, der ich auch die Aufzeichnung und Transkription verdanke (siehe oben Anm. 17). 
Wir haben es in unserem Fall des Ausstellungsbesuches - im Grunde nicht anders als im Fall des Spielens in der Mehrzwecksporthalle - damit zu tun, dass die beschriebenen Ko-Orientierungen, -ordinationen und -operationen systematisch durch die Gestaltung des Raums nahegelegt sind: in diesem Fall (anders als in der Mehrzwecksporthalle) durch eine ganze Tradition der Ausstellung von Objekten in einem ansonsten so gut wie leeren weißen Raum, der vor allem durch seine Leere (durch größtmögliche Abwesenheit von Ablenkungen) signifikant ist und damit alles unter Kunstverdacht stellt, was in einem solchen Raum nicht offenkundig funktional motiviert ist (wie z.B. eine Steckdose oder die Beschläge an Türen und Fenstern):

Die ideale Galerie hält vom Kunstwerk alle Hinweise fern, welche die Tatsache, daß es „Kunst“ ist, stören könnten. Sie schirmt das Werk von allem ab, was seiner Selbstbestimmung hinderlich in den Weg tritt. Dies verleiht dem Raum eine gesteigerte Präsenz [...] Etwas von der Heiligkeit der Kirche, etwas von der Gemessenheit des Gerichtssaals, etwas vom Geheimnis des Forschungslabors verbindet sich mit chicem Design zu einem einzigartigen Kultraum der Ästhetik. ... Eine Galerie wird nach Gesetzen errichtet, die so streng sind wie diejenigen, die für eine mittelalterliche Kirche galten. Die äußere Welt darf nicht hineingelassen werden [...] Die Wände sind weiß getüncht. Die Decke wird zur Lichtquelle. [...] In dieser Umgebung wird ein Standaschenbecher fast zu einem sakralen Gegenstand, ebenso wie der Feuerlöscher in einem modernen Museum einfach nicht mehr wie ein Feuerlöscher aussieht, sondern wie ein ästhetisches Scherzrätsel. Hier erreicht die Moderne die endgültige Umwandlung der Alltagswahrnehmung zu einer Wahrnehmung rein formaler Werte. (O'Doherty 1996, S. 9 ff.)

Dass wir an diesen white cube so sehr gewöhnt sind, ändert, wie Brian O'Doherty in seinem viel zitierten Essay gezeigt hat, nichts an der Unwahrscheinlichkeit dieser Art von Raum gewordener Ausstellungskommunikation. Es ist also schon sehr viel passiert, bevor wir den Raum betreten. Ausstellungsmacher können davon ein Lied singen. ${ }^{36}$

Wenn wir uns für Situierung interessieren, sollten wir uns die raumgebundene und raumbasierte Kommunikation nicht entgehen lassen. Wir verstehen sonst die Situierung nicht.

\section{Fazit}

Die anhand der Fallbeobachtungen illustrierten Anforderungen verdeutlichen, wie das „hier“, der Raum der Interaktion, durch Situierungsaktivitäten ins Spiel kommt. Die folgende Abbildung fasst diese Anforderungen im Sinne charakteristischer Situierungsprobleme zusammen:

36 Sehr instruktiv unter dem Aspekt der Veränderung von Wahrnehmungskulturen durch Ausstellungstechniken sind die „Zurichtung des Umraums“ in Ausstellungen seit dem 17. Jahrhundert und ihre jeweils zeitgenössische Reflexion (Hinweise dazu bei Schwarte 2005, S. 292 ff. und natürlich auch bei O'Doherty 1996). 


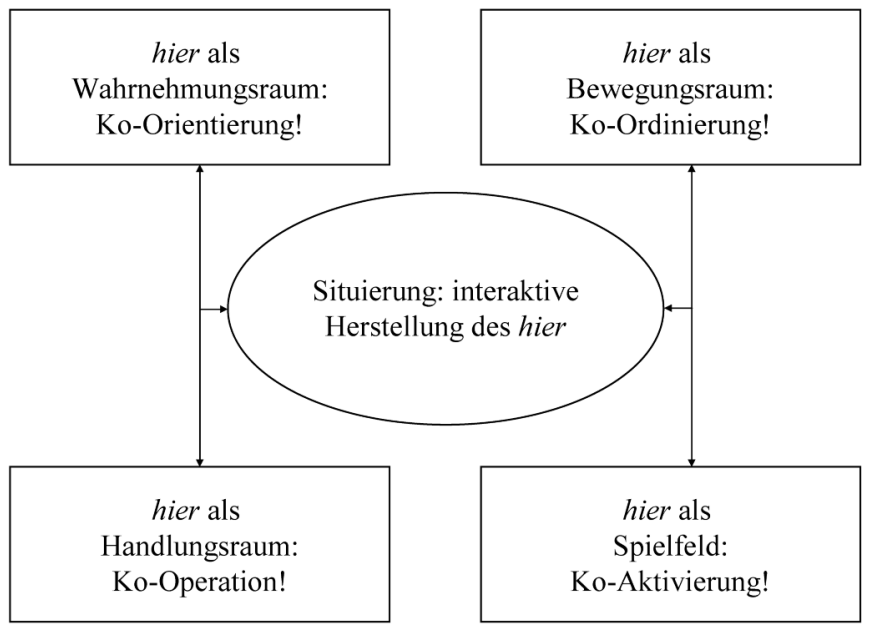

Abb. 8: Situierungsprobleme

Das „hier“ ist zunächst in einem elementaren Sinne ein Raum für Wahrnehmungen, in dem sich die Beteiligten zurechtfinden und orientieren müssen und in dem sie sich ihre Orientierungen wechselseitig aufzeigen müssen. Das Problem, das daraus für die Interaktion erwächst, ist ein Ko-Orientierungsproblem. Mit der Bearbeitung und Lösung dieses Problems wird der Raum für die Interaktion sensorisch erschlossen und in seiner Wahrnehmbarkeit relevant gemacht. Die interaktive Herstellung der räumlichen Bedingungen der Sprechsituation geschieht maßgeblich in diesem Medium der Ko-Orientierung und den sich dabei vollziehenden Wahrnehmungswahrnehmungen.

Das „hier“ ist des Weiteren ein Raum für Bewegungen, in dem sich die Beteiligten positionieren müssen und in dem sie sich ihre Positionen und Navigationen wechselseitig aufzeigen müssen. Das Problem, das daraus für die Interaktion erwächst, ist ein Ko-Ordinierungsproblem. Mit der Bearbeitung und Lösung dieses Problems wird der Raum für die Interaktion motorisch erschlossen und in seiner Betret- und Begehbarkeit interaktiv relevant gemacht. Das Ergebnis der Ko-Ordinierung sind typische Konfigurationen der Körper der Anwesenden im Raum, ohne die keine Interaktion denkbar wäre: Begriffe wie „face-to-face“, „face-to-back“ oder „side-by-side“ deuten solche Konfigurationen an, lenken aber bereits von der Vielfalt der unter Anwesenden möglichen Positionierungs- und Navigationsmöglichkeiten ab. ${ }^{37}$

Das „hier“ ist weiterhin ein Raum für Handlungen, in dem die Beteiligten nicht nur hin- und herschauen und hin- und herlaufen, sondern agieren und in dem sie sich ihr Agieren wechselseitig aufzeigen müssen, indem sie ihre Wahrnehmungen und Bewegungen als sozial sinnvoll demonstrieren

37 Weiterführend sind hier die von A. Kendon eingeführten „focus formation systems“ (Kendon 1990). 
und aufeinander abstimmen. Das Problem, das daraus für die Interaktion erwächst, ist ein Ko-Operationsproblem. Mit der Bearbeitung und Lösung dieses Problems wird der Raum für die Interaktion handlungspraktisch erschlossen und in seinem Handlungspotential (in seiner Behandelbarkeit) interaktiv relevant gemacht. Das Ergebnis der Ko-Operation ist dann eine bestimmte soziale Praxis, die den Wahrnehmungs- und Bewegungsraum mehr oder weniger intensiv in Anspruch nehmen kann: Ein Gespräch am runden Tisch, das den Körper etwa zur Hälfte unsichtbar lässt und - solange alle sitzen bleiben - allenfalls das motorische Potential der „Oberkörper“, des Kopfes und der Arme ausschöpfen mag (siehe dazu das bei Schmitt/ Deppermann in diesem Band analysierte Beispiel), ist im Hinblick auf KoOrientierungen und Ko-Ordinierungen der Anwesenden, also sensorisch und motorisch, viel weniger anspruchsvoll als ein Ballspiel ein Boxkampf oder ein Tan:

Je intensiver der Wahrnehmungs- und Bewegungsraum durch die Interaktion in Anspruch genommen wird, desto anschaulicher tritt schließlich hervor, dass das „hier" auch ein Raum für (Sprach- und Interaktions)Spiele, ein Spielfeld, ist, das die Beteiligten durch ihre Spielzüge („,moves“i.S.v. Goffman 1974) aktivieren müssen. Das Problem, das daraus für die Interaktion erwächst, ist ein Ko-Aktivierungsproblem. Mit der Bearbeitung und Lösung dieses Problems wird der Raum für die Interaktion gewissermaßen theatral erschlossen und in seinem Potential als Bühne für Interaktions- und Sprachspiele interaktiv relevant gemacht. „Interaktion im Raum“ heißt auch, dass Ko-Orientierung, Ko-Ordinierung und Ko-Operation nicht immer wieder voraussetzungslos wie von Neuem zustande gebracht werden müssen, sondern mittels gesellschaftlicher Spielräume (Bühnen) an etablierte Interaktionsrituale anschließen können. Der Raum der Interaktion ist in diesem Sinne fast immer auch ein gesellschaftlicher Spielraum.

Insbesondere dort, wo das Zusammensein institutionalisiert und organisiert ist, kann man auf hoch voraussetzungsreiche Spielräume mit wahrnehmungs-, bewegungs- und handlungsrelevanten Markierungen treffen, die ihren Ausdruck in der Architektur von Gebäuden (wie dem Gericht, dem Krankenhaus oder der Universität), der Ausgestaltung ihrer Innenräume bis hin zur Möblierung des Raums gefunden haben. Es sind solche Spielräume der Gesellschaft, in denen sich, interaktionstheoretisch formuliert, der Anschluss von Interaktion an Gesellschaft alltäglich vollzieht, indem sich Situierung und Kontextualisierung (siehe oben 2.) auf eine sehr effektive Weise überlappen. Hier vor allem muss man suchen, wenn man den viel zitierten Mikro-Makro-Link (Habscheid 2000) zwischen Interaktion und Gesellschaft finden möchte.

Wenn man so argumentiert, erweist sich das Verhältnis zwischen KoOrientierung, Ko-Ordinierung, Ko-Operation und Ko-Aktivierung als ein Verhältnis zunehmender Voraussetzungshaftigkeit: gewissermaßen am An- 
fang steht die Ko-Orientierung (damit beginnt ja die Interaktion: ein bezeichnender Zusammenfall von Interaktionseröffnung und Situierung), gewissermaßen am Ende steht die Ko-Aktivierung des Spielraumes, die alle anderen Situierungs-Anforderungen einschließt.

Mit ihrer durchgängigen Betonung von Wahrnehmung, Bewegung, Handlung und Spiel könnten die vorgestellten Überlegungen womöglich als ein Beitrag zur Analyse der Welt des Sports verstanden werden, in der es auf Sprache und die Beobachtung von Sprache (durch Linguisten und Linguistinnen) nicht ankommt. Das wäre ein Missverständnis. Es kommt mir nur so vor, als ob die Welt des Sports - stärker vielleicht noch als die in dieser Hinsicht oft in Anspruch genommene Welt des Theaters ${ }^{38}$ - besonders geeignet wäre, zu verstehen, was Situierung bedeutet und welche Rolle die Sprache dabei spielt.

\section{Literatur}

Auer, Peter (2004): Sprache, Grenze, Raum. In: Zeitschrift für Sprachwissenschaft 23, S. 149-180.

Peter Auer (i.d.Bd.): Sprachliche Landschaften. Die Formung des Raums durch die geschriebene Sprache

Backhaus, Peter (2007): Linguistic landscapes. A comparative study of urban multilingualism in Tokyo. Clevedon.

Bernhard, Gerald/Siller-Runggaldier, Heidi (2008): Sprache im Raum - Raum in der Sprache. Akten der sprachwissenschaftlichen Sektion des Deutschen Italianistentages in Bochum, 23.-25. März 2006. (= Spazi comunicativi 4). Frankfurt a.M.

Bickel, Balthasar/Nichols, Johanna (2006): Oceania, the Pacific Rim and the theory of linguistic areas. Proceedings of the 32nd Annual Meeting of the Berkeley Linguistics Society. Internet: www.uni-leipzig.de/ bickel/research/papers/bickel_nichols_bls32.pdf (Stand: Oktober 2009).

Bloom, Paul Peterson (Hg.) (1996): Language and space. Cambridge, MA.

Breidenstein, Georg (2004): KlassenRäume - eine Analyse räumlicher Bedingungen und Effekte des Schülerhandelns. In: Zeitschrift für qualitative Bildungs-, Beratungs- und Sozialforschung 5, 1, S. 87-107.

Bühler, Karl (1982): Sprachtheorie. Die Darstellungsfunktion der Sprache. Stuttgart/ New York.

Buss, Mareike/Habscheid, Stephan/Jautz, Sabine (Hg.) (2009): Theatralität des sprachlichen Handelns. Eine Metaphorik zwischen Linguistik und Kuturwissenschaften. München.

Crabtree, Andy (2000): Remarks on the social organisation of space and place. In: Journal of Mundane Behavior 1/1, S. 25-44.

38 Vgl. dazu den gerade erschienenen Sammelband Buss/Habscheid/Jautz (Hg.) (2009). 
Deppermann, Arnulf/Schmitt, Reinhold (2007): Koordination. Zur Begründung eines neuen Forschungsgegenstandes. In: Schmitt (Hg.), S. 15-54.

Döring, Jörg/Thielmann, Tristan (Hg.) (2008): Spatial turn. Das Raumparadigma in den Kultur- und Sozialwissenschaften. Bielefeld.

Dünne, Jörg/Günzel, Stephan (Hg.) (2006): Raumtheorie. Grundlagentexte aus Philosophie und Kulturwissenschaften. Frankfurt a.M.

Frank, Roslyn M./Dirven, René/Ziemke, Tom/Bernárdez, Enrique (Hg.) (2008): Body, language and mind. Bd. 2: Sociocultural situatedness. (= Cognitive Linguistics Research 35.2). Berlin/New York.

Fricke, Ellen (2007): Origo, Geste und Raum - Lokaldeixis im Deutschen. (= Linguistik - Impulse \& Tendenzen 24). Berlin/New York.

Garfinkel, Harold (1967): Studies in ethnomethodology. Englewood Cliffs.

Goffman, Erving (1964): The neglected situation. In: Gumperz, John J./Hymes Dell (Hg.): The ethnography of communication. In: American Anthroplogist, 6, 2, S. 133-136.

Goffman, Erving (1974): Das Individuum im öffentlichen Austausch. Mikrostudien zur öffentlichen Ordnung. Frankfurt a.M.

Goffman, Erving (1977): Rahmen-Analyse. Ein Versuch über die Organisation von Alltagserfahrungen. Frankfurt a.M.

Goodwin, Charles (2000): Action and embodiment within situated human interaction. In: Journal of Pragmatics 32, S. 1489-1522.

Gülich, Elisabeth/Mondada, Lorenza (2008): Konversationsanalyse. Eine Einführung am Beispiel des Französischen. (= Romanistische Arbeitshefte 52). Tübingen.

Habscheid, Stephan (2000): Das „Mikro-Makro-Problem“ in der Gesprächsforschung. In: Gesprächsforschung - Online-Zeitschrift zur verbalen Interaktion 1, S. 125 148. Internet: www.gespraechsforschung-ozs.de/heft2000/ga-habscheid.pdf (Stand: Oktober 2009).

Habscheid, Stephan et al. (i.d.Bd.): Artikulationsarbeit und mediengestützte Ortserkundung. Multimodale und multilokale Kommunikation in Notfalleinsätzen

Hanks, William F. (1990): Referential practice. Language and lived space among the Maya. Chicago.

Hausendorf, Heiko (1992): Gespräch als System. Linguistische Aspekte einer Soziologie der Interaktion. Opladen.

Hausendorf, Heiko (2000): Zugehörigkeit durch Sprache. Eine linguistische Studie am Beispiel der deutschen Wiedervereinigung. (= Reihe Germanistische Linguistik 215). Tübingen.

Hausendorf, Heiko (2003): Deixis and speech situation revisited. The mechanism of perceived perception. In: Lenz, Friedrich (Hg.): Deictic conceptualisiation of space, time and person. (= Pragmatics \& beyond, N.S. 112). Amsterdam, S. 249-269.

Hausendorf, Heiko (2006): Gibt es eine Sprache der Kunstkommunikation? Linguistische Zugangsweisen zu einer interdisziplinären Thematik. In: Paragrana. Internationale Zeitschrift für Historische Anthropologie 15, S. 65-98. 
Hausendorf, Heiko (2007): Was kommt als Nächstes? Fokussierungen revisited. In: Hausendorf (Hg.), S. 221-246.

Hausendorf, Heiko (Hg.) (2007): Gespräch als Prozess. Linguistische Aspekte der Zeitlichkeit verbaler Interaktion. (= Studien zur Deutschen Sprache 37). Tübingen.

Hausendorf, Heiko/Kesselheim, Wolfgang (2008): Textlinguistik fürs Examen. (= Linguistik fürs Examen 5). Göttingen.

Heath, Christian/Hindmarsh, Jon (2000): Configuring action in objects. From mutual space to media space. In: Mind, Culture, and Activity 7, S. 81-104.

Herrmann, Theo/Schweizer, Karin (1998): Sprechen über Raum. Sprachliches Lokalisieren und seine kognitiven Grundlagen. Bern.

Hickmann, Maya/Robert, Stéphane (2006): Introduction. Space, language, and cognition. Some new challenges. In: Hickmann/Robert (Hg.), S. 1-15.

Hickmann, Maya/Robert, Stéphane (Hg.) (2006): Space in languages. Linguistic systems and cognitive categories. (= Typological Studies in Language 66). Amsterdam.

Hindmarsh, Jon/Heath, Christian (2000): Embodied reference. A study of deixis in workplace interaction. In: Journal of Pragmatics 32, S. 1855-1878.

Jones, Christopher B./Purves, Ross S./Clough, Paul D./Joho, Hideo (2008): Modelling vague places with knowledge from the Web. In: International Journal of Geographic Information Systems, 22, 10, S. 1045-1065.

Kallmeyer, Werner/Schütze, Fritz (1976): Konversationsanalyse. In: Studium Linguistik 1, S. 1-28.

Keller, Rudi (1995): Zeichentheorie. Zu einer Theorie semiotischen Wissens. Tübingen/Basel.

Kendon, Adam (1990): Conducting interaction. Patterns of behavior in focused encounters. (Studies in Interactional Sociolinguistics 7). Cambridge.

Kesselheim, Wolfgang (2009): Wissensvermittlung in der Museumsausstellung als Herausforderung für die Linguistik. In: Stenschke, Oliver (Hg.): Wissenstransfer und Diskurs. (= Transferwissenschaften 6). Frankfurt a.M. u.a., S. 245-266.

Kesselheim, Wolfgang/Hausendorf, Heiko (2007): Die Multimodalität der Ausstellungskommunikation. In: Schmitt (Hg.), S. 339-375.

Knoblauch, Hubert (2005): Video-Interaktions-Sequenzanalyse. In: Wulf/Zirfas (Hg.), S. 263-275.

Leroi-Gourhan, André (1980): Hand und Wort. Die Evolution von Technik, Sprache und Kunst. Frankfurt a.M.

Levinson, Stephen C. (1996): Language and space. In: Annual Review of Anthropology 25, S. 353-382.

Levinson, Stephen C. (2003): Space in language and cognition. Explorations in cognitive diversity. Cambridge.

Levinson, Stephen C./Wilkins, David (Hg.) (2006): Grammars of space. Explorations in cognitive diversity. Cambridge. 
Loenhoff, Jens (2002): Sensomotorische Bedingungen von Kommunikation und Handlung. In: Hahn, Kornelia/Meuser, Michael (Hg.): Körperrepräsentationen. Die Ordnung des Sozialen und der Körper. Konstanz, S. 45-69.

Loenhoff, Jens (2003): Grundlagen der kommunikativen Dimension von Körperbewegung und Tanz. In: Klinge, Antje/Leeker, Martina (Hg.): Tanz Kommunikation Praxis. Münster, S. 17-31.

Löw, Martina (2001): Raumsoziologie. Frankfurt a.M.

Luhmann, Niklas (1984): Soziale Systeme. Grundriß einer allgemeinen Theorie. Frankfurt a.M.

Mondada, Lorenza (2007): Interaktionsraum und Koordinierung. In: Schmitt (Hg.), S 55-93.

Mulder, Walter de (1996): Demonstratives as locating expressions. In: Pütz/Dirven (Hg.), S. 29-47.

Müller, Cornelia/Bohle, Ulrike (2007): Das Fundament fokussierter Interaktion. Zur Vorbereitung und Herstellung von Interaktionsräumen durch körperliche Koordination. In: Schmitt (Hg.), S. 129-165.

Norris, Sigrid (2004): Analyzing multimodal interaction. A methodological framework. New York.

O'Doherty, Brian (1996): In der weißen Zelle. Inside the white cube. (= Internationaler Merve-Diskurs 190). Berlin.

Oevermann, Ulrich (1996): Krise und Muße. Struktureigenschaften ästhetischer Erfahrung aus soziologischer Sicht. Internet: www.w-f-k.de/PDF-Dateien/Ulrich\%200ever mann,\%20Krise\%20und\%20Musse.pdf (Stand: Oktober 2009).

Park, Robert E. (1926): The urban community as a spatial pattern and a moral order. In: Burgess, Ernest W. (Hg.): The urban community. Selected papers from the Proceedings of the American Sociological Society. Chicago, S. 3-18.

Polenz, Peter von (1988): Deutsche Satzsemantik. Grundbegriffe des Zwischen-denZeilen-Lesens. Berlin/New York.

Posner, Roland/Krampen, Martin (Hg.) (1995): Kommunikation im Straßenverkehr. In: Zeitschrift für Semiotik 17, S. 1-2.

Pütz, Martin/Dirven, René (Hg.) (1996): The construal of space in language and thought. (= Cognitive Linguistics Research 8). Berlin.

Richardson, Tim/Jensen, Ole B. (2003): Linking discourse and space: Towards a cultural sociology of space in analysing spatial policy discourses. In: Urban Studies 40, S. $7-22$.

Schegloff, Emmanuel A./Sacks, Harvey (1973): Opening up closings. In: Semiotica 8, S. 289-327.

Schlögel, Karl (2003): Im Raume lesen wir die Zeit. Über Zivilisationsgeschichte und Geopolitik. München. 
Schlottmann, Antje (2005): Rekonstruktion alltäglicher Raumkonstruktionen. Eine Schnittstelle von Sozialgeographie und Geschichtswissenschaft? In: Geppert, Alexander C.T. (Hg.): Ortsgespräche. Raum und Kommunikation im 19. und 20. Jahrhundert. Bielefeld, S. 107-133.

Schmauks, Dagmar (2002): Orientierung im Raum. Zeichen für die Fortbewegung. (= Probleme der Semiotik 20). Tübingen.

Schmitt, Reinhold (2006): Videoaufzeichnungen als Grundlage für Interaktionsanalysen. In: Deutsche Sprache 34, S. 18-31.

Schmitt, Reinhold (Hg.) (2007): Koordination. Analysen zur multimodalen Interaktion. (= Studien zur Deutschen Sprache 38). Tübingen.

Schmitt, Reinhold/Deppermann, Arnulf (i.d.Bd.): Die multimodale Konstitution eines imaginären Raums als interaktive Problemlösung.

Schroer, Markus (2007): Räume, Orte, Grenzen. Auf dem Weg zu einer Soziologie des Raums. Frankfurt a.M.

Schroer, Markus (2008): „Bringing Space back in“-Zur Relevanz des Raums als soziologischer Kategorie. In: Döring/Thielmann, S. 125-148.

Schütz, Alfred (1972): Gemeinsam Musizieren. In: Schütz, Alfred: Gesammelte Aufsätze. Bd. II: Studien zur soziologischen Theorie. Den Haag, S. 129-150.

Schwarte, Ludger (2005): Das Einräumen von Bildlichkeit. Wahrnehmungshandlungen und Ausstellungsarchitektur. In: Wulf/Zirfas (Hg.), S. 279-299.

Schweizer, Harro (Hg.) (1985): Sprache und Raum. Ein Arbeitsbuch für das Lehren von Forschung. Stuttgart.

Scollon, Ron/Scollon, Suzie Wong (2003): Discourses in place. Language in the material world. London.

Vater, Heinz (1991): Einführung in die Raum-Linguistik. Hürth-Efferen.

Vom Lehn, Dirk/Heath, Christian (2007): Perspektiven der Kunst - Kunst der Perspektiven. In: Hausendorf, Heiko (Hg.): Vor dem Kunstwerk. Interdisziplinäre Aspekte des Sprechens und Schreibens über Kunst. München, S. 147-170.

Weigel, Sigrid (2002): Zum „topographical“ turn. Kartographie, Topographie und Raumkonzepte in den Kulturwissenschaften. In: KulturPoetik - Zeitschrift für kulturgeschichtliche Literaturwissenschaft 2, S. 151-165.

Weinrich, Harald (1993): Textgrammatik der deutschen Sprache. Mannheim/Leipzig/ Wien/Zürich.

Willems, Herbert/Eichholz, Daniela (2008): Die Räumlichkeit des Sozialen und die Sozialität des Raumes. Schule zum Beispiel. In: Willems, Herbert (Hg.): Lehr(er)buch Soziologie. Für die pädagogischen und soziologischen Studiengänge. Bd. 2. Wiesbaden, S. 865-907.

Wulf, Christoph/Zirfas, Jörg (Hg.) (2005): Ikonologie des Performativen. München. 



\title{
Die multimodale Konstitution eines imaginären Raums als interaktive Problemlösung
}

\begin{abstract}
In linguistischen Untersuchungen erscheint sprachliche Raumreferenz gemeinhin als eine Aktivität, die notwendig ist, um dem Hörer/Leser die räumliche Lokalisierung von Objekten zu ermöglichen. In diesem Beitrag wollen wir zeigen, dass die sprachliche und kinesische Konstitution von Raum in der multimodalen Interaktion eine flexible kommunikative Ressource ist, die auch unabhängig von solchen Referenz-identifizierenden Erfordernissen eingesetzt werden kann.

Anhand der Videoaufnahme einer Lehr-Lern-Interaktion zeigen wir, wie die sprachliche und körperlich enaktierende Konstitution eines imaginären Raums eingesetzt wird, um eine komplexe Sachverhaltsdarstellung auf einen spezifischen Adressaten und dessen Verständnisprobleme zuzuschneiden. Im Zentrum der Datenanalyse steht zum einen die Rekonstruktion der interaktionsstrukturellen Einbettung der Raumkonstitution, die verdeutlicht, dass sie als Verfahren kommunikativ verwendet wird, weil andere Verfahren der Vermittlung abstrakter Sachverhalte bereits gescheitert sind. Zum anderen zeigen wir, wie sprachliche und kinesische Aktivitäten der Akteure systematisch bei der multimodalen Raumkonstitution zusammenwirken und wie durch sie vier unterschiedliche Dimensionen von Raum in der Interaktion (objektiv-physikalischer Raum, Interaktionsraum, individueller Verhaltensraum und imaginärer Raum) organisiert und aufeinander bezogen werden.

Dabei wird deutlich, dass die sozialsymbolische Kodierung von Räumen und die Überblendung verschiedener Dimensionen von „Raum“ als rekurrente Phänomene in der multimodalen Raumkonstitution eingesetzt werden.
\end{abstract}

\section{Einleitung}

In linguistischen Untersuchungen erscheint sprachliche Raumreferenz gemeinhin als eine Aktivität, die notwendig ist, um dem Hörer/Leser die räumliche Lokalisierung von Objekten zu ermöglichen und diese zu identifizieren (vgl. z.B. Linde/Labov 1975; Herrmann/Schweizer 1998; Levinson 2003; Fricke 2007; Berthele 2007; Tenbrink 2007, S. 183-199). Forschungsparadigmen sind die Untersuchung von per Instruktion elizitierten Wegauskünften, Raumbeschreibungen oder Objektlokalisierungen. Der Verweis auf Räumliches und seine Beschreibung sind in solchen Kontexten die primäre und meist auch die alleinige Interaktionsaufgabe. Die bisherige Forschung zur sprachlichen Raumkonstitution erweckt daher den Eindruck, als werde Raumreferenz stets um ihrer selbst willen unternommen. ${ }^{1}$ Folglich

$1 \quad$ Anders ist es im Falle der Erforschung räumlicher Metaphorik (vgl. z.B. Lakoff/Johnson 1980; Tenbrink 2007). Dort stellt sich natürlich die Frage, welche spezifische Funktionen der 
entsteht in derartigen Untersuchungen gar nicht erst die Frage, welche Funktion der Raumkonstitution interaktiv zukommt, ob es nicht auch Fälle von Raumkonstitution gibt, die nicht durch primär raumbezogene Informationsbedürfnisse motiviert sind, und wie sich solche andersartigen Motivationen in der Art und Weise der Raumkonstitution reflektieren.

In diesem Beitrag befassen wir uns mit einer solchen andersartigen Motivation von Raumkonstitution in der Interaktion. Wir möchten zeigen, dass die sprachliche und leibliche Konstitution von Raum in der multimodalen Interaktion eine flexible kommunikative Ressource ist, die auch unabhängig von Erfordernissen der Lokalisierung und Identifikation von Referenten zur Vermittlung komplexer abstrakter Konzepte eingesetzt werden kann. Dabei wird deutlich, dass die Funktion der Raumkonstitution und ihre konkrete Ausgestaltung nur aufgrund ihrer Einbettung in eine Interaktionssequenz zu verstehen ist. Die Raumkonstitution ist damit das Produkt einer Interaktionsgeschichte, auf die sie in funktionaler wie reflexiver Weise reagiert.

Grundlage unserer Untersuchung ist die Videoaufnahme einer LehrLern-Interaktion, in der vom Dozenten ein imaginärer Raum schrittweise konstituiert wird. Wir stellen zunächst die interaktive Vorgeschichte der Raumkonstitution im Fallbeispiel dar (Abschnitt 2). Sie zeigt, dass Raumkonstitution hier kommunikativ verwendet wird, nachdem andere Verfahren der Vermittlung abstrakter Sachverhalte gescheitert sind. Anschließend folgt die detaillierte Analyse der einzelnen Schritte der multimodalen Konstitution eines imaginären Raums (Abschnitt 3-4). Deren Abschluss bildet die Reformulierung der räumlichen Konstitutionsspezifik als Ergebnis der Bearbeitung basaler Anforderung der Etablierung und Ausgestaltung eines imaginären Raumes unter den faktischen Bedingungen von Interaktion (Abschnitt 5). Wir abstrahieren dann, wie sprachliche und kinesische Aktivitäten der Akteure systematisch bei der multimodalen Raumkonstitution zusammenwirken und wie durch sie vier unterschiedliche Dimensionen von Raum in der Interaktion (Umgebungsraum, Interaktionsraum, individueller Verhaltensraum und imaginärer Raum) organisiert und aufeinander bezogen werden (Abschnitt 6-7). Schließlich weisen wir die interaktive Funktion der Raumkonstitution als Verfahren eines dozentenseitigen recipient design aus und diskutieren, wieso sie als interaktives Verfahren der Vermittlung komplexer, abstrakter Konzepte besonders geeignet ist (Abschnitt 8).

Verwendung von ,Raum‘ als konzeptueller Ressource für die Repräsentation der Verhältnisse in einer Zieldomäne leistet. Unsere Untersuchung bezieht sich jedoch nicht auf räumliche Metaphorik, sondern auf die Konstruktion imaginärer Räume. 


\section{Die vorausgehende Interaktionsgeschichte: Gescheiterte Versuche einer Konzeptvermittlung}

Wir analysieren einen Ausschnitt aus einer Arbeitssitzung von vier Filmstudenten und zwei Dozenten (Regie, Drehbuch) in einer Filmhochschule. Im Rahmen dieser so genannten „Pitchings“ (Heidtmann 2009) werden Ideen für Filme entwickelt. Im Verlaufe eines solchen Pitchings entsteht ein interaktives Problem: Einer der Dozenten (DO) bemerkt, dass der Drehbuchautor (ST) den Ausdruck „Struktur“ im alltagsweltlich-indifferenten Sinne benutzt, nicht aber entsprechend seiner fachlichen Terminologisierung einer dramaturgischen Struktur mit einem Helden, einem Ziel, einem Hindernis und Problemfaktoren. Der Dozent versucht daraufhin, den Studenten auf unterschiedliche Weise auf die problematische Verwendungsweise aufmerksam zu machen und ihm die Relevanz von Struktur im dramaturgischen Sinne zu vermitteln. ${ }^{2}$ Als seine Vermittlungsbemühungen scheitern, ändert der Dozent seine Strategie. Er liefert mit dem Beginn von „Romeo und Julia“ (nach der Version „William Shakespeare's Romeo and Juliet“ (Regie: Baz Luhrman) mit Leonardo DiCaprio in der Rolle des Romeo aus dem Jahre 1996) ein Beispiel für eine gelungene Exposition, das er als narrative Performance gestaltet. Dabei konstituiert er schrittweise einen komplexen imaginären Raum, in dem er unterschiedliche Charaktere des Dramas zueinander positioniert und agieren lässt.

\subsection{Die interaktive Vorgeschichte: problematischer Strukturbegriff}

\subsubsection{Der Anfangsverdacht: Distanzierung von der Ausdrucksverwendung}

Der Drehbuchautor hatte eine Geschichte vorgelegt, die von den Dozenten harsch kritisiert worden war. Gegen die Kritik der Dozenten führte er den Begriff der „Struktur“ ins Feld: für mich das interessanteste an dem was wir da abgegeben haben is die struktur. Diese Verwendung führt beim Dozenten offenbar zum Anfangsverdacht, der Drehbuchautor verstehe den Strukturbegriff nicht im dramaturgischen Sinne und wisse insbesondere nicht, was er für die Konstruktion seiner Geschichte impliziere. Diesen Verdacht expliziert er jedoch nicht; vielmehr gibt er zu verstehen, dass er die mit dem Strukturbegriff implizierte Anforderung an eine Geschichte im vorliegenden Drehbuch nicht bewältigt sieht.

\footnotetext{
$2 \quad$ Ausschnitte dieses Beispiels werden als dozentenseitiges Verfahren der Wissensvermittlung
} in Heidtmann (2009, S. 218-220) beschrieben. 


\subsubsection{Stabilisierung einer Partnerhypothese: Nachfrage}

Der Drehbuchautor insistiert wenig später wiederum auf der Qualität des Drehbuchs unter Verweis auf dessen struktur. Der Dozent formuliert daraufhin seine Zweifel am Strukturverständnis des Studenten ich bin nicht SICHer ob sie- (.) das wort strukTUR wirklich: inhaltlich MEInen; und fragt dann explizit nach wenn sie jetzt strukTUR, meinen sie das im sinne von dramaTURgischer strukTUR? Die lapidare Antwort des Drehbuchautors ( $j a$ ja) scheint dem Dozenten zu bestätigen, dass der Student kein adäquates Verständnis von „Struktur" hat.

\subsubsection{Strategiewechsel I: Maieutisches Fragen und Kritik}

Der Dozent geht nun zu einem maieutischen Verfahren über (vgl. Hanke 1991). Hatte er bis dato versucht, den Studenten durch die Formulierung seiner Zweifel zur Selbsterkenntnis zu bringen, thematisiert er nun nicht mehr den Strukturbegriff als solchen. Vielmehr stellt er jetzt Fragen nach der Exposition der Geschichte, die darauf abzielen, dass der Student die Unangemessenheit ihrer Gestaltung selbst erkenne. Die maieutische Strategie führt jedoch auch nicht dazu, dass dieser den strukturellen Aufbau seines Drehbuchs als problematisch erkennt. Der Dozent formuliert schließlich eine deutliche Kritik an der Struktur der Exposition $<<t, k$ narrend $>a ̈ b$ der der der der $>$ MÜLLtransporter, (---) erZÄHLT uns übe:r; (-) unseren HAUPTcharakter nix. (Z. 097-100, Anhang). ${ }^{3}$ Diese wird vom Drehbuchautor jedoch bagatellisierend zurückgewiesen der DER ä:b- (-) legt en bisschen $<<$ all $>$ ne STIMM > $\downarrow$ ung an; (-) einfach- (Z. 103-106).

\subsubsection{Strategiewechsel II: Beispielnarration}

Der Dozent markiert daraufhin, dass stimmung keine Kategorie sei, die für die dramatische Struktur relevant ist. Er wechselt erneut seine Vermittlungsstrategie. Er geht nun zu einem Beispiel, der Exposition von „Romeo und Julia“, über, damit sie m mich verSTEHen. (Z. 115). Der erneute Strategiewechsel verdeutlicht das Scheitern der bisherigen Vermittlungsbemühungen.

ich $\mathrm{MACH}<<$ dim>mal $\mathrm{n}$ mal $\mathrm{n}$ BEIspiel;

115 damit sie m mich verSTEHen.>

116 (1.5)

117 ähm-

3 Das Beispiel ist transkribiert nach GAT (Selting et al. 1998). Der analysierte Transkriptausschnitt und der relevante Kontext finden sich im Anhang (Abschnitt 8). 


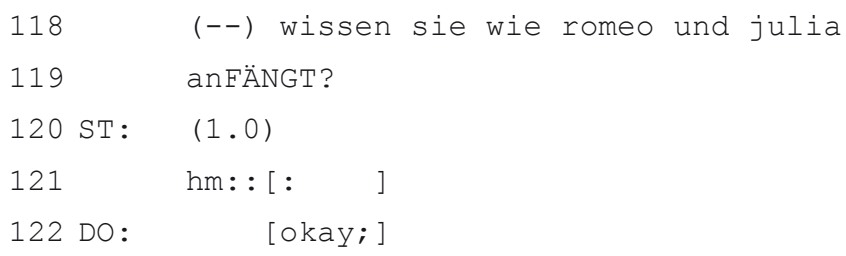

Die Beispielnarration beinhaltet zentral die multimodale Konstitution eines imaginären Raums. Bevor wir diese im Detail analysieren, fassen wir die interaktionsgeschichtlichen Bedingungen für ihr Zustandekommen kurz zusammen: Der Student hatte nicht auf die Vermittlungsbemühungen und die Angebote zum inhaltlichen Austausch reagiert und selbst keine Versuche unternommen, sein Verständnis von „Struktur“ zu verdeutlichen. Der Dozent setzt nun anstelle der bisherigen, zunächst abstrakten, dann zunehmend konkreter am Drehbuch des Studenten ansetzenden Fragen und Feststellungen, die auf den Gewinn der Selbsterkenntnis des Studierenden aus waren, die von ihm selbst vorgenommene Exemplifizierung als Vermittlungsverfahren ein.

Die Frage des Dozenten wissen sie wie romeo und julia anFÄNGT? (Z. 118119) bietet dem Studenten nochmals die Chance, sich selbstbestimmt mit der Dozentenkritik und seinem eigenen „Struktur“-Begriff auseinanderzusetzen. Als er auch sie nicht nutzt, startet der Dozent die Realisierung seines angekündigten Beispiels.

\section{Der imaginäre Raum der Exposition von „Romeo und Julia“"}

Im Folgenden wollen wir uns den Beginn der Exemplifizierung des Dozenten im Detail anschauen und uns dabei primär auf die Verfahren und Systematik konzentrieren, mit denen er den Raum konstituiert, den er für die Beispielrealisierung braucht. Wir wollen an dieser Stelle explizit darauf hinweisen, dass diese Raumkonstitution keine zwangsläufige Folge der Konstruktion eines Beispiels ist, sondern die Implikation der vom Dozenten gewählten Variante. Wir werden bei der Analyse auch immer danach fragen, in welcher Rolle der Dozent beim Aufbau und der Differenzierung seines Raumes/seiner Räume jeweils agiert und durch welche Mittel dies verdeutlicht wird.

\subsection{Eröffnung des imaginären Positionierungsraums}

Der Dozent beginnt die Beispielrealisierung unmittelbar mit einem Kernerzählsatz: 


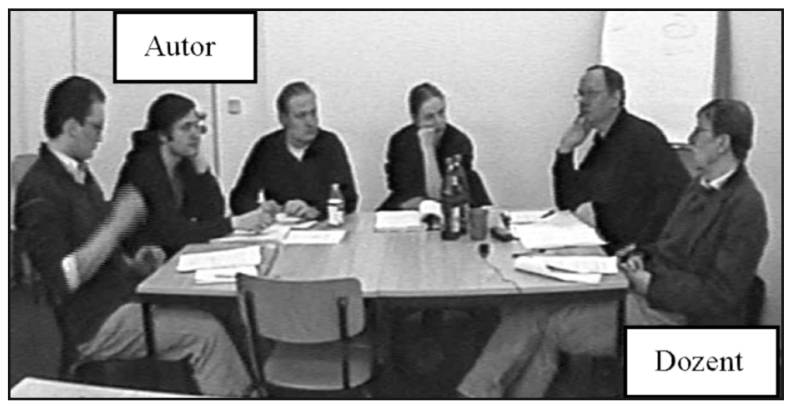

123 DO: da <<dim>GEHT ne GANG die STRABe runter; $>$

Wie die meisten Leser wissen werden (mit Sicherheit jedoch der Dozent weiß), fängt Romeo und Julia weder bei Shakespeare noch in der fraglichen Verfilmung mit der Szene an, die der Dozent mit seinem ersten Erzählzug etabliert. In beiden Fällen ist der Prolog, in dem die globale Struktur der gesamten Geschichte entworfen wird, dem faktischen Handlungsgeschehen vorangestellt. Ein Verweis auf den Prolog - und damit den tatsächlichen Anfang von Romeo und Julia - würde dem Dozenten jedoch bei seinem Versuch, dem Drehbuchautoren das Wesen der dramatischen Struktur exemplifizierend zu vermitteln, nicht nur nicht weiter helfen, sondern diesen sogar konterkarieren.

Die Tatsache, dass der Dozent den Prolog überspringt und sogleich mit der Darstellung der Handlungen der Protagonisten beginnt, ist eine erste empirische Evidenz für die reflexive Struktur seiner Beispielkonstruktion. Bereits der Beginn seines Beispiels reflektiert zentrale interaktionsstrukturelle Aspekte und Relevanzen der Situation „Pitching“: Die Studierenden lernen im Rahmen ihrer Ausbildung mit filmischen Mitteln eine Geschichte zu erzählen. Zentrale Voraussetzung dafür ist, ihre Protagonisten durch konkretes Handeln in ihrer wesentlichen Orientierung, ihren Zielen, Widersprüchen und Wünschen zu charakterisieren. Es geht gerade nicht darum, - wie dies im Prolog geschieht - sie in reflexiver, kategorialer und evaluativer Weise sprachlich vorzustellen oder zu beschreiben.

Das Drehbuch, welches das studentische Team vorgelegt hat, muss daher ohne die kontextualisierende Einführung eines Prologs auskommen bzw. die zentralen Informationen des Prologs handlungsmäßig und schrittweise etablieren. Um also die Vergleichbarkeit der studentischen Exposition mit der von Romeo und Julia zu maximieren und dadurch die Verständlichkeit der Beispielkonstruktion und ihre didaktische Funktionalität abzusichern, adaptiert der Dozent den Anfang des Dramas an die Struktur der studentischen Vorlage.

Während der Dozent in der Rolle des Erzählers sagt, dass eine Gang eine Straße hinuntergeht, behält er seine schon seit längerer Zeit statische 
Körperpositur bei: Er sitzt mit in seinem Schoß verschränkten Händen, die unter der Tischplatte ruhen, und in zurückgelehnter Haltung (Rücken an der Stuhllehne) am Tisch (Abb. 1).

Bereits in diesem ersten Erzählzug finden sich Aspekte, die raumkonstituierend sind:

$d a$

Für da (Z. 120) lassen sich zwei unterschiedliche Lesarten entwickeln:

1) Die erste Lesart begreift da als anaphorischen Bezug auf den Anfang von Romeo und Julia und damit primär als Hinweis auf die Exposition als aktuell zur Diskussion stehender dramaturgischer Sachverhalt. Das $d a$ wäre dann eine in der Form einer Raumreferenz verdichtete Reformulierung im Sinne „am Anfang von Romeo und Julia geht ne Gang die Straße runter".

2) Die zweite begreift da als raumdeiktisches Element. Es ist ein Verweis auf eine Räumlichkeit, die erst durch das, was noch in ihr passieren wird, nach und nach spezifiziert wird. Das da hat im Sinne von Goodwin (2003) die Qualität einer „projektiven Indexikalisierung“, die für eine nachfolgende Spezifizierung einen ersten, zunächst noch unstrukturierten Referenzrahmen etabliert.

die Straße

Eine Straße ist zweifelsohne ein komplexes räumliches Gebilde. Sie besitzt gewisse Ausmaße und Eigenschaften, die sie beispielsweise von einem Pfad oder einem einfachen Weg unterscheidet; sie ist zudem einer spezifischen architektonischen Umgebung assoziiert wie etwa einem Bürgersteig, Häusern (einem Straßenzug) und verweist damit auf einen öffentlichen sozialen Raum. Dies ist er mit keinerlei Zugangsbeschränkungen oder Sonderrechten für bestimmte Personen ausgestattet.

eine Gang

Eine Gang ist zwar selbst kein Raum, sondern eine soziale Gruppe, die jedoch durch eine spezifische Form des Raumbezuges charakterisierbar ist: Eine Gang besitzt und beansprucht Raum im Sinne eines eigenen Territoriums, in dem sie das Sagen hat, das sie beschützt, kontrolliert und gegen andere Gangs verteidigt.

runtergehen

„Runtergehen“ ist ein dynamisches, raumbezogenes Konzept, das eine zielorientierte Bewegung von A nach B in einem Raum mit einer gewissen Tiefe und Komplexität beschreibt. 
Die letzten drei Aspekte, die jeweils getrennt für sich betrachtet sehr unterschiedliche räumliche bzw. raumbezogene Implikationen haben, bilden zusammengenommen als geht ne Gang die Straße runter einen Raum, der in seiner Beschaffenheit und Struktur unweigerlich ein spezifischer sozialer Raum ist.

Dieser lässt sich nicht nur hinsichtlich seiner Relevanz für die Gang, sondern auch für diejenigen relativ präzise beschreiben, die der Gang begegnen. Es ist ein sozialer Raum, den die Gang durch eine spezifische kollektive Handlung (die Straße runter gehen) für ihre Selbstdarstellung benutzt. Wenn eine Gang die Straße runter geht, dann ist nicht primär die Überbrückung der Entfernung von A nach B der zentrale Punkt. Es geht vielmehr um eine spezifische Beanspruchung und In-Besitznahme des öffentlichen Raumes. Es handelt sich um eine aggressive Form der Selbstpräsentation, um eine bewusste Art, sich einem potenziellen Gegner zu zeigen, oder um die Einschüchterung derjenigen, die die Straße zufällig als Passanten benutzen.

Eine Gang, die die Straße hinuntergeht, konstituiert einen anderen sozialen Raum als die Krankenschwester oder die Reisegruppe, die die Straße hinunter gehen. Es ist zudem eine Form räumlicher Präsenz, die hinsichtlich der Formation, die die Gangmitglieder gemeinsam herstellen, charakterisiert werden kann: Diese werden keinen Gänsemarsch bilden, wie etwa Ausflügler aus dem Kindergarten, sondern die Straße möglichst „raumfüllend" beanspruchen. Es ist letztlich eine Form der Raumbeanspruchung, die Aggressivität symbolisiert und grundsätzlich auf Konfrontation ausgelegt ist.

Wir wissen zum jetzigen Zeitpunkt zwar welche Bewegungsrichtung die erste Gang hat, wir wissen allerdings (noch) nicht, wo genau sie sich auf der Straße bewegt: rechts, mehr in der Mitte oder links. Wir haben uns (auch weil der Sinn, wie sie noch sehen werden, von hinten kommt) für die - von der Origo des Sprechers aus gesehen - rechte Straßenseite entschieden.

Wir werden bei unseren folgenden Ausführungen die raumkonstituierenden Leistungen des Dozenten und die aufeinander folgenden Konstitutionsschritte in Form einer Skizze präsentieren. Die Skizzen sind nicht nur ein sinnvolles Medium der Visualisierung imaginärer Strukturen, sondern vor allem auch eine anschauliche Darstellung der sukzessiven Veränderungen des imaginären Raumes und seiner sich schrittweise verdichtenden und ausdifferenzierenden sozialen Struktur. Wir werden bei der Präsentation der Skizzen der Orientierung des Dozenten folgen und - soweit dies möglich ist - seiner grundlegenden Differenzierung und Abfolge der eingesetzten Verfahren der Raumkonstitution jeweils in einer eigenen Darstellung wiedergeben.

Wir werden nicht die gesamte Analyse auf dem bislang praktizierten detaillierten Explikationsniveau durchführen, sondern wollten gleich zu Beginn einmal exemplarisch auf die Reichhaltigkeit räumlicher Implikationen 
und die Permanenz impliziter Raumkonstitution allein durch das Medium Sprache verweisen. Wir wollen verdeutlichen, dass dies gerade auch dann der Fall ist, wenn Raumkonstitution nicht die primäre Aufgabe der sprachlichen Aktivitäten ist.

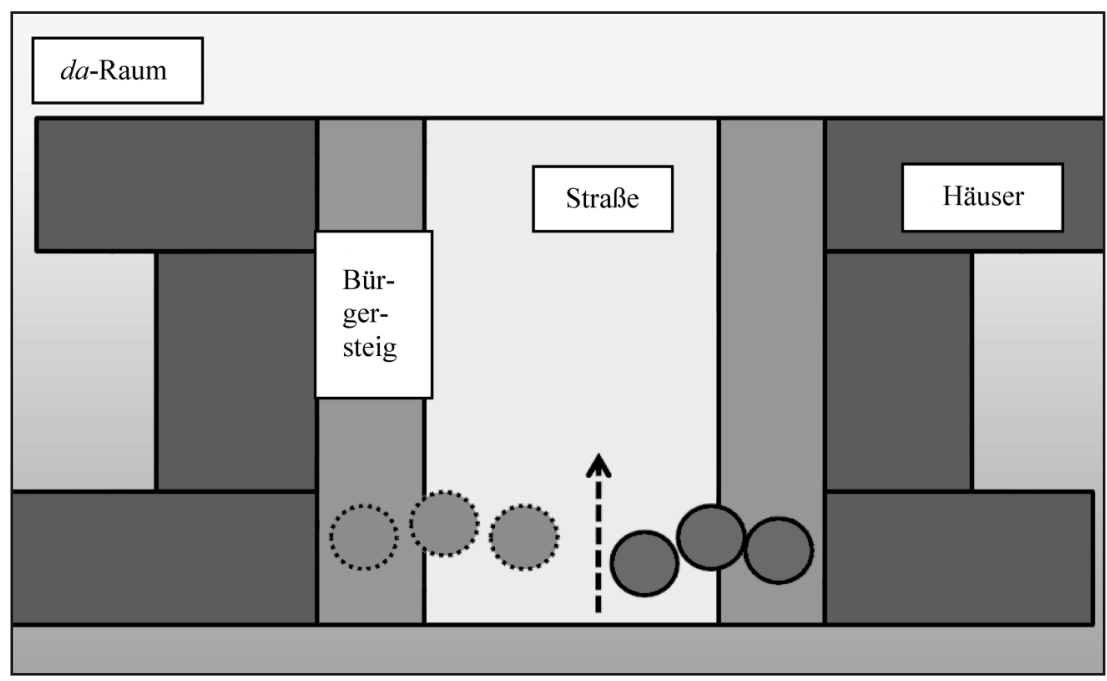

Skizze 1: Narrative Etablierung von Gang 1 im imaginären Raum

Legende:

$$
\begin{aligned}
& \mathbf{O}=\text { Gang } 1 \quad=\text { Alternativposition von Gang } 1 \\
& \hat{\mathbf{i}}=\text { Bewegungsrichtung (runtergehen) }
\end{aligned}
$$

Wir sind zudem nicht primär an der kaum hintergehbaren räumlichen Implikationen der Sprache an sich, sondern an dem Raum interessiert, den der Dozent als Bestandteil seiner alternativen Vermittlungsbemühungen im Kontext der Beispielkonstruktion explizit herstellt. Die kurze Explikation liefert jedoch folgende interessante Einsicht: Bereits in dem ersten kurzen Erzählzug liegt in impliziter Anlage die Struktur der Sozialität des Raumes als Potenzial und als eine fallspezifische Möglichkeit gegründet, die der Dozent im weiteren Verlauf seiner Beispielausführung herstellen und auch explizit verbalisieren wird. Schauen wir uns also die weitere Entwicklung des Beispiels und der Raumkonstitution an.

\subsection{Interaktionsstrukturierung und Verstehenssicherung}

$$
\begin{array}{ll}
124 \mathrm{DO}: & (-) \quad[j a ?] \\
125 \mathrm{ST}: & \quad[' \mathrm{mhm} ?]
\end{array}
$$




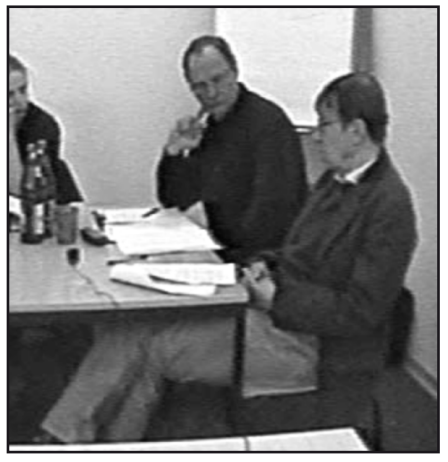

Abb. 2

$126 \mathrm{DO}: \quad(--)<<$ t $>$ ey-

Das ja? des Dozenten, das in Überlappung mit dem Rückmelder ' $m h m$ ? des Autoren realisiert wird, ist ein an den Studenten gerichtetes Vergewisserungssignal. Damit wechselt der Dozent aus der Rolle des Erzäblers in die des Interaktionsorganisators, der mit dieser verstehenssichernden Aktivität zum ersten möglichen Zeitpunkt in der Erzählung die didaktische Funktion seiner Darstellung verdeutlicht und den Studenten darüber hinaus zwingt, die bisher gelieferte Information explizit als verstanden zu bestätigen. Der Dozent realisiert damit auch einen räumlichen Wechsel. Er verlässt den mit da referenzierten Raum, in den hinein er die Gang positioniert hat, und agiert nun als Interaktionsmanager im gemeinsam mit den andern Anwesenden konstituierten Interaktionsraum. Wir haben es also mit zwei verschiedenen Räumen zu tun, in denen sich der Dozent in unterschiedlichen Beteiligungsrollen bewegt und die für die Bearbeitung seiner Vermittlungsanforderungen relevant sind: den Interaktionsraum und den imaginären Positionierungsraum.

Nach „erzwungener“ Rückmeldung des Studenten fährt der Dozent in der Entwicklung seines Beispiels fort, kehrt dabei jedoch nicht wieder zu dem mit da eröffneten Positionierungsraum zurück. Vielmehr eröffnet er einen dritten Raum: Es ist eine imaginäre Bühne, auf der er die zuvor positionierte Gang nunmehr mittels einer enaktierenden Darstellung in kategoriengebundener Weise präsentiert und vorführt.

Wir benutzen „Enaktieren“ im Folgenden zur Beschreibung eines interaktionsstrukturell motivierten, abhängigen sekundären Verfahrens. Die Abhängigkeit des Verfahrens zeigt sich formal betrachtet in seiner sequenziellen Nachordnung bzw. in der Vorgängigkeit eines relevanten Bezugsverfahrens. In unserem Fall wird Enaktieren systematisch eingesetzt zur Bearbeitung der durch eine vorgängige verbale soziale Kategorisierung (eine Gang) etablierten Anforderung nach situationsbezogener Spezifikation und Ausdifferenzierung der sozialen Kategorie. 
Es ist für Enaktieren konstitutiv, dass kontrastiv zur sprachlichen Kategorisierung noch andere Modalitäten als Ressource eingesetzt werden, die gerade nicht reflexiver, sondern demonstrativer Natur sind (Gestikulation, Blickverhalten, körperlich proxemisches Verhalten etc.). Man könnte auch sagen, dass - unter Bezug auf Schütz (1981) - situationsrelevante Aspekte des in der Kategorie sedimentierten sekundären Sinns, nahkontextuell und sequentiell nachgeordnet im Medium primärer Sinnkonstitution wieder aufgelöst werden. Man hat es letztlich mit einer Verfahrensbündelung bzw. einem Dualverfahren zu tun, das aus einer vorgängigen „sozialen Kategorisierung“ und einer nachfolgenden „Enaktierung“ besteht und das die zwei fundamentalen Modi der Sinnkonstitution in konvergierender Weise nutzt. ${ }^{4}$

\subsection{Eröffnung der Bühne}

\subsubsection{Auftritt der ersten Gang}

Mit diesem enaktierenden Zug seiner Beispielrealisierung verändert sich das Gesamtverhalten des Dozenten grundlegend. Er gibt seine statische Körperpositur und Handhaltung auf und wechselt in einen performativ-enaktierenden Modus.

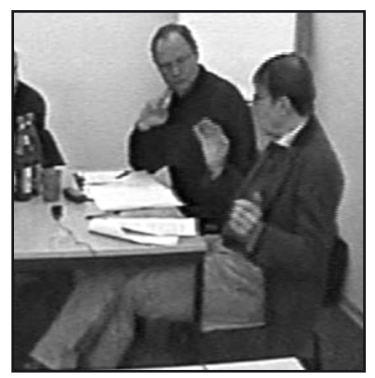

Abb. 3

126 DO: $\quad(--)<<t>$ ey-

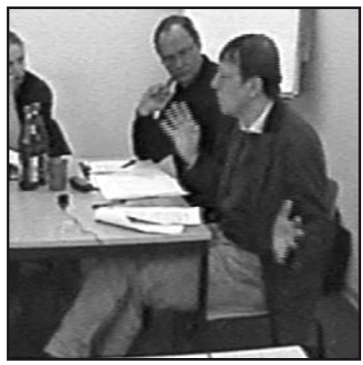

Abb. 4

\section{DO: (--) was S LOS alder;}

4 Enaktieren unterscheidet sich diesbezüglich von interaktionsstrukturell eher flexiblen, gesprächsrhetorischen Verfahren wie beispielsweise „Inszenieren“ (Schmitt 2003), mit dem es jedoch teilweise synonym verwendet wird. 


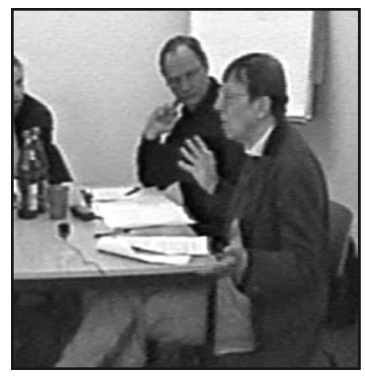

Abb. 5

128 DO: WO is randale; $>$

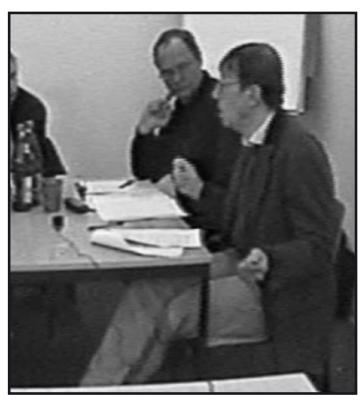

Abb. 6

129 DO: (-) nich?

$130 \mathrm{ST}:(-) \mathrm{mhm}$ ?

Seine Interaktionsbeteiligung ändert sich vor allem auf drei Ebenen, die wir im Folgenden im Auge behalten werden:

- die Stilistik des Sprechens,

- das körperliche Ausdrucksverhalten,

- die interaktive Beteiligungsrolle, in der der Dozent agiert.

Der Dozent geht dazu über, auf der Bühne als eines der Gangmitglieder zu agieren. Er spricht nun leiser, mit tieferer, knarrender, leicht gepresster Stimme. Es ist erkennbar nicht seine eigene Stimme, sondern er benutzt Jugendslang (Lexik: alder, randale; ey als attention getter, verschliffene Provokationsformel: was s LOS). Neben der verbalen und körperlichen Enaktierung des Verhaltens eines Gangmitglieds expliziert er mit wo is randale (Z. 128) auch dessen mentale Handlungsorientierung. Schon kurz vor Beginn dieses Turns schlüpft der Dozent in die Rolle des Gangmitglieds: Er gibt seine statische Oberkörperhaltung auf und löst beide Hände aus der Schoßhaltung, führt sie nach oben gut sichtbar über die Tischplatte und breitet Arme und Hände seitlich aus (Abb. 3-5). Seine Hände befinden sich nun rechts und links neben seinem Oberkörper, er spreizt alle Finger und bringt beide Handflächen nach vorne geöffnet in eine fast vertikale Position. Er schiebt dabei seinen Oberkörper, der mit dem Rücken an der Stuhllehne angelehnt 
war, etwas nach vorne. Mit Oberkörper und Kopf wippt er sechs Mal leicht nach rechts und links, wobei diese Bewegung auch die Unterarme und beide Hände integriert und teilweise noch leicht in seinem rechten Bein, das er über das linke geschlagen hat, sichtbar ist.

Diese Performance des Dozenten ist dominant von ihm aus nach vorne rechts, zum Drehbuchautoren hin, ausgerichtet. Er spricht nicht nur als Gangmitglied, er enaktiert auch dessen Gang durch die Stilisierung einer auf Wahrnehmbarkeit und Provokation angelegten, kategorientypischen Männlichkeitsdemonstration. Diese wippende Bewegung beendet der Dozent exakt mit einem erneuten Vergewisserungssignal nich? (Z. 129), das er deutlich lauter und höher spricht (Abb. 6).

Dadurch, dass der Dozent den Studenten erneut zur Verstehensdokumentation auffordert, verdeutlicht er, dass er mit dem ersten Zug seiner Inszenierung fertig ist. Zugleich schließt er die Finger beider Hände zu einer losen Faust und rückt sowohl mit dem Rücken wie auch mit dem Gesäß wieder in Richtung Stuhllehne. Die veränderte Finger- und Handgestik und die Rückkehr zur eigenen Stimme kontextualisieren den Übergang von der Enaktierung des Gangmitglieds zur Rolle des Lehrers und damit das Verlassen der Bühne und den Wiedereintritt in den gemeinsamen Interaktionsraum. Er nimmt seine Hände jedoch nicht wieder zurück in die home position (Sacks/Schegloff 2002), sondern bringt sie für alle sichtbar oberhalb der Tischplatte zur Ruhe, ohne sie jedoch dort abzulegen. Er kehrt auch mit seinem Oberkörper nicht vollständig in die Ausgangsposition zurück. Beides projiziert, dass der Dozent mit seiner Performance weitermachen wird.

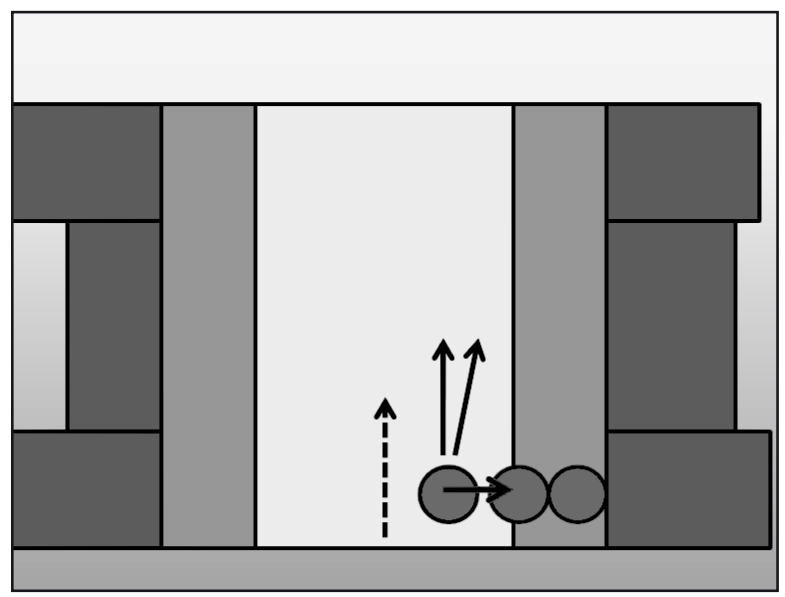

Skizze 2: Enaktive Positionierung Gang 1

Legende:

$\rightarrow=$ Adressierungsrichtung

$\uparrow=$ Blickrichtung 
Ziehen wir an dieser Stelle ein erstes Zwischenfazit:

- Wir können sehen, dass der Dozent in zwei unterschiedlichen Räumen - dem Interaktionsraum und dem imaginären Positionierungsraum und in verschiedenen Beteiligungsrollen agiert.

- Die Symbolisierung der Räume erfolgt

a) mittels spezifischer Sprechweisen, wodurch die Räume zu eigenständigen „Sprachräumen“ (Hausendorf in diesem Band) werden und

b) mittels spezifischer körperlicher Verhaltensweisen, die sich als besondere Form der Gestikulation und der Oberkörperbewegung und der Körper- und Blickorientierung zeigt.

- Auch die Performance als Gangmitglied und seine didaktische Strukturierung als Lehrer sind durch klare Grenzmarkierungen (Pausenklammer) und die punktgenaue Koordination zwischen den rollengebundenen Sprechweisen und den anderen Ebenen des multimodalen Ausdrucks konturiert und eindeutig voneinander abgegrenzt.

- Die Konstitution des imaginären Raumes weist zudem eine klare Sequenzialität auf: Zuerst wird der Raum narrativ strukturiert, dann wird in den etablierten Strukturen agiert.

\subsubsection{Auftritt der zweiten Gang}

Der Dozent führt nun parallel zur Darstellung der ersten Gang die zweite Gang ein. Erneut beschreibt er aus der Erzählerrolle das Auftauchen der zweiten Gang: da kommt ne ANdere gang (Z. 131). Wieder eröffnet er die Beschreibung mit $d a$, mit dem er die zweite Gruppe im gleichen Raum positioniert, in dem bereits die erste Gang unterwegs ist (vgl.: da $<<$ dim $>$ GEHT ne GANG die STRAße runter; > , Z. 123). Beide Gangs werden dann zueinander in Beziehung gesetzt, die zweite Gang adressiert die erste. Der Dozent wechselt nunmehr wieder seine Rolle und wandelt sich vom Erzähler zum Mitglied der zweiten Gang $\langle<h\rangle$ EY MANN DA geNAU (.) auf EUCH ham wir geWARtet; $>$ (Z. 132-133).

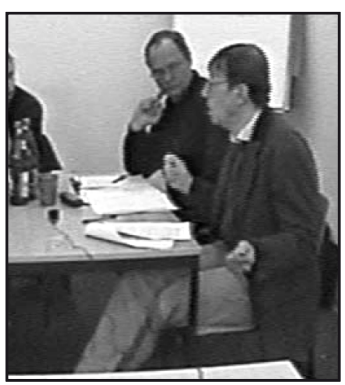

131 DO:

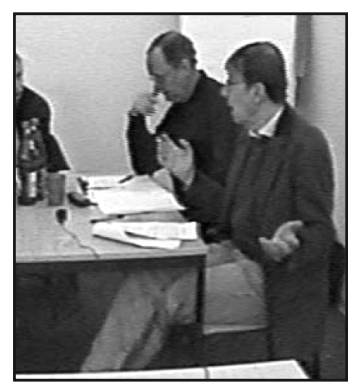

Abb. 7-8

ANdere gang und sagt 


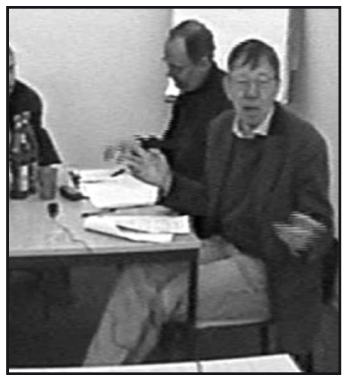

Abb. 9

$<<\mathrm{h}>$ EY MANN DA geNAU (.)

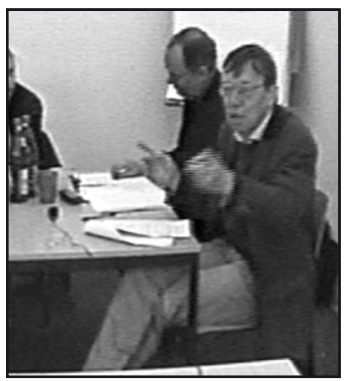

Abb. 10

$<<$ h $>$ EY MANN DA geNAU(.)

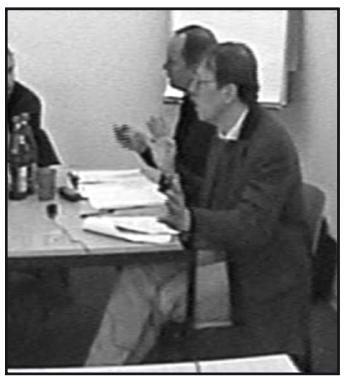

Abb. 11

133 DO: auf EUCH ham wir geWARtet; >

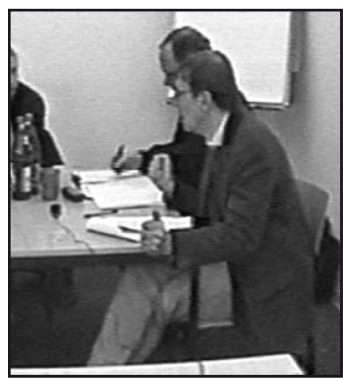

Abb. 12
$134 \mathrm{DO}$ :
(-) ja? (1.2)
135
(1.2) 
Wieder wird das Mitglied der zweiten Gang durch eine Sprechweise charakterisiert, die der ersten sehr ähnlich ist. Die Rede inszeniert er als dreiteiligen Turn, der strukturell dem des zuvor enaktierten gegnerischen Gangmitglieds sehr ähnlich ist:

- attention getter.

- 1. Formulierung der Provokation: was los alder - da genau

- 2. Formulierung der Provokation: wo is randale - auf euch baben wir gewartet

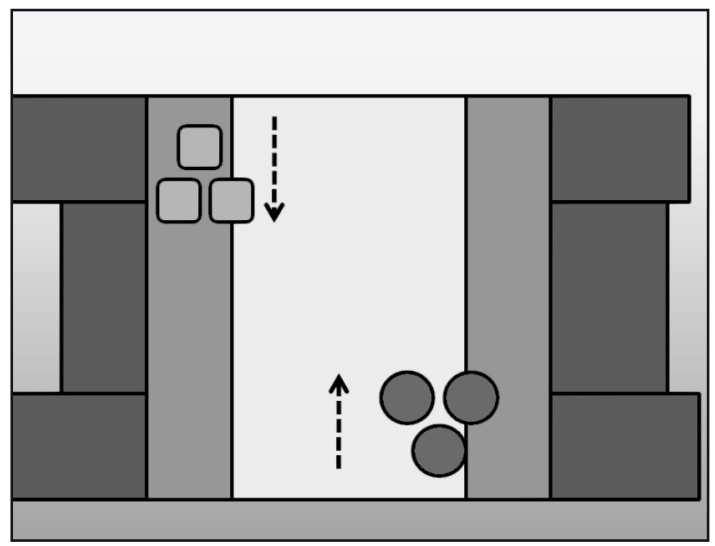

Skizze 3: Narrative Positionierung Gang 2

Legende:

$\square=$ Gang $2 \quad \dot{\mathbf{V}}=$ Bewegungsrichtung (kommen)

Anders als bei der ersten Gruppe steht im körperlichen Ausdruck jedoch nicht die Verkörperung des Gehens im Zentrum der Performance, sondern der Prozess des Suchens und Findens eines Gegners (Abb. 9-10). Dies verdeutlicht der Dozent durch die Drehung des Oberkörpers weit nach links, er lässt seinen Blick schweifen, deutet im Moment des Erkennens mit seiner linken Hand mit ausgestrecktem Zeigefinger in Richtung des Gegners, ehe er bei EUCH wieder zur Mitte zurückkehrt (Abb. 11), um seine Inszenierung der zweiten Gang abzuschließen. Analog zur Verdeutlichung der Position der ersten Gang im imaginären Raum, wird auch hier die Position der zweiten Gang durch den Blick nach links zur ersten Gang (auf der andern Straßenseite) markiert.

Wie bei der Darstellung der ersten Gang wechselt der Dozent, als er seine Enaktierung beendet hat, wieder in die Lehrerrolle: Er spricht wieder lauter und höher und ballt seine Finger zur Faust (Abb. 12). Wieder produziert er ein Vergewisserungssignal ( $j a$ ? ), das er mit einer kurzen Pause von seiner Performance absetzt. Der Dozent benutzt also die gleichen, ebenso 
systematisch und punktgenau multimodal und narrationsstrukturell koordinierten Verfahren der Enaktierung und des Wechsels unterschiedlicher Beteiligungsrollen.

Hatte er bei der performativen Darstellung der ersten Gang seine Enaktierung primär nach vorne-rechts ausgerichtet, so orientiert er sich nun bei der Einführung der zweiten Gang vorne-links. Die beiden Gangs sind nun also in einem Raum positioniert, in dem durch die körperliche Ausrichtung der Enaktierung und die sprachlichen Konzepte „,runter gehen“ und „kommen“ eine klare Opposition etabliert ist: Gang eins ist auf der einen, Gang zwei auf der anderen Straßenseite positioniert. Der im ersten Schritt aufgebaute imaginäre Raum wird weiter in Kraft gehalten und für die weitere Konstitution genutzt: Die zweite Gang entdeckt die erste Gang genau da im imaginären Raum, wo sie der Dozent positioniert und in Bewegung gebracht hatte. Der imaginäre Positionierungsraum ist dadurch nicht nur formal, sondern auch sozial und zeitlich strukturiert.

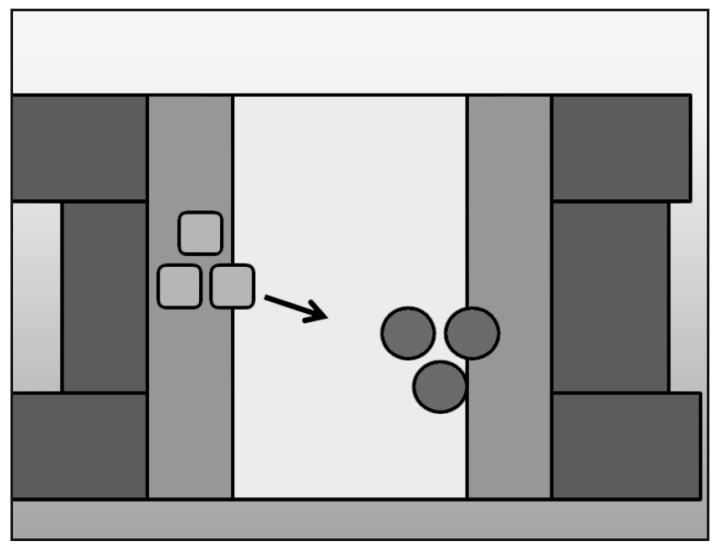

Skizze 4: Enaktive Positionierung Gang 2

Legende:

= Blick- und Adressierungsrichtung

Erst mit der Ausrichtung der enaktierenden Darstellung und der sprachlichen Adressierung der zweiten Gang ist auch die erste präzise in einem Rechts-Links-Schema verortet. Diese muss sich auf der rechten Seite (der Straße/des imaginären Raumes) befinden. Denn nur dann kann sie im Rahmen der durch die beiden Bewegungskonzepte „runter gehen“ und „kommen“ etablierte Perspektivität durch die nach links orientiere Bezugnahme der zweiten Gang adressiert werden. Hier kommt nun ein den vorliegenden Fall transzendierender, allgemeiner Aspekt zum Ausdruck, der für die Strukturierung und Perspektivierung imaginärer Räume insgesamt 
relevant ist. Die positionale Verdeutlichung handelnder Protagonisten in ihrer raumbezogenen Indexikalität muss nicht bereits mit dem Akt ihrer Positionierung mit erledigt werden. Vielmehr können diese Leistungen auch retrospektiv verdeutlichend erbracht werden: Die Positionierung der zweiten Gang zeigt dabei, wo sich die erste Gang befinden muss.

Der Vorteil einer solchen retrospektiven Positionierung besteht unter anderem in der damit zusammenhängenden Ökonomisierung der Raumkonstitution. Die Protagonisten können zunächst etabliert, charakterisiert und dann erst schrittweise durch die Orientierung beim Enaktieren in ihrer problembezognen Relationierung präzisiert werden. Man kann dabei aufgrund der Konstitutionslogik, die der Raumausgestaltung zugrunde liegt, präzise erschließen, wer wo platziert ist. Bei der Tatsache, dass die erste Gang von der zweiten als linksstehend indiziert wird, spielt die konkrete Seitlichkeit jedoch keine Rolle. Was relevant ist, ist vielmehr die präzise Modellierung der Konfliktstruktur durch die klare oppositive Positionierung der beiden Gangs.

Auf diese - gleichermaßen präzise und ökonomische Weise - wird genau das und genau so viel von der Konstellation narrativ etabliert und inszeniert, wie für die Funktionalität der Raumkonstitution als Verdeutlichung einer konkreten Konfliktstruktur nötig ist. Dass dabei ein Rechts und Links entsteht, ist nur wichtig als notwendige Voraussetzung für das „dazwischen gehen" des Sheriffs. Relativ zu diesen beiden Aspekten wird die Strukturierung des Raumes ausgestaltet. Es geht also nicht darum, die tatsächliche, komplexe und unübersichtliche Situation des Films abzubilden, sondern um die räumliche Darstellung einer idealisierten vereinfachten oppositiven Struktur. Bereits von Beginn an manifestiert sich, dass es nicht darum geht, anderswo existente Räume imaginierend ab- oder nachzubilden. Das didaktisch motivierte Ziel besteht vielmehr darin, einen imaginären Raum den spezifischen, durch die Interaktionsgeschichte motivierten pragmatischfunktionalen Zwecken gemäß zu modellieren und auszugestalten.

Es wird deutlich, dass wir es bei der im Imaginationsraum angelegten Konstellation nicht nur mit räumlichen Koordinaten zu tun haben. Es sind vielmehr unterschiedliche Protagonisten mit spezifischen, in diesem Fall korrespondierender sozialer Ausstattung und Orientierung, wodurch eine grundsätzlich räumlich-soziale Struktur entsteht. Der Imaginationsraum und das darin entworfene Geschehen besitzen darüber hinaus auch eine klare zeitliche Struktur. Die beiden Gangs befinden sich nicht nur in einem gemeinsamen Raum, sondern bewegen sich auch tatsächlich gemeinsam in diesem, was bedeutet, dass sie zum einen auch in einer gemeinsamen Zeit agieren und somit den Gesetzen der Sequenzialität unterworfen sind. Die zeitliche Struktur kann dahingehend präzisiert werden, dass die zweite Gang nicht sofort nach der ersten die Szene betritt. Vielmehr ist die erste Gang bereits eine Weile unterwegs, ehe sie auf die zweite Gang trifft. 
Nur durch die in der Zeit abgelaufene Bewegung der beiden Gangs (,runtergehen“ - „kommen“) ist es möglich, dass es zu der verbalen Adressierung kommt. Die beiden Gangs müssen sich im Laufe der Beispielkonstruktion sehr weitgehend angenähert und damit die potenzielle Konflikthaftigkeit (Randale, auf euch gewartet) der Situation verschärft haben.

\subsubsection{Konflikteskalation}

Nach der Enaktierung der beiden Gangs auf der Bühne ballt der Dozent beide Hände zu Fäusten (Abb. 12). Im Kontext des bislang inszenierten Aufeinandertreffens der beiden Gruppen verkörpert diese Haltung das narrativ bereits angelegte Konfliktpotenzial der Begegnung. Seine Entladung enaktiert er anschließend in einer gleichermaßen minimalistischen wie komplexen Weise.

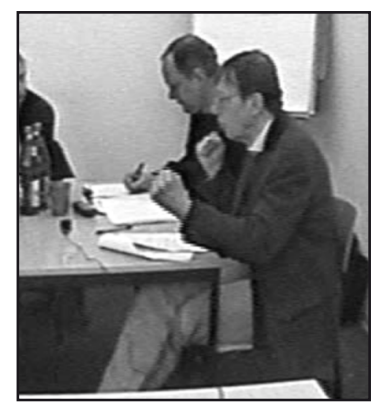

Abb. 13

136 DO: boff;

Der Dozent hebt beide Fäuste in die Höhe, führt im Stile eines Boxers seine linke Faust als Führhand etwas weiter nach vorne (zu einem imaginären Gegner) und hält die rechte als Schlaghand und zur eigenen Deckung zurück, etwas höher und näher an seinem Körper platziert. Während dieser Darstellung eines Boxers äußert er die Interjektion boff; (Abb. 13).

So klar diese Darstellung ein Emblem für die Konflikteskalation ist, so komplex ist sie in Bezug auf die Beteiligungsrolle, die der Dozent mit ihr einnimmt und hinsichtlich des Raums, in dem er dabei agiert. Er agiert in einem „Rollenmix“, der verschiedene Perspektiven miteinander vermischt. Verbale Äußerung und körperlicher Ausdruck ergänzen sich hier nicht wie zuvor in redundanter Weise zur Enaktierung einer einzigen Rolle. Sprache und körperliche Aktivitäten werden vielmehr lokal als autonome Ausdrucksmittel für die gleichzeitige Bearbeitung unterschiedlicher Aufgaben eingesetzt. Die an Sprechblasen in einem Comic erinnernde, onomatopoetische Interjektion boff bringt die Dynamik der Konflikteskalation zum Ausdruck und ist in diesem Sinne der maximal verdichtete Endpunkt der bislang narrativ entwickelten Struktur. 
Hans agiert dabei - was die Körperlichkeit der Darstellung betrifft (als Boxer) - auf der Bühne als eines der zum Kampf bereiten Gangmitglieder. Sprachlich hingegen kommentiert er diese Haltung, tritt also aus der Rolle des Boxers heraus und agiert als Erzähler, der einen auf einen Jugendlichen zugeschnittene metakommunikativen Kommentar realisiert.

Der Dozent agiert bei der Realisierung des boff auch wieder in unterschiedlichen Räumen: zum einen auf der Bühne, dem Platz der Enaktierung, zum anderen im Interaktionsraum, dem Platz vermittlungsspezifischer Verdeutlichungsleistungen. Die Perspektiven der Akteure, des Erzählers und Lehrers werden hier also in einem anschaulichen multimodalen Emblem des dargestellten Konfliktes kondensiert.

Darüber hinaus besitzt boff auch raumkonstituierende Implikationen. Dieser lautmalerische Ausdruck und die Boxerpose verdeutlichen nämlich, dass sich die beiden Gangs nicht mehr nur in Ruf-, sondern inzwischen auch in Schlagweite befinden. Sie haben sich inzwischen so weit angenähert, dass sie eine fokussierte Interaktion auf der Grundlage unmittelbarer körperlicher Kontakte starten können.

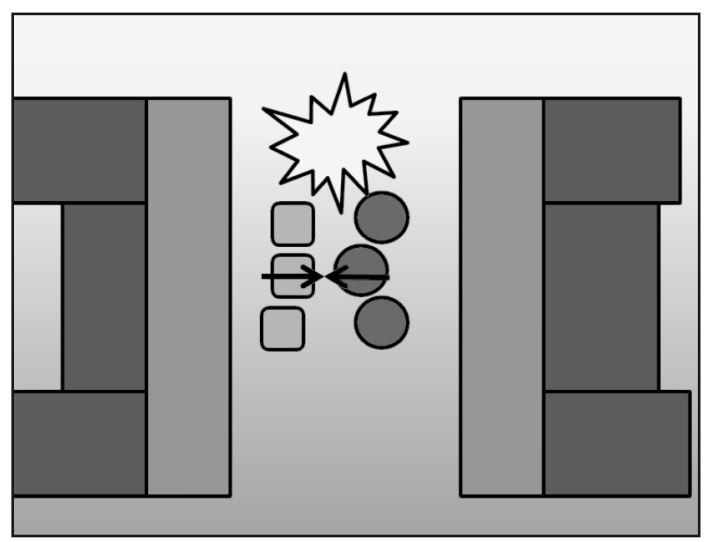

Skizze 5: Narrative/Enaktierte Positionierung der beiden Gangs (boff)

Legende:

$\longrightarrow \leftarrow=$,Verhaltensrichtung“ beider Gangs

Wir werden an dieser Stelle die detaillierte Rekonstruktion der Beispielentwicklung beenden. Da der Dozent bei seiner weiteren Entwicklung in systematischer und rekurrenter Weise die bereits beschriebenen Verfahren der Raumkonstitution und Indikation, der Charakterisierung der unterschiedlichen Protagonisten und die Symbolisierung seiner eigenen Beteiligungsrolle einsetzt, würde eine detaillierte Analyse über den aktuellen Punkt hinaus keinen wirklich neuen strukturellen Befund mehr zu Tage fördern.

Wir werden jedoch die weitere Entwicklung des Beispiels - soweit es für die Frage der Raumkonstitution wichtig ist - kurz beschreiben. 
Zunächst wollen wir jedoch die Gelegenheit zu einer zweiten Zusammenfassung nutzen.

Die bisherige Analyse bestätigt sehr weitgehend die Einsichten, die sich bereits im ersten Resümee gezeigt haben. Sie macht somit die Systematik und Rekurrenz der multimodalen Raumkonstitution des Dozenten deutlich:

- Es werden zwei unterschiedliche Räume konstituiert: der Interaktionsraum und der imaginäre Raum.

- In diesen beiden Räumen agiert der Dozent in drei verschiedenen Rollen: Im Interaktionsraum ist er Lehrer und Interaktionsstrukturierer; im imaginären Raum agiert er zum einen als Erzähler, zum anderen als Enaktierer.

- Die Positionen innerhalb dieser Räume werden systematisch durch unterschiedliche multimodale Konstitutionsverfahren gekennzeichnet.

- Erneut zeigt sich die klare sequenzielle Ordnung von

1) vermittlungsbezogenen Aktivitäten im Interaktionsraum,

2) narrativer Strukturierung des imaginären Positionierungsraumes und

3) enaktierender Verdeutlichung der Protagonisten dieses Raumes.

3.3.4 Namensgebung und Re-Positionierung

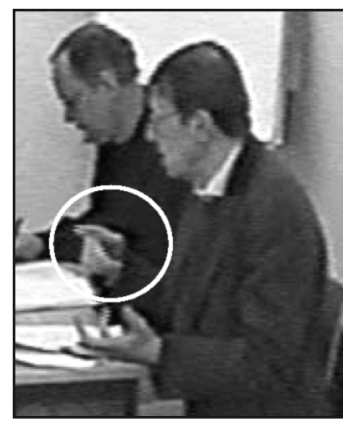

Abb. 14

137 DO: (--) die einen sind die CApulets,

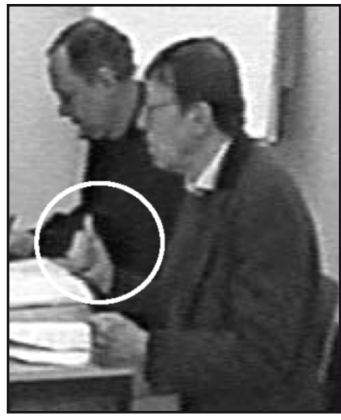

Abb. 15 
Als nächstes werden die Gangs namentlich vorgestellt (die einen sind die CApulets, und nach einer abermaligen kurzen Pause $<<\operatorname{dim}>$ und die anderen sind die DINGsens da; $>$. Die erste Gang, die Capulets, werden im Einklang mit ihren Koordinaten im Positionierungsraum mit dem gestreckten Zeigefinger der rechten Hand als links stehend ausgewiesen (Abb. 14). Die Dingsens (Montagues) werden dagegen - ebenfalls mit dem Daumen der rechten Hand - nach rechts verwiesen (Abb. 15). Der Dozent folgt also bei seiner Beispielentwicklung systematisch den von ihm selbst etablierten räumlichen Strukturen und verfestigt sie dadurch.

Im nächsten Schritt erfolgt der Auftritt des Sheriffs. Auch dabei wiederholt sich die Systematik von Etablierung im Positionierungsraum und der enaktierenden Darstellung auf der Bühne. Bei der Etablierung und der anschließenden Enaktierung des Prinzen orientiert sich der Dozent mit seinem Körper konsequent mittig nach vorne, während die Gangs rechts und links positioniert wurden. Diese Mittigkeit wird auch verbal durch das Konzept „dazwischen gehen“ formuliert.

140 DO: (--) und?

141 (--) wer geht dazWISCHen?

$142 \mathrm{ST}:(--) \mathrm{mh}$;

143 DO: (-) der SHEriff geht dazwischen;

144

der PRINZ geht <<all>dazwischen und sagt; >

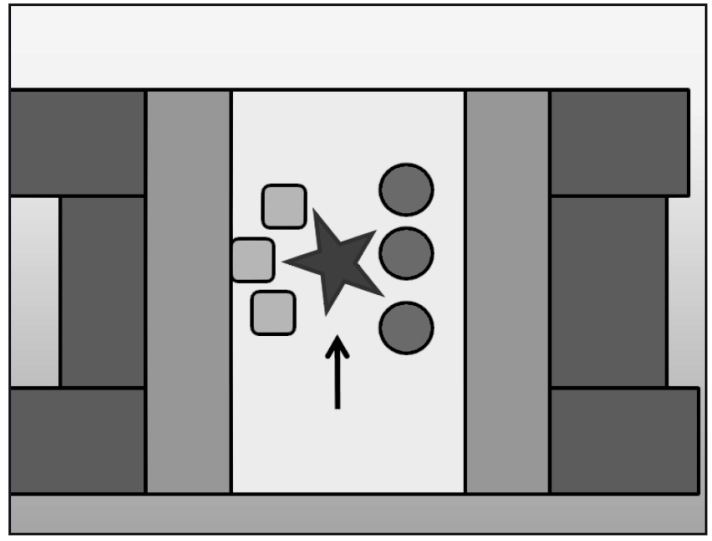

Skizze 6: Narrative Positionierung des Sheriffs/Prinzen (dazwischen gehen)

Der neue Akteur, der Sheriff, wird - im Unterschied zu den beiden Gangs, die beidhändig enaktiert wurden - durch die rechte Hand symbolisiert: Mit ausgestrecktem Zeigefinger und angehobenem Unterarm führt der Dozent zunächst eine Heranhol-Gestikulation und dann eine Mischung aus Zeigeund Mahngestikulation aus (Abb. 17-25, siehe unten). An dieser Stelle tre- 
ten erstmals in dieser Narration die verbale Einführung eines Akteurs und seine multimodale Enaktierung auseinander. Die Zeigegeste, die projektiv die folgende Warnung des Sheriffs verkörpert, setzt schon vor seiner verbalen Einführung ein; und bereits vor der folgenden Wiedergabe der ÄuBerung des Sheriffs verändert der Erzähler seine Stimme zunehmend in Richtung der Stimmgebung, die dann die folgende Rede des Sheriffs auszeichnet. Der Dozent wird langsamer, leiser und tiefer, die Stimme wird zur Knarrstimme. Stimme und Gestik sind diesmal nicht segmental kookkurrent mit den eingenommenen Rollen, beide antizipieren vielmehr die folgende Transition zwischen Erzähler und Geschichtenfigur.

Die gestikulatorischen Aktivitäten des Dozenten im Zusammenhang mit der Etablierung des Sheriffs lohnen eine etwas genauere Betrachtung. Dabei werden zwei Aspekte deutlich, die für unser auf Raum bezogenes Erkenntnisinteresse von Bedeutung sind: 1) die sequenzielle Ordnung der Gestikulation und 2) die Koordination der bei der Enaktierung eingesetzten modalen Ressourcen.

Ad 1): Die sequenzielle Ordnung der Gestikulation besteht aus zwei unterschiedlichen Teilen.

Der erste Teil ist eine Heranhol-Gestikulation, die mit gekrümmtem Zeigefinger realisiert wird (Abb. 16-21). Diese Gestikulation wird nicht simultan mit der enaktierenden Positionierung des Sheriffs/Prinzen realisiert, sondern erfolgt bereits bei dessen narrativer Etablierung. Es ist also noch nicht der Dozent als Sheriff, der diese Gestikulation ausführt.

„Heranhol“-Gestikulation
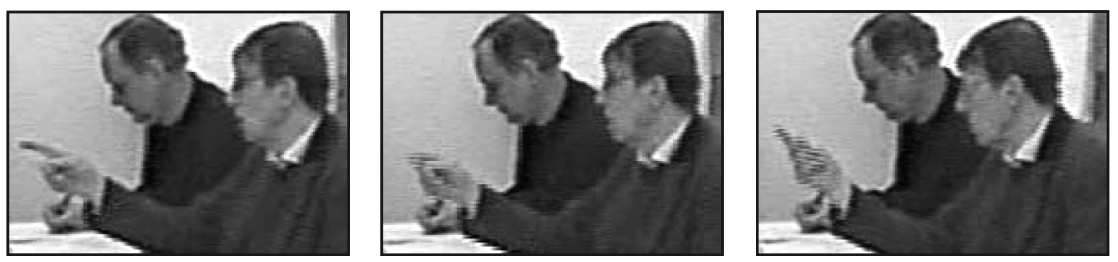

143 DO: (-) der SHEriff geht dazwischen;
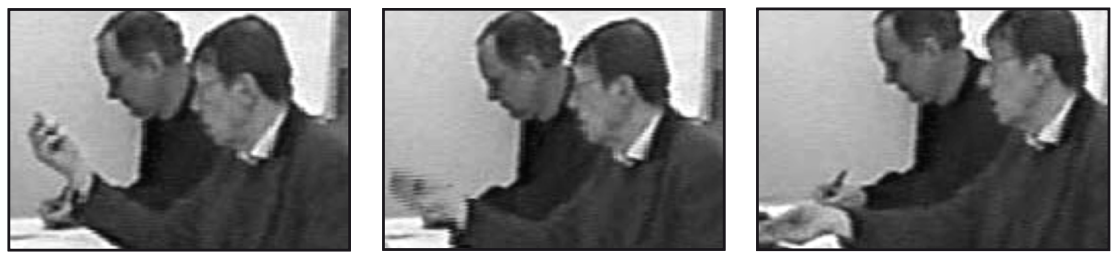

144

der PRINz geht <<all>dazwischen und sagt; >

Abb. 16-21 
Der zweite Teil ist eine Zeige- bzw. Ermahn-Gestikulation, die mit ausgestrecktem Zeigefinger ausgeführt wird (Abb. 22-24).
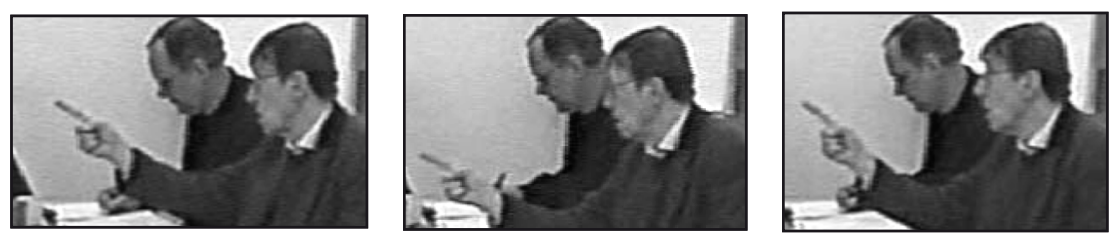

Abb. 22-24

Beide gestikulatorischen Segmente sind in erkennbarer Kontrastivität realisiert. Die Heranhol-Gestikulation ist dynamisch hinsichtlich der Höhe ihrer Ausführung und bezogen auf die Haltung der Finger und der Hand. Die Zeige- und Ermahngestikulation ist hinsichtlich der Finger- und Handhaltung hingegen statisch (der Zeigefinger bleibt die ganze Zeit über gestreckt und in die Höhe weisend). Lediglich die Ausführungshöhe variiert im persönlichen Verhaltensraum des Dozenten.

Ad 2:) Der zweite Aspekt ist die Koordination der gestikulatorischen Aktivitäten mit der verbalen Äußerungsproduktion. Die Koordination der sprachlichen Aktivitäten - vor allem in sprechrhetorisch relevanten Zusammenhängen der detaillierenden Charakterisierung der Agenten des imaginären Raumes und bei der Markierung der unterschiedlichen Beteiligungsweisen des Dozenten - war bislang durchgehend durch eine Systematik der Synchronität und des gemeinsamen Wechsels der beteiligten Modalitätsebenen charakterisiert. Hier an dieser Stelle jedoch tritt diese Systematik der Koordination zu Gunsten einer monomodalen Eigenständigkeit der gestikulatorischen Aktivitäten gegenüber den verbalen Aktivitäten des Dozenten zurück.

Die gestikulatorischen Aktivitäten erfolgen erkennbar und bedeutungstragend früher als die verbalen. Die Heranhol-Gestikulation ist vollständig „autonom“, d.h. sie begleitet nicht die Enaktierung, und auch der Beginn der Ermahn- und Zeigegestikulation liegt vor der verbalen Enaktierung des neuen Protagonisten. Durch diese zeitliche Vorgängigkeit erhalten beide Gestikulationen eine pragmatische Eigenständigkeit, die unabhängig von der Äußerungsproduktion des Dozenten in seiner Rolle als Sheriff/Prinz ist.

Dies hängt damit zusammen, dass sowohl das gestikulatorische Heranholen als auch die Zeige- und Ermahn-Aktivität im Interaktionsraum Adressierungsqualität besitzen. Der heranholende und der ausgestreckte und ermahnende Zeigefinger sind, genau wie der Blick des Dozenten, auf den Drehbuchautoren gerichtet. Diese Adressierung und die Vorgängigkeit der Gestikulation vor der enaktierenden Verbalisierung des Prinzen als neuem Agenten im imaginären Raum verleihen der Geste die zusätzliche Bedeutung, dass auch der Drehbuchautor ermahnt wird. Der Dozent realisiert hier also erneut eine Rollenmischung aus enaktierendem Erzähler und Leh- 
rer, agiert also sowohl im imaginären Raum als auch im Interaktionsraum. Dabei dient das gestikulatorische Heranholen gewissermaßen der Vorbereitung dieser Adressierungsdopplung: Der Drehbuchautor wird - metaphorisch gesprochen - zu den beiden Gangs hinzu geholt und dann mit diesen zusammen ermahnt.

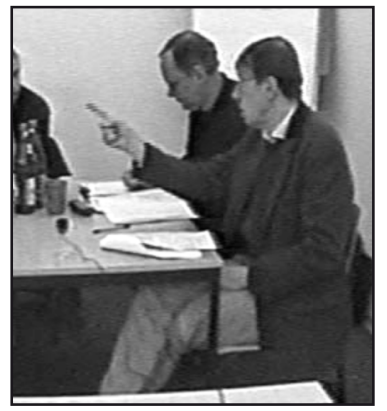

Abb. 25

$145 \mathrm{DO}: \quad<<\mathrm{p}>$ leute;

146 PASST mal auf;

147 (--) wenn das noch EI:Nmal passiert hier;

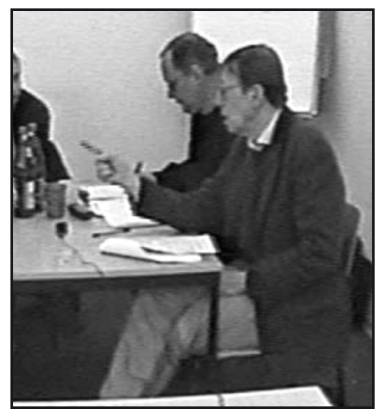

Abb. 26

148 DO: (-) dann-

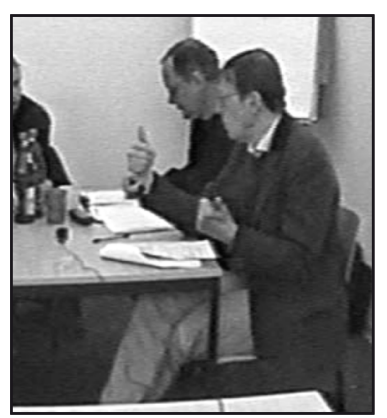

Abb. 27

(1.7)

150 DO: fliecht ihr hier aus der geMEINde; 


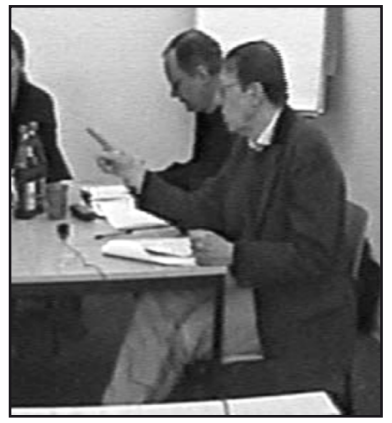

Abb. 28

151 DO: (-) dann werdet ihr vogelfrei;>

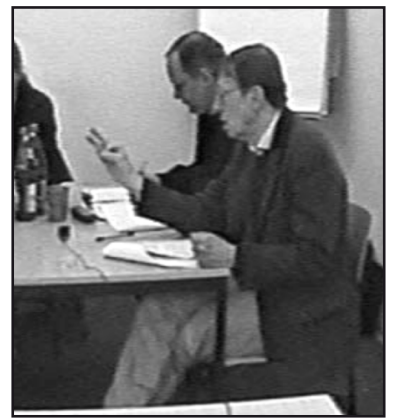

Abb. 29

$152 \mathrm{ST}:(---)$ ' $\mathrm{mhm}$;

153

(1.2)

Während die beiden Gangs sprachlich als Jugendliche enaktiert wurden, spricht der Prinz als Erwachsener und als Vertreter der Obrigkeit, die mit der Macht ausgestattet ist, den beiden Kontrahenten sehr weitreichende Konsequenzen anzudrohen. Die Stimme des Prinzen ist sehr weich und zunächst bedrohlich leise (bei $<<p>$ leute; PASST mal auf;), er hat keine Knarrstimme, sondern die Stimmbänder schwingen harmonisch.

Als letzter Schritt der Konstitution des Positionierungsraums deutet der Dozent bei der gestischen Darstellung des Rauswurfes, den der Sheriff den beiden Gangs androht, mit dem Daumen der rechten Hand nach rechts, mit dem Daumen der linken Hand nach links (Abb. 27). Der Rauswurf der beiden Gegner wird also relativ zu den etablierten Raumkoordinaten realisiert, die beide Parteien und der Prinz im imaginären Positionierungsraum einnehmen: Die Capulets fliegen nach links raus, die Dingsens (Montagues) nach rechts; beide von der Mitte aus gesehen, die der Prinz eingenommen hatte, als er dazwischen gegangen war (Abb. 30). 


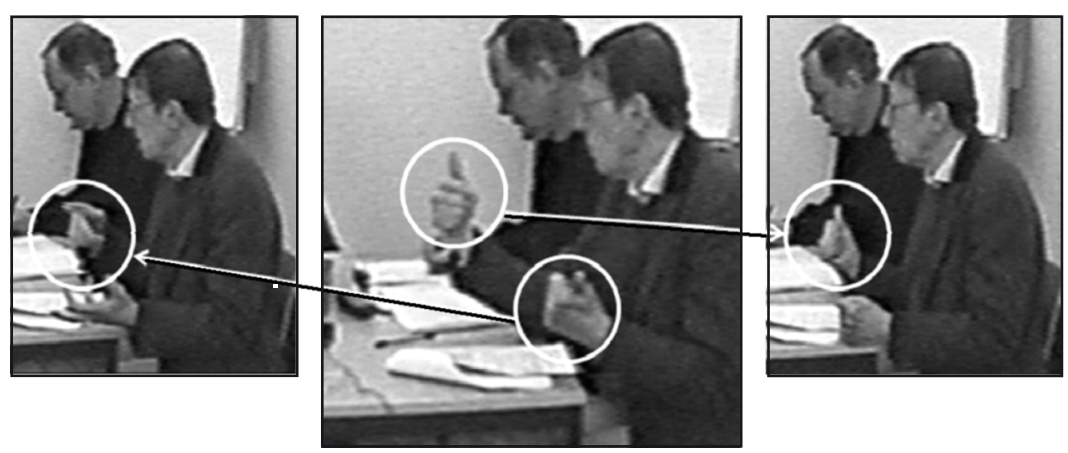

Abb. 30: Etablierung (links und rechts) und Rauswurf aus der Gemeinde (Mitte)

Die rechte und die linke Abbildung zeigen die gestikulatorische Verdeutlichung der räumlichen Positionen der beiden Gangs bei ihrer Einführung in den imaginären Raum: links die Capulets (siehe Abb. 14), rechts die Dingsens (Montagues) (Abb. 15). Die mittlere Abbildung verdeutlichte die positionale Konstanz der beiden Gangs im imaginären Raum zum Zeitpunkt des angedrohten Rauswurfs: Jede Gang fliegt auf ihrer Seite aus der Gemeinde.

\section{Rückführung zum kategorial-abstrakten Vermittlungsdiskurs}

Nachdem der Dozent die Erzählung der Ereignisse der Exposition abgeschlossen hat, verdeutlicht er zusammenfassend die dramatische Struktur der von ihm gerade erzählten und enaktierten Exposition:

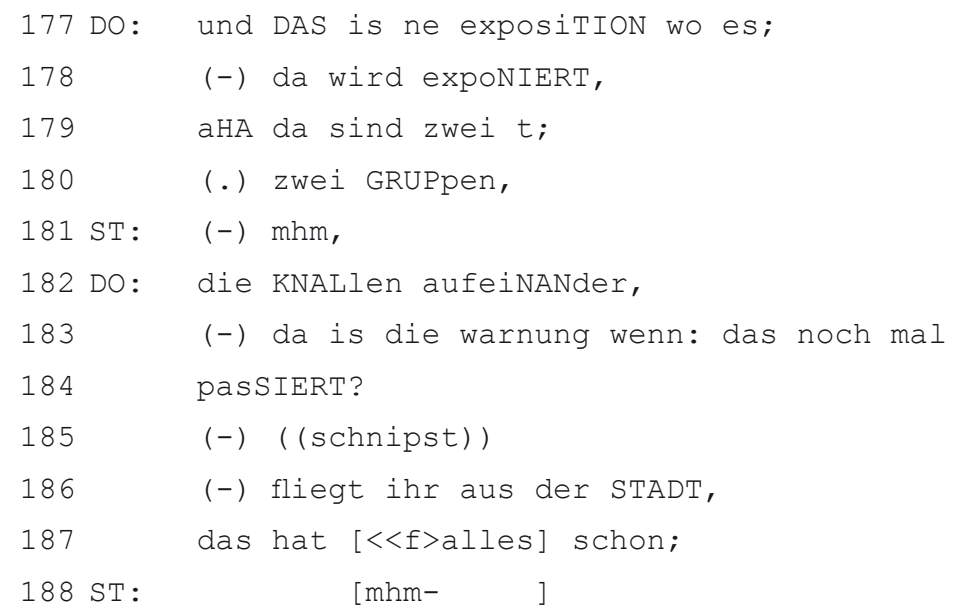


189 DO: GANZ> unmittelbar was;

$190 \quad(-) \quad<$ dim>MIT <<dim>unserer geschichte

191

zu tun; $>$

Mit dieser Strukturverdeutlichung macht der Dozent nochmals klar, worin die besondere dramaturgische Qualität seines Beispiels besteht: Jedes Element der Exposition hat eine unmittelbare Relevanz für die Handlung, die sich im Verlauf des Dramas entfalten wird. Die interaktive Funktion dieses Beispiels arbeitet er weiter heraus durch die folgende negativ evaluative Kontrastierung mit dem studentischen Drehbuch:

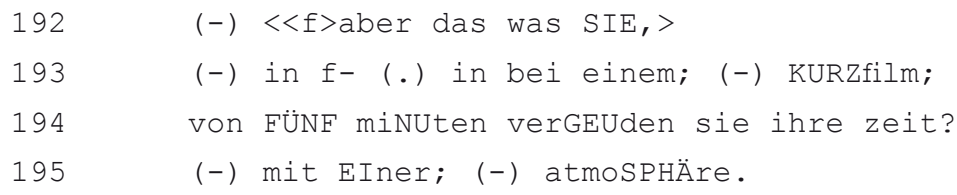

Mit der zu exposiTION (Z. 177) kontrastierenden, abgewerteten Kategorie atmoSPHÄRE rekontextualisiert er die von ihm abgelehnte Kategorie des Studenten; er bezieht seine Ausführungen somit zurück auf den Ausgangspunkt der Beispielnarration. Der Dozent verdeutlicht rückwirkend, dass seine narrative Performance einem argumentativen Zweck diente, nämlich die Unzulänglichkeit der Exposition des studentischen Drehbuchs durch den Vergleich mit einer gelungenen aufzuweisen und dadurch die Irrelevanz von atmoSPH ÄRE als dramaturgischer Kategorie zu verdeutlichen.

\section{Spezifik der Raumkonstitution als „Problemlösung“}

Betrachtet man das, was der Dozent in dem von uns analysierten Ausschnitt macht, im konversationsanalytischen Verständnis als Lösung interaktiver Probleme, so lassen sich die folgenden Problemaspekte angeben, als deren Lösung die rekonstruierte Spezifik der Raumkonstitution im interaktionsstrukturellen Kontext entwickelt wird.

Damit der Dozent im Rahmen seiner alternativen Vermittlungsbemühungen (ein raumbasiertes Beispiel mit konkret handelnden Agenten, die in ihrer spezifischen Qualität enaktierend vorgeführt werden, um damit die dramaturgische Funktionalität und Struktur einer Exposition zu verdeutlichen) Raum als Ressource überhaupt nutzen kann, muss er

a) Raum als relevante Größe etablieren,

b) die Positionierung, Relationierung und soziale Kategorisierung der Agenten, die im etablierten Raum/den etablierten Räumen handeln und aufeinander stoßen, aufzeigen,

c) verdeutlichen, in welchem Raum er sich gerade befindet, 
d) seine raumspezifische Beteiligungsrolle verdeutlichen,

e) die Beziehung, der unterschiedlichen Räume untereinander aufzeigen und

f) die Funktionalität, die die Räume für die Konstruktion des Beispiels besitzen, verdeutlichen.

Wir werden uns bei unserer weiteren Reflexion der Analyseergebnisse primär um die schrittweise Etablierung und Aufrechterhaltung des da-Raumes kümmern, den wir als Positionierungsraum bezeichnen. Wir werden dabei vor allem die Positionierung der verschiedenen Agenten des Raumes, deren Relationierung und Kategorisierung sowie die Beziehung des Positionsraumes zur „Bühne“ und zum „Interaktionsraum“ in den Fokus nehmen.

\section{Die Multidimensionalität von Raum in der Interaktion}

Nachdem in der Fallanalyse gezeigt wurde, wie verschiedene Räume durch unterschiedliche Verfahren konstituiert und markiert werden, möchten wir nun explizit die verschiedenen Dimensionen von Raum, die im Beispiel relevant werden, differenzieren und ihr Verhältnis zueinander klären. Die Literatur zur Raumkonstitution und Deixis geht in der Tradition Bühlers in Beispielen wie dem unsrigen von zwei Räumen aus: dem Wahrnehmungsraum („,demonstratio ad oculos“, Bühler 1934, S. 80 ff.) und dem Vorstellungsraum (Deixis am Phantasma; vgl. etwa Bühler 1934, S. 125 ff.; Fricke 2007; Sitta 1991). In Anknüpfung an neuere Untersuchungen zur Raumkonstitution in der multimodalen Interaktion (z.B. Goodwin 2003; Mondada 2005; 2007) müssen wir jedoch von einer komplexeren Konstellation mehrerer aufeinander bezogener Räume ausgehen, welche die dynamische Räumlichkeit der sozialen Interaktion als solcher zentral in der theoretischen Konzeption von ,Raum` mitberücksichtigt. Vier Räume lassen sich differenzieren:

1) Der Raum als sozio-physische Umgebung

2) Der Interaktionsraum

3) Der individuelle Verhaltensraum

4) Der imaginäre Raum

\subsection{Raum als Umgebung}

Hiermit meinen wir den physikalischen, territorial-architektonischen und sozial kodierten Raum. Dies ist der Raum, wie er unabhängig von einer in ihm stattfindenden Interaktion von einem Beobachter zu beschreiben wäre. Dieser Raum ist eine physikalische Größe mit Tiefen- und Breitendimensionen, physikalischen Begrenzungen und enthaltenen Körpern, die in so- 
zialer Beschreibung durch seine innenarchitektonische Ausstattung gegeben sind. Definiert wird der Raum(ausschnitt, den die Kamera zeigt,) durch die zusammengestellten Tische, die einen großen Tisch bilden und die besondere Anordnung der Stühle, die zu einer bestimmten Konstellation der Interaktionsbeteiligten führt.

Dieses physikalische Arrangement ist sozial kodiert und hat dadurch spezifische Implikationen für die Interaktionen, die in ihm stattfinden können. Zu diesen gehört, dass man in diesem Raum Aktivitäten erwarten kann, die sich relativ eng um den Tisch herum entfalten werden. Die TischStühle-Konstellation verweist auf eine dominante usuelle Funktionalität, für die der Raum ausgestattet worden ist: Es geht um die primär sprachliche Kooperation mehrerer Personen im Sitzen. Darüber hinaus vermittelt das Arrangement als weiteren erwartbaren Aspekt der Interaktion eine gewisse Statik und Konstanz nicht nur der Positionen und Präsenzformen der Interaktionsbeteiligten, sondern auch der Kooperationsform die sie gemeinsam praktizieren werden. „Raum als Umgebung“ beinhaltet also physikalische und soziale bzw. symbolische Aspekte, die jedoch allein schon deskriptiv kaum klar zu differenzieren sind. Eine theoretisch denkbare Subdifferenzierung eines physikalischen von einem sozial(symbolisch)en Raum ist daher für unsere Zwecke nicht sinnvoll. Der entscheidende Punkt für unsere Systematik ist vielmehr, dass Räume aufgrund ihrer physikalischen Bedingungen und aufgrund sozialer Codierungen Restriktionen, Möglichkeiten und Erwartungen mit sich bringen, die unabhängig von der in ihnen stattfindenden Interaktion (in einer Kultur) für die Interaktanten gelten und sich auf die in ihm stattfindenden Interaktionen auswirken (vgl. Goffman 1961).

\subsection{Raum als Interaktionsraum}

In ihrer Interaktion konstituieren die Beteiligten aus dem Umgebungsraum ein für die Zwecke des gemeinsamen Handelns konstituierten sozialen Relevanzrahmen, den wir als „Interaktionsraum“ bezeichnen (siehe Schmitt/ Deppermann 2007; Mondada 2007). Der Interaktionsraum hat eine soziophysische Dimension, die Beteiligungsstruktur (participation framework: Goffman 1981; Goodwin/Goodwin 2004), die in den proxemischen Relationen und positionalen Strukturen der Beteiligten besteht (siehe auch Kendon 1990). Der Interaktionsraum ist stets ein orientierter Raum: Die Beteiligten sind aufeinander und ggfs. auf spezifische Wahrnehmungsfoki als Teil dieses Raums bezogen. Diese Orientierung konstituiert sich durch die leibliche Ausrichtung der Interaktanten (z.B. face-to-face, side-by-side, body torque; Schegloff 1998; Proxemik, Blickkontakt) und ihren Bezug auf gemeinsame Wahrnehmungsobjekte und Demonstrata, die durch die Interaktion selbst (z.B. durch Blickrichtung, Zeigen, Deixis) relevant gemacht werden. Der Interaktionsraum ist ein prozessualer, aktivitätskonstituierter Raum, der nicht un- 
abhängig vom Handeln der Beteiligten „in ihm“ existiert (siehe Schmitt (Hg.) 2007). Die Herstellung und Veränderung des Raums ist pragmatisch durch die Kooperation in Bezug auf gemeinsame Handlungsaufgaben, die mit ihnen zusammenhängenden Beteiligungsweisen der Einzelnen und ihre in diesem Kontext relevanten räumlichen Orientierungen bestimmt.

\subsection{Raum als individueller Verhaltensraum}

Individuelle Verhaltensräume sind unter einer sozialen Perspektive personenzentrierte Teilbereiche des Interaktionsraumes. Sie können charakterisiert werden als individuelle, sozial-territoriale Umgebung von einzelnen Interaktionsbeteiligten (Goffman 1963). Obwohl personal gebunden, werden auch die individuellen Verhaltensräume letztlich durch gemeinsame - eigene und fremde - Definitionsleistungen konstituiert. Zu diesen Definitionsleistungen gehören beispielsweise proxemische Aspekte wie Positionierung zu den anderen Interaktionsteilnehmern (vgl. Hall 1966; Scollon/Wong Scollon 2003), die Körperpositur sowie die gestikulatorischen und in unserem Fall sehr prägnant auch die enaktierenden Aktivitäten des Akteurs. ${ }^{5}$ Die Begrenzung(en) individueller Verhaltensräume werden teilweise durch symbolische Grenzziehungen markiert. Hierzu zählen beispielsweise das Arrangement der Arbeitsutensilien, abgestellte Gläser und Flaschen etc. Diese individuellen Verhaltensräume werden (mit-)konstituiert durch korrespondierende oder konkurrierende Orientierung und Respektierung der anderen Beteiligten. Individuelle Verhaltensräume sind wie Interaktionsräume, da sie an die Körperlichkeit der Interaktionsteilnehmer gebunden sind, grundsätzlich dynamisch - und in unserem Fall nicht unbedingt an die Sitzposition gebunden. Durch Aufstehen und Bewegung im Raum können individuelle Verhaltensräume modifiziert und erweitert werden.

\subsection{Raum als imaginärer Raum}

Unter der für Interaktionsräume konstitutiven Bedingung von Wahrnehmungswahrnehmung (vgl. Hausendorf 2003) können Teilnehmer mit ihren multimodalen Aktivitäten imaginäre räumliche Konfiguration entwerfen und diese Räume durch ihre Aktivitäten ausgestalten und für eine gewisse Zeit aufrecht erhalten. Mit „imaginären Raum“ meinen wir hier räumliche Strukturen, die in der Interaktion symbolisch konstruiert werden und auf die referiert wird, die aber für die Interaktionsbeteiligten in der Interaktionssituation nicht visuell wahrnehmbar sind. Der imaginäre Raum kann empirisch nicht als mentaler Raum untersucht werden, sondern nur in Bezug auf seine Verfahren der kommunikativen Konstitution. Deshalb benutzen wir hier nicht den gängigen mentalistischen Begriff „Vorstellungsraum“

Vgl. auch die Konzeption des „gesture space“ bei McNeill (1992, S. 89). 
(Bühler 1934, S. 125 ff.), sondern den Begriff „imaginärer Raum“. Imaginäre Räume sind zeichenkonstituiert (vgl. Fricke 2007, S. 87, 128 ff., 249 ff.). Ihre Herstellung erfordert interaktive Arbeit, denn grundsätzlich zeichnen sich imaginäre Räume durch eingeschränkte Dauerhaftigkeit und ephemere Objekthaftigkeit aus, außer wenn sie beispielsweise qua Zeichnung objektiviert sind (vgl. die Tabelle in Fricke 2007, S. 257). Imaginäre Räume werden in Bezug auf die pragmatischen und thematischen Anforderungen der Interaktion konstituiert und stellen einen Beitrag zu deren Bearbeitung dar.

\section{Multimodale Verfahren der Konstitution von imaginären Räumen}

\subsection{Die schrittweise Konstitution des imaginären Raums}

Die Schaffung und Ausgestaltung eines imaginären Raums geschieht in drei systematischen Schritten:

a) Die Raumkonstitution nimmt ihren Ausgang im Interaktionsraum, aus dem heraus der imaginäre Raum etabliert wird.

b) Der imaginäre Raum wird narrativ durch Erzählsätze konstituiert, in unserem Fall durch den orientierenden Satz da geht ne gang die straße runter. ${ }^{6}$ Der Sprecher ist hier also Erzähler im Interaktionsraum.

c) Die Origo des Sprechers wird nun in diesen narrativ geschaffenen Raum versetzt, in unserem Beispiel in die erste Gang, die als erste in diesen Raum positioniert wurde. Der Sprecher ist nun die Figur, die im imaginären Raum enaktiert wird. Die gleiche Abfolge von erstens narrativer Einführung der Figur und ihrer räumlichen Positionierung im imaginären Raum und zweitens Versetzung der Sprecher-Origo in diese Figur durch Enaktierung wiederholt sich bei der zweiten Gang und dem Sheriff/Prinz. Wir sehen also, dass (wie dies auch Fricke 2007, S. 70 und 87 f. feststellt) die Konstitution des imaginären Raums die unabdingbare Voraussetzung für die anschließende Versetzung der Origo in diesen ist.

In der Literatur wird immer wieder hervorgehoben, dass das Vokabular der Räumlichkeit die wichtigste Quelle für das Vokabular der Zeitlichkeit sei. ${ }^{7}$

Im Sinne von Labov/Waletzky (1973) handelt es sich um einen orientierenden Satz, der das narrative Geschehen grob situiert, zugleich aber auch schon ein Kernerzählsatz ist, da er eine erste komplikationsrelevante Handlung beschreibt.

7 Diese linguistische Fundierung von Zeitlichkeit in Räumlichkeit wird sowohl in Bezug auf die Sprachgeschichte bzw. Etymologie (Hopper/Traugott 2003, S. 84-87; Haspelmath 1997), als auch in Bezug auf die individuelle Sprachentwicklung (Clark 1973) und die mentale Konzeptualisierung im Sinne von ,Raum`als root metaphor für ,Zeit' (Lakoff/Johnson 1980) postuliert. 
Bei der Raumkonstitution in der Interaktion sehen wir ein umgekehrtes Fundierungsverhältnis: Räumlichkeit kann sich nur in Zeitlichkeit entfalten. Es ist unmöglich, eine komplexe räumliche Konstellation monothetisch (wie Husserl schrieb) zu kommunizieren, man muss sie in polythetischen, d.h., einzelnen aufeinander folgenden Akten entfalten. Unser Fallbeispiel hat gezeigt, dass dafür nicht nur die strukturelle Latenz, d.h., die fortdauernde Geltung und mentale Verfügbarkeit von Äußerungen, die auf Räumliches Bezug nehmen, eine Voraussetzung ist. Das Gleiche gilt auch für Gesten und Enaktierungen: Nur auf dem Hintergrund einer vorangehenden Gestikulation und Enaktierung gewinnt eine folgende ihren relationalen Sinn als Schritt und Komponente der weiteren Ausgestaltung eines komplexen räumlichen Szenarios. Ihre räumliche Bedeutung ist sequenzabhängig. So partizipieren etwa in unserem Beispiel die Deutung der Geste und die lexikalische Referenz des „Dazwischengehens“ (des Sheriffs/Prinzen) am aufgebauten Referenzrahmen der physischen Konfrontation der Gangs, durch den sie eine literale und nicht bloß metaphorische Interpretation im Kontext des imaginären Raums gewinnen. Diesen Rahmen selbst können Geste und Raumvokabular aber nicht gleichzeitig mit ihrer Produktion konstituieren. Wie wir bei der Enaktierung der zweiten Gang und ihres Verhältnisses zur ersten sehen, funktioniert diese interpretative Anreicherung nicht nur prospektiv im Sinne einer zunehmenden Spezifikation durch neue Elemente. Sie kann genauso retrospektiv funktionieren, indem nämlich die Positionierung eines neuen Elements (hier: eines Akteurs) im Raum ein schon früher eingeführtes Element in seiner räumlichen Position und Dynamik genauer bestimmt. So wird im Beispiel die Position der ersten Gang auf der Straße erst im Nachhinein, durch die auf sie bezogene Positionierung der zweiten Gang klar. In diesen Hinsichten ist die Zeitlichkeit der Interaktion Voraussetzung für die Konstitution von Räumlichkeit.

Doch Zeitlichkeit ist wenigstens in unserem Beispiel noch in einer anderen Weise an der Konstitution von Räumlichkeit beteiligt. Der Dozent staffiert nicht nach und nach eine statische Situation aus, sondern er entwirft ein dynamisches Szenario, in dem die räumlichen Verhältnisse gerade durch ihre Veränderung Kontur gewinnen: Auch die statischen „Momentaufnahmen" der Verhältnisse im Interaktionsraum gewinnen nur durch die Darstellung von sie verändernden Handlungen Kontur, so z.B. im boff (Z. 136), das mit der Darstellung der physischen Konfrontation zugleich die räumliche Position der Gangs zueinander neu bestimmt.

\subsection{Modalitätsspezifik der Raumkonstitution}

Die Schaffung und Ausgestaltung eines imaginären Raums entsteht durch den Einsatz unterschiedlicher, systematisch miteinander verknüpfter Verfahren. Die initiale verbale Konstitution eines nicht präsenten Raums durch 
eine Beschreibung ist die Konstitutionsgrundlage für alle weiteren Schritte (siehe 6.2). Dieser Raum wird durch verbale und gestische Ressourcen schrittweise weiter ausgestaltet. Er wird dabei nicht nur narrativ konstituiert, sondern auch enaktierend zu einer Bühne verwandelt, auf der der Dozent nunmehr die Origones der Figuren in diesem Raum verkörpert. In unserem Beispiel werden für die Konstitution des imaginären Raums nicht nur räumliche Deixis und Zeigegesten benutzt, sondern weitere Verfahren, die jeweils eine ganz spezifische Funktion innerhalb des Gesamtzusammenhangs der Raumkonstitution haben:

a) Raumvokabular: da, kommt, runtergehen, dazwischengehen und rausfliegen sind Ausdrücke, die räumliche Verhältnisse relational bzw. deiktisch repräsentieren und die perspektivisch auf die Origo des Konzeptualisierers der Szene bezogen sind (vgl. Fillmore 1997). Das räumliche Vokabular im Beispiel situiert das Geschehen in der Nähe-Distanz-Dimension: Es ist so ausgewählt, dass mit ihm der Prozess der räumlichen Annäherung der Gangs und ihrer Trennung durch den Sheriff/Prinz dargestellt wird.

b) Zeigegesten im imaginären Raum sind im Beispiel die Geste des Entdeckens der ersten Gang durch die zweite, die Geste des Prinzen, der auf die Gangs ermahnend zeigt und die Zeigegesten des Rausfliegens nach rechts und links. Diese Gesten situieren die Figuren im imaginären Raum in einer Links-rechts-Dimension, die orthogonal zur sprachlich realisierten Dimension der räumlichen Annäherung und Trennung ist. Im Beispiel präzisieren Gestik und Sprache einander also nicht einfach wechselseitig, wie dies für das Verhältnis von Zeigegesten und sprachlichen Deiktika sonst üblich ist, sondern die Gestik bearbeitet eine zweite Dimension des Raums, die von der ersten unabhängig ist und einen eigenständigen Beitrag zu Ausgestaltung der Szene leistet. Dabei scheint charakteristisch, dass genau diejenigen Raumverhältnisse sprachlich codiert sind, welche für den übergeordneten Darstellungszweck, nämlich die räumliche Verdeutlichung der Konfliktdramaturgie, konstitutiv sind. Den Gesten dagegen kommt ihnen gegenüber nur eine weiter ausgestaltende Funktion zu. Diese Verteilung scheint zu reflektieren, dass (im untersuchten Beispiel) in Bezug auf den imaginären Raum die deskriptive Sprache gegenüber der Gestik die tragfähigere, die Verständigung eindeutiger sichernde Ressource der Referenzkonstitution ist, weshalb sie die Aufgabe übernimmt, die für den Darstellungszweck zentralen räumlichen Gegebenheiten darzustellen. ${ }^{8}$ Eine umgekehrte Aufgabenverteilung zwischen Sprache und Gestik scheint in Bezug auf imaginäre Räume, die nicht graphisch o.ä. repräsentiert sind, schlecht vorstellbar.

$8 \quad$ Wichtig für dieses Argument ist, dass die sprachlichen Ausdrücke nicht nur deiktisch sind, sondern hinreichend deskriptiven, symbolischen Gehalt haben, um einen in sich qualitativ ausdifferenzierten Raum zu konzeptualisieren. 
c) Leibliche Enaktierungen der Bewegung im Raum über die Gesten hinaus: Die Inszenierung des Gehens der Gang mit dem Oberkörper (raumbeanspruchendes Verhalten), der Blick der zweiten Gang zur ersten, die Boxkampfgeste, die ermahnende Zeigefingergeste des Sheriffs/Prinzen sind Enaktierungen der Figuren. Sie eröffnen zusätzlich zu Nähe-Distanz und links-rechts eine weitere Ebene räumlicher Information, nämlich die qualitative Ausdifferenzierung der konkreten leiblichen Inkarnationen sozialer und handlungsbezogener Typik.

d) Räumliche Verhältnisse werden sprachlich nicht nur durch ein auf Raumreferenz spezialisiertes Vokabular verdeutlicht. Soziale Kategorisierungen und Handlungsbeschreibungen haben ebenfalls räumliche Implikationen. Der Raum ist auch ein sozial codierter: Die Beschreibung sozialer Handlungen wie „Da geht 'ne Gang die Straße runter.“, die onomatopoetische Charakterisierung des körperlichen Konflikts boff und das Dazwischengehen des Prinzen/Sheriffs gestalten den imaginären Raum sozial und räumlich aus. Der Mitvollzug dieses sozialräumlichen Szenarios erfordert ein Wissen um sozial-räumliche Handlungsskripts (vgl. Goodwin 2003): Z.B. muss dem Zuhörer klar sein, dass das Gehen einer Gang einen Territorium beanspruchenden gesturalen Habitus impliziert (den das Gehen einer Krankenschwester bspw. nicht implizieren würde), und dass boff einen weiteren Eskalationsschritt zum physischen Konflikt bedeutet, welcher die räumliche Konstellation dahingehend vorantreibt, dass die Gangs nunmehr in unmittelbarem Körperkontakt geraten sind.

Damit die unterschiedlichen multimodalen Verfahren der Raumkonstitution allerdings so zusammenwirken können, dass sich für den Rezipienten ein zunehmend ausgestalteter imaginärer Raum entwickelt, ist zusätzlich erforderlich, dass der Rezipient sie als kohärente Ereignisfolge interpretiert. Diese temporalen Kohärenzverhältnisse werden nämlich nicht explizit, etwa durch Konnektoren und temporale Adverbiale wie und dann, nachdem, als nächstes etc., codiert. Nur unter einer temporalen Kohärenzpräsumption erscheinen die einzelnen Äußerungen, Gestikulationen und Enaktierungen des Dozenten nicht als isolierte Setz-Akte in einem amorphen Raum, sondern als konsistent aufeinander bezogene Ausgestaltungen einer konfrontativen sozialräumlichen Konstellation.

\subsection{Konstitutionsverhältnisse und Überblendungen der Räume}

Mit seinen verschiedenen Beteiligungsrollen, die er durch unterschiedliche sprachliche, stimmliche, gestische und enaktierende Verfahren verdeutlicht, macht der Dozent die unterschiedlichen Räume und die in ihnen geltenden Strukturen klar unterscheidbar (vgl. a. Schmitt/Deppermann 2009). Er ist 
1) als Körper im physikalischen Raum mit den andern Körpern kopräsent und

2) sitzt als Dozent mit den Studierenden im gemeinsamen Interaktionsraum.

3) Durch seine kinesische Aktivität in seinem individuellen Verhaltensraum

4) enaktiert er die Figuren auf der Bühne des imaginären Raums,

5) den er als Erzähler innerhalb des Interaktionsraums konstituiert hat.

Der imaginäre Raum wird also durch zwei gänzlich verschiedene Praktiken, nämlich diegetisches Erzählen und leibliches Enaktieren innerhalb des imaginären Raums als Bühne realisiert. Diese beiden Praktiken erzeugen zwei Sprecherrollen (Erzähler vs. enaktierte Figur), die durch jeweilige Gestik, körperliche Beteiligungsweisen, Stimmprofile und räumliche Origones mit entsprechend unterschiedlichen räumlichen Positionen gekennzeichnet sind.

Obwohl hinsichtlich Beteiligungsstatus des Sprechers und repräsentationalem Bezug der Darstellung die Räume klar zu unterscheiden sind, gibt es im untersuchten Interaktionsausschnitt Momente, in denen sie einander überblenden. Eine solche Überblendung im Sinne eines conceptual blends findet zum einen zwischen Erzählen und Enaktieren statt. ${ }^{9}$ Im boff des Dozenten und in der dazu von ihm eingenommene Boxergeste überblenden sich Erzähler und Figur: Mit der Geste enaktiert er die Kampfgeste der Konfliktparteien, der Ausdruck boff ikonisiert den Lärm des Zusammenpralls - soweit agiert der Dozent auf der Bühne; doch andererseits sagt natürlich keiner der Kämpfer boff, sondern boff fungiert als Beschreibung und ist damit Teil der Narration. Und der Dozent stellt hier kein identifizierbares Individuum, sondern einen generalisierten Kämpfer dar. Eine zweite Überblendung, diesmal zwischen Interaktionsraum und Bühne, entsteht in der Ermahnung des Prinzen. Die heranholende Geste mit dem gekrümmten Zeigefinger und die anschließende mahnende Zeigefingergeste, die der verbalen Ermahnung des Sheriffs/Prinzen vorausgehen, sind zunächst einmal nicht bzw. nicht nur im imaginären Raum vom enaktierten Sheriff/Prinz auf die Streitparteien als intendiertem Referenten gerichtet. Sie werden im Interaktionsraum vom Lehrer genau auf den Drehbuchautor, dem die Belehrung gilt, als Demonstratum gerichtet, der damit im Interaktionsraum als primärer Adressat der Belehrung definiert wird. Solche Überblendungen von Räumen sind lokal scharf begrenzte Phänomene, die eine stabile Struktur von Räumlichkeit voraussetzen, bezogen auf die sie kontrastiv zur Gel-

$9 \quad$ Es handelt sich um conceptual blending im Sinne von Fauconnier/Turner (2002) und Turner (2007). Beim conceptual blending werden Komponenten zweier konzeptueller Domänen miteinander zu einem neuen Konzept verschmolzen. Im Gegensatz zur Metapher handelt es sich nicht um eine Übertragung der Verhältnisse von einer Quelldomäne in eine Zieldomäne, sondern um die Amalgamierung von ausgewählten Aspekten aus zwei verschiedenen Domänen, während andere Aspekte aus den Ursprungsdomänen nicht in den blend eingehen. 
tung kommen können. Im Fall der Ermahnung zeigt sich dabei, dass das semiotische Verhältnis unterschiedlicher Ausdrucksressourcen (hier: Sprechen und Gestik) nicht statisch gesehen werden darf, sondern in Abhängigkeit von den pragmatischen Strukturen der Interaktion (hier: der übergeordneten Funktion der Beispielkonstruktion als Vermittlungsverfahren für einen spezifischen Adressaten) rekonstruiert werden muss.

\section{Raum als Ressource des recipient design}

Dass der Dozent zur Vermittlung des Konzepts dramatischer „Struktur“ ein räumlich strukturiertes, narrativ inszeniertes Beispiel realisiert, ist keineswegs zwangsläufig. Er hätte auch die Möglichkeit gehabt, eine abstrakte Beschreibung zu liefern. Die Wahl einer narrativ-enaktierenden Beispielrealisierung reagiert auf die eingangs rekapitulierte Interaktionsgeschichte der gescheiterten Vermittlungsbemühungen. Sie ist damit recipient designed, d.h., an den spezifischen Rezipienten (den Drehbuchautor) und dessen Reaktionen und sein aus ihnen zu erschließendes Wissen angepasst, während sie zugleich diesen als einen bestimmten Rezipienten mit bestimmten Eigenschaften positioniert. ${ }^{10}$ Recipient design ist ein konversationsanalytisches Konzept, das von Sacks (1992) in den frühen 1970er Jahren entwickelt wurde (vgl. Malone 1997, S. 100-119). Sacks/Schegloff/Jefferson (1974, S. 727) definieren es wie folgt:

By ,recipient design' we refer to a multitude of respects in which the talk by a party in a conversation is constructed or designed in ways which display an orientation and sensitivity to the particular other(s) who are co-participants. In our work, we have found recipient design to operate with regard to word selection, topic selection, admissibility and ordering of sequences, options and obligations for starting and terminating conversations etc., as will be reported in future publications.

Die Beispielkonstitution ist ein auf den Studenten bezogenes, „spätes“ Vermittlungsverfahren, das dem Scheitern der vorangegangenen Versuche, ihn zur Einsicht in die Unzulänglichkeit seines dramaturgischen Strukturbegriffs zu bringen, und seiner uneinsichtigen Reaktion auf diese Versuche Rechnung trägt. Die Raumkonstitution gewinnt in unseren Daten ihre spezifische Funktionalität also als Verfahren des recipient design durch ihren spezifischen Kontrast zu den vorangegangenen, begrifflich und argumentativ-maieutisch ausgerichteten Vermittlungsbemühungen. Raumreferenz wird hier als eine Ressource für andere, nicht der räumlichen Orientierung und Lokalisierung dienende Interaktionszwecke eingesetzt. Die Raumkonstitution ist funktional auf den Interaktionsverlauf der gescheiterten Vermitt-

10 Die narrative Performance wird in Schmitt/Deppermann (2009) ausführlicher in Bezug auf ihr recipient design analysiert. Zum Konzept der (Fremd-)Positionierung siehe Lucius-Hoene/ Deppermann (2002, Kap. 8.2; 2004). 
lung, die vorangehenden Reaktionen des Drehbuchautors und die Interaktionsaufgaben des Pitchings im didaktischen Kontext der Filmhochschule bezogen.

Diese funktionelle Motivation der Raumkonstitution bestimmt jedoch nicht nur ihren interaktiven Zweck. Vielmehr können wir sehen, wie die einzelnen Details der Raumkonstitution genau dieser übergeordneten pragmatischen Zwecksetzung, der sie sich verdankt, angepasst sind. Der Dozent macht nicht einfach ein Beispiel, sondern er führt konkret vor, wie eine Exposition filmisch ausgestaltet wird. Das verlangt eine räumlich-sozial gestaltete Szene mit Akteuren, die durch ihr Handeln gleich zu Beginn die Konfliktstruktur des gesamten Filmes verdeutlichen. Dabei transformiert er die unübersichtliche Situation der Exposition der filmischen Version von „Romeo und Julia“" auf ihre sozial-räumliche Grundstruktur. So erleichtert er die Erkenntnis der dramaturgischen Grundstruktur eines in der Exposition angelegten, das Drama vorantreibenden Konflikts. Ganz im Sinne der leichten Erkenntnis strukturiert der Dozent den imaginären Raum Schritt für Schritt und in klar oppositiver Anlage der Figuren und ihrer Handlungen. Die Art und Weise der sprachlichen Raumkonstitution reflektiert genau, wozu sie produziert wird: Es wird nur genau so viel an sprachlicher Raumreferenz vorgenommen wie zur Darlegung der Konfliktdramaturgie notwendig ist. Alle zusätzlichen Informationen, die z.B. notwendig wären, wenn man eine genaue Skizze zeichnen, die Kontrahenten in geographisch bestimmbaren Bereichen lokalisieren oder ihre Herkunft und ihre räumliche Position nach der Konfliktschlichtung erfahren wollte, unterbleiben. Wir rechnen damit, dass diese Anpassung des Umfangs und der Präzision der Raumkonstitution an den übergeordneten pragmatischen Darstellungszweck nicht nur in unseren Daten zu finden ist, sondern ein generelles Merkmal von Raumreferenz und Raumbeschreibungen ist, das bisher nur weitgehend unbemerkt blieb, da diese Aufgaben stets als informationeller Selbstzweck gegeben waren, nicht aber - wie hier - im Dienste anderer Interaktionsaufgaben standen. Dies ist eine Hypothese, die in weiteren Forschungen zu testen wäre. ${ }^{11}$

Die besondere Eignung von Raumkonstitution als Ressource des recipient design in unserem Falle sind also

- die Möglichkeit, ein Problem erfahrungsnah und kognitiv relativ voraussetzungslos zu veranschaulichen;

- das Potenzial, die dramatische Grundstruktur von Opposition und Konflikt metonymisch zu verdeutlichen;

11 Schon lange bekannt ist allerdings eine verwandte Form des recipient design von Raumbeschreibungen an pragmatische Relevanzen, nämlich die Adaptation der Termini der Raumbeschreibung an das Vorwissen des Kommunikationspartners (vgl. Schegloff 1972; Clark/ Wilkes-Gibbs 1986; Isaacs/Clark 1987). 
- die räumliche Inkarnation sozialer Kodierungen, die nicht ausführlich beschrieben wird, sondern durch die Darstellung der kategoriengebundenen Handlungen der Figuren assoziationsreich (,inference-rich“, Sacks 1992, S. 40) evoziert werden kann.

Der Dozent nutzt also die besonderen performativen, kognitiven und experientiellen Potenziale der Raumkonstitution konsequent für die Verfolgung eines didaktischen Zwecks in der Interaktion mit einem spezifischen Rezipienten in Anpassung an das ihm zugeschriebene Verstehensproblem und die ihm zugeschriebenen Verstehenskapazitäten. Er reagiert damit also genau auf den Rezipienten, als der sich der Drehbuchautor in der zurückliegenden Interaktion selbst positioniert und angeboten hat.

\section{Anhang (analysierter Transkriptausschnitt)}

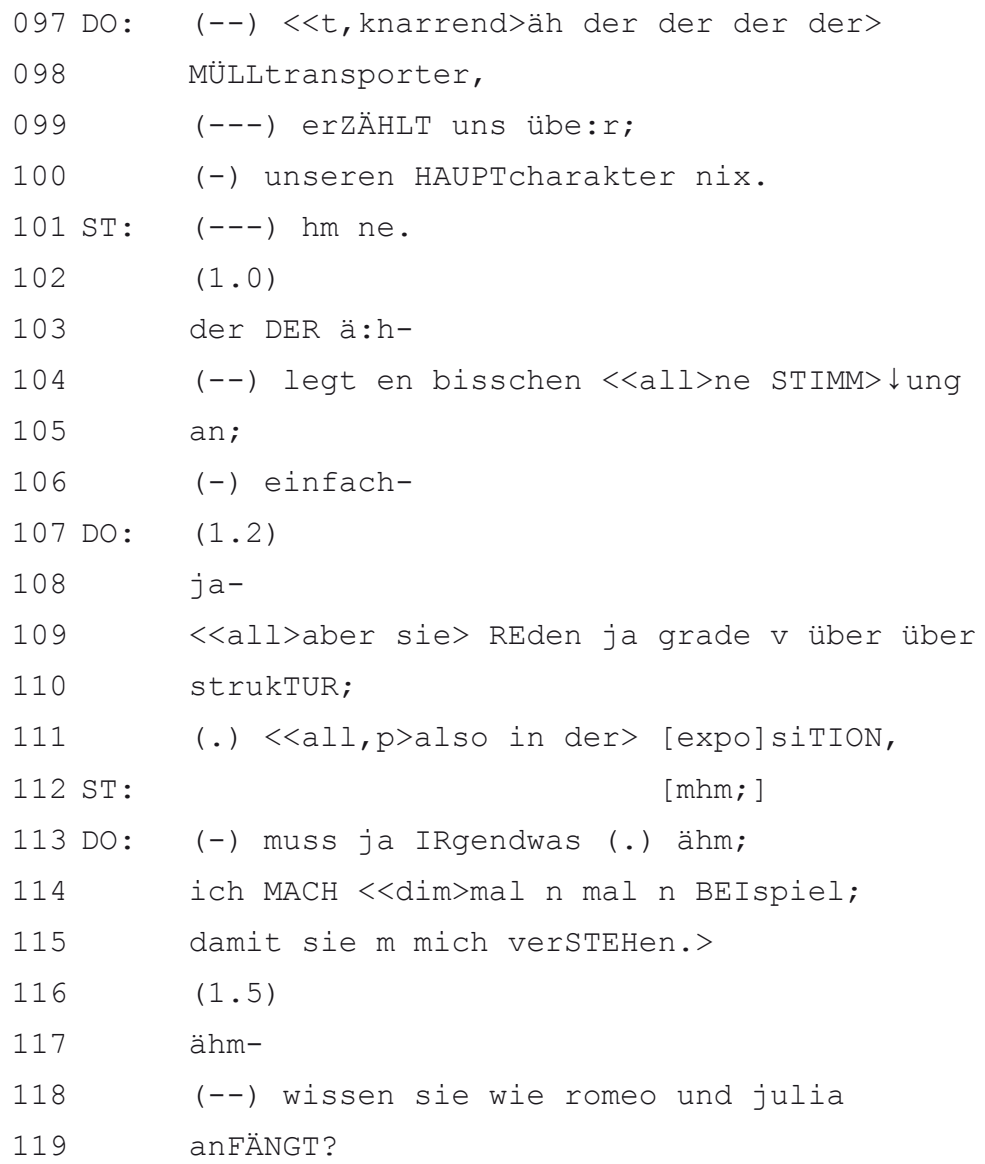


$120 \mathrm{ST}$

$(1.0)$

121

$h m::[: \quad]$

$122 \mathrm{DO}:$

[okay; ]

123

da $<<$ dim $>$ GEHT ne GANG die STRAße runter; $>$

124

(-) $[j a ?]$

$125 \mathrm{ST}:$

['mhm?]

126 DO: $\quad(--)<<t>$ ey-

$127(--)$ was 5 LOS alder;

128 WO is randale; $>$

$129 \quad(-)$ nich?

$130 \mathrm{ST}: \quad(-) \mathrm{mhm}$ ?

131 DO: (--) da kommt ne ANdere gang und sagt $<<$ h $>$ EY MANN DA geNAU (.)

133 auf EUCH ham wir geWARtet; $>$

134

(-) ja?

135

(1.2)

136

boff;

137

(--) die einen sind die CApulets,

138

$(-) \quad<$ dim>und die anderen sind die

139

DINGsens da;>

140

$(--)$ und?

141

$(--)$ wer geht dazWISCHen?

$142 \mathrm{ST}:(--) \mathrm{mh}$;

143 DO: (-) der SHEriff geht dazwischen;

144

der PRINZ geht <<all>dazwischen und sagt; >

145

$<<$ p leute;

146

PASST mal auf;

147

(--) wenn das noch EI:Nmal passiert hier;

148

(-) dann-

149

(1.7)

150

fliecht ihr hier aus der geMEINde;

151

(-) dann werdet ihr Vogelfrei; $>$

$152 \mathrm{ST}:(---)$ ' mhm;

153

(1.2)

$((\ldots))$ 


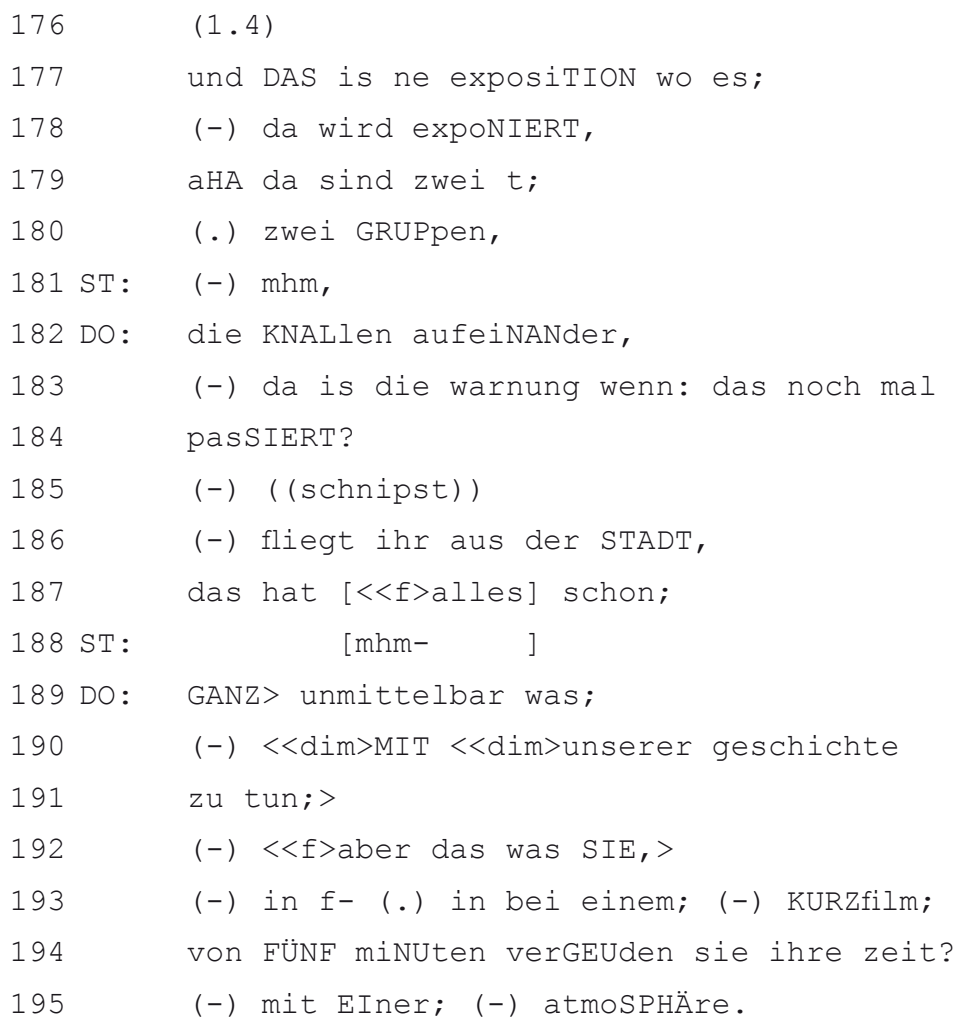

\section{Literatur}

Berthele, Raphael (2007): Ort und Weg. Die sprachliche Raumreferenz in Varietäten des Deutschen. Rätoromanischen und Französischen. Berlin.

Blühdorn, Hardarik (2003): Rauminformation und Demonstrativität. In: Deutsche Sprache 30, S. 252-275.

Bühler, Karl (1934): Sprachtheorie. Jena.

Clark, Herbert H. (1973): Space, time, semantics, and the child. In: Moore, Timothy E. (Hg.): Cognitive development and the acquisition of language. New York, S. 28-64.

Clark, Herbert H./Wilkes-Gibbs, Deanna (1986): Referring as a collaborative process. In: Cognition 22, S. 1-39.

Fauconnier, Gilles/Turner, Mark (2002): The way we think. Conceptual blending and the mind's hidden complexities. New York.

Fillmore, Charles (1997): Lectures on deixis. Stanford, CA.

Fricke, Ellen (2007): Geste, Origo, Raum. Berlin. 
Goodwin, Charles (2003): Pointing as situated practice. In Kita, Sotaro (Hg.): Pointing: Where language, culture and cognition meet. Mahwah, NJ, S. 217-41.

Goffman, Erving (1961): Encounters: Two studies in the sociology of interaction. Indianapolis.

Goffman, Erving (1963): Behaviour in public places. New York.

Goffman, Erving (1981): Footing. In: Goffman, Erving: Forms of talk. Philadelphia, S. 124-159.

Goodwin, Charles/Goodwin, Marjorie Harness (2004): Participation. In: Duranti, Alessandro (Hg.): A compagnion to linguistic anthropology. Oxford, S. 222-244.

Hall, Edward T. (1966): The hidden dimension. Garden City, NY.

Hanke, Mike (1991): maieutike techne. Zum Modell der sokratischen Gesprächstechnik. In: Flader, Dieter (Hg.): Verbale Interaktion. Stuttgart, S. 50-91.

Haspelmath, Martin (1997): From space to time. Temporal adverbials in the world's languages. München.

Hausendorf, Heiko (2003): Deixis and speech situation revisited. The mechanism of perceived perception. In: Lenz, Friedrich (Hg.): Deictic conceptualization of space, time, and person. Amsterdam, S. 249-269.

Hausendorf, Heiko (i.d.Bd.): Interaktion im Raum - Interaktionstheoretische Bemerkungen zu einem vernachlässigten Aspekt von Anwesenheit.

Heidtmann, Daniela (2009): Multimodalität der Kooperation im Lehr-Lern-Diskurs. Wie Ideen für Filme entstehen. (= Studien zur Deutschen Sprache 50). Tübingen.

Herrmann, Theo/Schweizer, Karin (1998): Sprechen über Raum. Bern.

Hopper, Paul J./Traugott, Elizabeth Closs (2003): Grammaticalization. 2. Aufl. Cambridge, UK.

Isaacs, Ellen A./Clark, Herbert H. (1987): References in conversations between experts and novices. In: Journal of Experimental Psychology: General 116, S. 26-37.

Kendon, Adam (1990): Conducting interaction. Cambridge, UK.

Labov, William/Waletzky, Joshua (1973): Erzählanalyse: Mündliche Versionen persönlicher Erfahrung. In: Ihwe, Jens (Hg.): Literaturwissenschaft und Linguistik. Bd. 2. Frankfurt a.M., S. 78-126.

Lakoff, Gordon/Johnson, Mark (1980): Metaphors we live by. Chicago.

Linde, Charlotte/Labov, William (1975): Spatial networks as a site for the study of language and thought. In: Language 51, S. 924-939.

Levinson, Stephen C. (2003): Space in language and cognition. Cambridge, UK.

Lucius-Hoene, Gabriele/Deppermann, Arnulf (2002): Rekonstruktion narrativer Identität. Opladen.

Lucius-Hoene, Gabriele/Deppermann, Arnulf (2004): Narrative Identität und Positionierung. In: Gesprächsforschung 5, S. 166-183. Internet: www.gespraechsforschung -ozs.de/heft2004/ga-lucius.pdf (Stand: 2009). 
Malone, Martin J. (1997): Worlds of talk. The presentation of self in everyday conversation, Cambridge.

McNeill, David (1992): Hand and mind. Chicago.

Mondada, Lorenza (2005): Espace, langage, interaction et cognition: une introduction. In: Intellectica 41-42, S. 7-23.

Mondada, Lorenza (2007): Interaktionsraum und Koordinierung. In: Schmitt (Hg.), S. 55-94.

Sacks, Harvey (1992): Lectures on conversation. Bd. 1. Oxford.

Sacks, Harvey/Schegloff, Emanuel A./Jefferson, Gail (1974): A simplest systematics for the organisation of turn-taking in conversation. In: Language 50, 4, S. 696-735.

Sacks, Harvey/Schegloff, Emanuel A. (2002): Home position. In: Gesture 2, 2, S. 133 146.

Schegloff, Emmanuel A. (1972): Notes on a conversational practice: Formulating place. In: Sudnow, David (Hg.): Studies in social interaction. New York, S. 75-119.

Schegloff, Emmanuel A. (1998): Body torque. In: Social Research 65, 3, S. 535-596.

Schmitt, Reinhold (2003): Inszenieren. Struktur und Funktion eines gesprächsrhetorischen Verfahrens. In: Gesprächsforschung - Onlinezeitschrift zur verbalen Interaktion 4, S. 186-250. Internet: www.gespraechsforschung-ozs.de/heft2003/ga-schmitt. pdf (Stand: Oktober 2009).

Schmitt, Reinhold (Hg.) (2007): Koordination. Analysen zur multimodalen Interaktion. (= Studien zur Deutschen Sprache 38). Tübingen.

Schmitt, Reinhold/Deppermann, Arnulf (2007): Monitoring und Koordination als Voraussetzung der multimodalen Konstitution von Interaktionsräumen. In: Schmitt (Hg.), S. 95-128.

Schmitt, Reinhold/Deppermann, Arnulf (2009): „damit sie mich verstehen“: Genese, Verfahren und recipient design einer narrativen Performance. In: Buss, Mareike/ Habscheid, Stephan/Jautz, Sabine/Liedtke, Frank/Schneider, Jan-Georg (Hg.): Theatralität des sprachlichen Handelns. München, S. 83-112.

Schütz, Alfred (1981): Der sinnhafte Aufbau der sozialen Welt. Eine Einleitung in die verstehende Soziologie. 2. Aufl. Frankfurt a.M.

Scollon, Ron/Wong Scollon, Suzanne (2003): Discourses in place: Language in the material world. London.

Selting, Margret/Auer, Peter/Barden, Birgit/Bergmann, Jörg/Couper-Kuhlen, Elizabeth et al. (1998): Gesprächsanalytisches Transkriptionssystem (GAT). In: Linguistische Berichte 173, S. 91-122.

Sitta, Georg (1991): Deixis am Phantasma. (= Bochumer Beiträge zur Semiotik 31). Bochum.

Tenbrink, Thora (2007): Space, time, and the use of language. (= Cognitive Linguistics Research 36). Berlin.

Turner, Mark (2007): Conceptual integration. In: Geeraerts, Dirk/Cuyckens, Hubert (Hg.): The Oxford handbook of cognitive linguistics. Oxford, S. 377-393. 

Stephan Habscheid / Jan Gerwinski / Tobias Dyrks /

Sebastian Denef / Leonardo Ramirez

\title{
Artikulationsarbeit und mediengestützte Ortserkundung
} Multimodale und multilokale Kommunikation in Notfalleinsätzen

\begin{abstract}
Im Kontext von Notfalleinsätzen (z.B. der Feuerwehr) müssen vielfältige raumbezogene Kommunikationsaufgaben bearbeitet werden. Bei der Verständigung zum Zweck kollektiver Orientierung und Navigation greifen die Beteiligten auf ein Ensemble technischer Medien zurück: Über etablierte Ressourcen - wie Funkgeräte und Mobiltelefone, Karten und Lagepläne, Kreide und Tafeln - hinaus werden heute in Übungs- und Schulungskontexten neuartige Steuerungs-, Lokalisierungsund Referenzierungshilfen auf der Basis elektronischer Geräte und Computernetze erprobt. Derartige Medien können hilfreich sein, wenn es um die sprachliche Artikulierbarkeit und die technische Visualisierung, Speicherung und Übermittlung von raumbezogener Bedeutung über raumzeitliche Distanzen hinweg geht. Gleichwohl treten in derart komplexen medialen Konstellationen unvermeidlich technisch-kommunikative Störungen auf, die ihrerseits durch die Beteiligten ,in situ“ sprachlich artikuliert und bearbeitet werden müssen. In solchen Störungsfällen werden Medialität und Intermedialität - als im Regelfall transparente Kommunikationsgrundlagen - interaktiv relevant und zum Thema der Kommunikation: Aus einem „Looking through“ wird ein semantisiertes „Looking at“ (Ludwig Jäger). Anhand audiovisueller Daten, die im Kontext von Notfallübungen erhoben wurden, wird ein Forschungsansatz vorgestellt, der darauf zielt, den Status sprachlicher Artikulationsarbeit für eine technisierte Interaktion im Rahmen kollektiver Ortserkundung und Navigation zu spezifizieren. Unter dem Aspekt der Anwendung wird auch die Frage erörtert, welche Relevanz derartigen Erkenntnissen für die Gestaltung medientechnischer Ressourcen für kritische Situationen zukommt.
\end{abstract}

\section{Problemhintergrund und Fragestellungen}

„Retten, Löschen, Bergen, Schützen“: Mit solchen Begriffen charakterisieren Einsatzkräfte zur Bewältigung von Notfallsituationen ihr Aufgabenfeld. Bei näherem Hinsehen geht es freilich bei dieser kollaborativen Praxis im Raum $^{1}$ immer auch wesentlich um Sprechen und Zeigen, Hören und Sehen, Mitteilen und Verstehen. Zugespitzt formuliert: Wie sich eine Notfallsituation entwickelt, ob sie erfolgreich bewältigt wird oder zur Krise eskaliert, vielleicht sogar zur Katastrophe, hängt wesentlich von symbolischer Interaktion ab, von situierten Prozessen der Zeichenwahrnehmung und Bedeutungskonstitution. - Eine alltägliche Szene: Im Rahmen einer Brandübung der Feuerwehr erteilt der Einsatzleiter (EL) zwei Feuerwehrleuten (FW1,

\footnotetext{
Vgl. dazu auch den Beitrag von Hausendorf (in diesem Band).
} 
FW2), die den ersten „Angriffstrupp“ bilden, den Befehl, zum Zweck der Menschenrettung unter Atemschutz (,PA“) mit einem bestimmten Wasserschlauch („C-Rohr") in das Gebäude vorzudringen:

Datum 1a: landmarke / Über den Treppenraum vor

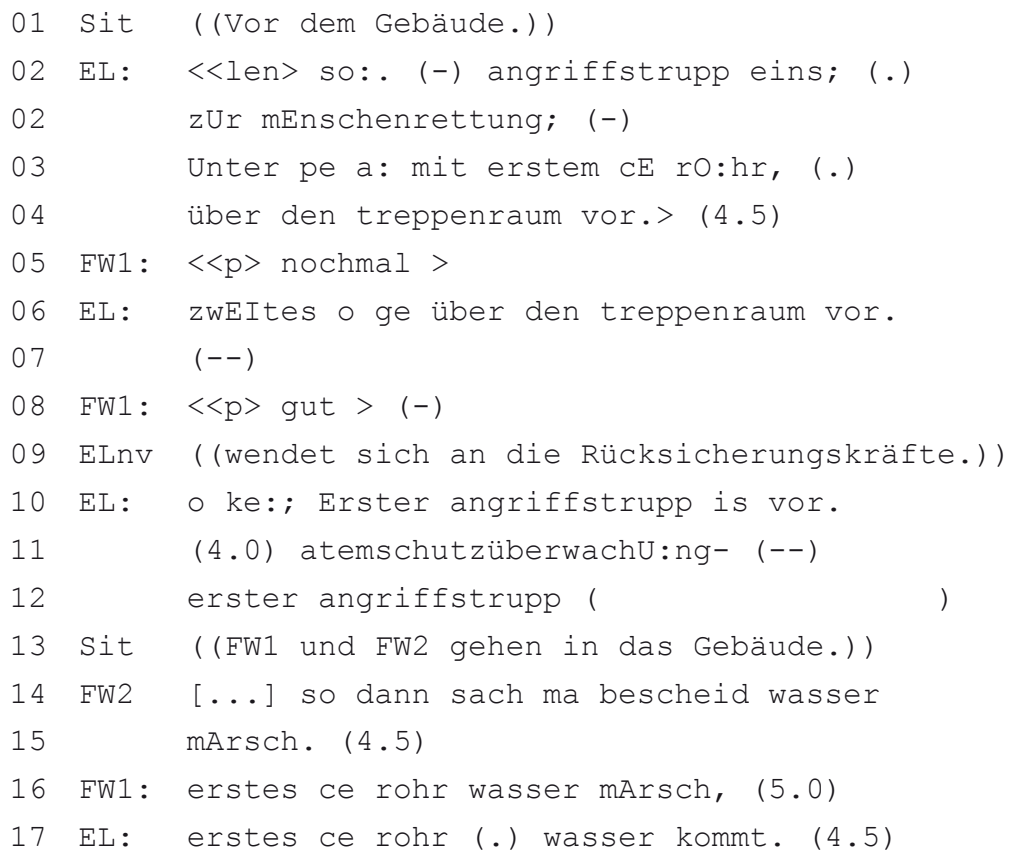

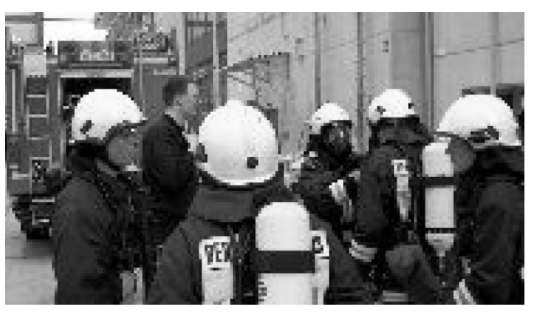

Abb. 1 (zu Datum 1, Z. 02)

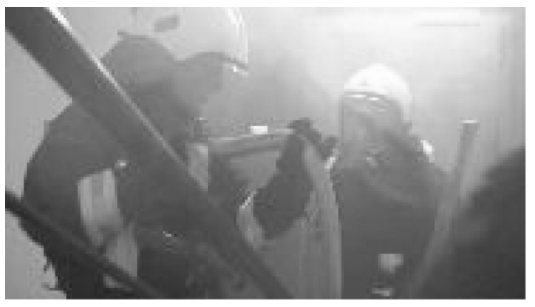

Abb. 3 (zu Datum 1, Z. 13/14)

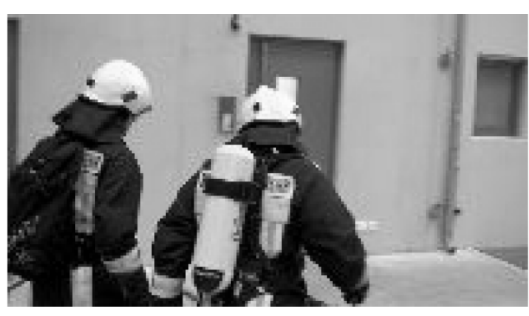

Abb. 2 (zu Datum 1, Z. 13)

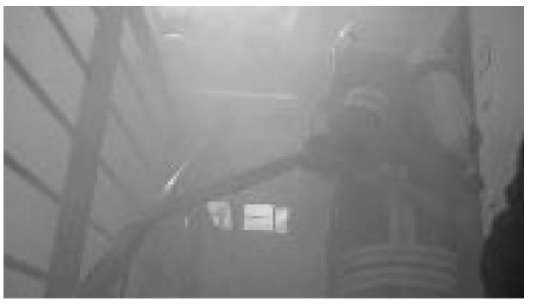

Abb. 4 (zu Datum 1, Z. 14) 
In derartigen Situationen weist sprachliche Kommunikation einige charakteristische Stilmerkmale auf: Knappheit (im Umfeld der Praxis), ${ }^{2}$ maximale Verständlichkeit, terminologische Präzision, hohe Adressivität. ${ }^{3}$ In diesem Sinne lässt sich bereits die Gestaltung der ersten Äußerungen des Einsatzleiters (Z. 02 ff.) in Datum 1 charakterisieren: Zunächst teilt er, durch sprachliche und parasprachliche Gliederungssignale (so, Pausen, Akzente) verständnisfördernd strukturiert, knapp die situationsspezifischen Spezifikationen des Einsatzbefehls mit und liefert so zugleich Kontextualisierungshinweise auf das selbstverständlich vorauszusetzende Handlungs- und Kontextwissen: Als die beiden adressierten Feuerwehrleute, der „erste Angriffstrupp“, explizit genannt wird, wenden sie sich in Erwartung der näheren Instruktionen für ihren Einsatz durch Körperdrehungen zum Einsatzleiter hin (Abb. 1). Die Mitteilung selbst wird laut gesprochen und deutlich artikuliert, sie ist fachsprachlich präzise formuliert: „,so: . (-) angriffstrupp eins; (.) zUr mEnschenrettung; (-) Unter pe a: mit erstem cE rO:hr, (.) über den treppenraum vor" (Z. 02 ff.). Nach einer fremdinitiierten, präzisierenden Selbstkorrektur (,zwEItes o ge“, Z. 06) und dem Aufbruch der beiden Feuerwehrleute (Abb. 2) äußert der Einsatzleiter die offizielle Feststellung zum Status der Mission („o ke:; Erster angriffstrupp is vor“, Z. 10), nun durch leichte Drehung des Oberkörpers an die Rücksicherungskräfte gewandt, ${ }^{4}$ denen im Anschluss der terminologisch präzise Befehl zur „Atemschutzüberwachung“ (Z. 11) erteilt wird.

Der stilistische Sinn einer Kommunikation diesen Typs verweist zum einen auf ihren wesentlichen Zweck: die effiziente und effektive organisatorische Steuerung eines arbeitsteiligen Einsatzes (im Raum)..$^{5}$ Über organisationale Hierarchieebenen hinweg, in denen Inititativ- und Kontrollkompetenzen für die Interaktion klar verteilt sind, verständigen sich die Beteiligten durch Befehls- und Bestätigungsketten miteinander darüber, was getan werden soll und getan wurde,

$2 \quad$ Vgl. zur Charakterisierung empraktischen Sprechens Bühler ([1934] 1999), der als Beispiele aufführt, dass ,ein wortkarger Gast im Kaffeehaus zum Kellner ,einen schwarzen` oder der Passagier im Straßenbahnwagen zum Schaffner, gerade aus' oder ,umsteigen' sagt, womit beide eine praktisch ausreichende Rede aus dem Gehege der Zähne entlassen haben“" (ebd., S. 155).

3 Vgl. Ayass (2001, S. 160), unter Bezug auf Fernsehwerbespots: „Mit diesem Begriff sollen alle Präsentationselemente bezeichnet werden, die den Adressaten explizit in die eigene Rede aufnehmen," wobei - im Blick auf die audiovisuelle Kommunikation - gleichermaßen sprachliche Anredeformen wie visuelle Adressierungsformen, z.B. Blickkontakt, in die Kategorie einbezogen werden.

$4 \quad$ Zur Etablierung von Interaktionsräumen durch körperliche Koordination vgl. Müller/Bohle (2007) und Mondada (2007).

5 Im Fall einer auch anwendungsorientierten Zielsetzung erscheint für ein konzeptuelles Mapping des Untersuchungsfeldes (hier: Notfalleinsätze) ein handlungstheoretischer Ansatz besonders geeignet, der Komponenten der Kommunikation auf der Basis der funktionalen Grundstruktur eines holistischen Aufgabenschemas systematisiert. Vgl. dazu Nowak (2007a, b) unter Bezug auf Spranz-Fogasy (2005). 


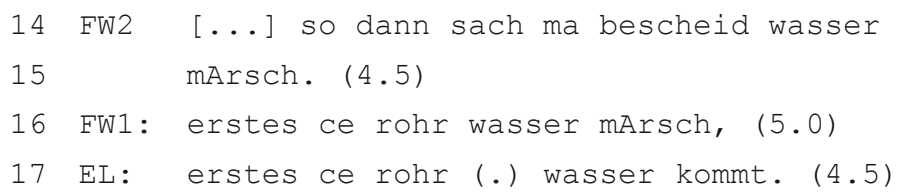

wer wohin gehen, und was er dort tun soll, wer wo war, und was hat er dort erledigt hat:

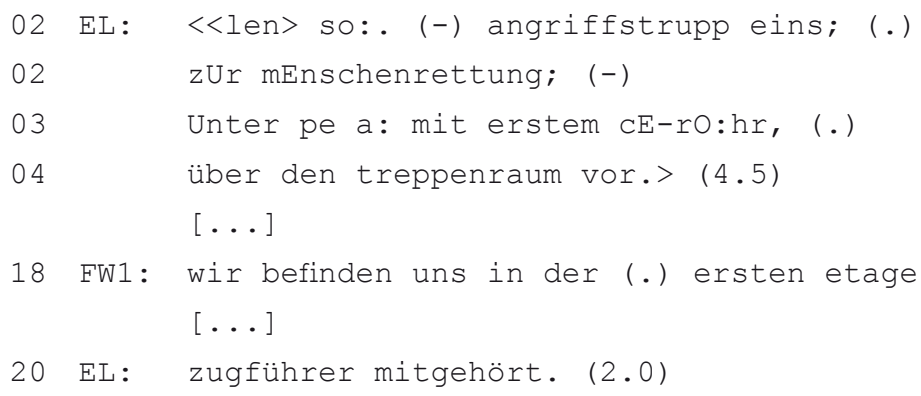

Dabei gilt es sich im Rahmen einer arbeitsteiligen Erkundung des Einsatzortes unter schlechten Sichtbedingungen zu verständigen über die Lokalisierung navigationsrelevanter Objekte und Mitspieler am Einsatzort: Wo sind Treppen, Türen, Eingänge, Ausgänge, wo sind Verletzte, wo die anderen Kollegen, wo sind Gefahrenstellen, wo ist das Feuer (vgl. unten, Datum 2)?

Bei der Bewältigung dieser Aufgaben greifen die Beteiligten auf ein Ensemble technischer Medien zurück. Dazu gehören traditionelle, etablierte Ressourcen wie Funkgeräte oder Lagepläne; darüber hinaus werden heute in Übungssituationen auch neuartige Medien auf der Basis digitaler Medien und Computernetze erprobt. Die Angewandte Informatik wirkt an der Praxis von Notfalleinsätzen insofern mit, als sie durch ihre gestalterische Methodik Kommunikationssituationen entwirft und durch ihre Artefaktgestaltung Einfluss auf die kommunikativen Handlungsspielräume der Nutzer nimmt. Derartige medientechnische Innovationen für „kritische Situationen", ihre Entwicklung im Kommunikationsprozess und die Implikationen ihrer Nutzung, besonders im Blick auf die Rolle der verbalen Interaktion in intermedialen Konstellationen, stehen im Mittelpunkt unseres Beitrags.

Vor diesem Hintergrund sind die Situationen, die uns interessieren, dadurch charakterisiert, dass zwei Handlungskontexte systematisch miteinander verknüpft sind: Zunächst, im inneren Rahmen, eine Krisen- oder Notfallübung, in unserem Fall eine Brandübung der Berufsfeuerwehr; zweitens die Beobachtung derartiger Situationen im Rahmen der Technologieentwicklung und die darauf bezogene Kommunikation zwischen Entwicklern 
und Einsatzkräften vor und nach den Übungen. Brandübungen gehören bei der Feuerwehr zum Arbeitsalltag, der durch kontinuierliches Training geprägt ist. In speziellen Trainingszentren, z.B. Feuerwehrschulen, werden im Rahmen simulierter Szenarien Techniken der Brandbekämpfung und Personenrettung erlernt und gemeinsam eingeübt. Neben dieser kontinuierlichen Übungskultur spielt auch die Nachbereitung der Einsätze im Ernstfall eine wichtige Rolle: Durch die Aufarbeitung erlebter Situationen werden bestehende Techniken verbessert und neue Ansätze entwickelt. Dabei stehen im Fokus aktueller Entwicklungen vor allem Kommunikationstechnologien, die die Orientierung von Feuerwehrleuten in fremden Umgebungen unter schlechten Sichtbedingungen unterstützen sollen.

Das ist die Brücke zum zweiten, äußeren Handlungskontext, hier kommen Institutionen der Technologieentwicklung ins Spiel, z.B. das Fraunhofer-Institut für Angewandte Informationstechnik (FIT). In diesem Rahmen wird das eben beschriebene sprachlich-mediale Handeln der Einsatzkräfte von Technologie-Entwicklern beobachtet, und es finden vor und nach den Übungen Gespräche zwischen Entwicklern und Einsatzkräften statt. In diesen Gesprächen wird die Nutzung der Medien reflektiert: der herkömmlichen Medien, aber auch der Innovationen, die in diesem Rahmen gemeinsam entwickelt und getestet werden. Diesen Gesamtzusammenhang bezeichnen Habscheid und Pipek (2008) als „Talking Labs“.

Eine technische Idee, die in einem derartigen Setting derzeit entwickelt wird, sind die so genannten „Landmarken“. Beim Projekt „Landmarke“ ${ }^{\text {“6 }}$ handelt es sich um ein Verbundvorhaben, das aus dem zivilen Sicherheitsforschungsprogramm der Bundesregierung gefördert wird. Daran beteiligt sind neun Partner aus Industrie, Forschung und - als Anwendungsfeld - der Feuerwehr, genauer der Berufsfeuerwehr und einer Feuerwehrschule. Im Mittelpunkt steht die technische Unterstützung für das Problemfeld der Navigation unter extrem schlechten Sichtbedingungen, wie sie für Notfalleinsätze der Feuerwehr charakteristisch ist. Traditionell orientieren die Feuerwehrleute sich selbst und ihre Kollegen anhand von Referenzpunkten, die sie in der näheren Umgebung über verschiedene Sinne wahrnehmen können. Als Referenzpunkte dienen teils Elemente der Raumausstattung, z.B. können Wände oder Türen ertastet werden. Teilweise werden zur Orientierung aber auch die Artefakte genutzt, die im Rahmen des Einsatzes von den Feuerwehrleuten selbst ausgebracht werden. So spielen z.B. die Schläuche auch zur Markierung von (Rück-)Wegen eine zentrale Rolle (vgl. Abb. 3).

Die Idee der Landmarken knüpft an derartige Praktiken an: Auf der Basis digitaler Medien und Netze sollen wichtige Orte gekennzeichnet und durch ein System farblicher Symbole mit Bedeutung versehen werden; z.B.

$6 \quad$ Siehe dazu die beiden Websites www.fit.fraunhofer.de/projects/softwaretechnik/landmarke.html und www.landmarke-projekt.de (Stand jeweils Oktober 2009) sowie Dyrks/Denef/Ramirez (2008). 
könnten rote Landmarken, gefährliche` Orte markieren, grüne Landmarken an den Türen Räume als ,bereits durchsucht ${ }^{6}$ kennzeichnen. ${ }^{7}$ Im Rahmen von Workshops in einer Feuerwehrschule werden derzeit gemeinsam mit den künftigen Nutzern verschiedene Designoptionen entwickelt und auf ihre Praxistauglichkeit hin erprobt. Die Landmarken werden zunächst durch einfache Darstellungsmittel simuliert, z.B. durch Plastikkugeln mit farbigen Leuchtdioden. Zukünftig soll es möglich sein, Landmarken-Symbole per Funkverbindung auszulesen bzw. zu verändern, und zwar durch Anzeigeund Eingabegeräte, die in die Kleidung der Feuerwehrleute integriert sind. Dazu müssen robuste mobile Computersysteme entwickelt werden, die trotz starker physischer und psychischer Belastung der Feuerwehrleute im Kontext von Notfalleinsätzen handhabbar sind.

Vor dem Hintergrund derartiger Herausforderungen zeichnet Weiser (1991) seine Vision eines Ubiquitous Computing: Irgendwann, so nimmt er an, werden digitale Geräte und Netze allgegenwärtig, in Alltagsgegenstände und Räume integriert sein. So könnten z.B. bei einem Feuerwehreinsatz Sensoren Bewegungen und Gesten der Beteiligten registrieren, Raumtemperaturen oder Körperfunktionen von Verletzten messen, Daten zur Statik der Gebäude explorieren.

Mögliche Konsequenzen für die Organisation komplexer Notfalleinsätze liegen auf der Hand: Die durch Ubiquitous Computing explorierten Informationen könnten informationstechnisch miteinander verrechnet werden und eine ,optimierte' Steuerung des kollektiven Einsatzes gewährleisten. Im Extremfall griffen die Alltagspraxis der Organisation und die technischen Infrastrukturen gleichsam lückenlos ineinander mit der Konsequenz, dass menschliches Verhalten durch unscheinbare Technologien registriert und auf dieser Basis gesteuert werden könnte. Die digitalen Medien verschwänden aus dem Bereich der Wahrnehmung, des Handelns und der interpersonalen Kommunikation.

Entgegen dieser Konzeption gehen wir heuristisch von einer umgekehrten Perspektive aus: Technik kann die Kommunikations- und Arbeitspraxis nicht von außen und umfassend determinieren, vielmehr müssen Kommunizierende und Arbeitende Technologien auch sinnhaft in ihre alltäglichen Kommunikations- und Arbeitsvollzüge einbetten, und sie müssen die Artefakte, gerade in Kontexten mit unvorhersehbarer Dynamik, jeweils situativ einpassen. So macht zum Beispiel die ständig verfügbare Vielfalt von Geräten und Vernetzungschancen, von Informationsquellen und Informationszugängen es notwendig, technische Infrastrukturen „in situ“,

Es geht also auch in unserem Untersuchungsfeld um die Ausstattung eines Raumes mit Markierungen (vgl. die Beiträge von Hausendorf und Auer in diesem Band), wobei der Raum in diesem Fall nicht bereits markiert ist, jedenfalls nicht durch die Institution Feuerwehr im Kontext des laufenden Einsatzes, sondern erst im Vollzug der kollaborativen Ortserkundung und Navigation markiert wird. 
entsprechend dem aktuellen Nutzungskontext zu verstehen und zu konfigurieren. Weil Alltagshandeln in vielen Situationen auch die Interaktion mit anderen Akteuren umfasst, wird diese Konfigurationsarbeit zu einer sprachlich-kommunikativen Aufgabe, die das instrumentelle Handeln beständig begleitet.

Betrachten wir dazu die kleine verbale Interaktionssequenz, die unmittelbar an die Szene aus Datum 1a anschließt:

Datum 1b: landmarke / Die erste Landmarke setzen

18 FW1: wir befinden uns in der (.) ersten etage

$19(1)(3.5)$

20 EL: zugführer mitgehört. (2.0)

$[\ldots]$

22 FW1nv ((FW 1 wendet sich an FW2.))

23 FW1: solln wa hier die erste landmArke ma

24 setzen? (3.0)

25 FW2: joa weiß ich net. (.) treppen[haus ( )

26 FW1: [u ge

27 machen wir Oben an die tür. (.) ( )

28 (--) hier könnten wa ne blaue setzten;

29 ne blaugelbe oder?

30 FW2: ja könnten wa auch machen. (--)

35 FW1nv ((wendet sich zu einem der Entwickler, der

36 die Landmarken mit sich führt.))

37 FW1: wolln wir hier erstmal eine setzen?

$38(3.5)$

39 FW2: aber die wissen ja (.) zweite o ge (-)

40 weiß ich nich. [denke

41 FW1: [ja gut denk ma hier wär

42 schon (---)

43 FW2: wär wohl übertrieben oder? (2.0)

44 kriegen wa mehr wAsser? (3.0)

45 FW1: einsatzleitung (

$46 \quad(1.5)$

47 EL: zugführer hört.

48 FW1: ja: geb ma wAsser auf das ce rohr; 
Die Beteiligten verständigen sich darüber, $o b$ sie in der aktuellen Situation eine Landmarke setzen wollen, wo genau diese Landmarke gegebenenfalls angebracht werden soll und welche Farbe, also welches Symbol hier besonders nützlich sein kann: „Solln wer hier die erste Landmarke ma setzen? [...] Hier könnten wer ne blaue setzen“" (Z. 23 ff.). Anders gesagt, handelt es sich hier um einen Fall von interaktiver, lokal situierter Medienkonfiguration. Diese wird im vorliegenden Fall erforderlich, weil der Aussagegehalt einer Landmarke hinsichtlich der Referenz vom Ort abhängig ist, an dem die Landmarke positioniert wird. Sie ähnelt in dieser Hinsicht einem Schild, z.B. „Frisch gestrichen!“, das eine bestimmte Information in einem physischen Kontext lokalisiert: In solchen Fällen, so wiederum Karl Bühler ([1934] 1999, S. 162), ,wird die Anheftung zum physischen, sinnlich manifesten Kriterium der Zuordnung“".

Dementsprechend hängt die aktualisierte Bedeutung der Landmarke immer auch davon ab, dass sie aus einer bestimmten Perspektive wahrgenommen und interpretiert wird: Zum Beispiel bezieht sie sich bei Platzierung an einer Tür auf den Raum, der vom Betrachter aus gesehen binter dieser Tür liegt. Die Feuerwehrleute, die Landmarken setzen, müssen dementsprechend die Perspektiven antizipieren, aus denen sie selbst oder andere diese Landmarken später wahrnehmen werden. Außerdem müssen sie die später relevanten Aspekte der aktuellen Situation unter Nutzung des farblichen Symbolsystems der Landmarken semantisch codieren.

Dabei ist zu bedenken, dass die Landmarken nicht nur, wie Warnschilder, handlungsrelevantes Wissen speichern und situativ verfügbar machen; sie dienen darüber hinaus in einem arbeitsteiligen Handlungskontext dazu, ortsbezogene Sachverhalte in der Arbeitskommunikation artikulierbar zu machen: So ermöglichen sie eine genaue Ortsreferenz und stellen, durch das farblich codierte Bedeutungssystem, ein Zeicheninventar für die Kommunikation in Standardsituationen zur Verfügung. Es lässt sich also festhalten, dass im Nutzungsfall das technische Medium Landmarke in eine konkrete Nutzungssituation eingepasst wird, und dass diese Aneignungspraxis gemeinsam mit anderen, im Modus der Kommunikation jeweils lokal geleistet wird.

Für eine Erforschung von Sprache im intermedialen Zusammenhang sind derartige Situationen äußerst aufschlussreich: Kommunikationsmedien, in unserem Beispiel das System der Landmarken, werden hier durch die Beteiligten selbst sprachlich dargestellt und diskursiv bearbeitet. Auf diese Weise wird Medialität - als eine im Regelfall transparente Kommunikationsgrundlage - augenblicklich thematisch, Medien und ihr Zusammenspiel geraten in den Fokus der Aufmerksamkeit. Im Folgenden sollen anhand audiovisueller Daten, die im Kontext von Notfallübungen erhoben wurden, derartige Praktiken näher betrachtet und das methodische Potenzial erörtert werden, das sie für eine Untersuchung von Sprache in intermedialen 
Zusammenhängen bieten. Dabei soll auch, unter dem Aspekt der Anwendung, die Frage erörtert werden, welche Relevanz derartigen Erkenntnissen für die Gestaltung medientechnischer Ressourcen für kritische Situationen zukommt. ${ }^{8}$

\section{Vorstellung des Datenmaterials}

Im Projekt Landmarke wird das Ziel verfolgt, neuartige Technologien für die Unterstützung von Erkundungstrupps bei der Orientierung und Navigation zu entwickeln. Diese Technologien sollen so gestaltet sein, dass die ausgeprägten menschlichen Fähigkeiten der Feuerwehrleute weiterhin zum Tragen kommen und genutzt werden. Um technische und menschliche Potentiale optimal aufeinander abzustimmen, sollen bereits bei der Entwicklung der Technologien die Erfahrungen der Feuerwehrleute einbezogen werden. Zu diesem Zweck führen Feuerwehrleute und Systementwickler gemeinsam Erkundungsübungen und Kreativworkshops durch. Diese werden im Rahmen der Entwicklung und Forschung beobachtet und durch Videoaufzeichnungen dokumentiert. Anders als in etablierten Ansätzen der Technologieentwicklung üblich, sind die Feuerwehrleute aus unserer Sicht nicht nur Endnutzer. Vielmehr sind sie auch Alltagsexperten für Navigation und Orientierung, die neue technische Artefakte auf konzeptioneller Ebene systematisch mit gestalten. Die Ideen werden von den Systementwicklern im Rahmen der technischen Machbarkeit umgesetzt, die Prototypen werden dann von den Alltagsexperten einem Praxistest unterzogen. So erkundet man gemeinsam, in mehreren Entwicklungsschleifen, Möglichkeiten für eine optimale Gestaltung.

Die Projektidee ist aus Vorarbeiten im europäischen Forschungsprojekt „WearIT@Work“ entstanden: Hier wurden im Rahmen empirischer Feldstudien mit der Pariser Feuerwehr Navigation und Orientierung von Erkundungstrupps als Problemfeld identifiziert. Im aktuellen Projekt, Landmarke, finden seit 2008 Workshops im Institut der Feuerwehr in Münster statt. Es handelt sich um die zentrale Ausbildungseinrichtung für Feuerwehrleute in Nordrhein-Westfalen, jährlich besuchen etwa 15.000 Feuerwehrleute dort Lehrgänge und legen Prüfungen ab. Zu diesem Zweck verfügt das Institut über eine der modernsten Übungsanlagen in Europa: Umgebungsbedingungen von Feuerwehreinsätzen können realitätsnah simuliert werden durch verschiedene Gebäudearchitekturen, Theaternebel, Lichteffekte und Geräuschkulissen.

Für Kommentare zu früheren Überlegungen und Textfassungen danken wir Florian Menz (Wien) und Arnulf Deppermann (Mannheim) sowie Volkmar Pipek (Siegen) und den Mitgliedern des Siegener SFB/FK 615 „Medienumbrüche“. 
Bereits im Vorfeld der ersten Landmarke-Übung waren Feuerwehrleute der Berufsfeuerwehr Köln an der theoretischen Ausarbeitung der Farbsymbolik beteiligt. Unmittelbar vor der ersten Übung wurde die vereinbarte Symbolik allen Beteiligten vorgestellt. Während der Übung wurden die Erkundungstrupps durch Helfer begleitet, die nach Bedarf die geforderten Landmarken anreichten. Nach den Übungen wurden die Abläufe und die von den Trupps getroffenen Entscheidungen zur Ausbringung der Landmarken noch einmal „,vor Ort" nachvollzogen. Die Übungen und Nachbesprechungen wurden auf Video bzw. bei schlechten Sichtverhältnissen ausschließlich durch Audioaufzeichnungen dokumentiert. Die Vorgehensweise der Systementwickler und die Art des Datenmaterials legte eine Zusammenarbeit mit der Medien- und Kommunikationslinguistik nahe. Eine solche Kooperation haben wir in den letzten Monaten erprobt, wobei wir zu heuristischen Zwecken mit den ersten Daten aus dem Landmarke-Projekt gearbeitet haben; insgesamt stehen bisher ca. 28 Stunden Video- und Audiomaterial in deutscher Sprache zur Verfügung. Zu Vergleichszwecken haben wir ergänzend französischsprachiges Material aus dem WearIT@WorkKontext herangezogen. Dabei handelt es sich um Videodaten im Umfang von ca. 15 Stunden, die den Einsatz verschiedener alter und neuer Medientechnologien dokumentieren.

\section{Sprache intermedial: Methodologie eines Untersuchungsansatzes}

Untersuchungen dieser Art können besonders von ethnographischen $\mathrm{Zu}-$ gängen profitieren, wie sie im Rahmen ethnomethodologisch inspirierter Ansätze - vor allem der Studies of Work (vgl. Garfinkel (Hg.) 1986, Button (Hg.) 1993 und Bergmann 2006) und der Workplace Studies (Suchman 1987; Luff/Hindmarsh/Heath (Hg.) 2000) entwickelt wurden: Demnach können Elemente sozialer Ereignisse - Akteure, Beziehungen, Aufgaben usw. nicht einfach als objektiv gegeben oder als vorab definiert gelten. Vielmehr werden sie kontinuierlich durch sprachlich-mediale Interaktion „im Vollzug" hervorgebracht. Dabei geben sich die Beteiligten von Moment zu Moment wechselseitig zu verstehen, wie sie die Situation aktuell wahrnehmen und deuten. Diese Reflexivität der Herstellung von Wirklichkeit im Kommunikationsvollzug ermöglicht ihre Beobachtung und Rekonstruktion im Rahmen empirischer Forschung, wobei in unserem Fall auch an Traditionen der „Raumlinguistik“ (vgl. z.B. Berthele 2006) anzuschließen ist.

Das Interesse der Workplace Studies gilt neben der sprachlichen Interaktion (als einer Form von Arbeit) besonders auch den Körpern und Räumen sowie den interaktiv relevanten und bearbeiteten Dingen: Gegenstände, Instrumente, Apparate, kommunikative Medien und Mediennetze, Text- und 
Bilddokumente. Zudem ist neben der Interaktion unter den räumlich anwesenden Personen auch die durch technische Medien vermittelte Interaktion mit räumlich entfernten Beteiligten von Belang. Schließlich sind die besonderen Bedingungen zu berücksichtigen, wie sie für die Kommunikation in Notfall- und Krisensituationen charakteristisch sind (vgl. Abschnitt 4). Diese Situationen sind für unsere Untersuchung vor allem insoweit von Interesse, wie es im Kontext von Notfalleinsätzen im Rahmen von Ortserkundung und Navigation zusätzlich zu kommunikativen Störungen und Krisen kommt. Wie bereits skizziert, bringen kommunikative Störungen es mit sich, dass Medien und ihr Zusammenspiel augenblicklich thematisch werden, in den Fokus der kommunikativen Aufmerksamkeit geraten; dabei sind sowohl der Störungs- als auch der Medienbegriff hier zunächst in einem weiten, hermeneutischen bzw. kulturwissenschaftlichen Sinne gefasst (vgl. Jäger 2004), so dass z.B. auch die metakommunikative Bearbeitung sprachlicher Missverständnisse als ein derartiger Sachverhalt aufgefasst werden kann. Von spezifischem Interesse sind in unserem Zusammenhang solche Fälle, bei denen (nach Auffassung der Beteiligten), technisch` bedingte Störungen, z.B. der tatsächliche oder vermeintliche Breakdown technischer Infrastrukturen, im Medium der Sprache bearbeitet werden. Für eine Untersuchung von Sprache in intermedialen Bezügen scheint uns dieser Gegenstand besonders aufschlussreich. Er soll im Folgenden terminologisch geschärft werden. Dabei dienen zwei kurze Beispiele aus dem französischen Datenmaterial zur Veranschaulichung.

In Kontexten der Mediennutzung treten unvermeidlich technisch-kommunikative Störungen auf, die durch die Beteiligten artikuliert und bearbeitet werden müssen. Diese Störungen können harmlos und alltäglich sein, Ludwig Jäger (2004, S. 41) spricht in einer hermeneutischen Tradition von der Störung ,als Produktivitätsprinzip sprachlicher Sinngenese“. - In Datum 2 berichtet ein Feuerwehrmann (FW1) nach einer Erkundung des Gebäudes einem Vorgesetzen (FW2), wobei er ein Zeichenbrett (Whiteboard) und einen Stift mit wasserlöslicher Farbe verwendet (vgl. Abb. 5 und 6):

Datum 2: WearIT / Dessine la pièce

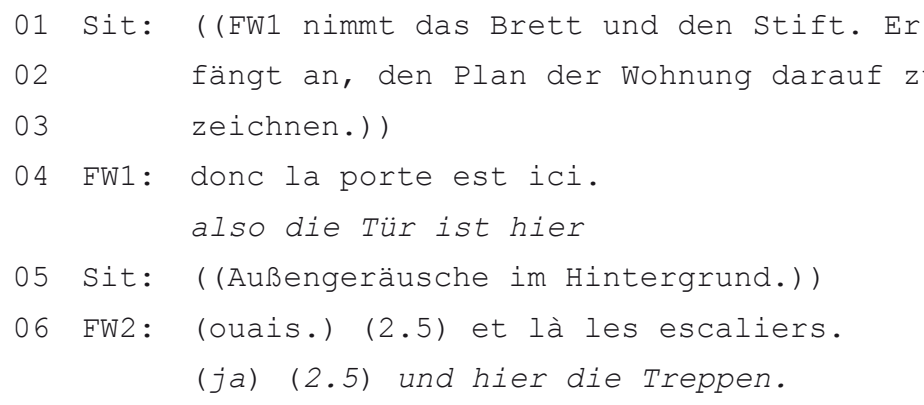


07 FW1: et euh y a environ six marches.

und hä es gibt ungefähr sechs Treppenstufen.

08 FW2: okay.

09 FW1: ( )

10 FW2: ensuite.

und dann.

11 FW1: ensuite on continue (.) y a une PIÈce (.)

12 à c=niveau là.

dann gehen wir weiter (.) es gibt einen

Raum (.) auf dieser Ebene.

13 FW2: ouais (.) VAS y! vas y. dessINE LA! la

14 pièce.

ja (.) mach mal! mach mal. zeichne ihn!

den Raum.

15 Sit: ((Fmw1 zeichnet den ersten Raum.))

16 FW1: hop.

17 FW2: ouai:s. ja.

18 FW1: alors Ici y a une autre MARche. (.)

19 on a trouvé le début du feu ici. (.)

20 à cet endroit

also hier gibt es eine weitere

Treppenstufe. (.) wir haben den Anfang

des Feuers hier gefunden.

21 [ 1 à .

[an dieser Stelle.

22 FW2: [d'accord. (.) donc là y a

[einverstanden. (.) also hier gibt es

23 FW2 [une bouteille.

[eine Flasche.

24 FW1: [une bouteille ici.

[hier eine Flasche.

25 FW2: ok.

26 Sit: ((Fwm1 fügt ein Kreuz auf dem Plan hinzu.)) 

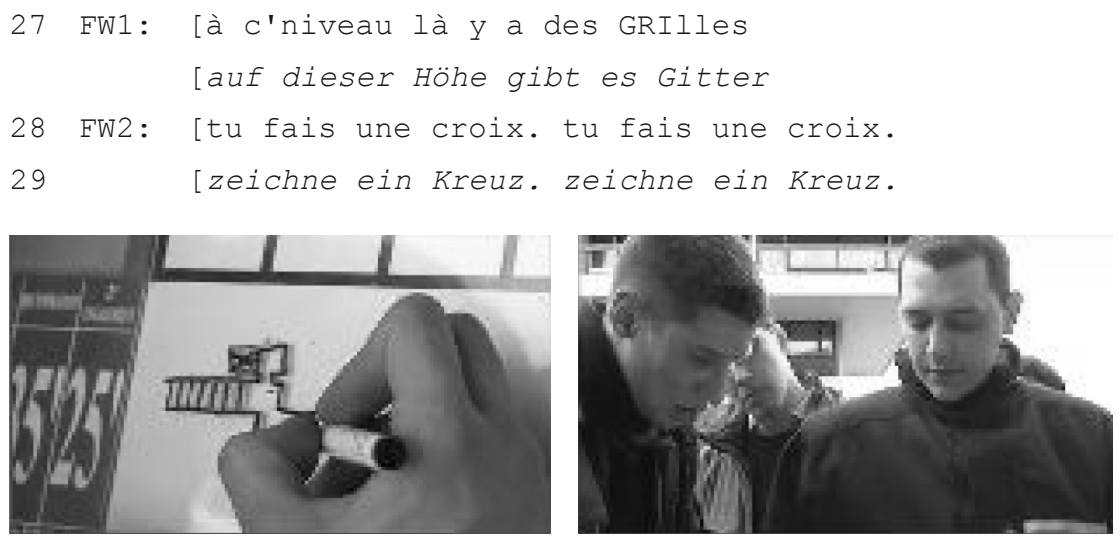

Abb. 5 und 6 (zu Datum 29)

Schon die eher traditionelle Kommunikationspraxis, die wir hier beobachten können, ist dadurch charakterisiert, dass Zeichenwahrnehmung und Bedeutungskonstitution auf intermedial miteinander verschränkten Zeichensystemen beruhen: gesprochene Sprache, Para- und Körpersprachliches, grafische Visualisierungen, Beschriftungen, Zeiggesten am grafischen Zeichenraum (vgl. dazu Fricke 2009).

Bemerkenswert ist aber vor allem, dass der Einsatzleiter den Fluss des Berichts massiv unterbricht. Er fordert den Berichterstatter nachdrücklich dazu auf, einen zunächst nur gesprochensprachlich dargestellten Raum zusätzlich anders lesbar zu machen, nämlich im Medium der Zeichnung: „VAS-y! vas-y. dessINE LA! la pièce“ (Z. 13 f.), was der Feuerwehrmann dann auch tut. Der weitere Interaktionsverlauf macht den Sinn dieser Transkription einer gesprochensprachlichen Äußerung durch eine Zeichnung deutlich: Dieser Sinn liegt darin, den Zeichenraum, der durch den Bericht erzeugt wird, auf einer Tafel temporär zu fixieren. So kann im weiteren Interaktionsverlauf durch sprachlich-gestische Zeigehandlungen darauf Bezug genommen werden: „, on a trouvé le début du feu ici. (.) à cet endroit“ (Z. 18 ff.). Und wieder folgt die Aufforderung zu einer Transkription von Sprache durch ein Bild, wobei der ikonische grafische Zeichenraum um ein nicht-sprachliches Symbol ergänzt wird: „tu fais une croix. tu fais une croix“ (Z. 28). In solchen Fällen liegen also zweifellos produktive - weil Sinn erzeugende - Kommunikationsstörungen vor.

Kommunikative Störungen können nicht nur „in situ“ produktiv sein, sondern auch im Blick auf längerfristige kommunikationstechnische oder organisatorische Innovationen. So lassen sich auf der Basis der eben dargestellten Beobachtungen zu herkömmlichen Visualisierungspraktiken Ideen

9 Das rechte Bild zeigt FW1 (links im Bild, beim Zeichnen und Erläutern) und FW2, das linke Bild die im Verlauf der zitierten Interaktion produzierte Zeichnung mit Treppe, Raum und Kreuz. 
für neue technische Repräsentationen entwerfen, z.B. die Idee digitaler bildlicher Zeichenräume, in denen die Feuerwehrleute durch Figuren ikonisch repräsentiert und lokalisiert werden. So können im Setting von Datum 3, auf der Basis einer Technik-Simulation, die Bewegungen der Einsatzkräfte (FW2, FW3) in einem digitalen Gebäudeplan, der auf dem Display des Einsatzleiters (EL) angezeigt wird, in Echtzeit verfolgt werden (vgl. Abb. 7 und 8). Dazu gaben menschliche Beobachter der Feuerwehrleute deren Positionen im Gebäude sekündlich von Hand in einen interaktiven Gebäudeplan ein, der dem Einsatzleiter angezeigt wurde. Ein Gesprächsausschnitt:

Datum 3: WearIT / Au point de départ

01 FW2: ouAIS C'EST une PoRte (ouais).

ja, es ist eine Tür (ja).

02 EL: donc (.) tu rentres dans cette PIÈce (.)

03 et à peu près au milieu de la pièce tu

04 vas trouver la bouTEIlle d'eau.

also (.) du gehst in diesen Raum rein (.)

und du wirst ungefähr in der Mitte des

Raums eine Wasserflasche finden.

05 FW2: (2.0) REÇU!

(2.0) verstanden!

06 EL: ((hustet)) ( ( $\mathrm{h} \mathrm{h})$ )

07 FW2: je l'ai TROUVÉE!

ich habe sie gefunden!

08 EL: ok. donc tu rssors (.) tu rviens à ton

09 point d dépa: : rt eu: :h dans la PIÈce.

ok. also du gehst wieder raus (.) du

kommst auf den Anfangspunkt zurück hm in

dem Raum.

10 FW2: d'Accord.

einverstanden.

11 FW3: le point d départ?

der Anfangspunkt?

12 FW2: on reVIENT au point de DÉpa: :rt (.) dans

13 la PIÈce.

wir gehen zum Anfangspunkt (.) in dem

Raum zurück. 

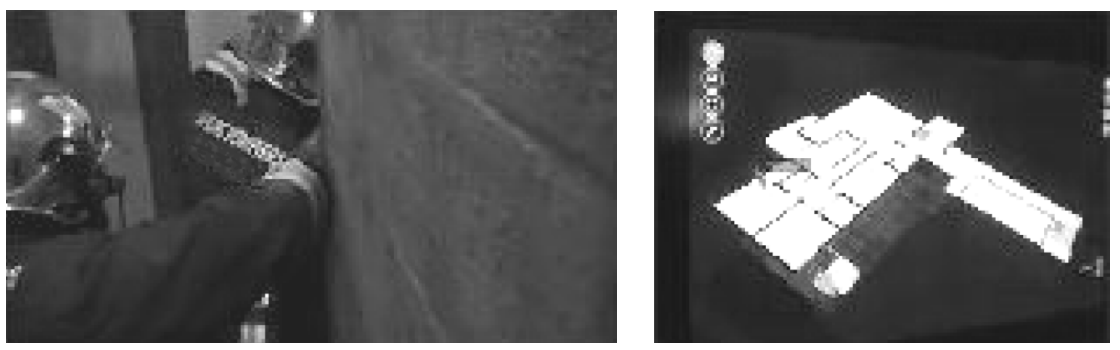

Abb. 7 und 8 (zu Datum $3^{10}$ )

An der Realisierung solcher Technologien wird in der Forschung gearbeitet, sie werfen allerdings im Blick auf ihre technische Machbarkeit Fragen auf, die derzeit nicht zu beantworten sind. Auch in kommunikativer Hinsicht erfordert die Entwicklung einer solchen Technologie sorgfältige Erwägungen auf der Grundlage empirischer Untersuchungen. Dementsprechend wurde im Rahmen des WearIT@Work-Projekts untersucht, wie sich durch die Nutzung derartiger Medien Erkundungspraktiken verändern würden.

Wie die Videodokumentation zeigt, bietet eine solche Technologie im Vergleich zur traditionellen Arbeit mit Tafel und Kreide spezifische Vorund Nachteile: Sie hat den Vorteil, dass die visuelle Repräsentation von Räumen und Akteuren sozusagen „live“, während des Einsatzes entsteht. Sie hat aber auch den Nachteil, dass die bildliche Repräsentation des Einsatzortes aus der verbalen Interaktionssituation herausgelöst ist, weil sie nur dem Einsatzleiter, nicht aber den Feuerwehrleuten zur Verfügung steht. Das kann zu erheblichen Verständigungsproblemen führen. Im vorliegenden Fall, auf der Basis der Simulation, ist die Lokalisierung der Akteure im digitalen Bildzeichenraum recht ungenau: Welcher reale Bewegungsumfang entspricht dem Vorrücken der Figur auf dem Monitor (vgl. Abb. 8)? Vor diesem Hintergrund und in Verbindung mit der medientechnischen Asymmetrie entsteht, so unsere Interpretation der Interaktion in Z. 08 ff., in dieser Situation eine Unklarheit hinsichtlich der sprachlichen Raumreferenz: Welcher der Räume ist gemeint, wenn in der Funkkommunikation vom „Anfangspunkt des Raumes“ die Rede ist?

Legt man diese Lesart zugrunde, so kann man die dann einsetzende Interaktion als einen Spezialfall „transkriptiver Störungen“ (Jäger 2004) auffassen: Ein schwer wiegendes Problem (also eine Störung auch im gemeinsprachlichen Sinne) auf der Ebene der Kommunikation veranlasst die Beteiligten dazu, den instrumentellen Handlungsvollzug, die Bearbeitung des Sachproblems, für einen Moment zu unterbrechen und eine Aushandlungs-

10 Die beiden Bilder zeigen die Situation zu Beginn des Ausschnitts: Links die beiden Einsatzkräfte (FW1, FW2) an der Tür des Gebäudes, rechts die visuelle Repräsentation - der digitale Gebäudeplan und die Bewegungen der Einsatzkräfte - auf dem Monitor des Einsatzleiters. 
bühne zu schaffen für eine Re-Lektüre der digitalen Kommunikationssituation im Medium der Sprache: „on reVIENT au point de DÉpa::rt (.) dans la PIÈce“ (Z. 12f.).

Im Unterschied zu den unproblematischen und produktiv bewältigten „Allerweltsstörungen“ des vorherigen Typs (vgl. Datum 2) geht mit derartigen problematischen Störungen in realen Notfallsituationen das Risiko einer Eskalation einher: Solche Kommunikationsstörungen stellen mithin Krisen 2. Ordnung dar, also Krisen auf der Ebene der Krisenbewältigung; Krisen 2. Ordnung ziehen die Aufmerksamkeit von den primären instrumentellen Handlungszielen ab, und sie unterhöhlen die kommunikativen Voraussetzungen, die für eine erfolgreiche Bewältigung der Krise unabdingbar sind.

An dieser Stelle liegt es nahe, das Konzept der Artikulationsarbeit einzubeziehen. Darunter versteht Strauss (1988) alle kommunikativen Aufgaben, die die Steuerung und Ausführung von kooperativen arbeitsteiligen Arbeitsaktivitäten im Rahmen eines Gesamtprojekts, von der Vision bis zur praktischen Umsetzung, betreffen. Artikulationsarbeit wird erforderlich durch Kontingenzen des kollaborativen Arbeitsablaufs, Arbeitende müssen sich darüber verständigen, welche Arbeitsschritte von wem zu vollziehen sind und wie die Aktivitäten der Beteiligten ineinander greifen. Sachverhaltsdarstellungen im Rahmen der Artikulationsarbeit können sich demnach beziehen auf die Vernetzung der Aufgaben und Elemente eines Gesamtprozesses, „the specific details of putting together tasks, task sequences, task clusters, and even the work done in aligning larger units such as subprojects, in order to accomplish the work" (Strauss 1988, S. 174f.), aber auch auf die Vernetzung der Aufgaben mit den Akteuren, seien es Individuen oder Abteilungen, und die Vernetzung der von den Akteuren geleisteten Arbeiten untereinander. ${ }^{11}$

Vor diesem Hintergrund unterscheiden Habscheid/Pipek (2008) zwischen Primär- und Sekundärartikulationen: Während Primärartikulationen unmittelbar auf die kollaborative Be- und Abstimmung der gemeinsamen Handlungsziele und Aufgaben bezogen sind, zielen Sekundärartikulationen auf eine Gestaltung und Sicherung der technisch-medialen Infrastrukturen und damit auf die Grundlagen der kommunikativen Handlungsfähigkeit. Mit anderen Worten verstehen wir unter Sekundärartikulation dasjenige kommunikative Handeln in informationstechnisch geprägten Handlungssituationen, das der Verständigung über kommunikationstechnische Geräte und Netze, ihre Konfiguration und Nutzung bzw. der Absicherung oder Wiedergewinnung der medientechnischen Ressourcen dient. Dazu gehört auch die Konfiguration der Landmarken, die handlungsrelevantes Wissen speichern und ortsbezogene Sachverhalte in der Arbeitskommunikation artikulierbar machen.

11 Ein ausführliches Beispiel zur Artikulationsarbeit im Rahmen eines spezifischen Arbeitsprozesses (einer medizinischen Patientenbetreuung) findet sich in Strauss et al. (1985, S. 151-190). 


\section{Ortserkundung in Notfallsituationen:} Von der Kommunikationsanalyse zur Mediengestaltung

Kommen wir vor diesem Hintergrund noch einmal auf die Landmarken zurück. Die vierte Situation wurde im Rahmen einer gleichsam „handlungsentlasteten" Übungssituation dokumentiert, in der die Ausbringung der Landmarken zum Gegenstand ausführlicher, systematischer Reflexionsprozesse wird (beteiligt ist neben Einsatzkräften und Einsatzleiter der Berufswehr auch ein Leiter des Ausbildungsinstituts, IL, wo die Übung stattfindet):

Datum 4: landmarke / Rot blau vor der Tür

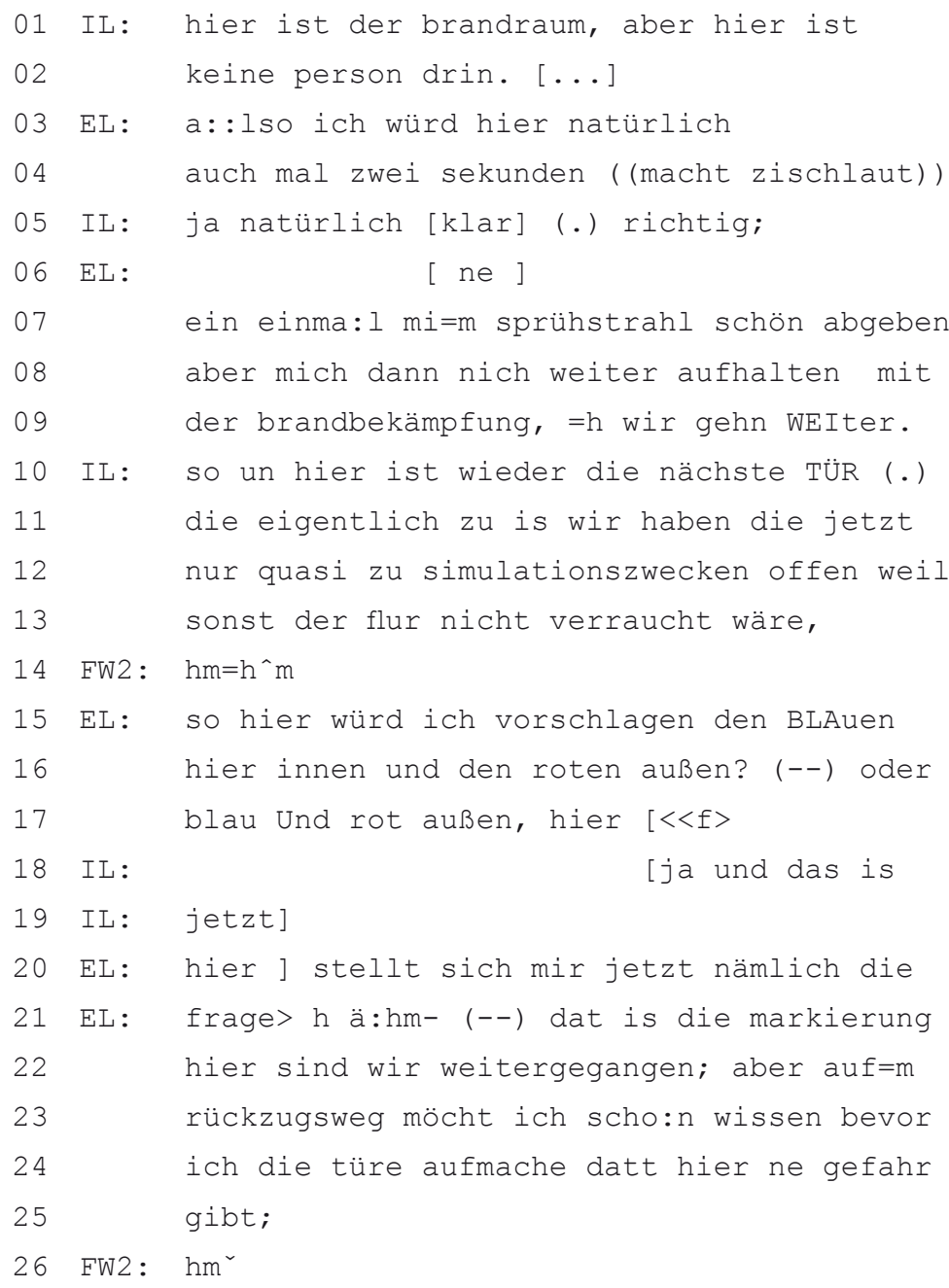


27 EL: dat heißt ich müsste jetzt hier eigentlich auf der andern seite ebenfalls ne markierung machen. [h aber welche

30 FW2:

[das heißt

31 EL: MARkierung?]

32 FW2: Jdas heißt im prinzip müsste ja 33 hier ne blaue- (.) UND hier rot blau,

34 EL: ja=a:-=

35 FW2: =oder?((Blick zu IL))

36 IL: ja wobei ich sach ma so wir ham wir hatten es is jetzt die frage der phase wenn wir quasi später diese interaktion haben

41 FW2: ja-

42 EL: also ok [rot blau (-) erledigt. ] 43 IL: [also wenn du hier deswegen vorne] 44 genau deswegen müsst ich hier eigentlich 45 rot blau vor der tür (.) also hier auf 46 dieser seite der tür sein rot und blau. 47 (--) EIgentlich; (.) wenn ich das jetzt 48 so=recht seh; 49 EL: =gehn wa davon aus wir ham en 50 intelligente:s ähm- (.) system mit 51 gedë:chtnis und wir hätten ein 52 dis!PLAY!, und wenn wir auf=m rückweg sin 53 dann zeigt der uns an auf der andern seite 54 is rot und blau.

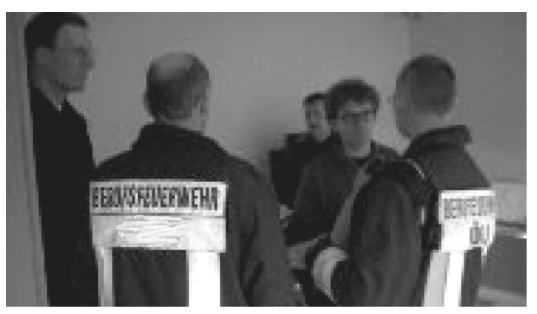

Abb. 9 (zu Datum 4, Z. 04)

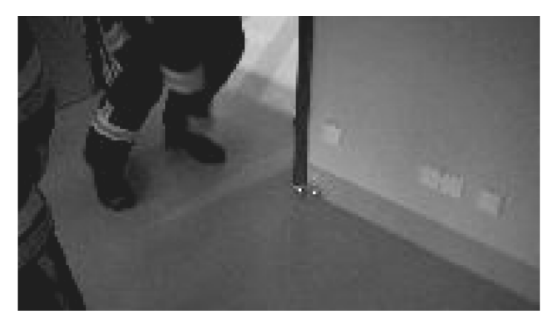

Abb. 10 (zu Datum 4, Z. 45 f.) 
Wie in Datum 1b verständigen sich auch in dieser Situation die Feuerwehrleute darüber, $o b$ sie im aktuellen Fall eine Landmarke setzen wollen, wo genau diese Landmarke gegebenenfalls angebracht werden soll und welche Farbe, also welches Symbol besonders nützlich ist. Dazu antizipieren sie im Gespräch hypothetisch die Perspektiven, aus denen sie selbst oder andere diese Landmarken später wahrnehmen werden. Außerdem verständigen sie sich darüber, wie die relevanten Aspekte der Situation durch das farbliche Symbolsystem der Landmarken so codiert werden können, dass sie einer späteren Rezeptionssituation verstanden werden (,aufm rückzugsweg möcht ich scho:n wissen bevor ich die türe aufmache datt hier ne gefahr gibt", Z. 22 ff.). Dazu werden verschiedene Optionen durchgespielt, den Aussagegehalt der Landmarken durch ihre räumliche Positionierung mitzubestimmen (,genau deswegen müsst ich hier eigentlich rot blau vor der tür (.) also hier auf dieser seite der tür sein rot und blau“, Z. 44 ff.).

Bemerkenswert ist in diesem Beispiel darüber hinaus, dass das Symbolsystem der Landmarken nicht nur - auf der Basis sprachlicher Transkriptionen - kreativ gebraucht, sondern auch durch die Nutzer strukturell weiterentwickelt wird. Da sich die intendierte Bedeutung nicht durch die Wahl einer farblichen Leuchtdiode ausdrücken lässt, werden musterhafte Verknüpfungen mehrerer Landmarken, z.B. rot und blau, an einem Ort in Erwägung gezogen und im Blick auf ihre Bedeutung erörtert. Insgesamt ist das Bemühen der Nutzer erkennbar, durch pragmatische und syntagmatische Verfahren - also durch situative Einpassung und Verknüpfung der Symbole komplexere Bedeutungen aufzubauen, die im ursprünglichen System der Landmarken gar nicht vorgesehen waren. Diese sprachlich fundierte Kreativität der Nutzer ist einerseits eine Quelle der Innovation, erfordert andererseits aber auch unter organisatorischen und technologischen Gestaltungsaspekten sorgfältige Abwägungen. ${ }^{12}$

Praktiken wie die gerade beschriebenen kommen in den Entwicklungsworkshops durchaus häufig vor. So gab es beispielsweise im ursprünglichen Konzept der Landmarken für die Markierung von Gefahrenpunkten nur eine Farbe, nämlich rot. Dementsprechend markierte während eines Übungseinsatzes ein Trupp einen Gasanschluss durch eine rote Landmarke. Als

12 Dabei liegt, wie von den Beteiligten im Aushandlungsprozess reflektiert, im Fall der Landmarken unter verstehenstheoretischen Aspekten eine besondere Herausforderung darin, dass die interaktive Bedeutungskonstitution im Rahmen der Landmarken-Ausbringung und diejenige im Rahmen der Landmarken-Rezeption zeitlich (und unter Umständen auch personell) auseinandertreten, was die Landmarken-Kommunikation einem zerdehnten, textuellen Kommunikationsprozess vergleichbar macht (vgl. Anmerkung 16); gleichzeitig handelt es sich um ein Zeichensystem, das in hohem Maße auf ,lokal' situierte Kontextualisierungen angewiesen ist. Die Untersuchung der Frage, welche Folgerungen daraus hinsichtlich der technischen Unterstützung einer auf Effizienz, Verständlichkeit, Präzision etc. zielenden Kommunikationspraxis zu ziehen sind, muss künftigen Studien im Rahmen des hier dargestellten Forschungsprogramms vorbehalten bleiben. (Wir danken Arnulf Deppermann für eine entsprechende Anregung.) 
man danach einen Raum mit Feuer entdeckte, entschied man sich in der Situation dafür, zwei rote Landmarken vor der Tür anzubringen. In einer Nachbesprechung wurden mögliche Konsequenzen für die Gestaltung des Symbolsystems der Landmarken erörtert. Unter anderem wurde vorgeschlagen, für Fälle wie den Gasanschluss eine weitere Farbe zur Markierung für ,Orte von besonderem Interesse ${ }^{6}$ vorzusehen. Andererseits ist aber zu bedenken, dass die Landmarken im Kontext von Notfalleinsätzen positioniert bzw. rezipiert werden müssen, also in Situationen, in denen Kommunikation notwendig ist, aber unter erheblich erschwerten Bedingungen stattfindet.

\section{Notfall, Krise, Katastrophe: Forschungshintergründe und Einordnung}

Nach kulturwissenschaftlichem Verständnis spielen für die Abgrenzung, Gewichtung, Erklärung und Bewältigung von Notfällen, Krisen und Katastrophen nicht nur positivistisch zu bestimmende, objektive Eigenschaften der materiellen Umwelt eine Rolle, vielmehr sind Unterschiede in der Identifikation und Deutung von Risiken und Krisen ebenso wie im Umgang damit auch als Elemente kulturell mehr oder weniger riskanter Lebensformen und Kommunikationsprozesse zu rekonstruieren (vgl. z.B. Douglas/Wildavsky 1982; Voss 2006). Dazu gehört neben der Antizipation künftiger Gefahren auch der retrospektive Umgang mit Katastrophen auf der Basis kultureller „Mythen“ (Clausen/Geenen/Macamo (Hg.) 2003) und medienrhetorischer Erwartungshorizonte (Knape 2005).

Für die praktische Bewältigung von Risiken ist freilich nicht nur eine historisch informierte, zentralisierte und theoretisch systematisierte öffentliche Reflexion möglicher Innovationsfolgen entscheidend (anticipation), sondern auch der dezentrale, flexible und kollektive Lernprozess (resilience), der in Verfahren des praktischen, kognitiven und kommunikativen Umgangs mit unvermeidlichen und kaum antizipierbaren Risiken resultiert (vgl. Wildavsky 1988). ${ }^{13}$ Dies korrespondiert in der jüngeren Forschung mit einem Turn der Erkenntnisinteressen von der Risiko-Politik zum lokalen Pannen-, Notfall- und Krisen-Management (vgl. Potthast 2007), dazu gehören auch die besonderen Anforderungen an sprachliche Kommunikation in „Hochrisikoumgebungen“ (vgl. zu einigen Aspekten Krifka et al. 2004). Bei der Bearbeitung von Notfällen kommt den bereits erwähnten Krisen 2. Ordnung besondere Relevanz zu (vgl. Abschnitt 3). Dementsprechend gilt in Teilen der Katastrophenforschung eine besondere Aufmerksamkeit dem Verhältnis zwischen materialen technischen Infrastrukturen („Technology

13 In derartigen Kontexten entstehen auch Anlässe zur längerfristigen kommunikativen Problembearbeitung, wobei neben sachorientierten, prospektiv-innovativen Verfahren auch ein retrospektiv-moralisierender Modus zu beobachten ist (Potthast 2007). 
on the floor") und deren kommunikativ vermittelten, dynamischen kognitiven Repräsentationen („Technology in the head“) (Weick 1990) - jedenfalls soweit Katastrophen nicht nur auf einem Versagen der Technik, sondern auch auf Interaktions- und Organisationsprozessen beruhen (vgl. Perrow 1999).

Vor dem Hintergrund dieser Entwicklungstendenzen richtet sich das Interesse der Forschung vor allem auf zwei Untersuchungsfelder: (1) Die Vorstellung vom Normalbetrieb verändert sich dahingehend, dass ein hyperstabiles Bild aufgegeben wird zugunsten der Einsicht, dass auch der organisationale Alltag durch eine Vielzahl kleiner Störungen und Pannen (bis hin zu Beinahe-Katastrophen) gekennzeichnet ist; mithin kann der Normalbetrieb nicht mehr einfach als gegeben vorausgesetzt werden, sondern beruht - besonders in Organisationen eines bestimmten Typs (Highly Reliable Organisations, HRO) - auf einer Vielzahl lokaler Kontroll-, Gewährleistungs- und Reparaturarbeiten. (2) Im Blick auf Krise, Notfall und Katastrophe geht es um Verlauf und Binnenstruktur, die kommunikative und kognitive Dynamik von Eskalation und Deeskalation. Bereits 1977 zählten Dynes/ Quarantelli in vier Fallstudien ca. 300 Aussagen zu Problemen der Kommunikation in den verschiedenen Phasen von Katastrophen (mitigation, preparedness, response, recovery). Vor diesem Hintergrund widmet man sich in den praxisorientierten Emergency Studies anhand historischer Fall- und ethnographischer Mikrostudien (Überblick: Drabek 2007) vielfach kommunikationsbezogenen Gegenständen, die meist in verhaltens- und sozialwissenschaftlichen Perspektiven kategorisiert werden, z.B. Kommunikation unter Stress, Persuasion und ,Compliance-Gaining', Entscheidungsprozesse, interorganisationale Kommunikation, Medientechnologien, öffentliche Krisenkommunikation von Organisationen.

Aus kommunikationslinguistischer Sicht liegt eine Strukturierung der Forschungslandschaft nach Aspekten wie Rollenkonstellationen, Sprache(n), Kommunikationsformen, Gesprächstypen, Datentypen (Realinteraktionen, Simulation, Inszenierung, ...), Organisationskontexten oder Dokumentations- und Aufbereitungsarten (z.B. Videoethnographie, Transkription) nahe. Dabei erscheint uns für ein konzeptuelles Mapping des Untersuchungsfeldes ein handlungstheoretischer Ansatz besonders geeignet, der Komponenten dieser Kommunikation auf der Basis der zeitlich-funktionalen Grundstruktur eines holistischen Aufgabenschemas rekonstruktionslogisch systematisiert (vgl. dazu Abschnitt 1 und Anmerkung 5). ${ }^{14}$

\footnotetext{
14 An dieser Stelle unserer Untersuchung macht sich ein Forschungsdesiderat schmerzlich bemerkbar, wie es für qualitative, empirisch orientierte Ansätze der (Angewandten) Sprachwissenschaft durchaus nicht untypisch ist. Fragt man nämlich danach, welche Erkenntnisse die kommunikationslinguistische Forschung bzw. benachbarte Ansätze der kultur- bzw. sozialwissenschaftlichen Diskursforschung zur Charakterisierung von Kommunikation in Notfall-, Krisen- und Katastrophensituationen bereitstellen kann, stößt man auf ein schwer übersehbares, heterogenes Feld von Einzelstudien, während es an einem systematisierenden
} 
Was nun derartige situierte Notfall- und Krisendiskurse betrifft, liegt ein deutlicher Schwerpunkt der bisherigen empirischen Forschung auf der ersten Phase von Notfallkommunikation, der Alarmierung durch Notrufe (vgl. Bergmann 1993, mit weiteren Literaturhinweisen). Ein Grund für diese Schwerpunktsetzung könnte sein, dass hier die Tätigkeiten fast ausschließlich sprachlicher bzw. parasprachlicher, prosodischer Natur sind. Dokumentiert man z.B. Telefonanrufe bei der Feuerwehr durch Audio-Aufzeichnung, so weisen diese Daten eine „natürliche“ Begrenztheit und Geschlossenheit auf (ebd., S. 291): Alles, was für die laufende Interaktion relevant ist, liegt in der Dokumentation vor. Dagegen befassen sich nur sehr wenige Arbeiten mit denjenigen multimodalen Diskursen, die in die Praxis der direkten Notfallbewältigung ,,vor Ort“ eingebettet sind.

Vor diesem Hintergrund lässt sich unser Gegenstandsbereich vorläufig wie folgt charakterisieren:

1) Es geht um die „mikrosoziologische“, kommunikative Dynamik von Eskalation/Deeskalation in der Phase der unmittelbaren Antwort auf einen Notfall, der Notfallintervention „vor Ort“.

2) Dabei richten wir unseren Fokus exemplarisch auf die Kommunikation der Institution Feuerwehr, speziell auf organisationsinterne Kommunikation während Feuerwehrnotfalleinsätzen in entsprechenden Rollenkonstellationen (Einsatzleiter, Angriffstrupps etc.).

3) Untersucht werden primär Daten in deutscher Sprache, das französische Material wird zu heuristischen Zwecken vergleichend herangezogen. Von Interesse sind alle Kommunikationsformen und Gattungen, an denen sprachliche Zeichen beteiligt sind. ${ }^{15}$

Überblick, der mehr wäre als der eine oder andere selektive Literaturbericht, mangelt. Die unzureichende Koordination des Forschungsfeldes behindert nicht nur die Rezeption einschlägiger Forschungsarbeiten in der Praxis und in den jeweils benachbarten Wissenschaftsdisziplinen, sondern auch die Weiterentwicklung etwa des kommunikationslinguistischen Forschungsgebietes selbst, ja, sie macht bereits die Erkundung des Forschungsgebietes zu einer schwierigen Aufgabe: Welche Konzepte und Kategorien können herangezogen werden, wenn es darum geht, das Feld der Notfall- und Krisenkommunikation zu strukturieren, Ausschnitte des eigenen Gegenstandsbereichs nachvollziehbar abzugrenzen und darauf bezogene Ausgangsprobleme und Forschungsfragen (etwa im Blick auf die Technologieentwicklung) zu formulieren? - Freilich nähme bereits die Vorstudie zu einer Metastudie, also die Entwicklung und Erprobung einer dem Untersuchungsfeld angemessenen qualitativen Methodik zur systematischen Auswahl, Analyse, Aggregation und Synthese der Ergebnisse unterschiedlicher qualitativer Diskursforschungen den Umfang eines komplexen Forschungsprojekts an, wie es etwa im Rahmen einer Dissertation zu bearbeiten ist (vgl. Nowak 2007a, b). Auch wenn eine Untersuchung dieser Art als solche in unserem Rahmen nicht zu leisten war, bot doch die Beschäftigung mit Nowaks „Metastudie über Diskursforschungen zu deutschsprachigen Arzt-Patient-Interaktionen" hilfreiche methodische Anregungen für ein erstes konzeptuelles Mapping und eine erste abgrenzende Charakterisierung des hier fokussierten und spezifisch perspektivierten Ausschnitts der Notfall-, Krisen- und Katastrophenforschung im Sinne sinnvoller Ein- und Ausschlusskriterien.

15 In der kommunikationslinguistischen Forschungspraxis wird der Gegenstandsbereich typischerweise auf bestimmte Kommunikationsformen eingegrenzt, etwa „Diskurse‘ im Hier 
4) Bei den Daten handelt es sich zwar um Simulationen, aber um solche, die nicht von wissenschaftlicher Seite initiiert werden, sondern im Rahmen der Übungs- und Schulungskultur von der Institution selbst. Diese authentischen Simulationen sind zugleich eingebettet in den Kontext von „Talking Labs“ (vgl. Abschnitt 1), damit kommen - im Sinne einer praxeologischen Erweiterung des Gegenstandsbereichs - auch Institutionen ins Blickfeld, die mit der Entwicklung von Medientechnologien für Notfalleinsätze befasst sind.

5) Die Daten werden durch Videoethnographie passiv-registrierend dokumentiert (Bergmann 1985) ${ }^{16}$ und durch Transkription interpretationsarm aufbereitet.

Wertet man die Forschungsliteratur unter diesem Fokus aus, kommen einige Charakteristika von Notfallsituationen ins Blickfeld, die auch für die vorliegende Untersuchung relevant sind: Mit Notfällen geht für die Betroffenen und potenziell auch für die professionellen Helfer die Erfahrung einer „Ent-Setzung“ alltäglicher Routinen und Begriffe einher (Clausen/Geenen/Macamo (Hg.) 2003): Alltägliche Muster sinnhafter Erfahrungsverarbeitung und Aufgabenbewältigung greifen nur noch partiell, die Situation droht der Kontrolle zu entgleiten. Auch professionelle Akteure können sich darauf nur bedingt einstellen, weil jede Krisensituation ihrer eigenen Dynamik folgt. Diese Erfahrung muss bereits in der Situation selbst kommunikativ bearbeitet werden. Dabei wird ein hoher Handlungsdruck erfahren, der

und Jetzt und von Angesicht zu Angesicht oder aus einer aktuellen Sprechsituation entbundene ,Texte“ (vgl. Ehlich 1994). Quer dazu lassen sich freilich sinnvoll weitere Grenzen ziehen (vgl. auch Adamzik 2008, S. 157 f.): So kann Kommunikation strukturiert sein als dialogische, wechselseitige ,symbolische Interaktion ${ }^{6}$ - diese kann synchron oder asynchron sein, an einem Ort oder auf mehrere Orte verteilt - oder als unidirektionale Aufzeichnung, Übermittlung und Rezeption symbolisch codierter „Botschaften“, und beide Konstellationen können mit jeweils guten Gründen als kommunikative Ur-Szene, als Modell von Kommunikation schlechthin aufgefasst werden (vgl. dazu Krämer 2008, die dem Botenmodell in dieser Hinsicht den Vorzug gibt). Noch einmal quer dazu liegen Unterscheidungen anhand der jeweils verwendeten natürlichen, technischen und kulturellen Medien (z.B. Stimme und Schrift, Buchdruck und Computer, gesprochene und geschriebene Sprache, aber auch statische und bewegte Bilder, Töne, Musik etc.) oder anhand komplexer Stilformationen (z.B. konzeptionelle Mündlichkeit und Schriftlichkeit). - Sicher gibt es für eine Begrenzung bzw. Binnengliederung des Gegenstandsbereichs entlang des einen oder anderen Kriteriums jeweils gute Gründe. Andererseits greifen aber, wie wir gesehen haben, die verschiedenen strukturellen Konstellationen, Materialitäten und Zeichenformationen der Kommunikation in praxeologischer Hinsicht vielfältig ineinander (und dass nicht erst seit dem gegenwärtigen Medienumbruch auf der Basis „multimedialer“ Computer und Computernetze). Wenn es also darum geht, an die Kategorien der Beteiligten anzuknüpfen, die in lebensweltlichen Erfahrungen verankert sind, erscheint es sinnvoll, auch auf derartige vorgängige Eingrenzungen und Gliederungen zunächst zu verzichten.

16 In seinem Artikel stellt Bergmann u.a. eine „registrierende Konservierung“ (mit „,nicht-rekonstruierender Datenbasis“, S. 309) einer „rekonstruierenden Konservierung“" gegenüber und stellt fest: „die audiovisuelle Fixierung ist im wesentlichen passiv“ (S. 305 f.). An anderer Stelle plädiert er für eine „naiv registrierende Handhabung der audiovisuellen Reproduktionstechniken“" (ebd., S. 301). 
Entscheidungen, Kooperation und Kommunikation unter allen Umständen notwendig macht. Physische Belastungen kommen noch hinzu. Unter diesen Umständen werden allzu komplexe und allzu offene Symbolsysteme für Produzenten und Rezipienten schnell dysfunktional.

Die Merkmale des fachlichen Sprachstils zeigen, worauf es hier vor allem ankommt: Knappheit, maximale Verständlichkeit, terminologische Präzision, hohe Adressivität (vgl. Abschnitt 1). Vor diesem Hintergrund ist für die Landmarken gemeinsam mit den Beteiligten eine überschaubare Auswahl von Bedeutungen zu treffen, die es den Beteiligten erleichtert, in einer räumlich verteilten und dynamischen sozialen Organisation von Moment zu Moment ein angemessenes $\mathrm{Ma}$ an wechselseitiger „Sichtbarkeit“ von Wahrnehmungen und Deutungen herzustellen.

\section{Fazit und Ausblick}

Wie unsere Untersuchungen zeigen, bleibt - entgegen Weisers Vision gerade die Nutzung neuer, digitaler Medien von sprachlicher Artikulation abhängig. Dieser Umstand lässt sich, auf der Basis der Beobachtungen, systematisch in viererlei Hinsicht erklären:

1) Durch komplexe Ensembles digitaler Geräte, kommunikationstechnischer Netze und sozialer Vernetzungschancen stehen kommunikative Potentiale zur Verfügung, zu deren je besonderer Realisierung es vielfältiger kommunikativer Aneignungsprozesse bedarf, etwa im Sinne einer „Verabredung“" oder „Aushandlung“"von Nutzungskonventionen. Dies gilt zunächst für die Phasen der Entwicklung, Erprobung und Einführung neuer Technologien. Welche Aushandlungsprozesse im Rahmen einer Routinisierung der Nutzung obsolet werden und welche - gerade im offenen, unvorhersehbaren Kontext von Notfall- und Krisensituationen - immer wieder situativ zu leisten sind, ist eine Frage, die im Blick auf bestimmte Technologien jeweils empirisch zu klären ist.

2) Im Prozess der kommunikativen Aneignung geraten mediale Vorrichtungen und alltägliche Bedeutungskonstitution in spannungsreiche Veränderungsdynamiken: Medien werden von den Nutzern nicht nur kreativ gebraucht, sondern auch - auf der Basis sprachlicher Transkriptionen - strukturell weiterentwickelt: So war etwa im Fall der Landmarken das Bemühen der Nutzer erkennbar, im Rahmen der Verständigung über den Einsatzort durch pragmatische und syntagmatische Verfahren komplexe Bedeutungen aufzubauen, die im ursprünglichen Symbolsystem der Landmarken gar nicht vorgesehen waren. Diese sprachlich fundierte Kreativität der Nutzer ist einerseits eine Quelle der Innovation, erfordert andererseits aber auch sorgfältige Abwägungen hinsichtlich der situierten Nutzungsrealitäten. In zeichentheoretischer Hinsicht rückt 
sie den Umstand ins Blickfeld, dass Intermedialität auch eine Quelle des Wandels von Symbolsystemen darstellt. Auch hier ist empirisch zu untersuchen, welche Gestaltungsmerkmale nach einer Entwicklungsphase technisch oder organisatorisch fixiert werden können bzw. inwieweit eine bestimmte Technologie und die organisatorischen Regelungen für ihre Nutzung so offen gestaltet werden müssen, dass im Alltag der Nutzung Weiterentwicklungen durch die Nutzer möglich bleiben.

3) Die enorme Ausdehnung des Erfahrungsraumes, wie sie durch „ubiquitäre" Computertechnologien ermöglicht wird - also das Potential, an praktisch jedem Ort sensorisch erfassbare bzw. digital aufbereitete Daten von praktisch jedem anderen Ort zu bekommen - macht mehr denn je eine situative Auswahl und Spezifikation des Informationsangebots erforderlich. So besteht im Krisenfall eine Herausforderung darin, unter erschwerten Koordinationsbedingungen von Moment zu Moment ein adressaten- und situationssensitiv angemessenes $\mathrm{Ma} ß$ an wechselseitiger Orientierung über relevante Orte, Mitspieler, Objekte, Infrastrukturen, Bewegungen etc. herzustellen. Dabei können Medientechnologien hilfreich sein, etwa wenn es um die Artikulierbarkeit, Visualisierung, Speicherung und situative Verfïgbarmachung von raumbezogener Bedeutung geht. Ihre Nutzung kann aber auch mit Risiken für die Verständigung verbunden sein, etwa dann, wenn durch Medien kommunikationsstrukturelle Asymmetrien - die relevanten Informationen sind ungleich verteilt (vgl. zum Beispiel Datum 3) - etabliert werden.

4) Schließlich müssen in jedem Störungs-, Pannen- oder Krisenfall spezifische Problemkonstellationen in der Kommunikation mit anderen verstanden und medientechnische Potentiale zu ihrer Bearbeitung genutzt werden. Gelingt dies nicht, liegen Störungen ,zweiter Ordnung vor. Diese ziehen die Aufmerksamkeit von den primären Handlungszielen $\mathrm{ab}$, und sie gefährden die kommunikativen Voraussetzungen, die für eine erfolgreiche Bewältigung der Krise erforderlich sind.

In methodischer Hinsicht, speziell für eine Erforschung von Sprache im intermedialen Zusammenhang sind derartige Situationen freilich besonders aufschlussreich: Kommunikationsmedien, in unserem Beispiel das System der Landmarken, werden hier durch die Beteiligten selbst sprachlich dargestellt und diskursiv bearbeitet. Auf diese Weise werden Medialität und Intermedialität - als im Regelfall transparente Kommunikationsgrundlagen interaktiv relevant und zum Thema der Kommunikation; aus einem „Looking through“ wird ein semantisiertes „Looking at“. Vor diesem Hintergrund kann eine medien- und kommunikationslinguistisch fundierte Analyse technikbezogener Artikulationsarbeit den Methodenkanon derjenigen Gestaltungsmethoden in der Informatik ergänzen, die sich einer dezidiert realitäts- und alltagsbezogenen Erfassung und Berücksichtigung von Nutzungssituationen verschrieben haben. 


\section{Literatur}

Adamzik, Kirsten (2008): Textsorten und ihre Beschreibung. In: Janich, Nina (Hg.): Textlinguistik. 15 Einführungen. Tübingen, S. 145-175.

Auer, Peter (i.d.Bd.): Sprachliche Landschaften. Die Formung des Raums durch die geschriebene Sprache.

Ayaß, Ruth (2002): Zwischen Innovation und Repetition: Der Fernsehwerbespot als mediale Gattung. In: Willems, Herbert (Hg.): Die Gesellschaft der Werbung. Kontexte und Texte. Produktionen und Rezeptionen. Entwicklungen und Perspektiven. Opladen, S. 155-171.

Bergmann, Jörg R. (1985): Flüchtigkeit und methodische Fixierung sozialer Wirklichkeit. Aufzeichnungen als Daten der interpretativen Soziologie. In: Bonß, Wolfgang/Hartmann, Heinz (Hg.): Entzauberte Wissenschaft: Zur Relativität und Geltung soziologischer Forschung. (= Sonderheft 3 der Sozialen Welt). Göttingen, S. $299-320$.

Bergmann, Jörg R. (1993): Alarmiertes Verstehen: Kommunikation in Feuerwehrnotrufen. In: Jung, Thomas/Müller-Doohm, Stefan (Hg.): Wirklichkeit im Deutungsprozeß. Verstehen und Methoden in den Kultur- und Sozialwissenschaften. Frankfurt a.M., S. 283-328.

Bergmann, Jörg R. (2006): Studies of work. In: Ayaß, Ruth/Bergmann, Jörg R. (Hg.): Qualitative Methoden der Medienforschung. Reinbek bei Hamburg, S. 391-405.

Berthele, Raphael (2006): Ort und Weg. Die sprachliche Raumreferenz in Varietäten des Deutschen, Rätoromanischen und Französischen. Berlin/New York.

Bühler, Karl ([1934] 1999): Sprachtheorie. Die Darstellungsfunktion der Sprache. 3. Aufl., ungekürzter Neudr. d. Ausg. Jena 1934. Stuttgart. [1. Aufl. Jena 1934].

Button, Graham (Hg.) (1993): Technology in the working order: Studies of work, interaction, and technology. London/New York.

Clausen, Lars/Geenen, Elke M./Macamo, Elisio (Hg.) (2003): Entsetzliche soziale Prozesse. Theorie und Empirie der Katastrophen . (= Konflikte, Krisen und Katastrophen - in sozialer und kultureller Sicht 1). Münster.

Corbin, Juliet M./Strauss, Anselm L. (1993): The articulation of work through interaction. In: The Sociological Quarterly 34, 1, S. 71-83.

Deppermann, Arnulf/Schmitt, Reinhold (2007): Koordination. Zur Begründung eines neuen Forschungsgegenstandes. In: Schmitt (Hg.), S. 15-54.

Douglas, Mary/Wildavsky, Aaron (1982): Risk and culture. An essay on the selection of technological and environmental dangers. Berkeley.

Drabek, Thomas E. (2007): Sociology, disasters and emergency management: History, contributions, and future agenda. In: McEntire, David A. (Hg.): Disciplines, disasters and emergency management: The convergence and divergence of concepts, issues and trends from the research literature. Springfield, IL, S. 61-74.

Dynes, Russell R./Quarantelli, Enrico L. (1977): Organizational communications and decision making in crises. Columbus, $\mathrm{OH}$. 
Dyrks, Tobias/Denef, Sebastian/Ramirez, Leonardo (2008): An empirical study of firefighting sensemaking practices to inform the design of ubicomp technology. In: Electronic Workshop Proceedings of the SIGCHI Conference on Human Factors in Computing Systems. Internet: http://dmrussell.googlepages.com/sensemakingwork shoppapers (Stand: November 2009).

Ehlich, Konrad (1994): Funktion und Struktur schriftlicher Kommunikation. In: Günther, Hartmut/Ludwig, Otto (Hg.): Schrift und Schriftlichkeit. Bd. 1. (= Handbücher zur Sprach- und Kommunikationswissenschaft 10). Berlin/New York, S. $18-41$.

Fricke, Ellen (2009): Deixis, Geste und Raum: Das Bühlersche Zeigfeld als Bühne. In: Buss, Mareike/Jautz, Sabine/Liedke, Frank/Schneider, Jan (Hg.): Theatralität sprachlichen Handelns. Eine Metaphorik zwischen Linguistik und Kulturwissenschaften. München, S. 165-186.

Garfinkel, Harold (Hg.) (1986): Ethnomethodological studies of Work. London.

Habscheid, Stephan/Pipek, Volkmar (2008): Talking Labs im Krisenmanagement. Artikulationsarbeit in offenen Innovationsprozessen des digitalen Medienumbruchs. In: Kulturwissenschaftliches Forschungskolleg SFB/FK 615 Medienumbrüche. Medienkulturen und Medienästhetik zu Beginn des 20. Jahrhunderts und im Übergang zum 21. Jahrhundert. Finanzierungsantrag 2009/2-2013/1. Bd. 2. Siegen, S. 495-526.

Hausendorf, Heiko (i.d.Bd.): Interaktion im Raum. Interaktionstheoretische Bemerkungen zu einem vernachlässigten Aspekt von Anwesenheit.

Jäger, Ludwig (2004): Störung und Transparenz. Skizze zur performativen Logik des Medialen. In: Krämer, Sybille (Hg.): Performativität und Medialität. München, S. 35-73.

Knape, Joachim (2005): Katastrophenrhetorik und Strukturdeterminiertheit der Medien. Am Beispiel des 11. September 2001. In: Knape, Joachim (Hg.): Medienrhetorik. Tübingen, S. 231-259.

Krämer, Sybille (2008): Medium, Bote, Übertragung. Kleine Metaphysik der Medialität. Frankfurt a.M.

Krifka, Manfred/Martens, Silka/Scharz, Florian (2004): Linguistics factors. In: Dietrich, Rainer/Childress, Traci Michelle (Hg.): Group interaction in high risk environments. Aldershot, S. 75-86.

Luff, Paul/Hindmarsh, Jon/Heath, Christian (Hg.) (2000): Workplace studies. Recovering work practice and informing system design. Cambridge.

Mondada, Lorenza (2007): Interaktionsraum und Koordinierung. In: Schmitt (Hg.), S. 55-93.

Müller, Cornelia/Bohle, Ulrike (2007): Das Fundament fokussierter Interaktion. Zur Vorbereitung und Herstellung von Interaktionsräumen durch körperliche Koordination. In: Schmitt (Hg.), S. 129-166.

Nowak, Peter (2007a): Eine Systematik sprachlichen Handelns von Ärzt/inn/en. Metastudie über Diskursforschungen zu deutschsprachigen Arzt-Patient-Interaktionen. Diss. Univ. Wien. 
Nowak, Peter (2007b): Metastudien-Methodik - ein neues Methodenparadigma für die Diskursforschung. In: Gesprächsforschung - Online-Zeitschrift zur verbalen Interaktion 8, S. 89-116. Internet: www.gespraechsforschung-ozs.de/heft2007/ga-nowak. pdf (Stand: Oktober 2009).

Perrow, Charles (1999): Normal accidents: Living with high risk technologies. 2. Aufl. Princeton, NJ.

Potthast, Jörg (2007): Die Bodenhaftung der Netzwerkgesellschaft. Eine Ethnografie von Pannen an Großflughäfen. Bielefeld.

Schmitt, Reinhold (Hg.) (2007): Koordination. Analysen zur multimodalen Interaktion. (= Studien zur Deutschen Sprache 38). Tübingen.

Schmitt, Reinhold/Deppermann, Arnulf (2007): Monitoring und Koordination als Voraussetzungen der multimodalen Konstitution von Interaktionsräumen. In: Schmitt (Hg.), S. 95-128.

Strauss, Anselm L. (1988): The articulation of project work: An organizational process. In: The Sociological Quarterly 29, 2, S. 163-178.

Strauss, Anselm/Fagerhaugh, Shizuko/Suczek, Barbara/Wiener, Carolyn (1985): Social organization of medical work. Chicago/London.

Suchman, Lucy A. (1987): Plans and situated actions: The problem of human-machine communication. Cambridge/New York.

Voss, Martin (2006): Symbolische Formen. Grundlagen und Elemente einer Soziologie der Katastrophe. Bielefeld.

Weick, Karl (1990): The vulnerable system: An analysis of the Tenerife air disaster. In: Journal of Management 16, 3, S. 571-596.

Weiser, Mark (1991): The computer for the 21st Century. In: Scientific American 265, 3, S. 94-104.

Wildavsky, Aaron B. (1988): Searching for safety. New Brunswick, NJ. 


\title{
Sprachliche Landschaften \\ Die Strukturierung des öffentlichen Raums durch die geschriebene Sprache ${ }^{1}$
}

\begin{abstract}
Es gehört zu den Gemeinplätzen der Linguistik, dass gesprochene Sprache situationsgebunden, geschriebene Sprache aber zumindestens tendenziell situationsgelöst sei und sich über Orte und Zeitpunkte hinweg transportieren lässt, ohne ihre Bedeutung wesentlich zu verändern. Eine große Menge von schriftlichen Zeichen ist allerdings genau durch das umgekehrte Phänomen gekennzeichnet: sie sind ortsstabil und in ihrer Bedeutung von ihrem lokalen Kontext abhängig. Die Schrift auf Schildern, Plakaten und anderen öffentlichen Zeichen ist eine spezifische Form von Sprache, die den gängigen Stereotype von Schriftlichkeit widerspricht, weil sie „ding“- bzw. „ortsfest" ist und funktional wie auch formal anderen Regelmäßigkeiten folgt als die meist betrachtete Schrift der Texte auf transportablen Trägern wie Buch, Zeitung, elektronischem Textdokument oder e-mail. Solche Funktionen von Schrift (wie Wegweisen, Orientierung geben, Erinnern und Appellieren, Zugehörigkeit signalisieren) sind seit deren Erfindung relevant gewesen; erst in jüngster Zeit werden aber orts- und dingfesten Zeichen unter dem Begriff der linguistic landscapes ins Blickfeld der Linguistik gerückt und systematisch untersucht. Das Forschungsinteresse liegt vor allem in der Beantwortung der Frage, wie öffentliche Zeichen Sprach-Räume konstituieren, und zwar insbesondere monolinguale oder bilinguale Räume in mehrsprachigen Gesellschaften. Der folgende Beitrag geht aber nur nebenbei auf solche Sprach-Räume ein; sein primäres Interesse gilt der Art und Weise, wie öffentliche, orts- und dingfeste Zeichen überhaupt Raum konstituieren, d.h. wie wir semiotisch dicht organisierte Räume ,lesen', um uns in ihnen zu orientieren.
\end{abstract}

\section{Die Mär von der Situationsunabhängigkeit der geschriebenen Sprache}

Es gehört zu den Allgemeinplätzen der Sprachwissenschaft, dass sich gesprochene und geschriebene Sprache durch ihren Bezug auf die Situation unterscheiden: während die gesprochene Sprache, wie vielleicht am prominentesten Karl Bühler dargelegt hat (Bühler 1934 [1982]), von der Sprechsituation - also der zeitlichen (HIC), räumlichen (NUNC) und personalen (EGO) Verankerung des Sprechakts - abhängt, sei die geschriebene Sprache von Zeit, Ort und Sprecher losgelöst und auf diese Weise transportabel, also situationsunabhängig verständlich. Das ist ohne Zweifel für einen großen Teil der schriftsprachlichen Produkte in Vergangenheit und Gegen-

Mein Dank für Kommentare und Hinweise geht an Karin Birkner, Arnulf Deppermann sowie Anja Stukenbrock. Einige der verwendeten Fotos gehen auf fieldwork von Studierenden des Studiengangs Master of European Linguistics (MEL) an der Universität Freiburg zurück. Auch ihnen sei hiermit gedankt! 
wart zutreffend, und es lässt sich daraus zu Recht ableiten, dass Schriftsprache ein Verfahren ist, das gesellschaftliche Gedächtnis zu objektivieren. Schrifttexte in Medien wie Büchern, Zeitungen oder dem Internet sind dazu geeignet, immer wieder (von unterschiedlichen Menschen an unterschiedlichen Orten und zu unterschiedlichen Zeitpunkten) gelesen zu werden. Diese situationsunabhängige Stabilität prädestiniert sie, den Wissenskanon einer Gesellschaft zu formen. Zu diesem Kanon gehören in ganz besonderer Weise auch normative Texte. Schrift etabliert so Traditionen und dadurch auch abstrakte gesellschaftliche Institutionen wie das Recht; sie sorgt für gesellschaftliche Stabilität (Ong 1982). Dazu trägt neben der Transportabilität der Texte auch ihre Reproduzierbarkeit bei, die von handgeschriebenen Textrollen und Büchern über Inkunablen und gedruckte Bücher bis zu elektronischen Texte in mehreren technologischen Revolutionen immer wieder radikal verbessert wurde.

Das ist jedoch nur ein Teil der Wahrheit, und nur ein Teil der Geschichte und Funktionalität der Schrift. Daneben gibt es eine andere Funktionalität, die mindestens ebenso alt ist, in der Forschung aber oft vergessen wird. In dieser Verwendung ist die Schrift unauflöslich mit dem Objekt, auf dem sie angebracht ist, oder dem Ort, an dem sich dieses Objekt befindet, verbunden, und kann ohne diese Dingfestigkeit und/oder Lokalisierung gar nicht verstanden werden. Schrift ist hier zwar vom Sprecher und von der Zeit gelöst, sie ist jedoch räumlich bzw. dinglich verankert. Bühler (1934 [1982], S. 159) erfasst einen Teil dieser Schriftfunktion, wenn er von symphysischen Zeichen spricht, die durch ihre „dingliche Anheftung“ gekennzeichnet sind. Dass es sich hier ebenfalls um eine der originären und primären Funktionen von Schrift handelt, bezeugen viele Schriftdokumente aus beginnenden und frühen Schriftkulturen. Eines der ältesten Schriftdokumente des Germanischen aus dem ansonsten kaum dokumentierten Nordwestgermanisch sind zum Beispiel die Hörner von Gallehus, die vermutlich anlässlich einer Sonnenfinsternis des Jahres 413 angefertigt wurden. Auf einem Horn befindet sich in Runeninschrift der Satz

\section{EK HLEWAGASTIZ HOLTIJAZ HORNA TAWIDO}

„Ich, Hlewagast, der Holte, habe das Horn gemacht“.

Es ist offensichtlich, dass die Schrift hier der Zuordnung eines Objekts zu einer Person (vermutlich des Auftraggebers) dient - eine der grundlegenden Funktionen von dingfester Schriftsprache. Der Satz löst zwar das deiktische Pronomen $e k$ durch Namensnennung auf. Die Nominalphrase borna lässt sich aber nicht referenziell interpretieren, wenn nicht das Objekt bekannt ist, auf das sie sich bezieht: nämlich auf das Horn, auf dem die Schrift angebracht ist. ${ }^{2}$

2 Eine moderne Form solcher dingfester Schriftverwendung untersucht Hausendorf (im Druck) - nämlich das „Kleingedruckte“ auf der Unterseite von Plastiktüten (Warning! Keep 
Auch ortsfeste Inschriften sind in den Schriftkulturen des Altertums weit verbreitet. Auf den ägyptischen Tempeln sind sie in der Regel mit Bildern verbunden. So steht in der Nordwestecke des Vestibüls der HathorKapelle im Hatschepsut-Tempel in Luxor aus dem 15. Jahrhundert v. Chr. die Königin Hatschepsut vor Hathor; zwischen beiden ist noch der Rest der erläuternden Inschrift zu sehen, die wohl vollständig lautete (erhalten ist nur der kursiv gedruckte Teil): „Der König von Ober- und Unterägypten [nämlich Tutmosis] hat ihr(?) Denkmal gemacht für ihre(?) Mutter Hathor, die Herrin von Dendera, sie (!) hat es gemacht [damit ihr] Leben gegeben werde wie Ra."

Die Inschrift ist dingfest (in Stein eingemeißelt), aber auch ortsfest: ihr Bezug auf den Tempel, auf dem sie steht, ist unerlässlich für die richtige Interpretation. Die Funktion der (In-)Schrift ist eine doppelte: einerseits errichtet Tutmosis ein Denkmal für seine Frau Hatschepsut (Ehrungsfunktion), andererseits wird der Tempel der Göttin Hathor geweiht (Weihefunktion). Die Ermahn- und Gedenkfunktion (unter die man die Ehrungsfunktion einordnen kann) ist für die öffentliche, orts- und dingfeste Schriftsprache bis heute typisch, die Weihe- oder Zueignungsfunktion ist hingegen heute selten.

Die beiden Beispiele belegen wie viele andere, dass die These, die Erfindung der Schrift sei essentiell mit der Situationsablösung von Sprache verbunden, nicht zutreffen kann - zumindest nicht in Bezug auf die Dimension des Orts. Die Zurschaustellung von Schrift im öffentlichen Raum ist vielmehr, wie Coulmas jüngst (2008) unter anderem am Beispiel des Codex Hammurabi und des Rosetta Stone zeigt, von grundsätzlicher Bedeutung, wenn man schriftlich fixierte Sprache verstehen möchte. Sie brachte eine wichtige Veränderung der Semiotik des menschlichen Lebensraums mit sich, die eng mit der Entwicklung urbaner Gesellschaften zusammen hängt.

Erst seit etwa 10 Jahren gibt es in der Linguistik eine Forschungsrichtung, die sich mit dieser ding- und vor allem ortsfesten Schriftverwendung im öffentlichen Raum beschäftigt und unter dem etwas irreführenden Begriff linguistic landscape research bekannt geworden ist (vgl. jüngst: Shohamy/ Gorter (Hg.) 2008). Sprachliche Landschaften werden in dieser Forschungstradition meist unter Rückgriff auf einen der ersten Beiträge zu diesem Thema eher aufzählend als definitorisch beschrieben:

The language of public road sings, advertising billboards, street names, place names, commercial shop signs, and public signs on government buildings combines to form the linguistic landscape of a given territory, region, or urban agglomerate. (Landry/Bourhis 1997, S. 25)

Es geht in den bisher publizierten Arbeiten praktisch immer um die Ökologie städtischer Räume, die durch die in ihnen öffentlich sichtbaren Zeichen

this bag away from babies and children!, u.Ä.). 
konstituiert oder zumindest gedeutet werden (vgl. aber Auer 2009). Dabei wurden in der überwiegenden Anzahl der Untersuchungen vor allem multilinguale Gesellschaften untersucht. Diese Einschränkung ist aber keineswegs zwingend; es bleibt sogar offen, bis zu welchem Grad und in welcher Art uns Untersuchungen der sprachlichen Landschaft tatsächlich helfen können, die Struktur einer mehrsprachigen Gemeinschaft besser zu verstehen. Zugleich fällt ein Mangel an theoretischer Reflexion auf, der nur selten zum Beispiel in Ron und Suzie Wong Scollons Arbeit über Discourse in Public Places (2003) - überwunden wird. Ich will im Folgenden eine über den Anwendungsaspekt der multilingualen Städte hinausgehende Orientierung in diesem neuen Forschungsgebiet geben und anhand von Beispielen aus ganz unterschiedlichen soziolinguistischen Kontexten grundsätzliche Klärungen versuchen. Berücksichtigt wird nur die Schnittmenge aus ortsgebundener Schrift (wie oben skizziert) und öffentlichem Sprachgebrauch. Es kommen im öffentlichen Sprachgebrauch durchaus auch andere Schriftzeichentypen vor als die symphysischen; umgekehrt sind nicht alle dingfesten Schriftverwendungen auch öffentlich.

\section{Der öffentliche Gebrauch der Sprache und die Ortsfestigkeit der Schrift}

\subsection{Wozu ortsgebundene Schrift?}

Wie stark öffentliche Räume durch Schrift bestimmt sein können, merken wir vor allem, wenn wir uns in einem Raum bewegen, der zwar offensichtlich durch Schriftzeichen geprägt ist (oder zumindest von ihnen gedeutet wird), in dem wir uns aber schrift-los zurecht finden müssen (etwa in einer japanischen Innenstadt). Andererseits ist offensichtlich, dass es Grade der sprachlichen Konstitution von Räumen gibt. Es scheint etwa nicht weiter erklärungsbedürftig, dass in ländlichen Regionen weniger Schriftzeichen zu sehen sind als in städtischen. Selbst in alten, stark vom Menschen geformten, aber dennoch ruralen Kulturlandschaften wird der Raum lediglich durch Wege, Landmarken und manchmal auch nicht-sprachliche Zeichen (,Steinmännchen'; vgl. Schmaucks 2002) strukturiert. Das deutet bereits auf eine erste wesentliche Eigenschaft der Kommunikation durch öffentliche, ortsgebundene Schrift hin: sie macht vor allem solche Räume les- und damit nutzbar, die nicht durch das routinemäßige Zusammenleben Ortskundiger gekennzeichnet sind. Diese Behauptung impliziert eine spezifische Sichtweise auf den Raum als Möglichkeit sozialen Handelns, wie sie etwa von Anthony Giddens (1984, Kap. 3 und [1979] 1995) entwickelt wird. Danach bedienen sich die Gesellschaftsmitglieder des Raums, um routinemäBig ablaufende Handlungen zu ermöglichen: der Raum bietet Schauplätze 
(locales), die bereits die Möglichkeit bestimmter Aktions- bzw. Interaktionsroutinen in sich tragen. Solange jeder weiß, welche Handlungen an welchen Orten möglich, unmöglich, erwünscht, notwendig, anzuraten etc. sind, ist es nicht notwendig, Schrift einzusetzen, um diese Handlungsräume zu eröffnen. Es ist ja allen bekannt, dass der Weg zu den Feldern an jenem Berg vorbei und an diesem Baum links abbiegend erreicht wird; dass es gefährlich ist, diesem glitschigen Abhang zu nahe zu kommen; dass hier Schutz vor einem Gewitter möglich ist; dass an jener Biegung ein Platz ist, um die Schafe weiden zu lassen etc. Die öffentliche Verwendung der Schrift wird dann relevant, wenn der Raum sich nicht ohne Weiteres in solche allgemein bekannte Orte routinehaften Handelns gliedert, sondern für bestimmte Nutzer erst interpretiert und Handlungstypen zugewiesen werden muss: sei es, dass die Handlungen zwar selbst routinisiert sind, die Nutzer aber die ihnen entsprechenden Orte nicht kennen (wir wissen, wie man in einen Zug steigt, aber nicht, wo der Zug nach Mannheim abfährt), sei es, dass die an einem Ort erforderlichen oder erwünschten Handlungen gerade nicht für die dem Nutzer bekannten Routinen geeignet sind (an diesem Ort darf nicht geraucht werden), sei es, dass routinehaften Handlungen ausnahmsweise nicht möglich sind, also eine Sondersituation eintritt (der Aufzug bleibt stecken, die Straße ist blockiert). Schließlich ist es auch möglich, dass öffentliche Schrift überhaupt erst in bestimmte Handlungsmuster einführt, die eben keine Routinen sind (die Bedienung eines Straßenbahnfahrkartenautomaten in einer fremden Stadt etc.). Umgekehrt gilt: Wer sich in einem durch öffentliche Zeichen dicht strukturierten Raum bewegt, um lediglich die darin angebotenen Orte für routinisierte Handlungen zu nutzen und überdies diese Orte kennt, ignoriert die öffentlichen Zeichen: wer jeden Tag denselben Zug nimmt, braucht keine Schilder und Inschriften im Bahnhof, um sich zu orientieren, er nimmt sie gar nicht mehr zur Kenntnis.

Die ortsfeste Schrift eröffnet also Handlungs-Räume. Sie bietet dazu die Möglichkeit von Interaktion zwischen dem Zeichenproduzenten (der oft anonym ist) und dem Zeichenrezipienten und ersetzt damit Formen der face-to-face-Kommunikation, die unzuverlässig und störungsanfällig sind: wir könnten einen (Orts-)Kundigen fragen, wo sich das Rathaus befindet, ob man hier die Straße überqueren darf, wie man sein Gepäck aufbewahren kann oder wie die Straße heißt, in der wir uns befinden, aber nicht immer steht ein solcher Kundiger zur Verfügung, nicht immer spricht er unsere Sprache, nicht immer gibt er zuverlässig Auskunft.

Durch ihre Lösung von der Kopräsenz von Zeichenproduzenten und -rezipienten ähnelt die öffentliche Schrift bei aller Differenz der situationsgelösten geschriebenen Sprache, deren Funktionalität ebenfalls nicht an die Kopräsenz der Interaktionspartner gebunden ist. Dennoch würde das Bild 
der ,zerdehnten“ Sprechsituation (Ehlich 1984) in die Irre führen: ortsfeste Schrift ist oft depersonalisiert und immer von der Origo des Sprechzeitpunkts losgelöst. ${ }^{3}$ Während der Begriff der zerdehnten Kommunikation zwischen Autor und Leser auf die Zeitdimension fokussiert (in der gerade die mangelnde Kopräsenz zum Problem wird), ist die öffentliche Schrift von vorne herein zeitneutral angelegt, sie bezieht sich ganz auf den Ort.

\subsection{Indexikalische und nicht-indexikalische öffentliche Schrift}

Die Forschung über linguistische Landschaften untersucht meist (der oben zitierten Definition bzw. Aufzählung folgend) alle sichtbaren Schriftzeichen im öffentlichen Raum. Tatsächlich sind aber mehrere semiotische Typen zu unterscheiden, die es fraglich machen, ob diese Eigenschaft - öffentliche Sichtbarkeit - überhaupt einen kohärenten und sinnvollen Phänomenbereich eingrenzt. Vor allem sind längst nicht alle öffentlichen Schriftverwendungen in dem Sinn indexikalisch, dass sie nur an und durch den Ort interpretierbar sind, an dem sie sich befinden. Der Unterschied lässt sich schnell erkennen, wenn Zeichen „außer Betrieb“ gestellt werden. Das Schild in Abb. 1 mit der Aufschrift Achtung Rutschgefahr und einem entsprechenden Piktogramm ${ }^{4}$ kann nicht mehr interpretiert werden, weil es keinen Ort hat, auf den es sich bezieht. Seine Indexikalität ist vorübergehend außer Kraft gesetzt. Natürlich hat das Zeichen - wie alle indexikalischen Zeichen, z.B. die deiktischen Personalpronomen - immer noch ein Verweispotenzial: wir wissen, was es bedeuten würde, wenn es in Betrieb wäre. Die Indexikalität des Zeichens wird also nicht durch die Form des Zeichens selbst stillgelegt (wenn man einmal von Fällen semiotischer overlays im Zeichen selbst absieht, etwa dem ,Ausstreichen' eines Verkehrsschilds durch die kreuzweise darauf geklebte Folie); die Stilllegung muss vielmehr selbst kontextualisiert und kontextuell erschlossen werden. In Abb. 1 wird sie durch die Stapelung der identischen Schilder und ihre Aufbewahrung neben dem Reinigungsgerät, also auf der sozialen ,Hinterbühne' (Goffman 1959) eines Bahnhofs, erreicht. Beide sind außer Betrieb, die Schilder und das Reinigungsgerät. Das Schild wird offensichtlich von demselben Personal, das auch die Reinigungsmaschine bedient, im Bedarfsfall so aufgestellt, dass dadurch eine Warnung vor glatten Böden nach der Reinigung ausgesprochen wird.

\footnotetext{
3 Vermeintliche Gegenbeispiele wie die oft zitierten personalisierten und von einer (faktisch nicht gelieferten) Zeitorigo abhängigen Notizen des Typs bin gleich zurück sind gerade deshalb keine Gegenbeispiele, weil sie einen Fall stukturell missglückter Kommunikation darstellen und so zeigen, wie orts- und dingfeste Schrift gerade nicht funktionieren kann.

$4 \quad$ Das Schild selbst belegt übrigens gut die oben skizzierte These, dass öffentliche Schrift das Verhalten in bestimmten Räumen im Falle des Nicht-Greifens von Routinen steuert: wo man sonst routinemäßig geht, sollte man es nicht tun, wenn das Schild aufgestellt ist.
} 


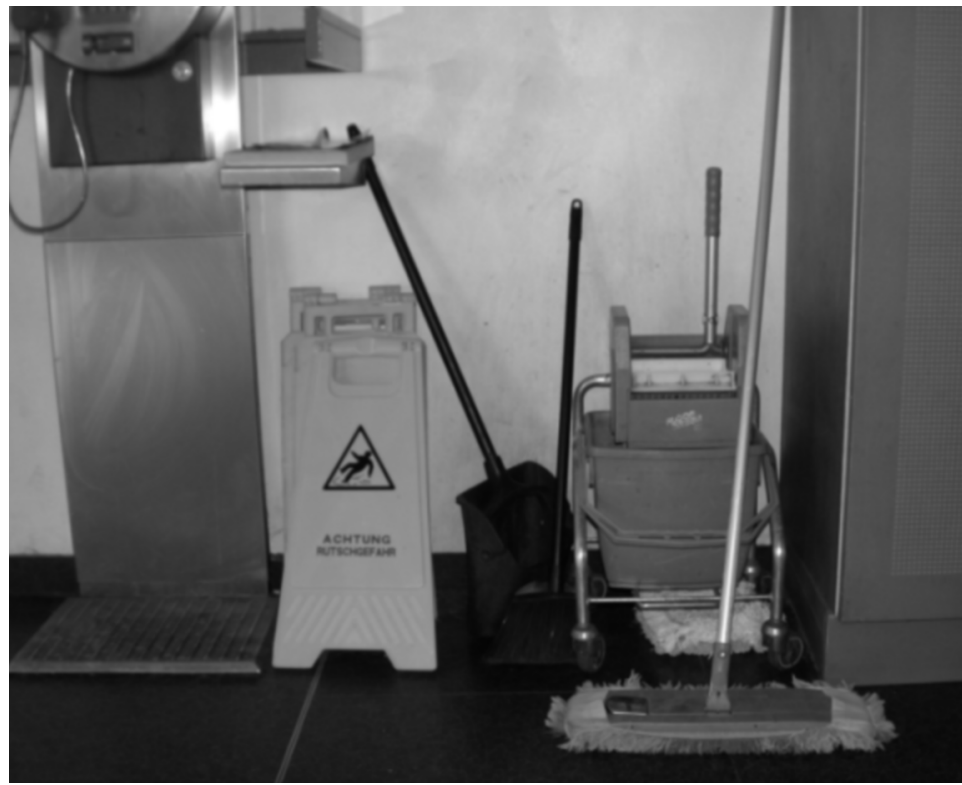

Abb. 1: Ortsgebundene (indexikalische) Schilder außer Betrieb (stillgelegte Indexikalität) (Freiburg, Hauptbahnhof).

Neben solchen temporär stillgelegten ortsgebundenen Zeichen gibt es solche, die permanent außer Betrieb genommen worden sind, also nur noch geschichtliche Zeichen sind. Selbst dann aber ist ihre einstige Funktionalität meist noch lesbar, auch wenn ihre Referenz nicht mehr sicher ist. Die Inschrift auf dem Horn von Gallehus ist nicht mehr interpretierbar, weil wir ,Hlewegast' nicht kennen. Dennoch können wir davon ausgehen, dass er durch die Inschrift seinen Status als Auftraggeber gekennzeichnet hat. Die leere, im Jugendstil gestaltete Vitrine in der Haupteinkaufsstraße in Helsinki in Abb. 2 trägt die schwedische Inschrift $A / B$ Fazers-Musikhandel (ein Pendant auf Finnisch befindet sich auf demselben Gebäude etwas entfernt). Sie hat offensichtlich keine Referenz mehr, denn weder ist in der Vitrine etwas ausgestellt, noch gibt es an dieser Stelle der Alexanderinkatu ein Musikwarengeschäft. Die Schrift indiziert aber nach wie vor durch ihre Ding- und Ortsfestigkeit die Zugehörigkeit der Vitrine zu einem Geschäft, das es nicht mehr gibt. Über Inferenzen lässt sich erschließen, dass sich an diesem Ort die Musikhandlung Fazer befunden haben muss: das Schild ist historisch.

Innerhalb der Gruppe der indexikalischen öffentlichen Schriftzeichen sind weitere Untergliederungen möglich. So lassen sich indexikalische Verfahren identifizieren, die mit der Kontiguität zwischen Zeichen und intendiertem Referenten arbeiten. Dies trifft auf die eigentlich dingfesten Zeichen (Horn von Gallehus) zu, aber auch auf die Schilder in Abb. 1, die durch die 
Verbindung mit dem Boden, auf den sie stehen, Bedeutung erlangen. Daneben stehen Zeichen, die auf einen mehr oder weniger weit entfernten Ort verweisen; der Prototyp ist der distal zeigende Wegweiser (vgl. Abb. 3).

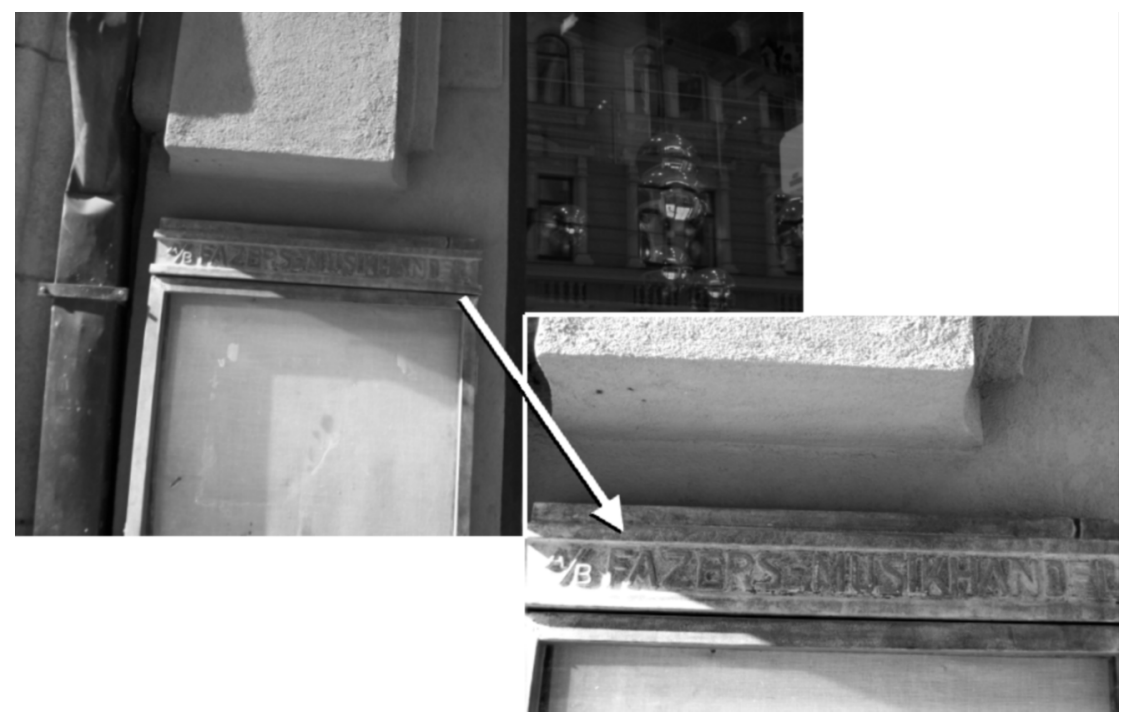

Abb. 2: Permanent stillgelegtes indexikalisches Zeichen: A/B Fazers Musikhandel (Helsinki, Alexanderinkatu; Foto K. Wagner).

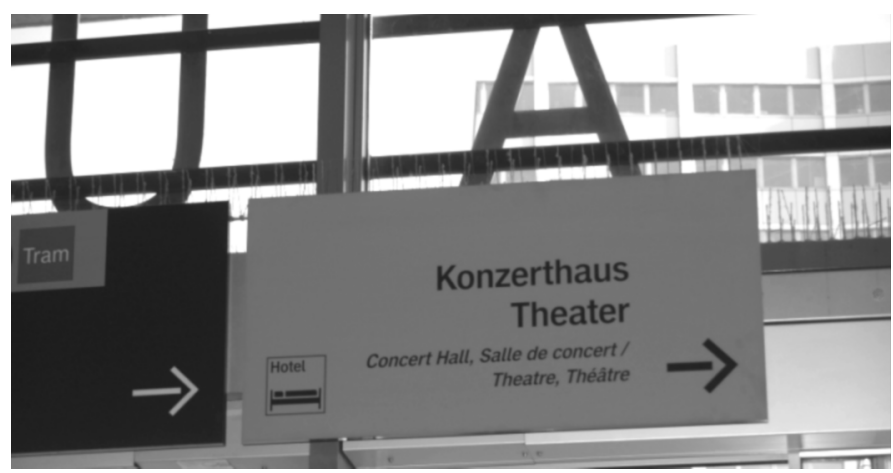

Abb. 3: Wegweiser (distaler Pointer), hohe Granularität, mehrsprachig deutschfranzösisch-englisch (Freiburg, Hauptbahnhof).

Das Beispiel aus Abb. 1 zeigt, dass ein indexikalisches Zeichen nicht auf ein spezifisches indexikalisches Sprachelement (wie „dieses Horn“) oder einen nichtverbalen pointer (den Pfeil in Abb. 3) angewiesen ist. Die Platzierung des Schilds mit der Aufschrift Achtung Rutschgefahr und dem entsprechenden icon (ausrutschendes Männchen) würde allein durch ihre räumliche Kontiguität mit dem Untergrund, auf den es sich bezieht, Bedeutung erlangen. 
(Dasselbe gilt für die Beispiele 2, 6, 7, 8, 9, 13-17.) Daraus ergibt sich als weitere Kategorisierungsmöglichkeit von indexikalischen Zeichen die Präsenz eines solchen pointers.

Schließlich lassen sich indexikalische Zeichen nach der Art subklassifizieren, in der sie sich auf den Ort beziehen. Die Identifizierung eines physikalischen Ort (wie in den bisher genannten Beispielen) als dem Thema der auf dem Zeichen verbalisierten rhematischen Information (,dieser Ort ist rutschig“, „dies ist eine Vitrine der Musikhandlung Fazer“ etc.) ist nur die einfachste Form dieses Bezugs. In anderen Fällen evoziert die öffentliche Schrift durch den Ort, an den sie angebracht ist, Wissensbestände, die für die Interpretation des Schriftzeichens unabdingbar sind. Etwa ist der Aufkleber auf dem in Abb. 12 dokumentierten Schild (Parkhauskasse: Automat steht im Parkdeck. kurz vor der Ausfahrt) deshalb indexikalisch, weil er eine ganze Handlungssequenz aufruft, die mit dem Benutzen des Parkhauses, an dessen Eingang er angebracht ist, verbunden ist. (Vgl. zu einem weiteren Beispiel Fußnote 5.)

Die Bedeutung öffentlicher, aber nicht indexikalischer, also nicht ortsgebundener und/oder dingfester Zeichen wird durch Veränderungen in der Platzierung hingegen nicht in derselben Weise berührt wie die indexikalischer. Sie können verstellt, abmontiert, in ihrer Richtung verändert werden, ohne dass sie ihre Funktion verlieren. Zu den nicht-indexikalischen Sprachzeichen im öffentlichen Raum gehört in der Regel die Werbung, aber auch transgressive (siehe unten, Abschnitt 2.8) Zeichen wie der kleine Aufkleber auf der Rückseite eines öffentlichen Verkehrszeichens in Abb. 4 mit der Aufschrift Schäuble is watching you - Stasi 2.0 und dem Bild des ehemaligen Innenministers des Bundes sowie viele Grafitti (Ausnahme sind die sog. Marken). Solche Zeichen können an vielen, oft an beliebigen Orten angebracht oder aufgestellt werden und sind überall in derselben Weise bedeutungsvoll und verständlich. ${ }^{5}$ Aus diesem Grund kann Werbung auch auf mobilen Objekten (Busse, Züge) angebracht werden. Das heißt natürlich nicht, dass solche nicht ortsgebundenen Zeichen nicht ebenfalls den Raum kolonialisieren und die Sprache territorialisieren, wie später noch ausgeführt wird (Abschnitt 2.8). Auch sind nicht-indexikalische öffentliche Zeichen an manchen Orten passender als an anderen; ein Reklameposter kann in einer Abstellkammer stehen, ein Werbeplakat im Museum hängen. Dann fehlt

\footnotetext{
Es gibt durchaus Fälle, in denen der Unterschied zwischen indexikalischer und nicht-indexikalischer öffentlicher Schrift nicht trivial ist, sondern eine genaue textuelle Analyse erfordert. Zum Beispiel sind die gedruckten Fahrpläne, die in deutschen Bahnhöfen aushängen, als Gesamttext kontextfrei verständlich. Die notwendige Information über die Gültigkeit des Fahrplans (,Sommerfahrplan 2009“) und den Ort, von dem die Züge abfahren oder wo sie ankommen, ist im Text selbst enthalten. Der Aushang ist funktional einer Version als Faltblatt oder „Städteverbindung“ äquivalent. Die ebenfalls funktional identischen Angaben auf den inzwischen üblichen elektronischen Anzeigetafeln über die abgehenden Züge sind hingegen indexikalisch in Zeit und Ort eingebunden.
} 
dem Zeichen sein intendierter Adressatenkreis. Dieser fehlende Kontext ist aber kein räumlicher. Die Zeichen sind in einer anderen Weise ,außer Betrieb" als die genannten indexikalischen Zeichen, denn sie konstituieren keinen Raum und sind von keinem Raum abhängig.

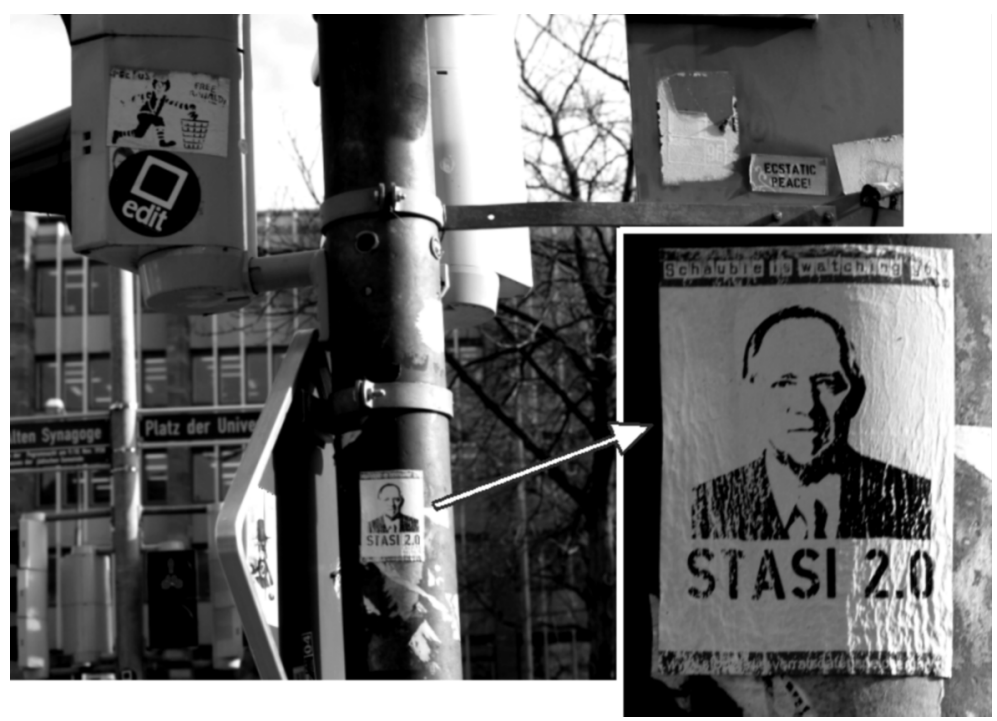

Abb. 4: Transgressives Zeichen, nicht-indexikalisch (Freiburg, Platz der Universität).

\subsection{Granularitätsstufen}

Ein zweites Manko der augenblicklichen Forschung über linguistic landscapes ist die Vernachlässigung der Granularität der öffentlichen Schriftzeichen. Nicht alle Schrift im öffentlichen Raum ist für dieselben Rezipienten gemacht; diese Rezipientenorientierung spiegelt sich in der Granularität des Zeichens wider. Sie bringt die intendierten Leser ins Spiel; allerdings nicht als Individuen, sondern in ihren sozialen Rollen. Diese Rollen sind in die Struktur des Zeichens eingeschrieben.

Hohe Granularität (also geringe Auflösung) ist zur allgemeinen und oberflächlichen Orientierung im Raum ausreichend. Ihr dienen Zeichen, die aus großer Entfernung gelesen werden können und die übergeordneten Handlungszielen (wie einen bestimmten Ort zu finden oder ihn mit einer bestimmten typischen Handlung zu identifizieren) zugeordnet sind (vgl. Abb. 3). Die intendierten Rezipienten dieser Zeichen sind in der Regel alle (nicht orts-kundigen) Menschen, die im öffentlichen Raum unterwegs sind. Geringe Granularität schränkt entweder die Gruppe der intendierten Rezipienten ein und selegiert dazu spezifischere soziale Rollen der Adressaten, oder sie dient subsidiären Handlungen innerhalb eines größeren Hand- 
lungssschemas. Solche Zeichen sind also nur für diejenigen Benutzer relevant, die sich bereits großflächig im Raum orientiert haben und nun spezifischere Informationen benötigen.

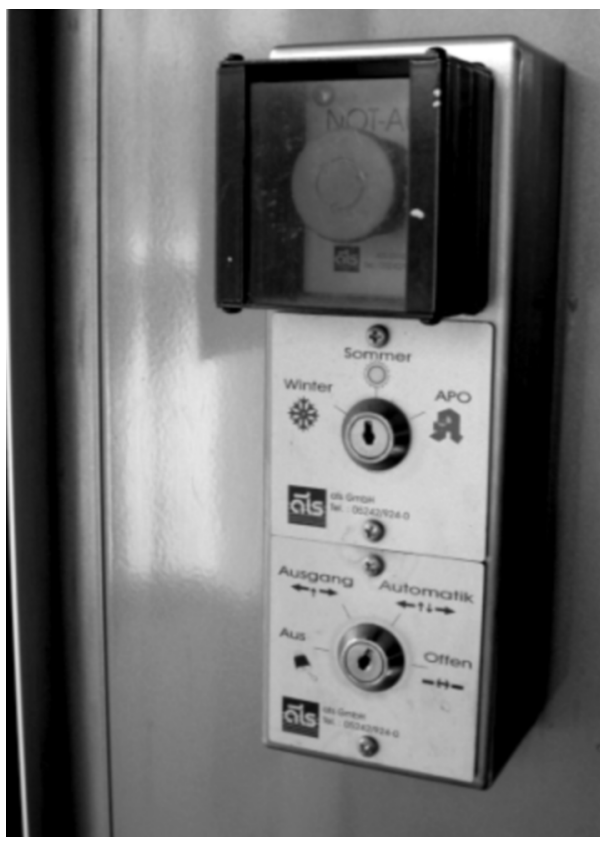

Abb. 5: Schließautomatik am Hauptportal des Freiburger Hauptbahnhofs: Zeichen mit geringer Granularität, das sich an spezifische Benutzergruppen richtet. Drei verschiedene Schilder in einem Ensemble und als Teil zweier Diskurse (Notfall und Bedienung).

Im ersten Fall haben wir es mit öffentlicher Schrift zu tun, die Handlungsräume eröffnet, die Spezialisten vorbehalten sind, z.B. dem Personal einer Institution oder Handwerkern, die sich in Notfällen im Raum orientieren müssen. Ein Beispiel ist in Abb. 5 zu sehen; die Anweisung zur Einstellung und Bedienung der automatischen Türen eines Bahnhofs per Hand ist sehr klein an der Bedienungsautomatik angebracht. Die normalen Benutzer sind weder interessiert noch berechtigt, diese Automatik zu bedienen. Besonders klein sind die Angaben über die herstellende Firma; sie selegieren nicht nur die spezialisierte Gruppe der Bahnhofsangestellten als soziale Adressaten, sondern sind überdies auch für sie nur in einem spezifischen Fall relevant, nämlich wenn ein Wartungstechniker der Firma zu informieren ist.

Im zweiten Fall werden öffentliche Schriftzeichen geringer Granularität im Zusammenhang einer einmal begonnenen Handlungsdurchführung gebraucht. Während zum Beispiel im Bahnhof Schilder mit hoher Granularität die Orientierung innerhalb des Gebäudes sowie den Weg aus dem Gebäude in die Stadt ermöglichen, sind Schilder geringer Granularität auf den Gepäcktrolleys angebracht (vgl. Abb. 6). Man kann sie erst aus der Nähe lesen, d.h. wenn man dabei ist, die subsidiäre Handlung des Gepäcktransports durch einen Gepäckwagen in Angriff zu nehmen. Noch kleiner 
- und in noch geringerer Granularität wieder auf einen Ausnahmefall hin orientiert - ist die Aufschrift auf diesem Schild, die Anweisungen gibt, wie man sich zu verhalten hat, wenn man das so beschilderte Objekt außerhalb des Bahnhofs findet. (Am kleinsten ist der TÜV-Stempel des DB-Geräteservice, der die Kontrolle der Funktionstüchtigkeit des Trolleys belegt.)

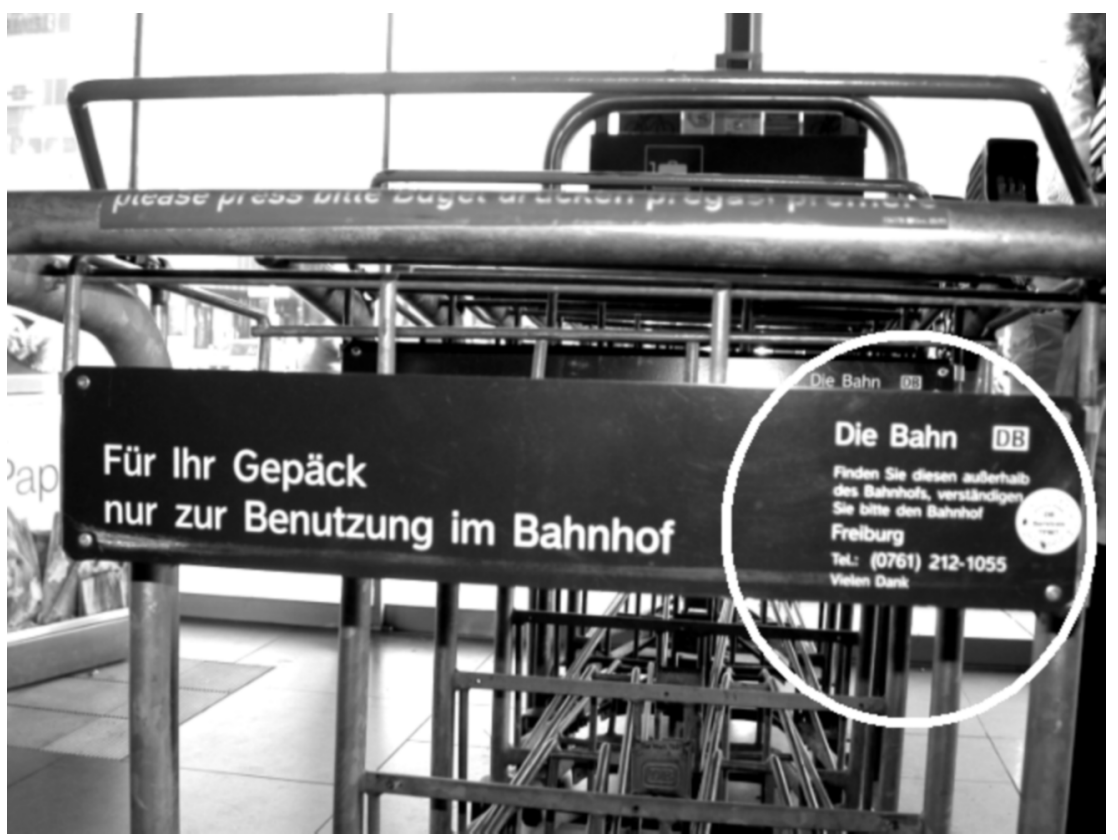

Abb. 6: Schild (und dreisprachiger Aufkleber englisch-deutsch-italienisch: please press bitte Bügel drücken pregasi premere) geringer Granularität für subsidiäre und Notfall-Handlungen (Freiburg, Hauptbahnhof). Die Abstufung der Schriftgrößen spiegelt die Spezialisierung der schriftlichen Hinweise wider (Nutzungsangabe im Normalfall/im Sonderfall/Aufkleber „TÜV“). Das Logo und die Aufschrift „Die Bahn“ zeigen Zugehörigkeit an.

\subsection{Schilder, ${ }^{6}$ Inschriften, Zettel und Aufkleber}

Eine dritte Unterscheidung betrifft die Materialität der öffentlichen Schriftzeichen und die damit zusammen hängende Frage der Begrenzung von Zeichen, also die Frage, was eigentlich zu einem Zeichen gehört. Inschriften sind dingfest: sie können nur schwer von der Oberfläche des Objekts entfernt werden, auf das sie sich beziehen. Zu diesem Typ gehören die eingangs diskutierten historischen Beispiele, aber auch edukativ-adhortative

\footnotetext{
Das Grimmsche Wörterbuch sagt zu Schild: „schild vorm bause, zum zeichen des dort betriebenen gewerbes: schild eines bäckers, eines kaufmanns, eines wirtshauses; ladenschild, herbergsschild, wirtshausschild $u$. ähnl. diese gewerbezeichen nannte man schilde, weil sie zunächst nur embleme entbielten und so sich den wappen verglichen." Im Vergleich zu dieser Definition ist die hier verwendete weiter und rein formal.
} 
Inschriften wie Die Wabrbeit wird ench frei machen ${ }^{7}$ auf dem Hauptgebäude der Freiburger Universität oder Häusernamen wie in Abb. 7. Weit häufiger ist im heutigen Stadtbild das Schild, auf dem die Schrift angebracht ist und das seinerseits mit dem Objekt direkt oder indirekt verbunden ist, auf das sich die Schrift bezieht. Das Schild ist ein Träger der Schrift, der zugleich durch seine Materialität die Grenzen des Zeichens markiert. Das Schild konstituiert also einen Rahmen, die bei der Inschrift gegebenenfalls erst geschaffen werden muss. Dadurch wird der so gerahmte Bereich als genau ein Zeichen konstituiert.

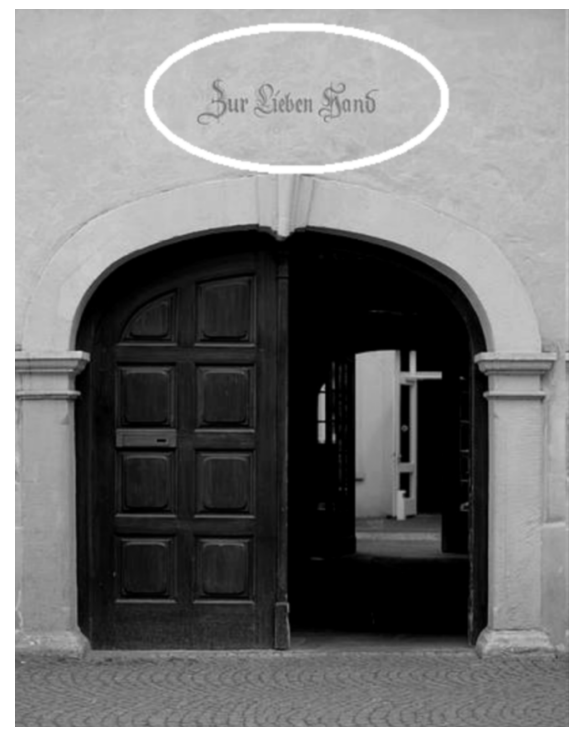

Abb. 7: Inschrift/Häusername (Freiburg, Innenstadt).

Dieses Zeichen kann allerdings komplex strukturiert sein (vgl. die Schilder in den Abb. 1, 3, 5, 6). Oft wird zum Beispiel Schrift mit nicht-sprachlichen Elementen kombiniert. Diese können ikonisch (Abb. 1) oder als pointer indexikalisch (im engeren Sinn des Wortes) sein. Pointer sind bei allen distal weisenden Zeichen (Wegweisern) obligatorisch (vgl. Abb. 3, 12). Mehrere durch ihre Materialität als Schilder konstituierte Einzelzeichen können aufeinander Bezug nehmen. So ist in Abb. 8 ein Ensemble (siehe unten Abschnitt 2.5) aus drei Schildern (Zeichen) abgebildet, wie sie für die heutige Verkehrsbeschilderung typisch ist. Das oberste, rein piktogrammatische

Der indexikalische Charakter dieser Inschrift mag nicht unmittelbar evident sein; wie eng die Bedeutung dieses Mottos mit dem Typ von Gebäude zusammenhängt, auf dem es angebracht ist, wird aber deutlich, wenn man die völlig andere Bedeutung im ursprünglichen $\mathrm{Zu}$ sammenhang (nämlich Joh 8,32) zum Vergleich heranzieht (dazu Kaiser 2003). Während im Johannes-Evangelium die Wahrheit mit Christus identifiziert wird, ist sie auf der Universität gerade aufklärerisch anti-klerikal gemeint. Diese Uminterpretation macht den so bestimmten sozialen Raum in einer ganz anderen Weise sozial nutzbar als das Bibelwort es täte. Sie konstituiert den akademischen Raum gegen die Kirche. 
Schild weist die Straße als Fussgängerzone aus; das darunter angebrachte Schild verwendet Schriftsprache, um die Gültigkeit des obersten Schilds auf die Zeiten des zweiwöchentlichen Marktes einzuschränken; schließlich nimmt ein drittes schriftsprachliches Schild Fahrradfahrer von dieser Einschränkung aus.

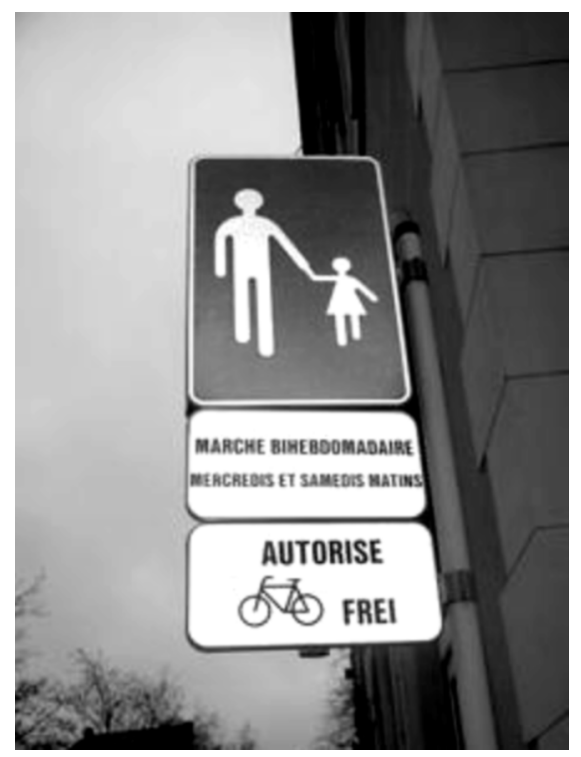

Abb. 8: Ensemble von drei Schildern aus einem Diskurs, eines davon mehrsprachig(deutsch/französisch). Funktion: Verbot bestimmter Raumnutzungen (regulatives Zeichen) (Luxemburg Stadt, Place Guillaume II).

Anders als bei Schildern ist die Grenze (der Rahmen) einer Inschrift oft problematisch; die Beantwortung der Frage, ob es sich um ein einzelnes, komplex strukturiertes, oder um mehrere Zeichen handelt, muss auf vielfältige gestalterische und inhaltliche Aspekte Bezug nehmen. In Abb. 9 ist es aus beiden Gründen naheliegend, die benennende Inschrift (Palladium) sowie die Inschrift zur Funktionsangabe (café \& tanzpalais) als ein Zeichen zu verstehen. In Abb. 10 ist es hingegen offen, ob die englische Inschrift auf der linken Eingangstür eines Geschäfts für Mobiltelefone in Helsinki als ein unabhängiges Zeichen zu verstehen ist, dem die finnische Inschrift auf der rechten Eingangstür als komplementäres, aber getrenntes Zeichen innerhalb eines Ensembles zugeordnet ist, oder ob beide Inschriften als Teil desselben Zeichens zu verstehen sind.

Zwischen Schildern und Aufschriften steht die Hybridkategorie des Aufklebers. Er ist in seiner Materialität gut abgegrenzt und präsentiert sich daher als ein Zeichen. Andererseits ist er in der Regel nur schwer von dem Objekt zu lösen, auf dem er angebracht ist. Dies machen sich gerade transgressive Aufkleber (vgl. Abb. 4) zunutze. Zettel, die angeheftet sind, sind temporäre Schilder, deren Flüchtigkeit gerade durch ihre gering Haftung betont wird. 


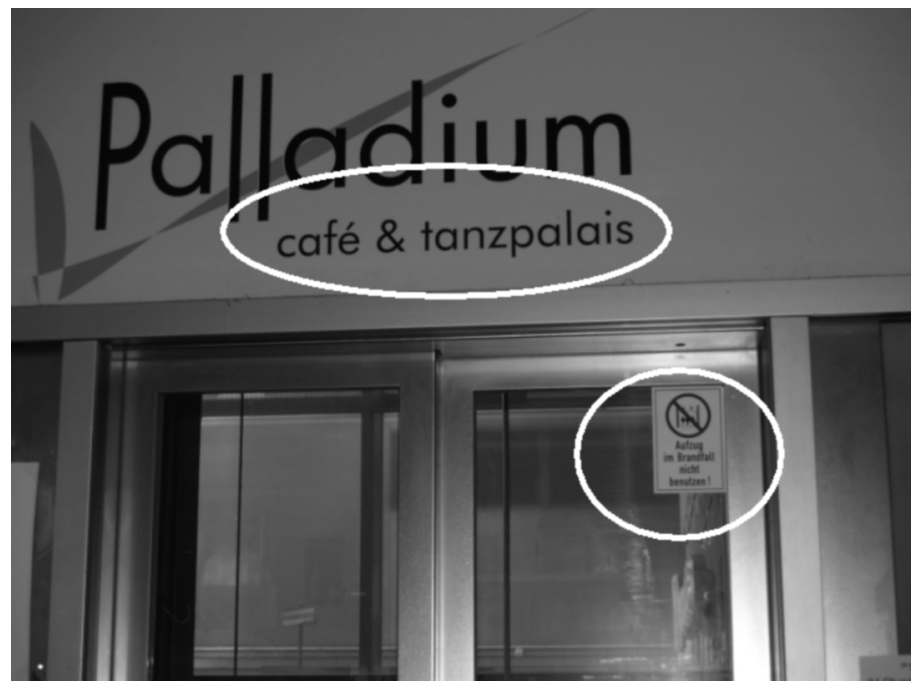

Abb. 9: Inschrift aus zwei Komponenten und Aufkleber (Freiburg, Hauptbahnhof). Funktion: Gebrauchsweise eines Orts (Palladium), Gebrauchsverbot eines anderen (Aufzug).

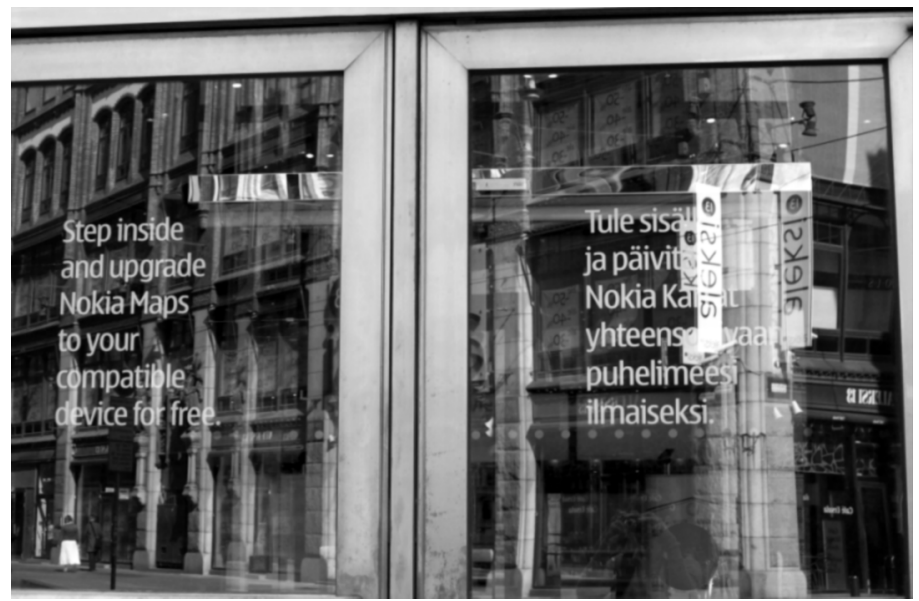

Abb. 10: Zwei Inschriften = zwei Zeichen? (Helsinki, Alexanderinkatu, Foto K. Wagner). Die linke Inschrift (Step inside and upgrade Nokia Maps to your compatible device for free) ist eine Übersetzung der rechten (Tule sisälle ja pä̈vitä Nokia kartat ybteensopivaan pubelimeesi ilmaiseksi).

\subsection{Ensembles, Diskurse, (Über-)Schichtungen}

Wie bereits gezeigt, stehen öffentliche, Schrift enthaltende Schilder, Aufkleber oder Inschriften oft nicht allein, sondern beziehen sich aufeinander. Dabei sind drei Arten der Bezugnahme zu unterscheiden. 
Unter einem Ensemble verstehe ich mehrere Schilder/Inschriften/ Zettel/Aufkleber, die in unmittelbarer Nähe zueinander stehen, also mit einem Blick wahrgenommen werden können, und die sich inhaltlich aufeinander beziehen. Ein typisches, schon diskutiertes Beispiel findet sich in Abb. 8. Davon ist eine zweite Art der Bezugnahme im öffentlichen Raum zu unterscheiden, in der nicht die Kopräsenz der Schilder/Inschriften/Aufkleber, sondern ihre formale und funktionale Ähnlichkeit ausschlaggebend ist. Ich spreche hier von einem Zeichendiskurs. ${ }^{8}$ Die Zeichen, die zu einem Diskurs gehören, sind typischerweise nicht zusammen sichtbar; der Zeichenrezipient nimmt aber die einzelnen Zeichen eines Diskurses in ihrer gegenseitigen Kohärenz und Bezugnahme war. Die Grundlage dieser diskursiven Kohärenz ist oft die formale Beschaffenheit des Zeichens (sein Design), die seinerseits auf einen identischen Zeichenproduzenten hinweist. Es gibt aber auch andere Diskurse konstituierende Faktoren wie Kontiguität (Ketten von Wegweisern, die den Weg zu einem Ziel definieren).

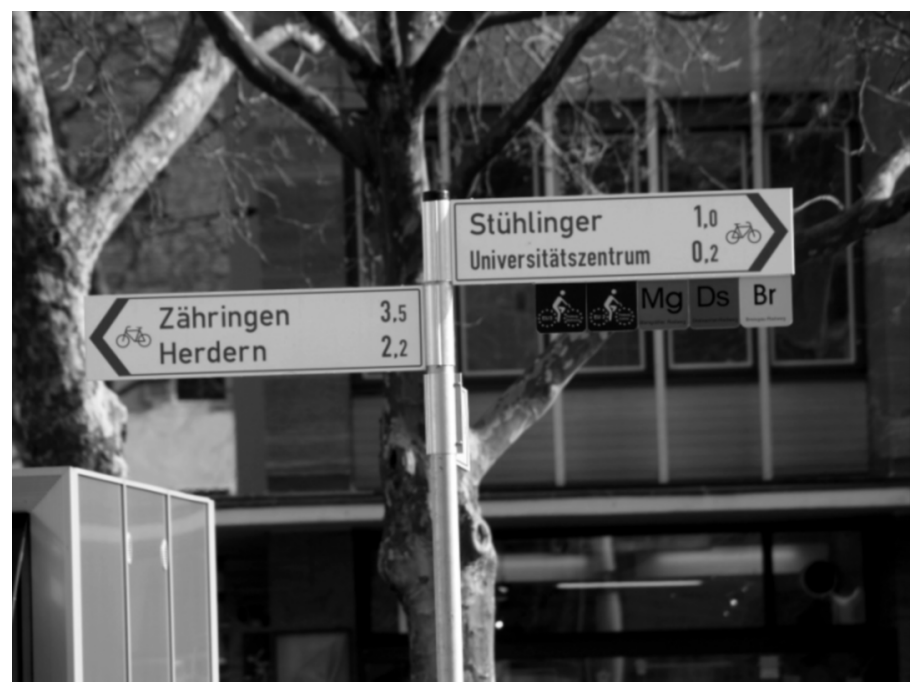

Abb. 11: Zeichen-Ensembles, Zeichen-Diskurse. Die hoch-granulären Wegweiser gehören einem anderen Diskurs an (= Radfahren in Freiburg) als die niedriggranulären (Europa-Fahrradwanderwege $3=$ Mulhouse/ Freiburg und 2 = Colmar/Freiburg; Fahrradwanderwege $\mathrm{Mg}=$ Markgräfler Land, $\mathrm{Ds}=$ Dreisamtal, $\mathrm{Br}=$ Breisgau $)$.

Abb. 11 zeigt beide Formen von Bezugnahmen. Alle Schilder bilden ein Ensemble, bei dem die Interpretation der kleineren Schilder rechts von der Pfeilrichtung des größeren Wegweisers darüber abhängen. Sie gehören aber drei verschiedenen Diskursen an. Einerseits gibt es zwei Wegweiser mit Ziel-

8 Der Begriff wird auch von Scollon/Scollon (2003) gebraucht, allerdings in einer weiteren Bedeutung. 
angaben innerhalb von Freiburg, die sich durch das identische Design und die identische Funktion (Orientierung für Radfahrer in der Stadt) als Mitglieder desselben Diskurses ausweisen, andererseits (etwas kleiner) zwei blaue Schilder mit abgerundeten Ecken, die Langstrecken-(Europa-)Fahrradwege nach Frankreich markieren, schließlich rechts davon drei kleinere farbige Schilder, die regionale Langstrecken-Fahrradwege in die Region beschildern. Diesen drei Diskursen schließen sich nicht nur die genannten, sondern zahlreiche andere Schilder an anderen Orten an, die dasselbe Design und dieselbe semiotische Struktur aufweisen.

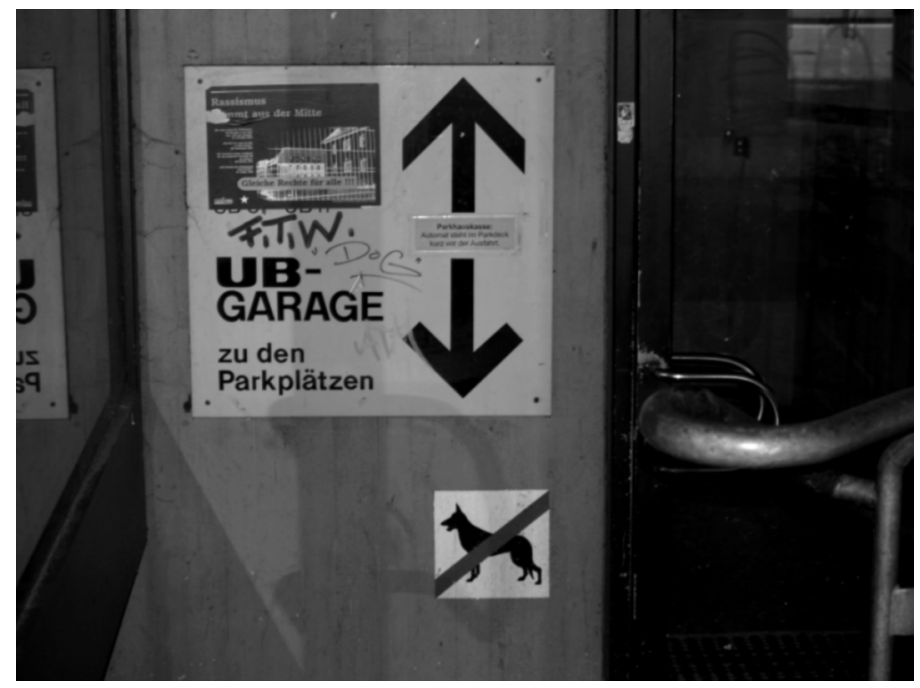

Abb. 12: Überschichtung von Zeichen (Freiburg, ehemalige UB-Garage). Die überschichtenden Zeichen sind teils indexikalisch (Aufkleber: Parkhauskasse: Automat stebt im Parkdeck kurz vor der Ausfabrt), teils nichtindexikalisch (= der transgressive Aufkleber Rassismus kommt aus der Mitte ... und Marken).

Eine dritte Art von Bezugnahme zwischen öffentlichen Schriftzeichen lässt sich am besten als (Über-) Schichtung (layering, Scollon/Scollon 2003) bezeichnen. Überschichtungen entstehen dann, wenn sekundäre Aufkleber und Aufschriften auf primären Zeichen angebracht werden. Erneut ist zwischen indexikalischen und nicht-indexikalischen überschichtenden Zeichen zu unterscheiden. Überschichtungen bringen den für öffentliche Schrift ungewöhnlichen Aspekt der Zeit ins Spiel: sie implizieren eine Trennung zwischen einem früheren (primären) und späteren (sekundären, tertiären ...) Zeichen. Beispiele reichen von autorisierten Ergänzungen und Hinweisen (etwa dem Aufkleber heute! auf einem Veranstaltungsplakat) bis zu transgressiven Zeichen, die öffentliche Zeichen in nicht autorisierter Weise karikieren oder subvertieren. In Abb. 12 ist das primäre Zeichen ein Schild, das 
vor dem Eingang in das Parkhaus der Universitätsbibliothek angebracht wurde. Es zeigt in Verbindung mit zwei Pfeilen den Weg ins Parkhaus, das man über Treppen nach oben und unten nach Betreten des Gebäudes erreichen kann. Zwischen den beiden Pfeilen ist - offensichtlich improvisiert ein dennoch autorisierter Aufkleber angebracht, der einen weiteren Hinweis gibt: Parkhauskasse: Automat stebt im Parkdeck kurz vor der Ausfahrt. Es handelt sich dabei um eine Überschichtung; das ursprüngliche Schild wurde später durch eine spezifischere Angabe zu einer subordinierten Handlung (Zahlen vor der Ausfahrt aus dem Parkhaus) ergänzt, ganz offensichtlich, weil die Benutzer des Parkhauses an diesem Eingang vergeblich nach einem Kassenautomaten suchten. Sowohl das primäre als auch das sekundäre Zeichen sind indexikalisch (wenn auch, wie bereits ausgeführt, in verschiedener Weise und in unterschiedlichen Granularitätsstufen). Darüber hinaus ist auf dem primären Zeichen jedoch ein weiterer Aufkleber zu sehen, der von einer Antifa-Gruppe stammt, die sich für gleiche Rechte für ausländische Häftlinge einsetzt. Dieses overlay ist kein indexikalisches Zeichen; es bezieht sich weder auf das primäre Zeichen noch ist es in seiner Interpretation vom Standort (oder Träger) abhängig. Dasselbe gilt für die ebenfalls in Überschichtung angebrachten Marken (F.T.W., dog, etc.).

\subsection{Die Grammatik ding- und ortsfester Schriftsprache}

Angesichts der fast ausschließlichen Beschäftigung mit Texten in Buchform und den entsprechenden schriftsprachlichen Grammatikstrukturen hat die Linguistik es bisher weitgehend versäumt, die typischen Strukturen dingund ortsfester Schriftsprache herauszuarbeiten und als Ergebnis der spezifischen Funktionalität dieser Schriftverwendung zu interpretieren. Es ist aber ganz offensichtlich, dass ding- und ortsfeste Schrift genauso wie mündliche Sprache und ortsungebundene Schriftsprache strukturelle Eigenschaften aufweist, die ihrer spezifischen Funktionalität geschuldet sind (vgl. dazu auch Schmitz in diesem Band). Schrift im öffentlichen Raum - besonders wenn sie hohe Granularität aufweist - hat normalerweise nicht viel Platz; sie soll aus der Distanz sichtbar sein. Hieraus ergeben sich Formen sprachlicher Indexikalität, die ihrerseits durch lokales (im wörtlichen Sinn: am Ort des Zeichens aufzufindendes) oder Weltwissen aufgefüllt werden müssen. Wir finden im öffentlichen Raum grammatische Konstruktionen, die in der situationsungebundenen Schriftsprache (wie auch in der gesprochenen Sprache) selten sind und daher oft als „randgrammatisch“ bezeichnet werden. Faktisch handelt es sich aber um häufige und problemlos interpretierbare Muster, die durchaus zum Zentrum unseres grammatischen Wissens gehören. Ein gutes Beispiel sind die modalen (sog. deontischen) Infinitive wie

\footnotetext{
$9 \quad$ Den Begriff verwendet Fries (1987) in einem sehr lesenswerten Artikel zu solchen Kon-
} struktionsformaten. 
Aufzug im Brandfall nicht benutzen! (Abb. 9)

Bitte Bügel drücken! (Abb. 6)

die ihre pragmatische Kraft ohne alle Morphologie eindeutig (wenn auch kontextabhängig) entwickeln können (vgl. die ausführliche Analyse in Deppermann 2007, Kap. 2), aber auch zahlreiche andere verblose oder nominalisierte Konstruktionen, wie

Bei Betreten der Gleise Lebensgefahr

Schwimmweste unter dem Sitz.

Verteiler Notstromaggregat

Achtung Rutschgefahr! (Abb. 1)

Zu den Parkplätzen (Abb. 12)

Für Ibr Gepäck - nur zur Benutzung im Bahnhof (Abb. 6)

Frei (Abb. 8)

Klärungsbedürftig ist insbesondere die Frage, wie diese im Vergleich zur nicht ortsgebundenen Schriftsprache grammatisch recht reduziert erscheinenden Konstruktionen im Verwendungskontext ohne Reste von Ambiguität erfolgreich funktionieren. Die Antwort ergibt sich aus einer Mischung zwischen Form/Funktion-Kopplung und Empraxis (Bühler 1934 [1982]). Form/Funktion-Kopplung bedeutet, dass bestimmte grammatische Konstruktionen mit bestimmten Zeichenfunktionen gekoppelt sind. Zum Beispiel beziehen sich deontische Infinitive in der Regel auf Objekte und Orte, die bestimmte Handlungen nahe legen. Diese Handlungen werden in der einen oder anderen Weise näher bestimmt oder eingeschränkt. Es findet also eine Kopplung zwischen der Funktion „Gebrauchsweisen vorschlagen/verbieten" (siehe 2.7, unten) und der Konstruktion statt, die gerade deshalb auf Angaben zu Zeit, Person, Modus verzichten kann (sie sind im Infinitiv neutralisiert). Andere Form/Funktion-Koppelungen sind die Konstruktion Achtung NP, die sich mit Zeichen verbindet, die Warnungen aussprechen, sowie die Konstruktion „z $2 u+$ def.Art $+\mathrm{N}$ “, die sich mit Wegweisern verbindet.

Die zweite Ressource, die die Zeichennutzer verwenden, um grammatisch einfache Formen eindeutig zu verstehen, ist die von Bühler so genannte empraktische Nennung (1934 [1982], S. 157-159), also die Tatsache, dass in bestimmten Situationen der Handlungskontext bereits so starke Vorgaben macht, dass eine sprachliche Explizierung verschiedener Situationsparameter nicht mehr nötig ist. Das betrifft in unserem Fall sicherlich den Adressaten, der das Zeichen rezipiert (ihm durch Blick zugewandt ist) und daher nicht mehr genannt werden muss. Darüber hinaus sind aber in der Situa- 
tion, in der das Zeichen rezipiert wird, oft auch schon bestimmte Handlungen naheliegend bzw. das Spektrum an Handlungsalternativen ist stark eingeschränkt. So ist die Beschilderung

\section{Für Ibr Gepäck}

empraktisch eingebunden in einen Handlungsablauf, den der Leser schon (zu planen) begonnen hat, wenn er vor dem Gepäcktrolley steht; dieser ist damit als Gegenstand der Charakterisierung eingeführt (der Adressat wird aus Höflichkeitsgründen, nicht aus Gründen der referenziellen Desambiguierung, dennoch in possessiver Form expliziert). In

\section{nur zur Benutzung im Babnhof}

fehlt in der Nominalisierung der Adressat, ebenso wie wiederum die Explizierung des Objekts der Benutzung. Die genaue Interpretation solcher öffentlichen Schriftverwendung ist allerdings trotz aller empraktischer Einbindung oft von kulturellen Wissensbeständen abhängig. So ist die ₹u-Konstruktion nicht nur oft auf Wegweisern anzutreffen, sie kommt auch mit der Funktion ,Benennung' auf Gasthausschildern und auf Häusern vor (Hausnamen). Um zu verstehen, dass das Schild in Abb. 7 nicht als Wegweiser dient, um den Besucher zur lieben Hand zu führen, sondern das Haus benennt, über dessen Eingang es steht, andererseits aber die Präpositionalphrase zu den Parkplätzen auf dem Schild in Abb. 12 nicht etwa den Namen des Parkhauses darstellt, sondern den Weg durch die Tür zu den Parketagen weist, erfordert Erfahrungswissen über typische Hausnamen, über die Unwahrscheinlichkeit, dass ein Parkhaus einen Namen trägt, über die Kopplung von Schrift und Pfeil etc. Selbst dieses Erfahrungswissen reicht jedoch nicht immer aus. Der Aufkleber Beide Scheiben einschlagen über den Notausgangsfenstern der ICE-Züge und neben einem roten Hammer ist nur verständlich, wenn man über das technische Wissen verfügt, dass ICE-Fenster doppelverglast sind und sich unter der zunächst eingeschlagenen Scheibe eine weitere befindet.

\subsection{Funktionen ortsfester Zeichen}

Die Funktionen öffentlicher Schrift sind grundsätzlich beschränkt. Es scheint, dass sich die im öffentlichen Raum verwendeten indexikalischen Zeichen, die Schriftsprache enthalten, exhaustiv folgenden Funktionsbereichen zuordnen lassen: 1) Benennen und Charakterisieren, 2) Zugehörigkeit markieren, 3) Gebrauchsweisen vorschlagen oder verbieten, 4) Wege weisen sowie 5) Ermahnen und Gedenken.

1) Benennen ist eine grundlegende Funktion öffentlicher Schrift, die in der heutigen Zeit vor allem der Orientierung dient. Benannt werden Bauwerke, vor allem aber Straßen und Plätze. Das typische Beispiel sind Häusernamen, 
die mit den Aufkommen von Straßennamen und Hausnummern zwar nicht mehr nötig wären, bei bedeutenden und großen Gebäuden (nicht zuletzt als Landmarken innerhalb der Stadt) aber weiterhin üblich sind. Benannt werden aber auch Abbildungen von Personen (etwa auf einem Denkmal oder einem Grabstein) sowie manchmal die Personen selbst; das berühmteste Beispiel ist die Beschilderung des gekreuzigten Iesus mit INRI, Namensschilder bei Kongressen oder auf Uniformen gehören in dieselbe Kategorie.

Das Benennen durch Eigennamen wie in den bisher genannten Fällen lässt sich auf das Benennen durch Gattungsnamen (Kategorisierung) erweitern. Hierzu gehören Produktnamen (Boeing 737 auf einem Flugzeug, Vaio auf einem Laptop), aber selbst ganze Objektkonstellationen; etwa wird der Inhalt eines Schaufensters auf Abb. 13 durch den finnisch-schwedisch bilingualen Aufkleber suvi - sommar auf dem Schaufenster zu einer Darstellung des Sommers (Sommermode, Picknick-Korb, Erdbeeren) zusammengefasst. Von solchen einfachen Kategorisierungen sind andere Verwendungen von Gattungsnamen zu unterscheiden, die nicht der Benennung dienen, sondern schon Angaben über mögliche oder unmögliche Handlungen implizieren (vgl. die Funktion 3 unten).

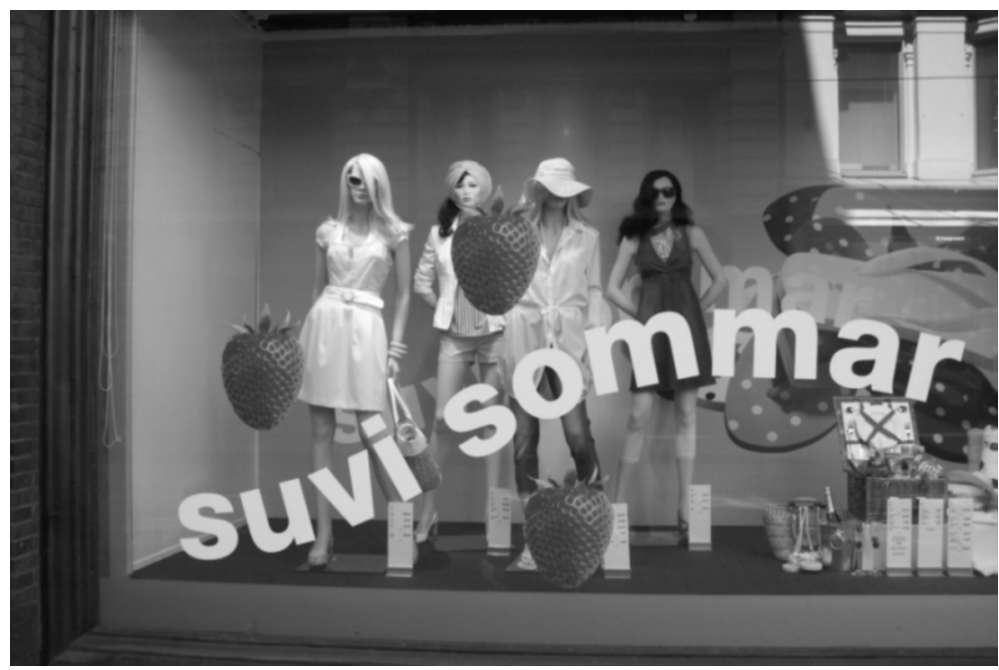

Abb. 13: Benennung eines Schaufensterinhalts durch einen Gattungsnamen (finnisch swi $=$ schwedisch sommar ,Sommer) (Helsinki, Stockmans, Foto K. Wagner).

Benannte Dinge, Personen, Orte und Institutionen werden gern durch Epitheta weiter charakterisiert: Iesus durch Herkunft und (ironischen) Titel (Iesus Nazarenus Rex Iudaeorum), Geschäfte durch eine Angabe zu ihrem Alter (seit 1911), Menschen durch Titel und Status (Dr. Müller, Abteilungsleiter, auf einem Namensschild), etc. 


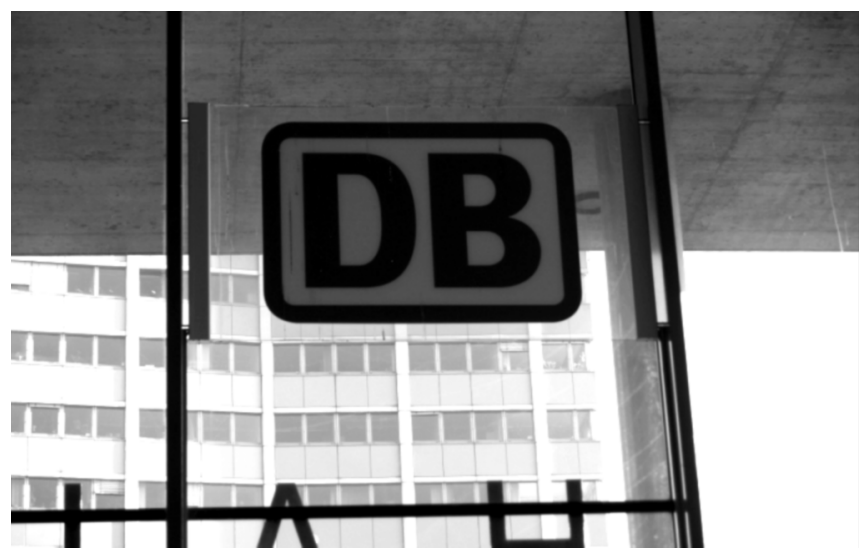

Abb. 14: Das große über dem Haupteingang angebrachte Logo der Deutschen Bahn markiert das Territorium des Konzerns und die Zugehörigkeit des Gebäudes zur Bahn (Freiburg, Hauptbahnhof).

2) Schrift im öffentlichen Raum vermittelt zudem Relationen zwischen Orten und (natürlichen oder juristischen) Personen, sie markiert also Zugehörigkeit. Die Art der Zugehörigkeit kann vielfältig sein. In einer wichtigen Form der Zugehörigkeitsmarkierung geht es um Besitz; die Schriftzeichen fungieren dann als Marken wie auf Abb. 14. Da der Besitz oft in seiner räumlichen Ausdehnung markiert wird, wird durch solche Schriftverwendung ein Territorium gekennzeichnet. In Abb. 14 gehört das so markierte Gebäude zum Beispiel zum Territorium der Deutschen Bahn (DB). Andere Zugehörigkeitsrelationen sind die des Erbauers, Architekten oder Finanziers; auf vielen Gegenständen in der Öffentlichkeit findet sich auch der Name und die Adresse des produzierenden Handwerkers. Es gibt auch sehr spezifische Zugehörigkeitsrelationen, die durch öffentliche Schrift hergestellt werden; etwa die Versicherung eines Gebäudes gegen Brand durch eine Plakette (die die Zugehörigkeit zu dieser Schutzgemeinschaft indiziert). Die Trennung zwischen reiner Zugehörigkeitsangabe und Indizierung einer Gebrauchsweise für das Objekt sind fließend. So wird auf dem Steuerungsinstrument in Abb. 5 einerseits durch die Angabe des Herstellers (ATS GmbH) eine Zugehörigkeitsrelation hergestellt (produzierende Firma), andererseits wird durch die Angabe der Telefonnummer auch eine Gebrauchsweise im Fall des Defekts der Türöffnungsanlage vorgeschlagen.

3) Während Benennung und Zugehörigkeitsmarkierung indirekt Handlungspotenziale eröffnen können (das durch den Namen identifizierte Wirtshaus ist das, in dem man einkehrt; der genannte Architekt bekommt einen neuen Auftrag ...), ist es heute die wichtigste Funktion öffentlicher, ortsfester Schrift, direkte Angaben zum Gebrauch eines Orts zu machen oder bestimmte Handlungen zu verbieten oder einzuschränken. Funktions- 
bezeichnungen finden sich auf vielen öffentlichen Gebäuden (Mädchenbildungsanstalt, Service point, Bäckerei). Dabei kommen jedoch nicht nur einfache Bezeichnungen vor, sondern auch mehr oder weniger ausführliche Angaben darüber, was an dem jeweiligen Ort zu finden ist (z.B. bei Restaurants in Form von Speisekarten), welche Öffnungszeiten gelten, wie Geräte zu bedienen sind etc. Zum Beispiel zeigt Abb. 9 einerseits den Eingang zu einem Lokal namens Palladium (Benennung), andererseits wird durch die kleiner (und damit untergeordnet) hinzugefügten Wörter Café \& Tanzpalais indiziert, in welcher Weise der so benannte Raum genutzt werden kann. Zu den Verboten gehören viele Verkehrsschilder (wie in Abb. 8), Verbote des Zutritts oder der Benützung von Aufzügen im Brandfall (wie in Abb. 9), etc. Manche Vorschläge für die Verwendung von Räumen sind sehr ausführlich; man vergleiche die Aufforderung auf dem Mobilfunkgeschäft in Helsinki (Abb. 10) Step inside and upgrade Nokia maps to your compatible device for free / Tule sisälle ja päivitä Nokia kartat ybteensopivaan pubelimeesi ilmaiseksi; andere sind knapp; vgl. den einfachen Aufkleber Ale Pabeier - Altpapier - Vieux papier auf einer Mülltonne in Abb. 15.

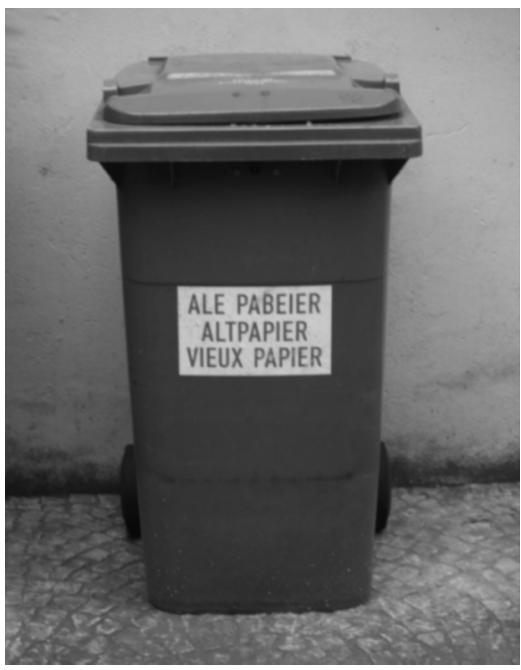

Abb. 15: Funktion Gebrauchsanweisung: Mülleimer mit dreisprachigem Aufkleber (Luxemburgisch, Deutsch, Französisch) in Luxemburg Stadt.

4) Die Funktion, Wege zu weisen, gehört sicherlich zu den wichtigsten und ältesten der ortsfesten Schrift. Dabei kann sowohl das Ziel benannt werden (vgl. Abb. 11, die weißen Schilder, Abb. 3) als auch der Weg (vgl. die farbigen Schilder auf Abb. 11). Wegweiser verweisen oft auf Orte, die nicht im visuellen Umfeld des Zeichenrezipienten sind, sie sind also nicht auf die visuelle Identifizierbarkeit des indizierten Objekts oder Orts angewiesen (der Pfeil fungiert als distaler pointer). Dabei darf man den Begriff Wegweiser nicht zu eng verstehen; auch in Abb. 12 wird dem Nutzer des Parkhauses der Weg gewiesen. 


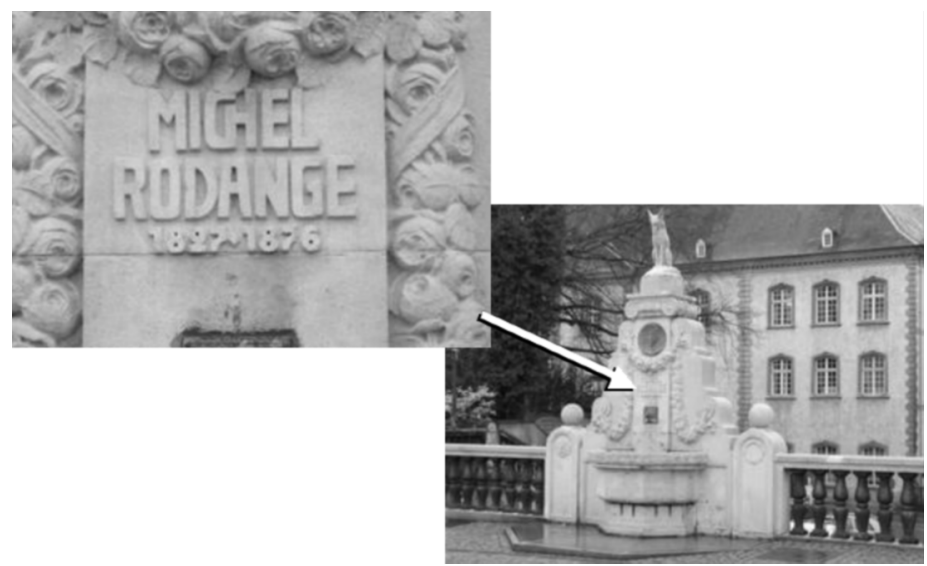

Abb. 16: Öffentliche Schrift (Inschrift) in der Funktion des Gedenkens (Luxemburg Stadt, Denkmal für den Autor des „Renert“, einer Adaption von Goethes „Reineke Fuchs“ in luxemburgischer Sprache).

5) Öffentliche Schrift kann schließlich dazu dienen, vergangener Ereignisse oder verstorbener Menschen zu gedenken (Abb. 16), und sie kann zu moralisch richtigem Verhalten ermahnen (Abb. 17 und 18).
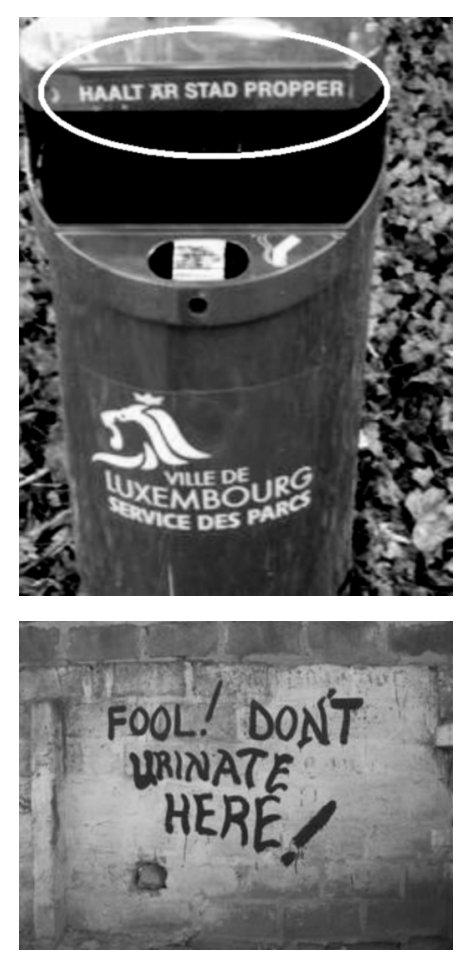

Abb. 17: Öffentliche Schrift (Inschrift) in der Funktion der Ermahnung (haalt är Stad propper = , haltet Eure Stadt sauber') (Luxemburg Stadt).

Abb. 18: Öffentliche Schrift (Inschrift) in der Funktion der Ermahnung: transgressives oder autorisiertes Zeichen? (Ghana, Accra). 


\subsection{Die Kolonialisierung des öffentlichen Raums durch die Schrift}

Die bisherige Forschung zu linguistischen Landschaften vernachlässigt nicht nur, wie sich in die schriftsprachlichen Zeichen die Art des potentiellen Rezipienten einschreibt, sie ignoriert oft auch die Seite des Zeichenproduzenten und damit die Formen von Agentivität und Macht, die mit der Gewalt über die Zeichenverwendung im öffentlichen Raum einher gehen. Es ist offensichtlich, dass die Möglichkeiten, im öffentlichen Raum durch Sprachzeichen Orte für soziale Handlungen zu konstituieren oder dort bestimmte Handlungen zu verbieten, nicht jedem Gesellschaftsmitglied gleichermaßen offensteht. In der Forschung wird oft - einem Vorschlag von Ben-Rafael et al. (2006, S. 14f.) folgend - zwischen ,top-down'-Zeichen (,issued by national and public bureaucracies - public institutions, signs on public sites, public announcement and street names") und „bottom-up“Zeichen, die von Privatpersonen geschrieben und angebracht werden, unterschieden. Diese Unterscheidung verkennt aber, dass die Ordnungsprinzipien, die die Gestaltung des öffentlichen Raums regulieren, die öffentlichen und privatwirtschaftlichen Agenten nicht auf ein Oben vs. Unten abbilden. Vielmehr wird die semiotische Gestaltungsmacht über Raumsegmente von zwei Prinzipien reguliert: nach dem einen Prinzip erwerben die (privaten) Besitzer von Raumsegmenten für diese Teile des Raums Gestaltungsprivilegien, nach dem anderen Prinzip behalten die öffentlichen (staatlichen) Institutionen Gestaltungsmacht über den gesamten übrigen, nicht in Privatbesitz befindlichen Raum.

Die im öffentlichen Raum sichtbaren Zeichen symbolisieren die Macht der Agenten, die sie angebracht oder aufgestellt haben; die Segmente des Raums, die die staatlichen und privatwirtschaftlichen Agenten dabei für sich beanspruchen, teilen den öffentlichen Raum annähernd vollständig auf, d.h. sie kolonialisieren ihn. Zeichen, die weder dem Prinzip des privaten Raumbesitzes noch dem Prinzip des öffentlich-staatlichen Raumprivilegs folgen, sind heutzutage automatisch transgressiv: sie sind ganz offensichtlich ohne Autorisierung angebracht und haben keine offizielle Autorität. Transgressive Zeichen konstituieren deshalb einen Gegendiskurs schon allein dadurch, dass sie die Kolonialisierung des öffentlichen Raums durch bestimmte Agenten staatlicher oder privater Art durchbrechen. Ihre reine Existenz ist angesichts der vollständigen Aufteilung des Raums unter seinen privatwirtschafltichen und staatlichen Kolonialisatoren provokativ. Oft sind sie klein und unauffällig und werden von der mainstream-Gesellschaft gar nicht wahrgenommen. Vorzugsweise werden sie an abseitigen Stellen angebracht, auf Rück- und Hinterseiten, auf stillgelegten und heruntergekommenen Gebäuden (vgl. Abb. 4, 12). Dass sie oft nur dem geübten Blick sichtbar werden und nur dem eingeweihten Blick verständlich sind, rückt 
sie in die Nähe alter subkultureller Zeichensysteme wie der Gaunerzinken, von denen sie sich allerdings dadurch unterscheiden, dass sie in der Regel nicht indexikalisch sind. ${ }^{10}$ Der transgressive Wirkungsgrad transgressiver Zeichen steigt, je mehr sie von der allgemeinen Öffentlichkeit nicht mehr ignoriert werden können.

Die Autorität eines Zeichens ergibt sich nur selten direkt aus der gesellschaftlichen Position seines Autors, denn öffentliche Zeichen sind gerade dadurch gekennzeichnet, dass kein spezifischer, persönlicher Autor zu identifizieren ist, der für sie verantwortlich ist. (Nur wenige Schilder sind wie die klischeehaften Verbotsschilder auf deutschen Spielplätzen mit autorisierenden Autorenangaben wie „Der Hausbesitzer“ versehen.) Es ist die Struktur des Zeichens selbst, die seine Autorität zu einem wesentlichen $\mathrm{Ma} ß$ garantieren muss. Um autoritative Zeichen zu verfassen, müssen Regeln eingehalten werden. Grosso modo gilt: je größer der technische Aufwand, mit dem das Zeichen hergestellt wurde, je größer also die Kosten, die seine Herstellung verursacht hat, je länger damit aber auch die Zeitdauer, für die es gelten soll, um so größer ist die Autorität des Zeichens. Improvisierte Zeichen (z.B. Zettel) haben deshalb weniger Autorität als industriell gefertigte, handgeschriebene noch weniger. Tatsächlich ist hier die Grenze zur Transgressivität fließend. Bei der in Abb. 18 gezeigten handgesprühten Inschrift auf einer Mauer in Accra/Ghana, weiß man nicht, ob es sich um ein transgressives Zeichen handelt, oder ob es legitim vom Besitzer dieses Raums angebracht wurde, der nur nicht über die Ressourcen verfügte, um dem Zeichen eine autoritativere Form zu geben. Vielleicht handelt es sich sogar um einen gesellschaftlichen Kontext, in dem der öffentliche Raum noch nicht so vollständig kolonialisiert ist, dass individuelle Agenten nur transgressiv in ihm tätig werden können. Der Autor wird sicherlich einen Grund gehabt haben, diese Inschrift anzubringen; ihr improvisierter Charakter lässt ihr aber (zumindest in unseren Augen) keine große Autorität zukommen.

\section{Abschließende Bemerkungen}

Ziel dieses Beitrags war es, einige grundlegende Überlegungen zur Analyse ortsfester Schrift anzustellen, die in unserem öffentlichen Leben eine große Rolle spielt. Dabei wurden einige Parameter entwickelt, die neben der semiotischen Struktur des Zeichens selbst, seiner Materialität und seiner Granularität, auch den Produzenten und Rezipienten des Zeichens ins Blickfeld rücken. Der öffentliche Schriftgebrauch erhält damit eine pragmatische Dimension.

10 Hierzu gehört auch der große Bereich der Graffiti, die allerdings zum großen Teil nicht sprachlich sind und deshalb hier nicht ausführlich berücksichtigt werden (vgl. etwa von Treeck 2003; Meier 2007). Graffiti sind indexikalisch, wenn sie als tags Raum territorialisieren und als Marken fungieren. 
Der primäre Gegenstand der heutigen Forschung über linguistic landscapes, nämlich die öffentliche Repräsentation der Sprachen einer mehrsprachigen Gesellschaft, ist damit noch gar nicht ins Blickfeld geraten, und in der Tat scheint es sinnvoll, solche Fragen als sekundäre Anwendungsfelder eine Forschungsrichtung zu sehen, die zunächst wesentlich grundlegendere Fragen zu klären hätte. Dennoch lässt sich nicht übersehen, dass alle Zeichen im öffentlichen Raum, die Sprache enthalten, einen wesentlichen Effekt haben: sie territorialisieren Sprache(n) nämlich, d.h. sie weisen Sprache(n) geografische Räume zu, in denen sie Gültigkeit beanspruchen können. Diese Gültigkeit haben bei nicht-transgressiven Zeichen im offiziellen Raum fast ausschließlich den Staats- und/oder Amtssprachen der betroffenen Länder. In offiziell mehrsprachigen Ländern wie Luxemburg (Abb. 8, 15) oder Finnland (Abb. 10, 13) sind die öffentlichen Schilder und Inschriften demselben Prinzip entsprechend mehrsprachig und symbolisieren damit die Gültigkeit von mehr als einer Sprache auf einem Territorium. $\mathrm{Zu}$ den Amts- bzw. Staatssprachen tritt in vielen Ländern die internationale lingua franca Englisch (Abb. 3, 4, 6), nur selten weitere große Verkehrssprachen wie Französisch (Abb. 3) oder gar Italienisch (Abb. 6). Nicht offiziell anerkannte Sprachen, zum Beispiel die von Immigrantengruppen, kommen abgesehen von transgressiven Zeichen fast nur in Verbotsschildern (vgl. Hinnenkamp 1989) sowie auf den privaten, in der Regel unprofessioniellen Schildern und Zetteln des Kleinhandels vor. Sie können in der Regel kein eigenes Territorium auf dem Gebiet der Mehrheitssprache(n) beanspruchen. Die Schrift im öffentlichen Raum trägt also wesentlich zur Territorialisierung von Sprachen bei: sie macht die Zuordnung von Räumen und Sprachen sichtbar. Der vorliegende Beitrag sollte allerdings auch zeigen, dass diese Zuordnung sich nur im größeren Zusammenhang einer Theorie der Schrift im öffentlichen Raum verstehen lässt, die es noch zu entwickelt gilt.

\section{Literatur}

Auer, Peter (2009): Visible dialect. In: Hovmark, Henrik/Stampe Sletten, Iben/Gudiksen, Asgerd (Hg.): I mund og bog. 25 artikler om sprog tilegnet Inge Lise Pedersen på 70-årsdagen d. 5. juni 2009. Kopenhagen, S. 31-46.

Ben-Rafael, Eliezer/Shohamy, Elana/Hasan Amara, Muhammad/Trumper-Hecht, Nira (2006): Linguist landscape as symbolic construction of the public space: The case of Israel. In: International Journal of Multilingualism 3, 1, S. 7-30.

Bühler, Karl (1934 [1982]): Sprachtheorie. Jena. [Ungek. Neudr. d. Ausg. Jena 1934. Stuttgart 1982].

Coulmas, Florian (2008): Linguistic landscaping and the seed of the public sphere. In: Shohamy/Gorter (Hg.), S. 13-24. 
Deppermann, Arnulf (2007): Grammatik und Semantik aus gesprächsanalytischer Sicht. (= Linguistik - Impulse und Tendenzen 14). Berlin.

Ehlich, Konrad (1984): Zum Textbegriff. In: Rothkegel, Annely/Sandig, Barbara (Hg.): Text - Textsorten - Semantik. Hamburg, S. 9-25.

Fries, Norbert (1987): Zu einer Randgrammatik des Deutschen. Zur Theorie randgrammatischer satzwertiger Konstruktionen. In: Meibauer, Jörg (Hg.): Satzmodus zwischen Grammatik und Pragmatik. (= Linguistische Arbeiten 180). Tübingen, S. 75-95.

Giddens, Anthony ([1979] 1995): Strukturierung und sozialer Wandel. In: Müller, HansPeter/Schmid,Michael (Hg.): Sozialer Wandel. Modellbildung und theoretische Ansätze. Frankfurt a.M., S. 151-191. [Originalausg. 1979].

Giddens, Anthony (1984): The constitution of society. Cambridge.

Goffman, Erving (1959): The presentation of self in everyday life. New York.

Hausendorf, Heiko (i.Dr.): Zwischen Linguistik und Literaturwissenschaft: Textualität revisited. In: Zeitschrift für germanistische Linguistik (ZGL) 36.

Hinnenkamp, Volker (1989): Interaktionale Soziolinguistik und Interkulturelle Kommunikation. Tübingen.

Kaiser, Gerhard (2003): Die Wahrheit wird euch frei machen: die Freiburger Universitätsdevise - ein Glaubenswort als Provokation der Wissenschaft. In: Wenzler, Ludwig (Hg.): Welche Wahrheit braucht der Mensch? Freiburg i.Br., S. 47-103.

Koß, Gerhard (2002): Namenforschung: eine Einführung in die Onomastik. 3., aktual. Aufl. (= Germanistische Arbeitshefte 34). Tübingen.

Landry, Rodrigue/Bourhis, Richard (1997): Linguistic landscape and ethnolinguistic vitality: an empirical study. In: Journal of Language and Social Psychology 16, 1, S. 23-49.

Meier, Stefan (2007): Stylelife - Graffiti als typografisches Ausdrucksmittel sozialen Stils. In: Kimminich, Eva/Rappe, Michael/Geuen, Heinz/Pfänder, Stefan (Hg.): Express yourself! Europas kulturelle Kreativität zwischen Markt und Underground. (= Cultural Studies 25). Bielefeld, S. 193-208.

Ong, Walter J. (1982): Orality and literacy. The technologizing of the word. London.

Schmauks, Dagmar (2002): Orientierung im Raum. Zeichen für die Fortbewegung. (= Probleme der Semiotik 20). Tübingen.

Scollon, Ron/Scollon, Suzie Wong (2003): Discourse in public places - language in the material world. London.

Shohamy, Elana/Gorter, Durk (Hg.) (2008): Linguistic landscape: expanding the scenery. London/New York.

Treeck, Berhard von (2003): Typografie als Mittel zur Identitätsbildung. In: Androutsopoulos, Jannis (Hg.): HipHop: Globale Kultur - Lokale Praktiken. Bielefeld, S. 102-120. 
Intermediale Relationen 

Ludwig Jäger

\title{
Intermedialität - Intramedialität - Transkriptivität Überlegungen zu einigen Prinzipien der kulturellen Semiosis
}

\begin{abstract}
In den unterschiedlichsten disziplinären Kontexten der Kultur- und Medienwissenschaften findet in den beiden letzten Jahrzehnten der Befund große theoretische Aufmerksamkeit, dass Medien intermedial aufeinander Bezug nehmen (Bolter/ Grusin 2001) und dass sie sich intramedial in rekursiven Schleifen auf sich selbst beziehen. Die kulturelle Semiosis wird - folgt man diesen Studien - auf einem Feld generiert, konserviert, gestört und fortgeschrieben, auf dem sich Kommunikation als semiologisches Spiel interagierender und miteinander verwobener Medien, als ein Ensemble von Praktiken „kultureller Rekonzeptualisierung“ (Manovich 2001) entfaltet. Der Beitrag vertritt die These, dass sich hinter der Vielfalt dieser kommunikativen Prozeduren in den Sprach-, Schrift- und Bildmedien, so unterschiedlich sie auch in medialer und ästhetischer Hinsicht sind, ein grundlegendes Verfahren der kulturellen Semiosis verbirgt, das sich als ein Verfahren transkriptiver Bezugnahme beschreiben lässt. Die Annahme, dass Transkription eine grundlegende Operation der kulturellen Semiosis, d.h. der Prozeduren kultureller (intraund intermedialer) Rekonzeptualisierung, darstellt, soll anhand einiger epistemologischer und zeichentheoretischer Prinzipien erläutert und theoretisch verständlich gemacht werden.
\end{abstract}

\section{Vorbemerkung}

Es ist genau zehn Jahre her, dass die Jahrestagung des Instituts für Deutsche Sprache mit dem Thema „Sprache und neue Medien“ den disziplinären Diskurs der germanistischen Sprachwissenschaft nachdrücklich auf seine theoretische Positionierung zu jenem grundlegenden Wandel der Kommunikationsverhältnisse hin befragte, der mit der globalen Evolution der sogenannten ,neuen Medien' verbunden war. Im Vorwort des Tagungsbandes dieser Tagung formulierte Werner Kallmeyer: „Der Ausdruck ,neue Medien im Titel ,Sprache und neue Medien' zielt auf elektronische Medien wie Computer und Internet, die sich in kurzer Zeit eine zentrale Stellung in der gesellschaftlichen Kommunikationsstruktur erobert haben“" (Kallmeyer 2000a, S. VII). Ohne Zweifel stellte diese Konferenz einen wichtigen Impuls für eine umfassendere Etablierung des Medienthemas in der germanistischen Sprachwissenschaft dar - bis hin zur Reflexion der Nutzung neuer Medien als methodischer Forschungsinstrumente. Freilich blieb der thematische Fokus der Jahrestagung von 1999 noch vornehmlich auf den Funktionswandel von Sprache in den neuen Medien gerichtet, d.h. - wie es 
ebenfalls bei Kallmeyer heißt - auf den „Wandel von Sprache und Kommunikationsformen unter dem Einfluss der neuen Medien“ (Kallmeyer 2000b, S. 293). So verdienstvoll dieses vor allem in der letzten Dekade prosperierende linguistische Forschungsparadigma nun ohne Zweifel nach wie vor ist, so adressiert es die Sprache doch eher als Patienten medialer Akteure, d.h. eher als Gegenstandsfeld medialer Wirkungen, denn als symbolisches System, das selbst Medium ist. Eben diese Kehrseite des Themenfeldes „Sprache und Medien“ nahm nun im letzten Jahrzehnt insbesondere der medientheoretische Diskurs der Kulturwissenschaften in den Blick, der nachdrücklich dazu beigetragen hat, die Medialität des Mediums Sprache selbst stärker in den Fokus der Aufmerksamkeit zu rücken (Jäger/Linz (Hg.) 2004; Krämer 2004), d.h. die Klärung einer Frage voranzubringen, die ich mir erlaubt habe, hier vor zehn Jahren zu stellen, nämlich „ob wir nicht $[\ldots]$ - bei aller Notwendigkeit, die immer komplexer werdenden Verhältnisse von Sprache und (neuen) Medien zu bestimmen - immer zugleich auch die Frage nach der Medialität des anthropologischen Rahmenmediums Sprache stellen müssen, weil sich vielleicht erst von hier aus Aufklärung darüber gewinnen läßt, was die Medialität von Medien ausmacht" (Jäger 2000, S. 10). Auch wenn über die - in dieser Frage versteckte, vielleicht anmaßend anmutende - kulturelle und theoretische Privilegierung der Sprache vor anderen Medien sicher kein konfliktfreies Einvernehmen in den Kulturwissenschaften herrscht - insbesondere nicht etwa aus der Perspektive des rezenten bildtheoretischen Diskurses (Mitchell 1995/2008; Boehm (Hg.) 1995; Boehm/Mersmann/Spies (Hg.) 2008) -, zeigen die intensiven Debatten über Sprache und Schrift (Stetter 1997; Grube/Kogge/Krämer (Hg.) 2005), über Sprache und Stimme (Waldenfels 1999; Epping-Jäger/Linz (Hg.) 2003; Kolesch/Krämer (Hg.) 2006), über Sprache und Gestik (Kendon/ Müller 2007 ff.), über das Verhältnis von Laut- und Gebärdensprachen (Fehrmann/Jäger 2004) sowie schließlich nicht zuletzt über die Beziehungen zwischen linguistic und pictorial turn (Mitchell 1995/2008), dass die Sprache selbst als ein multimodales (Fricke 2008) und zudem in verschiedenen medialen Formaten auftretendes Medium (Jäger 2001), wenn man so will, als ein Intermedium, sowohl in den Kulturwissenschaften allgemein als auch in der Sprachwissenschaft - wie insbesondere auch das Programm dieser Tagung zeigt - wieder erhöhte theoretische Aufmerksamkeit genießt. In der Sprachwissenschaft zeigt sich zudem in der Hinwendung zur Medialitätsdimension der Sprache zugleich zumindest partiell eine Abkehr vom medialitätsfeindlichen Paradigma des linguistischen Kognitivismus und das heißt von dem, was ich die „Medialitätsvergessenheit der Sprachtheorie“ (Jäger 2000, S. 26 ff.) genannt habe.

Der sich deutlich belebende Diskurs über Medialität im Allgemeinen und Sprachmedialität im Besonderen, von dem sich offenbar auch das Pro- 
gramm dieser Tagung anregen ließ, hat sich im Horizont eines breiteren medialitätstheoretischen Forschungsfeldes in den Kulturwissenschaften entfaltet, das inzwischen den gemeinsamen theoretischen Rahmen für eine Reihe von geistes- und kulturwissenschaftlichen Einzeldisziplinen bereitstellt. Dieses Forschungsfeld nimmt - anders als etwa die sozialwissenschaftliche Kommunikations- und Medienforschung, die weithin durch das Paradigma der Medienwirkung bestimmt ist und im Wesentlichen als geklärt voraussetzt, was Medien sind - gerade die Medialität der Medien und auch die des Mediums Sprache in den Blick, weil es die Frage nicht für theoretisch belanglos hält, was Medien sind (Münker/Roesler (Hg.) 2008) oder besser, wie Medien operieren: Medialität und Mentalität, Medialität und Performativität, Medialität und Theatralität (Buss et al. 2009); und auch wieder die Frage nach dem Verhältnis von Medialität und Zeichenhaftigkeit (Winkler 1997, 2008; Wirth 2008) tritt ebenso in den Fokus der Forschung wie der Bild-Sprach-Zusammenhang (Holly 2008), das Problem der Stimmlichkeit, der Schriftlichkeit oder der Raumsituiertheit von Sprache. Wie sichtbar sich dieses Forschungsparadigma, das in den letzten zehn Jahren nicht unwesentlich von einer Gruppe von kulturwissenschaftlichen DFG-Sonderforschungsbereichen etwa in Berlin, Köln, Siegen und Gießen konturiert worden ist, inzwischen etabliert hat, lässt sich auch daran ablesen, dass der Wissenschaftsrat in seinen jüngsten „Empfehlungen zur Weiterentwicklung der Kommunikations- und Medienwissenschaften in Deutschland“ (2007) in seiner Übersicht über das disziplinäre Feld neben den sozialwissenschaftlichen Kommunikationswissenschaften und der Medieninformatik als dritte Konstituente eine Wissenschaftsgruppe nennt, die er unter dem Titel „kulturwissenschaftliche Medialitätsforschung" zusammenfasst. Ich betrachte deshalb auch die diesjährige Jahrestagung des IDS als einen diskursiven Beitrag zur weiteren Profilierung einer kulturwissenschaftlichen Medialitätsforschung und insbesondere als einen Beitrag zur theoretischen Aufhellung des Begriffs der Medialität. Ohne Zweifel lässt sich der Begriff der Medialität - und deshalb ist der Tagungstitel glücklich gewählt - nicht ohne die Diskussion dessen klären, was unter ,Intermedialität ${ }^{`}$ und - wie ich hinzufügen möchte - ,Intramedialität verstanden werden soll. Meinem Beitrag zum Tagungsthema liegt deshalb die These zugrunde, dass ein angemessener Begriff von Medialität nur über die Analyse der Begriffe ,Intramedialität ${ }^{\star}$ und ,Intermedialität ${ }^{\natural}$ gewonnen werden kann, wobei ich - wie im Folgenden deutlich werden soll - beide als operative Begriffe verstehen will, das heißt als Begriffe, mit denen ein bestimmtes Verfahren der Medien beschrieben werden kann - das Verfahren der Transkription. ,Transkriptivität', der dritte Begriff, der im Folgenden eine Rolle spielen wird, soll dabei nicht nur mit Blick auf die Sprache, sondern darüber hinaus auf das Feld der kulturellen Semiosis insgesamt bezogen werden. 


\section{Kulturelle Semiosis und die ,Logik der Transkription}

Dass Medien intermedial aufeinander Bezug nehmen, dass sie sich intramedial in rekursiven Schleifen auf sich selbst beziehen, dass sie also ihre eigenen Hervorbringungen unablässig zum Ausgangspunkt von Resemantisierungen, von Um- und Überschreibungen machen, ist ein Phänomen, auf das vor allem in jüngerer Zeit in den unterschiedlichsten disziplinären Kontexten der Kulturwissenschaften wachsende Aufmerksamkeit gerichtet wird. In den Kunstwissenschaften sind Begriffe wie der der „Metakunst" ${ }^{\text {“1 }}$ bzw. der „metapeinture“ gängige Beschreibungskategorien für die Kunst des 20. Jahrhunderts: Stoichita (1993/1998) etwa hat es als ein Kennzeichen der modernen Malerei angesehen, dass sie selbstreferentiell geworden sei, und deshalb von einem ,autoreferentiellen Malereidiskurs“ der Moderne gesprochen, ${ }^{2}$ und Mitchell hebt in seiner Bild-Theorie hervor: „Selbst-Referenz ist ein zentrales Thema modernistischer Ästhetik und ihrer verschiedenen postmodernen Revisionen. ${ }^{\text {" }}$ Bezugnahmeformen dieser Art bestimmen auch andere Medien und kulturelle Praktiken: das Remake im Film, Appropriationen in der Fotografie 4 oder Cover-Hits und Samplings in der Unterhaltungsmusik. Die Musik insgesamt ist wie vielleicht keine andere Kunst durch Verfahren der bearbeitenden Selbstbezugnahme, durch Verfahren des Arrangements, der Kontrafaktur, der Parodie und Umorchestrierung, durch Revision, Variation und Improvisation ${ }^{5}$ geprägt. Auch Sprache scheint in geradezu paradigmatischer Form durch ihr Vermögen rekursiver Selbstbezugnahme bestimmt zu sein, durch das Vermögen, Ausschnitte der Rede gleichsam stillzustellen und sie - wie etwa Gülich/Kotschi oder Mar-

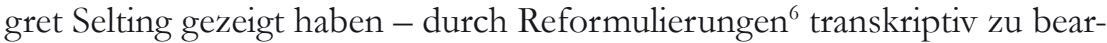
beiten, ${ }^{7}$ eine autoreferentielle Selbstlektüre, die Almuth Grésillion ${ }^{8}$ auch für das literarische Schreiben als bestimmendes operatives Moment herausgearbeitet hat.

\footnotetext{
Vgl. etwa Zuschlag (2002).

Vgl. hierzu Zuschlag (2002, S. 177).

Vgl. Mitchell (1995, S. 35): „Self-reference is a central issue in modernistic aesthetics and its various postmodern revisions."

4 Zum Problem des transkriptiven Verhältnisses von Original und Kopie in Fällen etwa des Samplings und der Appropriation Art vgl. Fehrmann/Linz/Schumacher/Weingart (2004). Zum Problem der Appropriationskunst vgl. etwa Amelunxen (1993) und Aigner (1993).

5 Vgl. Leopold (Hg.) (1992), hier Leopold (1992, S. 8); vgl. ebenso die Beiträge in Buschmeier/ Konrad/Riethmüller (Hg.) (2008).

6 Vgl. hierzu etwa Gülich/Kotschi (1996).

7 Mit transkriptiven Bearbeitungen sind selbstexplikative und kooperative Verständigungshandlungen gemeint, wie sie etwa in der Ethnomethodologie untersucht worden sind: Reparatur-Sequenzen, ,in denen ein Interaktionspartner - oft in einer Nebensequenz [...] eine vorausgegangene Äußerung korrigiert oder präzisiert oder ein vom Rezipienten der Äußerung signalisiertes Verstehensproblem bearbeitet“" (Selting 1987, S. 128); vgl. hierzu insgesamt Jäger (2004).

$8 \quad$ Vgl. Grésillion (1995, S. 8, Anm. 9).
} 
Auch jenseits der Selbstreferentialität des Schreibaktes lassen sich - etwa in Kristevas (1969) Begriff der „Intertextualität“ oder in Genettes (1993, S. 9) Kategorie der „Transtextualität“ - literarische Bezugnahmeformen ausmachen, durch die Texte ,in eine manifeste oder geheime Beziehung zu anderen Texten" (ebd.) gebracht und so die Verwebungsdichte generiert wird, durch die literarische Universen bestimmt sind.

Schließlich lässt sich auch im Zeitalter der, neuen Medien' - so Bolter und Grusin ${ }^{9}$ - die Logik der intermedialen Verhältnisse als eine Logik der „Remediatisierung“ („remediation") beschreiben: Medien treiben - so Manovich - sowohl auf der Inhalts- als auch auf der Formebene durch Übersetzung, Umgestaltung und Umformung von anderen Medien die Prozesse der „kulturellen Rekonzeptualisierung“ voran. ${ }^{10}$

\section{Transkriptivität: Zeichen- und erkenntnistheoretische Sondierungen}

Hinter der hier nur angedeuteten Vielfalt der „Praktiken der Selbst- und Fremd-Bezugnahme" ${ }^{11}$ die die Verfahren der Sprache, der Künste, der Kommunikationsmedien ${ }^{12}$ und der neuen Medien ${ }^{13}$ - und damit wesentliche Teile der kulturellen Semiosis - bestimmen, lässt sich nun - so unterschiedlich sie auch in medialer und ästhetischer Hinsicht ausgeprägt sein mögen - eine grundlegende Verfahrenslogik ausmachen, die ich in verschiedenen Arbeiten vorgeschlagen habe, als eine ,Logik der Transkription zu verstehen (vgl. Jäger 2008a). In alle diese Verfahren der intra- und intermedialen Kopplung und Bezugnahme ist - so meine These - eine allgemeinere mediale Operationslogik eingeschrieben, die für die Sprach-, Schrift- und Bildmedien ebenso gilt wie für die sogenannten ,neuen Medien': Für alle diese Medien- und Zeichensysteme ist es charakteristisch, dass sie ihre sinngenerierenden und sinntransformierenden Leistungen we-

9 Bolter/Grusin (2001, S. 45): „[W] call the representation of one medium in another remediation, and will argue that remediation is a defining characteristic of the new digital media." Ebenso etwa S. 55: „It would seem, then, that all mediation is remediation. [...] No medium, it seems, can now function indepedently and establish its own seperate and purified space of cultural meaning. “

10 Vgl. Manovich (2001, S. 47): „In new media lingo, to 'transcode' something is to translate it into another format. The computerization of culture gradually accomplishes similar transcoding in relation to all cultural categories and concepts. That is, cultural categories and concepts are substituted, on the level of meaning and/or language, by new ones that derive from the computer's ontology, epistemology, and pragmatics. New media thus acts as a forerunner of this more general process of cultural reconceptualization."

11 Vgl. zu diesen „Praktiken des Sekundären“ auch insgesamt Fehrmann/Linz/Schumacher/ Weingart (Hg.) (2004).

12 Vgl. hierzu etwa Luhmann (1997a, S. 190-412).

13 Vgl. etwa Manovich (2001). 
sentlich in semiologischen Prozeduren der inter- und intramedialen Bezugnahme organisieren. Diese Prozeduren sollen im Folgenden am Leitfaden von fünf heuristischen Prinzipien zur intra- und intermedialen Bezugnahme näher in den Blick genommen werden.

\subsection{Das Spur-Prinzip ${ }^{14}$}

Für das Modell der Intra- und Intermedialität, das ich hier skizzieren möchte, ist die Maxime Brandoms zentral, dass die Fähigkeit von Subjekten, mit Zeichen auf Gegenstände einer transsemiotischen Welt Bezug zu nehmen, in Begriffen der Fähigkeit erklärt werden muss, mit Zeichen auf Zeichen Bezug zu nehmen. Man könnte diese Maxime auch so formulieren, dass ,in der Reihenfolge semantischer Erklärungen der Inferenz Vorrang vor der Referenz eingeräumt werden muß“ (Brandom 2001, S. 9). Mit dieser Priorisierung inferentieller vor referentiellen Bezugnahmen bindet Brandom den repräsentationalen Gehalt von Begriffen und Behauptungen, kurz die interne Sphäre des Mentalen an den externen Raum medialer Diskursivität. ${ }^{15}$ Sein Begriff der ,expressiven Vernunft“ lässt sich insofern auch als der einer diskursiven oder - allgemeiner - medialen Vernunft verstehen: Für Brandom sind kognitive Operationen als mentale Prozesse, die referentielle Bezugnahmen ermöglichen, auf die expressive Spur ihrer medialen Erscheinung angewiesen, weil sich erst hier, im medialen Raum kommunikativer Bezugnahmen, sowohl Subjekte möglicher Referenzhandlungen als auch Welten ausbilden können, auf die referiert werden kann.

Brandoms Privilegierung inferentieller Bezugnahmen (vor referentiellen) - von der bei der Erörterung des Interpretations-Prin₹ips noch näher die Rede sein wird - muss im Horizont einer zugleich epistemologischen und semiologischen Grundannahme gelesen werden, die sich in der sprachphilosophischen Kritik des frühen 19. Jahrhunderts an der cartesianisch-kantischen Subjekt- und Sprachidee ausgebildet hat. Der Kern dieser Hypothese lässt sich so formulieren, dass in dem Tripel ,Erkenntnissubjekt - Zeichen - Erkenntnisobjekt ${ }^{\star}$ das Zeichen insofern eine zentrale Rolle spielt, als es eine notwendige Entstehungs- und Bestandsbedingung für die beiden anderen Konstituenten darstellt. Sowohl die begriffliche Ausdifferenzierung der Welt als auch die Herausbildung des Bewusstseins, das sich auf sie bezieht, sind ohne den medialen ,Umweg' semiologischer Selbstlektüre und zeichenvermittelter Interaktion mit anderen, d.h. ohne intra- und intermediale Bezug-

14 Vgl. zum Spur-Begriff etwa die Arbeiten in Fehrmann/Linz/Epping-Jäger (Hg.) (2005); ebenso Krämer/Kogge/Grube (Hg.) (2007).

15 Vgl. Brandom (2001, S. 207 ff.); vgl. etwa auch Brandom (2000, S. 399 f.): „Die für uns charakteristische Verstandesfähigkeit ist ein Status, der im Rahmen einer Struktur wechselseitigen Anerkennens gewonnen wird [...]. Der spezifisch diskursive Charakter dieser normativen sozialen Struktur [...] besteht in der inferentiellen Gliederung dieser Anerkennungspraktiken. Wir sind diejenigen, die Gründe für das, was wir sagen und tun, geben und verlangen.“ 
nahmen, nicht möglich. Erst auf dem Umweg einer semiologisch vermittelten Selbstlektüre - die zugleich in ein komplexes Netzwerk kultureller Texturen eingewoben ist - kann das Subjekt sich in seiner Erkenntnisbeziehung zur Welt konstituieren. ${ }^{16}$ Man könnte mit Blick auf unser Thema auch sagen, dass sich in gewissen Sinne Medialität in die Unmittelbarkeit einnistet, in der sich das Subjekt auf sich selbst und seine Erkenntniswelt bezieht.

Die Figur der zeichenvermittelten und bewusstseinskonstitutiven Rückwendung des Subjektes auf sich selbst hatte zum ersten Mal Humboldt in seiner Sprach- und Zeichenphilosophie entfaltet. Gegenüber der cartesianisch-kantischen Subjektidee machte er geltend, dass die ,innerliche intellectuelle Thätigkeit“ eines solipsistischen Subjektes ,gewissermassen spurlos vorübergehend“" (Humboldt GS 7, S. 53) wäre, wenn sie sich nicht an die Äußerlichkeit des Lautes in der Rede binde. Ohne eine solche mediale Vermittlung des Mentalen könne - so Humboldt (ebd.) - „das Denken [...] nicht zur Deutlichkeit gelangen, die Vorstellung nicht zum Begriff werden“. Die Äußerlichkeit der Rede, der performative Auftritt der Zeichen im Horizont von Zeichennetzwerken, ist für Humboldt jener mediale Ort, an dem allein es möglich wird, „,den Gedanken [...] zur Rückwirkung auf das Subject, aus sich heraus und sich gegenüber zu stellen" (Humboldt GS 5, S. 455). „Ohne diese, wo die Sprache mitwirkt, [...] immer vorgehende Versetzung in zum Subject zurückkehrende Objectivität ist die Bildung des Begriffs, mithin alles wahre Denken unmöglich.“ (ebd., S. 377) $\cdot{ }^{17}$ Erst in der Spurenlese, der Relektüre, in der der ,Geist" der medialen Spur der eigenen mentalen Akte begegnet, in der Transkription des Mentalen in die semiologischen Register des Medialen, kann sich begriffliche Distinktivität einstellen und ein Subjekt möglicher begrifflicher Unterscheidungshandlungen konstituieren.

Bereits Humboldt entwirft dabei die medial vermittelte autoreferentielle Selbstbegegnung des Geistes als ein Verfahren, in dessen Vollzug der vorgängige Begriff im Akt seiner Bezeichnung in gewissem Sinne erst hervorgebracht wird: Die Selbstlektüre des Geistes nimmt die Form einer ,Begriffsbezeichnung' an, in der - wie Humboldt (GS 5, S. 436) formuliert - „die Bezeichnung erst das Entstehen des zu Bezeichnenden vor dem Geiste vollendet". Das Vorgängige, das zu Bezeichnende, wird erst in der Nachträglichkeit der Bezeichnung, gleichsam in einer transkriptiven Umschrift, konstituiert.

16 Obwohl das epistemologische Modell der Semiologie des auslaufenden 19. Jahrhunderts nicht direkt auf Bruno Latours Actor-Network-Modell abgebildet werden kann - so müssen etwa bei Latour ,actors' nicht notwendig , human actors' sein -, stimmen doch beide Ansätze in der Bestimmung des Akteur-Netzwerk-Verhältnisses überein: „No net exists independently of the very act of tracing it, and no tracing is done by an actor exterior to the net." (Latour 1996, S. 378).

17 Vgl. auch Humboldt (GS 6, S. 155 und GS 7, S. 55); vgl. hierzu ausführlich Jäger (1988). 
Man könnte auch, obgleich für Derrida wohl zuletzt Humboldt als Bürge des Gedankens in Frage käme, eine solche spurtheoretische Überlegung mit Derrida in Verbindung bringen. Wie vor ihm Humboldt skizziert Derrida die theoretischen Umrisse einer - wie man sie nennen könnte - transzendental-medialen Bedingung von Mentalität, die gegen die Metaphysik der „Innerlichkeit der Seele“" (Derrida 1974, S. 61) das Draußen exteriorer Zeichenprozesse in Stellung bringt: Er wendet sich insbesondere gegen die Idee eines „transzendentalen Signifikats“ als „Ausdruck reiner Intelligibilität“ (ebd., S. 28), gegen die Metaphysik der „Selbstpräsenz der Seele im wahren Logos" (ebd., S. 61). ${ }^{18}$ In einem gleichsam medientheoretischen Gestus insistiert er gegenüber den klassischen Zeichen- und Bewusstseinsphilosophien auf der grundlegenden Bedeutung des Signifikanten für die Konstitution des Signifikats; die Vorgängigkeit des Zeichensinns und des Bewusstseins, das ihn erzeugt, lässt sich immer nur auf dem Weg der nachträglichen Prozessierung durch materielle Zeichen herstellen; die Privilegierung des Signifikats ist illegitim, weil ein Bezeichnetes unabhängig von der Phänomenalität des Zeichens nicht existent sein könnte: „Es gibt [...] keine Phänomenalität, welche das Zeichen oder den Repräsentanten reduziert, um schließlich das bezeichnete Ding im Glanz seiner Präsenz erstrahlen zu lassen.“ (Derrida 1974, S. 86).

Derridas Angriff richtet sich also - wie zuvor der Humboldts - auf die Metaphysik der Präsenz, die Idee der unmittelbaren „Selbstpräsenz des cogito" (ebd., S. 26) und seiner signifikativen Leistungen, indem er die Untilgbarkeit des medialen „Aufschubs“ ${ }^{19}$ der sich der „Exteriorität des Signifikanten“ (ebd., S. 29) bedienen muss, exponiert, eines medialen Aufschubs, der für den Prozess der Selbstkonstitution des Geistes und seiner Sinnproduktionen absolut unabdingbar ist. Die Vorgängigkeit des Sinns ist deshalb - ebenso wie das mentale System, das ihn generiert - für Derrida immer notwendig auf die Nachträglichkeit einer medialen Spur der eigenen Aktivität verwiesen: Das einfache „Frühersein der Idee“ oder der ,inneren Absicht" gegenüber ihrer medialen Prozessierung ist ein Vorurteil (vgl. Derrida 1976, S. 24). Mit Freud betrachtet er die ,Umschrift' des Unbewussten in einen Bewusstseinstext nicht als einen Prozess der nachträglichen ,Übersetzung' eines ,Ursprünglichen': Vielmehr ist bereits der ,ursprünglich` unbewusste Text

aus Archiven gebildet, die immer schon Umschriften sind. [...] Alles fängt mit einer Reproduktion an. ,Immer schon' heißt Niederschlag eines Sinns, der nie gegenwärtig war, dessen bedeutete Präsenz immer ,nachträglich', im Nachherein und zusätzlich rekonstruiert wird. Das Aufgebot des Nachtrags ist hier ursprünglich und untergräbt das, was man nachträglich als Präsenz rekonstruiert. (Derrida 1976, S. 323)

18 Dass hierbei nach Derridas Ansicht immer die Stimme als Komplize der reinen Selbstaffektion auftritt, soll hier aus den dargelegten Gründen ausgeblendet werden.

19 Vgl. hierzu etwa Derrida (2003, S. 118 ff.). 
Die Umschrift, die Transkription, vollzieht sich in der Nachträglichkeit einer Bezeichnung, die erst - wie Humboldt formuliert hatte - das vorgängig zu Bezeichnende vor dem Geiste vollendet.

Sinn lässt sich also für Derrida wie für Freud und Humboldt ,nicht in der ursprünglichen oder in einer modifizierten Form der Präsenz denken. “ (Derrida 1976, S. 323). Im „Spiel des Bezeichnens“ wird mit dem Signifikanten kein vorgängiger Sinn substituiert, weil dieses Zeichen-Substitut so Derrida (ebd., S. 424) - nichts ersetzt, „das ihm irgendwie präexistiert hätte." Sinn ist - wie man in Husserlscher Terminologie sagen könnte - in seiner semantischen Evidenz nicht in ursprünglicher „Selbsthabe“, sondern als Ergebnis der diskursiven Leistung einer nachträglichen „Selbstgebung “ kurz: allein als das Ergebnis einer transkriptiven Umschrift, einer zugleich nachträglichen und für das Vorgängige konstitutiven semiologischen Bezugnahme gegeben. „Der Gehalt des Geistes“ - formuliert Cassirer (1964, S. 18) „erschließt sich nur in seiner Äußerung“"

Am Ende meines kleinen spurtheoretischen Exkurses lässt sich also mit Blick auf den zeichen- und erkenntnistheoretischen Rahmen einer Theorie der Intermedialität als erster Befund festhalten: Transkriptive Bezugnahmen sind mediale Verfahren der Konstitution des Mentalen: Sie sind der operative Modus, in dem der Geist sich selbst in Figuren der medialen Nachträglichkeit auf die Spur kommt. Diese suspendieren gleichsam die Unmittelbarkeit des Selbst- und Weltbezugs, in die sie sich als mediale Verfahren einschreiben.

\subsection{Das Interpretations-Prinzip}

Dass die kulturelle Semiosis der systematische Ort ist, an dem Zeichensubjekte ihre mentale Identität über die Spur medialer Zeichenhandlungen konstituieren, verweist auf eine weitere wesentliche epistemologisch-semiologische Voraussetzung einer Theorie intra- und intermedialer Transkriptivität: Die Semiosis ist nämlich nicht nur das mediale Feld, auf dem Subjekte sich als Subjekte konstituieren, sondern uno actu zugleich die semiologische Bühne, auf der sich kulturelle Welten in ihrer begrifflichen Ordnung herstellen, jene Welten also, in denen und in Berug auf die die Subjekte handeln. Eine prämediale Welt möglicher Bezugnahme bzw. eine prämediale ,Sprache des Geistes' kann es dann ebenso wenig geben wie Subjekte, die ihren medialen Zeichenhandlungen als selbstpräsente Cogitos vorauslägen.

Für die Genese der kulturellen Semantik heißt dies: Die Konstitution und Beglaubigung von Sinn lässt sich nicht auf dem Wege der jeweiligen referentiellen Abgleichung von Zeichensystemen mit einer medientranszendenten Realwelt bzw. ihren kognitiven Repräsentationen vollziehen. Vielmehr kann die semantische Ratifizierung von Sinn ihren Ort zum einen 20 Vgl. Husserl (1929, S. 140 ff.). 
nur innerhalb des Horizontes von und zum anderen nur in wechselseitiger Bezugnahme zwischen medialen und semiologischen Darstellungssystemen haben. Eine ,beobachtungsinvariante Welt“ steht - wie Luhmann (1992, S. 75) bemerkt - für die Prüfung des Adäquationsgrades semiologischer Darstellungssysteme nicht zur Verfügung: ,[D]ie Welt kann nicht von auBen beobachtet werden, sondern nur in ihr selbst, das heißt: nur nach Maßgabe von [...] Bedingungen, die sie selbst bereitstellt" (ebd.).

Die Geltung und die semantische Evidenz von kulturellem Sinn, wie er von sprachlichen und nichtsprachlichen Medien generiert wird, verdanken sich deshalb einem Prinzip, das man Interpretations-Prinzip nennen könnte und das zugleich ein Intermedialitäts-Prinzip ist. Das referentielle Verwenden von Zeichen zur Bezugnahme auf eine (zeichentranszendente) Welt ist kein denkbares Fundament für die sinnkonstitutiven Leistungen von Zeichensystemen. ${ }^{21}$ Aus einer ontologischen Weltwabe lässt sich ebenso wenig semantischer Honig saugen wie aus den mentalen Leistungen eines vorsprachlichen Geistes. Sprach- und Mediensysteme, die auf eine semantische Referenzfunktion eingeschränkt blieben, könnten keine Sprach- oder Mediensysteme im definitorischen Sinne sein.

Was in einer paradigmatischen Weise für natürliche Sprachen gilt, scheint eine Eigenschaft von Mediensystemen insgesamt zu sein: dass sie nämlich in einem für sie konstitutiven Sinne über die Möglichkeit verfügen müssen, die semiologischen Mittel, mit denen ihre Verwender interagieren und durch die sie sich auf die Welt beziehen, jederzeit als solche Mittel zu fokussieren, zu thematisieren und sie im Interesse der Selbst- und Fremdverständigung in autoreferentiellen oder interaktiven semiologischen Aktivitäten semantisch zu bearbeiten. ${ }^{22}$ Die Fähigkeit, selbst hervorgebrachte oder kommunikativ vorgefundene symbolische Artefakte zu zitieren, zu paraphrasieren, zu explizieren, zu erläutern oder zu interpretieren, um auf diese Weise ihren

21 Vgl. hierzu Saussures Überlegungen in den Gartenhausnotizen: Gegen die Annahme, dass man bei Worten, die sich „auf einen materiellen Gegenstand“ beziehen, sagen könnte, „daß das Wesen des Gegenstandes selbst tatsächlich so beschaffen ist, daß es dem Wort eine positive Bedeutung gibt“, wendet er ein: „Ich kenne tatsächlich keinen Gegenstand, zu dessen Bezeichnung nicht einer oder mehrere angeblich zusätzliche Begriffe hinzukommen, die aber im Grunde ganz genauso wichtig wie der Hauptbegriff sind - selbst wenn der fragliche Gegenstand die Sonne, das Wasser, die Luft, der Baum, die Frau, das Licht usw. wäre. Derart, daß alle diese Bezeichnungen in Wirklichkeit ebenfalls negativ sind und nur im Verhältnis zu den Begriffen etwas bedeuten, die in anderen ebenfalls negativen Termen enthalten sind, derart, daß sie sich niemals auf einen in sich bestimmten Gegenstand beziehen wollen und in Wirklichkeit diesen Gegenstand [...] nur auf indirekte Weise, durch und unter der Perspektive dieses oder jenes besonderen Begriffs berühren“" (Saussure 2003, S. 141 f.).

22 Vgl. Brandom (2001, S. 210 f.): „Auf der Seite der propositional gehaltvollen Sprechakte [...] schlägt sich die wesentliche inferentielle Gliederung des Propositionalen in der Tatsache nieder, daß das Spiel des Gebens und Verlangens von Gründen das Herzstück der spezifisch sprachlichen Praxis ist. [...] Ansprüche bzw. Behauptungen dienen als Gründe und bedürfen ihrerseits der Begründung oder Rechtfertigung. Sie verdanken ihre Gehalte teilweise der Rolle, die sie in einem Netzwerk von Inferenzen spielen." 
Verwendungssinn fortzuschreiben, muss als ein Vermögen angesehen werden, das für das operative Wissen der Akteure konstitutiv ist, die sich in der Sphäre des Medialen bewegen.

Ehe es also Medienakteuren möglich ist, mit Zeichen auf die Welt zu referieren, muss das Spiel der Bezugnahme von Zeichen auf Zeichen möglich sein, müssen die Bedeutungen von Zeichen in dem Sinne verfügbar sein, dass ihre Vernetzung mit anderen Zeichen im System einer Sprache oder eines nichtsprachlichen Mediensystems aufgerufen, also das semantische Netzwissen ${ }^{23}$ bei Bedarf transkriptiv in Bezugnahmehandlungen aktiviert werden kann.

Die repräsentativ-referentielle Zeichen-Welt-Relation wäre in sich völlig unzureichend für die Gewährleistung semantischer Bezugnahmen, weil die referentielle Bezugnahme die Möglichkeit der zeichensystem-inhärenten Bezugnahme der Zeichen aufeinander - also das Spiel intra- und intermedialer Bezugnahmen - voraussetzt: „Zeichen referieren“ - so Deacon (1997, S. 99) - ,nicht direkt auf die Gegenstände in der Welt, sondern indirekt dadurch, dass sie auf andere Zeichen verweisen" [diese und die folgenden Übersetzungen von mir, L.J.]. Die medienimmanente Genese des Sinns folgt also einem semiotischen Gesetz, das Peirce (1984, S. 173) so formuliert hat: „Aus der Tatsache, dass jeder Gedanke ein Zeichen ist, folgt, dass der Gedanke einen weiteren Gedanken adressieren muß, weil darin das Wesen des Zeichens besteht. [J]eder Gedanke muss durch einen anderen Gedanken interpretiert worden sein." Es gibt - so Peirce (ebd., S. 224) „keine Ausnahme von dem Gesetz, dass jedes Gedanken-Zeichen durch ein folgendes übersetzt oder interpretiert worden sein muss [...].“

Für die Sprache etwa heißt dies: Mit sprachlichen Ausdrücken auf die Welt Bezug nehmen zu können, setzt voraus, dass die semantischen Gehalte der sprachlichen Äußerungen, mit denen Sprecher einen solchen Bezug herstellen, in ihrer Implizitheit expliziert, in ihrer Unklarheit erläutert, in ihrer Unverständlichkeit paraphrasiert sowie gegenüber Zweifeln legitimiert und begründet werden können etc., setzt also voraus, dass die Sprecher in einen Diskurs transkriptiver - in gewissem Sinne interpretierender - Bezugnahme auf ihren eigenen Sprachgebrauch einzutreten vermögen. ${ }^{24}$ Ein solches transkriptives Vermögen ist ein Grundprinzip der Pro-

\footnotetext{
23 Vgl. hierzu de Saussures Theoriefragment ,Notes Item', in dem er die Netzverwobenheit sprachlicher Zeichen theoretisch entfaltet (Saussure 1974, S. 35 ff. (3306-3324 = N 15.1-19)); vgl. hierzu Jäger (1986).

24 Das Verfügen über begriffliche Gehalte, das eine zentrale Voraussetzung der Bezugnahme auf transsemiotische Sachverhalte darstellt, ist - so Brandom (2000, S. 26) - eine „sprachliche Angelegenheit, nicht in dem Sinn, daß man sprechen muß, um es zu tun, sondern in dem Sinn, daß man ein Mitspieler im wesentlich sprachlichen Spiel des Gebens und Verlangens von Gründen sein muß, um [zum Verfügen über begriffliche Gehalte] in der Lage zu sein“. Brandom geht hier davon aus, „daß die Eigenschaft, über propositionale Gehalte zu verfügen, anhand der Praktiken des Lieferns und Forderns von Gründen zu verstehen [ist]. Eine
} 
zessierung von kultureller Semantik. Es gilt in einer sicher noch näher zu untersuchenden Weise auch für andere Medien- und Zeichensysteme - für bestimmte Formen des Piktoralen etwa oder die Musik - und insbesondere für deren intermediales Zusammenspiel.

Semantiken verdanken sich also epistemologisch nicht einem Reich medienfreier Kognition oder einer ontologischen Ordnung der ,Welt selbst'. Ihre Funktion kann sich in den verschiedenen Medien nicht darin erschöpfen, Weisen bereitzustellen, in denen eine prämediale (,ontologische) Welt dargestellt, abgebildet, gespiegelt zu werden vermag. Wir verfügen - so Rorty (1994, S. 321) - über keinen „transzendentalen Standpunkt außerhalb unserer gegenwärtigen Darstellungssysteme, von dem aus wir die Relation zwischen diesen Darstellungen und ihrem Gegenstand untersuchen könn $[t]$ en", über keinen exzentrischen archimedischen Punkt also, der es uns erlaubte, die Adäquatheit unserer Bezugnahmen auf die Welt unabhängig von medialen Darstellungssystemen zu beurteilen. Wir müssen uns vielmehr immer auf Semantiken stützen, für die das Interpretations-Prin₹ip konstitutiv ist. Semantiken dieses Typs verdanken sich Zeichensystemen, die es in einem gewissen Sinn nur erlauben, weitere semiologische Eintragungen in eine immer schon semiologisch strukturierte Welt vorzunehmen. ${ }^{25}$

Die Genese, Fortschreibung und Geltungsauszeichnung von Sinn operiert also über verschiedene Arten der Bezugnahme, die sich in einem erkenntnistheoretischen Sinn nicht vorgängig zwischen Zeichensystemen und der Welt abspielen, ${ }^{26}$ sondern die sich prioritär einmal zwischen verschiedenen (medialen) Zeichensystemen - also intermedial - und zum zweiten auch innerbalb desselben Zeichensystems - also intramedial - vollziehen. Transkriptionen sind die grundlegenden Verfahrensformen, die auf beiden Ebenen der Bezugnahme die kulturelle Semantik in Bewegung halten (vgl. Jäger 2008a). Dies ist der zweite Befund, den ich mit Blick auf den zu skizzierenden Rahmen einer Theorie der intra- und intermedialen Transkrip-

zentrale Behauptung lautet, daß diese Praktiken als soziale Praktiken zu verstehen sind - ja als sprachliche." (Brandom 2000, S. 219).

25 Natürlich müssen Sprachen, wie Peirce gezeigt hat, über Mittel verfügen, die es erlauben, die ,wirkliche“ Welt von einer, imaginären“ Welt zu unterscheiden: „Die wirkliche Welt kann von einer imaginären Welt nicht durch irgendeine Beschreibung unterschieden werden. Daher sind Pronomina und Indices notwendig" (CP 3.363, hier zitiert nach Peirce 1970, S. 104); vgl. hierzu auch Pape (1999, S. 7). Allerdings gilt auch - wie Brandom im Anschluss an Sellars gezeigt hat - für indexikalische Sätze, „daß sogar nichtinferentielle Berichte inferentiell gegliedert sein müssen“ (Brandom 2001, S. 70). ,[W] esentlich indexikalische Überzeugungen [besitzen] zwar eine besondere Art des auf Gegenstände bezogenen Gehalts, den andere Überzeugungen nicht haben, allerdings sollte man sich diese Gegenstandsbezogenheit nicht als nichtbegriffliches Element ihres Gehaltes vorstellen; vielmehr ist die besondere Art des $\mathrm{Zu}$ gangs zu jenen Gegenständen [...] eine besondere Art des begrifflich gegliederten Zugangs“" (Brandom 2000, S. 765). Brandom hält deshalb den intralingualen Bezug (Wort-Wort-Bezug) für „basaler“ als den Wort-Welt-Bezug (vgl. Brandom 2000, S. 442).

26 Natürlich kann man mit Zeichensystemen auf die Welt Bezug nehmen, aber nicht auf eine, die ohne Zeichensysteme strukturiert wäre. 
tivität festhalten möchte. Der Suspendierung des unmittelbaren Bezugs des Subjektes auf sich selbst, das des ,Umwegs' symbolischer Entäußerungen, einer medialen Spur seiner mentalen Aktivität bedarf, entspricht eine zweite konstitutive Suspendierung, nämlich die der Möglichkeit des unmittelbaren Bezugs auf eine Welt möglicher Referenz. Aus der Idee der Transkriptivität folgt also eine doppelte Suspendierung erkenntnistheoretischer Unmittelbarkeit, an deren Ort die Prozeduren medial vermittelter Selbst- und WeltBezugnahme treten.

\subsection{Das Medialitäts-Prinzip}

Spur-Prinzip und Interpretations-Prinzip schieben also unabweislich die Mittelbarkeit des Medialen in das Feld epistemologischer Unmittelbarkeit ein. Die Idee der Transkriptivität rehabilitiert die in der aristotelisch-kantischen Tradition der Sprach- und Zeichentheorie ebenso wie in ihren rezenten Ausläufern, etwa der kognitivistischen Linguistik, ignorierte und ausgeblendete „Materialität der Kommunikation“, ${ }^{27}$ und das heißt, sie setzt Materialität, Performativität und Äisthetik von Zeichen- und Mediensystemen theoretisch wieder in ihr Recht.

Wenn es zutrifft, dass Zeichen im Zuge der Semiosis weder unmittelbar auf den Attributreichtum einer zeichentranszendenten Welt noch unmittelbar auf die mentalen Hervorbringungen einer vorsprachlichen,Sprache des Geistes' zurückgreifen können, werden sie selbst zum Diskursort der Sinnproduktion: Ihre Funktion kann dann nicht mehr auf die der Repräsentation, des Transports bzw. der Übertragung von Inhalten beschränkt werden, weil sie konstitutiv an der Genese dieser Inhalte beteiligt sind. Was übertragen wird, muss zunächst - um einen Terminus Humboldts zu verwenden ,ausgemittelt ${ }^{\natural}$, d.h. in semiologischen Bezugnahmehandlungen konstituiert worden sein, und es kann jederzeit in störungsinduzierten kommunikativen Anschlusshandlungen aufgehoben, dementiert, verschoben oder affirmiert - kurz: transkribiert - werden. Die Genese von Sinn ist insofern eng mit der Medialität der Zeichensysteme verschaltet, in denen er hervorgebracht wird.

In der Tat sind in sprachlichen und nicht-sprachlichen Medien die jeweiligen Arten von Bedeutungsgehalten eng mit den jeweiligen materiellen Zeichensubstraten verknüpft; sie liegen diesen nicht als ,neutrale kognitive Formen voraus. ${ }^{28}$ Die Annahme, dass - wie etwa noch Wittgenstein im

$27 \quad$ Vgl. Gumbrecht/Pfeiffer (Hg.) (1988).

28 Es gibt - wie Saussure für die Sprache formuliert - „keine positive Trennlinie zwischen dem Begriff des Wortes und dem Begriff des Begriffs, der im Wort ist" (Saussure 2003, S. 151); Saussure insistiert darauf, dass ,weder der Begriff noch das Zeichen, weder die Verschiedenheit der Zeichen noch die Verschiedenheit der Begriffe jemals für sich genommen einen gegebenen Term ausmachen: Gegeben ist nur die Verschiedenheit der Zeichen, die unauflöslich und auf unendlich komplexe Weise mit der Verschiedenheit der Begriffe verbunden ist. Indem sich diese beiden chaotischen Bereiche [les deux chaos] vereinigen, entsteht eine Ordnung." (ebd., S. 114; vgl. ebenso S. 136). 
Tractatus (im Anschluss an ein aristotelisches Modell von Mentalität und Medialität) annimmt - sich die logische Form eines Gedankens identisch sowohl im Gedanken als auch in einem gesprochenen oder geschriebenen Satz, der den Gedanken zum Ausdruck bringt, repliziert, muss nun zurückgewiesen werden. Unter den Bedingungen der Transkriptivität kann es die identische Replikation eines, kognitiven Originals' in verschiedenen Zeichenformaten nicht geben. Wir können - wie Danto (1995, S. 134) formuliert - nicht mehr voraussetzen, „daß dieselbe Form sozusagen in drei verschiedenen Medien verkörpert wird, dem Medium des Gedankens, des Schreibens und des Sprechens". Die Semantik etwa der Bilder - oder anderer nichtsprachlicher Medien - besteht deshalb auch nicht darin, dass sie etwas bildlich sagen, was auch sprachlich oder anders hätte gesagt werden können. Neutrale Inhalte bzw. Informationen, die gleichsam unversehrt (,originaliter') zwischen verschiedenen Medien übertragen werden können, sind nicht denkbar, weil es nur mediale Varianten von Inhalten gibt, für die kein prämediales Original existiert. Jede Form der Übertragung eines Inhaltes aus einem in ein anderes Medium nimmt deshalb notwendig die Form der Transkription, d.h. der Neukonstitution unter medial veränderten Bedingungen an.

Wie meine bisherigen Bemerkungen deutlich machen sollten, führen die theoretischen Konsequenzen, die sich aus dem Spur-Prinzip und dem Interpretations-Prinzip ergeben, zu einem Medienbegriff, der mit der Auffassung, Medien seien technische Mittel der Informationsübertragung, nicht kompatibel ist. Ein solcher Übertragungs-Begriff ${ }^{29}$ von ,Medium ' ist ohne Zweifel weder für technische noch für semiologische Medien und insbesondere nicht für das Medium Sprache angemessen. Die semantischen Gehalte von Zeichen gehen ihrer Übermittlung durch Zeichenausdrücke nicht als kognitives Reservoir voraus. Sie werden nicht als transzendente Signifikate in den Diskurs eingespeist, sondern dieser ist der generische Ort der Hervorbringung von Sinn. Die von der Epistemologie der Störung bewirkte doppelte Suspendierung der Unmittelbarkeit (die der Introspektion und der Referens) ist also zugleich mit einer Rehabilitierung medialer Mittelbarkeit verbunden.

\subsection{Das Rekursions-Prinzip}

Ein wesentlicher Verfahrensmodus von symbolisch-medialen Systemen besteht - wie bereits bei der Betrachtung des Spur- und der InterpretationsPrinzips deutlich geworden ist - in der transkriptiven Wiederverarbeitung von medialen bzw. symbolischen Hervorbringungen, die bereits zuvor in diesen Systemen generiert worden waren: „, [A]lle Medien hängen“ - wie Bolter/Grusin formulieren - „in Zyklen der Remediatisierung von anderen

29 Dass der Begriff der ,Übertragung‘ jenseits von Sender-Empfänger-Modellen der Kommunikation medientheoretisch angemessen rekonstruiert werden kann, hat Hartmut Winkler gezeigt; vgl. etwa Winkler (2004). 
Medien ab [...].“30 Sowohl Individuen als auch kulturelle Systeme organisieren den semantischen Prozess wesentlich über Formen der autoreferentiellen, intra- und intermedialen Selbstverarbeitung, der rekursiven Rückwendung des Systems auf sich selbst: Es ist diese Rekursivität, die - wie Luhmann formuliert ${ }^{31}$ - „Anwendung des Verfahrens auf die Resultate des Verfahrens “32, also etwa die Anwendung von Kommunikation auf die Resultate von Kommunikation, die ein „Eigenverhalten“, eine „Eigenwertproduktion" des Systems erzeuge.

Die Pointe dieses Luhmannschen Gedankens ${ }^{33}$ lässt sich im Hinblick auf Medien- und Kommunikationssysteme vielleicht so formulieren: Symbolische Systeme tendieren dazu, als Gewinn aus der für sie charakteristischen Verfahrensform der rekursiven Selbstverarbeitung Eigensinn ${ }^{34}$ zu generieren. Dies gilt insbesondere für Sprache, die in paradigmatischer Weise über die Eigenschaft verfügt, sich rekursiv auf sich selbst zurückzubiegen und so die eigene Zeichenverwendung fortlaufend zum Gegenstand weiterer thematisierender, kommentierender, explizierender oder zitierender Zeichenverwendungen zu machen, zum Objekt also selbstbezüglicher semiologischer Operationen, in denen sich das zeigt, was man die ,rekursive Transkriptivität‘ der Sprache nennen könnte.

Bereits die außerhalb des Verfahrensraumes der Schrift operierende Rede verfügt über das Vermögen der Isolierung und Stillstellung von Redeausschnitten sowie der Bearbeitung der stillgestellten ,Elemente und damit über eine Form des autoreferentiellen Bezuges von Sprache auf Sprache. ${ }^{35}$ Mit der Schrift entstehen dann neue Formen der intramedialen Bezugnahme, bypoleptische Bezugnahmen von Texten auf Texte, wie Raible $(1995)^{36}$ sie genannt hatte, wobei auch noch für neue Digitalmedien die Remediation eines Mediums durch ein anderes als „defining characteristic“ angesehen werden muss - wie Bolter/Grusin (2001, S. 45) formulieren. Alle Stillstellungs-Artefakte unserer medialen Kulturen - Bilder, Texte, Partituren, Speicherungen

30 Vgl. Bolter/Grusin (2001, S. 55): ,[A]ll media depend on other media in cycles of remediation $[\ldots] . “$

31 Vgl. Luhmann (1997a, S. 217 f., S. 614, S. 888).

32 Vgl. Luhmann (1997, S. 213 f.): ,Er [der Begriff ,Eigenverhalten'] bezeichnet eine im rekursiven Verfahren der Anwendung des Verfahrens auf die Resultate des Verfahrens sich einstellende Stabilität.“

33 Ich möchte allerdings weder Luhmanns Medium/Form-Unterscheidung, noch deren Applikation auf Sprache übernehmen: Die These Luhmanns, Sprache sei ein „Nichtsystem“, das „Systembildungen im Bereich von Bewußtsein und Kommunikation erst ermöglicht", kann hier nicht diskutiert werden (vgl. Luhmann 1992, S. 51). Auch seine Behauptung, die Sprache sei kein System von Zeichen (ebd., S. 51 f.), beruht auf einer ziemlich unzulänglichen Kenntnis der Zeichentheorien etwa de Saussures, dem er eine abbildtheoretische Konzeption unterstellt.

34 Vgl. hierzu etwa Jäger (2005a).

35 Vgl. hierzu ausführlich Jäger (2005b).

36 Vgl. zum Begriff „Hypolepsis“ Assmann (1992, S. 282, S. 286 ff.). 
jedweder Art - dürfen so verstanden werden als Adressen möglicher Bezugnahmen, möglicher transkriptiver Adressierungen in den Archiven des kulturellen Gedächtnisses. Selbstberüglichkeit wäre also eine der grundlegenden Quellen kultureller Semantik, ein Verfahren, in dem in der Rückwendung eines symbolischen Systems auf sich selbst symbolische Artefakte aus ihren vorgängigen diskursiven Zirkulationsbedingungen gelöst und zur Bearbeitung bzw. Wiedereinfädelung in den semantischen Haushalt unter neuen Kontextbedingungen vorübergehend stillgestellt, zitiert, paraphrasiert, expliziert - kurz: de- und rekontextualisiert - werden.

Der vorübergehende oder länger anhaltende Zustand des Herausgelöstseins symbolischer Zeichenketten aus der Transitorizität ihrer Performanz ist insofern keine privilegierte Eigenschaft der Schrift oder anderer Stillstellungs-Artefakte, die die Verfahren der Medien ständig hervorbringen, sondern ein Durchgangsstadium in kommunikativen Prozessen, in dem mediale Entitäten eine vorübergehende oder dauerhafte ,Starre' derart annehmen, dass auf sie kommunikativ Bezug genommen werden kann, Sinn generiert und weiterverarbeitet zu werden vermag.

Unabhängig davon, ob die temporäre oder länger andauernde Stillstellung symbolischer Ketten die Form der Schrift annimmt oder die Form von in mündlichen Traditionen erstarrten ,fixed texts “"37 oder die der Paraphrase, der Explikation bzw. des Zitats in sprachlichen oder bildlichen Medien: In allen diesen Formen haben wir es mit einer rekursiven Alternierung von Stillstellung und intra- bzw. intermedialer Bewegung zu tun, die prinzipiell der Bearbeitung und Konstitution von Sinn im semantischen Haushalt von Kulturen zugrunde liegt. Transkriptive Verfahren, so lässt sich beim gegenwärtigen Stand unserer Überlegungen resümieren, sind jene Verfahren der remediatisierenden Bezugnahme von Symbolsystemen auf Symbolsysteme, durch die der Sinnkonstitutionsapparat der kulturellen Semantik als ein Apparat fortwährender De- und Rekonzeptualisierung in Gang gehalten wird. In die Konstitution von Sinn ist immer eine mediale Bewegung eingeschrieben, in deren Vollzug sich Medien in einer rekursiven Geste auf sich selbst oder auf andere Medien beziehen: Eine rekursionsfreie Konstitution von Sinn kann es nicht geben. Immer sind es Spuren vergangener Mediationen, auf die interpretierend in rekursiver Rückwendung Bezug genommen werden muss, damit in den Verfahren der kulturellen Semantik Sinn generiert werden kann.

\subsection{Das Störungs-Prinzip}

In gewissem Sinne können die bislang skizzierten Prinzipien als Voraussetzungen eines fünften Prinzips angesehen werden, das ich das Störungs-Prinzip nennen möchte. Wenn sich die Prozesse kultureller Sinnbildung not-

\footnotetext{
Vgl. hierzu Vansina (1973, S. 145).
} 
wendig im Modus der intra- und intermedialen Bezugnahme von Zeichen auf Zeichen, bzw. von Medien auf Medien vollziehen, so ist offensichtlich, dass in den Sprachspielen der kulturellen Semantik die Stadien der unproblematischen Geltung von Sinn von jenen unterschieden werden müssen, in denen das Spiel transkriptiver Bezugnahmen, der kulturellen Rekonzeptualisierungen, jeweils immer wieder in Gang kommt, wobei auch in die Stadien und Momente ,ungestörter' Semantik ,Störung' untilgbar als jene andauernde Fragilität eingeschrieben ist, von der jederzeit Prozesse der Remediation ihren Ausgang nehmen können. Ich möchte diese beiden Stadien medialer Kommunikation, das der unproblematischen Geltung von Sinn und das seiner jeweiligen Rekonzeptualisierung, - was ich an anderer Stelle ausführlicher diskutiert habe - als Stadien der ,Transparenz' und der ,Störung ${ }^{6}$ unterscheiden. ${ }^{38}$

Störung und Transparenz sollen dabei verstanden werden als zwei polare funktionale Zustände medialer Performanz, die konstitutiv eingeschrieben sind in das Verfahren der intra- und intermedialen Transkription. Transkription ließe sich dann beschreiben als der jeweilige Übergang von Störung zu Transparenz, von De- zu Rekontextualisierung der fokussierten Zeichen/Medien. Während Störung als Ausgangspunkt das transkriptive Verfahren der Remediation in Gang setzt und das Zeichen/Medium als (gestörter) Operator von Sinn in den Fokus der Aufmerksamkeit rückt, lässt sich Transparenz als der Zustand ungestörter medialer Performanz ansehen, in dem das jeweilige Zeichen/Medium mit Bezug auf den Gehalt, den es mediatisiert, verschwindet, transparent wird.

Transparenz soll also nicht - wie verschiedentlich in der medientheoretischen Debatte angenommen wurde - als eine quasi ontologische Eigenschaft von Medien angesehen werden, die - so etwa Engell und Vogl - dazu neigen, in Bezug auf das, was sie mediatisieren, ,gleichsam unwahrnehmbar, anästhetisch zu werden“, ${ }^{39}$ sondern vielmehr als ein funktionales Stadium symbolischer Interaktion, in dem die jeweils verhandelten Semantiken in ihrer Geltung unproblematisch sind und einen gleichsam ungestörten Realismus des Mediatisierten ermöglichen.

Realismus ist freilich, wie Goodman (1997, S. 45) feststellt, medienrelativ: „[E]r wird durch das Repräsentationssystem festgelegt, das für eine gegebene Kultur oder Person zu einer gegebenen Zeit die Norm ist", bzw. durch das mediale Dispositiv, in dem sich Kommunikation jeweils vollzieht. Der Realismus, mit dem symbolische Mittel repräsentieren, ist dabei umso höher, je vertrauter (transparenter) die gewählten Mittel sind. Mediale Darstellungen erscheinen uns dann realistisch, wenn „die Praxis [...] die Symbole so transparent [hat] werden lassen, daß wir uns einer Anstrengung

\footnotetext{
38 Vgl. Jäger (2004).

39 Vgl. Engell/Vogl (1999, S. 10); vgl. auch Krämer (2001, S. 157).
} 
oder irgendwelcher Alternativen oder der Tatsache, daß wir interpretieren, überhaupt nicht bewußt sind" (Goodman 1997, S. 44). In kommunikativen Zuständen dieser Art wird die Mediatisiertheit des Realen „durch unsere Neigung verschleiert, einen Bezugsrahmen dann nicht zu spezifizieren, wenn er unser eigener ist" (ebd., S. 45). Es zeigt sich hier, dass - wie Bolter/ Grusin (2001, S. 53) vermuten - in Mediensysteme grundsätzlich das Begehren eingeschrieben ist, „hinter die Grenzen der Repräsentation zu gelangen und das Reale selbst zu erreichen".

,Störung" soll also jeder Zustand im Verlauf einer Kommunikation heiBen, der bewirkt, dass ein Zeichen/Medium (operativ) seine Transparenz verliert und in seiner Materialität wahrgenommen wird, und ,Transparenz jeder Zustand, in dem die Kommunikation nicht, gestört' ist, also das Zeichen/Medium als Medium nicht im Fokus der Aufmerksamkeit steht.

Die These, die hier vertreten wird, ist also die, dass die Transparenz des Mediums keine ,Eigenschaft ${ }^{c}$ des Mediums ist, sondern ein Aggregatzustand, den das Medium dann annimmt, wenn die mediatisierte Semantik als stilles Wissen kommunikativ nicht, gestört' ist, ebenso wie umgekehrt Störung kein parasitärer Defekt der Kommunikation ist, sondern jener kommunikative Aggregatzustand, in dem das Zeichen/Medium als solches sichtbar und damit semantisierbar wird, jener Zustand also, der, wenn er eintritt, immer mit Remediatisierungs-, d.h. Transkriptionsbedarfen verknüpft ist, ohne dass dieser Prozess der ständigen Transformation fragiler semantischer Gleichgewichtszustände jemals unterbrochen werden könnte. Intra- und intermediale Transkriptivität markieren insofern im Bereich der kulturellen Semiosis ein Feld medialer Operationen, die fortwährend zwischen der fragilen Geltung unproblematischer Semantik auf der einen sowie Prozessen transkriptiver Rekonzeptualisierungen auf der anderen Seite oszillieren.

\section{Kleines Resümee}

Meine bisherigen Sondierungen auf dem Feld der epistemologischen und semiologischen Voraussetzungen einer Theorie der Intermedialität lassen sich in aller Vorläufigkeit so zusammenfassen, dass die Zeichen- und Mediensysteme, aus denen sich die Semantik von Kulturen speist, über keine systemtranszendenten Quellen für den Prozess der Konstitution und Evidenzauszeichnung von Sinn verfügen. Hierin liegt ihre Fragilität und Brüchigkeit und zugleich die Notwendigkeit, fortwährend in Verfahren der remediatisierenden Bezugnahme einzutreten. Die Verfahren der kulturellen Semiosis sind deshalb notwendigerweise darauf verwiesen, im Falle der Irritation, der Störung etablierter Semantiken, auf immer schon semiologisch konstituierten Sinn zurückzugreifen und ihn unter je spezifischen 
diskursiven Bedingungen ,kulturell zu rekonzeptualisieren“ ${ }^{40}$ d.h. den Bedingungen der Verfahren transkriptiver Bezugnahme zu unterwerfen. Intraund intermediale Transkriptionen reagieren dabei etwa auf Resonanzstörungen, auf Verschiebungen in den Ökonomien individueller und kultureller Aufmerksamkeit, ${ }^{41}$ d.h. auf Irritationen in jenen ,übergeordnete[n] kulturelle[n] Optionen, Wertsetzungen, Institutionen", die - wie Aleida Assmann (2001, S. 17) gezeigt hat - „,ür die spezifische Ausformung von [kultureller] Aufmerksamkeit mit verantwortlich sind. ${ }^{\text {“42 }}$ Sie reagieren aber auch auf die Umbrüche, von denen die politischen und kulturellen Rahmenbedingungen von medialen Dispositiven immer wieder betroffen werden. Immer dann gerät das Spiel medialer Bezugnahmepraktiken in Bewegung: In den Diskursen der kulturellen Semiosis erodiert nun die unproblematische Geltung tradierter Semantiken, die in ihrer Evidenz ${ }^{43}$ irritiert und als irritierte in das mediale Spiel der transkriptiven Maschine eingespeist werden. Es ist also könnte man sagen - eine Epistemologie der Störung, die in den Remediationen und Rekonzeptualisierungen der kulturellen Semantik untilgbar am Werke ist und die intra- und intermedialen Bewegungen symbolisch-medialer Systeme in Gang hält.

\section{Literatur}

Aigner, Carl (1993): Diskurse der Bilder. Photokünstlerische Appropriationen kunsthistorischer Werke. In: Seipel (Hg.), S. 38-42.

Amelunxen, Hubertus von (1993): Aneignung und Simulakrum. Die Einholung des Anderen in der Fotografie. In: Seipel (Hg.), S. 23-37.

Assmann, Aleida (2001): Einleitung. In: Assmann/Assmann (Hg.), S. 11-24.

Assmann, Aleida/Assmann, Jan (Hg.) (2001): Aufmerksamkeiten. (= Archäologie der literarischen Kommunikation VII). München.

Assmann, Jan (1992): Das kulturelle Gedächtnis. Schrift, Erinnerung und politische Identität in frühen Hochkulturen. München.

Boehm, Gottfried (Hg.) (1995): Was ist ein Bild? (= Bild und Text I). 2. Aufl. München.

Boehm, Gottfried/Mersmann, Birgit/Spies, Christian (Hg.) (2008): Movens Bild. Zwischen Evidenz und Affekt. München.

Bolter, Jay David/Grusin, Richard (2001): Remediation. Understanding new media. 4. Aufl. London.

Brandom, Robert B. (2000): Expressive Vernunft. Begründen, Repräsentation und diskursive Festlegung. Frankfurt a.M.

40 Vgl. Manovich (2001, S. 47).

41 Vgl. hierzu Franck (1998); ebenso Assmann/Assmann (Hg.) (2001).

42 Die Irritation semantischer Evidenz von Sinn ist bereits auf der Mikroebene interpersonaler Kommunikation der Auslöser von transkriptiven Operationen. Vgl. hierzu Jäger (2004).

43 Zum Begriff der semantischen Evidenz vgl. Jäger (2008b). 
Brandom, Robert B. (2001): Begründen und Begreifen. Eine Einführung in den Inferentialismus. Frankfurt a.M.

Buschmeier, Gabriele/Konrad, Ulrich/Riethmüller, Albrecht (Hg.) (2008): Transkription und Fassung in der Musik des 20. Jahrhunderts. Beiträge des Kolloquiums in der Akademie der Wissenschaften und der Literatur, Mainz, vom 5. bis 6. März 2004. Stuttgart.

Buss, Mareike/Habscheid, Stephan/Jautz, Sabine/Liedtke, Frank/Schneider, Jan Georg (Hg.) (2009): Theatralität des sprachlichen Handelns. Eine Metaphorik zwischen Linguistik und Kulturwissenschaften. München.

Cassirer, Ernst (1964): Philosophie der symbolischen Formen. Darmstadt.

Danto, Arthur C. (1995): Abbildung und Beschreibung. In: Boehm (Hg.), S. 125-147.

Deacon, Terrence W. (1997): The symbolic species. The co-evolution of language and the brain. New York/London.

Derrida, Jacques (1974): Grammatologie. Frankfurt a.M.

Derrida, Jacques (1976): Die Schrift und die Differenz. Frankfurt a.M.

Derrida, Jacques (2003): Die Stimme und das Phänomen. Frankfurt a.M.

Engell, Lorenz/Vogl, Joseph (1999): Vorwort. In: Pias, Claus/Vogl, Joseph/Engell, Lorenz/Fahle, Oliver/Neitzel, Britta (Hg.): Kursbuch Medienkultur. Die maßgeblichen Theorien von Brecht bis Baudrillard. Stuttgart, S. 8-11.

Epping-Jäger, Cornelia/Linz, Erika (Hg.) (2003): Medien/Stimmen. (= Mediologie 9). Köln.

Fehrmann, Gisela/Jäger, Ludwig (2004): Sprachbewegung und Raumerinnerung. Zur topographischen Medialität der Gebärdensprache. In: Lechtermann, Christina/ Morsch, Carsten/Wenzel, Horst (Hg.): Kunst der Bewegung. Kinästhetische Wahrnehmung und Probehandeln in virtuellen Welten. (= Publikationen zur Zeitschrift für Germanistik 8). Bern, S. 311-341.

Fehrmann, Gisela/Linz, Erika/Schumacher, Eckhard/Weingart, Brigitte (2004): Originalkopie. Praktiken des Sekundären - Eine Einleitung. In: Fehrmann/Linz/Schumacher/Weingart (Hg.), S. 7-17.

Fehrmann, Gisela/Linz, Erika/Schumacher, Eckhard/Weingart, Brigitte (Hg.) (2004): Originalkopie. Praktiken des Sekundären. (= Mediologie 11). Köln.

Fehrmann, Gisela/Linz, Erika/Epping-Jäger, Cornelia (Hg.) (2005): Spuren - Lektüren. Praktiken des Symbolischen. München.

Franck, Georg (1998): Ökonomie der Aufmerksamkeit. München.

Fricke, Ellen (2008): Grundlagen einer multimodalen Grammatik des Deutschen: Syntaktische Strukturen und Funktionen. Habilitationsschrift, Europa-Universität Viadrina Frankfurt a.d. Oder. Ms.

Genette, Gérard (1993): Palimpseste. Die Literatur auf zweiter Stufe. Frankfurt a.M.

Goodman, Nelson (1997): Sprachen der Kunst. Entwurf einer Symboltheorie. Frankfurt a.M. 
Grésillion, Almuth (1995): Über die allmähliche Verfertigung von Texten beim Schreiben. In: Raible, Wolfgang (Hg.): Kulturelle Perspektiven auf Schrift und Schreibprozesse. Tübingen, S. 1-36.

Grube, Gernot/Kogge, Werner/Krämer, Sybille (Hg.) (2005): Schrift. Kulturtechnik zwischen Auge, Hand und Maschine. München.

Gülich, Elisabeth/Kotschi, Thomas (1996): Textherstellungsverfahren in mündlicher Kommunikation. Ein Beitrag am Beispiel des Französischen. In: Motsch, Wolfgang (Hg.): Ebenen der Textstruktur: Sprachliche und kommunikative Prinzipen. (= Reihe germanistische Linguistik 164). Tübingen, S. 37-80.

Gumbrecht, Hans Ulrich/Pfeiffer, K. Ludwig (Hg.) (1988): Materialität der Kommunikation. Frankfurt a.M.

Holly, Werner (2008): Audiovisuelle Sigetik. Über verborgene Bedeutungen im BildSprach-Zusammenhang. In: Pappert, Steffen/Schröter, Melani/Fix, Ulla (Hg.): Verschlüsseln, Verbergen, Verdecken in öffentlicher und institutioneller Kommunikation. Berlin, S. 147-169.

Humboldt, Wilhelm v. ([1936] 1968): Gesammelte Schriften, hg. v. d. Kgl. Preuß. Akad. d. Wiss. (Leitzmann, Gebhardt, Richter). 17 Bde. Berlin. [zitiert als Humboldt GS mit Band- und Seitenzahl].

Husserl, Edmund (1929): Formale und transzendentale Logik. Versuch einer Kritik der logischen Vernunft. Halle.

Jäger, Ludwig (1986): Der saussuresche Begriff des Aposème als Grundlagenbegriff einer hermeneutischen Semiologie. In: Jäger, Ludwig/Stetter, Christian (Hg.): Zeichen und Verstehen. Akten des Aachener Saussure-Kolloquiums 1983. (= Aachener Studien zur Semiotik und Kommunikationsforschung 3). Aachen, S. 7-33.

Jäger, Ludwig (1988): Über die Individualität von Rede und Verstehen. Aspekte einer hermeneutischen Semiologie bei Wilhelm von Humboldt. In: Frank, Manfred (Hg.): Individualität. (= Poetik und Hermeneutik XIII). München, S. 76-94.

Jäger, Ludwig (2000): Die Sprachvergessenheit der Medientheorie. Ein Plädoyer für das Medium Sprache. In: Kallmeyer (Hg.), S. 9-30.

Jäger, Ludwig (2001): Sprache als Medium. Über die Sprache als audio-visuelles Dispositiv des Medialen. In: Wenzel, Horst/Seipel, Wilfried/Wunberg, Gotthart (Hg.): Audiovisualität vor und nach Gutenberg - Zur Kulturgeschichte der medialen Umbrüche. (= Schriften des Kunsthistorischen Meseums 6). Wien, S. 19-42.

Jäger, Ludwig (2004): Störung und Transparenz. Skizze zur performativen Logik des Medialen. In: Krämer, Sybille (Hg.): Performativität und Medialität. München, S. 35-74.

Jäger, Ludwig (2005a): Vom Eigensinn des Mediums Sprache. In: Busse, Dietrich/Niehr, Thomas/Wengeler, Martin (Hg.): Brisante Semantik. Neuere Konzepte und Forschungsergebnisse einer kulturwissenschaftlichen Semantik. (= Reihe Germanistische Linguistik 259). Tübingen, S. 45-64.

Jäger, Ludwig (2005b): Versuch über den Ort der Schrift. Die Geburt der Schrift aus dem Geist der Rede. In: Grube/Kogge/Krämer (Hg.), S. 187-209. 
Jäger, Ludwig (2008a): Transkriptive Verhältnisse. Zur Logik intra- und intermedialer Bezugnahmen in ästhetischen Diskursen. In: Buschmeier/Konrad/Riethmüller (Hg.), S. 103-134.

Jäger, Ludwig (2008b): Indexikalität und Evidenz. Bemerkungen zum Problem der deiktisch-indexikalischen Bezugnahme. In: Wenzel, Horst/Jäger, Ludwig (Hg.) (in Zusammenarb. m. Robin Curtis u. Christina Lechtermann): Deixis und Evidenz. (= Rombach-Wissenschaften, Reihe Scenae 8). Freiburg i.Br., S. 289-315.

Jäger, Ludwig/Linz, Erika (Hg.) (2004): Medialität und Mentalität. Theoretische und empirische Studien zum Verhältnis von Sprache, Subjektivität und Kognition. München.

Kallmeyer, Werner (2000a): Vorwort. In: Kallmeyer (Hg.), S. VII-IX.

Kallmeyer, Werner (2000b): Sprache und neue Medien - zum Diskussionsstand und zu einigen Schlussfolgerungen. In: Kallmeyer (Hg.), S. 292-315.

Kallmeyer, Werner (Hg.) (2000): Sprache und neue Medien. Jahrbuch des Instituts für Deutsche Sprache 1999. Berlin/New York.

Kendon, Adam/Müller, Cornelia (Hg.) (2007 ff.): Gesture Studies. Amsterdam/Philadelphia. [Buchreihe].

Kolesch, Doris/Krämer, Sybille (Hg.) (2006): Stimme. Annäherung an ein Phänomen. Frankfurt a.M.

Krämer, Sybille (2001): Sprache, Sprechakt, Kommunikation. Frankfurt a.M.

Krämer, Sybille (2004): Performativität und Medialität. München.

Krämer, Sybille/Kogge, Werner/Grube, Gernot (Hg.) (2007): Spur. Spurenlesen als Orientierungstechnik und Wissenskunst. Frankfurt a.M.

Kristeva, Julia (1969): Sēmeiotikē. Recherches pour une sémanalyse. Paris.

Latour, Bruno (1996): On actor-network-theory. A few clarifications. In: Soziale Welt 47, S. 369-381.

Leopold, Silke (1992): Einleitung: In Leopold (Hg.), S. 7-10.

Leopold, Silke (Hg.) (1992): Musikalische Metamorphosen. Formen und Geschichte der Bearbeitung. (= Bärenreiter Studienbücher zur Musik 2). Kassel.

Luhmann, Niklas (1992): Die Wissenschaft der Gesellschaft. Frankfurt a.M.

Luhmann, Niklas (1997): Die Gesellschaft der Gesellschaft. Frankfurt a.M.

Manovich, Lev (2001): The language of new media. London.

Mitchell, William J.T. (1995): Picture theory. Chicago/London.

Mitchell, William J.T. (2008): Bildtheorie. Hrsg. u. m. e. Nachwort v. Gustav Frank. Frankfurt a.M.

Münker, Stefan/Roesler, Alexander (Hg.) (2008): Was ist ein Medium? Frankfurt a.M.

Pape, Helmut (1999): Indexikalität der Erfahrung oder Objektivität des Wissens. In: Zeitschrift für Semiotik 21/1, S. 3-14. 
Peirce, Charles S. (1970): Schriften II. Vom Pragmatismus zum Pragmatizismus, mit einer Einführung hrsg. v. Karl-Otto Apel. Frankfurt a.M.

Peirce, Charles S. (1984): Writings. A chronological edition. Vol. 2: 1867-1871. Bloomington.

Raible, Wolfgang (1995): Arten des Kommentierens - Arten der Sinnbildung - Arten des Verstehens. Spielarten der generischen Intertextualität. In: Assmann, Jan/Gladigow, Burkhard (Hg.): Text und Kommentar. Archäologie der Literarischen Kommunikation IV. München, S. 51-73.

Rorty, Richard (1994): Der Spiegel der Natur: Eine Kritik der Philosophie. 3. Aufl. Frankfurt a.M.

Saussure, Ferdinand de (1974): Cours de linguistique générale. Édition critique par Rudolf Engler. Tome 2, fascicule 4, Appendice. Wiesbaden.

Saussure, Ferdinand de (2003): Wissenschaft der Sprache. Neue Texte aus dem Nachlaß, herausgegeben und mit einer Einleitung versehen von Ludwig Jäger, übersetzt und textkritisch bearbeitet von Elisabeth Birk und Mareike Buss. Frankfurt a.M.

Seipel, Wilfried (Hg.) (1993): Diskurse der Bilder. Photokünstlerische Reprisen kunsthistorischer Werke. Katalog Kunsthistorisches Museum Wien. Wien.

Selting, Margret (1987): Reparaturen und lokale Verstehensprobleme oder: Zur Binnenstruktur von Reparatursequenzen. In: Linguistische Berichte 108, S. 128-149.

Stetter, Christian (1997): Schrift und Sprache. Frankfurt a.M.

Stoichita, Victor I. (1998): Das selbstbewußte Bild - Vom Ursprung der Metamalerei. München. [frz. (1993): L'instauration du tableau - Métapeinture à l'aube des temps modernes].

Vansina, Jan (1973): Oral Tradition. A Study in Historical Methodology. 2. Aufl. Harmondsworth.

Waldenfels, Bernhard (1999): Vielstimmigkeit der Rede. Frankfurt a.M.

Winkler, Hartmut (1997): Docuverse. Zur Medientheorie der Computer. München.

Winkler, Hartmut (2004): Übertragen - Post, Transport, Metapher. In: Fohrmann, Jürgen (Hg.): Rhetorik. Figuration und Performanz. Stuttgart/Weimar, S. 283-294.

Winkler, Hartmut (2008): Zeichenmaschinen. Oder warum die semiotische Dimension für eine Definition der Medien unerlässlich ist. In: Münker/Roesler (Hg.), S. 211-221.

Wirth, Uwe (2008): Die Frage nach dem Medium als Frage nach der Vermittlung. In: Münker/Roesler (Hg.), S. 222-234.

Wittgenstein, Ludwig (1984): Tractatus logico-philosophicus. In: Wittgenstein, Ludwig: Werkausgabe Bd. 1. Frankfurt a.M.

Zuschlag, Christoph (2002): Vom Kunstzitat zur Metakunst. Kunst über Kunst im 20. Jahrhundert. In: Mai, Ekkehard/Wettengl, Kurt (Hg.): Wettstreit der Künste. Malerei und Skulptur von Dürer bis Daumier. Köln, S. 171-189. 



\title{
Martin Steinseifer
}

\section{Prägnanzen}

\section{Bilder und ihre Effekte in der pragmatischen Linguistik}

\begin{abstract}
Der Beitrag nimmt die verbreitete Annahme einer besonderen Überzeugungskraft von Bildern zum Anlass, nach dem Ort einer solchen medienspezifischen Wirkungsweise im Rahmen einer pragmatischen Linguistik zu fragen. In exemplarischen Analysen wird gezeigt, wie Fotografien in journalistischen Printmedien eingesetzt werden, um Bedeutungen, die ihnen durch die umstehenden Texte ,zugeschrieben' und so stabilisiert werden, ein besonderes Maß an Plausibilität zu verleihen. Dieser inter-mediale Evidenzeffekt wird als Prägnanz bezeichnet. Zu seiner theoretischen Begründung wird der Peircesche Begriff der Ikonizität mit dem Konzept der ,ikonischen Differenz ${ }^{6}$ aus der phänomenologischen Bildtheorie Gottfried Boehms verbunden. Denn beide stellen heraus, dass die wahrnehmbaren Eigenschaften der Zeichenform ein notwendiges Komplement zu symbolischen Schematisierungen im Prozess der Sinnkonstitution bilden. Diese Verschränkung zwischen Ikonizität und Symbolizität prägt sowohl die Konstitution dessen, was ein gegenständliches Bild in seinen Teilen wiedererkennbar zeigt, als auch dessen, was es als Ganzes - durch die Anordnung von Elementen auf einer begrenzten Fläche - darstellt. Die sichtbare Form dieser Anordnung wird als Grundlage für das besondere Prägnanzpotenzial von Bildern in der Zusammenstellung mit Texten identifiziert. Gestützt auf Beispiele wird zwischen einer schematischen und ikonischen Variante der Prägnanz unterschieden und das methodische Vorgehen reflektiert. Die pragmatische ,Effektivität ${ }^{`}$ der wahrnehmbaren Zeichenform, die in den Varianten der Prägnanz fassbar wird, ist allerdings nicht auf die intermediale Konstellation von Text und Bild beschränkt, weswegen der Beitrag mit dem Ausblick auf eine linguistische Phänomenologie der Textgestalt schließt.
\end{abstract}

\section{Hinführung}

Es gehört zum gesellschaftlichen Common sense, dass Bilder auf eine besondere Weise wirken. Für dieses Wissen steht unter anderem die Rede von der Macht der Bilder. Diese Redeweise fungiert als eine Art Beschwörungsformel, um Bilder entweder besonders attraktiv oder besonders gefährlich erscheinen zu lassen. Mit Blick auf die Formel ist allerdings weniger der beschwörende Gestus von Interesse, sondern vielmehr der Hinweis auf eine besondere mediale Wirkungsweise, durch die sich Bilder auszeichnen zielt er doch auf kommunikative Effekte, die von bestimmten visuell wahrzunehmenden Eigenschaften der Zeichenform ausgehen. Bildliches lenkt in anderer Weise als Sprachliches den Blick auf die Oberfläche. Ein verstärktes ,Augenmerk' auf Qualitäten der Zeichenform ist jedoch auch für eine pragmatische Linguistik notwendig, die sich Wörter wie Medialität, Medienspezifik, multimediale oder multimodale Kommunikation auf die Fahnen schreibt. 
Nachdem es lange Zeit kaum ein linguistisches Interesse an Bildern und ihrem Verhältnis zu sprachlichen Ausdrucksformen oder sprachlichen Handlungen gab - Manfred Muckenhaupts grundlegende Arbeit zu Text und Bild (1986) war im Bereich der germanistischen Linguistik eine Ausnahmeerscheinung - ändert sich diese Situation seit einigen Jahren. Die Gründe dafür dürften ebenso in Veränderungen des (massen-)medialen wie des akademischen Kommunikationsalltags zu suchen sein, die auf neue technische Möglichkeiten der Herstellung und Verbreitung von Bildern sowie deren Verbindung mit Schriftzügen und Texten zu „Sehflächen“ zurückgehen. ${ }^{1}$ Nicht nur das World Wide Web bietet sich seinen Nutzerinnen und Nutzern als eine Vielzahl solcher Sehflächen dar, auch auf Tagungen und in Lehrveranstaltungen ist es inzwischen fast obligatorisch, mündlichen Vorträgen durch begleitende Sehflächen die Form einer multimodalen ,Präsentation' zu geben - relativ unabhängig von der Rolle, die Bilder und ,bildgebende Verfahren' im wissenschaftlichen Erkenntnisprozess spielen. Die linguistische Hinwendung zu Bildern ist daher auch kein Einzelfall. Sie findet im Zusammenhang mit einem disziplinübergreifend wachsenden Interesse an Bildern und Bildlichkeit statt, das seit den 1990er Jahren als pictorial (Mitchell 1994) bzw. iconic turn (Boehm 1994) der Kulturwissenschaften propagiert wurde. Dieses neue Interesse gewinnt im englischsprachigen Raum unter den Bezeichnungen Visual Culture bzw. Visual Studies ${ }^{2}$ institutionelle Gestalt, während es im deutschsprachigen Raum in den kontroversen Bemühungen um eine Bildwissenschaft zu greifen ist, die das etablierte Gegenstandsfeld der Kunstgeschichte überschreitet. ${ }^{3}$

Betrachtet man die linguistischen Ansätze der letzten Jahre in diesem weiteren Rahmen, dann fällt die zentrale Rolle auf, die für sie eine semantische und funktionale Integration von Text und Bild spielt, wobei die kom-

1 „Sehflächen lesen“ ist der Titel eines Themenhefts der Zeitschrift Der Deutschunterricht (2005, Ulrich Schmitz/Ursula Renner), das sich dem Verhältnis und den Verbindungen von Sprache und Bild widmet. Neben diesem geben die beiden Themenhefte der Mitteilungen des Deutschen Germanistenverbandes „Sprache und Bild“ (51 (1+2)/2004, Werner Holly/Almuth Hoppe/Ulrich Schmitz) und der Zeitscbrift für Germanistische Linguistik, „Schrift - Text - Bild“ (2007, Christa Dürscheid), sowie der Band Schmitz/Wenzel (2003) einen Einblick in die aktuelle Diskussion der deutschsprachigen Linguistik. Als wichtige Impulsgeber fungieren die schon genannten Ulrich Schmitz $(2003,2005,2008)$ und Werner Holly $(2005,2009)$, sowie Hartmut Stöckl, insbesondere mit seiner Monographie „Die Sprache im Bild - das Bild in der Sprache“ (2004a).

2 Vgl. für einen Überblick über das keineswegs homogene Feld die Einleitung in Elkins (2003), sowie die Debatte, die im Jorunal of Visual Culture im Anschluss an einen Aufsatz von Mieke Bal (2003) geführt wurde. In den Reaktionen von Norman Bryson, James Elkins, William J.T. Mitchell und anderen wird die Spannbreite von Objekten, Theorien und Methodologien deutlich.

3 Neben den unterschiedlichen Ansätzen aus dem Bereich der Kunstgeschichte von Bredekamp (2003), Belting (2001) und Boehm (2007a) ist hier insbesondere der programmatische philosophische Entwurf einer ,allgemeinen Bildwissenschaft" von Sachs-Hombach (2003) zu nennen. 
munikative Einheit aus bildlichen und sprachlichen Teilen zumeist wiederum als Text verstanden wird - Fix (1996, S. 116) etwa spricht von einem „Supertext“", Stöckl (2004a, S. 97 u.ö.) vom „Gesamttext“". Sie fällt auf, weil in den bildwissenschaftlichen Projekten nicht nur das Zusammenspiel von Bildern und Texten kein derart bevorzugter Untersuchungsgegenstand ist, wie für eine sich dem Visuellen öffnende Sprachwissenschaft, sondern weil die Beschäftigung mit der sichtbaren Form zudem immer wieder zur scharfen Abgrenzung von Bild und Sprache führt, die als Ausdrucksformen mit einer je eigenen medialen Wirkungsweise angesehen werden. Auch wenn diese Abgrenzung in erster Linie darauf zielt, Bilder gegenüber einer sprachzentrierten philosophischen Tradition als eigenständiges Erkenntnismedium zu rehabilitieren, so betrifft sie doch auch die linguistischen Bemühungen um ein semiotisch begründetes Verständnis von Bildern als Texten, die leicht unter den Verdacht der Fortschreibung eines solchen Linguozentrismus geraten. Man muss beide Vorgehensweisen allerdings nicht als sich wechselseitig ausschließende Alternativen begreifen, sondern kann sie auch als unterschiedlich akzentuierte Konsequenzen aus zwei gemeinsamen Grundeinsichten auffassen: Auf der einen Seite besteht Einigkeit darin, dass Bilder eine unersetz- und unverzichtbare Rolle im kommunikativen Haushalt nicht erst unserer spätmodernen Gesellschaft spielen und daher mehr als bisher der Analyse bedürfen. Auf der anderen Seite besteht weitgehende Einigkeit darin, dass Bilder keine der doppelten Artikulation und der propositionalen Struktur sprachlicher Zeichen entsprechende Struktur aufweisen und es daher auch keine der Sprache vergleichbare Grammatik bzw. Syntax des Bildes gibt. ${ }^{4}$

In diesem Beitrag soll daher ein pragmatischer Theorierahmen skizziert werden, in dem sich beide Vorgehensweisen aufeinander beziehen lassen, wobei sich das alltägliche Zusammenspiel von Bildern und Texten gerade als Kehrseite der medialen Eigenständigkeit erweisen wird. Den Ausgangspunkt dafür bildet die pragmatistische Zeichenphilosophie von Charles Sanders Peirce - insbesondere seine bekannte Trichonomie von Ikon, Index und Symbol. Diese Trias ist allerdings nur dann weiterführend, wenn die mit ihr verbundene logische Unterscheidung von Möglichkeiten der Objektrelation im Zeichenprozess nicht, wie es keineswegs nur in der Linguistik verbreitet ist, in erster Linie zur Bildung unterschiedlicher Zeichenklassen verwendet wird, sondern Ikonizität, Indexikalität und Symbolizität

Die Versuche der strukturalistischen Bildsemiotik während der 1970er Jahre, eine kombinatorische Syntax des Bildes zu entwickeln, konnten sich nicht durchsetzen. Vgl. dazu die knappen Bemerkungen bei Nöth (2000, S. 478 ff.) sowie die Kritik bei Sonesson (1993) und Sachs-Hombach (2003, S. 100 ff.), der seiner Arbeit leider dennoch Morris' Trennung in Syntax, Semantik und Pragmatik zu Grunde legt. Die Grammar of Visual Design von Gunter Kress und Theo van Leeuwen (1996) ist gerade keine Fortschreibung dieser strukturalistischen Tradition einer formalen, kompositorischen Bildsyntax, sondern eine Weiterentwicklung der funktional begründeten social semiotics Michael A.K. Hallidays. 
als drei konstitutive Dimensionen jeder Semiose - dem Prozess der Verbindung eines Repräsentamens (einer materiellen Zeichenform) mit einem Objekt durch einem Interpretanten - verstanden werden. ${ }^{5}$ Dann liefert nämlich die ,Ikonizität den Ansatzpunkt für eine Pbänomenologie der Zeichenform, die eine Analyse der symbolischen Momente bei der Etablierung von Bedeutungen ergänzen kann und so zu einem Verständnis der spezifischen medialen Wirkungsweise von Bildern hinführt. ${ }^{6}$ Die konsequente Verbindung von Ikonizität und Symbolizität eröffnet nämlich die Möglichkeit, wichtige Einsichten auch von solchen Ansätzen der Bildtheorie aus dem Bereich der Kunstgeschichte und Philosophie aufzunehmen, die selbst eine phänomenologische Vorgehensweise als Alternative zur Semiotik propagieren. Das soll am Beispiel der Bildtheorie von Gottfried Boehm erläutert werden.

Zur Verdeutlichung der Argumentation werden Beispiele der Verwendung von Fotografien in journalistischen Printmedien herangezogen. Das ist ein Gegenstand, dem eine bildtheoretisch ausgerichtete Kunstgeschichte bisher kein großes Interesse entgegengebracht hat - wohl weil sie diese Fotografien primär als illustrative Abbildungen ohne großen ästhetischen Eigenwert ansieht. Und in der Tat kann eine semantische Analyse des TextBild-Verhältnisses in vielen Fällen Dopplungen oder Redundanzen ${ }^{7}$ konstatieren. In geradezu plakativer Weise ist das etwa bei einer Titelseite des SPIEGEL aus dem Mai des Jahres 1972 der Fall (Abb. 1). Die Titelzeile lautet „Bomben in der Bundesrepublik“ und sie ist in ein Bild gesetzt, das drei

5 Eine klassifizierende Verwendung, die auf Peirce eigene Bemühungen um eine tragfähige Klassifikation von Zeichenphänomenen zurückgeht, findet sich etwa im Semiotik-Kapitel des Studienbuchs Linguistik (Linke/Nussbaumer/Portmann 2004, S. 19), ihr Status als semiotisches Allgemeingut zeigt sich aber auch darin, dass in Winfried Nöths Handbuch der Semiotik (2000, S. 178 ff.) Symbol, Index und Ikon je ein eigenes Kapitel gewidmet ist. Gerade im Kapitel zum Ikon deutet jedoch auch Nöth an, dass die Verwendung der Termini zu differenzieren ist, wenn man sie in Bezug setzt zu den drei universalen Kategorien, die den Ausgangs- und Bezugspunkt der Peirceschen Zeichenphilosophie bilden. Während nämlich einerseits die möglichen Zeichenklassen logisch aus den Kategorien abgeleitet werden (vgl. etwa Nomenklatur und Unterteilung der triadischen Relationen, 1903 (Peirce 1983, S. 121-138)), ist jede wirkliche Semiose durch ein Zusammenspiel aller Dimensionen gekennzeichnet. Das verdeutlichen immer wieder auch die Analysen von konkreten Zeichenverwendungen, die sich in Peirces Texten jenseits der definitorischen Passagen finden. Vgl. etwa seine Ausführungen zum gemalten Porträt einer Person in den Entwïrfen für ein Logikbuch, MS 425 A, 1902 (Peirce 1986, S. 391), auf die ich weiter unten in Abschnitt 1 zurückkomme.

6 Auf eine Diskussion der indexikalischen Dimension und ihres Verhältnisses zu den beiden anderen Dimensionen der Objektrelation muss im Rahmen dieses Aufsatzes verzichtet werden. Der Anteil, den sie gerade im Fall von Fotografien an der besonderen Überzeugungskraft von Bildern hat, soll damit allerdings keineswegs bestritten werden. Vgl. dazu Steinseifer (im Erscheinen) sowie die Überlegungen zur ,indexikalischen Evidenz“ bei Jäger (2008). Seine auf Peirce gestützte Kritik an der späten fototheoretischen Position von Barthes ([1980] 1985) kann in großen Teilen komplementär zu der hier entwickelten Argumentation gelesen werden.

7 So der semiotische Terminus, der auf Barthes ([1964] 1990, S. 38) zurückgeht. Stöckl (2004a, S. 254) bezeichnet diesen ,unauffälligen Normalfall“" als Parallelisierung. 
solche Bomben zeigt. Das Bild verdoppelt hier also einen Teil der Bedeutung, die auch mit sprachlichen Mitteln zum Ausdruck gebracht wird. Allerdings muss man sich gerade angesichts solcher überdeutlichen Fälle von Verdopplung fragen, warum Bilder denn dann überhaupt verwendet werden, und vermuten, dass der Grund dafür nicht einfach in ihrer Semantik liegen kann. Fällt sie als Grund aus, rücken pragmatische Fragen notwendig in den Mittelpunkt: Ein Grund für die Verwendung von Bildern ist die spezifische Überzeugungskraft, die Bilder dem verleihen, was sie im jeweiligen Zusammenhang darstellen. Für diese Überzeugungskraft soll hier die Bezeichnung Prägnanz vorgeschlagen werden.

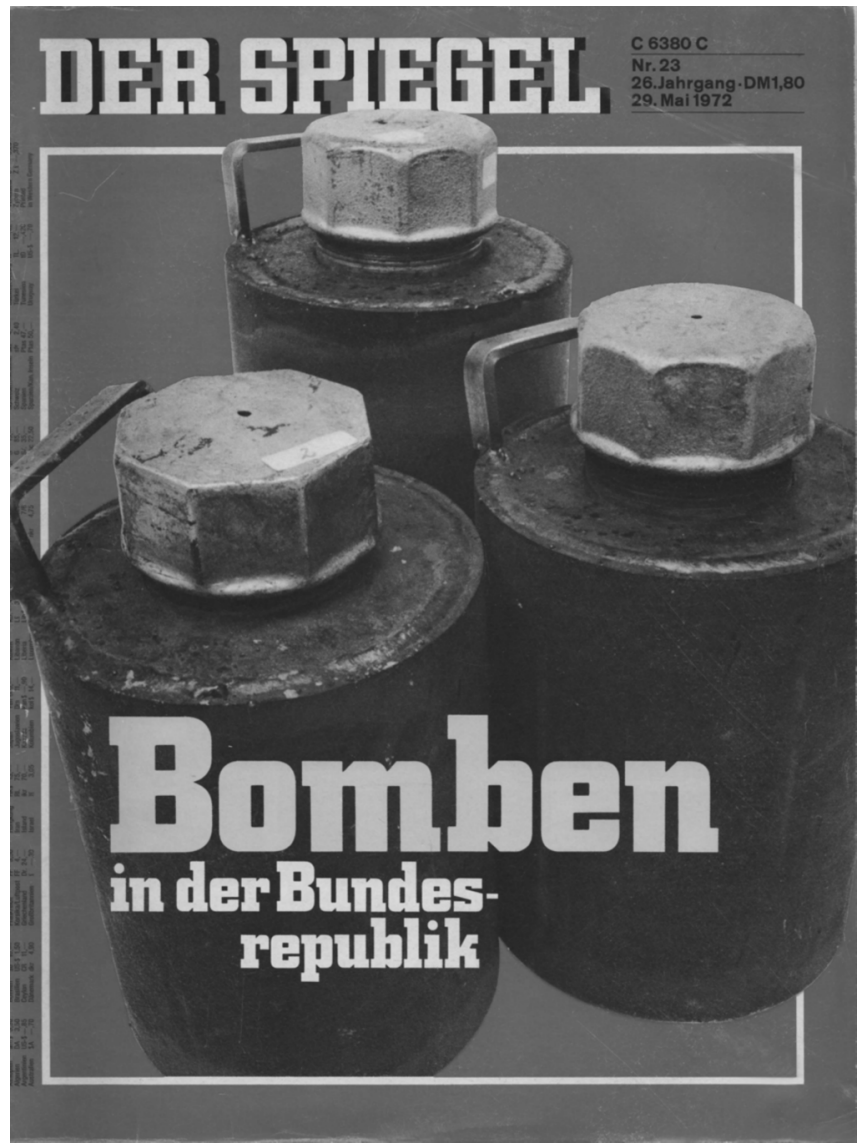

Abb. 1: SPIEGEL 23, 29.5.1972, Titel

Wenn als Beispiele Beiträge aus der Auseinandersetzung mit ,Terrorismus ${ }^{c}$ in der Bundesrepublik von vor 30 Jahren herangezogen werden, hat das allerdings einen weiteren Grund. Im Hinblick auf diesen „linken Ter- 
rorismus ${ }^{\text {“8 }}$ wie auch auf andere brisante und gesellschaftlich folgenreiche Ereigniszusammenhänge, wird nämlich eine zweite Frage wichtig, die sich ebenfalls nur pragmatisch beantworten lässt: Wie kommt es dazu, dass aus der enormen Zahl von publizierten Bildern nur bestimmte wiederverwendet werden, die dann im kollektiven Gedächtnis für ein Ereignis stehen? Zu diesen bis heute bekannten Bildern des ,Terrorismus'-Diskurses gehören die ,Bomben` des SPIEGEL-Titels sicher nicht, wohl aber das folgende Bild vom Ort der Entführung des damaligen Arbeitgeberpräsidenten HannsMartin Schleyer durch ein Kommando der, Roten Armee Fraktion' am 5. September 1977, das kurze Zeit nach dem Attentat in der Illustrierten STERN erschien (Abb. 2). Dafür dass sich dieses Bild als ,Foto-Ikone' (vgl. Brink 1998; Koetzle 2002) diskursgeschichtlich durchgesetzt hat, ist nicht nur die Brutalität der dargestellten Gewaltereignisse und der Stellenwert des sogenannten „Deutschen Herbstes“ im Terrorismus-Zusammenhang der 1970er Jahre verantwortlich. Es wird sich zeigen, dass neben diesen bildexternen auch bestimmte bildliche Eigenschaften entscheidend sind, die für ein besonderes Prägnanzpotenzial sorgen.

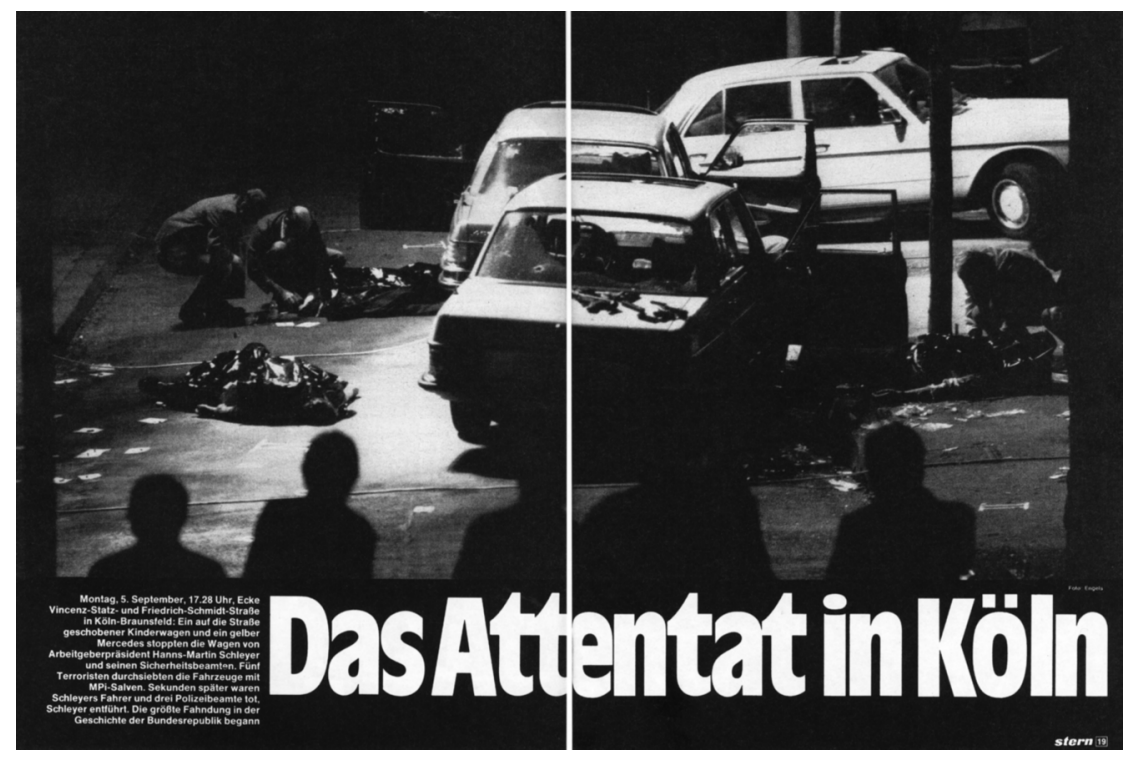

Abb. 2: STERN 38, 8.9.1977, S. 18-19

Fotografien in Printmedien sind aber noch aus einem dritten Grund interessant: Der diskursive Zusammenhang, in dem Bilder etwas darstellen, wird hier nämlich gerade nicht allein durch Bilder konstituiert, sondern

$8 \quad$ So die Kategorisierung im Titel der zweibändigen Geschichte dieses Ereigniszusammenhangs, die am Hamburger Institut für Sozialforschung entstanden ist (Kraushaar 2006). 
ebenso - und in erster Linie - durch schriftliche Texte. Entsprechend muss auch die Prägnanz als inter-mediale Größe verstanden und analysiert werden. Sie ist ein Effekt, der im Zusammenspiel ,zwischen' Textteilen und Bildern entsteht, wenn diese als Teile eines Kommunikationsangebots ${ }^{9}$ verstanden werden, das damit zu einem Beitrag in einem Diskurszusammenhang wird. Erst in einem solchen (thematisch bestimmten) kommunikativen Verwendungszusammenhang kann sich das spezifische Prägnanzpotenzial eines Bildes auswirken. Die Frage nach der spezifischen Wirkungsweise von Bildern ist also gerade nicht durch ihre isolierte Betrachtung zu beantworten, sondern in einer pragmatischen Perspektive rückt sie die wechselseitige Bezogenheit der beiden Ausdrucksformen Sprache und Bild in den Blick. Die Beziehung von Text und Bild lässt sich semiotisch rekonstruieren, sie ist allerdings gerade nicht symmetrisch: Sondern indem Texte bzw. Textteile in Text-Bild-Zusammenstellungen die Darstellungsbedeutung der verwendeten Bilder stabilisieren, profitieren sie umgekehrt von der Überzeugungskraft, die von wahrnehmbaren Eigenschaften der Zeichenform der Bilder ausgehen.

Dieser Zusammenhang soll im Folgenden in drei Schritten entfaltet werden: Zunächst wird die ,ikonische Differenz', die im Zentrum der Bildtheorie Gottfried Boehms steht, auf die ikonische Dimension der Semiose bei Peirce bezogen, um so die Rolle von Eigenschaften der sichtbaren Zeichenform hervortreten zu lassen (1). Dabei werden zugleich die Unterschiede bildlicher Sinnkonstitution zu außerbildlichen Wahrnehmungsprozessen deutlich, so dass in einem zweiten Schritt eine Sinn- bzw. Bedeutungsebene eingeführt wird, die der spezifischen Verschränkung ikonischer und symbolischer Momente bei gegenständlichen Bildern Rechnung trägt und die als Ebene der ,Darstellung' bezeichnet wird (2). Auf dieser Basis können dann in einem dritten Schritt zwei idealtypische Varianten von Prägnanzeffekten in Text-Bild-Zusammenstellungen unterschieden werden (3). Die Frage nach,Qualität ${ }^{`}$ und ,Effektivität ${ }^{`}$ der wahrnehmbaren Zeichenformen ist aber nicht auf die inter-mediale Konstellation von Text und Bild beschränkt. Als Frage nach der medialen, Wirkungsweise' kann sie ebenso an sprachliche Zeichenformen gestellt werden. Der Ausblick auf eine pragmatisch-linguistische Phänomenologie der Textgestalt wird daher den Beitrag beschließen (4).

Kommunikationsangebot ist eine medienneutrale Bezeichnung für das wahrnehmbare Ganze, das als Träger von Text und Bild fungiert. Schmidt ([1980] 1991, S. 61 f.) bestimmt solche „phyischen Wahrnehmungsangebote“, die als Mittel kommunikativer Handlungen dienen, ebenfalls medienneutral als Kommunikatbasen: „Kommunikatbasen bestehen aus solchen materialen Kommunikationsmitteln, die ein Kommunikationsteilnehmer produziert und die andere Kommunikationsteilnehmer aufgrund der Struktur ihres Wahrnehmungsapparates sowie durch Anwendung von regelhaften bzw. konventionalisierten Operationen als solche Gegenstände erkennen, denen sie Bedeutungen, Sinnbezüge und Relevanzen zuordnen und eventuell Handlungen als Konsequenzen daran anzuschließen gelernt haben.“ 


\section{Ikonische Sinnkonstitution - Boehm und Peirce}

Die Arbeiten des Philosophen und Kunsthistorikers Gottfried Boehm können in der aktuellen bildwissenschaftlichen Diskussion stellvertretend für eine Gruppe von theoretischen Ansätzen stehen, die man phänomenologisch nennen kann, insofern sie dafür eintreten, Bilder in erster Linie als Sichtbarkeitsgebilde, als visuell gestaltete Flächen, zu verstehen. Diese Ansätze und auch die bildtheoretischen Überlegungen von Boehm wurden in linguistischen Zusammenhängen allerdings bisher kaum aufgegriffen. Eine Anknüpfung wird an der Oberfläche dadurch erschwert, dass in phänomenologischen Ansätzen der Zeichenbegriff als bildtheoretischer Grundbegriff - zum Teil in schroffer Weise - abgelehnt wird. ${ }^{10}$ Bilder als Zeichen zu verstehen, reduziere diese entweder auf bloße Stellvertreter für eine bildunabhängige Sache ${ }^{11}$ oder unterstelle, in Analogie zur Sprache, eine arbiträre Relation von Ausdruck und Bedeutung sowie eine prädikative Struktur. Beides verstelle aber den Blick für die Besonderheit bildlicher Sinnkonstitution. „Bilder", so heißt es bei Boehm

besitzen eine eigene, nur ihnen zugehörige Logik. Unter Logik verstehen wir: die konsistente Erzeugung von Sinn aus genuin bildnerischen Mitteln. Und erläuternd fügen wir hinzu: diese Logik ist nicht-prädikativ, das heißt nicht nach dem Muster des Satzes oder anderer Sprachformen gebildet. Sie wird nicht gesprochen, sie wird wahrnehmend realisiert. (Boehm [2004] 2007b, S. 34)

Den Kern dieser Logik und damit auch seines bildtheoretischen Ansatzes bildet für Boehm eine spezifische Differen₹, die er „ikonische Differen₹" (ebd., S. 49) nennt - wobei ikonisch in seinen Texten konsequent mit bildlich zu übersetzen ist: Es ist die Differenz zwischen dem, was Betrachter bei der Betrachtung eines Bildes vor sich sehen, und dem, was sie darin (wieder-)erkennen. Boehm sieht im Vollziehen dieser Differenz ein Moment des ,Umspringens ${ }^{c}$ von Wahrnehmung in Sinn, das an außerbildliche Wahrnehmungserfahrungen anschließt, zugleich aber in charakteristischer Weise über diese hinausgeht. ${ }^{12}$

10 Diese Ablehnung durchzieht die philosophische Phänomenologie von ihren Anfängen an. In besonders zugespitzter Weise hat sie Lambert Wiesing (2005, bes. S. 30 f.) unter Rekurs auf Edmund Husserl noch einmal formuliert. Die Hürde, die damit für eine produktive linguistische Rezeption verbunden ist, zeigt sich indirekt etwa an der ebenfalls recht pauschalen Kritik Stöckls (2004a, S. 64 f. Anm. 28 und S. 92 f.), der den antisemiotischen Zügen phänomenologischer Ansätze seinerseits Inkonsequenzen vorwirft, ohne diese genauer aufzuzeigen. In erster Linie zieht er sich auf die Position zurück, dass diese Ansätze allenfalls für bestimmte Bildtypen besonders der künstlerischen Avantgarden Relevanz beanspruchen könnten, nicht aber für den massenmedialen Bildgebrauch.

11 Vgl. Boehm (1978, S. 453 f.): „Bilder sind nicht Substitute von Sachlagen, d.h. Sachlagen im Bild noch einmal, schon deshalb nicht, weil ,Sach'-Elemente des Bildes von der Weise ihres Erscheinens, Wirkens und Bedeutens nicht separiert werden können. Auch die Verwendung des semiotischen Zeichenbegriffs auf das Bild, die auf der Trennung von Signifikanten und transzendentem sprachförmigem Signifikat beruht, bricht aus eben diesen Gründen zusammen."

12 Die zentrale Rolle, die der Differenz als Ausgangspunkt für die Konstitution von Sinn gegeben wird, unterscheidet die Bildtheorie Boehms von solchen phänomenologischen Ansät- 
Was damit gemeint ist, lässt sich anhand der oben bereits erwähnten Doppelseite aus dem STERN (Abb. 2) nachvollziehen. Wenn man diese Seite ansieht, dann sieht man nicht einfach eine Fläche mit hellen und dunklen Flecken, sondern erkennt zugleich drei Fahrzeuge und wahrscheinlich noch einiges mehr. Außerdem sieht man sofort, dass es sich um die Seite aus einer Illustrierten handelt. Eine Antwort auf die Frage, wie Betrachter dazu kommen, in der schwarz-grau-weißen Fläche all dies zu erkennen, muss zwei Ebenen der Sinnkonstitution berücksichtigen und damit zwei Formen der Differenzbildung voneinander unterscheiden: ${ }^{13}$ eine Ebene, auf der die bildliche Sinnkonstitution eng auf außerbildliche Prozesse der Wahrnehmung bezogen ist und eine, durch die sie sich als bildliche von diesen unterscheidet.

Auf einer ersten Ebene kann man festhalten, dass die drei Fahrzeuge erkennbar werden, weil sie in der Wahrnehmung als bestimmte Figuren von einem unbestimmten Umfeld oder Grund unterschieden werden. Boehm beschreibt diesen Prozess folgendermaßen:

Wenn wir von Bildern reden (flachen, plastischen, technischen, räumlichen etc.), meinen wir eine Differenz, in der sich eine oder mehrere thematische Brennpunkte, die unsere Aufmerksamkeit binden, auf ein unthematisches Feld beziehen. (Boehm [2004] 2007b, S. 48 f.)

Auf das Beispiel bezogen: Damit Fahrzeuge erkannt werden können, muss die materielle Oberfläche des Bildes so gestaltet sein, dass sie entsprechende Unterscheidungen ermöglicht und sie dem Betrachter nahe legt. Sinnvoll werden diese allerdings nur, indem sie zum Anlass eines wiedererkennenden Sehens ${ }^{14}$ werden, bei dem die aktuell sichtbaren Kontraste einer Reihe früherer Seherfahrungen zugeordnet werden.

Diese sinnkonstituierende Zuordnung, die in der Regel unbewusst erfolgt, ist allerdings zunächst einmal noch nichts, das für Bilder spezifisch wäre. Denn in jedem optischen Wahrnehmungsprozess werden aktuellen Qualitäten im Wahrnehmungsfeld, wie etwa visuellen Kontrasten, Wahr-

zen, die im Rückbezug auf Husserl die Besonderheit des Bildes in einer spezifischen sichtbaren Präsenz sehen (vgl. insb. Wiesing 2005). Boehm selbst sieht Verbindungspunkte zum Saussureschen Sprachdenken (Boehm 1978, S. 460) und es ist dieser Grundzug der Sinnkonstitution durch Differenzen, der seine theoretischen Überlegungen bei aller Betonung der Eigenständigkeit von Bildphänomenen für den hier vertretenen pragmatischen Ansatz anschließbar macht.

13 Diese Unterscheidung ist bei Boehm angelegt, wird von ihm aber nicht immer explizit markiert.

14 Wiedererkennendes Sehen ist einer der Kernbegriffe der Ikonik Max Imdahls, einer kunstwissenschaftlichen Methodologie, die in ihren theoretischen Implikationen mit der Bildtheorie von Boehm über weite Strecken kompatibel ist - eine Kompatibilität, die einen biografischen Anhalt darin hat, dass Boehm nach einer philosophischen Promotion bei Hans-Georg Gadamer in Heidelberg als Assistent von Imdahl an der Bochumer Ruhr-Universität arbeitete. Jede ikonische (d.h. am Rahmen der Ikonik orientierte) Bildanalyse erfordert nach Imdahl eine Verbindung des „,wiedererkennende Gegenstandssehen[s]“ mit einem sehenden Sehen, das die „formale Ganzheitsstruktur“ eines Bildes als eines flächigen Objekts - seine „planimetrische Komposition“ - erschließt (Imdahl [1980] 1996, S. 487). 
nehmungsobjekte zugeordnet. Das setzt „Synthesen“ ${ }^{15}$ wie Boehm es unter Rückbezug auf Kant nennt, oder Schematisierungen voraus. Die Schematisierungen bestehen in Erfahrungen und Gewohnheiten, die das Sehen vororientieren. Und sie sind der Grund dafür, dass Peirce im Unterschied zur Phänomenologie Husserls ${ }^{16}$ den Wahrnehmungsprozess semiotisch versteht. Als wiedererkanntes Objekt ist der Gegenstand der Wahrnehmung gerade nicht unmittelbar sichtbar präsent, sondern nur vermittelt über Erfahrungen, die die Zuordnung regeln. Versteht man mit Peirce Symbole als Zeichen, die in einer solchen Regelmäßigkeit der Zuordnung begründet sind, die wie er an einer Stelle lapidar und zugleich konsequent pragmatistisch formuliert - ,mit ihren Bedeutungen durch ihre Verwendung verknüpft worden sind ${ }^{\text {" }}{ }^{17}$ dann wird deutlich, dass mit der Orientierung durch Erfahrung schon in der Semiose der Wahrnehmung ein symbolisches Moment wirksam ist. Es tritt bei Bildern noch stärker hervor. Allerdings handelt es sich auch bei gegenständlichen Bildern nicht um idealtypische Symbole. Denn wie in der außerbildlichen Wahrnehmung hängt die Wiedererkennbarkeit von Gegenständen im Bild nicht allein von dem etablierten Zuordnungsschema ab, sondern zugleich in hohem Maße von den Eigenschaften - von den Qualitäten - die aktuell sehend wahrgenommen werden. Es ist insofern für Peirce - wie für Boehm, dessen Terminologie sich hier mit der von Peirce berührt in der bildlichen wie auch in der außerbildichen Wahrnehmung ein ikonisches Moment wirksam. Denn die Begründung einer Zeichenrelation in Qualitäten des Repräsentamens bzw. Zeichenträgers ist für Ikone charakteristisch. Peirce bestimmt das Ikon idealtypisch als Zeichen, das „sich auf das von ihm denotierte Objekt lediglich aufgrund von Eigenschaften bezieht, die es selbst besitzt" ${ }^{\text {"18 }}$ In dieser Zuspitzung ist das Ikon die bloße Möglichkeit eines Zeichens, aber entscheidend an dieser Bestimmung ist die Betonung von Eigenschaften des Zeichenträgers als Ausgangspunkt von ,ikonischen ${ }^{6}$ Semiosen. Sie wird leicht dadurch verdeckt, dass Peirce im Zusammenhang mit seinen Definitionen des Ikon gerade in frühen Texten immer wieder auf eine Relation der Nachahmung oder auf die Ähnlichkeit zwischen Zeichenträger und Objekt abhebt. ${ }^{19}$ Geht man jedoch von der zitierten Defi-

15 „Die ikonische Differenz vergegenwärtigt eine visuelle Kontrastregel, in der zugleich ein Zusammensehen angelegt ist. Ikonische Synthesen sind bereits in der Struktur unserer Wahrnehmung angelegt.“" (Boehm [2004] 2007b, S. 49). Vgl. zum entsprechenden Begriff der „figürlichen Synthesis" sowie der Rolle von Begriffsschemata für die Wahrnehmung bei Kant den Beitrag von Lohmar (1993), der zudem - bei allen Differenzen der jeweiligen Ansatzpunkte - hinsichtlich der orientierenden Rolle von Erfahrungen deutliche Parallelen zwischen Kants Konzeption und Husserls Phänomenologie der Auffassung aufweist.

16 Vgl. etwa Husserl ([1913] 1992, \43).

17 Peirce (1986, S. 193 (Die Kunst des Räsonierens, MS 404, 1893)). Vgl. auch die folgende Definition: „Ein Symbol ist ein Zeichen, dessen zeichenkonstitutive Beschaffenheit ausschließlich in der Tatsache besteht, daß es so interpretiert werden wird.“ (Peirce 1983, S. 65).

18 Peirce (1983, S. 124 (Nomenklatur und Unterteilung der triadischen Relationen, 1903)).

19 Vgl. etwa Peirce (1986, S. 193 (Die Kunst des Räsonierens, MS 404, 1893) oder S. 205 (Kurze Logik, 1895)). 
nition aus, wird deutlich, dass Ähnlichkeitsurteile gerade nicht die selbstevidente Voraussetzung ikonischer Relationen sind. Sie sind vielmehr das Resultat von Semiosen, in denen jeweils durch gegebene Eigenschaften motivierte, ikonische Bezugsmöglichkeiten über eine Folge von direkten Zuordnungen, bei denen mit der notwendig konkreten Herstellung von Bezügen auch ein indexikalisches Verweismoment ins Spiel kommt, zur symbolischen Gewohnheit geworden sind. Diese Verbindung der drei Dimensionen zeigt auch die folgende Passage:

Wir sagen über ein Porträt einer Person, die wir nicht kennen, es sei überzeugend.
Soweit es mich bloß aufgrund dessen, was ich darin sehe, veranlaßt, mir eine Vor-
stellung von der dargestellten Person zu bilden, ist es ein Ikon. Aber in Wirklichkeit
ist es kein reines Ikon, weil ich weiß, daß ich stark von der Wirkung beeindruckt
bin, die - vermittelt über den Künstler - durch das Aussehen des Originals verur-
sacht wurde und also in einer genuin obsistenten Relation zum Original steht [als
solche bezeichnet Peirce hier den Index; Anm. d. Autors]. Nebenbei bemerkt, ich
weiß, daß Porträts nicht die leiseste Ähnlichkeit mit ihrem Original haben, außer in
bestimmten konventionellen Hinsichten und nach einer konventionellen Werte-
skala und so weiter. (Peirce 1986, S. 391 (Aus den Entwürfen für ein Logikbuch,
MS 425 A, 1902))

Wichtiger als der an dieser Stelle eher problematische Rekurs auf das indexikalische Moment der Semiose - das für den Umgang mit Porträts in der Tat wichtige Wissen um eine wirkliche Verbindung zwischen Porträtbild und Porträtiertem lässt sich kaum auf eine Verursachungsrelation reduzieren - ist die Betonung der Tatsache, dass sich der Ähnlichkeitseindruck immer bestimmten ,konventionellen Hinsichten' verdankt und dass sich die Überzeugungkraft eines Bildes mithin dem Zusammenspiel ikonischer und symbolischer Momente verdankt.

In dem Ausgehen von Eigenschaften liegt der Verbindungspunkt zwischen der Peirceschen Bestimmung ikonischer Zeichen und der phänomenologischen Bildtheorie Boehms. Anders als Peirce, dem es im Rahmen seiner philosophischen Semiotik nicht um eine Bildtheorie geht, betont Boehm allerdings neben den Gemeinsamkeiten zugleich den Unterschied zwischen außerbildlichen Wahrnehmungsprozessen und derjenigen Form einer Sinnkonstitution durch Differenzen, wie sie für Bilder charakteristisch ist. Die ikonische Differenz bezieht sich bei Boehm immer auch und in erster Linie auf diese zweite Ebene der Sinnkonstitution, die dadurch entsteht, dass bei Bildern sichtbare Kontraste auf einer begrenzten und überschaubaren Fläche fixiert sind. Das , unthematische Feld' der oben zitierten Passage, auf dem sich etwas erkennbar abzeichnet, hat nämlich beim Bild stets feste Grenzen. Das führt dazu, dass die einzelnen Teile, die als Figuren wiedererkannt werden können, nicht nur in einem sichtbaren Verhältnis zu ihrem relativ unbestimmten Umfeld stehen, sondern zugleich auch zur Bildfläche als einem - in seinen Grenzen wiederum bestimmten - Ganzen. Bilder sind 
- wie Boehm an einer anderen Stelle schreibt - „,nicht einfach geformte Dinge [...], sondern komplexe, dem Auge dargebotene Anordnungen, in denen dies oder jenes erscheint" (Boehm 1999, S. 170).

Entsprechend sind auch in dem Beispiel aus dem STERN nicht nur einfach drei Fahrzeuge und einige Figuren erkennbar, sondern sie sind zugleich in einer bestimmten Weise im Bild angeordnet, die sehend nachvollzogen werden kann. ${ }^{20} \mathrm{Zu}$ dieser Anordnung gehört die Tatsache, dass am unteren Bildrand eine Reihe von dunklen Silhouetten platziert sind, die den Betrachtern eine bestimmte Blickrichtung vorschlagen. ${ }^{21}$ Sie offerieren, dem Straßenverlauf, der mit der Bordsteinkante am linken Bildrand markiert wird, entlang der beiden vorderen Wagen in den Bildraum hinein zu folgen (Abb. 3).

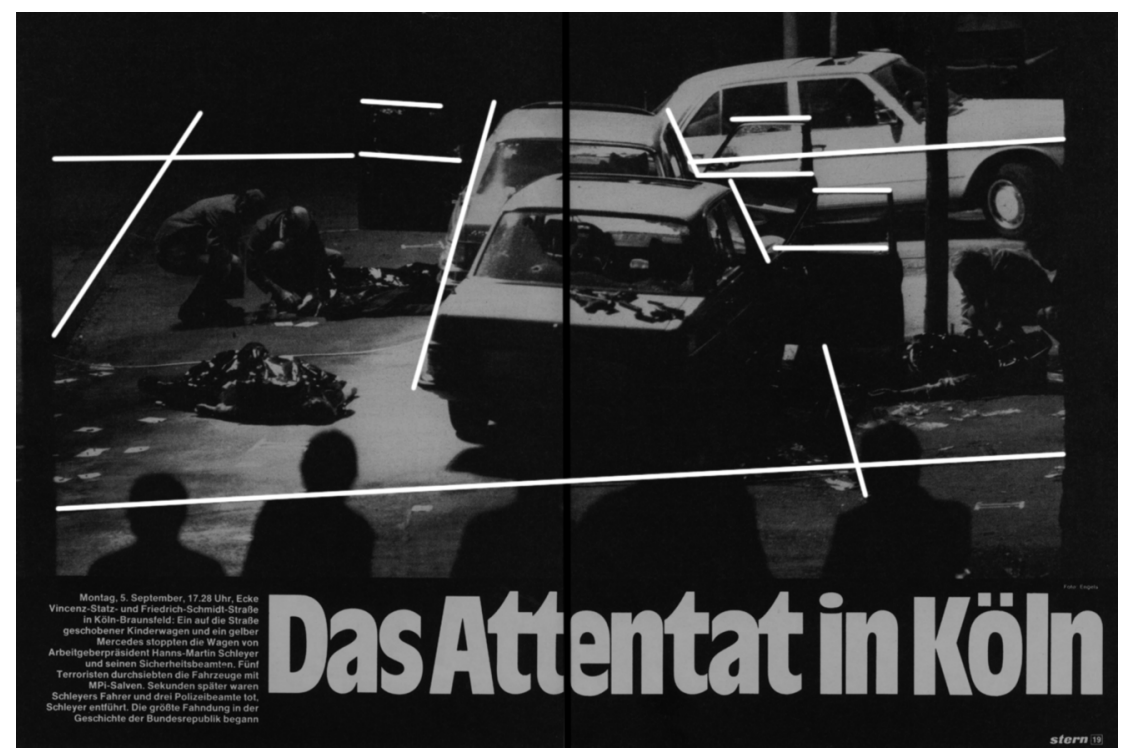

Abb. 3: Hervorhebung von Bildlinien

$20 \quad$ Für dieses sehende Sehen als Komplement zum wiedererkennenden Seben spielen in den Analysen Imdahls (siehe oben Anm. 14) immer wieder Bildlinien eine entscheidende Rolle.

21 Fehrmann/Linz (2008) führen verschiedene experimentelle Befunde dafür an, dass gerade ein abgewendeter Blick auch in statischen Bildern „das Mitvollziehen einer identifizierenden Bewegung herausfordert" (S. 280) und insofern bilddeiktisch funktioniert: Er wird als ,,als deiktischer Index rezipiert und damit von Betrachter - anders als der direkte, primär adressierende Blick - zu einer Verweishandlung vervollständigt" (S. 281). Das berührt sich mit Überlegungen bei Kemp ([1985] 1996, S. 247 ff.), der in seinen Analysen von Bildern aus dem Kanon der Kunstgeschichte allerdings zu einer etwas anderen Unterscheidung kommt. Er unterscheidet zwischen Rezeptionsvorgaben, wie sie Figuren machen, die den Betrachter direkt adressieren und auf einen Bildteil verweisen, und Rezeptionsangeboten durch Betrachterfiguren, die ihn eher vorsichtig auf etwas hinführen. 
Die durch diese Anordnung betonte Senkrechte wird im oberen Bilddrittel allerdings von der Waagerechten des dritten Wagens gekreuzt. Die Zierleiste des Wagens findet ihre bildliche Fortsetzung auf der linken Seite in der Grenze zum Schwarz des Hintergrundes. Unterstrichen wird diese Waagerechte durch die Konturen der aufgerissenen Türen an den vorderen Wagen, und schließlich noch durch eine feine Linie im unteren Bilddrittel, die anhand von anderen Bildern als Markierungsband der Spurensicherung identifiziert werden kann. So legt der Bildaufbau es dem Betrachter nahe, den Ereignisverlauf, in dem die Wagen von Schleyer und seinen Begleitern von den Attentätern abrupt zum Stillstand gebracht wurden, visuell nachzuvollziehen. Hinzu kommt, dass inmitten der Szenerie und fast genau in der Mitte der Bildfläche das Ereignis der tödlichen Schüsse in Form einer Kombination sichtbarer Spuren ins Bild gesetzt wird: Denn hier ist die zerstörte Heckscheibe des hinteren Wagens platziert und direkt darunter sind die zurückgelassenen Tatwaffen zu sehen, die auf dem Kofferraumdeckel liegen. Die Figuren im Vordergrund orientieren nicht nur den Blick, sondern unterstreichen, wenn man sie als spectators bzw. als Publikum versteht, auch die Spektakularität des Geschehenen. Die Fotografie ist damit mehr als ein dokumentarischer Beweis, der sich dem indexikalischen Charakter der fotografischen Technik verdankt. Durch die Anordnung der Elemente und die Ausrichtung an Bild-Linien wird sie zu einer visuell überzeugenden Veranschaulichung des „Attentats“ und seines Verlaufs. Die Pressefotografie, die erst nach der Tat entstanden ist, kann diesen Verlauf gerade nicht in einem direkten Sinne abbilden. Sie macht die Brutalität des Vorgehens aber in diesem Fall mit genuin bildlichen Mitteln nachvollziehbar.

Diese knappe Beispielanalyse kann andeuten, was es in Boehms Sinn heißt, dass mit der Fixierung und Positionierung sichtbarer Größen im Rahmen der Bildfläche neue Möglichkeiten der Sinnbildung entstehen. Sie resultieren daraus, dass die gestaltete Fläche als materielles Objekt mit bestimmten Eigenschaften - Farben, Kontrasten, usw. - angesehen werden kann und dass sie zugleich im sehenden Nachvollziehen ihrer Anordnung als Bild mit einem bestimmten Sinn verstanden werden kann. In dieser Gleichzeitigkeit von Sehen und Verstehen liegt für Boehm die Besonderheit bildlicher Sinnkonstitution. ${ }^{22}$ Die beständige Rückverwiesenheit des Sinns an die Qualitäten der Oberfläche ist aus seiner Sicht der Grund für die besondere Überzeugungskraft von Bildern, für ihre Evidenz (vgl. Boehm 2007a, S. 16).

22 Vgl. Boehm (1999, S. 170): „Wer den Gehalt eines jeweiligen Bildes [...] im Kontext anderer Bilder verstehen will, der muss sich auf Distinktionen einlassen, die er am jeweiligen Artefakt abliest. Abliest an der spezifischen Differenz, die mediale Prämissen und Formentscheidungen jeweils miteinander ausgebildet haben." 


\section{Die symbolische Dimension - Darstellung als schematisierte Anordnung}

Als konstitutiv für Boehms Konzept der ikonischen Differenz erweist sich ein Spannungsverhältnis zwischen dem schematisierten Wiedererkennen von wahrnehmungsbezogenen Bildbedeutungen und dem am einzelnen Bild sehend nachzuvollziehenden und darin visuell überzeugenden Bildsinn. Die Tendenz Boehms, dieses Spannungsverhältnis als eines zwischen stabilisierten Bedeutungen auf der Ebene von einzelnen wiedererkennbaren Bildteilen und einem hochgradig an die individuelle Bildanordnung gebundenen Sinn auf der Ebene des Bildes als Ganzem anzusiedeln, ist allerdings nicht ganz unproblematisch, wenn man weniger als der Kunsthistoriker Einzelbilder wie Gemälde, sondern den massenmedialen Gebrauch von Bildern analytisch in den Blick nimmt. Denn dann wird auch auf der Ebene des Bildes als Ganzem die Frage nach einer durch Schematisierungen des Gebrauchs stabilisierten, überindividuellen Bedeutung wichtig, für die Boehm sich allenfalls am Rand interessiert. Die folgende Grafik verdeutlicht diesen Zusammenhang.

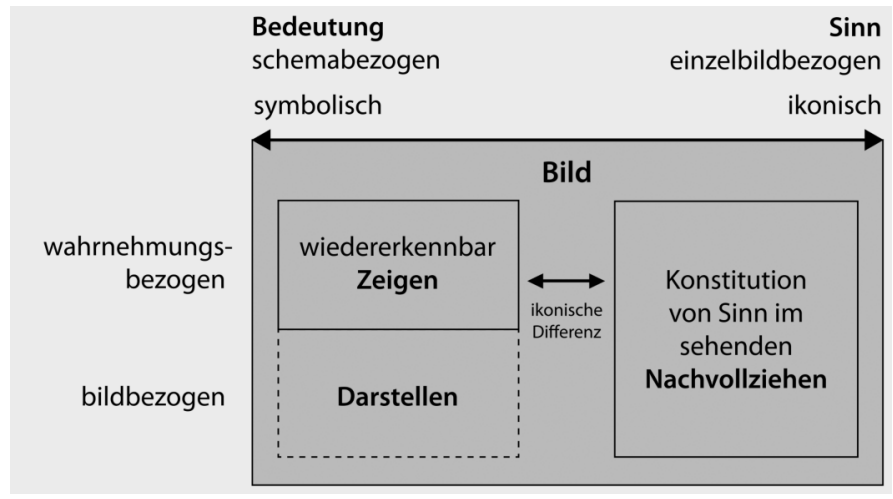

Grafik 1: Bezugsgrößen der bildlichen Sinnkonstitution

Um auch terminologisch zu unterscheiden: Es geht nicht nur darum, was Teile eines Bildes wiedererkennbar zeigen, sondern was es als Ganzes erwartbar darstellt. Das Problem lässt sicht erneut am Beispiel aus dem STERN verdeutlichen. In dem Bild sind nämlich nicht nur Autos und andere Dinge erkennbar, es ist auch ein Tatort zu sehen. Er ist kein weiterer Gegenstand, den ein Teil des Bildes wiedererkennbar zeigt, sondern ein Sachverhalt. Das Sehen dieses Sachverhalts liegt auf einer anderen Ebene. Denn um einen Tatort zu sehen reicht es nicht, einfach die einzelnen gezeigten Gegenstände wiederzuerkennen, zusätzlich braucht es eine Kenntnis davon, wie ein Tatort - der Ort eines kurze Zeit zurückliegenden Gewaltgeschehens - üblicherweise bildlich dargestellt wird. Um ohne weitere Hinweise in dem Bild 

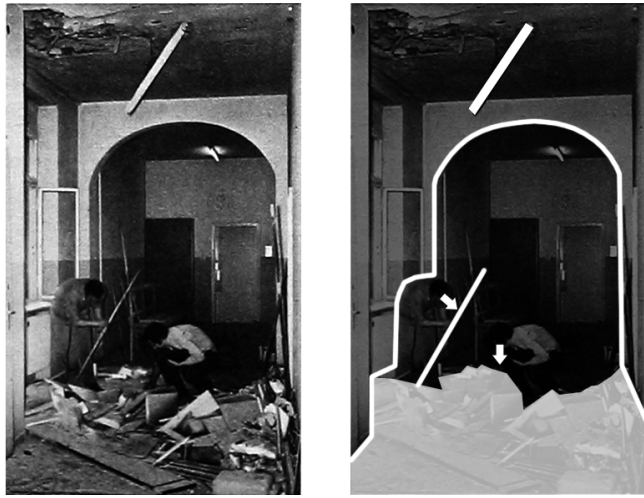

Abb. 4: QUICK 23, 31.5.1972, S. 16 (Ausschnitt)
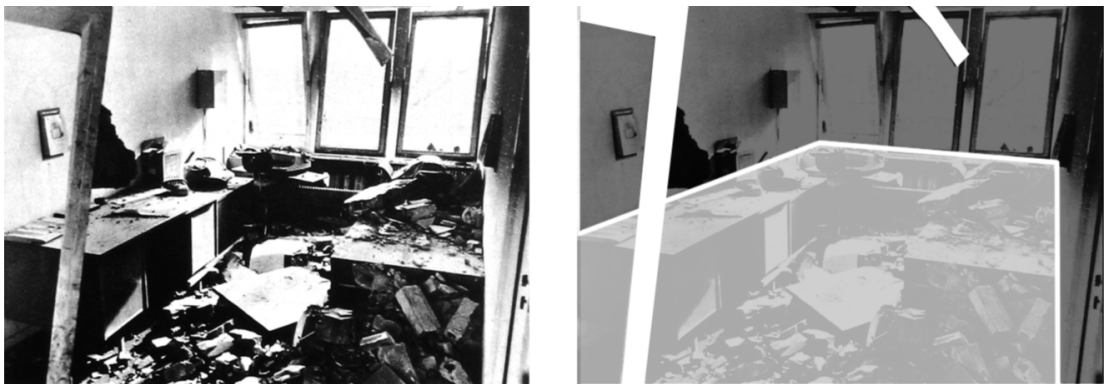

Abb. 5: SPIEGEL 23, 29.5.1972, S. 24 (Ausschnitt)
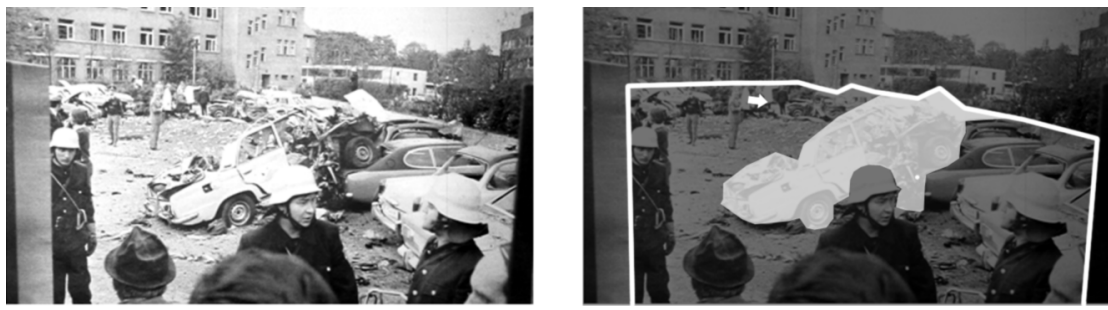

Abb. 6: STERN 23, 28.5.1972, S. 154 (Ausschnitt)
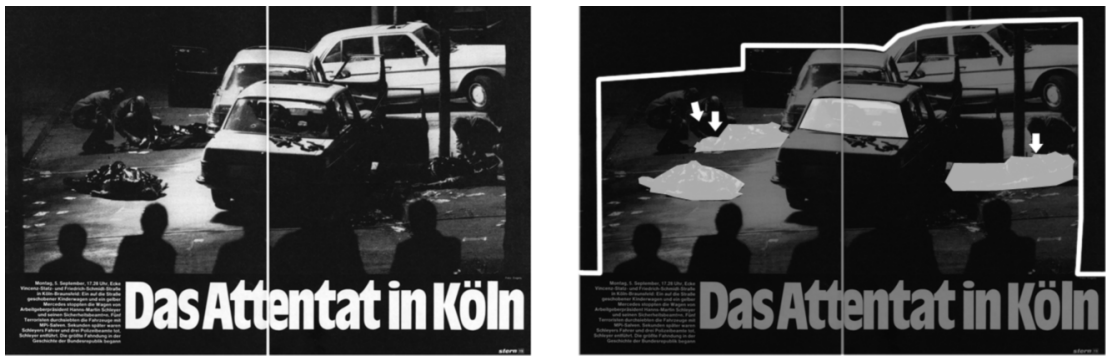

Abb. 7: STERN 38, 8.9.1977, S. 18-19, jeweils links Original rechts mit Markierungen 
einen Tatort zu sehen, müssen Betrachter in der Erfahrung mit anderen Bildern ein mehr oder weniger flexibles Schema aufgebaut haben, das es ihnen erlaubt, das Bild in eine Reihe mit diesen anderen Bildern zu stellen und so als Darstellung eines Tatorts zu verstehen.

Anhand einer entsprechenden Reihe von Bildern lassen sich daher auch rekonstruktiv die bildlichen Bestandteile eines solchen Tatort-Schemas gewinnen (Abb. 4, 5, 6, 7):

- Zunächst einmal wird durch einige Teile des Bildes eine räumliche Situation angedeutet, damit ein Ort erkennbar werden kann. Die Bilder von den Orten der Anschläge auf das Hamburger Springer-Haus (Abb. 4) und das Polizeipräsidium im Augsburg (Abb. 5) zeigen durch Wandfluchten links und rechts (sowie in einem Fall auch eine Deckenflucht am oberen Bildrand), die auf eine Stirnwand im Hintergrund zulaufen, einen Raum als Tatort an: Die Wände umschließen nach drei Seiten die Bodenfläche eines Innenraumes, der sich zum Betrachter hin öffnet. Der Blick auf die beiden weiteren Bilder kann zeigen, dass diese bildliche Anordnung, die an einen Bühnenraum denken lässt, nicht einfach das zufällige Nebenprodukt des Fotografierens in Innenräumen ist. Denn die Rahmung einer Fläche nach links und rechts sowie zum Hintergrund hin findet sich in abgewandelter Form auch hier.

- An den so markierten Orten werden als weiterer Bildbestandteil Gegenstände platziert, an denen Spuren der Tat erkennbar sind. Besonders deutlich ist dies beim Bild des Münchener Anschlags, bei dem auf der gerahmten ,Bühnenfläche' ein Fahrzeug mit deutlichen Zerstörungsspuren zu sehen ist, das zugleich im Zentrum der gesamten Bildfläche steht. Zerstörungsspuren finden sich in den Innenraumbildern aber auch an den rahmenden Teilen; auffällig sind insbesondere Teile der Deckenverkleidung, die von oben schräg in den Raum hineinreichen. Sie fallen gleichsam , aus dem Rahmen', ebenso wie die Fensterflügel im Vorder- und Hintergrund des SPIEGEL-Bildes. Eine solche schräge Positionierung im Bild, die als Abweichung von der üblichen Ausrichtung der Gegenstände die Aufmerksamkeit auf sich zieht, findet sich schließlich auch bei dem zerstörten Fahrzeug des Bildes aus München.

- Die prominente - meist zentrale - oder ungewöhnliche - in den Beispielen zumeist schräge - Positionierung der Gegenstände im Bild trägt bereits dazu bei, die Aufmerksamkeit des Betrachters auf die Folgen der Gewaltanwendung als Hauptbestandteil des Tatort-Motivs zu lenken. Ein weiteres bilddeiktisches Mittel, das für Tatortbilder typisch ist, sind die bereits erwähnten Betrachterfiguren im Bild. Das sind neben Personen in Rückenansicht am unteren Bildrand, die als Zuschauer am Ort des Geschehens den Betrachterblick in den ,Bühnenraum‘ hinein lenken, auch Personen, die zwischen den zerstörten Gegenständen platziert sind und deren Blick auf die Spuren gerichtet ist. 
Keiner der Bestandteile ist in der vorgeführten Form unersetzlich für eine Tatortdarstellung, aber zusammen bilden sie eine prototypische Konstellation. Diese Konstellation ist allerdings nicht mehr einfach ein Schema der außerbildlichen Wahrnehmung, sondern eine bildbezogene Größe - eine schematisierte Verbindung von wiedererkennbaren Elementen in ihren üblichen Anordnungen auf der Bildfläche. Sie kann als Motiv bzw. Motivtyp oder eben als Darstellungsschema bezeichnet werden. Die Schematisierung und ihre Verbindung mit einer Darstellungsbedeutung ist ein Produkt des Bildgebrauchs und hat damit nach Peirce symbolischen Charakter. Doch sind es erneut die variablen sichtbaren Eigenschaften der einzelnen Bilder, die es erlauben, sie in eine Reihe von Tatort-Darstellungen zu stellen. Auch auf der Ebene der Darstellung verbindet sich also die symbolische Dimension in der Semiose mit der ikonischen, die dafür sorgt, dass die jeweiligen Einzelbilder immer auch mehr oder weniger typische Vertreter des motivischen Paradigmas sind. In der obigen Grafik ist diese Gleichzeitigkeit der beiden Dimensionen in Form einer polaren Skala berücksichtigt. Deren Endpunkte sind durch die idealtypischen Peirceschen Bestimmungen des Ikons und des Symbols definiert, die als Reinformen gerade nicht vorkommen. Die skalare Darstellung hält jedoch fest, dass die Semiose stärker durch den Bezug auf ein Schema geprägt und damit ,symbolischer' sein kann. Das resultiert dann in relativ stabilen Bedeutungen - sei es auf der auf die außerbildliche Wahrnehmung bezogenen Ebene des wiedererkennbaren Zeigens oder auf der bildbezogenen Ebene der Darstellung. Die Semiose kann umgekehrt aber auch ,ikonischer' sein, wenn sie stärker an den wahrnehmbaren Eigenschaften des einzelnen Bildes und ihrem Beitrag zur Sinnbildung orientiert ist, für die sich Boehm in erster Linie interessiert. Das Ergebnis ist in diesem Fall ein jeweils neu vom Einzelbild her zu gewinnender und daher kommunikativ weit weniger gut stabilisierbarer Sinn.

\section{Prägnanz in Text-Bild-Zusammenstellungen}

Die bisherige Rekonstruktion der Darstellungsbedeutung von Bildern ist allerdings noch unvollständig. Denn ein Betrachter, der das STERN-Bild gemäß dem Tatort-Schema versteht, kann nicht nur sehen, sondern auch sagen, dass es einen Tatort darstellt. Diese Kopplung ist kein Zufall. Der Darstellungsbedeutung liegt nämlich immer schon eine Beziehung von Text und Bild zugrunde. Als situationsübergreifend erwartbare Größe resultiert die Bedeutung nicht allein aus einem wiederholten Bildgebrauch, sondern auch daraus, dass vergleichbaren Bildern bei deren Verwendung immer wieder ein entsprechender Darstellungs-Sinn durch Textteile zugeschrieben wurde. ${ }^{23}$ Zwei Beispiele, bei denen leichte Varianten des STERN-Fotos ver-

\footnotetext{
$23 \quad$ Im Fall von Printmedien ist hierbei in erster Linie an Bildunterschriften zu denken, doch
} auch die Haupt- und Zwischenüberschriften der Text-Beiträge können allein aufgrund ihrer 
wendet werden, können dies belegen (Abb. 8, 9). Das erste stammt aus einer rückblickenden Darstellung der Schleyer-Entführung in Buchform, die von den zwei STERN-Journalisten Kai Hermann und Peter Koch noch 1977 unter dem Titel Entscheidung in Mogadischu veröffentlicht wurde (Hermann/ Koch 1977, S. 6-7). Der oben links ins Bild gesetzte Textteil beginnt mit der Zeile „Der Tatort:“ Abgesetzt durch den Doppelpunkt schließt sich in den folgenden Zeilen eine genauere Lokalisierung des Ortes und die Einordnung einzelner Bildteile in den Ereigniszusammenhang an. Sie werden durch diese Zuschreibung zu Elementen der Tatortdarstellung erklärt: „die Vincenz-Statz-Straße im Kölner Villenvorort Braunsfeld. Vorn das Fahrzeug der Wachmannschaft, dann der Wagen Schleyers und hinten das von den Terroristen zur Hälfte quer über die Fahrbahn gefahrene Auto. Die toten Opfer des Überfalls sind mit Plastikplanen zugedeckt. Kriminalbeamte sichern Spuren“. Das zweite Beispiel stammt aus einem SPIEGEL-Heft des vergangenen Jahres (H. 37, 8.9.2008. S. 43), in dem in einer Titelgeschichte zum Kino-Film Der Baader-Meinhof-Komplex den Bildern von Filmszenen Pressefotos der Ereignisse gegenüberstellt wurden. Auch hier erklärt der ins Bild gesetzte Textteil das Foto zu einem Bild des „Tatort[s] der SchleyerEntführung in Köln 1977“.

Solche Beispiele ließen sich leicht vermehren, doch schon diese Auswahl macht deutlich: Darstellungsbedeutungen werden nicht allein durch vergleichbare bildliche Anordnungen konstituiert, sondern werden im kommunikativen Gebrauch von Text-Bild-Zusammenstellungen stabilisiert. Sie entstehen - so kann man unter Rückgriff Ludwig Jägers Konzeption kultureller Semantik formulieren - in intermedialen Transkriptionen (vgl. Jäger 2002, S. 29 ff.). Bestimmte Aspekte eines bildlichen Zeichens bekommen durch die sprachliche Transkription den Status von Skripten, sie werden durch die auf sie bezogenen Textteile lesbar gemacht. Das kann auf der Ebene des wiedererkennbaren Zeigens oder der Ebene des Darstellens geschehen. Doch das Bild ${ }^{24}$ wird durch diese Transkription gerade nicht ersetzt. Es bleibt eine gleichzeitig sichtbare Größe, auf die sich das schriftliche Transkript stützt. Ein entsprechender Textteil transkribiert also nicht nur das Bild, schreibt ihm aktuell einen bestimmten Sinn zu und trägt damit vielleicht im Diskurszusammenhang dazu bei eine Darstellungsbedeutung zu stabilisieren. Er setzt im gleichen Moment darauf, dass dieser Sinn in der Betrachtung des Bildes auch aktuell erfahrbar wird.

Position auf der Seite immer wieder als Zuschreibungen verstanden werden. Darüber hinaus nehmen Überschriften oder weitere Textpassagen in einigen Fällen explizit (etwa über deiktische Ausdrücke), häufiger allerdings implizit (über Beschreibungen von Objekten oder Sachverhalten, die parallel bildlich dargestellt - und in den Bildunterschriften benannt - werden) auf die abgedruckten Bilder Bezug, und werden so als Zuschreibungen lesbar.

24 Als Prätext bzw. Präskript in der Terminologie Jägers, die allerdings mit ihrer schriftsprachlichen Metaphorik an dieser Stelle, die das semiotische Material diesseits des intermedialen Transkriptionsvorgangs bezeichnet, eine linguistisch zwar verbreitete, aber deswegen nicht minder problematische Analogie von Text und Bild stützt (vgl. Steinseifer 2009). 


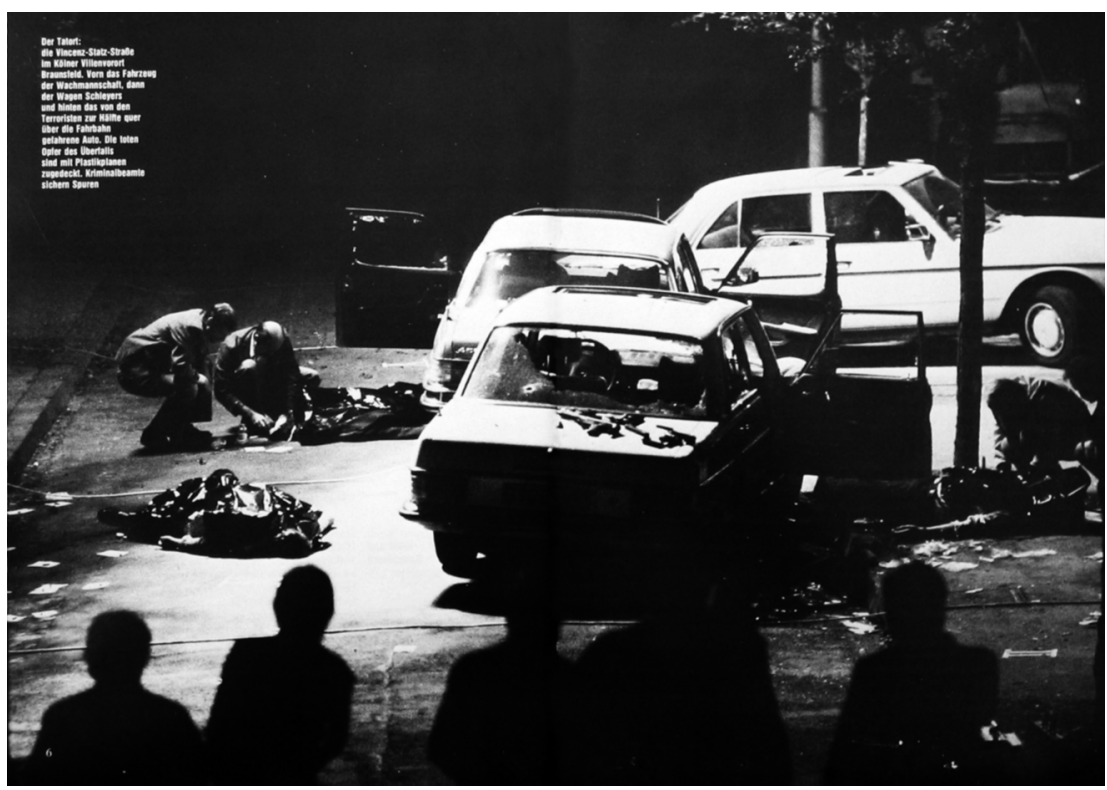

Abb. 8: Hermann/Koch 1977, S. 6-7

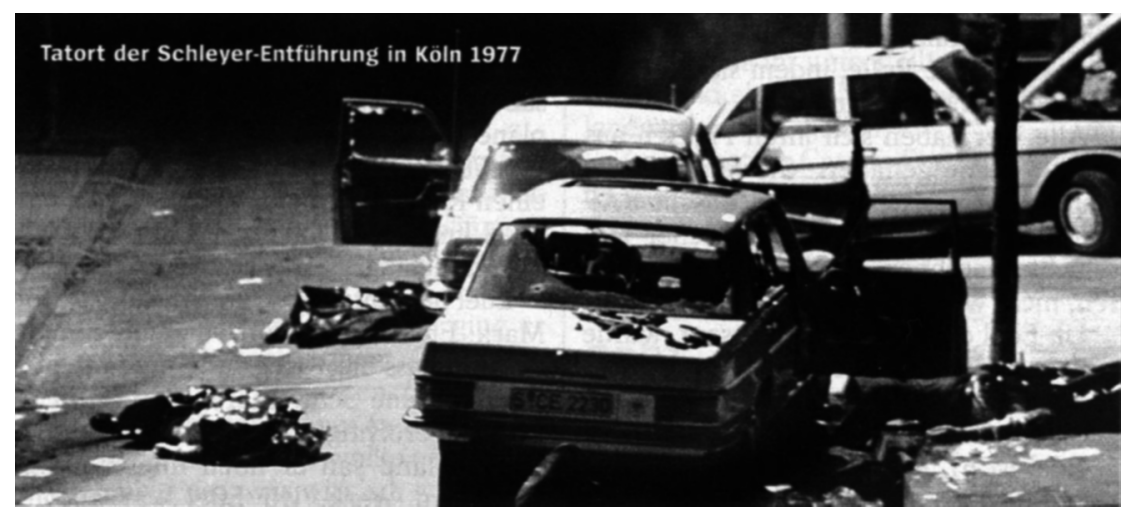

Abb. 9: SPIEGEL 37, 8.9.2008. S. 43 (Ausschnitt)

Dieser umgekehrte Zusammenhang deutet sich bei Jäger an, wenn er davon ausgeht, dass die Skripte, obwohl sie erst in der Transkription konstituiert werden, doch zugleich einen gegenüber dieser autonomen Status bekommen. In Bezug auf Bilder schreibt er, dass ,es gerade die Verwendung der diskursiven Sprache als Transkriptionsmedium ist, die das Bild als Bild in einen interventionsfähigen Skript Status versetzt" (Jäger 2002, S. 34). Die Begründung, die er anschließend gibt, - „deshalb nämlich, weil die diskursive Beschreibungssprache im Hinblick auf die Bildlektüre, die sie vor- 
schlägt, wahrheitswertfähig und insofern hinsichtlich ihrer Angemessenheit befragbar ist." - ist dann aber doch sehr stark von der sprachlichen Seite und dem Geschäft des philosophisch interessierten Interpreten her gedacht. Im massenmedialen Alltag der Vertextung von Bildern und ihrer Rezeption sind Konstellationen, die eine Intervention gegen deutende Zuschreibungen provozieren, selten. Doch auch in den Fällen, in denen eine Angemessenheit der schriftlichen Transkription zu konstatieren ist, hat die gleichzeitige Sichtbarkeit des Bildes, seine mediale Autonomie, einen Effekt. Insofern sie nämlich den zugeschriebenen Sinn nicht zurückweist, sorgt die zusätzliche Anwesenheit der bildlichen Zeichenform dafür, dass die Transkription plausibel erscheint. Die Zusammenstellung mit dem Bild kann so dem sprachlich artikulierten Sinn eine besondere, zusätzliche Überzeugungskraft bzw. Evidenz verleihen. ${ }^{25}$

Diesen Fall von Evidenz, der in der konkreten Text-Bild-Zusammenstellung wirksam wird, bezeichne ich als Prägnan₹. Ich wähle damit bewusst eine Bezeichnung, die linguistisch nur wenig vorbelastet ist, ${ }^{26}$ gleichwohl aber nicht ohne einschlägige Vorgeschichte. Denn Prägnanz ist ein Grundbegriff der Gestalttheorie (vgl. Hüppe 1984), jener zu Beginn des 20. Jahrhunderts entstandenen Richtung der Psychologie, die davon ausgeht, dass die Wahrnehmung immer durch Gestalten orientiert ist, durch phänomenale Ganzheiten, auf die einzelne Wahrnehmungsreize bezogen werden. Die Tendenz, Reizkonstellationen entlang solcher prägnanten Gestalten zu ordnen, konnte in Wahrnehmungsexperimenten mit einfachen geometrischen Formen empirisch bestätigt werden. ${ }^{27}$ Gleichzeitig konnten jedoch die Versuche, die so ausgezeichneten, guten Gestalten' durch Kriterien wie Regelmäßigkeit, Einfachheit bzw. Komplexität oder Symmetrie zu bestimmen, um durch Gestaltgesetze Prägnanzwirkungen vorhersagen zu können, nicht überzeugen, so dass die formalen Kriterien selbst bei einfachen geomet-

25 Nach Jägers Klassifikation handelt es sich um einen Fall von epistemischer Eviden₹ bei der „das semiotische Verfahren, dem sie sich verdankt, unter bestimmten Bedingungen selber unsichtbar bleibt, weil es hinter seiner Evidenz erzeugenden Wirkung verschwindet" (2008, S. 313).

26 Eine Ausnahme ist die Verwendung in der Textverständlichkeitsforschung. In Anlehnung an instruktionspsychologische Arbeiten der 1970er und 1980er Jahre wird mit Prägnanz hier das Verhältnis von semantischer Struktur und dem Umfang der zu ihrer Artikulation verwendeten Zeichen bezeichnet, wobei sowohl eine in Bezug auf eine bestimmte Textfunktion minimal komplexe semantische Struktur als auch ein in Bezug auf diese Struktur minimaler Zeichenaufwand als ökonomisch und damit prägnant gilt (vgl. zusammenfassend Göpferich 2008, bes. S. 303).

27 So konnte z.B. gezeigt werden, dass die Wahrnehmung eines Winkels, dessen Öffnungsgrad kontinuierlich verändert wird, etwa ab einem Öffnungsgrad von $85^{\circ}$ bis zu einem Öffnungsgrad von $95^{\circ}$ als ,ungefähr Rechter Winkel ${ }^{*}$ wahrgenommen wird, und ab einem Öffnungsgrad von $175^{\circ}$ als , leicht abgeknickte Gerade'. Bezugsgrößen wie spitzer, rechter, stumpfer Winkel und Gerade werden daher als Prägnanzstufen bezeichnet (vgl. für weitere Beispiele Hüppe 1984, S. 11 ff.). 
rischen Phänomenen um nicht-formalisierbare semantische Kriterien wie eine vorgeblich größere Bedeutungsfülle der , guten Gestalt' ergänzt wurden (ebd., S. 22 ff.). Diese Einsicht der Gestalttheorie in die Verschränkung von Wahrnehmungseindrücken und Bedeutungszusammenhängen verweist erneut auf die notwendige Verbindung der ikonischen und symbolischen Dimension in der Analyse von Zeichenprozessen. Die Verschränkung von Wahrnehmung und Bedeutung prägte auch die Übernahme des Prägnanzbegriffs in Ernst Cassirers Entwurf einer Philosopbie der symbolischen Formen. Wenn Cassirer unter symbolischer Prägnanz, „die Art [versteht], in der ein Wahrnehmungserlebnis, als ,sinnliches ${ }^{6}$ Erlebnis, zugleich einen bestimmten nicht-anschaulichen Sinn in sich fasst und ihn zur unmittelbaren konkreten Darstellung bringt" (Cassirer [1929] 1954, S. 235), dann verweist der nicht-anschauliche Sinn auf die in der Wahrnehmung immer schon vollzogene, durch die Erfahrung vermittelte Orientierung auf ein Ganzes, das nicht in der Summe der wahrgenommenen Teile und ihrer materiellen Eigenschaften aufgeht. Erfahrung versteht dabei auch Cassier als Form der symbolischen Synthese. Sie ist ein „theoretisches Gefüge“", das allerdings wiederum nur in der Verbindung mit der „konkreten Fülle“ materieller Qualitäten für Prägnanzeffekte sorgt.

Die ,Teilhabe‘ an diesem Gefüge gibt der Erscheinung erst ihre objektive Wirklichkeit und ihre objektive Bestimmtheit. Die ,symbolische Prägnanz', die sie gewinnt, entzieht ihr nichts von ihrer konkreten Fülle; aber sie bildet zugleich die Gewähr dafür, daß diese Fülle nicht einfach verströmt, sondern sich zu einer festen, in sich geschlossenen Form rundet. (ebd., S. 237)

Die hier vorgeschlagene Bestimmung von Prägnanz nimmt die Formorientierung der Gestalttheorie ebenso auf, wie die Verbindung von Gestalt und Gehalt - von Formeigenschaften mit einem Sinn -, ist aber deutlich spezifischer als diejenige Cassirers. Sie reserviert den Terminus für den Fall, dass ein gegenständliches Bild dem, was es in einem immer auch durch Texte konstituierten Diskurs-Zusammenhang mehr oder weniger erwartbar darstellt, zusätzliche Plausibilität verleiht. Je klarer einzelne Textteile in einer Text-Bild-Zusammenstellung - aufgrund ihrer Position oder aufgrund dessen, was sie sprachlich artikulieren - transkriptiv auf ein Bild oder mehrere Bilder zu beziehen sind, umso mehr profitieren sie umgekehrt von Prägnanzeffekten, die von wahrnehmbaren Eigenschaften der Zeichenform der entsprechenden Bilder ausgehen.

Was damit als Prägnanz bezeichnet wird, ist zwar auf den Sinn des jeweiligen Bildes bezogen, es handelt sich aber nicht einfach um eine weitere Stufe der Bedeutung oder der intermedialen Transkription. Die Prägnanz gehört als Evidenzeffekt, der von den sichtbaren Qualitäten des Bildes ausgeht, vielmehr zu den medienspezifischen Bedingungen transkriptiver Prozesse, in denen Bedeutungen fassbar werden. Dabei kommen ikonische 
und symbolische Momente zusammen, indem materielle Eigenschaften der Bildfläche zu Impulsgebern der Semiose werden und auch eine bereits etablierte Bedeutung immer wieder neu stützen. Die obige Grafik ist dann um diese Wechselbeziehung zwischen Bild und Text zu ergänzen. Der Pfeil für die Zuschreibung an das Bild steht dabei dem symbolischen Pol näher, nicht nur da die Schriftzeichen der Texte selbst dominant symbolischen Charakter haben, sondern auch - und in erster Linie - da sie zur symbolischen Stabilisierung der Bildbedeutung beitragen. Der gegenläufige Pfeil für den Prägnanzeffekt des Bildes steht dem ikonischen Pol näher, da die Überzeugungskraft von medienspezifischen Qualitäten ausgeht, von der sichtbaren Form, in der das Bild einen Sinn artikuliert.

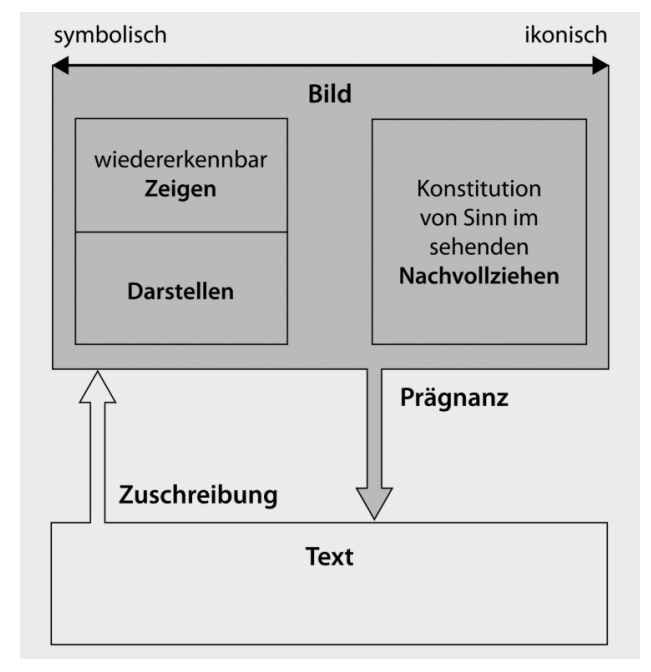

Grafik 2: Der Ort des Prägnanzeffekts in der TextBild-Zusammenstellung

Der Pfeil steht aber mit Absicht eher in der Mitte. Denn in Bezug auf die beiden Pole der Skala lassen sich wiederum idealtypisch zwei Varianten von Prägnanzeffekten unterscheiden. Das Unterscheidungskriterium ist, ob es sich - im Boehmschen Sinn - um die Evidenz eines einzelnen Bildes mit seiner besonderen Anordnung handelt, oder ob von einer bildlichen Anordnung ein Prägnanzeffekt ausgeht, weil sie als konkrete sichtbare Form zugleich ins Schema passt, das heißt: weil sie zum prototypischen Kernbereich der Varianten eins Motivtyps zu zählen ist. Der Unterschied zwischen beiden Varianten lässt sich erneut an den bereits diskutierten Beispielen von Text-Bild-Zusammenstellungen erläutern.

Bei der Text-Bild-Zusammenstellung der SPIEGEL-Titelseite kommt es für einen Prägnanzeffekt zunächst einmal darauf an, dass die ,Bomben in der Bundesrepublik', von denen die Titelzeile handelt, im verwendeten 
Bild erkannt werden können. Dazu wird hier eine bildliche Form gewählt, die typischerweise verwendet wird, um mit einem Bild darzustellen, wie das Gezeigte aussieht: Die thematischen Figuren sind im Zentrum platziert und heben sich vor einem einfarbigen, in diesem Fall orange-roten Hintergrund ab, der den Rest der Bildfläche einnimmt. Bilder, die gemäß diesem weitgehend themenunspezifischen Darstellungsschema aufgebaut sind, finden sich typischerweise in Warenkatalogen oder als Personendarstellungen im Bereich der Bewerbungsfotos. Aber auch im Artikel zur „Bomben in der Bundesrepublik"-Titelseite finden sich weitere entsprechende Darstellungen von „selbstgebastelten Sprengkörper[n]“ (SPIEGEL 23, 29.5.1972, S. 29, Abb. 10), die nicht nur ein Bild davon vermitteln, wie die gezeigten Molotow-Cocktails und Brandbomben aussehen, sondern als prägnante Darstellungen dieser Objekte den Berichten über die Eskalation der Gewalt durch die „,Stadtguerilleros ““ in Gestalt der „Baader-Meinhof-Gruppe“ zusätzlich Nachdruck verleihen.$^{28} \mathrm{Da}$ diese erste Variante von Prägnanzeffekten eng mit dem Erkennen eines Bild-Schemas und seiner Bedeutung - hier dem Darstellen des Aussehens - verbunden ist, kann man auch von schematischer Prägnanz. sprechen. Mit der Dominanz des Schemabezugs hängt auch der befremdliche Effekt zusammen, der im Fall der SPIEGEL-Titelseite entsteht, wenn man den Text der Titelzeile entfernt. Dann sind nämlich kaum noch Bomben zu erkennen. Da sich das Darstellungsschema nämlich dadurch auszeichnet, dass die Figur-Grund-Unterscheidung extrem betont wird, liefert das Bild keine weiteren Verstehenshinweise, sondern setzt voraus, dass man weiß, was das Bild zeigt, dass man den Gegenstand, dessen Aussehen dargestellt wird, wiedererkennen kann. Wenn man für den gezeigten Gegenstand noch kein wahrnehmungsbezogenes Schema ausgebildet hat, gelingt dies nur dank der benennenden Zuschreibung. Daran wird erneut deutlich, dass die Prägnanz, obwohl sie mit wahrnehmbaren Eigenschaften der bildlichen Ausdrucksform zusammenhängt, selbst keine Eigenschaft des Bildes ist, sondern ein inter-medialer Effekt der Bildverwendung.

28 Die Selbstbezeichnungen „Stadtguerrilla“ und „Stadtguerillero“ werden in dem Artikel in distanzierende Anführungszeichen gesetzt, während „Baader-Meinhof-Gruppe“ die im SPIEGEL zu dieser Zeit übliche Fremdbezeichnung für die Rote Armee Fraktion (RAF) ist. Über die für den Terrorismus-Zusammenhang typische Annahme einer Eskalation der Gewalt wird im Artikel des SPIEGEL der Bezug zur Studentenbewegung hergestellt: ,Was einst an Deutschlands Hochschulen als Massenaufstand gegen überkommene Autoritäten und für eine bessere Welt begonnen, die ,Außerparlamentarische Opposition“ (Apo) auf den langen Marsch durch die Institutionen gebracht, Tausende zu Knüppelorgien und Steineschlachten auf die Straße getrieben hatte, mündet endgültig im kriminellen Untergrund. Was mit Transparenten (,Haut den Springer auf die Finger), mit Pudding-, Tomaten-, und Eierwürfen begann, mit Molotow-Cocktails und Brandschatzung (,Burn, warehouse, burn') eskalierte, ist jetzt bei Raub, Mord und Totschlag angekommen." (SPIEGEL 23, 29.5.1972, S. 24-34, hier S. 25). 


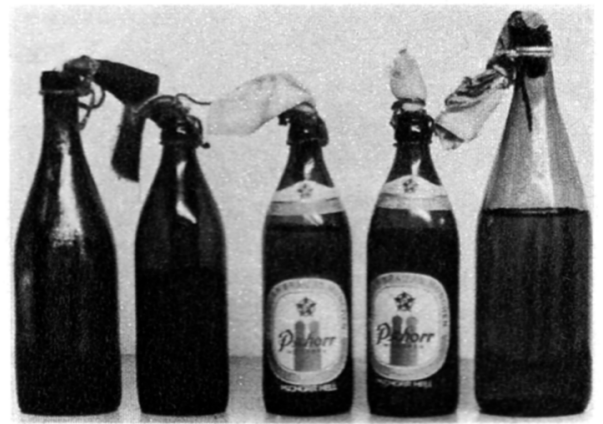

Molotow-Cocktail (Münchner Altersheim)

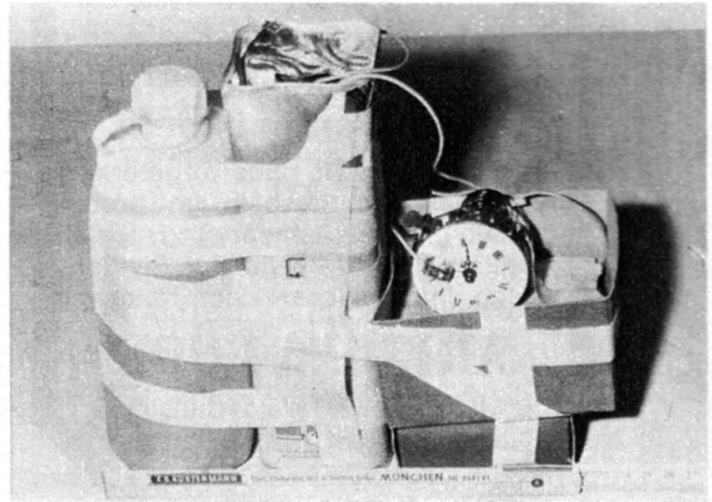

Brandbombe (Münchner Justizgebäude)

Abb. 10: SPIEGEL 23, 29.5.1972, S. 29

Der Vergleich der Bilder des Artikels mit der Titelseite macht neben dem Schema allerdings auch eine Besonderheit des Titelbildes deutlich. Auf dem Titel wird nämlich durch die Art, wie die Gegenstände im Bildfeld positioniert sind, nicht nur das Aussehen der Bomben dargestellt. Zugleich wird auch noch ihre Größe betont, indem sie über den weißen Rahmen, der üblicherweise das Titelbild begrenzt, hinausreichen, den SPIEGEL-Schriftzug überlagern und rechts an den Rand der Bildfläche stoßen. Diese Betonung der Größe erfolgt mit bildlichen Mitteln, die ebenso konventionell sind, wie sie nur anhand der jeweils sichtbaren Konstellation nachvollziehbar werden. Man kann diese Positionierung im Bild als Betonung der Bedrohung, die von den ,Bomben in der Bundesrepublik ${ }^{6}$ ausgeht, verstehen: Sie sprengen gleichsam den Rahmen. Und man kommt dann in den Bereich der zweiten ikonischen Variante der Prägnanz. Man muss das Bild aber nicht so verstehen, damit es im Bezug auf den Text qua Schema einen verstärkenden Effekt hat und für Prägnanz sorgt. 
Auch das STERN-Bild vom Ort der Entführung in Köln war bereits auf ein Darstellungsschema bezogen worden, das im diskursiven Zusammenhang von "Terrorismus" relevant ist: Es stellt einen Tatort dar, indem es eine Reihe von Dingen in einer bestimmten Konstellation zeigt. Dabei war schon angedeutet worden, dass es sich nicht einfach nur um eine dem Schema entsprechende Tatortdarstellung handelt, sondern dass - mehr noch als bei den Bomben des SPIEGEL-Titels - die konkrete bildliche Form einen pragmatischen Mehrwert bietet. Das Bild macht durch die Positionierung der Gegenstände im Bildfeld zugleich das ,Attentat' in seinem Verlauf nachvollziehbar. Das Bild, so könnte man nun sagen, ,übererfülltt damit das Darstellungsschema und wird im Zusammenhang ikonisch prägnant. Diese ikonische Prägnanz wird im Vergleich mit einem weiteren Bild deutlich, das denselben Tatort darstellt (Abb. 11). Es handelt sich um eine Fotografie, die am Tag nach dem Attentat auf der Titelseite der BILD-Zeitung abgebildet war.

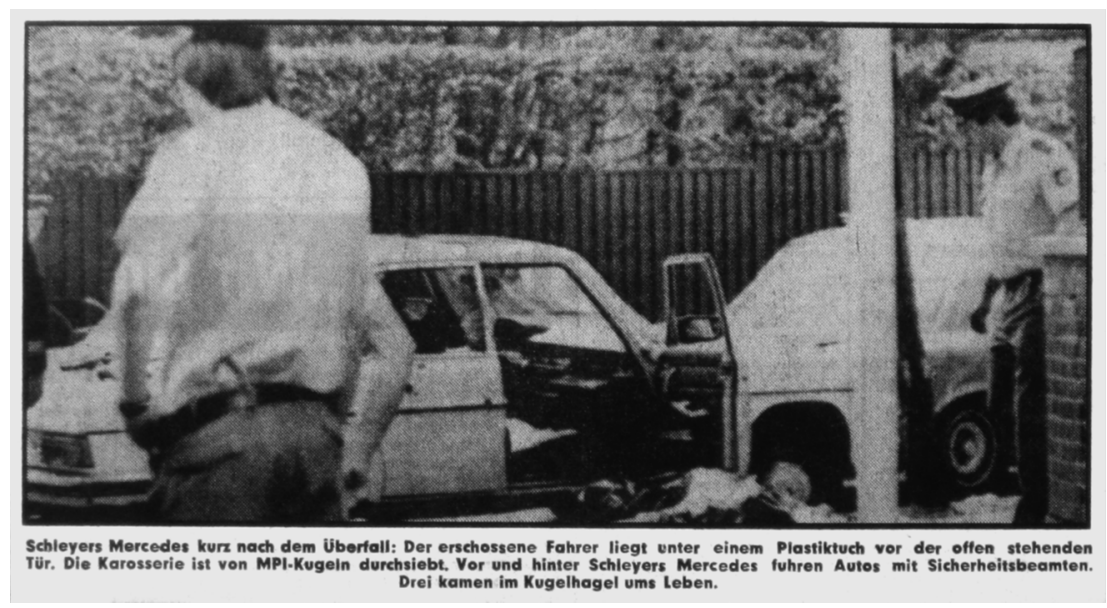

Abb. 11: BILD-Zeitung (Druck in Frankfurt), 6.9.1977, S. 1 (Ausschnitt)

Auch bei dieser Fotografie sind Autos, Leiche und Polizisten so zusammengestellt, dass das Bild gemäß dem Tatort-Schema interpretiert werden kann. Doch wird in der dargebotenen Seitenansicht auf zwei der Fahrzeuge von der Beifahrerseite der Tatverlauf gerade nicht nachvollziehbar, der auch hier in der Bildunterschrift angedeutet wird. Beim STERN-Foto ließ sich die Kreuzung von vertikalen und horizontalen Linien im Bild auf den Moment der Entführung Schleyers beziehen, bei dem seine Wagenkolonne gestoppt und seine Begleiter erschossen wurden. Beim Foto aus der BILDZeitung ist etwa die dominante weiße Linie, die das Bild im rechten Fünftel vertikal durchzieht, nicht in vergleichbarer Weise motivierbar. Sie ist allenfalls als Ausschnitt aus einem Laternenpfahl im Vordergrund erkenn- und so auf der Ebene des Zeigens interpretierbar. Im Bildzusammenhang 
durchschneidet sie jedoch die relevante Blickachse des rechts zu erkennenden Polizisten, durch die die Aufmerksamkeit auf die abgedeckte Leiche am unteren Rand gelenkt wird. Der oberflächennahe Vergleich von sichtbaren Eigenschaften - von Linienzügen und ihrer Anordnung im Rahmen der Bildfläche - liefert also Hinweise auf ein im Diskurszusammenhang unterschiedliches bildliches Überzeugungspotenzial der beiden Darstellungen desselben Tatorts. Dieser bildanalytisch gewonnene Befund wird durch die Verwendungsgeschichte der Bilder gestützt. Während das Foto der BILD-Zeitung nur dieses eine Mal erschien, werden Varianten des STERN-Fotos bis heute als Bilder des Ereignisses wiederverwendet. ${ }^{29}$ Die Tatsache, dass es gerade dieses Tatortbild ist, das bis heute als diskursiver Index ${ }^{30}$ funktioniert - als Bild, das verwendet wird, um das Ereignis der Schleyer-Entführung, die Ereignisse des sogenannten „Deutschen Herbstes“ oder gleich den ganzen Terrorismus-Zusammenhang der 1970er Jahre aufzurufen -, ist ein diskursgeschichtliches Indiz für das unterschiedliche Prägnanzpotenzial, das mit der sichtbaren Form der beiden Bilder verbunden ist.

Bei Peirce heißt es an einer Stelle im Hinblick auf das ikonische Zeichen, dass „durch seine direkte Beobachtung andere Wahrheiten über sein Objekt entdeckt werden können als jene, die für seine Konstruktion hinreichend waren". ${ }^{31}$ Diese Stelle kann man im vorliegenden Zusammenhang auch so verstehen, dass von der konkreten Ausdrucksform und ihren wahrnehmbaren Eigenschaften im Zeichenzusammenhang ein pragmatischer Mehrwert ausgehen kann, der nicht auf die Zuordnung zu einem symbolischen Schema reduzierbar ist. Dieser Fall kann daher als ikonische Prägnanz bezeichnet werden. Das Bild aus dem STERN mag einfach als Darstellung eines Tatorts entstanden sein. Die konkrete bildliche Gestalt ermöglicht es aber, in ihm mehr zu sehen. Sie ermöglicht es, anhand des statischen Bildes zugleich den Geschehensverlauf nachzuvollziehen. Die Pressefotografie entspricht also nicht nur dem Tatort-Schema, sondern wird aufgrund ihrer ikonischen Qualitäten in späteren Verwendungen zum diskursiven Index, zum Ereignisbild.

29 Ein Beispiel für eine solche Verwendung wurde oben bereits erwähnt (Abb. 9). Weitere Beispiele sind die Abbildungen auf den Umschlägen des Buchs zu Heinrich Breloers TV-Dokudrama Todessspiel (Köln 1997) und zu Anne Siemens' Geschichte des Terrorismus der 1970er Jahre aus der Perspektive der Opfer (Für die RAF war er das System, für mich der Vater. München 2007), sowie die Verwendung als einzige Abbildung im Abschnitt Terrorismus von Hermann Glasers Deutsche Kultur. Ein bistorischer Überblick von 1945 bis zur Gegenwart (München/Wien 1997, S. 325).

30 Vgl. zur Begründung dieses Terminus als einer semio-pragmatisch konsistenten Alternative zur verbreiteten Bezeichnung so verwendeter Bilder als (Foto-)Ikonen Steinseifer (im Erscheinen).

31 Peirce (1986, S. 250 f.) (Über die Einheit hypothetischer und kategorischer Propositionen, MS 787, 1897). 
Betrachtet man die Analysen zu den unterschiedlichen Ausprägungen von Prägnanzeffekten unter methodologischen Gesichtspunkten, zeigt sich noch einmal die pragmatische Grundorientierung der vorgeschlagenen Annäherung an die medienspezifische Wirkungsweise von Bildern in ihrer $\mathrm{Zu}$ sammenstellung mit Texten. Denn sowohl bei der schematischen wie auch bei der ikonischen Prägnanz ist eine Bestimmung des jeweiligen Effekts nur im Verwendungszusammenhang möglich: Unter Verwendungszusammenhang ist dabei zum einen die Zusammenstellung von Bild und Text im jeweiligen Kommunikationsangebot zu verstehen, in der transkriptiv ein Darstellungssinn fixiert wird, ${ }^{32}$ und zum anderen der größere Diskurszusammenhang, in dem einer als relevant etablierten und auch sprachlich artikulierbaren Bedeutung durch ein konkretes Bild zusätzliche Überzeugungskraft verliehen wird. Die mediale Wirkungsweise von Bildern wird in dem skizzierten theoretischen Rahmen also rekonstruktiv ${ }^{33}$ fassbar, indem zwei analytische Schritte methodisch miteinander verbunden werden: Das einzelne Bild wird zunächst einmal diskursanalytisch auf den kommunikativen Zusammenhang mit seinen Darstellungsschemata und transkriptiv etablierten Bedeutungen bezogen. Auf dieser Basis kann der formanalytische Vergleich mehrerer Bilder verdeutlichen, ob sie in den Text-Bild-Zusammenstellungen schematisch prägnant wirken und in welchem Maße sie darüber hinaus über ein ikonisches Prägnanzpotenzial verfügen.

\section{Effekte diesseits der Bilder - Ausblick auf eine pragmatische Phänomenologie}

Nach diesen Überlegungen zur Analyse von Prägnanzeffekten in Text-BildZusammenstellungen soll der Blick abschließend noch einmal zurück auf die Sprache gelenkt werden. Denn man kann sich fragen: Gibt es auch bei sprachlichen Zeichen vergleichbare Effekte der wahrnehmbaren Zeichenform, die für die Verwendung konstitutiv sind, die sich aber nicht einfach semantisch fassen lassen? Der nächstliegende Bereich, in dem man diese Frage stellen kann, ist sicher die visuelle Gestalt schriftlicher Texte. Das ist ein Bereich, der zusammen mit demjenigen der Text-Bild-Zusammenstellungen in letzter Zeit ebenfalls zunehmend die Aufmerksamkeit der Textlinguistik findet. Da Textseiten wie Bilder zweidimensionale visuelle Objekte sind, können Layoutphänomene gleichsam als bildliche Seite von Texten angesehen werden. Entsprechend heißt es bei Christa Dürscheid (2008, S. 273): „Weiter kann man den Standpunkt vertreten, dass Texte allein aufgrund ihres Layouts Bildcharakter haben." Schon der unmittelbar folgende Satz

\footnotetext{
32 Siehe erneut oben Anm. 23.

33 In Hausendorfs Sinn einer „Rekonstruktion des Prozesses der Textkonstitution“ (2008, S. 323).
} 
macht allerdings deutlich, dass der Zugriff auf diesen Bildcharakter zunächst einmal ganz selbstverständlich in einem semantischen Rahmen erfolgt, und in dem die Eigenständigkeit des bildlichen Moments als Konnotation gefasst wird: „Dieses ,Textbild“ stellt eine eigene, konnotative Bedeutungsebene dar, die den Text gewissermaßen überlagert.“

Eine semantische Analyse von Layoutphänomenen ist vielen Fällen möglich und es gibt darunter auch solche, in denen deren Eigenständigkeit so schwach ausgeprägt ist, dass kaum von einer konnotativen Bedeutungsebene auszugehen ist: Etwa bei Spiegelstrichen, die zusammen mit Einrückungen und Absätzen als Gliederungssignal für eine Reihe gleich gewichteter Aspekte stehen. Sie bilden als festgelegtes typographisches Element sogar den Ausgangs- und Bezugspunkt weitergehender sprachlicher Grammatikalisierungen, worauf Kirsten Adamzik (1995) schon vor einigen Jahren unter dem Stichwort, graphischer Stil' hingewiesen hat. Ähnliches ließe sich für Überschriften und ihr Verhältnis zum jeweiligen Haupttext zeigen.

Wenn man allerdings ganze Zeitungsseiten in den Blick nimmt, dann stoßen solche eher sprachanalogen semantischen Analysen - wie sie etwa Gunter Kress und Theo van Leeuwen im Rahmen ihrer critical layout analysis (1998) vorschlagen - an ihre Grenzen. Denn auf dieser Ebene kommen neben schematisierten Bedeutungen wiederum verstärkt Wirkungen ins Spiel, die von der konkreten Anordnung ausgehen (siehe auch Spitzmüller in diesem Band) und die auch mit Hilfe des Konnotationsbegriffs kaum zu erfassen sind. Das deutet sich auch bei Stöckl, dessen Überlegungen zu einer linguistischen Analyse der typographischen Gestalt von Texten ebenfalls semantisch ansetzen, an, wenn er schreibt:

Typographie ist relativ eng an die Funktionsweise von Sprache bzw. an den Text gebunden. Typographische Ressourcen überformen und wirken zurück auf die sprachlichen - sie operieren über dem kommunikativ-pragmatischen Phänomen Text, er ist ihr Wirkungsrabmen. (2004b, S. 21; Hervorhebung durch den Autor)

Ich möchte daher im Rahmen einer pragmatischen „Semiotik der Textgestalt“ (Raible 1991), von der Wolfgang Raible bereits vor fast 20 Jahren sprach, im Zusammenhang mit Layoutfragen ebenfalls für eine Phänomenologie der Zeichenform plädieren. Eine solche phänomenologische Perspektive, wie sie auch Heiko Hausendorf und Wolfgang Kesselheim (2008, S. 18) im Rahmen ihres textlinguistischen Entwurfs einfordern, müsste ergänzend zur ,Semantik ${ }^{6}$ einzelner Layoutelemente die mediale Wirkungsweise der sichtbaren Zeichenform stärker berücksichtigen. Dabei würde ich erneut zwei Varianten von Effekten unterscheiden, die den beiden Formen der Prägnanz entsprechen.

Das Layout einer Seite kann allein darin ,effektiv' sein, dass es durch die Gestaltung und Platzierung einzelner Textelemente die sichtbaren Differenzen bereitstellt, die nötig sind, um ein Erfassen der Textstruktur möglich 
zu machen: Die bereits erwähnten Spiegelstriche dürfen trotz der mit ihnen verbundenen grammatischen Besonderheiten als Layoutelemente nicht im Textblock untergehen, sondern um als spracbliche Gliederungshinweise funktionieren zu können, müssen sie visuell abgesetzt sein. Ist diese Bedingung erfüllt, dann kann man von einem funktional angemessenen Layout sprechen, wobei die Angemessenheit sich immer einerseits an domänenspezifischen Standards der Gestaltung - oder an „typographischen Dispositiven“, wie Stöckl (2004b, S. 43) es nennt - bemisst und andererseits am Sinn des jeweiligen Textes. Im Fall der STERN-Seite (Abb. 2) erlaubt etwa allein die Größe der Schrifttypen und die relative Position eine Unterscheidung von Überschrift und Leadtext, auch wenn die Überschrift „Das Attentat in Köln“ nicht über, sondern neben diesem Text am unteren Seitenrand steht. Dadurch werden beide allerdings zugleich auch - gemäß einem weiteren Schema - als Bildunterschriften lesbar. Die Effekte des Seitenlayouts können aber auch über eine solche textfunktionale Angemessenheit hinausgehen. Im SPIEGEL-Beispiel (Abb. 1) erlauben es die gewählten Schriftgrößen, -typen, -farben und Positionen zunächst einmal ebenfalls, den einzelnen Textteilen eine funktionale Bedeutung zuzuordnen, die dem Schema der Titelseite entspricht. Zugleich ist jedoch die spezifische Anordnung der Titelzeile nicht allein qua Angemessenheit im Rahmen dieses Schemas zu verstehen. Die Differenz in Größe und Farbe zwischen dem Substantiv Bomben und der folgenden Ortsangabe in der Bundesrepublik ist zwar schematisch betrachtet eine Gewichtung, die mit der syntaktischen Struktur korrespondiert. In besonderer Weise wirksam wird sie aber erst im konkreten Seitenzusammenhang, der in diesem Fall visuell durch das hinterlegte Bild der Bomben strukturiert wird. Das gilt noch einmal besonders für die Trennung des Wortes Bundesrepublik. Diese ist nämlich weder semantisch motiviert noch wäre sie satztechnisch notwendig - in der Zeile wäre ja noch genug Platz (vgl. Abb. 12). Plausibel wirkt sie allein durch ihre Position auf der Seite, denn hier ist sie auf die Kontur einer der Bomben bezogen. Während eine durchlaufende Zeile eher die Flächigkeit der Seite betonen würde, verstärkt der Zeilenumbruch die räumliche Wirkung der ,formatsprengenden 'Bomben und damit die Bedrohung für die Bundesrepublik, die von ihnen ausgeht.

Solche Effekte der Anordnung sind aber nicht auf den Fall beschränkt, dass ein Bild als visueller Bezugspunkt dient. Ein Beispiel dafür bietet die Titelseite der BILD-Zeitung vom 13. Mai 1972 (Abb. 13), auf der unter der Schlagzeile „Bomben-Terror“ über dieselben Gewalt-Ereignisse berichtet wird wie im SPIEGEL-Heft. Interessant am Layout der Seite sind besonders die vier gerahmten Textfelder unter der Titelzeile, die - das verdeutlicht ein weiterer Rahmen - zum selben Artikelzusammenhang gehören. Die vier Textfelder sind jeweils ähnlich aufgebaut. Sie bestehen aus einem schwarz hinterlegten oberen Teil, in dem jeweils in weiß der Name einer 

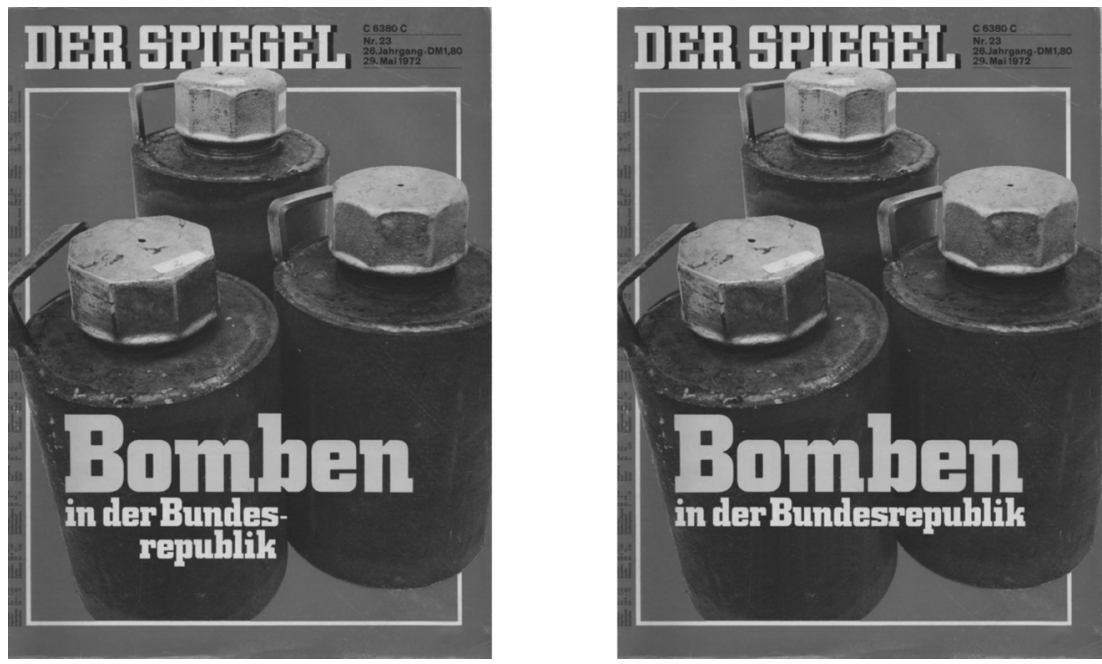

Abb. 12: SPIEGEL 23, .5.1972, Titel: links original, rechts modifiziert

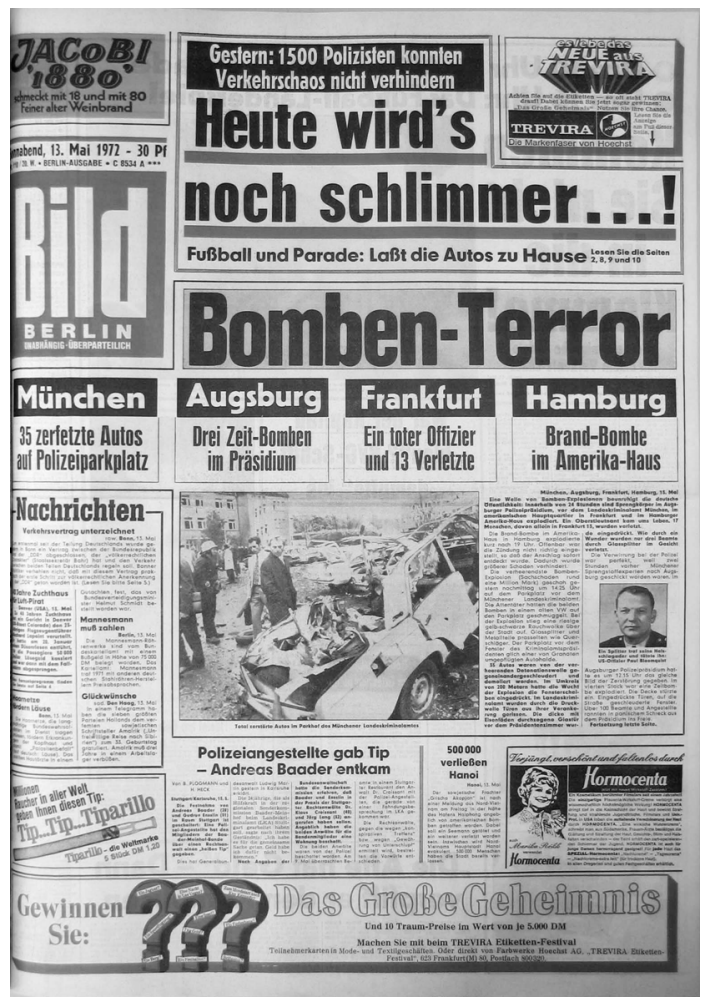

Abb. 13: BILD-Zeitung (Berlin-Ausgabe), 13.5.1972, S. 1 
Großstadt zu lesen ist und einem durch eine feine Rahmenlinie damit verbundenen unteren Teil, in dem in jeweils zwei Textzeilen auf einen Anschlag eingegangen wird, der - so ist diese Konstellation zu verstehen - in dieser Stadt stattgefunden hat. Die Felder können daher in textfunktionaler Hinsicht als visuelle Alternative zu Spiegelstrichen angesehen werden, ermöglichen sie doch wie diese die reihende Anordnung von Aspekten. Doch visuell nimmt die Reihe in Form der Kästen die ganze Breite der Seite ein sie greift nach links sogar über die Überschrift hinaus - und die Namen der Anschlagsorte sind durch Position und Farbgestaltung hervorgehoben. Durch diese Anordnung wird mit visuellen Mitteln die Gleichreitigkeit und die weite räumliche Verteilung der Anschläge deutlich gemacht und so die ubiquitäre Bedrohung durch ,Bombenterror ${ }^{6}$ - überall, jederzeit kann ein Anschlag verübt werden - im Seitenzusammenhang plausibel, auch ohne dass diese Behauptung mit sprachlichen Mitteln explizit formuliert werden muss.

Diese letzten Beispiele können nur andeuten, in welcher Weise nicht nur die kommunikative Verwendung von Bildern, sondern auch diejenige der Schrift in Texten durch die sichtbare Form der artikulierten Zeichen ,ikonisch ' mitbestimmt ist. Die vorgeschlagene phänomenologische Perspektive bietet die Möglichkeit, bei Layoutanalysen neben der Semantik einzelner Elemente die auf die Ausdrucksform bezogenen Wirkungszusammenhänge zu berücksichtigen. Gerade die Beschäftigung mit Bildern und ihren Besonderheiten kann also die pragmatische Linguistik - auf theoretischer wie methodologischer Ebene - zu einer konsequenteren Berücksichtigung der medialen Dimension von Sprache und Kommunikation hinführen. Um diesen Effekt zu erreichen, muss der Rahmen einer linguistischen Phänomenologie, der im vorliegenden Beitrag skizziert wurde, allerdings ebenso synchron und diachron durch weitere Untersuchungen an Material aus anderen Kommunikationsbereichen ausgefüllt werden, wie er im Zuge solcher Untersuchungen zu differenzieren und zu erweitern ist.

\section{Literatur}

Adamzik, Kirsten (1995): Syntax und Textgliederung. Hypotaktischer Stil, Nominalstil und graphischer Stil. In: Hindelang, Götz (Hg.): Der Gebrauch der Sprache. Festschrift für Franz Hundsnurscher zum 60. Geburtstag. Münster, S. 15-42.

Bal, Mieke (2003): Visual essentialism and the object of visual culture. In: Journal of Visual Culture 2, 1, S. 5-32.

Barthes, Roland ([1964] 1990): Rhetorik des Bildes. In: Barthes, Roland: Der entgegenkommende und der stumpfe Sinn. Kritische Essays III. Frankfurt a.M., S. $28-46$. [Zuerst in: Communications 4 (1964), S. 40-51].

Barthes, Roland ([1980] 1985): Die Helle Kammer. Bemerkung zur Photographie. Frankfurt a.M. [Zuerst: La chambre claire. Note sur la photographie. Paris 1980]. 
Belting, Hans (2001): Bild-Anthropologie - Entwürfe für eine Bildwissenschaft. München.

Boehm, Gottfried (1978): Zu einer Hermeneutik des Bildes. In: Gadamer, Hans-Georg/Boehm, Gottfried (Hg.): Seminar: Die Hermeneutik und die Wissenschaften. Frankfurt a.M., S. 444-471.

Boehm, Gottfried (1994): Die Wiederkehr der Bilder. In: Boehm, Gottfried (Hg.): Was ist ein Bild? München, S. 11-38.

Boehm, Gottfried (1999): Vom Medium zum Bild. In: Spielmann, Yvonne/Winter, Gundolf (Hg.): Bild - Medium - Kunst. München, S. 165-178.

Boehm, Gottfried (2007a): Wie Bilder Sinn erzeugen. Die Macht des Zeigens. Berlin.

Boehm, Gottfried ([2004] 2007b): Jenseits der Sprache. Anmerkungen zur Logik der Bilder. In: Boehm (2007a), S. 34-73. [Zuerst in: Maar, Christa/Burda, Hubert (Hg.): Iconic Turn. Die neue Macht der Bilder. Köln 2004, S. 28-43].

Bredekamp, Horst (2003): A neglected tradition? Art history as "Bildwissenschaft". In: Critical Inquiry 29, 3, S. 418-428.

Brink, Cornelia (1998): Ikonen der Vernichtung. Öffentlicher Gebrauch von Fotografien aus nationalsozialistischen Konzentrationslagern nach 1945. (= Schriftenreihe des Fritz-Bauer-Instituts 14). Berlin.

Cassirer, Ernst ([1929] 1954): Philosophie der symbolischen Formen. Dritter Teil: Phänomenologie der Erkenntnis. Darmstadt. [Zuerst: Berlin 1929].

Dürscheid, Christa (2008): Schrift - Text - Bild: Ein Brückenschlag. In: Zeitschrift für germanistische Linguistik 35, 3, S. 269-282.

Elkins, James (2003): Visual studies: a skeptical introduction. New York u.a.

Fehrmann, Gisela/Linz, Erika (2008): Der hypnotische Blick. Zur kommunikativen Funktion deiktischer Zeichen. In: Wenzel/Jäger (Hg.), S. 261-288.

Fix, Ulla (1996): Textstile und KonTextstile. Stil in der Kommunikation als umfassende Semiose von Sprachlichem, Parasprachlichem und Außersprachlichem. In: Fix, Ulla/ Lerchner, Gotthard (Hg.): Stil und Stilwandel. (= Leipziger Arbeiten zur Sprachund Kommunikationsgeschichte 3). Frankfurt a.M., S. 111-132.

Göpferich, Susanne (2008): Textverstehen und Textverständlichkeit. In: Janich, Nina (Hg.): Textlinguistik. 15 Einführungen. Tübingen, S. 291-312.

Hausendorf, Heiko (2008): Zwischen Linguistik und Literaturwissenschaft: Textualität revisited. Mit Illustrationen aus der Welt der Urlaubsansichtskarte. In: Zeitschrift für germanistische Linguistik 36, 3, S. 319-342.

Hausendorf, Heiko/Kesselheim, Wolfgang (2008): Textlinguistik fürs Examen. (= Linguistik fürs Examen 5). Göttingen.

Hermann, Kai/Koch, Peter (1977): Entscheidung in Mogadischu: die 50 Tage nach Schleyers Entführung. Dokumente, Bilder, Zeugen. Hamburg.

Holly, Werner (2005): Zum Zusammenspiel von Sprache und Bildern im audiovisuellen Verstehen. In: Busse, Dietrich/Niehr, Thomas/Wengeler, Martin (Hg.): Brisante Semantik. Neuere Konzepte und Forschungsergebnisse einer kulturwissenschaftlichen Semantik. (= Reihe germanistische Linguistik 259). Tübingen, S. 373-353. 
Holly, Werner (2009): Der Wort-Bild-Reißverschluss. Über die performative Dynamik der audiovisuellen Transkriptivität. In: Feilke, Helmuth/Linke, Angelika (Hg.): Oberfläche und Performanz. (= Reihe germanistische Linguistik 283). Tübingen, S. 93-110.

Hüppe, Angelika (1984): Prägnanz - Ein gestalttheoretischer Grundbegriff. Experimentelle Untersuchungen. München.

Husserl, Edmund ([1913] 1992): Ideen zu einer reinen Phänomenologie. (= Gesammelte Schriften 5). Hamburg. [Zuerst: Halle 1913].

Imdahl, Max ([1980] 1996): Kontingenz - Komposition - Providenz. Zur Anschauung eines Bildes von Giotto. In: Imdahl, Max: Gesammelte Schriften. Bd. 3: Reflexion - Theorie - Methode. Hrsg. v. Gottfried Boehm. Frankfurt a.M., S. 464-500. [Zuerst in: neue hefte für philosophie 18-19 (1980), S. 151-177].

Jäger, Ludwig (2002): Transkriptivität. Zur medialen Logik der kulturellen Semantik. In: Jäger, Ludwig/Stanitzek, Georg (Hg.): Transkribieren - Medien/Lektüre. München, S. 19-41.

Jäger, Ludwig (2008): Indexikalität und Evidenz. Skizze zum Verhältnis von referentieller und inferentieller Bezugnahme. In: Wenzel/Jäger (Hg.), S. 289-315.

Kemp, Wolfgang ([1985] 1996): Kunstwerk und Betrachter: Der rezeptionsästhetische Ansatz. In: Belting, Hans et al. (Hg.): Kunstgeschichte. Eine Einführung. 5., überarb. Aufl. Berlin, S. 240-257. [1. Aufl. Berlin 1985].

Koetzle, Hans-Michael (2002): Photo Icons. Die Geschichte hinter den Bildern. 1827 1991. 2 Bde. Köln.

Kraushaar, Wolfgang (Hg.) (2006): Die RAF und der Linke Terrorismus. 2 Bde. Hamburg.

Kress, Gunther/van Leeuwen, Theo (1996): Reading images. The grammar of visual design. London/New York.

Kress, Gunther/van Leeuwen, Theo (1998): Front pages: (The critical) analysis of newspaper layout. In: Bell, Alan/Garrett, Peter (Hg.): Approaches to media discourse. Oxford, S. 186-219.

Linke, Angelika/Nussbaumer, Markus/Portmann, Paul R. (2004): Studienbuch Linguistik. 5., erw. Aufl. (= Reihe germanistische Linguistik 121). Tübingen.

Lohmar, Dieter (1993): Grundzüge eines Synthesis-Modells der Auffassung: Kant und Husserl über den Ordnungsgrad sinnlicher Vorgegebenheiten und die Elemente einer Phänomenologie der Auffassung. In: Husserl-Studies 10, S. 111-141.

Mitchell, W.J. Thomas (1994): Picture theory. Essays on verbal and visual representation. Chicago/London.

Muckenhaupt, Manfred (1986): Text und Bild: Grundfragen der Beschreibung von TextBild-Kommunikationen. (= Tübinger Beiträge zur Linguistik 271). Tübingen.

Nöth, Winfried (2000): Handbuch der Semiotik. 2., vollst. neu bearb. u. erw. Aufl. mit 89 Abbildungen. Stuttgart/Weimar.

Peirce, Charles Sanders (1983): Phänomen und Logik der Zeichen. Herausgegeben und übersetzt von Helmut Pape. Frankfurt a.M. 
Peirce, Charles Sanders (1986): Semiotische Schriften. Bd. 1. Frankfurt a.M.

Raible, Wolfgang (1991): Die Semiotik der Textgestalt. Erscheinungsformen und Folgen eines kulturellen Evolutionsprozesses. Heidelberg.

Sachs-Hombach, Klaus (2003): Das Bild als kommunikatives Medium. Elemente einer allgemeinen Bildwissenschaft. Köln.

Schmidt, Siegfried J. ([1980] 1991): Grundriß der Empirischen Literaturwissenschaft. Frankfurt a.M. [Zuerst: Braunschweig 1980].

Schmitz, Ulrich (2003): Lesebilder im Internet. Neue Koalitionen und Metamorphosen zwischen Text und Bild. In: Zeitschrift für Germanistik. Neue Folge 3, S. $605-628$.

Schmitz, Ulrich (2005): Blind für Bilder. Warum sogar Sprachwissenschaftler auch Bilder betrachten müssen. In: Osnabrücker Beiträge zur Sprachtheorie 69, S.187-227.

Schmitz, Ulrich (2008): Bildakte? How to do Things with Pictures. In: Zeitschrift für Germanistische Linguistik 35, 3, S. 419-433.

Schmitz, Ulrich/Wenzel, Horst (Hg.) (2003): Wissen und neue Medien. Bilder und Zeichen von 800 bis 2000. (= Philologische Studien und Quellen 177). Berlin.

Sonesson, Göran (1993): Die Semiotik des Bildes: Zum Forschungsstand am Anfang der 90er Jahre. In: Zeitschrift für Semiotik 15/1-2, S. 127-160.

Spitzmüller, Jürgen (i.d.Bd.): Typografische Variation und (Inter-)Medialität. Zur kommunikativen Relevanz skripturaler Sichtbarkeit.

Steinseifer, Martin (2009): Sichtbar verkörperte Artikulationen - Was wird aus dem Text(-Begriff) angesichts der Konjunktur des Performativen? In: Buss, Mareike et al. (Hg.): Theatralität des sprachlichen Handelns. Eine Metaphorik zwischen Linguistik und Kulturwissenschaften. München, S. 143-163.

Steinseifer, Martin (i.Ersch.): Ereignisbilder - Zum Verhältnis von Indexikalität, Symbolizität und Ikonizität bei Pressefotografien. In: Boehm, Gottfried/Egenhofer, Sebastian/Spies, Christian (Hg.): Zeigen. Die Rhetorik des Sichtbaren. München.

Stöckl, Hartmut (2004a): Die Sprache im Bild - Das Bild in der Sprache. Zur Verknüpfung von Sprache und Bild im massenmedialen Text. (= Linguistik - Impulse \& Tendenzen 3). Berlin/New York.

Stöckl, Hartmut (2004b): Typographie: Gewand und Körper des Textes - Linguistische Überlegungen zu typographischer Gestaltung. In: Zeitschrift für Angewandte Linguistik 41, S. 5-48.

Wenzel, Horst/Jäger, Ludwig (Hg.) (2008): Deixis und Evidenz. (= Rombach Wissenschaften, Reihe Scenae 8). Freiburg i.Br.

Wiesing, Lambert (2005): Artifizielle Präsenz. Studien zur Philosophie des Bildes. Frankfurt a.M. 
Werner Holly

\title{
Besprochene Bilder - bebildertes Sprechen Audiovisuelle Transkriptivität in Nachrichtenfilmen und Polit-Talkshows
}

\begin{abstract}
Als eine wichtige Form der intermedialen Einbindung von Sprache wird technisch kombinierte (,sekundäre“) Audiovisualität beschrieben, wie sie prototypisch im Fernsehen vorkommt. Nach allgemeinen Strukturen von sekundärer Audiovisualität wird der Begriff der Transkriptivität (nach Jäger) kurz dargestellt: das „AndersLesbar-Machen“ von Zeichen im gleichen oder einem anderen Zeichensystem. Danach werden zwei Spielarten von Fernsehaudiovisualität behandelt: Nachrichtenfilme als Zusammenspiel von Sprechertext mit vorgefertigten Bildsequenzen, nach bestimmten Mustern von wechselseitiger Transkription, die Anforderungen der Darstellbarkeit und Glaubwürdigkeit genügen sollen. In Polit-Talkshows werden die Sprecherbeiträge von Kamerainszenierungen mit drei Funktionen transkribiert: (a) Abwechslung und Gliederung, (b) Sprecherprofilierung und (c) Profilierung von Beteiligungsrollen anderer Teilnehmer.
\end{abstract}

\section{Sprache pur? Sprache medial und intermedial}

Das Thema dieses Bandes: „Sprache intermedial: Stimme und Schrift, Bild und Ton" gibt zu denken. Dass sich Sprachwissenschaft auch für Stimme und Schrift interessiert, ist noch nicht weiter verwunderlich, obgleich in der Geschichte der Disziplin bekanntlich über weite Strecken ausgeblendet war, dass Sprache nicht nur geschriebene Sprache ist, womit außer der gesprochenen Sprache auch gleich die Spezifik der geschriebenen Sprache aus dem Blick geraten war. Sprache wurde viel zu lange wie ein amediales Etwas behandelt. Immerhin hat die Differenz von Schriftlichkeit und Mündlichkeit inzwischen die Dignität eines Handbuchgegenstands erreicht. Aber wie können Bild und Ton (also auch nicht-stimmlicher Ton) zum Gegenstand von Sprachwissenschaft werden? Bleibt man nur bei den Bildern: Dies mag nach modischer (vielleicht sogar schon wieder altmodischer) Anbiederung an einen „iconic“ oder „visual“" oder „pictorial turn“ klingen, an die großen Schlagworte vom „Zeitalter der Bilder“, von der „Visualisierung der Kommunikation" durch neue und inzwischen längst mittelalte Medien, an den Bild-Boom in allen möglichen Wissenschaften. Und dann: Sollten und können Linguisten sich überhaupt mit Bildern beschäftigen? Ist das nicht das Feld anderer? 
Bevor ich mich in derlei Bedenken verliere, gebe ich kleine Beispiele, die andeuten sollen, dass Medialität und Intermedialität von Sprache jenseits aller Moden nicht nur linguistisch behandelt werden sollten, sondern auch behandelt werden müssen. Ich zitiere exemplarisch drei historische Aussprüche:

(1) „Platz an der Sonne“

(2) „Seit 5 Uhr 45 wird jetzt zurückgeschossen“

(3) „Ich bin ein Berliner“

Sie stehen verdichtend für historische Ereignisse, als Symbole für deutsche Geschichte des vorigen Jahrhunderts: für deutsches Weltmachtstreben, den deutschen Angriff auf Polen und die Situation im geteilten Berlin. Diese drei Phraseme und ihre Verankerung im kulturellen Gedächtnis zeigen zugleich, wie sich die mediale Situation im Laufe dieses Jahrhunderts verändert hat: (1) können wir bestenfalls zurückverfolgen bis zur Verschriftlichung der Rede des Staatssekretärs von Bülow, die er in der Reichstagssitzung vom 6.12.1897 gehalten hat; (2) haben wir als so genannten O-Ton im Ohr, in Wirklichkeit nicht - wie der Ausdruck O-Ton nahe legt - das Original, sondern eine Tonaufzeichnung von Hitlers Reichstagsrede vom 1.9.1939, die natürlich die Spur ihrer Technik enthält; (3) schließlich ist als Filmausschnitt aus Wochenschauen geläufig, aber die meisten Zeitgenossen haben die Rede, aus der das Zitat stammt, als Fernsehübertragung wahrgenommen. Auch die Nachgeborenen kennen nicht nur den Wortlaut, nicht nur die Stimme Kennedys mit seiner typischen Sprechweise, man sieht in den sattsam bekannten Filmdokumenten bis heute, wie auch sein sichtbares Auftreten zu seinem (seit Obama wieder vielbeschworenen) Charisma beiträgt: Er hatte nicht nur beste Redenschreiber, sondern war eben auch ein glänzender Rhetoriker, der wusste, wie gelungene actio bewerkstelligt wird. Die Bilder (siehe Abb. 1-4) dieses „medialen Geschichtsklischees“ “ zeigen Ernst in staatsmännischer Pose, dann Lächeln, Winken, verlegenen BubenCharme mit Krawattenesteln; die Bildmontage gibt übrigens immer mal auch Naheinstellungen von einzelnen Zuschauern und ihrer Begeisterung.

Schon allein deshalb müssen wir Sprache intermedial betrachten. Wenn wir sprachliche Diskursereignisse angemessen beschreiben wollen, müssen wir ihre Medialität einbeziehen, sei es Schrift, sei es Stimme, aber eben nicht nur Stimme, sondern auch deren Überformung durch technische Medien, und vor allem ihre Einbettung in und Verknüpfung mit allen möglichen Arten von Sichtbarem und Hörbarem, den Körper im Raum - überhaupt Visuelles, und falls dabei technische Medien im Spiel sind: was und wie sie dies zeigen und hören lassen. Alles andere ist zwar Sprache pur, eine zu wissenschaftlichen Zwecken manchmal nützliche und deshalb erlaubte Reduktion, aber eben eine Reduktion, deren wir uns bewusst bleiben müssen und die wir nicht prinzipiell und „ohne Not“ vornehmen dürfen.

Siehe zu diesem Phänomen des kulturellen Gedächtnisses Holly (2003). 

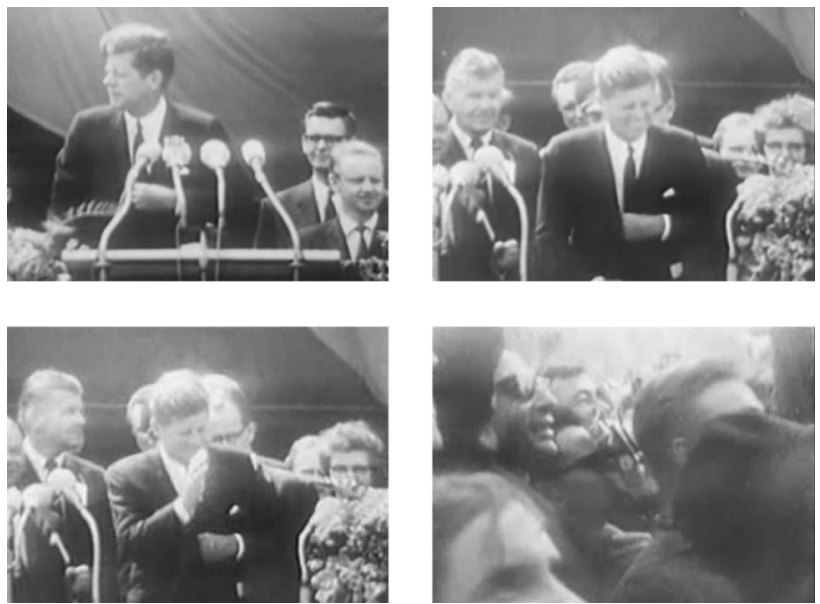

Abb. 1-4: Kennedy vor dem Rathaus Schöneberg

\section{Audiovisualität}

Im Folgenden werde ich eine Variante der intermedialen Einbettung und Verknüpfung von Sprache behandeln, die man als ,sekundäre Audiovisualität ${ }^{`}$ charakterisieren kann. Audiovisualität (als eine Form der Intermedialität oder Multimodalität) heißt zunächst nur, dass in den entsprechenden Kommunikationsformen beide Modes, Akustisches und Optisches, genutzt werden können. ,Primär audiovisuell' sind alle face-to-face-Formen, auch die nicht-konversationellen Meso-Formen, zu denen man auch Vorträge zählen kann, in denen ja, wie gerade die antike Rhetorik wusste, die actio, also die gesamte körperliche, auch visuell wahrgenommene Performanz nicht wenig beiträgt. Wichtiger wird das Visuelle noch, wenn zusätzliche optische Stützen in Form von Tafelanschrieben, Folien usw. dazukommen. Visuell und auditiv operiert auch das räumliche kommunikative Arrangement, das dann in meinem zweiten Untersuchungsfeld, den Talkshows, eine erhebliche Rolle spielt.

Bei räumlicher Entkopplung der Beteiligten kann man dann von ,sekundärer' Audiovisualität sprechen; hier besorgen Kameras Bilder und Mikrofone Töne; vor allem ist die Kombination beider Modes hier nicht mehr nur das spontane Produkt körpernaher Semiose (Sprachlaute, Mimik, Gestik, Kinesik), sondern es muss technisch bewerkstelligt werden, wie beide zusammenkommen. Die Kamera kann nun, wie meine Augen bei der Rezeption auch, Sprecher zeigen oder auch anderes. Während meine Augen aber nur über ein sehr begrenztes Potenzial in der Lieferung von „Ansichten“ verfügen, kann eine Bildmontage alles Mögliche zu einem Sprachtext kombinieren, nicht zuletzt können auch andere Töne dazukommen. 


\begin{tabular}{|l|l|l|}
\hline Zeichenarten & <wahrnehmungsnah> & <arbiträr> \\
\hline $\begin{array}{l}<\text { körpernah>, } \\
<\text { temporär }>\end{array}$ & Gestik, Mimik & Lautsprache \\
\hline $\begin{array}{l}<\text { körperunabhängig }>, \\
<\text { fixiert }>\end{array}$ & Bild, Film & $\begin{array}{l}\text { Schriftsprache, abstrakte } \\
\text { Symbole }\end{array}$ \\
\hline
\end{tabular}

Abb. 5: Zeichenarten (nach Sachs-Hombach 2003, S. 96)

Das kleine Schema (Abb. 5) veranschaulicht auch die semiotische Leistungsfähigkeit der Tonfilmkombination, die Vorzüge arbiträr körpernaher mit denen körperunabhängiger und wahrnehmungsnaher Zeichen verbindet; zugleich sind beide, Lautsprache und Film, linear in einem Bewegungs- und Zeitablauf (der Film erzeugt zumindest die Illusion von Bewegtheit) und können so eine gemeinsame narrative oder berichtende Dynamik entwickeln, weil sie nicht nur additiv operieren. „Filme sind“ - so Angela Keppler (2006, S. 73) - ,ein virtueller Bewegungsraum, der uns nicht allein in Bewegungen des Sehens, sondern auch des Hörens und mit ihnen in eine komplexe Bewegung des Verstehens versetzt.“

Ich werde hier beide Typen von sekundärer Audiovisualität behandeln, den, der überwiegend Sprecher mit ihrer Gestik und Mimik zeigt (dafür behandle ich das Genre, Polit-Talkshows'), und den, der meist anderes zeigt (in so genannten ,Nachrichtenfilmen). Letztere liefern Bilder, die besprochen werden, „besprochene Bilder“; erstere zeigen meist - oder besser ,bebildern“ - Sprecher, „bebildertes Sprechen“. Wie Bilder und Sprache zusammenkommen, in meinem Fall, wie sie in den beiden Typen, die ich unterschieden habe, zusammengebracht werden, so dass sie zusammen ein Bedeutungspotenzial generieren, soll der Gegenstand dieses Beitrags sein. Ich werde also nichts über die Rezeption dieser Genres sagen, sondern beschränke mich auf das, was man in der Medienwissenschaft eine „Produktanalyse" nennt, die gewissermaßen präfigurierte Möglichkeiten der Rezeption herausarbeitet.

Zuvor will ich auf einige Literatur verweisen, die sich mit dem audiovisuellen Sprach-Bild-Zusammenhang beschäftigt hat. Erstaunlich ist, dass sich die Film- und Fernsehwissenschaft kaum für die Frage zu interessieren scheint, wie Wort und bewegte Bilder zusammengehen. Dies ist einer der Gründe, warum hier ein Feld für Linguisten ist, andere scheinen sich an Sprache nicht so recht heranzutrauen. Bei den wenigen Arbeiten, die wirklich auch bewegte Bilder und Sprache behandeln (die meisten analysieren statische Bilder und Schrift), geht es verständlicherweise meist um Spiel- 
filme (z.B. Rauh 1987) oder um Nachrichtenformate im Fernsehen; die Nicht-Linguisten (wie etwa Brosius 1998) schreiben zwar über Bildfunktionen, das Sprachverstehen wird aber nur sehr oberflächlich thematisiert, noch pauschaler der Zusammenhang zwischen beiden; für Diskussionsoder Talksendungen beschränken sich die meisten (auch Holly/Kühn/ Püschel 1986) auf pauschale Hinweise auf die Bildkomponente in angefügten Kapiteln (so auch die Politikwissenschaftler Meyer/Ontrup/Schicha 2000).

Als gewinnbringend hervorheben möchte ich hier zum einen die Tradition der britischen „social semiotics“, die vor allem mit den Namen Gunther Kress und Theo van Leeuwen verbunden ist und auf die Hallidaysche Funktionalgrammatik zurückgreift, und zum andern die Arbeit von Harald Burger. Beide erfassen die Sprach-Bild-Beziehungen in Termini der formalen und semantischen Passung und der pragmatisch-funktionalen Bezugnahme. Dabei greift van Leeuwen auch auf die beiden Typen zurück, die schon Roland Barthes ([1964] 1990, S. 34) als „Funktionen“ der „sprachlichen Botschaft in bezug auf die [...] bildliche Botschaft" unterschieden hat: ,Verankerung, durch die aus einem vagen Bildinhalt etwas ausgewählt und gewissermaßen festgenagelt wird, und ,Relaisfunktion', die etwas Eigenständiges hinzufügt. Einen zusammenfassenden Überblick über „visual-verbal linking" gibt van Leeuwen (2005, S. 230) im folgenden Schema (Abb. 6):

\begin{tabular}{|c|c|c|}
\hline \multicolumn{3}{|c|}{ Image-text relations } \\
\hline Elaboration & $\begin{array}{l}\text { Specification } \\
\text { Explanation }\end{array}$ & $\begin{array}{l}\text { The image makes the text more specific (illustration) } \\
\text { The text makes the image more specific (anchorage) } \\
\text { The text paraphrases the image (or vice versa) }\end{array}$ \\
\hline Extension & $\begin{array}{l}\text { Similarity } \\
\text { Contrast } \\
\text { Complement }\end{array}$ & $\begin{array}{l}\text { The content of the text is similar to that of the image } \\
\text { The content of the text contrasts with that of the image } \\
\text { The content of the image adds further information to } \\
\text { that of the text, and vice versa ('relay') }\end{array}$ \\
\hline
\end{tabular}

Abb. 6: Überblick über „visual-verbal linking“ (aus: van Leeuwen 2005, S. 230)

Man kann sehen, wie die Hallidayschen Begriffe ,Elaboration', unterteilt in ,Specification' und ,Explanation', und ,Extension' auf die Sprach-BildBeziehung übertragen werden. Zugleich tauchen altbekannte Begriffe für semantische Relationen wieder auf: Similarity, Contrast, Complement.

Burgers relativ reichhaltige Darstellung der Sprach-Bild-Relationen (2005, S. 400-424), die vor allem auf Fernsehen gemünzt sind, zieht drei Dimensionen heran: er gliedert sie 1. formal, 2. semantisch, 3. pragmatisch-funktional. Unter dem ersten Gesichtspunkt sind (nach Rauh 1987, S. 89 ff.) die Differenzen von synchron/asynchron, syntop/asyntop und intradiegetisch/ 
extradiegetisch, die zur Unterscheidung von On-, Off- und Oversituationen dient, relevant; außerdem die simultan/asimultan-Differenz. Für semantische Beziehungen unterscheidet er auf einer Skala von „,konvergent -

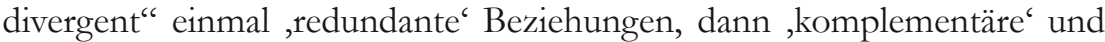
schließlich ,rhetorische' (Metonymie, Metapher). Funktional-pragmatisch unterscheidet er von „Text zu Bild“ zwei: ,Monosemieren' (mit und ohne explizite Deixis) und ,Metakommunikative Kommentierung“. Für „Bild zu Text" gibt es fünf Funktionen: Referenzsicherung, Veranschaulichung, Authentizität, Aktualität, Weckung von Interesse. Die letzte Reihe knüpft an die zahlreichen Bildfunktionskataloge an, die vor allem seit Huth (1985) für informative Fernsehsendungen und auch in andern Zusammenhängen entwickelt worden sind.

Natürlich sind solche Kategorienraster, so nützlich und unumgänglich sie sein mögen, immer nur grobe Anhaltspunkte; sie können eine differenziertere Analyse anregen, aber nicht ersetzen. Vor allem wären weitere Erklärungen wünschenswert, die auf die spezifische Semantik der einzelnen Zeichenarten eingehen und durchsichtig machen, in welchen Fällen welche Relation hergestellt wird, kurz: die Frage geht nach typischen Mustern der Sprach-Bild-Kombination, die sich aus der autochthonen Semantik der beiden ableiten lassen. Im Weiteren will ich zunächst nach solchen Mustern für die Nachrichtenfilmanalyse suchen, dazu aber die Analyse auch theoretisch unterfüttern und einen zweiten, ganz anders ansetzenden Vorschlag für die Kamerainszenierung in Talkshows exemplarisch-ausschnitthaft präsentieren.

\section{Transkriptivität}

Zunächst und möglichst kurz zum theoretischen Unterbau. Fragt man nach der grundsätzlichen Struktur von Beziehungen zwischen Zeichen, kommt man in der Sprache zu syntaktischen Mustern, die in der Regel durch Formelemente kodiert sind. Solche sind zwischen Wörtern und Bildern in Tonfilmen selten zu finden, regelmäßig allenfalls in einem sehr rudimentären pragmatischen Modus, der durch Nebeneinander-Positionierung oder Gleichzeitigkeit der Wahrnehmbarkeit indiziert ist. Was gleichzeitig oder benachbart sprachlich und bildlich wahrnehmbar gemacht wird, wird wohl schon etwas miteinander zu tun haben, so darf nach der allgemeinen Griceschen Kooperationsmaxime vermutet werden. Spezifischere Bande werden dagegen semantische Bezüge liefern, die in unserem Wissen verankert sind, dadurch dass wir sprachliche und bildliche Informationen aufeinander beziehen können. In der Sprache sind natürlich auch explizite bilddeiktische Ausdrücke möglich. Forscher mit einer Neigung zu Eyetracking-Experimenten können die Bezugnahmen in Print- oder Online- 
Textflächen aus dem Hin- und Herspringen der Augenbewegungen von Wort zu Bild erschließen, allerdings kaum beim Betrachten und Hören von Tonfilmen, wo das Auge zwar beobachtbar von Wort zu Bildinhalt geführt werden kann, aber sicher nicht umgekehrt.

Ludwig Jäger (2002, 2004, in diesem Band) hat die Idee entwickelt, dass die Generierung von Bedeutungen grundsätzlich durch die ,transkriptive Bezugnahme von Zeichen auf Zeichen zu erklären ist, nicht in erster Linie durch den Bezug von Zeichen auf Sachen, zu denen wir ja keinen unmittelbaren Zugang haben. Das impliziert zwar ein Problem des Anfangs, aber Jäger löst es durch eine „metaleptische“ Figur: Auch aus einem noch bedeutungslosen Ausdrucksmaterial, einem ,Präskript', wird durch ein Verfahren der Bezugnahme, das er gewollt metaphorisch "Transkription“ nennt, nachträglich etwas Lesbares oder besser Verstehbares, ein ,Skript', allerdings nicht in beliebiger Weise; es gibt Angemessenheitskriterien, die geltend gemacht werden können. Die Ontogenese der Sprach- oder der Malkompetenz liefert hierfür schöne Belege. Überhaupt kann man nun sagen, dass Transkription dazu dient, etwas „,besser lesbar, anders lesbar, manchmal gerade weniger lesbar" zu machen und man kann einen intramedialen Bezug zwischen Zeichen derselben Art von einem intermedialen zwischen verschiedenen Zeichenarten, z.B. zwischen Sprach- und Filmbildzeichen, unterscheiden. Bilder machen zugehörige Sprachzeichen anders lesbar und umgekehrt. Hier noch ein Hinweis: Wenn man nun verkürzend davon spricht, dass Sprache Bilder und umgekehrt „transkribieren“, dann ist das kein Ausweis von vorpragmatischem Denken, sondern die simple Gewohnheit, pingelige Redeweisen wie „mit Sprache transkribiert ein Sprecher oder Hörer ein Bild“ etwas zu vereinfachen. Die Pointe der Transkriptionsidee ist ja gerade, dass man nicht an vorgängige Inhalte glaubt, die von Ausdrucksseiten bloß repräsentiert werden. Ohne Zeichenbenutzer bedeuten Ausdrücke nichts, wie denn auch?

Man kann aber fragen, was die Transkriptivitätsidee für die Analyse intermedialer Texte leistet. In meinen Augen wäre es schon genug, wenn sie hinreichend deutlich machte, wie die Generierung von Sprach-Bild-Bedeutungskomplexen im Rahmen eines allgemeinen Modells der Semiose anzusiedeln ist. Sie modelliert vor allem aber, dass solche Bedeutungskomplexe nicht in der bloßen Addition von Sprach- und Bildbedeutungen entstehen, sondern dass sie das Ergebnis höchst dynamischer Prozesse sind, in denen sie sich durch wechselseitige Bezugnahmen aufbauen, immer natürlich unter Einbeziehung aller Arten von Kontext- und Schemawissen, das auf beiden Seiten angestoßen werden kann.

Eine wirklich problematische Frage für eine konsequent handlungstheoretische Fundierung sehe ich eher darin, dass die durch eine nicht völlig kontrollierbare Kombination entstehenden Bedeutungspotenziale keineswegs alle intendiert, also gemeint sind, dass also so etwas wie ein semio- 
tischer Überschuss entsteht, der von Rezipienten gedeutet werden kann, obwohl es sich nicht um Ergebnisse von kommunikativen Handlungen dreht, eher um Zufallsprodukte, die zum Ausdruck kommen, ohne zum Ausdruck gebracht zu werden, Phänomene der dritten Art vielleicht. ${ }^{2}$

Ich will es jetzt bei diesen kurzen Bemerkungen zur Transkriptivität belassen und zu meinen konkreten Analysefeldern weitergehen. Zuvor die These, die ich dabei verfolge:

Fernsehaudiovisualität kann analysiert werden als wechselseitige dynamische intermediale Transkriptivität, performiert nach Mustern einer Logik, die vor allem begründet ist in den spezifischen Potenzialen und Defiziten der jeweiligen Semantiken von gesprochener (teilweise auch geschriebener) Sprache und (überwiegend) bewegten Bildern, nach Bedürfnissen bestimmter Genres, wobei auch allgemeines und kulturelles Kontext- und Schemawissen herangezogen wird.

\section{Sprach-Bild-Transkriptionen I: \\ Besprochene Bilder - Nachrichtenfilme}

Das Beispiel, das ich heranziehen werde, geht auf Material der Agentur APTN vom Juli 2005 zurück, das in drei verschiedenen Verarbeitungen durch verschiedene Sender dokumentiert ist. Ich beschränke mich hier aus Gründen der gebotenen Kürze (siehe zu weiteren Analysen des Materials auch Holly 2008 und 2009) auf die ZDF-Version, die mit 25 sec die kürzeste ist. Sie zeigt 6 Einstellungen, zu denen wir 4 Spracheinheiten hören. Das ZDF zeigt nur einen kleinen Ausschnitt des angebotenen Filmmaterials, wie man einer so genannten „Shotlist" der Agentur entnehmen kann, die sie zusammen mit einer „Storyline“ möglichen Interessenten anbietet, beides übrigens schon Sprach-Bild-Transkriptionen. Dabei wird im ZDF die erste Einstellung des Ausgangsmaterials an die vorletzte Position montiert, ein entscheidendes Detail der letzten Einstellung ist übrigens weggelassen.

APTN-Shotlist: 1.7.2005, Turkey Shooting:

(1) Exterior of Justice Ministry building, ambulance outside

(2) Suspect runs out of building and through garden

(3) Police chasing and firing at suspect (AUDIO: gunfire)

(4) Tracking shot, police chasing suspect

(5) Suspect lying on ground surrounded by police

(6) Suspect sitting up

Ausführlicher dazu Holly (in Vorbereitung). 
(7) Police shooting suspect

(8) Bomb disposal expert in protective clothing, pan to suspect moving head

(9) Security asking camera to move away

(10) Police forming a cordon in front of suspect

(11) Bomb disposal expert moving in to suspect

(12) Bomb disposal expert cutting clothing off suspect ...

(13) Second bomb disposal expert being sent away

(14) Cutaway to police

(15) Bomb disposal expert cutting clothing off suspect, examining object found on suspect, suspect moving head

(16) Cutaway of police and people gathered at scene

(17) Bomb disposal expert with tan cylinder found on suspect

(18) Police arguing with cameraman

(19) Officials at scene

(20) Bomb disposal expert

(21) Officials outside Ministry building

(22) Wide of officials outside building

(23) Bomb disposal expert

(24) Scene of crime officer putting on protective suit

(25) Pan from building to police standing in line

ZDF-Auswahl:

(2) Suspect runs out of building and through garden

(3) Police chasing and firing at suspect (AUDIO: gunfire)

(10) Police forming a cordon in front of suspect

(12) Bomb disposal expert cutting clothing off suspect ...

(1) Exterior of Justice Ministry building, ambulance outside

(15) Bomb disposal expert cutting clothing off suspect, examining object found on suspect, (suspect moving head)

Nun werde ich dieses Filmchen, das in einem Nachrichtenblock gesendet wurde, anhand von Standbildern der einzelnen Einstellungen (E 2, 3, 10, $12,1,15)$ veranschaulichen, dann den Sprechertext, den man in vier Einheiten (I-IV) gliedern kann, wiedergeben und anschließend anhand einer Tabelle, die beide kombiniert, auf die transkriptiven Muster eingehen. 


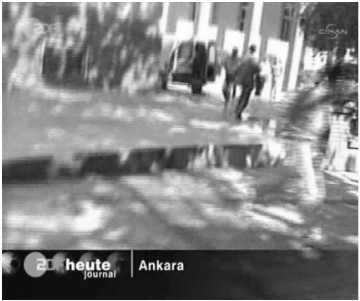

$\mathrm{E}(2)$

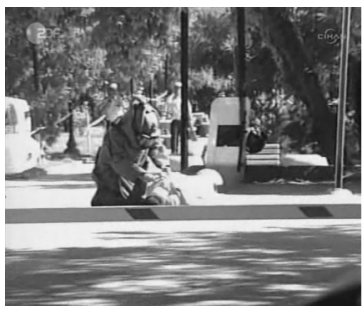

E (12)

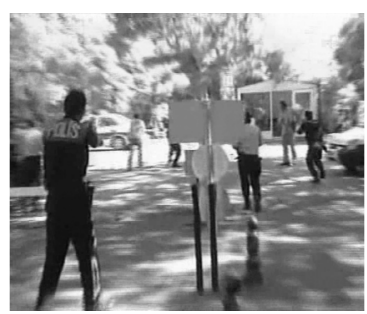

E (3)

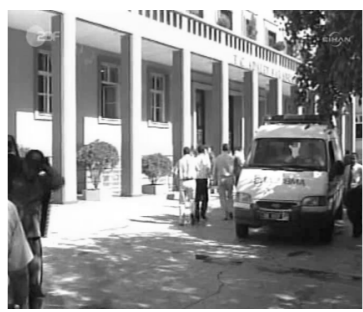

E (1)

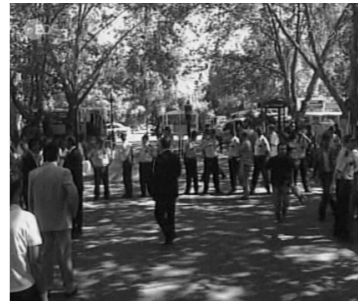

E (10)

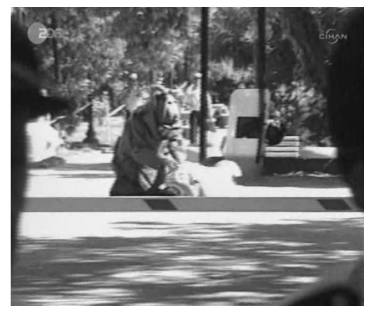

$\mathrm{E}(15)$

Abb. 7-12: Einstellungen des ZDF-Nachrichtenfilms

Sprechertext:

(I) in der türkischen hauptstadt Ankara hat die polizei offenbar einen bombenanschlag auf das justizministerium verbindert [2]

(II) die beamten erschossen den mutmaßlichen attentäter nach einer kurzen verfolgungsjagd auf offener straße [3, 10]

(III) er soll zuvor versucht haben in das gebäude einzudringen und dort einen sprengsatz zu zünden $[12,1]$

(IV) angeblich war er mitglied einer linksextremistischen terrorgruppe [15]

Die Übersichtstabelle (Abb. 13) zeigt zum einen, dass nominierende/referierende Bezüge vom Sprachtext zum Bildtext gehen, die Referenzobjekte im Bild identifizieren, und zwar in einer vorausweisenden/kataphorischen Richtung (wie bei polizei oder regierungsgebäude) und in einer rückverweisenden/anaphorischen Richtung (wie bei attentäter und verfolgungsjagd). Das nominalisierende Kompositum verfolgungsjagd bezieht sich allerdings nicht nur auf ein einzelnes Referenzobjekt, sondern auf eine Proposition. Insofern liegt hier eine etwas andere Beziehung vor. In beiden Fällen gehen die Bezüge nach dem Muster, Mit Worten sehen', eigentlich merkwürdig, wenn man an die berühmte Formel vom Bild, das mehr als tausend Worte sagt, denkt.

Zugleich transkribieren die Bilder in jeweils umgekehrter Richtung die sprachlichen Ausdrücke zum Zwecke der Authentisierung, sie vermitteln uns den Eindruck von Augenzeugenschaft, und sie plausibilisieren das Gesagte durch Evidenz, indem sie einen simplen, aber anschaulichen Miniplot 
unterlegen; hier so etwas wie: Mann wird von Polizei verfolgt und erschossen. (Im Übrigen können die Bildbeschreibungen der Shotlist als ,ethnographische Daten“ genommen werden, die es dem beschreibenden Wissenschaftler ersparen, eigene Bildbeschreibungen spekulativ auf den Sprachtext hin zu konstruieren. Ich habe hier lediglich zusätzliches Wissen getilgt, mit dem schon die Shotlist-Beschreibungen die Bilder anreichern.)

\begin{tabular}{|c|c|}
\hline Sprachtext & Bildtext \\
\hline $\begin{array}{l}\text { (I) in der türkischen hauptstadt Ankara } \\
\text { hat die polizei offenbar einen bomben- } \\
\text { anschlag auf das justizministerium }\end{array}$ & $\begin{array}{l}\text { (2) Mann läuft aus Gebäude durch } \\
\text { Parkstraße }\end{array}$ \\
\hline $\begin{array}{l}\text { verhindert (II) die beamten erschosser } \\
\text { den mutmaßlichen attentäter nach } \\
\text { einer }\end{array}$ & (3) Polizei verfolgtinn und schießt \\
\hline kurzen verfolgungsjagd auf offener & (10) Kordon von Polizisten \\
\hline $\begin{array}{l}\text { straße (III) er soll zuvor versucht haben } \\
\text { in das regierungsgebäude. }\end{array}$ & $\begin{array}{l}\text { (12) Marnn in Schutzanzug beugt } \\
\text { sich über Liegenden }\end{array}$ \\
\hline $\begin{array}{l}\text { einzudringen und dort einen } \\
\text { sprengsatz zu zünden }\end{array}$ & (1) Außenansicht von Gebäude \\
\hline $\begin{array}{l}\text { (IV) angeblich war er mitglied einer } \\
\text { linksextremistischen terrorgruppe }\end{array}$ & $\begin{array}{l}\text { (15) Mann in Schutzanzug beugt } \\
\text { sich über Liegenden }\end{array}$ \\
\hline
\end{tabular}

Abb. 13: Transkriptionsbeziehungen I Sprachtext - Bildtext

\begin{tabular}{|l|l|}
\hline Sprachtext & Bildtext \\
\hline $\begin{array}{l}\text { (I) in der türkischen hauptstadt Ankara } \\
\text { hat die polizei offenbar einen bomben- } \\
\text { anschlag auf das Justizministerium }\end{array}$ & $\begin{array}{l}\text { (2) Mann läuft aus Gebäude durch } \\
\text { Parkstraße }\end{array}$ \\
\hline $\begin{array}{l}\text { verhindert (II) die beamten erschossen } \\
\text { den mutmaßlichen attentäter nach } \\
\text { einer }\end{array}$ & (3) Polizei verfolgt inn und schießt \\
\hline $\begin{array}{l}\text { kurzen verfolgungsjagd auf offener } \\
\text { straße (III) er soll zuvor versucht haben } \\
\text { in das regierungsgebäude }\end{array}$ & $\begin{array}{l}\text { (12) Mann in Schutzanzug beugt } \\
\text { sich über Liegenden }\end{array}$ \\
\hline $\begin{array}{l}\text { einzudringen und dort einen } \\
\text { sprengsatz zu zünden }\end{array}$ & (1) Außenansicht von Gebäude \\
$\begin{array}{l}\text { (IV) angeblich war er mitglied einer } \\
\text { linksextremistischen terrorgruppe }\end{array}$ & $\begin{array}{l}\text { (15) Mann in Schutzanzug beugt } \\
\text { sich über Liegenden }\end{array}$ \\
\hline
\end{tabular}

Abb. 14: Transkriptionsbeziehungen II Sprachtext - Bildtext 
Darüber hinaus (siehe Abb. 14) verknüpft die überlappende Montage (wir sehen (3) bzw. (12) schon, während (I) und (II) noch zu hören sind), indem die Bilder an die gerade zu Ende gehenden Propositionen semantisch andocken und sie entsprechend transkribieren: (3) zeigt, wie (I) gemacht wurde (Detaillierung), (12) zeigt, wie das ,Ergebnis“ oder die ,Folge' von (II) aussieht. Solche semantischen Relationierungen verdichten auf der Basis von allgemeinem Welt- und Schemawissen das Verstehen des Gesamttexts.

Mit diesen sehr elementaren Mustern der Bildsemantisierung und Bildaufschließung einerseits, der Sprachauthentisierung und Sprachveranschaulichung andererseits ist aber nur die Oberfläche der wechselseitigen SprachBild-Transkriptionen erfasst. Natürlich gibt es aufgrund weiterer Leistungen von Sprache und Bild weitere, subtilere Beziehungen, die ich hier nur andeuten kann. Schaut man sich den Sprachtext genauer an, stellt man fest, dass er relativ autark formuliert ist. Er weist mit seiner Text-Struktur (Leadsatz, Ereignisverlauf, Vorgeschichte, Hintergrund) die typischen Züge einer Pressemeldung auf und könnte ebenso gut ohne Bildunterstützung verstanden werden.

Leadsatz

(I) in der türkischen hauptstadt Ankara hat die polizei offenbar einen bombenanscblag auf das justizministerium verbindert

Ereignisverlauf (II) die beamten erschossen den mutmaßlichen attentäter nach einer kurzen verfolgungsjagd auf offener straße

Vorgeschichte (III) er soll ₹wvor versucht haben in das gebäude einzudringen und dort einen sprengsatz, zu zünden

Hintergrund (IV) angeblich war er mitglied einer linksextremistischen terrorgruppe

Dies ist nicht bei allen solchen unterlegten Sprechertexten so. Manchmal gibt es mehr oder weniger explizite Verweise auf die Bildkomponente, so auch in einer $\mathrm{CNN}$-Version desselben Materials, wo die Moderatorin aus dem Off die laufenden Bilder kommentiert und auf den chaotischen Charakter der bildlich vermittelten Szene verweist: as you can see there is some of the chaos caught on tape. In anderen Fällen sind die Hinweise weniger explizit, unterscheiden sich aber schon stark von dem Pressemeldungsstil, der ohne Bildtranskription möglich ist.

Zu diesem Stil gehören auch die nachrichtentypischen Heckenausdrücke, die das Gesagte relativierend immunisieren sollen. In jeder Aussage ist die epistemische Sprechereinstellung explizit abgeschwächt, durch zwei Modaladverbien (I offenbar, IV angeblich), ein vom Sprachhandlungsverb mutmaBen abgeleitetes Adjektiv (II) und inferentiellen Gebrauch des Modalverbs sollen (III). Zugleich werden handfeste sprachliche Bewertungen vorgenommen, durch deontische Wörter wie bombenanschlag (I), attentäter (II), sprengsatz (III), linksextremistisch, terrorgruppe (IV), die allesamt moralische und 
sehr starke Negativ-Beurteilungen des Erschossenen zum Ausdruck bringen oder implizieren. Dagegen kann man der Formulierung erschossen ... auf offener straße (II) eine gewisse Skandalisierung des polizeilichen Vorgehens entnehmen.

Die unterschiedlich deutlichen und unterschiedlich gradierten Bewertungen des Erschossenen und der Polizei können auch als ausgleichende Kommentare zu den Bildern gelesen werden, die umgekehrt zwar das gewaltsame Vorgehen der Polizei zeigen, nicht aber das des mutmaßlichen Attentäters, der sichtbar nur als Opfer in Erscheinung tritt, nicht als Täter. Hier liefert die Sprache in der ,Relaisfunktion' einen eigenen Beitrag zum intermedialen Textganzen. Insofern transkribieren die wahrheitswertabschwächenden und abgestuft evaluativen Sprachelemente die Bilder in Richtung einer Relativierung und einer entdramatisierenden Tendenz, zu der auch die routinierte Prosodie der Sprecherinnenstimme beiträgt, so dass letztlich der gesamte Vorfall, vor allem das Vorgehen der Polizei zwar zunächst kritisiert, dann aber doch durch die dagegen stehenden Bewertungen des Erschossenen „normalisiert“, d.h. als irgendwie balanciert eingeordnet werden.

Dies scheint auch erforderlich, denn die Bilder sind auf Dramatisierung und Sensationsverstärkung hin angelegt. Nicht ohne Grund versucht schon das Begleitmaterial der Agentur in einer Mischung aus Warnung und Kaufanreiz die Sensationsträchtigkeit der Bilder zu markieren, mit dem Hinweis auf der Einleitungsmaske: ,,++CLIENTS PLEASE NOTE THAT PACKAGE CONTAINS FOOTAGE OF SUSPECT BEING SHOT+++". Auch die Qualität der Einstellungen und des O-Tons kann in diese Richtung wirken.

So geben die Einstellungen (2) und (3) (siehe oben) durch die Bewegung einen unmittelbaren Eindruck vom aktuellen Ablauf der Szene, die Kamera fängt mit wackelnden Bildern direkt ein, was als Ereignis berichtenswert ist, den Fluchtversuch des Protagonisten und die Verfolgung durch die Polizei, (3) enthält dazu noch Tonaufzeichnungen der Schüsse, was die Shotlist als „(AUDIO: gunfire)“ und damit wiederum als dramatisches Element notiert. In der ZDF-Version ist zwar nicht zu sehen, wie der Mann niedergeschossen wird, aber die „Ergebnisbilder“ (12) und (15) (siehe oben) zeugen durch zwei Elemente von der Dramatik der Szene: Sie sind erkennbar mit einem Teleobjektiv durch die Absperrungskette der Polizei gefilmt, zeigen also etwas, was nicht gezeigt werden soll. Das Bild von der Absperrkette (10) (siehe oben) begleitet die Aussage von der Erschießung, woraus man paradoxerweise schließen muss, dass sie eben nicht ganz auf offener straße stattfand (der Duden notiert dafür als Bedeutung: ,vor den Augen aller, die sich auf einer Straße befinden). Und man sieht den Bombenentschärfer in seinem gespenstisch wirkenden Schutzanzug, was als Anzeichen für die situative Gefahr gedeutet werden kann. Da man nicht erkennen 
kann, dass der Beamte nach dem Sprengsatz sucht, und auch der Sprechtext dies nicht erläutert, bleibt es bei der optischen Dramatisierung ohne den ursprünglich informativen Wert der Szene.

Zusammenfassend: Für die Beschreibung der transkriptiven Muster sind Genre-Spezifika zu berücksichtigen. Die Filme, die ich analysiert habe, sind Teile von Nachrichtensendungen, die vorgeben, ein möglichst genaues und „objektives“ Abbild der Wirklichkeit zu erzeugen, auch wenn wir wissen, dass dies nicht möglich ist. Es geht also um Ereignisse der Wirklichkeit, die deshalb für die (hier audiovisuellen) Texte zwei zentrale Aufgaben stellen; sie müssen: (a) darstellen, was passiert ist, und (b) beglaubigen, dass es so passiert ist; es geht also um Darstellbarkeit und Glaubwürdigkeit.

Fragt man danach, wozu die Bilder die Sprachtranskription verwenden, wenn schon nicht brauchen, kommt man auf einen Darstellbarkeitmalus bzw. -bonus von Bild und Sprache (siehe Abb. 15). Umgekehrt profitiert auch die sprachliche Darstellung von der Bildtranskription, insofern als fotografische Bilder die grundsätzliche Brüchigkeit von symbolischen Zeichen, ihren Glaubwürdigkeitsmalus, durch eine indexikalische Struktur zu kompensieren scheinen: Wider besseres Wissen, glauben wir Bildern, die angeblich nicht lügen, mehr; sie haben sicherlich einen Glaubwürdigkeitsbonus.

\begin{tabular}{|l|l|l|}
\hline & \multicolumn{1}{|c|}{ Bilder } & \multicolumn{1}{c|}{ Sprache } \\
\hline darstellbar? & $\begin{array}{l}\text { Darstellbarkeitsmalus: } \\
\text { Ich kann nicht alles (genau) } \\
\text { zeigen }\end{array}$ & $\begin{array}{l}\text { Darstellbarkeitsbonus: } \\
\text { Ich kann fast alles (genau) } \\
\text { sagen }\end{array}$ \\
\hline glaubwürdig? & $\begin{array}{l}\text { Glaubwürdigkeitsbonus: } \\
\text { Was ich zeige, hat } \\
\text { Beweiskraft }\end{array}$ & $\begin{array}{l}\text { Glaubwürdigkeitsmalus: } \\
\text { Nicht alles, was ich sage, hat } \\
\text { Beweiskraft }\end{array}$ \\
\hline
\end{tabular}

Abb. 15: Potenziale/Defizite (Boni/Mali) von Sprache und Bild

Dazu kommen aber weitere, subtilere Funktionen. Zusammenfassend kann man die wechselseitige Sprach-Bild-Transkription des kurzen ZDF-Berichts als ein wohlbalanciertes Zusammenspiel von bildlich vermitteltem Plot, der durchaus eine gewisse Dramatik vermittelt, und einem im Meldungsstil sachlich verankernden Sprachtext, der durch detaillierte Propositionen die Bilder aufschließt, dabei bewertend kommentiert und mit relativierenden bzw. legitimierenden Formulierungen alles Brisante wieder normalisiert. Verallgemeinernd kann man für das Verfahren der Nachrichtenfilm-Audiovisualität folgende Aspekte festhalten: 
- „Oszillieren“ zwischen Sprache und Bild als wechselseitige ,Transkription',

- typische Konstellationen/Muster und Abfolgen von Sprach- und Bildfunktionen,

- performative transkriptive Dynamik, wie in einem Reißverschluss,

- auf der Grundlage von eigenständigen semantischen Eigenschaften der verschiedenen Zeichentypen,

- auf der Grundlage von Kontext- und Schemawissen.

\section{Sprach-Bild-Transkriptionen II: Bebildertes Sprechen - Polit-Talkshows}

Es ist sofort klar, dass in Polit-Talkshows, die ich jetzt anhand eines Beispiels behandeln will, das Sprach-Bild-Verhältnis völlig anders als in den Nachrichtenfilmen gestaltet ist. Während dort reichhaltigstes Bildmaterial durch einen Voice-over-Sprecher gewissermaßen „besprochen“ wird, sind hier von Vornherein (fast nur) Sprecher im Fokus, die nun von Kameras gezeigt werden, deren Rede gleichsam „bebildert“ werden muss (siehe auch Holly in Vorbereitung). ${ }^{3}$

Diese fundamentale Umgewichtung soll nun aber nicht bedeuten, dass nicht in beiden Fällen wechselseitige Transkriptionen im Spiel sind. Oft sind schon beim Drehen der Nachrichtenfilmbilder spracbliche Konzepte und Schemata relevant; erst recht wirken bei der Auswahl der montierten Einstellungen auch Erfordernisse und Konventionen der Nachrichtensprache und - wie gezeigt wurde - deuten nicht nur die Sprechertexte die Bilder aus, sondern diese wirken auch auf das Sprachverstehen ein. Komplementär dazu ist zwar die Rede der Talkshowteilnehmer in einem gewissen Sinne primär, andererseits ist sie von Anfang an von der Tatsache beeinflusst, dass die Sprecher, ihre räumliche Präsenz, ihre körperliche Performanz und deren Inszenierung gesehen werden können, und zwar durch die Augen von Kameras. Wie jemand spricht und wie seine Rede verstanden wird, hängt auch davon ab, ob und wie ich ihn performierend sehen kann, wo er agiert und wie er mir gezeigt wird.

Das visuell Relevante in solchen performativen Gesprächssendungen kann entsprechend (siehe schon Holly/Kühn/Püschel 1986, S. 177-198) in drei Dimensionen erfasst werden:

a) Räumliches Arrangement: Setting, Design, Szenerie;

b) Körpersprachliches: Mimik, Gestik, Kinesik, Proxemik;

c) Kamerainszenierung: Einstellungen in Abfolgen (durch Umschnitte) mit Zooms, Schwenks, Fahrten; Inserts.

3 Von den immer häufiger verwendeten Einspielfilmchen soll hier abgesehen werden; siehe dazu Klemm (in Vorbereitung). 
Hier will ich mich ausschließlich mit dem dritten Aspekt befassen, der allerdings insofern die beiden ersten einschließt, als er darüber entscheidet, was von diesen und wie wir sie als Zuschauer überhaupt wahrnehmen können. Dabei verfolge ich - wiederum im Rahmen des Transkriptivitätsmodells folgende These:

Die Kameraführung in Polit-Talkshows generiert durch die Selektion von Einstellungen und Umschnitten neue Bedeutungskomponenten, die sprachliche Äußerungen „transkribieren“, d.h. überformen, implizit kommentieren und dadurch ,anders lesbar" machen. Brisant ist vor allem, dass so dem Sprecher die alleinige Auktorialität entzogen wird und er die „performative Letztfassung" seiner Äußerungen nicht mehr selbst kontrolliert, sondern sich partiell an Instanzen technischer Medialität ausliefert, die dann auch nahezu unmerklich auf den Rezipienten wirken können.

Bei dem Versuch, diese Bild-Sprach-Transkriptionsprozesse deutend zu erfassen, lassen sich wiederum drei Aspekte oder Funktionen der Kamerainszenierung unterscheiden:

1) Profilierung des (thematischen und kommunikativen) Verlaufs durch Abwechslung, Gliederung, Strukturierung (auf der Makro- und Mikroebene);

2) Profilierung der Sprecher(selbst)darstellung durch dynamische Gestaltung der Sprecheridentität auf der Mikroebene;

3) Profilierung der Beteiligungsrollen anderer (Adressaten, Unterstützer Gegner) und Verweise auf Kontexte (Personen als Frame-Repräsentanten) durch Gestaltung der Beziehungen zwischen den Protagonisten und zum Diskurs.

Die Kamerainszenierung betrifft also elementare Funktionsfelder des ubiquitären „Vorbereichs“ jeder Kommunikation, nämlich ihre Organisation und die Bearbeitung von Beziehungen und Identitäten der Kommunizierenden.

Die Beispielsendung, auf die ich mich beziehe, ist die Ausgabe der Sendereihe „Maybrit Illner“ vom 29. März 2007 mit dem Thema: „Lebenslänglich, trotzdem frei: Gnade für die RAF?"; sie stand im Kontext der Frage, wie sich der Bundespräsident zum Gnadengesuch des RAF-Häftlings Christian Klar verhalten solle. Als Protagonisten waren 5 Gäste geladen, die von der Moderatorin Maybrit Illner (auf der Abb. 16 unten 3. v.l.) zu Beginn folgendermaßen vorgestellt wurden:

- Ina Beckurts - ibr mann wurde von RAF-terroristen ermordet [2. v.r.];

- Rupert von Plottnitz - er hat RAF-terroristen verteidigt [ganz r.];

- Claus Peymann - der Berliner intendant hat Christian Klar ein praktikum in seinem theater angeboten [2. v.l.];

- Roland Koch - der hessische ministerpräsident fordert: leute wie Peymann dürfen dieses schreckliche kapitel deutscher geschichte nicht noch verklären [3. v.r.];

- und Klaus Bölling - der ehemalige regierungssprecher meint: die geschichte der $\mathrm{R} A \mathrm{~F}$ ist nicht wirklich zu ende [ganz l.]. 


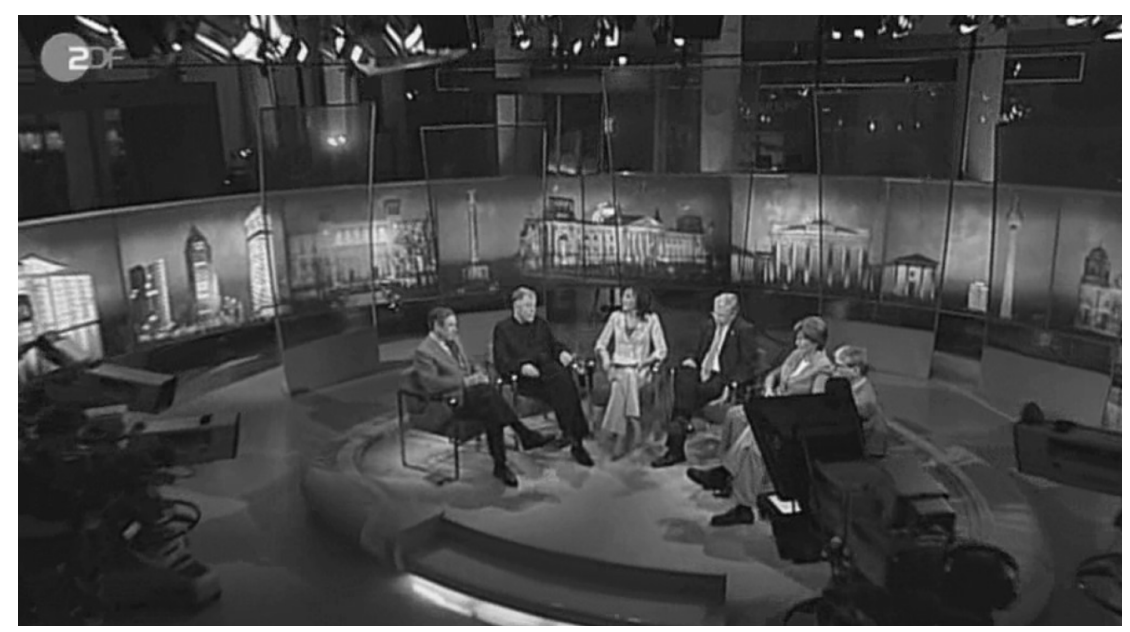

Abb. 16: Setting und Teilnehmer „Maybrit Illner“, 29. März 2007

Bevor ich kurz auf die drei genannten Funktionen der Kamerainszenierung eingehe, gebe ich einen schematischen Überblick über die Einstellungen während der ersten Runde von Beiträgen der Gäste, die von der Moderatorin nacheinander durch Interviewfragen regelrecht abgerufen werden. Das Schema (Abb. 17) zeigt (von unten gelesen), wie die Beiträge immer länger werden (von anfänglich knapp 1 Minute bei Peymann auf über 4 Minuten bei Bölling), was natürlich auch damit zu tun hat, dass jeder folgende Sprecher auch das bisher von andern Gesagte aufgreifen und kommentieren möchte.

Zur ersten Funktion der Kamerainszenierung, die für Abwechslung, Gliederung und Strukturierung steht, soll hier nur kurz festgehalten werden (ausführlicher Holly in Vorbereitung): Das Schema zeigt auch, wie Bilder vom jeweiligen Sprecher (im Schema hell gefärbt) im Wechsel mit anderen Einstellungen zu sehen sind, die nicht nur den Sprecher, sondern auch anderes zeigen: andere Teilnehmer, die als Rezipienten der jeweiligen Sprecheräußerung ins Bild kommen, oder aber den Sprecher mit anderen zusammen, dazu Schwenks und Fahrten. Es ist auffällig, dass die Moderatorin öfters gegen Ende der Beiträge eingeblendet wird, so dass der Sprecherwechsel auch schon optisch vorbereitet wird.

Der häufige Wechsel der Bilder erzeugt also Abwechslung und Reizerneuerung, er entspricht damit aber auch unserem natürlichen Blickverhalten, das nicht über längere Zeit starr auf ein Objekt gerichtet bleibt. Es gibt also nur relativ kurze Zeitspannen der Kamerazuwendung; die Einstellungen vom Sprecher sind im Durchschnitt 9,5 sec lang, die von anderen 4,7 sec. Zur ständigen Reizerneuerung gehört auch, dass - anders als früher in solchen Sendungen - die Kamera fast niemals stillhält, sondern auch noch die Einstellungen einzelner Gäste durch minimale Zooms und Schwenks nahezu unmerklich variiert. 


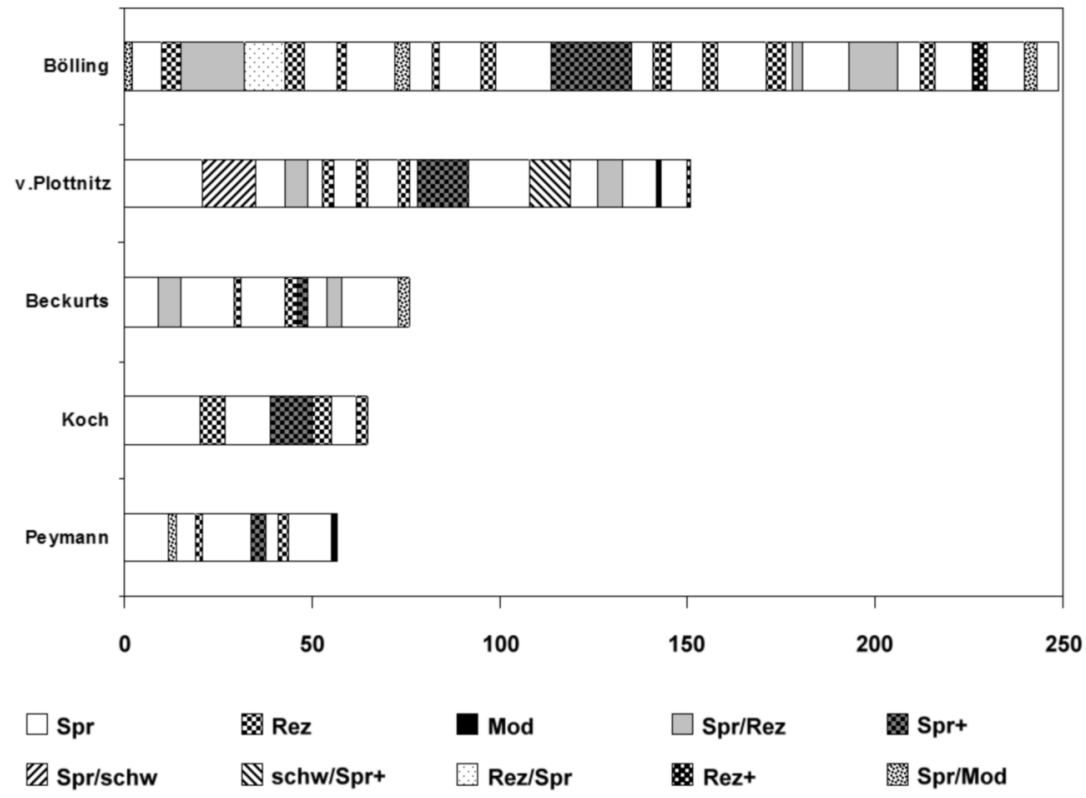

Abb. 17: Schema der Kameraeinstellungen in der 1. Runde von „Maybrit Illner“

$\mathrm{Zu}$ dieser mikrostrukturellen Gliederung kommt eine makrostrukturelle, die durch Umschnitte, größere Kamerabewegungen und gliedernde Einblendungen (sogenannte Bauchbinden) markiert werden. Immer häufiger werden auch Einspielfilmchen dazu genutzt, neue Subthemen oder andere Aspekte mit anderen Argumenten zum Thema einzubringen, wobei auch musikalische Elemente eine Rolle spielen.

Die zweite Funktion der Kamerainszenierung dient der zusätzlichen Profilierung des jeweils gezeigten Sprechers, der während seiner Rede zwischen $55 \%$ und $80 \%$ der Zeit (gemessen in dieser ersten Runde) allein im Bild ist; wie lange wir ihn allein sehen, hängt allerdings auch von der Gesamtlänge seines Beitrags ab und von der Häufigkeit, mit der er sich auf andere bezieht, was dazu führt, dass sie zur besseren Orientierung gezeigt werden. Die Konzentration der Kamera auf den Sprecher entspricht unserer natürlichen Erwartung, den Sprecher auch optisch zu identifizieren und ihm beim Reden zuzuschauen, damit wir auch die visuellen Botschaften, die er körpersprachlich mitliefert, verfolgen können. Natürlich wird durch die nahe Kameraeinstellung, die bei Sprecherbildern überwiegt, seine Mimik und Gestik überproportional fokussiert und damit verstärkt. Dazu kommen die aus der sozialsemiotischen visuellen Analyse von Bildern (Kress/ van Leeuwen 1996; Jewitt/Oyama 2001) bekannten Funktionen von Kameraperspektiven, die ihren drei Dimensionen bestimmte, wenn auch prinzipiell ambivalente Bedeutungspotenziale zuweist: 
- Einstellungsgröße: Distanz-Respekt/Intimität-Intensität

- Winkel horizontal: Involvement-Identifikation/Detachment-Skepsis

- Winkel vertikal: sozialer Status (Macht/Ohnmacht)

Wie schon angedeutet, handelt es sich nur um Potenziale, die erst in und von den jeweiligen Kontexten und Interpretationen aktiviert werden müssen. Den meisten Einfluss haben hier die Einstellungsgrößen und horizontalen Winkel, während die vertikalen Winkel in solchen Talkshows nur wenig variiert werden.

Zusammenfassend lässt sich festhalten, dass die Kameraführung permanent Ressourcen für eine sekundäre, sehr subtile „Kontextualisierung“ des Sprechers generiert, die jeweils zwischen Polen sozialer Semiotik operiert. Mit den Augen der Kamera wird uns der Sprecher gewissermaßen aus einer bestimmten Haltung gezeigt: Spricht er (nach „Meinung“ der Kamerainszenierung) so, dass man ihm näherkommen oder von ihm abrücken will, dass man ihm ,auf den Zahn fühlen“ muss oder respektvoll Abstand hält, dass man ihn frontal mit offenem Interesse von vorne betrachtet oder „skeptisch“ von der Seite? Die Kameraprofilierung des jeweiligen Sprechers erlaubt also Rückschlüsse auf die Äußerung des Sprechers, sie kann gedeutet werden als visuelles face work im Sinne Goffmans, indem sie relevante Aspekte der Beziehung zum Sprecher optisch wahrnehmbar zum Ausdruck bringt.

Die dritte Funktion der Kamerainszenierung, die ich hier etwas ausführlicher behandeln will, betrifft die externe Kontextualisierung von Beteiligungsrollen und Frames, also die Frage, wie durch die Einblendung anderer Teilnehmer der jeweilige Redebeitrag im Hinblick auf Positionen anderer profiliert wird, um diskursive Spannungen und Verstärkungen zu erzeugen.

Wenn Hörer im Bild zu sehen sind, handelt es sich immer um eine gezielte Auswahl. Dabei gibt es grundsätzlich zwei Möglichkeiten. Die Entscheidung der Bildregie, einen Teilnehmer (oder das Publikum) zu zeigen, kann zurückgehen auf den Sprecher selbst, der durch direkte Anrede oder durch Erwähnung einen Diskussionspartner ins Spiel bringen kann. Oder aber es handelt sich direkt um eine Wahl der Bildregie, die damit die Kontextualisierung eines Anwesenden als betroffen, als zustimmend oder ablehnend vornimmt. Mit dem Zeigen eines anderen Teilnehmers werden also implizit Beteiligungsrollen zugeschrieben, es werden Diskussionsrollen und damit Beziehungen zwischen den Teilnehmern inszeniert und zugleich wird so der vorangegangene oder aktuelle Sprechertext in einer bestimmten Weise transkribiert, ihm werden andere Beteiligte zugeordnet. Dabei sind die Hörer fast immer ,groß“ oder ,sehr groß“ im Bild, denn man soll von ihren Mienen sehr differenziert ablesen können, wie sie zum Gesagten stehen, es geht um ihre mimischen Kommentare. 
Darüber hinaus werden Personen als „Framevertreter“ gezeigt. Hat sich ein Teilnehmer explizit zu einem Thema oder Subthema geäußert, kann er von da an als Vertreter des entsprechenden semantischen Frames gelten, so dass seine Reaktion bei Wiedererwähnung des Frames von Interesse ist; so werden Kohärenzen visuell kontextualisiert, Frames auch optisch verstärkt. Zugleich werden Erwartungen geweckt, dass potenzielle Kontroversen sichtbar werden könnten, nach dem Motto: „Mal sehn, wie x dazu steht.“

Diese Verfahren sollen nun an einem Beispiel veranschaulicht werden. Im Verlauf der ziemlich langen Ausführungen von Klaus Bölling (siehe Abb. 18) werden gehäuft andere Beteiligte gezeigt, insgesamt in 18 Einstellungen (im Schema dunkler), gegenüber 14 ausschließlich vom Sprecher (im Schema heller). Ich greife nun die Einstellungssequenz 26-29 heraus, um zu sehen, wie der Sprechertext mit der Einstellungssequenz zusammenspielt.

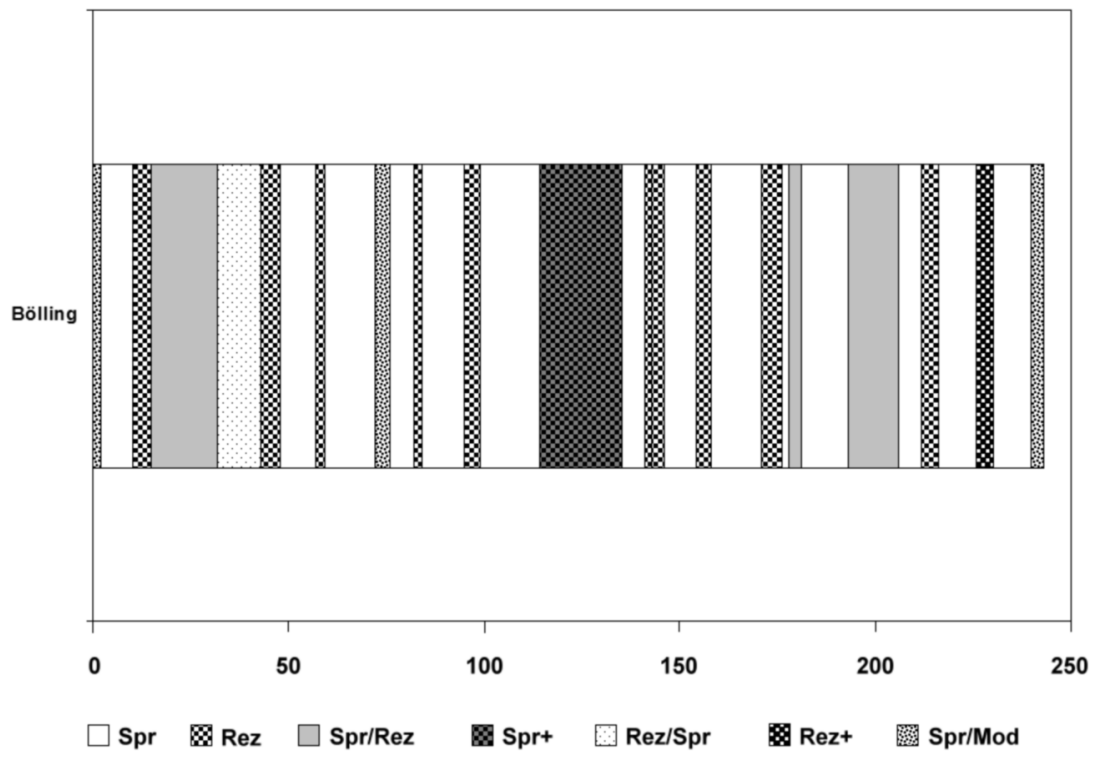

Abb. 18: Einstellungssequenz Bölling

Bölling, der während dieser Passage nur zwei Mal alleine im Bild ist, äußert dabei folgenden Sprachtext:

[26 Bö] bestimmte islamistische fundalisten [sic] sagen wir sind gesinnungstäter wir wollen die scharia und wir orientieren uns an den gesetzen des kóran und morgen // [27 Schwenk Ohr Bö Koch-Illner-Peymann/Zoom] frisch drauf los so geht das nicht wir müssen eh / alle rechtsstaatlichen gesetze regeln müssen wir / beachten und wenn herr Peymann äh diesem mann eine chance geben will da würde ich gar nicht protestieren // [28 Bö] ich sehe nur dass der herr Klar äh nicht nur gar keine reue zeigt und was reue kamman // [29 Plottnitz] spielen reue kamman heucheln sie kann auch mal $[\ldots]$ 
Während Bölling im Kontext der Terrorismusdebatte für eine harte Haltung des Staates plädiert und dazu auch islamistische Fundamentalisten anführt (im Eifer als „Fundalisten“ bezeichnet), wird als potenzieller Unterstützer Koch über den Hinterkopf von Bölling eingeblendet. Da Kochs Mimik aber zurückhaltend bis skeptisch bleibt, schwenkt die Kamera über Illner auf Peymann, als Bölling diesen gerade erwähnt. Daraufhin bleibt die Kamera auf Peymann und zoomt ihn ein bisschen näher heran, fast bis zur Großaufnahme, wie sie für solche Zwecke üblich ist (siehe Abb. 19-23).
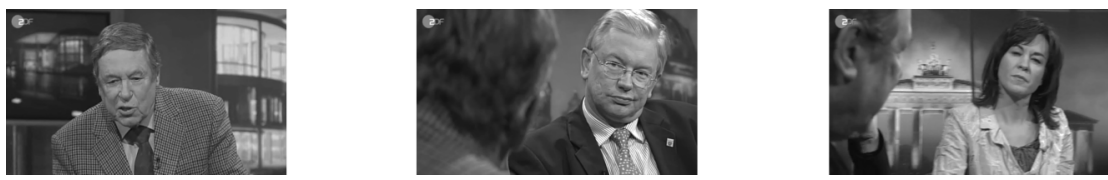

Abb. 19-21: Bölling als Sprecher, Koch als Unterstützer, Schwenk über Illner

Als Bölling im weiteren Verlauf seiner Argumentation auf die Frage kommt, ob Christian Klar, um den es die ganze Zeit eigentlich geht, Reue zeigt, wird nun von Plottnitz eingeblendet (Abb. 24), der sich in seinem Statement explizit zur Frage geäußert hatte, ob die Terroristen Reue zeigen. Dort hatte er gesagt:

vielleicht noch ein satz zu der reue weil das auch überall ne rolle spielt $[\ldots]$ ob es renebezengungen gegeben hat des weiß wissen nur die die die akten kenn // des sin ja nichtöffentliche verfahren
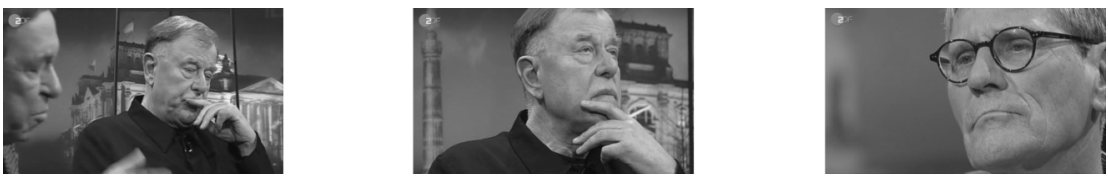

Abb. 22-24: Schwenk auf Peymann, Peymann herangezoomt, von Plottnitz wegen „Reue“

Hier zeigen sich also die verschiedenen Verfahren in der Einblendung von Beteiligten: Man zeigt solche, die aufgrund von Vermutungen der Bildregie in einem bestimmten Verhältnis zum Gesagten stehen, dann erwähnte Beteiligte, schließlich solche, die im bisherigen Verlauf der Debatte für ein bestimmtes Thema relevant sind.

Es gilt also: Die (meist kurze) Einblendung von Mitdiskutanten (meist in Großaufnahme), die sie zu „markierten Hörern“ macht, ist zugleich eine externe Weise, den Sprechertextabschnitt zu „kontextualisieren“, als besonders relevant im Hinblick auf den Gezeigten, der zum Adressaten, Unterstützer oder Kontrahent bzw. zum Repräsentanten eines Themas stilisiert oder als solcher hervorgehoben wird; damit wird der Sprechertext (nachträglich) profilierend ,transkribiert", zum Zweck der dramatisierenden Kommentierung. Dabei werden die Beteiligten typisiert: Ihnen werden von Anfang an (schon in der Vorstellung und immer wieder durch Inserts mit 
Etikettierungen) stereotype Rollen im entsprechenden Diskurszusammenhang zugewiesen, z.B. als Provokateure, Scharfmacher, Kontrahenten, Betroffene, Unterstützer, Neutrale. Diese Typisierungen strukturieren die gesamte Dramaturgie, von der Einladung über die Sitzordnung, die Vorstellung bis hin zu den Inserttexten. Die Kameraführung inszeniert dann unterstützend entsprechende Interaktions- und Konfliktlinien.

Fragt man zusammenfassend danach, wie die Kamerainszenierung in PolitTalkshows den Sprachtext transkribiert, lässt sich festhalten: Die Muster der Sequenzierung von Einstellungen durch Umschnitt kann man als ,kulturelle Praktiken" der Bedeutungskonstitution auffassen. Im Zusammenhang mit Sprachperformanz handelt es sich um ein „sekundäres System“, das Sprachliches überformt. Es ist ein implizites, unauffälliges, dennoch nicht beliebiges Vorgehen, das ohne explizites Regelwerk betrieben wird. Je nach Erfahrung und Ausbildungsstand der Macher ist es mehr oder weniger reflektiert. Meine bisherige Analyse stützt sich überwiegend auf die Produktanalyse und einige generelle Beobachtungen bei der Produktion solcher Sendungen. Dazu müssten aber Produktionsanalysen kommen, die im Stile der „work place studies“ nach dem impliziten Wissen der Macher forschen.

Die hier angestellten Überlegungen erscheinen mir in dreierlei Hinsicht relevant. Medientheoretisch können sie als Beleg dafür gesehen werden, wie ein Mediendispositiv, eine technische Struktur, gleichsam „hinter dem Rücken" der Akteure wirkt. Kommunikationstheoretisch handelt es sich um mehrfach gefilterte Botschaften; im Sinne Luhmanns geht es um „Beobachtung von Beobachtung von Beobachtung" - der Zuschauer sieht, wie die Kamera sieht, wie die Akteure etwas sehen. Die Sichtweisen der Kamera sind dabei zumeist „transparent" und „naturalisiert", indem sie wirken, auch ohne dass wir sie bewusst wahrnehmen.

\section{Kurzes Fazit}

Technische (,sekundäre“) Audiovisualität generiert hochkomplexe Bedeutungen, und zwar durch die getrennte und kombinierte Inszenierung semantisch heterogenen Materials, das durch wechselseitige Transkription nach bestimmten Mustern aufeinander bezogen ist. Solche Muster müssen genre- und kommunikationsformspezifisch beschrieben und analysiert werden, was hier an zwei Beispielen von Fernsehsendungen ausschnitthaft versucht wurde.

In Nachrichtenfilmen geht es um die Darstellbarkeit und Glaubwürdigkeit von Ereignissen, wobei die kommunikativen Konstruktionen hergestellt werden durch typische Konstellationen von wechselseitig aufeinander 
bezogenen Sprach- und Bildfunktionen, die sich auf der Basis von Kontext- und Schemawissen in einer performativen transkriptiven Dynamik wie einem Reißverschluss verbinden.

In Polit-Talkshows transkribiert die Kamerainszenierung SprecheräuBerungen zum Zwecke von a) Abwechslung und Gliederung, b) Sprecherprofilierung und c) Profilierung von Beteiligungsrollen anderer, so dass die Organisation des Gesprächs übersichtlicher und die Beziehungsgestaltung zu und zwischen den Beteiligten intensiver und für den Zuschauer attraktiver werden (Stichwort: Quote!).

\section{Literatur}

Barthes, Roland ([1964] 1990): Die Rhetorik des Bildes. In: Barthes, Roland: Der entgegenkommende und der stumpfe Sinn. Frankfurt a. M., S. 28-46. [Frz. Orig. 1964].

Brosius, Hans-Bernd (1998): Visualisierung von Fernsehnachrichten. Text-Bild-Beziehungen und ihre Bedeutung für die Informationsleistung. In: Kamps, Klaus/Meckel, Miriam (Hg.): Fernsehnachrichten. Prozesse, Strukturen, Funktionen. Opladen/Wiesbaden, S. 213-224.

Burger, Harald (2005): Mediensprache. Eine Einführung in Sprache und Kommunikationsformen der Massenmedien. 3., völlig neu bearb. Aufl. Berlin/New York.

Girnth, Heiko/Michel, Sascha (Hg.) (i.Vorb.): Multimodale Kommunikation in PolitTalkshows. Stuttgart.

Holly, Werner (2003): „Ich bin ein Berliner“ und andere mediale Geschichts-Klischees. Multimodale Stereotypisierungen historischer Objekte in einem Fernsehjahrhundertrückblick. In: Schmitz, Ulrich/Wenzel, Horst (Hg.): Wissen und neue Medien. Bilder und Zeichen von 800 bis 2000. (= Philologische Studien und Quellen 177). Berlin, S. 215-240.

Holly, Werner (2008): Audiovisuelle Sigetik. Über verborgene Bedeutungen im BildSprach-Zusammenhang. In: Pappert, Steffen/Schröter, Melani/Fix, Ulla (Hg.): Verschlüsseln, Verbergen, Verdecken in öffentlicher und institutioneller Kommunikation. (= Philologische Studien und Quellen 211). Berlin, S. 147-169.

Holly, Werner (2009): Bildüberschreibungen. Wie Sprechtexte Nachrichtenfilme lesbar machen (und umgekehrt). In: Diekmannshenke, Hajo/Klemm, Michael/Stöckl, Hartmut (Hg.): Bildlinguistik. Berlin. [ersch. demn.].

Holly, Werner (i.Vorb.): Bildinszenierung in Talkshows. Medienlinguistische Anmerkungen zu einer Form von „Bild-Sprach-Transkription“. In: Girnth/Michel (Hg.).

Holly, Werner/Kühn, Peter/Püschel, Ulrich (1986): Politische Fernsehdiskussionen. Zur medienspezifischen Inszenierung von Propaganda als Diskussion. (= Medien in Forschung + Unterricht, Serie A, 18). Tübingen.

Huth, Lutz (1985): Bilder als Elemente kommunikativen Handelns in Fernsehnachrichten. In: Zeitschrift für Semiotik 7, S. 203-234. 
Jäger, Ludwig (2002): Transkriptivität. Zur medialen Logik der kulturellen Semantik. In: Jäger, Ludwig/Stanitzek, Georg (Hg.): Transkribieren. Medien/Lektüre. München, S. $19-41$.

Jäger, Ludwig (2004): Die Verfahren der Medien: Transkribieren - Adressieren - Lokalisieren. In: Fohrmann, Jürgen/Schüttpelz, Erhard (Hg.): Die Kommunikation der Medien. (= Studien und Texte zur Sozialgeschichte der Literatur 97). Tübingen, S. 69-79.

Jäger, Ludwig (i.d.Bd.): Intermedialität - Intramedialität - Transkriptivität. Überlegungen zu einigen Prinzipien der kulturellen Semiosis.

Jewitt, Carey/Oyama, Rumiko (2001): Visual meaning. A social semiotic approach. In: van Leeuwen, Theo/Jewitt, Carey (Hg.): Handbook of visual analysis. London u.a., S. 134-156.

Keppler, Angela (2006): Mediale Gegenwart. Eine Theorie des Fernsehens am Beispiel der Darstellung von Gewalt. Frankfurt a.M.

Klemm, Michael (i.Vorb.): Zur Gestaltung und strukturellen Rolle der Einspielfilme in „Hart, aber fair". In: Girnth/Michel (Hg.).

Kress, Gunther/van Leeuwen, Theo (1996): Reading images. The grammar of visual design. London/New York.

Meyer, Thomas/Ontrup, Rüdiger/Schicha, Christian (2000): Die Inszenierung des Politischen. Zur Theatralität von Mediendiskursen. Wiesbaden.

Rauh, Reinhold (1987): Sprache im Film. Die Kombination von Wort und Bild im Film. Münster.

Sachs-Hombach, Klaus (2003): Das Bild als kommunikatives Medium. Elemente einer allgemeinen Bildwissenschaft. Köln.

van Leeuwen, Theo (2005): Introducing social semiotics. London/New York. 


\title{
Schrift an Bild im World Wide Web \\ Articulirte Pixel und die schweifende Unbestimmtheit des Vorstellens
}

\begin{abstract}
Wie wirkt sich die je spezifische Materialität von Sprache auf die Gestalt unserer Zeichen und damit auf die Bildung unserer Vorstellungen aus? Das wird hier am Beispiel von Schrift im World Wide Web untersucht. Unter dem Einfluss technisierter Materialität, Medialität und Multimodalität bildet sich eine Schriftlichkeit aus, deren Erscheinungsform und Bedeutung aus dem semiotischen Zusammenspiel von Sehflächen-Design, Bild und Text erwächst. Vor dem Hintergrund einer medial gestützten Geschichte kommunikativer Abstraktion, in deren Verlauf Leib und Seele im Bewusstsein auseinander traten, und anhand charakteristischer Beispiele aus dem WWW werden Entstehungsbedingungen, Eigenschaften und Leistungen solch ,tertiärer Schriftlichkeit' erläutert.
\end{abstract}

\section{Semiotechnik - what else?}

Bitte schauen Sie zunächst den Werbefilm „Mistaken“ im World Wide Web an: www.nespresso-whatelse.com. ${ }^{1}$ Was haben Sie hier gesehen?

\subsection{Erstes Beispiel: Situiert und verkörpert}

Wir haben eine künstlich arrangierte Situation sozialer Interaktion erlebt, die in jeder Hinsicht möglichst alltäglich erscheinen soll (und in die wir durch die Hintergrundgeräusche als voyeuristisch teilnehmende Beobachter möglichst authentisch einbezogen werden sollen), obgleich wir natürlich wissen, dass es um Werbung geht, die sich versteckt: Der berühmte Schauspieler und Regisseur George Clooney inszeniert sich als zuerst richtig, dann vermeintlich irrtümlich erkannte Alltagsperson. Augenzwinkernd spielt das filmische Theater im Theater mit der fragilen Balance von Fiktion und Wirklichkeit, Maskerade ohne Maske.

Medial wird hier natürliche Face-to-face-Kommunikation ${ }^{2}$ vorgeführt mit allen deren Kennzeichen: Personen in ihrer gesamten Körperlichkeit interagieren in einer ganz bestimmten (typischerweise einzigartigen, unwiederholbaren) Situation. In der englischsprachigen Literatur gibt es dafür die knappen Schlagwörter embodiment and situatedness (Verkörperung und Situiertheit). Beide gelten der modernen Cognitive Science (und in deren Rahmen

\footnotetext{
$\overline{1}$ Er stammt aus dem Jahre 2008 und findet sich als 31-Sekunden-Film mehrfach auch in www. youtube.com, z.B. über die Suchwörter „Nespresso Clooney 2008“.

2 Weinrich (1988, S. 81) nennt das „Blickstellung“.
} 
auch der kognitiven Linguistik) als die charakteristischen Merkmale ,natürlicher ${ }^{6}$ Kommunikation. ${ }^{3}$ Auf den ersten Blick erscheinen diese beiden Merkmale im Beispiel auch so. Auf den zweiten Blick (den Blick hinter die Kulissen) wissen wir natürlich, dass gerade diese beiden Eigenschaften hier als scheinbar authentisch nur simuliert wurden (denn mediale Kommunikation ersetzt ja gerade ,natürliche' Unmittelbarkeit). Auf den dritten Blick jedoch können wir in unserem eigenen Leben beobachten, wie mediale Kommunikation immer tiefer in unseren Alltag einwandert und ,natürliche' Face-toface-Kommunikation durchdringt und umgestaltet.

Je weiter menschliche Geschichte voranschreitet, desto mehr wird Kommunikation (wie die meisten anderen Lebensbereiche auch) technisiert und dadurch verändert.

\subsection{Zweites Beispiel: Technische Simulation und Schrift}

Die folgenden Überlegungen gelten einem ganz kleinen Aspekt innerhalb dieses Jahrtausende alten und sich immer schneller beschleunigenden Vorgangs zunehmender Technisierung von Kommunikation und seiner Auswirkungen auf Sprache, nämlich der Veränderung von Schriftlichkeit auf hochauflösenden Bildschirmen. Es geht also nicht um die äußere Erscheinung von Schrift, ${ }^{4}$ sondern um Schriftlichkeit (im Gegensatz etwa zu Mündlichkeit und Bildlichkeit) als allgemeine Ausdrucksform. Ich möchte zeigen, wie Schriftlichkeit sich ändert unter dem Einfluss dreier zunehmend technisierter Faktoren, nämlich MATERIALITÄT, MEDIALITÄT UND MULTIMODALITÄT.

Betrachten Sie dieses Beispiel aus der gleichen Werbekampagne:

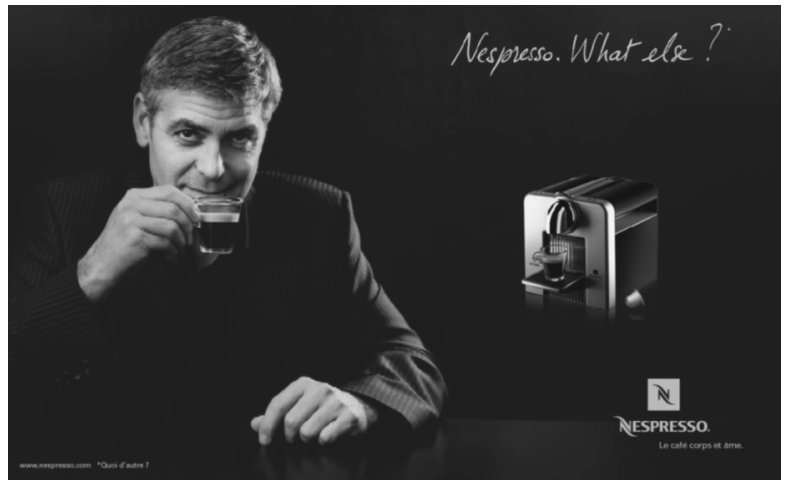

Abb. 1: Nespresso-Werbung (Werbeplakat am Flughafen Paris-Orly Dezember 2008) ${ }^{5}$

Vgl. z.B. Gibbs (2006).

Für Schriftschnitt, Zeichensatz, Typographie, Kalligraphie etc. eröffnen sich durch Digitalisierung auch neue Perspektiven, doch das ist ein Thema für sich. Vgl. z.B. Spitzmüller (2006) und Wehde (2000).

5 www.effie.fr/palmares/2007/nespresso/Affiche/nespresso_affiche2.pdf (Stand: Januar 2009). 
Unsere schriftgewohnte Leseblickrichtung von links nach rechts verknüpft das Glas Kaffee an Clooneys Lippen (body) mit dem perspektivisch kleineren, sonst gleichen Glas an der Kaffeemaschine (Technik). In diese elliptisch konzentrierte, minimalistische Situation werden wir durch Clooneys freundlichen Blick einbezogen. Unmittelbar nach diesem Bildfang nehmen wir rechts oben ein handschriftliches Textfeld wahr. Mit Clooney und Kaffeemaschine verbindet es sich zu einem imaginären Dreieck. So wirkt es als Sprechblase, das mit seinem elliptischen Slogan-Text „Nespresso. What else?“ die medial fehlende Mündlichkeit ersetzt. Clooney scheint uns direkt anzusprechen. Sein Ausdruck (vornehmlich mimisch übers Gesicht), die Darstellung (vornehmlich über das Bild der Kaffeemaschine) und der Appell (vornehmlich über den Wortlaut) sind fein säuberlich auf die drei Ecken verteilt, als sollte Bühlers (1934, S. 28) Organon-Modell illustriert werden. In diesem wohlgeplanten Zusammenspiel trägt Schrift keine Bedeutung für sich allein, sondern nur in Verbindung mit den Bildern, hier also aus der simulierten Interaktionssituation heraus. Weil wir das meiste aus der Situation verstehen, kann der Text so knapp und grammatikarm sein: drei lexikalische Morpheme ohne grammatische Markierung und zwei Interpunktionszeichen. MATERIELLE, MEDIALE und MODALE Konstellationen prägen den Text.

\subsection{Thema und Gegenstand des Aufsatzes}

Ich möchte in diesem Beitrag darlegen, wie sich die materielle Grundlage von Sprache auf die Gestalt unserer Zeichen auswirkt und damit auf die Bildung dessen, was wir ausdrücken, also auf unsere Vorstellungen.

Dabei konzentriere ich mich auf diejenigen Fallgruppen, in denen sichtbare öffentliche Kommunikation sich heute am häufigsten vollzieht, nämlich auf Text-Bild-Verbindungen, wie sie uns auf Sehflächen fast überall umgeben. ${ }^{6}$ Sehflächen sind Flächen, auf denen Texte und Bilder in geplantem Layout gemeinsame Bedeutungseinheiten bilden. ${ }^{7}$ Hier wiederum

Christina Weiss bemerkte schon 1984 zu Beginn des Vorwortes zu ihrer Dissertation von 1982: „Die Orte der Sprache sind allgemeiner geworden. Sprache begegnet uns körperhafter und bildhafter denn je in der unmittelbaren Umwelt. Wir leben inmitten eines riesigen Sprachgewimmels und Wortgedröhns, das wir pausenlos - routiniert - verarbeiten: aus Bildund Tongeräten, aus gedruckter Massenware, von Plakaten und Schildern herab, von einer längst überdosierten Menge der Gegenstandsverpackungen rückt uns die Sprache auf Schritt und Tritt zu Leibe. Die öffentliche Textbegegnung ist sehlastig. Die Sprache, die uns umfängt, nehmen wir in der Mehrzahl als Bild bzw. in der Kombination mit Bildern wahr. Wir sehen die Sprache, bevor wir sie lesen, wir registrieren - bewußt oder unbewußt - diverse Schrifttypen, -größen und -farben. Buchstaben und Wörter fügen sich nahtlos in die Reihe der Alltagsalphabete aus Bildzeichen und Sehsignalen." (Weiss 1984, S. 7).

Siehe Schmitz (im Druck). „Seh-Texte“ hingegen nennt Weiss (1984, S. 16) - im Anschluss an Ferdinand Kriwet (dazu Weingart 2007) - künstlerische Arbeiten, „,welche durch die Reflexion auf die Möglichkeiten ihres Ausdrucksmediums in dessen Grenzbereiche vordringen 
beschränke ich mich auf die avantgardistischste Kommunikationsform, das World Wide Web. Es setzt Trends auch für andere, ältere und trägere Kommunikationsformen (z.B. Plakate, Zeitschriften, Schulbücher u.a.). Und ich kümmere mich weniger um Beziehungen zwischen Text und Bild (die zu untersuchen auch sehr spannend ist) ${ }^{8}$ als vielmehr um Veränderungen an Schriftlichkeit selbst: Wie reagiert Schrift auf die technisierte MATERIALITÄT, MEDIALITÄT UND MULTIMODALITÄT in Hypermedia? Folglich geht es um „Schrift an Bild im World Wide Web“.

Das gezeigte Beispiel (Abb. 1) steht vertretungsweise für viele. Sie alle treten an einer bestimmten Stelle in einer großen historischen Entwicklung auf, die - vordergründig unsichtbar - in sie eingeschrieben ist. Es ist eine medial gestützte Entwicklung kommunikativer Abstraktion, in deren Verlauf Leib und Seele im Bewusstsein auseinandertreten.?

\subsection{Gliederungsausblick}

Auf diese Geschichte gehe ich im 2. Teil kurz ein. Im dann folgenden 3. Teil plädiere ich dafür, beim Nachdenken über Zeichen nicht deren Körper zu vergessen. Teil 4 unterscheidet Material, Medium und Kommunikationsform als Ressourcen und stets wirksame Rahmenbedingungen menschlicher Kommunikation. Teil 5 beschreibt deren ausdrucks- und Teil 6 deren inhaltsbezogene Auswirkungen auf Sehflächen im Web. Der abschließende 7. Teil diskutiert performative Effizienz und Lust unter den Bedingungen technisch erzeugter Situiertheit von Kommunikation.

\section{Kommunikative Abstraktion durch Technik}

\subsection{Unmittelbare Kommunikation}

1) Kommunikation verläuft prototypisch und zuerst interaktiv mit allen Sinnen zwischen zwei oder mehreren Partnern, die sich am selben Ort und zur gleichen Zeit in einer gemeinsamen Situation, also auch in einem gemeinsamen Wahrnehmungsraum befinden. In menschlichen Gesellschaften bildet sich dafür phylo- wie ontogenetisch mündlich-verbaler Austausch als

und in gleicher Weise mit bildnerischen wie mit sprachlichen Mitteln arbeiten“, insbesondere visuelle Poesie. Vgl. auch Linck/Rentsch (Hg.) (2007), daneben Eckkrammer/Held (Hg.) (2006).

8 Allgemein dazu siehe z.B. Stöckl (2004); zu Text-Bild-Beziehungen im Www Runkehl (2005), Schmitz (2003), Siever (2005), Storrer (2004); zu Bild-Diskursen im Netz Meier (2008); vgl. auch Vlasic/Schweiger (1998).

9 Die Entwicklung des abendländischen Dualismus von Leib/Körper vs. Seele/Geist mit seinen zeichentheoretischen Implikationen braucht hier nicht detailliert nachvollzogen zu werden (vgl. dazu - etwa neben Hörisch 1992 - die Artikel „Doppelnatur“, „Leib, Körper“, „Leib-Seele-Verhältnis“, „Geist“" und „Seele“ in Ritter/Gründer/Gabriel (Hg.) 1971-2007). Es kommt hier nur ,auf das populäre Bewußtsein“ (ebd., Bd. 2, Sp. 282) an. 
vorrangiger Modus aus, bleibt aber in nonverbale Modi (z.B. Gestik und Mimik) eingebettet. Dieser erste Kommunikationstyp heißt (sachlich nicht ganz zutreffend) unmittelbare Kommunikation, weil nur der menschliche Körper ohne technische Unterstützung als Medium dient. Er ist also MULTIMODAL und MONOMEDIAL.

2) Im Laufe der (Entwicklungs- wie Individual-)Geschichte wird diese ursprüngliche Kommunikationsform immer mehr ergänzt durch zunehmend abstrakte Kommunikationsformen: Elemente der ursprünglichen Situation (a) fallen weg und (b) werden (teilweise) durch technische Mittel ersetzt; „semiologisch integrierte Aktivität“ (Harris 2008, S. 18) wird also komplexer. (i) Kommunikation löst sich ab von der unmittelbaren Einbindung in arbeitsteilig-praktische Überlebensprozesse. Sie dient auch Magie, religiösen Praktiken und spielerischer Lebensfreude. (ii) Zunehmend wird Sprache auch als Reflexionsmittel benutzt. Philosophie, Mathematik und intellektuelle Berufe entstehen. ${ }^{10}$ (iii) In dieser Linie von Entsinnlichung und Vergeistigung entdeckten unsere Vorfahren vor wenigen Jahrtausenden mit der Erfindung von Schrift eine andere materielle und modale Grundlage von Sprache: Neben den akustischen tritt ein optischer Träger, statt Mund und Ohr fertigen Hand und Auge die Botschaft. ${ }^{11}$

\subsection{Zerdehnte Kommunikation}

Die neuen Übertragungsmittel sind nicht mehr flüchtig, sondern beständig. So erlaubt Schrift Kommunikation und Überlieferung unabhängig von Raum und Zeit, also - wie Ehlich (1983, S. 32) sagt - in einer „zerdehnten Sprechsituation“. Das hat natürlich Folgen für die sprachliche Form. Schriftsprache entsteht. Alles muss ausformuliert werden, was der Empfänger über die Situation des Senders nicht wissen kann, weil ein gemeinsamer Wahrnehmungsraum fehlt. Und weil nicht unmittelbar reagiert oder rückgefragt werden kann, muss kohärenter Sinn in kohäsiven Texten ausgeprägt werden, die als geschlossene Monologe und mehr oder weniger autonome Ganzheiten möglichst aus sich selbst verstanden werden können. Entsprechend werden grammatisch wohlgeformte Sätze in klarer innerer Gliederung und möglichst geregelten Mustern (Textsorten) erwartet. So kann man sagen, „daß mit der Erfindung der Schrift die Spezifik des Texts materialisiert wird.“ (ebd., S. 39) Und mittels Schrift können auch die Formen gesellschaftlichen Wissens anders organisiert werden, weil das Gedächtnis entlastet wird.

Zwar wird sowohl beim Verfertigen als auch beim Lesen schriftlicher Texte zuerst noch laut gelesen. Für die Antike resümiert Ludwig (2005, S. 72 f.) sogar: „Texte gibt es eigentlich nur als gesprochene.“ Doch von

\footnotetext{
$10 \quad$ Soweit vgl. Malinowski (1974).

11 Zur Evolution von Sprache insgesamt vgl. Leroi-Gourhan (1980).
} 
Anfang an unterstützt Schrift Reflexion, nicht zuletzt auch über Sprache selbst. Oder, wie Humboldt (1994c, S. 100) sagt: „Ihre allgemeinste Wirkung ist, dass sie die Sprache fest heftet, und dadurch ein ganz andres Nachdenken über dieselbe möglich macht."

Im Anschluss an Ehlichs Ausdruck nenne ich diesen zweiten Typ gesellschaftlicher Verständigung zerdehnte Kommunikation. Zerdehnte Kommunikation ist tendenziell MONOMODAL und MONOMEDIAL; prototypisch funktioniert sie über klar ausformulierte Ganztexte.

\subsection{Verdichtete Kommunikation}

Mit wachsender gesellschaftlicher Differenzierung wird dieser Typ immer komplexer, so dass daneben allmählich ein zusätzlicher dritter Typ heranwächst, den ich verdichtete Kommunikation nennen möchte. Zunächst, vor einem halben Jahrtausend, lässt die Erfindung des Buchdrucks ${ }^{12}$ als zweite kommunikationstechnische Revolution den zerdehnten Raum zwischen den Kommunikationspartnern auf völlig neuartige und vielfältige Weisen ausfüllen. Reichweite und Frequenz der Fernkommunikation werden erhöht, neue Funktionen entdeckt, für Materialien, Modi, Gestaltung und Formen der fixierten Botschaften ungeahnte Variationen entwickelt, und es entstehen neue schriftliche Standardsprachen, zugerichtet - wie Giesecke (2006, S. 489) sagt - „auf die technischen Parameter“ des Buchdrucks. ${ }^{13}$ Schrift steigt zum dominanten und angesehensten Kulturträger auf; ${ }^{14}$ Mündlichkeit und Bildlichkeit treten demgegenüber zurück.

Audiovisuelle Medien im 20. Jahrhundert dann (bis etwa 1990) erweitern das mediale Spektrum. Telefon (gesprochene Sprache), Schallplatte und Hörfunk (plus Ton und Musik), Film und Fernsehen (plus bewegte Bilder) technisieren immer mehr Kommunikationskanäle und untergraben allmählich die vorübergehende Monopolstellung der Schrift. Derart verdichtete Kommunikation muss nicht notwendig mehr zerdehnt, sondern kann teilweise synchron geschehen. Gleichzeitig wandern Zeichen aus individueller Verfügung heraus und treten Individuen massenhaft gegenüber fast als ein Lärm und Rauschen, in dem sinnvolle Orientierung eigener Kulturtechniken bedarf. (Man stelle sich dagegen vor, welch eine geringe Informationsmenge, wie wenig Wissen also ein Proto-Google in der Antike hätte verwalten müssen.) Verdichtete Kommunikation ist MULTIMODAL und MULTIMEDIAL.

\footnotetext{
12 Dazu Giesecke (2006 [1991]); vgl. auch Füssel (1999).

13 In gleicher Weise hat im 20. Jahrhundert der Hörfunk zur Durchsetzung einer überregionalen mündlichen Standardsprache beigetragen.

14 Luthers (1521, S. 98) später zum Schlagwort gewordene Wendung „solam scripturam regnare" trifft über den Bibelbezug hinaus einen Kern des kulturellen Wandels.
} 
Und dann, erst in unserer Generation, tritt mit dem hochentwickelten Computer eine semiotische Universalmaschine auf den Plan, die fast alles Kommunizierbare technisieren kann - auch wenn die Hardware (der materielle Körper) derzeit immer noch recht beschränkt daher kommt: viel Material, kleine, starre, schwere Bildschirme, träge Akkus, immer noch zahlreiche Kabel, umständliche Peripherie-Geräte. ${ }^{15}$ Über all das werden wir in 20 Jahren lachen. Freyermuth (2005, S. 19, 21 f.) hat zu Recht darauf hingewiesen, dass erst die digitale Technik eine wirkliche Verschmelzung der verschiedenen Medien ermöglicht und dass Hardware immer mehr durch Software ersetzt wird - mit der Folge, dass materieller Mangel, technische Beschränkungen und materiale Differenzen schwinden.

Für unser Thema spielt aber nur die Oberfläche eine Rolle, also die so genannte ,Schnittstelle zwischen Mensch und Maschine, insbesondere der Bildschirm. ${ }^{16}$ Computerkommunikation technisiert tendenziell alle Dimensionen der ursprünglichen Kommunikationssituation, macht also die bisherigen mediengeschichtlich erzwungenen Einschränkungen und daraus erwachsenden Abstraktionen bei der Technisierung natürlicher Kommunikation möglichst rückgängig: 1) Mit multimodalen Zeichen kann die Einbindung der Kommunikationspartner in eine mehr oder weniger gemeinsame Situation hergestellt (z.B. in Videokonferenzen) oder zumindest simuliert (z.B. in Chats) werden. 2) Das Maß an zeitlicher Zerdehnung kann beliebig manipuliert werden bis hin zur völligen Aufhebung in simultaner Online-Kommunikation. 3) Räumliche Distanzen werden kaum noch als solche erlebt. Je mehr Eigenschaften unmittelbarer Kommunikation (Typ I) technisierte Kommunikation sich anverwandeln kann, desto erfolgreicher wandert sie in Alltagskommunikation ein und durchzieht sie. Das ist das bestimmende Merkmal verdichteter Kommunikation (Typ III): Sämtliche Arten technisierter und unmittelbarer Kommunikation spielen gleichzeitig und hochkomplex eng zusammen.

Einerseits ist erstaunlich, dass die Evolution das noch mitmacht und die biologischen Möglichkeiten menschlicher Körper nicht an ihre Grenzen stoßen. Andererseits werden stets neue, aus der Sicht der alten oft hybride, Kommunikationsformen und Ausdrucksweisen erfunden, die den neuen Bedingungen möglichst gut angepasst sind ${ }^{17}$ - so auch die unten zu beschreibenden Spielarten von Schriftlichkeit.

15 „noch obsiegt der Widerstand der Materie über den menschlichen Willen“ - so begründet Stefan Zweig (1997, S. 153) den beschränkten Rhythmus menschlicher Bewegung bis weit ins 19. Jahrhundert hinein.

16 Ich denke hier nur an PCs und Laptops. Für die viel kleineren Multimedia-Handys wurden teils semiotisch schlankere Text-Bild-Kombinationen entwickelt.

17 Und - worauf Raab (2008, S. 45) hinweist - ,immer wieder Sehattraktionen bieten, welche die Wahrnehmung in neue, unbekannte Blickräume und Blickweisen überführen, die das Sehfeld über den Horizont hinaus erweitern und dem Betrachter immer wieder die Grenzenlosigkeit des Sichtbaren und noch zu Schauenden vor Augen führen.“ 
Für die Zukunft können wir also erwarten, dass Kommunikation noch dichter, komplexer und multimodaler wird. Digitalisierung macht technische Kommunikation immer flexibler und ihre materiellen Grundlagen weniger sperrig und weniger sichtbar. In der weitgehend schriftgebundenen Phase zerdebnter Kommunikation wanderten Zeichen aus unmittelbaren Situationen aus in scheinbar selbständige zweite Welten. Kien in seiner Bibliothek in Canettis Roman „Die Blendung“ (1936) steht emblematisch dafür. Im gegenwärtigen Zeitalter dichter Kommunikation wird der Bibliomane von Computersüchtigen in Second Worlds abgelöst; gleichzeitig durchdringt technisierte Kommunikation aber auch, viel stärker als früher, den ,normalen' Alltag und wächst in unmittelbare Kommunikation ein. Dabei verliert Schrift ihren viele Jahrhunderte währenden dominanten Status an einen multimodal-barocken Kommunikationsraum mit allerdings neuartigen, dezentralen Herrschaftsstrukturen. Er trägt und prägt die meisten Diskurse. Schriftlichkeit nimmt darin neue Funktionen und Formen an.

Das heißt mitnichten, dass Materialität verschwände, also in ,Immaterialität ${ }^{\dagger}$ aufginge. Doch die Art und Weise, wie wir unsere Vorstellungen in Zeichen materialisieren, folgt natürlich auch jetzt den neuen physikalischen Bedingungen.

\section{Res cogitans extensa}

Die skizzierte Entwicklung zunehmender Abstraktion und teilweise Technisierung von Elementen der ursprünglichen, unmittelbaren Kommunikation förderte unsere geistigen Abstraktionsfähigkeiten und schließlich -gewohnheiten. Empraktische Tätigkeit tritt, wie bei Kien, in den Hinter-, geistige Arbeit im Feld der Zeichen in den Vordergrund. Schon die berühmteste Darstellung der Ursprungssituation, Bühlers (1934, S. 102-120) Hier-jetzt-ich-Origo, abstrahiert stark von der dialogischen Wechselseitigkeit der Sprecher-Hörer-Rollen und argumentiert vornehmlich aus der egozentrischen Sicht eines der Partner. ${ }^{18}$ Ganz allgemein denken erwachsene Menschen weniger aus der direkten Begegnung mit materiellen Gegebenheiten heraus als viel mehr geistig vermittelt über Zeichen. Im Laufe der Menschheitsgeschichte bildete sich immer umfassender eine scheinbar eigenständige Welt aus Zeichen aus, durch die hindurch wir die materielle Realität wahrnehmen. ${ }^{19}$

18 Weinrich (1988, S. 82) weist auf die egocentric fallacy hin, der Bühler unter dem Einfluss von Fichtes idealistischer Philosophie erlegen sei. „Wenn Sprache nämlich in ihrer kommunikativen Natur an das Substrat des Leibes gebunden ist, kann sie nicht bei einem einsamen Ich ihren Ausgang nehmen, sondern hat als ihre origo die kommunikative Dyade, bestehend aus einem Sprecher/Hörer und einem Hörer/Sprecher, die beide kommunikativ gleichberechtigt sind.“

19 Vgl. Peirce (1967, S. 42): „Wir haben kein Vermögen, ohne Zeichen zu denken.“ (CP 5.265). 
Dieser Verlauf unterstützte in dem Bild, das wir uns von unserer Welt machen, die Vorstellung von einer (dann leichtfertig als ontologisch gedachten) Zweiteilung/Dichotomie: Auf der einen Seite (unten) die res extensa (body, Materie; eher Hölle, unten, Hauptschule, Handwerker im blue collar), auf der anderen die res cogitans (mind/soul, Geist/Seele; eher Himmel, oben, Gymnasium, Wortwerker im white collar). Descartes, auf den die griffigen lateinischen Termini zurückgehen, sah das wesentlich differenzierter ${ }^{20}$ doch durchzieht die religiös untermauerte und dogmatisch trivialisierte Tradition den abendländischen Alltagsdiskurs. (Sie erinnern sich an das NespressoLogo unten rechts im vorigen Beispiel:)

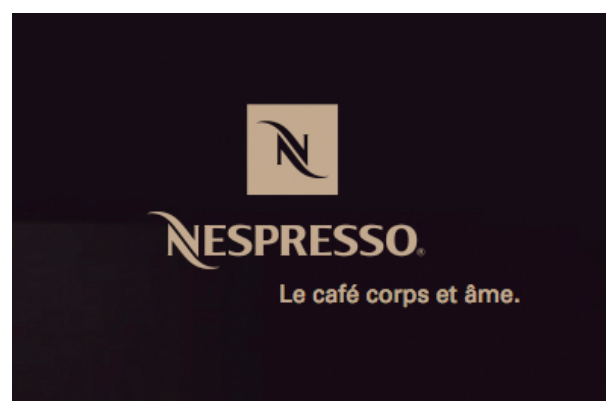

Abb. 2: Nespresso-Logo (Ausschnitt aus Abb. 1)

In Wirklichkeit gibt es keine res cogitans ohne extensa. Insbesondere - das möchte ich zeigen - prägt die materielle Grundlage die Form unserer Zeichen mit. Doch ein Großteil der linguistischen Theorie im 20. Jahrhundert bewegt sich im Diskurs über Sprache, wie er Typ II (zerdehnte Kommunikation zwecks möglichst unveränderter Aufbewahrung und Überlieferung im Botenmodell) ${ }^{21}$ entspricht. Darin kommt es ja auf den Wortlaut an, den identischen Sinn, der möglichst getreu zu übermitteln und zu verstehen ist. Und dafür spielt die abstrakte Norm die entscheidende Rolle; eigene Merkmale der äußeren Form, vor allem aber der materiellen Grundlage, sind in ihrer für diesen Zweck störenden Widerspenstigkeit möglichst zu neutralisieren. ${ }^{22}$ Durch Konzentration auf die Form ist (oder vielleicht: war?) Materialität, der ,Körper` unserer Mitteilungen, weitgehend aus dem Blickfeld der Sprachwissenschaft verschwunden - ähnlich wie der menschliche Körper aus dem Blickfeld der Mainstream-Psychologie geriet (Costall 2007, S. 56, 58-64). So wurden Aura, Stimme und Stimmung, Aussprache, Ak-

20 Vgl. etwa Costall (2007, S. 57 f.).

21 Dazu Krämer (2008).

22 Solches Denken beförderte ,a semiotics in which matter did not matter. [...] In disregarding matter in this way, linguists and semioticians followed a cultural trend in which the de-contextualised power of design reigned over the specifities, the practicalities and the realities of everyday life and art" (Kress/Van Leeuwen 2001, S. 69 f.). 
zent, Prosodie, Intonation, Gestik, Mimik, Proxemik, Handschrift und alle individuell-performativen Merkmale von Kommunikation marginalisiert oder psychologisiert. ${ }^{23}$

Man denke an das bilaterale Zeichenmodell der mittelalterlichen Scholastik, das über Saussures (1967) Cours wieder Einfluss gewann. ${ }^{24}$ Jede Verbindung von Ausdruck und Inhalt gilt als Zeichen. Der Strukturalismus konzentriert sich dabei auf die Form beider Seiten. In der eben skizzierten Tendenz, geistige von körperlichen Erscheinungen zu isolieren, werden materielle Grundlagen von Zeichen ignoriert. ${ }^{25}$ Eine vollständige Skizze hingegen müsste so aussehen:

\begin{tabular}{|c|c|c|c|}
\hline \multicolumn{3}{|c|}{ Verbindung durch sich bietende Gelegenheit oder bewusste Wahl } \\
\hline \multicolumn{2}{|c|}{ MATERIELLER TRÄGER } & \multicolumn{2}{|c|}{ GEISTIGE FORM } \\
\hline Rohstoff & Form & Ausdruck & Inhalt \\
\hline Verbindung durch körperliche Tätigkeit & \multicolumn{3}{|c|}{ Verbindung durch Konvention } \\
\hline
\end{tabular}

Wenn Menschen (ja stets durch Zeichenbildung) kommunizieren, prägen sie einem materiellen Träger (Schallwellen, Farbpigmenten u.a.) durch körperliche Tätigkeit Formen auf, die sie als konventionalen Ausdruck intentionaler Inhalte verstehen. Aus Natur wird Kultur. In günstiger Routine geschieht das reibungslos. Erst unter widrigen Umständen oder bei großer Kreativität wird die Spannung zwischen totem Rohstoff und lebendiger Mitteilung spürbar. Doch immer prägt die materielle Grundlage die Form des Ausdrucks mit.

Noch im Diskurs über „Materialität““ wird Material verleugnet. ${ }^{26}$ Der damals wegweisende, über 900 Seiten starke Sammelband von Gumbrecht/ Pfeiffer (Hg.) (1988) über „Materialität der Kommunikation“ kreist um „Se-

23 Vgl. dazu auch Koch/Krämer (Hg.) (1997), darin insbesondere die Einleitung der Herausgeber. Krämer (1997, S. 107 f.) erinnert in diesem Band u.a. auch daran, wie Derrida die abendländische Reflexion über Schrift „als Symptome einer mißglückten Verdrängung“ deutet: „Verdrängt werden dabei die für die Schrift konstitutiven Phänomene der Materialität, der Äußerlichkeit, der Abwesenheit und der Nicht-Ursprünglichkeit; das sind aber allesamt Phänomene, welche die philosophische Plausibilität einer Idealität des Sinns, einer Metaphysik der Präsenz und einer am intentionalen Bewußtsein orientierten Theorie des Geistes unterminieren könnten.“ - Zur Materialität von Schrift vgl. etwa Greber/Ehlich/Müller (Hg.) (2002).

24 „Ich nenne die Verbindung der Vorstellung mit dem Lautbild das Zeichen.“ (Saussure 1967, S. 78). Der authentische Saussure allerdings erfasst erheblich intensiver das performative Zeichenspiel; vgl. etwa Jäger (2008).

25 „Das sprachliche Zeichen ist also etwas im Geist tatsächlich Vorhandenes.“ (Saussure 1967, S. 78).

26 Etwa in der Art des Philosophenkongresses über die Frage, ob der Gelbe Fluss wirklich oder nur in den Köpfen existiert: Sämtliche Teilnehmer kamen durch eine Überschwemmung ums Leben, weshalb die Frage bis heute „ungelöst“ blieb (Brecht 1967, S. 2211 f.). 
mantiken von Materialität" (Pfeiffer 1988, S. 17) und beschäftigt sich gleichermaßen mit dem menschlichen Körper bzw. Leib, mit Apparaten, Medien und materiellen Trägern von Kommunikation als selbst (angeblich) nicht sinnhaften Voraussetzungen von Sinn. Ich meine mit ,Materialität ${ }^{27}$ hier nicht das Reden über derlei unterschiedliche Dinge, sondern viel nüchterner und ganz einfach die stoffliche Grundlage von Zeichen, das Material, mit dem wir Zeichen bauen, also den physikalischen Träger von Sinn. Das wirft die simple Frage auf: Was macht die Tinte (oder eben das Pixel) mit dem Sinn? ${ }^{28}$ Führt, zum Beispiel, Handschrift zu anderen Texten - hier Thomas von Aquin -

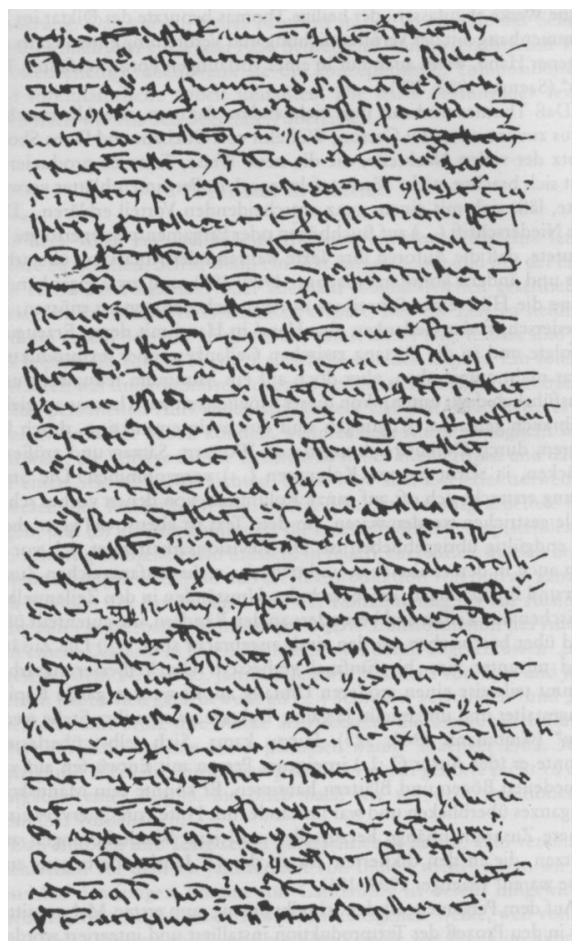

Abb. 3: Thomas von Aquins Handschrift ${ }^{29}$

$27 \quad$ Zur wechselvollen Geschichte des „Materie“-Begriffs siehe Detel et al. (1980).

28 Krämer (2008, S. 295) meint, in metaphysischer Sicht erscheine die Unmittelbarkeit des materiellen Zeichenträgers als „Oberfläche, die es zu durchdringen gilt, um zu dem nicht mehr sichtbaren, vielmehr nur noch interpretierbaren Zeichensinn zu gelangen“. Beim Medium dagegen verhalte es sich genau umgekehrt: „Die Unmittelbarkeit des medial zur Erscheinung kommenden Sinns bildet demgegenüber eine Oberfläche, die es zurückzulassen gilt, um in ihrer $>$ Tiefe $<$ erst die verborgene Materialität des Mediums freizulegen." Das scheint mir wirklich sehr metaphysisch.

29 Ludwig (2005, S. 177), dort mit Quellenangabe. 
als Mündlichkeit, SMS, Chat oder ein Textverarbeitungsprogramm; und erzeugen unterschiedliche technische Plattformen unterschiedliche performative Effekte? (Hier US-Präsident Obamas Unterschrift:)

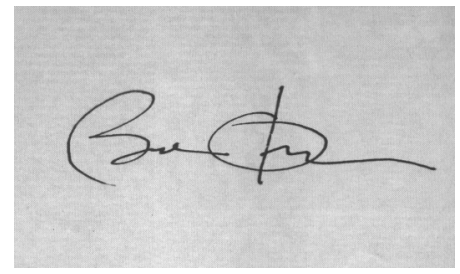

Abb. 4: Barack Obamas Unterschrift ${ }^{30}$

Um solche Fragen ${ }^{31}$ zu beantworten, müssen wir zunächst drei variable Rahmenbedingungen erörtern, welche menschliche Kommunikation in entscheidender Weise tragen und prägen, nämlich die stoffliche Grundlage der Zeichen (Material), das genutzte Kommunikationsgerät (Medium) und die situativ bzw. medial ermöglichte kommunikative Konstellation (Kommunikationsform).

\section{Rahmenbedingungen menschlicher Kommunikation}

\subsection{Material - Medium - Kommunikationsform}

In Auseinandersetzung mit ihren Lebensbedingungen schaffen sich Menschen das, was sie brauchen. (Piaget (z.B. 1975) beschrieb das als Wechselspiel von Assimilation und Akkommodation.) So auch Sprache: „Das Bedürfnis schuf sich sein Organ“ (Engels 1962, S. 446). Und ihre Erzeugnisse wirken wieder auf sie zurück. Das gilt auch für Veränderungen im Kommunikationsgefüge. Wachsende gesellschaftliche Bedürfnisse treiben Menschen dazu an, ihre Kommunikationsbedingungen zu bearbeiten, um kommunikative Potentiale zu erweitern. Zu diesen Bedingungen zählen insbesondere Material, Medium und Kommunikationsform. ${ }^{32}$ Im aktuellen Stadium dichter Kommunikation treiben drei Neuerungen die Entwicklung maßgeblich voran: das Material Pixel, das Medium Bildschirm und die

\footnotetext{
30 Frankfurter Allgemeine Zeitung, 22.1.2009, S. 1.
}

31 Schnell gesellen sich verwandte hinzu, zum Beispiel (um zwei schriftbezogene Extreme zu nennen): Was geschieht auf dem Weg von der Dichterhandschrift zur kritischen Edition (etwa Hölderlin 1975-2008), was bei der Verschriftung von Mündlichkeit (dazu etwa Ingenhoff/Schmitz 2000)? Dieser Aufsatz konzentriert sich auf eine Fallgruppe (Pixelschrift an Pixelbild) in der Hoffnung auf möglichst genaue und partiell dennoch exemplarische Teilantworten.

32 Der begrifflichen Klarheit und intellektuellen Fruchtbarkeit halber unterscheide ich bewusst zwischen diesen dreien (stoffliche Grundlage von Zeichen, Kommunikationsgerät und situativ bzw. medial ermöglichte kommunikative Konstellation). Diese Unterscheidung wird nicht allgemein anerkannt; zur Diskussion vgl. Schneider (2008, S. 243 f. (Anm. 245)). 
Kommunikationsform Hypermedia (insbesondere World Wide Web). Gemeinsam tragen sie dazu bei, dass viele der klassischen Vorteile unmittelbarer Kommunikation technisch wenigstens teilweise simuliert und einschränkende Reduktionen zerdehnter Kommunikation partiell aufgehoben werden können. Das verändert auch Schriftlichkeit.

Betrachten wir zunächst ein konkretes Beispiel (Kap. 4.2) und widmen uns anschließend den drei genannten Faktoren in abstrakterer Weise (Kap. 4.3 bis 4.5).

\subsection{Drittes Beispiel: Komponierte Schriftfragmente}

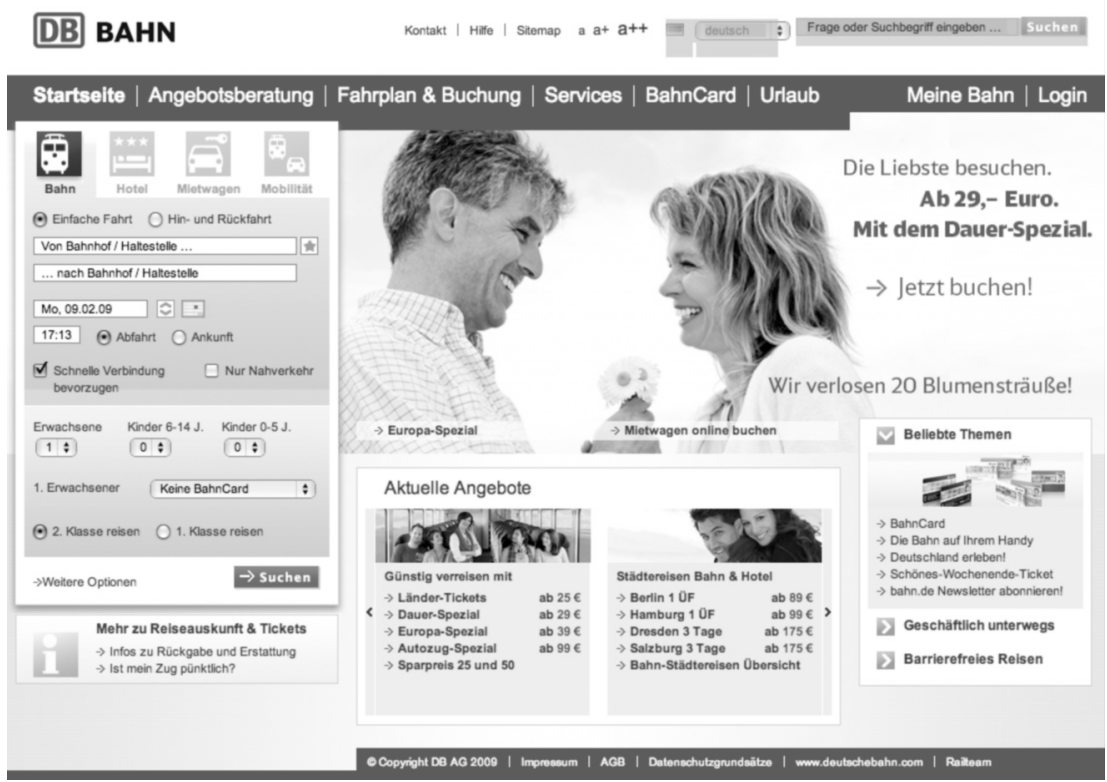

Abb. 5: bahn.de (www.bahn.de (Stand: 9.2.2009))

Verglichen mit dem (vorigen) Clooney-Beispiel (Abb. 1) enthält dieses sehr viel mehr Text. Die Bilder dienen nur zur Dekoration und laden den Text kaum oder gar nicht auf. Doch das Layout, also die Platzierung und visuelle Gestaltung und Begleitung des Textes auf der Fläche, ist für sein Verständnis unerlässlich. Als fortlaufender Fließtext ließe er sich nicht entschlüsseln. Das Layout, nicht Grammatik, sorgt für Gliederung und Kohäsion. Ansatzweise war das auch bei herkömmlichen Papierformularen schon so. Doch auf dem hypermedialen Bildschirm übernehmen (teilweise konventionalisierte) Flächenverteilung, Farbgebung, unterschiedlich gestaltete Kästchen und Piktogramme viel mehr Anteile der Botschaft, so dass der wohlplatzierte Text noch ganz erheblich kürzer werden kann. Man betrachte etwa 
das linke (knappe) Drittel von Beispiel 3. Dort zählen wir 48 Wörter (25 davon sind Substantive), drei Abkürzungen sowie einige Ziffern, Zahlen und 18 Interpunktionszeichen. Außer beim Vierwortsatz in der letzten Zeile beschränkt sich Syntax auf die lineare Anordnung der Elemente. Leicht flektiert werden nur je drei Substantive und Adjektive im Nominativ; Kasus spielen keine Rolle. Artikel und Adverbien kommen nicht vor. Material, Medium und Kommunikationsform ziehen eine Schriftlichkeit nach sich, die mit den gewohnten klassischen Formen wenig gemein hat.

\subsection{Material Pixel}

Das Wort Pixel ist eine Kreuzung aus englisch pictures (kurz pix) und element und bezeichnet eben als kleinste Bildeinheit einen Bildpunkt, nämlich die kleinste Einheit einer digitalen Rastergrafik, wie sie heute auf Bildschirmen dargestellt wird. Gutenbergs mobile Lettern erlaubten die bis dahin unvorstellbare massenhafte Reproduktion von Texten, indem sie den schriftlichen Wortlaut in kleinste Einheiten des Druckens zerteilen ließen. Diese Lettern mussten allerdings zu Hunderttausenden handgreiflicher Werkstücke teuer gegossen werden. Die viel winzigeren Pixel hingegen treiben Gutenbergs Modularisierungs-Idee auf die Spitze. Sie können in praktisch beliebig gigantischer Anzahl fast kostenlos hergestellt werden. Thre stoffliche Grundlage ist minimal, sie sind von jeder Bindung an semiotische Systeme (z.B. Buchstaben) befreit und können eben deshalb alle visuellen Kommunikationsmodi gleichermaßen darstellen. ${ }^{33}$ Bei hinreichend feiner Körnigkeit verliert dabei der technische Gegensatz von analoger und digitaler Signalverarbeitung seine Bedeutung für die menschliche Wahrnehmung. ${ }^{34}$

Weil jedes klitzekleine Pixel einzeln manipuliert werden kann, verschwindet auch der technisch bedingte Unterschied zwischen Text und Bild; und in beiden Modi werden neue Potentiale freigesetzt. Anfang 2009 wurden 14 weltberühmte Gemälde aus dem Prado im Internet zugänglich gemacht, und zwar jeweils als Foto aus rund 14.000 Megapixeln..$^{35}$ Das heißt, die Fläche eines Gemäldes wird auf 14 Milliarden Pixel verteilt (eintausendvierhundert Mal so viel wie bei einer modernen Digitalkamera). Das erlaubt nicht nur unendliche Reproduktion an beliebigem Ort zu beliebiger

\footnotetext{
33 Pixel setzen digitale Informationen in Erscheinungsformen um, die von menschlichen Sinnesorganen wahrgenommen werden können. Mit entsprechender Soft- und Hardware können digitale Informationen physikalisch auch anders realisiert werden, so dass multimodale Botschaften auf ein und derselben technischen Plattform übermittelt werden können. In diesem Beitrag geht es aber nur um Schrift an und als Bild.

34 Insoweit wird auch der oft betonte Gegensatz zwischen kontinuierlichen (etwa mündlichen) und disjunktiven (etwa schriftlichen) Kommunikationsmitteln hinfällig. Darüber wundert sich schon Fischer (1997, S. 98), zumal es seine äußerst intelligenten Beobachtungen über Schrift als Notation teilweise in Frage stellt.

35 www.google.com/prado (Stand: 17.1.2009).
} 
Zeit, sondern auch eine völlig andere Wahrnehmung. Man kann wie mit der Lupe in kleinste Details sehen, die das bloße Auge vor dem Original nicht wahrnähme.

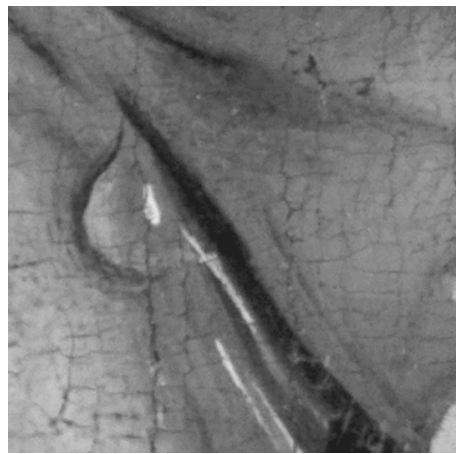

Abb. 6: Roger van der Weyden: Kreuzabnahme (ca. 1435) (Ausschnitt Träne)

Der Betrachter erhält ganz andere Eindrücke von den Maltechniken, den Proportionen, den Verhältnissen zwischen Detail und Ganzem. Digitalisierung verändert Produkt und Blick schon bei alten, handgemalten Bildern. Welch völlig neuartige Bilder erst können aus einzeln steuerbaren Pixeln angefertigt werden! Und wie verändert sich Schrift als Bild!?

Indem Pixel die materiellen Grundlagen von Zeichen miniaturisieren, entstofflichen (,virtualisieren') sie sie scheinbar. Das erleichtert und beschleunigt die sonst ja doch schwerfällige technische Kommunikation. Wenn Stoff zum Ausdruck von Zeichen verwendet wird, soll er als (eigentlich hinderlicher) Stoff (außer in künstlerischer Subversion) nicht mehr wahrgenommen werden. So verschwinden auch die einzelnen Pixel im Gesamtbild. In dem Maße, wie sie etwa bei vielfacher Vergrößerung in ihrer Körnigkeit als Material (physische Grundlage) sichtbar werden, tritt der Sinn, wie wir am Prado-Beispiel sahen, zurück. Dass der materielle Zeichenträger aber bis in Mikrodimensionen hinein manipuliert werden kann, die dem bloßen Auge nicht mehr zugänglich sind, eröffnet fast unbegrenzte Möglichkeiten, Zeichen nach Belieben zu bilden und formen.

\subsection{Medium Bildschirm}

Medien seien hier als Kommunikationsgeräte verstanden, also als technische Hilfsmittel der Kommunikation. ${ }^{36}$ Bildschirme, die farbig leuchtenden

36 Zur Vieldeutigkeit des Medienbegriffs vgl. Habscheid (2000), zur Begriffsgeschichte Hoffmann (2002). - Weite Mediendefinitionen gehen, auch bei Schneider (2006; z.B. S. 83-86), stets mit begrifflichen Vagheiten einher, die theoretische Unklarheiten oder Widersprüche erzeugen. Schneiders Argumente gegen die Fassung von ,Medien`als Kommunikationsgeräten scheinen mir hinfällig, wenn man in einer performanzorientierten Perspektive neben Medien auch Modi der Kommunikation berücksichtigt, nämlich visuelle (mimisch, gestisch, schriftlich, bildlich, ...), auditive (mündlich, tonal, ...), taktile etc. 
Fenster ins Web, sind unhandlich, schwer und bieten (meist) nur eine recht kleine Fläche. ${ }^{37}$ Anders als auf Papier wird deren Inhalt zwar ständig geändert, doch lokal auch vergessen: Sie liefern nichts als perfektionierte $\mathrm{Pa}-$ limpseste. Das potenziert, beschleunigt, fragmentiert und dezentriert Kommunikation. Die innere (semiotische) Beweglichkeit wird noch erkauft mit äußerer (materieller) Schwerfälligkeit. Ganz im Kontrast zur virtuos-virtuellen Schwerelosigkeit der Inhalte haftet noch zu viel wuchtige Materie am Gerät, und die jeweils aktuelle Sehfläche ist vergleichsweise winzig. Der Bildschirm ist der Engpass im Zugang zum Web. Das erzwingt besondere Präsentationsweisen, nämlich schnell überschaubare Fragmente in Modulbauweise zur schnellen Selbstmontage (siehe Kap. 5).

\subsection{Kommunikationsform WWW}

Das World Wide Web ist die universalste, dichteste und reichhaltigste technische Kommunikationsform. ${ }^{38}$ Eine von beliebig vielen Institutionen und Personen bereit gestellte, grundsätzlich unendlich große, endlos erweiterbare und durch Hyperlinks beliebig untereinander vernetzbare Menge unterschiedlichster Informationen in sämtlichen digitalisierbaren Modi steht über Computer und ggf. andere Technologien (z.B. Mobiltelefone) allen Menschen auf der Welt zur Verfügung, die Zugang dazu haben (derzeit weit über eine Milliarde). ${ }^{39}$ Der fast grenzenlose Umgang mit Informationen aller Art erlaubt früher ungeahnte Möglichkeiten, macht es aber auch schwer, sich darin zurechtzufinden. Eines von mehreren Mitteln, Orientierungsverlust (lost in hyperspace) und kognitiver Überforderung (cognitive overload) entgegenzuwirken, ist ein besonderer Umgang mit Schrift. Und darauf gehe ich nun ein.

\section{Schrift für Blicke}

\subsection{Tertiäre Schriftlichkeit}

Die alte Kulturtechnik Schreiben hat oft ihre Funktionen, Materialien, Mittel, Formen und Erscheinungsweisen verändert. ${ }^{40}$ Mit der neuen Konstella-

37 Schon für Schrift auf Papier betont Mon (1995, S. 9), wie wichtig „,das format des spielraums und der lichtwert der druckbilder“ seien, „weil sich auf diese weise lesewerte über den bloBen wortsinn hinaus verkörpern."

38 Kommunikationsformen sind ,allein durch situative bzw. mediale Merkmale definiert, in kommunikativ-funktionaler Hinsicht also nicht festgelegt" (Brinker 2001, S. 139).

392007 fand Google über eine Billiarde Seiten (einzelne URLs), doch „Strictly speaking, the number of pages out there is infinite." (http://googleblog.blogspot.com/2008/07/we-knew-webwas-big.html (Stand: 6.2.2009). Internet-Statistiken: www.studeo.de/imafdi/statistik.htm (Stand: 6.2.2009).

40 Vgl. die einschlägigen Artikel in Günther/Ludwig (Hg.) (1994) sowie Ludwig (2005). 
tion von Pixeln auf Bildschirmen als Zugang zum hypermedialen WWW tritt wieder etwas Neues auf. Schrift - anders als gesprochene Sprache - war zwar immer schon visuell. ${ }^{41}$

Daß Sprache eine sinnlich wahrnehmbare Gestalt hat, daß das Bild durch Hinzufügung von Wortelementen und Schrift eine zusätzliche, gezielte geistige Dimension erhalten kann, wußten schon die frühesten Künste. (Weiss 1984, S. 7) (2 $^{42}$

Und schon (oder erst) im frühen Mittelalter wurden Texte so gegliedert, dass man „eine visuelle Vorstellung“ von ihnen bekommen konnte (Ludwig 2005, S. 119, vgl. S. 127 f.). Doch heute, im Zeitalter dichter Kommunikation und digitaler Techniken, metamorphiert Schrift selbst zum Bild. ${ }^{43}$ Eine neue Etappe von Schriftlichkeit (mit Vorläufern in alten Medien) kommt zur Blüte.

In Fortführung von Ongs (1987, S. 135-137) Unterscheidung in primäre und sekundäre Mündlichkeit kann man drei grundsätzlich verschiedene Arten von Schriftlichkeit unterscheiden (Schmitz 2006a, b). Klassische Schriftlichkeit in ihrer prototypischen Form (z.B. in Briefen, Protokollen oder Romanen) kommt monomodal (also rein schriftlich) daher, fixiert Sprache als mehr oder weniger endgültigen Text, dient zerdehnter Kommunikation und ist entsprechend auf situationsentbundene Abstraktion ausgerichtet sowie auf „analytische Reflektivität“ (Ong 1987, S. 136), geprägt von inhaltlicher Planung, sorgfältiger Form und innerer Abgeschlossenheit (autonomer Kohäsion und Kohärenz). Weitgehend im Gegensatz dazu entwickelt sich heute, im Zeitalter digitaler Medien, (z.B. in Chats) eine halbspontane (ich nenne sie sekundäre) Schriftlichkeit, die einige Merkmale kultiviert oder simuliert, die man sonst aus mündlicher Kommunikation gewohnt ist (vgl. z.B. Dürscheid 2003; Storrer 2001; Thaler 2005). An sehr viel ältere Vorläufer hingegen (z.B. in manchen mittelalterlichen Handschriften ${ }^{44}$ in Werbeplakaten und Illustrierten) knüpft eine in dieser Art ebenfalls neue, dritte Art von Schriftlichkeit mit eigenen Formen an. Sie

41 Grundsätzlich dazu Krämer (2003).

42 Unterschiedlichste „Formen visueller Textgestaltung oder Text-Bilder tauchen seit der hellenistischen Zeit in der Literaturgeschichte zu fast allen Zeiten immer wieder auf." (Weiss 1984, S. 17)

43 Wie so oft ist Kunst auch hier Vorreiterin. So bemerkt Weiss (1984, S. 13) über Concept Art und moderne Literatur im 20. Jahrhundert: „Es entstehen Texte, die zwischen Bild und Sprache nicht zu trennen brauchen, sondern ihre Aussagekraft aus beiden Medien beziehen. Die Schreib- bzw. Lese-Fläche ist zur eigentlich syntaktischen Dimension des Textes geworden.“ - Daraus folgt nicht, dass eine ,Logik des Schreibens“ einer ,Logik des Bildes“ unterworfen würde, wie Kress (2003, S. 163 f., passim) meint; zur Diskussion Schmitz (2006b, S. $84-189$ ff.).

44 Vgl. z.B. Ernst (2003). Im frühen Mittelalter werden erstmals bildhafte Elemente so in geschriebene Texte hinein verlegt, ,dass sie dort einen anderen Sinn erhielten“ (Ludwig 2005, S. 101). Bei tertiärer Schriftlichkeit heute verhält es sich teilweise genau umgekehrt; vor allem aber wird die gesamte Formenskala zwischen bildnahen und schriftnahen Elementen ausgenutzt. 
tritt überall dort auf, wo die visuelle Erscheinung und Umgebung von Schrift eine Rolle für ihr Verständnis spielt, insbesondere dort, wo Texte und Bilder auf ein und derselben Sehfläche platziert werden.

Heute sind die meisten visuellen Botschaften in öffentlicher Kommunikation als Sehflächen gestaltet, auf denen Layout, Bilder, Texte, Wörter und andere sichtbare Zeichen komplexe Beziehungen untereinander eingehen. Unter solchen Bedingungen ändert sich Schriftlichkeit selbst. Ihre optische Erscheinungsform wird nicht nur zu dekorativ-ästhetischen Zwecken, sondern in bedeutungsvoller Absicht gestaltet; sie nimmt einige Eigenschaften von Bildern an, geht Koalitionen mit ihnen ein oder ganz in ihnen auf; und sie ändert ihre innere Form von hierarchischer zur modularer Organisation. Tertiäre Schriftlichkeit nenne ich also solche, die Schrift als nichtautonomes Element in multimodalen Kontexten, vor allem in Text-Bild-Gefügen erscheinen lässt. Sie kommt in vielen Kommunikationsformen vor, von Texten an Waren über Plakatierung und Beschilderung im öffentlichen Raum bis zu Presse und anderen Papiermedien, am prägnantesten jedoch im World Wide Web. Denn nur auf Computerbildschirmen verschwindet der bisher (außer bei Handschrift) stets radikale technische Unterschied zwischen schriftlichen Texten und Bildern: Beide werden mit genau den gleichen technischen Mitteln und Einheiten dargestellt, nämlich mit beliebig steuerbaren einzelnen Pixeln.

\subsection{Viertes Beispiel: Pixeltext}
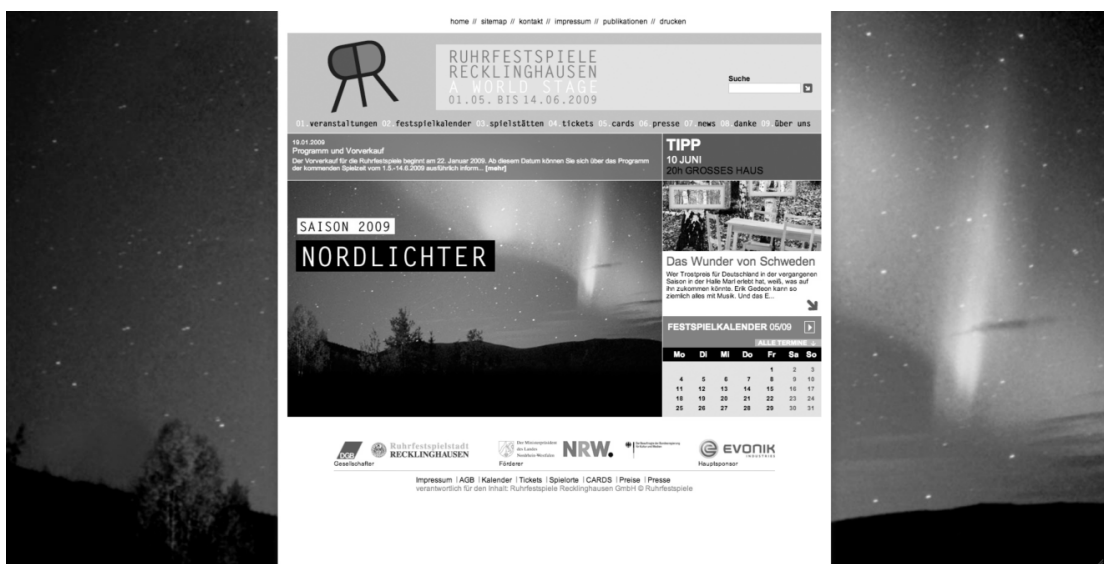

Abb. 7: Ruhrfestspiele (a) (www.ruhrfestspiele.de (Stand: 9.2.2009))

Auf einer Nordlichtlandschaft scheint ein bedrucktes Papier zu liegen, das jenes Hintergrundfoto wiederholt. (Spiel mit den Medien: Bild im Bild, simuliertes Papier auf dem Bildschirm.) Dieses vermeintliche Blatt enthält eine hybride Mischung aus Plakat, Pinnwand, Flyer, Werbelogos, Fragment eines Zeitungsartikels, Kalender und allerlei Hyperlinkbeschriftungen. 


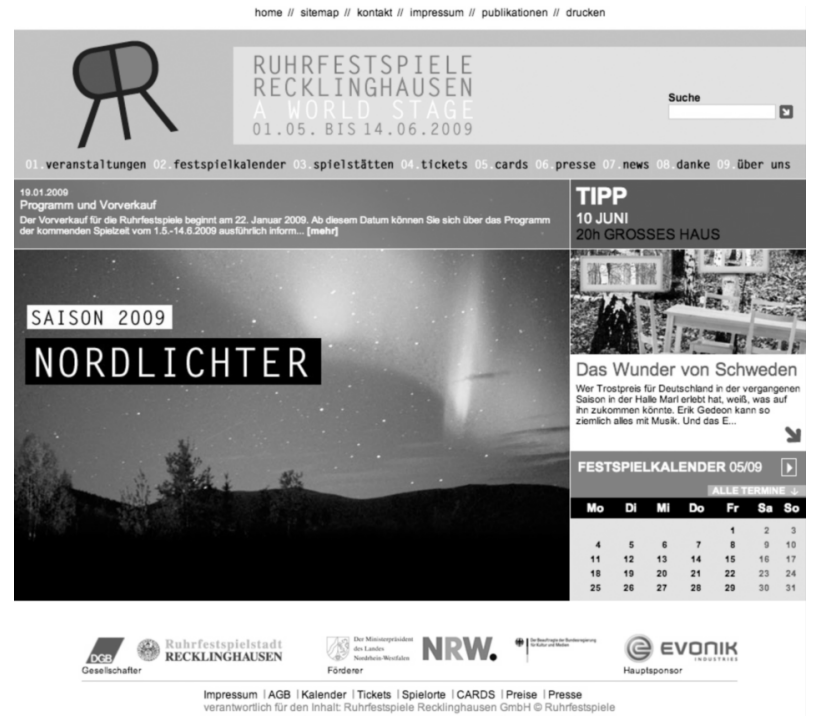

Abb. 8: Ruhrfestspiele (b) (www.ruhrfestspiele.de (Stand: 9.2.2009))

Die zahlreichen Einzelelemente werden allein übers Design zu einer kohärenten Gesamtbotschaft zusammengehalten, die beim ersten Blick verstanden wird etwa als ,Alles über die Ruhrfestspiele'. Trotz eines erheblichen Textanteils dominiert der visuelle Gesamteindruck samt (mehr dekorativen und suggestiven als informativen) Bildern und Seitengestaltung. Es gibt keinen einzigen vollständigen zusammenhängenden Text, sondern nur Fragmente, die wie Paratexte ${ }^{45}$ erscheinen, ohne sich jedoch auf einen Haupttext zu beziehen. Diese Elemente können großenteils nur dank ihrer Platzierung im Gesamtbild verstanden werden. Als fortlaufend gelesene Buchstabenkette ergeben sie keinen Sinn. Weil (mit zwei Ausnahmen) die kleinen sprachlichen Module nicht zu größeren sprachlichen Einheiten zusammengebaut werden, bedarf es keiner Grammatik; deren restliche Spuren (vor allem in Pluralmorphemen) regulieren Wortbildung und nicht Syntax.

Auch die beiden längsten Texte bleiben Fragment. Beide brechen, kaum begonnen, mit drei Punkten ab und erweisen sich als Türöffner für Texte hinter den Links. „Programm und Vorverkauf“ (weiß auf blau oben links) führt zur Wiederholung des gleichen Textes (schwarz auf weiß) und einen einzigen Satz mit 9 Wörtern. ${ }^{46}$ „Das Wunder von Schweden“ (rot auf weiß rechts in der Mitte) dient als Appetitanreger für einen Text hinter dem roten Pfeil, der herkömmliche Kohäsion und Kohärenz gerade nicht anstrebt, sondern die Botschaft in fast beliebig verteilbare Bauklötzchen zerlegt:

\footnotetext{
45 Paratexte sind einladend, beschreibend, orientierend, kommentierend oder ergänzend begleitende Nebentexte zu Haupttexten. Detailliert - allerdings nur für Bücher - Genette (1989).

46 „Das komplette Programmheft können Sie sich unter Publikationen herunterladen.“
} 


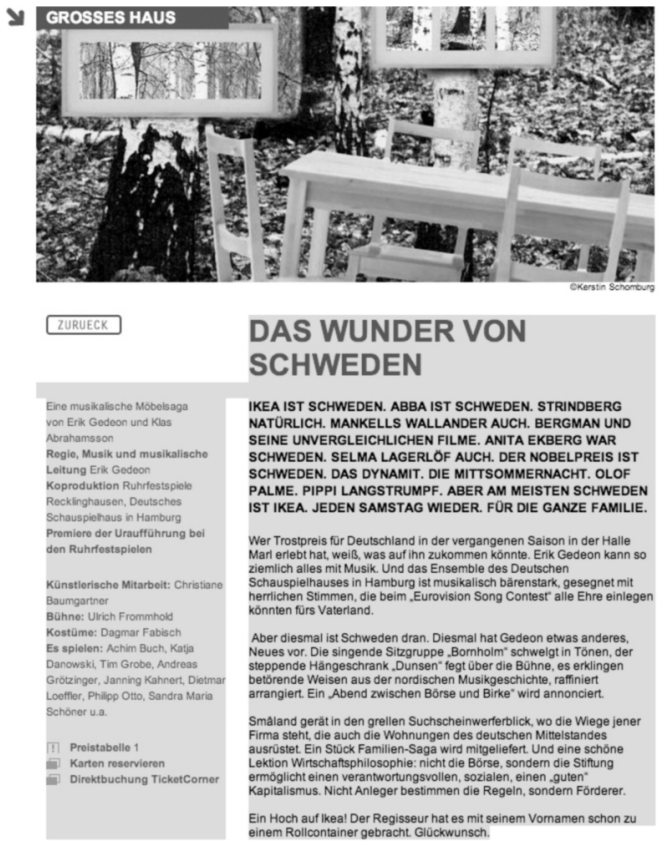

Abb. 9: Ruhrfestspiele (c) (www.ruhrfestspiele.de/veranstaltungen/veranstaltung detail.php?ver_id=30\&ter_id=121 (Stand: 9.2.2009))

Ikea ist Schweden. Abba ist Schweden. Strindberg natürlich. Mankells Wallander auch. Bergman und seine unvergleichlichen Filme. Anita Ekberg war Schweden. Selma Lagerlöf auch. Der Nobelpreis ist Schweden. Das Dynamit. Die Mittsommernacht. Olof Palme. Pippi Langstrumpf. Aber am meisten Schweden ist Ikea. Jeden Samstag wieder. Für die ganze Familie.

Wer Trostpreis für Deutschland in der vergangenen Saison in der Halle Marl erlebt hat, weiß, was auf ihn zukommen könnte. Erik Gedeon kann so ziemlich alles mit Musik. Und das Ensemble des Deutschen Schauspielhauses in Hamburg ist musikalisch bärenstark, gesegnet mit herrlichen Stimmen, die beim „Eurovision Song Contest" alle Ehre einlegen könnten fürs Vaterland.

Aber diesmal ist Schweden dran. Diesmal hat Gedeon etwas anderes, Neues vor. Die singende Sitzgruppe „Bornholm“ schwelgt in Tönen, der steppende Hängeschrank „Dunsen“ fegt über die Bühne, es erklingen betörende Weisen aus der nordischen Musikgeschichte, raffiniert arrangiert. Ein „Abend zwischen Börse und Birke" wird annonciert.

Smâland gerät in den grellen Suchscheinwerferblick, wo die Wiege jener Firma steht, die auch die Wohnungen des deutschen Mittelstandes ausrüstet. Ein Stück Familien-Saga wird mitgeliefert. Und eine schöne Lektion Wirtschaftsphilosophie: nicht die Börse, sondern die Stiftung ermöglicht einen verantwortungsvollen, sozialen, einen ,guten“ Kapitalismus. Nicht Anleger bestimmen die Regeln, sondern Förderer.

Ein Hoch auf Ikea! Der Regisseur hat es mit seinem Vornamen schon zu einem Rollcontainer gebracht. Glückwunsch. 
Da werden 214 Wörter auf 29 Sätze verteilt (Durchschnittslänge 7,4 Wörter), davon 12 Ellipsen und 7 Sätze mit dem Hauptverb „ist“ oder „war“. Von den restlichen 10 Sätzen (Durchschnittslänge 13 Wörter) sind sechs kurze einfache Hauptsätze, zwei Hypotaxen und nur zwei jeweils dreiteilige Satzgefüge. Der gesamte Text enthält sehr wenige explizit kohäsive Mittel (z.B. Rekurrenzen, Pronomen), die dann auch nur über sehr kurze Strecken wirken. Wer den Text als kohärent verstehen möchte, muss viel Vorwissen über die einschlägige Kulturszene sowie über Ikea aktivieren. Er will aber gar nicht als kohärenter Ganztext gelesen werden, sondern reiht einzelne Gedankenfetzen assoziativ und in fast beliebiger Folge um das hinter „Schweden“ versteckte Leitmotiv Ikea: eher Sprachcluster für selektive Wahrnehmung als linearer Text für sinnsuchende Lektüre.

Auf diese Weise unterwirft sich sogar der vergleichsweise lange Text, der ohnehin erst bei Aufruf durch Mausklick sichtbar wird, den streifenden Rezeptionsgewohnheiten für Bilder. So werden auch Texte „schnelle Schüsse ins Gehirn“, wie Kroeber-Riel (1993, S. ix) das für Bilder meint.

\subsection{Grammatik und Design}

Bilder werden vom ersten Gesamteindruck einer ganzen Gestalt zu den Teilen hin wahrgenommen, in die man bei genauerer Betrachtung dann näher eindringen kann. Bei herkömmlichen (längeren) Texten verhält es sich umgekehrt: Kleinere Teile (z.B. Wörter und Satzglieder) werden nach und nach zu größeren Ganzen (z.B. Teilsätzen und Sätzen) gefügt. Diesen Lektüreprozess unterstützt der Schreiber durch konventionelle Kohäsionsbildung. In monomodaler (primärer) Schriftlichkeit konnte er dabei zunächst notgedrungen allein auf grammatische Mittel zurückgreifen. Erst nach und nach wurde die physikalische Tatsache, dass Schrift visuell wahrgenommen wird, für die Gestaltung eines Schriftbildes ausgenutzt: Wortzwischenräume (Spatien), Interpunktion, Unterscheidung von Majuskeln und Minuskeln sowie immer weitere typographische und layouterische Mittel wurden entdeckt. ${ }^{47}$ Der Dichter Franz Mon (1995, S. 9) erinnert daran, „daß lesen ein umfassenderer vorgang ist als das entziffern von buchstaben, das ordnen fixierter zeichen zu einem sinn. [...] ein blatt papier, von ein paar wasserspritzern getroffen, ist bereits lesezusammenhang." Erst in tertiärer (bimodaler ${ }^{48}$ Schriftlichkeit jedoch verschmelzen Text und Bild zu gemeinsam getragenen Botschaften. Nutzer nehmen derartige Botschaften (z.B. auf Webseiten) eher als Bild denn als klassischen (monomodalen) Text wahr. ${ }^{49}$

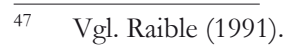

48 Bimodal-tertiäre Schriftlichkeit kann auch von weiteren (z.B. akustischen) Modi begleitet werden. Das scheint zwar ihre Rezeption, kaum aber ihre Struktur zu ändern und kann an dieser Stelle nicht näher untersucht werden.

49 Vgl. „Web users tend to scan pages, rather than read them.“ (Gahran 2002).
} 
Als Leser dieses Aufsatzes haben Sie das eben in den Abbildungen 7 und 8 selbst erlebt; sehr viel authentischer wirkt natürlich ein Blick auf diese oder andere Originalseiten am Bildschirm im Web.

So werden Kohäsion und Kohärenz auf solchen Sehflächen auch mehr durch visuelle als durch sprachliche Mittel erzielt. Die auf Anhieb (top down) erblickte Gestalt steuert die Wahrnehmung eher und stärker als ein zeitlich nach und nach (bottom up) aufgebauter Wortlaut. Fläche dominiert Linie; Design hat Vorrang vor Grammatik und macht sie (wie in den Abb. 5, 7 und 8) teilweise entbehrlich. Ja, die planmäßige Gestaltung der Fläche als Kohäsionsmittel entlastet Grammatik so sehr, dass sogar in längeren Texten (wie in unserem Beispiel Abb. 9) traditionelle Syntax teilweise aufgelöst wird. ${ }^{50}$

Tertiäre Schriftlichkeit in verdichteter, multimodaler Kommunikation verzichtet auf diejenigen Elemente, die typischerweise und spezifisch für primäre Schriftlichkeit in zerdehnter, monomodaler Kommunikation notwendig waren und sind. Es verhält sich wie immer in der Sprachgeschichte, nämlich „daß funktionslos gewordene Teile der Rede schwinden“ (Horn 1923, S. 2) ${ }^{51}$ Oder, etwas umständlicher, aber auch präziser formuliert: Um kommunikativen Aufwand und kommunikatives Ergebnis in ein möglichst effizientes Verhältnis zu bringen, bedarf es umso weniger ausgefeilter Grammatik, je massiver Ordnungssysteme nonverbaler Modi mitwirken. ${ }^{52}$

Im multimodalen Zusammenhang der Sehfläche Bildschirm tritt Grammatik einige ordnende Funktionen an Design ab, wird also schlanker. Wenn - mit Weinrich (1988, S. 86) - „die Grammatik in ihrem anthropologischen Kernbereich nichts anderes ist als das Gedächtnis des Leibes oder genauer gesagt zweier Leiber", so braucht man das bei leibentbundener, technisierter Kommunikation nicht mehr in dieser Weise und in diesem Maße. Denn Erinnerung wird in erheblichem Grade an leibferne Quellen delegiert ${ }^{53}$ die in multimodalem Zusammenspiel auf unterschiedlichste Ordnungsformen zurückgreifen.

50 Dieser linguistische Befund über profane Sehflächen modifiziert und schärft die allgemeine und teils metaphorisch formulierte Bemerkung von Weiss (1984, S. 16) über künstlerische Seh-Texte: „Die grammatikalische Syntax wird durch eine Bild-Syntax ergänzt bzw. ersetzt.“

51 Im Anschluss an einen Gedanken von Behaghel greift Horn mit dieser Auffassung die Lehre von der Allgemeingeltung der Lautgesetze an: „,Wenn es richtig ist, daß funktionslose Bestandteile der Rede schwinden, entgegen den ,Lautgesetzen', dann ist es auch sehr wohl denkbar, daß funktionswichtige Bestandteile bewahrt bleiben den ,Lautgesetzen“ zum Trotz. Die Funktion beherrscht das Lautgeset\%:" (Horn 1923, S. 131).

52 Vgl. den Überblick über „Elemente effizienter Kommunikation“ bei Roelcke (2002, S. 70), der für multimodale Kommunikate an einigen Stellen spezifiziert und ergänzt werden kann.

53 Vgl. schon Platon $(1958$, S. 55 = 275a) über Schrift: „Denn diese Erfindung wird den Seelen der Lernenden vielmehr Vergessenheit einflößen aus Vernachlässigung der Erinnerung““. 
Schrift in der Nähe von Bildern, vor allem auf dicht gefüllten Bildschirmflächen, neigt zu Kleinteiligkeit: einfache Module statt komplexer Strukturen, sichtbares Nebeneinander statt intellektuell zu erschließender Hierarchie, analytischer statt synthetischer Sprachbau. ${ }^{54}$

Das entspricht auch den Vorschlägen, die in Stilratgebern für Webdesigner gegeben werden, prägnant zusammengefasst in der Maxime „Keep it short or break it up!“汭 „Der Texter portioniert seine Information in für sich stehende und in sich verständliche Module. Er bricht den Text in Informationshäppchen auf (Break it up!), die der User anklicken kann, wenn er will (Detail on Demand). ${ }^{656}$

Text auf Webseiten liefert oft Kleinstinhalte (microcontent), z.B. in Titeln, Überschriften, Teasern, ${ }^{57}$ Index-Elementen, Bildlegenden und anderen Paratexten, webspezifisch aber auch in Orientierungshilfen, Linkbeschriftungen und sonstigen Navigations- und Aufmerksamkeitssteuerern. ${ }^{58}$ Die kleinteilig-modulare Architektur ohne größere Sinnbögen strahlt auch auf etwas längere Texte aus, wie sie seltener auf der ersten und häufiger auf der zweiten Ebene einer Website stehen.

Alles in allem wird das Verhältnis von Teilen und Ganzen in einem Zusammenspiel von Grammatik und Design organisiert: Grammatik und Design teilen sich die architektonische Aufgabe der Konstruktion von Sinn. Je augenfälliger die visuelle Gestaltung der Sehfläche Botschaften trägt und den Handlungsraum ihrer Nutzerin oder ihres Nutzers gliedert, ${ }^{59}$ desto weniger braucht Grammatik die verbalen Anteile zu strukturieren. Design entlastet Grammatik; Grammatik kann folglich einfacher (weniger komplex) werden.

In anderer Weise kennen wir ein solches Zusammenspiel zwischen Sprachgrammatik und Ordnungssystemen nonverbaler Modi bereits aus der unmittelbaren mündlichen Kommunikation. In dem Maße, wie die Ge-

54 Im menschheitsgeschichtlichen Maßstab argumentiert Wunderlich (2008) dafür, dass Morphologie „möglicherweise älter als Syntax“ (S. 254) und heute „unnütz“ (S. 252) sei. Reiche Morphologie sei „ein Übergangszustand von Sprache, die im Zuge der Bevölkerungszunahme zunächst um eine transparente Syntax ergänzt und später vielfach reduziert wurde“ (S. 258). In dieser Perspektive könnte, eine Epoche später, die Syntax von Schriftlichkeit in technisiert-multimodaler Umgebung zunächst um visuelles Design ergänzt und später, wo unnütz geworden, vielfach reduziert werden. Das würde auch universale Verständigung über die Grenzen einzelner Sprachen hinweg erleichtern. Vielleicht wären wir dann weniger auf dem Weg zu global Englishes als vielmehr zu global visual design.

55 Amy Gahran zugeschrieben, z.B. laut Alkan (2002, S. 28).

56 Alkan (2002, S. 29). Ähnlich z.B. Radtke/Pisani/Wolters (2006, S. 258 f.) u.v.a.

57 Teaser, im Web meist auf anklickbaren Teaserflächen, kündigen als Kurztexte jeweils einen längeren Text an.

58 „Microcontent is all the short bits of text that help guide the user or provide an ,at-a-glancec overview of what a given page is about." (Gahran 2002).

59 „Durch das Design des Interface wird der Handlungsraum des Nutzers von Produkten gegliedert." (Bonsiepe 1996, S. 26). 
sprächspartner auf Informationen aus dem gemeinsamen Wahrnehmungsraum zurückgreifen und sich mit Gestik, Mimik, Blickkontakt und direkter Körperkommunikation verständigen, kommt der dabei gesprochene Wortlaut mit knappen und entsprechend grammatikarmen Ellipsen aus. ${ }^{60} \mathrm{In}$ technisch vermittelter dichter Kommunikation wird das multimodale Setting mit Geräten hergestellt, aber auch hier ist Sprache mit anderen Modi verwoben. So wird Kress/Van Leeuwens (2001, S. 4) Gedanke plausibel, dass multimodale Texte im Gegensatz zu reiner Sprache nicht mit doppelter, sondern mit vielfacher Artikulation arbeiten: „,we see multimodal texts as making meaning in multiple articulations" ${ }^{\text {. }}{ }^{1}$

\section{Multimodale Ausdrucksformen}

\subsection{Articulirte Pixel (mit fünftem und sechstem Beispiel)}

Natürlich werden wir weiterhin die geniale Erfindung unserer Vorfahren nutzen, mittels ,doppelter Artikulation' (Martinet 1963, S. 21 f.) zu kommunizieren, also mit einer großen Anzahl bedeutungstragender Morpheme, die aus einer kleinen Menge bedeutungsunterscheidender Phoneme zusammengesetzt werden. Schon für primäre Schriftlichkeit in zerdehnter Kommunikation reicht das aber nicht aus: Spatien, Interpunktion und andere visuelle Lesehilfen kommen hinzu. Tertiäre Schriftlichkeit in verdichteter Kommunikation nutzt, wie wir sahen, weitere Mittel zur visuellen Artikulation von Botschaften. Pixel auf Bildschirmen bieten dafür eine ideale materielle Grundlage.

So wie - nach Humboldt (1994d, S. 133) - ,alles Sprechen darin besteht, die schweifende Unbestimmtheit des blossen Vorstellens durch die Schärfe des articulirten Lautes zu heften“, so muss in der multimodalen Umgebung des World Wide Web „die schweifende Unbestimmtheit des blossen Vorstellens “ an ,die Schärfe articulirter Pixel' gebunden werden, um kommunizierbare Klarheit zu gewinnen. Die andere materielle Grundlage des Zeichens (Pixel statt Laut) erlaubt und erzwingt andere Wege der Artikulation, also der Form(ulier)ung von Vorstellungen. Eine visuell durchgestaltete Sehfläche aus dem Web zieht andere Arten von Botschaften und anderen Umgang damit nach sich.

60 Vgl. z.B. Bühler (1934, S. 155-158).

61 Vgl. ebd., S. 111 f. - Kress/Van Leeuwen (2001) beziehen ,Design' nicht auf die visuelle Gestaltung von Objekten, sondern auf die Gestaltung des multimodalen Zusammenspiels von Botschaften. „Design stands midway between content and expression. It is the conceptual side of expression, and the expression side of conception.“ (ebd., S. 5). ,[The idea of design is] a deliberateness about choosing the modes for representation, and the framing for that representation.“ (ebd., S. 45). „The design process reshapes, transforms, both writing and image, both as realisational material and as discourses (as well as scripts and genre), and as existing potential shapings." (ebd., S. 64). 


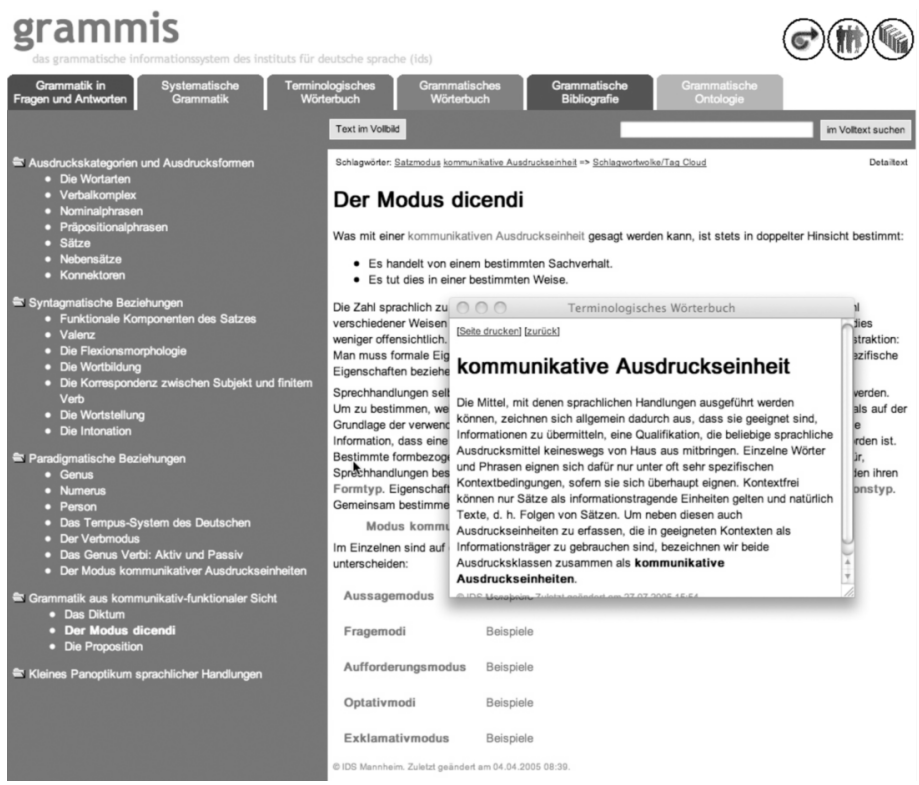

Abb. 10: Grammis ${ }^{62}$

\section{KIA ERHÖHT DIE UMWELTPRÄMIE!}
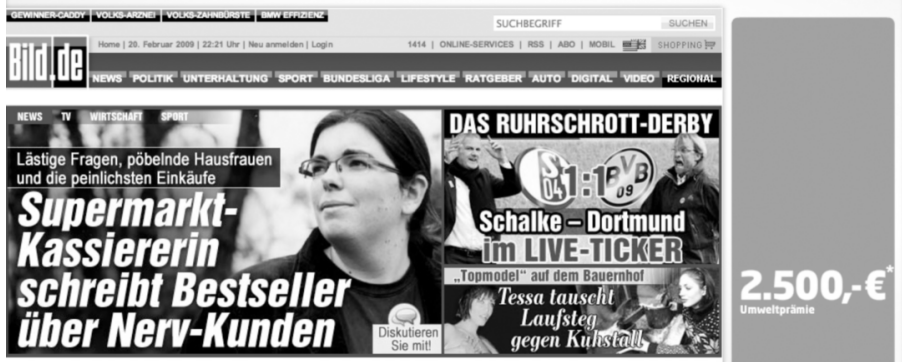

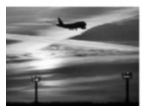

neues RANking

Fliegen am

sichersten?

Ein nouvos Ranking dor IATA
20igt, wo Fliogon am

sichersiten ist und wo

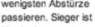

(asien. mont
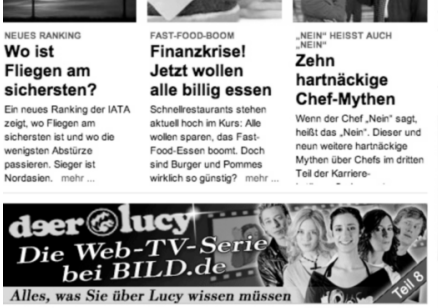
Finanzkrise Jetzt wollen alle billig esse Schnolvestaurants stoher (t) ood-Essen boomt Doch
NEIN" HEISST AUOA Zehn

hartnäckige Chef-Mythen Wenn dor Chet ,Nein' sagt, (a) Tei dee Karriere.

niswsichen

21:23 UHR Oberstes Schwoizer Gericht verbiolo

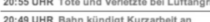
20:49 UHR Bahn kündigt Kurzarboil an 20:44 UHR Rötgens mit USA-Rolso zutrieden

Abb. 11: bild.de (www.bild.de (Stand: 20.2.2009)

62 http://hypermedia.ids-mannheim.de/pls/public/sysgram.ansicht?v_typ=d\&v_id=2044 (Stand: 20.2.2009), 
Grammis, das grammatische Informationssystem des IDS, bildet nicht geradewegs die in Buchform erschienene IDS-Grammatik (Zifonun et al. 1997) ab; bild.de ist nicht die für den Bildschirm übersetzte Bild-Zeitung. ${ }^{63}$ Beispielsweise nutzt Grammis im Druck unmögliche Hyperlinks mit der Folge anderer Textauswahl und -aufteilung; und die hier gezeigte Titelseite von bild.de enthält viel mehr und andere, meist kleinflächigere Einheiten und kürzere Texte als die gedruckte Titelseite des gleichen Tages. Systematische Untersuchungen charakteristischer Merkmale unterschiedlicher Text-BildSorten in verschiedenen Kommunikationsformen gibt es noch nicht. Jeder Nutzer und jede Verfasserin hat aber - wie beim kindlichen Spracherwerb mindestens ein intuitives Wissen über unterschiedliche Leistungen, Möglichkeiten und Qualitäten gesprochener, geschriebener, multimodaler und hypermedialer Texte erlangt und kann mehr oder weniger geschickt damit umgehen.

Ist Sprache - wiederum mit Humboldt (1963, S. 418) ${ }^{64}$ - „die sich ewig wiederholende Arbeit des Geistes, den articulirten Laut zum Ausdruck des Gedanken fähig zu machen", so arbeitet der Webseitengestalter mit multimodalen Ressourcen, um articulirte Pixel (und ggf. Töne etc.) ${ }^{65}$ ausdrucksfähig zu machen. Während „die Verwandlung der Welt in Sprache [...] auch vermittelst ihres grammatischen Baues" geschieht (Humboldt 1994e, S. 167), ${ }^{66}$ tritt auf Sehflächen Design als symbolische Kraft hinzu. Hatte Humboldt die „,intellectuellen Verfahren“ der Sprachen vergleichend untersucht, ${ }^{67}$ so stehen eine ähnlich vergleichende Design- und gar Multibzw. Hypermodalitätswissenschaft noch aus. Humboldt als Idealist konzentriert sich auf die Form des Ausdrucks, nicht die materielle Grundlage, lässt aber - vor allem im Vergleich von Lautsprache und Schriftsprache doch durchblicken, dass auch Stoff und Modus eine Rolle spielen. Schließlich liege „das ganze grammatische Streben der Sprache“ „in der Darstellung der Verstandeshandlung durch den Laut" (Humboldt 1994b, S. 58 f.). „Allein das tönende Wort ist gleichsam eine Verkörperung des Gedanken, die Schrift eine des Tons“ (Humboldt 1994c, S. 100); ,und so kann die Uebertragung des erst als Ton gehefteten Gedanken auf einen Gegenstand des Auges, nach Massgabe der Art, wie sie geschieht, dem Geiste sehr ver-

63 Zumal das Hauptfeld oben links sich alle paar Sekunden verändert und ein Klick auf das Foto unten rechts zu einem Videofilm führt.

64 Eine zusammenfassende Darstellung des artikulatorischen Geschäfts der Sprache nach Humboldt gibt Trabant (2008, S. 25-46).

65 Wie gesagt: Dieser Beitrag konzentriert sich auf Schrift an Bild. Das sind nur zwei Fäden aus in vielen Fällen tatsächlich komplexerer Multimodalität (mit gesprochener Sprache, Ton, Animation u.a. sowie ggf. Bedingungen der Rezeptionssituation).

66 Vgl. „die sprachbildende Kraft der Sprache in dem Acte der Verwandlung der Welt in Gedanken“ (Humboldt 1963, S. 413).

67 „Es kann scheinen, als müssten alle Sprachen in ihrem intellectuellen Verfahren einander gleich seyn." (Humboldt 1963, S. 464). 
schiedne Richtungen geben. Offenbar aber müssen, wenn die Gesammtwirkung nicht gestört werden soll, das Denken in Sprache, die Rede und die Schrift übereinstimmend gebildet, und wie aus Einer Form gegossen seyn.“ (Humboldt 1994c, S. 100).

Das hier angestrebte Ideal der gleichen Grammatik für Laut- und Schriftsprache kann, soweit überhaupt, natürlich nur dort gelten, wo ein Modus (geschriebene Sprache) den anderen (gesprochene Sprache) ersetzen soll (partiell also in primärer Schriftlichkeit). In bi- oder multimodalen Konstellationen wie auf Sehflächen hingegen ergänzen verschiedene Modi einander. Gerade aus dem synergetischen Zusammenspiel von Design und Grammatik und damit eben auch ,verschiedner Richtungen des Geistes“ soll sich eine „Gesammtwirkung“ ergeben, die im Idealfall Teilleistungen einzelner Modi übersteigt. Die Architektur doppelter Artikulation von Sprache wird eingebaut in die multiple Artikulation multimodaler Diskurse.

\subsection{Schweifende Unbestimmtheit}

Unterschiedliche materielle Zeichenträger ziehen also unterschiedliche Ausdrucksformen nach sich und können andere Denkweisen nahelegen. Ein Bild kann nicht ohne weiteres in einen Text übersetzt werden, ein kohärenter Ganztext nicht umstandslos in einen Hypertext, primäre nicht einfach in tertiäre Schriftlichkeit und jeweils umgekehrt. Konkret lässt sich das nur an einzelnen Fällen studieren; und kein Material setzt der „Unbestimmtheit des blossen Vorstellens" (Humboldt 1994d, S. 133) unverrückbare Grenzen. Jedes Material aber eignet sich für unterschiedliche Zwecke unterschiedlich gut und fordert andere Gestaltungskräfte heraus, erst recht in Verbindung mit neuen Medien und Kommunikationsformen.

So wirkt Koch/Oesterreichers (1985 und 1994) damals wegweisende Unterscheidung in mediale bzw. konzeptionelle Mündlichkeit und Schriftlichkeit mittlerweile etwas altmodisch - und zwar nicht nur, wie Dürscheid (2003) zeigt, wegen eines zu engen Medienbegriffs und neuer (quasi-synchroner) Kommunikationsformen, sondern weil diese beiden sprachlichen sehr oft von nonverbalen Modi begleitet und beeinflusst werden. Wir werden über konzeptionelle Bildlichkeit ${ }^{68}$ und konzeptionelle Bi- und Multimodalität nachdenken müssen. Der Alltagsmensch beherrscht sie längst. Möglicherweise entstehen auch neue Weisen der Weltaneignung (Cassirer 1923-1929) bzw. Welterzeugung (Goodman 1984) daraus. Das kann an dieser Stelle nur angedeutet werden und ist eingehende Untersuchungen wert.

Kress/Van Leeuwen (2001, S. vii) weisen zu Recht darauf hin, dass die Frage, was ein Modus ist, viel weniger fruchtbar ist als die Frage, wie Menschen die Vielfalt semiotischer Ressourcen nutzen, um in konkreten gesellschaftlichen Zusammenhängen Zeichen zu erzeugen. Tatsächlich gebe es 68 Allgemein einführend zu Bildern überhaupt Bruhn (2009). 
weder eine strikte Arbeitsteilung noch undurchlässige Grenzen zwischen verschiedenen Kommunikationsmodi (z.B. Bild, Ton, Musik im Film) (ebd. S. 2, 125). Vielmehr, so können wir sagen, nutzen Menschen sie in unterschiedlicher Mischung je nach den gegebenen Zwecken und Möglichkeiten.

Relevante Unterschiede zwischen Modi liegen, so Kress/Van Leeuwen (2001, S. 126), nicht in physischen Beschränkungen des verwendeten Materials, sondern in dem Maß an Arbeit, das eine Gesellschaft hineingesteckt hat, um es im Rahmen multimodaler Ensembles für kommunikative Zwecke tauglich zu machen - oder, wie Humboldt sagen würde, um es zum Ausdruck des Gedanken fähig zu machen. In manchen Konstellationen, das können wir beobachten, werden z.B. Gebärden für besonders geeignete semiotische Ressourcen gehalten, in anderen Laute, Lettern oder eben Pixel.

Tatsächlich aber ist multimodale Kommunikation der Normalfall..$^{69}$ Das war durch die lange Vorrangstellung monomodal schriftlicher Text im Zeitalter des Buchdrucks (also wegen technischer Beschränkungen in zerdehnter Kommunikation) aus dem Blick geraten. „In every mode of the multimodal ensemble there is always 'work' with all the available representational forms, and such work is always meaningful." (Kress/Van Leeuwen 2001, S. 112).

Ich habe mich hier auf die Veränderung von Schrift im Konzert multimodaler Kommunikation konzentriert. Ein vollständiges Bild zeigt sich erst, wenn das Zusammenspiel aller semiotischer Ressourcen im Hinblick auf die jeweiligen Verständigungszwecke betrachtet wird. Alltagsmenschen tun das immer schon mehr oder weniger spontan. Die Arbeit wissenschaftlicher Empirie und Reflexion kann helfen, transparenter, verständlicher, verfügbarer und vielleicht auch besser zu machen, was wir tun.

\section{Ausblick}

\subsection{Performative Effizienz}

Formen der Organisation und Übermittlung von Sinn richten sich danach, was sich für erfolgreiche Kommunikation unter den gegebenen Konstellationen als am effizientesten erweist. Das führt in (mündlich-multimodaler) unmittelbarer, (schriftlich-monomodaler) zerdehnter und (technisiert-multimodaler) verdichteter Kommunikation zu jeweils anderen Formaten und Figuren. So schlagen materielle Grundlagen, bei unserem Thema das technische Arrangement von Pixeln auf Bildschirmen zum hypermedialen World Wide Web, auf die Formung der Sprache durch. Die - in Humboldts Diktion „sich ewig wiederholende Arbeit des Geistes“, articulirte Pixel zum Aus-

$69 \quad,[\mathrm{M}]$ eaning is made in many different ways, always, in the many different modes and media which are co-present in a communicational ensemble.“ (Kress/Van Leeuwen 2001, S. 111). 
druck von Botschaften fähig zu machen, erzeugt neuartige Text-Bild-Gestalten, in denen Grammatik und Design als Institutionen der Ordnung zusammenspielen, welche sich in ihrem Vollzug ständig erneuern.

Autonome (monomodale) Schriftlichkeit musste vom Ich/Du-JetztHier der unmittelbaren Face-to-Face-Kommunikation abstrahieren, um zerdebnte Kommunikation überhaupt möglich zu machen. Verdichtete Kommunikation heute holt, wie Clooneys Eingangsbeispiel (Kap. 1.1) zeigte, mit digitalen Techniken immer mehr Elemente von Situiertheit und Verkörperung zurück in kommunikative Ereignisse, wenngleich in technisch konstruierter Weise. So wirkt sie lebendiger, schneller, vielseitiger, beweglicher, performativer als rein schriftlicher Austausch ${ }^{70}$ und kann deshalb auch tiefer in unmittelbare Kommunikation eingebettet werden. Schnelle Wechsel, handelnde Teilhabe, transparente Inszenierung, aktuelle Aufführung und semiotische Kreativität kommen in multimodalem Verkehr - wenngleich technisch vermittelt - spürbarer und körpernäher zur Geltung als in rein schriftlichen Texten. ${ }^{71}$ Der schriftaffine ideologische Unterschied von res cogitans und res extensa wird unterminiert.

All das gilt umso stärker, je beweglicher Sehflächen sind, im Web also je mehr Hyperlinks genutzt werden. Doch auf Hyperformative konnte ich im beschränkten Rahmen dieses Aufsatzes nicht eingehen.

Wie Gesellschaften insgesamt werden mit der Zeit auch ihre Kommunikationsinstrumente komplexer - zumal die alten neben den neuen und teils unter ihrem Einfluss ja fortbestehen. Tertiäre Schriftlichkeit verdrängt nicht die alten Formen, sondern ergänzt und erweitert sie, eröffnet also neue Potentiale, die - wie immer - unterschiedlich intensiv und unterschiedlich gut genutzt werden können. Denken wir an den antiken Schreiber, der beim Wechsel von Mündlichkeit zu Schriftlichkeit das Trägermaterial ${ }^{72}$ tauscht: „die flüchtige Luft gegen den beständigen Papyrus, eine zeitliche gegen eine räumliche Ordnung, Sukzession gegen Linearität. Die Frage ist, ob er die Möglichkeiten, die das neue Medium bietet, genutzt hat und - inwieweit. Er hat von ihnen“, so meint Ludwig (2005, S. 60), „nur in einem sehr bescheidenen Maße Gebrauch gemacht".

$70 \quad$ Nicht zufällig erlebte die wissenschaftliche Isolierung sprachlicher Kompetenz von zugleich abgewerteter Performanz ihren Höhepunkt am Ende des Gutenberg-Zeitalters, als die ersten Computer mit Schrift programmiert werden konnten.

71 Vgl. Wulf/Zirfas (2005, S. 8): „Die Perspektive des Performativen rückt die Inszenierungsund Aufführungspraktiken sozialen Handelns, deren wirklichkeitskonstitutive Prozesse sowie den Zusammenhang von körperlichem und sprachlichem Handeln, Macht und Kreativität in den Mittelpunkt" und ,führt zu einem performativen Wahrnehmungs- und Raumbegriff, in dessen Rahmen die Rhythmen des Zusammenspiels von Ordnung und Bewegung, Erinnerung und Erwartung, Teilhabe und Distanz neu in den Blick geraten" (ebd., S. 12). - Zur aktuellen Debatte über Medialität und Performanz vgl. etwa Krämer (2000), Krämer (Hg.) (2004), Schneider (2008).

72 Ludwig (2005, S. 60) schreibt hier „Medium“. 
Wer sich im Web artikuliert, tauscht bewegliche Lettern gegen einzeln programmierbare Pixel, langsames, fest bedrucktes Papier gegen schnelle, veränderliche Bildschirme, materiell räumliche Ordnung gegen zwar virtuell räumliche, oberflächlich sichtbar jedoch flächige und zeitlich bewegliche Ordnung, bedächtiges Lesen gegen flottes Streunen, kurz: überschaubar stabile Informationswelten gegen unendlich variable Komplexität. Einige Beispiele haben wir oben betrachtet. Es ist aber wahrscheinlich, dass es nicht - wie bei Schrift - Jahrtausende dauern wird, bis die kommunikativen Möglichkeiten, welche die neuen materiellen Eigenschaften und technischen Bedingungen bieten, auch erkundet und ausgenutzt werden, sondern nur Jahrzehnte.

\subsection{Siebtes Beispiel: Bestimmt ausschweifen}

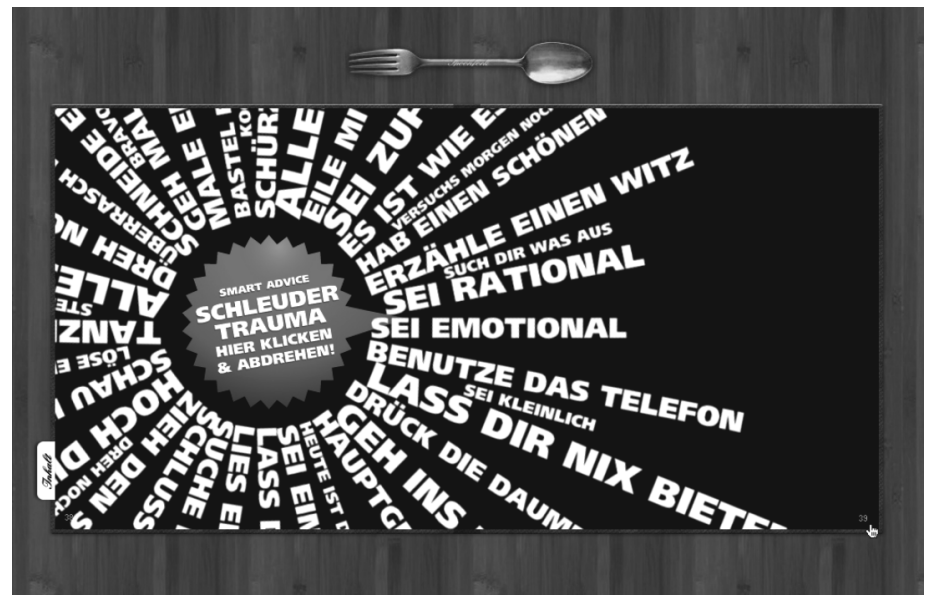

Abb. 12: www.spoonfork.de (Stand: 9.2.2009)

Abb. 12 kann, weil in die primäre Schriftlichkeit dieses Aufsatzes gezwängt, nur eine magere schwarzweiße Reproduktion eines bewegungslos gestellten Ausschnittes vergleichsweise weit entwickelter tertiärer Schriftlichkeit geben. Der geneigte Leser möge deshalb jetzt umschalten zu www.spoonfork.de und dort frei umherschweifen. In diesem Online-Magazin wird (jeden Monat neu) ein präzise arrangiertes Feuerwerk webgestalterischer Möglichkeiten vorgeführt. Hier tanzen Pixel, beleben den Bildschirm, erfrischen Schrift an Bild. Eine multimodale Vielfalt technisch-semiotischer Ressourcen wird in einer Weise durchgearbeitet, welche die schweifende Unbestimmtheit des Vorstellens teils in bewegliche Bahnen lenkt, teils noch weiter ausschweifen lässt. Humboldt hätte seine Freude daran. 


\section{Literatur}

Alkan, Saim Rolf (2002): Texten für das Internet. Ein Handbuch für Online-Redakteure und Webdesigner. Bonn.

Bonsiepe, Gui (1996): Interface. Design neu begreifen. Mannheim.

Brecht, Bertolt (1967): Turandot oder Der Kongreß der Weißwäscher. In: Brecht, Bertold: Gesammelte Werke in 20 Bänden. Bd. 5. Frankfurt a.M., S. 2193-2270.

Brinker, Klaus (2001 [1985]): Linguistische Textanalyse. Eine Einführung in Grundbegriffe und Methoden. 5. Aufl. Berlin.

Bruhn, Matthias (2009): Das Bild. Theorie - Geschichte - Praxis. Berlin.

Bühler, Karl (1934): Sprachtheorie. Die Darstellungsfunktion der Sprache. Jena.

Canetti, Elias (1936): Die Blendung. Roman. Wien/Leipzig/Zürich.

Cassirer, Ernst (1923-1929): Philosophie der symbolischen Formen. 3 Bde. Berlin.

Costall, Alan (2007): Bringing the body back to life: James Gibson's ecology of agency. In: Ziemke, Tom/Zlatev, Jordan/Frank, Roslyn M. (Hg.): Body, language and mind. Bd. 1: Embodiment. Berlin/New York, S. 55-83.

Detel, Wolfgang/Schramm, Matthias/Borsche, Tilman/Piepmeier, Rainer/Hucklenbroich, Peter (1980): [Artikel] Materie. In: Ritter/Gründer/Gabriel (Hg.) (19712007), Bd. 5., Sp. 870-924.

Dürscheid, Christa (2003): Medienkommunikation im Kontinuum von Mündlichkeit und Schriftlichkeit. Theoretische und empirische Probleme. In: Zeitschrift für Angewandte Linguistik 38, S. 37-56.

Eckkrammer, Eva Martha/Held, Gudrun (Hg.) (2006): Textsemiotik. Studien zu multimodalen Texten. Frankfurt a.M. u.a.

Ehlich, Konrad (1983): Text und sprachliches Handeln. Die Entstehung von Texten aus dem Bedürfnis nach Überlieferung. In: Assmann, Aleida/Assmann, Jan/Hardmeier, Christof (Hg.): Schrift und Gedächtnis. Beiträge zur Archäologie der literarischen Kommunikation. München, S. 24-43.

Engels, Friedrich (1962 [1876]): Dialektik der Natur. Anteil der Arbeit an der Menschwerdung des Affen. In: Marx, Karl/Engels, Friedrich: Werke. Bd. 20. Berlin, S. $444-455$.

Ernst, Ulrich (2003): Die Kreuzgedichte des Hrabanus Maurus als multimediales Kunstwerk. Textualität - Ikonizität - Numeralität. In: Schmitz, Ulrich/Wenzel, Horst (Hg.): Wissen und neue Medien. Bilder und Zeichen von 800 bis 2000. Berlin, S. 13-37.

Fischer, Martin (1997): Schrift als Notation. In: Koch/Krämer (Hg.), S. 83-101.

Freyermuth, Gundolf S. (2005): Der große Kommunikator. Soziale Konsequenzen von media merging und Transmedialisierung. In: Siever/Schlobinski/Runkehl (Hg.), S. $15-45$.

Füssel, Stephan (1999): Gutenberg und seine Wirkung. Frankfurt aM./Leipzig. 
Gahran, Amy (2002): In online writing, little things mean a lot. www.contentious.com/ 2006/03/14/in-online-writing-little-things-mean-a-lot (Stand: Januar 2009).

Genette, Gérard (1989): Paratexte. Das Buch vom Beiwerk des Buches. Frankfurt a.M. [frz. 1987].

Gibbs, Raymond W. (2006): Embodiment and cognitive science. Cambridge u.a.

Giesecke, Michael (2006 [1991]): Der Buchdruck in der frühen Neuzeit. Eine historische Fallstudie über die Durchsetzung neuer Informations- und Kommunikationstechnologien. 4. Aufl. Frankfurt a.M. [1. Aufl. Frankfurt a.M. 1991].

Goodman, Nelson (1984): Weisen der Welterzeugung. Frankfurt a.M. [amerik. 1978].

Greber, Erika/Ehlich, Konrad/Müller, Jan-Dirk (Hg.) (2002): Materialität und Medialität von Schrift. Bielefeld.

Gumbrecht, Hans Ulrich/Pfeiffer, K. Ludwig (Hg.) (1988): Materialität der Kommunikation. Frankfurt a.M.

Günther, Hartmut/Ludwig, Otto (Hg.) (1994): Schrift und Schriftlichkeit. Ein interdisziplinäres Handbuch internationaler Forschung. 1. Halbbd. (= Handbücher zur Sprach- und Kommunikationswissenschaft 10.1). Berlin/New York.

Habscheid, Stephan (2000): ,Medium“ in der Pragmatik. Eine kritische Bestandsaufnahme. In: Deutsche Sprache 28, S. 126-143.

Harris, Roy (2008): Die integrale Zeichenkonzeption. In: Zeitschrift für Semiotik 30, S. $11-28$.

Hölderlin, Friedrich (1975-2008): Sämtliche Werke. Hrsg. v. Dietrich E. Sattler. Frankfurt a.M./Basel u.a. [,Frankfurter Ausgabe"].

Hörisch, Jochen (1992): Brot und Wein. Die Poesie des Abendmahls. Frankfurt a.M.

Hoffmann, Stefan (2002): Geschichte des Medienbegriffs. (= Archiv für Begriffsgeschichte, Sonderheft 2002). Hamburg.

Horn, Wilhelm (1923 [1921]): Sprachkörper und Sprachfunktion. 2. Aufl. Leipzig.

Humboldt, Wilhelm von (1963 [1830-1835]): Ueber die Verschiedenheit des menschlichen Sprachbaues und ihren Einfluss auf die geistige Entwicklung des Menschengeschlechts [= Einleitung zum Kawiwerk]. In: Humboldt, Wilhelm von: Werke in fünf Bänden. Hrsg. v. Andreas Flitner und Klaus Giel. Bd. III: Schriften zur Sprachphilosophie. Darmstadt, S. 368-756. [Originalausg. 1830-1835].

Humboldt, Wilhelm von (1994a): Über die Sprache. Reden vor der Akademie. Hrsg. v. Jürgen Trabant. Tübingen/Basel.

Humboldt, Wilhelm von (1994b [1822]): Ueber das Entstehen der grammatischen Formen, und ihren Einfluss auf die Ideenentwicklung. In: Humboldt (1994a), S. 52 81. [Originalausg. 1822].

Humboldt, Wilhelm von (1994c [1824]): Ueber die Buchstabenschrift und ihren Zusammenhang mit dem Sprachbau. In: Humboldt (1994a), S. 98-125. [Originalausg. 1824].

Humboldt, Wilhelm von (1994d [1826]): Ueber den grammatischen Bau der Chinesischen Sprache. In: Humboldt (1994a), S. 126-142. [Originalausg. 1826]. 
Humboldt, Wilhelm von (1994e [1827]): Ueber den Dualis. In: Humboldt (1994a), S. 143-169. [Originalausg. 1827].

Ingenhoff, Diana/Schmitz, H. Walter (2000): Über den Gegenstand gesprächsanalytischer Transkriptionen. In: Hess-Lüttich, Ernest W. B./Schmitz, H. Walter (Hg.): Botschaften verstehen. Kommunikationstheorie und Zeichenpraxis. Festschrift für Helmut Richter. Frankfurt a.M. u.a., S. 143-154.

Jäger, Ludwig (2008): Aposème und Parasème: Das Spiel der Zeichen - Saussures semiologische Skizzen in den „Notes“. In: Zeitschrift für Semiotik 30, S. 49-71.

Koch, Peter/Krämer, Sybille (Hg.) (1997): Schrift, Medien, Kognition. Über die Exteriorität des Geistes. Tübingen.

Koch, Peter/Oesterreicher, Wulf (1985): Sprache der Nähe - Sprache der Distanz. Mündlichkeit und Schriftlichkeit im Spannungsfeld von Sprachtheorie und Sprachgeschichte. In: Romanistisches Jahrbuch 36, S. 15-43.

Koch, Peter/Oesterreicher, Wulf (1994): Schriftlichkeit und Sprache. In: Günther/Ludwig (Hg.), S. 587-604.

Krämer, Sybille (1997): Schrift und Episteme am Beispiel Descartes'. In: Koch/Krämer (Hg.), S. 105-126.

Krämer, Sybille (2000): ,Performativität' und ,Verkörperung‘. Über zwei Leitideen für eine Reflexion der Medien. In: Pias, Claus (Hg.): Neue Vorträge zur Medienkultur. Weimar, S. 185-201.

Krämer, Sybille (2003): > Schriftbildlichkeit< oder: Über eine (fast) vergessene Dimension der Schrift. In: Krämer, Sybille/Bredekamp, Horst (Hg.): Bild - Schrift - Zahl. München, S. 157-176.

Krämer, Sybille (Hg.) (2004): Performativität und Medialität. München.

Krämer, Sybille (2008): Medium, Bote, Übertragung. Kleine Metaphysik der Medialität. Frankfurt a.M.

Kress, Gunther (2003): Literacy in the New Media Age. London/New York.

Kress, Gunther/Van Leeuwen, Theo (2001): Multimodal discourse. The modes and media of contemporary communication. London.

Kroeber-Riel, Werner (1993): Bildkommunikation. Imagerystrategien für die Werbung. München.

Leroi-Gourhan, André (1980): Hand und Wort. Die Evolution von Technik, Sprache und Kunst. Frankfurt a.M. [frz. 1964/1965].

Linck, Dirck/Rentsch, Stefanie (Hg.) (2007): Bildtext - Textbild. Probleme der Rede über Text-Bild-Hybride. Freiburg i.Br. u.a.

Ludwig, Otto (2005): Geschichte des Schreibens. Bd. 1: Von der Antike zum Buchdruck. Berlin/New York.

Luther, Martin (1521): Assertio omnium articulorum M. Lutheri per bullam Leonis X. novissimam damnatorum. In: Luther, Martin (1883 ff.): D. Martin Luthers Werke. Kritische Gesammtausgabe. Bd. 7. Weimar, Sp. 91-151. 
Malinowski, Bronislaw (1974): Das Problem der Bedeutung in primitiven Sprachen. In: Ogden, Charles K./Richards, Ivor Armstrong (Hg.): Die Bedeutung der Bedeutung. Eine Untersuchung über den Einfluß der Sprache auf das Denken und über die Wissenschaft des Symbolismus. Frankfurt a.M., S. 323-384. [engl. 1923].

Martinet, André (1963): Grundzüge der Allgemeinen Sprachwissenschaft. Stuttgart u.a. [frz. 1960].

Meier, Stefan (2008): (Bild-)Diskurs im Netz. Konzept und Methode für eine semiotische Diskursanalyse im World Wide Web. Köln.

Mon, Franz (1995 [1959]): artikulationen. In: Mon, Franz: Gesammelte Texte 2: Poetische Texte 1951-1970. Berlin, S. 5-39. [hier: „text und lektüre“, S. 9 f.].

Ong, Walter J. (1987): Oralität und Literalität. Die Technologisierung des Wortes. Opladen. [amerik. 1982].

Peirce, Charles Sanders (1967): Einige Konsequenzen aus vier Unvermögen [amerik. 1868]. In: Peirce, Charles Sanders: Schriften zum Pragmatismus und Pragmatizismus. Hrsg. v. Karl-Otto Apel. Frankfurt a.M., S. 40-87.

Pfeiffer, K. Ludwig (1988): Materialität der Kommunikation? In: Gumbrecht/Pfeiffer (Hg.), S. 15-28.

Piaget, Jean (1975): Nachahmung, Spiel und Traum. Die Entwicklung der Symbolfunktion beim Kinde. Stuttgart. [frz. 1945].

Platon (1958): Phaidros [griech. ca. 450 v. Chr.]. In: Platon: Sämtliche Werke. Hrsg. v. Walter F. Otto, Ernesto Grassi und Gert Plamböck. Bd. 4. Hamburg, S. 7-60.

Raab, Jürgen (2008): Visuelle Wissenssoziologie. Theoretische Konzeption und materiale Analysen. Konstanz.

Radtke, Susanne P./Pisani, Patricia/Wolters, Walburga (2006 [2001]): Handbuch Visuelle Mediengestaltung. 3. Aufl. Berlin.

Raible, Wolfgang (1991): Die Semiotik der Textgestalt. Erscheinungsformen und Folgen eines kulturellen Evolutionsprozesses. Heidelberg.

Ritter, Joachim/Gründer, Karlfried/Gabriel, Gottfried (Hg.) (1971-2007): Historisches Wörterbuch der Philosophie. 13 Bde. Basel.

Runkehl, Jens (2005): Text-Bild-Konstellationen. In: Siever/Schlobinski/Runkehl (Hg.), S. 202-218.

Roelcke, Thorsten (2002): Kommunikative Effizienz. Eine Modellskizze. Heidelberg.

Saussure, Ferdinand de (1967): Grundfragen der allgemeinen Sprachwissenschaft. Hrsg. v. Charles Bally und Albert Sechehaye. 2. dt. Aufl. Berlin. [frz. 1916].

Schmitz, Ulrich (2003): Lesebilder im Internet. Neue Koalitionen und Metamorphosen zwischen Text und Bild. In: Zeitschrift für Germanistik, Neue Folge XIII, 3/2003, S. $605-628$.

Schmitz, Ulrich (2006a): Tertiäre Schriftlichkeit. Text-Bild-Beziehungen im World Wide Web. In: Schlobinski, Peter (Hg.): Von *hdl* bis *cul8r*. Sprache und Kommunikation in den Neuen Medien. (= Thema Deutsch 7). Mannheim u.a., S. 89-103. 
Schmitz, Ulrich (2006b): Schriftbildschirme. Tertiäre Schriftlichkeit im World Wide Web. In: Androutsopoulos, Jannis K./Runkehl, Jens/Schlobinski, Peter/Siever, Torsten (Hg.): Neuere Entwicklungen in der linguistischen Internetforschung. (= Germanistische Linguistik 186-187). Hildesheim u.a., S. 184-208.

Schmitz, Ulrich (i.Dr.): Sehflächenforschung. Eine Einführung. In: Diekmannshenke, Hajo/Klemm, Michael/Stöckl, Hartmut (Hg.): Bildlinguistik. Berlin.

Schneider, Jan Georg (2006): Gibt es nichtmediale Kommunikation? In: Zeitschrift für Angewandte Linguistik 44, S. 71-90.

Schneider, Jan Georg (2008): Spielräume der Medialität. Linguistische Gegenstandskonstitution aus medientheoretischer und pragmatischer Perspektive. Berlin/New York.

Siever, Torsten (2005): Internetwerbung: Alter Wein in neuen Schläuchen? In: Siever/ Schlobinski/Runkehl (Hg.), S. 219-241.

Siever, Torsten/Schlobinski, Peter/Runkehl, Jens (Hg.) (2005): Websprache.net. Sprache und Kommunikation im Internet. Berlin/New York, S. 219-241.

Spitzmüller, Jürgen (2006 [2002]): Typographie. In: Dürscheid, Christa (Hg.): Einführung in die Schriftlinguistik. 3. Aufl. Göttingen, S. 207-238.

Stöckl, Hartmut (2004): Die Sprache im Bild - das Bild in der Sprache. Zur Verknüpfung von Sprache und Bild im massenmedialen Text: Konzepte. Theorien. Analysemethoden. Berlin/New York.

Storrer, Angelika (2001): Getippte Gespräche oder dialogische Texte? Zur kommunikationstheoretischen Einordnung der Chat-Kommunikation. In: Lehr, Andrea/ Kammerer, Matthias/Konerding, Klaus-Peter/Storrer, Angelika et al. (Hg.): Sprache im Alltag. Beiträge zu neuen Perspektiven in der Linguistik. Herbert Ernst Wiegand zum 65. Geburtstag gewidmet. Berlin/New York, S. 439-465.

Storrer, Angelika (2004): Text-Bild-Bezüge und Nutzermetaphern im World Wide Web. In: Mitteilungen des Deutschen Germanistenverbandes 51.1, S. 40-57.

Thaler, Verena (2005): Zur Problematik der Synchronizität computervermittelter Kommunikation. In: Zeitschrift für Angewandte Linguistik 43, S. 79-101.

Trabant, Jürgen (2008): Was ist Sprache? München.

Vlasic, Andreas/Schweiger, Wolfgang (1998): Bilder im World Wide Web. Ein Experiment zum Einfluß der Bebilderung in Online-Nachrichtenangeboten auf die Rezeption. In: Prommer, Elizabeth/Vowe, Gerhard (Hg.): Computervermittelte Kommunikation. Öffentlichkeit im Wandel. Konstanz, S. 39-65.

Wehde, Susanne (2000): Typographische Kultur. Eine zeichentheoretische und kulturgeschichtliche Studie zur Typographie und ihrer Entwicklung. Tübingen.

Weingart, Brigitte (2007): „Sehtextkommentar“. Zu den Bilderschriften und Schriftbildern Ferdinand Kriwets. In: Linck/Rentsch (Hg.), S. 85-116.

Weinrich, Harald (1988): Über Sprache, Leib und Gedächtnis. In: Gumbrecht/Pfeiffer (Hg.), S. 80-93. 
Weiss, Christina (1984): Seh-Texte. Zur Erweiterung des Textbegriffes in konkreten und nach-konkreten visuellen Texten. Zirndorf.

Wulf, Christoph/Zirfas, Jörg (2005): Bild, Wahrnehmung und Phantasie. Performative Zusammenhänge. In: Wulf, Christoph/Zirfas, Jörg (Hg.): Ikonologie des Performativen. München, S. 7-32.

Wunderlich, Dieter (2008): Spekulationen zum Anfang von Sprache. In: Zeitschrift für Sprachwissenschaft 27.2, S. 229-265.

Zifonun, Gisela/Hoffmann, Ludger/Strecker, Bruno u. a. (1997): Grammatik der deutschen Sprache. 3 Bde. (= Schriften des Instituts für Deutsche Sprache 7.1-7.3). Berlin/New York.

Zweig, Stefan (1997 [1927]): Sternstunden der Menschheit. Vierzehn historische Miniaturen. Frankfurt a.M. 


\title{
Multimodal - intertextuell - heteroglossisch: Sprach-Gestalten in „Web 2.0“-Umgebungen
}

\begin{abstract}
Web-Umgebungen wie virtuelle soziale Netzwerke und Videoportale sind von Tendenzen der Partizipation, Konvergenz und Multimedialität gekennzeichnet. Diese bedeuten eine Herausforderung für sprachanalytische Zugänge, die digitale Kommunikationsformen separat voneinander untersuchen und auf mikrolinguistische Phänomene bei nur geringer Beachtung ihrer komplexen soziomedialen Rahmenbedingungen abheben. Im Beitrag wird ein bildschirm-basierter Ansatz entworfen, der Web-Umgebungen als semiotische Räume begreift, die von Nutzern in ihren spezifischen soziokulturellen Umständen und vor der Folie technologischer Potenziale und Grenzen aufgefüllt und ausgestaltet werden. Sprache ist eine wesentliche, aber nicht die einzige Ressource dieses digitalen kommunikativen Handelns, und ihre Verwendung ist in der Spannung zwischen technologischer Vorprägung und situierter Medienaneignung zu untersuchen. Im Kern des Ansatzes liegt die Unterscheidung von zwei analytischen Dimensionen. Die erste unterscheidet vier Leistungen von Sprache in Web-Umgebungen: Organisation, Selbstdarstellung, Spektakel und Interaktion. Die zweite erfasst drei für Web 2.0 charakteristische Prozesse der Sprach- und Textgestaltung: Multimodalität, Intertextualität und Heteroglossie. Wie diese beiden Kategorienbündel eine Grundlage für weiterführende Fragestellungen bilden können, wird am Beispiel des Dialektgebrauchs auf einer Videoplattform diskutiert.
\end{abstract}

\section{Einleitung}

Trotz ihrer Bedeutung in der Öffentlichkeit und Alltagskultur haben gegenwärtige Entwicklungen in der Netzkommunikation, die oft mit dem Stichwort „Web 2.0“ belegt werden, aus linguistischer Sicht noch kaum Beachtung gefunden. Ziel dieses Beitrags ${ }^{1}$ ist es, Rahmenbedingungen für die Untersuchung von Web 2.0-Umgebungen zu erörtern und einen Analyserahmen zu skizzieren bzw. exemplarisch anzuwenden. Der Beitrag gliedert sich in drei aufeinander aufbauende Teile. In einem ersten Schritt diskutiere ich Kennzeichen von Web 2.0, hebe die Bedeutung von Partizipation und Konvergenz für kommunikatives Handeln hervor und gehe der Frage nach, wie die linguistische Internetforschung auf diese Entwicklungen reagieren kann. Im Kern des Beitrags liegt der Umriss eines bildschirm-basierten Zugangs zu Web 2.0-Umgebungen. Dieser umfasst zwei Kategorien-Sets, die als Antworten auf zwei grundlegende Fragen verstanden werden können: Erstens, wie trägt Sprache zur Konstitution gegenwärtiger Web-Umgebun-

\footnotetext{
1 Der Vortragsstil wurde weitgehend beibehalten.
} 
gen bei? Zweitens, welche Diskursprozesse kennzeichnen diese Umgebungen? Die analytische Ausfächerung dieser Kategorien und deren Querbezüge sollen einen deskriptiven Rahmen abstecken, in dem Innovationen gegenwärtiger Netzkommunikation genauso ihren Platz finden wie Traditionen der linguistischen Internetforschung. Anschließend wird an einem Fallbeispiel exemplarisch vorgeführt, wie die beiden Kategoriensets empirisch ineinander greifen und analytisch eingesetzt werden können. Viele der nachfolgend diskutierten Phänomene sind nicht völlig neu, sondern vielmehr als Fortsetzung, teilweise auch Potenzierung bestehender Muster und Tendenzen zu verstehen. Zudem geht es mir weniger um eine erschöpfende Erläuterung als um die programmatische Skizze, die exemplarische Erfassung ihrer Facetten und ihrer Zusammenwirkung.

\section{Das „soziale Netz“ und seine Kennzeichen}

Das Schlagwort „Web 2.0“ hat in den letzten Jahren wie fast kein anderes das öffentliche Verständnis von Entwicklungen in der Netzkommunikation geprägt. Dabei ist Web 2.0 kein Fachterminus, sondern ein vager, assoziationsreicher Begriff, der einer präzisen Definition entbehrt und nach Ansicht vieler Beobachter für den Fachdiskurs eher ungeeignet ist (Scholz 2008; Maaß/Pietsch 2007; Ebersbach/Glaser/Heigl 2008, S. 23; Beiträge in Zimmer 2008). Wenn er hier dennoch Verwendung finden soll, dann einerseits mit der gebührenden Distanz und aus einer kritischen Metaperspektive, andererseits aber, weil er den Anschluss linguistischer Überlegungen an interdisziplinäre und öffentliche Diskurse über Technologie, Gesellschaft und Kommunikation signalisiert.

Seit seiner Prägung (O'Reiley 2005) wird der Begriff an Merkmalslisten veranschaulicht. Wikipedia zum Beispiel schlägt folgende „characteristics of Web 2.0" vor: „rich user experience, user participation, dynamic content, metadata, web standards, scalability" (en.wikipedia.org 2009), während ein anderer Beobachter folgende „Key Aspects of Web 2.0“ unterscheidet (Hinchcliffe 2006):

- The Web and all its connected devices as one global platform of reusable services and data

- Data consumption and remixing from all sources, particularly user generated data

- Continuous and seamless update of software and data, often very rapidly

- Rich and interactive user interfaces

- Architecture of participation that encourages user contribution

Allerdings neigen solche Listen dazu, technologische (etwa: metadata) und gesellschaftliche (z.B. rich user experience) Aspekte des Netzes nebeneinander zu stellen, ohne deren wechselseitiges Verhältnis zu berücksichtigen. Eine 
zweite und meines Erachtens einleuchtendere Begriffserläuterung ist die zugespitzte Gegenüberstellung zwischen Web 2.0 und „Web 1.0“, einer retrospektiv geprägten Bezeichnung für das frühe Netz der 1990er Jahre (O'Reiley 2005). Demnach bestand Web 1.0 aus „traditionellen“ Websites, die nur von ihren Besitzern bzw. Produzenten verändert werden konnten, während die Nutzer ${ }^{2}$ auf die Rezeption der bereitgestellten Inhalte eingeschränkt waren. Die interaktiven Anwendungen des Internet wie Email, Newsgroups, Mailinglisten und Chatkanäle, die das ursprüngliche Hauptgebiet der linguistischen Internetforschung darstellten, operierten noch separat vom Web 1.0 und gingen ihm historisch voraus. Die Unterscheidung zwischen dem Web als Informationsquelle (,Web 1.0“) und den interaktiven Internet-Diensten war noch bis zu Beginn dieses Jahrzehnts allgemein üblich.

Eben diese Unterscheidung fällt nun mit Web 2.0 in sich zusammen. Sein erstes Kennzeichen, Partizipation, ist wesentlich weiter aufgefasst als interpersonale Kommunikation im sprachwissenschaftlichen Sinn. Web 2.0Umgebungen sind keine Ansammlungen redaktionell aufbereiteter Inhalte, sondern stellen Infrastrukturen bereit, die von Nutzern - freilich bei entsprechender Hardware-Ausstattung und passendem Breitband-Zugriff rezeptiv und produktiv angeeignet werden. Innerhalb der von der jeweiligen Plattform gesetzten thematischen, technischen und semiotischen Grenzen werden Inhalte von den Nutzern selbst beigesteuert - hochgeladen, modifiziert, kommentiert, mit anderen Inhalten verknüpft usw. Dadurch „kann jeder durchschnittlich befähigte Nutzer, selbst wenn er nicht programmieren kann, viel leichter als bisher aktiv an der Informations- und Meinungsverbreitung teilnehmen“ - das Motto lautet: „Jeder kann mitmachen“ (de. wikipedia.org 2009). In diesem Sinne ist Web 2.0 durch eine „Architektur des Mitwirkens" (Hinchcliffe 2006) gekennzeichnet; von Randow (2007) bezeichnet es als „Medium der Beteiligung“:

Das Web 2.0 ist ein Medium der Beteiligung. (...) Der Erfolg von Angeboten wie YouTube oder MySpace rührt nicht zuletzt daher, dass hier jedermann sein Zeug raufladen kann, um wenigstens einmal Prominenz zu erfahren, Mikroprominenz. (Randow 2007)

Dem Beteiligungsprinzip kommen die Stichworte „Plattform“ und „Umgebung" entgegen, wie sie in diesem Beitrag verwendet werden. Dabei ist mit „Umgebung“ ein semiotischer Raum gemeint, in dem Nutzer verschiedene Handlungsmöglichkeiten zur Verfügung haben, während „Plattform“ eine spezifische technisch-institutionelle Basis für die Verwendung digitaler Kommunikationstechnologien meint. So stellen virtuelle soziale Netzwerke vielschichtige Kommunikationsumgebungen dar, jedes einzelne davon ist eine spezifische Vernetzungsplattform mit eigenen Partizipationsbedingungen und Gestaltungskonventionen.

Ich verwende das generische Maskulinum. 
Das Prinzip der Beteiligung tritt auf den unter Web 2.0. zusammengefassten Umgebungen auf unterschiedliche Weise in Erscheinung. Im Folgenden sollen nur zwei Umgebungstypen Berücksichtigung finden: Vernetzungs- und Medienplattformen.

Vernetzungsplattformen (andere gängige Bezeichnungen sind „(virtuelle) soziale Netzwerke“, „Social-Network-Dienste“, „, social network sites") ermöglichen ihren Nutzern die Einrichtung einer Profilseite und die Vernetzung mit anderen Profilseiten. Facebook und MySpace sind die international wohl bekanntesten Plattformen dieser Art, zu ihnen gesellen sich eine Vielzahl anderer, darunter auch regional- bzw. sprachspezifischer Varianten. Nach boyd (2008) weisen social network sites drei distinktive Merkmale auf: a) Profile - individuelle „virtuelle Körper“, die unter Zuhilfenahme der jeweils verfügbaren semiotischen Ressourcen gestaltet werden; b) Freunde - die auf der Plattform sichtbar gemachten sozialen Beziehungen; und c) Kommentare - Beiträge, die „Freunde“ auf den Profilseiten anderer „Freunde“ hinterlassen. ${ }^{3}$

Mediaplattformen (auch content sharing sites, media sharing sites oder social sharing genannt) dienen der Bereitstellung digitaler Medientexte wie Fotos, Videos und Musik für eine meist unbegrenzte Netzöffentlichkeit. Von der Produktionsseite her weisen Mediaplattformen wie flicker und YouTube eine Bandbreite privater, kommerzieller und institutioneller Nutzung auf, wobei im Folgenden nur der private Bereich interessiert. In Analogie zu den Vernetzungs- lassen sich auch für Mediaplattformen drei Kennzeichen bestimmen: a) Präsentation jeder Medieneinheit auf einer dezidierten Webseite, b) Nutzungsstatistiken wie Aufrufe, Bewertungen und Herkunft der Besucher und c) eine Kommentierungsmöglichkeit.

Eine zweite sprach- und diskursanalytisch relevante Dimension der gegenwärtigen Netzentwicklung, die in den erwähnten Merkmalsauflistungen weniger deutlich zum Ausdruck kommt, wird unter dem Dachbegriff Konvergenz zusammengefasst. Damit ist allgemein die Zusammenführung, Verflechtung und Verschmelzung von technischen und kommunikativen Prozessen und Aktivitäten der Medienproduktion bzw. Medienrezeption gemeint. In der medienwissenschaftlichen Diskussion wird Konvergenz verschiedenartig definiert und analytisch ausgelegt (vgl. Jenkins 2006; Hasebrink/Mikos/Prommer (Hg.) 2004). Für meine Zwecke unterscheide ich in Bezug auf Netzkommunikation drei Teilaspekte von Konvergenz: Integration, Einbettung und Modularität.

\footnotetext{
Soziale Netzwerke bedeuten nach boyd (2008) einen Paradigmenwechsel weg von den viel beachteten und untersuchten virtuellen Gemeinschaften. Das regelmäßige virtuelle „Miteinander" von Gleichgesinnten auf einer spezifischen Plattform (Chat- oder Forumsgemeinschaften) wird abgelöst durch losere, heterogenere Ansammlungen von „Individuen“, deren Gemeinschaftlichkeit nicht erst online, sondern in erster Linie offline entsteht; dieser Unterscheid dürfte auch auf die linguistische Beschäftigung mit dem Netz Auswirkungen haben (vgl. etwa die Operationalisierung von virtuellen Gemeinschaften bei Herring 2004).
} 
Mit „Integration“ ist gemeint, dass ehemals separate digitale Kommunikationsformen auf das Web übertragen und innerhalb ein und derselben Plattform ausgeführt werden. Beispielsweise bietet die Vernetzungsplattform facebook eine Reihe von Kommunikationsmöglichkeiten, die traditionellen Internet-Diensten ähneln bzw. diese integrieren: die persönlichen Nachrichten sind vergleichbar zu Emails, die „Chat"-Funktion ist im Grunde ein Instant Messenger für den individuellen quasi-synchronen Austausch; Beiträge auf der „Wand“ eines „Freundes“ ähneln den früheren Gästebucheinträgen auf einer persönlichen Homepage, und Gruppendiskussionen sind das strukturelle Äquivalent zu Newsgroups oder Webforen. Insofern sprengen gegenwärtige Vernetzungsplattformen frühere Klassifizierungen digitaler Kommunikationsformen (etwa nach Herring 2001 oder Döring 2003), da sie mehrere Zellen auf einmal belegen. „Einbettung“ meint die Möglichkeit, digitale Texte auf nahezu beliebige Weise zu vervielfältigen und auf Webseiten zu platzieren; so lassen sich beispielsweise YouTubeVideos auf eine Blog- oder Profilseite einbetten, wo sie weiter kommentiert werden können. Durch Einbettung werden der Umlauf und die Kombinierbarkeit digitaler Inhalte potenziert. „Modularität“ meint schließlich die Zusammensetzung von Webseiten aus separaten Textelementen („Modulen"), die auch in anderen Kombinationen auftreten können. Eine Spielart von Modularität ist das als Mashup bekannte Verfahren, wodurch eine individuelle Seite aus Inhalten aus verschiedenen Quellen collagenartig zusammengestellt wird; dies entspricht dem Web 2.0-Kennzeichen „Data consumption and remixing from all sources" (nach Hinchcliffe 2006).

Zieht man die skizzierten Prozesse zusammen, so erscheint Web 2.0 als ein Entwicklungsmoment der „Neuen Medien“, das von der Koexistenz unterschiedlicher, teilweise gegensätzlicher Elemente und Prozesse gekennzeichnet ist: Privates und Öffentliches, Professionelles und Amateurhaftes, Globales und Lokales kommen auf engstem Raum, auf ein und derselben Plattform oder sogar Webseite, in neuartigen Kombinationen zusammen.

\section{Web 2.0 vor der Folie der linguistischen Internetforschung}

Partizipation und Konvergenz sind nun im Hinblick auf ihre sprachlichdiskursiven Auswirkungen und Implikationen zu bedenken. Gleich an dieser Stelle sei angemerkt, dass das Verhältnis zwischen medien- und sprachwissenschaftlichen Perspektiven auf Web 2.0 sich nicht auf einen direkten disziplinären Transfer von Kategorien und Kriterien erschöpft. Die Tatsache, dass manche der bisherigen Beobachtungen und Typologien sprachanalytisch anschlussfähig erscheinen, bedeutet noch nicht, dass gesamte Merkmalslisten wie die eingangs zitierten übernommen und linguistisch be- 
legt werden könnten. Außerdem mag eine sprachwissenschaftliche Perspektive auf Web 2.0 auch Tendenzen aufspüren und Relevanzen setzen, die aus Sicht anderer Disziplinen weniger interessant oder sichtbar sind.

In diesem Sinne ist zunächst zu konstatieren, dass das Stichwort „Partizipation" mit unabhängig belegten Tendenzen des digitalen Sprachgebrauchs sehr gut vereinbar ist. Durch Partizipation - und das heißt: durch die außerinstitutionelle, nichtprofessionelle Produktion öffentlich zugänglicher Texte - kann sich der Anteil informeller schriftlicher Kommunikationsstile im öffentlichen Netzraum noch weiter erhöhen und verfestigen. Dies schließt den Einzug mündlichkeitsnaher Schreibstile in herkömmliche Domänen konzeptioneller Schriftlichkeit sowie die erhöhte Sichtbarkeit von Nonstandardvarietäten mit ein. Partizipation und Konvergenz bewirken, dass Rollentrennungen zwischen Produzenten/Informationsanbietern und Rezipienten/Konsumenten zunehmend aufgelockert und Grenzen zwischen unterschiedlichen Diskurstypen, Gattungen und Schreibstilen zunehmend verwischt werden. Institutionell produzierte und Nutzer generierte Inhalte können nun nebeneinander erscheinen und neue Kombinationen eingehen - ein Prozess, der beispielsweise beim Besuch von Bewertungsplattformen oder Onlineshops, die Kundenrezensionen einbinden, leicht erkennbar ist. Durch Konvergenz wird zudem die Komplexität der semiotischen Zusammensetzung digitaler Umgebungen erhöht. Die Teilaspekte der Einbettung und Modularität bedeuten, dass einzelne Webseiten aus Elementen ganz verschiedener Herkunft - und damit auch potenziell uneinheitlicher Autorenschaft, Gattung und Stillage - zusammengesetzt sind.

Die künftige Auseinandersetzung linguistischer Forschung mit diesen Prozessen ${ }^{4}$ wird auf eine inzwischen reichhaltige Forschungslage zurückgreifen können, die es ermöglicht, Web 2.0 nicht als ein vermeintlich völlig neues Phänomen zu begreifen, sondern seine innovativen Facetten vor der Folie früherer Stadien von Netzkommunikation einzuschätzen. Andererseits werden sich dabei nicht alle bisherigen Ansätze als gleichermaßen produktiv und anschlussfähig erweisen. An dieser Stelle sei insbesondere auf zwei Forschungsprämissen aufmerksam gemacht, die von den gegenwärtigen Entwicklungen meines Erachtens in Frage gestellt werden: die analytische Trennung von Kommunikationsformen und die Dekontextualisierung sprachlicher Daten.

Damit ist erstens die verbreitete Praxis gemeint, Sprachgebrauch im Internet separat für einzelne Kommunikationsformen zu untersuchen und als Ergebnis Listen von vermeintlich anwendungsspezifischen Sprach- und Stilmitteln aufzustellen. Dadurch haben sich die einzelnen digitalen Kommu-

Beiträge zu Web 2.0-Umgebungen aus spezifisch sprach bzw. textanalytischer Perspektive sind noch rar (vgl. Baron 2008; Honeycutt/Herring 2009; Meier i.Vorb. und die methodologische Diskussion in Markham/Baym (Hg.) 2009; abwesend hingegen bei Rowe/Wyss (Hg.) 2009). Fachliteratur gibt es lediglich zu Blogs, die hier jedoch nicht berücksichtigt werden. 
nikationsformen zu Leitkategorien für die konzeptionelle und analytische Gliederung des Feldes entwickelt, wie man an der Organisation mehrerer einschlägiger Publikationen erkennen kann. Gegen eine Fortführung dieser analytischen Trennung in der Web 2.0-Ära spricht zum einen das damit einhergehende Risiko eines latenten technologischen Determinismus, d.h. der impliziten oder expliziten Annahme, dass das Kommunikationsverhaltens durch die Kommunikationstechnologie bestimmt wird (Hutchby 2001). Indem man Sprachgebrauch im Internet prinzipiell nach der Kommunikationsform ausfächert, wird diese zum zentralen Kontextaspekt erhoben, was einen Vorrang technisch-medialer vor situativen und sozialen Kontextaspekten impliziert (vgl. kritisch dazu Androutsopoulos 2007b). Zum anderen nimmt die Unterscheidungskraft der Kommunikationsformen mit ihrer massenhaften Verbreitung ab: Wenn Emails gesamtgesellschaftlich allgegenwärtig sind, verliert die Kategorie „Sprache der Email“ ihre Bedeutung. ${ }^{5}$ Nicht zuletzt ist die analytische Orientierung an einzelnen Anwendungen nicht in der Lage, Kommunikationsprozesse zu erfassen, die sich quer durch verschiedene Plattformen erstrecken, beispielsweise die spezifische Koordination von Spielumgebung, Chat, Forum und Blogs bei Online-Gamern.

Der zweite Punkt betrifft die Dekontextualisierung von Sprache aus dem digitalen Kommunikationsprozess. Dies ist erst einmal eine legitime, gewissermaßen unvermeidliche methodische Konsequenz eines linguistischen Zugangs zu computervermittelter Kommunikation, sofern die Mikroanalyse sprachlicher Prozesse (u.a. das Verhältnis von Mündlichkeit/Schriftlichkeit, Aspekte von Sprachökonomie und -variation, Innovation und Wandel) eine Reduktion des semiotisch reichhaltigen Geschehens in Online-Umgebungen auf ihre (schrift-)sprachlichen Anteile voraussetzt. Damit geht oft auch ein auf die jeweilige Kommunikationsform reduziertes Kontext-Verständnis einher. In früheren Stadien internet-basierter Kommunikation wurde dieses Vorgehen zweifellos auch von den „schriftstarken“ Anwendungen begünstigt. Denn Chats, Newsgroups oder Emails sind semiotisch verhältnismäßig ,arme“ Umgebungen, in denen Schrift die zentrale, wenn nicht die ausschließliche semiotische Ressource darstellt. Allerdings stellen die gegenwärtigen, semiotisch reichhaltigen Web 2.0-Umgebungen dringende Fragen über den Anteil von Multimedialität und Multimodalität an der Erzeugung von kommunikativem Sinn und über das Zusammenspiel von Sprache mit anderen Zeichensystemen. ${ }^{6}$ Beispielsweise ist zu beobachten,

5 Vgl. bereits Schmitz (2002) und neuerdings auch Baron (2008). Damit geht die Vergänglichkeit digitaler Technologien im Medienwandel einher: Manche der früher gern untersuchten „interaktiven Dienste“ werden mit der Konvergenz des Web 2.0. allmählich obsolet. Newsgroups und Internet Relay Chat z.B. sind aus der Perspektive der heute heranwachsenden Generation von Internetnutzern bereits als veraltet zu bezeichnen (vgl. Thimm 2008, S. 333).

$6 \quad$ Ich unterscheide Multimedialität (Koexistenz und Kombination verschiedener Medien) und Multimodalität (Koexistenz und Kombination verschiedener semiotischer Modalitäten, Zeichensysteme in einem Text). 
dass dialogische Kommunikation in Vernetzungsplattformen eng mit Multimedia-Inhalten verzahnt ist, so dass z.B. ein eingebettetes Video als Auslöser für eine dialogische Sequenz auf einer Profilseite fungiert (siehe auch Abschnitt 6 unten). Gewiss lassen sich die Forschungsfragen der linguistischen Internetforschung auch an Web 2.0-Daten weiter verfolgen; durch eine voreilige Loslösung der linguistischen Komponente aus dem Bildschirmkontext und eine Reduktion desselben auf den Aspekt der Kommunikationsform wird man jedoch das Spezifische des Web 2.0 nicht in den Griff bekommen.

\section{Ein bildschirm-basierter Ansatz}

Statt einer einfachen Fortsetzung bisheriger analytischer Praktiken stellt uns Web 2.0 also vor die Aufgabe, einen neuen Rahmenansatz und ein neues Beschreibungsvokabular zu entwickeln, die auf gegenwärtige digitale Kommunikationsumgebungen abgestimmt sind und ihre Spezifika zu erfassen vermögen (vgl. auch Thimm 2008, S. 333).

In meinem Zugang werden computervermittelte Sprach- und Interaktionsprozesse in ein Spannungsfeld zwischen technisch-medialen Einschränkungen einerseits, sozialen und situativen Kommunikationsbedingungen andererseits platziert. Während die jeweils herangezogenen Kommunikationstechnologien einen Rahmen von Möglichkeiten und Einschränkungen abstecken, können sie einen spezifischen Sprachgebrauch nicht erzwingen oder determinieren; maßgeblich für diesen ist letztlich die individuelle bzw. gemeinschaftliche Aneignung dieser Technologien vor der Folie spezifischer sozialer und situativer Bedingungen. Hutchby bringt den Zusammenhang folgendermaßen zum Ausdruck:

We need to develop a framework that argues both that technologies for communication do indeed bring into existence - in the sense of enable and promote - new forms of participatory possibilities in human interaction, new categories of what might be called 'localized social identities', and that these new forms of interaction are at the same time the product of humans' active appropriation and configuration of the technology in pursuit of their own purposes. (Hutchby 2001, S. 7-8)

Daher ist die Untersuchung der sprachlichen Kennzeichen einzelner Kommunikationsformen zwar als erster deskriptiver Schritt notwendig, aber nicht ausreichend. Die Frage ist nicht nur, welche kommunikativen Möglichkeiten und Grenzen die Technologien des „Mitmachnetzes“ anbieten, sondern auch, wie vor der Folie dieser Bedingungen mit und in neuen Medien tatsächlich gehandelt wird.

Die Bezeichnung des Zugangs als „bildschirm-basiert“ verweist auf die Herkunft der untersuchten Daten und gleichzeitig auf den Kontrast zu nutzer-zentrierten Analysen ab, wie sie für Online-Forschung jenseits der 
Linguistik charakteristisch sind. Nutzer-zentrierte Ansätze legen den Schwerpunkt auf die Nutzer und ihre Aktivitäten vor dem Bildschirm, die mittels Interviews, Fragebögen, Fokusgruppen usw. untersucht werden. Ein bildschirm-basierter Ansatz konzentriert sich, ganz in der Tradition der linguistischen Internetforschung, auf Online-Texte bzw. -Aktivitäten. Vereinfacht gesagt sind die primären Analyseeinheiten nicht User, sondern Texte unterschiedlicher Größenordnung, die von einzelnen Webseiten über Diskussionsstränge bis hin zu gesamten Websites reichen. Der Ansatz schließt die ethnografische Beobachtung von Online-Prozessen sowie direkte Kontakte zu den Beteiligten mit ein (vgl. Androutsopoulos 2008).

Um der Komplexität von Web 2.0-Umgebungen gerecht zu werden, plädiere ich für eine Kombination von linguistischen bzw. semiotischen Analyseverfahren auf unterschiedlichen Strukturebenen in Verbindung mit einem dynamischen Verständnis von Interaktions- und Kontextualisierungsprozessen. Dabei werden Impulse aus der linguistischen Internetforschung, Sozio- und Diskurslinguistik, Medienlinguistik und Stilanalyse integriert (siehe Androutsopoulos 2007a, 2009; Coupland 2007; Herring 2004; Sandig 2006). Als oberste analytische Einheit ist die einzelne Webseite anzusehen. Auf Vernetzungsplattformen ist dies die einzelne Profilseite (einschließlich ihrer durch Tabellenreiter bzw. Navigationspunkte zu erreichenden Unterseiten), auf Mediaplattformen die einzelne Mediaseite (z.B. Video- oder Fotoseite) einschließlich des angeschlossenen Produzentenprofils und der Kommentare. Die Entscheidung für diese Analyseeinheit ist funktional und ethnografisch motiviert, d.h. dezidierte Profil- und Mediaseiten bilden jeweils funktionale Einheiten, an denen sich Online-Nutzer selbst orientieren. Am anderen Ende des analytischen Kontinuums liegen linguistische bzw. interaktionsanalytische Kategorien, beispielsweise der expressive Gebrauch von Orthografie oder Interpunktion, Ellipsen, sprachliche Höflichkeit usw. Das Ziel ist, den analytischen Fokus auf spezifische linguistisch-interaktionale Prozesse mit einem ganzheitlichen Verständnis der funktionalen Komplexität und Vielfalt von Web 2.0-Umgebungen zu verbinden.

In diesem Zusammenhang ist auch das Titel-Stichwort „Sprach-Gestalten" in seiner Ambiguität zu betrachten. Als Verbalkonstruktion verstanden - (durch) Sprache gestalten - bezieht es sich auf die kreativen Leistungen der Beteiligten, die sich in den gewählten digitalen Räumen ihre Identitäten und Beziehungen herbei schreiben; als Nominalkonstruktion - im Sinne von „Sprachgestalt" - verweist es auf die am Bildschirm sichtbaren semiotischen Konstrukte und Prozesse, die maßgeblich durch Sprache entstehen und sinnvoll gemacht werden. 


\section{Vier Leistungen von Sprache in Web 2.0-Umgebungen}

Vor diesem Hintergrund sollen nun zwei Kategorien-Sets vorgestellt werden, die in ihrem Zusammenspiel ein deskriptives Raster zur Erkundung von Web 2.0-Umgebungen ergeben. Ein dem anschließenden Fallbeispiel entnommenes Screenshot (Abb. 1) begleitet die Diskussion. Die erste Dimension ist die Unterscheidung von vier typischen Funktionen von Sprache in der Konstitution von Web 2.0-Umgebungen. Ich bezeichne sie mit den Stichworten Selbstdarstellung, Interaktion, Organisation und Spektakel.

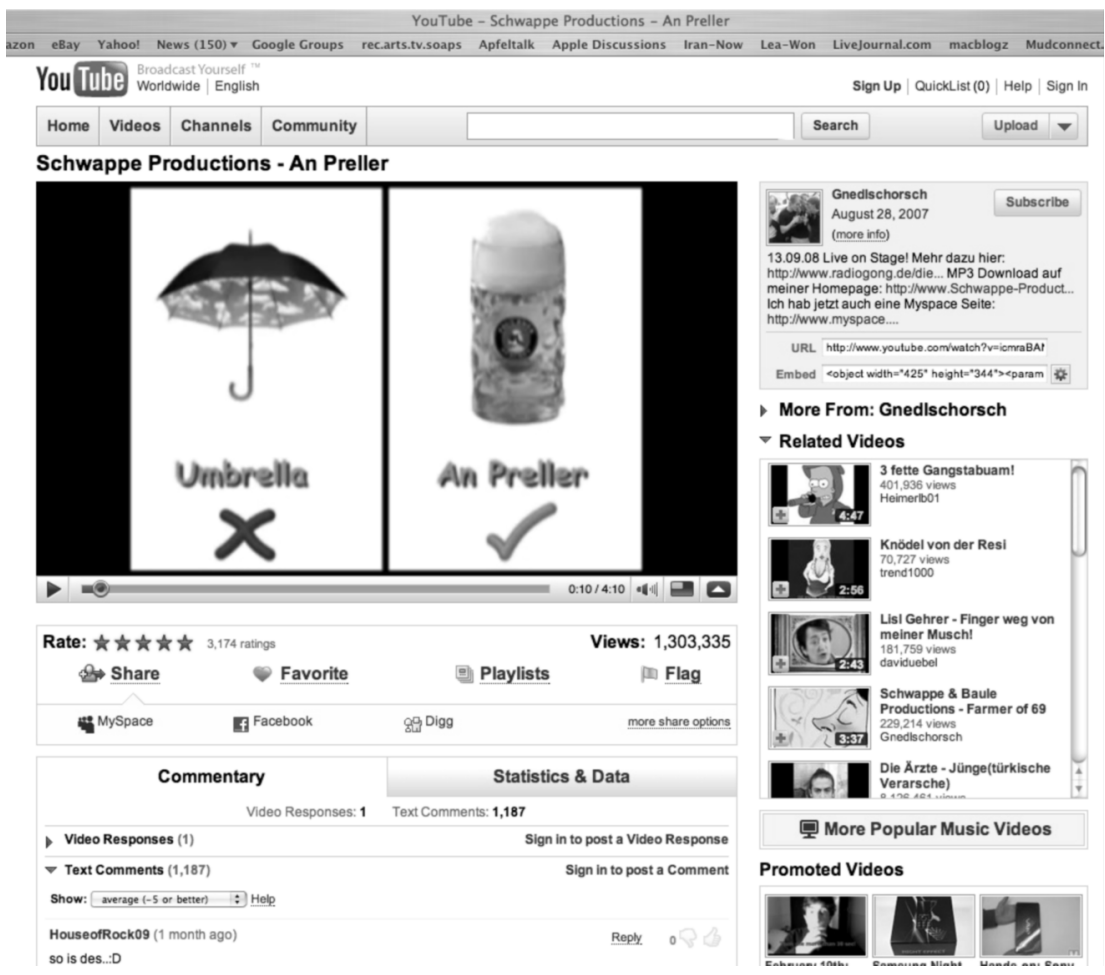

Abb. 1: Screenshot von „Schwappe Productions - An Preller“

Zunächst ist Sprache die wohl wichtigste (jedoch nicht die einzige) Ressource für die Selbstdarstellung der Nutzer auf Profilseiten. Sie wirkt dabei zusammen mit anderen semiotischen Möglichkeiten (Fotos, Weblinks, Hintergrundfarbe, Medieneinbettung usw.), die von allen gängigen Vernetzungsplattformen in unterschiedlichen Kombinationen angeboten werden. Heutige Profilseiten stehen in der Tradition der persönlichen Homepage, und Leitkategorien der früheren Homepageforschung sind auf sie anwendbar (vgl. Döring 2002; Chandler 1998; Stern 2008). Im Vergleich zu frü- 
heren Homepages sind heutige Profilseiten durch stärkere Serialisierung und Standardisierung einerseits, größere Spielräume für Individualisierung andererseits gekennzeichnet. Profilseiten fußen auf den generellen Voraussetzungen und Beschränkungen ihrer jeweiligen Vernetzungsplattform, die die äußere Form der Profile auf spezifische Weisen einschränken, indem sie bestimmte Modifikationsparameter erlauben oder ausschließen. Gleichzeitig verfügen die User über zahlreiche Optionen der Individualisierung, wozu auch ein leichter Umgang mit Multimedia gehört. Dadurch erweitert sich insbesondere das Repertoire der indirekten Hinweise auf Identität bzw. Persönlichkeit. Waren diese früher auf aufgelistete Weblinks beschränkt, können heute auch die eingebundenen Medianinhalte, die sichtbar aufgelisteten Freunde, die abonnierten Gruppen usw. die gleiche Funktion erfüllen. Auch die Verflechtung von Selbstdarstellung mit den Besucher-Rückmeldungen ist auf gegenwärtigen Profilseiten im Vergleich zu den früheren Gästebuchkommentaren enger geworden.

Die Interaktionsfunktion von Sprache - d.h. die Nutzung geschriebener Sprache zum interpersonalen Austausch - blickt ebenfalls auf eine längere Tradition der „getippten Gespräche“ (Storrer 2001) zurück, und frühere Forschungsergebnisse zur computervermittelten Interaktion scheinen auch für Web 2.0-Umgebungen in vielen Punkten noch gültig. Gleichzeitig werden die Möglichkeiten computervermittelter Interaktion neu kontextualisiert. Beispielsweise stellt die historisch recht neue, inzwischen weit verbreitete Kommentierung eines gegebenen Referenztextes (Blog-Beitrag, Video, Foto, Musik) spezifische Bedingungen der Kohärenzbildung dar. Anders als auf Foren bzw. Chats ist das Verhältnis zwischen den einzelnen Kommentaren weniger als Interaktion und mehr als Dialog mit dem Referenztext zu bezeichnen. Ähnliches gilt für die auf Vernetzungsplattformen zu beobachtenden Augenblicksdialoge, die sich anlässlich eines eingebetteten Videos bzw. einer Veränderung der Statuszeile entfalten.

In ihrer Organisationsfunktion trägt Sprache zusammen mit anderen semiotischen Mitteln (Farbe, Bilder, Piktogramme, Layout) dazu bei, die Bildschirmoberfläche als einen kohärenten virtuellen „Raum“ zu konstituieren, der Nutzerhandlungen ermöglicht und vorstrukturiert. Die zentrale Leistung sprachlicher Einheiten ist hier ihre Doppelfunktion als Überschriften und Hyperlink-Indikatoren, mittels derer Nutzer-Aktivitäten ausgeführt werden. Freilich ist diese Leistung konstitutiv für das WorldWideWeb überhaupt; spezifisch für Web 2.0 ist allenfalls ihre zunehmende Komplexität. Gegenwärtige Webseiten bestehen zu einem nicht geringen Anteil aus organisierender Sprache. Dazu zähle ich die verschiedenen Navigationsleisten, die überwiegend aus einfachen Nomina oder Verben, Nominal- bzw. Verbalphrasen bestehen. Auf jeder YouTube-Seite zum Beispiel (vgl. Abb. 1) findet man über dem Videofenster eine erste Navigationsleiste 
links (Startseite, Videos, Kanäle, Community), eine weitere oben rechts (Konto erstellen, Anmelden, Abonnements, Protokoll, Video bocbladen), eine Reihe von Optionen direkt unter dem Videofenster (Favorit, Weiterleiten, Playlists, Melden) usw. All diese lexikalischen Einheiten, deren Kohäsion zueinander und ihrer Umgebung multimodal strukturiert ist, stellen Hyperlinks dar, die die vorliegende Seite zu anderen Seiten bzw. Nutzeraktivitäten verknüpfen. Daran sieht man, dass die Organisationsdimension von Sprache von syntaktischer Reduktion charakterisiert ist und Textkohärenz innerhalb einer „visual syntax“ (van Leeuwen 2004, S. 17) hergestellt wird, der Typografie, Farbgebung und Layout angehören.

Dass die Organisationsleistung von Sprache in der linguistischen Internetforschung verhältnismäßig wenig Beachtung gefunden hat (vgl. aber Schmitz 2003 und in diesem Band), hängt sowohl mit dem Schwerpunkt auf interpersonaler dialogischer Netzkommunikation als auch mit einer allgemeinen Vernachlässigung von Multimodalität in der Linguistik zusammen (van Leeuwen 2004). Das enge funktionale Zusammenspiel mit anderen semiotischen Ressourcen bedeutet auch, dass die organisierende Sprache des Webs mit ausschließlich linguistischen Kategorien nur bedingt zugänglich ist. Zu den linguistisch zugänglichen - und spannenden - Fragen gehören beispielsweise die von globalen Web 2.0-Plattformen angebotenen Sprachoptionen und die stilistische Ausgestaltung der Linkbezeichnungen bzw. Navigationspunkte. Überprüft man beispielsweise, in welchen Sprachen das Videoportal YouTube verfügbar ist, so sieht man u.a. Nederlands oder Svenska, nicht aber Ukrainisch, Punjabi oder Arabisch. Daran schließt die Frage an, nach welchen Kriterien solche Sprachoptionen angeboten werden und wie sich die Relevanz der Sprecherzahlen zum wirtschaftlichem Gewicht einzelner Nationalsprachen verhält (vgl. auch Kelly-Holmes 2006).

Vor diesem Hintergrund heben sich Spektakel als wichtigste Innovation der Web 2.0-Ära ab. Als „Spektakel“ bezeichne ich Medientexte, die durch Nutzer auf Mediaplattformen hochgeladen und dort verfügbar gemacht werden. Es handelt sich in der Regel um multimodale bzw. -mediale Texte, die Sprache mit einschließen aber nicht auf diese beschränkt sind, typischerweise also Videos, Songs, Fotos. ${ }^{7}$ Die Metapher impliziert, dass diese Texte hauptsächlich als Unterhaltung wahrgenommen und ähnlich wie z.B. massenmediale Angebote konsumiert werden. Sie impliziert ferner, dass sie an eine Zuschauerschaft gerichtet sind und deren Reaktion suchen, die üblicherweise in Form von Kommentaren beigesteuert wird.

Die Bedeutung der Spektakel für die linguistische Untersuchung von Web 2.0 erschließt sich vor dem Hintergrund der Forschungslage in mehrfacher Hinsicht. Erstens eröffnet sich hier eine völlig neue Dimension von

Der Begriff umfasst zunächst Medientexte aller Art, selbst ohne Beteiligung von Sprache; in diesem Beitrag werden allerdings nur Videos berücksichtigt. 
„Sprache in neuen Medien“: War gesprochene Sprache im Netz bisher marginal, tritt sie nun in zahlreichen Kombinationen von Multimodalität und Gattung in Erscheinung. Spektakel sind bezüglich ihrer Gattungszugehörigkeit und stilistischen Beschaffenheit völlig offen, daher ist gesprochene Sprache in Spektakeln durch eine einfache Unterscheidung von konzeptioneller Mündlichkeit bzw. Schriftlichkeit noch nicht hinreichend beschrieben. Gleichzeitig sind Spektakel - wie unten noch im Detail auszuführen - mit der sie umgebenden digitalen Schriftlichkeit vielfach intertextuell verbunden.

Zweitens deutet die Spektakel-Metapher darauf hin, dass auf Mediaplattformen gestellte Nutzerproduktionen öffentliche Aufmerksamkeit jenseits des Massenmediensystems erlangen können. In meinen Beobachtungen und Fallanalysen von YouTube belege ich mehrere Beispiele für deutschsprachige Spektakel, die mehrere Millionen Zugriffe und tausende Kommentare erhalten, obwohl sie ihrer Ästhetik nach wohl keinen Zugang zum institutionellen Mediensystem gefunden hätten. Ein solcher Fall ist auch das in der Abbildung 1 gezeigte Video (siehe Abschnitt 7). Mit dem Kulturwissenschaftler John Fiske kann man hier sagen, dass auf Mediaplattformen außerinstitutionelle Primärtexte entstehen (Fiske 1987), die ganz ohne professionelle Produktion, „massentaugliche“ Ästhetik und sprachliche Standardisierung eine Massenaufmerksamkeit jenseits der Kontrollmechanismen der Medienindustrie nach sich ziehen (Androutsopoulos 2003). Dies ist soziolinguistisch insofern von Interesse, als Standardsprachlichkeit als Grundbedingung öffentlicher Kommunikation weiter aufgelockert und gleichzeitig auch die Sichtbarkeit von Nonstandardvarietäten potenziell gesteigert wird. Weitere linguistische Konsequenzen ergeben sich aus der Tatsache, dass Mediaplattformen Dreh- und Angelpunkt einer florierenden Kultur der multimedialen Aneignung und Verfremdung massenmedialer Materialien sind (vgl. hierzu Jenkins 2006). Viele Spektakel leben aus ihren intertextuellen Bezügen zur lokalen, nationalen oder auch globalen Populärkultur, und die Möglichkeit, Parodien von Massenkultur als Mittel sozialer oder politischer Kritik zu nutzen, gilt als Antrieb für die Popularität amateurhafter Videoproduktionen (siehe Jenkins 2006, S. 281 ff.).

Gleichzeitig sind Spektakel bezüglich ihrer Gattungszugehörigkeit wenig kontextualisiert. Ihnen fehlen die rahmenden Informationen, die in den konventionellen Massenmedien durch Sekundärtexte (in der Begrifflichkeit von Fiske 1987) wie Ankündigungen, Programmhinweise, Trailer, Rezensionen usw. geliefert werden. Bei Spektakeln hat man außer Titel, Tags und bestenfalls einigen Stichworten in der Produzentenbox (auf dem Bildschirm oben recht zu sehen) noch keine weitere rahmende Information. Dadurch entsteht eine Interpretationslücke, die in den Kommentaren aufgegriffen und teilweise auch gefüllt wird. 


\begin{tabular}{|l|l|l|l|}
\hline \multicolumn{1}{|c|}{ Dimension } & Hauptkennzeichen & \multicolumn{1}{|c|}{ Akteure } & \multicolumn{1}{c|}{$\begin{array}{c}\text { Typische } \\
\text { Umgebung }\end{array}$} \\
\hline Organisation & $\begin{array}{l}\text { Beitrag zum Web- } \\
\text { design }\end{array}$ & $\begin{array}{l}\text { Website-Administra- } \\
\text { toren bzw. -Designer }\end{array}$ & VP \& MP \\
\hline $\begin{array}{l}\text { Selbstdarstel- } \\
\text { lung }\end{array}$ & $\begin{array}{l}\text { Ressource für Profil- } \\
\text { seiten }\end{array}$ & $\begin{array}{l}\text { Individuelle Nutzer } \\
\text { (Profilseitenbesitzer) }\end{array}$ & VP \\
\hline Spektakel & $\begin{array}{l}\text { Teil des von Nutzern } \\
\text { hochgeladenen Multi- } \\
\text { media-Materials }\end{array}$ & Nutzer & $\begin{array}{l}\text { MP (und ein- } \\
\text { gebettet in } \\
\text { VP) }\end{array}$ \\
\hline Interaktion & $\begin{array}{l}\text { Interpersonale Kom- } \\
\text { munikation zwischen } \\
\text { Nutzern, Kommentie- } \\
\text { rung von Spektakeln } \\
\text { und anderen Referenz- } \\
\text { texten }\end{array}$ & $\begin{array}{l}\text { Mehrfachautoren- } \\
\text { schaft }\end{array}$ & VP \& MP \\
\hline
\end{tabular}

Tab. 1: Vier Dimensionen von Sprache in Web 2.0-Umgebungen (VP: Vernetzungsplattformen; MP: Mediaplattformen)

Die vier Dimensionen von Sprache in Web 2.0-Umgebungen, deren Hauptkennzeichen in Tabelle 1 zusammengefasst werden, treten in der Empirie stets in Kombinationen auf. So besteht eine enge Verbindung zwischen Selbstdarstellung und Interaktion, indem Elemente der persönlichen Selbstdarstellung und Besucherkommentare nebeneinander erscheinen und Bezug aufeinander nehmen (beispielsweise wenn auf facebook die Veränderung der Statuszeile eine Kommentarsequenz veranlasst). Die Dimensionen der Selbstdarstellung und des Spektakels treten in einen Dialog dadurch, dass auf Profilseiten eingebettete Videos, Musikstücke oder Fotos als Mittel der Selbstdarstellung herangezogen und interaktiv kommentiert werden. Ein Zusammenspiel von Spektakel und Interaktion ist für alle Mediaplattformen konstitutiv, indem hochgeladenen Inhalte von Zuschauern kommentiert und bewertet werden. Diese Wechselwirkungen und Querverbindungen haben analytisch zur Konsequenz, dass man stets Relationen zwischen den einzelnen Dimensionen und deren Erscheinungsformen unter die Lupe nimmt.

\section{Diskursprozesse in Web 2.0-Umgebungen}

In einem zweiten Schritt unterscheide ich für Web 2.0-Umgebungen typische Diskursprozesse und belege diese mit den Bezeichnungen „Multimodalität", „Intertextualität“ und „Heteroglossie“. Dieses zweite Kategorien-Set fokussiert auf die Sprach- bzw. Textanalyse. Gefragt wird nicht nach den Leistungen von Sprache in der Konstituierung von Online-Kom- 
munikation, sondern nach Eigenschaften von konkreten Online-Texten und -Interaktionen. Dabei besteht keine einfache Korrespondenz zwischen den beiden Kategoriensets. Beispielsweise tritt Multimodalität in allen vier Funktionsdimensionen in Erscheinung, und ein und dieselbe Funktionsdimension kann multimodale, intertextuelle und heteroglossische Züge aufweisen. Auch hier geht es mir um Facetten der drei Prozesse, um ihre vielfältigen Erscheinungsformen und ihr Verhältnis zu massenmedialen bzw. netzspezifischen Diskurstraditionen. Die Frage ist also nicht: „Was sind diese Prozesse?“, sondern: „In welchem Sinne kann man von ihnen sprechen, und wie treten sie in Web 2.0 in Erscheinung?"

Die Dimension der Multimodalität lenkt unsere Aufmerksamkeit auf die Gesamtheit der semiotischen Ressourcen, die auf einer Webseite in spezifischen Kombinationen miteinander auftreten und zur Konstitution textueller Einheiten beitragen. Neben den in allen visuellen Medien üblichen Sprache/Bild-Kombinationen umfassen Web 2.0-Seiten weitere Verbindungen aus Text, Ton und bewegtem Bild. Ihre Fülle und Ubiquität legen nahe, dass der veränderte Umgang mit Multimedia und Multimodalität ein zentrales Kennzeichen von Web 2.0-Umgebungen darstellt. Wie multimodale Kompositionen zu analysieren sind, dafür stehen verschiedene Ansätze zur Verfügung, auf die hier nicht weiter eingegangen werden kann. ${ }^{8}$ Ein Desideratum ist der Vergleich zwischen Plattformen hinsichtlich ihrer Palette an multimodalen Optionen sowie zwischen Nutzungsstilen hinsichtlich der tatsächlichen Umsetzung dieser Optionen. Beispielsweise unterscheiden sich gängige Vernetzungsplattformen darin, welche multimodalen Ressourcen zugelassen oder eingeschränkt werden. So lässt MySpace die Manipulation von Hintergrund-, Box- und Schriftfarben zu und erlaubt die freie Platzierung von Textboxen sowie die Einbettung von Musik, während all diese Optionen der Selbstdarstellung auf anderen Plattformen nicht verfügbar sind (vgl. boyd 2008). Eine weitere Frage ist nach den Wechselwirkungen von Multimodalität und verbaler Online-Interaktion. Die Einbettung multimodaler Materialien in einen Interaktionsbeitrag bzw. -strang gehört genauso dazu wie die Frage, wie sich die Orientierung der Kommentare auf ein Foto oder Video deiktisch niederschlägt.

Auch im Bereich der Intertextualität - der Bezugnahme von Texten auf andere Texte - lassen sich „ältere“ und „neuere“ Erscheinungsformen unterscheiden. Bestimmte Spielarten intertextueller Beziehungen auf Web 2.0Seiten sind genauso in anderen Medien vorzufinden und greifen auf rhetorische Traditionen zurück. Dies gilt insbesondere für die „enge“ intertextuelle Bezugnahme auf spezifische Prätexte, die unverändert oder verändert (als Zitate, Anspielungen usw.) in den Referenztext eingehen und dort typischerweise an funktional exponierten Stellen wie Titeln und Überschriften erscheinen. Darüber hinaus sind in Vernetzungs- und Mediaplattformen

$8 \quad$ Z.B. Kress/van Leeuwen (2001); Stöckl (2004); Schmitz (2003). 
auch innovativere intertextuelle Spielarten zu beobachten. Ein Beispiel ist die zitathafte Verwendung von Hyperlinks und eingebetteten Inhalten. So kann auf Vernetzungsplattformen beobachtet werden, dass Kommentare auf einer Profilseite auch Photos, Videos oder Hyperlinks enthalten, welche den sprachlich ausformulierten Beitrag nicht (nur) ergänzen, sondern vielmehr ersetzen: Man antwortet sozusagen durch ein Bild, ein Video oder einen Link, so dass diese Beitrags-, bisweilen auch Sprechhandlungscharakter gewinnen.

Besondere Beachtung verdient das Geflecht von Textbeziehungen innerhalb der bzw. rund um Spektakel. Auf der Videoplattform YouTube manifestiert sich Intertextualität zunächst einmal als Beziehung zwischen einem Spektakel und den (massenmedialen) Quellen, die dieses zitiert, verwandelt oder parodiert. Intertextuelle Bezüge prägen auch das Verhältnis zwischen Spektakeln und den umliegenden Seitenelementen. Während Verbindungen thematischer oder gattungsspezifischer Art zwischen einem Spektakel und den in der Seitenleiste gelisteten ,ähnlichen Videos“ durch die Plattform-Datenbank geknüpft werden, sind Verbindungen zwischen Spektakel und einer „Video-Antwort“ das Ergebnis gezielter Nutzeraktivität, um in einen filmischen Dialog mit einem Referenzvideo zu treten. Nicht alle Videos erhalten Videoantworten, sie können aber weit mehr als nur eine erhalten, so dass die Videoantwort auch als Indikator von $\mathrm{Zu}$ schauer-Engagement verstanden werden kann. Ein weiterer intertextueller Verbund entsteht zwischen Spektakel und anschließender Kommentierung. Dabei dienen Kommentare nicht einfach der (sachlichen oder affektiven) Bewertung, sondern leisten weitere rhetorische und kontextualisierende Funktionen: Ähnlich wie Zuschauerkommentare können sie Fragmente des Spektakels aufnehmen und wiederholen, Aspekte seiner lokalen Rezeption und Zirkulation aufgreifen. Damit können sie auch Kontext- und Hintergrundinformation liefern, die den meisten amateurhaft produzierten Spektakeln fehlen. Diese Bemerkungen zeigen, dass ,Intertextualität sowie das weitere damit verbundene Begriffsfeld als deskriptive und interpretative Schlüsselkategorien für die Untersuchung von Web 2.0-Umgebungen geeignet ist.

Das Konzept der ,Heteroglossie‘ bezieht sich auf das Verhältnis zwischen Sprachen bzw. Sprechweisen mit unterschiedlichen sozialen bzw. ideologischen Perspektiven innerhalb einer Äußerung oder eines Textes. Der Begriff wurde von der Sprach- und Diskurstheorie von Mikhail Bakhtin (Bakhtin 1981) in die Literatur- und Sprachwissenschaft übernommen und ist bereits auf die Untersuchung von Mediendiskursen übertragen worden (siehe z.B. Busch 2004). Gängige Definitionen von Heteroglossie (etwa bei Bailey 2007, S. 257) heben zum einen auf die Koexistenz von verschiedenen Zeichen oder „Stimmen“ innerhalb einer Äußerung bzw. eines Textes $\mathrm{ab}$, zum anderen auch auf die Spannung und Konfliktrelation zwischen die- 
sen Zeichen aufgrund ihrer gesellschaftlichen und historischen Assoziationen. ${ }^{9}$ Damit geht Heteroglossie an einem entscheidenden Punkt über den Begriff der sprachlichen Variation hinaus, der in der linguistischen Internetforschung Einsatz findet (vgl. Beiträge in Androutsopoulos 2006). Während Variation und Variationsanalyse quantitative Verhältnisse zwischen verschiedenen (Bündeln von) Formvarianten innerhalb einer Einzelsprache erfassen, fängt Heteroglossie auch ein weiteres Kennzeichen von Sprache im Internet auf: die immer wieder hervorgehobene Koexistenz, Mischung oder auch Kontrastierung verschiedener Sprachen, Varietäten oder Sprachstile, gegebenenfalls auch in multimodalen Zusammenhängen. ${ }^{10}$

Analytisch ist Heteroglossie ein relationales Konzept, d.h. man identifiziert nicht einzelne sprachliche Varietäten oder Stilmerkmale, sondern Relationen zwischen Elementen die in einem Diskursausschnitt koexistieren. In Vernetzungs- und Mediaplattformen sind solche Relationen an mehreren Erscheinungsstellen potenziell zu finden. Durch Konvergenz (siehe Abschnitt 2) entsteht in Web 2.0-Umgebungen eine Vielzahl von „,kleinen“ Gelegenheiten der Koexistenz von unterschiedlichen Sprech- und Schreibweisen, die man mit dem Konzept der Heteroglossie auf das Verhältnis zwischen semiotischer und soziokultureller Differenz überprüfen kann. Ein Beispiel ist die Koexistenz von professionell und nutzerseitig erstellten Inhalten, die durch ihren Stil die unterschiedliche Rolle und Perspektive, der sie entstammen, kontextualisieren. Für eine weitere Bestimmung kann man zunächst auf die vier Funktionsdimensionen von Sprache in Web 2.0 zurückgreifen:

- Zwischen Organisation und den anderen drei Funktionsdimensionen können heteroglossische Kontraste dadurch entstehen, dass die Sprache der Spektakel bzw. interaktiven Beiträge mit der Sprache des Organisationsrahmens nicht übereinstimmt. Für Sprecher einer in den Einstellungsoptionen der Plattform nicht enthaltenen Sprache ist der Kontrast zwischen Sprache der Inhalte und Sprache der Seitenbedienung allgegenwärtig.

- Zwischen Spektakel und Interaktion entstehen heteroglossische Spannungen dadurch, dass sich Sprache im Spektakel von den konversationellen Stilen der Kommentareinträge unterscheidet, wobei solche Unterschiede auch selbst Gegenstand der Kommentierung werden können.

9 Bakhtin beschreibt Heteroglossie u.a. als „,co-existence of socio-ideological contradictions between the present and the past, between differing epochs of the past, between different socio-ideological groups in the present, between tendencies, schools, circles and so forth" (Bakhtin 1981, S. 291). Duranti schreibt dazu: ,the speech of any one person is filled by many different voices or linguistically constructed personae" (Duranti 1997, S. 75 f.).

10 Vgl. u.a. Runkehl/Schlobinski/Siever (1997); Georgakopoulou (2003); neuerdings auch Tsiplakou (2009) und Tagliamonte/Denis (2008). Letztere sehen in der „consistent juxtaposition of ,forms of a different feather" ein ,quintessential characteristic of IM discourse“ (Tagliamonte/Denis 2008, S. 26). 
- Innerhalb der Funktionsdimensionen der Selbstdarstellung und Interaktion können heteroglossische Relationen dadurch entstehen, dass die Beteiligten die sozialen Assoziationen verschiedener Sprachstile mehr oder weniger bewusst nutzen, um unterschiedliche Standpunkte, Beziehungsstrategien usw. zu kontextualisieren (vgl. Androutsopoulos 2007a).

\section{Ein Fallbeispiel: Varietätendynamik auf YouTube}

Abschließend möchte ich an einem Fallbeispiel aufzeigen, wie auf der Grundlage der vorgestellten Leitkategorien weiterführende Fragestellungen aufbauen können. Das Beispiel bezieht sich auf Formen und Funktionen sprachlicher Varietäten in der computervermittelten Kommunikation und greift damit eine Frage auf, die in der Forschung bereits beachtet worden ist, sich aufgrund der erläuterten Bedingungen der gegenwärtigen WebUmgebungen jedoch erneut und unter veränderten Vorzeichen stellt. Ging es beispielsweise in der Chat-Kommunikation um die schriftliche Repräsentation von Regionaldialekten und ihren strategischen Einsatz in OnlineInteraktionen (vgl. z.B. Siebenhaar 2006), so stellen sich mit Blick auf Mediaplattformen auch die Fragen, welche Möglichkeiten die „Medienproduktion von unten " für die Repräsentation lokaler Sprechweisen eröffnet, ob außerinstitutionell produzierte Spektakel neue Freiräume für Dialekte anbieten und wie die soziale Bedeutung von Varietäten in Spektakeln und ihren Kommentaren ausgehandelt wird. ${ }^{11}$

Als Beispiel für diese Fragestellungen sei das Bairische herangezogen. Empirischer Ausgangspunkt für die Frage, wie und wozu bairische Dialekte in Spektakeln verwendet werden, sind die Schlagworte („Tags"), mit denen Videos auf Mediaplattformen versehen werden. Videos mit dem Attribut „bairisch“ (bzw. auch bayrisch, boarisch) lassen einen nicht näher definierten Bezug zum Bairischen erwarten, dessen genauere Beschaffenheit analytisch festzustellen ist. Eine erste Sichtung des YouTube-Bestandes an derart getaggten Videos ${ }^{12}$ führt zur Unterscheidung von drei Kategorien, die sich von ihrer Herkunft und Produktionsweise her unterscheiden: a) Auszüge aus Filmen, Serien oder sonstigen bereits veröffentlichen Medieninhalten, b) Eigenproduktionen (z.B. selbst aufgenommene Szenen in einem Bierzelt), c) Modifizierungen massenmedialen Materials (z.B. „PulpFiction auf Bayrisch").

11 Die nachfolgende Diskussion greift auf Überlegungen zurück, die gemeinsam mit Horst Simon (King's College London) entwickelt wurden.

12 Am 12. Juni 2009 fand man auf YouTube 912 mit bayrisch, 206 mit bairisch und 262 mit boarisch getaggte Videos. Dabei bezieht sich bairisch speziell auf die bairische Dialektgruppe, bayrisch auf die Region Bayern (faktisch aber auch auf die bairischen Dialekte) und boarisch ist eine dialektal markierte Variante. Das Verhältnis der Tags zum Inhalt der Videos und deren regionalen und regionalsprachlichen Orientierung müsste freilich erst einmal genauer untersucht werden. 
Alle diese Videos sind grundsätzlich multimodal, sofern sie gesprochene Sprache, Ton und bewegtes Bild (und möglicherweise auch Untertitel) beinhalten. Wir können fragen, wie die jeweiligen multimodalen Kombinationen zur Konstitution eines „bairischen“ Bezugs beitragen. Zweitens können „bairische“ Videos verschiedene intertextuelle Relationen aufweisen. Dies ist vor allem bei jenen Videos der Fall, die das mediale Modifizierungspotenzial des Web 2.0 durch die Neuvertonung, -bebilderung oder -synchronisierung medialer Materialien stärker ausnützen. Solche Videos haben auch ein heteroglossisches Potenzial, das sich in ihrer Relation zu Quelle bzw. zu den umgebenden Textelementen zeigt. Beispielsweise können Dialekt/ Hochdeutsch-Kontraste humoristisch oder parodistisch aufgebaut werden.

Solche heteroglossischen Relationen scheinen in der Gruppe der modifizierten „bairischen“ Videos, die mit der Verfremdung massenmedialen Materials arbeitet, am deutlichsten ausgeprägt. Ein Beispiel für dieses Verfahren ist das Amateurvideo "An Preller“ (Abb. 1), das den US-amerikanischen Popsong „Umbrella“ als Grundlage benutzt, wobei die Originalmelodie von einem neuen Liedtext überlagert und mit einem neuen Video versehen wird. ${ }^{13}$ Es handelt sich gewissermaßen um eine „bebilderte Kontrafaktur", sofern die Melodie behalten, der Text aber umgedichtet und der Song durch eine Sequenz statischer Bilder ,umbebildert" wird. ${ }^{14}$

Textbeispiel 1: Songtext „An Preller“, erste Strophe und Refrain (0:33-1:13), Verschriftung nach den Untertiteln

1. Am Wochenend in Bayern / gengan die Leid gern feiern

2. I mach des a recht gern / Noch ist der Absturz fern

3. Aber dann kaffst da a Mass / Und scho steigt der Spaß

4. Nach Nummer 8 jedoch / Hat der Spaß boid a Loch

5. I hob / scho wieder an Rausch in der Fotzn / Hearst des is doch echt zum Kotzen

6. Koaner versteht mi wei i so lall / Zefix bin I scho wieder prall

7. Draußt werds scho langsam wieder heller / Aber mi drabts nur oibe schneller

8. Wei i hob scho wieder an so an Preller! / i hob scho wieder an so an Preller!

Auf Basis des vorgestellten Ansatzes lässt sich „An Preller“ auf seine multimodale Konstitution, intertextuelle Verflechtung sowie heteroglossische Zusammensetzung untersuchen. Im Folgenden werden diese drei Schritte als Hintergrund gesetzt und die Aufmerksamkeit auf die Stilisierung des bairischen Dialekts im Video gerichtet. Heuristische Leitfragen der Analyse sind:

13 Das Video ist unter http://www.youtube.com/watch?v=icmraBAN4ZE abrufbar, eine Lektüre begleitende Rezeption wird empfohlen. Hintergrundinformation zum Original bietet http://en. wikipedia.org/wiki/Umbrella_(song). Die 2007 nur wenige Monate nach dem Original publizierte „bairische Fassung“ weist zum Erhebungsstichtag 1.362.584 Aufrufe, 1.235 Kommentare und zwei Videoantworten auf (Stand: 12.06.2009).

14 Das Stichwort „Kontrafaktur“ verdanke ich Jana Tereick. 
- Welche bairischen Dialektmerkmale liegen vor?

- Wie wird Dialekt im Video behandelt, wie ist sein Einsatz durch Gattung, Handlungsstruktur und Bildkomponente motiviert?

- Wie gehen die Kommentare mit Dialekt als Teil des Spektakels bzw. als eigene stilistische Ressource um?

- Wie wird Dialekt im Spektakel bzw. in den Kommentaren mit sozialen Kategorien gekoppelt?

- Allgemein, wie gewinnt der Dialektgebrauch seinen Sinn unter den Rahmenbedingungen der Videoplattform?

Meine These lautet, dass die Bedeutung des Dialektgebrauchs in „An Preller“ und anderen „bairischen“ YouTube-Spektakeln nicht allein aus der Dialektalitätsstufe und nicht nur aus der sprachlichen Dimension dieser Videos zu erschließen ist. Vielmehr entsteht sie in der Zusammenwirkung aller semiotischen Dimensionen des Spektakels sowie in dem Dialog zwischen Spektakel und Kommentaren.

In den bisher gesichteten „bairischen“ YouTube-Videos sind die Stufe und der Umfang des Dialektgebrauchs nicht von vornherein abgegrenzt. Realistischer, konversationeller Dialekt kommt genauso vor wie ein stilisierter Dialekt mit einzelnen, salienten Merkmalen vor der Folie einer regionalen Standardsprache (vgl. Birkner/Gilles 2008). Im Beispiel „An Preller" findet ein „flaches“, urbanes Bairisch Verwendung. Dennoch weist die (männliche) singende Stimme ausreichende und konsistente Unterschiede zum Standarddeutschen auf - in der Lautung, im Wortschatz und teilweise auch der Syntax - um als Dialektstimme eingestuft zu werden. Typische Merkmale des Bairischen finden sich im Vokalismus, den Pronomina sowie im Dialektwortschatz, das durch seine Platzierung im Titel und Refrain eine wichtige Rolle bei der Identifizierung des Textes als „dialektal“ spielt. Ein Dialektausdruck (an Preller, ein Rausch') dient als Dreh- und Angelpunkt der Parallelisierung zwischen den beiden Fassungen.

Die Analyse des Dialekts im gesprochenen Songtext ist zu ergänzen durch die sprachliche wie auch bildliche Kontextualisierung von Dialekt im Video. Auffallend ist zunächst, dass der Songtext dialektal untertitelt wird (vgl. Textbeispiel 1), was die Präsenz von Dialektalität im Video weiter verstärkt. Andere Aspekte von Schriftsprache im Video verstärken seinen heteroglossischen Charakter. Standarddeutsch ist in den Endtiteln sowie in mehreren Bildern (als eingebettete Legende) zu lesen, stellenweise sind auch Englisch (do not disturb) sowie „bairisches Englisch“ (Pardy ends, mit Abbildung der Lenisierung des alveolaren Plosivs) zu sehen. Damit wird die im Video dominante Dialektstimme durch schriftliche Spuren anderer Sprachen bzw. Varietäten ergänzt.

Daraus geht hervor, dass die Leistung von Dialekt als Lokalitätsmarker ohne eingehende Beachtung des Bildtextes nicht vollständig einzuschätzen ist. Daher ist die linguistische durch eine multimodale sowie intertextuelle 
Analyse zu ergänzen, bei denen die Beschaffenheit des Bildtextes, SpracheBild-Passungen sowie der Beitrag des Bildlichen zur Konstituierung lokaler Bezüge und Identitäten im Vordergrund stehen. Leitfragen sind hier: Welches semiotische Material wird im Bildtext des Spektakels als Folie herangezogen und kombiniert? Wie ist das Verhältnis zwischen der dialektalen Stimme und dem bewegten Bild strukturiert?

Grundsätzlich haben wir es bei „An Preller“ mit einer Bricolage (Chandler 1998) zu tun, bei der Bilder aus verschiedenen Referenzbereichen neu zusammengesetzt werden. Sequenziell vorgehend ist der Beginn des Videos mit zahlreichen lokalen Emblemen durchsetzt. Noch vor dem Beginn des Songtextes (0:06) sieht man eine Gegenüberstellung eines Regenschirmes („Umbrella“) und der bairischen Maß, die das Titel gebende Wortspiel visualisiert (siehe Abb. 1). Bayerische Flagge und Landkarte sowie die Paulaner$\mathrm{Maß}$ leisten in den ersten 60 Sekunden eine lokale Einrahmung des Spektakels und begleiten dabei die sprachliche Konstitution des lokalen Kontextes (vgl. Textbeispiel 1, Zeilen 1-2). Anschließend werden aus Webforen bekannte Smiley-Grafiken mit trinkenden und feiernden Figuren gezeigt, wodurch die Zeilen 2-4 bebildert werden. Quer durch das gesamte Video werden Regionalembleme mit Bildern aus der deutschen Populärkultur ${ }^{15}$ und der Internetkultur zusammengemischt und sequenziell dem Songtext angepasst. Die Bilder sind dabei ikonisch oder metonymisch zum Gesagten platziert, sie werden dadurch desambiguiert und tragen zur Kohärenz des multimodalen Gesamttextes bei. Gleichzeitig sind sie im Sinne einer visuellen Intertextualität interpretierbar, d.h. tragen durch ihre Ästhetik und Herkunftsdomänen zur (komplexeren) Interpretation und kulturellen Positionierung des Gesamttextes bei. Wichtig ist, dass hier keine ästhetische Einheitlichkeit, sondern eine Kontrastierung von lokalem, nationalem, globalem Material entsteht.

Die Analyse des Spektakels ist im Sinne der aufgestellten Programmatik durch die der Kommentare zu ergänzen, die auf ihre Sprechhandlungen, ihre intertextuellen Bezüge zum Spektakel bzw. untereinander sowie ihre stilistischen Selektionen untersucht werden. Gefragt wird, wie die Kommentare den lokalen Bezug und die lokale Rezeption des Videos thematisieren; ob und wie sie den Dialektgebrauch kommentieren; in welcher Varietät bzw. Stillage sie verfasst sind, und ob dadurch - in Abhängigkeit von Referenz und Sprechhandlung - eine Konvergenz zum bzw. Divergenz vom Sprechstil des Videos erzielt wird.

So fällt bei der Analyse eines Samples ${ }^{16}$ auf, dass viele Kommentare zu "An Preller" eine Beziehung zum Bairischen bzw. zu Bayern durch propositionalen Gehalt, intertextuelle Referenzen oder den eigenen Dialekt-

\footnotetext{
15 Wieder erkennbare Bilder sind u.a. der Altkanzler Kohl (2:29) und das Sandmännchen (3:44).

16 Gesichtet wurde ein Sample von 500 Kommentaren bzw. ca. 40\% der Gesamtanzahl zum Zeitpunkt der Erhebung.
} 
gebrauch herstellen. Insbesondere positive Bewertungen und affirmative Kommentare sind öfters im Dialekt und können dadurch als Fälle von Konvergenz angesehen werden. Das Verhältnis von „An Preller“ zum Originalsong wird gelegentlich als antagonistisch thematisiert (ca. 15 Fälle in meinem Sample, eine Auswahl sieht man in Textbeispiel 2), d.h. „An Preller" wird als eine Art symbolischer Widerstand zum Original, das im Sommer 2007 intensiv in den Massenmedien gespielt wurde, gefeiert und explizit als Parodie desselben klassifiziert.

Textbeispiel 2: Kommentare zu An Preller mit Bezug auf das Original

- so sebr wie ich das original hasse, liebe ich diese version

- Also des is die viel bessere Version von Umbrella $=D$

- von wegen parodie das hier is das original ;) umbrella is eh en scheiß lied aber das bier wird bald kult sein

Textbeispiel 3: Kommentare zu An Preller mit Bezug auf seinen lokalen Umlauf

- seit tagen singen wir den song an jeder party!

- in unsana niederbayerischen schui kursiert des scho lang wieder auf de handys...

- will ich im Radio bören!

Darüber hinaus lassen die Kommentare Aspekte der lokalen Nutzung und Popularität des Videos erkennen (Textbeispiel 3). Beispielsweise impliziert die gestellte Frage, ob man das Lied herunterladen könne, eine Nutzungsabsicht in Situationen jenseits des Rechners und des Internet. Es finden sich Hinweise, dass der Song auf Partys gespielt werden sollte bzw. gespielt wurde, wobei diese Nutzungsberichte teilweise selbst im Dialekt verfasst sind. Andere Kommentare setzen „An Preller“ pro- oder retrospektiv in Kontext des Oktoberfestes 2007, etwa mit der Prognose Wiesnhit 2007! oder dem Hinweis, dass der Song tatsächlich in den Partyzelten gespielt wurde. An diesen Beispielen erkennt man, wie bereits in der theoretischen Diskussion angedeutet, die vielfältigen Diskursfunktionen der Kommentare und ihre Kontextualisierungsleistung, die sich in drei Bereichen verdichtet: Metasprachliche Dialektthematisierung, antagonistischer Vergleich zum Original und Hinweise auf die lokale Rezeption und Zirkulation des Songs.

\section{Schlussfolgerung und Ausblick}

Die Analyse hat den Dialektgebrauch im YouTube-Video „An Preller“ in einem mehrfachen Zusammenhang verortet: in der Zusammenwirkung der verschiedenen Medien und Modalitäten, dem Verhältnis zwischen Spektakel und anschließenden kommentierenden Diskurs sowie dem Verhältnis 
zur Konstruktion lokaler Identitäten. Zentral für die Sinnstiftung des Dialekts ist in diesem Beispiel die multimodale Inszenierung lokaler Stereotype vor der Folie globaler Populärkultur. ${ }^{17}$ „An Preller“ präsentiert sich als Stilisierung lokaler Kultur und Lebenswelt, und der Dialekt wird als „natürliche" Stimme dieser Lebenswelt platziert, was in den Kommentaren eher bestätigt als bestritten wird. Gleichzeitig ist der Dialekt Teil einer von Kontrasten geprägten, heteroglossischen Gegenüberstellung zum Original: Der weiblichen, professionellen, leidenschaftlichen Stimme von Rihanna steht hier eine männliche, untrainierte, apathisch klingende Stimme entgegen, der Romantik und aufwändigen Produktion des Originaltextes wird eine amateurhafte Trash-Ästhetik gegenübergestellt. Dies führt nicht zu einer negativen Rezeption des „bairischen“ Spektakels in den Kommentaren, sondern im Gegenteil zu einer begeisterten Aufnahme. „En Preller“ - wie auch andere als „bairisch“ verschlagwortete Videos auf YouTube - wird wohl als eine lokale Antwort auf globale Popkultur interpretiert und gefeiert, und die Bedeutung des Dialektgebrauchs ist auch in diesen Kontext zu stellen. In anderen Worten erschöpft sich der soziale Sinn des Dialekts nicht auf eine tradierte Verbindung zwischen Sprache und lokaler Identität, sondern diese Verbindung wird als Lokalstereotyp in einem Dialog zwischen globaler und lokaler Kultur evoziert und durch Verfahren der Multimodalität, Intertextualität und Heteroglossie herausgearbeitet.

Der Beitrag hat diese drei Konzepte als Grundlage eines deskriptiven Zugangs zu Sprache in Web 2.0-Umgebungen vorgeschlagen. Angesichts der semiotischen und medialen Reichhaltigkeit, die Web 2.0-Umgebungen kennzeichnet, werden inklusive und relationale sprach- und diskursanalytische Zugänge benötigt, die „cross-modally“ (van Leeuwen 2004, S. 15), d.h. an Sprache, Bildern und anderen Modalitäten angewandt werden können und Relationen zwischen Modalitäten, Texten und Codes in den Vordergrund rücken. Bei angemessener empirischer Weiterentwicklung können diese Kategorien einen ganzheitlichen Zugang zu gegenwärtigen Web-Umgebungen ermöglichen, der die in der linguistischen Internetforschung bisher verfolgten Fragestellungen nicht ausschließt oder ersetzt, sondern integriert und kontextualisiert.

\section{Literatur}

Androutsopoulos, Jannis (2003): HipHop und Sprache: Vertikale Intertextualität und die drei Sphären der Popkultur. In: Androutsopoulos, Jannis (Hg.): HipHop: globale Kultur - lokale Praktiken. (= Cultural Studies 3). Bielefeld, S. 111-136.

Androutsopoulos, Jannis (2006): Introduction: Sociolinguistics and computer-mediated communication. In: Journal of Sociolinguistics 10, 4, S. 419-438.

17 Dieser Zusammenhang wird in Androutsopoulos (ersch.demn.) vertieft. 
Androutsopoulos, Jannis (2007a): Style online: Doing hip-hop on the German-speaking Web. In: Auer, Peter (Hg.): Style and social identities. (= Language, Power and Social Process 18). Berlin/New York.

Androutsopoulos, Jannis (2007b): Neue Medien - neue Schriftlichkeit? In: Mitteilungen des Deutschen Germanistenverbandes 1, S. 72-97.

Androutsopoulos, Jannis (2008): Potentials and limitations of discourse-centered online ethnography. In: Language@Internet 5, article 8. Internet: www.languageatinternet. de/articles/2008 (Stand: November 2009).

Androutsopoulos, Jannis (2009): The study of language and space in media discourse. In: Auer, Peter/Schmidt, Jürgen E. (Hg.): Language and space: An international handbook of linguistic variation. Bd. I: Theory and methods. (= Handbücher zur Sprach- und Kommunikationswissenschaft 30,1). Berlin/New York, S. 740-758.

Androutsopoulos, Jannis (ersch.demn.): Localising the global on the participatory web. In: Coupland, Nikolas (Hg.): Handbook of language and globalization. Oxford.

Bakhtin, Mikhail (1981): Discourse in the novel. In: Bakhtin, Mikhail (Hg.): The Dialogic Imagination: 4 essays. (= University of Texas Press Slavic series 1). Austin, S. $259-422$.

Bailey, Benjamin (2007): Heteroglossia and boundaries. In: Heller, Monica (Hg.): Bilingualism: A social approach. New York, S. 257-274.

Baron, Naomi S. (2008): Always on: language in an online and mobile world. Oxford.

Birkner, Karin/Gilles, Peter (2008): Dialektstilisierung im Reality-Fernsehen. In: Christen, Helen/Ziegler, Evelyn (Hg.): Sprechen, Schreiben, Hören. Zur Produktion und Perzeption von Dialekt und Standardsprache zu Beginn des 21. Jahrhunderts. Wien, S. 101-130.

boyd, danah m. (2008): Why youth (heart) social network sites: The role of networked publics in teenage social life. In: Buckingham (Hg), S. 119-142.

boyd, danah m./Ellison, Nicole B. (2007): Social network sites: Definition, history, and scholarship. In: Journal of Computer-Mediated Communication 13, 1, article 11. Internet: http://jcmc.indiana.edu/vol13/issue1/boyd.ellison.html (Stand: November 2009).

Buckingham, David (Hg) (2008): Youth, identity, and digital media. Cambridge.

Busch, Brigitta (2004): Sprachen im Disput. Medien und Öffentlichkeit in multilingualen Gesellschaften. Klagenfurt.

Chandler, Daniel (1998): Personal home pages and the construction of identities on the Web. Internet: www.aber.ac.uk/media/Documents/short/webident.html (Stand: November 2009).

Coupland, Nikolas (2007): Style. Language variation and identity. Cambridge.

Coupland, Nikolas (2009): The mediated performance of vernaculars. In: Journal of English Linguistics 37, 3, S. 284-300.

Crystal, David (2006): Language and the Internet. 2. Aufl. Cambridge.

de.wikipedia.org (2009): Web 2.0. Internet: http://de.wikipedia.org/wiki/Web_2.0 (Stand: November 2009). 
Döring, Nicola (2002): Personal home pages on the Web: A review of research. In: Journal of Computer-Mediated Communication 7, 3. Internet: http://jcmc.indiana. edu/vol7/issue3/doering.html (Stand: November 2009).

Döring, Nicola (2003): Sozialpsychologie des Internet: die Bedeutung des Internet für Kommunikationsprozesse, Identitäten, soziale Beziehungen und Gruppen. 2., vollst. überarb. u. erw. Aufl. (= Internet und Psychologie 2). Göttingen u.a.

Duranti, Alessandro (1997): Linguistic Anthropology. Cambridge.

Ebersbach, Anja/Glaser, Markus/Heigl, Richard (2008): Social web. Konstanz.

en.wikipedia.org (2009): Web 2.0. Internet: http://en.wikipedia.org/wiki/Web_2.0 (Stand: November 2009).

Fiske, John (1987): Television culture. London/New York.

Georgakopoulou, Alexandra (2003): Computer-mediated communication. In: Verschueren, Jef/Östman, Jan-Ola/Blommaert, Jan/Bulcaen, Chris (Hg.): Handbook of pragmatics (2001 installment). Amsterdam/Philadelphia, S. 1-20.

Hasebrink, Uwe/Mikos, Lothar/Prommer, Elisabeth (Hg.) (2004): Mediennutzung in konvergierenden Medienumgebungen. München.

Heidemann, Julia (2009): Online Social Networks - Ein sozialer und technischer Überblick. In: Informatik-Spektrum.

Herring, Susan C. (2001): Computer-mediated discourse. In: Schiffrin, Deborah/Tannen, Deborah/Hamilton, Heidi E. (Hg.): The handbook of discourse analysis. Malden, S. 612-634.

Herring, Susan C. (2004): Computer-mediated discourse analysis: An approach to researching online communities. In: Barab, Sasha A./Kling, Rob/Gray, James H. (Hg.): Designing for virtual communities in the service of learning. Cambridge/ New York, S. 338-376.

Herring, Susan C. (2007): A faceted classification scheme for computer-mediated discourse. In: Language@Internet, 4, article 1. Internet: www.languageatinternet.de/ articles/2007/761/index_html/ (Stand: November 2009).

Hinchcliffe, Dion (2006): The state of Web 2.0. In: Dion Hinchcliffe's Web 2.0 Blog, 2. April 2006. Internet: http://web2.socialcomputingjournal.com/the_state_of_web_20. htm (Stand: November 2009).

Honeycutt, Courtenay/Herring, Susan C. (2009): Beyond microblogging: Conversation and collaboration via Twitter. Proceedings of the Forty-Second Hawaii International Conference on System Sciences (HICSS-42). Los Alamitos. Internet: http://ella. slis.indiana.edu/ herring/honeycutt.herring.2009.pdf (Stand: Dezember 2009).

Hutchby, Ian (2001): Conversation and technology: From the telephone to the Internet. Cambridge.

Jenkins, Henry (2006): Convergence culture: Where old and new media collide. New York.

Jones, Rodney (2004): The problem of context in computer-mediated communication. In: LeVine/Scollon (Hg.), S. 20-33. 
Kelly-Holmes, Helen (2006): Multilingualism and commercial language practices on the Internet. In: Journal of Sociolinguistics 10, 4, S. 510-523.

Kress, Gunther/van Leeuwen, Theo (2001): Multimodal discourse: The modes and media of contemporary communication. London.

LeVine, Philip/Scollon, Ron (Hg.) (2004): Discourse and technology: Multimodal discourse analysis. Washington, D.C.

Maaß, Christian/Pietsch, Gotthard (2007): Web 2.0 als Mythos, Symbol und Erwartung. (= Diskussionsbeiträge der Fakultät für Wirtschaftswissenschaft der FernUniversität in Hagen 408). Internet: www.fernuni-hagen.de/www2bonsai/wiwi/forschung/beitraege/ pdf/db408.pdf (Stand: November 2009).

Markham, Annette N./Baym, Nancy (Hg.) (2009): Internet inquiry: Conversations about method. Thousand Oaks.

Meier, Stefan (i.Vorb.): ,Share your Fotos. Watch the world‘ - Zur Nutzung und Konventionalisierung von Fotografie als Mittel visueller Imagekonstruktion im Social Web. In: Hess-Lüttich, Ernest W. B./Kimminich, Eva/Sachs-Hombach, Klaus/ Wenz, Karin (Hg.): Zeichenmaterialität, Körpersinn und (sub)kulturelle Identität, Kodikas/Code. Ars Semeiotica. Tübingen.

O'Reilly, Tim (2005): What is Web 2.0 - design patterns and business models for the next generation of software. Internet: www.oreillynet.com/pub/a/oreilly/tim/news/2005 /09/30/what-is-web-20.html (Stand: November 2009).

Paolillo, John (1999): The virtual speech community: Social network and language variation on IRC. In: Journal of Computer-Mediated Communication 4, 4. Internet: http://jcmc.indiana.edu/vol4/issue4/paolillo.html (Stand: November 2009).

Randow, Gero von (2007): Leben im Netz. In: Die Zeit, 18.01.2007. Internet: www.zeit. de/2007/04/01-Leben-im-Netz?page=all (Stand: November 2009).

Rowe, Charley/Wyss, Eva L. (Hg.) (2009): Language and new media: Linguistic, cultural, and technical evolutions. Cresskill.

Runkehl, Jens/Schlobinski, Peter/Siever, Torsten (1998): Sprache und Kommunikation im Internet: Überblick und Analysen. Opladen.

Sandig, Barbara (2006): Textstilistik des Deutschen. 2., völlig neu bearb. u. erw. Aufl. Berlin.

Schmitz, Ulrich (2002): E-Mails kommen in die Jahre. Telefonbriefe auf dem Weg zu sprachlicher Normalität. In: Dürscheid, Christa/Ziegler, Arne (Hg.): Kommunikationsform E-Mail. (= Textsorten 7). Tübingen, S. 33-56.

Schmitz, Ulrich (2003): Lesebilder im Internet. Neue Koalitionen und Metamorphosen zwischen Text und Bild. In: Zeitschrift für Germanistik, Neue Folge XIII, 3, S. 605-628.

Schmitz, Ulrich (i.d.Bd.): Schrift an Bild im World Wide Web. Articulirte Pixel und die schweifende Unbestimmtheit des Vorstellens.

Scholz, Trebor (2008): Market ideology and the myths of Web 2.0. In: First Monday 13, 3. Internet: www.uic.edu/htbin/cgiwrap/bin/ojs/index.php/fm/article/viewArticle/2138/ 1945 (Stand: November 2009). 
Siebenhaar, Beat (2006): Code choice and code-switching in Swiss-German Internet Relay Chat rooms. In: Journal of Sociolinguistics 10, 4, S. 481-509.

Stern, Susannah (2008): Producing sites, exploring identities: Youth online authorship. In: Buckingham (Hg.), S. 95-118.

Stöckl, Hartmut (2004): Die Sprache im Bild - Das Bild in der Sprache. Zur Verknüpfung von Sprache und Bild im massenmedialen Text. (= Linguistik - Impulse \& Tendenzen 3). Berlin.

Storrer, Angelika (2000): Was ist ,hyper ${ }^{6}$ am Hypertext? In: Kallmeyer, Werner (Hg.): Sprache und neue Medien. (= Jahrbuch des Instituts für Deutsche Sprache 1999). Berlin/New York, S. 222-249.

Storrer, Angelika (2001): Getippte Gespräche oder dialogische Texte? Zur kommunikationstheoretischen Einordnung der Chat-Kommunikation. In: Lehr, Andrea et al. (Hg.): Sprache im Alltag. Beiträge zu neuen Perspektiven in der Linguistik. Berlin, S. 439-465.

Tagliamonte, Sali A./Denis, Derek (2008): ,Linguistic ruin? LOL!‘ Instant messaging and teen language. In: American Speech 83, 1, S. 3-34.

Thimm, Caja (2008): Technically-mediated interpersonal communication. In: Antos, Gerd/Ventola, Eija (Hg.): Handbook of interpersonal communication. Berlin, S. 331-354.

Tsiplakou, Stavroula (2009): Doing bilingualism: Language alternation as performative construction of online identities. In: Pragmatics 19, 3, S. 361-391.

van Leeuwen, Theo (2004): Ten reasons why linguists should pay attention to visual communication. In: LeVine/Scollon (Hg.), S. 7-19.

Zimmer, Michael (2008): Critical perspectives on Web 2.0. In: First Monday 13, 3. Internet: www.uic.edu/htbin/cgiwrap/bin/ojs/index.php/fm/issue/view/263 (Stand: November 2009). 

Angela Keppler

\title{
Die wechselseitige Modifikation von Bildern und Texten in Fernsehen und Film
}

\begin{abstract}
Es scheint eine Selbstverständlichkeit zu sein, dass Bild und Text sowie Bild und Klang einander in den audiovisuellen Prozessen filmischer Produkte wechselseitig konturieren. Dieser geläufige Befund jedoch bedarf weiterer Klärung. Vor allem die wissenschaftliche Analyse von Sendungen des Fernsehens operiert nicht selten weiterhin mit irreführenden Hierarchien zumal zwischen Text und Bild, so als würde der Bildverlauf eine weitgehend autonome Bedeutung des im sprachlichen Text Gesagten lediglich modifizieren oder transformieren. Demgegenüber vertritt der Beitrag die These, dass Bild und Text in filmischen Erzeugnissen jeglicher Art gleichursprünglich an der Konstitution der in ihnen präsentierten Gehalte beteiligt sind. Es wird gezeigt, dass dieser basale audiovisuelle Zusammenhang auch dort besteht, wo eines dieser Elemente - etwa der mündliche Dialog oder ein verbaler Kommentar - den Verlauf eines Films oder einer Filmsequenz zu dominieren scheint, und folglich, dass er alle filmischen Genres einschließlich der Sendetypen des Fernsehens gleichermaßen prägt. Eine Interpretation ausgewählter Beispiele stützt das Plädoyer für ein nichthierarchisches Verständnis der Bedeutungsdimensionen in den Produktionen von Film und Fernsehen.
\end{abstract}

Innerhalb der Film- und Fernsehwissenschaft ist es längst zu einer Selbstverständlichkeit geworden, dass Bild und Text sowie Bild und Ton einander in den audiovisuellen Prozessen filmischer Produkte wechselseitig konturieren. Diesem Befund möchte ich nachgehen und ihm dabei einige Aspekte abgewinnen, die vielleicht noch nicht hinreichend selbstverständlich sind. Ich werde die These vertreten, dass Bild und Ton in filmischen Erzeugnissen jeglicher Art gleichursprünglich an der Konstitution der in ihnen präsentierten Gehalte beteiligt sind - und zwar gerade auch dort, wo eines dieser Elemente - etwa der mündliche Dialog oder ein verbaler Kommentar - in bestimmten Formaten oder Sequenzen sowohl des Spielfilms als auch des Fernsehens zu dominieren scheint.

Filmische Produkte stellen eine Einheit von akustischer und visueller Bewegung dar. Bei dem Verhältnis von visueller und akustischer Dimension handelt es sich hier keineswegs um ein additives, sondern durchweg um ein integrales Verhältnis: der Klang fügt dem Bild nicht nur etwas hinzu, der Klang verwandelt das Bildgeschehen, das seinerseits das modifiziert, was akustisch vernehmbar ist. Gesprochene Sprache, Musik und andere Geräusche bilden eine integrale Dimension des filmischen Bewegungsbildes. Wie Schnitt, Montage, Kameraführung, Lichtregie, Farbgebung und dergleichen sorgen 
Sprache und Musik für den spezifischen Rhythmus eines ganzen Films. Zugleich sind sie wesentliche Medien der in Filmen verkörperten Gehalte: sie transportieren Stimmungen, vermitteln Informationen, geben Rätsel auf oder führen in die Irre, beruhigen oder beunruhigen, wiegeln auf oder wiegeln ab, stellen klar oder lassen im Unklaren. Zusammen bilden Bild und Klang die in einem filmischen Verlauf geschaffenen und von ihm gezeigten Situationen. Die Anerkennung und Interpretation dieses Zusammenhangs von visueller und akustischer Bewegung ist daher die erste Aufgabe einer Wissenschaft des filmischen Bildes, gleich ob sie sich seinen Realisierungen im Kino, im Fernsehen oder in anderen Kontexten der Produktion und Rezeption widmet. ${ }^{1}$

Mein Beitrag hat drei Teile. Ich werde zunächst mit einigen grundsätzlichen Bemerkungen etwas genauer an die Komplexität der Verhältnisse zwischen Bild und Text sowie Bild und Ton in filmischen Produkten erinnern. Durch eine Interpretation von vier kurzen Beispielen aus Kino und Fernsehen werde ich anschließend für ein strikt nichthierarchisches Verständnis der Bedeutungsdimensionen in den Produktionen beider Medien argumentieren. Zum Schluss werde ich andeuten, wie sich auf dieser Basis die mediale Differenz zwischen Kino und Fernsehen begreifen lässt.

\section{I.}

Als bildliches Medium gehört der Film - nach der Terminologie von Nelson Goodman (1995, Kap. IV) - zu den syntaktisch und semantisch dichten Zeichen, die im Unterschied zur gesprochenen und geschriebenen Sprache keine eindeutige Trennung der bedeutungsbildenden Komponenten und der Bezugsgegenstände dieser Zeichen erlaubt. Aus diesem Grund ist alle Aussicht auf eine wie immer geartete Grammatik der filmischen Rede vergebens. Nichtsdestotrotz ist das filmische Bild durch Einstellung, Schnitt, Montage, Kameraführung, Farb- und Lichtregie ein vielfach artikuliertes Bild, und es ist für die Filmanalyse entscheidend zu verfolgen, was in diesen Prozessen geschieht: wie die Objekte, Szenen, Personen, Verläufe durch die filmische Aufnahme dargeboten werden, welche Zeit zu ihrer Wahrnehmung bleibt, welche Ansichten jeweils präsentiert und montiert werden usw. Trotz vieler Typisierungen in filmischen Verfahren finden sich hier aber keine abgegrenzten Elemente wie Buchstaben, Worte oder Sätze der Sprache, da sich das Bild des Films - als Spezies des Bildes - nicht aus distinkten Zeichen und Gruppen von Zeichen zusammensetzt, deren Anordnung einen buchstäblichen Text der Kommunikation ergeben würde. Es bietet sich vielmehr in der Fülle und Bewegung seiner Elemente dar, an der

$1 \mathrm{Zu}$ den bildtheoretischen Voraussetzungen und methodischen Konsequenzen dieses Verständnisses vgl. Keppler (2005). 
geübte Zuschauer signifikante Dinge und Ereignisse, Figuren und Handlungen, Zustände und Verläufe erkennen. Außerdem wäre mit einer Beschränkung auf diese Aspekte wiederum nur von der visuellen Sprache des Films die Rede, nicht aber von der tatsächlichen Artikuliertheit der Filme, die wir in Kino und Fernsehen zu sehen bekommen. Ebenso unangemessen wäre es freilich, Filme als eine Kombination mehrerer „Sprachen“ - z.B. der bildlichen, der musikalischen und der verbalen - zu verstehen. Was wir jeweils sehen und hören, ist eine audiovisuelle Komposition, die es gerade in der Integration ihrer Elemente zu verstehen gilt. Daher ist die Rede von einer Sprache des Films allein in metaphorischer Bedeutung sinnvoll. Metaphorisch verstanden, lenkt sie die Aufmerksamkeit auf die gesamte Dramaturgie von Filmen und hebt die Interdependenz ihrer Formelemente hervor. Wie diese Integration aber auch jeweils geleistet wird, ob synchron oder asynchron, harmonisch oder dissonant, kontrastreich oder kontrastarm, alles dies sind Fälle der Einheit von Klang und Bild im filmischen Prozess. Was durch Filme gleich welcher Art kommuniziert wird, ergibt sich stets aus dieser ihrer gesamten Dramaturgie: Keine der beteiligten Dimensionen, weder das bildliche, noch das musikalische, noch das sprachliche oder das übrige akustische Geschehen dürfen bei der Interpretation filmischer Produkte vernachlässigt werden, so sehr eine analytische Trennung häufig sinnvoll ist. Denn keine ist allein für den Gehalt von Filmen verantwortlich. ${ }^{2}$

Unter der Überschrift eines Zusammenhangs von Text und Bild kann deshalb vieles angesprochen sein. In einem eher semiotischen Kontext werden manchmal auch Bilder und Bildverläufe als Texte klassifiziert, womit es Verhältnisse zwischen Arten von Texten wären, die hier angesprochen sind. Wenn dagegen von Bild und Text die Rede ist, kann einerseits das Verhältnis von Bild und Schrift und andererseits, jedenfalls sobald man auch filmische Bilder im Auge hat, dasjenige von Bild und verbaler Rede gemeint sein; drittens schließlich kann die Wendung als ein Stellvertreter für den allgemeinen Zusammenhang von Bild und Ton aufgefasst werden. Welche Terminologie man aber auch im Einzelnen bevorzugen mag: Sobald wir über filmische Produkte sprechen, ist mit einer potentiellen Interaktion aller dieser Elemente zu rechnen. Denn da sie in vielen konventionalisierten Formen wenn auch, wie gesagt, auf sehr unterschiedliche Weise - oft alle versammelt sind, trägt von Fall zu Fall gerade die Abwesenheit zum Beispiel der

\footnotetext{
Obwohl dies - wie gesagt - in der Forschung über Film und Fernsehen ein weithin akzeptierter Grundsatz ist, vermögen nicht alle methodischen Vorgehensweisen ihm tatsächlich zu entsprechen. Ein Beispiel wäre die in Deutschland durch Gerd Albrecht (1964) bekannt gemachte quantitative Inhaltsanalyse; ein aktuelles Beispiel wäre Grimm (2006). Auch die ethnomethodologische Konversationsanalyse z.B. von Nachrichteninterviews im Fernsehen schenkt der visuellen Präsentation allzu wenig Beachtung (vgl. Heritage/Clayman/Zimmermann 1988); Gleiches gilt für Untersuchungen aus dem Umkreis der sozialwissenschaftlichen Hermeneutik, z.B. Reichertz (2000). Zur Kritik an diesen Ansätzen siehe Keppler (2006, S. 96-104).
} 
Musik, der Stimme, anderen Arten des Tons und sogar des Bildes zur spezifischen Dramaturgie filmischer Verläufe bei. ${ }^{3}$ Wir müssen also, um es ein wenig paradox zu sagen, im Blick auf Film wie Fernsehen manchmal selbst dort von Stimme und Schrift, Bild und Ton sprechen, wo diese gar nicht alle zusammen kommen.

In diesen allgemeinen Bemerkungen liegt bereits eine deutliche Warnung vor einer im Ansatz hierarchischen Auffassung der für filmische Verläufe konstitutiven medialen Dimensionen. ${ }^{4}$ Dies gilt meines Erachtens auch für die visuellen Relationen von Bild und Schrift, insbesondere aber für die audiovisuellen von Bild (einschließlich der Schrift) und Ton. Da ich anhand meiner Beispiele vorwiegend die Letzteren kommentieren werde, sei ein weiterer Hinweis vorausgeschickt. Zu den vergleichsweise wenigen Filmtheoretikern, die die auditive Dimension von Filmen wirklich ernst genommen haben, zählt Gilles Deleuze. Das 9. Kapitel des zweiten Bandes seiner Filmtheorie, das mit „Die Bestandteile des Bildes“ überschrieben ist, handelt deshalb ausführlich von der Rolle des Tons im filmischen Geschehen. Unter anderem heißt es dort:

Es ist oftmals erwähnt worden, daß es nur eine Tonspur, aber zumindest drei Gruppen von Tönen gibt, nämlich Reden, Geräusche und Musik. Möglicherweise müssen wir aber eine größere Gruppe von akustischen Elementen unterscheiden: Geräusche (die einen Gegenstand isolieren und sich voneinander abheben); Töne (die Bezüge markieren und untereinander in gegenseitigem Bezug stehen); Lautbildungen (die Bezüge zerlegen und bei denen es sich um Schreie, aber genauso gut um regelrechten Jargon handeln kann, wie in den Slapstik-Tonfilmen von Chaplin oder Jerry Lewis); schließlich Reden und Musik. (Deleuze 1991, S. 300) ${ }^{5}$

So sehr man diese Liste noch verlängern könnte, so sehr mag sich hier zugleich die Frage stellen, ob nicht diese Komplexitäten der Klangregie vor allem auf den Kinofilm zutreffen (dem Deleuzes Überlegungen ausschließlich gewidmet sind), aber gerade nicht auf die spezifische Ästhetik des Fernsehens, die doch alles in allem - bildlich wie klanglich und erst recht klangbildlich - mit schlichteren Mitteln operiert.

3 In Alejandro González Iñárritus Beitrag zu dem Episodenfilm 11'09"01 (Frankreich 2002) z.B. bleibt das Bild über weite Strecken schwarz; ähnliche Effekte gibt es in Abbas Kiarostamis Five (Iran 2003).

$4 \quad$ Als „hierarchisch“ bezeichne ich dabei die Auffassung, in bestimmten Formaten zumal des Fernsehens stelle das Wort gegenüber dem Bild den primären Bedeutungsträger der filmischen Kommunikation dar; denkbar ist aber auch der umgekehrte Fall. Ein klassisches Beispiel einer solchen Vorrangsthese stellt Hegels in seinen Vorlesungen über die Ästhetik vertretene Annahme dar, in der Poesie hätten die durch das Wort evozierten Vorstellungen ein grundsätzlich größeres Gewicht als der Klang. In der Kommunikationswissenschaft finden sich solche Hierarchisierungen in hohem $\mathrm{Ma}$ bei der Anwendung quantitativer wie qualitativer Methoden der Inhaltsanalyse; vgl. Merten (1995), Bonfadelli (2002) sowie kritisch Keppler (2006, S. 98 ff.).

5 Vgl. ebd.: „Die Stimme ist nicht von den Geräuschen zu trennen, die sie oftmals unvernehmbar macht." 
Eine solche Annahme erschiene mir jedoch höchst irreführend. Im Kinofilm und im Fernsehen, so möchte ich darlegen, haben wir es durchweg mit einer dichten Interaktion zwischen visuellem und akustischem Geschehen zu tun. Hier wie dort werden der Raum und die Zeit des Bildgeschehens durch den Einsatz eines reichen Spektrums akustischer Mittel gebildet; hier wie dort greift die bildliche Dramaturgie permanent in die Gestaltung des auf der akustischen Ebene Vermittelten ein. Der kommunikative Gehalt, sei es einzelner Sequenzen, sei es von Sendebeiträgen und Sendungen sowie dokumentarischen oder fiktionalen Filmen im Ganzen, ergibt sich stets aus der Verzahnung von visuellen und akustischen Strukturen. Deshalb spreche ich von einer grundsätzlichen und konstitutiven, für das filmische Medium in allen seinen Spielarten charakteristischen Modifikation des Bildes durch den Ton und des Tons durch das Bild. Dass dies so ist und wie es sich vollzieht, möchte ich nun an jeweils zwei Beispielen aus dem Bereich des Spielfilms und des Fernsehens verdeutlichen. Der Vergleich der kommentierten Filmausschnitte soll einerseits die Spannweite der Kombination von Bild und Ton in beiden Medien exemplarisch verdeutlichen. Zum andern kann die Interpretation des zweiten, dritten und vierten Beispiels demonstrieren, wie wenig der verbale Diskurs allein für die Realisierung filmischer Darbietungen verantwortlich ist. ${ }^{6}$

II.

In meinem ersten Beispiel werden keinerlei Worte gewechselt, dennoch spielen Bild, Schrift und Klang auf eine intensive Weise ineinander. Es handelt sich um eine Sequenz aus Michelangelo Antonionis Film Zabriskie Point aus dem Jahr 1970. Zwei Studenten befinden sich auf einer Fahrt durch Los Angeles zu dem von Protesten und Polizeieinsatz geprägten Campus ihrer Universität. In den knapp zehn Minuten davor war eine längere Passage mit revolutionärem und scheinrevolutionärem Gerede unter Studenten zu sehen. In ihr hat sich der Held des Films zu der Bereitschaft bekannt, in der Revolte sein Leben aufs Spiel zu setzen, was er im Verlauf der Handlung, allerdings in einer eher existentiellen Manier - und mit am Ende tödlichem Ausgang - auch tun wird. Danach werden kurz die beiden anderen Hauptfiguren eingeführt, ein kapitalistischer Bauunternehmer und die Studentin, die der Held auf seiner Flucht ins Death Valley treffen wird. Es folgt ein abrupter Übergang zu einer Sequenz, in der der Held und sein Zimmergenosse durch Los Angeles zum Campus fahren, deren erste 150 Sekunden eine hochimaginative bildliche und klangliche Komposition entwerfen.

Die Interpretation der letzteren wird durch Transkripte unterstützt, nicht jedoch die des ersten Ausschnitts, da selbst ein detailliertes Protokoll dieser hochkomplexen Sequenz nicht gerecht werden kann. Zum Verfahren der Transkription und dessen Bedeutung für die Analyse filmischer Produkte vgl. Keppler (2006, Kap. 3: Eine Methode der Fernsehanalyse). 
Aber auch sprachlicher Text ist in dieser Passage massiv präsent. Er tritt dem Betrachter auf zahlreichen Reklametafeln und -aufschriften entgegen, die zusammen mit den Bildern im Stadtbild sowie den vorbeiziehenden Gewerbeanlagen und Fahrzeugen für den Eindruck einer surreal-chaotischen Zivilisationswüste sorgen. Für eine Fülle von Signalen sorgt hier allein schon die Schrift. Eine entscheidende Rolle aber spielt zudem die akustische Regie. Zunächst wird die Fahrt von ganz realistischen Geräuschen begleitet, bis nach 23 Sekunden, direkt nach dem Geräusch der quietschenden Reifen des um eine Kurve biegenden Pick-Ups schrille und harte elektronische Musikklänge einsetzen, die sich in der Folge nahezu ununterscheidbar mit dem Verkehrslärm der Stadt mischen (die Originalmusik zu diesem Film stammt von der Gruppe Pink Floyd); zu hören sind Motorgeräusche, das Rattern eines Zuges, Huplaute und Sirenenklänge. Mit diesem Klangdschungel korrespondiert ein vorübergehendes Intransparentwerden des Bildverlaufs, als ein vorbeifahrender Güterzug so ins Bild gesetzt wird, dass sich alle fixierbaren Gestalten in einer Art filmischem ActionPainting vorübergehend auflösen, wiederum scharf kontrastiert von der Palmenallee, die in Richtung des Campus führt. Von dem Einsetzen der Musik bis zum Schnitt in die Allee vergeht gerade mal eine gute Minute. Sie führt in und durch einen verstörenden, ebenso zersplitterten wie enervierenden Geschehensraum, in dem jene strukturelle Gewalt schon am Werk ist, von der die Erzählung handeln wird. Dieser filmische Bewegungsraum ist gleichermaßen durch Bild und Klang synthetisch und synergetisch hergestellt. Er bildet nach dem aufgeputschten Durcheinanderreden der Studenten das weit kürzere zweite Präludium des Films, das den erzählten Ereignissen wortlos vorausgreift. Zusammen erzeugen Bild und Klang eine Atmosphäre gesellschaftlicher Hochspannung, die sich am Schluss des Films in einer von der weiblichen Heldin imaginierten, über insgesamt fünf Minuten hinweg zunächst in Originalgeschwindigkeit und realistischer Akustik, nach anderthalb Minuten dann - von einer psychedelischen Rockmusik unterlegt - in Superzeitlupe mehrfach wiederholten Explosion einer Hotelanlage entlädt.

Mein zweites Beispiel ist eine Szene aus Martin Scorseses Film GoodFellas aus dem Jahr 1990. Nach einer guten Viertelstunde befinden wir uns am Ende der Vorgeschichte der Erzählung, in der die Betrachter ausführlich in das Milieu dieses Films eingeführt worden sind. Die Sequenz wird eingeleitet durch einen in Aufsicht vollzogenen Schwenk über einen Tisch in einem italienischen, von der Mafia frequentierten Restaurant. Der Zuschauer ist durch eine vorangegangene Kamerafahrt bereits in die halbseidene Atmosphäre dieses Lokals eingeführt worden. Dazu war, wie auch am Anfang der Passage, die ich kommentieren möchte, die Stimme der von Ray Liotta gespielten Hauptfigur Henry Hill aus dem Off zu hören, die über den ganzen Film hinweg immer wieder die Ereignisse aus einer sentimental 
auf seine Mafia-Zeit rückblickenden Perspektive kommentiert. Hier wird mit Worten der Entwicklung der Handlung vorausgegriffen, freilich ohne etwas über ihren Verlauf zu verraten. Darin liegt eine Distanzierung und zugleich Verklärung, die aber - wiederum über den ganzen Film hinweg immer wieder aufgehoben wird, um von den Stationen einer am Ende desaströsen Mafia-Karriere von innen heraus zu erzählen. So auch in diesem Ausschnitt. Nachdem die Stimme des retrospektiven Erzählers verklungen ist, erhebt sich zunächst der junge Held und kurz darauf sein älterer Kumpan Jimmy Conway von der Tafel, um sich mit einem neu hinzugekommenen, etwas vierschrötigen Gast an der Bar zu treffen. Daraufhin kommt es für eine knappe Minute zu einem kurzen konspirativen Dialog, der sich akustisch und bildlich in einem Binnenraum des zuvor etablierten filmischen Raums abspielt.

Der vor diesem Dreiergespräch zu hörenden Stimme aus dem Off kommt an dieser Stelle vor allem die dramaturgische Funktion zu, in Ergänzung und durchaus auch Abhebung von den sichtbaren Szenen das Selbstbild der Akteure zu konturieren. Sie kommentiert keinen bestimmten Vorgang, der sich auf der Leinwand abspielt, sondern gibt vielmehr das Lebensgefühl dieser verschworenen Gemeinschaft (und vor allem des Helden) wieder, getragen vom Halblicht des von Rot- und Schwarztönen geprägten Ambientes. Die anscheinend im Restaurant erklingende Musik und die vernehmbaren Gesprächsfetzen halten die Szene für ein erneutes Eintauchen der Handlung in ihren imaginativen Raum bereit. Dass die erklingende Musik nicht eindeutig innerhalb der Szene verortet ist, wird an ihrem plötzlichen Anschwellen deutlich, als der von Robert de Niro gespielte Jimmy Conway aufsteht und sich zu der abseits in Gang gekommenen Besprechung zwischen Henry Hill und dem Neuankömmling gesellt, bei der es um die Planung eines größeren Gelddiebstahls geht - eine akustische Zäsur, die einen kurzen Zwischenakt einleitet, bevor es an der größeren Tafelrunde zu lebhaften Auseinandersetzungen kommt.

GoodFellas (R: Martin Scorsese, USA 1990), Ausschnitt

\begin{tabular}{|c|c|c|c|}
\hline Nr. & Bild & & Ton \\
\hline$\frac{01}{108}$ & $\begin{array}{l}\text { A, } S^{1, o} \text { : Jimmy Conway }(J C) \text { geht durch ein } \\
\text { Restaurant zur Bar, } \\
\mathrm{N}, \mathrm{S}^{\mathrm{l}} \text { : JC reicht lächelnd Robert } \\
\text { McMahon (MM) am } \mathrm{BR}^{\text {re }} \text { die Hand, } \\
\\
\mathrm{S}^{\mathrm{l}, \mathrm{o}} \text { : JC wendet sich Henry Hill (HH) zu, HH } \\
\text { blickt kurz nach li, dann wieder zu JC, } \\
\text { kurze Zeigegeste mit der Hand am BR }\end{array}$ & $\begin{array}{l}\text { Mu: } \\
\text { (JC): } \\
(\mathrm{MM}): \\
(): \\
(): \\
\text { Mu: } \\
\text { G: } \\
\text { HH: }\end{array}$ & $\begin{array}{l}((\text { Streichermusik })) \\
\text { hey, }() \\
()(\text { good to see you }) \\
((\text { lachen })) \\
()(\text { yeah }) \\
(\text { (Streicher werden leiser })) \\
((\text { HG: Gläserklirren })) \\
<<\text { p }>\text { te'=tell= him what }=\text { you }>\end{array}$ \\
\hline
\end{tabular}




\begin{tabular}{|c|c|c|}
\hline$\frac{\text { Nr. }}{\text { Zeit }}$ & Bild & Ton \\
\hline$\frac{02}{\prime 02}$ & $\begin{array}{l}\mathrm{N}: \mathrm{BR}^{\mathrm{li}} \mathrm{HH} \text { von re hinten, } \mathrm{BH}^{\mathrm{li}} \mathrm{JC} \text { im Profil } \\
\text { von re, } \mathrm{BH}^{\mathrm{re}} \mathrm{MM} \text {, } \\
\mathrm{JC} \text { stößt am } \mathrm{BR}^{\mathrm{u}} \text { mit einem Schnapsglas mit } \\
\mathrm{MM} \text { an }\end{array}$ & $\begin{array}{ll}\text { Mu: } & ((\text { HG: Streichermusik })) \\
\mathrm{HH}: & <<\mathrm{p}>\text { were telling me (my friend })> \\
\mathrm{G}: & ((\text { Gläserklirren })) \\
\mathrm{MM}: & \text { too good=to be true; }\end{array}$ \\
\hline$\frac{03}{\prime 02}$ & $\begin{array}{l}\mathrm{N} \text { : } \mathrm{BH}^{\mathrm{re}} \mathrm{JC} \text { im Profil von li, } \mathrm{BH}^{\mathrm{li}} \mathrm{HH} \text { nach li } \\
\text { gelehnt, blickt JC an, } \\
\mathrm{JC} \text { stößt mit seinem Glas am } \mathrm{BR}^{\mathrm{u}} \text { mit } \mathrm{HH} \text { an, } \\
\mathrm{HH} \text { grinst, JC blickt kurz nach re, setzt sein } \\
\text { Glas an und legt den Kopf in den Nacken, } \\
\text { HH nippt an seinem Glas und schaut dabei } \\
\text { JC an }\end{array}$ & $\begin{array}{l}\text { ((HG: Streichermusik })) \\
\text { haha:: } \\
((\text { Gläserklirren }))\end{array}$ \\
\hline$\frac{04}{\prime 05}$ & $\begin{array}{l}\text { N: BM JC im Profil von re, } \\
\text { setzt sein Glas ab, blickt kurz zu MM, dann } \\
\text { nach u, } \\
\text { BHre MM vornübergebeugt, den Kopf zu JC } \\
\text { gewandt, richtet sich auf, breitet seine Arme } \\
\text { aus und lehnt sich wieder nach vorn, } \\
\text { JC trinkt einen Schluck aus einem Glas, BR } \\
\text { HH vornübergebeugt, setzt das Glas ab, } \\
\text { senkt seinen Oberkörper Richtung Tisch und } \\
\text { blickt JC und MM an }\end{array}$ & $\begin{array}{ll}\text { Mu: } & ((\text { HG: Streichermusik })) \\
\text { MM: } & <<\mathrm{p}>\text { big score coming from Air } \\
& \text { Fra:nce; }(.) \text { (anyway) } \\
\text { G: } & (\text { Klopfen })) \\
& \\
\text { MM: } & \text { Ba::gs of money } \\
& \text { like this comin=in; } \\
& (-) \text { kay, }\end{array}$ \\
\hline$\frac{05}{106}$ & $\begin{array}{l}\text { N: } \mathrm{BH}^{\text {li } H H} \text { kauend, blickt nach re o zu JC, } \\
\text { BRre MM von hinten li mit starken Kopf- } \\
\text { gesten, JC starrt geradeaus, zieht an Zigarette, } \\
\text { beugt sich etwas herunter, blickt kurz zu MM } \\
\text { und nickt leicht }\end{array}$ & $\begin{array}{l}((\mathrm{HG} \text { : Streichermusik)) } \\
<<\mathrm{p}>\text { (from touris') an American } \\
\text { (serviceman will) change their money } \\
\text { (according to) French money } \\
\text { send=them back? here }>\end{array}$ \\
\hline$\frac{06}{109}$ & $\begin{array}{l}\mathrm{N}: \mathrm{BH}^{\mathrm{li}} \mathrm{HH} \text { von hinten re, die Hand nahe am } \\
\text { Kinn, } \\
\text { BM JC im Profil, } \\
\text { BHre MM blickt nach re u, } \\
\text { alle vornübergebeugt, HH und JC MM } \\
\text { zugewandt, MM grinst, } \\
\text { JC nickt, } \\
\text { HH richtet sich kurz auf, deutet mit } \\
\text { Salzgebäck in seiner Hand auf JC, JC dreht } \\
\text { den Kopf nach li }\end{array}$ & 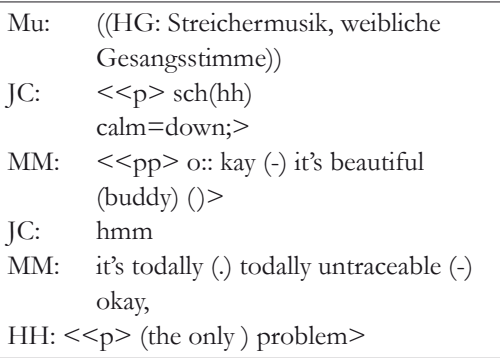 \\
\hline$\frac{07}{' 05}$ & $\begin{array}{l}\text { N: } \mathrm{BH}^{\mathrm{li}} \mathrm{HH} \text {, vornübergebeugt, den Kopf } \\
\text { schräg haltend, } \\
\text { schaut JC an, seine li Hand am } \mathrm{BR}^{\mathrm{u}, \mathrm{li}}, \mathrm{JC} \text { in } \\
\mathrm{BM} \text { im Profil von li und MM am } \mathrm{BR}^{\mathrm{re}} \text { von } \\
\text { hinten li blicken HH an, } \\
\text { HH mit Handgesten, } \\
\text { schüttelt leicht den Kopf, } \\
\text { nickt schwach, } \\
\text { JC wendet den Kopf zu MM }\end{array}$ & 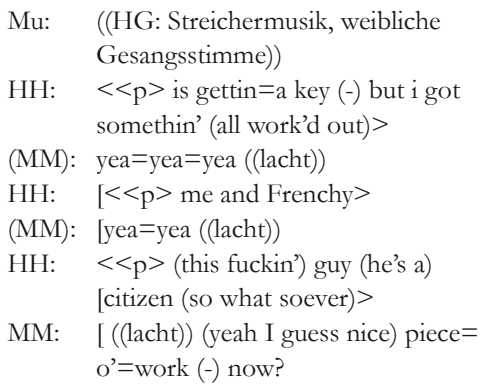 \\
\hline
\end{tabular}




\begin{tabular}{|c|c|c|c|}
\hline$\frac{\text { Nr. }}{\text { Zeit }}$ & Bild & \multicolumn{2}{|r|}{ Ton } \\
\hline$\frac{08}{' 06}$ & $\begin{array}{l}\text { N: BH } H^{\text {li }} \text { Hinterkopf und re Wange von } \mathrm{HH} \text {, } \\
\text { die Hand am Mund, BM JC im Profil von re, } \\
\text { BHre MM den beiden zugewandt, alle stark } \\
\text { vornübergebeugt, } \\
\text { HH und JC blicken MM an, } \\
\text { MM zieht die Augenbrauen hoch, blinzelt } \\
\text { und nickt, JC nickt, den Kopf leicht geneigt, } \\
\text { hebt kurz die Hand, wendet sich zu HH }\end{array}$ & $\begin{array}{l}\text { Mu: } \\
\text { MM: } \\
\text { (): } \\
\text { MM: } \\
\text { (): } \\
\text { HH: }\end{array}$ & $\begin{array}{l}((\mathrm{HG} \text { : Streichermusik, weibliche } \\
\text { Gesangsstimme })) \\
<<\text { p }>\text { if I'm right }(-) \text { there could be } \\
\text { like häelf }=\text { a mil comin' }(-)> \\
\text { hm=hm } \\
<<\text { p }>\text { o:hl cash }> \\
\text { hm }=\text { hm } \\
<<\text { p }>\text { an }=\text { he said }>\end{array}$ \\
\hline$\frac{09}{\prime 03}$ & $\begin{array}{l}\mathrm{N} \text { : } \mathrm{BH}^{\text {li }} \mathrm{HH}, \mathrm{BM} \mathrm{JC} \text { im Profil von li; } \mathrm{BE}^{\mathrm{re}, \mathrm{o}} \\
\mathrm{MM} \text { von li hinten, alle vorgebeugt, } \\
\mathrm{HH} \text { zu JC und MM gebeugt, JC wendet den } \\
\text { Kopf zu HH, dann zu MM; VG aufsteigen- } \\
\text { der Zigarettenrauch }\end{array}$ & $\begin{array}{l}\text { Mu: } \\
\text { HH: } \\
\text { MM: }\end{array}$ & $\begin{array}{l}\text { ((HG: Streichermusik, weibliche } \\
\text { Gesangsstimme) } \\
<<\mathrm{p}>\text { the best time is probably over } \\
\text { the weekend }(-) \text { [so maybe sadurday }=> \\
\text { [oh yes }\end{array}$ \\
\hline$\frac{10}{\prime 04}$ & $\begin{array}{l}\text { N: } \mathrm{BH}^{\mathrm{li}} \mathrm{HH} \text { von hinten, zu MM gewandt; } \mathrm{BM} \\
\mathrm{JC} \text { im Profil von re, blickt } \mathrm{MM} \text { an; } \mathrm{BH}^{\mathrm{re}} \mathrm{MM} \text {, } \\
\text { blickt JC an, Geste mit offener Handfläche, } \\
\text { schüttelt schnell den Kopf, richtet sich leicht } \\
\text { auf und beugt sich wieder runter, schüttelt } \\
\text { erneut den Kopf, zieht die Augenbrauen } \\
\text { hoch und lächelt breit; VG aufsteigender } \\
\text { Zigarettenrauch }\end{array}$ & $\begin{array}{l}\text { Mu: } \\
\text { HH: } \\
\text { MM: }\end{array}$ & $\begin{array}{l}\text { ((HG: Streichermusik, weibliche } \\
\text { Gesangsstimme })) \\
\text { night, } \\
<<\text { p }>\text { (we = got }=\text { a) Jewish holiday on } \\
\text { monday }(--) \text { hey won't find= out till } \\
\text { tuesday (1) }>\text { beautiful }\end{array}$ \\
\hline
\end{tabular}

Das durchweg in Nahaufnahme präsentierte - hier zu zwei Dritteln protokollierte - Gespräch zwischen den drei Männern an der Bar wird alternierend von rechts und links aufgenommen (Einstellungen 02-10), dem jeweiligen der beiden Sprecher zugewandt, die dem in ihrer Mitte stehenden Jimmy den Coup schmackhaft machen. Die Drei stecken ihre Köpfe zusammen; sie hecken sichtbar etwas aus, wie es selbst dann verständlich wäre, wenn man ihre Worte nicht verstehen könnte. Die Nahsicht der Bildführung lässt sie eine Enklave innerhalb des übrigen Raums bilden. Diese Abkapselung wird zugleich durch den Flüsterton des Gesprächs bewirkt, dem gegenüber alle Hintergrundgeräusche nun fast ganz zurückgenommen werden. Obwohl es sich nur um einen kurzen Dialog handelt, arbeiten auch hier Ton und Bild Hand in Hand; zusammen erzeugen sie eine insuläre Episode innerhalb des zwielichtigen Glamours der abendlichen Geselligkeit.

Mein nächstes Beispiel präsentiert eine Gesprächssituation ganz anderer Art. Es handelt sich um einen Ausschnitt aus der politischen Talkshow Anne Will, ausgestrahlt in der ARD am 23. 9. 2007. Das Thema der Sendung lautete: „Deutschland vor dem Anschlag? Das Kalkül mit der Angst“. Geladen - und in einem Halbkreis um die Moderatorin gruppiert - waren die Politikerin Renate Künast (RK) und der Politiker (und Innenminister) Wolfgang Schäuble (WS) auf der linken, sowie der Politiker (und ehemalige Innenminister) Gerhart Baum (GB) und der israelische Diplomat Avi Pri- 
mor (AP) auf der rechten Seite. Im Verlauf der Sendung haben die politischen Kontrahenten Baum und Schäuble ein etwas überraschendes Männerbündnis gegen Renate Künast geschlossen, der sie mit überlegenem Lächeln und spitzen Bemerkungen den Wind aus den Segeln zu nehmen versuchen. In der Sequenz, auf die es mir hier ankommt, setzt sich ein schon länger andauernder Kampf um das Rederecht fort.

Talkshow: Anne Will (ARD), 23.9.2007

Thema: „Deutschland vor dem Anschlag? Das Kalkül mit der Angst“, Ausschnitt

\begin{tabular}{|c|c|c|}
\hline Nr. & Bild & Ton \\
\hline $\mathrm{Zcil}$ & & \\
\hline $\begin{array}{l}01 \\
8\end{array}$ & $\begin{array}{l}\mathrm{D}\left(\mathrm{US}^{\mathrm{T}}\right) \text { : Renate Künast }(\mathrm{RK}) \text { blickt nach } \\
\text { rechts, gestikuliert } \\
\mathrm{Z}^{\text {h }} \text { G:RK }\end{array}$ & 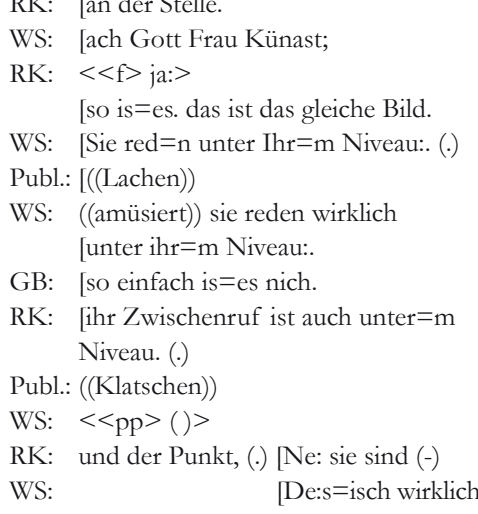 \\
\hline$\frac{02}{4}$ & $\begin{array}{l}\text { T: Studiopublikum, mehrere Personen } \\
\text { klatschen in die Hände, vereinzeltes } \\
\text { Kopfschütteln, } \\
\mathrm{F}^{\mathrm{h}}, \mathrm{S}^{\text {re, },} \text {, Personen stellen das Klatschen } \\
\text { sukzessive ein }\end{array}$ & $\begin{array}{ll}\text { RK: } & {[\text { warte }=\text { ma })(-)} \\
\text { WS: } & {[\text { traurig }} \\
\text { AW: } & \text { Was [haben Sie Herr Baum gegen } \\
\text { GB: } \quad[\text { also äh }(.) \text { ja ich }=\text { möcht }=\text { an } \\
& \text { Herrn } \\
\text { AW: } & \text { [Online Durchsuchungen? } \\
\text { RK } & {[\text { wir müssen an de:r Stelle diese }} \\
& \text { Vo:rschläge auch zu Ende }=\text { denken } \\
& \text { und }\end{array}$ \\
\hline$\frac{03}{4}$ & $\begin{array}{l}\text { N: RK blickt nach rechts, wiederholte Auf- } \\
\text { und Abbewegung der rechten Hand }\end{array}$ & 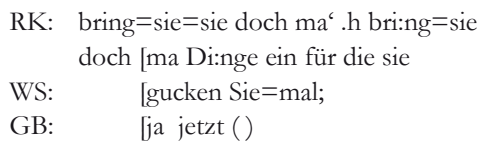 \\
\hline$\frac{04}{6}$ & $\begin{array}{l}\mathrm{N}\left(\mathrm{US}^{\mathrm{l}}\right) \text { : Gerhard Baum }(\mathrm{GB}) \text { nach links } \\
\text { vorne gelehnt, blickt nach links und deutet } \\
\text { mit ausgestrecktem Zeigefinger der rechten } \\
\text { Hand nach links, }\end{array}$ & $\begin{array}{l}\text { RK: }[\text { Mehrheiten her:stell }=\mathrm{n} \text { könn }=\mathrm{n} \\
\text { WS: }[\text { (jetzt lassen sie mich mal) zwei Sätze } \\
\text { GB: }[(\text { ) (.) ja:...hh } \\
\text { WS: sagen. }\end{array}$ \\
\hline
\end{tabular}




\begin{tabular}{|c|c|c|c|}
\hline Nr. & Bild & \multicolumn{2}{|r|}{ Ton } \\
\hline & $\begin{array}{l}\text { GB nimmt die Hand zurück und lehnt sich } \\
\text { nach rechts, GB lehnt sich zurück und zieht } \\
\text { die rechte Schulter hoch }\end{array}$ & $\begin{array}{l}\text { RK: } \\
\text { WS: } \\
\text { GB: } \\
\text { RK: } \\
\text { GB: }\end{array}$ & $\begin{array}{l}\text { statt immer nur das Absolut:istische zu } \\
\text { fordern mit dem sie } \\
\text { [die Frei:,heit (einreissen). } \\
\text { [es foddet doch; es foddet doch } \\
\text { [also wir wir sprechen ni‘ (.) wir } \\
\text { [das ist unser Sicherheitsproblem. } \\
\text { [sprechen (.) wir sprechen, }\end{array}$ \\
\hline$\frac{05}{3}$ & $\begin{array}{l}\text { N }\left(A S^{1}\right) \text { : Wolfgang Schäuble (WS) mit leicht } \\
\text { nach vorn gesenktem Kopf, blickt nach links } \\
\text { unten, } \\
\text { WS blickt auf und wendet den Kopf nach } \\
\text { rechts }\end{array}$ & $\begin{array}{l}\text { RK: } \\
\text { WS: } \\
\text { GB: } \\
\text { WS: } \\
\text { AW: } \\
\text { GB: } \\
\text { AW: } \\
\text { WS: }\end{array}$ & $\begin{array}{l}\text { [auch bei (online). } \\
{[<<\mathrm{f}>\text { Es fordert doch niemand }} \\
{[()} \\
\text { [Absoltutisch:tisches. }>\text {.h } \\
\text { [wir machen } \\
\text { [(also wir wir spreche wir sprechen) } \\
\text { [on:line Durchsuchungen; } \\
\text { [der }=\mathrm{s}\end{array}$ \\
\hline$\frac{06}{3}$ & $\begin{array}{l}\text { G }\left(\mathrm{US}^{\mathrm{l}}\right) \text { : Anne Will (AW) wendet Kopf und } \\
\text { Oberkörper sehr schnell nach rechts } \\
\text { AW nickt mehrmals kurz, lächelt }\end{array}$ & $\begin{array}{l}\text { AW: } \\
\text { GB: } \\
\text { AW: } \\
\text { GB: } \\
\text { WS: } \\
\text { GB: } \\
\text { WS: }\end{array}$ & $\begin{array}{l}\text { [für oder wider; okay? }(.) \\
{[\text { (wir) besprechen aber ein se:hr }} \\
\text { [des machen wir jetzt mal. hh } \\
\text { [schwieriges Problem. } \\
{[\text { der sach' der Sachverhalt }} \\
{[<<\text { p }>\text { (wir sprechen gleich darüber) }>} \\
{[\text { der Sachverhalt war doch }}\end{array}$ \\
\hline$\frac{07}{16}$ & $\begin{array}{l}\text { HT: Studiogäste, } \mathrm{F}^{\mathrm{re}}, \mathrm{S}^{\mathrm{li}}, \mathrm{Z}^{\mathrm{v}} \text { : } \\
\text { HN: WS mit nach vorne geneigtem Kopf, } \\
\text { blickt zu RK, WS wendet den Kopf zu AW, } \\
\text { AW blickt auf WS, WS Geste mit der linken } \\
\text { Hand,blickt nach rechts, nach links, schüttelt } \\
\text { leicht den Kopf; } \\
Z^{\mathrm{v}} \text { :N: WS blickt nach rechts, legt die linke } \\
\text { Hand auf seine Brust }\end{array}$ & WS: & $\begin{array}{l}\text { ganz einfach; (.) .hh die Sicherheits- } \\
\text { behörden; }<<\mathrm{p}>\text { übrigens auch die } \\
\text { Juschtiz die Bundesanwalt }>\text { schaft } \\
\text { hat gesagt weil Kommunikation nicht } \\
\text { nur üb=r Tele:fon erfolgt sondern } \\
\text { auch über .h Indernet }(.) \text { äh=m } \\
\text { tun wir in entsprechender An: } \\
\text { wendung der Strafprozessordnung; } \\
\text { dafür bin ich nicht zuschdändig } \\
\text { sondern die Juschtizminischter, }(.)\end{array}$ \\
\hline
\end{tabular}

Wie schon zuvor, erheben Baum und Schäuble in Wort und Bild, sowohl verbal als auch mimisch, immer wieder Einspruch gegen Künasts Ausführungen (verbal vor allem in E 01 und 02, gestisch insbesondere in E 04 und 05). Auch die Moderatorin versucht zwischendurch zu Wort zu kommen (E 05 und 06), aber schließlich kann Schäuble sich durchsetzen - und dies nicht allein verbal (E 06 und v.a. 07). Denn von einer Halbtotalen (E 07), die alle fünf am Gespräch beteiligten Personen erfasst, bewegt sich die Kamera in diesem Augenblick per Fahrt, Schwenk und Zoom mit einer vergleichsweise großen, ausholenden Geste frontal auf den Minister Schäuble zu und unterstreicht gleichsam das Wort, das er sich zunächst durch einfaches Weiterreden erstritten hat. Mit dieser auffälligen Geste der Kamera wird er 
bildlich aus allen herausgehoben als einer, der die Dinge zurecht rücken kann; sie verleiht ihm eine Autorität, die Künast in der gesamten Sequenz davor gerade durch die Bildregie nicht gewährt wurde. ${ }^{7}$

In dieser Szene wird deutlich, dass die Bildregie hier weitgehend unabhängig von der Kraft und dem Gewicht der jeweils verbal geäußerten Standpunkte einen eigenen rhetorischen Standpunkt zu formulieren vermag. Sie hebt die Position des Innenministers Schäuble dramaturgisch so heraus, dass seine Position rein choreografisch als die Überlegene erscheint. Die Bildsprache der Sendung gewichtet das in ihr verbal und nonverbal Gesagte und legt damit etwas nahe, das vor allem durch die Form der bildlichen Präsentation durchaus nachdrücklich artikuliert wird. Dies ist keineswegs ein Einzelfall. Denn generell ist von Talkshows zu sagen, dass sie alles andere als ein gefilmtes Radio darstellen, bei dem man sich das von der Bildregie Dargebotene auch sparen könnte. Denn der allein sichtbare, nicht aber hörbare Dialog der Mienen und Gesten, der Körperhaltung, je nach Sendung auch der Bewegung der Moderatoren, mit einem Wort: der bildlich bewegte und dadurch auf besondere Weise bewegende Schauplatz des verbalen Austauschs ist wesentlich für das, was sich in diesen Sendungen abspielt. Überspitzt gesagt: Das Bild macht die Musik, der Ton bewegt die Bilder.

Dies aber bedeutet: Nicht allein in dem Filmdialog des vorigen Beispiels, auch in dieser Talkshow-Szene ergibt sich der volle kommunikative Gehalt der präsentierten Gesprächssituation allein aus der Einheit von bildlicher und akustischer Dimension. Trotzdem operiert die Kamera in beiden Fällen auf höchst unterschiedliche Weise. Während die wechselnden KameraEinstellungen in dem Dialog aus GoodFellas untrennbar mit der Situation verbunden bleiben, die sie zusammen mit der Tonspur erzeugen, spielt die Kamera in dem ostentativen Schwenk und Zoom auf Schäuble gleichsam ein eigenes Spiel. Sie erzeugt Verbindungen innerhalb eines fortlaufenden Live-Gesprächs, das den Fernsehzuschauern ständig - und erkennbar - aus den Perspektiven verschiedener Kameras dargeboten wird, die das Geschehen aus jeweils ibrer Perspektive darbieten. In der gezeigten Einstellung kann die Kamera deshalb (innerhalb der von der Regie arrangierten Montage) als ein eigener Akteur auftreten, der zu dem übertragenen Gesprächsgeschehen eine auffällige Stellung bezieht. Die Kameraführung schafft hier nicht - wie in GoodFellas - eine eigene abgegrenzte Szene innerhalb einer bereits etablierten größeren Szene, sondern interveniert gleichsam in das Gespräch, indem sie mit ihrer Sicht auf es zugleich eine Ansicht über es formuliert.

Mithilfe meines vierten - und letzten - Beispiels möchte ich einen weiteren Vergleich vornehmen. Ich beziehe mich auf eine Passage aus einem Korrespondentenfilm, der in der Sendung Weltspiegel wiederum in der ARD am 7.9.2003 ausgestrahlt wurde. ${ }^{8}$ In seinem ersten Teil berichtet er von

Für eine ausführlichere Interpretation des Kontexts dieses Ausschnitts vgl. Keppler (2009).

Für eine Analyse des gesamten Magazinfilms vgl. Keppler (2006, S. 230-237). 
einer Fahrt von Jordanien nach Bagdad. Ein Flüchtlingslager, der Grenzposten, ein Café, eine Raststätte sind die ersten Stationen. Es wird viel aus dem fahrenden Auto gefilmt; dazwischen sind Statements von Einheimischen geschnitten; dies verleiht der Eröffnung einen leicht epischen Rhythmus. Dann geht es weiter in Richtung Falludscha, der, wie es in dem Bericht schon vorher geheißen hatte, „Hochburg des Widerstands der SaddamAnhänger gegen die Amerikaner und die Hochburg der Wegelagerer entlang dieser Autobahn“. Auf diesem Weg wird das Fernsehteam Zeuge einer Schießerei zwischen der Polizei und einer Bande von Autodieben.

Weltspiegel (ARD), 7.9.2003

Thema: Mit US-Soldaten in Bagdad auf Patrouille

\begin{tabular}{|c|c|c|c|}
\hline Nr. & Bild & & Ton \\
\hline$\frac{01}{7}$ & $\begin{array}{l}\text { HN: Auto, } S^{\text {li, o }} \text {, dahinter drei Männer, } \\
\text { lachend zu Mann mit Maschinengewehr } \\
\text { (MG), im HG Gebäude }\end{array}$ & $\begin{array}{l}\mathrm{G}: \\
\mathrm{R}^{\mathrm{m}}:\end{array}$ & $\begin{array}{l}((\text { HG: Stimmen })) \\
\text { auch der neuen Polizei wird nicht viel } \\
\text { zugetraut }(-) \text { dabei haben sie vielleicht } \\
\text { den gefährlichsten Job im }\end{array}$ \\
\hline$\frac{02}{3}$ & $\begin{array}{l}\mathrm{T}, \mathrm{B}^{\mathrm{hk}}\left(\mathrm{S}^{\mathrm{li}}, \mathrm{S}^{\mathrm{re}}\right) \text { : Mann rennt von Straße in } \\
\text { Steppe, duckt sich, schaut nach hinten, } \\
\text { Kamera folgt ihm }\end{array}$ & $\begin{array}{l}\mathrm{G}: \\
\mathrm{R}^{\mathrm{m}}:\end{array}$ & $\begin{array}{l}\text { ((HG: Rauschen, Schüsse)) } \\
\text { ganzen Irak wie wir kurze Zeit später } \\
\text { heute nachmittag miterleben können }\end{array}$ \\
\hline$\frac{03}{5}$ & $\begin{array}{l}\text { A, } B^{\text {hk }}: \text { Mann vor geöffnetem Kofferraum } \\
\text { eines Autos, } S^{\text {li }}, S^{\text {re, o }}, F^{v} \text { in Kniehöhe, mehrere } \\
\text { Männer laufend }\end{array}$ & $\begin{array}{l}\mathrm{G}: \\
\mathrm{R}^{\mathrm{m}}:\end{array}$ & $\begin{array}{l}\text { ((HG: Rauschen, Schüsse)) } \\
\text { bei Falludscha geraten wir in eine } \\
\text { Schießerei zwischen Gangstern und } \\
\text { einer Polizeitruppe }\end{array}$ \\
\hline$\frac{04}{3}$ & $\begin{array}{l}\text { HT, } Z^{\text {h, l }} \text { : Mann mit MG rennt auf die } \\
\text { Kamera zu, schießt }\end{array}$ & $\begin{array}{l}\mathrm{G}: \\
\mathrm{R}^{\mathrm{m}}:\end{array}$ & $\begin{array}{l}\text { ((HG: Schüsse)) } \\
\text { Autodiebstahl. }\end{array}$ \\
\hline$\frac{05}{3}$ & $\begin{array}{l}\text { W, B }{ }^{\text {hk }} \text { : Straße, Leitplanke, dahinter mehrere } \\
\text { Personen in Wüste, zwei Autos, Luft } \\
\text { flimmert }\end{array}$ & $\begin{array}{l}\mathrm{G}: \\
\mathrm{R}^{\mathrm{m}}:\end{array}$ & $\begin{array}{l}\text { ((HG: Fahrtwind })) \\
\text { die drei Gangster werfen sogar mit } \\
\text { Granaten auf die schwach }\end{array}$ \\
\hline$\frac{06}{7}$ & $\begin{array}{l}\mathrm{T}, \mathrm{B}^{\mathrm{hk}} \text { : am } \mathrm{BR}^{\text {li }} \text { Polizist mit MG, Auto, zwei } \\
\text { Männer stehen vor einem liegenden Mann, } \\
\text { winken, Auto fährt schnell durchs Bild }\end{array}$ & $\begin{array}{l}\mathrm{G}: \\
\mathrm{R}^{\mathrm{m}}:\end{array}$ & $\begin{array}{l}((\text { HG: Schreie })) \\
\text { bewaffneten Polizisten }(-) \text { die } \\
\text { Verbrecher entkommen mit ihren } \\
\text { schnellen Autos (.) ein Polizist liegt } \\
\text { schwer verletzt am Boden }\end{array}$ \\
\hline$\frac{07}{7}$ & $\begin{array}{l}\text { HN, } F^{v, h k} \text { : fahrender Pickup, auf Ladefläche } \\
\text { der Verwundete, } \\
\text { Polizisten beugen sich über ihn, viel Blut um } \\
\text { sie herum }\end{array}$ & $\begin{array}{l}\mathrm{G}: \\
\mathrm{R}^{\mathrm{m}}:\end{array}$ & $\begin{array}{l}((\text { Fahrgeräusche '1sec laut, dann } H G)) \\
\text { verzweifelt versuchen seine Kollegen } \\
\text { ihn zu (.) reanimieren= vergeblich (.) } \\
\text { diese Polizeiautos sind viel }\end{array}$ \\
\hline$\frac{08}{13}$ & $\begin{array}{l}\text { T, } F^{v, ~ l i, ~ h k ~}: \text { Aufnahme aus dem Auto, im } \\
\text { Außenspiegel Blick auf Hütten }\end{array}$ & $\begin{array}{l}\mathrm{G}: \\
\mathrm{R}^{\mathrm{m}}:\end{array}$ & $\begin{array}{l}\text { ((HG: Fahrgeräusche)) } \\
\text { zu langsam haben kein Blaulicht und } \\
\text { keine Sirene }\end{array}$ \\
\hline
\end{tabular}




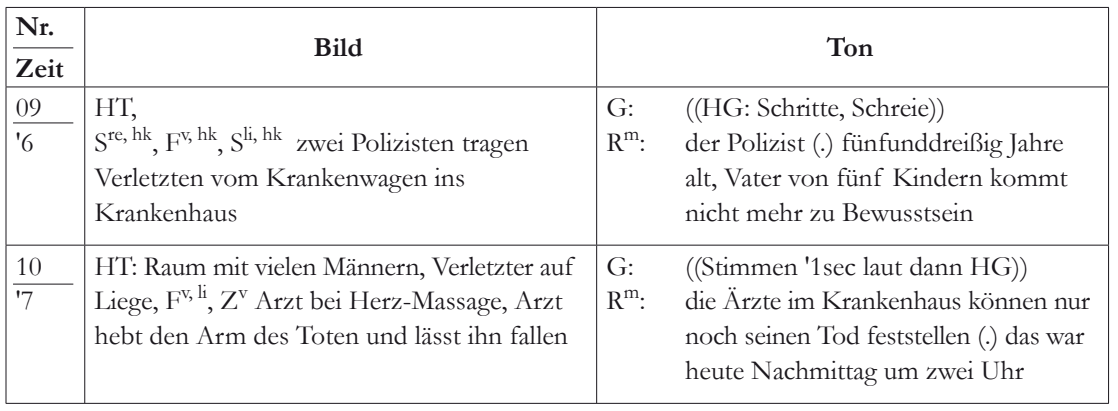

Liest man in diesem Transkript allein den von dem - in der Anmoderation der Sendung namentlich genannten - Korrespondenten Jörg Armbruster gesprochenen Text, so könnte man denken, dieser enthalte bereits alle relevanten Informationen über den berichteten Vorgang. So sehr dieser Kommentar aber auch unabhängig von den ihm unterlegten Bildern als Nachricht verstanden werden kann, der Filmbericht geht in seinen verbalen Mitteilungen keineswegs auf. Zunächst ist festzuhalten, dass der gesprochene Kommentar zu den im Bild sichtbaren Ereignissen hier eine deutlich andere Rolle spielt als derjenige am Beginn der besprochenen Sequenz aus GoodFellas. Dort wird - wie im Verlauf des Films immer wieder - die Stimme aus dem Off in das Geschehen der Spielhandlung eingeflochten, um ihr eine zusätzliche zeitliche Dimension zu geben und ihr vom Ende der erzählten Geschichte her eine vorgreifend melancholische Perspektive zu verleihen. Die kommentierende Rede fügt sich auf diese Weise in den Großrhythmus der fiktionalen (wenn auch auf wahren Begebenheiten basierenden) Erzählung ein (wie es mit anderen Mitteln durch die Klangkollage während der Fahrt durch Los Angeles in Zabriskie Point geschieht). In dem Magazinfilm dagegen wird nichts kunstvoll eingeflochten; der Bericht des Korrespondenten wird über das zusammengeschnittene Bildmaterial darüber gesprochen. Anders als in GoodFellas wird genau das kommentiert, was in den Bildverläufen zu sehen ist. Jedoch bedeutet dies kein Weniger an Interaktion zwischen Bild und Ton. Wir haben es hier lediglich mit anderen Korrespondenzen zwischen Bild und gesprochenem Text zu tun.

Für den Duktus dieser Kommentierung ist dabei zunächst die genaue Datierung äußerst wichtig. Der Film handelt von der gefährlichen Arbeit der Polizisten im Irak, „wie wir“ - gemeint ist das Team des Korrespondenten, angesprochen sind aber auch die Zuschauer, die hiervon noch am selben Tag im Fernsehen erfahren - „heute Nachmittag miterleben können" (E 02). Am Ende dieser Passage wird diese Datierung noch einmal ausdrücklich wiederholt; die Zuschauer sehen eine Szene, so der Reporter, die sich „heute Nachmittag um zwei Uhr“ ereignet hat (E 10). Durch die genauen zeitlichen Angaben, das Präsens, mit dem der Bericht eingeleitet wird und nicht zuletzt durch die Kameraführung - u.a. den sichtbaren Ein- 
satz einer Handkamera (E 03, 05, 07, 09) - wird ein hoher Anspruch auf Authentizität erhoben: Der Journalist ist dabei gewesen, als es auf dem Weg nach Bagdad zu tödlicher Gewalt gekommen ist. Der Umstand, dass der genaue Verlauf der Gewalthandlung in den Bildern nicht zu erkennen ist, widerspricht diesem Anspruch nicht, sondern bestätigt ihn vielmehr in ausgezeichneter Weise. Denn die plötzlich eingetretene Situation macht eine geordnete Darstellung ihres Verlaufs durch das von den Ereignissen überraschte und seinerseits bedrohte Team unmöglich. Man sieht einen Polizisten eine Straße entlang rennen (E 03), dann entnehmen weitere Polizisten Waffen aus ihrem Fahrzeug, einer von ihnen schießt eher planlos ins Weite (E 04), abseits der Straße sieht man einige Autos und Personen stehen (E 05), dann rückt der angeschossene Polizist ins Bild (E 06), über dessen blutigen Abtransport (E 07-09) in ein Krankenhaus und die dortige Feststellung seines Todes (E 10) abschließend berichtet wird.

Der entscheidende Punkt aber ist: Es müssen nach Kinostandards unbeholfene Bilder sein, die glaubhaft von einem Geschehen in der unmittelbaren Vergangenheit berichten. Denn die plötzlich eingetretene Situation, so kann jeder am Bildschirm es mitverfolgen, macht eine dramaturgisch wohlkalkulierte, aus dem Zentrum des Geschehens operierende Darstellung ihres Verlaufs unmöglich. Dass dies wir als Zuschauer dem Bildverlauf ansehen können, ist hier ein wesentlicher Teil der Botschaft, der das verbal Gesagte nicht allein illustriert, sondern mit großem Nachdruck visuell bezeugt. Auch hier, so meine ich daher, liegt ein nichthierarchisches Verhältnis von Bild und Ton vor. Der Korrespondent muss sich nicht auf das Hörensagen ungenannter Zeugen verlassen, sondern er hat mit eigenen Augen gesehen, was dort vorging, und er lässt es uns, die Zuschauerinnen und Zuschauer am Bildschirm, kraft der eingefangenen Bilder mit unseren Augen sehen. Diese Übertragung der Zeugenschaft leistet hier der bildliche Verlauf.

\section{III.}

Ich breche meine kleine Beispielreihe an dieser Stelle ab und komme zu meinen grundsätzlichen Überlegungen zurück. Ich habe zu Beginn die These vertreten, dass Bild und Ton in filmischen Erzeugnissen jeglicher Art gleichursprünglich an der Konstitution der in ihnen präsentierten Gehalte beteiligt sind. Dies, so hatte ich gesagt, ist gerade auch dort der Fall, wo eines dieser Elemente den filmischen Verlauf zu dominieren scheint. Diesem Schein war insbesondere die Interpretation des letzten Beispiels gewidmet, aber auch die Analyse der Dialogszene in Scorseses Film. Dabei hat sich gezeigt, dass das, was dominant zu sein scheint, in diesen beiden Fällen das gesprochene Wort, gar nicht allein dominant ist, ja mehr noch: es gar nicht allein dominieren kann. Freilich: Wenn dominieren in Szenen wie diesen bedeutet, als erstes aufzufallen, allein bereits wesentliche Informationen zu 
enthalten und in diesem Sinn die Führung der Wahrnehmungssteuerung zu übernehmen, dann kann man sagen, dass in dem Korrespondentenfilm und vielleicht auch in der kleinen Dialogszene aus GoodFellas das gesprochene Wort dominiert. Aber eben nur dann. Denn sobald man unter dem Dominieren des filmischen Tons gegenüber dem filmischen Bild - oder umgekehrt des Bildgeschehens gegenüber dem Klanggeschehen, wie es die Szene aus Zabriskie Point nahe legen könnte - eine Relation der einseitigen Abhängigkeit der einen gegenüber der anderen Dimension verstünde, läge man zuverlässig falsch. Erst recht läge falsch, wer ein solches Dominieren, wo es denn überhaupt gegeben ist, als ein Verhältnis der Determination begreifen würde. Denn so sehr Bild und Ton je für sich genommen wesentliche Informationen über das jeweils Dargebotene enthalten können, die Botschaft, Erzählung, Atmosphäre und Geste eines filmischen Produkts formulieren sie immer zusammen. Das ist es, was ich meine, wenn ich von einem nichthierarchischen Verhältnis von Bild und Ton im Kino und Fernsehen gleichermaßen spreche. Immer geschieht Modifikation des Bildes durch Text und Ton und umgekehrt; sobald wir von filmischen Prozessen sprechen, kann von einseitigen Abhängigkeiten keine Rede sein.

Doch gerade wenn dies zutreffend sein sollte, stellt sich sogleich eine andere Frage - diejenige nach dem Unterschied zwischen der Ästhetik des Kinofilms und derjenigen des Fernsehens. Denn die Standardauffassung lautet, dass die beiden Medien sich insbesondere an der Art der Dominanz von Bild und Ton unterscheiden. In einer Erörterung dieses Verhältnisses in seinem Buch über Visible Fictions beispielsweise geht John Ellis von einer „unterschiedlichen Ton/Bild-Balance“ in Kino und Fernsehen aus. „Im Fernsehen verankert gewöhnlich der Ton die Bedeutung, im Film hingegen das Bild" (Ellis 2001, S. 60). . Dies klingt genau wie die Fehldeutung, die ich gerade kritisiert habe. Interessanterweise jedoch fährt Ellis fort: „In beiden Fällen handelt es sich um eine Frage der Gewichtung und nicht um einfache Abhängigkeiten des einen vom anderen. In beiden Medien existieren Bild und Ton in einem Wechselverhältnis, sie treten nicht als getrennte Einheiten auf“" (ebd.). Diese für sich genommen einleuchtende Aussage ist allerdings mit dem zuvor geäußerten Gedanken einer konträren Verankerung der Bedeutung einerseits im Bild und andererseits im Ton nur schwerlich vereinbar.

Worin die strukturelle Differenz von Kino und Fernsehen stattdessen besteht, möchte ich abschließend kurz andeuten. Hier ist erstens der von Raymond Williams (1974) wirkungsmächtig analysierte Flow-Charakter der Fernseherfahrung zu nennen. Dieser ist dadurch gekennzeichnet, dass das Fernsehen seinen Zuschauern die seit längerem zunehmend genutzte Möglichkeit bietet, nicht so sehr einzelne Sendungen (einschließlich der

$9 \quad$ Vgl. ebd. S. 66: „Die unterschiedliche Gewichtung zwischen Sehen und Hören erzeugt eine qualitativ andere Beziehung zur Fernsehsendung. Nicht dass die Erfahrung weniger intensiv wäre als im Kino; sie hat vielmehr ihre eigene Form." 
gezeigten Spielfilme), sondern Segmente diverser Sendungen in einem beliebigen Wechsel zu verfolgen. Hier ist zweitens daran zu erinnern, dass das Fernsehen seinen Zuschauern stets - simultan wie sukzessiv - ein ganzes Kaleidoskop von Gattungen präsentiert, die in ausdrücklicher oder stillschweigender Interferenz auch dort miteinander verbunden bleiben, wo die Betrachter von Anfang bis Ende bei einer Sendung verweilen (vgl. Keppler 2006, S. 82 ff.). Drittens spielt - durchaus! - der Ton eine besondere Rolle in der Fernsehkommunikation. In einer subtilen Untersuchung über den Television Sound hat Rick Altman diesem die Funktion zugeschrieben, die oft durch vielerlei häusliche Aktivitäten abgelenkten Zuschauer ,zum Bild zurückzurufen“ (Altman 2001, S. 400). Das Fernsehen, sagt Altman, gibt den Zuschauern, auch wenn sie in der Küche oder anderswo im Haushalt zugange sind, „das Gefühl (...), alles wirklich Wichtige“ werde im Fernsehen durch den Ton ,angekündigt“" (Altman 2001, S. 394). Ankündigung aber meint hier keineswegs, dass im Fernsehton tatsächlich alles „,wirklich Wichtige" zum Ausdruck käme, dass also der Gehalt von Sendungen, die sich so bemerkbar machen, vorwiegend in ihrer akustischen Dimension verankert wäre. Vielmehr gilt der von Altman analysierte Lockruf des Fernsehtons gerade der Einheit von Bild und Ton, deren Attraktionen auch die vom Schauen abgelenkten Zuschauer erreichen sollen. In diesem Sinn - aber auch nur in diesem - macht der Ton weniger $i m$ als vielmehr beim Fernsehen durchaus eine besondere Musik.

\section{Anhang: Transkriptionssystem}

\section{Beschreibungsinventar für das tabellarische Filmprotokoll und Erläuterung der Abkürzungen für visuelle und auditive Elemente}

\section{Visuelle Dimension}

1.1 Kameraoperationen

1.1.1 Einstellungsgrößen

D Detailaufnahme: eng begrenzter Bildausschnitt, Großaufnahme von Gegenständen.

G Großaufnahme: Konzentration auf den Kopf / das Gesicht bis zum Hals.

N Nahaufnahme: Brustbild; Darstellung von Personen vom Kopf bis Mitte des Oberkörpers; neben den mimischen werden auch gestische Elemente sichtbar. Oft für die Darstellung von Diskussionen und Gesprächen verwendet.

HN Halbnah: Darstellung Kopf bis zur Taille; Aussagen über die unmittelbare Umgebung der abgebildeten Personen werden möglich. Oft zur Darstellung von Personen im Dialog. 
HT Halbtotale Einstellung: Menschen von Kopf bis Fuß, oft zur Darstellung von Personengruppen verwendet.

T Totale: ganze Person mit Umgebung; gibt einen Überblick über den Handlungsraum.

1.1.2 Kamerabewegungen

Z Zoom

F Fahrt

S Schwenk

TS Tiefenschärfe

hk Handkamera

B Bewegte Kamera

Richtung der Kamerabewegung (jeweils hochgestellt hinter Kamerabewegung)

$\begin{array}{llll}\mathrm{v} & \text { nach vorn } & \mathrm{o} & \text { nach oben } \\ \mathrm{h} & \text { nach hinten } & \mathrm{u} & \text { nach unten } \\ \mathrm{li} & \text { nach links } & \text { re } & \text { nach rechts }\end{array}$

1.1.3 Kameraperspektive (in Klammer hinter Einstellungsgröße)

AS Aufsicht / Vogelperspektive

US Untersicht / Froschperspektive

1 leicht

s stark

1.2 Schnitt

Ü Überblende: Einzelbilder von Einstellung A überlappen mit Einzelbildern von Einstellung B

- Schnitt: auf letztes Einzelbild von Einstellung A folgt unmittelbar erstes Einzelbild von Einstellung B

1.3 Elemente der Bildkomposition

\subsubsection{Insert}

Inbalt des Inserts kursiv; Besonderbeiten (Groß- / Fettschrift etc.) werden übernommen 
Die wechselseitige Modifikation von Bildern und Texten in Fernsehen und Film

1.3.2 Lokalisierung von Personen oder Gegenständen im Raum

$\begin{array}{llcl}\text { VG } & \text { Vordergrund } & \text { BR } & \text { Bildrand } \\ \text { HG } & \text { Hintergrund } & \text { BH } & \text { Bildhälfte } \\ \text { BM } & \text { Bildmitte } & & \end{array}$

\section{Akustische Dimensionen}

2.1 SprecherInnen

NN bei bekannten SprecherInnen Abkürzung des Vornamens und des Nachnamens

(A) SprecherIn ist vermutlich SprecherIn A

( ) SprecherIn nicht identifizierbar

2.2 Gesprochene Sprache (wird nach Bedarf erweitert nach den Regeln des GAT-Transkriptionssystems für gesprochene Sprache (vgl. Selting et al. (1998))

(.)

$(-),(--),(--)$

(2)

[

ja:::

?

,

;

.

$=$

hm, ja, nee

$\mathrm{hm}=\mathrm{hm}, \mathrm{ja}=\mathrm{a}$, nei $=$ ein

,hm'hm

waru'

.h, .hh, .hhh

h, hh, hhh
Mikropause unter 0.25 Sek. Dauer

geschätzte Pausen von ca. 0.25 - 0.75 Sek. Dauer

geschätzte Pause in Sekunden ab Pausendauer von ca. 1 Sek.

Beginn einer Überlappung bzw. gleichzeitiges Sprechen

Dehnung; Anzahl der Doppelpunkte entspricht Länge der Dehnung

stark steigende Intonation

schwach steigende Intonation

schwach fallende Intonation

stark fallende Intonation

Verschleifung innerhalb von Einheiten, z.B. und=äh

einsilbige Rezeptionssignale

zweisilbige Signale

mit Glotalverschlüssen, meistens verneinend

Abbruch eines Wortes oder einer Äußerung

hörbares Einatmen, je nach Dauer

hörbares Ausatmen, je nach Dauer 
a(h)ber

((lacht))

()

(und)

$<<\mathrm{f}>>$

$<<\mathrm{ff}>>$

$<<\mathrm{p}>>$

$<<\mathrm{pp}>>$
Aspirationslaut oder Lachpartikel beim Sprechen

Umschreibung von para-linguistischen Information (Lachen, Husten, Räuspern etc.), äußere Klammer kennzeichnet Anfang und Ende

unverständliche Textpassage

vermuteter Wortlaut, nicht sicher rekonstruierbar

forte, laut, (z.B. $<<$ f $>$ Hi:lfe: $>$ )

fortissimo, sehr laut

piano, leise

pianissimo, sehr leise

Es ist wichtig, hier zu beachten, dass Satzzeichen in den Filmprotokollen nicht im üblichen Sinn zur Interpunktion verwendet werden, sondern dazu, steigende bzw. fallende Intonation am Satzende zu markieren! Um die Lesbarkeit der Filmprotokolle zu verbessern, haben wir in Abweichung von den GAT-Konventionen im gesprochenen Text die Groß- und Kleinschreibung beibehalten; dies betrifft jedoch nicht die Markierung von Satzenden bzw. -anfängen.

\section{Literatur}

Adelmann, Ralf et al. (Hg.) (2009): Grundlagen zur Fernsehwissenschaft: Theorie, Geschichte, Analyse. Konstanz.

Albrecht, Gerd (1964): Die Filmanalyse - Ziele und Methoden. In: Everschor, Franz (Hg.): Filmanalysen 2. Düsseldorf, S. 233-270.

Altman, Rick (2001): Fernsehton. In: Adelmann (Hg.), S. 388-412.

Bonfadelli, Heinz (2002): Medieninhaltsforschung: Grundlagen, Methoden, Anwendungen. Konstanz.

Deleuze, Gilles (1991): Das Zeit-Bild. (= Kino 2). Frankfurt/M.

Ellis, John (2001): Fernsehen als kulturelle Form. In: Adelmann (Hg.), S. 44-73.

Goodman, Nelson (1995): Sprachen der Kunst. Frankfurt a.M.

Grimm, Jürgen (2006): Super Nanny. Ein TV-Format und sein Publikum. Konstanz.

Heritage, John/Clayman, Steven E./Zimmerman, Don H. (1988): Discourse and message analysis. The micro-structure of mass media messages. In: Hawkins, Robert P./Wiemann, John M. / Pingree, Suzanne (Hg.): Advancing communication science: Merging mass and interpersonal processes. London, S. 77-109.

Keppler, Angela (2005): Die Einheit von Bild und Ton. Zu einigen Grundlagen der Filmanalyse. In: Mai, Manfred/Winter, Rainer (Hg.): Das Kino der Gesellschaft - die Gesellschaft des Kinos. Interdisziplinäre Positionen, Analysen und Zugänge. Köln. S. $60-78$. 
Keppler, Angela (2006): Mediale Gegenwart. Eine Theorie des Fernsehens am Beispiel der Darstellung von Gewalt. Frankfurt a.M.

Keppler, Angela (2009): Das Gesagte und das Nichtgesagte. Was die Dramaturgie politischer Talkshows zeigt. In: Girnth, Heiko/Michel, Sascha (Hg.): Multimodale Kommunikation in Polit-Talkshows. [Ersch. demn.].

Merten, Klaus (1995): Inhaltsanalyse: Einführung in Theorie, Methode und Praxis. 2., verb. Aufl. Opladen.

Reichertz, Jo (2000): Die frohe Botschaft des Fernsehens. Kulturwissenschaftliche Untersuchung medialer Diesseitsreligion. Konstanz.

Selting, Margret et. al. (1998): Gesprächsanalytisches Transkriptionssystem. In: Linguistische Berichte 173, S. 91-122.

Williams, Raymond (1974): Television, technology and cultural form. London. 



\title{
Christofer Jost / Klaus Neumann-Braun / Axel Schmidt
}

\section{Bild-Text-Ton-Analysen intermedial - am Beispiel von Musik(video)clips}

\begin{abstract}
Der Musikclip gehört seit den 1980er Jahren zum Forschungsbereich diverser Disziplinen und gilt Vielen als intermediales Phänomen schlechthin. Als problematisch erweist sich allerdings nach wie vor, dass das klangliche Material des Clips, populäre Musik, eine Herausforderung nicht nur für die Musikwissenschaften darstellt - greifbar wird dies mit Blick auf die anhaltenden Diskussionen um einen adäquaten Begriff der populären Musik. Darüber hinaus gilt Musik allgemein als ,Sonderfall' für den Bereich der Medien-, Sprach- und Kulturwissenschaften, da an ihr weder rein medienästhetische noch kommunikations- und informationstheoretische Begriffe in ausreichender Weise greifen. Die Entwicklung eines transdisziplinär nachvollziehbaren Objektverständnisses des Musikclips bleibt daher desiderabel.

Der Beitrag zum Thema „Bild-Text-Ton-Analysen“ resultiert aus einer intensivierten Begegnung von Medienwissenschaft und Musikwissenschaft. Im Artikel wird die Konstitution von Bedeutung im intermedialen Zusammenspiel von Sprache/Text, Stimme und Musik fokussiert. Dies geschieht auf Grundlage einer näheren Bestimmung der Analysekriterien, die im Hinblick auf den speziellen Fall des popmusikalischen Umgangs mit Sprache erforderlich sind. Ziel ist es, die Bedeutungssedimente von vokaler Performanz im Kontext von populärer Musik offenzulegen. Für die Betrachtung des Musikclips ist dies ein wesentlicher Zwischenschritt. Anhand der Darstellung der klanglich-materiellen Vorprägungen gilt es, die Möglichkeitsbedingungen der (nachträglichen) intermedialen Transformation von Sprache auf die Bildebene auszuloten. In finaler Wendung ist es dann möglich, das inter- bzw. plurimediale Amalgam von Text-Stimme-Musik als Generator von Bedeutungsüberschüssen einzufassen.
\end{abstract}

\section{Einleitung}

Im Rahmen unseres Basler Forschungsschwerpunkts ,Populärkulturanalysen' widmen wir uns bereits seit langer Zeit der Untersuchung des audiovisuellen Klein-Formats Musikvideoclip. Wir haben uns zum einen mit dem Aspekt der Distribution von Clips, also dem Musikfernsehen (MTV, VIVA u.a.) beschäftigt. Dieses hat sich in den vergangenen Jahren in gravierender Art und Weise weiter entwickelt. Das klassische Umfeld des Fernsehanbieters MTV wurde programmlich stark verändert: MTV ist inzwischen zu einem TV-Sender für verschiedenste Jugend-affine TV-Angebote wie Soaps, Reality-Serien, Comics usf. geworden (offline) mit einem geradezu radikal ausgebauten Netzangebot (online) (für eine aktuelle Marktsichtung siehe Schmidt/Neumann-Braun/Autenrieth 2009). 
Zum anderen haben wir uns mit den Clips selbst beschäftigt und Produktanalysen ${ }^{1}$ durchgeführt. Diese haben sich in der Hauptsache auf die Aspekte Bild und Text bezogen und die Rekonstruktion von Orientierungsund Deutungsmustern ${ }^{2}$ - beides soziologische Termini - zum Ziel gehabt. Methodisch wurden die Songtexte auf texthermeneutischer Methodengrundlage interpretiert, sodann die Bilder der Clips: Kurz gesagt wurde dabei ein Gesamtablaufprotokoll erstellt, es wurden einzelne Clip-Teilsequenzen identifiziert und über das Verfahren von Schlüsselbildern, also einzelnen Stills, bildhermeneutisch analysiert. In einem nächsten Schritt wurden die Ergebnisse der Text- bzw. Bildanalyse in Beziehung gesetzt mit der Intention, den intermedialen Zusatznutzen der Verschränkung von Text und Bild zu bestimmen. Die Kernfrage liegt auf der Hand: Welcher Mehrwert ergibt sich daraus, dass ein Song nicht nur zu hören sondern (dabei) auch zu sehen ist?

Recht stiefmütterlich behandelt wurde bei diesem Vorgehen leider der Ton, was - vorsichtig formuliert - recht unglücklich ist, da bekanntlich in Clips bereits vorliegende Songs bebildert werden. In der Regel kreiert ein Musiker einen Song, der in der Folge von einem Regisseur visuell ,umgesetzt $^{6}$ wird. Ein Song vereint also die beiden Elemente Text und Ton, die ihrerseits im Clip durch ein drittes Element, das Bild/die Bilder, erweitert werden. Und mehr noch: Der Songtext wird nicht im Medium der Schriftlichkeit präsentiert, also nicht als zu lesender Text, sondern er wird vorgetragen, gesungen, gesprochen - jedenfalls , performed'. Clips sind also recht komplexe Phänomene - wie komplex wird im Weiteren noch genauer vorzustellen sein.

Es dürfte mit diesen wenigen Ausführungen bereits deutlich geworden sein, dass die bisherigen Analysen (eigene wie fremde) alles andere als zufrieden stellend zu bewerten sind - im Gegenteil: Sie sind deutlich unterkomplex und dies in zweierlei Hinsicht: Erstens werden die einzelnen Elemente des Clips für sich allein genommen nicht hinreichend untersucht - als Desiderat lässt sich hier insbesondere der Ton benennen. Zweitens wird der spezifischen Komponente der Intermedialität von Bild - Text Ton kaum hinreichend Beachtung geschenkt.

Unser aktuell durchgeführtes Forschungsprojekt, ${ }^{3}$ vom Schweizerischen Nationalfond finanziert, widmet sich genau diesem Ziel - nämlich der Entwicklung eines Analyseinstrumentariums zu einer hinreichend umfassen-

Vgl. Neumann-Braun (Hg.) (1999).

Vgl. grundlegend Oevermann (2001a und b), Lüders (1991), Lüders/Meuser (1997), Meuser/Sackmann (Hg.) (1991).

3 Das Forschungsprojekt trägt den Titel „Bild-Text-Ton-Analysen am Beispiel der Gattung Videoclip. Entwicklung eines integrierten Analyseinstrumentariums zur Interpretation von Musikvideos" und wird von Prof. Dr. Klaus Neumann-Braun am ifm Basel geleitet (Laufzeit 07/2008 bis 07/2011; SNF-Aktenzeichen: 100012-119936/1). Mitwirkende Forschungsmitarbeiter sind Daniel Klug und Dr. Christofer Jost sowie Dr. Axel Schmidt. Wir danken Daniel Klug und Arnulf Deppermann für instruktive Diskussionshinweise sowie Vanessa Kleinschnittger für die Durchsicht des Manuskripts. 
den Bild-Text-Ton-Analyse audiovisueller Formate, das insbesondere in der Lage ist, das intermediale Verschränkungsverhältnis und dessen Wirkungen zu erhellen.

Der Rahmen dieses Artikels ist eng gesteckt, eine umfassende Einlösung dieses Desiderats ist naheliegenderweise an dieser Stelle nicht möglich. Wir wollen uns deshalb beschränken und uns erstens ,nur ${ }^{6}$ mit dem Verschränkungsverhältnis von Musik und Sprache beschäftigen - ein Verhältnis, dem innerhalb des Clips eine besondere Rolle zukommt. Zweitens stellen wir an dieser Stelle noch nicht das soeben annoncierte Methodeninstrumentarium vor sondern vielmehr ein Begriffsinventarium, das insbesondere an der Schnittstelle von Musik- und Kulturwissenschaft die Relation von Musik und Sprache kriterial einzuholen bemüht ist. Diese gleichsam auf den AudioBereich des Clips fokussierten Überlegungen reflektieren dieses Thema drittens aus der Perspektive der Medien- und Kommunikationswissenschaft sowie der Musikwissenschaft, also relevanten Nachbardisziplinen der Sprachwissenschaft.

\section{Zur Bestimmung des Verhältnisses von Musik und Sprache im Musikvideoclip}

Zur hinführenden Bestimmung des Verhältnisses von Musik und Sprache im Musikclip sollen zunächst drei zusammenbängende Fragekomplexe behandelt werden, welche zentral für unsere fokussierte Thematik sind und diese zudem einleitend verorten sollen:

- Welchen Konstitutionsprinzipien folgen Musikclips?

- Inwiefern sind Musikclips intermedial?

- Und: Inwiefern kommt dem Verhältnis von Musik und Sprache innerhalb von Musikclips eine besondere Rolle zu?

Begonnen werden soll mit folgender Ausgangsbeobachtung: Wer sich mit Musikclips - zunächst verstanden als audiovisuelle Medienprodukte, welche einen Popsong zu Werbezwecken visualisierend begleiten und i.d.R. via TV-Ausstrahlung distribuiert werden ${ }^{4}$ - beschäftigt, stellt recht schnell dreierlei fest:

- Es handelt sich erstens um semiotisch komplexe Phänomene (mehrere Zeichensysteme und Gestaltungstraditionen ${ }^{5}$ sind in unterschiedlichen Bezugsverhältnissen involviert), welche

$4 \quad$ Weitere Definitionen des Musikclips finden sich bei Bergermann (2003), Keazor/Wübbena (2005), Weibel (1987) und Neumann-Braun/Schmidt (1999).

$5 \quad$ Lull (1987) betont, dass Clips als Synthesen aus verschiedenen (populären) Kunstformen zu verstehen sind: Sie beinhalten nicht nur die visuelle Präsentation eines Songs, sondern darüber hinaus Tanz, Choreographie, Schauspielerei, Narrationen/Storys, Mode, Kostümierung/Styling, Beleuchtung, Starinszenierungen und visuelle Techniken (etwa Effekte und Animation). 
- zweitens gezwungen sind, ein künstlerisches Konzept auf kleinstem Raum zu entwickeln, ${ }^{6}$ was sie

- drittens häufig dadurch erreichen, dass sie mit traditionellen Darstellungskonventionen brechen (etwa Erzähltraditionen oder filmischen Konventionen).

Clips wirken daher häufig dicht, überladen und zusammenhangslos - letzteres insbesondere dann, wenn man auf die Bildebene fokussiert und diese an üblichen Film- bzw. Erzählcodes misst (also etwa minimale Anforderungen an eine Geschichte, Kausalität/plot, Aufbau einer fiktionalen, diegetischen Welt etc.). Kobärenz erhält die Bildebene des Clips u.a. durch den Rekurs auf den Akt der Klangerzengung bzw. die musikalische Aufführungspraxis, also unter Rückgriff auf eine durch die Alltagserfahrung vermittelte (soziale) Handlung.7 Diese ist mit Blick auf das dem Clip zugrunde liegende Primärprodukt, nämlich den Popsong (als, Werk') bzw. den Tonträger (als Speichermedium) bzw. die Schallaufzeichnung (als technisch-apparativer Speicherprozess) allerdings weder sichtbar noch rückholbar und das aus drei Gründen: Erstens weil die realweltliche Klangerzeugung bzw. Aufführung als einmaliges Ereignis unwiederbringlich Vergangenheit geworden ist (Flücbtigkeit); zweitens bleibt die aufgezeichnete Musik immer dieselbe, ist und kann also nicht Resultat einer zukunftsoffenen (sozialen) Handlung im Hier und Jetzt sein (Reproduzierbarkeit); ${ }^{8}$ und drittens wird Akustisches und Visuelles qua Speichermedium zeitlich und räumlich entkoppelt (Effekt der Phonographie). ${ }^{9}$ Dennoch ist die musikalische Aufführungspraxis sehr wohl imaginierbar oder - stärker formuliert - wird durch Musik und insbesondere die Popmusik, welche erst in und durch Aufführungspraxen lebt, imaginativ auch forciert. ${ }^{10}$

$6 \quad$ Die meisten Clips bewegen sich in einem Zeitrahmen von 3-5 Minuten und sind damit an die übliche Länge eines Popsongs gebunden. Diese für ein audiovisuelles Produkt relative Kürze wurde in der Literatur immer wieder als konstitutives Merkmal von Musikclips betont und zwingt die Clipregisseure - grob gesprochen - zu Strategien der Komprimierung (was im Einzelfall höchst Verschiedenes bedeuten kann, nämlich etwa Bilder nur assoziativ zu verketten, ikonisch aufgeladene (Schlüssel-)Bilder zu bemühen, auf narrative oder gegenständliche Bilder ganz zu verzichten, mit Redundanzen zu arbeiten u.v.m.).

7 Vgl. Wulff (1999).

$8 \quad$ Sie bedarf daher als phonographische Musik zunächst keiner Interpretation (sondern nur das Drücken einer play-Taste), ganz im Gegensatz zur Aufführung von Kunstmusik, welche immer als Interpretation eines Werks begriffen wird (vgl. Helms 2003b).

9 Dies fundiert die sog. acousmatische Erfahrung (Großmann 1998, S. 110) bzw. acousmatischen Sounds. Chion fasst diese (unter Rekurs auf Pierre Schaeffer) als „sounds one hears without seeing their orginating cause" (1994, S. $71 \mathrm{ff}$.) und versteht die betreffenden Medien als „acousmatic media“, das sind ,all which transmit sounds without showing their emitter“ (ebd.). Visualisierung respektive ,Acousmatisierung' begreift Chion als (In-)Visibilisierung der Klangquelle. Dies geschieht im Musikclip, wenn die Darstellung zwischen Performance und NichtPerformance hin- und herwechselt (allerdings auch im Falle der Performance auf simulativer Ebene; siehe unten).

10 Rösing (2003) unterscheidet systematisch verschiedene Möglichkeiten audiovisueller MusikWahrnehmung respektive verschiedene Formen der Verkopplung von Auditivem und Visu- 
Grundlage hierfür sind in und durch Alltagserfahrungen (Welt- und Sozialitätsidealisierungen) fundierte ,Normal- b₹w. Ursprungsformen ${ }^{611}$ realweltlicher Musikaufführungen, welche als rezeptionslenkendes Hintergrundwissen der audiovisuellen Wahrnehmung von Clips fungieren und im Falle von Musikclips die Form annehmen, dass a) gehörte Musik durch Musiker erzeugt wird (Musik wird bewirkt; Kausalität/Notwendigkeit) und b) diese Musik typischerweise in der Lage ist, musikrezeptionstypisches Anschlussverhalten (etwa Tanz) hervorzubringen (Musik bewirkt etwas; Möglichkeit/Wahrscheinlichkeit/Typikalität). Hieraus ergibt sich ein für die Konstitution des Clips konstitutiver Effekt. Musike als Klangereignis lässt als Bewirktes Bilder ibrer Erzeugung respektive Auffübrung (Performance) und als Bewirkendes Bilder typischen Rezeptionsverbaltens (etwa Tanz, konzeptionell: Choreographie), natürlich" bzw. ,tonaffin erscheinen (siehe Schaubild 1 und 2), so dass aufgrund der aus der natürlichen Wahrnehmung herrührenden Erfahrung visualisierte klangerzeugende Ereignisse kausal interpretiert werden (also gewissermaßen ,naturalisiert ${ }^{6}$ ) und daher die visuelle Komponente ,Musik-Performance‘ im Musikclip simulativ musikerzengend eingesetzt wird. Mit anderen Worten: Durch die Darstellung einer Musik-Performance im Clip entsteht der Eindruck, es handle sich um eine Dokumentation der Aufführungspraxis bzw. gar um eine (zumindest das akustische) Medium erzengende Handlungswiedergabe. ${ }^{12}$ Oder um mit Helms zu sprechen: „Das Video gibt vor [...] Musik-Machen beobachtbar zu machen. ${ }^{\text {" } 13}$ All dies steht Musikclips als strukturelles Potenzial der Be-

ellem im Rahmen von Musikrezeption, welche bei der natürlichen Einheit musikerzeugender Praxis ihren Ausgang nimmt (Konzert), unterschiedliche Stufen der Imagination durchläuft, um schließlich bei ,realen' (also nicht bloß imaginierten) Visualisierungen a) im Zuge der Entkopplung von Original-Ton und visueller Wahrnehmung (etwa Reisemusik), b) im Rahmen von Primärmedien (Bühnenmusik wie im Falle von Ballet, Oper etc.) sowie c) im Rahmen audiovisueller Produkte (Film, Musikclip) anzukommen.

11 Vgl. hierzu Großmann (1998, S. 109).

12 Helms (2003a) folgend lässt sich zeigen, dass Clips wie Handlungswiedergaben wirken. Denn: Durch die Simulation einer Musik-Performance, die gerade aufgezeichnet wird (erste Simulationsebene), entsteht zudem der Eindruck, dass diese Performancehandlung zugleich auch das Medium selbst, also den Clip, erzeugt (zweite Simulationsebene). Obwohl beides - sowohl die den Clip erzeugenden Handlungen (also die Kamerahandlungen des ,korporierten Regisseurs' i.S.v. Reichertz $(1992,2005)$ ) als auch die Materialität des Mediums (Magnetband, Datei, Übertragung etc.) - visuell nicht zugänglich ist. „Das Video gibt vor - augenfälliger als die Schallaufzeichnung -, Musik-Machen beobachtbar zu machen. Dagegen entzieht sich dem Beobachter das Ding, das Material der Aufzeichnung" (Helms 2003a, S. 102). Und weiter: „Die Unzulänglichkeit der dinglichen Gestalt des Mediums lässt den Eindruck entstehen, die am Bildschirm oder Lautsprecher beobachtete Handlung sei identisch mit der Handlung des Musikers, die das Medium erzeugte. Es entsteht die Vorstellung einer ,Aufzeichnung"“" (ebd., S. 103).

13 Dieser Eindruck wird durch einen weiteren, technischen (Zwischen-)Schritt der Medienentwicklung fundiert: Während Phonographie und Photographie das Akustische und Visuelle trennten, isolierten und in Daten unterschiedlicher Physikalität zerlegten (vgl. Kittler 1999), überwand der Tonfilm durch entsprechende optoelektrische Verfahren (Lichtton) diese Trennung wieder. Auf diese Weise wurden Aufnahmen möglich, die sowohl das Akustische 
deutungsgenerierung prinzipiell zur Verfügung und kommt umso stärker zur Geltung, je mehr und ,natürlicher' (respektive unartifizieller) ein Clip mit Performance- respektive Choreographie-Anteilen arbeitet. ${ }^{14}$

\begin{tabular}{|c|c|c|c|c|c|}
\hline Musikauffiubrung (Bild) & $\rightarrow$ & $M u$ & $i k$ (Ton) & $\rightarrow$ & Tanz (Bild) \\
\hline Ursache & & $\begin{array}{l}\text { Wirkung } \\
\text { (Bewirktes) }\end{array}$ & $\begin{array}{c}\text { Ursache } \\
\text { (Bewirkendes) }\end{array}$ & & Wirkung \\
\hline
\end{tabular}

Schaubild 1: Musik als Bewirkendes und Bewirktes

Wählt der Clip allerdings als visuelle Darstellungsinhalte weder Performance ${ }^{15}$ noch Tan ${ }^{16}$ und hält zudem die visuelle Binnenstruktur ungegenständlich und nonnarrativ $v^{17}$ (also etwa im Falle von Graphiken), so entsteht der Eindruck eines invertierten Bild-Ton-Verbältnisses. ${ }^{18}$

Dieses kommt - grob gesprochen - dadurch zustande, dass die natürliche Wahrnehmungseinheit der Musikaufführung aufgelöst und die dadurch entstehende ,visuelle Leerstelle ${ }^{619}$ mit zunächst, tonfremd' erscheinenden Bildern aufgefuillt wird, welche sich mehr oder weniger weit von der (imaginierbaren) ,natürlichen' Wahrnehmungssituation Musik erzeugender Musiker entfernen (weit: Konzeptclip; nah: Performance-Clip) und aufgrund der simultanen Darbietung im Audiovisuellen zwangsläufig auf die Musik bezogen werden: Da das Visuelle nun nicht mehr den Ton zu erzeugen scheint (der musizierende Musiker ist verschwunden) und auch nicht mehr als typische Folge der Musik gelesen werden kann (es tanzt auch niemand), scheint nun in Ermangelung einer ,natürlichen Erklärung' in umgekehrter Weise der Ton das Bild hervorzubringen bzw. das Bild erscheint als Visualisierung des Tons. Aufgrund dessen sind Musikclips in besonderer Weise in der Lage mit (populärkulturellen) Versatzstücken ${ }^{20} \mathrm{zu}$ arbeiten, also sinnhafte Zusammenhänge bloß fragmentarisch anzudeuten und assoziativ zu verketten, da solche als zunächst

als auch Visuelle einer ,realen' Situation synchron fixierten, kurz: Aufzeichnungen im Sinne von Dokumentationen (footage). Diese neuerliche mediale ,Normalität' (,Film und Fernsehen') macht sich der Musikclip zunutze, um sie seinerseits wieder zu verfremden.

14 Dass Performance(-anteile) in Clips unterschiedlichen Graden der Verfremdung unterliegen und dieses Kriterium als systematischer Ausgangspunkt einer Typologisierung von Musikclips gelten kann, hebt insbesondere Altrogge (2000) hervor.

15 Siehe Beispiel 1 (Still aus Green Day, „American Idiot").

16 Siehe Beispiel 2 (Still aus Gwen Stefani, „Hollaback Girl“).

17 Siehe Beispiel 3 (Still aus Gnarls Barkley, „Crazy“).

18 In besonders radikaler Form gilt dies im Rahmen oszilloskopischer Anordnungen, da das Visuelle in diesem Fall eine technisch-physikalische Transformation des Tons darstellt, also im Peirce'schen Sinn als indexikalisches Zeichen zu verstehen wäre, wodurch das Bild nicht bloß so wirkt, als sei es vom Ton hervorgebracht, sondern es in einem physikalischen Sinn auch tatsächlich ist.

19 Vgl. Großmann (1998, S. 110).

20 Etwa Zeitungsbilder, Portraits/Konterfeis, Bildikonen, konventionalisierte Bildfolgen, popmusikalische Aufführungen als eingestreute Sinnfragmente etc. 
,tonfremd' wahrgenommenen Bilder eben unter der ästhetischen Prämisse der Inversion ,gelesen' werden. ${ }^{21}$ Diese Merkmale der Zitativität, Assoziativität und Inversion mach(t)en den Musikclip zu einem Paradefall der sich etwa zur gleichen Zeit (1980er Jahre) etablierenden Intermedialitätsforschung.

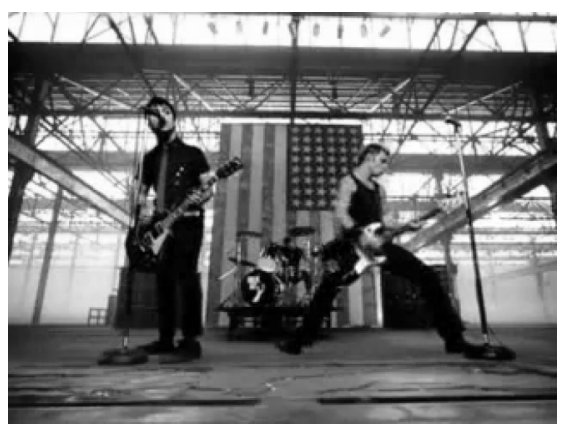

Beispiel 1: Green Day - „American Idiot“

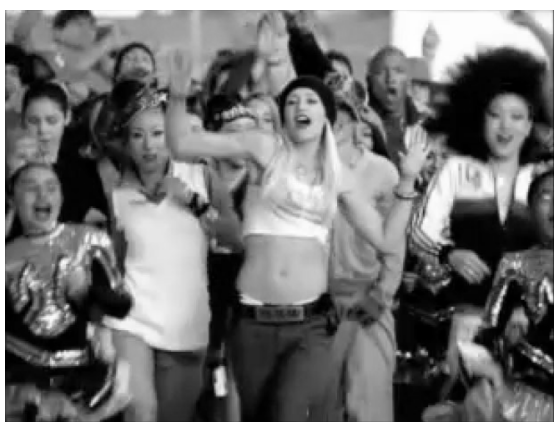

Beispiel 2: Gwen Stefani - „Hollaback Girl“

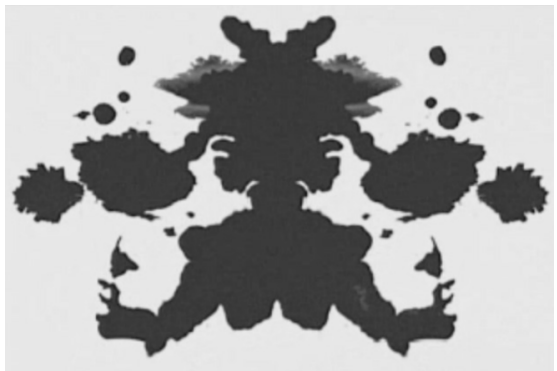

Beispiel 3: Gnarls Barkley - „Crazy“

$21 \quad$ Die meisten Clips zeigen durch Performance- und Choreographieanteile auch, was näher läge bzw. erwartbarer/,natürlicher' wäre und etablieren damit einen archimedischen Punkt, wodurch ,tonfremde` Bilder als ,Abweichungen` von einem Idealtypus (im Weber'schen Sinn) markiert werden. 
Versucht man nun vor diesem Hintergrund Musikclips mit Blick auf gängige Intermedialitätssystematiken zu verorten, ${ }^{22}$ so lässt sich zeigen, dass - neben vielen anderen möglichen Berührungspunkten - eine für systematische Zwecke besonders bedeutsame, strukturelle Eigenheit des Musikclips ins Auge sticht, nämlich: Die prototypisch als intermedial begriffenen Phänomene im Clip entstehen vornehmlich im Verbältnis Bild-Ton $(=A V),{ }^{23}$ welches jedoch seinerseits auf einem basaleren, intermedialen Verbältnis der Tonspur selbst beruht, nämlich dem Verbältnis von Sprache und Musik in der musikalischen Performance. Dass diese für Musikclips grundlegende Beobachtung plausibel und für das vorliegende Thema relevant ist, lässt sich mit Blick auf einschlägige Erkenntnisse der Intermedialitätsforschung wie folgt zeigen:

Erstens lässt sich unschwer erkennen, dass Musikclips zum einen plurimediale Phänomene sind, d.h. - der Systematik Rajewskys (2002) folgend konventionell als distinkt wahrgenommene Medien sind, die mehrere Zeichensysteme involvieren; aber zum anderen aufgrund ihrer - historisch betrachtet - relativen Neuartigkeit ebenso gut als intermediale Phänomene im Sinne einer Medienkombination begriffen werden können, d.h. als Verschränkung mehrerer Medien und/oder Symbolsysteme (also etwa Musik und Filmbild oder Bildlichkeit und Oralität usw.), welche allesamt im Endprodukt material präsent sind.

Zweitens lässt sich engführend auf das $A V$-Verbältnis unschwer zeigen, dass oben angedeutete Strukturmerkmale des Musikclips Korrespondenzen mit gängigen Konzepten und Subdimensionen von Intermedialität aufweisen. Dies sei hier nur angedeutet:

- Das Merkmal der Zitativität korrespondiert mit dem Konzept der intermedialen Bezugnabmen, ${ }^{24}$ verstanden als Rekurse auf altermediale Produkte

$22 \quad$ Verwendet wurden hier vor allem die Arbeiten von Rajewsky (2002), Schröter (1998) und Leschke (2007).

23 Ausgeblendet bleibt hier die Materialität des jeweiligen Trägermediums (also: Filmstreifen vs. Magnetband vs. Datei) bzw. die technisch-apparative Ebene (also: Filmkamera/-projektor vs. Videokamera/-player/Bildschirm vs. digitale Kamera/Monitor), damit auch die (technische und perzeptive) Spezifik des generierten Bildes (Leinwandbild vs. Monitorbild) sowie die entsprechenden Mediensysteme (Kinematographie, Video, digitaler Film). Dies geschieht trotz des Umstands, dass gerade die Mediendifferenz ,Film/Video' als typisch für die Gattung ,Videoclip“ erachtet wurde (vgl. etwa Kerscher/Richard 2003), da diese Differenz als Abgrenzungskriterium wohl für die Anfänge des Genres, nicht aber für heutige Produktionen geeignet ist. Entsprechend wurde die Bezeichnung, Videoclip“ respektive ,Musikvideo einem Vorschlag von Jacke (2003) folgend - durch die Bezeichnung, Musikclip“ ersetzt. Die vorliegende Betrachtung beschränkt sich zudem auf die durch Apparate generierte Oberfläche (Bildschirm), d.h. auf das Produkt als kommunikativ-semiotisches Phänomen unter Ausblendung seines technisch-apparativen Zustandekommens.

24 Die Idee der intermedialen Bezugnahme nimmt ihren Ausgang beim Konzept der Intertextualität (siehe zusammenfassend Fix 2001) bzw. Transtextualität (nach Genette 2004) und erweitert diese um den Aspekt der Mediendifferenz im Falle der Intermedialität im Vergleich zur Intertextualität. Während im Falle der Intertextualität keine Mediengrenzen überschritten 
und/oder semiotische Systeme, wobei letatere im kontaktnehmenden Medium material nicht präsent sind. ${ }^{25}$

- Transmedialität, verstanden als die Wanderung medienunspezifischer Phänomene, lässt sich am Merkmal der Assoziativität festmachen, da der Musikclip hier auf formalästhetische Gestaltungstraditionen und -prinzipien insbesondere des frühen Avantgardefilms (etwa Collage, Rhythmus als gemeinsame Grundlage von Auditivem und Visuellem, Sichtbarmachung von Sound etc.) zurückgreift. ${ }^{26}$

- Das invertierte Bild-Ton-Verhältnis schließlich verweist auf einen intermedialen Produkten häufig zugeschriebenen Effekt, nämlich jenen der Synästhesie. ${ }^{27}$ Hiermit ist das bereits oben angedeutete Phänomen gemeint, dass Clips den Eindruck eines Hörens von Bildern vermitteln bzw. von Bildern, die musikalisch-klangliche Qualitäten zu haben scheinen. ${ }^{28}$

werden (Bezug von Literatur auf Literatur, von Text auf Text), kann sie aus der Perspektive der Intermedialität, für welche die Überschreitung von Mediengrenzen konstitutiv ist (etwa Bezug von Literatur auf Film), als ein (bedeutsamer) Fall von Intramedialität (Bezugnahmen innerhalb eines Mediums) gelten.

25 Mit Spielmann (1998) lassen sich solche Bezugnahmen etwa am Beispiel des Films zeigen, welcher auf die Malerei dergestalt rekurrieren kann, dass Gemälde im Film zu sehen sind oder aber die Bildgestaltung der Malerei (bzw. des Tafelbildes) formale Prinzipien (etwa eine zentripetale Art der Kadrierung oder eine an zentralperspektivischen Idealen orientierte Kameraführung (dies zeigt Spielmann an den Filmen von Peter Greenaway)) entlehnt, ohne dass der Film in einem ontologischen bzw. substantiellen Sinn Malerei sein könnte, da er - was die medial-materiale Basis anbelangt - auf die Fixierung von Lichtverhältnissen auf Zelluloid und deren Projektion angewiesen ist und die Mittel der Malerei - Leinwand und Farbe - daher nur simulieren, nicht aber tatsächlich verwenden kann.

26 Vgl. hierzu Bódy/Weibel (Hg.) (1987); Deutsches Filmmuseum Frankfurt (Hg.) (1993); Paech (1994).

27 Clips sind konzeptionell darauf angelegt, Ton zu visualisieren (siehe auch Rösing 2003); daher auch die (ent-)sprechenden Bezeichnungen wie „Augenmusik“ (Barth/Neumann-Braun 1996), ,,Tönende Bilder“ (Altrogge 2000), „Werbende Klangaugen“ (Hausheer 1994), „Visueller Sound“ (Hausheer/Schönholzer (Hg.) 1994), „The Look of Sound“ (Aufderheide 1986) und „Visuelles Radio“ (Bechdolf 1996), durch welche Musikclips häufig charakterisiert wurden. Daher lässt sich auch - Schmidbauer/Löhr (1996) folgend - beim Clip weniger von einem Soundtrack (Tonspur eines Films), also einer Musik zum Bild, als vielmehr von einem ,visual track' zur vorgängigen Musik sprechen.

$28 \mathrm{Zu}$ verstehen ist dies im Sinne einer Farblichtmusik, d.h. einer Verkopplung auf der Ebene der technischen Signale und nicht der Symbole (vgl. Großmann 1998, S. 111), welche entweder auf subjektiver, synästhetischer Intuition (prominentestes Beispiel: das Farbenklavier des russischen Komponisten Alexander Skrjabin) oder auf objektiver, physikalischer Transformation (etwa im Falle des, Optophons‘ (Raoul Hausmann, 1922)) beruhen kann. Insbesondere die Arbeiten des Experimentalfilmers Oscar Fischinger - so Großmann (1998) - legen Zeugnis vom Versuch ab, die Grenzen von Ton- und Bildkanal zu überwinden (seine „TonOrnamente“ (1932) etwa versuchen dies gewissermaßen physisch, da sie eine Visualisierung der Tonspureinschreibungen im Tonfilmstreifen, also innerhalb einer mit Lichttonverfahren arbeitenden Filmkamera darstellen). Musikclips folgen grosso modo eher ersterem Prinzip, wobei der synästhetische Eindruck die Suche sowohl nach formalen (etwa Cut-Rhythmus-Korrespondenzen) und als auch semantischen (etwa Songtext-Bild-Relationen in Form von Illustrationen) Konnexen evoziert. 
Der entscheidende Punkt ist nun drittens, dass Clips häufig auf obige, weil hervorstechende und auffällige, pluri- $b$ zw. intermediale Merkmale reduziert werden und dabei das primäre und tiefer greifende Verbältnis von Sprache und Musike übersehen wird. Stärker formuliert: Erst diese asymmetrische Verschachtelung von Symbolsystemen im Musikclip vermag jene intermedialen Verhältnisse, jene Ästhetik hervorzubringen, für die der Clip sprichwörtlich geworden ist („Clipästhetik") (siehe Schaubild 2).

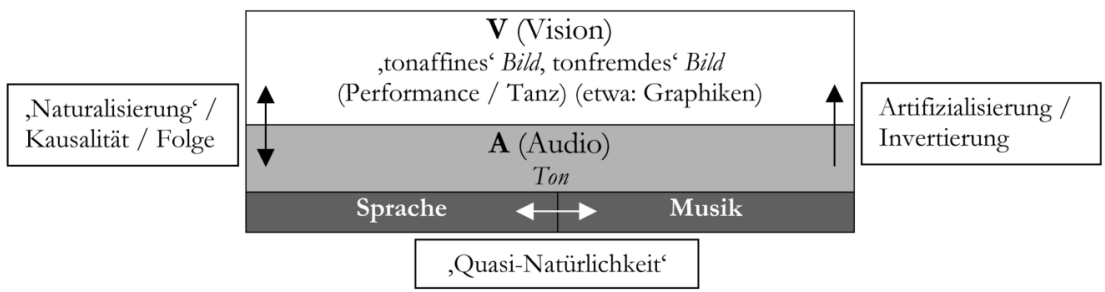

Schaubild 2: Asymmetrische Verschachtelung der Symbolebenen und Bild-Ton-Verhältnisse im Clip

Daher soll im Folgenden der Audio-Bereich des Clips fokussiert werden, also die Tonspur, da diese produktionsästhetisch primär ist und - mit Blick auf Semiose-Prozesse - aus oben genannten Gründen ,natürlicher' wirkt. Umgekehrt ist es gerade deshalb auch jener Bereich, der schwieriger , auseinanderzudividieren` (also zu analysieren) ist, der in Musikclipanalysen bäufig stillschweigend vorausgesetżt wird und dessen intermediale Bedeutungspotenz̧iale aufgrund dessen vernachlässigt respektive gar nicht erst analytisch fruchtbar gemacht werden.

\section{Text-Ton-Relationen und Popularmusikforschung}

Wenn im Folgenden von der Relation von Musik und Sprache die Rede ist, so soll insbesondere auf die analytischen Anforderungen eingegangen werden, die sich mit diesem Beziehungsgeflecht in populärer Musik verbinden. Es sei an dieser Stelle hervorzuheben, dass in jüngster Zeit eine Reihe von Beiträgen zur Sprache in populärer Musik erschienen ist, die in unterschiedlichen Perspektivierungen die phänomenalen Eigenschaften von Sprache in PopStücken ausloten und dadurch insgesamt zu einem differenzierten Erkenntnisstand bezüglich dieser Bedeutungsebene beitragen. ${ }^{29}$ Ihre informative Dichte kann jedoch nicht darüber hinwegtäuschen, dass in der Popularmusikforschung eine allgemeine Unklarheit bezüglich des analytischen Umgangs mit den klanglichen Dimensionen und in der Folge mit der Bedeutungskonstitution durch musikalische Klanglichkeit herrscht. ${ }^{30}$ Die

$29 \quad$ Vgl. Bielefeldt (2008); vgl. Klein (2008); vgl. Bowman (2003).

30 Vgl. Wicke (2003). 
folgenden Ausführungen sind demnach an die globale Zielperspektive gekoppelt, den reflexiven Schärfegrad im Spannungsfeld von Material und Analyse zu erhöhen. In diesem Kontext werden auch grundlegende theoretische Fragestellungen zur Popularmusikforschung tangiert. Im Hinblick auf dieses Vorhaben kommt der Verschränkung der Symbolsysteme populäre Musik und Sprache durchaus eine Schlüsselposition zu. Gelingt es entlang der in diesem semiotischen ,Fusionskern' eingelagerten intertextuellen Rekurspotentiale ein Beobachtungssystem zu etablieren, so ist zu erwarten, dass hiervon Impulse für die Beobachtung weiterer klangübergreifender Zusammenhänge in populärer Musik ausgehen. Nachfolgend sind es nun Überlegungen zur Pragmatik von Gesang, die in diesen Methodologie-Komplex einführen.

Im Rahmen von Popularmusik- und Clipforschung gilt es als gesicherte Erkenntnis, dass das Verhältnis von Ton und Text subsidiär in den globalen Zusammenhang von Musik und Sprache eingelagert ist. ${ }^{31}$ Hierdurch wird nicht grundlegend die Sinnhaftigkeit einer Text-Analyse in Frage gestellt. Entscheidend ist nur, welchen Stellenwert man ihr in einer integrierten (Bild-)Text-Ton-Analyse zuteil werden lässt. Angesichts der phänomenalen Zusammenhänge in einem sprachbasierten Musikstück erscheint diese Analyse als Nebenschauplatz. Denn der Text wird gesungen/vorgetragen, materialisiert sich also erst im performativen Vollzug der Stimme. ${ }^{32}$ Jene Materialisierung durch die Stimme bleibt während eines Konzerts flüchtig, erscheint im Speichermedium Tonträger indes in verewigter Form. Die Sprachzeichenhaftigkeit von Gesang wird dadurch nicht grundlegend in Abrede gestellt. Für die Konstituierung und Sedimentierung von Bedeutung in vokalen Formaten sind jedoch nunmehr die Relationen zwischen Materialhaftigkeit einer Performance und Zeichenhaftigkeit des textuellen Basismaterials bedeutsam. ${ }^{33}$ Den Text singen bedeutet gleichsam, Sinnzusammenhängen in expressiver Flüchtigkeit eine Gestalt zu geben, auf Bedeutungen aus zu sein. Gegebenenfalls kann dies auch zur Folge haben, dass Bedeutungen des Texts unterminiert werden, er also eine Umwertung über sich ergehen lassen muss. Sei es, er wird nach einer spezifisch musikalischen Logik neu-rhythmisiert, oder bestimmte Silben werden verschluckt oder einfach aufgrund des sinnlichen Potentials von Melos und Timbre, das Sinn temporär außer Kraft setzt oder in den Hintergrund drängt. ${ }^{34}$

\footnotetext{
31 Vgl. Vernallis (2002); vgl. Frith (1996, S. 159).

32 Siehe hierzu u.a. Krämer (2006).

33 Der Zusammenhang von Materialhaftigkeit und Zeichenhaftigkeit einer Aufführungssituation nimmt allgemein eine zentrale Position in den Diskussionen zum Performativitätsbegriff ein. Allgemein ist in den kulturwissenschaftlichen Diskursen eine verstehenskategorische Verschiebung zugunsten der Begriffe Ereignis oder Präsenz zu beobachten. Für den Bereich der performativen Ästhetik siehe hierzu Fischer-Lichte (2004). Im Hinblick auf epistemologische Fragestellungen siehe Gumbrecht (2004). 
Die genannten Aspekte treffen auch auf den Spezialfall von (gesungener) Sprache in populärer Musik zu. Dem ist jedoch als wesentlicher Aspekt anzufügen, dass das Vokale in populären Bereichen auf den spezifischen Traditionslinien von Blues, Jazz und Schlager aufbaut. ${ }^{35}$ Bereits in jenen historischen Sparten war der Gesang von einer eigentümlichen Verschmelzung von sozialem Verbalisationsgestus und traditionellen gesanglichen Elementen durchdrungen. Eine weitere Ausdehnung des vokalen Repertoires im Sinne fortwährender Synthetisierung fand dann mit Beginn der Rock'n'RollÄra und in den Folgejahrzehnten statt. Insbesondere die dem Alltäglichen entstammenden Formen der Verbalisierung wie z.B. Schreien, Sprechen, Flüstern - direkt zu veranschaulichen an Genres wie Heavy Metal, Hip Hop und Chanson - haben mehr und mehr zu einer stilistisch-ästhetischen Etablierung von Pop-Sprache und -Stimme jenseits des traditionellen Gesangs ${ }^{36}$ geführt. Das Phänomen Rap ist diesbezüglich nur eines unter vielen repräsentativen Beispielen, das aufzuzeigen vermag, dass Sprache und Stimme im Sinne einer eigenen popularmusikalischen Idiomatik funktionieren.

Wendet man nun die Ausführungen zur Spezifik der vokalen Gestaltung in populärer Musik zurück auf die analytischen Anforderungen von populärer Musik, so wird deutlich, dass der Gesangsbegriff aufgrund seiner präskriptiven Anteile nur begrenzt von Nutzen ist. Demgegenüber vermeidet die Bezeichnung vokale Performanz begriffsbedingte Vor-Aussagen. Eine begriffliche Neu-Orientierung an ebenjener Bezeichnung sei an dieser Stelle empfohlen, denn sie führt über die Zwischenstufe einer Ausweitung des analytischen Vokabulars schließlich zu einem höheren reflexiven Schärfegrad. Hiernach ist durch vokale Performanz eine übergeordnete Verstehenskategorie geschaffen, entlang derer es möglich ist, klanglich-vokale Ereignisse auf das eigentümliche Wechselspiel von gesanglichen Anteilen und alltagssprachlichen Gesten hin zu durchleuchten. ${ }^{37}$

35 Vgl. Wicke (1992, S. 452 ff.). Die genannte Trias rekurriert auf den historischen Tatbestand, dass populäre Musik im Allgemeinen und das Vokale im Speziellen sich in großen Teilen aus folkloristischen Elementen, vor allem afro-amerikanischer Provenienz, speisen. Im gleichen Zuge darf aber der Einfluss der europäischen Spiel- und Singtradition - hier repräsentiert durch den Schlager - nicht marginalisiert erscheinen. So zeichnen sich im Schlager die Traditionslinien der populären europäischen Musiktradition ab (vgl. Middleton 2001, S. 63).

36 Die Bezeichnung ,traditioneller Gesang ${ }^{c}$ wird an dieser Stelle nicht als polares Gegenmodell zu vokaler Performanz in populärer Musik aufgestellt. Vielmehr gilt es die Bezeichnung als Eingrenzung von vokalen Gattungen zu begreifen, die in Herkunft, Aufführungspraxis und Stilistik eine geringe Nähe zur populären Musik aufweisen. Hierzu zählt zum einen der Klassische Gesang, der u.a. durch Begriffe wie Konzertgesang, Operngesang, Lied- und Oratoriengesang repräsentiert wird. Zum anderen ist hiermit auf das Gros der volksmusikalischen Gattungen weltweit verwiesen, die auf orale Tradierung und organisch-akustische Klangerzeugung aufbauen.

37 Simon Frith bewertet die Integration von Umgangssprache in die ästhetische Form des Songs als eigentümliche ,Erhöhung' ebenjenes Sprachstils. Die Verschränkung von Umgangssprache und Musik ist infolgedessen Keim fortwährender Spannungsproduktion (vgl. Frith 1996, S. 168). Bei Dieter Baacke finden sich Ansätze einer gesamttheoretischen Fun- 
Mit dem Verweis auf die humanen respektive sozialen Eigenschaften von vokaler Performanz in populärer Musik ist ein erster Schritt zur analytischen Neu-Vermessung vollzogen worden. Der zweite Schritt erfolgt über den Rekurs auf ein weiteres determinierendes Bezugssystem: die Aufnahmetechnik. Das Aufnahme-Studio hat mit seinen sich ständig vervollkommnenden technischen Möglichkeiten zur Differenzierung und Beeinflussung von Klang, insbesondere seit Einführung der Mehrspurtechnik, einen immer größeren Stellenwert in der Entwicklung der populären Musik bekommen. ${ }^{38}$ Die Aufnahme selbst gründet sich auf den Dreischritt Tonaufnahme, Abmischung und Mastering. Die musikalische Performance im Studio wird in Form einer Tonspur fixiert. Mehrere Tonspuren übereinandergelegt ergeben dann den Song bzw. den Tonträger. Auf der Basis von Soundprozessoren (auch Klangeffekte genannt) und Mastering-Einstellungen kann die klangliche Wahrnehmung entscheidend beeinflusst werden. ${ }^{39}$

Die Aufnahme vermag es, den Interpreten bzw. die Interpreten präsent erscheinen zu lassen, wenn beispielsweise durch das Zusammenspiel von Echo- und Kompressor-Effekten in der Wahrnehmung des Hörers bestimmte Vorstellungen von Körperlichkeit und Räumlichkeit hervorgerufen werden. Dem ist aus Sicht des Performativitätsdiskurses anzufügen, dass die Stimme auf dem Tonträger nicht im Sinne tatsächlicher Präsenz erfahren wird. Vielmehr wird auf Grundlage von Präsenz-Effekten der Schein von Gegenwärtigkeit erzeugt. ${ }^{40}$ Nichtsdestoweniger bleibt der ursprüngliche Präsenzkontext, in dem Stimme entsteht, auf dem auditiven Speichermedium subjektiv imaginierbar. Die Aufnahme ist gewissermaßen mit performativen Anteilen aufgeladen. Simon Frith leuchtet ebenjene Aspekte stimmlicher Medialität und Performativität weiter aus. Er formuliert diesbezüglich die Ansicht, dass die grundlegende Vorstellbarkeit stimmlicher Ereignis-

dierung des populären Felds, die eine ähnliche Richtung einschlagen. So geht Baacke in Anlehnung an den Bricolage-Begriff davon aus, dass das kulturelle Territorium der populären Musik geprägt ist durch eine ständige Neuanordnung und Rekontextualisierung von Objekten, Tönen und Kombinationen, mit dem Ziel, neue Bedeutungen herzustellen und damit das vorhandene Gesamtsystem von Bedeutungen neu zu ordnen (vgl. Baacke 1998, S. 45). Dass diese Entstehung kultureller Bedeutung nicht allein Produkt symbolischer Kommunikation zwischen Akteur und Rezipient ist, sondern sich auch auf ökonomische Belange zurückführen lässt, muss an dieser Stelle ins Gedächtnis gerufen werden. Die Identifikation der sich dahinter verbergenden Mechanismen ist Aufgabe musiksoziologischer Forschung und kann entsprechend im Rahmen dieses Beitrags nicht erfolgen. Es sei diesbezüglich auf die Arbeit Peter Wickes verwiesen, der sich rezeptions- und markttheoretisch dem populären Gesamtfeld annähert und aus dieser Perspektive zu der Einsicht einer zunehmenden Pluralisierung und Fragmentarisierung populärer Musik gelangt (vgl. Wicke 1993, S. 36 ff.).

38 Vgl. Wicke/Ziegenrücker (2001, S. 515).

39 Vgl. Hawkins (2000). Hawkins gelangt in seiner Materialanalyse zu der Einsicht, dass die harmonische Komplexität des betrachteten Songs auf die spezifische Bearbeitung und Abmischung der Tonspuren zurückgeht, d.h. die Medialität des Tonträgers rahmt Produkt und Rezeption gleichermaßen.

40 Vgl. Fischer-Lichte (2004, S. 174). 
kontexte ein zentrales theoretisches Apriori zum Phänomen Pop-Stimme bildet. Darauf aufbauend apostrophiert er vier Imaginationsebenen, die die Interpretationsmöglichkeiten von Stimme in populärer Musik markieren. Hiernach wird die Stimme in einem Song vorgestellt als musikalisches Instrument, Körper, Person und Charakter. ${ }^{41}$ Alle vier Ebenen werden analytisch-interpretativ relevant gesetzt. Für unseren methodologischen Blick auf das Themenspektrum Text-Ton ist dies dahingehend bedeutsam, als dass hierdurch das Erfordernis artikuliert wird, um das Phänomen Stimme herum einen transdisziplinär verständlichen Begründungszusammenhang zu entwickeln, der sowohl spezifisch musikalischen als auch performativen Perspektivierungsansätzen standhält.

Führt man nun die ursprüngliche Frage nach der Bedeutung des Texts in Popsongs mit den vorangegangen Ausführungen zusammen, so lässt sich als eine Art Zwischenfarit festhalten, dass die Bedeutungsebene Text in der übergeordneten Kategorie des Vokalen aufgeht. Das Vokale selbst ist als ein Netzwerk von musikalischen Elementen, Stimm-Körper, personalbiographischen Spuren, sozio-kulturellen Charakter-Figuren, audiotechnischen Prozessen und semantischen Feldern zu abstrahieren - ein Netzwerk, das im Vortrag einzelner Solisten materiell greifbar wird. ${ }^{42}$ Für die Analyse ist hiermit angedeutet, dass es sich im Falle stimmlicher Performanz um eine klangliche Hervorbringung handelt, der das ,Äußerliche innerlich zu sein scheint. Das gesungene Wort und die Geste können folglich als Variablen eines dynamischen Ausdruckskomplexes verstanden werden, die je nach Aufführung und Aufführungskontext bestimmte Ausprägungen zeitigen. ${ }^{43}$

Die entscheidende Weichenstellung im analytischen Umgang mit populärer Musik offenbart sich in dem Moment, in dem man das konkrete Material vorliegen hat. Zweierlei ist hier zu berücksichtigen: Zum einen existieren popularmusikalische Formate wie Song und Clip als mediale Produkte - ersterer (vornehmlich) als Tonträger, letzterer als Synthese aus Tonträger

41 Vgl. Frith (1996, S. 187). Auf das mediale Bezugssystem Technik/Aufnahmetechnik wird in Friths Modell auf der ersten Ebene des musikalischen Instruments Stimme eingegangen. So wird der gekonnte Umgang mit dem Mikrophon als wesentlicher Bestandteil musikalischstimmlicher Kunstfertigkeit verstanden (vgl. ebd., S. 188).

42 Siehe hierzu auch die Ausführungen Christian Bielefeldts zum Bedeutungsnetzwerk des Phänomens Stimme im populären Kontext (vgl. Bielefeldt 2008).

43 Der genannte Begründungszusammenhang von gesungenem Wort, Stimme, Geste, Aufführung und Kontext geht auf die Ausführungen Paul Zumthors zum Oralitätsbegriff zurück. Hierin setzt Zumthor ferner die Variablen Akteur und Medien zentral. In diesem Sinne beschreibt er einen umfassenden Deutungskomplex, der auch im Hinblick auf die nicht originär musikalischen Materialaspekte populärer Musik seine Gültigkeit behält (vgl. Zumthor 2002, S. 243). Zumthor gibt aber an anderer Stelle zu bedenken, dass es problematisch wäre, jede gestische und mimische Qualität in ein Zeichensystem zu verorten. Allerdings kann die Geste Zeichen in dem Maße sein, als sie kulturell bedingt ist oder in einem bestimmten Milieu eine konventionelle Bedeutung trägt (vgl. Zumthor 1988, S. 712). 
und Bewegtbildspur. ${ }^{44}$ In Entsprechung ihrer jeweiligen technischen Dispositionalität bringen sie die Inhalte, die sie übertragen, auf eine bestimmte Art und Weise hervor. ${ }^{45} \mathrm{Zum}$ anderen meint die Begriffskomponente ,Ton', dass verschiedene Tonspuren in Gestalt von musikalisch-klanglichen Sukzessionsverläufen zusammengefasst werden. Was sich angesichts dieser Unterscheidung andeutet, ist die Tatsache, dass die performativen, sprachsemantischen und medialen Deutungshorizonte mit Blick auf den (popular-)musikalischen Vortrag nur von begrenzter Reichweite sind. Besonders augenscheinlich wird dies entlang der Bedeutungsebene des rein Instrumentalen. Diese führt in eine originär musikalische Konstitutionslogik ein, die sich Fragen etwa der Gestenhaftigkeit oder Denotativität nicht grundsätzlich verschließt, aber nur unzureichend durch diese einzufassen ist. An einem einfachen Experiment lässt sich die eigentümliche Sonderstellung von Musik demonstrieren: Stellt man bei der Betrachtung des musikbasierten Audiovisionsformats Clip den Ton stumm, so entsteht auf der Bildebene eine sonderbar anmutende Reihung von visuellen Ereignissen, seien es Handlungs- und Bewegungsabläufe, Gesten, mimische Ausdrücke oder Setting-Arrangements. Zudem wäre es möglich, dass der Betrachter eines solchen Experiments gar nicht anders kann, als eine musikalische Tonspur zu imaginieren. In den theoretischen Diskurs zurückübertragen heißt dies, dass die Musikebene einen übergeordneten Sinnzusammenhang herzustellen scheint. Unterstützt wird diese Annahme dadurch, dass die Musik, in Form des Songs, beim bloßen Hören schon als sinnhaft erfahren wird. ${ }^{46}$ Mit Blick auf das oben erwähnte Ausgangskonstrukt eines dynamischen Aus-

$44 \quad$ In Clips mit diegetischem Sound wird zudem eine musikfremde Tonspur integriert.

45 Bei Sybille Krämer wird diese Auffassung als kleinster gemeinsamer Nenner der Medialitätsdebatte identifiziert (vgl. Krämer 2004, S. 23). Aufgrund der diesbezüglich vorliegenden Fülle an Positionen kann im Rahmen dieses Beitrags nicht auf einzelne Medialitätskonzepte eingegangen werden. Aufzuzeigen ist lediglich, dass Tonträger und Musikclip auch als Teil eines umfassenden Medialitätsdiskurses zu erfassen sind. Fragen der Medialität sind im Bereich der Musikwissenschaft bislang nur mit Zurückhaltung diskutiert worden sind. So besteht bezüglich des Zusammenhangs von Elektroakustik und musikalischer Ästhetik noch grundsätzlicher Aufklärungsbedarf (vgl. Böhme-Mehner/Mehner/Wolf (Hg.) 2008).

46 Insgesamt sei an dieser Stelle eine inhaltliche Abgrenzung gegenüber der Gattung Filmmusik vorgenommen - aus diesem Grund auch die terminologische Festlegung ,musikbasierte $\mathrm{Au}$ diovisionsformate'. Neben dem Musikclip zählen zu den musikbasierten Formaten im populären Sektor noch die musikalischen Großformen Rock-/Pop-Konzert, Musical und Musikfilm. Der Hauptunterschied zwischen vorgenannten Formaten und Filmmusik besteht darin, dass die Musik im Film der Untermalung und Verstärkung der bildlichen Ebene dient (vgl. Bullerjahn 2001, S. 20 ff.). Gemäß der oben genannten Terminologie würde es sich hier um ein bildbasiertes Audiovisionsformat handeln. Nichtsdestoweniger lässt sich auch an Filmmusik aufzeigen, dass musikalische Klanglichkeit ab einem gewissen Grad inhaltlich-struktureller Konsistenz im Hörer sinnhafte respektive sinnliche Bezüge herzustellen vermag. So wird dies am Markt-Phänomen der sogenannten Original-Soundtracks evident. Diese Tonträger enthalten zumeist nur die jeweilige Musik, die im Film erklingt. Bemerkenswert ist, dass sie in nicht unerheblichem Maße vertrieben und konsumiert werden, also eine, sinnlichsinnhafte 'Unterhaltungssituation herstellen. 
druckskomplexes ist also zu präzisieren, dass die Musik hierin zentral gesetzt werden muss. Die sich im Song realisierenden musikalischen Strukturen formen den Nukleus des gesamten Ausdruckskomplexes (Bild-)Text/Stimme-Ton. Das bedeutet für die Analyse, dass alle Materialebenen nur unter Bezugnabme zur Musik zu beschreiben und deuten sind.

Eine solche analytische Prämisse soll nicht dazu führen, dass der Musikwissenschaft im Hinblick auf das interdisziplinäre Forschungsobjekt Musikclip eine exponierte Stellung zuteil wird. Es gilt vielmehr, den analytischen Raum im Spannungsfeld von Musik-, Sprach- und Medienwissenschaft so zu vermessen, dass eine Ordnung von Analysefeldern, Konzepten und Begriffen entsteht, die in finaler Wendung eine gegenstandsangemessene Betrachtung des Musikclips ermöglicht. Insgesamt ist anzuregen, dass die genannten Disziplinen ihre Zusammenarbeit systemisch begreifen, d.h. im Sinne einer materialbezogenen kulturwissenschaftlichen Reflexion ${ }^{47}$ Zuletzt muss es sowohl für Musikwissenschaft als auch für Sprach- und Medienwissenschaft darum gehen, die jeweils im Song oder Clip enthaltenen kulturellen Codes analytisch-interpretativ zu repräsentieren. Der Aspekt kultureller Konventionalisierung ist disziplinübergreifend von erkenntnisleitendem Interesse. Kulturelle Konventionen entstehen als Folge des reziproken Beziehungsgeflechts sozialer Praxis und ästhetischer Produktion. Sie bilden den Nährboden, aus dem die Objekte der Populärkultur ihr spezifisches Verständigungs- und Wirksamkeitspotential ziehen. ${ }^{48}$ Alle Disziplinen, die sich mit Gegenständen populärer Kultur beschäftigen, stehen somit vor der Aufgabe, kollektive Bedeutungsfelder in den Verästelungen unterschiedlicher Materialzusammenhänge hervor zu fördern.

\section{Materialanalyse aus musikwissenschaftlicher Perspektive: Exkursivität und Rekursivität}

Im Folgenden soll ein globaler analytischer Ansatz zu populärer Musik vorgestellt werden - die Betrachtung von Text-Ton-Relationen ist diesem immanent. Eingedenk der im vorangegangenen Abschnitt angedachten inter-

47 Jobst P. Fricke entwirft einen systemischen Ansatz aus dem Blickwinkel der Musikwissenschaft heraus. Gefordert wird eine grundlegende Besinnung auf den gemeinsamen Forschungsgegenstand. Um diesen bündeln die beteiligten Disziplinen ihre Kompetenzen. Möglich erscheint dies, da Musik auf dreierlei Weise Gegenstand wissenschaftlicher Betrachtungen sein kann: als notiertes Werk, als akustisches Phänomen und als erlebter Klang. Daraus folgt, dass Musik als menschliches Phänomen nur von den Eigenschaften, Möglichkeiten und Zielen des Menschen aus zu verstehen ist. Systemisch zu arbeiten bedeutet danach, dieses komplexe Gefüge von Wirkungsgrößen in seinem dynamischen Verhalten zu betrachten (vgl. Fricke 2003).

48 Nach Hans Otto Hügel entfalten die Objekte der Populärkultur ihren spezifischen Reiz dadurch, dass sie fortwährend zwischen den Registern des Sozialen und Ästhetischen changieren (vgl. Hügel 2003). 
disziplinären Zusammenarbeit ließe sich die Ausführung dieses Ansatzes als primär musikwissenschaftliches Unterfangen begreifen, da als Analysematerial zunächst der Tonträger vorliegt. Nichtsdestoweniger ist bereits auf der musikanalytischen Ebene eine Vermittlung zwischen performativen, medialen und sprachsemantischen Deutungshorizonten vorgesehen. Der Gedanke der Vermittlung kann indes nicht darüber hinwegtäuschen, dass die andauernden Bedeutungsverschiebungen im Spannungsfeld von Sozialität und Ästhetizität eine Herausforderung für die Analyse darstellen. Abhilfe schafft diesbezüglich der Umweg über die Abstrahierung des binären Codes sozial/ästhetisch auf der Folie des Objektes selbst. So ist für das theoretische Verständnis von Popsongs die der Luhmann'schen Systemtheorie entlehnte Vorstellung einer Zwei-Seiten-Form hilfreich. ${ }^{49}$ Deren zwei Seiten - denkbar als Innen- und Außenseite - stehen in keinem eindeutigen Zuordnungsverhältnis. Während die Innenseite im Medium des Klangs durch eine bestimmte Kopplung an Elementen konstituiert wird, wird die Außenseite durch die Möglichkeiten, die das Medium des sozialen Sinns bietet, generiert. Ein Phänomen wie Stimme fungiert in diesem Relationsgefüge als bedeutendes Verbindungsstück, da es Melos und sozialen Verbalisationsgestus aufeinander bezieht. Sie ist qua ihrer spezifischen Position prädestiniert, ein Übermaß an Bedeutungszusammenhängen herzustellen.

Das bedeutet nunmehr, dass die Forschenden angeleitet sind, materielle Zusammenhänge so offenzulegen, dass ein grundlegendes Verständnis für das Verhältnis von musikalischen und nicht-musikalischen Bedeutungsfeldern möglich wird. Es gilt hierbei zu berücksichtigen, dass das jeweilige Klangmaterial durch äußere Faktoren wie Medienwahl, Aufführungskontext, Genrezugehörigkeit und Oeuvrebezug determiniert wird. Im Zusammenschluss fungieren sie als eine Art Produktionsgedächtnis, welches daran erinnert, dass die vielfältigen Materialsynthesen in den medialen Settings einem ästhetischen Ereignishorizont entspringen, der mit einem bestimmten Künstler oder Genre in Verbindung gebracht wird. ${ }^{50}$ An ebenjenen Faktoren können alsdann materialspezifische Interpretationslinien vorbereitet werden. Peter Wicke leitet hieraus ein methodologisches Verdikt ab, nämlich dass

die klangstrukturellen Konfigurationen eines Stückes kontextabhängig vorstellbar sind, ohne ihre internen strukturellen Determinanten deshalb an eine Konstellation aus situations- und wahrnehmungsabhängigen Beliebigkeiten zu überschreiben. (Wicke 2003, S. 122)

\footnotetext{
49 Vgl. Luhmann (1995, S. 169).

50 Diesbezüglich sei auf Dietrich Helms verwiesen, der insgesamt für einen erweiterten Materialbegriff optiert, der sich vom traditionellen Verständnis der Werkimmanenz emanzipiert (vgl. Helms 2002).
} 
Die Bedeutung des Kontextbegriffs für die Analyse kann nicht unterschätzt werden. An ihm manifestiert sich die doppelseitige Fragerichtung des NachInnen und Nach-Außen. ${ }^{51}$ Die Folgen für die Analyse sind derart, dass das konkrete Klangmaterial entlang verschiedener Analysefelder enggeführt werden muss. Dabei sind zwei Betrachtungsebenen zu beachten: eine exkursive, die vom reinen Materialbezug ,abschweift ${ }^{\star}$ und soziale, performative und mediale Deutungshorizonte auf sich vereint und eine rekursive, die sich klangimmanent kapriziert. Mit dem Begriff der Exkursivität sind die Analysefelder Genre ${ }^{52}$, Performance/Performanz ${ }^{53}$ und Medium ${ }^{54}$ impliziert.

51 Die Bedeutung des Kontextbegriffs lässt sich beispielsweise am Phänomen der Coverversion demonstrieren. In einem Coversong werden musikalische Strukturen in andere zeitliche und ästhetische Kontexte übertragen. Fragen wie etwa jene der Wirksamkeit der Musik oder der interpretativen Gestaltung können nur hinreichend entlang eines entsprechenden Kontextverständnisses gekärt werden.

52 Nach einer Definition von Franco Fabbri besagt Genre, dass musikalische Ereignisse (reale oder mögliche) sich zu Netzwerken verbinden, deren Aneignung durch sozial verbindliche Regeln definiert wird (vgl. Fabbri 1982, S. 52). Dem ist die Auffassung von Genre als kommunikatives Konzept anzufügen, welches impliziert, dass die Reziprozität von Interpret und Publikum stets von neuem exklusive Beziehungszusammenhänge generiert (vgl. Hamm 2000, S. 298). Was an beiden Definitionen zu Tage tritt, ist die Tatsache, dass die Zugehörigkeitskontexte musikalischer Zeichen als transzendierend und sich-stets-dynamisierend gelesen werden müssen. Angesichts einer solchen Unübersichtlichkeit musikalisch-sozialer Verständigung sei für die konkrete Analyse empfohlen, den Genrebezug in Form von ,GenreIndikationen' zu identifizieren. Hierdurch wird das Transitorische von Genre allgemein betont. So ist für die Materialanalyse die Einsicht bedeutsam, dass hier im Sinne qualitativer Methodik vorgegangen wird, d.h. sozial-kommunikative Bezüge können nur ,stichprobenartig ${ }^{\prime}$ innerhalb eines zeitlich und sachlich gerahmten Kontextes bestimmt werden. Darüber hinaus soll angeregt werden, Oeuvrebezüge und sprachsemantische Bedeutungsfelder als Teil des Genrezusammenhangs aufzufassen. Dies kann in Form einer Bestimmung von Topoi, musikalisch und sprachlich, geschehen, mit denen der/die Künstler auf eine bestimmte Art und Weise umgeht bzw. umgehen.

53 Im deutschsprachigen Diskurs zur populären Musik lassen sich die Begriffe Performance und Performanz ergänzend gebrauchen. Ersterer hat sich im deutschen Sprachraum allgemein im Hinblick auf die Beschreibung des (künstlerischen) Akts der Darstellung, den Moment der Aufführung und die Präsenz von Akteuren durchgesetzt (vgl. Schumacher 2002, S. 384). Dieser umfassende Aspekt des Ereignischarakters von Musik ist für den popularmusikalischen Diskurs zentral, da es sich bei populärer Musik nicht selten um eine musikalische Interaktionshandlung handelt, deren Vollzug gemäß der Möglichkeiten des jeweiligen medialen Settings inszeniert wird. Fokussiert eine Forschungsfrage diesen Ereignischarakter des Zusammenspiels von Akteuren (Live oder im Tonstudio), so scheint der Gebrauch des Performance-Begriffs naheliegend. Hingegen werden die Vorzüge von Performanz in dem Moment sichtbar, da man sich der Beschreibung einzelner Materialebenen zuwendet - das englische ,Performance' wäre hier aufgrund seines integrierenden semantischen Gehalts irreführend. Im Ganzen muss es in der Analyse darum gehen, musikalisch-klangliche Hervorbringung auf performative Bezüge hin zu untersuchen. Dieses Unterfangen behielte auch im Falle der Feststellung der Negation performativer Bezüge seine Legitimation - eine erste Aussage zum Material wäre sodann hergestellt.

54 Es wird hier von einem weitgefassten Medienbegriff ausgegangen, der die Vielfalt des gesellschaftlichen Mediengebrauchs widerspiegelt. In ihm werden Gattungs- und Distributionsaspekte integrierend behandelt. Diese Auslegung erscheint erforderlich, da es insbesondere im Fall von populärer Musik deutlich zu machen gilt, dass der Medienbegriff unterschiedliche 
Jene Felder werden explizit als musikanalytisch relevant gesetzt. An ihnen erfolgt eine kontextuelle Verortung des Materials, durch die der Schärfegrad der Beobachtung erhöht wird. Der Kontextbegriff versucht der eigentümlichen Dynamik Herr zu werden, dass sich entlang musikalischer Handlungen, hervorgebracht in medialen Settings, zeitlich bedingte Verständigungsverhältnisse zwischen Publikum und Interpret konstituieren. Die Deskription der kontextuellen Ausgangslage erscheint angesichts der mannigfachen Materialtransformationen, die sich aufgrund ständiger Medienwechsel in der populären Musikpraxis vollziehen, unentbehrlich. Wenn beispielsweise ein Song in Form einer Aufnahme betrachtet wird, werden Fragen der Genrebezogenheit und Performativität zunächst im Hinblick auf seine spezifische Medialität als Tonträger zu beantworten sein, es sei denn, die Forschungsfrage intendiert ausdrücklich etwas anderes. Auch können eine Aufnahme der Band X und eine Live-Performance der Band Y nur unter Bedingung einer entsprechend ausformulierten Forschungsfrage beobachtet werden.

Mit der rekursiven Betrachtungsebene bewegt sich die Analyse auf der Ebene der Musikimmanenz - dem originären Terrain der Musikwissenschaft. Verschiedene musikalische Dimensionen wie Formverlauf, Stimme, Instrumentierung, Harmonien, Motive, Sound, Rhythmus, und die Bedeutungsebene Text werden hier aufeinander bezogen. In einem Transkriptionsschema gilt es diese vertikal zu schichten. Dieses Vorgehen wird dem Postulat der Ausführlichkeit aber auch jenem der Gegenstandsangemessenheit gerecht. So weisen Begriffe wie die des Sounds oder des Rhythmus ${ }^{55}$ darauf hin, dass die musikalischen Strukturen im Pop-Kontext nicht im Sinne einer Musik als Text ${ }^{56}$, sondern als klangsinnliche Texturen zu lesen sind. ${ }^{57}$

mediale Settings und Formate impliziert, in denen das klangliche Ereignis nicht nur vermittelt sondern auch in ein bestimmtes Licht gerückt wird, d.h. es wird im jeweiligen Medium von neuem kontextualisiert und infolge re-materialisiert. Die wesentlichen medialen Settings und Formate populärer Musik sind: Tonträger, Konzert, Clip, Film und Internet.

55 Als Umsetzungsoption ist anzudenken, die Dimensionen Motive, Sound und Rhythmus zu einer Betrachtungsebene zusammen zu ziehen. Daran soll deutlich werden, dass es bei der rekursiven Analyse nicht darum gehen kann, einen Materialaspekt wie Rhythmus grundsätzlich durchgehend zu transkribieren. Die finale Entscheidung zugunsten der ausführlichen Visualisierung eines bestimmten musikalischen Ereignisses sollte auf die spezifische Beschaffenheit des Materials und die zu erwartenden Aussagen durch die Transkription zurückgeführt werden.

56 Dietrich Helms postuliert eine allgemeine Abkehr von der klassischen Musiktheorie. Er begründet dies mit Unbehagen gegenüber dem Musikverständnis, das der Musiktheorie zugrunde liegt. Hiernach stützt sich diese auf das Paradigma einer musica poetica, einer werkgewordenen Musik, die in der Anordnung des Materials eine Aussage des Komponisten codiert. In diesem Sinne spiegelt sie nur einen zeit- und kulturbedingten Ausschnitt musikalischer Praxis wieder (vgl. Helms 2003b, S. 200).

57 Bei Martin Pfleiderer wird Sound als Klanggeflecht gedeutet und in ein dreigliedriges hierarchisches Ordnungssystem eingefügt, das zwischen Mikro-, Meso- und Makroebene unterscheidet. Entsprechend dieser Reihenfolge sind es Einzelsounds, Klangfolgen/-gestalten 
Darüber hinaus zieht die Forderung nach Rekursivität auch eine Neu-Gewichtung des musikanalytischen Blicks nach sich. Gemeint ist die Fokussierung auf die Relationalität der klanglichen Elemente. ${ }^{58}$ Rekursivität verinnerlicht die Zielvorstellung, dass das Klangmaterial in seinem begrenzten Inventar an Elementen durch sich selbst definiert wird, d.h. jeder beliebige Punkt durch das musikalisch-klangliche Strukturgeflecht selbst verständlich gemacht werden kann. Mit dem Begriff der Rekursivität sind einerseits die Grenzen einer solchen Betrachtung mit formuliert - die Komplementierung daher durch die exkursive Betrachtungsebene -, andererseits wird dadurch, dass die Wirkungszusammenhänge der Elemente hervorgefördert werden, der Blick auf ebenjene Aspekte des Klangmaterials geschärft, die für die Bedeutungskonstitution in bestimmten Kontexten eine Rolle spielen können. Dies ist nicht zuletzt für die Identifikation und Interpretation audiovisueller Korrespondenzverhältnisse im Musikclip eine wesentliche Vorstufe.

Zum Abschluss dieses globalen methodologischen Umrisses gilt es die Einsicht zu festigen, dass Musikwissenschaft und alle Disziplinen, die an der Beobachtung populärer Musikformate beteiligt sind, vor der Aufgabe stehen, kollektive Bedeutungsfelder in unterschiedlichen Materialkontexten hervor zu fördern. Es ist davon auszugehen, dass sich zukünftige Materialanalysen als sehr aufschlussreich erweisen werden, wenn es darum geht, die kulturellen Kontexturen innerhalb des sich ausdehnenden Netzwerks populäre Musik näher zu beleuchten. Durch den besprochenen Teilaspekt Text-Ton wird diese Annahme unterstützt. So entwickelt Stimme in der Kontaktzone zur Musik ein Spiel mit Vorstellungen von Körperlichkeit,

und Klangtexturen die den Gesamtkomplex Musik und dessen Rezeption prägen (vgl. Pfleiderer 2003).

58 Eine nähere Erläuterung des Rekursivitätsbegriffs scheint an dieser Stelle erforderlich, da im Folgenden im Sinne methodischer Heuristik argumentiert wird. Hierzu sei auf den Song als die zentrale klanglich-materielle Hervorbringung populärer Musikpraxis und außerdem auf seine Funktion als ein Unterhaltung ermöglichendes Objekt eingegangen - durch die unterhaltungstheoretische Aspektualisierung soll allerdings nicht die Kunstfertigkeit populärer Musikproduktion in Frage gestellt wird. Als Unterhaltungsobjekt schafft der Song eine "Sonderrealität der Unterhaltung“ (Luhmann 2004, S. 100), indem er bestimmte musikalisch-klangliche Ereignisse aufeinander bezieht und miteinander verschmilzt, andere hingegen ausschließt. Als musikalische Kleinform wiederum setzt er einen spezifischen Umgang mit musikalischer Sukzessivität voraus. Für den Hörer bedeutet der Umstand der Standardisierung im Kleinformat, dass er sich grundsätzlich in diesem Format zurechtfindet. Vor dem eigentlichen Hörakt hat der Hörer eine Ahnung davon, in welchem klanglichen Rahmen sich der Song bewegen wird - Irritationen inbegriffen. Die Regelhaftigkeit ist die Voraussetzung dafür, dass der Song als Unterhaltungsobjekt überhaupt seine Wirkung entfalten kann. Durch den Aspekt der Wirksamkeit ist gleichsam aufgezeigt, dass Regelhaftigkeit nicht mit der Herstellung von Einförmigkeit und Wiederholung gleichzusetzen ist. Der Song kann folglich als Schema vorgestellt werden. Ein solches Schema zwingt nicht zu Wiederholungen, es legt Handeln nicht fest, da seine Funktion gerade darin liegt, Spielraum für frei gewähltes Verhalten zu generieren (vgl. Luhmann 2004, S. 193). Die Folge hiervon ist, dass sich im einzelnen Song Ähnlichkeits- bzw. Differenzverhältnisse zu Song-Paradigmen abzeichnen (vgl. Shave 2008, S. 42 ff.). 
Persönlichkeit und Charakterlichkeit - ein Mehr an Bedeutungen ist die Folge. Der Ausblick auf das Zusammenspiel von Bild, Text und Ton im Musikclip lässt erahnen, dass hier Bedeutung von neuem konstituiert wird. Ein tiefergehendes Verständnis für die musikalischen Materialzusammenhänge wird helfen, diese Bedeutungsproduktion zu entziffern.

\section{Literatur}

Altrogge, Michael (2000): Tönende Bilder. Interdisziplinäre Studie zu Musik und Bildern in Videoclips und ihre Bedeutung für Jugendliche. Bd. 1-3. Berlin.

Aufderheide, Pat (1986): Music videos: The look of sound. In: Journal of Communication 36, S. 57-78.

Baacke, Dieter (1998): Neue Ströme der Weltwahrnehmung und kulturelle Ordnung. In: Baacke, Dieter (Hg.): Handbuch Jugend und Musik. Opladen, S. 29-57.

Barth, Michael/Neumann-Braun, Klaus (1996): Augenmusik. Musikprogramme im deutschen Fernsehen - am Beispiel von MTV. In: Landesanstalt für Kommunikation Baden-Württemberg (LFK) (Hg.): Fernseh- und Radiowelt für Kinder und Jugendliche. Villingen, S. 249-265.

Bechdolf, Ute (1996): Music video histories. In: Hackl, Christiane/Prommer, Elizabeth/Scherer, Brigitte (Hg.): Models und Machos? Frauen- und Männerbilder in den Medien. (= Kommunikation audiovisuell 21). Konstanz, S. 277-299.

Bergermann, Ulrike (2003): Videoclip. In: Hügel (Hg.), S. 478-482.

Bielefeldt, Christian (2008): Voices of Prince. In: Bielefeldt/Dahmen/Grossmann (Hg.), S. 201-219.

Bielefeldt, Christian/Dahmen, Udo/Grossmann, Rolf (Hg.) (2008): PopMusicology. Perspektiven der Popmusikwissenschaft. Bielefeld.

Bódy, Veruschka/Weibel, Peter (Hg. ) (1987): Clip, Klapp, Bum. Von der visuellen Musik zum Musikvideo. Köln.

Böhme-Mehner, Tatjana/Mehner, Klaus/Wolf, Motje (Hg.) (2008): Elektroakustische Musik - Technologie, Ästhetik und Theorie als Herausforderung an die Musikwissenschaft. Essen.

Bowman, Rob (2003): The determining role of performance in the articulation of meaning: the case of „Try a Little Tenderness“. In: Moore, Allan F. (Hg.): Analyzing Popular Music. Cambridge, S. 103-130.

Bullerjahn, Claudia (2001): Grundlagen der Wirkung von Filmmusik. Augsburg.

Chion, Michel (1994): Audio-vision: sound on screen. New York.

Deutsches Filmmuseum Frankfurt (Hg.) (1993): Sound \& Vision. Musikvideo und Filmkunst. Frankfurt a.M.

Fabbri, Franco (1982): A theory of musical genres: two applications. In: Horn, David/ Tagg, Philip (Hg.): Popular music perspectives. Göteborg/Exeter, S. 52-81.

Fischer-Lichte, Erika (2004): Ästhetik des Performativen. Frankfurt a.M. 
Fix, Ulla (2001): Aspekte der Intertextualität. In: Brinker, Klaus/Burkhardt, Armin/ Ungeheuer, Gerold et al. (Hg.): Text- und Gesprächslinguistik/Linguistics of Text and Conversation. (= Handbücher zur Sprach- und Kommunikationswissenschaft/ Handbooks of Linguistics and Communication Science 16.2). Berlin/New York, S. 449-457.

Fricke, Jobst P. (2003): Systemische Musikwissenschaft. In: Niemöller, Klaus Wolfgang/ Gätjen, Bram (Hg.): Perspektiven und Methoden einer systemischen Musikwissenschaft. Frankfurt a.M., S. 13-21.

Frith, Simon (1996): Performing rites. On the value of popular music. Cambridge.

Genette, Gérard (2004): Palimpseste: die Literatur auf zweiter Stufe. Frankfurt a.M.

Großmann, Rolf (1998): Wo beginnt Intermedialität? Latente Prämissen und Dimensionen eines klärungsbedürftigen Konzepts. In: Helbig, Jörg (Hg.): Intermedialität: Theorie und Praxis eines interdisziplinären Forschungsgebiets. Berlin, S. 108-119.

Gumbrecht, Hans Ulrich (2004): Diesseits der Hermeneutik. Die Produktion von Präsenz. Frankfurt a.M.

Hamm, Charles (2000): Genre, performance, and ideology in the early songs of Irving Berlin. In: Middleton (Hg.), S. 297-306.

Hausheer, Cecilia (1994): Werbende Klangaugen. In: Hausheer/Schönholzer (Hg.), S. 186-197.

Hausheer, Cecilia/Schönholzer, Annette (Hg.) (1994): Visueller Sound. Musikvideos zwischen Avantgarde und Populärkultur. Luzern.

Hawkins, Stan (2000): Prince: Harmonic analysis of ,Anna Stesia‘. In: Middleton (Hg.), S. $58-70$.

Helms, Dietrich (2002): Musikwissenschaftliche Analyse populärer Musik? In: Rösing, Helmut/Schneider, Albrecht/Pfleiderer, Martin (Hg.): Musikwissenschaft und populäre Musik. Versuch einer Bestandsaufnahme. (= Hamburger Jahrbuch für Musikwissenschaft 19). Frankfurt a.M., S. 91-103.

Helms, Dietrich (2003a): In Bed with Madonna. Gedanken zur Analyse von Videoclips aus medientheoretischer Sicht. In: Helms/Phleps (Hg.), S. 99-117.

Helms, Dietrich (2003b): Vom System Ton zum System Sound. In: Phleps/Appen (Hg.), S. 197-228.

Helms, Dietrich/Phleps, Thomas (Hg.) (2003): Clipped Differences. Geschlechterrepräsentationen im Musikvideo. (= Beiträge zur Popularmusikforschung 31). Bielefeld.

Hügel, Hans-Otto (2003): Einführung. In: Hügel (Hg.), S. 1-22.

Hügel, Hans-Otto (Hg.) (2003): Handbuch Populäre Kultur. Begriffe, Theorien und Diskussionen. Stuttgart.

Jacke, Christoph (2003): Kontextuelle Kontingenz. Musikclips im wissenschaftlichen Umgang. In: Helms/Phleps (Hg.), S. 27-40.

Keazor, Henry/Wübbena, Thorsten (2005): Video thrills the radio star. Musikvideos: Geschichte, Themen, Analysen. Bielefeld.

Kerscher, Gottfried/Richard, Birgit (2003): MoVie und MuVi. Zur Interpretation bewegter Bilder in Film und Musikvideoclip als Bildwissenschaft und ,kritische Stil- 
analyse‘. In: Ehrenspeck, Yvonne/Schäffer, Burkhard (Hg.): Film- und Fotoanalyse in den Erziehungswissenschaften: ein Handbuch. Opladen, S. 203-225.

Kittler, Friedrich A. (1999): Gramophone, film, typewriter. Stanford, CA.

Klein, Richard (2008): Das Narrative der Stimme Bob Dylans. In: Bielefeldt/Dahmen/ Grossmann (Hg.), S. 220-240.

Krämer, Sybille (2006): Die „Rehabilitierung der Stimme“. Über die Oralität hinaus. In: Kolesch, Doris/Krämer, Sybille (Hg.): Stimme. Annäherung an ein Phänomen. Frankfurt a.M., S. 269-295.

Krämer, Sybille (2004): Was haben „Performativität“ und „Medialität“ miteinander zu tun? In: Krämer, Sybille (Hg.): Performativität und Medialität. München, S. 11-32.

Luhmann, Niklas (1995): Die Kunst der Gesellschaft. Frankfurt a.M.

Luhmann, Niklas (2004): Die Realität der Massenmedien. 3. Aufl, Wiesbaden.

Lüders, Christian (1991): Deutungsmusteranalyse. Annäherungen an ein risikoreiches Konzept. In: Garz, Detlef/Kraimer, Klaus (Hg.): Qualitativ-empirische Sozialforschung. Opladen, S. 377-408.

Lüders, Christian/Meuser, Michael (1997): Deutungsmusteranalyse. In: Hitzler, Ronald/ Honer, Anne (Hg.): Sozialwissenschaftliche Hermeneutik: eine Einführung. Opladen, S. 57-80.

Lull, James (1987): Popular music and society. London.

Leschke, Rainer (2007): Einführung in die Medientheorie. München.

Meuser, Michael/Sackmann, Reinhold (Hg.) (1991): Analyse sozialer Deutungsmuster. Pfaffenweiler.

Middleton, Richard (Hg.) (2000): Reading pop. Approaches to textual analysis in popular music. Oxford.

Middleton, Richard (2001): Musikalische Dimensionen. Genres, Stile, Aufführungspraktiken. In: Wicke, Peter (Hg.): Rock- und Popmusik. Handbuch der Musik im 20. Jahrhundert. Bd. 8. Laaber, S. 63-106.

Neumann-Braun, Klaus (Hg.) (1999): Viva MTV! Popmusik im Fernsehen. Frankfurt a.M.

Neumann-Braun, Klaus/Schmidt, Axel (1999): McMusic. Einführung. In: NeumannBraun (Hg.), S. 7-42.

Oevermann, Ulrich (2001a): Zur Analyse der Struktur von sozialen Deutungsmustern. In: Sozialer Sinn 1 S. 3-34.

Oevermann, Ulrich (2001b): Die Struktur sozialer Deutungsmuster - Versuch einer Aktualisierung. In: Sozialer Sinn 1, S. 35-82.

Paech, Joachim (1994): Bilder-Rhythmus. In: Hausheer/Schönholzer (Hg.), S. 46-63.

Pfleiderer, Martin (2003): Sound. Anmerkungen zu einem populären Begriff. In: Phleps/ Appen (Hg.), S. 19-29.

Phleps, Thomas/Appen, Ralf von (Hg.) (2003): Pop Sounds. Klangtexturen in der Popund Rockmusik. (= Texte zur populären Musik 1). Bielefeld.

Rajewsky, Irina O. (2002): Intermedialität. Tübingen u.a. 
Reichertz, Jo (1992): Der Morgen danach. Hermeneutische Auslegung einer Werbefotographie in zwölf Einstellungen. In: Hartmann, Hans A./Haubl, Rolf (Hg.): Bilderflut und Sprachmagie. Fallstudien zur Kultur der Werbung. Opladen, S. 141-164.

Reichertz, Jo (2005): Wissenssoziologische Verfahren der Bildinterpretation. In: Mikos, Lothar/Wegener, Claudia (Hg.): Qualitative Medienforschung. Ein Handbuch. Konstanz, S. 141-152.

Rösing, Helmut (2003): Bilderwelt der Klänge - Klangwelt der Bilder. Beobachtungen zur Konvergenz der Sinne. In: Helms/Phleps (Hg.), S. 9-26.

Schmidbauer, Michael/Löhr, Paul (1996): Das Programm für Jugendliche: Musikvideos in MTV Europe und VIVA. In: Televizion 9, S. 6-32.

Schmidt, Axel/Neumann-Braun, Klaus/Autenrieth, Ulla (2009): Viva MTV! reloaded. Musikfernsehen und Videoclips crossmedial. Baden-Baden.

Schröter, Jens (1998): Intermedialität. In: Montage a/v 7, 2, S. 129-154.

Schumacher, Eckhard (2002): Performativität und Performance. In: Wirth, Uwe (Hg.): Performanz. Zwischen Sprachphilosophie und Kulturwissenschaft. Frankfurt a.M., S. 383-402.

Shave, Thomas (2008): Communicative contract analysis: an approach to popular music analysis. In: Organised Sound 13, S. 41-50.

Spielmann, Yvonne (1998): Intermedialität: das System Peter Greenaway. München.

Vernallis, Carol (2002): The functions of lyrics in music video. In: Journal of Popular Music Studies 14, S. 11-31.

Weibel, Peter (1987): Was ist ein Videoclip? In: Bódy/Weibel (Hg.), S. 274-275.

Wicke, Peter (1992): Jazz, Rock und Popmusik. In: Stockmann, Doris (Hg.): Volks- und Popularmusik in Europa. (= Neues Handbuch der Musikwissenschaft 12). Laaber, S. 445-477.

Wicke, Peter (1993): Vom Umgang mit Popmusik. Berlin.

Wicke, Peter/Ziegenrücker, Kai-Erik/Ziegenrücker, Wieland (2001): Handbuch der populären Musik. 4. Aufl. Mainz.

Wicke, Peter (2003): Popmusik in der Analyse. In: Vendrix, Philippe (Hg.): Acta Musicologica. Bd. 75. Basel, S. 107-126.

Wulff, Hans-Joachim (1999): The Cult of Personality - authentisch simulierte Rockvideos. In: Neumann-Braun (Hg.), S. 262-278.

Zumthor, Paul (1988): Körper und Performanz. In: Gumbrecht, Hans Ulrich/Pfeiffer, Karl Ludwig/Elsner, Monika (Hg.): Materialität der Kommunikation. Frankfurt a.M., S. 703-714.

Zumthor, Paul (2002): Mündlichkeit/Oralität. In: Barck, Karl-Heinz/Frontius, Martin/ Schlenstedt, Dieter/Steinwachs, Burkhart/Wolfzettel, Friedrich (Hg.): Ästhetische Grundbegriffe. Historisches Wörterbuch in sieben Bänden. Bd. 4: Medien - Populär. Stuttgart, S. 234-256. 